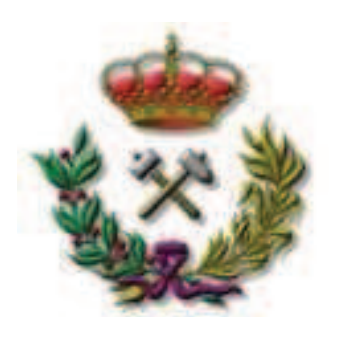

ESCUELA TÉCNICA SUPERIOR DE INGENIEROS DE MINAS

Programa de Ingeniería de los Recursos Minerales,

Materiales, Energía y Medio Ambiente

TESIS DOCTORAL

DEPARTAMENTO DE INGENIERÍA GEOLÓGICA Y MINERA

\title{
TEORÍAS Y TECNOLOGÍAS APLICADAS AL ESPESADO DE ESTÉRILES Y SU IMPACTO EN LA SOSTENIBILIDAD DE LAS OPERACIONES MINERAS
}

Director: Dr. Carlos Grima Olmedo

JOSÉ ANTONIO BUTRAGUEÑO MUÑOZ

Julio 2015 


\section{AGRADECIMIENTOS}

Una vez completado el trabajo y con el deber cumplido es momento de hacer memoria y reconocer la labor de las personas que han colaborado, de una forma u otra, en esta tesis doctoral.

En primer lugar, recordar de forma muy emotiva para mi primer director de tesis, el Dr. Ángel Rodríguez-Avello Sanz, tristemente fallecido en 2014. Ángel fue siempre una inspiración para comenzar este trabajo; siempre le agradeceré su confianza mostrada en mi persona desde mis primeros años de estudiante en la Escuela de Minas de Madrid. Su valía como profesor, investigador, profesional y amigo estuvo siempre suficientemente demostrada. Quisiera destacar también la faceta personal, dedicación y trabajo que compartió con sus alumnos.

También quiero expresar mi gratitud al profesor Dr. Carlos Grima Olmedo por retomar el trabajo que Ángel no pudo terminar, agradecer su orientación, dirección, ayuda, colaboración e interés en la difusión de esta tesis doctoral, que sin él no hubiera sido posible.

Mencionar a las empresas e instituciones que han colaborado con el suministro de las muestras para ensayos, datos de proceso y ensayos de laboratorio realizados en sus instalaciones, especialmente a Minas de Aguas Teñidas y Minerales del Brezo; así como al Departamento de Ingeniería de Materiales de la E.T.S. de Ingenieros de Minas de Madrid por su interés en este trabajo.

Por último agradecer a mi familia su paciencia y apoyo mostrado durante todos estos años y por comprender que la investigación necesita dedicación; deseando que todos ellos se sientan parte fundamental de este proyecto. 
A Rezeda, Laura y Raúl. 


\section{ÍNDICE}

AGRADECIMIENTOS .II

ÍNDICE IV

LISTA DE FIGURAS

LISTA DE TABLAS

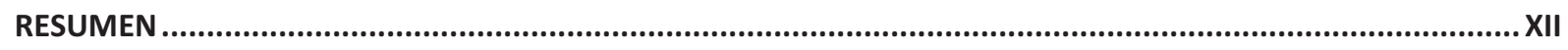

ABSTRACT

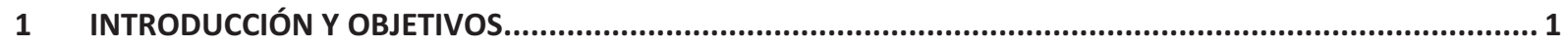

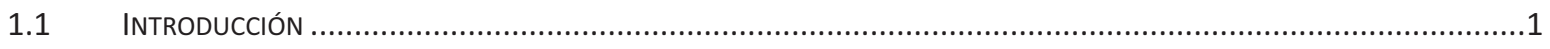

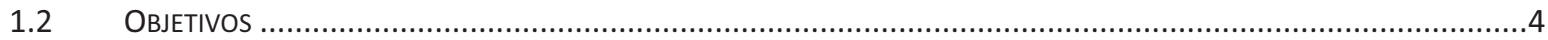

2 ESTADO DEL ARTE

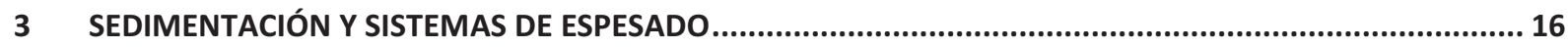

ESPESADORES Y ESPESADO

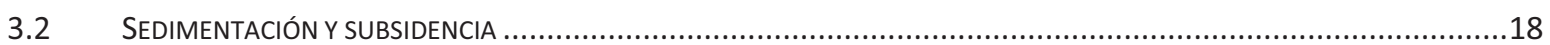

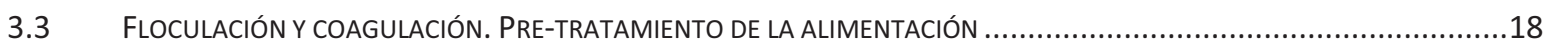

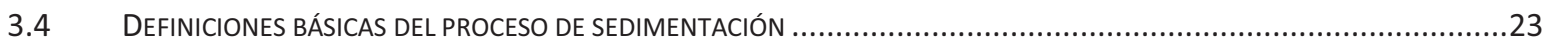

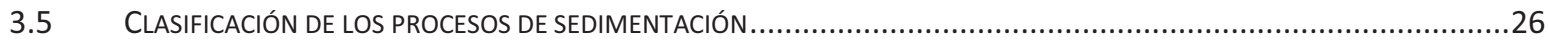

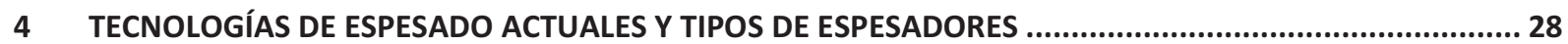

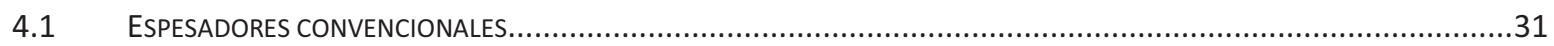

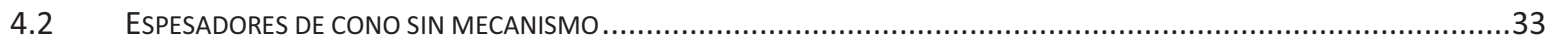

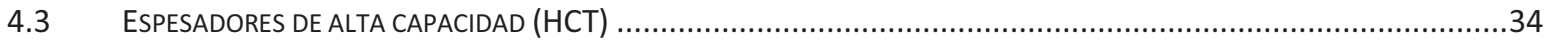

4.4 TECNOLOGÍA Y DESARROLLO DE LOS ESPESADORES DE ALTO RATIO DE ALIMENTACIÓN (HRT) ...................................36

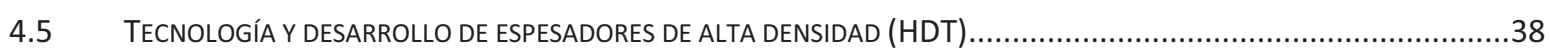

4.6 TECNOLOGÍA Y DESARROLLO DE ESPESADORES DE CONO PROFUNDO .........................................................4

4.7 APLICACIONES DEL ESPESADOR DE CONO PROFUNDO EN EL TRATAMIENTO DE ESTÉRILES.....................................58

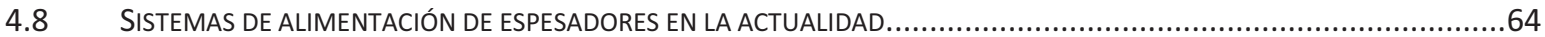

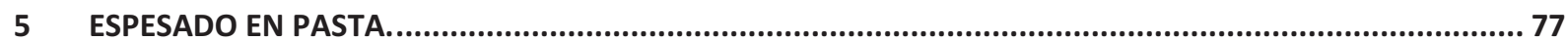

5.1 IMPORTANCIA DE LA REOLOGÍA EN LA ESTRATEGIA DE IMPLEMENTACIÓN DE UN SISTEMA DE ESPESADO EN PASTA..........78

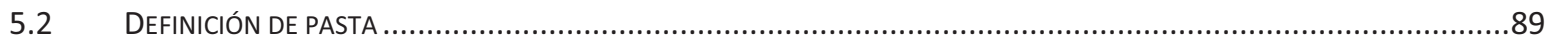

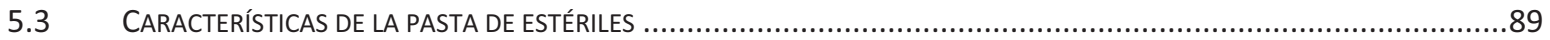

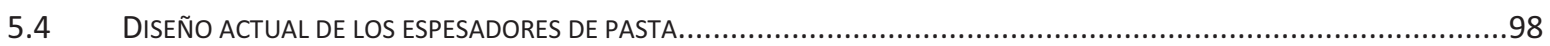

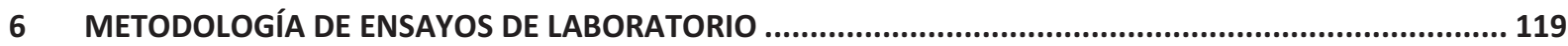




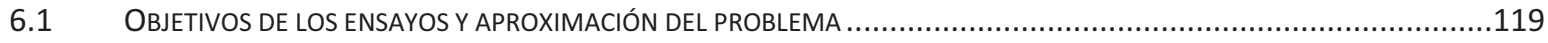

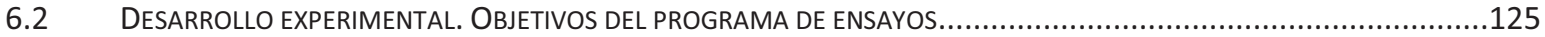

6.3 METOdología de ENSAYOS Y USO DEL ESPESADOR DE TUBO PROFUNDO DE LABORATORIO ..................................136

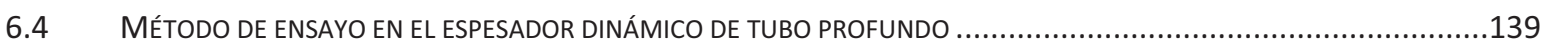

6.5 RECOGIDA DE DATOS DE LABORATORIO. PRESENTACIÓN DE RESULTADOS E INFORME........................................141

6.6 MetOdología DE LOS ENSAYOS PARA LA CARACTERIZACIÓN DE LA PASTA ......................................................147

6.7 METOdOLOGÍA DE LOS ENSAYOS DE LABORATORIO PARA CARACTERIZACIÓN DE LA PASTA ......................................149

7 APLICACIÓN DEL MODELO EXPERIMENTAL CON DIFERENTES MATERIALES. ......................................169.

7.1 DeSARROLLO EXPERIMENTAL CON LA MUESTRA M-100. ESTÉRILES DE FLOTACIÓN. .........................................172

7.2 DESARROLLO EXPERIMENTAL CON MUESTRA M-101. ESTÉRILES DE FLOTACIÓN. .............................................180

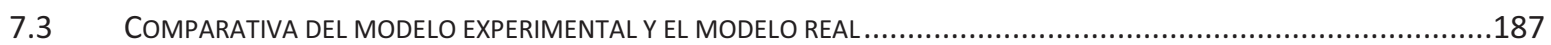

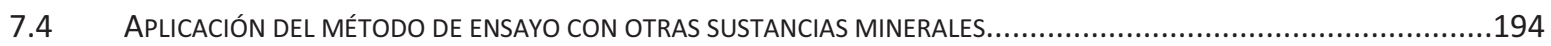

7.5 CONCLUSIONES SOBRE LAS PRUEBAS REALIZADAS Y EL MODELO EXPERIMENTAL ..............................................202

8 APLICACIÓN DEL MODELO A UN CASO REAL DE ESPESADO DE ESTÉRILES DE MINA ........................... 204

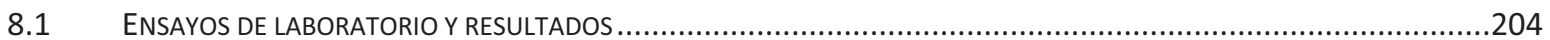

8.2 ENSAYO EN ESPESADOR DINÁMICO DE TUBO PROFUNDO DE 5,5 LITROS DE CAPACIDAD ......................................212

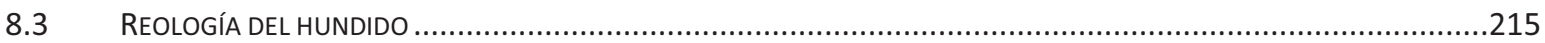

8.4 CONCLUSIONES DE LOS ENSAYOS REALIZADOS SOBRE LA MUESTRA DE ESTÉRILES M-074 …..............................219

8.5 ESTUDIO Y ALTERNATIVAS DE DISEÑO DEL EQUIPO DE ESPESADO EN EL YACIMIENTO DE LAZA ...............................220

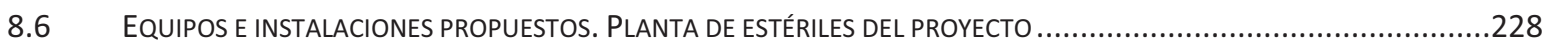

8.7 COSTES DE CAPITAL DEL PROYECTO DE ESPESADO DE ESTÉRILES DEL YACIMIENTO DE LAZA...................................235

8.8 COSTES DE OPERACIÓN PARA LA PLANTA DE ESPESADO DE ESTÉRILES LAZA-ORENSE.........................................240

8.9 OBSERVACIONES SOBRE LA MUESTRA DE ESTÉRILES DEL YACIMIENTO DE LAZA ............................................246

8.10 CONCLUSIONES SOBRE LOS ENSAYOS DE LOS ESTÉRILES DEL YACIMIENTO DE LAZA ............................................249

8.11 SOSTENIBILIDAD DE LAS OPERACIONES DE ESPESADO EN PASTA .............................................................250

8.12 SOSTENIBILIDAD DE LAS OPERACIONES DE DEPOSICIÓN DE ESTÉRILES EN SUPERFICIE ........................................253

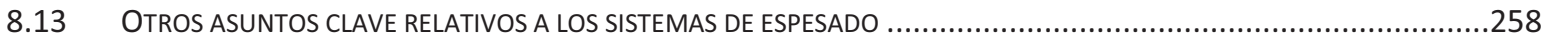

8.14 DESARROLLO SOSTENIBLE Y BENEFICIOS ECONÓMICOS, MEDIOAMBIENTALES Y SOCIALES.....................................259

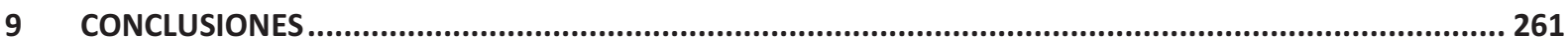

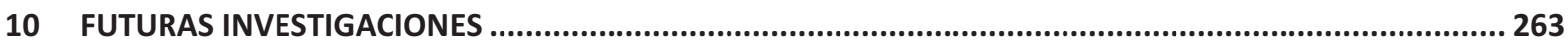

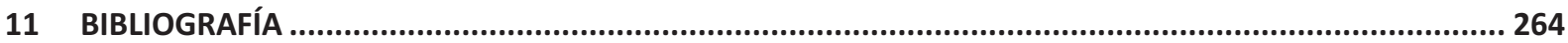

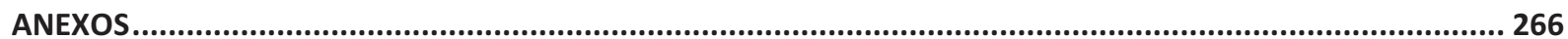




\section{LISTA DE FIGURAS}

Figura 3-1: Espesador de estériles operando en la mina Cerro Verde (Chile) . .................................. 16

Figura 3-2: Zonas de sedimentación y etapas del proceso en un espesador.................................... 17

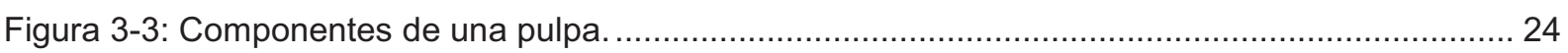

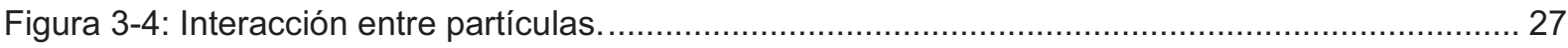

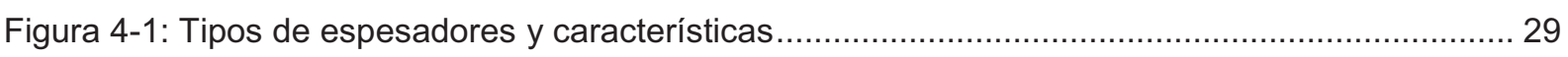

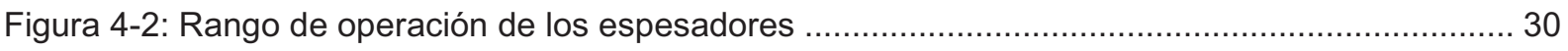

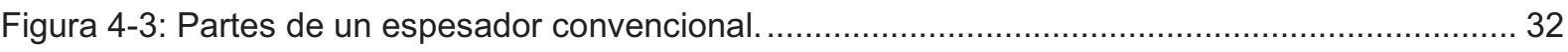

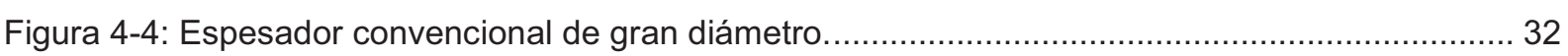

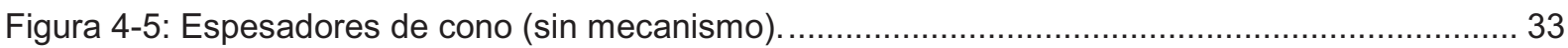

Figura 4-6: Esquema de operación de un espesador de cono sin mecanismo. ................................... 34

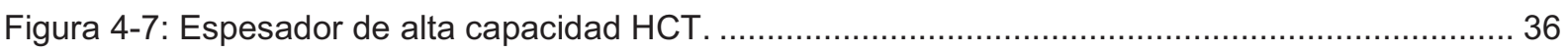

Figura 4-8: Instalación de dos espesadores HRT de 6 metros de diámetro....................................... 37

Figura 4-9: Detalle del mecanismo de un espesador HRT . ........................................................... 38

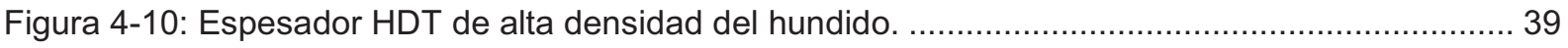

Figura 4-11: Tensión de fluencia en espesadores de estériles....................................................... 40

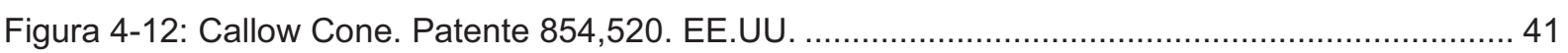

Figura 4-13: Espesador de lecho profundo año 1953. Alemania..................................................... 42

Figura 4-14: Espesador de cono profundo. National Coal Board. ...................................................... 43

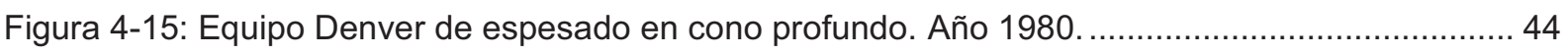

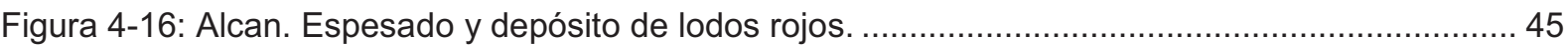

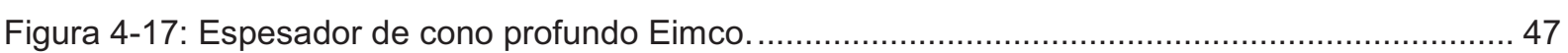

Figura 4-18: Equipos instalados por tecnologías (1987-2012) …................................................ 52

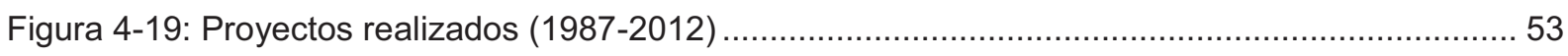

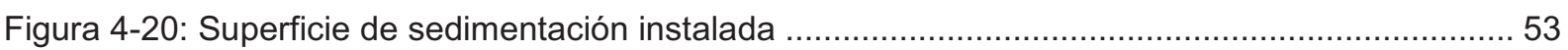

Figura 4-21: Diámetros instalados. Tecnología HDT para estériles. ............................................... 54

Figura 4-22: Total área instalada. Tecnología HDT para estériles. ..................................................... 55

Figura 4-23: Diámetros instalados. Tecnología DCT para estériles. ................................................ 56

Figura 4-24: Total área instalada. Tecnología DCT para estériles. .................................................. 56

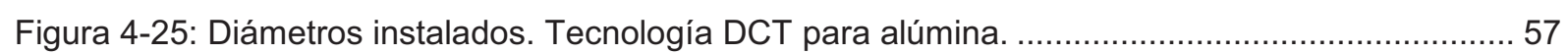

Figura 4-26: Total área instalada. Tecnología DCT para alúmina. .................................................. 57

Figura 4-27: Balsa de estériles de flotación en Somincor (Portugal). ................................................ 59

Figura 4-28: Sistema convencional de almacenamiento de estériles en balsas. .................................. 60

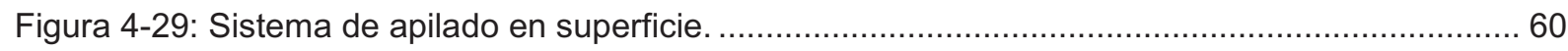

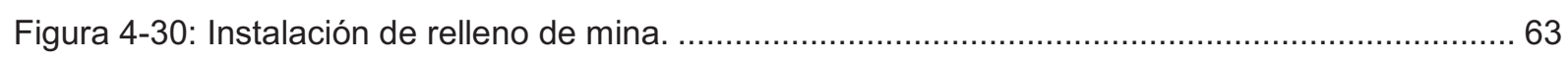

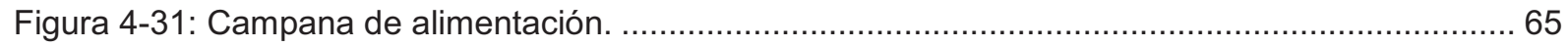

Figura 4-32: Curvas típica dosificación floculante frente a contenido en sólidos en la alimentación. .. 67

Figura 4-33: Campana de alimentación con sistema de eductor. Esquema....................................... 68 
Figura 4-34: Sistema de alimentación con eductor de canal abierto. ............................................ 70

Figura 4-35: Sistema de alimentación con eductores en tubería..................................................... 71

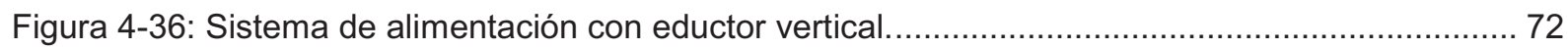

Figura 4-37: Evolución de la forma de la campana de alimentación. ..................................................... 73

Figura 4-38: Pruebas de laboratorio con diferentes tipos de campana. .............................................. 73

Figura 4-39: Modelo CFD para las campanas tangencial y envolvente............................................ 74

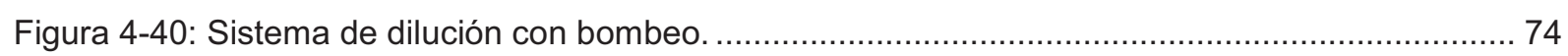

Figura 4-41: Sistema de dilución con bombeo montado en un espesador HDT. ............................... 75

Figura 4-42: Diseño de campana de alimentación con bafles internos. .............................................. 76

Figura 5-1: Secuencia de diseño de un sistema de espesado de pasta.............................................. 79

Figura 5-2: Ciclo de diseño y ensayos de laboratorio de un sistema de espesado en pasta. .............. 80

Figura 5-3: Descripción del modelo de viscosidad según Newton................................................... 81

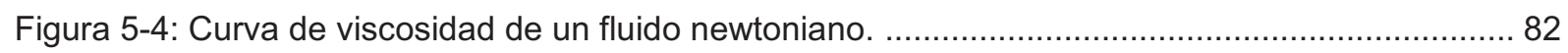

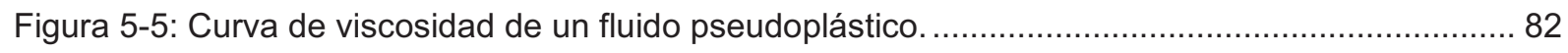

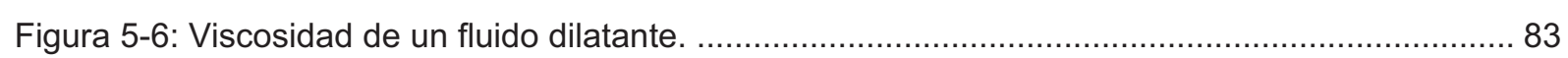

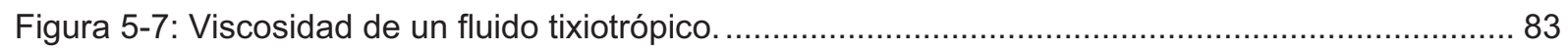

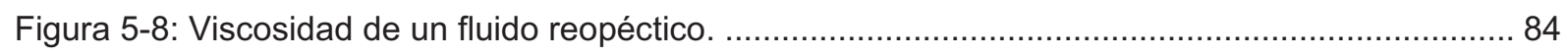

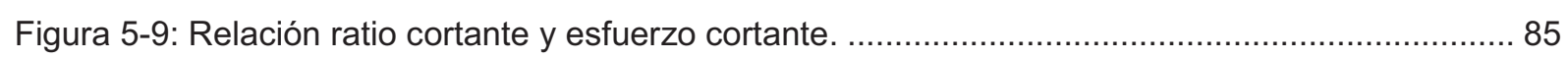

Figura 5-10: Curvas de flujo para una muestra de relleno de mina. ............................................... 88

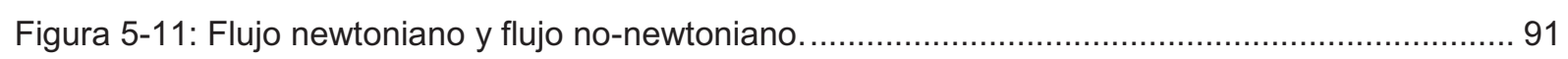

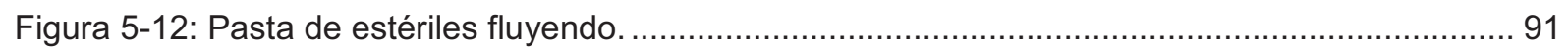

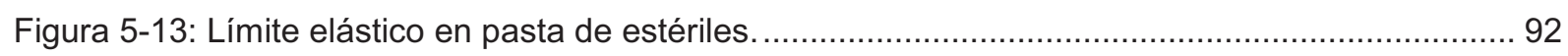

Figura 5-14: Límite elástico en suspensiones de sólidos................................................................... 93

Figura 5-15: Operación de un espesador según la curva de tensión de fluencia. .................................. 94

Figura 5-16: Efecto de la profundidad del lecho de lodos en un espesador....................................... 95

Figura 5-17: Profundidad de lecho de lodos frente al contenido en sólidos. ........................................ 96

Figura 5-18: Espesador de cono profundo con tanque de acero y puente diametral. ........................ 102

Figura 5-19: Geometría y partes de un espesador de pasta. ........................................................... 103

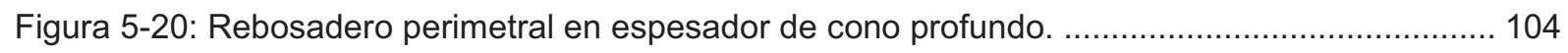

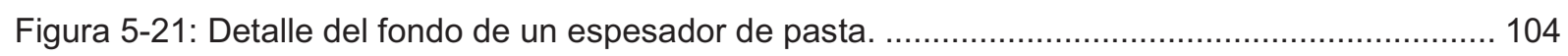

Figura 5-22: Boca de hombre en cilindro de descarga de un espesador de pasta. ............................ 106

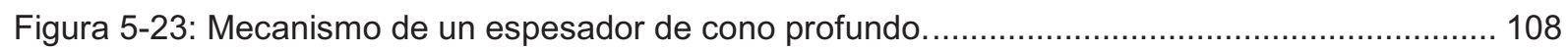

Figura 5-24: Mecanismo interno de un espesador de cono profundo................................................. 109

Figura 5-25: Espesador de alta densidad con cabeza de accionamiento tipo columna. .................... 112

Figura 5-26: Cabeza de accionamiento tipo puente en espesador de pasta .................................... 113

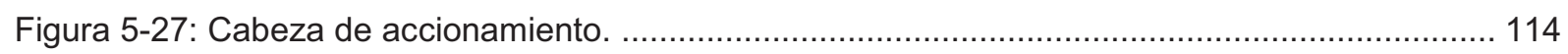

Figura 5-28: Mecanismo interno de un espesador de cono profundo de 18 metros. ....................... 117

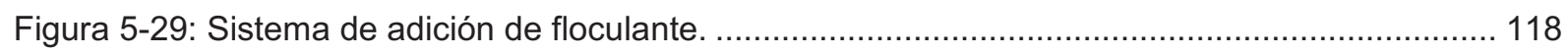

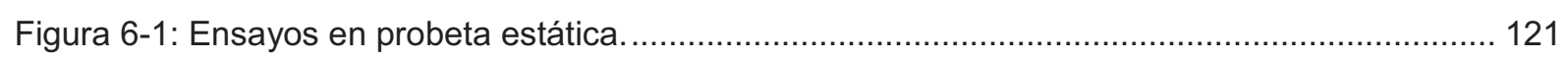

Figura 6-2: Espesador de tubo profundo de laboratorio. ........................................................... 122 


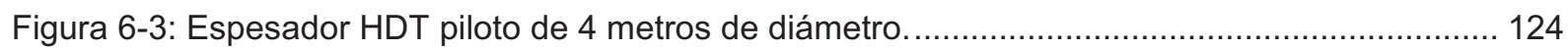

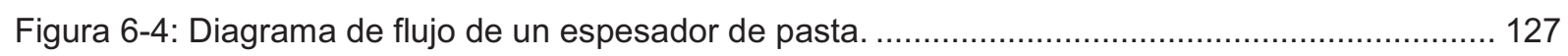

Figura 6-5: Espesador de tubo profundo (dinámico) de laboratorio.................................................. 129

Figura 6-6: Mecanismo interno del espesador de tubo profundo.................................................. 131

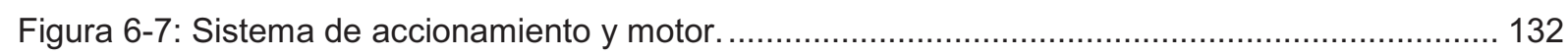

Figura 6-8: Sistema de alimentación del espesador de tubo profundo........................................... 133

Figura 6-9: Esquema del espesador de tubo profundo de un módulo. .............................................. 135

Figura 6-10: Esquema del espesador de tubo profundo de dos módulos. ....................................... 136

Figura 6-11: Espesador de tubo profundo de un módulo en operación............................................ 140

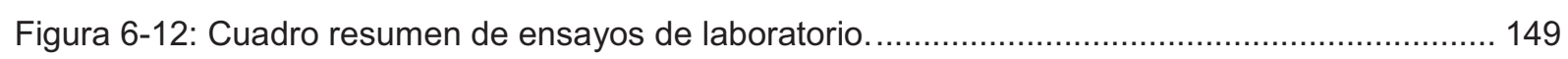

Figura 6-13: Tamizadora de laboratorio y tamices de ensayo. ........................................................ 150

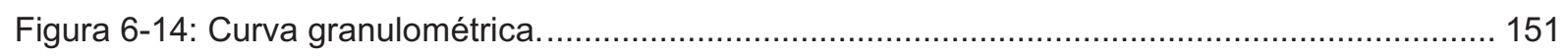

Figura 6-15: Ensayos de sedimentación para elección de floculante. .............................................. 156

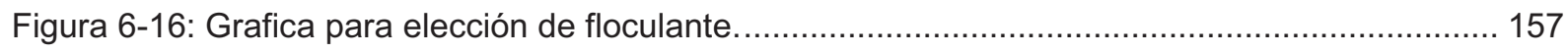

Figura 6-17: Curva de flujo de sedimentación. Dosificación-velocidad de sedimentación. ................. 158

Figura 6-18: Curva de flujo de sedimentación. Dosificación-flujo de sólidos.................................... 159

Figura 6-19: Ensayo en probeta de $2000 \mathrm{ml}$ con finos de feldespato.............................................. 160

Figura 6-20: Curva de sedimentación de ensayo en probeta de $2000 \mathrm{ml}$. ...................................... 161

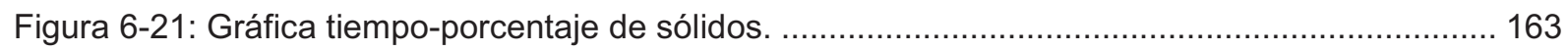

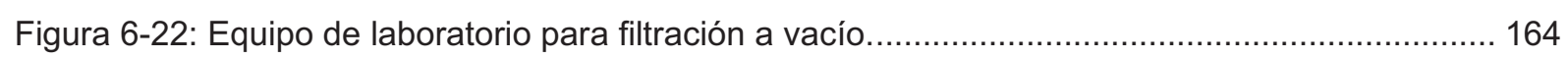

Figura 6-23: Viscosímetro de paletas para ensayo de la tensión de fluencia..................................... 165

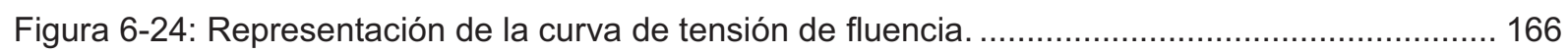

Figura 6-25: Procedimiento del ensayo de asentamiento. ............................................................. 167

Figura 6-26: Ensayo de asentamiento de estériles de flotación. ................................................. 168

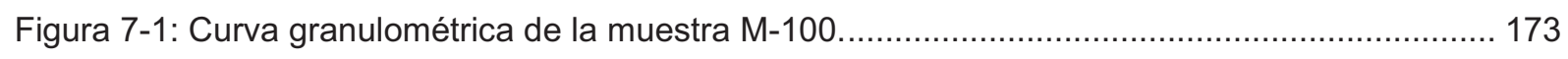

Figura 7-2: Elección de floculante. Ensayo de la muestra M-100 .................................................. 174

Figura 7-3: Gráfica de selección de floculante sobre la muestra M-100 ....................................... 175

Figura 7-4: Grafica de flujo de sedimentación de la muestra M-100. .............................................. 176

Figura 7-5: Alimentación de la probeta de tubo profundo con muestra M-100 ................................ 177

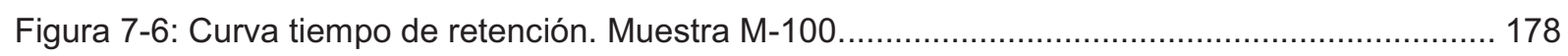

Figura 7-7: Curva tensión de fluencia-contenido en sólidos. Muestra M-100 .................................... 179

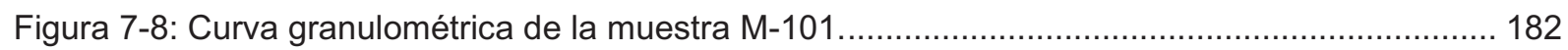

Figura 7-9: Gráfica de selección de floculantes sobre la muestra M-101......................................... 183

Figura 7-10: Gráfica de flujo de sedimentación de la muestra M-101 ............................................. 184

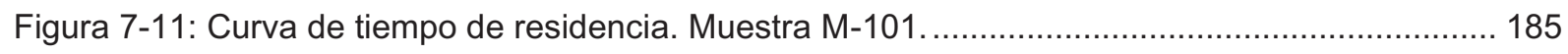

Figura 7-12: Curva tensión de fluencia-contenido en sólidos. Muestra M-101................................. 186

Figura 7-13: Curvas de contenido en sólidos-tiempo de residencia. Muestra M-100........................ 194

Figura 7-14: Flujo de sedimentación para finos de caliza. .............................................................. 197

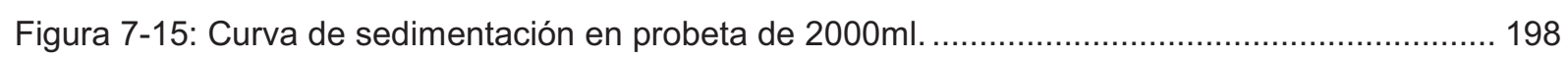

Figura 7-16: Espesador dinámico con finos de caliza................................................................. 199 


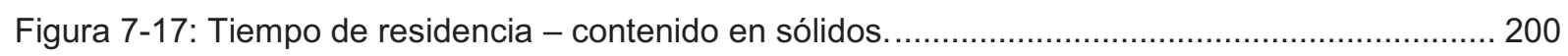

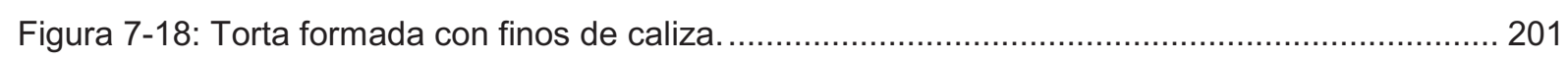

Figura 7-19: Ensayo de asentamiento para feldespato potásico. ................................................ 201

Figura 7-20: Curva de asentamiento para feldespato potásico. ..................................................... 202

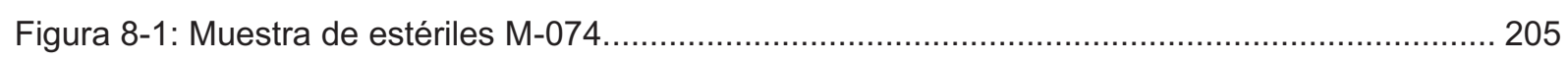

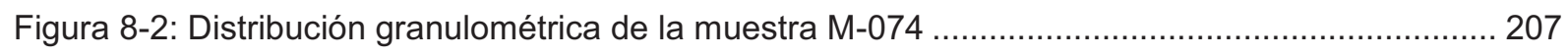

Figura 8-3: Gráfica de selección de floculante. Muestra M-074 .................................................... 208

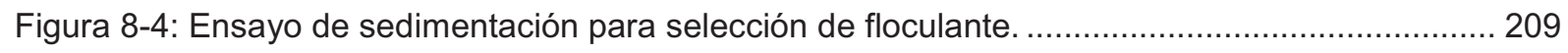

Figura 8-5: Gráfica de flujo de sedimentación. Muestra M-074 ................................................... 210

Figura 8-6: Gráfica de velocidad de sedimentación. Muestra M-074.............................................. 211

Figura 8-7: Curva de sedimentación en probeta de 2 litros. Muestra M-074 .................................... 212

Figura 8-8: Etapas de ensayo dinámico en el espesador de laboratorio. .......................................... 214

Figura 8-9: Curva tiempo de residencia-contenido en sólidos. Muestra M-074 ................................. 215

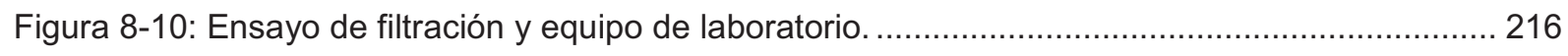

Figura 8-11: Ensayos de asentamiento en probeta. Muestra M-074 ............................................ 218

Figura 8-12: Rango de operación para estériles del yacimiento de Laza. ....................................... 218

Figura 8-13: Plano de situación de los equipos. ....................................................................... 227

Figura 8-14: Diagrama de proceso para espesado de estériles de baja densidad............................ 229

Figura 8-15: Diagrama de proceso para espesado de estériles de alta densidad.............................. 230

Figura 8-16: Diagrama de proceso para espesado de estériles en forma de pasta. .......................... 231

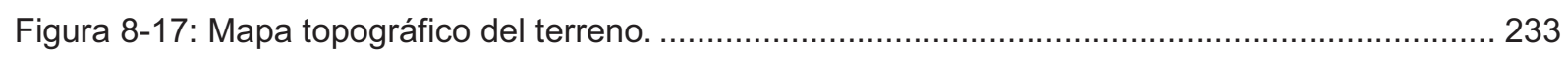

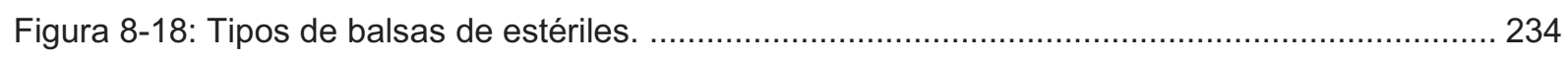

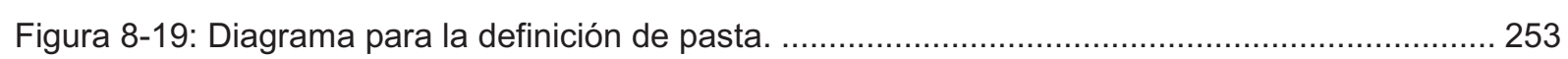




\section{LISTA DE TABLAS}

Tabla 3-1: Variables de una pulpa.

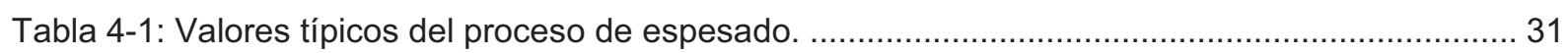

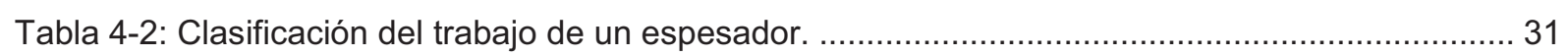

Tabla 4-3: Listado de proyectos mundiales de pasta...................................................... 48

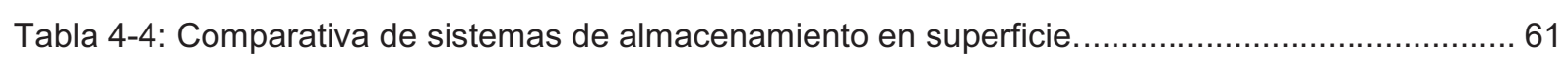

Tabla 5-1: Características de los tipos de tanques. ................................................... 101

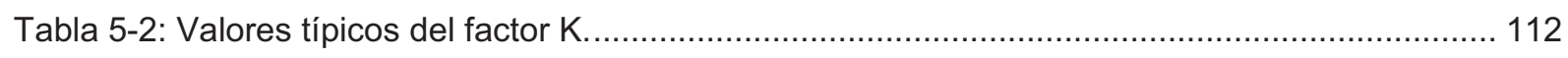

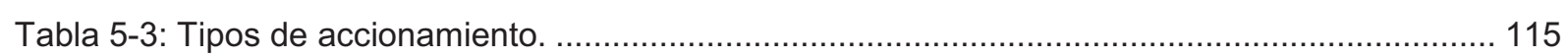

Tabla 6-1: Relación altura/diámetro típica para espesadores de pasta...................................... 130

Tabla 6-2: Preparación de muestras y lecho de lodos. .......................................................... 138

Tabla 6-3: Peso específico del agua en función de la temperatura. .......................................... 153

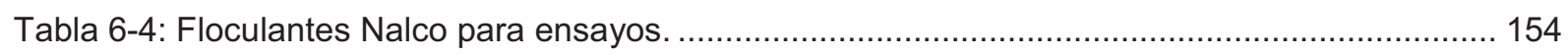

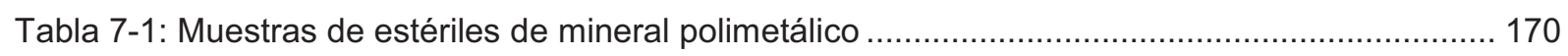

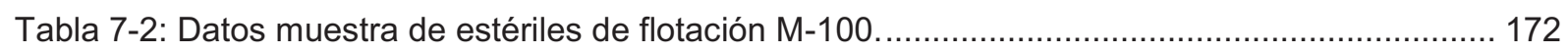

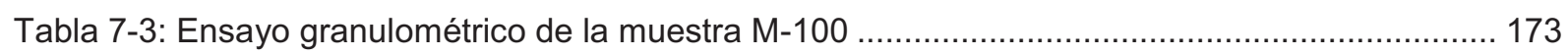

Tabla 7-4: Floculante Nalco empleados en los ensayos de la muestra M-100. ............................174

Tabla 7-5: Ensayo en probeta de 2000 ml. Muestra M-100.............................................. 176

Tabla 7-6: Datos tensión de fluencia-contenido en sólidos. Muestra M-100................................... 179

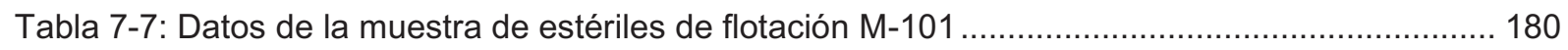

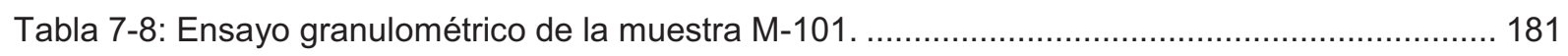

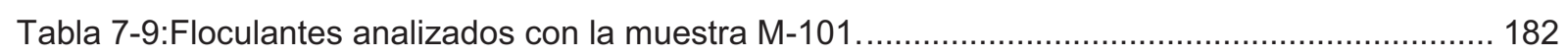

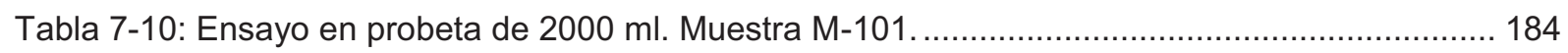

Tabla 7-11: Datos tensión de fluencia-contenido en sólidos. Muestra M-101.................................. 186

Tabla 7-12: Datos de proceso y diseño del espesador de 18 metros en MATSA. ............................ 188

Tabla 7-13: Parámetros promedio de operación del espesador de 18 metros............................... 188

Tabla 7-14: Comparativa espesador de laboratorio y espesador de 18 metros. Muestra M-100...... 189

Tabla 7-15: Datos de proceso y diseño del espesador de 24 metros en MATSA. .............................. 189

Tabla 7-16: Parámetros promedio de operación del espesador de 24 metros.............................. 190

Tabla 7-17: Comparativa espesador de laboratorio y espesador de 24 metros. Muestra M-101...... 190

Tabla 7-18: Espesador de 18 metros en MATSA. Escenarios de operación.................................. 192

Tabla 7-19: Comparativa de valores con máximo caudal de alimentación.................................... 192

Tabla 7-20: Valores promedio para el diseño de espesadores de pasta.................................. 193

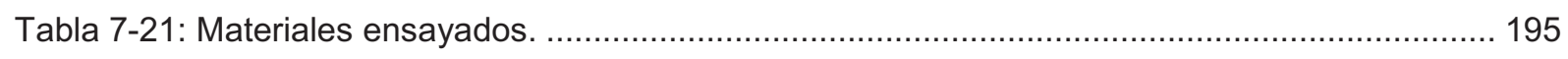

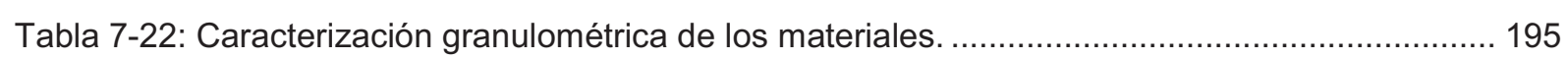

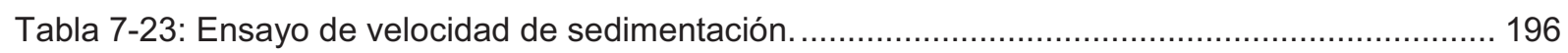

Tabla 7-24: Flujos de sedimentación de los materiales. ........................................................ 197 


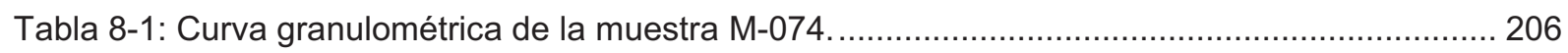

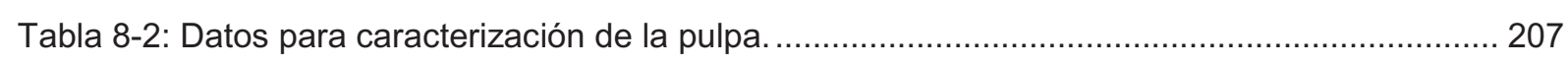

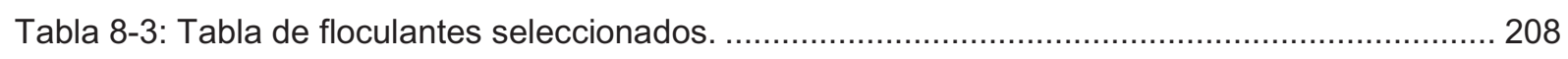

Tabla 8-4: Resumen de datos ensayo en probeta de 2 litros. ........................................................... 212

Tabla 8-5: Tipo de espesador y tensión de fluencia característica. .................................................. 217

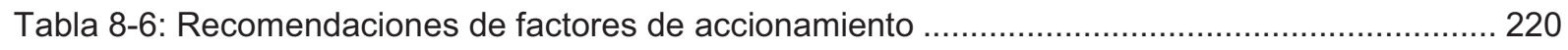

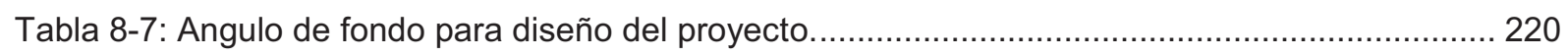

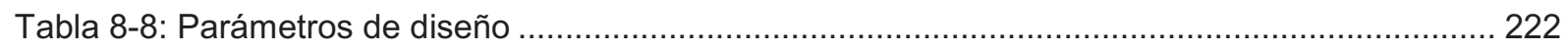

Tabla 8-9: Datos de proceso para espesador de pasta. Proyecto de Laza....................................... 223

Tabla 8-10: Datos de proceso para espesador HDT. Proyecto de Laza. .......................................... 224

Tabla 8-11: Datos de proceso para espesador HRT. Proyecto de Laza. ........................................... 225

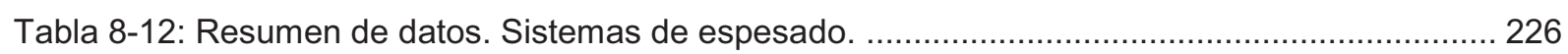

Tabla 8-13: Volúmenes de balsa de estériles para el proyecto Mina de Laza. .................................. 234

Tabla 8-14: Estimación de costes para el proyecto de tratamiento de estériles................................. 235

Tabla 8-15: Costes de capital para el proyecto de espesado en baja densidad ................................ 237

Tabla 8-16: Costes de capital para el proyecto de espesado en alta densidad (HDT)...................... 238

Tabla 8-17: Costes de capital para el proyecto de espesado en pasta ............................................ 239

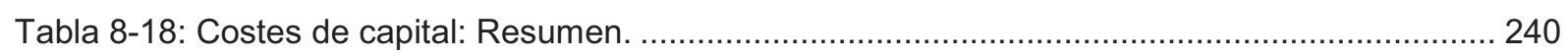

Tabla 8-19: Consumo de agua en la operación de espesado de estériles. ........................................ 241

Tabla 8-20: Potencias y consumos eléctricos para un sistema de baja densidad.............................. 242

Tabla 8-21: Potencias y consumos eléctricos para un sistema de media densidad (HDT)................ 243

Tabla 8-22: Potencias y consumos eléctricos para un sistema de alta densidad. Pasta. ................... 244

Tabla 8-23: Consumo eléctrico y coste anual ............................................................................... 245

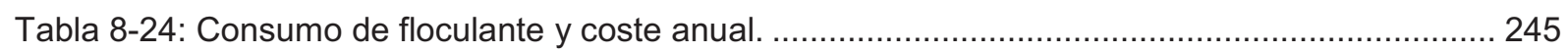

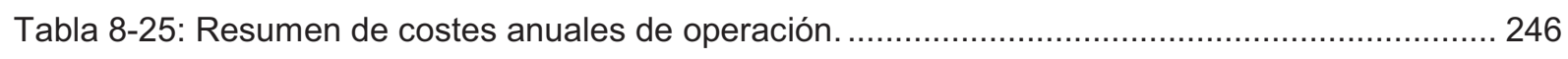

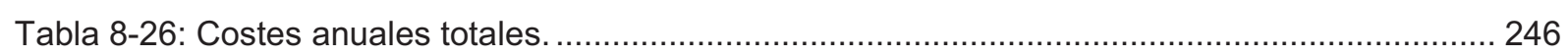

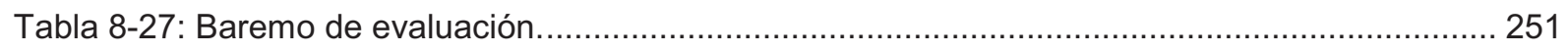

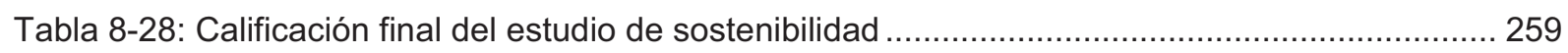




\title{
Resumen
}

El interés en el uso de estériles espesados con alta densidad o en forma de pasta se ha incrementado recientemente de forma significativa en la industria minera. Las razones para considerar esta nueva tecnología varían según los proyectos, pero normalmente incluyen: la necesidad de conservar y ahorrar agua, disminuir el riesgo de rotura de las balsas, operaciones de relleno de mina, facilitar la clausura de la mina o incluso reducir de forma general los costes del proyecto.

La tesis describe los principios de diseño y las características de operación de los equipos de espesado en forma de pasta y como obtener una pasta de estériles a partir de finos para producir una suspensión no sedimentable de un alto contenido en sólidos con una reología no newtoniana.

Se ha fabricado un espesador dinámico de laboratorio, basado en un equipo real, para espesar pequeñas muestras de material en las primeras etapas de cualquier proyecto minero. Se ha desarrollado una metodología de ensayos en laboratorio y se ha probado con una variedad de muestras para comprobar la viabilidad del método propuesto. Los ensayos de laboratorio usando el espesador dinámico produjeron una pasta de estériles no sedimentable con alto contenido en sólidos y aproximaron los datos necesarios que pueden ser utilizados para diseñar el equipo de espesado en pasta y las instalaciones de transporte de la pasta para apilado en superficie o relleno de mina.

Se demostrará con un caso práctico que la pasta puede ofrecer una alternativa atractiva a la operación tradicional de estériles, aunque siempre es necesaria una caracterización de la pasta como pre-requisito para su uso.

\begin{abstract}
Interest in the potential use of high density and paste thickening tailings has recently increased significantly in the mining industry. Reasons for considering this new technology vary across projects, but commonly include the need to conserve and save water, perceived lower risk of failure of damps, backfill mine operations, potential easier closure or even reduced overall project costs. The thesis describes the principles of design and general operating characteristics of paste thickening equipment and how to get a tailing paste from fine tails to produce a non-settling suspension of relatively high solids content with a non-newtonian rheology.

A dynamic laboratory thickener was fabricated, based on the real equipment, to thick small samples of material in earliest stages of any mining project. A laboratory testing methodology has been developed and conducted on a variety of samples to check the feasibility of the method.

Laboratory tests using the dynamic thickener produced non-settling paste tailings with high content of solids, approaching the needed data which can be used to design the paste thickening equipment and transporting facilities of paste for stacking on surface or mine backfill.

It will be demonstrated with a practical case that paste may offer an attractive alternative to traditional tailings management; however a comprehensive characterization of the paste is always a prerequisite for its use.
\end{abstract}




\section{Introducción y objetivos}

\subsection{Introducción}

Cualquier proyecto minero utiliza grandes volúmenes de agua, este gasto de agua implica impactos que se dejan sentir a través de las operaciones mineras, en la descarga y almacenamiento de los vertidos de sólidos, estériles, almacenamiento de minerales, residuos de proceso, aguas de proceso y polvo. Incluso en el desmantelamiento y cierre de las minas las fugas y filtraciones desde almacenamientos y depósitos en pilas de mineral o estéril pueden tener consecuencias medioambientales y sociales muy serias. Cuánto mayores son los depósitos y mayor es su exposición al medioambiente, más problemáticos son los daños que pueden originar. Como resultado de estos problemas, las compañías mineras, a la vez que intentan disminuir los costes para ajustarse a los actuales mercados de minerales, están comenzando a mirar más de cerca los costes que representa el uso del agua en las explotaciones mineras. Por todo esto y para minimizar la huella creada por el uso del agua, las compañías mineras intentan encontrar las soluciones para reducir este impacto, lo que está adquiriendo una importancia cada vez mayor en todos los proyectos mineros durante los últimos años.

El espesado de estériles y su uso como material de relleno en las explotaciones subterráneas está siendo cada vez más usado como una forma de eficiencia operacional de las explotaciones, y en parte es visto también como una solución a los problemas del agua. Estos problemas provienen por la alteración o el desequilibrio de tres aspectos relativos a la sostenibilidad de los proyectos mineros: medioambiental, social y económico.

El espesado de estériles y su tecnología hacen que un proyecto sea sostenible, protege los recursos del agua de su agotamiento y el potencial impacto que tendría, a la vez que permite reservas de terrenos para otros usos que no sean el almacenamiento de residuos o estériles; o al menos reducir el área afectada por los residuos.

Incluso en regiones del mundo donde existe abundancia de agua, existen presiones sobre las compañías mineras para usar la menor cantidad de agua de proceso posible. Esto en parte es debido a la aplicación de criterios medioambientales que intentan prevenir daños a los ecosistemas mediante la reducción del uso del agua por parte de las operaciones mineras.

Buscando maneras de usar la menor cantidad de agua posible se ayuda a las compañías mineras a cumplir con los requerimientos medioambientales y regulaciones que le son impuestas desde los gobiernos y otras entidades reguladoras.

Estas presiones sobre los proyectos mineros significan que el almacenamiento en estado de lodos o pulpas poco espesadas está siendo cada vez menos práctico y menos utilizado. Una de las razones es la alta demanda de agua que esta operación implica y otra es el riesgo creciente de una rotura o fallo de la presa que contiene estos estériles. El espesado de estériles para eliminar agua de las pulpas da una oportunidad al agua para ser reciclada y bombeada de nuevo a la planta para su reutilización. Además, se consiguen unas presas de estériles menos permeables, decreciendo la potencial entrada de aire y agua en los residuos lo que minimiza la oxidación y las aguas ácidas de mina. 
Adicionalmente si esta pasta es depositada en parte en la explotación subterránea en forma de relleno, se produce una menor área geográfica afectada por los depósitos de estériles superficiales. Todo esto se traduce en una menor área afectada por la operación minera, una menor área superficial a ser recuperada y una menor área a ser monitorizada tras el cierre de la mina. Esto también reduce las probabilidades de contaminación de acuíferos por vertidos desde las pilas de mineral o balsas y reduce la exposición de los ecosistemas a los residuos, lo que ahorra superficie para otros usos de la tierra.

En muchos lugares donde se disputa cada litro de agua por la agricultura, la población, la industria, etc. las partes involucradas que viven cerca de la mina, y que sienten que si sus necesidades de suministro de agua no están siendo consideradas adecuadamente por la operación y planificación de la mina, éstas pueden mostrar su disconformidad de muchas maneras, incluso paralizando el proyecto minero.

Tomando los pasos adecuados para minimizar el uso del agua y vigilando este requisito durante la vida de la mina se puede hacer cambiar de opinión a las partes interesadas, y mejorar las relaciones, incluyendo la población residente cercana, el gobierno y otras organizaciones. Esto deriva en la habilidad de la compañía minera para trabajar con las necesidades financieras de la comunidad para cumplir con sus objetivos sin dañar su imagen o reputación. Los aspectos medioambientales y sociales de la minería son cada vez más importantes para el desarrollo financiero de cualquier proyecto. Esto proviene parcialmente a través de la reducción de los costes de capital, y más opciones de fuentes de ingresos o financiación para una compañía, que es vista por la comunidad como responsable social y medioambiental en todos los aspectos, incluyendo por supuesto, el uso del agua.

Uno de los equipos clave que las plantas de tratamiento de estériles es la instalación de equipos de espesado en forma de pasta. Con el diseño y la filosofía de control que se describen en el presente trabajo, hacen de los estériles una pasta característica para ser empleada en los procesos de deposición o relleno de mina.

Mientras que se afrontan los costes asociados con el espesado de estériles y sus instalaciones, las mejoras tecnológicas están ayudando a inclinar la balanza hacia las compañías mineras. A medida que los costes del uso del agua aumentan y la cantidad de agua disponible disminuye, se puede crear un conflicto entre la operación minera y la comunidad que la rodea. Estas mejoras posibles incluyen el diseño de plantas de pasta para estériles aprovechando las últimas tecnologías de los espesadores de pasta. Hay también mejoras en las formas de determinar por adelantado si los estériles de pasta son aprovechables para el espesado, incrementando el uso y reciclado del agua que puede ser usada de nuevo mediante un acondicionamiento o tratamiento para ser reutilizable, minimizando así los problemas sociales y medioambientales, evitando así desastres como el de la mina de Aznalcóllar ocurrido en España en 1998.

En los últimos años se está imponiendo en todas las operaciones mineras, tanto de nueva apertura como existentes, el uso de los sistemas de espesado de estériles en forma de pasta, representando una revolución que ha cambiado el concepto de operación y planificación de los proyectos mineros, especialmente en el aspecto del tratamiento de estériles de metales base. La 
tecnología para el tratamiento de espesado de pasta junto con el desarrollo de los espesadores de cono profundo por parte de los suministradores de equipos de proceso ha hecho posible este cambio y su aplicación en la mayoría de los proyectos de minería metálica en operación y en fase de desarrollo.

En esta tesis doctoral se recoge la elaboración de un trabajo nacido con un espíritu ambicioso e innovador de desarrollar un método de ensayo para los modernos sistemas de sedimentación y espesado de estériles. La idea fundamental es describir las teorías de la sedimentación, la descripción de los sistemas actuales de espesado en forma de pasta y el desarrollo de un método de análisis de laboratorio fiable y escalable, para el diseño de los equipos industriales a partir de pequeñas muestras de material.

El método descrito lleva asociado un ahorro importante de costes y tiempo en las primeras etapas de la ingeniería del proyecto de tratamiento de estériles de mina.

La realización de esta tesis doctoral ha requerido de un estudio en profundidad del estado del arte y el concepto actual de los equipos de espesado de estériles; para ello en el capítulo 2, se revisan los últimos proyectos de este tipo realizados en el mundo y su aportación al tratamiento de estériles.

El capítulo 3; introduce los espesadores y equipos de espesado así como los floculantes y la operación de sedimentación y una serie de definiciones básicas para entender los términos empleados en el texto.

El capítulo 4, aborda las diferentes tecnologías de espesado y tipos de espesadores con especial interés en dos equipos fundamentales: los espesadores de cono profundo y los espesadores de alta densidad en el hundido (HDT), los cuales representan la última tecnología disponible para los proyectos de espesado de estériles en forma de pasta.

Los sistemas de espesado en pasta se desarrollan el capítulo 5, donde se describen las fases de ingeniería y los aspectos claves que deben ser tenidos en cuenta por los ingenieros de proceso en todos los proyectos de pasta. El diseño actual de los equipos de espesado de estériles y la última tecnología aplicada en estos proyectos se aborda en profundidad en este capítulo.

En el capítulo 6, se presenta la metodología y los ensayos de laboratorio para la caracterización de la pasta con el objetivo de obtener de cada una de las muestras los parámetros necesarios para el diseño y operación de los equipos de espesado. Se introduce un sistema de ensayo en espesador de tubo profundo de laboratorio que reproduce las condiciones de operación de los equipos industriales, como los ensayos que determinan las características finales que tendrá la pasta formada y que sirve de punto de inicio para el diseño del equipo de espesado e instalaciones necesarias.

En el capítulo 7, se han realizado una metodología y un conjunto de estudios previos de laboratorio con diferentes materiales para comprobar la viabilidad del método de ensayo, a lo largo del texto, se resumen las pruebas iniciales que se realizaron con diferentes materiales con el objetivo de validar el método de ensayo propuesto mediante una comparativa de los resultados obtenidos en laboratorio con los datos de espesadores de pasta en operación. 
En el capítulo 8, se aplica el método sobre un caso real de espesado de estériles de mina, en este caso se estudian los estériles de la Mina de Laza en Orense a partir de una muestra de finos obtenidos por molienda en seco en el laboratorio.

Se ha realizado en este capítulo un estudio de la sostenibilidad de las operaciones mineras con tratamiento de estériles en forma de pasta donde se evalúan las diferentes tecnologías y los factores que afectan a este tipo de operaciones con el objetivo de obtener un resumen de los beneficios económicos, medioambientales y sociales del uso de los sistemas de espesado de estériles analizados en el trabajo.

En el capítulo 9 se presentan las conclusiones obtenidas sobre los ensayos y la metodología propuesta así como las conclusiones del método propuesto para el tratamiento de los estériles del yacimiento de Laza en Orense.

Finalmente, en el capítulo 10 se proporciona una serie de pautas para la continuación de la investigación de otros casos de interés como son: los estudios de los procesos de bombeo y la tecnología disponible para el bombeo de pasta con alto contenido en sólidos y una alta tensión de fluencia, tal y como se obtiene en los modernos espesadores de pasta; o bien el estudio del comportamiento de los estériles en su deposición y almacenamiento en depósitos de pasta en superficie.

\subsection{Objetivos}

Los objetivos de la presente tesis doctoral son la investigación y análisis de los diferentes equipos y tecnologías existentes para el espesado de estériles en forma de pasta y lodos generados por las operaciones mineras, así como el estudio del diseño, mejoras y métodos empleados para la deposición de estos lodos y la recuperación del agua contenida en ellos.

La tesis doctoral centra su interés en los espesadores de cono profundo para pasta y los espesadores de alta densidad en el hundido debido al creciente interés del sector minero en la gestión y manejo de estos estériles y las necesidades crecientes de agua en las explotaciones mineras. Es reconocido que la reutilización del agua de proceso es esencial para la sostenibilidad de las explotaciones de acuerdo a las normativas y regulaciones locales y gubernamentales y también para la sostenibilidad económica y social de la operación.

Se estudian y analizan todos los elementos que forman un espesador de pasta y los avances que han sido introducidos en los últimos años en este tipo de equipos, incluyendo los sistemas de alimentación e instrumentación y control de los equipos.

Un objetivo fue el establecimiento de una metodología de ensayos de laboratorio alternativa al uso de los métodos clásicos de ensayo de sedimentación en probeta por lotes. Esto se debe de conseguir mediante la creación de un equipo de laboratorio capaz de reproducir las operaciones de espesado en pasta de forma continua para probarlo con diferentes materiales. Este sistema de espesado continuo debe ser capaz de simular un proceso de sedimentación y espesado continuo. El estudio desarrolla los ensayos de laboratorio, procedimientos y equipos necesarios para la caracterización de la pasta imprescindible en las fases de estudio y viabilidad del proyecto minero. 
El método propuesto incluye la descripción y operación de un equipo de laboratorio que ha sido fabricado con el fin de simular el proceso de sedimentación y espesado. Este equipo es de fácil implantación y puede tratar pequeñas muestras de material disponibles en las primeras etapas del proyecto. El método obtenido ha sido comparado con los resultados obtenidos en diferentes espesadores de pasta en operación, con el objetivo final de validar la metodología, ensayos y método de escalado propuestos en esta tesis doctoral.

Por último se realiza el estudio de un caso práctico de la gestión de estériles mineros mediante espesadores de pasta, analizando su viabilidad, la reutilización del agua de proceso y su impacto económico, social y medioambiental. 


\section{Estado del arte}

Una de las aplicaciones más importantes de la separación sólido-líquido es la recuperación de agua de las pulpas o suspensiones químicas o metalúrgicas por medio del espesado. Esencialmente, el espesado comprende la sedimentación de las partículas en cuestión, bajo la influencia de la fuerza gravitacional, para conseguir un producto con un alto contenido en sólidos superior a la suspensión original de la alimentación. Una variación del método de espesado es la clarificación, dependiendo de si se desea obtener un líquido clarificado más que una pulpa espesa. El espesado es sin duda, el método más empleado a escala industrial para la recuperación de agua a causa de su bajo coste y su básico principio de operación. Probablemente su única desventaja sea el espacio necesario para la implantación, si bien es cierto que con los modernos métodos de espesado de pasta y espesado de alta densidad, cada vez es menor el requerimiento de espacio dedicado a esta operación. También el tiempo de proceso requerido es un factor clave de esta operación frente a otros equipos de separación sólido-líquido, como la filtración o la centrifugación. Aunque el elemento tiempo supone retener y mantener una determinada cantidad de sólidos en el equipo para lograr un mayor tiempo de residencia, no es un problema proporcionar una cierta capacidad de almacenamiento en un espesador. Esto puede ser incluso útil, en el caso de paradas de la planta o en operaciones más o menos discontinuas.

Los espesadores continuos presentan dos procesos que ocurren normalmente en ellos y que son fenómenos ampliamente estudiados: la sedimentación y la compactación. Sin embargo como en otros muchos procesos tecnológicos, la práctica ha precedido a la teoría y en muchos casos continua siendo así. Las teorías sobre el espesado han aparecido desarrolladas como método científico desde principios del siglo XX. A los largo de estos cien años se han producido muchas mejoras en el estudio y comprensión de este fenómeno, originándose una gran evolución y se han propuesto muchos modelos y teorías obtenidas a partir de la investigación [10].

El fallo básico en la predicción de un espesador y sus requerimientos de diseño a partir de los ensayos en laboratorio es: que el estándar de sedimentación en una probeta estática no es una réplica exacta de las condiciones que posteriormente van a existir en el espesador comercial, aunque se pueden aproximar considerando varios factores clave. Por lo tanto, un modelo consistente de espesado ayudaría a la interpretación de la curva de sedimentación en probetas y ayudaría a compensar sus limitaciones de forma calculada. Los procedimientos de diseño de los espesadores involucran el uso de factores de seguridad empíricos basados generalmente en la experiencia de los proyectos e investigaciones realizadas. La realización de cualquier método fiable debe incluir una aproximación real al sistema y modo de operación de los modernos sistemas de espesado en forma de pasta.

Otro problema fundamental, es que si bien el comportamiento de una partícula simple sedimentando en un volumen infinito de líquido es un proceso bien conocido y estudiado, el proceso de sedimentación es un proceso mucho más complejo. En el proceso pueden existir diversas partículas, con diferentes pesos específicos, formas irregulares, diversos tamaños y concentraciones que hacen que existan interferencias entre las partículas y las leyes clásicas de la 
clasificación no sean fiables. La consideración en la construcción y modo de operación de un espesador industrial muestra de forma inmediata las diferencias que se experimentan, y que no son simuladas en un ensayo de laboratorio o que pueda a ser llevado a cabo en un medio o probeta de pequeña capacidad para hacer ensayos por lotes. Debido a su proceso continuo, el flujo de los materiales dentro de un espesador unido a su movimiento, hace que las partículas a sedimentar experimenten comportamientos complejos que no pueden ser previstos mediante ensayos en una probeta estática. Obviamente, los métodos semicontinuos o los equipos piloto trabajando en continuo proporcionan la mejor forma de predecir los requerimientos de diseño de los equipos de sedimentación; aunque la desventaja de estos métodos es siempre el elevado volumen de pulpa necesario para realizar estos ensayos, siendo su coste más elevado y con un tiempo de ejecución también más elevado, que realizando los ensayos de laboratorio [8].

En el pasado la claridad del rebose de los espesadores no había sido un punto crítico en la mayoría de las operaciones y el trabajo del espesador era simplemente producir un lodo en el hundido con un contenido en sólidos más o menos elevado, sin importar otras características del lodo formado, como son la tensión de fluencia, viscosidad, etc. Sin embargo, en los últimos años, debido a los estrictos controles de contaminación, la recuperación y recirculación de aguas, la claridad del rebose, etc. en los modernos sistemas de espesado de estériles en forma de pasta; estas características está llegando a tener la misma importancia que la cantidad de los lodos y el contenido en sólidos obtenidos en el hundido.

También la necesidad de ser capaz de transportar el producto hundido mediante bombeo, fija los límites de la concentración del hundido. Esto resalta la aproximación limitada a menudo tomada por el tratamiento de espesado como el proceso unitario y no como la parte integral de todo el proceso minero. La importancia de determinar las características reológicas del hundido tiene una gran importancia en los modernos espesadores de pasta y condiciona las etapas posteriores de bombeo y deposición [32].

De las muchas publicaciones revisadas sobre la teoría de espesado, muy pocas dan un balance de la multitud de modelos y teorías que existen para explicar las teorías de sedimentación a lo largo de las décadas y el desarrollo que han tenido conforme avanzan las tecnologías y equipos de espesado.

En general, las pulpas de estériles a sedimentar se caracterizan por tener un amplio rango en sus tamaños de partículas y presentan un problema en la operación de espesado, debido a que se produce una segregación por tamaños durante el proceso de sedimentación. En las pulpas de minerales, los materiales más finos, en general constituidos por arcillas, imponen una limitación muy severa al proceso de separación sólido-líquido. En estos casos, los aditivos químicos conocidos como floculantes o coagulantes, según su modo de actuar, se emplean de forma general para facilitar la agregación de las partículas. El resultado final es que durante el proceso de sedimentación, las partículas pequeñas son aglomeradas a otras mayores, resultando en una sedimentación más rápida y unos reboses más clarificados. La adecuación de floculantes y coagulantes para una pulpa en particular y su dosificación óptima requiere en cierta medida un número amplio de ensayos, y en muchos casos de pruebas y errores. La evaluación económica 
del uso de floculantes y coagulantes como método de tratamiento de la alimentación, previo al espesado es principalmente una decisión económica [10].

En los últimos años se han realizado progresos significativos de los reactivos usados en la floculación, los cuales poseen la capacidad de flocular las suspensiones de sólidos. Esto ha permitido que en todas las operaciones se puedan usar estos reactivos químicos en el campo de la separación sólido-líquido, particularmente en la sedimentación. El uso de floculantes en la industria minera para la sedimentación de suspensiones de partículas sólidas no es una idea nueva, ya que lleva implantada varias décadas, especialmente el uso de reactivos inorgánicos, existiendo el dicho dentro del sector minero de: "si no funciona, añade cal"; para referirse a los procesos de filtración, sedimentación y flotación, como solución a los problemas de cualquier operación [8].

Todas las materias coloidales y las pulpas en general, envejecen por procesos químicos como oxidación, reducción, etc. lo cual hace que varien sus propiedades físico-químicas, afectando a sus propiedades de sedimentación. Esto puede originar que las muestras enviadas al laboratorio para realizar ensayos de sedimentación sobre ellas puedan estar limitadas por este factor de envejecimiento. Por tanto, es muy común hacer ensayos en la propia planta para evitar estos problemas en el transporte de la planta al laboratorio.

Para la preparación de los reactivos de floculación, es importante que la concentración, tanto de la pulpa como de los reactivos sean conocidas de la forma más precisa posible. Cuando los agentes floculantes se añaden a las suspensiones, es mejor añadirlos de forma diluida a partir de soluciones homogéneas respetando los procesos y tiempos de preparación, para que se produzca un buen contacto entre las partículas en suspensión y el floculante. En el caso de concentraciones de sólidos muy elevadas y que necesitan ser ensayadas, el operador debe diluir la pulpa para observar los efectos del floculante sobre la pulpa mediante ensayos.

Para la evaluación de los floculantes en laboratorio, lo primero es preparar varias muestras de floculantes diferentes que pueden funcionar con un determinado material. En muchos casos la experiencia previa del ingeniero de proceso proporciona una excelente guía de cómo utilizar cada tipo de floculante y la cantidad necesaria. Las muestras de pulpa a flocular serán colocadas en varias probetas, para que cada uno de los floculantes puedan ser ensayado de forma independiente y evaluado de forma visual. La evaluación entre las distintas muestras, se basa en la comparación entre muestras en cuanto a la velocidad de sedimentación, la claridad del sobrenadante, tiempo de reacción del floculante, etc. Una vez realizado estos ensayos previos con la determinación de que reactivos producen el efecto deseado y cual no, lo que representa una primera selección del tipo de floculante a emplear. Estos ensayos previos deben de evaluar la dosificación de floculante requerida y el tiempo de reacción. En muchos casos, la combinación de floculante así como el ajuste del pH de la pulpa con ácidos o bases, pueden mejorar los resultados de un reactivo determinado.

Es importante realizar estos ensayos de floculación, como se detalla en la parte experimental de este trabajo para llegar al floculante óptimo que tenga el efecto deseado sobre la pulpa y con un mínimo coste. Una vez que el número de floculantes ha sido reducido y se han elegido uno o dos 
tipos que han resultado efectivos para la aplicación a analizar, se debe determinar la dosificación adecuada. Dependiendo de los resultados observados en la muestra, se prueban diversas muestras con cantidades establecidas previamente de floculante para ver los resultados y obtener conclusiones sobre los resultados. De esta forma la dosificación óptima del floculante se puede determinar de forma rápida. Esto se realiza de modo visual en la mayoría de los casos, aunque en determinadas operaciones que requieran una buena clarificación del sobrenadante pueden utilizarse ensayos específicos para cuantificar esta clarificación. Todos estos ensayos y sus resultados definen el floculante más económico para la pulpa ensayada.

En el caso de aplicaciones de espesado, una vez que se ha determinado el tipo y dosificación de floculante adecuada, se realizarán los test en probetas de dos litros de capacidad o en otros dispositivos de laboratorio. Las bases de diseño previamente establecidas indicarán los costes de operación y el consumo en gramos por tonelada de material tratado.

Donde se requieren más de un floculante para alcanzar los resultados esperados en la operación de sedimentación, la evaluación del floculante se complica. Sin embargo, el establecimiento de un procedimiento de ensayos en laboratorio ayuda a realizar una evaluación precisa.

Incluso antes de los estudios de Coe y Clevenger, en el año 1916 era costumbre llevar a cabo el diseño de espesadores industriales partiendo de los ratios de sedimentación obtenidos a partir de observaciones en probetas de laboratorio estáticas. Esto se conoce como los ensayos de sedimentación en probeta y es usado hoy en día como punto de partida en el diseño de cualquier tipo de espesador, incluidos los espesadores de pasta. En los ensayos en probetas, una columna de suspensión inicialmente a una concentración uniforme se deja sedimentar y la altura de la interfase es monitorizada en el tiempo, Las probetas de uno o dos litros son las más comunes y utilizadas en este tipo de pruebas. Una concentración uniforme inicial, puede ser obtenida por la inversión de la probeta o bien por su mezcla con agitación, pero cualquiera que sea el método debe tenerse cuidado en no causar la degradación de las partículas a analizar. En los ensayos de laboratorio es necesario generalmente algún tipo de floculante para producir una línea nítida de demarcación entre el líquido sobrenadante y la pulpa; esta línea se denomina interfase [8]. Los flóculos orgánicos producen los mayores ratios de sedimentación pero pueden hacer menos dependientes las predicciones de diseño a partir de los ensayos de laboratorio. Es común también emplear paletas que se hacen girar de forma lenta y manual para simular el movimiento de las rasquetas del espesador industrial en las pruebas de laboratorio. El objetivo del ensayo consiste en representar la curva de sedimentación y obtener el punto de compresión, sin atender a otras características de los lodos, como pueden ser las propiedades reológicas y la tensión de fluencia de los lodos en el hundido. Muchas de las teorías que defienden el concepto del punto de compresión muestran una frecuente incapacidad para el ámbito de tratar pulpas con floculantes a base de polímeros que son los que se utilizan actualmente.

En las teorías antiguas, existen evidencias de conflicto de si la entrada de la alimentación a un espesador debería causar una perturbación que permita que la dilución y la circulación de la pulpa tenga lugar, o por el contrario, si la entrada de la alimentación al espesador debería ser tan inactiva como sea posible. La última visión es favorable para prevenir la clasificación y la 
consecuente formación de un lecho de flóculos, como afirman Scott y Alderton [8]. Sin embargo hoy en día se conoce que cierto grado de agitación es beneficioso, especialmente si se utilizan floculantes y polímeros. Es por ello, que los modernos espesadores de pasta incorporan siempre alguno de estos sistemas de regulación de la agitación y dilución en su sistema de alimentación. Un obstáculo importante en los comienzos, es el efecto del espesador y la profundidad del sedimento en el proceso de espesado, donde la subsidencia de compresión es el cuello de botella del proceso de sedimentación. Aquí aparece, sin duda la importancia de la altura del sedimento en su asistencia a la compactación del lecho de lodos. Aunque la importancia de la profundidad en un espesador fue descubierta muy tempranamente en la evaluación de la teoría de espesado, donde la gran dificultad se experimentó cuando se quiso cuantificar sus efectos. Las teorías desarrolladas más recientemente parecen estar en el camino correcto para cuantificar el efecto de la profundidad [19] y ahora se conoce que tiene una gran influencia en el proceso de pulpas para obtener una pasta.

En el pasado, es una costumbre habitual de la industria minera y metalúrgica emplear las teorías de Talmage y Fitch y de Coe y Clevenger (a menudo en la forma del método de construcción de Oltmann) para predecir los requerimientos del área de espesado a partir de ensayos de laboratorio, utilizando factores empíricos y poco fiables, ya que una probeta estática por lotes no simula con exactitud los procesos que ocurren en los modernos sistemas de espesado en pasta.

Para cualquier teoría, es mejor depender de un sistema específico bajo consideración y aquí de nuevo la experiencia juega un papel muy importante. Generalmente el método de Coe y Clevenger tiende a subestimar el área requerida, mientras que el método de Talmage y Fitch tiende a sobrestimar el área. Una estimación conservadora en el diseño es usualmente lo mejor de las dos opciones posibles, para permitir fluctuaciones de alimentación y un ligero incremento de producción sin reemplazar los mejores equipos. A causa de esto y de su simplicidad experimental es preferido el método de Talmage y Fitch.

En casos donde la concentración del hundido es de importancia crítica, como en el caso del espesado en forma de pasta, los ensayos de laboratorio en probeta clásicos pueden ser considerados no satisfactorios cuando el requerimiento de la concentración del hundido está por encima del $50 \%$ en peso, o donde los tiempos de compresión son largos (superiores a 6 horas), no hay un punto de compresión definido o hay una ausencia de formación de canales en el régimen de compresión. En estos casos es necesario un método sustitutivo para los ensayos, bien en probeta dinámica, como se propone en el presente trabajo, o bien a nivel piloto en planta.

La tecnología de espesado ha recorrido un gran camino en los últimos 40 años. Ahora existe un gran consenso sobre la operación de mecanismos en los distintos regímenes del proceso y requerimientos de diseño, que son en general bien predichos a partir de ensayos en probeta o planta piloto.

Otro punto a favor de utilizar los ensayos en probetas dinámicas para la predicción del espesador de pasta es que los espesadores comerciales suelen ser operados a su máxima capacidad. Consecuentemente, las condiciones estacionarias de funcionamiento no se alcanzan frecuentemente en la práctica en los espesadores. 
La profundidad de los sedimentos juegan un papel importante en todas las teorías de espesado modernas y en las últimas décadas se han desarrollado teorías para cuantificar los efectos de la profundidad del lecho de lodos, y que estas teorías iniciales de Kos y Ardojan no determinaron de forma precisa. Aunque sea de naturaleza empírica, el método de Coe y Clevenger usado junto con la regla de los tres pies (0,9 metros) son adecuadas para casi todas las operaciones mineras y metalúrgicas de espesadores convencionales, si bien, este modelo es de difícil aplicación en los modernos espesadores de pasta, donde el lecho de lodos puede alcanzar más de 10 metros de altura [21].

En las últimas dos décadas el crecimiento de los equipos de espesado en forma de pasta y su aceptación por la industria mientras en general, ha supuesto un reconocimiento a la tecnología de espesado en forma de pasta como un importante proceso para la mejora del manejo de estériles, recuperación de agua de proceso y disminución de los costes de operación [3]. La importancia de este proceso de tratamiento continua en la actualidad y demanda nuevas mejoras en la tecnología de aplicación y predicción de los resultados esperados.

Desde hace pocos años, el uso de espesadores de pasta que eran habituales en las operaciones de alúmina, han sido aplicados en operaciones de espesado de estériles de metales base [32]. Existen algunas aplicaciones de espesadores de pasta en el tratamiento de estériles de níquel, cobre, zinc, oro, etc. $Y$ dentro del sector minero ha sido reconocido recientemente su potencial y ventajas para concentrar estériles en forma de pasta, que es una suspensión de sólidos no sedimentable y no segregable. Los beneficios de esta nueva tecnología aplicada a los estériles son fundamentalmente dos: la eliminación de grandes balsas de estériles y la recuperación del agua de proceso debido a la alta concentración conseguida en el hundido del espesador [31].

Las primeras instalaciones de espesadores de cono profundo datan del año 1998 con aplicación del espesado de estériles en forma de pasta fuera del sector de la alúmina [21]. Es a partir del año 2005 cuando se ha generalizado el desarrollo de la tecnología de espesado en alta densidad y en forma de pasta así como su aplicación en circuitos de lavados a contracorriente.

Históricamente, los espesadores mecánicos son usados de forma general en la industria minera desde hace más de 100 años para la recuperación de agua de los estériles así como para el clarificado de este agua. Un espesador típico consiste en un tanque con fondo cónico y un mecanismo interno de rasquetas con un movimiento lento [9]. Antes que los floculantes a base de polímeros fueran introducidos, los espesadores eran de gran diámetro y baja altura ocupando grandes áreas de terreno y necesitando de un alto tiempo de reposo para conseguir sedimentar los sólidos. Uno de los primeros avances realizados en la operación de espesado fue el uso de floculantes que permitieron aumentar la velocidad de sedimentación de los sólidos, lo que se tradujo inmediatamente en una reducción del área de sedimentación necesaria. El problema era sedimentar partículas difíciles o muy finas, lo cual se pudo abordar hace pocas décadas con la aparición de sistemas de alimentación específicos para estos materiales y los floculantes a base de polímeros.

Existe una amplia literatura para la predicción de los sistemas de espesado convencionales y amplia información para determinar mediante ensayos de sedimentación [10] el diseño y 
dimensionado de los espesadores convencionales atendiendo a las teorías clásicas y que se pueden encontrar en numerosos manuales [35].

Normalmente, siempre se han diferenciado entre dos grandes ramas teóricas para explicar el proceso de sedimentación en espesadores, por un lado las teorías de sedimentación de zona y por otro, las teorías de subsidencia de compresión. Estas teorías clásicas han sido de aplicación en el diseño de equipos y predicción de procesos de los equipos convencionales o los sistemas de espesado de alta capacidad, en cambio no se ajustan a los modernos sistemas de espesado en pasta. Se han resumido las principales discusiones y teorías de la sedimentación de zona desde principios de siglo XX hasta la década de 1960, con las teorías de: Mishler; Coe y Clevenger; Kynch; Talmage y Fitch; Oltman y Yoshioka entre otros. Estas teorías desarrolladas en las primeras décadas del uso de los espesadores convencionales están basadas en la línea de interfase definida producida por la concentración de sólidos y la velocidad de sedimentación. Por el contrario las teorías de compresión se basan en el principio de la compresión que originan las partículas sedimentadas una sobre otra en pulpas altamente concentradas y floculadas. Es a partir de la década de 1960 cuando se empiezan a desarrollar diferentes teorías de espesado con subsidencia de compresión que proporcionará más tarde la teoría ampliamente aceptada de la formación de una red de sólidos y floculante que hace aumentar la fuerza de compresión en el lecho de lodos. Así surgieron nuevas teorías como las de Coe y Clevenger de 1961 y de otros autores como: Roberts y Ardojan, para explicar este fenómeno. Todas ellas se pueden considerar el inicio de los modernos espesadores de pasta que se van a desarrollar con la aparición de los floculantes poliméricos y las mejoras introducidas en los espesadores convencionales especialmente en los sistemas de alimentación. Es por tanto, a partir de la década de 1960 cuando se comienza a considerar la altura del lecho de lodos dentro del espesador como un factor determinante en el incremento de la concentración de sólidos en el hundido [7].

En todas las teorías clásicas, los ensayos por lotes en probeta a escala de laboratorio eran a menudo el único medio disponible para el dimensionado de espesadores debido a restricciones económicas, de tiempo y a la disponibilidad de grandes muestras de ensayos. Son numerosos los autores que han propuesto sistema de ensayos y análisis de los resultados obtenidos en estos ensayos de espesadores convencionales [17].

Los últimos avances en la tecnología de espesado en forma de pasta [12] y los nuevos diseños de partes internas del equipo de espesado, como son, los sistemas de alimentación [15]; geometría del tanque [16] y los mecanismos [5]; hacen que los métodos clásicos de ensayo en laboratorio se presenten como insuficientes y poco precisos para determinar y diseñar el equipo de espesado en forma de pasta o alta densidad. La evolución de los mecanismos y sistemas de alimentación han cambiado de forma radical en la última década. El diseño de estas partes del espesador avanza en la dirección de optimizar el consumo de floculante y alcanzar una mayor concentración de sólidos en el hundido. Los retos de hoy en día consisten en obtener unos ensayos fiables y con una garantía de proceso aceptable. La escasa bibliografía referente a los sistemas de pasta y el diseño de los equipos de espesado forma parte de la propiedad intelectual y tecnológica de las 
empresas y no se encuentra ampliamente difundida, lo que representa un reto para la búsqueda de información para un trabajo de este tipo.

Para explicar el fenómeno de la formación de pasta a partir de finos o estériles hay que tener en cuenta la alta tecnificación que han tenido los espesadores y el aumento de los sistemas de control, bombeo, instrumentación de campo y los floculantes; todo ello ha permitido avanzar en el proceso de separación sólido-líquido en las operaciones mineras [28].

Los primeros espesadores de cono profundo o de pasta estaban basados en la geometría del tanque para conseguir una alta concentración de sólidos, donde no importaban las características reológicas de los lodos obtenidos en el hundido.

Existen numerosos artículos y autores que han elaborado diferentes métodos de ensayo de laboratorio o piloto en equipos similares, pero no se tiene constancia de un método completo de análisis de los sólidos y la pulpa sedimentada [22] y otros sistemas de ensayos tienen una gran capacidad que es inviable en las primeras etapas del proyecto o en las fases de estudio del proyecto minero [19], donde la cantidad de muestra disponible es muy reducida.

Es importante destacar los avances aparecidos en las últimas décadas en cuanto a sistemas de alimentación y al uso de floculantes a base de polímeros que permiten a los espesadores de alta densidad y de pasta alcanzar altos rendimientos [17]; [18]. Sobre este aspecto es escasa la literatura y se debe profundizar en este asunto como una pieza clave de los modernos sistemas de espesado.

Se han agrupado todos los tipos de espesadores utilizados y no se han encontrado en la literatura referencias al desarrollo y crecimiento que han experimentado los equipos de espesados de estériles en forma de pasta ya que se encuentra dispersa. Las dos principales tecnologías de espesado en forma de pasta: de alta densidad y pasta, se han actualizado analizando las tendencias de los equipos utilizados en multitud de proyectos en los últimos veinte años.

En diferentes artículos publicados [2]; [13]; [26] y [33] se aportan datos generales sobre los sistemas de ensayos para pasta pero de una forma dispersa y sin una continuidad en el método, por un lado se encuentran los sistemas de ensayo con equipos piloto y por otro los sistemas de ensayo de laboratorio. Hasta la fecha, la información se encuentra muy dispersa y cada artículo está adaptado a las necesidades del ensayo específico y por tanto, no se ha encontrado ningún texto que proponga un método de ensayo general aplicable a cualquier pulpa de estéril.

En general estos espesadores de pasta crean un hundido de una mayor densidad que los espesadores convencionales y aunque se aproximan a las concentraciones de sólidos en el hundido que se pueden alcanzar con un sistema de filtrado, el coste de operación es mucho menor que en éstos. Estos sistemas de filtrado permiten la deposición de estériles en superficie donde la tecnología en pasta tiene unas nuevas características reológicas que entran en juego en el diseño de los depósitos o balsas de estériles permitiendo la recuperación de una mayor cantidad de agua y una menor huella en la deposición de estériles. En general la creación de una buena pasta dependerá de la distribución de partículas de los sólidos, y es reconocido que se necesita cierto contenido en finos para poder aglomerar las partículas sólidas presentes en la pulpa [20]. 
La creación de una metodología de ensayo para el estudio de la pasta y su comportamiento reológico en las primeras etapas del proyecto [4], es importante para evaluar los sistemas de espesado, transporte y deposición de estériles viables en cada caso [6]; [11]. El reto del diseño de la metodología es que en las primeras etapas del proyecto el ingeniero de proceso cuenta con muestras de estériles muy escasas y por tanto la metodología a aplicar debe ser precisa y lo más completa posible a fin de obtener la mayor cantidad de datos posibles del sistema de espesado en forma de pasta.

La determinación de las propiedades reológicas de la pasta permite diseñar los sistemas de tratamiento de estériles y por tanto los sistemas de transporte y deposición más adecuados en cada etapa del proyecto [30]. Esto permite la esencial reutilización del agua de proceso de la operación minera así como mejorar la sostenibilidad de la operación económica y medioambientalmente de acuerdo a las normativas y regulaciones.

La mejora y aplicación de diferentes tecnologías a los sistemas de espesado ha hecho posible este importante crecimiento de los espesadores de pasta. Uno de los mayores proyectos de espesado de estériles en operación fue realizado en Oriente Medio, compuesto por doce espesadores de cono profundo de 24 metros de diámetro con tecnología de espesado en forma de pasta, tratando 87.000 toneladas por día de estériles de mineral de cobre.

Estos avances han hecho que muchos proyectos se planteen la posibilidad de instalar estos equipos incluso en operaciones existentes con un alto tonelaje de estériles a tratar, esto fue posible a partir del año 2009 , donde se produjo un paso adelante en el diseño de los espesadores con la construcción de los mayores espesadores de estériles para pasta. La introducción de una columna central que soporta la cabeza de accionamiento, pudiendo prescindir del puente del espesador como elemento de soporte del accionamiento. Esto permite a la tecnología de espesadores de cono profundo moverse por encima de los 24 metros diámetro, como venía siendo habitual, y poder alcanzar hasta 55 metros de diámetro. El nuevo diseño de espesadores está actualmente en 40 metros de diámetro, donde cada una de estas unidades puede tratar hasta 18.000 toneladas por día de estériles de mineral de cobre; siendo éstos los mayores instalados actualmente en el mundo.

Con la tecnología de espesado en pasta, los fabricantes han continuado en el desarrollo de nuevas aplicaciones y el nuevo diseño en innovaciones de las instalaciones, con un amplio campo de posibilidades con la amplia gama de equipos existentes, se están explorando nuevas aplicaciones para el manejo de estériles y su almacenamiento, lo que podría dar lugar en condiciones ideales a minas sin necesidades de operar con una balsa de estériles.

Mientras el crecimiento ha sido imparable en la construcción y puesta en marcha de equipos de cono profundo, en un amplio rango de instalaciones y materiales, algunos de los proyectos más innovadores de los últimos años han progresado y se encuentran en operación.

Dos grandes proyectos hasta ahora, para espesado de estériles de cobre, han sido entregados recientemente en 2012 y 2013. Un proyecto de 87.000 t/día se encuentra en operación en Medio Oriente en la mina Sar Cheshmeh y dos espesadores de 40 metros de diámetro para tratar 36.000 t/día de estériles fueron puestos en marcha en 2012 en la mina de cobre Wushan en China. 
En España se cuenta con esta tecnología de espesado en pasta en algunas minas, como por ejemplo el espesador de pasta para estériles de 24 metros de diámetro que se encuentra ya construido y que es uno de los mayores de Europa Occidental en esta aplicación cuando entre en servicio en el año 2015.

Las unidades de 40 metros de diámetro incorporan un nuevo concepto en la tecnología de construcción de los equipos de espesado de estériles, donde la columna central soporta el accionamiento, lo cual abre la puerta a diámetros mayores de los 24 metros, que estaban limitados por las cabezas de accionamiento con soporte sobre el puente del espesador.

Actualmente los espesadores de 24 metros de diámetro con cabeza de accionamiento sobre puente incorporan la gama de hasta $2,45 \mathrm{MN} \cdot \mathrm{m}$ de par de giro. Las unidades de accionamiento sobre columna, llegan a un par de accionamiento de hasta $13 \mathrm{MN} \cdot \mathrm{m}$, que pueden ser montadas en espesadores de cono profundo de hasta 55 metros de diámetro.

El futuro del desarrollo de los equipos de espesado de pasta hace posible la innovación y el crecimiento continuo de estos equipos, abriendo el campo de investigación a nuevos sistemas, mecanismos, sistemas de floculación, transporte de pasta de estériles mineros e incluso novedosos sistemas de operación mineros, como es el caso del relleno de mina (backfill). Todos estos avances abren nuevas vías de investigación de aplicaciones y sistemas así como la mejora continua de los sistemas existentes. Con el objetivo de profundizar en los sistemas y tecnologías de espesado en forma de pasta y evaluar su aplicación en el tratamiento de los estériles de metales base, se ha elaborado la presente tesis doctoral. 


\section{Sedimentación y sistemas de espesado}

\subsection{Espesadores y espesado}

Un espesador es esencialmente un tanque de sedimentación usualmente de forma circular, aunque puede tener otras formas desde cuadrada hasta decagonal. La mayoría de espesadores están provistos de un fondo cónico, provisto de un mínimo de dos brazos con rasquetas para tratar el producto sedimentado y aproximarlo hasta el punto de descarga en la parte central del espesador, por donde se extrae por bombeo el hundido. El tamaño de un espesador puede variar entre unos pocos metros hasta decenas de metros de diámetro, como se muestra en la figura 3-1: Espesador de estériles operando en la mina Cerro Verde (Chile).

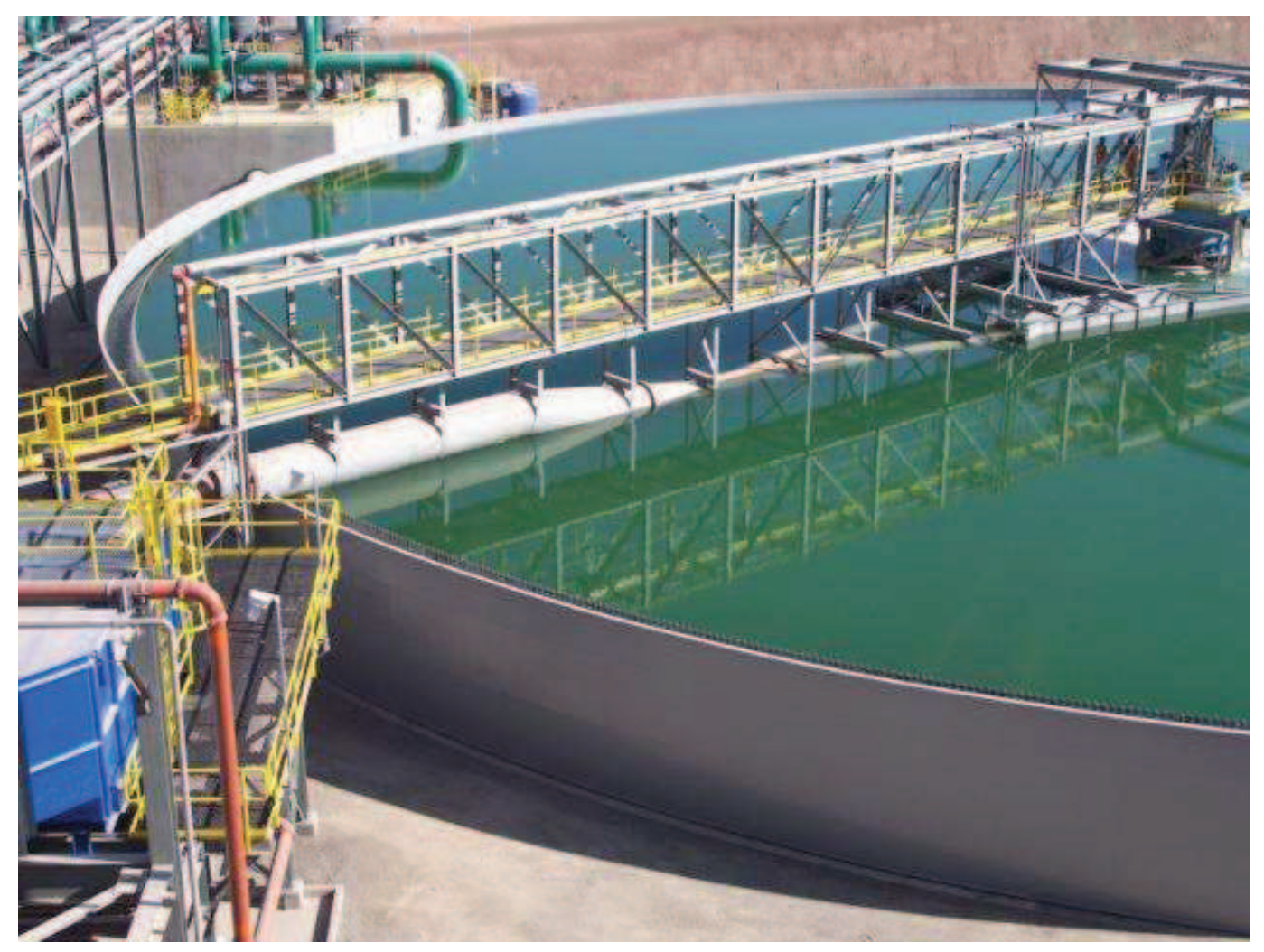

Figura 3-1: Espesador de estériles operando en la mina Cerro Verde (Chile). (Fuente: Cortesía de FLSmidth Dorr-Oliver Eimco Spain S.L.)

El conjunto de brazos y eje es accionado por un mecanismo localizado en el centro del equipo habitualmente. El eje vertical que hace girar las rasquetas generalmente está rodeado por un anillo fabricado en chapa que puede girar o no, solidario con el eje y que se denomina campana de alimentación "feedwell". En algunos equipos, el conjunto de rasquetas es movido por un trole accionado por un grupo de tracción que se mueve por la circunferencia exterior del equipo, en lugar de estar localizado en el centro. El líquido sobrenadante o rebose "overflow", descarga por la parte superior del tanque de un vertedero perimetral.

Para las operaciones de mayor tamaño se emplean espesadores que trabajan de forma continua quedando los operados de forma semicontinua para operaciones piloto u operaciones de baja 
inversión de capital. Estos equipos semicontinuos trabajan de la siguiente forma: rellenando el tanque con la suspensión de sólidos en el líquido, seguido de un llenado continuo con un pulpa más diluida de forma pausada, consiguiendo de esta forma un rebose clarificado. Cuando el lecho de lodos ha alcanzado una altura determinada se para la operación, se decanta el sobrenadante y el tanque es vaciado para comenzar un nuevo proceso.

Los espesadores que trabajan de forma discontinua han caído en desuso y hoy en día todos operan de forma continua implicando una retirada de lodos continua del hundido. La figura 3-2: Zonas de sedimentación y etapas del proceso en un espesador; muestra las diferentes zonas y características y etapas del proceso de espesado desde la alimentación en la campana central hasta la retirada de lodos del hundido.

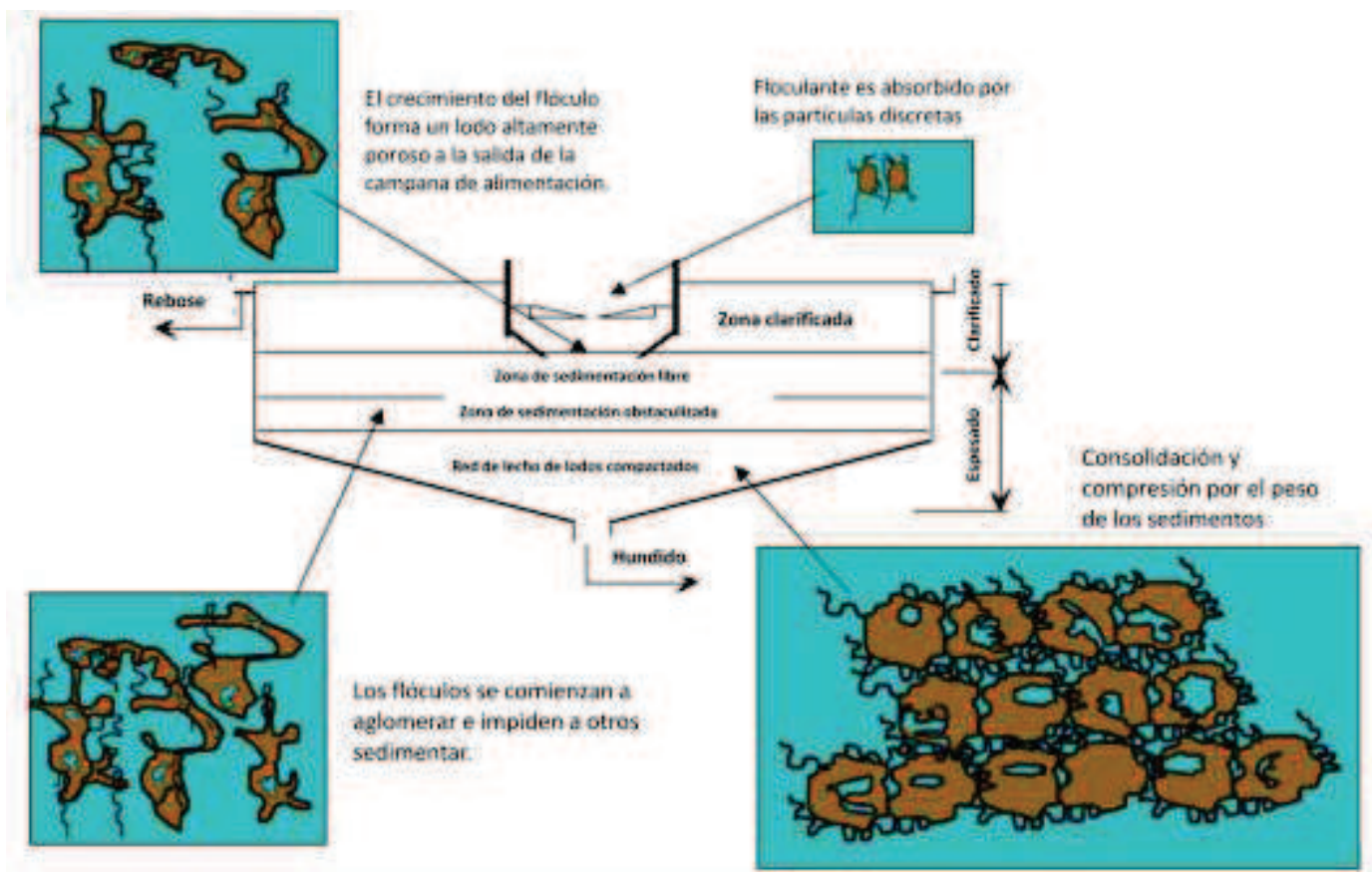

Figura 3-2: Zonas de sedimentación y etapas del proceso en un espesador. (Fuente: adaptado de Loan C., et al. Get Set Go, Outotec)

La capacidad de tratamiento de un espesador continuo es controlada casi siempre, por una concentración de sólidos requerida en el hundido: una pequeña disminución en la concentración del hundido, puede causar un gran aumento en la salida de sólidos por el rebose. La sobrecarga es generalmente medida por el incremento del bombeo del hundido a expensas de obtener un producto menos concentrado por el hundido del espesador.

Los espesadores continuos son operados generalmente con un nivel de lodos bajos y temporalmente son sobrecargados para acomodar incrementos de alimentación sin incrementar el ratio de descarga y poder mantener el lecho de lodos en el fondo.

La capacidad de tratamiento de agua clarificada de un espesador depende de los materiales más finos de la alimentación y el grado de claridad requerido en el rebose durante la operación. En el espesador, la alimentación que sale por la parte inferior de la campana de alimentación, se divide en un flujo ascendente (flujo líquido) y un flujo descendente (flujo de sedimentación) existiendo el 
peligro que los finos entren en la corriente ascendente, lo que implica una limitación en el volumen de líquido producido en el rebose. Sin embargo en la mayoría de los casos, la producción del espesador está limitada por el hundido, más que por el rebose y en otros muchos casos, un espesador se puede operar a casi su máxima capacidad con un nivel bajo de lodos, en función de otros factores del proceso, como son: la velocidad de sedimentación, velocidad de floculación, etc. La sobrecarga proporcionada por un incremento en la alimentación de sólidos, puede sin embargo llevar al lecho de lodos hasta el rebose del espesador, reduciendo la claridad del rebose con sólidos. Es común operar los espesadores con un margen de seguridad razonable, por debajo de su máxima capacidad, para permitir fluctuaciones de sobrecarga en la alimentación. Sin embargo donde se emplean varios espesadores, esta práctica puede resultar antieconómica, siendo el mejor modo de operación trabajar con el menor número de espesadores posibles a su máxima capacidad, usando un control de densidad o automatización para permitir uno o más espesadores en reserva cuando los niveles de lodos comienzan a ascender, evitando así el cortocircuito del rebose.

\subsection{Sedimentación y subsidencia}

El término general de sedimentación se aplica para describir el proceso en el cual todo tipo de sólidos (partículas) caen a través de un medio fluido (gas o líquido) debido a la fuerza gravitatoria. El término sedimentación se utiliza para describir el fenómeno de caída y asentamiento en el cual las partículas son suspendidas por fuerzas hidrodinámicas exclusivamente; y donde el fenómeno de la compresión se encuentra ausente. Para pulpas en las que existe compresión, en las cuales hay partículas que descansan unas sobre otras, se utiliza el término de subsidencia, que se cree más adecuado. La sedimentación y subsidencia pueden formar parte de dos etapas del mismo proceso de asentamiento, donde la transición de una etapa a otra se produce a medida que se avanza en el tiempo. Inicialmente las partículas sedimentan de forma libre y separada, con el flujo de retorno del líquido desplazándose entre las partículas individuales: esto constituye la etapa de sedimentación. Conforme transcurre el tiempo, las partículas van descansando unas sobre otras y existe un comportamiento de subsidencia en la pulpa que origina una compresión. Tanto la sedimentación como la subsidencia son procesos comunes que se dan en el espesado de pulpas.

\subsection{Floculación y coagulación. Pre-tratamiento de la alimentación}

El entendimiento del fenómeno teórico de la floculación ayuda en gran medida en los ensayos y aplicaciones de esta ciencia. Este estudio está principalmente definido por el campo de la química de coloides, ya que la materia a tratar es generalmente coloidal y la mayoría de los floculantes orgánicos son fundamentalmente de este tipo.

Los coloides con sustancias que en un medio homogéneo, normalmente agua, en el caso de la minería, son capaces de contener partículas dispersas. Se acepta comúnmente que el rango de estas partículas coloidales está entre 0,001 y 0,5 micras. Sin embargo partículas mayores de 0,5 a 20 micras de diámetro, pueden tener también propiedades coloidales y son de aplicación en este 
rango de dimensiones. Los materiales y estériles a sedimentar en la industria minero-metalúrgica y química están en el rango de 0,1 a 150 micras, mientras otras industrias como el tratamiento de aguas residuales o municipales sí contienen una parte importante de sustancias coloidales con tamaños inferiores a 1 micra. Es este tipo de sustancias, presentes de modo aislado o mezcladas con materiales más gruesos, son los que se ven afectados por el uso de floculantes y los que a menudo requerirán su uso para una floculación y sedimentación efectiva.

\subsubsection{Naturaleza físico-química de la materia coloidal}

Más que el tamaño, la característica que más distingue a la partícula coloidal es su completa falta de inercia a sedimentar. Las partículas están en un movimiento rápido debido a las colisiones moleculares, adhiriéndose unas a otras por las cargas eléctricas que rodean a las partículas. Por tanto son partículas cargadas con un potencial medible y definido conocido como potencial zeta, y en una determinada suspensión, todas las partículas similares tendrán la misma carga, con lo cual se repelen unas a otras. Si esta carga potencial, puede ser reducida o anulada, las partículas se aglomeran unas a otras, debido a la presencia de otras fuerzas como por ejemplo, las fuerzas de Van der Waals. Estas partículas irán aumentando gradualmente su tamaño hasta que se forme una partícula mayor que sea capaz de sedimentar. Éste es uno de los mecanismos de la floculación: aquel que sea capaz de proporcionar una reducción del potencial zeta y cause la coagulación de las partículas. La carga se crea por la atracción de un ión particular desde la solución hacia la superficie de la partícula. La otra mitad de la molécula, que es el ión con la carga opuesta, es atraída indirectamente y a una distancia importante de la partícula. La distancia entre la capa de iones cercana a la partícula y la capa difusa de los iones cargados de forma opuesta, crea un potencial y la partícula adquiere una carga eléctrica de los iones absorbidos más próximos. La floculación se consigue añadiendo un ión cargado de forma opuesta que será atraído de forma más fuerte al ión absorbido que su homólogo habitual.

Este contacto con la capa de iones exterior reduce el potencial zeta y finalmente se produce el efecto de coagulación descrito anteriormente.

Este tipo de coloide es denominado hidrofóbico, lo que implica que no se mezcla con agua, siendo éstos generalmente las sustancias inorgánicas: óxidos metálicos, sulfatos, cloruros, etc. que cuando han floculado, normalmente no pueden ser dispersados de nuevo. El ión que es absorbido es el menos soluble o la sustancia más débilmente ionizada, y que formaría uno de los componentes de la partícula aglomerada.

En general los iones monovalentes, tipo sodio, potasio, cloro, bromo, etc. tienen un menor efecto. Los iones bivalentes, calcio, magnesio, sulfato, etc. tienen un poder de floculación de 80 veces mayor que los monovalentes. Los iones trivalentes tipo aluminio o fosfato, tienen un efecto mayor que los bivalentes.

Los ácidos en general floculan partículas con cargas negativas y los alcalinos flocularán partículas con cargas positivas mejor que los iones monovalentes de sales. En cualquier caso, el ión no atraído a la partícula absorbida (con la misma carga) no tiene efectos en la floculación a pesar de su valencia. Finalmente las mezclas de iones monovalentes y bivalentes tienen un poder de floculación más débil que las sustancias por separado. Esto se puede observar en la floculación de 
salmueras, que son normalmente muy difíciles de flocular. Hay que señalar, que en ocasiones, donde se añade un ión polivalente, las partículas serán dispersadas de nuevo si el agente químico que causa la floculación, es añadido en exceso. Esto se debe a una inversión de la carga de la partícula, que ha absorbido el ión de la floculación, y que ha recibido su carga. Normalmente si la adicción continúa con la misma carga, provoca la floculación debido al ión cargado opuestamente, de su homólogo absorbido. Esto destaca una de las desventajas del uso de los productos reactivos, que es su sobredosificación, tanto en una planta en operación como en los ensayos que se realizan en el laboratorio.

Otro tipo básico de coloide es la partícula hidrofílica. A menudo esta es una macromolécula formada a partir de un polímero constituido por moléculas más cortas y simples, como por ejemplo el almidón, albúmina, acido silícico y toda una serie de polímeros químicos, tanto aniónicos como catiónicos que existen actualmente en el mercado de los floculantes.

Estas sustancias en general, no deben su estabilidad sólo a los iones absorbidos, que pueden ser pocos, si es que existen, sino que también es debido a su interacción con las moléculas de agua. Las moléculas de agua pueden ser comparadas con imanes ya que presentan dos polos: positivo y negativo. Ciertas partes químicas de las grandes moléculas de los grupos del carboxilo o de la amina, tienen también este efecto polarizado, resultando en que las moléculas son absorbidas en la superficie de la partícula, próximas a este grupo de polos.

Otros tipos de absorción son los debidos a los puentes de hidrógeno. El resultado final en todos los casos es que la partícula está rodeada por una capa protectora de moléculas de agua que previenen su unión a otras partículas.

Se necesitan concentraciones más elevadas de electrolitos para flocular las partículas coloidales hidrofílicas. Por tanto, si los iones deben ser eliminados, estas partículas serán dispersadas de nuevo. La acción de la mayoría de floculantes orgánicos sobre ambos tipos de partículas colídales es muy diferente y dependerá del tipo de electrolito utilizado. Los floculantes orgánicos son también coloides del tipo hidrofílico. Presentan grupos de polos que pueden ser atraídos por partículas cargadas u otras moléculas polares, adhiriéndose a numerosas partículas. Finalmente las partículas pequeñas crecen formando un flóculo debido a la interacción entre las moléculas de floculante y las partículas en suspensión. Algunos de estos floculantes poseen una carga, como un ión formando un electrolito inorgánico, que puede ayudar a la floculación mediante la reducción del potencial zeta, pero parece probable que la mayor parte de los floculantes orgánicos deben su poder de coagulación a su gran tamaño y a la interacción de un tipo u otro entre las cadenas moleculares existentes en los floculantes y en las partículas. Los electrolitos y los floculantes orgánicos a menudo funcionan bien juntos, donde ninguno por separado sería efectivo. Esto puede ser debido a varias reacciones, pero principalmente se puede explicar como una reducción del potencial zeta por los electrolitos permitiendo la absorción de los grupos polares de los floculantes orgánicos que actúan sobre la partícula.

Los floculantes inorgánicos poseen en ocasiones una efectividad muy lenta, ya que el crecimiento de las partículas (coalescencia) depende de la probabilidad de colisión de las partículas. Los floculantes orgánicos, por el contrario, son extremadamente rápidos en su acción y por tanto 
pueden ser usados para acelerar la floculación normal con electrolitos. Las partículas mayores de un tamaño coloidal, presentan muchas de éstas propiedades y serán floculadas o dispersadas de forma similar. En algunos casos las partículas inorgánicas de tamaño más grande que el tamaño coloidal, pueden llegar a ser revestidas con un coloide hidrofílico, que hace que la partícula tenga un comportamiento mejor que el de un coloide. El exceso de la dosificación de floculante puede provocar esta condición que es a menudo, muy difícil de compensar. Otros factores, como la radiación, temperatura, ondas de sonido y la agitación pueden proporcionar una buena floculación, o en otras ocasiones reducir la estabilidad del coloide. Generalmente estas condiciones son utilizadas como asistencia y ayuda a la acción de los floculantes químicos.

\subsubsection{Aspectos prácticos de la floculación. Tipos de floculantes.}

Las pulpas con dificultados de filtrado, debido al cegado de las telas o baja porosidad de la torta por contener partículas muy finas, o que presentan un ratio de sedimentación muy bajo incluso a concentraciones de sólidos bajas, son las más apropiadas para el tratamiento con adición de floculantes. La investigación normalmente hecha por ensayo y error, puede dar sus frutos, si bien; el método basado en los ensayos de laboratorio o el uso de equipos piloto puede reducir los errores. La mayoría de partículas finas y ultra finas son complejas de tratar y probablemente no haya un caso particular que pueda describir el comportamiento de este tipo de materiales, con lo que los operadores de la planta deberán hacer pruebas para comprobar su sedimentación y aplicar el mejor método posible.

a) Floculantes inorgánicos.

La cal en forma de hidróxido de calcio, el cloruro cálcico, el sulfato de amonio, cloruro férrico, sulfatos de hierro, silicato de sodio, ácido acético, y otros ácidos similares, son todos buenos floculantes de los sistemas coloidales. Raramente estas sustancias son utilizadas en combinación con otras, excepto la cal y las sales férricas. Es muy frecuente usarlas de forma conjunta con floculantes orgánicos, donde por separado no tienen un buen efecto o no trabajan bien solos. Generalmente el aditivo químico inorgánico se añade primero y es mezclado con la suspensión, permitiendo un intervalo de tiempo para actuar y después se añade el reactivo orgánico. Los reactivos inorgánicos son añadidos normalmente como soluciones o pulpas, aunque se puede emplear su adicción en seco en los grandes equipos de sedimentación. Los lodos de cal pueden ser preparados con concentraciones de hasta el $20 \%$ y puesto que los otros reactivos son todos solubles, la concentración de la disolución está limitada si se van añadir posteriormente otros reactivos.

La adición en seco o a pequeña escala, hasta $50 \mathrm{~kg}$ por hora aproximadamente, no está recomendada y se prefiere en la mayoría de las operaciones, su adicción como una solución preparada. La concentración de reactivos inorgánicos, cuando se añaden al material a ser tratado y no es una operación crítica, se proporciona una agitación importante en el punto de adición. En caso de materiales muy viscosos o pulpas muy espesas, es común añadir el reactivo muy diluido que siempre será más fácilmente dispersable a través de la pulpa a flocular. Por el contrario los 
reactivos orgánicos deben ser añadidos siempre en estado de solución, como se explicará más adelante.

La cal es el floculante inorgánico más importante y más ampliamente utilizado en el sector minero y en el tratamiento de aguas industriales. En las pulpas a sedimentar, la cal no es efectiva por sí sola, pero en conjunto con un floculante orgánico se hace muy efectiva, aunque siempre existen excepciones. Por ejemplo, la adición de cal siempre mejora la claridad del rebose en la sedimentación, pero un exceso de cal, con pH mayor de 9, puede ser causa de una sedimentación más lenta y un hundido más diluido. Utilizada como floculante para muchas pulpas mejora la filtración, especialmente en aquellas partículas difícilmente filtrables, como arcillas, finos, lodos de fundición, etc. La cal no tiene competencia desde el punto de vista económico y de efectividad del producto en muchas operaciones y procesos mineros.

b) Floculantes orgánicos.

El número de reactivos de floculación del tipo de polímeros sintéticos se encuentra en constante expansión y todos los fabricantes presentan cada vez más tipos y mejores floculantes en el mercado. Estos reactivos orgánicos son siempre añadidos a la pulpa a flocular en forma de soluciones diluidas excepto algunos tipos que no son utilizados mucho como pueden ser la goma guar, almidón, etc. Las soluciones en general deben ser preparadas con la técnica adecuada ya que, de no ser así, no serán efectivos o no alcanzarán el máximo rendimiento. Como todos los reactivos, en general es suficiente añadir el polvo seco en los tanques de agitación de preparación y bombeo. Para prevenir las aglomeraciones y facilitar la mezcla y preparación, el producto debe ser añadido por debajo de la superficie del líquido para que sea mojado el reactivo de forma inmediata. Algunas compañías de fabricantes de reactivos: Dow Chemical, Co; Basf; Nalco, etc. disponen de dispositivos específicos de mezcla y dosificación de sus reactivos, lo que facilita la preparación del floculante de forma adecuada. Los alimentadores vibrantes en seco para alimentar el polvo de reactivos floculantes pueden utilizarse en el caso que el líquido sea agitado de forma enérgica y el producto se mezcle rápidamente. Seguidamente a la formación y mezcla del producto floculante, la agitación debe realizarse durante un tiempo de retención, estimado por cada fabricante, para completar la disolución. En ocasiones, pueden ser recomendables periodos de envejecimiento de varias horas del floculante antes de ser utilizado en la operación.

Los reactivos orgánicos se añaden de forma diluida como práctica habitual en la alimentación del espesador, normalmente a la concentración de entre $0,05 \%$ y $1 \%$ en peso, pero siempre será una función del tipo de pulpa a flocular, de las recomendaciones del fabricante del producto y de la experiencia de los ingenieros de proceso. La disolución normalmente se realiza con agua fresca aunque se puede realizar con agua procedente del rebose del espesador, todo esto depende del proceso. Es normal que existan diversos puntos de adicción de floculante al circuito de espesado antes de llegar a la campana de alimentación. Es cualquier caso, siempre es importante una mezcla rápida de floculante y pulpa a flocular, respetando los tiempos de formación y crecimiento de los flóculos formados. 
c) Limitaciones en el uso de floculantes

Las consideraciones del coste del reactivo o sustancia impone la primera restricción en el uso del floculante. Si en la filtración o espesado funciona sin floculación, es poco probable justificar su uso por efecto de la reducción del tamaño del equipo. El coste de un equipo mayor generalmente, tendrá menor coste que un floculante caro usado durante varios años de operación del equipo. Por otro lado, si el equipo ya se encuentra instalado y el uso de floculante puede incrementar considerablemente la producción, la parte económica se puede determinar fácilmente para revisar los costes de capital y operación. La mayoría de las operaciones que requieren el uso de floculantes son aquellas que simplemente no trabajarían dentro de unos límites prácticos sin ellos. En hidrometalurgia o aplicaciones químicas los floculantes inorgánicos a menudo aportan impurezas al sistema que no se pueden tolerar. Los floculantes orgánicos raramente afectan al sistema debido a sus propiedades inertes. Muchos operadores se preocupan por el efecto del floculante en los circuitos de la planta, debido a la recirculación y al aumento de las concentraciones. A menos que se añada un exceso de floculante, casi todos serán absorbidos por los sólidos si tiene la cualidad de flocularlo y una acumulación de los reactivos químicos orgánicos en el circuito es altamente improbable.

\subsection{Definiciones básicas del proceso de sedimentación}

A continuación se exponen las definiciones básicas sobre pulpas de mineral y la relación existente entre masa, concentración, peso específico y otras variables de los diferentes componentes que forman la pulpa. Cuando se trabaja con pulpas (mezcla de mineral con agua), es necesario expresar la proporción relativa en que se encuentran el mineral y el agua.

Estas relaciones son importantes para determinar y expresar las características de las pulpas y el diseño de los equipos de espesado, transportes por tubería, bombeo y deposición en balsas o galerías de los materiales sedimentados.

\subsubsection{Pulpas. Componentes y relaciones básicas.}

Una pulpa mineral se puede definir como: la mezcla de material molido y agua. En el caso de la sedimentación de pulpas los tamaños del material, bien sea mineral o estéril, está generalmente por debajo de 300 micras, siendo los tamaños habituales las fracciones de 10 a 150 micras para el sólido seco, en el caso de estériles de metales base.

En la figura 3-3: Componentes de una pulpa; y en la tabla 3-1: Variables de una pulpa; se muestran los materiales que intervienen en la formación de una pulpa mineral. 


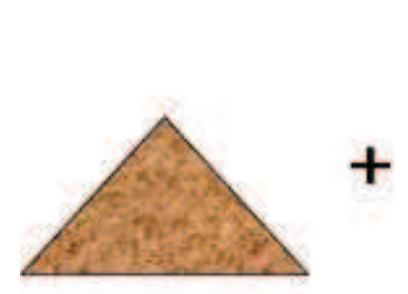

Sólido

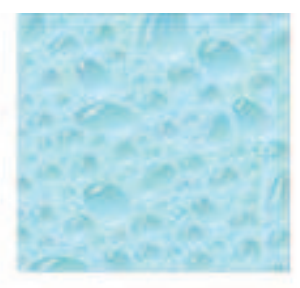

Líquido

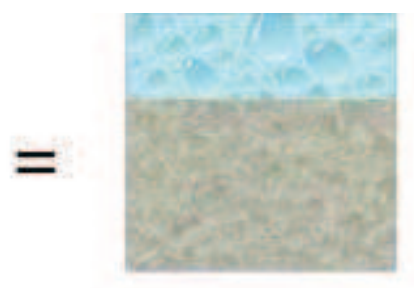

Pulpa

Figura 3-3: Componentes de una pulpa.

(Fuente: Elaboración propia)

Tabla 3-1: Variables de una pulpa.

\begin{tabular}{|l|l|l|}
\hline Peso de sólido: $P_{S}$ & Peso de líquido: $P_{L}$ & Peso de pulpa: $P_{P}$ \\
\hline Densidad de sólido: $\rho_{S}$ & Densidad de líquido: $\rho_{L}$ & Densidad de pulpa: $\rho_{P}$ \\
\hline Volumen de sólido: $V_{S}$ & Volumen de líquido: $V_{L}$ & Volumen de pulpa: $V_{P}$ \\
\hline
\end{tabular}

Fuente: Elaboración propia.

Las relaciones fundamentales entre sólidos, líquido y pulpa son las siguientes:

Peso de la pulpa: $P_{P}=P_{S}+P_{L}$

Volumen de pulpa: $\mathrm{V}_{\mathrm{P}}=\mathrm{V}_{\mathrm{S}}+\mathrm{V}_{\mathrm{L}}$

Siempre se verifican las siguientes relaciones:

$$
\begin{aligned}
& P_{P}=V_{p} \cdot \rho_{P} \\
& P_{S}=V_{s} \cdot \rho_{s} \\
& P_{L}=V_{L} \cdot \rho_{L}
\end{aligned}
$$

a) Proporción de sólidos en peso (S), expresada en tanto por ciento.

$$
S=\frac{P_{S}}{P_{P}}=\frac{P_{S}}{P_{S}+P_{L}}
$$

b) Dilución (d), adimensional.

$$
d=\frac{P_{L}}{P_{S}}
$$

c) Proporción de sólidos en volumen (v), expresada en tanto por ciento.

$$
v=\frac{V_{s}}{V_{P}}=\frac{V_{s}}{V_{s}+V_{L}}
$$

d) Concentración de sólidos en peso (C), expresada en gramos/litro. 


$$
C=\frac{P_{s}}{V_{p}}
$$

Es frecuente expresar la concentración $\mathrm{C}$, en $\mathrm{g} / \mathrm{l}$, aunque es posible expresarla en otras unidades, como: $\mathrm{kg} / \mathrm{l} ; \mathrm{kg} / \mathrm{dm}^{3}$ o $\mathrm{t} / \mathrm{m}^{3}$.

\subsubsection{La pulpa "ideal"}

Una pulpa ideal es aquella en la cual la velocidad de sedimentación es función de la concentración local, única y exclusivamente, aunque la relación no debe ser necesariamente lineal. Muy pocas pulpas son realmente ideales, pero algunas se aproximan a esta situación para concentraciones muy bajas.

Los materiales granulares muestran la mejor aproximación a la pulpa ideal, pero las arcillas y limos en suspensión a menudo se desvían de la situación ideal de forma considerable, especialmente si se emplean floculantes orgánicos.

\subsection{3 Área unitaria de espesado}

El área unitaria, $\mathrm{A}$, medida en $\mathrm{m}^{2} / \mathrm{t} / \mathrm{d}$ ía, es el área de un espesador requerida para tratar una unidad de masa de sólidos en una unidad de tiempo, o simplemente el área requerida por unidad producida para una separación determinada. El área unitaria es un parámetro importante a considerar cuando se diseña cualquier tipo de espesador.

\subsubsection{Flujo de sólidos}

El flujo de sólidos o flujo, simplemente, $\psi$, con unidades de $\mathrm{t} / \mathrm{m}^{2} /$ día, es el ratio de flujo másico de sólidos por unidad de área, o lo que es lo mismo es igual a la concentración por la velocidad.

El flujo más restrictivo o flujo limitante es inversamente proporcional al área unitaria.

Podemos distinguir entre:

El flujo de sedimentación en probeta o simplemente flujo, se define por la expresión: $\psi=U \cdot C$.

$\mathrm{Si}$ en un ensayo en probeta consideramos la suspensión como un todo estacionario y el flujo de sólidos que desciende es igual al flujo de agua de retorno que desciende.

En espesadores continuos, la suspensión se mueve hacia abajo en función de la gravedad y de la retirada de lodos del hundido. Aquí los sólidos sedimentan con una velocidad incrementada debido a la suma de dos componentes: la velocidad inducida, $\mathrm{V}$, debido a la retirada de lodos del hundido y la velocidad de sedimentación debida a la gravedad, U. Por tanto el flujo de sólidos, $\psi$, viene dado por las expresiones 3-10 y 3-11:

$$
\psi=C(U+V)
$$

La subida del flujo de agua bajo las condiciones de espesado continuo es igual a: $V-C \cdot(U+V)$. E término capacidad es usado para indicar el flujo de operación de un espesador. 


$$
\Psi=\frac{Q^{\prime} C_{o}}{A}=\frac{Q}{A}
$$

Donde:

Q' es el ratio de flujo volumétrico en $\mathrm{m}^{3} /$ día

$C_{o}$ es la concentración de la alimentación en $\mathrm{kg} / \mathrm{m}^{3}$

A es la sección transversal del espesador en $\mathrm{m}^{2}$

Q es el ratio de alimentación en $\mathrm{kg} / \mathrm{día}$

\subsubsection{Unidades de concentración}

En ocasiones, el los cálculos de espesado, se utilizan las diluciones D y las concentraciones en volumen $\mathrm{R}$, ambas adimensionales.

Estas variables se definen por las ecuaciones 3-12 y 3-13:

$$
\begin{gathered}
D=\frac{\text { Volumen total }}{\text { Volumen de sólidos }}=\frac{1}{R} \\
R=\frac{1}{D}=\frac{\text { Volumen de sólidos }}{\text { Volumen total }}=\frac{w \cdot \rho}{\left(C \cdot \rho_{s}+w \cdot \rho_{s}-w \cdot \rho\right)}
\end{gathered}
$$

Donde:

$$
\begin{aligned}
& \text { w es el porcentaje de sólidos en peso } \\
& \rho_{\mathrm{s}} \text { es la densidad de los sólidos en } \mathrm{t} / \mathrm{m}^{3} \\
& \rho \text { es la densidad del líquido }
\end{aligned}
$$

Ratio de líquido/sólidos en peso viene dado por la expresión 3-14:

$$
\text { Ratio }=\frac{(1-R) \cdot \rho}{R \cdot \rho_{s}}
$$

Peso / volumen concentración, se deduce de la expresión 3-15:

$$
C=R \cdot \rho_{s}
$$

\subsection{Clasificación de los procesos de sedimentación}

Una clasificación aproximada de los procesos de sedimentación se puede realizar a partir de la concentración de sólidos en suspensión y el grado de interacción entre las partículas presentes. Una propuesta de clasificación se da en la figura 3-4: Interacción entre partículas. 
La clarificación en general, es un proceso que no se analizará, ya que los objetivos del estudio de la presente investigación están centrados en la pasta de estériles mineros. Este tipo de sedimentación en el que las partículas colisionan y floculan durante el proceso, es importante en los procesos de tratamiento de aguas residuales y tratamiento de efluentes. La colisión entre partículas puede ocurrir con un movimiento browniano con velocidades de sedimentación diferenciales, siendo aquí, donde las partículas más rápidas sedimentan afectando a la sedimentación de otras más lentas debido al proceso de barrido y un movimiento circular, como resultado del giro del mecanismo del espesador.

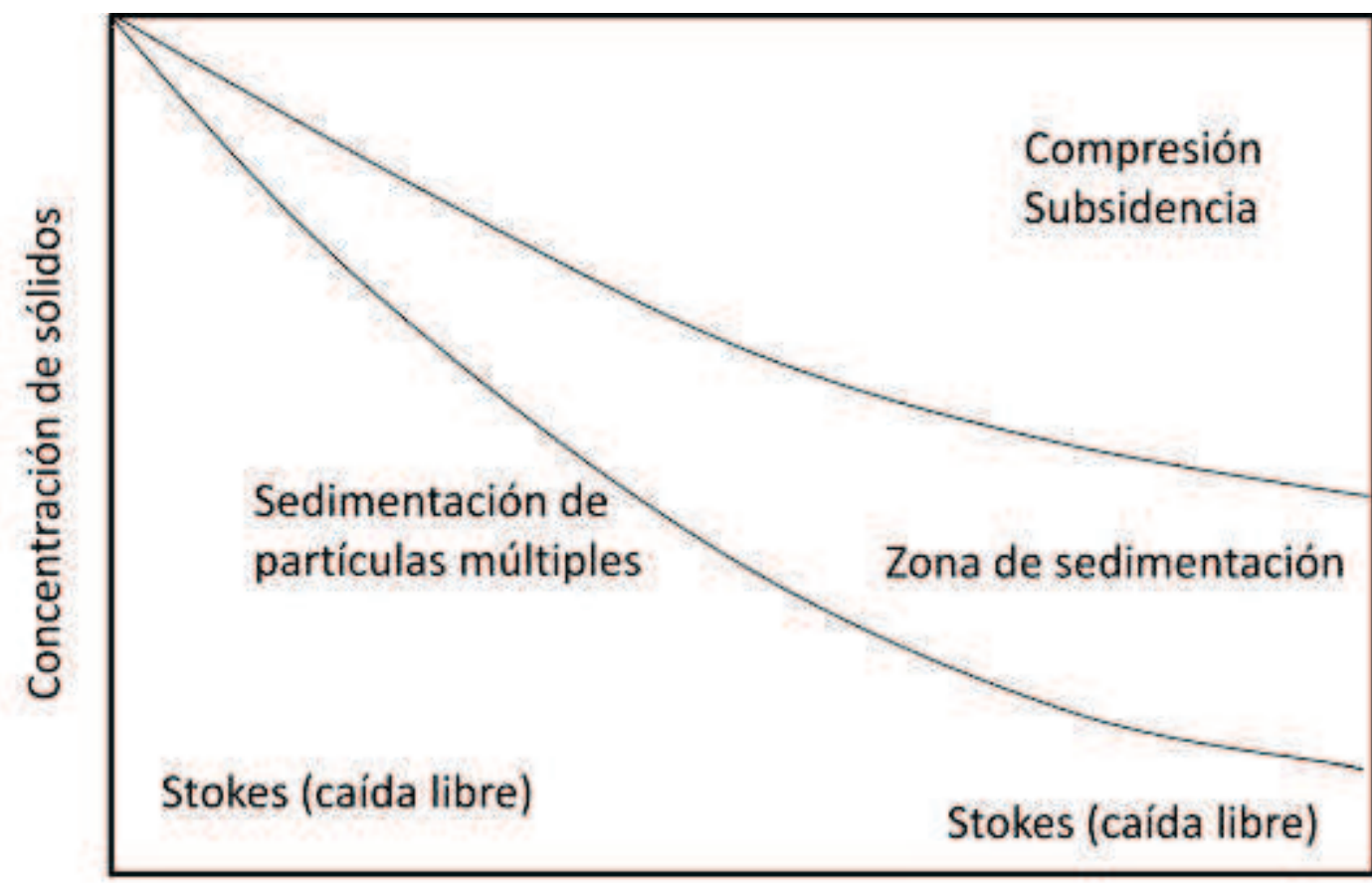

Partículas

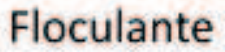

Figura 3-4: Interacción entre partículas.

(Fuente: Elaboración propia)

Este tipo de sedimentación puede ser descrito satisfactoriamente en términos de cinética de segundo orden, donde el ratio de retirada de partículas simples de la suspensión es proporcional al cuadrado de la concentración de partículas. Este modo de sedimentación no forma parte de este estudio, y por tanto sólo se mencionará de forma breve. 


\section{Tecnologías de espesado actuales y tipos de espesadores}

Como se ha mencionado anteriormente, los espesadores son equipos de separación sólido-líquido en los que una suspensión de sólidos formando una pulpa, se alimentan a un tanque provisto de un mecanismo interno que mediante la acción de la gravedad permite concentrar los sólidos en el fondo y hace fluir el agua clarificada hacia la superficie para ser recogida en el rebose del tanque. Por lo tanto, el principio básico del espesador es la sedimentación por gravedad de los sólidos contenidos en la pulpa.

Por lo general las partes que integran estos equipos de sedimentación en esencia son las mismas, si bien los equipos más modernos presentan avances y nuevas tecnologías aplicadas principalmente a los componentes que integran el mecanismo interno, lo que proporciona un mayor rendimiento en su operación. El espesador genera una pulpa de mayor densidad en el fondo del tanque del espesador que es extraída por bombeo generalmente, mientras que se recupera el agua liberada por la zona superior del rebose que se recoge por gravedad en la mayoría de las ocasiones. Otras veces los procesos se pueden complicar debido a las posibles recirculaciones de los lodos espesados hacia el tanque del espesador, o bien, hacia la alimentación del equipo.

Las partes principales que componen cualquier espesador, de forma genérica se pueden dividir en:

a) Tanque con puente o superestructura que soporta el mecanismo y el accionamiento.

b) Mecanismo interno de rasquetas.

c) Sistema de accionamiento de rasquetas.

d) Sistema de alimentación y dosificación de floculante.

e) Cono de descarga del tanque.

f) Instrumentación y equipos auxiliares.

De entre todos los tipos de espesadores existentes, se describen los equipos más utilizados actualmente, que forman la mejor tecnología disponible para la separación sólido-líquido. Básicamente se pueden clasificar en seis tipos los modelos de espesadores disponibles en el mercado, atendiendo a sus características de operación y formas constructivas:

a) Espesadores convencionales.

b) Espesadores de cono sin mecanismo.

c) Espesadores de alta capacidad (HCT).

d) Espesadores de alto ratio de alimentación (HRT).

e) Espesadores de alta densidad en el hundido (HDT).

f) Espesadores de cono profundo o de pasta.

Todos ellos trabajan en esencia bajo el mismo principio de sedimentación por gravedad, con el objetivo de realizar la separación sólido-líquido, pero las diferencias entre unos y otros se 
encuentran fundamentalmente en su mecanismo interno y en la geometría del tanque, que determinan la concentración de sólidos en el hundido y la cantidad de agua recuperada. En la figura 4-1: Tipos de espesadores y características; se representan las peculiaridades de los principales tipos de espesadores y sistemas de las tecnologías de separación sólido-líquido más habituales.

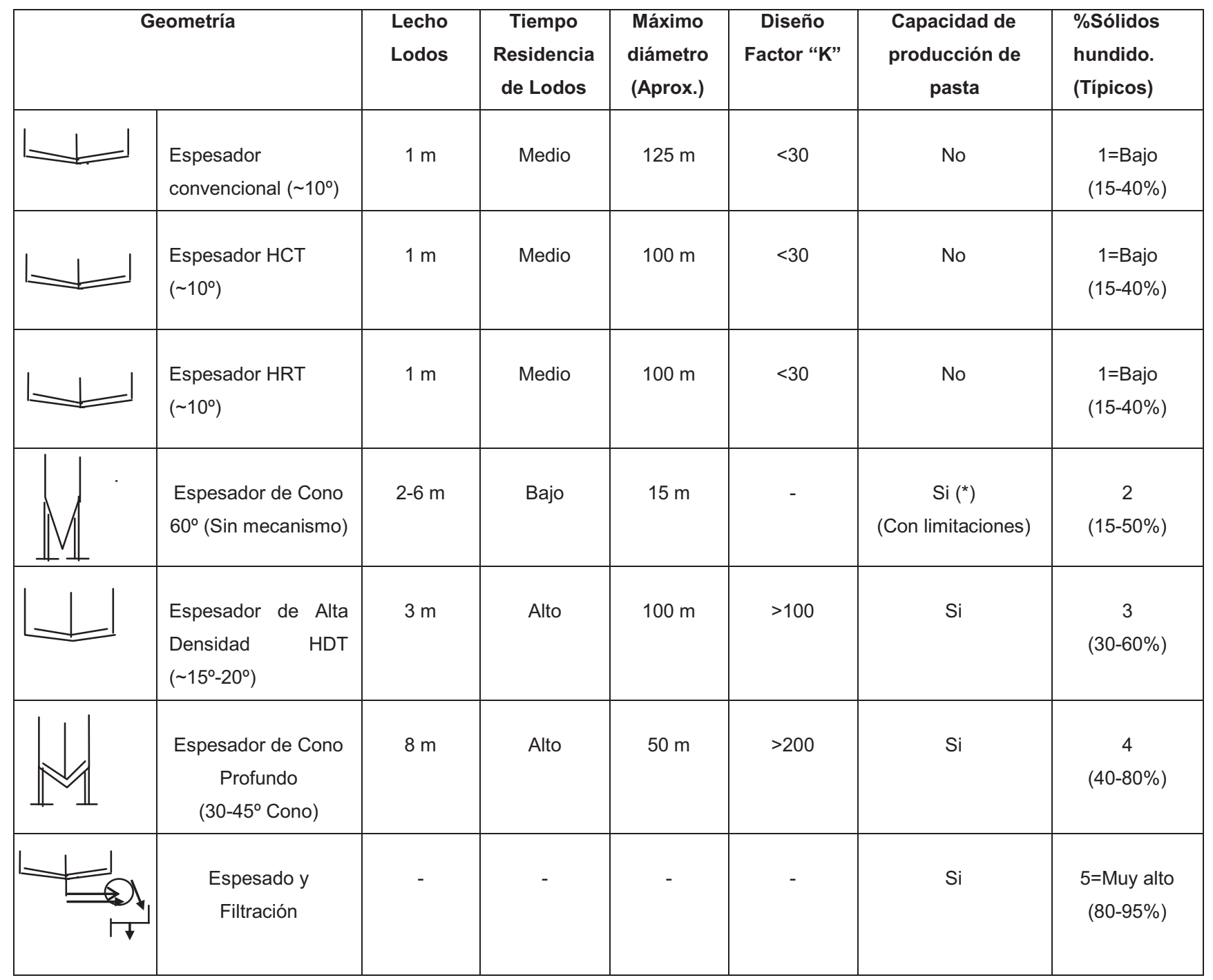

Figura 4-1: Tipos de espesadores y características

(Fuente: Sloote, S., et al. Paste Thickening Iron Ore Tailings. VI Brasilian Symposium on Iron Ore)

Si se atiende a las características de la pulpa obtenida en el hundido producida por estos equipos existen dos principales: el contenido en sólidos y la tensión de fluencia del lodo espesado. Como se observa en la figura 4-2: Rango de operación de los espesadores; atendiendo a estos criterios, a medida que aumenta el contenido en sólidos es normal que aumente la tensión de fluencia, esto es debido al tipo de equipo y modo de operación de éste. El presente estudio se centra en los espesadores que son capaces de producir una pasta o un lodo con alta concentración de sólidos en peso, generalmente por encima del $50 \%$ y una alta tensión de fluencia, normalmente por encima de $50 \mathrm{~Pa}$. 
En este trabajo se describen los tipos principales de espesadores con especial interés en los grupos de espesadores de pasta y espesadores de alta densidad en el hundido HDT.

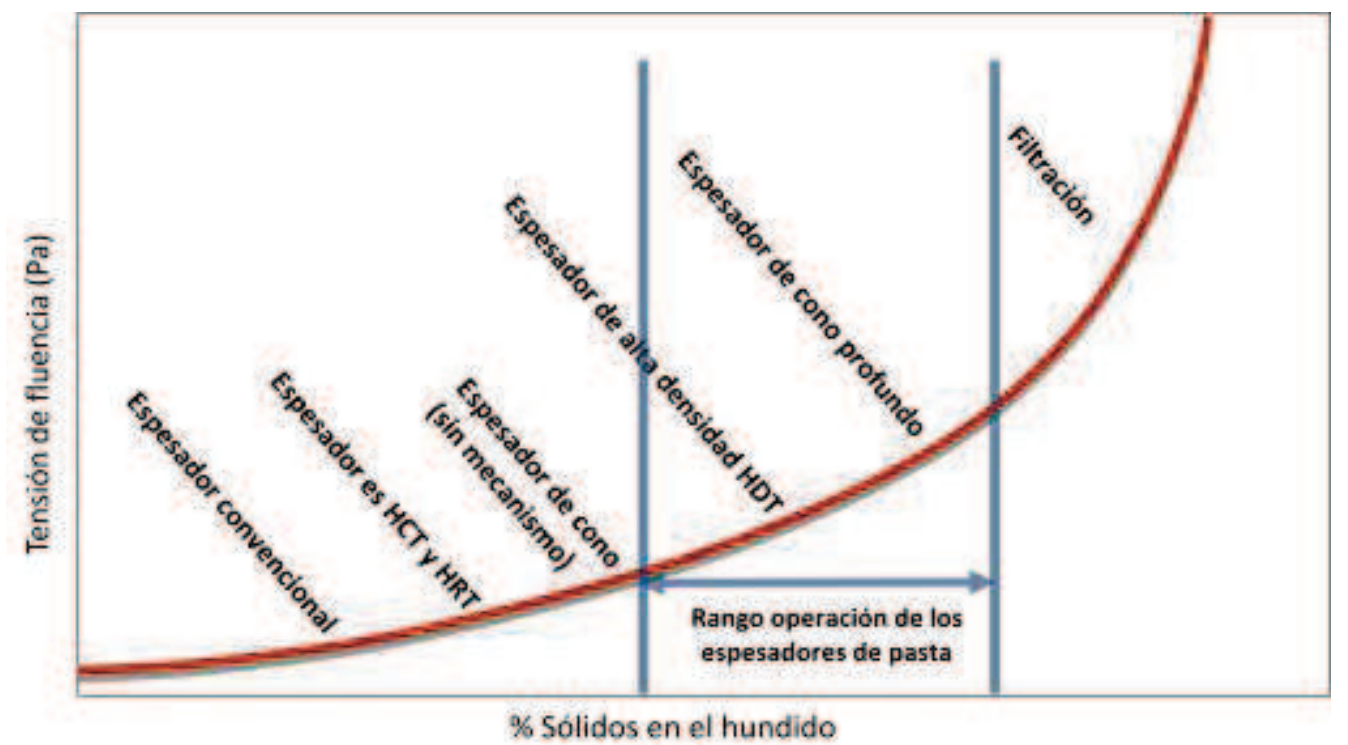

Figura 4-2: Rango de operación de los espesadores (Fuente: Elaboración propia)

El uso de un tipo u otro de espesador o clarificador dependerá del tipo de operación, material de alimentación y de los usos finales tanto de los lodos del hundido como del rebose clarificado.

Todos los materiales a tratar presentan una serie de características en el proceso de espesado, especialmente cuando se tratan en espesadores convencionales o de alto ratio de alimentación HRT. Estos valores típicos de espesado se definen en base a la experiencia de las operaciones y sirven como una primera aproximación en el diseño de los equipos cuando no se dispone de ensayos de laboratorio o piloto. En la tabla 4-1: Valores típicos del proceso de espesado; se definen tres parámetros básicos para los espesadores de tipo convencional, en el tratamiento de diversas pulpas. Estos datos de proceso básicos son: el contenido en sólidos de la alimentación, el contenido en sólidos esperado en el hundido y el área unitaria promedio medida en $\mathrm{m}^{2} / \mathrm{t} / \mathrm{día}$.

También es posible definir una clasificación adoptada en la industria minera que define el tipo de trabajo de los espesadores y de su mecanismo de accionamiento para hacer rotar las rasquetas del fondo en un lecho de lodos. En el caso de los espesadores convencionales, espesadores de alta capacidad y de alto ratio de alimentación, se ha convenido tradicionalmente en clasificar la tarea o trabajo a realizar por los espesadores en cuatro tipos: ligero, normal, fuerte y extrafuerte.

En la tabla 4-2: Clasificación del trabajo de un espesador; se detallan las características del material a tratar y que definen el esfuerzo a realizar por el mecanismo del espesador. Generalmente en las operaciones mineras los espesadores de este tipo se dimensionan para tareas fuertes o extrafuertes. 
Tabla 4-1: Valores típicos del proceso de espesado.

\begin{tabular}{|l|c|c|c|}
\hline \multirow{2}{*}{\multicolumn{2}{c}{ Tipo de pulpa }} & \multicolumn{2}{c|}{ Valores típicos del proceso de espesado } \\
\cline { 2 - 4 } & \% sólidos & $\%$ sólidos & Área unitaria \\
\cline { 2 - 4 } & ALIMENTACIÓN & HUNDIDO & m $^{2} /$ t/día \\
\hline Lodos rojos alúmina. Proceso Bayer & $6 \%-8 \%$ & $15 \%-25 \%$ & $0.9-1.4$ \\
\hline Lodo cálcico. Industria papelera & $8 \%-10 \%$ & $30 \%-45 \%$ & $1.3-1.7$ \\
\hline Concentrado de cobre & $15 \%-30 \%$ & $50 \%-65 \%$ & $0.2-1.9$ \\
\hline Estériles de cobre & $10 \%-30 \%$ & $40 \%-80 \%$ & $0.4-0.9$ \\
\hline Mineral de hierro & $20 \%-30 \%$ & $60 \%-70 \%$ & $0.04-0.08$ \\
\hline Estériles de mineral de hierro & $5 \%-10 \%$ & $45 \%-65 \%$ & $0.4-1.0$ \\
\hline Concentrado de plomo & $20 \%-25 \%$ & $50 \%-70 \%$ & $0.2-0.6$ \\
\hline Estériles de lixiviación de manganeso & $1 \%-3 \%$ & $6 \%-12 \%$ & $10.0-20.0$ \\
\hline Concentrado de zinc & $10 \%-20 \%$ & $50 \%-60 \%$ & $0.3-0.7$ \\
\hline Estériles de lixiviación de zinc & $5 \%-10 \%$ & $20 \%-35 \%$ & $0.8-1.5$ \\
\hline Concentrado de níquel & $3 \%-8 \%$ & $55 \%-65 \%$ & $0.5-2.0$ \\
\hline Arcillas de lavado de áridos & $5 \%-10 \%$ & $25 \%-35 \%$ & $1.0-5.0$ \\
\hline
\end{tabular}

(Fuente: Eimco Process Equipment Co. Clarifier and Sludge Thickener Sales Manual. Eimco 1989)

Tabla 4-2: Clasificación del trabajo de un espesador.

\begin{tabular}{|c|c|c|c|c|}
\hline \multirow[b]{3}{*}{ CONCEPTO } & \multicolumn{4}{|c|}{ Clasificación del trabajo en espesadores } \\
\hline & \multicolumn{4}{|c|}{ Espesadores convencionales, HCT y HRT } \\
\hline & Ligero & Normal & Fuerte & Extrafuerte \\
\hline Carga de sólidos en $\mathrm{m}^{2} / \mathrm{t} /$ día & $>5$ & $1.4-5.0$ & $0.5-1.4$ & $<0.5$ \\
\hline Concentración en el hundido (\% sólidos) & $<5 \%$ & $5 \%-30 \%$ & $30 \%-50 \%$ & $>50 \%$ \\
\hline Porcentaje de sólidos inferior a 74 micras & $100 \%$ & $85 \%-100 \%$ & $50 \%-85 \%$ & $<50 \%$ \\
\hline Porcentaje de sólidos superior a 200 micras & $0 \%$ & $0 \%-5 \%$ & $5 \%-15 \%$ & $>15 \%$ \\
\hline Peso específico de sólidos & $1.0-1.25$ & $1.25-3.0$ & $3.0-4.0$ & $>4.0$ \\
\hline Valores típicos de $\mathrm{K}$ en N/m & $15-58$ & $73-131$ & $146-292$ & $>292$ \\
\hline Valores típicos de $\mathrm{K}$ en lb/ft & $1-4$ & $5-9$ & $10-20$ & $>20$ \\
\hline
\end{tabular}

(Fuente: Eimco Process Equipment Co. Clarifier and Sludge Thickener Sales Manual. Eimco 1989)

\subsection{Espesadores convencionales}

Los espesadores convencionales son bien conocidos desde hace décadas. Éstos forman el conjunto de equipos de diseño y funcionamiento más simple de la familia de espesadores existentes. Fueron los primeros espesadores que se comenzaron a usar a principios del siglo XX y últimamente han caído en desuso con la aplicación de nuevas tecnologías de espesado de estériles y el aumento de las capacidades de tratamiento de las plantas actuales y el uso de modernos sistemas de instrumentación y control.

El equipo es esencialmente un tanque de sedimentación usualmente de forma circular, provisto de un fondo cónico con inclinaciones desde $5^{\circ}$ hasta $10^{\circ}$ con la horizontal. El mecanismo tiene un mínimo de dos brazos con rasquetas para arrastrar el producto sedimentado y aproximarlo hasta 
el punto de descarga en la parte central del espesador, por donde se extrae por bombeo el hundido. El conjunto de brazos y eje es accionado por un mecanismo localizado en el centro del equipo generalmente. El eje vertical que hace girar las rasquetas generalmente está rodeado por un anillo fabricado en chapa que puede girar o no, solidario con el eje y que se denomina campana de alimentación de diseño muy simple. El líquido sobrenadante o rebose descarga por la parte superior del tanque de un vertedero perimetral. En la figura 4-3: Partes de un espesador convencional y en la figura 4-4: Espesador convencional de gran diámetro; se muestran las partes que componen el espesador convencional.

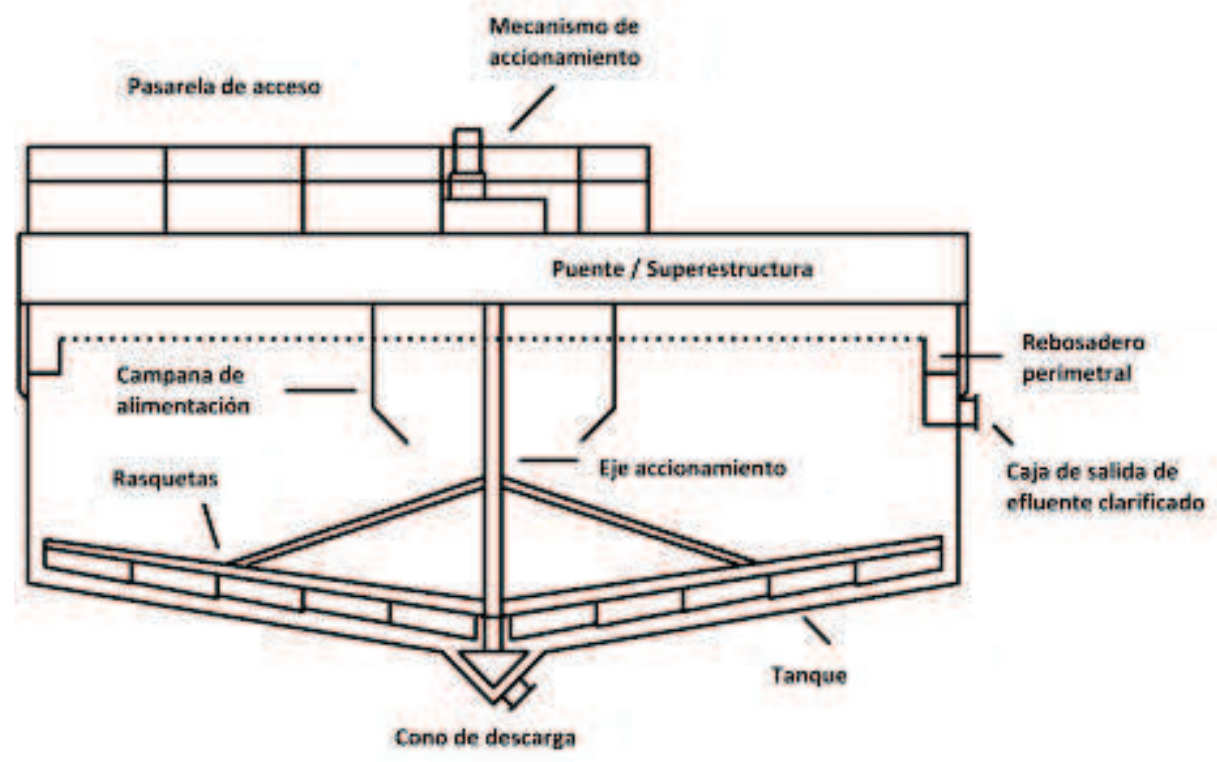

Figura 4-3: Partes de un espesador convencional.

(Fuente: Elaboración propia)

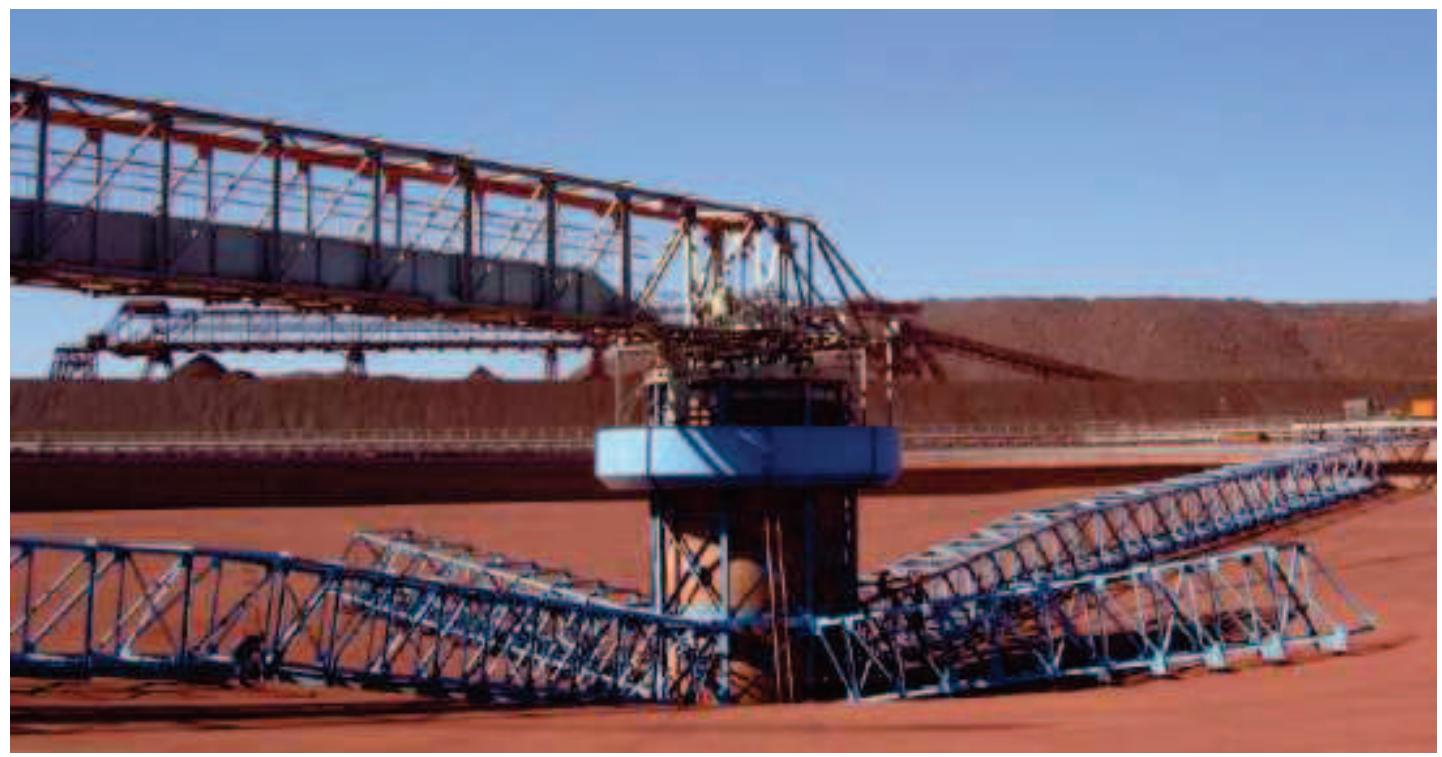

Figura 4-4: Espesador convencional de gran diámetro. (Fuente: Cortesía de FLSmidth Dorr-Oliver Eimco Spain, S.L.) 


\subsection{Espesadores de cono sin mecanismo}

Los espesadores de cono sin mecanismo, son un nuevo desarrollo en la tecnología de sedimentación y es básicamente una combinación de espesador y clarificador en una sola unidad. Estos equipos pueden hacer ambas tareas en un solo tanque produciendo hundidos con alto contenido en sólidos y un rebose muy clarificado simultáneamente.

En la figura 4-5: Espesadores de cono (sin mecanismo); se muestran dos espesadores de este tipo de 12 metros de diámetro. Una desventaja de este tipo de espesador es que presenta una limitación constructiva hasta diámetros de 14-15 metros por lo que su capacidad de tratamiento se encuentra limitada.

En cualquier caso, el diseño de estos equipos permite un alto grado de sedimentación sin pérdidas en la claridad del rebose, reduciendo el espacio requerido para este tipo de instalaciones debido a su esbeltez y alcanzando una relación diámetro/altura de hasta 3:1.

Estos equipos se pueden considerar una evolución de los conocidos equipos del tipo "lamellas" o de placas inclinadas, pero con un diseño más simple y práctico compuesto por cilindros clarificadores verticales que aumentan el rendimiento del equipo y mejorar la operación.

Estos equipos están compuestos por: tanque, cono de descarga, cilindros clarificadores y conos centrales de desagüe, dispuestos como se observa en la figura 4-6: Esquema de operación de un espesador de cono sin mecanismo.

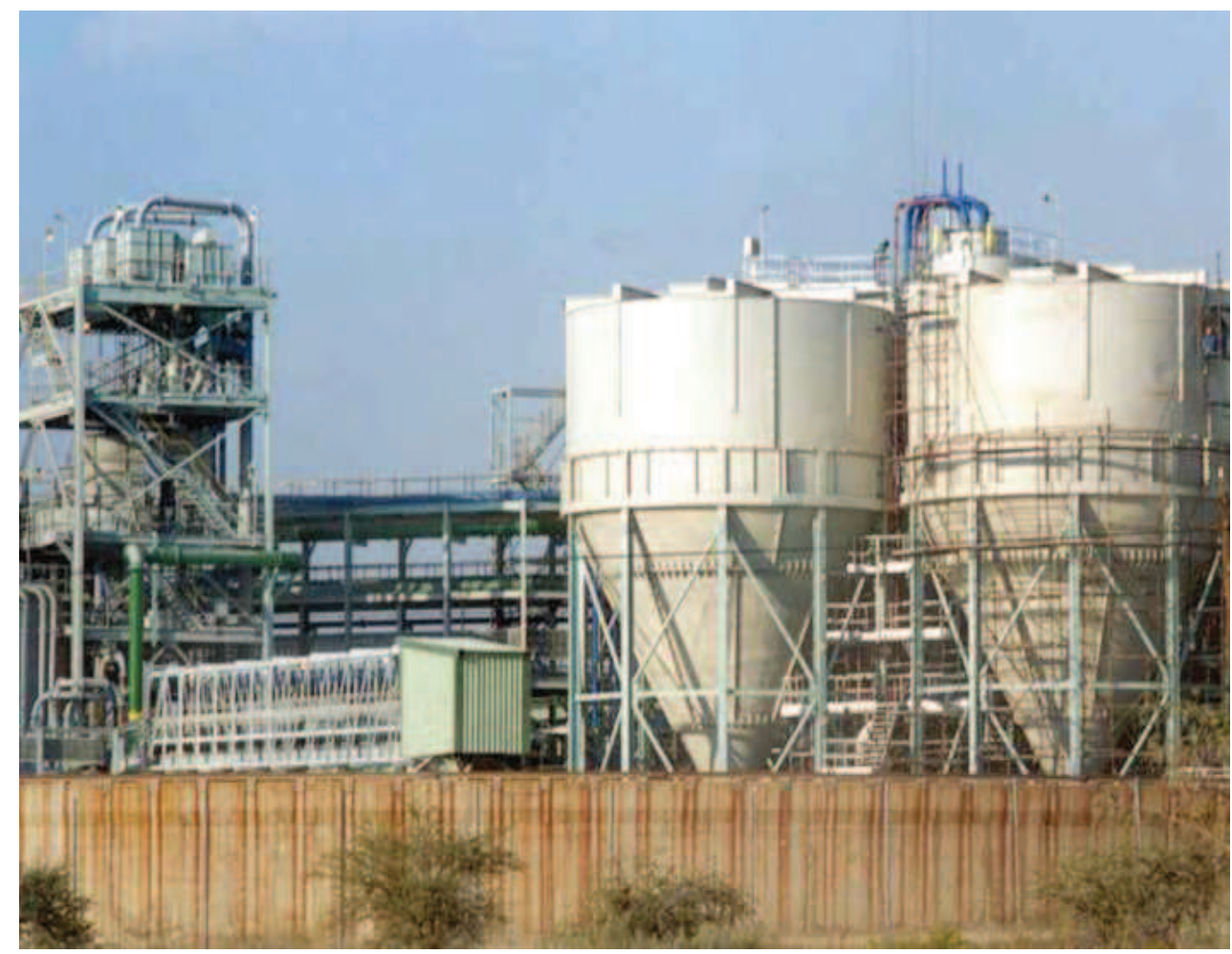

Figura 4-5: Espesadores de cono (sin mecanismo). (Fuente: Cortesía de FLSmidth S.A.) 


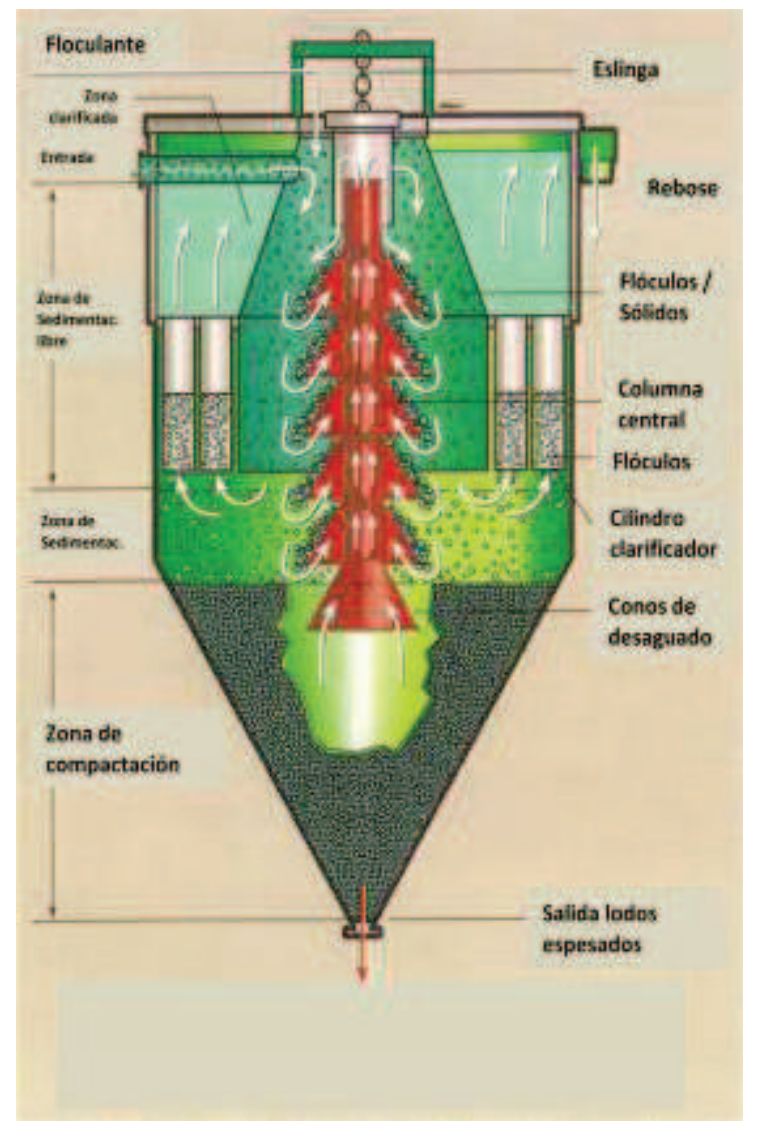

Figura 4-6: Esquema de operación de un espesador de cono sin mecanismo. (Fuente: Cortesía de FLSmidth S.A.)

\subsection{Espesadores de alta capacidad (HCT)}

Los espesadores de alta capacidad HCT (High Capacity Thickener), surgen a partir de espesadores convencionales a los que es necesario sacar el provecho de la eficiencia y el uso económico de los nuevos floculantes a base de polímeros que comenzaron a aparecer hace algunas décadas. Una sobredosis de estos reactivos puede alcanzar los resultados deseados pero en muchos casos resultaban muy costosos, lo que implicó diseñar sistemas de alimentación que maximizaran la eficiencia del floculante. En segundo lugar, con tiempos de retención cortos, la claridad del rebose podía sufrir una merma en su calidad y claridad, resultando en grandes pérdidas de material por el rebose. En tercer lugar, desde que los flujos de alimentación son menos uniformes y con cambios bruscos de caudal, era requerido un sistema de alimentación que regulara estas variaciones. Finalmente sería necesario un equilibrio razonable entre la capacidad del equipo y la densidad del hundido requerida.

Con la atención de la industria centrada en el desarrollo de los dispositivos de alto ratio de alimentación "High Rate Thickener" (HRT) y alta capacidad "High Capacity" (HCT) aprovechando los nuevos floculantes disponibles en el mercado, fue necesario el desarrollo sistemas que utilizasen a pleno rendimiento las capacidades de la floculación. Por tanto, el sector minero y los operadores de planta estaban demandando un uso eficiente del floculante, empleando la mínima 
cantidad de floculante para alcanzar el mayor grado de floculación. Fueron empleadas varias aproximaciones que usaban la energía de la corriente de alimentación para proporcionar la mezcla hidráulica de la alimentación y la solución de floculante, que incluso hoy en día es utilizada en forma de sistemas de eductores o similares. Sin embargo, casi todos los métodos eran susceptibles a los cambios en el caudal de entrada, a la viscosidad de la pulpa y a otros factores, así como a los problemas de escalado de los modelos de laboratorio a los reales.

Esta dificultad fue solventada con equipos de mezclado, donde agitadores mecánicos usados en equipos de filtración, eran empleados para mezclar las soluciones concentradas de floculante con pulpas espesas que alimentaban los filtros, llegando a obtenerse buenos resultados. En primera instancia, esto se podía aplicar a los espesadores y a la sedimentación con un gran éxito, puesto que las suspensiones de la alimentación serían más diluidas y por tanto eran más fácilmente mezclables. Aunque un mezclador o agitador imparte un esfuerzo cortante a la suspensión, es también capaz de mezclar dos flujos de forma casi instantánea, de forma uniforme y rápida, siendo éste uno de los principales requerimientos en la floculación con polímeros. Un balance razonable entre este esfuerzo destructivo y una mezcla homogénea, era fácilmente obtenible con la elección del agitador adecuado a cada pulpa, la velocidad de giro y el tiempo de retención apropiado. Los diferentes agitadores empleados pueden tener altos o bajos esfuerzos cortantes, dependiendo del tipo, pero en general se usaban aquellos que tuvieran una capacidad de mezcla rápida. Experimentalmente se encontró que si la adición floculada era continua mientras la pulpa estaba siendo mezclada con un nivel razonable de esfuerzo cortante aplicado sobre la pulpa, la partícula floculada que se había formado, continuaba creciendo y llegaba a ser más densa y por tanto más fácilmente sedimentable.

Debido a la importancia de una alimentación continua y de flujo constante, casi todos los equipos de espesado, desde los espesadores de alta capacidad hasta los espesadores de pasta más modernos instalan un tanque de desaireación previo. En este tanque es frecuente comenzar la primera dosificación de floculante. Como se ve en la figura 4-7: Espesador de alta capacidad HCT; este tanque se coloca adosado al tanque del espesador y está conectado con la campana de alimentación central. 


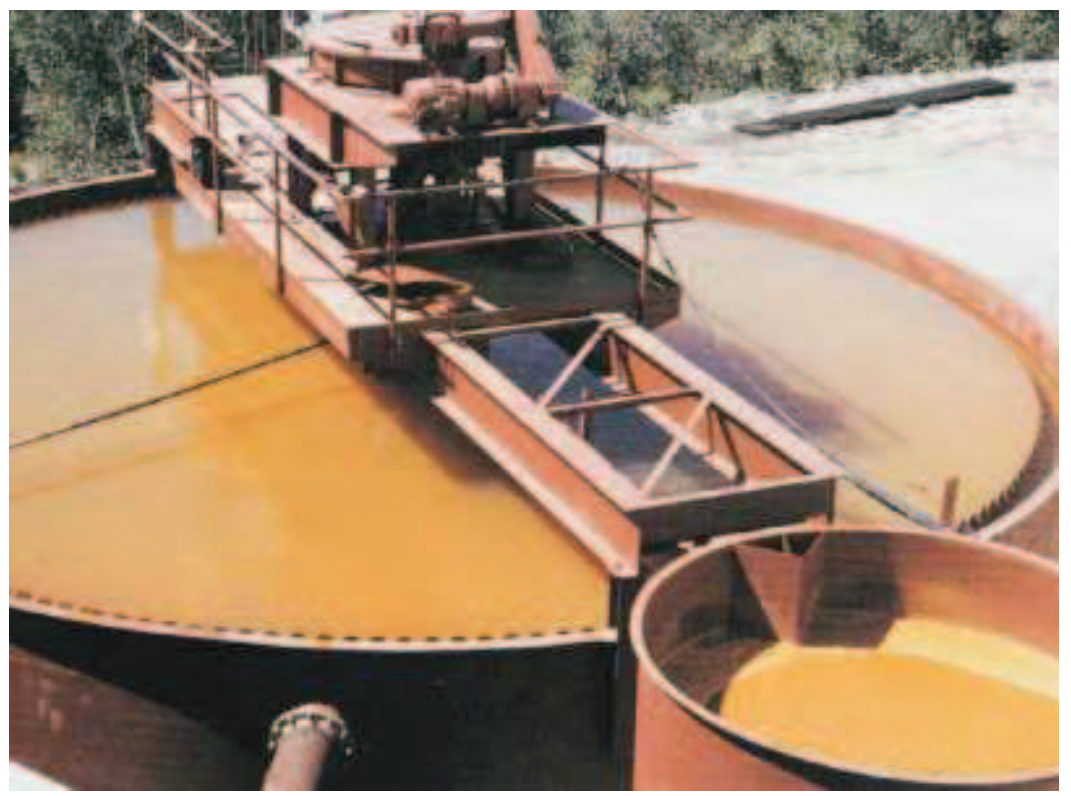

Figura 4-7: Espesador de alta capacidad HCT.

(Fuente: Cortesía de FLSmidth Dorr-Oliver Eimco Spain, S.L.)

El desarrollo de los espesadores de alta capacidad mostró que con su modo de operación y características se obtenían importantes beneficios y se optimizaba el uso de floculante principalmente por las siguientes causas:

a) Se produce una mezcla rápida entre el floculante y la pulpa.

b) La adición por etapas del floculante se debe realizar en al menos tres etapas.

c) La introducción de los lodos floculados se hace en la parte superior del lecho de lodos para una máxima floculación y mejor claridad del rebose.

d) En la zona de placas inclinadas y en la parte superior de la entrada de la alimentación se produce la ruptura de las fluctuaciones que pudieran existir en la alimentación.

e) Suficiente volumen de compresión sobre la entrada de la alimentación proporciona mayores densidades del hundido.

f) Existe un mayor par de arrastre en las rasquetas al manejar una mayor carga por unidad de área.

\subsection{Tecnología y desarrollo de los espesadores de alto ratio de alimentación (HRT)}

Los espesadores de alto ratio de alimentación, conocidos por las siglas "HRT" o "Hi-Rate" cuentan con un sistema de alimentación característico y una forma particular de introducir la pulpa en la campana de alimentación. En esencia son espesadores con una geometría convencional, en el que se ha sustituido la clásica campana de alimentación con descarga directa desde la tubería de alimentación por un sistema mucho más eficiente que optimiza el consumo de floculante y aumenta la producción de los lodos espesados y por lo tanto con una mayor capacidad de tratamiento y un menor consumo de floculante. 
Como se ha comentado, la geometría del tanque no ha variado con respecto al convencional, ya que siguen teniendo taludes del fondo de aproximadamente $10^{\circ}$ de inclinación con la horizontal, pero cuentan con un sistema de alimentación de alto rendimiento, bien sea un sistema de autodilución o bien un sistema de control de la floculación en la campana de alimentación.

En la figura 4-8: Instalación de dos espesadores HRT de 6 metros de diámetro; se muestran estos espesadores operando con concentrado de mineral previos a la etapa de filtración. El éxito del diseño de estos equipos se encuentra en el funcionamiento de su campana de alimentación.

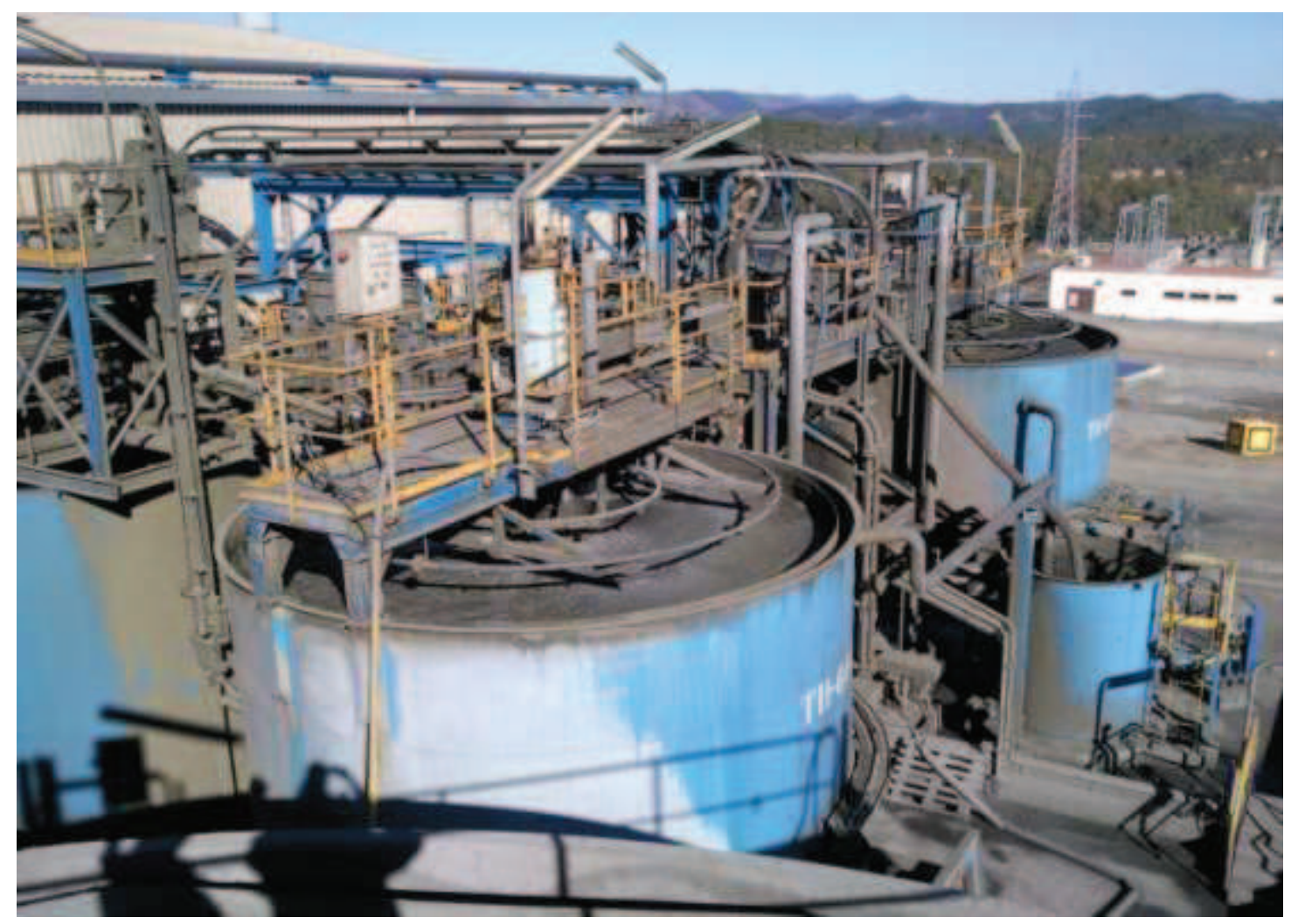

Figura 4-8: Instalación de dos espesadores HRT de 6 metros de diámetro.

(Fuente: Minas de Aguas Teñidas S.A.U.)

En general, las campanas de estos equipos producen la autodilución y la mezcla íntima entre el floculante y la pulpa alimentada sin necesidad de accionamientos y turbinas como era el caso de los espesadores de alta capacidad "HCT". Las campanas de estos espesadores son del tipo "Fitch" o un modelo evolucionado, si bien están provistos de otros sistemas más actuales como es la alimentación con eductores para autodilución y campanas con bafles interiores para controlar la energía del flujo de pulpa alimentada.

En estos espesadores se produce la autodilución debido al flujo de la pulpa y a que los floculantes o reactivos son inyectados en diversas etapas a lo largo del canal o tubo de alimentación y dentro de la propia campana de alimentación. Con esto se consigue una mejora en el control de la floculación, originándose con el sistema eductor una turbulencia y dilución junto a una agitación suave para conseguir la optimización de la floculación. Esto provoca que la dilución y mezcla se produzca de forma efectiva en la zona previa a la entrada de la campana de alimentación, e influye 
directamente sobre las partículas de sólidos para crear los flóculos. En la figura 4-9: Detalle del mecanismo de un espesador HRT; se puede apreciar los componentes de un sistema de alimentación con eductores.

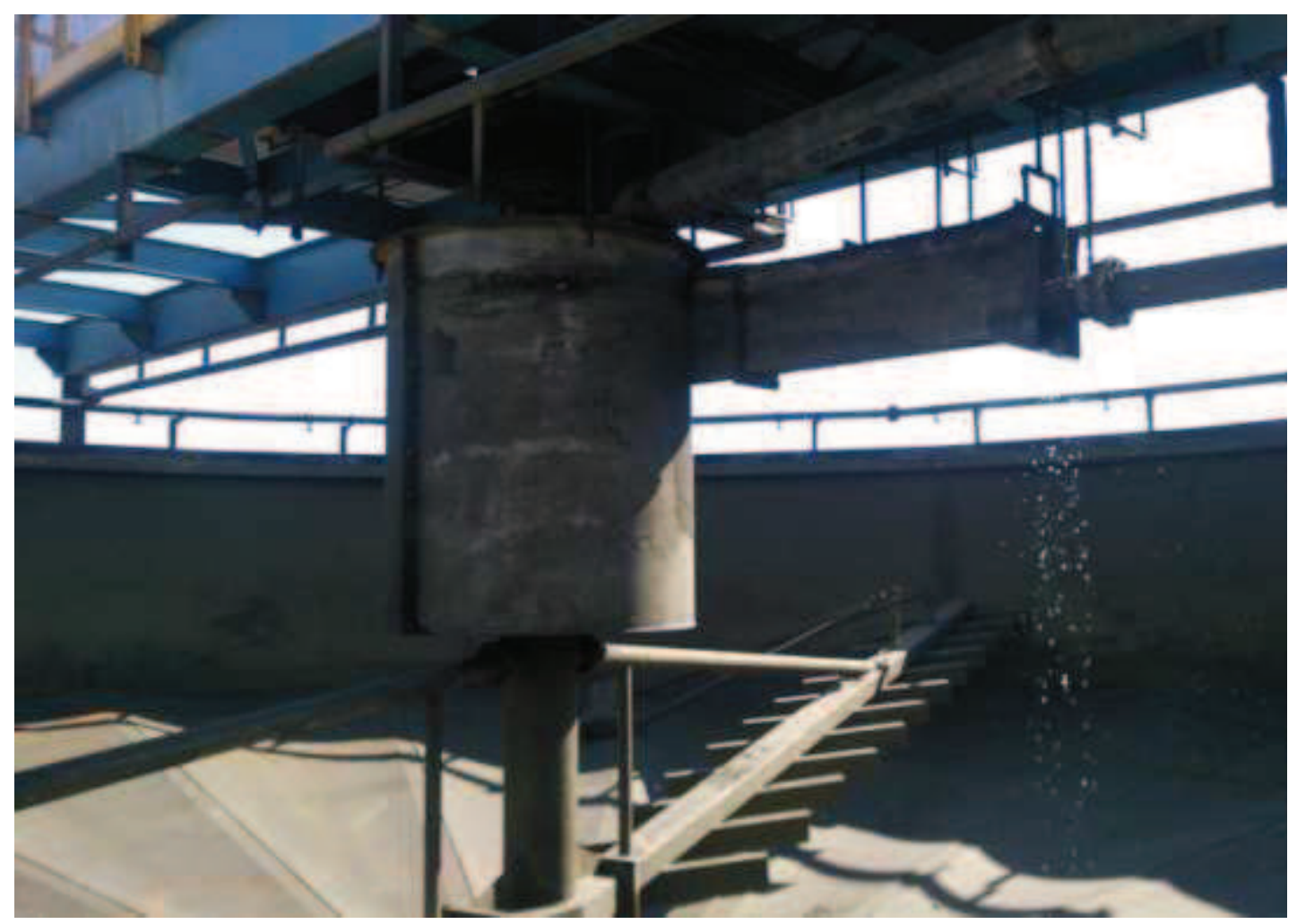

Figura 4-9: Detalle del mecanismo de un espesador HRT. (Fuente: Cortesía de FLSmidth Dorr-Oliver Eimco Spain, S.L.)

Con estos sistemas de espesadores de alto ratio de alimentación, se consiguen espesadores más compactos, con menor superficie de implantación, un aumento del ratio de sedimentación de sólidos, un menor consumo de floculantes y un mayor control de la operación del espesador; todo ello sin partes móviles, agitadores o turbinas en la parte interior de la campana de alimentación, lo que representa un avance con respecto a los espesadores convencionales y de alta capacidad HCT vistos anteriormente, a la vez que se obtiene un ahorro en los costes de operación y mantenimiento, ya que no existen partes móviles ni motores de accionamiento para producir la mezcla de pulpa y floculante.

\subsection{Tecnología y desarrollo de espesadores de alta densidad (HDT)}

En la tecnología de espesado de estériles existe una serie de equipos importantes por su utilización en esta tarea y que se operan actualmente. Estos espesadores no llegan a alcanzar una verdadera pasta en los lodos del hundido, como el espesador de cono profundo, pero llegan a alcanzar considerables concentraciones de sólidos en peso y una tensión de fluencia elevada, 
dando como resultado un fluido no-newtoniano. Estos equipos son los Espesadores de Alta Densidad en el hundido, conocidos como Espesadores HDT (High Density Thickener). De todos los equipos que se analizan, éstos pueden considerarse un equipo de transición o intermedio entre los espesadores convencionales y los espesadores de pasta, tanto por las características de operación como por su diseño geométrico.

Estos espesadores de alta densidad del hundido constituyen una tecnología moderna aparecida y desarrollada al tiempo que los espesadores de cono profundo, coincidiendo con el uso general de sistemas de alimentación con dilución y el empleo de floculantes a base de polímeros.

Hoy en día, para el tratamiento de estériles se usan tanto el espesador de alta densidad en el hundido como el espesador de pasta, donde la elección dependerá de los caudales de alimentación y las características necesarias en los lodos espesados para su deposición o tratamiento posterior.

En general los equipos de alta densidad en el hundido (HDT) tienen un menor coste de inversión que los espesadores de cono profundo para la misma capacidad de tratamiento de sólidos. En la figura 4-10: Espesador HDT de alta densidad del hundido; se observan las principales características de estos equipos y la única diferencia que presentan con los espesadores de cono profundo son las dimensiones del tanque, tanto el diámetro como la altura de virola lateral. En el esquema se puede apreciar también el sistema de alimentación con eductores que se instala generalmente en este tipo de equipos.

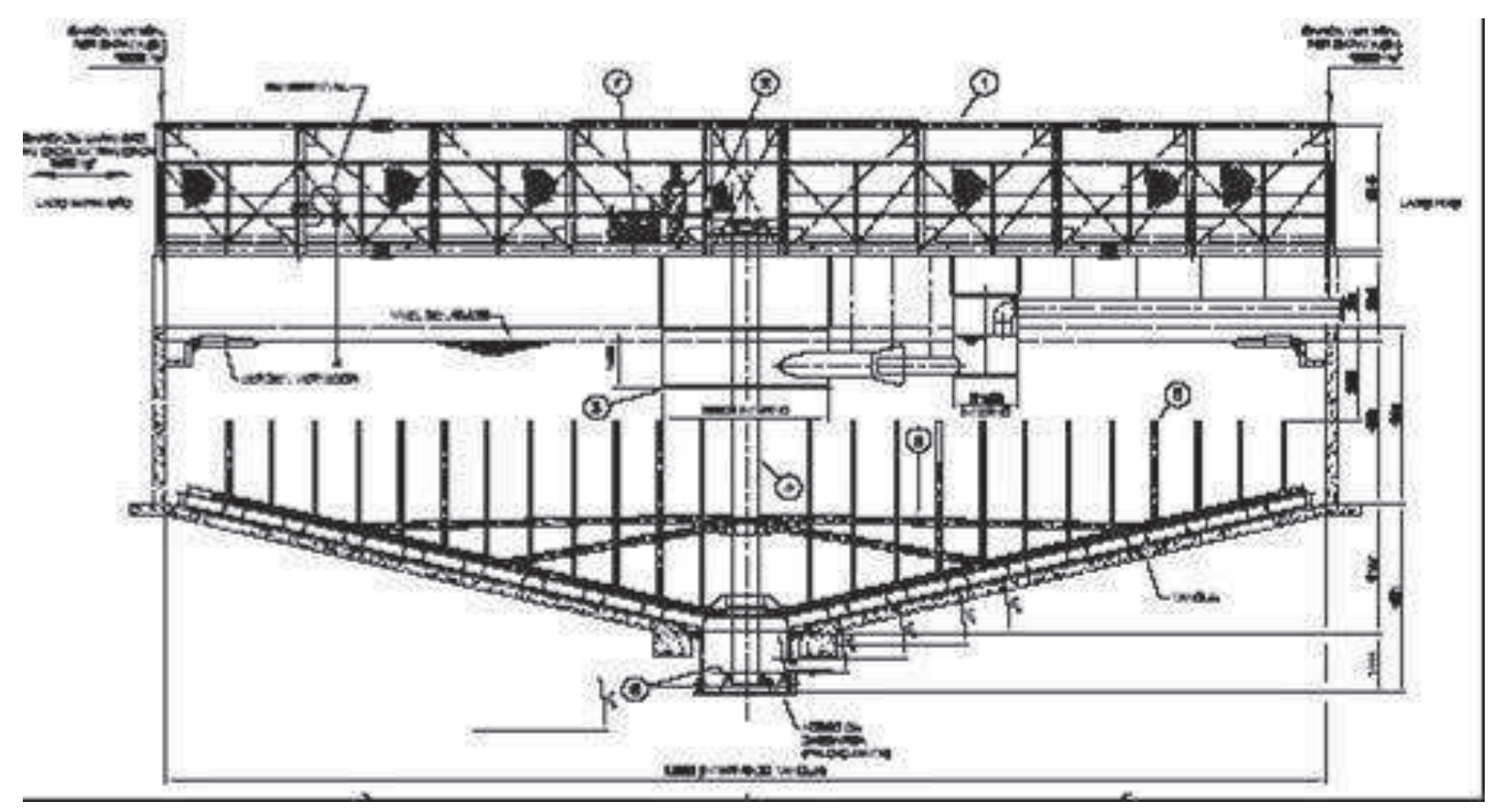

Figura 4-10: Espesador HDT de alta densidad del hundido. (Fuente: Cortesía de FLSmidth S.A.)

Los espesadores HDT de alta densidad en el hundido, se comenzaron a desarrollar para ir sustituyendo a los espesadores convencionales en el tratamiento de los estériles mineros, a medida que la capacidad necesaria crecía con los grandes yacimientos puestos en operación en 
los últimos años. Su aplicación surge con la necesidad de eliminar una mayor cantidad de agua en las pulpas de estériles con grandes ratios de alimentación de sólidos al espesador. Por tanto, era necesario desarrollar un equipo que alcanzara mayores tasas de sólidos en el hundido y que fuera capaz de tratar grandes tonelajes pero sin un coste de inversión excesivo. Al desarrollarse los espesadores de alta densidad en el hundido con sistemas de alimentación más eficientes, se comprobó que el equipo producía en el hundido unos lodos espesados con alta tensión de fluencia, que era la necesaria para la deposición de los estériles y que se recuperaba una mayor cantidad de agua comparado con otros sistemas convencionales.

En la figura 4-11: Tensión de fluencia en espesadores de estériles; se observan las principales diferencias y características de los equipos dedicados a la operación de espesado de estériles.

El interés de este estudio se centra principalmente en el estudio de los equipos de espesado de estériles con equipos que producen una pasta con alto contenido en sólidos y una alta tensión de fluencia.

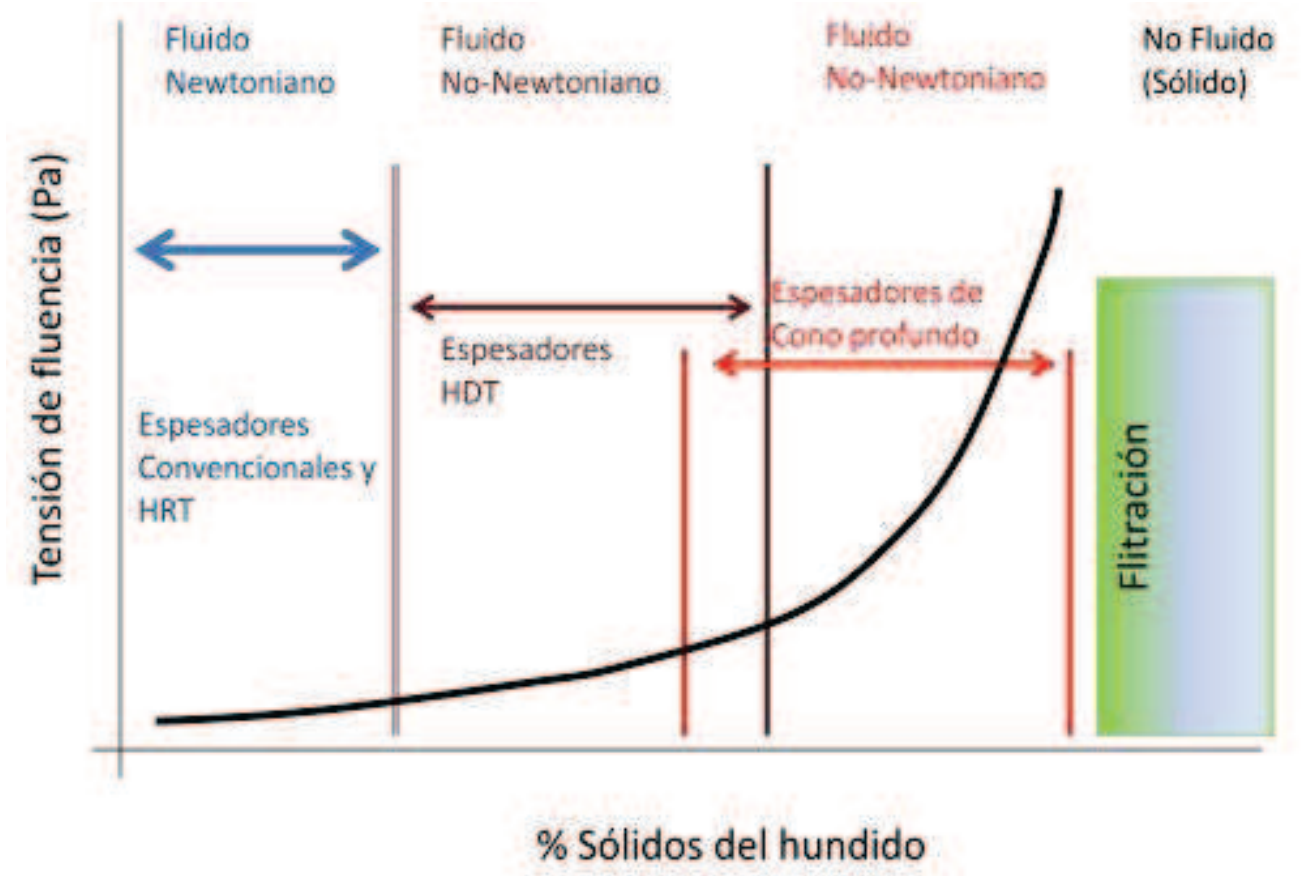

Figura 4-11: Tensión de fluencia en espesadores de estériles.

(Fuente: Elaboración propia)

Atendiendo a la tensión de fluencia alcanzada por los lodos en el hundido en cada uno de los diferentes equipos, se aprecia que existe una diferencia importante entre los tres principales grupos de espesadores. Para establecer unos límites convencionales y admitidos internacionalmente en casi todos los proyectos, la tensión de fluencia alcanzada en cada uno de los tipos de equipos, se puede delimitar como sigue:

a) Espesadores convencionales y de alta capacidad HRT: donde la tensión de fluencia se situaría entre 1 y $50 \mathrm{~Pa}$ con un contenido en sólidos del hundido de $30-50 \%$, dependiendo de las características del sólido a tratar. 
b) Espesadores de alta densidad del hundido HDT: con una tensión de fluencia situada entre 50 y $125 \mathrm{~Pa}$, con una concentración en el hundido de entre el 50-65\% de sólidos en peso.

c) El último grupo serían los espesadores de pasta o espesadores de cono profundo donde se alcanzan tensiones de fluencia en el hundido desde $125 \mathrm{~Pa}$ hasta más de $500 \mathrm{~Pa}$, y donde se puede llegar a concentraciones del hundido desde el $60 \%$ hasta el $80 \%$ de sólidos en peso.

\subsection{Tecnología y desarrollo de espesadores de cono profundo}

\subsubsection{Historia de la tecnología de espesado en pasta}

Todos los avances tecnológicos de los últimos años han sido enfocados a la reducción del tamaño de los equipos, aumento de la capacidad de tratamiento y la optimización del uso de floculantes y el aumento del contenido en sólidos del hundido para una mayor recuperación del agua contenida en los estériles.

A partir de las primeras aplicaciones de espesado a principios del siglo XX, se desarrollaron los primeros espesadores de cono que finalmente han evolucionado en el espesador de cono profundo actual para la producción de pasta. Estos equipos tenían la característica de disponer de una altura lateral mucho mayor que los espesadores convencionales, lo cual permitía un alto lecho de lodos en su interior, mucho mayor que otros espesadores de la época.

Así, los primeros conos profundos aparecidos y patentados en Estados unidos, como por ejemplo la patente 854,520 sobre el "Callow Cone" del año 1907, nos muestra los primeros espesadores de cono. Ver figura 4-12: Callow Cone. Patente 854,520. EE.UU.

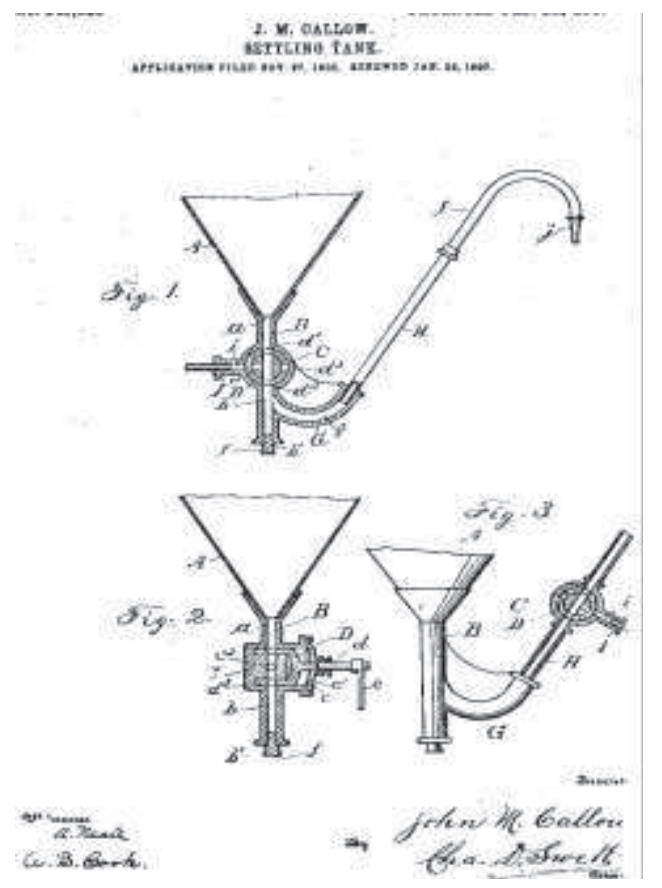

Figura 4-12: Callow Cone. Patente 854,520. EE.UU.

(Fuente: F. Baczek. Deep Cone Paste Thickeners and High Density Thickeners. Internal Report Dorr-Oliver Eimco Annual Meeting 2004) 
No es hasta mediados de los años 50 cuando surge una nueva patente en Alemania, con el número 749,736 en el año 1953 , donde se muestra un equipo que mejora la separación sólidolíquido mediante el proceso de sedimentación, utilizando un tanque con unas medidas poco convencionales para la época, como se puede ver en la figura 4-13: Espesador de lecho profundo año 1953. Alemania.
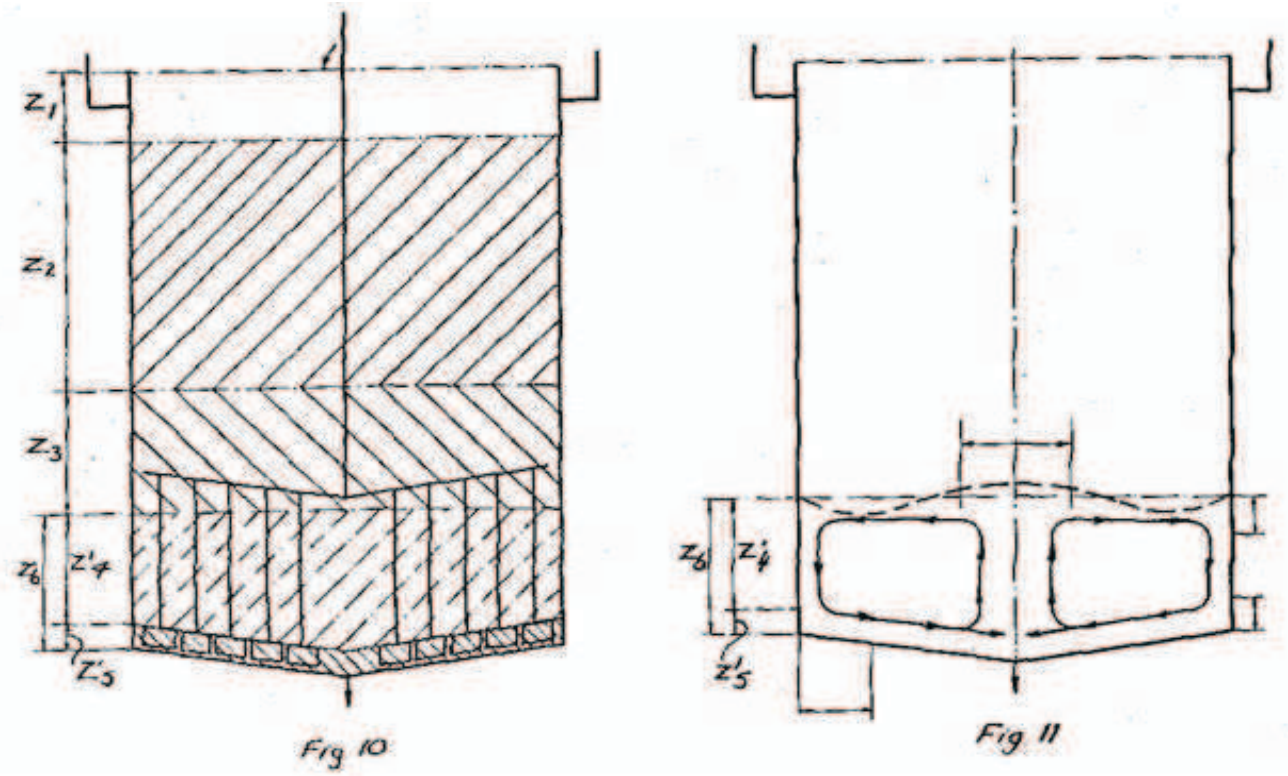

Figura 4-13: Espesador de lecho profundo año 1953. Alemania.

(Fuente: F. Baczek. Deep Cone Paste Thickeners and High Density Thickeners. Internal Report Dorr-Oliver Eimco Annual Meeting 2004)

Este equipo consiste en un espesador con una geometría similar al espesador de pasta actual, pero basado en los mismos principios que sus predecesores: mantener un lecho de lodos de gran profundidad.

Es a principios de los años 60 cuando se comienza a estudiar en serio la posibilidad de realizar equipos que pueden considerarse el inicio de los espesadores de pasta actuales. Es en el Reino Unido, con la aplicación y la investigación de la empresa nacional del carbón (National Coal Board), donde comienzan a aplicarse espesadores de forma cónica con dimensiones de 4,2 metros de diámetro y 6 metros de profundidad, provistos de rasquetas internas donde se conseguirán densidades del hundido de hasta el $55-65 \%$ en peso y que son capaces de descargar el hundido sobre cinta transportadora. La empresa National Coal Board, desarrolló y probó el espesador con estériles y donde la altura del lecho de lodos, había crecido drásticamente, comparado con los espesadores convencionales. Esto permitía que el espesador pudiera tener un lecho compacto y de mucha mayor altura para conseguir una mayor compresión en el fondo y un mayor tiempo de residencia de los lodos espesados. El ratio altura/diámetro de estos espesadores era de 1:1 o superior. Ver figura 4-14: Espesador cono profundo. National Coal Board.

Ya entonces en los estudios realizados por el National Coal Board del Reino Unido, se reconocen los aspectos críticos que deben ser controlados en los espesadores de cono profundo y que afectan a los resultados de la operación:

- Una floculación efectiva. 
- Diseño de la campana de alimentación.

- El ángulo de inclinación del fondo del tanque.

- Trabajar mecánicamente el lecho de lodos con rasquetas para permitir la liberación del agua contenida en el hundido.

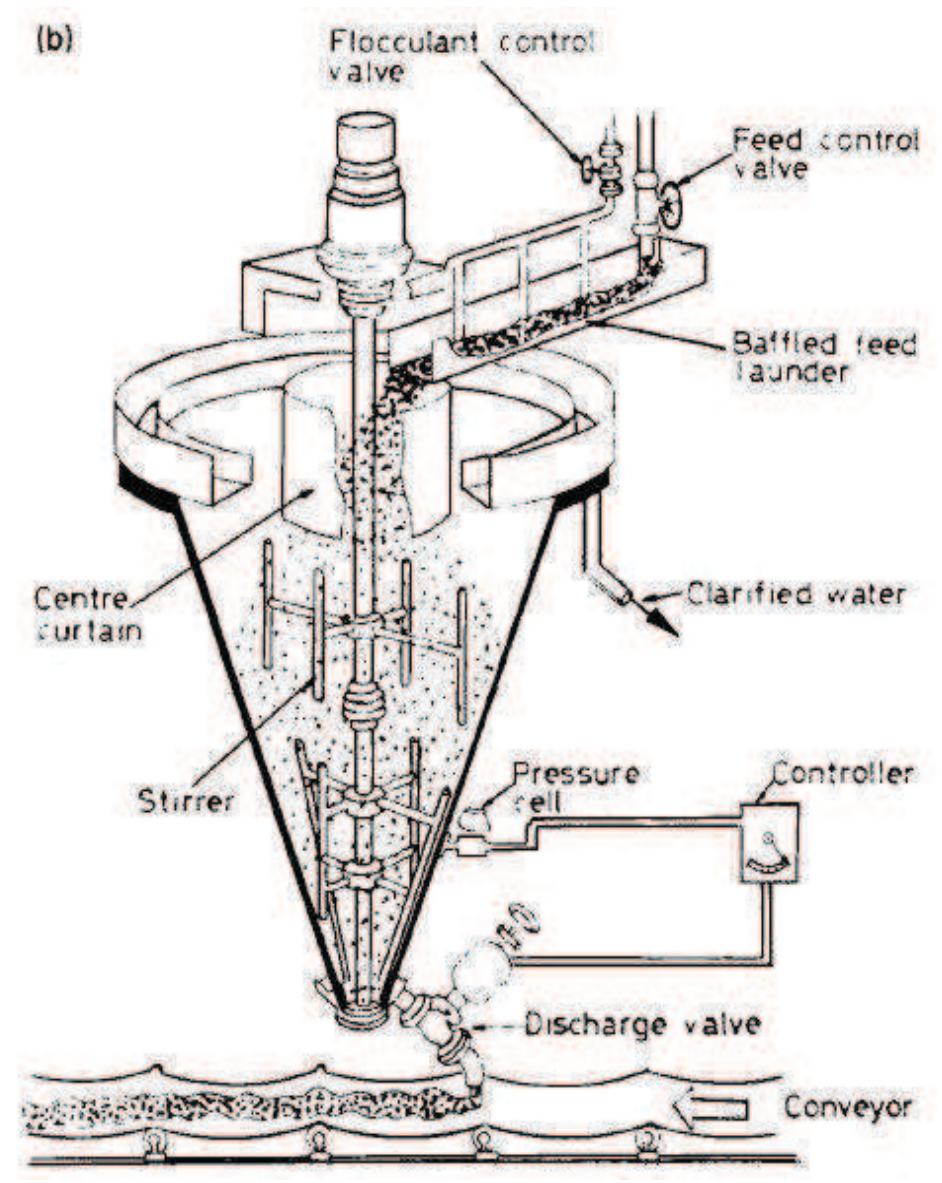

Figura 4-14: Espesador de cono profundo. National Coal Board.

(Fuente: F. Baczek. Deep Cone Paste Thickeners and High Density Thickeners. Internal Report Dorr-Oliver Eimco Annual Meeting 2004)

Como se muestra en la figura 4-15: Equipo Denver de espesado de cono profundo. Año 1980. Este equipo cuenta con todos los requisitos anteriores: control de la adición de floculante, fuerte inclinación del fondo del tanque, rasquetas para remover el lecho de lodos y una campana de alimentación para hacer más eficiente la floculación.

Otro avance significativo en el desarrollo de los espesadores de cono profundo fueron las investigaciones realizadas por la compañía de aluminio Alcan. Esta compañía desarrolló y patentó sus propios espesadores de cono profundo para sus procesos de espesado de alúmina. Sus investigaciones empezaron en los años 70 en Jamaica y Canadá, para el espesado de los lodos rojos del proceso de tratamiento de la bauxita y en este caso el modelo sería un espesador de cono profundo igual a los espesadores de pasta actuales, con dimensiones de 10 metros de diámetro y 14 metros de altura lateral en la virola que mediante la incorporación del mecanismo de 
rasquetas se obtenía un contenido en sólidos en el hundido del 30-31\% en peso frente al $15-17 \%$ que se obtenía en los espesadores convencionales. Esto representa un avance significativo en el espesado de lodos rojos y rápidamente fue adoptado por todas las operaciones del grupo Alcan.

En el año 1993, Alcan tenía en sus factorías de alúmina 30 equipos de espesadores de cono profundo operando en sus instalaciones por todo el mundo.

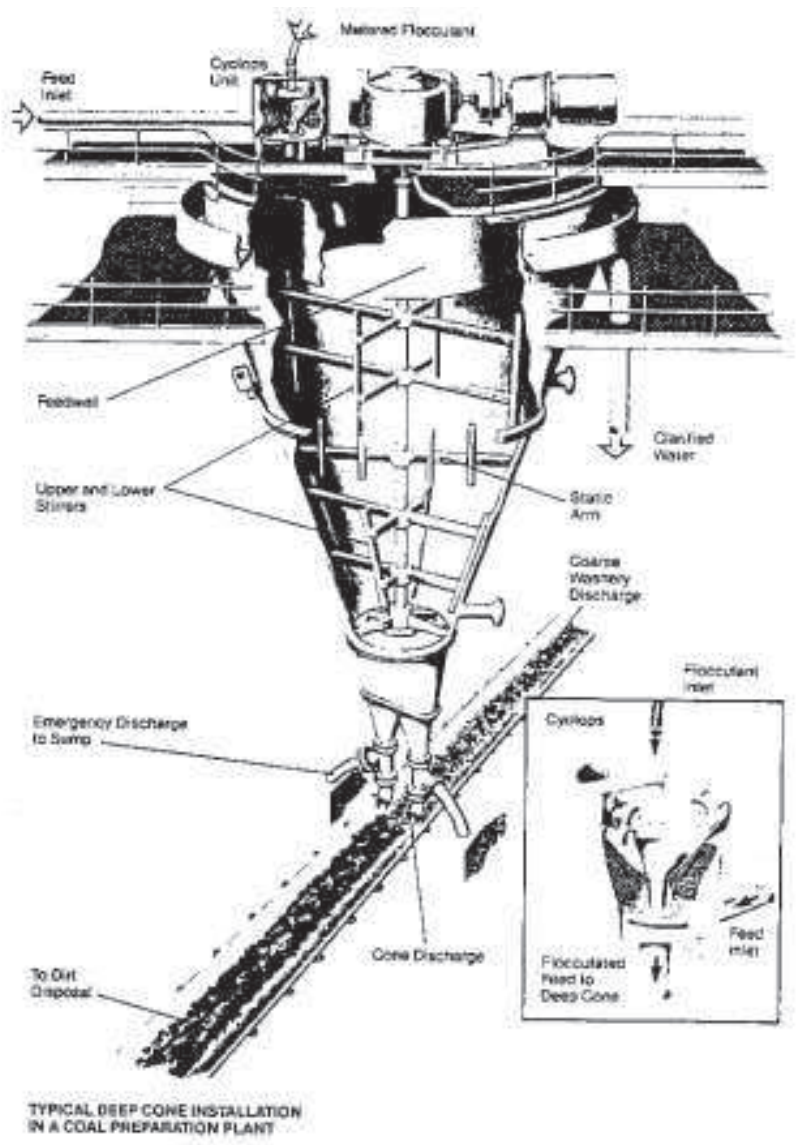

Figura 4-15: Equipo Denver de espesado en cono profundo. Año 1980.

(Fuente: F. Baczek. Deep Cone Paste Thickeners and High Density Thickeners. Internal Report Dorr-Oliver Eimco Annual Meeting 2004)

En la figura 4-16: Alcan. Espesado y depósitos de lodos rojos; se muestran este tipo de instalaciones típicas para el depósito de estériles de bauxita.

Es a comienzos de los años 90, cuando se inicia una nueva revolución en los equipos de espesado y de la tecnología de espesado en pasta, con la aparición de espesadores de alta densidad del hundido (Espesadores HDT), con la incorporación de mejores técnicas en la campana de alimentación y el uso de los floculantes de base polimérica.

Todos estos avances ayudan a maximizar la densidad del hundido, con un equipo que presenta una geometría y tamaño similares a los espesadores convencionales, con ratios de altura/diámetro de 1:1, y que producen una alta densidad el hundido.

La idea del espesador de lecho profundo fue por tanto mejorada por la empresa Alcan International en la década de 1980 al utilizar este concepto junto con el alto rendimiento que habían adquirido los floculantes en esa época, estableciendo los primeros diseños de rasquetas y 
campanas de alimentación, adaptados al proceso de espesado de estériles de bauxita. Alcan llamaba a su diseño el "Deep Thickener", (Espesador Profundo). Originalmente desarrollado para el espesado de los estériles de bauxita, o lodos rojos, para formar una pasta que se pueda apilar, el espesador "Alcan Deep Thickener" fue introducido en otras aplicaciones fuera del campo de la alúmina en 1996 bajo la licencia de EIMCO (ahora FLSmidth) donde fue y sigue siendo comercializado como Eimco Deep Cone Paste Thickener (Espesador de Pasta de Cono Profundo Eimco).

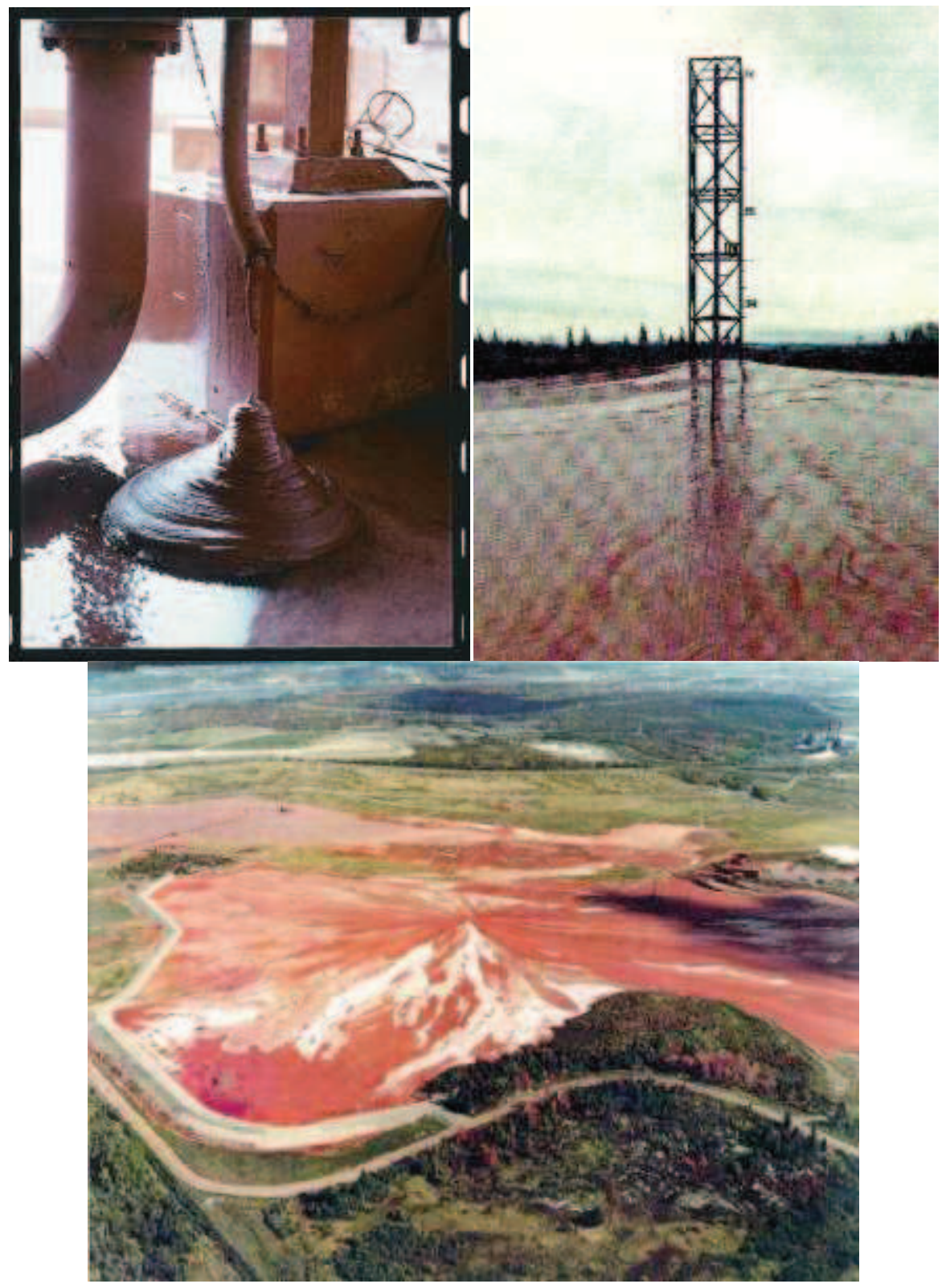

Figura 4-16: Alcan. Espesado y depósito de lodos rojos. (Fuente: Cortesía de FLSmidth Dorr-Oliver Eimco Spain, S.L.)

El estándar de la compañía Eimco (ahora FLSmidth) está provisto de rasquetas interiores y tiene un ratio de altura/diámetro típico de 1:2 con un talud del cono inferior que varía entre $30^{\circ}$ y $45^{\circ}$ que varía según la geometría del tanque y del lodo a tratar. 
Esta geometría le proporciona una alta compresión de la capa de lodo y un elevado lecho de lodos consiguiendo con ello alcanzar la máxima concentración de sólidos en el hundido y llegar a un hundido dentro del rango de la pasta.

Esta compañía tiene una larga e importante historia como líder en el diseño y venta de estos equipos, siendo pionera en el desarrollo de los espesadores desde los primeros espesadores convencionales hasta los más modernos espesadores de alta capacidad y espesadores de cono profundo. Aunque el presente estudio no estará limitado por los fabricantes, si no que se estudiarán todas las opciones y tendencias existentes actualmente para el espesado de estériles. Esta empresa adquirió el diseño de lecho profundo a la compañía Alcan, lo que ha contribuido de forma significativa a su liderazgo en la tecnología de espesado en pasta.

Por lo tanto, el paso definitivo para la introducción del espesador de cono profundo en otras aplicaciones diferentes de los estériles de bauxita, fue la adquisición en 1996 de la licencia de Alcan International por parte de Eimco, ahora FLSmidth, para desarrollar la tecnología del espesador de cono profundo fuera del campo de la alúmina e introducirlo en el espesado de estériles de minería metálica. El espesador pasó a llamarse Eimco Deep Cone Thickener, ver figura 4-17: espesador de cono profundo Eimco.

La etapa de introducción del equipo en las operaciones mineras de metales base para el tratamiento de estériles no fue fácil en un primer momento por las desconfianza inicial de los clientes y operadores para adquirir un equipo que tenía un coste de capital muy superior a otros equipos de espesado, pero que podía proporcionar muchos beneficios en la operación del tratamiento de estériles y la recuperación de aguas de proceso. En los últimos años se ha demostrado que es una de las mejores tecnologías disponibles para el tratamiento y espesado de estériles de mina, principalmente. 


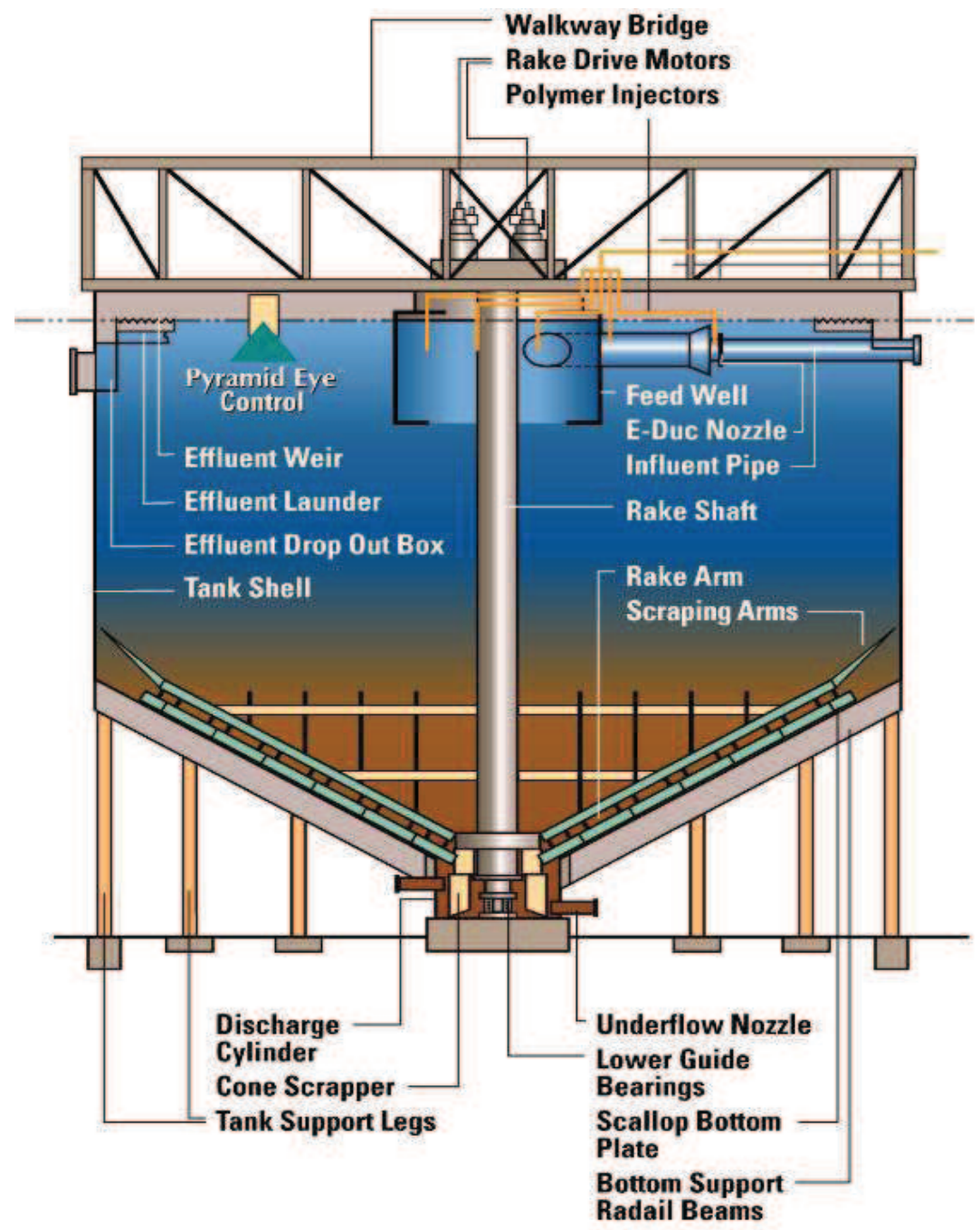

Figura 4-17: Espesador de cono profundo Eimco.

(Fuente: Cortesía FLSmidth S.A.)

\subsubsection{Histórico de grandes proyectos de sedimentación y análisis}

Para comprender la importancia que las tecnologías de sedimentación de lodos en forma de pasta o de alta densidad en el hundido, han ido adquiriendo a lo largo de los últimos años, se han recopilado los datos de los grandes proyectos e instalaciones realizados en los últimos 25 años, donde se han instalado este tipo de equipos. La tabla 4-3: Listado de proyectos mundiales de pasta, recopila la mayoría de los grandes proyectos realizados a nivel mundial y que han utilizado los sistemas y tecnología de espesado en pasta, con espesadores de cono profundo o de espesado en alta densidad en el hundido con equipos de espesado "High Density" (HDT). Hay que notar, que no es una lista exhaustiva y existen muchos más equipos e instalaciones de otros suministradores diferentes de FLSmidth y Dorr-Oliver Eimco, que no se detallan en la tabla 4-3. 
Tecnologías de espesado actuales y tipos de espesadores

Tabla 4-3: Listado de proyectos mundiales de pasta.

\begin{tabular}{|c|c|c|c|c|c|c|c|}
\hline Proyecto & País & Año & Tecnología & Operación & $\begin{array}{c}\mathrm{N}^{\circ} \\
\text { Espesadores }\end{array}$ & $\begin{array}{l}\text { Diámetro } \\
\qquad(\mathrm{m})\end{array}$ & $\begin{array}{c}\text { Total } \\
\text { Área } \\
\text { instalada } \\
\text { (m2) }\end{array}$ \\
\hline Alunorte & Brasil & 2006 & DCT & Alúmina & 5 & 19,5 & 1493 \\
\hline Alunorte & Brasil & 2006 & DCT & Alúmina & 3 & 15 & 530 \\
\hline Alunorte & Brasil & 2004 & DCT & Alúmina & 3 & 15 & 530 \\
\hline Alunorte & Brasil & 2004 & DCT & Alúmina & 3 & 19,5 & 896 \\
\hline Alunorte & Brasil & 2000 & DCT & Alúmina & 2 & 16,5 & 428 \\
\hline Alunorte & Brasil & 2000 & DCT & Alúmina & 4 & 12 & 452 \\
\hline Utkal & India & 2008 & DCT & Alúmina & 3 & 15 & 530 \\
\hline Utkal & India & 2008 & DCT & Alúmina & 6 & 16,5 & 1283 \\
\hline Zhongzhou & China & 2003 & DCT & Alúmina & 2 & 16 & 402 \\
\hline Alunorte & Brasil & 1996 & DCT & Alúmina & 2 & 18 & 509 \\
\hline $\begin{array}{l}\text { BHP Billiton / } \\
\text { Worsley }\end{array}$ & Australia & 2011 & DCT & Alúmina & 1 & 16,5 & 214 \\
\hline Guizhou & China & 2001 & DCT & Alúmina & 6 & 12 & 679 \\
\hline Nalco & India & 2006 & DCT & Alúmina & 5 & 15 & 884 \\
\hline Alcan & USA & 2001 & DCT & Alúmina & 4 & 5 & 79 \\
\hline $\begin{array}{l}\text { BHP Billiton / } \\
\text { Worsley }\end{array}$ & Australia & 2004 & DCT & Alúmina & 4 & 16,5 & 855 \\
\hline Rusal / Nikolaev & Rusia & 2004 & DCT & Alúmina & 2 & 18 & 509 \\
\hline Ormet & $\begin{array}{l}\text { USA, } \\
\text { Louisiana }\end{array}$ & 2000 & DCT & Alúmina & 8 & 12 & 905 \\
\hline Shanxi & China & 2004 & DCT & Alúmina & 2 & 20 & 628 \\
\hline Nalco & India & 2006 & DCT & Alúmina & 1 & 20 & 314 \\
\hline Nalco & India & 2002 & DCT & Alúmina & 2 & 20 & 628 \\
\hline Hindalco / Muri & India & 2005 & DCT & Alúmina & 6 & 12 & 679 \\
\hline Hindalco/ Renukoot & India & 2006 & DCT & Alúmina & 1 & 20 & 314 \\
\hline Hindalco/ Renukoot & India & 2005 & DCT & Alúmina & 2 & 16,5 & 428 \\
\hline $\begin{array}{c}\text { Rio Tinto Alcan / } \\
\text { Gove }\end{array}$ & Australia & 2005 & DCT & Alúmina & 4 & 18 & 1018 \\
\hline $\begin{array}{c}\text { Rio Tinto Alcan / } \\
\text { Gove }\end{array}$ & Australia & 2005 & DCT & Alúmina & 4 & 24 & 1810 \\
\hline $\begin{array}{c}\text { Votarantim, SA Inds. } \\
\text { / CNT }\end{array}$ & Brasil & 2007 & DCT & CCD & 1 & 20 & 314 \\
\hline BEMA / Kupol & Rusia & 2005 & DCT & CCD & 6 & 14 & 924 \\
\hline OCP Bunge & Marruecos & 2012 & DCT & Concen & 1 & 20 & 314 \\
\hline OCP Line $\mathrm{E}$ & Marruecos & 2012 & DCT & Concen & 5 & 20 & 1571 \\
\hline OCP PMP & Marruecos & 2012 & DCT & Concen & 2 & 15 & 353 \\
\hline Hecla & $\begin{array}{l}\text { USA, } \\
\text { Idaho }\end{array}$ & 2005 & DCT & Concen & 2 & 3 & 14 \\
\hline Cable Sands & Australia & 2001 & DCT & Estériles & 1 & 8 & 50 \\
\hline $\begin{array}{c}\text { Minera Res. / Murrin } \\
\text { Murrin }\end{array}$ & Australia & 2003 & DCT & Estériles & 1 & 20 & 314 \\
\hline Navoi & Uzbekistan & 2005 & DCT & Estériles & 1 & 16 & 201 \\
\hline Galvani & Brasil & 2007 & DCT & Estériles & 1 & 11 & 95 \\
\hline Doberseck & Rusia & 2007 & DCT & Estériles & 1 & 16 & 201 \\
\hline Fernald & USA, Ohio & 2003 & DCT & Estériles & 1 & 4,4 & 15 \\
\hline
\end{tabular}


(Continuación tabla 4-3)

\begin{tabular}{|c|c|c|c|c|c|c|c|}
\hline $\mathrm{OCl}$ & $\begin{array}{c}\text { USA, } \\
\text { Wvoming }\end{array}$ & 1999 & DCT & Estériles & 1 & 15 & 177 \\
\hline $\begin{array}{c}\text { Sumitomo / Coral } \\
\text { Bay }\end{array}$ & Filipinas & 2010 & $\mathrm{DCT}$ & Estériles & 1 & 14 & 154 \\
\hline Shell / Albian Sands & Canada & 2006 & DCT & Estériles & 1 & 5 & 20 \\
\hline DeBeers & Sudáfrica & 2003 & DCT & Estériles & 5 & 15 & 884 \\
\hline DeBeers Voorspoed & Sudáfrica & 2006 & $\mathrm{DCT}$ & Estériles & 2 & 18 & 509 \\
\hline Ekapa Mining & Sudáfrica & 2002 & DCT & Estériles & 1 & 15 & 177 \\
\hline $\begin{array}{c}\text { Compass } \\
\text { Resources/ Browns } \\
\text { Oxide }\end{array}$ & Australia & 2006 & DCT & Estériles & 1 & 14 & 154 \\
\hline $\begin{array}{c}\text { Cambior / Camp } \\
\text { Caiman }\end{array}$ & $\begin{array}{l}\text { French } \\
\text { Guiana }\end{array}$ & 2006 & $\mathrm{DCT}$ & Estériles & 1 & 20 & 314 \\
\hline EAM Region & $\begin{array}{c}\text { Middle } \\
\text { East }\end{array}$ & 2008 & $\mathrm{DCT}$ & Estériles & 12 & 24 & 5429 \\
\hline $\begin{array}{c}\text { Oregon Resources } \\
\text { Corp. }\end{array}$ & USA & 2010 & DCT & Estériles & 1 & 15 & 177 \\
\hline Somincor & Portugal & 2004 & DCT & Estériles & 1 & 8 & 50 \\
\hline Aurex & Perú & 2012 & DCT & Estériles & 1 & 7 & 38 \\
\hline $\mathrm{OCP}$ & Marruecos & 2006 & DCT & Estériles & 1 & 10 & 79 \\
\hline DeBeers / Snap Lake & Canada & 2005 & DCT & Estériles & 2 & 10 & 157 \\
\hline $\begin{array}{c}\text { COEUR / San } \\
\text { Bartolome }\end{array}$ & Bolivia & 2005 & DCT & Estériles & 1 & 14 & 154 \\
\hline New Jersey Mining & USA & 2006 & DCT & Estériles & 1 & 3.5 & 10 \\
\hline Enami / Delta & Chile & 2009 & DCT & Estériles & 1 & 12 & 113 \\
\hline Myduk & $\begin{array}{l}\text { Medio } \\
\text { Oriente }\end{array}$ & 2003 & DCT & Estériles & 4 & 16 & 804 \\
\hline Glencore / Iscaycruz & Perú & 2002 & DCT & Estériles & 1 & 11 & 95 \\
\hline $\begin{array}{c}\text { Jiangxi Copper } \\
\text { WuShan }\end{array}$ & China & 2007 & DCT & Estériles & 2 & 40 & 2513 \\
\hline Las Cenizas & Chile & 2011 & DCT & Estériles & 1 & 17 & 227 \\
\hline $\begin{array}{c}\text { Somincor / Neves } \\
\text { Corvo }\end{array}$ & Portugal & 2008 & DCT & Estériles & 2 & 18 & 509 \\
\hline $\begin{array}{c}\text { Alaska Gold/ Rock } \\
\text { Creek }\end{array}$ & $\begin{array}{l}\text { USA, } \\
\text { Alaska }\end{array}$ & 2006 & DCT & Estériles & 1 & 14 & 154 \\
\hline HuiZhe Yunnan & China & 2004 & $\mathrm{DCT}$ & Estériles & 1 & 11 & 95 \\
\hline $\begin{array}{c}\text { Iberian Minerals } \\
\text { Corp. / Aguas } \\
\text { Tenidas } \\
\end{array}$ & España & 2007 & DCT & Estériles & 1 & 18 & 254 \\
\hline Stillwater & $\begin{array}{c}\text { USA, } \\
\text { Montana }\end{array}$ & 1998 & DCT & Estériles & 1 & 12 & 113 \\
\hline $\begin{array}{c}\text { Vendanta PLC / } \\
\text { Lisheen }\end{array}$ & Irlanda & 2003 & DCT & Estériles & 1 & 18 & 254 \\
\hline Doe Run / Cobriza & Perú & 2008 & DCT & Estériles & 1 & 20 & 314 \\
\hline Doe Run / Cobriza & Perú & 2004 & DCT & Estériles & 1 & 14 & 154 \\
\hline Volcan / Chungar & Perú & 2007 & $\mathrm{DCT}$ & Estériles & 1 & 17 & 227 \\
\hline $\begin{array}{c}\text { Silver Wheaton / } \\
\text { Yauliyacu }\end{array}$ & Perú & 2001 & $\mathrm{DCT}$ & Estériles & 1 & 14 & 154 \\
\hline $\begin{array}{l}\text { Atlantic Ltd. / } \\
\text { Windimurra }\end{array}$ & Australia & 2007 & DCT & Estériles & 1 & 20 & 314 \\
\hline Hecla / Lucky Friday & $\begin{array}{l}\text { USA, } \\
\text { Idaho }\end{array}$ & 2007 & DCT & Estériles & 1 & 10 & 79 \\
\hline IFM & RSA & 2010 & DCT & Estériles & 1 & 5 & 20 \\
\hline $\begin{array}{c}\text { Xstrata / Asturiana } \\
\text { Zinc }\end{array}$ & España & 2004 & DCT & Estériles & 3 & 10 & 236 \\
\hline
\end{tabular}


(Continuación tabla 4-3)

\begin{tabular}{|c|c|c|c|c|c|c|c|}
\hline Buxton Lime & Inglaterra & 2002 & DCT & Feed & 2 & 15 & 353 \\
\hline Alcoa / Kwinana & Australia & 1989 & HDT & Alúmina & 1 & 75 & 4418 \\
\hline Alcoa / Wagerup & Australia & 1991 & HDT & Alúmina & 1 & 75 & 4418 \\
\hline Alcoa / Pinjarra & Australia & 1987 & HDT & Alúmina & 1 & 90 & 6362 \\
\hline Baja Mining / Boleo & México & 2008 & HDT & CCD & 6 & 60 & 16965 \\
\hline MCC / Ramu & PNG & 2007 & HDT & CCD & 7 & 36 & 7125 \\
\hline Norilsk / Tati & Botswana & 2007 & HDT & CCD & 7 & 35 & 6735 \\
\hline Metorex / Ruashi & DRC & 2006 & HDT & CCD & 4 & 22,5 & 1590 \\
\hline $\begin{array}{l}\text { Freeport McM/T. } \\
\text { Fungurume }\end{array}$ & DRC & 2007 & HDT & CCD & 6 & 31 & 4529 \\
\hline Vale / Clarabelle & Canada & 2001 & HDT & Concen & 2 & 30 & 1414 \\
\hline Bozshakol & Kazajistán & 2012 & HDT & Estériles & 1 & 45 & 1590 \\
\hline Rhone Poulenc & $\begin{array}{c}\text { USA, } \\
\text { Wyoming }\end{array}$ & 1998 & HDT & Estériles & 1 & 23 & 415 \\
\hline $\begin{array}{c}\text { Williamson Energy / } \\
\text { Mach }\end{array}$ & USA & 2009 & HDT & Estériles & 1 & 20 & 314 \\
\hline $\begin{array}{c}\text { Petro-Canada / Fort } \\
\text { Hills }\end{array}$ & Canada & 2010 & HDT & Estériles & 2 & 80 & 10053 \\
\hline Suncor & Canadá & 2012 & HDT & Estériles & 2 & 70 & 7697 \\
\hline $\begin{array}{c}\text { Fortescue Metals } \\
\text { Group }\end{array}$ & Australia & 2010 & HDT & Estériles & 2 & 20 & 628 \\
\hline $\begin{array}{c}\text { Ivanhoe Rio } \\
\text { Tinto/Oyu Tolgoi }\end{array}$ & Mongolia & 2005 & HDT & Estériles & 2 & 80 & 10053 \\
\hline MAK & Mongolia & 2012 & HDT & Estériles & 2 & 60 & 5655 \\
\hline $\begin{array}{l}\text { Minera Lumina / } \\
\text { Caerones }\end{array}$ & Chile & 2010 & HDT & Estériles & 3 & 45 & 4771 \\
\hline Shell / Jack Pine & Canada & 2006 & HDT & Estériles & 1 & 70 & 3848 \\
\hline $\begin{array}{l}\text { Augusta Res. } \\
\text { Rosemont }\end{array}$ & USA & 2009 & HDT & Estériles & 2 & 50 & 3927 \\
\hline Cluff Resources & Canada & 2000 & HDT & Estériles & 1 & 25,7 & 519 \\
\hline IAM Gold / Essakane & $\begin{array}{l}\text { Burkina } \\
\text { Faso }\end{array}$ & 2009 & HDT & Estériles & 2 & 37 & 2150 \\
\hline $\begin{array}{c}\text { Antofagasta } \\
\text { Min./Esperenza } \\
\end{array}$ & Chile & 2008 & HDT & Estériles & 3 & 60 & 8482 \\
\hline CODELCO / Andina & Chile & 2007 & HDT & Estériles & 1 & 43 & 1452 \\
\hline Lihir & PNG & 2010 & HDT & Estériles & 1 & 48 & 1810 \\
\hline $\begin{array}{l}\text { COEMIN / San } \\
\text { Esteban }\end{array}$ & Chile & 2011 & HDT & Estériles & 1 & 22 & 380 \\
\hline $\begin{array}{c}\text { CITIC Pacific Mining } \\
\text { / Sino }\end{array}$ & Australia & 2010 & HDT & Estériles & 2 & 90 & 12723 \\
\hline $\begin{array}{l}\text { BHP Billiton / } \\
\text { Olympic Dam }\end{array}$ & Australia & 1994 & HDT & Estériles & 2 & 37 & 2150 \\
\hline MIM / Ernest Henry & Australia & 1996 & HDT & Estériles & 1 & 55 & 2376 \\
\hline Galmoy & Irlanda & 1998 & HDT & Estériles & 1 & 31 & 755 \\
\hline $\begin{array}{c}\text { Fortescue Metals / } \\
\text { Cloudbreak }\end{array}$ & Australia & 2006 & HDT & Estériles & 1 & 38 & 1134 \\
\hline
\end{tabular}

(Fuente: Cortesía de FLSmidth Dorr-Oliver Eimco Spain, S.L.)

Con los datos de la tabla 4-3 y su análisis, se han realizado una serie de gráficos y estudios para analizar cómo ha evolucionado la tendencia hasta ahora y qué se puede esperar de la tendencia en un futuro para este tipo de equipos. Este análisis se centra sobre el total de 104 grandes proyectos mineros o equipos en operación entre 1987 y 2012. El total de equipos instalados es 
muy superior ya que diversos proyectos han requerido de más de un espesador para los caudales a tratar. El total de equipos analizados durante este periodo es de: 169 equipos instalados con tecnología de espesado en cono profundo y de 70 equipos con tecnología de alta densidad en el hundido (HDT), instalados a lo largo del mundo en diversas operaciones como son: tratamiento de estériles de metales base, instalaciones de alúmina, circuitos de lixiviación, espesado de concentrados, etc.

A continuación se exponen los datos y gráficas a nivel general de cómo han evolucionado las instalaciones de estos equipos, para realizar un análisis más exhaustivo por tecnologías y tipos de operación en función de los materiales a tratar en cada uno de los proyectos. Se ha realizado también un análisis sobre las áreas de sedimentación construidas para cada una de las tecnologías, sobre los que se extraerán las conclusiones que permitan averiguar cómo será el desarrollo en el futuro de estas instalaciones de tratamiento de estériles. Observando los datos de los equipos instalados para el tratamiento de estériles de metales base fundamentalmente, se extraen dos conclusiones principales: el diámetro medio en cada tecnología y el área total instalada para cada proyecto aumenta a medida que avanza la implantación de estos equipos a lo largo de los años. En el caso de la tecnología HDT para estériles, el diámetro medio instalado fue de 45 metros, con un área promedio instalada de $2150 \mathrm{~m}^{2}$ de superficie de sedimentación en cada proyecto. Las variaciones oscilan entre los 90 metros de diámetro hasta los espesadores más pequeños de 20 metros de diámetro, siendo el mayor proyecto construido el de Citic Pacific Mining (Australia) en el año 2010, con dos espesadores de 90 metros de diámetro para el tratamiento de estériles.

En el caso de la tecnología de espesado en pasta para el tratamiento de estériles de metales base, el diámetro medio instalado ha sido de 14 metros con un área promedio de $157 \mathrm{~m}^{2}$ de área de sedimentación existiendo variaciones en el diámetro desde los 40 metros en el proyecto de Jiangxi Copper WuShan (China) en el año 2007, hasta los pequeños equipos de espesado en pasta de 3,5 metros de diámetro usados como instalaciones piloto. En cuanto al área instalada por proyecto en este tipo de tecnología, el mayor proyecto instaló 12 espesadores de pasta de 24 metros de diámetro en Oriente Medio, con una superficie de sedimentación de $5429 \mathrm{~m}^{2}$. Éste es uno de los proyectos más grandes de tratamiento de estériles construido hasta la fecha.

En la tabla 4-3, se han incluido todos los equipos disponibles aunque en el análisis se ha descartado el uso de los datos de operaciones de lixiviación o circuitos a contracorriente CCD por ser una muestra de elementos poco representativa en el total de los datos disponibles. Por lo tanto sólo se utilizarán los datos relativos a las instalaciones de tratamiento de estériles de minería metálica y alúmina.

Separando los datos de la tabla 4-3, por tecnologías y estableciendo dos categorías en función del tipo de espesador: espesadores de pasta "DCT" y espesadores de alta densidad en el hundido "HDT", se obtiene la figura 4-18: Equipos instalados por tecnologías (1987-2012), donde se aprecia un fuerte crecimiento de los equipos de espesado en pasta, llegando a su punto máximo en el año 2005 donde se instalaron 28 unidades de estos equipos. La tecnología HDT, tiene su máximo en el año 2007 con 21 unidades instaladas como se comprueba en la figura 4-18. 
En el análisis de proyectos realizados por tecnologías, el máximo en la tecnología DCT se produce entre los años 2005 y 2008, sufriendo un parón importante con la escasez de inversiones debido a la bajada de materias primas en 2008-2009, donde muchos proyectos se tuvieron que posponer algunos años hasta su construcción. Es a partir de 2011 y 2012 cuando ambas tecnologías están retomando los valores de años anteriores conforme los precios de las materias primas continúan altos y se van desarrollando proyectos a nivel mundial.

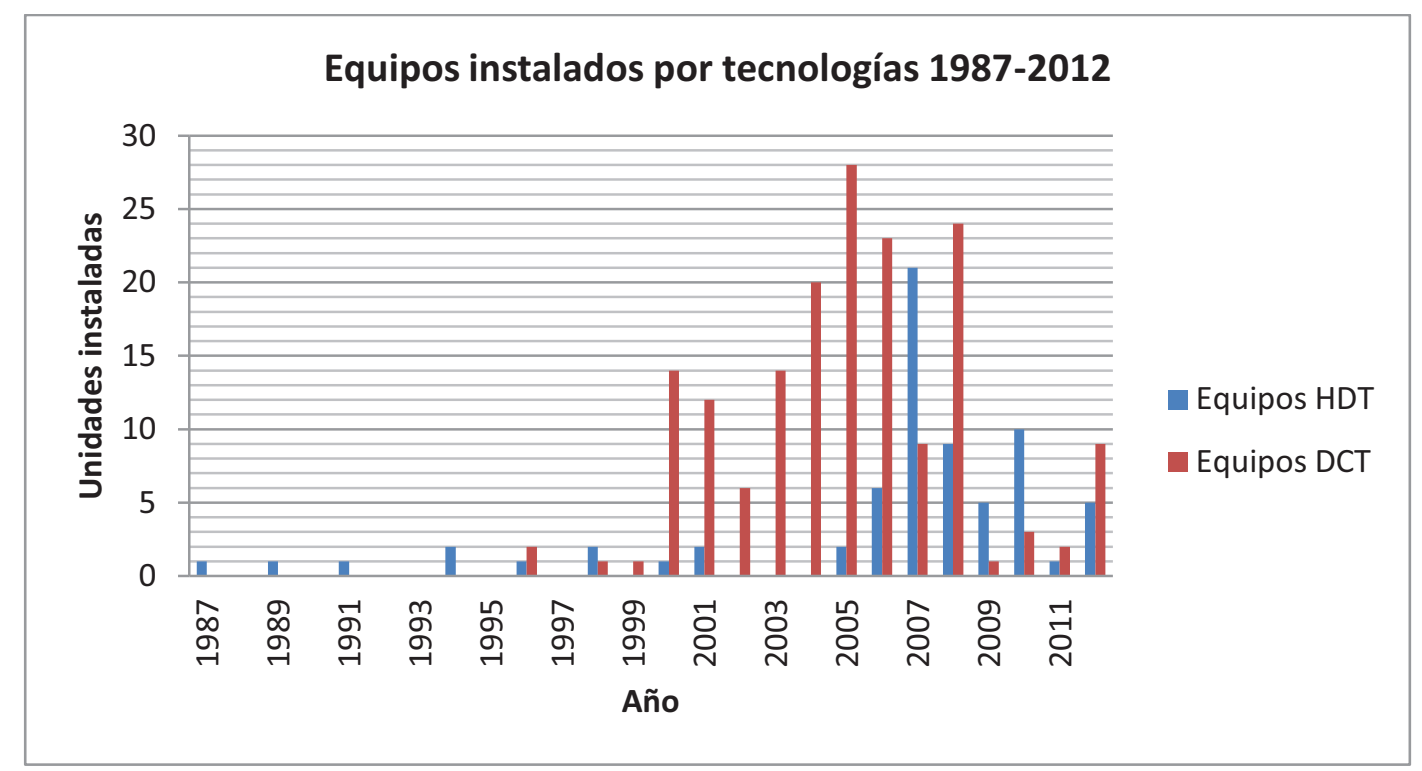

Figura 4-18: Equipos instalados por tecnologías (1987-2012) (Fuente: Elaboración propia)

En la figura 4-19: Proyectos realizados (1987-2012); se observa como después de un periodo de expansión de las operaciones en el periodo 2004-2007, se produce un decrecimiento en los proyectos mineros durante el año 2008 , coincidiendo con la crisis mundial. Afortunadamente, esta disminución fue algo momentáneo y los proyectos mineros retomaron el crecimiento a partir del año 2010. 


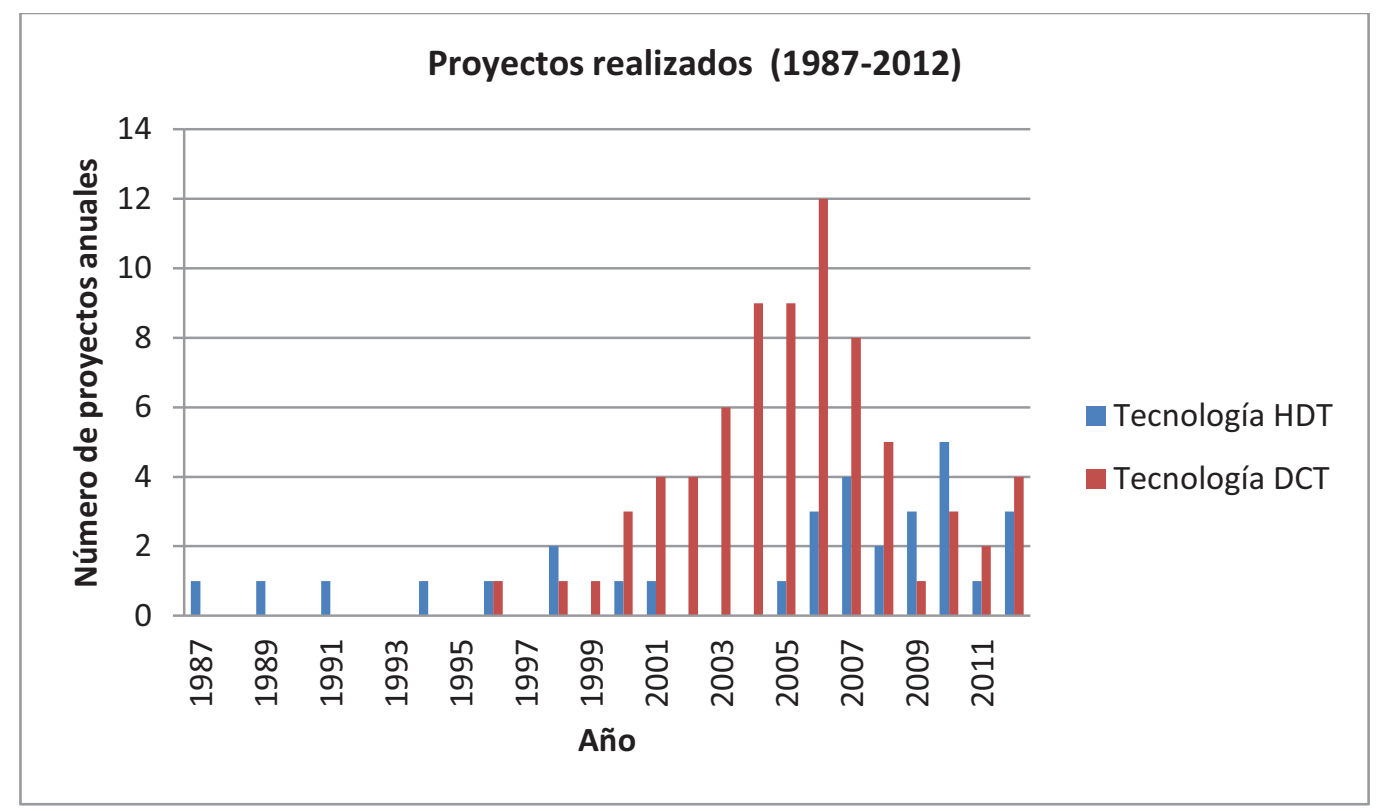

Figura 4-19: Proyectos realizados (1987-2012)

(Fuente: Elaboración propia)

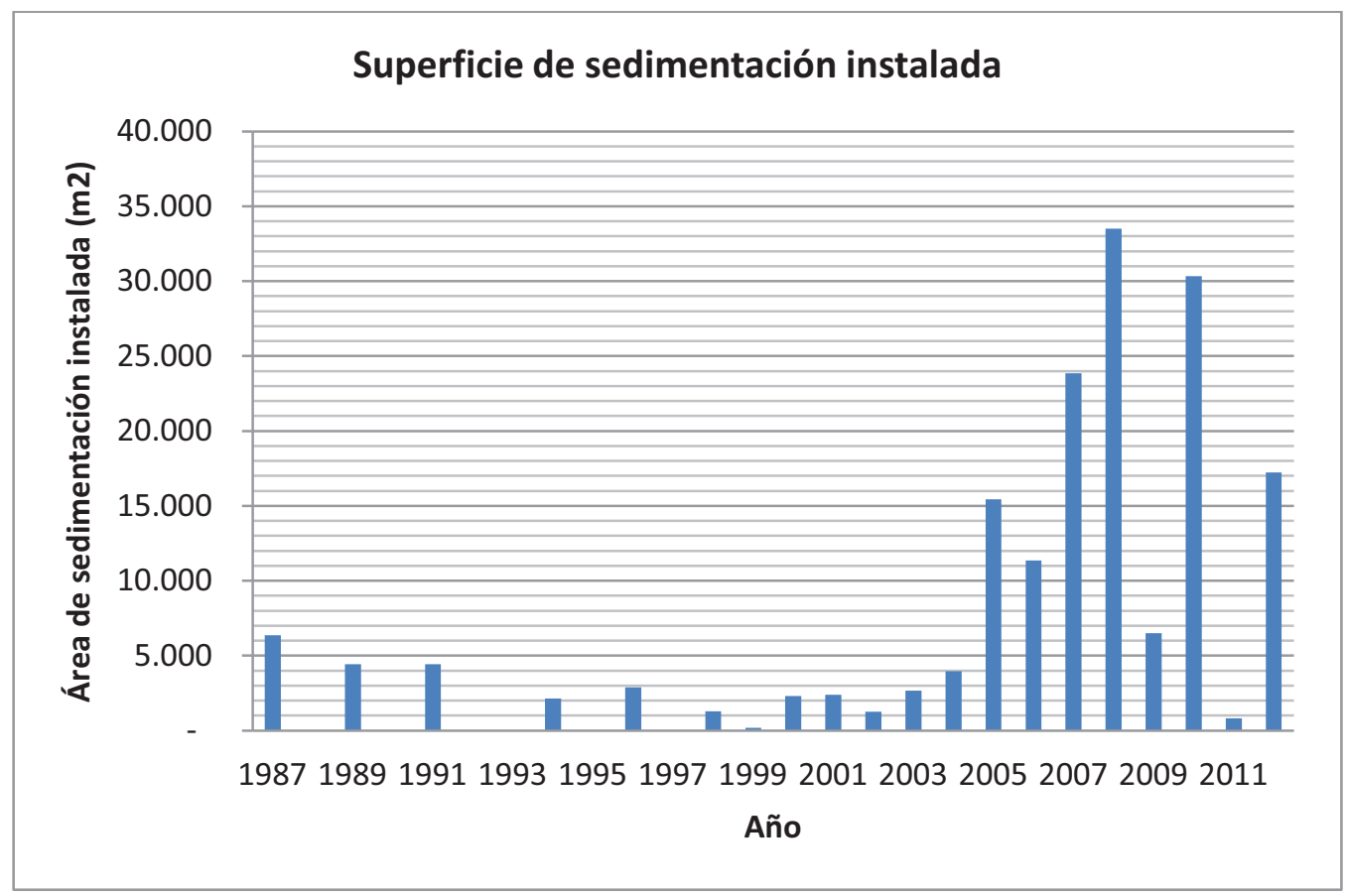

Figura 4-20: Superficie de sedimentación instalada (Fuente: Elaboración propia)

Un estudio de la superficie de sedimentación instalada en cada uno de los años analizados en el periodo 1987-2012, se muestra en la figura 4-20: Superficie de sedimentación instalada; donde se observa que el área instalada en cada nuevo proyecto crece significativamente. Si se evalúan las figuras 4-19 y 4-20, se observa que el área de sedimentación instalada anual crece en los años 2010 y 2012 especialmente, es similar a la de años anteriores del periodo 2005-2008; mientras que el número de equipos vendidos entre 2010 y 2012 es muy inferior, lo cual significa que los 
equipos y proyectos cada vez son mayores y con el transcurso del tiempo se necesitan de equipos de mayor capacidad para obtener las producciones requeridas, conforme los proyectos van aumentando su capacidad. Este fenómeno se observa en todos los equipos de minería en todas las plantas y equipos de trituración, molienda, filtración, sedimentación, etc.

Se ha realizado una nueva subdivisión de los datos disponibles para analizar las aplicaciones mayoritarias en el listado. El conjunto de operaciones que más datos registra es el espesados de estériles de la minería de metales base y el espesado de lodos rojos de bauxita, donde comenzó el desarrollo de los espesadores de cono profundo.

Por lo tanto, se van a analizar a continuación las diferentes operaciones, distinguiendo entre tecnologías de espesado en forma de pasta y de alta densidad (DCT y HDT), analizando los diámetros instalados en los proyectos y la totalidad del área de sedimentación instalada en cada año.

De la figura 4-21: Diámetros instalados. Tecnología HDT para estériles; y la figura 4-22: Total área instalada. Tecnología HDT para estériles; se aprecia un crecimiento a lo largo de los años del tamaño de los equipos, lo que significa en el caso de la tecnología HDT para estériles de metales base, que cada vez los proyectos son mayores y las necesidades de tratamiento de estériles son mayores, lo cual implica la construcción de equipos de mayor capacidad y tamaño.

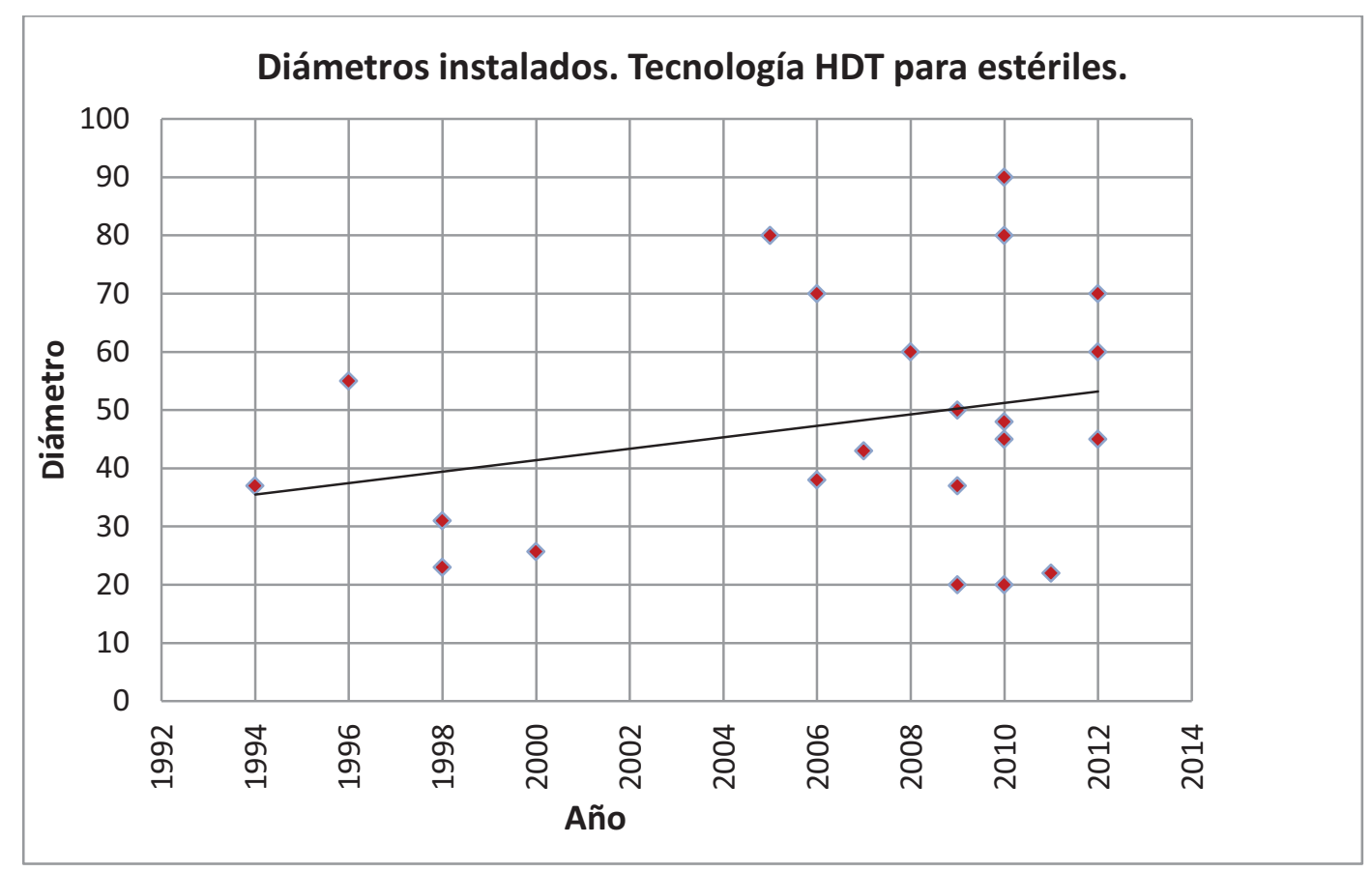

Figura 4-21: Diámetros instalados. Tecnología HDT para estériles. (Fuente: Elaboración propia) 


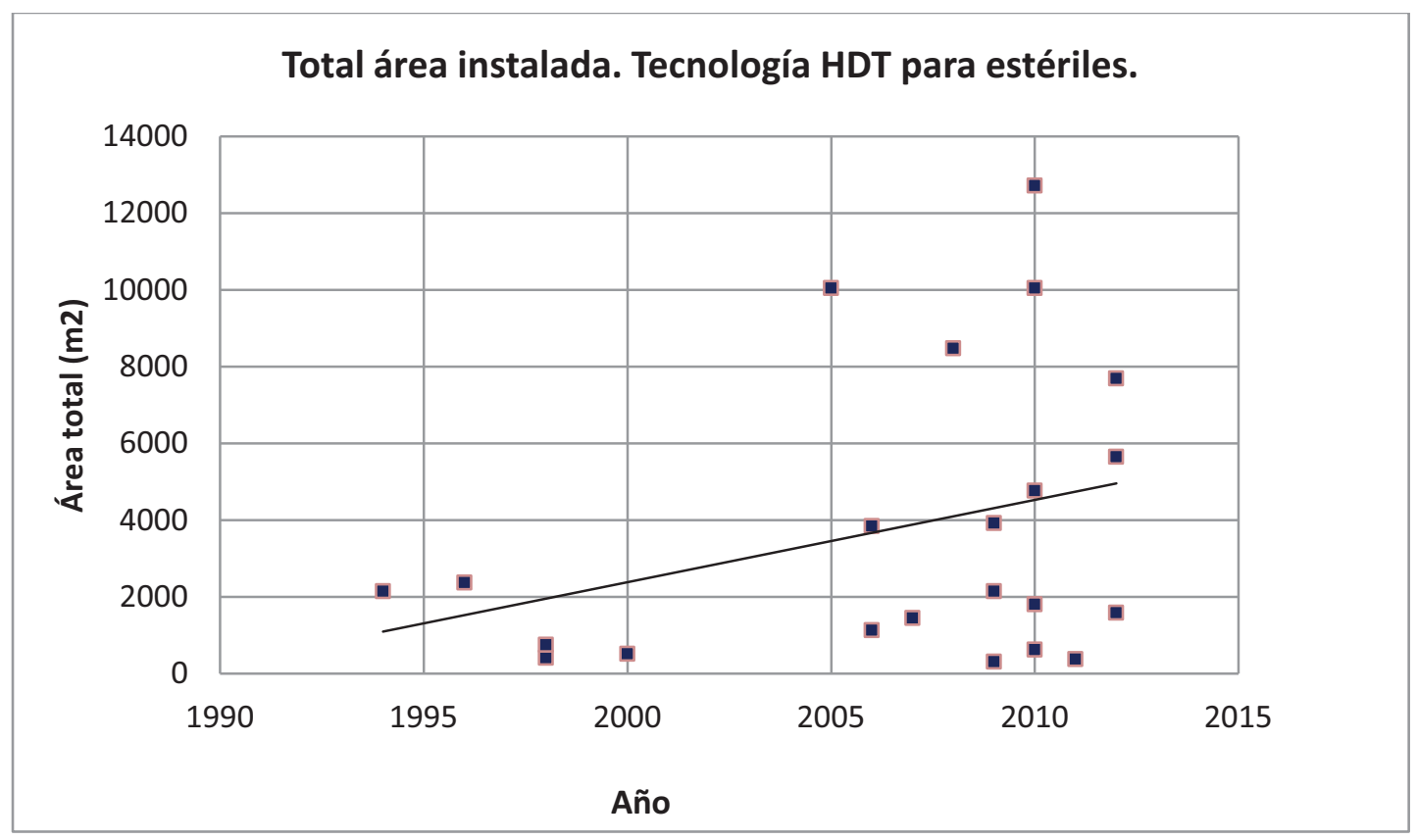

Figura 4-22: Total área instalada. Tecnología HDT para estériles. (Fuente: Elaboración propia)

De la figura 4-23: Diámetros instalados. Tecnología DCT para estériles; y la figura 4-24: Total área instalada. Tecnología DCT para estériles; se observa un comportamiento similar si bien no es tan acusado como en el caso de la tecnología HDT, pero sí se puede afirmar que tanto el diámetro de los equipos, como el área instalada en cada nuevo proyecto va aumentando progresivamente con el paso del tiempo.

Una tendencia similar se aprecia en la figura 4-25: Diámetros instalados. Tecnología DCT para alúmina; y en la figura 4-26: Total área instalada. Tecnología DCT para alúmina; donde la tendencia de los nuevos proyectos es ir hacia áreas de sedimentación mayores en los proyectos con la instalación de equipos de mayores diámetros.

Como conclusión de las gráficas y datos del análisis, se puede confirmar que la tecnología de espesado en pasta para el tratamiento de estériles, tanto en sistema de espesadores de cono profundo como en espesadores de alta densidad en el hundido, va en aumento y cada vez es más frecuente su instalación en todos los proyectos mineros a medida que es necesario el procesamiento de mayores tonelajes de mineral para obtener el metal. Esto es debido en gran medida a que los yacimientos que se descubren van disminuyendo sus leyes y por tanto, es necesaria una mayor capacidad de alimentación a la planta. Esto produce una mayor cantidad de estériles que necesitan ser tratados de forma adecuada para recuperar el agua contenida en los mismos antes de ser depositados en el vertedero de estériles. 


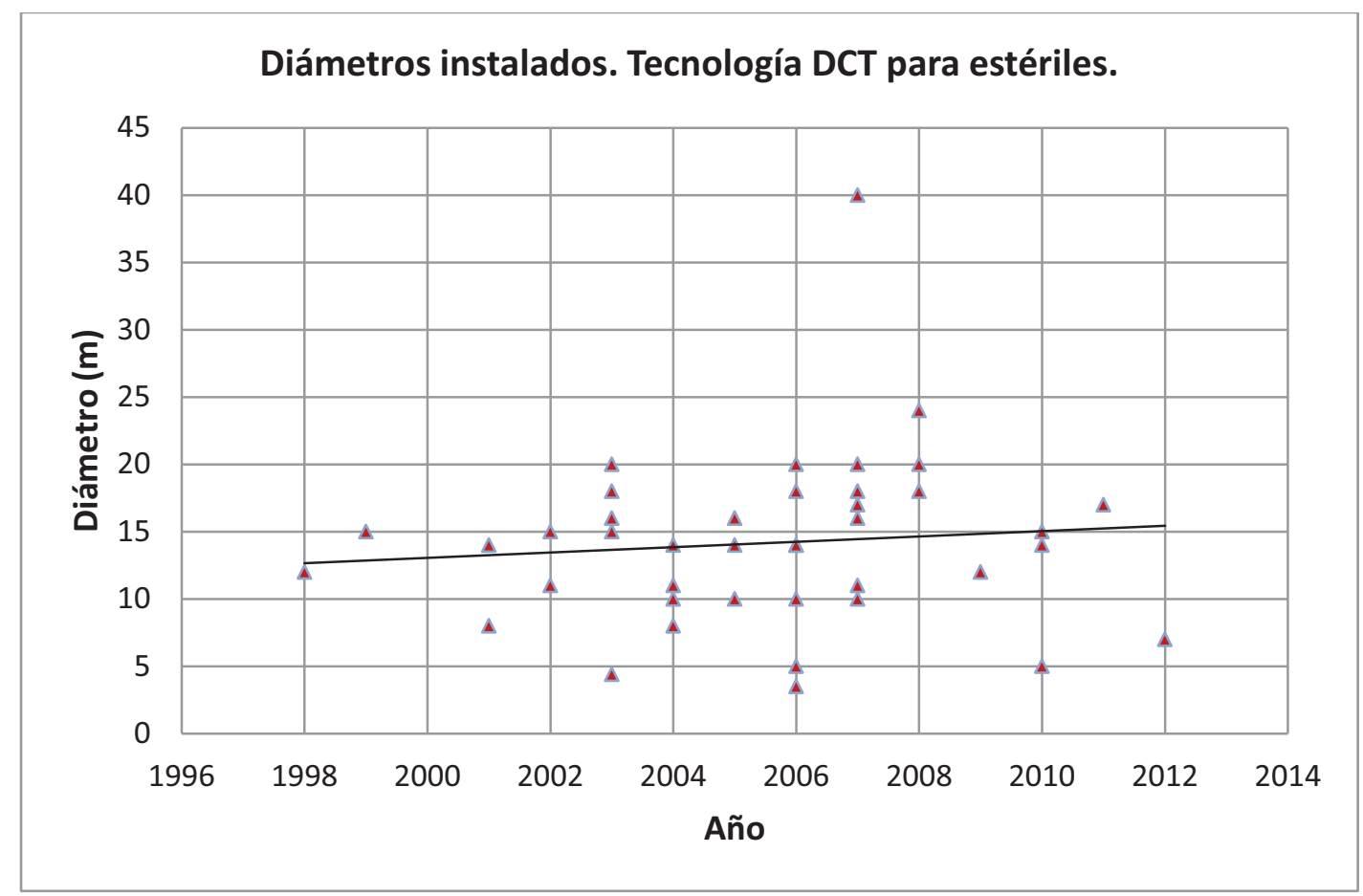

Figura 4-23: Diámetros instalados. Tecnología DCT para estériles. (Fuente: Elaboración propia)

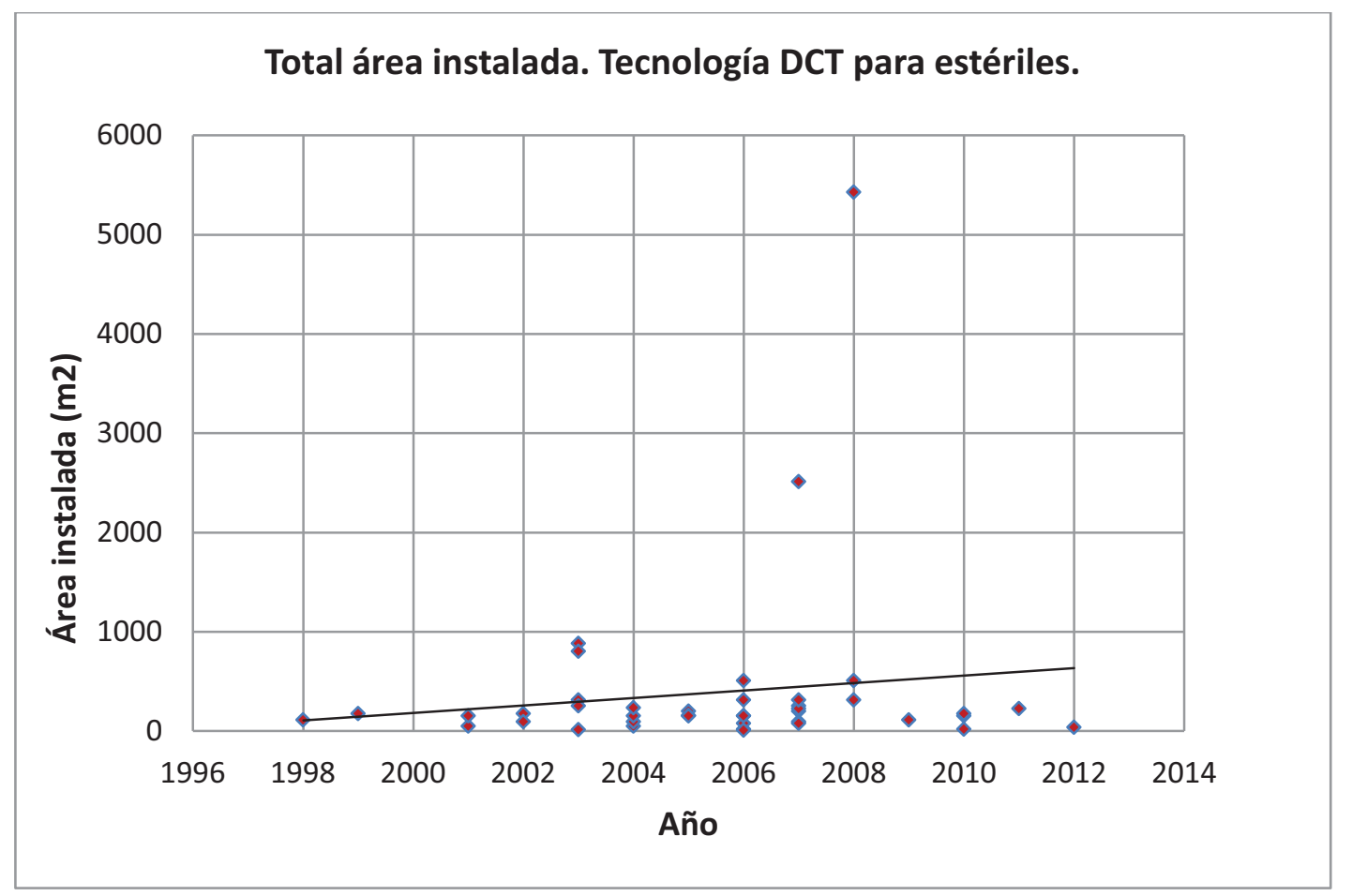

Figura 4-24: Total área instalada. Tecnología DCT para estériles.

(Fuente: Elaboración propia) 


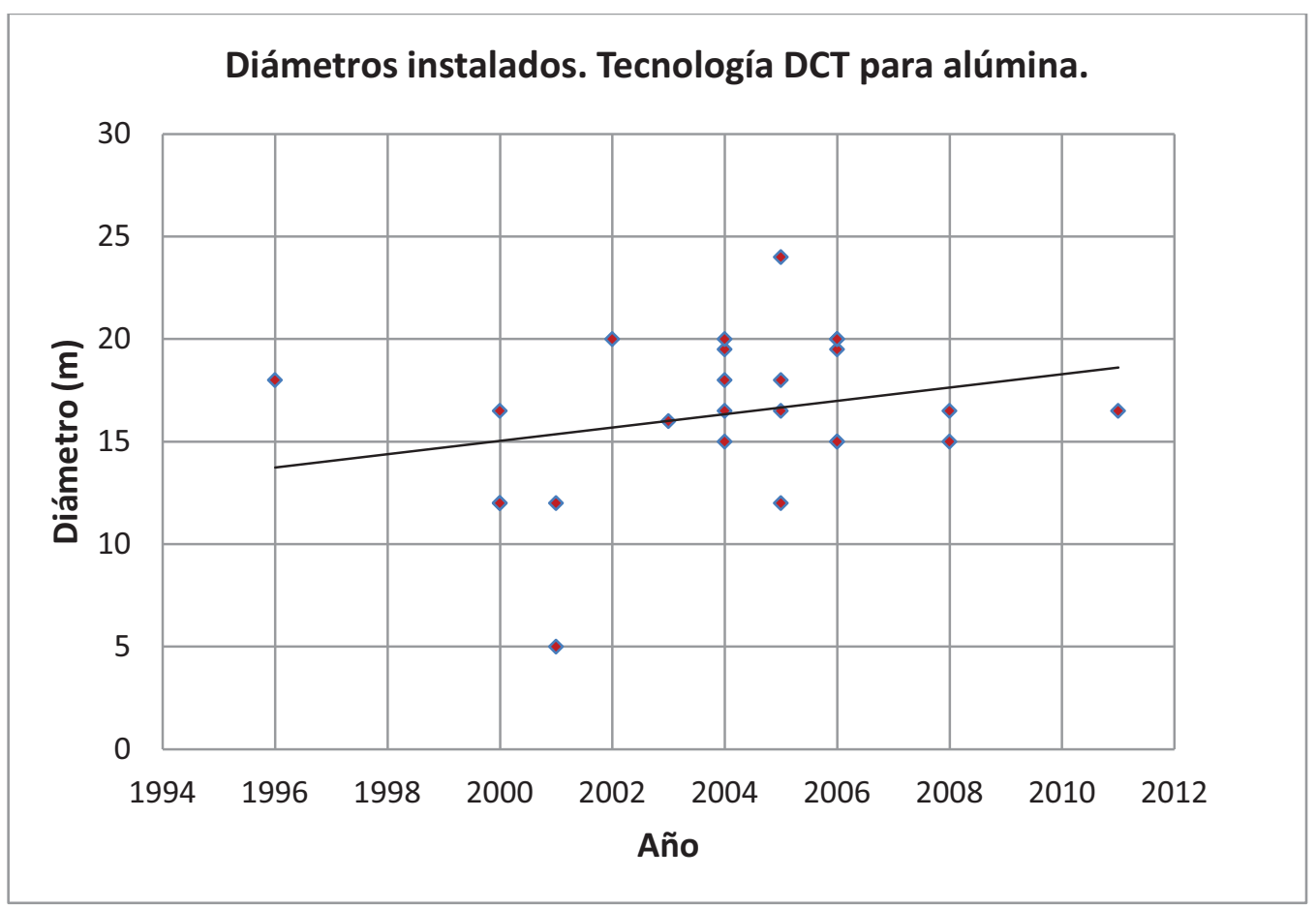

Figura 4-25: Diámetros instalados. Tecnología DCT para alúmina. (Fuente: Elaboración propia)

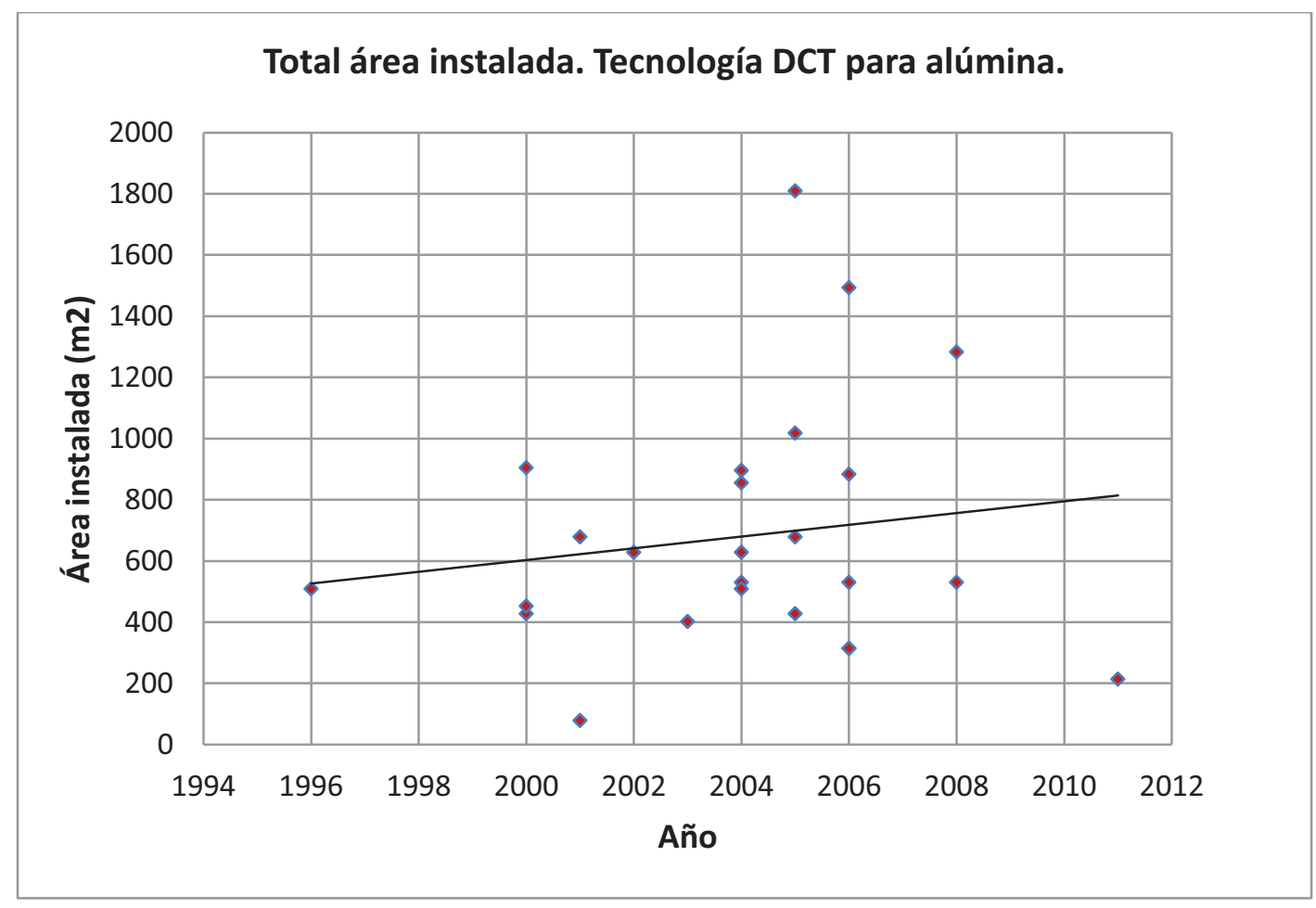

Figura 4-26: Total área instalada. Tecnología DCT para alúmina.

(Fuente: Elaboración propia) 


\subsection{Aplicaciones del espesador de cono profundo en el tratamiento de estériles}

El uso de espesadores de cono profundo, sin necesidad de una etapa de filtración posterior, produce una pasta no segregable y no sedimentable, con una reología de los lodos no newtoniana. Esta aplicación de espesado en pasta aplicada a los estériles mineros y otros materiales diferentes al proceso de la alúmina, es relativamente nueva y con un interés creciente en todo el sector minero. El reconocimiento a nivel mundial de las ventajas de esta tecnología de convertir en pasta los estériles mineros, hace posible obtener nuevas formas para la recuperación del agua utilizada en los procesos, incrementando el rendimiento a la vez que surgen nuevos métodos y sistemas de almacenamiento y deposición de estos estériles mineros.

En este punto se describen las principales aplicaciones de los espesadores de cono profundo, con especial atención a la deposición de estériles en superficie y a las operaciones de relleno de mina. Estas novedosas aplicaciones están dando lugar a un cambio en el sistema de operación de muchas minas, como por ejemplo, con la eliminación de balsas de estériles con bajo contenido en sólidos, reutilización de los estériles para relleno de huecos mineros en operaciones de corte y relleno, así como mejoras en los circuitos de lavado a contracorriente (CCD) y un mejor uso del agua disponible en los proyectos y operaciones mineras, optimizando su gestión.

Se han seleccionado dos tipos de operaciones típicas en las que los espesadores de cono profundo están aventajando al uso de otros equipos y sistemas utilizados de forma tradicional hasta hace pocos años. Estas operaciones son:

a) Apilado y deposición de estériles en superficie.

b) Fabricación de pasta para relleno de labores mineras.

Por lo tanto estos métodos de manejo de estériles que incluyen equipos de espesado de cono profundo, los cuales son utilizados para maximizar la recuperación de agua, como paso previo al bombeo de los estériles a los depósitos o las plantas de relleno de interior de mina fundamentalmente.

\subsubsection{Apilado en superficie de estériles}

En general, tradicionalmente, las pulpas de estériles de los procesos de flotación o lixiviación eran mayoritariamente depositadas en balsas de estériles. Los problemas de seguridad, medioambientales y de ocupación del terreno por las balsas de estériles han sido ampliamente evaluados en la literatura existente; siendo bien conocidas sus ventajas y desventajas. En la figura 4-27: Balsa de estériles de flotación en Somincor (Portugal); se muestra la extensión que pueden alcanzar estos depósitos, los cuales implican en su construcción una gran obra de ingeniería para hacer estas estructuras seguras durante toda la vida de la explotación, a la vez que se facilita su clausura llegado el momento. 


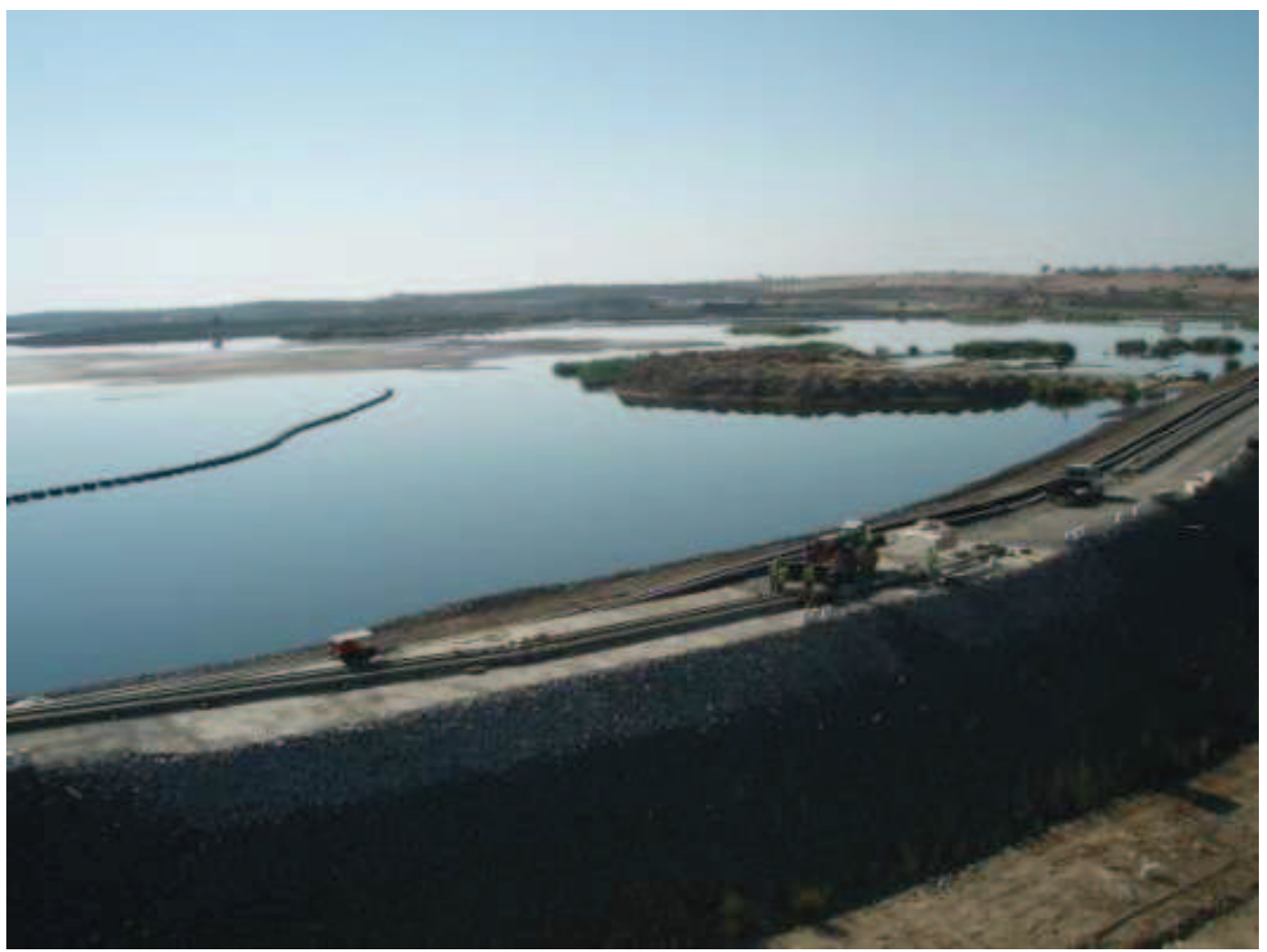

Figura 4-27: Balsa de estériles de flotación en Somincor (Portugal).

(Fuente: Cortesía de Sociedade Mineira de Neves-Corvo)

El apilado de pasta en superficie, como una alternativa a las balsas con estériles de bajo contenido en sólidos, es la deposición de los estériles en forma de pasta sobre el terreno, en forma de una suspensión de sólidos no segregables, no sedimentables y con mínima liberación del agua contenida. Existen varios métodos de análisis del apilado dependiendo de la topografía del terreno disponible y la reología esperada en la pasta de estériles. En la figura 4-28: Sistema convencional de almacenamiento de estériles en balsas; se muestra el método de almacenamiento de estériles mediante la creación de dos diques de contención que almacenan los estériles en forma de pulpa aprovechando la topografía del terreno. Una alternativa a este método es la producción de unos estériles de alto contenido en sólidos y con una alta tensión de fluencia que hace posible su almacenamiento en la superficie sin necesidad de diques, o que en caso de tenerlos el riesgo de rotura sea mínimo debido a la alta tensión de fluencia de los estériles que contienen. 


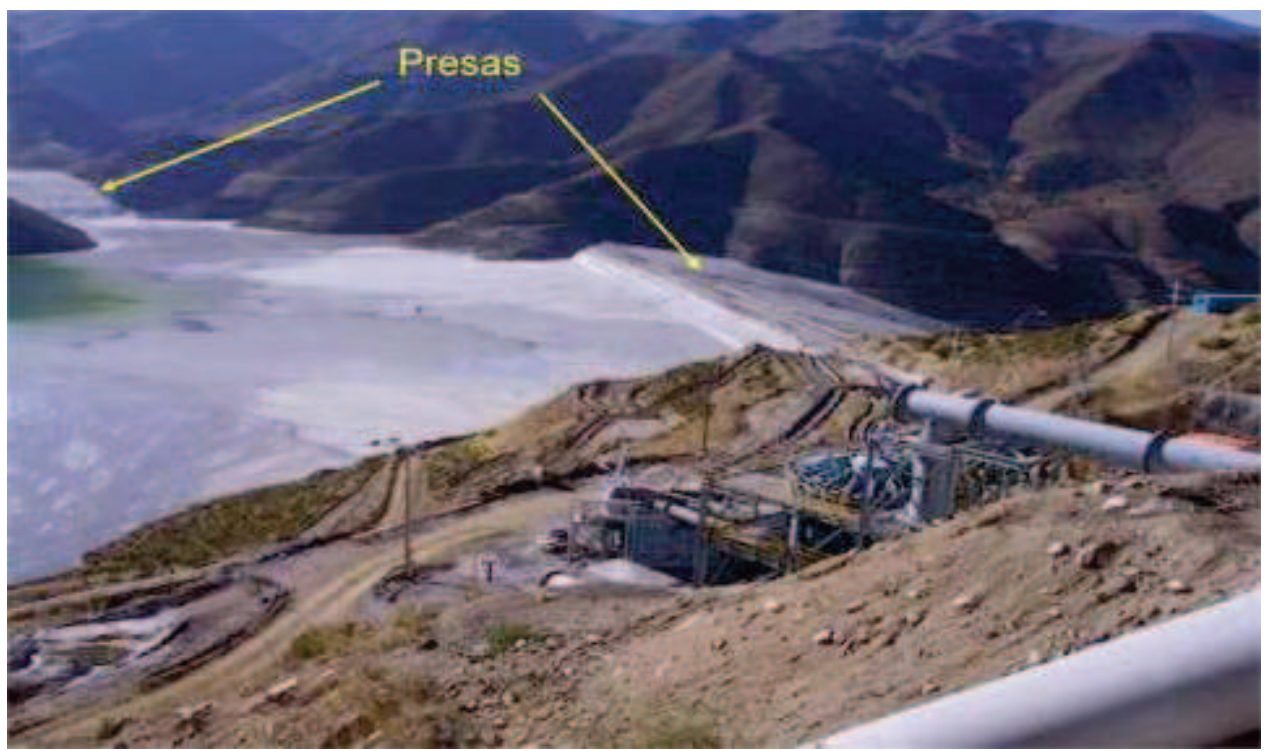

Figura 4-28: Sistema convencional de almacenamiento de estériles en balsas.

(Fuente: F. Baczek. Deep Cone Paste Thickeners and High Density Thickeners. Internal Report Dorr-Oliver

Eimco Annual Meeting 2004)

En general se pueden almacenar estériles en forma de pasta con taludes de hasta el $5-7 \%$ de pendiente. Esto es posible con la utilización de espesadores de cono profundo y el espesado en forma de pasta para deposición directa sobre la superficie del terreno. La figura 4-29: Sistema de apilado en superficie; muestra el esquema típico de un sistema de apilado de estériles en forma de pasta utilizando un espesador de cono profundo. La concentración del hundido del espesador de pasta debe cumplir los requerimientos del lugar de deposición, es decir el talud de apilado y permitir que la pasta sea bombeable fuera del espesador y transportable hasta el lugar de deposición.

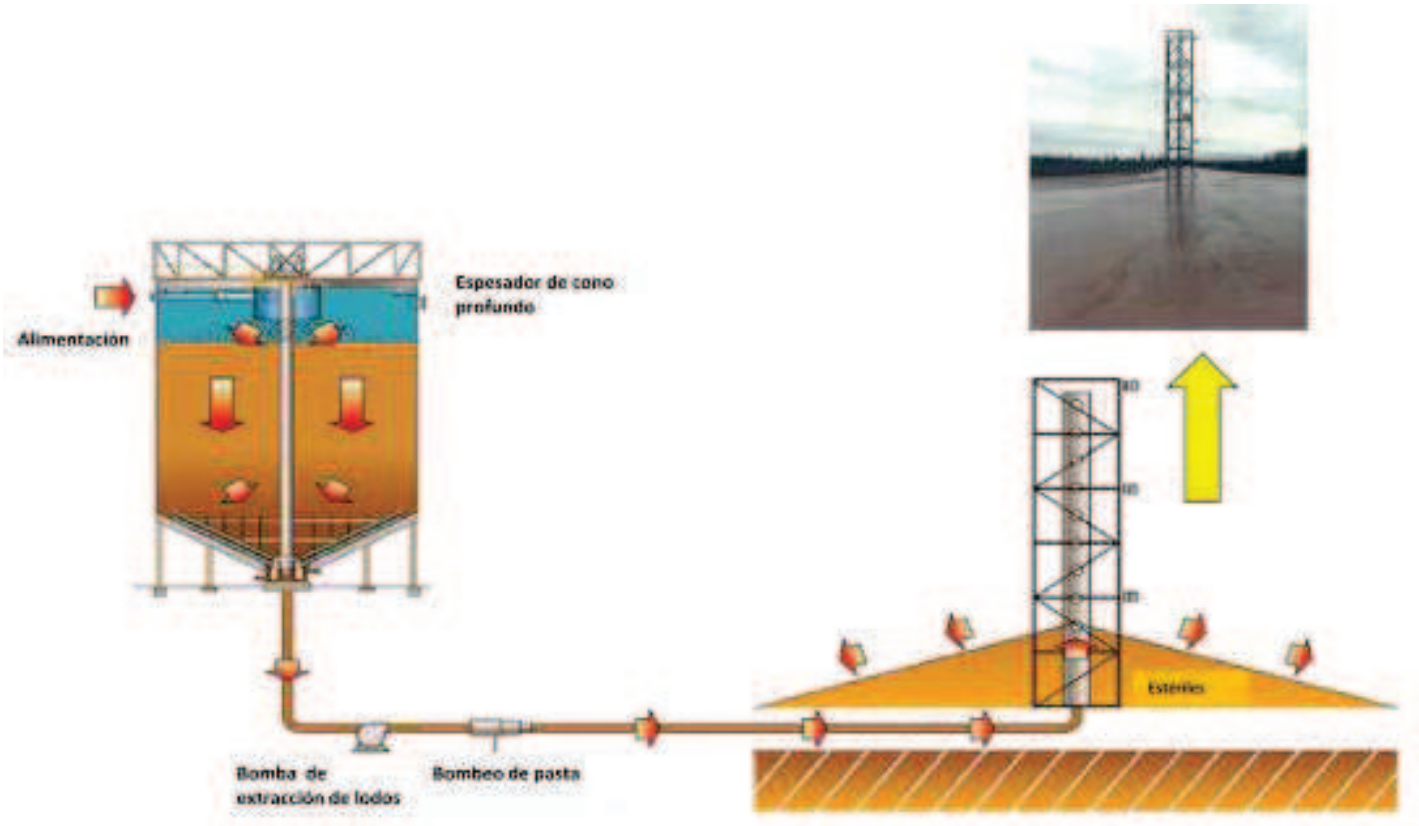

Figura 4-29: Sistema de apilado en superficie. 
(Fuente: adaptada de F. Baczek. Deep Cone Paste Thickeners and High Density Thickeners. Internal Report Dorr-Oliver Eimco Annual Meeting 2004)

Dependiendo de la distancia entre el espesador y el lugar de apilado de los estériles y de las características reológicas de la pasta, se podrán utilizar bombas centrífugas o bien, bombas de desplazamiento positivo para el transporte de estériles en forma de pasta; todo dependerá de los valores característicos y propiedades de la pasta formada, de ahí la importancia de la caracterización de la pasta en las primeras etapas del proyecto.

El método de apilado de estériles en forma de pasta proporciona una serie de ventajas significativas frente al sistema de almacenaje en balsas convencionales. El primer beneficio es el uso de una menor área de almacenamiento; una mayor recuperación del agua de proceso y por tanto con menor riesgo de rotura, menor contaminación por filtración al subsuelo y una mejor disposición del terreno para ser recuperado al final de la vida de la mina.

En cuanto a las ventajas ambientales del apilado de estériles espesados de alta densidad o en forma de pasta se comparan en la tabla 4-4: Comparativa de sistemas de almacenamiento en superficie; donde se enumeran las ventajas de los modernos sistemas de manejo de estériles con respecto a los espesadores convencionales.

Tabla 4-4: Comparativa de sistemas de almacenamiento en superficie.

\begin{tabular}{|c|c|c|}
\hline & Balsa de lodos convencional & Depósitos de lodos espesados \\
\hline $\begin{array}{l}\text { Volumen de } \\
\text { almacenamiento }\end{array}$ & $\begin{array}{l}\text { Gran volumen con el 20-25\% } \\
\text { sólidos }\end{array}$ & $\begin{array}{l}\text { 1/6 parte del volumen } \\
\text { convencional al } 60 \% \text { de sólidos }\end{array}$ \\
\hline Agua en el almacenamiento & $\begin{array}{l}\text { Requiere presa de retención de } \\
\text { aguas }\end{array}$ & $\begin{array}{l}\text { Normalmente no requiere presa, } \\
\text { sólo apilado }\end{array}$ \\
\hline Riesgo de rotura de la presa & Riesgo bajo-medio & Bajo o mínimo riesgo \\
\hline Ahorro de agua & $\begin{array}{l}\text { No efectivo, gran pérdida por } \\
\text { evaporación }\end{array}$ & El agua se recupera en planta \\
\hline Contaminación de acuíferos & Severo & Bajo o nulo \\
\hline $\begin{array}{l}\text { Riesgo de licuefacción de } \\
\text { los estériles }\end{array}$ & Alto riesgo & Bajo Riesgo \\
\hline $\begin{array}{l}\text { Uso de la tierra tras el cierre } \\
\text { de la operación }\end{array}$ & $\begin{array}{l}\text { Dificultad en la reclamación de } \\
\text { la tierra }\end{array}$ & $\begin{array}{l}\text { El drenaje de la superficie facilita } \\
\text { la recuperación del terreno }\end{array}$ \\
\hline Contaminación de agua & $\begin{array}{l}\text { Grandes cantidades a decantar } \\
\text { para su uso y sistema de } \\
\text { bombeo necesario para su uso }\end{array}$ & $\begin{array}{l}\text { Sólo el rebose puede requerir } \\
\text { recirculación o mantenimiento }\end{array}$ \\
\hline Polvo generado & $\begin{array}{l}\text { Segregación de partículas } \\
\text { pueden ser aerotransportadas }\end{array}$ & No es problema \\
\hline $\begin{array}{l}\text { Superficie empleada en las } \\
\text { balsas o pilas de } \\
\text { almacenamiento }\end{array}$ & Gran superficie & Superficie que puede ser limitada \\
\hline
\end{tabular}




\subsubsection{Pasta para relleno de labores de interior}

El proceso de relleno hidráulico de huecos mineros usando los productos gruesos de los estériles mineros es conocido desde hace décadas. Más innovador resulta el proceso de utilizar todas las partículas de estériles (finos y gruesos) en esta operación. Dependiendo del tipo de relleno necesario, la operación dependerá de los materiales disponibles en la mina, así como de las propiedades de los estériles espesados. Por ejemplo, si se requiere un relleno de alta resistencia mecánica, es frecuente su mezcla con cemento Portland en amasadora para adaptar las características mecánicas y la tensión de fluencia al bombeo y transporte requerido. En otras operaciones si los materiales de relleno son excesivamente finos, es normal mezclarlos con arena (0-6 mm) y cemento para conseguir la resistencia mecánica requerida en el proyecto.

El método convencional para la preparación de la pasta de relleno es mediante el espesado de los estériles procedentes de flotación de metales base, seguido por un sistema de filtración, siendo muy utilizados los sistemas de filtros de discos a vacío. El agua puede mezclarse con la torta filtrada para ajustarla a las necesidades del proceso posteriores, como puede ser el amasado con cemento Portland.

La tensión de fluencia y el contenido en sólidos requerido para la pasta de relleno se determina mediante la planificación de la operación de la mina, que incluye parámetros tales como: método de explotación, ciclo de acceso a las labores mineras, seguridad, disponibilidad de material, esquema de explotación y requerimientos de resistencia mecánica. Dependiendo de los parámetros de diseño y características reológicas de la pasta, es posible que con bajas tensiones de fluencia o baja altura de asentamiento medido con ensayo de asentamiento o viscosímetro, y la pasta pueda ser enviada desde el propio espesador de cono profundo sin pasar por la operación de filtrado descrita anteriormente. En las decisiones de diseño es importante la experiencia en las operaciones existentes y los datos recogidos en plantas piloto. La figura 4-30: Instalación de relleno de mina; muestra una planta típica de este tipo de sistemas para operaciones de relleno con pasta. También es normal disponer en la planta de una balsa para depositar los estériles, ya que el proceso de relleno no siempre funciona de forma continua y donde la pasta puede necesitarse de forma intermitente o discontinua, dependiendo de la planificación de la explotación de la mina o paradas para mantenimiento de alguno de los equipos.

La experiencia muestra que un diseño del espesador de cono profundo apropiado, puede funcionar de forma efectiva en las operaciones semi-continuas; esto es debido a la gran capacidad de almacenaje de lodos y al par de diseño que proporciona el accionamiento sobre el mecanismo para seguir girando, aunque el nivel del lecho de lodos ascienda debido a este almacenamiento de los sólidos sedimentados. El tiempo de almacenamiento requerido y el contenido en sólidos debe ser ajustado a la planificación de la operación prevista en la mina.

Con estos resultados tan versátiles de la operación de espesadores de cono profundo en este tipo de plantas, la instalación de espesadores de pasta va en aumento en los últimos años, a medida que la tecnología se va desarrollando y va siendo mejor conocida a través del desarrollo e implantación de nuevos sistemas de relleno de pasta a lo largo del mundo. 


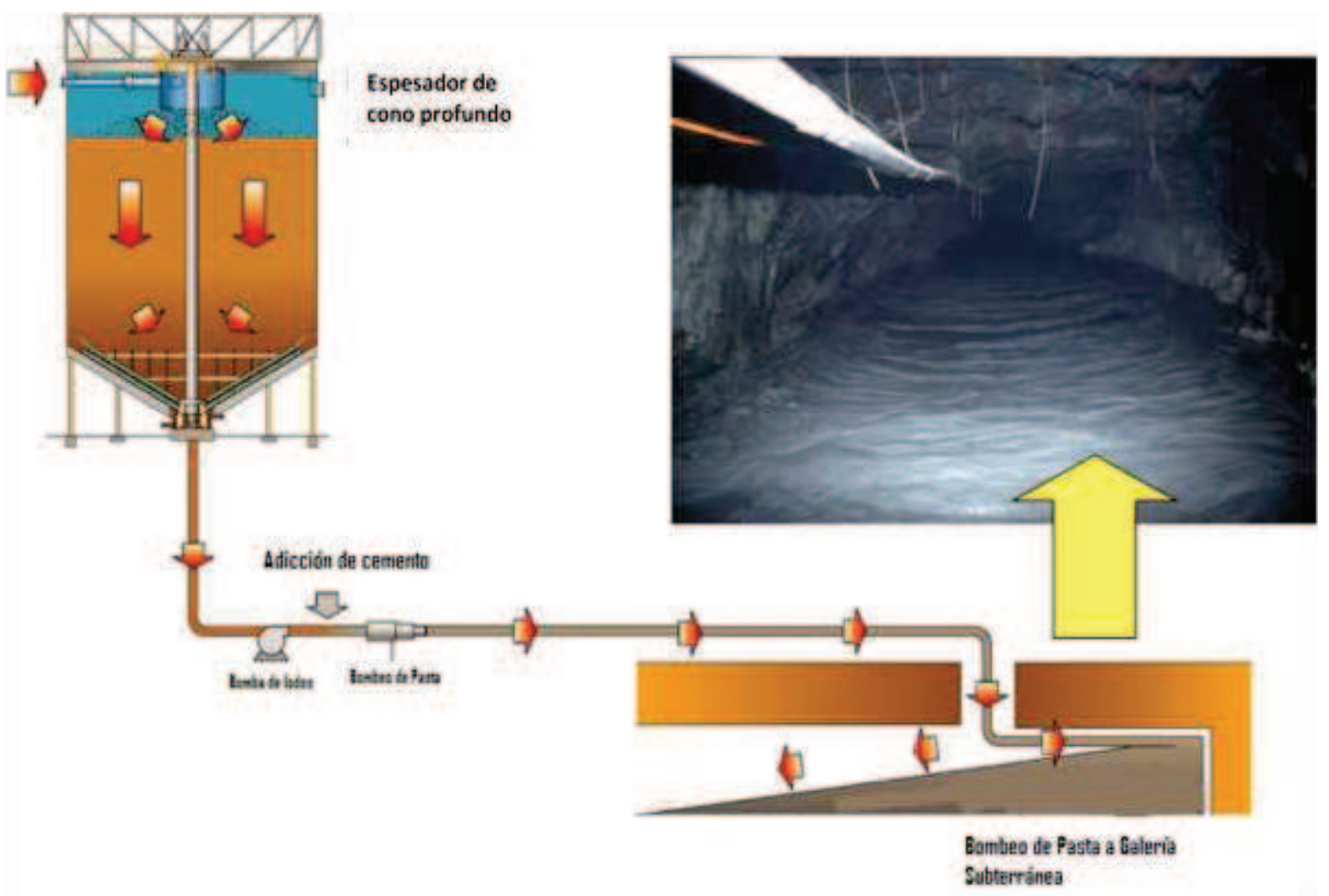

Figura 4-30: Instalación de relleno de mina.

(Fuente: adaptada de F. Baczek. Deep Cone Paste Thickeners and High Density Thickeners. Internal Report Dorr-Oliver Eimco Annual Meeting 2004)

La planta de relleno de pasta generalmente consiste en un espesador de cono profundo, un silo de cemento, un edificio anexo para albergar las estaciones de bombeo y dosificaciones de reactivos provista de una sala de control eléctrica y de autómatas.

En general el espesador recibe los materiales o estériles procedentes de una operación de flotación de metales base, la concentración en sólidos en la alimentación varía desde 15\% hasta el $30 \%$; en caso de estériles con densidades medias de 2,5 a $4,0 \mathrm{~kg} / \mathrm{dm}^{3}$, se pueden obtener fácilmente contenidos en sólidos en el hundido del $65-80 \%$ con cierto tiempo de retención en el espesador, con lo que se obtiene una gran mejora en la productividad de la mina con un sistema de relleno en forma de pasta, esto es evidente especialmente en operaciones de corte y relleno, ya que se produce el sostenimiento de los huecos, aumenta la seguridad y se reducen las necesidades de terrenos en superficie para balsas o vertederos de estériles.

El espesador produce la pasta a la concentración de sólidos requerida o a una determinada consistencia de la pasta, basado en unos parámetros definidos, que es la medida común de la pasta en la industria del relleno de mina. El hundido es bombeado con bombas a una mezcladora donde se añade por lo general cemento. Esta mezcla es entonces enviada a la mina por gravedad o mediante una bomba de desplazamiento positivo si se requiere en función de las distancias de bombeo o altura manométrica necesaria. 
Las ventajas del uso de espesadores de pasta en estas operaciones de relleno de mina son las siguientes:

a) Se consigue alta resistencia con menor cantidad de cemento.

b) No es necesario eliminar agua de los huecos mineros ya que son rellenados con pasta.

c) Debido a que es una pasta y es un lodo no segregado, las partículas gruesas no necesitan ser eliminadas previamente al espesado.

d) Los finos permanecen en suspensión y no se pierden o segregan debido al alto límite de fluencia de los lodos.

e) La necesidad de filtros posteriores puede ser eliminada o el área de filtración, como poco, es reducida.

f) El relleno de pasta permite el uso del método de corte y relleno haciendo las labores mineras más seguras.

\subsection{Sistemas de alimentación de espesadores en la actualidad}

El diseño de la campana a pesar de su alta influencia en el desarrollo y operación del espesador, es una parte que ha tenido una escasa innovación, aparentemente en los últimos 20 años. Si bien esta afirmación es por temas de diseño o forma externa más que por el sistema de funcionamiento o de operación, donde sí existen grandes avances. Es en los últimos años, con la puesta en servicio de grandes espesadores de pasta y de alta densidad en el hundido, cuando se han retomado los estudios e investigaciones para conseguir mejorar su diseño y rendimiento. Habida cuenta que el proceso de sedimentación requiere de una buena floculación previa, los últimos esfuerzos de investigación se han centrado en el diseño de la campana de alimentación, que es un área donde realmente se cuenta con obtener grandes beneficios para la operación. Por tanto, en la campana de alimentación donde se produce el movimiento relativo entre sólidos y líquido, se puede describir un perfil de ratios de esfuerzos. Este perfil de esfuerzos es importante para alcanzar una buena mezcla entre el sólido y el floculante con el consiguiente crecimiento del flóculo en la campana antes de pasar al tanque de sedimentación, lo que asegura una buena operación del equipo de espesado.

Todos los diseños actuales se basan en aprovechar la energía del flujo de la pulpa a alimentar, controlando sus ratios de esfuerzo y la energía a la entrada de la campana de alimentación, dentro de la campana y a la salida de ésta. Un esfuerzo alto en la parte superior de la campana o en la zona de entrada (tubería o canal) está asociado con la disipación de energía del flujo de alimentación. Es en la zona alta de la campana donde la dilución de la pulpa, en caso de ser necesaria, se produce y donde el floculante empieza a dispersarse dentro de la pulpa. Aguas abajo, siguiendo el recorrido de la pulpa en la campana de alimentación los ratios de turbulencias bajos y una agitación suave, están asociados con el crecimiento del flóculo. El ratio de turbulencia tiene que ser moderado para permitir la colisión entre flóculos y el "engorde" de éstos, pero sin provocar su rotura. Finalmente el material floculado sale de la campana de alimentación y entra en 
el cuerpo del espesador para su sedimentación. Este proceso permite un flóculo maduro y donde se mantiene el tamaño del flóculo, que es fundamental para alcanzar altos ratios de sedimentación y la máxima densidad de la pulpa.

A la vez que los suministradores de equipos de espesado de pasta desarrollan espesadores cada vez con mayores capacidades y diámetros, para acomodarse a las demandas de producciones crecientes, las tareas asignadas a la campana de alimentación como son: disipación de energía, dilución de la alimentación, formación del flóculo y distribución del material floculado; son cada vez más importantes para conseguir una pasta de alta densidad en el hundido del espesador.

Una de las claves para producir pasta o espesado de estériles en un espesador es asegurar que el diseño de la campana de alimentación del espesador proporciona las condiciones adecuadas de floculación. Esto implica que la fase de ingeniería, debe comprender al menos dos importantes soluciones en el diseño de la campana para obtener los siguientes resultados:

a) Por un lado, absorber el rango de variabilidad o fluctuaciones que presenta la alimentación, incluyendo las variaciones de caudal, contenido en sólidos, densidad del mineral, dosificación de floculantes y granulometría.

b) Administrar de forma eficiente el floculante o una mezcla de floculantes para tratar los tipos de mineral existentes teniendo en cuenta las características químicas del agua y los puntos de dosificación de floculantes.

Siguiendo la investigación y aplicación en esta área en los últimos años, uno de los fundamentos para la obtención de pasta, es que se requiere un control importante de la floculación y también manejar de forma correcta cómo las partículas sólidas y el floculante son puestas en contacto con el adecuado tiempo de residencia. En la figura 4-31: Campana de alimentación; se puede observar un sistema de alimentación con eductores operando en un espesador de pasta moderno.

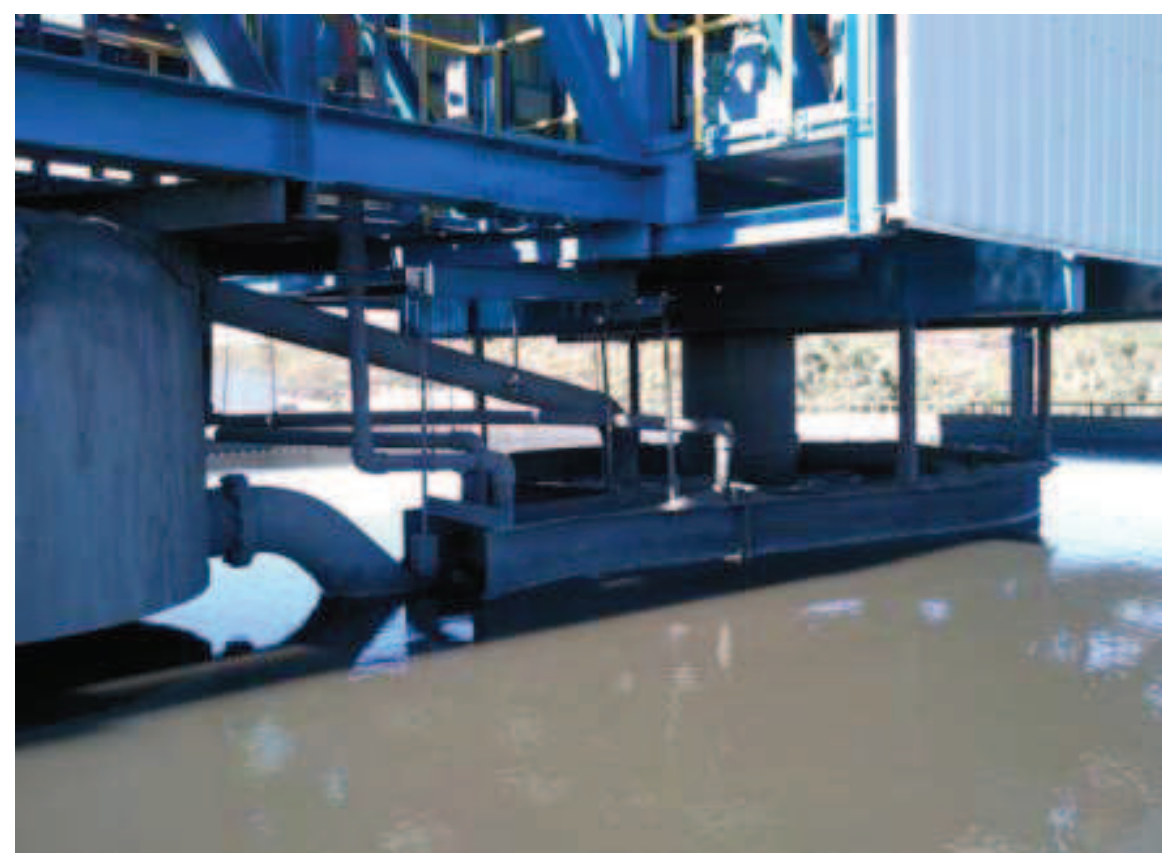

Figura 4-31: Campana de alimentación. (Fuente: Minas de Aguas Teñidas, S.A.U.) 
La mayoría de espesadores instalados en la industria minera desde hace años, especialmente desde 1990, han sido diseñados para operar con el empleo de floculantes poliméricos que mejoran el rendimiento del espesador y reducen sustancialmente el tamaño del equipo y por tanto la inversión de costes de capital. Los espesadores instalados hace más de 30 años pueden o no, haber sido diseñados para su uso con los modernos floculantes que existen actualmente en el mercado, pero la tendencia general hacia el incremento de capacidad de las operaciones, ha resultado en que estas unidades se han comenzado a operar con floculantes modernos y necesitan por tanto, de una reforma de su sistema de alimentación para aumentar su capacidad y adoptar las condiciones de operación óptimas de los nuevos floculantes. El coste del reactivo usado en la floculación puede ser importante y en ocasiones representa un coste de operación alto. Por tanto, cualquier sistema que mejore la eficiencia del uso del floculante que contribuya a unos costes de operación menores para el proceso y la planta, deben de ser tenidos en cuenta por el operador. Este hecho no era muy conocido ni estaba muy bien visto desde los primeros días de la utilización de los floculantes a base de polímeros, aunque ahora es una práctica común diluir la alimentación de la pulpa del espesador hasta una concentración óptima creando un efecto beneficioso en la floculación de las partículas sólidas.

Los ensayos en laboratorio con muestras en probeta a una determinada dosificación de floculante y un contenido en sólidos, se pueden emplear para establecer la alimentación de sólidos óptima para un determinado floculante y concentración de sólidos. Esto es sólo necesario para medir el ratio de sedimentación inicial para varias concentraciones de sólidos, multiplicando este valor por la concentración de sólidos en el ensayo y realizando la gráfica correspondiente con este valor, el flujo de sedimentación en $\mathrm{t} / \mathrm{m}^{2} / \mathrm{h}$ frente a la concentración de la alimentación. Una curva típica está representada en la figura 4-32: Curva típica dosificación de floculante frente a contenido en sólidos de la alimentación. Ordinariamente se ha observado que hay un rango óptimo que se extiende generalmente entre el $5 \%$ y el $15 \%$ para la mayoría de los materiales ensayados en este estudio, en el que el flujo alcanza un máximo para una dosificación particular. Si los ensayos de sedimentación fueran continuados hasta la concentración final, se encuentra que la mínima área unitaria se repite para esta misma concentración óptima de sólidos en la alimentación. 


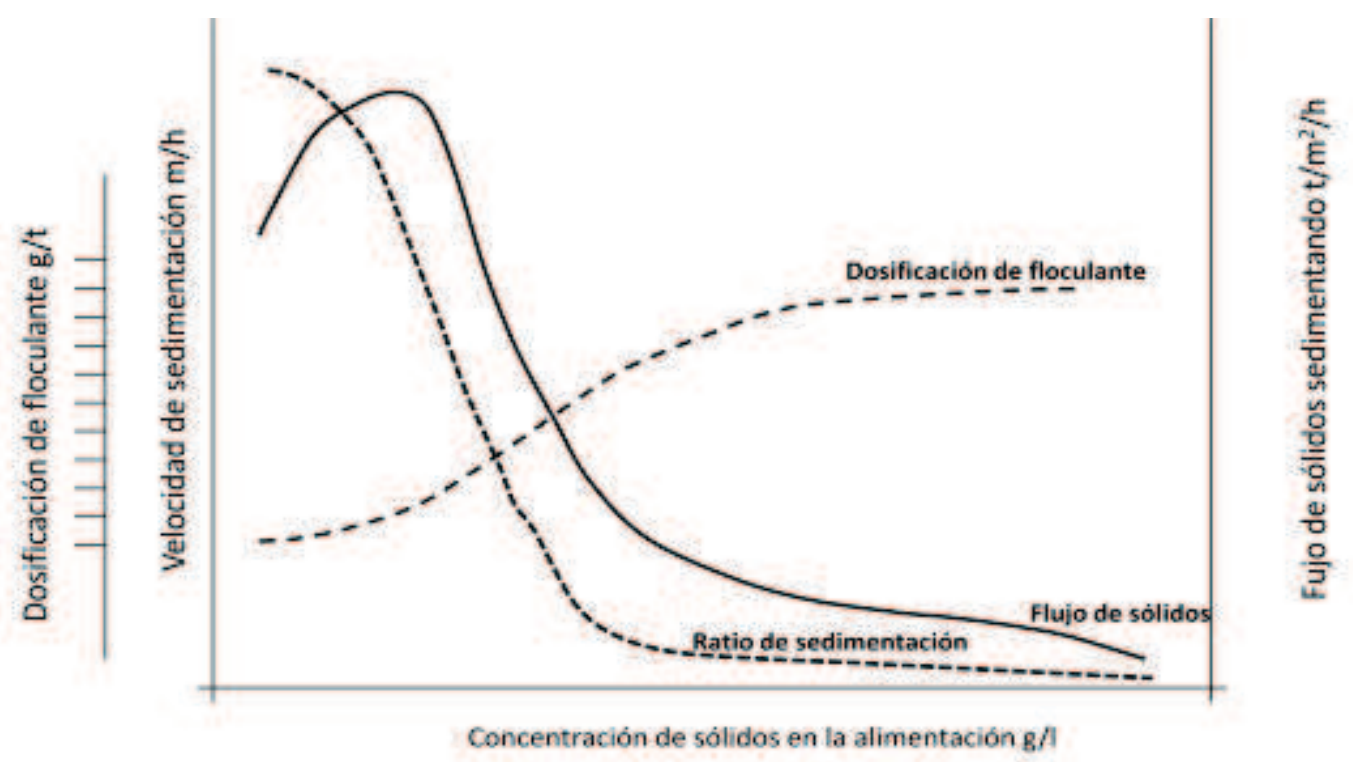

Figura 4-32: Curvas típica dosificación floculante frente a contenido en sólidos en la alimentación.

(Fuente: Elaboración propia)

Una explicación exacta a este comportamiento de las pulpas no está bien definido, pero está relacionado probablemente, con el área total de la superficie de la partícula en un volumen específico de pulpa. Esto está indicado por la dilución requerida en varias aplicaciones diferentes donde el rango de tamaños de partículas es diferente. Un considerable número de los procesos de molienda y metalúrgicos que ocurren a una concentración determinada, que es sobre el punto óptimo para que la floculación sea más eficiente. Normalmente, los estériles de flotación procedentes de un proceso típico de flotación tienen una concentración entre el $25 \%$ y el $35 \%$ de sólidos en peso; y en la mayoría de los casos, la concentración óptima de la alimentación está normalmente entre el $5 \%$ y el $15 \%$ para la mayoría de los floculantes utilizados. En circuitos de lixiviación, particularmente con materiales extremadamente finos donde el $80 \%$ o más está por debajo de las 325 mallas Tyler (44 micras) de tamaño de partículas, la concentración óptima de sólidos en la alimentación varía desde el $5 \%$ al $10 \%$ generalmente; en el caso de arcillas, caolines finos y materiales similares con tamaños de partículas finas generalmente por debajo de 10 micras, requieren diluciones de menos del 3\% para obtener las condiciones de floculación óptimas, como norma general. En cualquier caso, es siempre recomendable la realización de ensayos de laboratorio para determinar las condiciones óptimas del proceso.

Es posible definir las partes comunes de las que constan estos sistemas de alimentación y que son comunes en la mayoría de espesadores y procesos de espesado: 
a) Tanque de alimentación en cabeza: donde descarga la pulpa desde la tubería de alimentación, sus funciones principales son proveer un flujo continuo a la boquilla eductora y así evitar la entrada de aire al circuito, es decir además tiene una función de tanque de desaireación.

b) Tubería de alimentación: une el tanque de alimentación con la boquilla eductora.

c) Boquilla eductora: su función es el aumento de la velocidad del flujo de pulpa para provocar una corriente en chorro que arrastre el agua sobrenadante cercana a la entrada de la tubería o el canal de mezcla.

d) Tubo o canal de mezcla: el objetivo es que la pulpa se diluya y se mezcle con el reactivo de floculación en este tramo del canal o tubería.

e) Campana de alimentación: es la parte final del sistema de eductores y común en todos los espesadores, lo cual permite el crecimiento del flóculo y la sedimentación de las partículas.

f) Puntos de dosificación de floculante: se encuentran distribuidos a los largo de todo el sistema pudiendo empezar la dosificación en el tanque de alimentación en cabeza y colocar varios puntos de adicción de floculante incluso hasta en la campana de alimentación.

En la figura 4-33: Campana de alimentación con sistema de eductor. Esquema; se muestra la configuración de uno de estos sistemas de alimentación y la configuración de las distintas partes que lo componen.

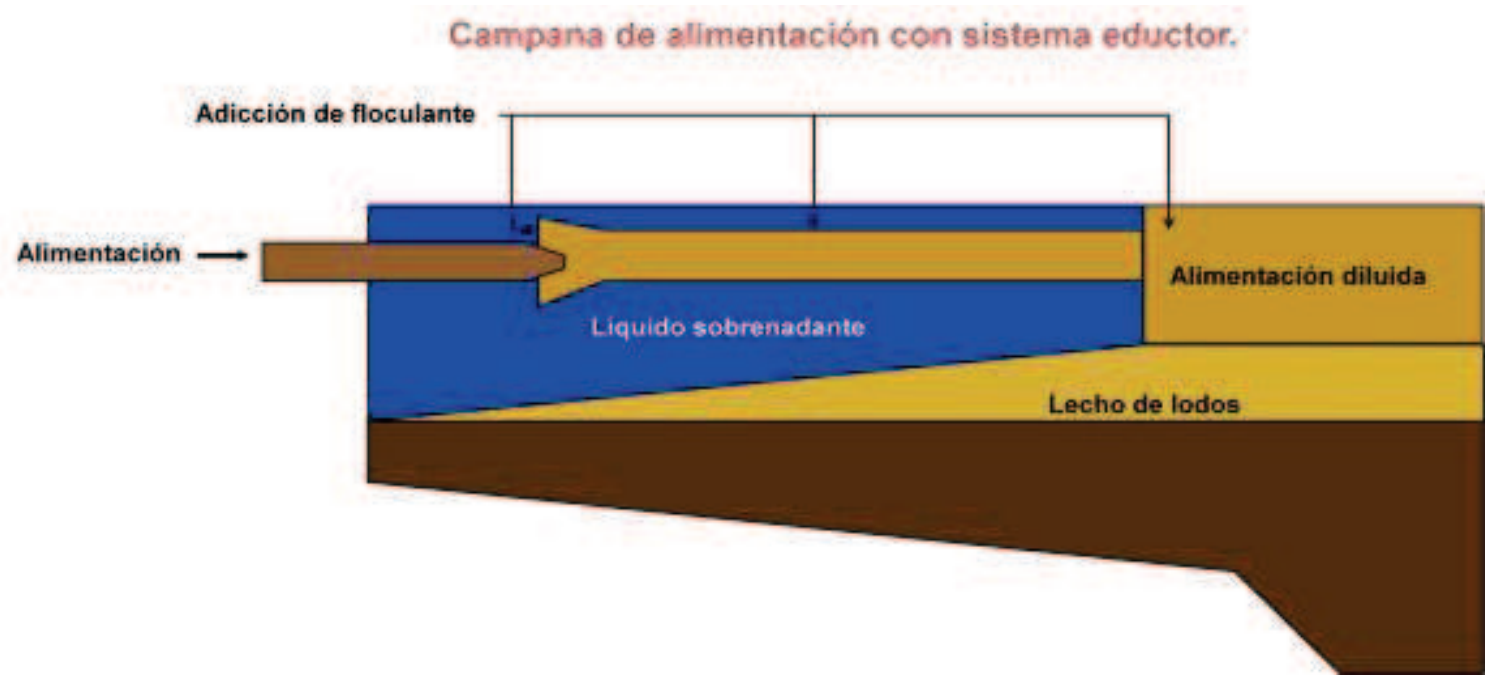

Figura 4-33: Campana de alimentación con sistema de eductor. Esquema.

(Fuente: Elaboración propia)

\subsubsection{Principio de funcionamiento del sistema de alimentación con eductores}

El sistema de alimentación provisto de eductor proporciona una mejora en el desarrollo y operación de espesadores a través de la dilución uniforme de la alimentación junto con una mezcla eficiente de floculante y la alimentación de pulpa al espesador. La pulpa alimentada al 
espesador es introducida a través del sistema de eductor patentado que mezcla uniformemente la pulpa con el líquido sobrenadante arrastrado hacia el interior junto con el floculante dosificado, antes de la entrada en la campana de alimentación del espesador. La predilución del floculante con el líquido clarificado asegura que la pulpa diluida es en todo momento floculada durante la mezcla, permitiendo la realización de las fases de formación y crecimiento del flóculo fundamentales para una buena sedimentación. Estas fases se aseguran usando las dimensiones apropiadas del canal o tubo de mezcla previo a la campana de alimentación.

Los ratios de dilución vienen definidos por el diseño del eductor y son uniformes para los rangos de dilución y alimentación establecidos. Este ratio de dilución debe ser evaluado previamente mediante ensayos de laboratorio. La dilución se produce por la transferencia de momento entre el flujo de alimentación de la pulpa y el líquido sobrenadante. El sistema de alimentación por eductores, normalmente está ubicado en la parte exterior de la campana de alimentación, presentando una entrada tangencial en ésta para su descarga. El sistema se puede aplicar tanto a instalaciones nuevas como a espesadores existentes que sean reformados para aumentar su capacidad de espesado.

Existen dos tipos principales de sistemas: de tubo y de canal, si bien los principios de funcionamiento son muy similares, la ventaja del sistema en canal es que permite la visualización de la marcha de la operación y permite cambios sencillos de los puntos de floculación, así como una fácil limpieza de las partes del canal y la boquilla. El modelo de canal es el que se ha impuesto hoy en día en todos los equipos de nueva construcción, siempre que las condiciones de operación y del grado de dilución requerido lo permitan.

El sistema de alimentación con eductores se ajusta por tanto, a todas las pulpas que requieren una reducción del contenido en sólidos para mejorar su ratio de sedimentación mediante una dosificación adecuada del floculante; y también es de aplicación a aquellas pulpas que aunque no sean floculadas, con la simple dilución de la alimentación se consiga una mejora de los ratios de sedimentación. Los límites mínimo y máximo habituales de dilución antes de la entrada en la campana de alimentación varían entre el $5 \%$ y el $15 \%$ generalmente. En la figura 4-34: Sistema de alimentación con eductor de canal abierto; se muestra la zona de entrada al canal de alimentación y la boquilla.

El sistema de alimentación provisto de eductores, presenta los siguientes beneficios frente a otros sistemas convencionales de alimentación de espesadores:

Una eficiente dilución y mezcla de la pulpa alimentada consigue los siguientes beneficios sobre la operación del equipo:

a) Una densidad y un flujo uniforme entrando a la campana de alimentación.

b) Buena mezcla y dispersión del floculante antes de entrar en la campana de alimentación.

c) Reducción de las turbulencias y esfuerzos que provocan la rotura de los flóculos, con una agitación suave.

d) Formación, crecimiento y maduración del flóculo antes de llegar a la campana de alimentación.

e) Evita la alta dosificación de floculante y por tanto un gasto innecesario de floculante. 


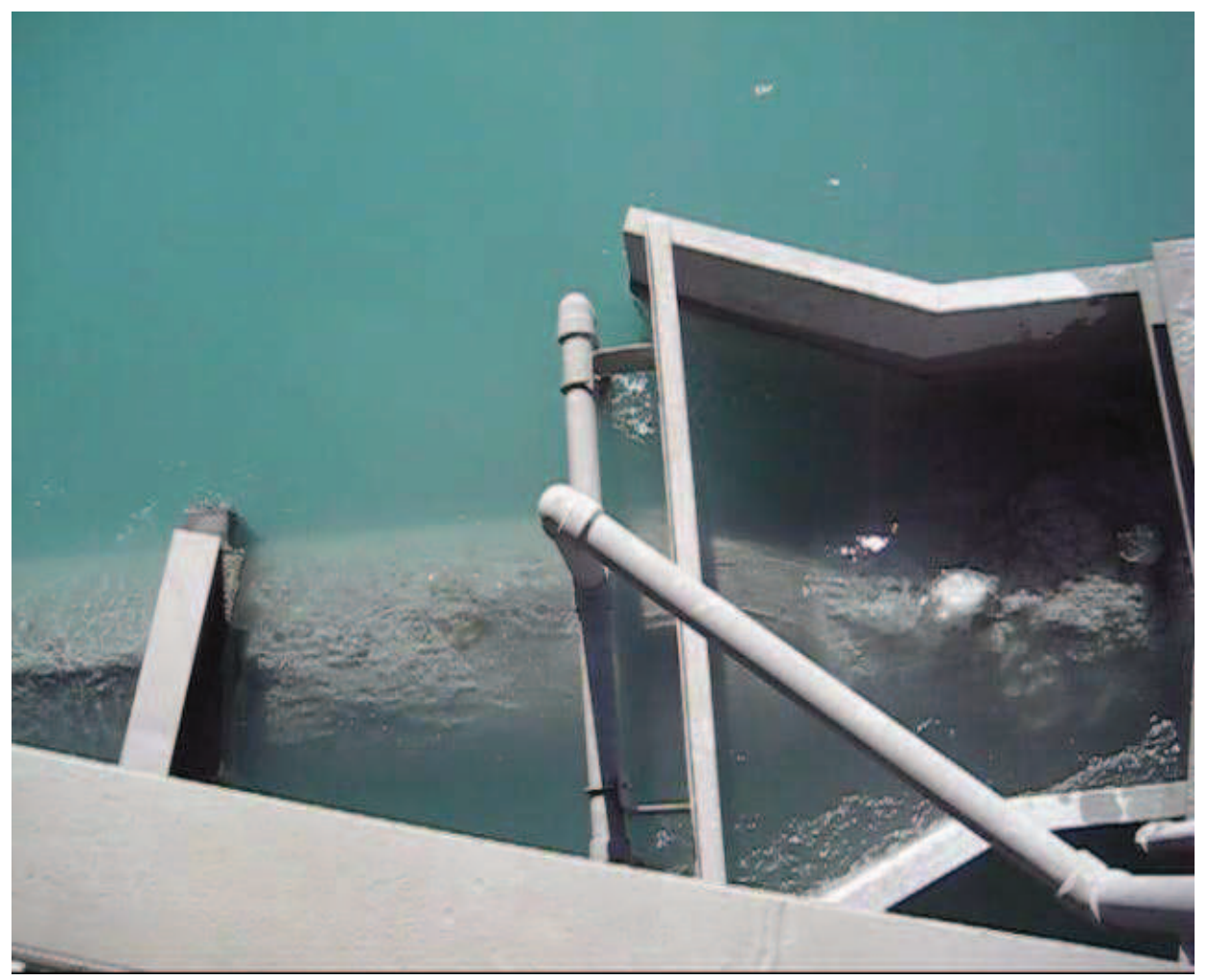

Figura 4-34: Sistema de alimentación con eductor de canal abierto. (Fuente: Cortesía de FLSmidth, S.A.)

Con estos sistemas de eductores $\mathrm{u}$ otros similares, se produce una mejora en la operación del espesador y una reducción de los costes de instalación y operación del equipo ya que se dan las siguientes circunstancias:

a) Un incremento del ratio de sedimentación.

b) Un incremento de la producción.

c) Menor consumo de floculante.

d) Mayores densidades del hundido.

e) Reducción del riesgo del transporte de sólidos al rebose del espesador.

f) Reducción de espumas en superficie.

g) No existen partes móviles ni motores adicionales en los sistemas basados en eductores.

h) Elimina la necesidad de un bombeo para recirculación que diluya la alimentación.

i) Reduce el arrastre de aire con la alimentación.

j) Bajo peso y reducidas cargas estructurales que no influyen en el diseño del puente del espesador.

\subsubsection{Sistemas de alimentación basados en eductores}

El diseño del sistema de alimentación con eductores está basado en el principio de aprovechar la energía cinética del flujo de alimentación para provocar que una boquilla cree un fuerza de 
aspiración para arrastrar el líquido sobrenadante alrededor de la boquilla. El diseño de la boquilla y tubería se selecciona en función de la concentración de sólidos deseada en la alimentación. Esto determina la velocidad en la boquilla que se debe emplear para calcular la caída de presión requerida para que se produzcan los efectos de dilución deseados. Estas geometrías varían en su forma, pero el sistema de funcionamiento es siempre el mismo. Los principales diseños existentes son:

a) Sistema de eductor en tubería.

b) Sistema de eductor en canal abierto.

c) Sistema de eductor en cono vertical.

Existen diversas variantes del sistema de alimentación, diseñados a la vez que se aplicaban los sistemas de alimentación en una búsqueda de adaptar el sistema a la operación y las características del material a sedimentar. Las variantes del sistema tienen un funcionamiento similar al sistema convencional descrito anteriormente y su implementación dependerá del tipo de producto, aplicación y dilución requerida.

El sistema de eductor con tubería, está basado en un sistema de tubo y boquilla para la alimentación de la pulpa y la dilución de la misma. Esta tubería se encuentra sumergida bajo el nivel superior del líquido en el espesador y consta de dos partes: el primer tramo de la tubería está formado por la tubería de la alimentación y la boquilla eductora. El segundo tramo comienza en la campana de entrada de agua de dilución y la tubería de mezcla hasta la campana de alimentación. La boquilla normalmente está introducida en la campana de entrada, al circular el flujo de pulpa entrante en el espesador se crea un chorro en la boquilla del sistema, que arrastra el agua sobrenadante, permitiendo la dilución en el interior de la tubería. Ver figura 4-35: Sistema de alimentación con eductores en tubería.

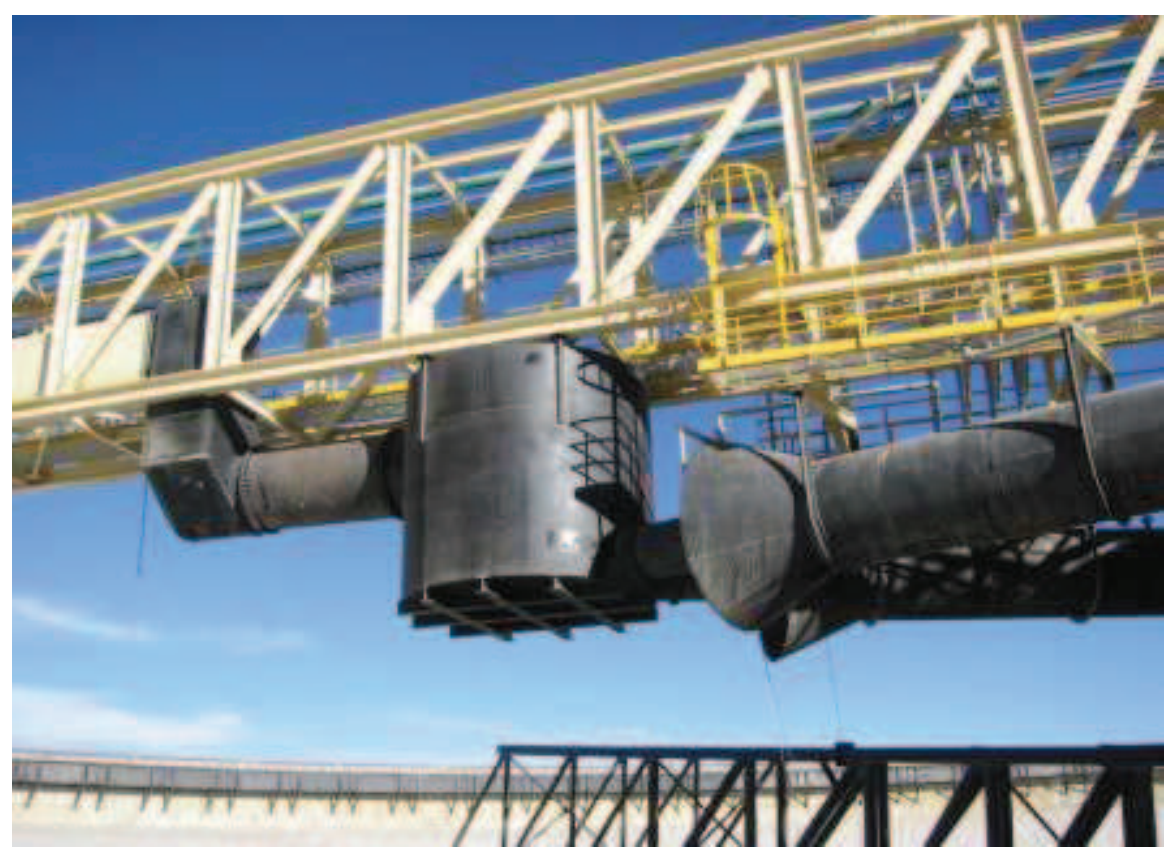

Figura 4-35: Sistema de alimentación con eductores en tubería. (Fuente: Cortesía de FLSmidth Dorr-Oliver Eimco Sapin, S.L.) 
Otro sistema similar a los eductores horizontales descritos anteriormente, que se pueden considerar convencionales, es el sistema de alimentación de cono vertical. Este sistema de alimentación se puede considerar un sistema de eductor trabajando de forma vertical. En la figura 4-36: Sistema de alimentación con eductor vertical; se muestra el esquema del funcionamiento y las partes que componen este conjunto, montado sobre el puente de un espesador de cono profundo para pasta.

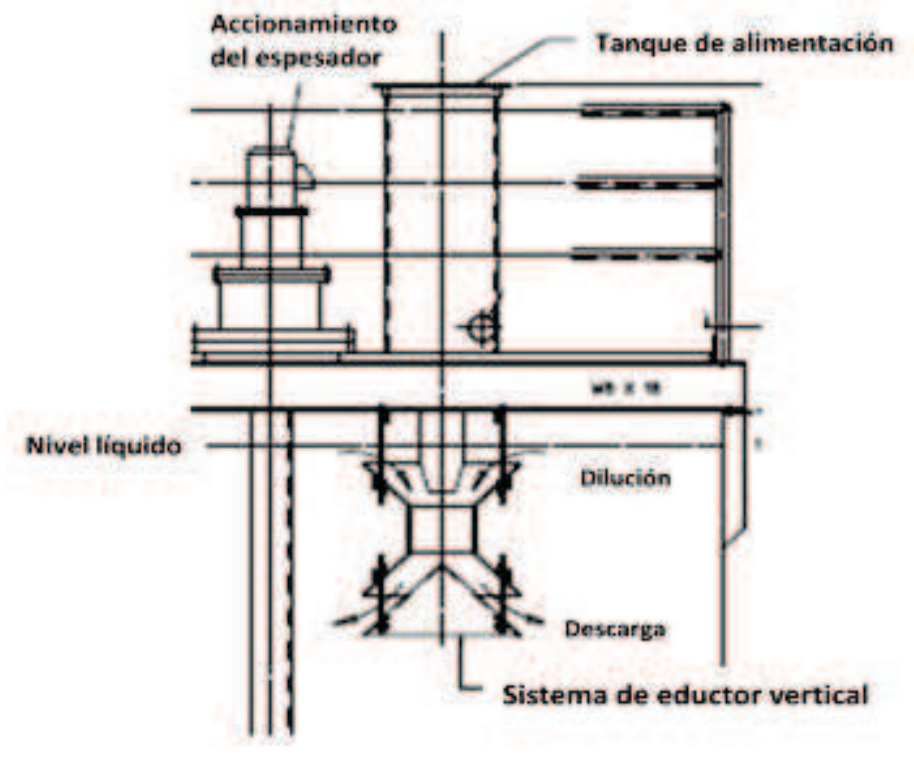

Figura 4-36: Sistema de alimentación con eductor vertical. (Fuente: Elaboración propia)

Una mejora del sistema de alimentación provisto de eductores, es el sistema de campana de alimentación con entrada envolvente. Este sistema diseñado mediante modelos matemáticos CFD (Computacional Fluid Dynamic) consiste en el mismo sistema de canal abierto con la diferencia del diseño original, en que la entrada del canal se hace a través de una voluta exterior que arranca en la campana de alimentación, proporcionando una distribución más uniforme dentro de la campana. Es importante señalar que entre las ventajas de esta variante más moderna del sistema de eductores, con sistema de entrada envolvente se encuentran:

a) Una mejor distribución del flujo saliente de la campana, por la parte inferior.

b) Más tiempo de residencia de la pulpa para un mismo volumen de campana de alimentación.

c) Evita la degradación de los flóculos formados.

d) Aumento del ratio de sedimentación.

En la figura 4-37: Evolución de la forma de la campana de alimentación se puede observar que la forma envolvente obtenida de forma teórica en simulaciones distribuye mejor la pulpa a la salida de la campana, lo que aumenta el rendimiento del sistema y proporciona una mejor distribución del lecho de lodos en el tanque del espesador. 


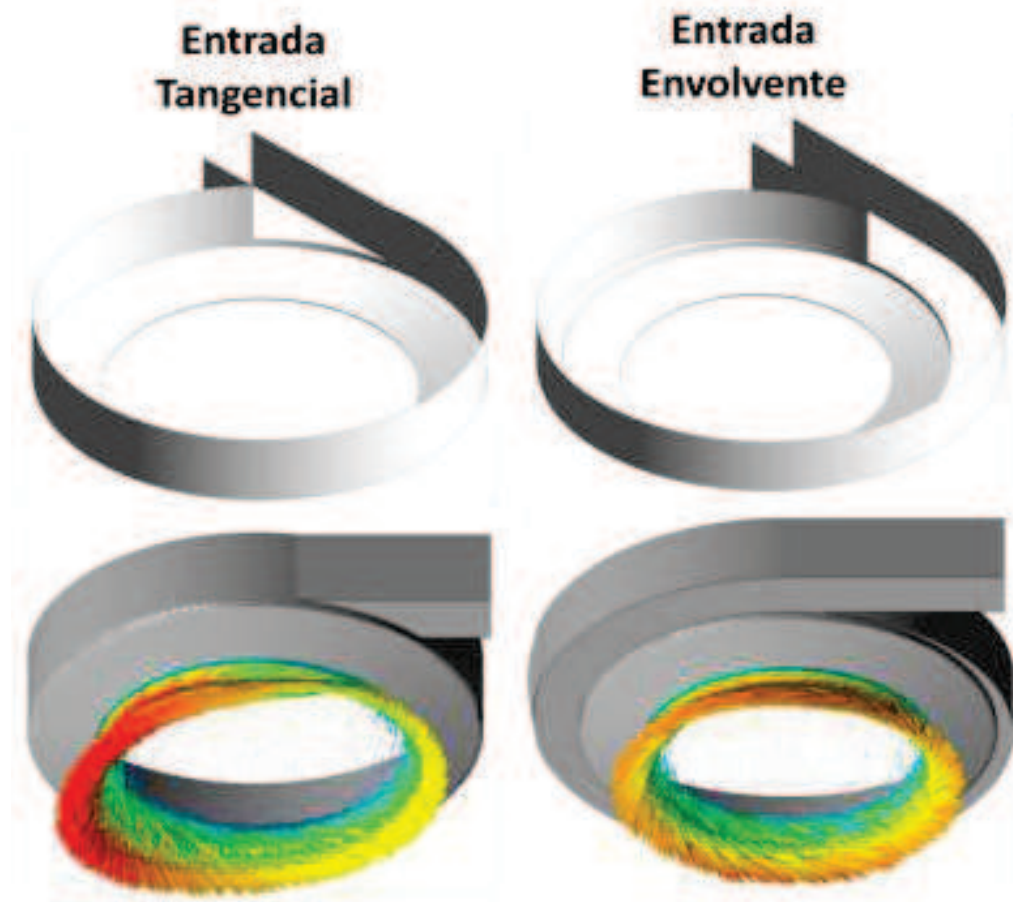

Figura 4-37: Evolución de la forma de la campana de alimentación. (Fuente: FLSmidth Dorr-Oliver Eimco Spain, S.L.)

Para comprobar la efectividad de la entrada envolvente frente a la entrada tangencial se han llevado a cabo simulaciones a escala de laboratorio para determinar la distribución y contrastar los resultados con el modelo CFD. En la figura 4-38: Pruebas de laboratorio con diferentes tipos de campana; y en la figura 4-39: Modelo CFD para las campanas tangencial y envolvente; se aprecia las diferencias del flujo de sedimentación de un tipo y otro.

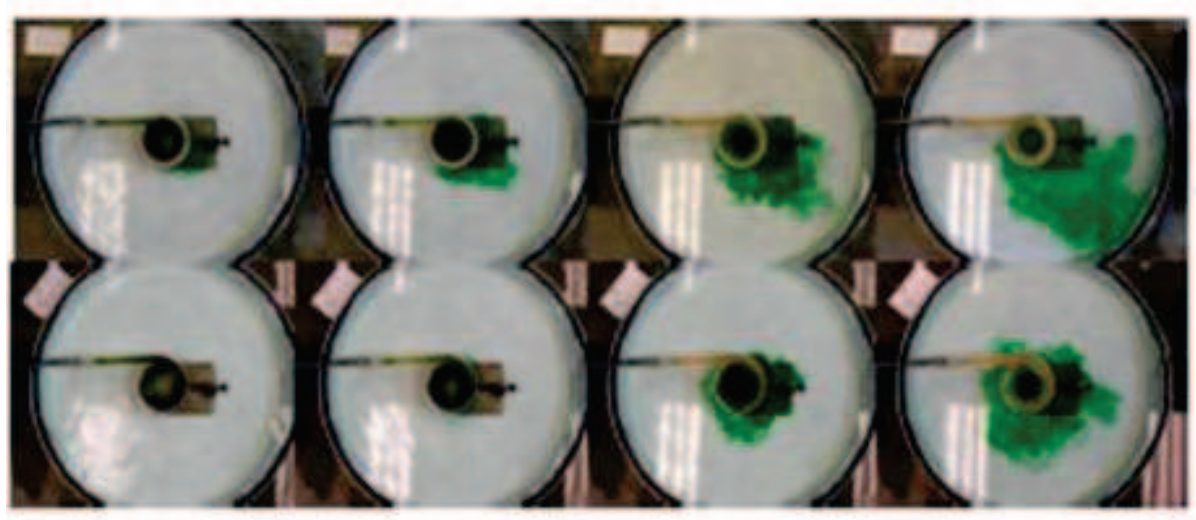

\section{Entrada} tangencial

\section{Entrada} envolvente

Figura 4-38: Pruebas de laboratorio con diferentes tipos de campana.

(Fuente: FLSmidth Dorr-Oliver Eimco Spain, S.L.) 


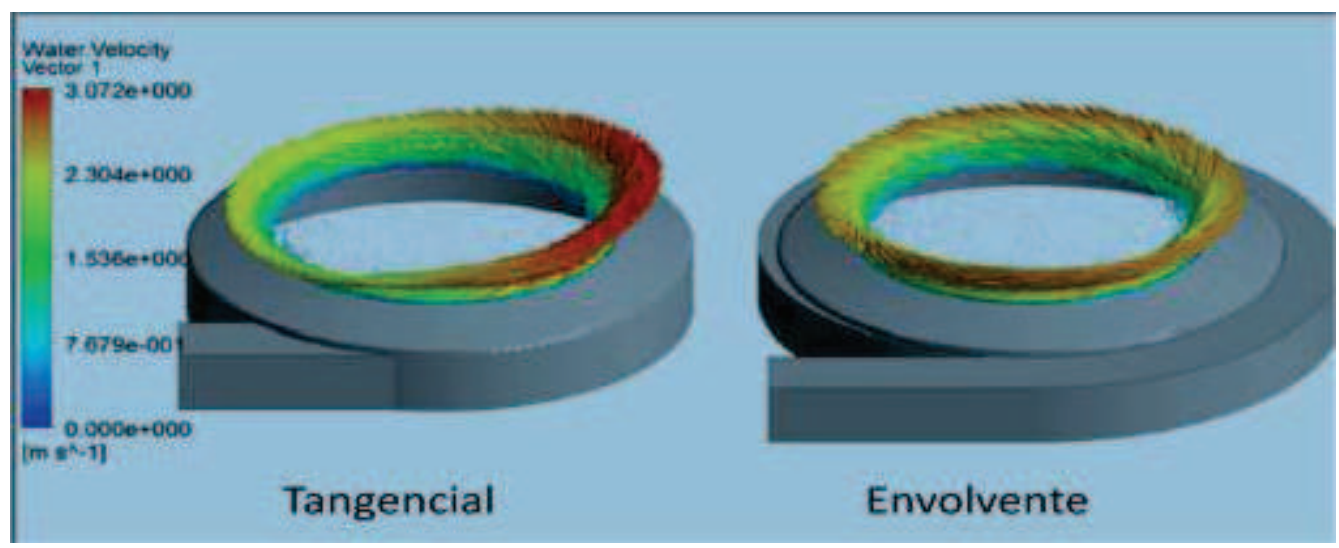

Figura 4-39: Modelo CFD para las campanas tangencial y envolvente. (Fuente: FLSmidth Dorr-Oliver Eimco Spain, S.L.)

\subsubsection{Sistemas de dilución con bombeo}

Los sistemas de dilución con bombeo en el propio canal de entrada, representan uno de los últimos avances en estos sistemas de alimentación de espesadores modernos. Se utilizan estos sistemas cuando existen variaciones en el ratio de alimentación del espesador, bien en el caudal, o bien en el contenido en sólidos. Este sistema asegura un flujo óptimo de entrada de agua de dilución. En la figura 4-40: Sistema de dilución con bombeo; se muestran los componentes principales, que son: el canal de entrada y el agitador que succiona el líquido sobrenadante hacia el canal.

El sistema de dilución con bombeo incorpora en el canal de entrada el agitador de velocidad variable y que se puede controlar con un sistema de control tipo PLC, variando la velocidad del agitador con las medidas en línea del caudal y densidad de la pulpa a alimentar. Esto permite optimizar la alimentación, la dilución y también la dosificación de floculante de forma precisa y exacta.

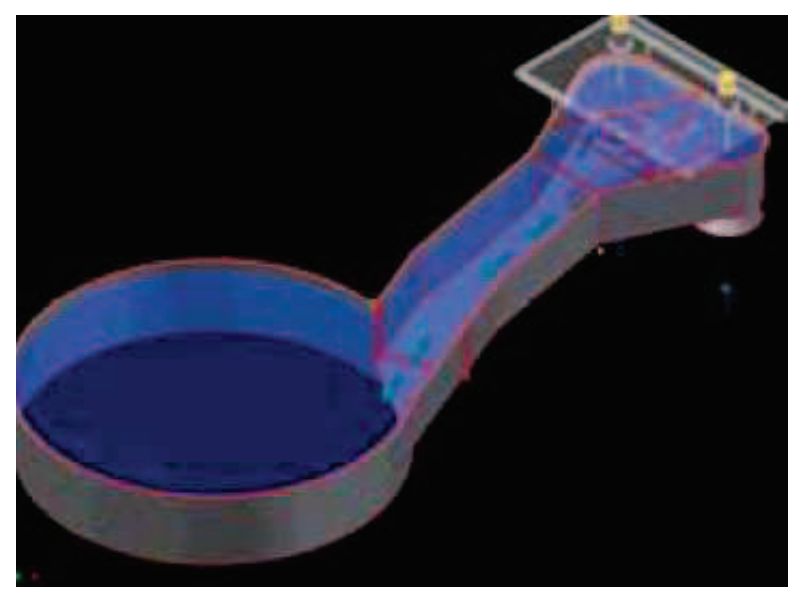

Figura 4-40: Sistema de dilución con bombeo. (Fuente: Cortesía de FLSmidth S.A.) 
En la figura 4-41: Sistema de dilución con bombeo montado en un espesador HDT, se pueden ver los principales componentes: tubería de alimentación, agitador inferior y canal de entrada a la campana.

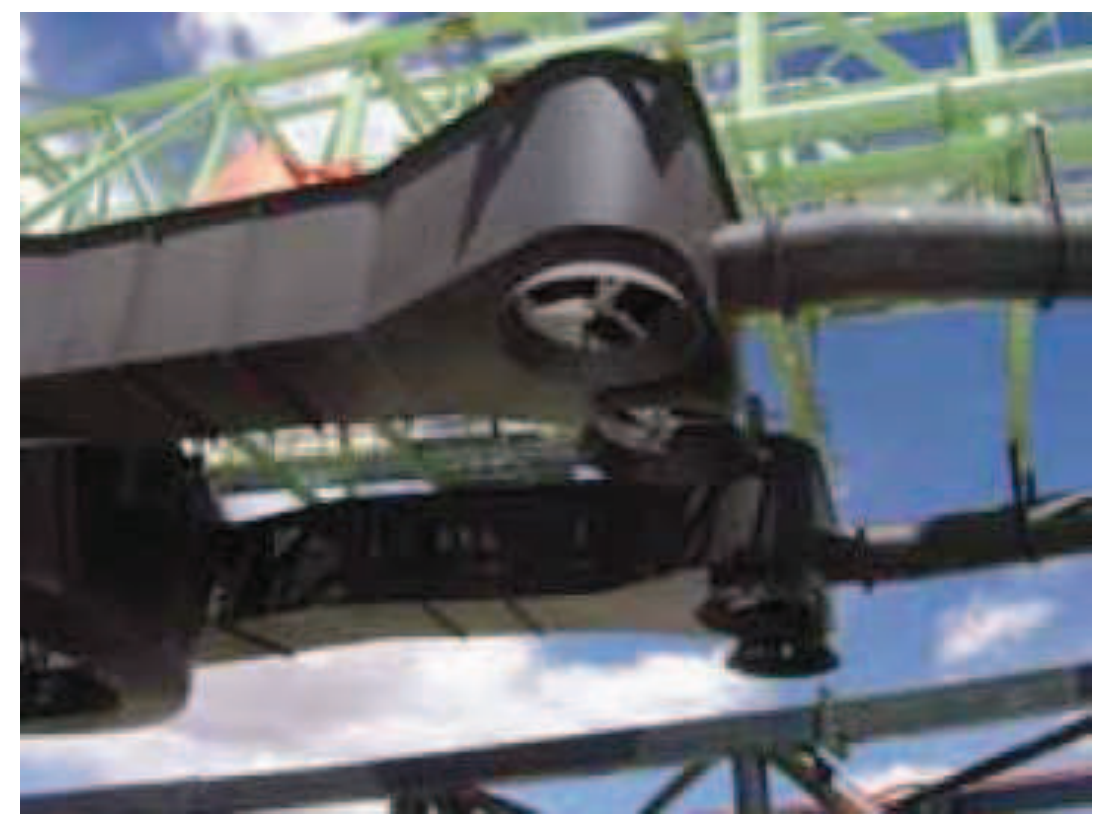

Figura 4-41: Sistema de dilución con bombeo montado en un espesador HDT. (Fuente: Cortesía de FLSmidth S.A.)

\subsubsection{Sistema de campanas de alimentación con bafles internos}

Otro de los fabricantes de equipos de espesado más importantes a nivel mundial, ha desarrollado sus propios sistemas de alimentación y campanas de alimentación para espesadores. Estos sistemas se basan en el aprovechamiento de la energía cinética del flujo de la pulpa a alimentar y en el manejo de la disipación de esa energía en el interior de la campana para conseguir la optimización de la mezcla entre el floculante y las partículas sólidas.

La alta energía producida por el flujo de pulpa que entra en la zona alta de la campana de alimentación es requerida para mantener una adecuada mezcla de alimentación, agua de dilución y floculante, especialmente en las campanas más grandes, mientras que la zona inferior o de baja energía se requiere una turbulencia que permita el crecimiento del flóculo. Por tanto la creación de dos zonas diferenciadas en la campana de alimentación, una con alta energía superior y otra de baja de turbulencia en la parte inferior aseguran el desarrollo de las dos funciones de forma efectiva.

El diseño en cuestión, incorpora unas placas horizontales imbricadas, con huecos entre ellas creando dos zonas dentro de la campana de alimentación. Las placas actúan como una retención, manteniendo la densidad de la pulpa entrante, actuando como bafles y eliminando la energía en exceso que existe en el caudal de alimentación. El diseño maneja la turbulencia para que exista una mezcla y al mismo tiempo separa la campana en dos zonas: una de alta energía superior y una de baja energía inferior. 
Un diseño único es con bandas horizontales radiales e inclinadas que incrementa el tiempo de residencia, disipa energía en la zona superior y elimina la posibilidad de incrustaciones de sólidos debido a su inclinación radial. En la figura 4-42: Diseño de campana de alimentación con bafles internos, se aprecia cómo es la disposición interna de estas placas y las dos zonas internas, en la parte superior la de alta energía y en la parte inferior de baja energía. Después de salir de la campana, los flóculos formados se mueven hacia abajo por la acción de la gravedad entrando en el cuerpo del espesador, primero en la zona de sedimentación libre, pasando por la zona de sedimentación obstaculizada y finalmente alcanzando el lecho de lodos.

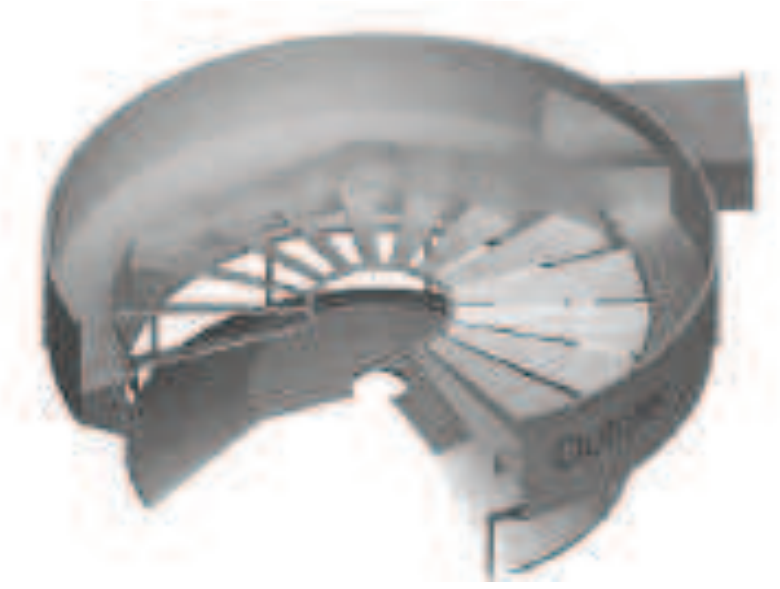

Figura 4-42: Diseño de campana de alimentación con bafles internos.

(Fuente: www.outotec.com)

En un ambiente cambiante y de aumento de producción en las operaciones mineras, la innovación que realmente afecta a la línea de fondo puede probar rápidamente su inversión inicial y reduce los costes de operación. Una campana de alimentación que proporcione realmente una alta eficiencia de espesado, puede representar un significante ahorro en la operación del equipo, reduciendo el consumo de floculante, aumentando la disponibilidad y minimizando los cortocircuitos con la pulpa sedimentada. 


\section{Espesado en pasta.}

Para la determinación del sistema de espesado en pasta, su diseño y condiciones de operación, se requiere un amplio entendimiento de las características reológicas del material a sedimentar, tanto de su comportamiento a esfuerzos cortantes como a esfuerzos de compresión. La implementación y optimización de una operación de espesado en forma de pasta involucra estudios reológicos concurrentes para determinar las características de la pasta obtenida.

La deposición de estériles espesados es definida como: cualquier sistema de tratamiento diseñado para aprovecharse de un espesado de estériles de alta densidad o en pasta para producir un residuo almacenable de forma estable por diversos métodos.

Este capítulo proporciona la información para asegurar que los aspectos reológicos de la pasta son tratados como parte del conjunto del diseño general y la estrategia del manejo de los estériles. El criterio principal para el éxito de un sistema de tratamiento de estériles en forma de pasta, es la implementación y la operación de forma segura, sostenible medioambientalmente y con el mínimo coste para la operación minera. La importancia de conseguir estas características comienza en la operación de espesado, donde bien en un espesador de pasta o de alta densidad se deben de conseguir las características de la pasta requeridas para la deposición final.

La explotación y manipulación de las características de transporte y deposición de los estériles son vitales para asegurar que el sistema de deposición adecuado es operado de forma exitosa.

Un sistema de deposición de estériles se selecciona y diseña para minimizar la energía de bombeo requerida y entregar el material con el caudal, tensión de fluencia y viscosidad requeridas para obtener el talud deseado o bien, con las características precisas para el relleno de mina. En este apartado se aborda la caracterización reológica para el diseño, planificación, operación y optimización de los sistemas de deposición de pasta que son considerados aquí; los cuales incluyen el apilado en seco, deposición de estériles espesados con columna central y el relleno de labores mineras con pasta.

Las industrias que producen residuos en forma de partículas en suspensión y pastas, tienden a almacenar estos residuos a una alta concentración de sólidos, lo que facilita una operación más responsable en el tratamiento de residuos y lo que es más importante, reduce el riesgo asociado a las balsas convencionales de estériles. Para eliminar el agua de forma efectiva de la pulpa, es esencial tener un conocimiento de la reología de la pasta frente a esfuerzos de compresión y esfuerzos cortantes, así como del comportamiento de los fluidos no newtonianos. El conocimiento básico tanto del esfuerzo cortante y la reología de compresión permitirá un óptimo diseño del sistema de tratamiento de espesado. La estrategia de deposición debe incluir en el examen del proceso global, el espesado, el bombeo y la deposición de estériles con una ingeniería concurrente que incluya la práctica de una floculación óptima cuando el residuo entra en la planta o equipo de espesado. Para que la estrategia de deposición sea efectiva y operada correctamente, es esencial que la especificación del residuo sea tenida en cuenta, así como una especificación del producto que saldrá de la planta. La implementación y optimización de los métodos de 
deposición de estériles en forma de pasta involucra tres estudios reológicos independientes para determinar las siguientes características:

a) La óptima concentración requerida para el manejo de estériles en el área de deposición.

b) Las condiciones óptimas para la línea de transporte mediante bombeo.

c) La viabilidad de retirar el agua de la pulpa a una determinada concentración de sólidos.

Los métodos técnicos señalados en este estudio proporcionan la caracterización reológica de la pasta requerida para completar estos estudios, a partir de la operación de espesado, como punto de partida que deberá ser estudiado con métodos de laboratorio en las primeras fases de viabilidad del proyecto.

Los factores medioambientales se transforman en económicos, empujando a las operaciones mineras a minimizar la producción de residuos, usando métodos de deposición en "seco" o con bajo contenido en agua, generalmente inferior al 15\%. El uso de la información reológica es de alta importancia para evaluar la nueva tecnología. Los principios dados en los ejemplos de este trabajo, pueden ser aplicados para muchas industrias que tratan un amplio rango de residuos, aunque el estudio centra su interés en los estériles de minería de metales base y los procesos de diseño de sistemas de espesado en pasta, fundamentalmente mediante el uso de espesadores de cono profundo y de alta densidad en el hundido.

\subsection{Importancia de la reología en la estrategia de implementación de un sistema de} espesado en pasta.

Al considerar la reología de los estériles en todos los puntos del proyecto durante la fase de diseño, las estrategias de implementación pueden ser desarrolladas para las nuevas operaciones o bien para optimizar las operaciones existentes, de forma que se reduzcan los costes de operación y el impacto en el medioambiente, produciéndose un aumento de la recuperación de agua. La estrategia propuesta en este capítulo busca el diseño de los procesos de tratamiento de estériles, su ajuste con el medioambiente y las áreas circundantes al proyecto, con la consideración necesaria para elegir tanto el método de operación como el modo de deposición de la pasta. En la figura 5-1: Secuencia de diseño de un sistema de espesado de pasta; se resumen los pasos necesarios en la determinación de un sistema genérico. Es importante destacar, que la secuencia de diseño va desde el punto de deposición de la pasta y fluye aguas arriba del proceso hasta la etapa de espesado. Mientras en la fase de experimentación y comprobación de las variables que dan lugar a la pasta, será en el sentido opuesto, donde primero se produce la experimentación y ensayos de laboratorio desde el espesador y se recorre el sistema aguas abajo contrastando los datos y características obtenidas en la fase de diseño.

En esta fase de diseño, en el punto 1 de la figura 5-1, se representa la elección del método de deposición y las propiedades reológicas requeridas para alcanzar el volumen y la superficie a alcanzar incluyendo la forma final del depósito de estériles. En general los métodos de deposición en superficie serán factibles en minas a cielo abierto, mientras que en las minas subterráneas existirá un sistema mixto de relleno de mina y balsa en superficie. 
El punto 2 de la figura 5-1, está referido al bombeo y las condiciones de la tubería para el transporte óptimo mientras que se aseguran que los estériles alcanzan el sitio de deposición con las condiciones reológicas necesarias para el método elegido o de diseño. Estos formarían los requerimientos de la tubería y bombeo del sistema. Las propiedades reológicas de la pasta pueden cambiar con las operaciones de bombeo y el transporte por tubería, siendo por tanto un punto de estudio en el proyecto.

Una vez que los problemas de deposición y transporte han sido cuantificados y optimizados en la fase de diseño sobre el papel, es posible determinar los requerimientos del espesado en pasta representado por el punto 3 de la figura 5-1. El espesador se diseña y opera para producir las propiedades de la pasta requeridas en el proyecto, mediante la determinación del tamaño del espesador, la geometría del tanque, el control de la floculación y el tratamiento de los materiales requerido. Si los requerimientos y características de la pasta obtenida en el espesador no pueden ser alcanzados, es necesario repetir el proceso y ajustar los parámetros a los datos obtenidos en la fase de experimentación en laboratorio o en planta piloto.

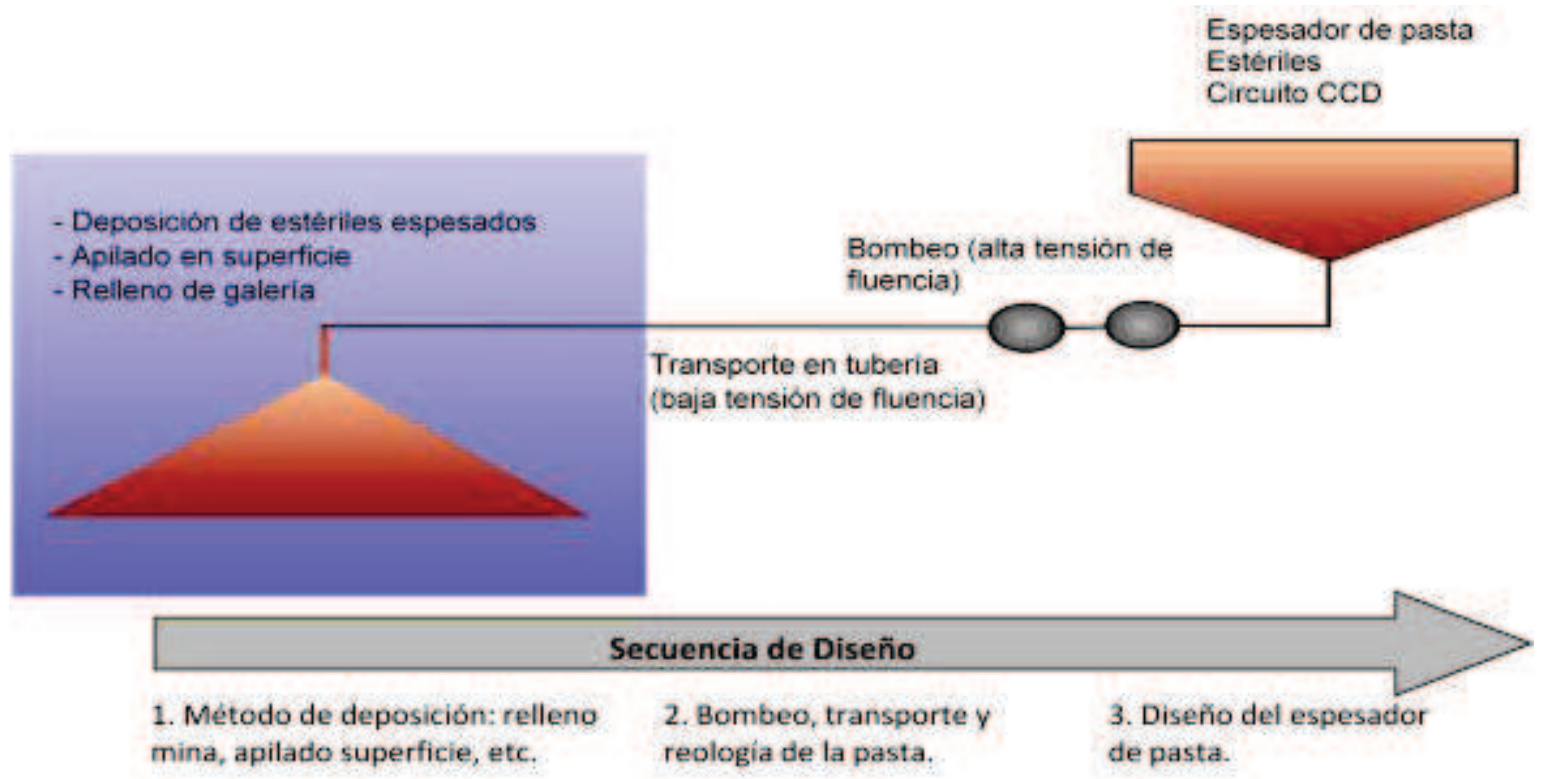

Figura 5-1: Secuencia de diseño de un sistema de espesado de pasta.

(Fuente: Adaptado de Boger D., Rheological Concepts; University of Melbourne. Australia 2006)

La fase de diseño en realidad se ha representado en la figura como un proceso lineal, sin embargo, en la realidad el sistema de tratamiento de estériles y el sistema de espesado en pasta deberán ser diseñados mediante un proceso iterativo por aproximación para optimizar la operación de espesado y deposición de estériles. Este proceso iterativo se muestra en la figura 5-2: Ciclo de diseño y ensayos de laboratorio de un sistema de espesado en pasta. Este ciclo de diseño estará basado en los datos obtenidos en laboratorio para lo cual, la secuencia de pruebas de laboratorio y conocimiento de datos será en sentido inverso al proceso de diseño, ya que primeramente habrá que conocer si los datos reales obtenidos mediante ensayos se adaptan a los datos de proceso previstos en el proyecto. 
En el proceso iterativo, la secuencia de diseño estima los datos de proceso, mediante la secuencia de avance aguas arriba en el proyecto, debe de ser refrendada por los datos obtenidos en la fase de experimentación en laboratorio o en planta piloto usando un material característico.

Por tanto, los datos del método de deposición, bombeo, transporte y el diseño del espesador de pasta obtenido de forma teórica, basados en datos preliminares o experiencias previas deben ser revisados y validados en el laboratorio. Si los datos obtenidos cumplen las condiciones de diseño, el proyecto comienza a estar definido. En caso contrario, el diseño debe ser revisado para ajustar los datos preliminares en cada una de las diferentes etapas con los datos que se obtienen en el laboratorio.

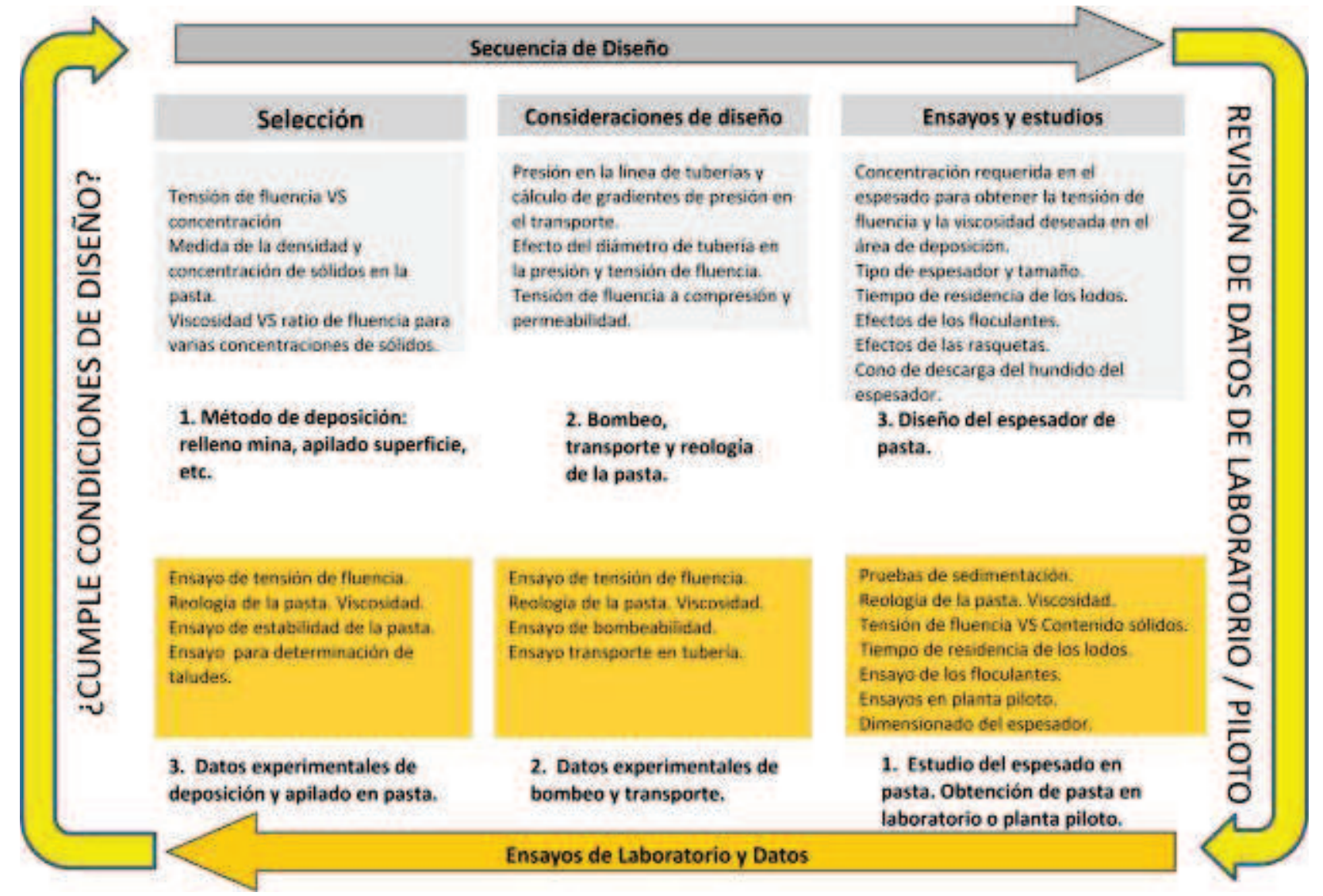

Figura 5-2: Ciclo de diseño y ensayos de laboratorio de un sistema de espesado en pasta.

(Fuente: Adaptado de Boger D., Rheological Concepts; University of Melbourne. Australia 2006)

\subsubsection{Conceptos reológicos para el diseño del sistema}

La reología se define como el estudio de la deformación y flujo de los materiales. Cuando se aplica una fuerza a un material líquido, el líquido fluirá como consecuencia de esta fuerza aplicada. Diferentes líquidos se resistirán a este flujo, unos más que otros y la medida de esta resistencia a fluir es la medida de la viscosidad del sistema. Newton fue el primero en introducir un modelo básico para la medida del flujo de un líquido entre dos placas paralelas como se representa en la figura 5-3: Descripción del modelo de viscosidad según Newton. 


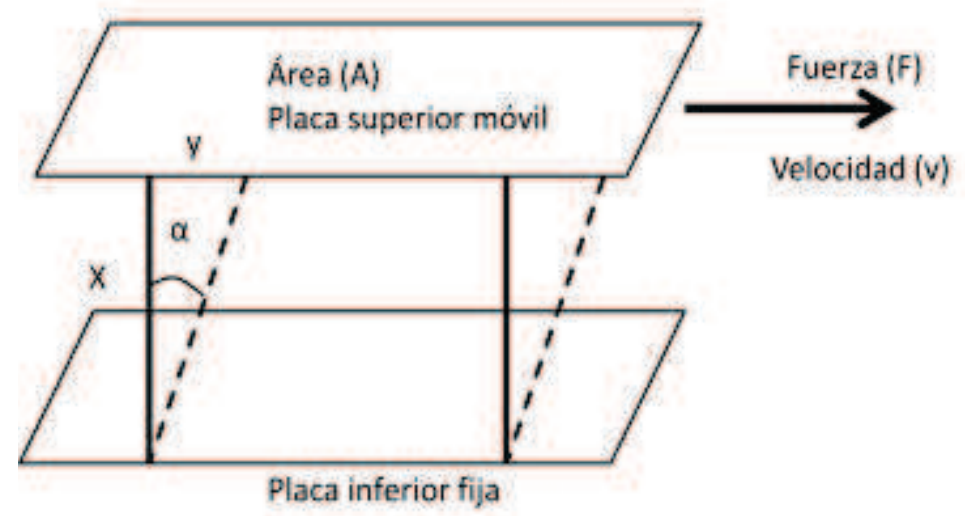

Figura 5-3: Descripción del modelo de viscosidad según Newton. (Fuente: Elaboración propia)

Usando este modelo de viscosidad es posible definir los términos más comunes usados en reología y aplicable a pastas de estériles.

a) Tensión de fluencia:

La fuerza experimentada por el líquido es proporcional al área de la placa superior y viene definida por la ecuación 5-1.

$$
\tau=\frac{F}{A}
$$

Donde:

$\tau$ es la tensión de fluencia medida en $\mathrm{N} / \mathrm{m}^{2}$ o Pascales $(\mathrm{Pa})$

$\mathrm{F}$ es la fuerza aplicada medida en $\mathrm{N}$

A es la superficie en $\mathrm{m}^{2}$

b) Ratio cortante:

Es el gradiente de velocidad o el ratio de cambio de velocidad a la que una capa se desplaza sobre la capa adyacente, creando un gradiente de velocidades, se define por la ecuación 5-2:

$$
\gamma=\frac{d v}{d x}
$$

Donde: $\gamma$ es el ratio cortante medido en $\mathrm{s}^{-1}$

c) Viscosidad:

Matemáticamente es el cociente entre la tensión de fluencia y el ratio cortante definido por la ecuación 5-3 y es la medida de la resistencia del fluido al movimiento, se mide en Poises o centipoises; $(1 \mathrm{cP}=1 \mathrm{mPa} \cdot \mathrm{s})$. 


$$
\eta=\frac{\tau}{\gamma}
$$

En la medición de la viscosidad de líquidos es importante tener en cuenta la temperatura a la que se hace la medida, ya que tiene una influencia considerable sobre la viscosidad.

En el caso de fluidos newtonianos, como el caso de agua, aceites, etc. la viscosidad del fluido es independiente del ratio cortante, o lo que es lo mismo, el ratio de deformación es directamente proporcional a la fuerza aplicada, como se muestra en la figura 5-4: Curva de viscosidad de un fluido newtoniano.
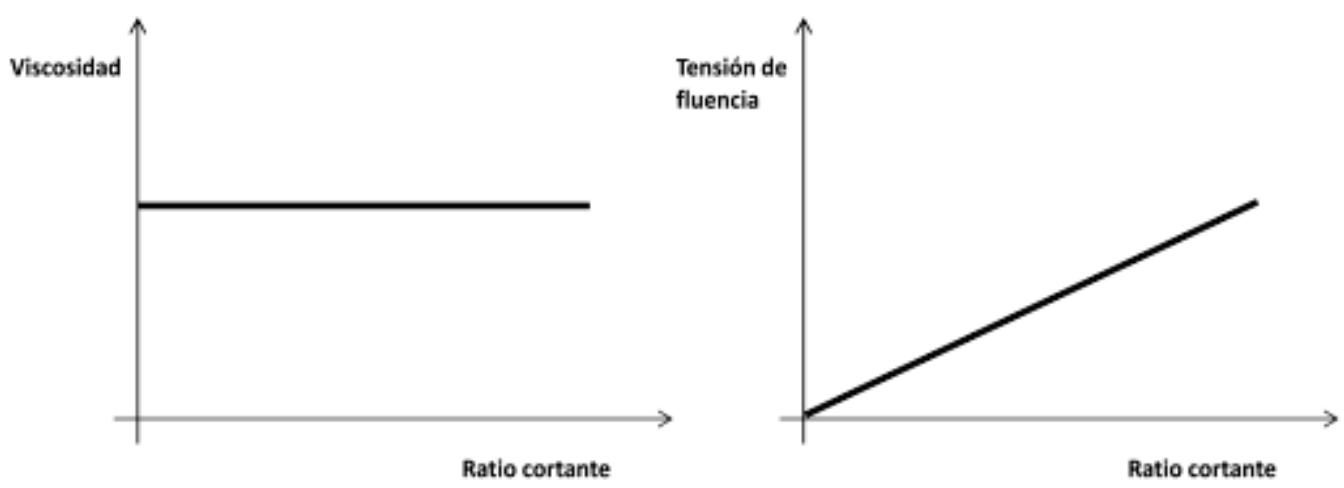

Figura 5-4: Curva de viscosidad de un fluido newtoniano.

(Fuente: Elaboración propia)

\section{Reología de la pasta:}

En los sistemas no newtonianos, como por ejemplo las pastas formadas a partir de estériles mineros, tienen un comportamiento que se desvía del flujo newtoniano característico. Los diversos tipos de flujos no newtonianos son: pseudoplástico, dilatante, tixiotrópico y reopéctico.

a) Material pseudoplástico

Un elevado número de pastas muestran un decrecimiento de la viscosidad cuando el ratio cortante se incrementa, este es el comportamiento pseudoplástico, conocido como "shear thinning". En la figura 5-5: Curva de viscosidad de un fluido pseudoplástico.

\section{Fluido pseudoplástico}
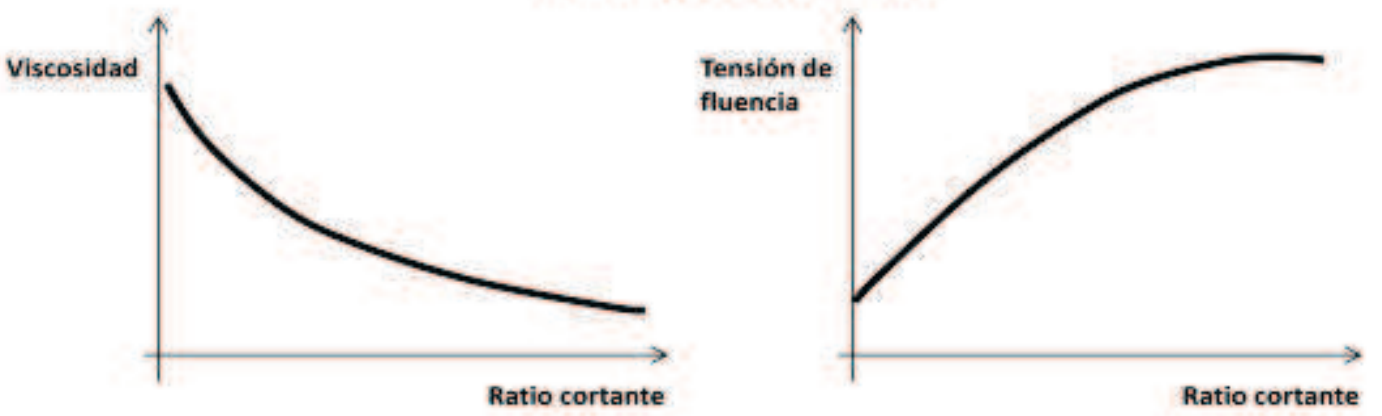

Figura 5-5: Curva de viscosidad de un fluido pseudoplástico.

(Fuente: Elaboración propia) 
b) Material dilatante

Los fluidos o pastas dilatantes muestran el comportamiento opuesto a los pseudoplásticos. Presentan un incremento de la viscosidad a medida que se incrementa el ratio cortante. Es poco frecuente en pastas o pulpas con alto contenido en sólidos. En la figura 5-6: Viscosidad de un fluido dilatante.

\section{Fluido dilatante}

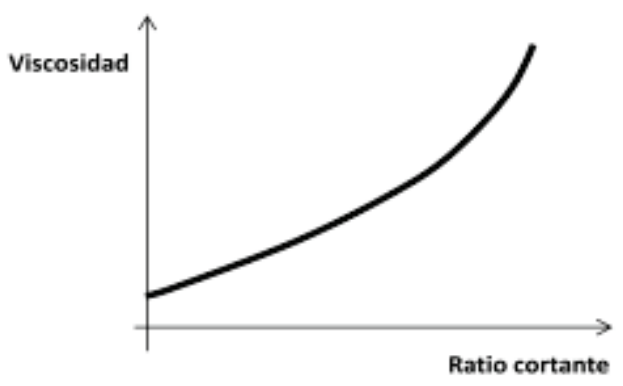

Figura 5-6: Viscosidad de un fluido dilatante. (Fuente: Elaboración propia)

c) Material tixiotrópico

Para los fluidos o pastas tixiotrópicas, la viscosidad decrece en el tiempo para un ratio cortante y constante aplicado durante este intervalo de tiempo, hasta que se alcanza un mínimo de viscosidad. Una vez que la fuerza cortante cesa, la viscosidad se recupera con el tiempo, presentando incluso un ciclo de histéresis, como se aprecia en la figura 5-7: Viscosidad de un fluido tixiotrópico.

\section{Fluido tixiotrópico}

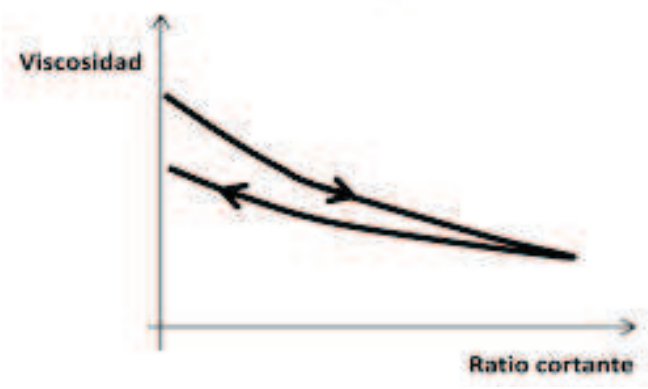

Figura 5-7: Viscosidad de un fluido tixiotrópico. (Fuente: Elaboración propia)

d) Material reopéctico

Los fluidos reopécticos tienen el comportamiento opuesto a los fluidos o pastas tixiotrópicos. Incrementan su viscosidad con el tiempo para un esfuerzo cortante y constante hasta que se alcanza un máximo, seguido de una reducción de la viscosidad en el tiempo cuando cesa el ratio cortante, como se muestra en la figura 5-8: Viscosidad de un fluido reopéctico. Este comportamiento es extremadamente raro en cualquier material. 


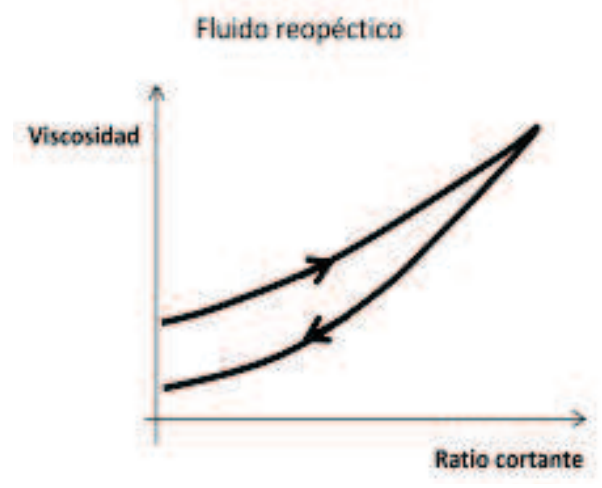

Figura 5-8: Viscosidad de un fluido reopéctico.

(Fuente: Elaboración propia)

Como se ha mencionado antes, en términos de mecánica de fluidos, los materiales se pueden clasificar en fluidos newtonianos y no-newtonianos. La viscosidad ( $\eta$ ) de un fluido se define como el ratio de esfuerzo cortante $(\tau)$ respecto al ratio de corte $(Y)$, como se muestra en la ecuación 5-4.

$$
\eta=\frac{\tau}{\gamma}
$$

Los fluidos newtonianos inelásticos muestran una relación lineal entre el esfuerzo cortante aplicado y el ratio de corte, como se muestra en la curva A de la figura 5-9: Relación ratio cortante y esfuerzo cortante; El flujo se inicia tan pronto como se aplica un esfuerzo cortante. La relación lineal entre el esfuerzo cortante y ratio de corte indica una viscosidad constante.

Los estériles de mineral espesados en general, muestran un comportamiento de fluido nonewtoniano donde el comportamiento de este flujo está caracterizado por la tensión de fluencia.

Esta tensión de fluencia $\left(\tau_{y}\right)$ se define como el esfuerzo cortante crítico que debe ser superado antes que se produzca una deformación irreversible y el movimiento del fluido se produzca. Para esfuerzos por debajo de la tensión de fluencia, la red de partículas que forma la pasta se deformará elásticamente, produciéndose la recuperación completa una vez que cesa el esfuerzo. Una vez que el límite de fluencia se ha superado, la pasta muestra un comportamiento similar a un líquido viscoso, donde esta viscosidad es normalmente una función decreciente del esfuerzo cortante. El comportamiento de la tensión de fluencia se muestra en las relaciones de las ecuaciones 5-5 y 5-6.

$$
\begin{gathered}
\gamma=0 ; \quad \tau<\tau_{y} \\
\tau=\tau_{y}+\eta \cdot \gamma \quad \tau>\tau_{y}
\end{gathered}
$$

La curva B de la figura 5-9, muestra una tensión de fluencia seguida por una relación lineal entre el esfuerzo y el ratio de esfuerzo, normalmente conocida como comportamiento de Bingham. Aunque no es una verdadera viscosidad de acuerdo a la ecuación 5-4, el gradiente de esta línea se denomina viscosidad plástica de Bingham.

Los valores típicos para los materiales y estériles mineros, son valores que van desde $30 \mathrm{~Pa}$ hasta $200 \mathrm{~Pa}$ de tensión de fluencia para la deposición de estériles de mina con bajo contenido en 
sólidos y de valores de $200 \mathrm{~Pa}$ hasta $700 \mathrm{~Pa}$ en el caso de operaciones de espesado en forma de pasta. Aunque estos límites de valores pueden variar dependiendo de cada proyecto y de las características reológicas de cada pasta formada. Será el técnico de proceso el que deba determinar los valores necesarios para cada tipo de operación, en función del destino final y uso requerido por la pasta generada a partir de los estériles mineros.

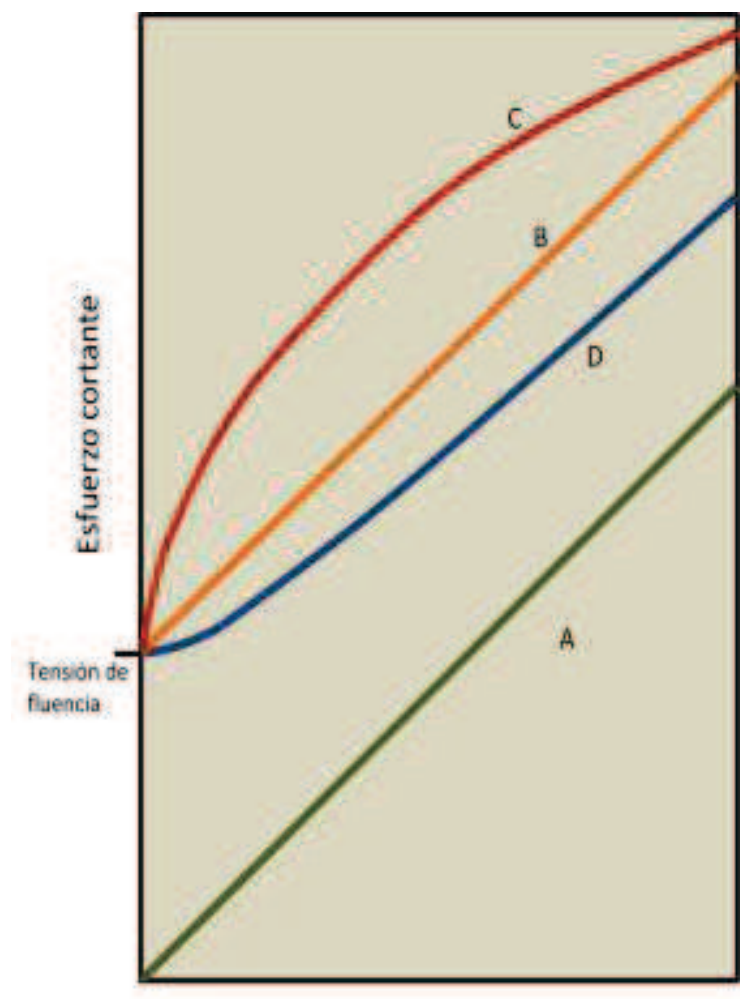

Ratio cortante

Figura 5-9: Relación ratio cortante y esfuerzo cortante.

(Fuente: adaptado de Boger D., Rheological Concepts; University of Melbourne. Australia 2006)

Además del comportamiento de la tensión de fluencia, la viscosidad del material varía con ratio cortante. A medida que se incrementa el ratio cortante, los materiales pseudoplásticos o similares, muestran un decrecimiento de la viscosidad (Curva $C$ de la figura 5-9). Los materiales con un comportamiento dilatante muestran un incremento con la viscosidad a medida que se incrementa el ratio cortante (curva D de la figura 5-9). El comportamiento dilatante, aunque es relativamente raro, se puede observar en algunas pulpas mineras. Para las diferentes categorías de fluidos, se utilizan diferentes modelos de flujo para describir el comportamiento que muestran estos materiales cuando fluyen. Las ecuaciones ampliamente utilizadas para el comportamiento dilatante o pseudoplástico son las ecuaciones del modelo de Ostwald-De Waele. El modelo de Bingham se utiliza para la tensión de fluencia en los materiales espesados y el modelo de Herschel Bulkley es el más utilizado para calcular la tensión de fluencia en materiales dilatantes y pseudoplásticos.

Las ecuaciones de cada uno de los modelos son las que se muestran en las siguientes relaciones: Modelo de Ostwald-De Waele, definido por la ecuación 5-7. 


$$
\tau=K \cdot \gamma^{n}
$$

Modelo de Bingham, en la ecuación 5-8:

$$
\tau=\tau_{B}=\eta_{B} \cdot \gamma
$$

Modelo de Herschel Bulkley, según la ecuación 5-9:

$$
\tau=\tau_{H B}+K \cdot \gamma^{n}
$$

En todas las ecuaciones anteriores, las constantes "K" $\mathrm{y}$ " $\mathrm{n}$ " se determinan de forma experimental en el laboratorio.

La naturaleza tixiotrópica de los estériles mineros es atribuida al alineamiento de las partículas y los flóculos en el campo del flujo. Un incremento en el esfuerzo cortante desde cero, resulta en el alineamiento instantáneo de las partículas en la dirección del esfuerzo cortante y por tanto presentan una menor resistencia a fluir. En general las suspensiones de sólidos de estériles en minería muestran un decrecimiento de su viscosidad con el incremento del esfuerzo cortante.

Los datos sobre pastas de estériles mineros no están a menudo disponibles para ratios de esfuerzos bajos, son difíciles de calcular y por tanto, una práctica común en el diseño es extrapolar la parte lineal de la curva, por ejemplo en la curva $C$ del figura 5-9, hasta el eje OY y denominar esto como la tensión de fluencia. Esta es la tensión de fluencia de Bingham que no guarda relación alguna con la tensión de fluencia del material. La parte lineal de la curva que se ajusta de esta forma algunas veces es apropiada para el diseño de tuberías mientras que una tensión de fluencia cuantificada de esta forma no es la más adecuada para el diseño de un espesador; por lo tanto, se deben realizar medidas en laboratorio con una precisión mayor para obtener la tensión de fluencia de la pasta.

El comportamiento más complicado de los fluidos no newtonianos que se observa en algunos finos de mineral, es un comportamiento dependiente de la variable tiempo. En este caso, el ratio de esfuerzo es una función tanto del ratio de cortante como del tiempo de aplicación del esfuerzo. Básicamente, este es el caso donde el alineamiento de las partículas o los flóculos ocurre en una escala de tiempo que puede ser observada en el viscosímetro. El comportamiento tixiotrópico de los estériles espesados es muy común, en donde la viscosidad decrece con el ratio cortante y el tiempo (fluidos tixiotrópicos). El comportamiento reopéctico es dependiente del tiempo con un comportamiento similar al dilatante, es poco común en los materiales de estériles mineros, pero cuando este se produce, puede dar a lugar a consecuencias desastrosas. En este caso, la viscosidad se incrementa con el ratio cortante y el tiempo. Este comportamiento es muy extraño para los ingenieros de diseño, donde la tendencia del proceso, cuando aparece éste fenómeno es incrementar la energía para el bombeo de la pasta.

\subsubsection{Medición de las propiedades reológicas}

Existe mucha literatura escrita sobre las propiedades reológicas y la medida de esta propiedad. Para suspensiones fluidas de partículas, en particular, para las suspensiones más concentradas 
como las que es posible encontrar en los procesos de espesado de estériles, muchos de los instrumentos y teorías reológicas disponibles no son aplicables. Todos los métodos basados en un pequeño espacio entre las superficies cortantes, como un plato geométrico, generalmente no se emplean en la industria minera. El instrumento más común usado en estos ensayos, que están basados en el flujo de Couette, donde se produce el confinamiento de la muestra entre una copa rotativa y un eje estacionario, y viceversa, entre la copa estática y un eje rotativo. En este caso, el torque es medido como una función de la velocidad rotacional y puede ser interpretado para determinar el esfuerzo cortante como una función del ratio de esfuerzo. La extrapolación del dato en el ratio de corte cero a partir de tal instrumento no es una buena forma de determinar la tensión de fluencia. La sedimentación de la muestra en un viscosímetro de Couette y el deslizamiento de la pasta sobre las paredes del recipiente son dos problemas comunes en este tipo de ensayos.

Otra forma de obtener la curva de esfuerzo cortante y ratio cortante es con un viscosímetro capilar o a partir de una tubería de ensayo en forma de bucle con un flujo laminar. En este caso, el esfuerzo cortante en la pared viene definido por la expresión

5-10:

$$
\tau_{w}=\frac{D \cdot \Delta_{p}}{4 \cdot L}
$$

Donde:

$\Delta_{p}$ es la caída de presión del flujo en una tubería de longitud $L$ que es medida como una función del ratio cortante aparente en la pared $8 \cdot V / D$;

D es el diámetro interior de la tubería

$\checkmark$ es la velocidad promedio en la tubería.

El ratio cortante en la pared viene relacionado por la ecuación 5-11:

$$
\gamma_{w}=\frac{3 n^{\prime}+1}{4 n^{\prime}} \cdot\left(\frac{8 \cdot V}{D}\right)
$$

Pudiéndose determinar a partir de la pendiente de una curva representada en coordenadas log-log del valor de $\tau_{w}$ respecto al valor de $8 \cdot V / D$. El ratio cortante que depende de la viscosidad es calculado por la expresión 5-12:

$$
\eta=\tau_{w} / \gamma_{w}
$$

Los datos de este tipo y las ecuaciones que los relacionan, son útiles para el diseño de las tuberías utilizadas en el transporte de la pasta y en la recirculación del hundido del espesador.

La figura 5-10: Curvas de flujo para una muestra de relleno de mina; representa las curvas de flujo para un material de relleno de mina con una tensión de fluencia de 250 Pa. Es importante notar la discrepancia de datos con ratios cortantes bajos, dependiendo del instrumento de medida utilizado. 


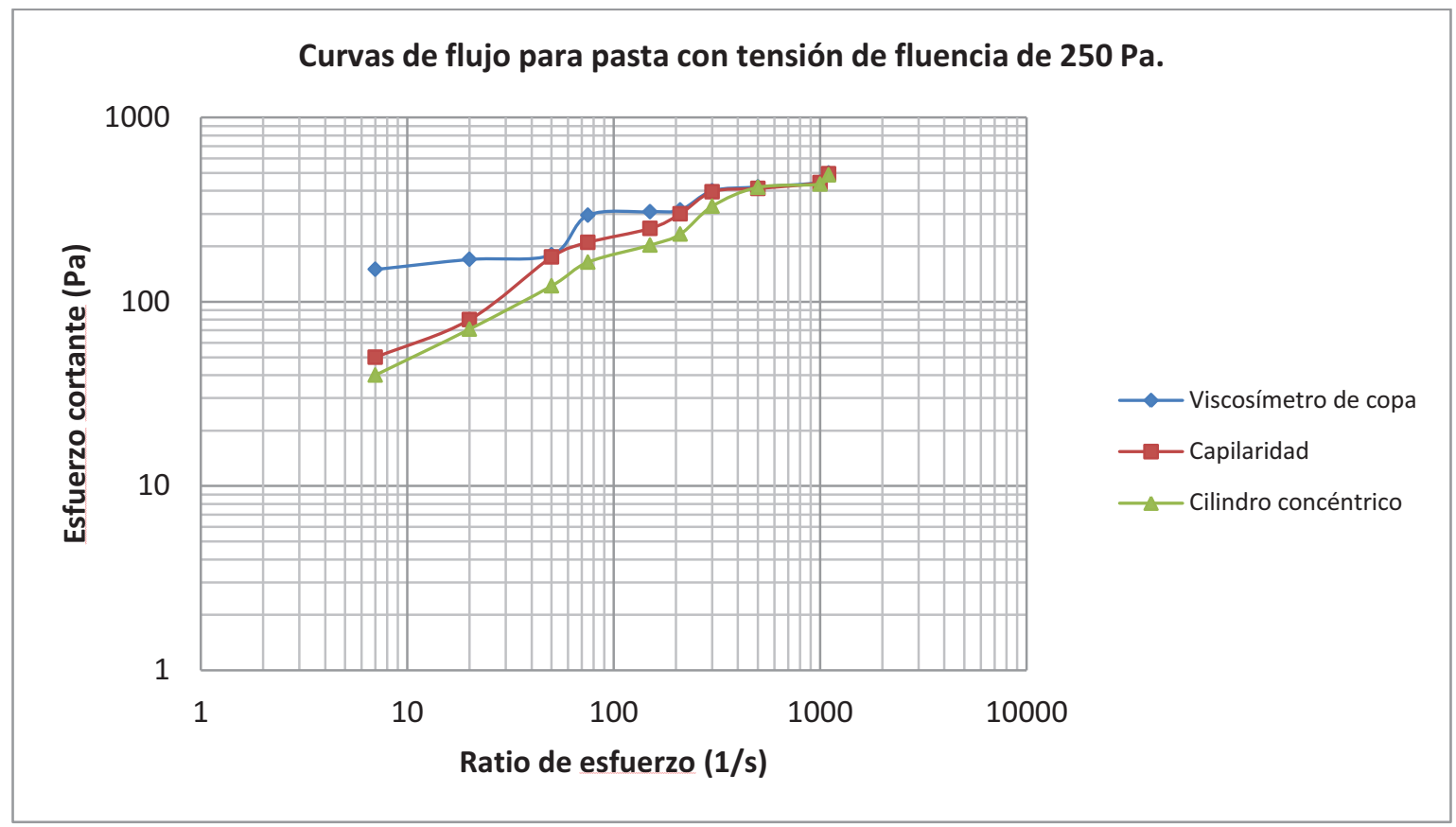

Figura 5-10: Curvas de flujo para una muestra de relleno de mina. (Fuente: Elaboración propia)

Los resultados de capilaridad y el cilindro concéntrico son similares para ratios de corte por encima de $300 \mathrm{~s}^{-1}$, pero se desvían y caen de forma significativa para ratios de corte bajos, comparado con los resultados obtenidos en el sistema de paletas y vaso. Si el cilindro rotativo interior en un aparato de Couette se reemplaza por unas paletas, los problemas relacionados con el deslizamiento desaparecen. Como ejemplo, la verdadera tensión de fluencia del material mostrada en el figura 5-11 es aproximadamente $250 \mathrm{~Pa}$, donde los datos obtenidos por el ensayo de capilaridad y el cilindro concéntrico presentan valores de $64 \mathrm{~Pa}$ y $17 \mathrm{~Pa}$ respectivamente, dependiendo de la extrapolación usada. Estas grandes diferencias pueden afectar significativamente al diseño del sistema de espesador de pasta. Por lo tanto, en general los resultados obtenidos en viscosímetro de cilindro concéntrico y en ocasiones el viscosímetro de capilaridad pueden tener errores significativos. Para la determinación de la tensión de fluencia de la pasta se debe de prestar especial atención, ya que es un dato básico en el proceso de diseño de los sistemas de deposición de estériles.

En resumen, las mediciones reológicas de mayor interés para los sistemas de espesado de pasta son obtenidas generalmente por dos métodos: mediante un viscosímetro y el sistema de vaso y paletas, que determinan tanto la tensión de fluencia, como la curva del ratio de corte y esfuerzo cortante para las suspensiones de pasta; o bien mediante el método empírico del ensayo de asentamiento. Este método es conocido como "slump test"; con el que se obtienen unos resultados extrapolables a los que se obtendrían en un viscosímetro, con la ventaja de poder realizarlo "in situ" sin necesidad de instrumentación de laboratorio. 


\subsection{Definición de pasta}

Se puede definir la pasta como: una suspensión homogénea de sólidos que tiene una mínima liberación de agua, entendiéndose como tal las suspensiones semisólidas que tienen un alto límite de fluencia, alto contenido en sólidos y propiedades reológicas bien definidas. El presente estudio se centra en las pastas obtenidas a partir del espesado de estériles mineros. Típicamente se puede afirmar que para considerar una pulpa como pasta tiene que tener un límite de fluencia superior a $50 \mathrm{~Pa}$.

Aunque la nomenclatura puede variar, la definición en sentido más amplio se fundamenta en las propiedades funcionales e inherentes del hundido obtenido en la operación de espesado: la no sedimentación, la no segregación del lodo y que se alcancen los requerimientos definidos de la aplicación.

El relleno con pasta en la minería subterránea y las operaciones de apilado en superficie requieren una relativa sedimentación con una suspensión de sólidos homogénea y una liberación mínima de agua.

Como ejemplos podemos citar, que una balsa de lodos o apilamiento de estériles puede requerir un talud de reposo de 1-3\% que sería equivalente a 50-80 Pa de límite de fluencia y por ejemplo una pasta para relleno de labores subterráneas puede requerir un descenso de hasta 220-250 mm en ensayos de asentamiento con $300 \mathrm{~mm}$ de altura inicial, equivalente a 100-150 Pa de límite de fluencia. Una torta obtenida por proceso de filtración a vacío, por ejemplo, tiene estas características; aunque lo interesante es conseguir este estado sin necesidad de una etapa de filtración posterior al espesado. A concentraciones de sólidos suficientemente altas, el hundido de un espesador de pasta o alta densidad puede tener estas propiedades. En una decantación a contracorriente o un proceso de recuperación de agua en espesador la "no" sedimentación y las características reológicas son propiedades que acompañan al primer objetivo de la concentración de sólidos. Generalmente el límite de fluencia del hundido no excederá de 100-150 Pa para no limitar el bombeo de la pasta.

Para los propósitos de este estudio se utilizará el término de pasta para referirse a los estériles o los materiales con las propiedades descritas anteriormente.

En los espesadores de cono profundo es importante, considerar el objetivo de la reología de la operación y su tamaño apropiado a la operación. Generalmente a mayor precisión de la reología requerida o solicitada, el equipo tendrá un coste mayor y una operación más compleja y delicada.

\subsection{Características de la pasta de estériles}

La experiencia en el diseño para espesado de pastas está en el campo del fabricante de equipos y mucha de esta información es restringida y confidencial. Sin embargo, se pueden estudiar y llegar a familiarizarse con las características particulares de la pasta que cualquier espesador dedicado a esta operación debe tener. Este conocimiento permitirá un grado de información que permite decidir y determinar si el fabricante de espesadores ha tenido en cuenta las consideraciones fundamentales para el espesado de pasta. Por ejemplo, una especificación para un espesador de 
pasta que no haya considerado la curva de tensión de fluencia debería ser examinado en profundidad para entender cómo es el rango de determinación de la pasta y cómo se ha realizado la concentración de sólidos máxima y el hundido esperado en el espesador.

\subsubsection{Reología de la pasta}

En general la ciencia del espesado convencional está basada en la producción de una pulpa en el hundido como opuesta al hundido de pasta. Para esta discusión, una pulpa es una suspensión de sólidos que sedimenta bajo una agitación insuficiente como puede ser el flujo en una tubería de una mezcla de líquido y sólidos a baja velocidad. Cuando ocurre la sedimentación hay una segregación de sólidos, de tal forma que sedimentan más rápidamente las partículas más pesadas seguidas de las partículas más ligeras. Las pulpas siguen generalmente, las reglas de los fluidos newtonianos. Para un fluido newtoniano la viscosidad permanece constante aunque el ratio de esfuerzo cortante varíe para una temperatura dada. El esfuerzo cortante es el movimiento de las partículas de una pasta, unas con respecto a otras y se impone por ejemplo en el flujo de las pulpas a través de una tubería o una bomba. Con altas velocidades del flujo de una pulpa o una pasta, el ratio de corte es mayor que el que se produce a bajas velocidades. Los tipos de suspensiones denominados pastas, no tienen las características de un fluido newtoniano y se denominan fluidos no-newtonianos. Para muchas pastas de estériles, los cambios de viscosidad varían con el cambio del ratio de corte. Algunas pasta referidas como tixiotrópicas, tienen la propiedad de cambiar la viscosidad con el tiempo manteniendo el esfuerzo cortante constante. Este carácter no-newtoniano crea un cambio en la reología de la pasta ya que éstas son expuestas a los diferentes ratios de corte y varias etapas durante las fases de espesado, transporte, bombeo, y deposición final. La implicación para el diseño de espesadores de pasta así como para el diseño de las tuberías y estaciones de bombeo, es que las leyes típicas para el flujo de fluidos que se emplean para elegir el diámetro de tuberías y tamaño de las bombas e incluso el tamaño de los tanques espesadores, no se pueden aplicar en el caso de manejo de pastas. El diseño de un sistema de espesado de pasta requiere datos y experiencias que no están fundamentadas en las referencias de la mecánica de fluidos tradicional. En la figura 5-11: Flujo newtoniano y flujo no-newtoniano; se pueden apreciar las diferencias y características de de cada uno de los flujos mencionadas anteriormente. 

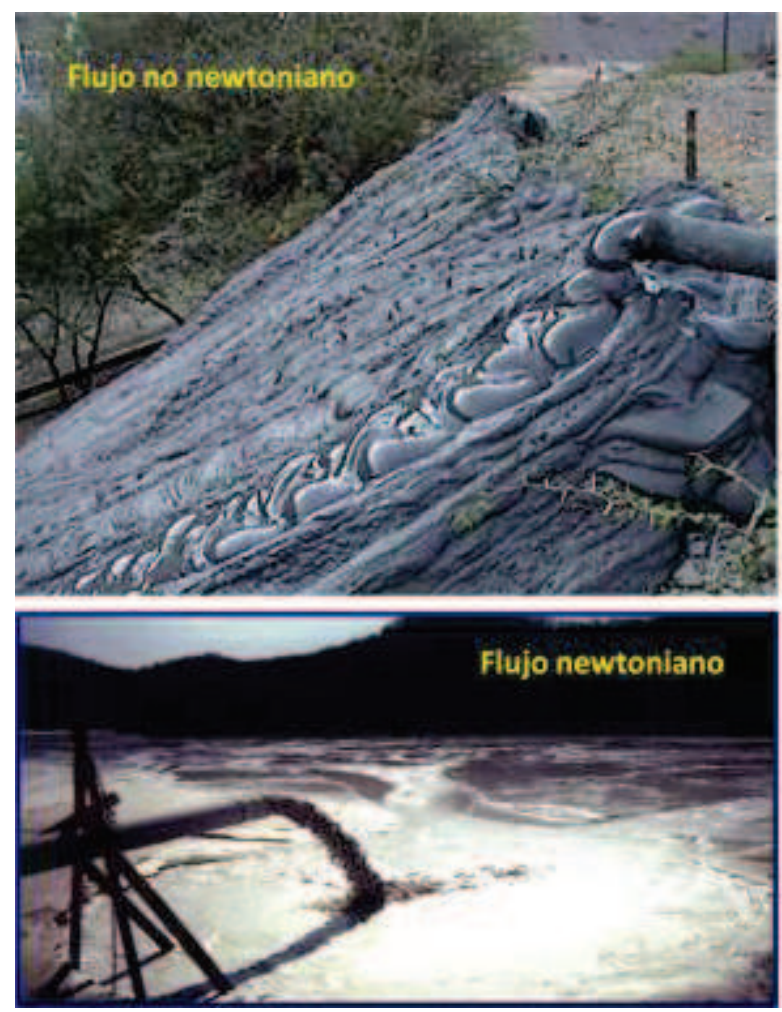

Figura 5-11: Flujo newtoniano y flujo no-newtoniano. (Fuente: Cortesía de Dorr-Oliver Eimco)

\subsubsection{Límite elástico}

Una de las características que definen a la pasta es el comportamiento semi-sólido de las pastas a medida que se incrementa la concentración en sólidos. Un ejemplo de una pasta de estériles se ve en la figura 5-12: Pasta de estériles fluyendo. Una pulpa que es básicamente un fluido newtoniano y que toma la forma del recipiente que lo contiene, la pasta por el contrario mantiene o puede mantener su forma original más o menos deformada y vendrá caracterizada por la concentración en sólidos que tenga esa pasta y su tensión de fluencia.

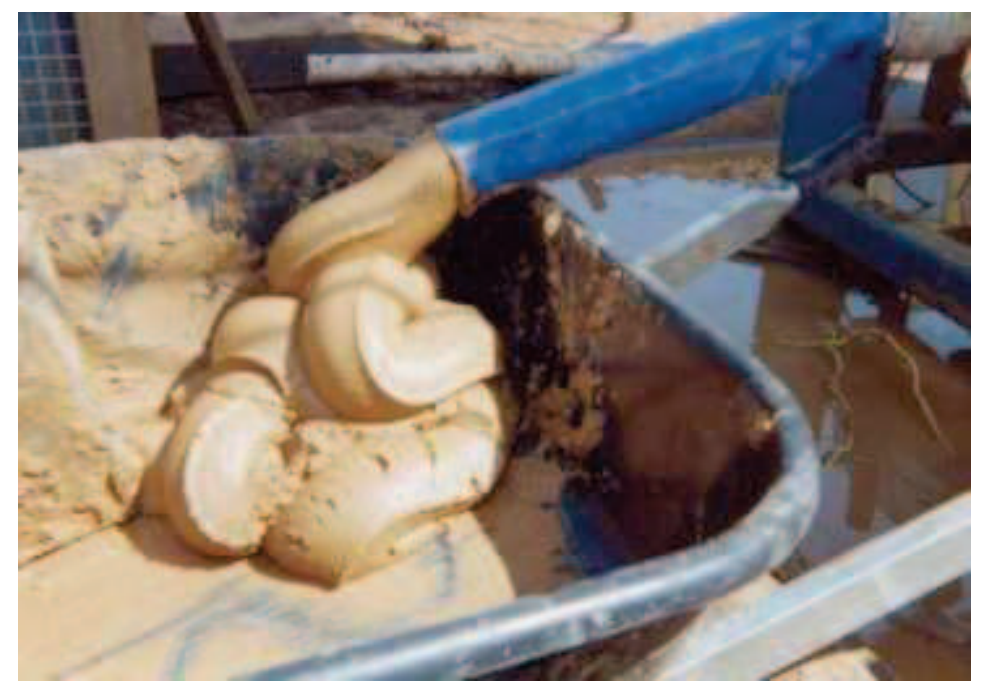

Figura 5-12: Pasta de estériles fluyendo. 
Es necesario aplicar un esfuerzo para que la pasta fluya. Esta presión es denominada por el término reológico de límite elástico y es una propiedad característica de los fluidos nonewtonianos. La figura 5-13: Límite elástico en pasta de estériles; ofrece una visión muy descriptiva del término de límite elástico. Como se muestra en la figura 5-23, cuando se vierte un fluido en una rampa inclinada, se produce el flujo del fluido (en el caso de fluidos newtonianos) que aunque tenga una viscosidad elevada, no presentan límite elástico y mediante la fuerza de la gravedad debida al plano inclinado, hace que fluya por la rampa. En cambio para pasta minerales con propiedades de fluido no-newtoniano, cuando se vierten en el plano inclinado, puede fluir o no fluir, dependiendo de si la fuerza de gravedad aplicada por la inclinación del plano es suficiente para alcanzar el valor del límite elástico de la pasta apilada sobre el terreno.

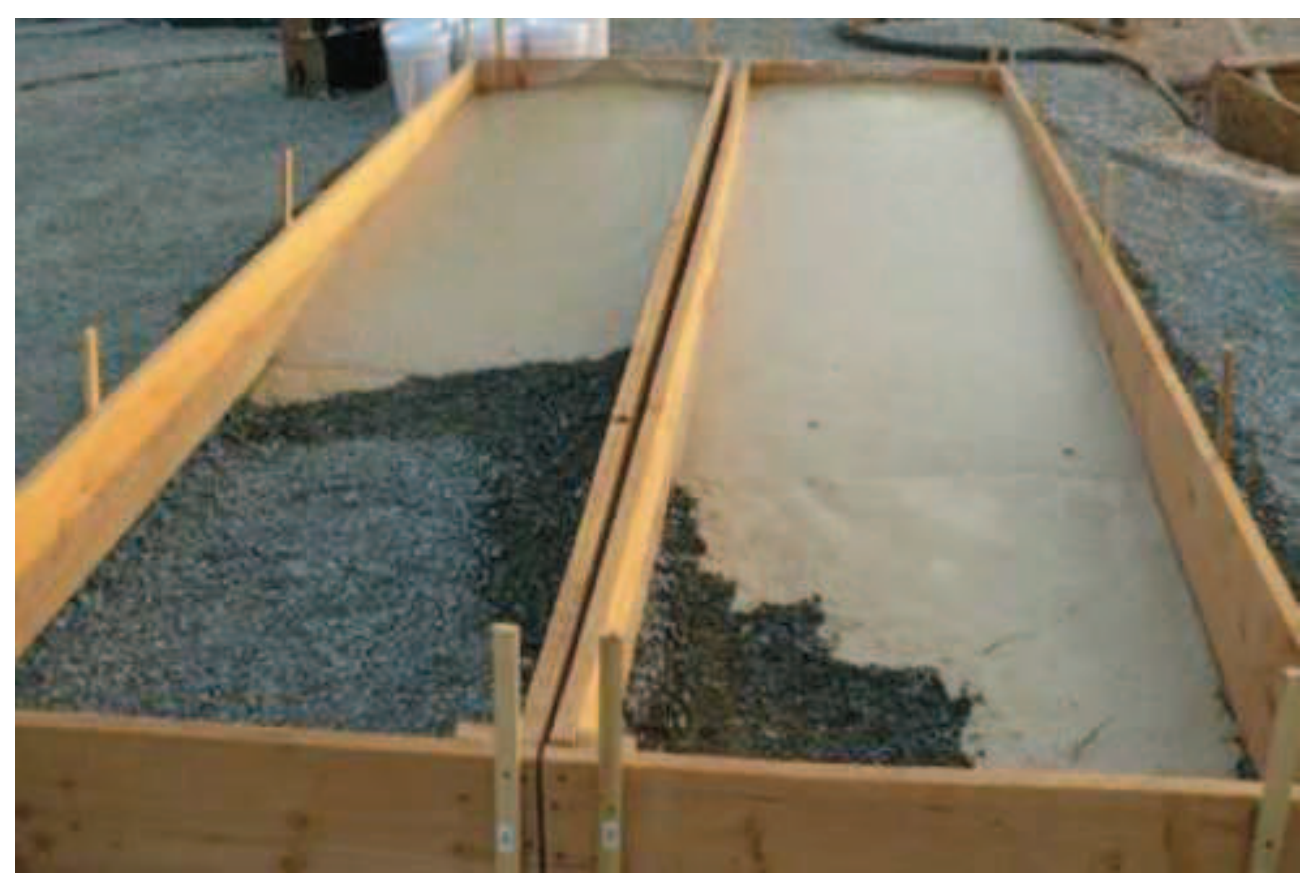

Figura 5-13: Límite elástico en pasta de estériles.

(Fuente: Cortesía de Dorr-Oliver Eimco)

La figura 5-14: Límite elástico en suspensiones de sólidos; ilustra la explicación física para la aplicación del límite elástico: cuando las suspensiones de sólidos llegan a ser suficientemente concentradas, las partículas finas, considerando que los tamaños menores de 10-20 micras, forman enlaces a través de atracciones electrostáticas. 


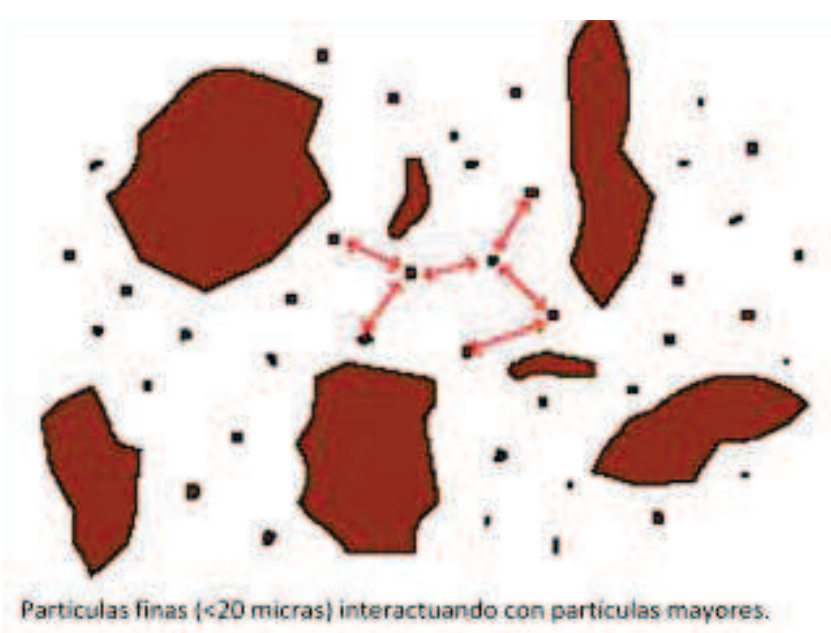

Figura 5-14: Límite elástico en suspensiones de sólidos. (Fuente: Cortesía de FLSmidth Dorr-Oliver Eimco Spain, S.L.)

Estas aglomeraciones de enlaces resultan en una red continua que se rompe sólo cuando se aplica una determinada tensión, que denominamos límite elástico. El concepto de la red de partículas finas cohesionadas, cuenta con otras de las propiedades de la pasta. Las partículas gruesas inmersas en esta red no pueden sedimentar ya que esta red actúa sobre ellas manteniéndose en suspensión en esta red. Este fenómeno es importante para las propiedades de una pasta, como son la no-sedimentación y la no-segregación de la pasta, importante en el diseño del apilado de estériles o el relleno de mina. La fluidificación por esfuerzo cortante, por ejemplo mediante un bombeo de la pasta, y la tixiotropía son dos características importantes del modelo descrito anteriormente.

La fluidificación se produce por el esfuerzo cortante aplicado sobre la pasta, esta fuerza aplicada produce una energía que distorsiona y rompe los enlaces entre las partículas finas, causando un cambio de la viscosidad de la pasta y permitiendo el movimiento de las partículas dentro de la masa de pasta. Esta perturbación y rotura de la red de enlaces es una función del ratio de corte como en el caso de pastas fluidificadas por esfuerzo cortante en el caso de materiales tixiotrópicos. Dependiendo de la rapidez con la que la red de enlaces es restablecida, la viscosidad y el límite elástico pueden recuperarse total o parcialmente una vez que la fuerza aplicada en forma de esfuerzo cortante ha cesado sobre la pasta.

El límite elástico depende de muchas propiedades incluyendo la temperatura, mineralogía, pH y concentración de sólidos. Dado un grupo constante de propiedades, los datos más importantes que se requieren para el diseño del espesador de pasta, muestra los cambios de límite elástico con el cambio de la concentración de sólidos. Esta correlación se muestra con la curva típica de límite elástico, como se muestra en la figura 5-15: Operación de un espesador según la curva de tensión de fluencia.

Los datos de esta curva pueden ser obtenidos realizando ensayos con un viscosímetro y tratando muestras con diferentes contenidos en sólidos y tamaños de partículas.

La forma exacta de la curva y la posición que adopta respecto a los ejes de concentración de sólidos y tensión de fluencia, varía en función de las diferentes pastas que se analizan y cada 
muestra tiene una curva característica. Sin embargo hay una característica común y es que la mayoría de las curvas tienen un rápido incremento de la tensión de fluencia al incrementarse el contenido en sólidos una vez que las suspensiones llegan al punto de no sedimentación. La curva de tensión de fluencia se refleja en la apariencia física de la pasta. Para pulpas con bajas concentraciones de sólidos, la tensión de fluencia tiende a cero cuando la concentración de sólidos se aproxima a cero. En algunas concentraciones de sólidos la tensión de fluencia llega a ser suficientemente alta para soportar las partículas y mantenerlas en suspensión como una pasta. A medida que la concentración de sólidos se incrementa y más partículas llega a ser nosedimentables y por tanto la pendiente de un apilado de pasta en superficie se incrementa. Con la concentración de sólidos suficientemente alta, la pasta llega a tener características similares a un material semi-sólido y presenta un comportamiento similar al que presentan los materiales de tortas obtenidas en un proceso de filtración.

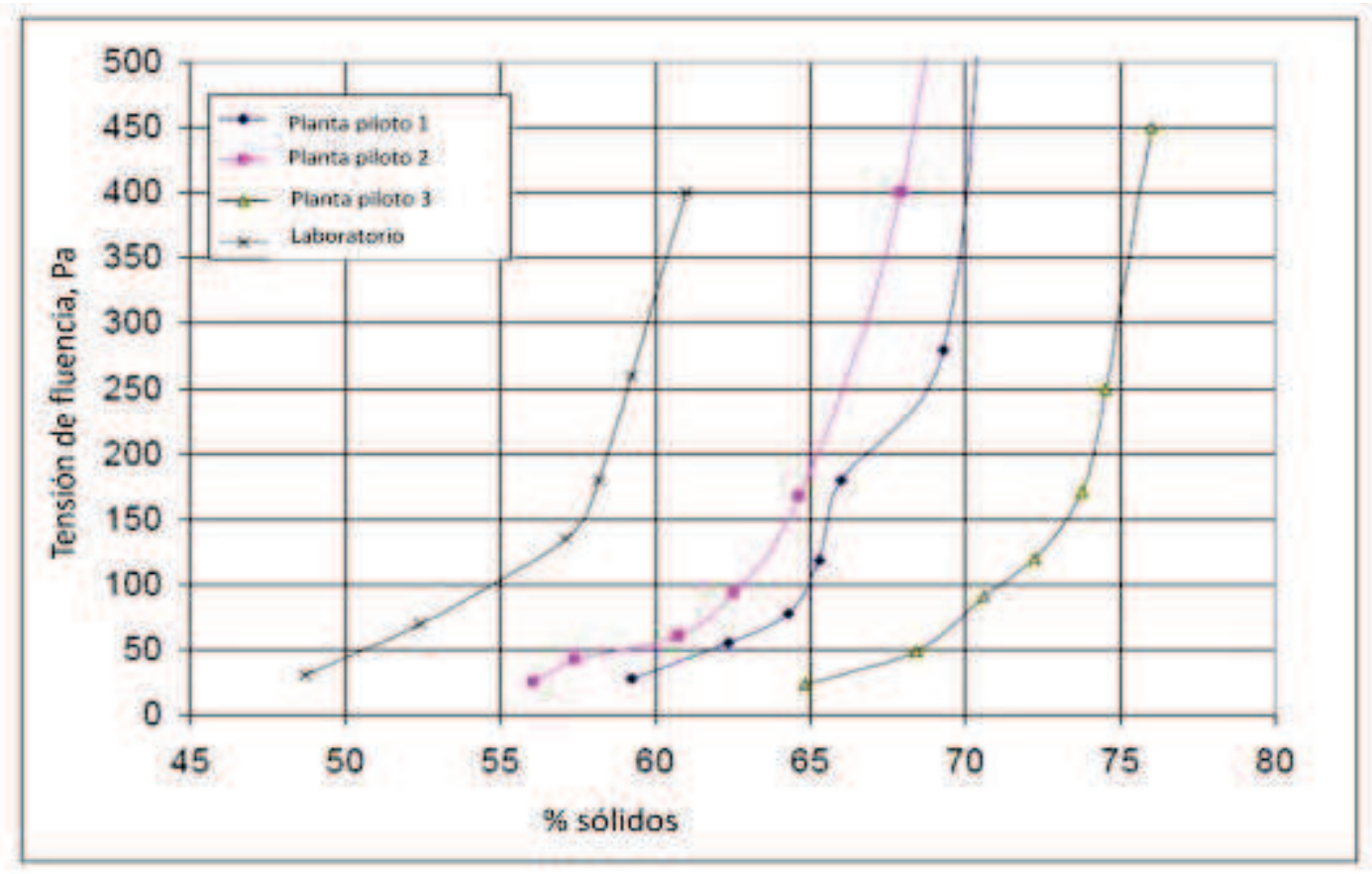

Figura 5-15: Operación de un espesador según la curva de tensión de fluencia.

(Fuente: adaptado de Boger D., Rheological Concepts; University of Melbourne. Australia 2006)

\subsubsection{Operación del espesador en la curva de tensión de fluencia}

Bajo la acción de la gravedad, el espesador de pasta fluirá a un punto dictado por la tensión de esfuerzo y parada. Este comportamiento es el reto para los diseñadores de espesadores de pasta. La pasta debe moverse a través del espesador, y ser entregada al sistema de bombeo para su transporte al punto de aplicación, la balsa o el depósito de pasta. Es útil identificar en la curva de tensión de fluencia el rango de sólidos sobre el cual el espesador de pasta se espera que opere con una concentración de sólidos en el hundido consistente y con una determinada reología. La adecuada interpolación de la curva de tensión de fluencia puede revelar la máxima concentración de sólidos del hundido de la pasta. De forma análoga, la curva proporciona una indicación de la máxima concentración bajo la cual la suspensión se presenta como una pulpa sedimentada y no 
como una pasta no sedimentable y no segregable. Esta curva proporciona un marco para evaluar en qué lugar del eje de concentración de sólidos debe operar el espesador de pasta para conseguir el objetivo de tensión de fluencia y contenido en sólidos.

\subsubsection{Lecho profundo en el espesador de pasta}

A diferencia de los espesadores convencionales o de pulpas, la sedimentación de compresión en el lecho de lodos es a menudo el factor que controla el ratio de espesado para los espesadores de pasta, y por tanto el parámetro que determina el área unitaria y la concentración de sólidos del hundido. La figura 5-16: Efecto de la profundidad del lecho de lodos en un espesador; muestra la importancia de la profundidad del lecho de lodos en un espesador de pasta con un diámetro determinado. El volumen de lodos requerido en el lecho del espesador de pasta por tonelada de sólidos al día o por unidad de volumen es representado frente a la profundidad del lecho de lodos, obteniendo la curva correspondiente. Si la profundidad del lecho de lodos no tiene efecto sobre el ratio de espesado, entonces la curva $A$, no será seguida, lo que representa un incremento proporcional en volumen unitario con la profundidad. Si el lecho de lodos tiene un efecto (curva B), el volumen unitario se incrementará a medida que la profundidad del lecho de lodos se incrementa.
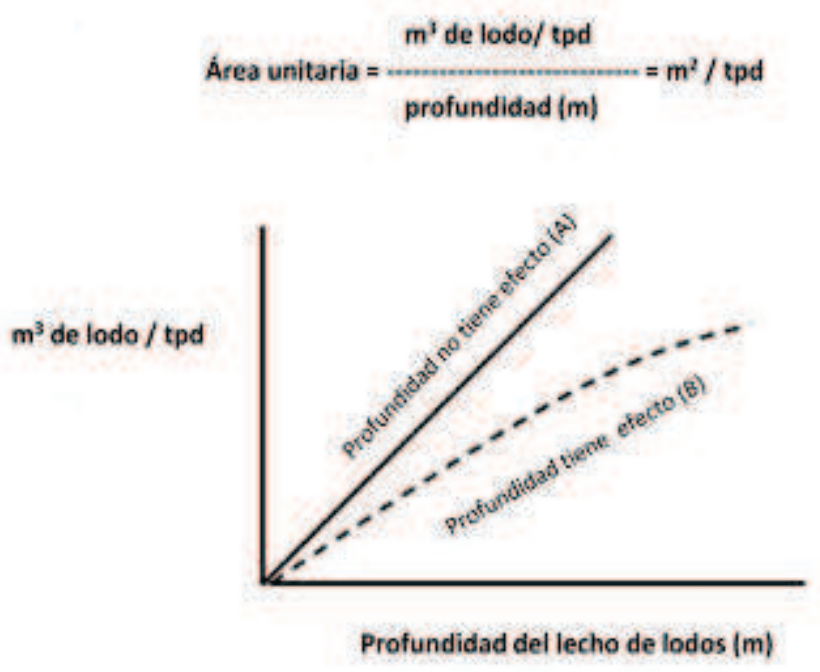

Figura 5-16: Efecto de la profundidad del lecho de lodos en un espesador. (Fuente: Cortesía de FLSmidth Dorr-Oliver Eimco Spain, S.L.)

En otras palabras, a mayor profundidad se requiere menos volumen de lodos en el espesador para producir una concentración de sólidos en el hundido determinada, para el mismo ratio de producción de sólidos. Esto se expresa de forma más clara si se emplea el área unitaria. Dividiendo la unidad de volumen por la profundidad se obtiene el área unitaria, según la expresión 5-15. 


$$
\text { Área unitaria }=m^{3} \text { de lodos } / \frac{t}{\text { día }} / \quad m \text { profundidad }=m^{2} / t / \text { día }
$$

A medida que la profundidad se incrementa, siguiendo la curva $\mathrm{B}$, el área unitaria decrece. Por tanto para una determinada producción de sólidos el diámetro decrece al incrementarse la profundidad. El efecto beneficioso del incremento de la profundidad del lecho lodos sobre el área unitaria alcanza un punto de retroceso de la disminución. La curva B, en la figura 5-16, empieza a hacerse plana donde el incremento en la profundidad no produce un cambio en el volumen unitario o en el área unitaria.

La figura 5-17: Profundidad de lecho de lodos frente al contenido en sólidos; muestra el efecto del lecho de lodos de una forma diferente. El perfil de concentración de sólidos en un espesador se muestra como porcentaje de sólidos frente al incremento de profundidad sobre la zona de rasquetas del espesador. En un punto el incremento en la concentración de sólidos, típicamente muestra pocos cambios con un incremento en la profundidad.

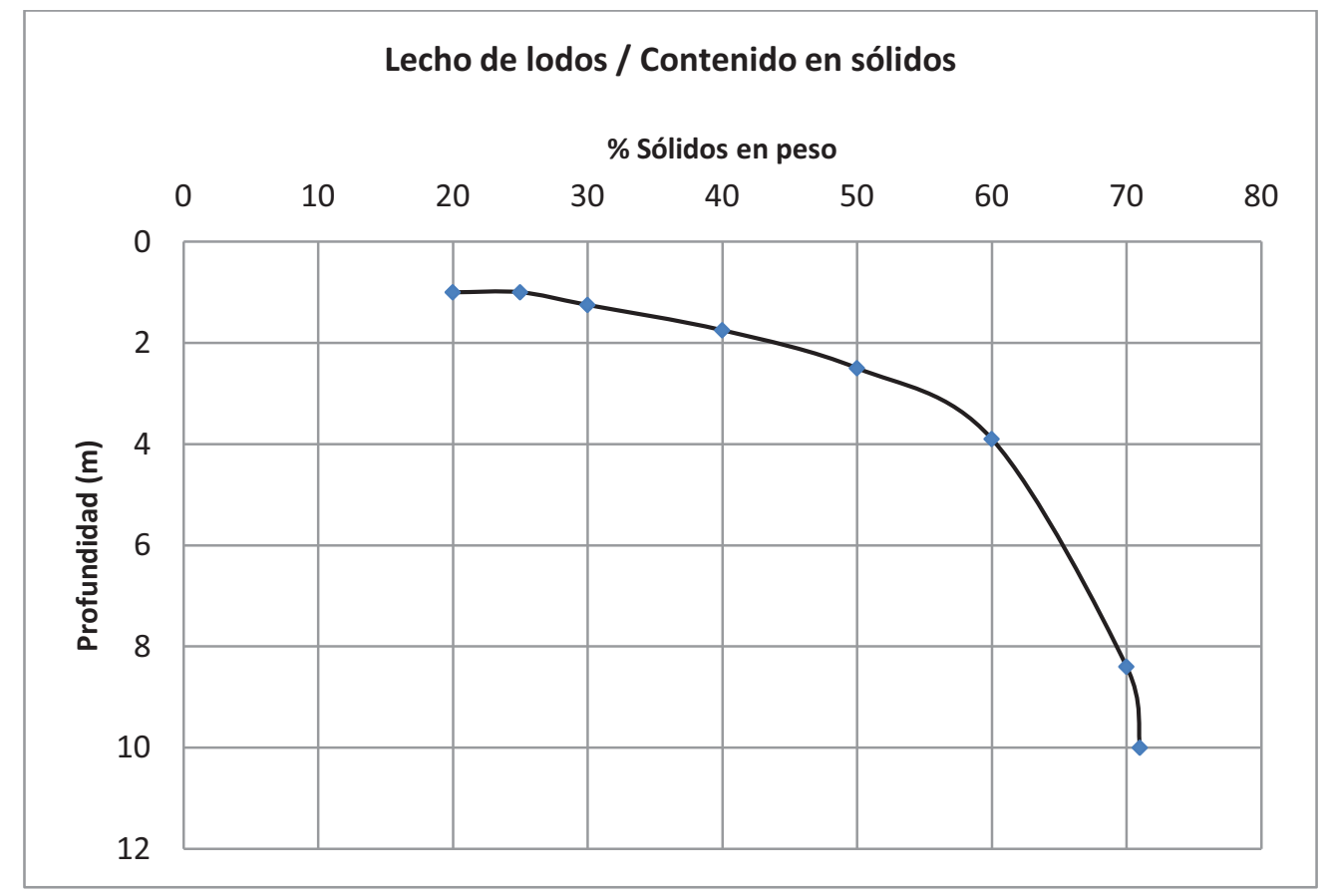

Figura 5-17: Profundidad de lecho de lodos frente al contenido en sólidos.

(Fuente: Elaboración propia)

El fabricante de equipos de espesado en cono profundo normalmente cuenta con una metodología para relacionar la profundidad del lecho de lodos y el volumen de la zona de compresión para dimensionar el espesador y obtener una determinada concentración de sólidos en el hundido. Es importante reconocer el efecto fundamental de la sedimentación en compresión y que el fabricante de equipos de espesado en forma de pasta tenga el método de evaluación de estos parámetros. Los ratios de espesado son controlados por la adecuada floculación y la gravedad, lo cual es único 
para cualquier tipo en particular de espesador de pasta. El tema más importante en el diseño de un espesador de pasta es cómo descargar el hundido lo más espesado posible en un proceso continuo sin necesidad de parar las rasquetas, atascos, u otros problemas asociados con las altas viscosidades de la pasta y la presencia de la tensión de fluencia. Este aspecto de diseño es uno de los más importantes. Espesar una pulpa de estériles a una alta concentración de sólidos con las propiedades de una pasta es inútil si la pasta no se puede sacar, bombear o transportar fuera del espesador.

El lecho de lodos en el espesador de pasta debe ser transportado al punto de descarga. Hay diferentes características del diseño de los espesadores de pasta que apuntan en esta dirección y que se mencionarán más adelante. Tres de los parámetros más importantes de diseño de un espesador de pasta son: la geometría del tanque, el diseño de rasquetas y el momento de giro de las rasquetas, existiendo otros parámetros también importantes como son: los sistemas de floculación y alimentación, que deben ser estudiados en el proyecto.

\subsubsection{Floculación efectiva para la producción de pasta}

Una floculación eficiente basada en la identificación del floculante adecuado, añadido en la dosificación óptima y el modo de adicción en la pulpa entrante, es la clave para el éxito de la operación de los espesadores de alta capacidad, en general, y no menos importante para los espesadores de pasta. Investigar la selección del floculante en un espesador de pasta es un aspecto clave en cualquier estudio de viabilidad y proyecto de un espesador. La selección del floculante en operaciones de pasta comprende generalmente varios ensayos, desde pruebas de laboratorio y comparaciones en probeta sobre pequeñas muestras para una primera estimación, hasta ensayos a gran escala en cilindros o equipos piloto. Este es el paso más importante y se realiza tanto por los fabricantes de equipos como por los fabricantes de floculantes y el usuario final. La mayoría de espesadores, incluyendo los espesadores de pasta, usan campanas de alimentación como punto de entrada en el equipo para los flujos de pulpas de estériles a sedimentar. Los modernos sistemas de alimentación tienen unas funciones importantes dentro del conjunto del espesador de pasta y por tanto es un elemento clave en cualquier espesador, como son:

a) Reduce la energía y turbulencia asociada del flujo de pulpa entrante en el espesador.

b) La pulpa puede introducirse a la profundidad requerida en cada caso en particular y a la profundidad necesaria.

c) Los sólidos son distribuidos a lo largo de toda la superficie del espesador.

d) Proporciona un punto de dilución de la alimentación, fundamentalmente para tener una floculación efectiva.

e) Proporciona los puntos de adicción de floculante para su correcta dosificación.

f) Proporciona el tiempo y condiciones de mezcla adecuadas para la floculación óptima, permitiendo el crecimiento del flóculo. 
g) En general cada fabricante de equipos tiene un diseño o varios diseños de campana en función del proceso o del material a tratar, estos diseños cumplen y optimizan todos los puntos señalados anteriormente.

En los siguientes capítulos se analizará el diseño actual de los espesadores de cono profundo que existen actualmente en el mercado para el espesado de estériles en forma de pasta, conocidos como espesadores de cono profundo así como de los sistemas de alimentación y floculación, en los que se centra la atención del presente estudio.

\subsection{Diseño actual de los espesadores de pasta}

Uno de los principales métodos para producir pasta o lodos de alta densidad en el hundido a partir de estériles mineros es el espesado de la pulpa en un espesador de cono profundo o un espesador de alta densidad tipo "HDT". Ésta es hasta el momento una de las soluciones más baratas, con bajos costes de operación y un bajo consumo energético. El espesador de pasta recibe la alimentación de estériles y floculante en forma de pulpa, sedimentando los sólidos a una concentración determinada.

En general los espesadores de pasta se utilizan para maximizar la recuperación de agua, producir una pasta de determinada características en el hundido y enviarla por bombeo para su apilado en superficie o bien, para ser utilizado como material de relleno de las explotaciones.

Para comenzar el diseño del equipo de espesado en pasta, el ingeniero debe definir previamente los objetivos a alcanzar con el equipo y entender los fundamentos del proceso; con estos datos preliminares bien definidos y estudiados mediante ensayos de laboratorio o en plantas piloto, se puede comenzar el diseño del proceso y del equipo de espesado.

El presente documento se centra en la fase de diseño del espesador de pasta; esto es, en el caso que nos ocupa, todo lo relacionado con el estudio del espesador de cono profundo y la pasta producida por el equipo. Las etapas relacionadas con el método de deposición y de transporte en tubería y bombeo de la pasta se tratan de forma sucinta en el texto para centrar el alcance del estudio en los equipos de espesado en pasta o alta densidad en el hundido y los procesos de separación sólido-líquido que se producen en estos equipos.

Las consideraciones más importantes para la selección, ingeniería y diseño del equipo de espesado de cono profundo capaz de espesar los estériles hasta conseguir una pasta son los siguientes:

a) Diseño efectivo de la campana de alimentación y sistema de dosificación de floculante.

b) Diámetro y geometría del tanque, seleccionando la adecuada unidad de área en $\mathrm{m}^{2} / \mathrm{t} / \mathrm{día}$ y definiendo la altura de lechos de lodos necesaria para obtener la densidad requerida del hundido. Definir el tiempo de residencia necesaria para alcanzar la densidad del hundido.

c) Selección del par de accionamiento y el correspondiente diseño del mecanismo que mejor se adapte a la operación para alcanzar la tensión de fluencia requerida.

d) Decidir la necesidad de incorporar al diseño las piquetas y su diseño en el mecanismo. 
e) Sistema de bombeo, sistema de descarga y sistema de recirculación de lodos en el espesador.

El diseño del equipo de espesado de estériles involucra una serie de fases para garantizar el éxito del mismo, hay que conocer las especificaciones u objetivos a alcanzar con el equipo, realizar los ensayos necesarios bien en laboratorio o en planta piloto y por último diseñar los elementos para que el espesador sea capaz de alcanzar el máximo desarrollo y alcanzar el tonelaje de material esperado.

Las fases necesarias para el proceso de diseño de un espesador de pasta o de alta densidad en el hundido son las que se relacionan a continuación:

a) Conocimiento de las especificaciones u objetivos a alcanzar en la operación:

1. Densidad del hundido o recuperación de agua

2. Tonelaje de diseño en sólidos por hora

3. Tamaño de partículas en la alimentación

b) A partir de los ensayos de laboratorio o en planta piloto se deben de medir y conocer el resto de parámetros necesarios para el diseño del espesador:

1. Ratio de dilución óptimo en la alimentación

2. Dosificación de floculante adecuada

3. Área unitaria de sedimentación

4. Velocidad de sedimentación

5. Tiempo de retención y altura del lecho de lodos

6. Tensión de fluencia esperada en el hundido

7. Porcentaje de sólidos en el hundido

c) El equipo así diseñado debe ser capaz de:

1. Proporcionar las condiciones de floculación adecuadas con un diseño de campana de alimentación adecuado.

2. Proporcionar el tiempo de retención esperado y la altura de lecho de lodos necesaria.

3. Talud de fondo y diseño del mecanismo más adecuados en función del proceso a realizar y de las características de la pasta.

4. Capacidad de accionamiento del mecanismo a una determinada tensión de fluencia de la pasta.

5. Descargar el hundido a la tensión de fluencia esperada.

Con estas tres fases de diseño anteriores y los datos calculados en cada una de ellas, el diseñador de equipos de espesado de estériles se encuentra en disposición de afrontar el proceso de ingeniería del nuevo equipo para el proceso de tratamiento de estériles requerido. 
El desarrollo de espesadores de alto rendimiento para la producción de pasta o lodos de alta densidad en el hundido, comienza siempre con una floculación eficiente. Los sólidos contenidos en la pulpa más la adicción de un floculante produce una solución floculada. El floculante requiere de los siguientes pasos para que se utilice de forma eficaz y eficiente:

a) Una correcta preparación y tiempo de actuación.

b) Adecuada concentración para su dispersión.

c) Un adecuado sistema de preparación, bombeo y puntos de adición de floculante.

d) Control de la dosificación óptima.

El objetivo final de todas estas acciones debe de ser maximizar el flujo de sedimentación y la densidad del hundido que es el producto de la reacción del floculante y los sólidos de la alimentación.

Todas las fases de ensayos y pruebas generan una serie de datos que el ingeniero de proceso debe saber interpretar para el éxito del diseño, si bien es importante la experiencia de otros proyectos similares realizados con anterioridad. Los detalles sobre las relaciones entre los equipos de espesado y los materiales a espesar, las características de la pasta, así como su relación con las dimensiones del equipo o partes que forman el espesador de cono profundo se describen en los puntos siguientes.

\subsubsection{Partes del espesador de pasta}

En éste y los siguientes puntos, se describen las partes más importantes de un espesador de cono profundo y se enumeran de forma breve las características y el método de elección de las diferentes variantes de cada elemento. Esta información puede variar de unos fabricantes a otros y en general forma parte de la propiedad tecnológica de las empresas por lo que no puede ser ampliada en exceso ya que pertenece a la propiedad intelectual de las empresas.

Los espesadores de pasta son equipos de operación compleja a escala real y por tanto, requieren de un buen entendimiento de la tecnología de la pasta y la tecnología de la sedimentación en los equipos.

En general, este tipo de espesadores de cono profundo, proporcionan un alto lecho de lodos en su interior lo que hace aumentar la presión, lo que unido al elevado ángulo del fondo del tanque y al innovador diseño de las rasquetas del mecanismo y el control de la reología del lodo mediante la instrumentación adecuada proporcionan la pasta requerida en un determinado proyecto.

Los espesadores de cono profundo incorporan las siguientes características en su diseño, si bien estas pueden variar de unos fabricantes a otros, en general son:

a) Mínimo diámetro del espesador (dimensionado con alta tasa de sedimentación de sólidos)

b) Reduce el coste de construcción y adquisición.

c) Minimiza el par necesario para hacer girar los brazos de rasquetas.

d) Minimiza el tiempo de respuesta ante los cambios en el proceso.

e) Máxima profundidad de la pulpa y alto lecho de lodos.

f) Evita la formación de huecos o canales en el fondo del espesador. 
g) Proporciona un alto tiempo de residencia para que el lodo elimine el licor contenido en el lecho de lodos formado.

h) Proporciona la compresión suficiente sobre la pulpa sedimentada para que elimine el licor contenido.

i) Elevado talud del fondo del tanque.

j) Permite el movimiento de la pasta hacia el cono de descarga

k) Permite el acceso de personal al cono de descarga y al interior del tanque desde la base.

l) Brazos de rasquetas optimizados para cada proceso en función de la reología de la pasta.

m) Produce canales para la salida del licor entre la pasta mediante piquetas verticales.

n) Proporciona un volumen confinado de pasta que permite la reducción de la tensión de fluencia de la pasta mediante la recirculación o movimiento de las rasquetas, lo que se conoce como: "shear thinning".

o) Tiene una geometría que simplifica la conexión de bombas de lodos.

\subsubsection{Diseño del tanque}

Los diseños actuales de tanques que existen para espesadores de cono profundo son principalmente atendiendo a los materiales de construcción y sus características, se diseñan con varias combinaciones: por un lado se encuentran tanques de acero al carbono soportados sobre pilares y tanques construidos en hormigón; por otro lado atendiendo a la forma de soporte de la cabeza de accionamiento estos pueden ser espesadores con puente diametral o espesadores con columna central. En general esto viene definido por el diámetro del tanque, siendo los espesadores de acero soportados sobre pilares y con puente diametral los espesadores inferiores a 25 metros, si bien se pueden llegar a diámetros de 28 metros. Los tanques de hormigón y soportes de columna se utilizan para diámetros superiores a 28 metros o para espesadores de pasta que necesiten un alto par de accionamiento y sean diseñados con cabezas de soporte en columna. La figura 5-18: Espesador de pasta con tanque de acero y puente diametral; muestra un esquema de un espesador de cono profundo de 18 metros de diámetro. Ver tabla 5-1: Características de los tipos de tanques.

Tabla 5-1: Características de los tipos de tanques.

\begin{tabular}{|c|c|c|c|}
\hline Material del tanque & Tipo de puente & Diámetros $(\mathrm{m})$ & Par máximo $(\mathrm{K}=300)$ \\
\hline Acero & Diametral & $1-24$ & $2.590 .000 \mathrm{~N} \cdot \mathrm{m}$ \\
\hline Hormigón / Acero & Diametral / Columna & $18-28$ & $3.527 .000 \mathrm{~N} \cdot \mathrm{m}$ \\
\hline Hormigón & Columna & $25-55$ & $13.600 .000 \mathrm{~N} \cdot \mathrm{m}$ \\
\hline
\end{tabular}

(Fuente: Elaboración propia)

La altura de la virola vertical lateral del tanque puede ser calculada teniéndose en cuenta las diversas alturas de las diferentes zonas que deben ser controladas para cada proceso. Estas dimensiones verticales son: altura del lecho de lodos, altura zona clarificada, zona de seguridad, profundidad de la campana de sedimentación y altura libre del tanque. 
La pared vertical del tanque es mucho mayor que en otros espesadores convencionales, el lecho de lodos puede alcanzar profundidades de hasta 10-12 metros e incluso estar próxima a la campana de alimentación.

La altura del lecho de lodos y la altura de la zona clarificada se fijan mediante los parámetros de tiempo de residencia, volumen de lodos necesario y ratio de ascenso.

Se define la zona de seguridad: como el espacio entre la interfase máxima del lodo en el diseño y el fondo de la campana de alimentación. Típicamente esta distancia es de 1-1,5 metros, pero en ocasiones puede llegar a ser mayor para permitir puntas en el caudal de alimentación. Esta distancia permite la distribución de la pulpa floculada en toda la superficie de sedimentación.

La profundidad de la campana de alimentación: se refiere a la sección de diseño de la campana de alimentación y la profundidad o altura de virola de la campana.

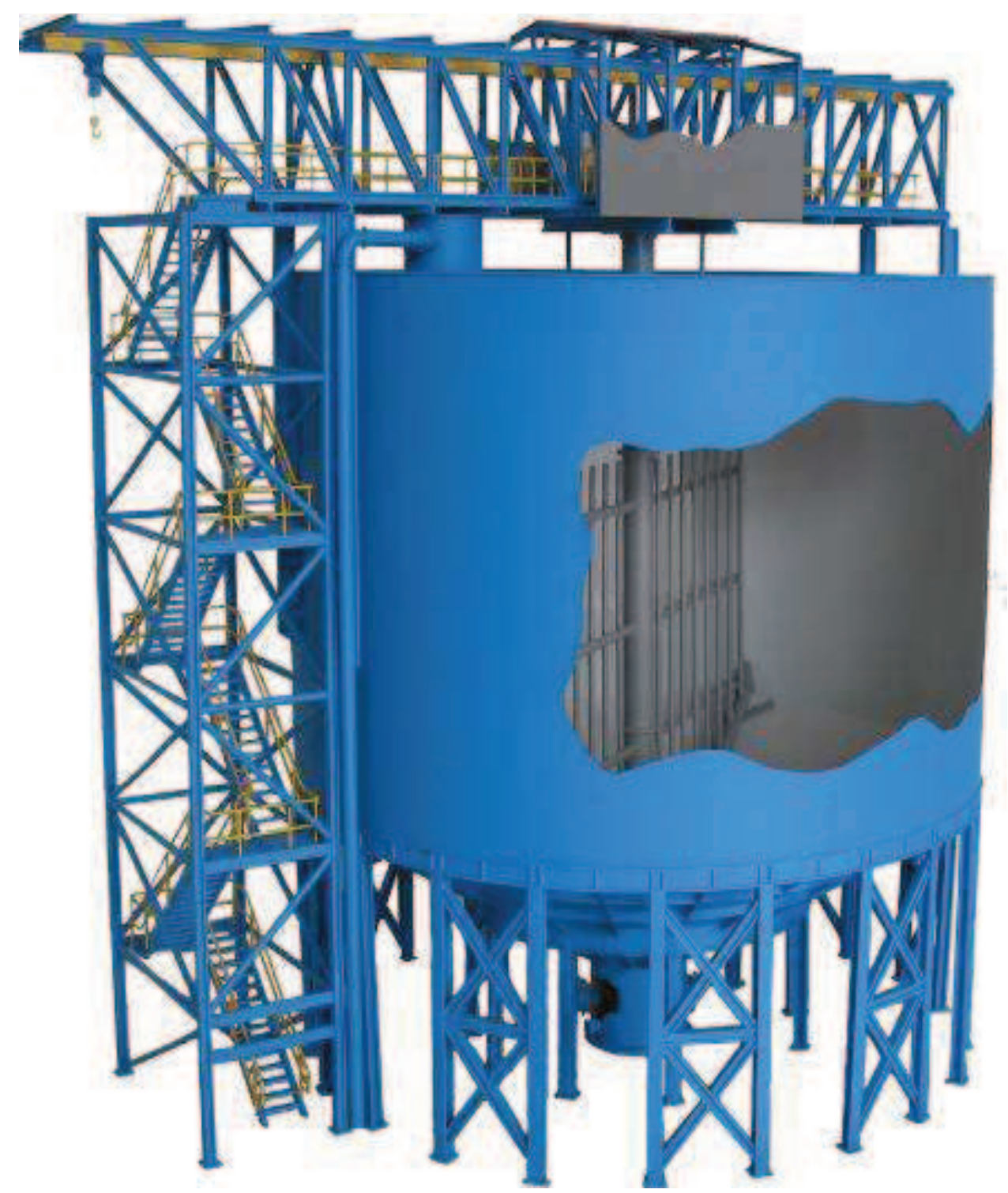

Figura 5-18: Espesador de cono profundo con tanque de acero y puente diametral. (Fuente: Cortesía de FLSmidth Dorr-Oliver Eimco Spain S.L.) 
La altura libre o parte superior del tanque hasta el borde superior de la virola lateral, es la altura de la parte no mojada del tanque. Para los espesadores de cono profundo es normalmente de 150$300 \mathrm{~mm}$, pero en general se pueden considerar mayores si se requieren, por ejemplo en el caso de condiciones de viento o por que se produzcan espumas en la superficie.

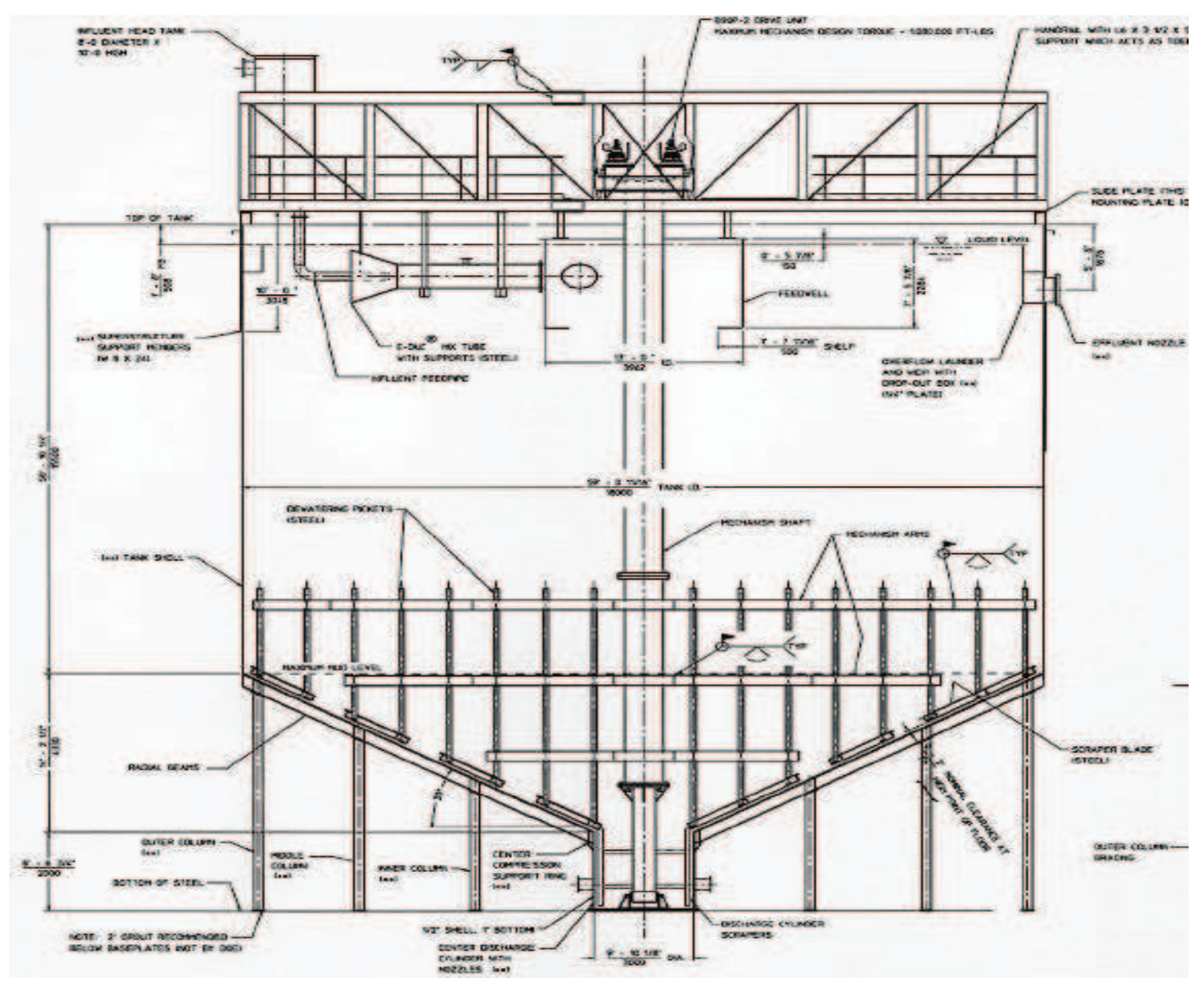

Figura 5-19: Geometría y partes de un espesador de pasta.

Fuente: Cortesía de FLSmidth Dorr-Oliver Eimco Spain S.L.)

Un croquis general de un espesador de pasta de 18 metros se puede ver en la figura 5-19: Geometría y partes de un espesador de pasta.

Los tanques de los espesadores necesitan para su funcionamiento un rebosadero, generalmente perimetral por donde se evacúa el líquido clarificado. Este rebosadero está formado por un canal perimetral que recoge todos el caudal del rebose para descargarlo generalmente por una caja de descarga colocada en la parte baja del canal y conectada a la brida de evacuación.

En la figura 5-20: Rebosadero perimetral en espesador de cono profundo; se muestra un sistema de rebose con pantalla almenada. Este tipo es el más común de todos aunque el diseño puede variar en caso de procesos especiales, como por ejemplo, con alto contenido en espumas en la superficie, etc. 


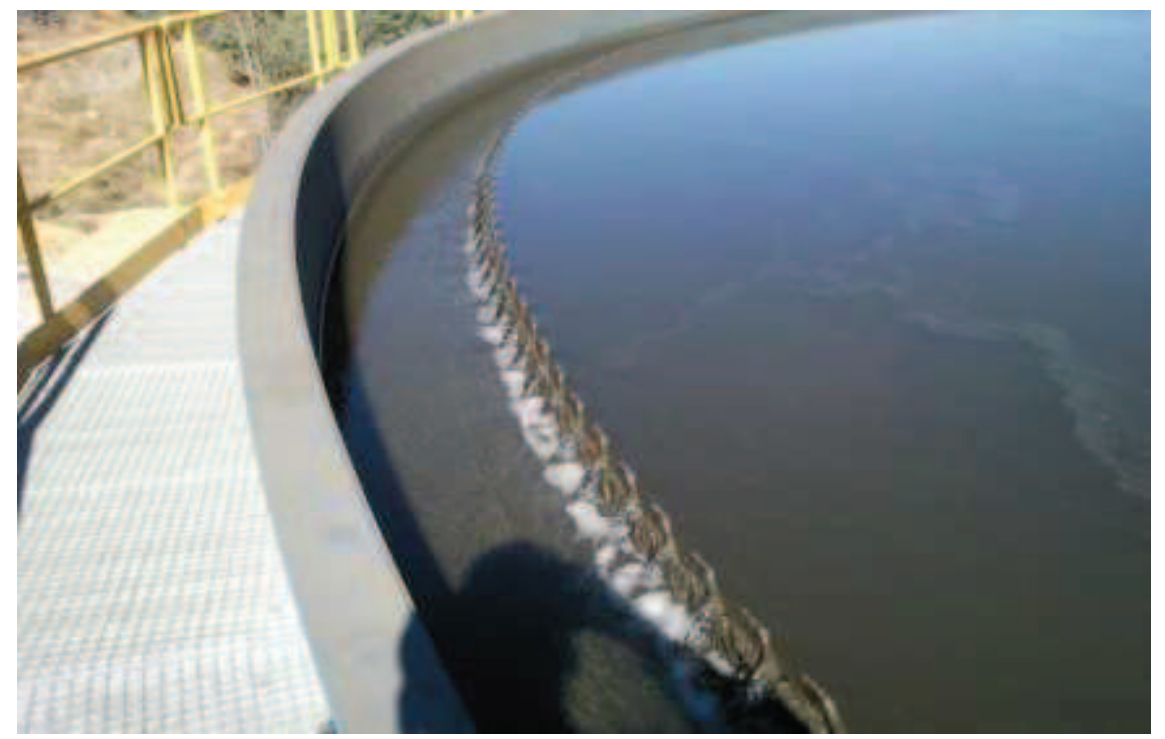

Figura 5-20: Rebosadero perimetral en espesador de cono profundo. Fuente: Cortesía de FLSmidth Dorr-Oliver Eimco Spain S.L.)

\subsubsection{Talud del fondo del espesador de pasta}

Los taludes del fondo normalmente de forma estándar se diseñan con ángulos de $30^{\circ} \circ 45^{\circ}$, como norma general en los espesadores de cono profundo. El criterio para elegir uno u otro es la distribución de partículas en la alimentación y el coste del equipo. Para tanques mayores de 12 metros de diámetro, el coste adicional de seleccionar un fondo de $45^{\circ}$ puede ser significativo en el coste total. En la figura 5-21: Detalle del fondo de espesador de pasta; se aprecia la inclinación del fondo de un espesador de cono profundo de 18 metros de diámetro, con fondo inclinado $30^{\circ}$. Esta inclinación varía con la geometría del tanque así como con los datos de proceso previstos: tipo de material a tratar, contenido en sólidos previsto, etc.

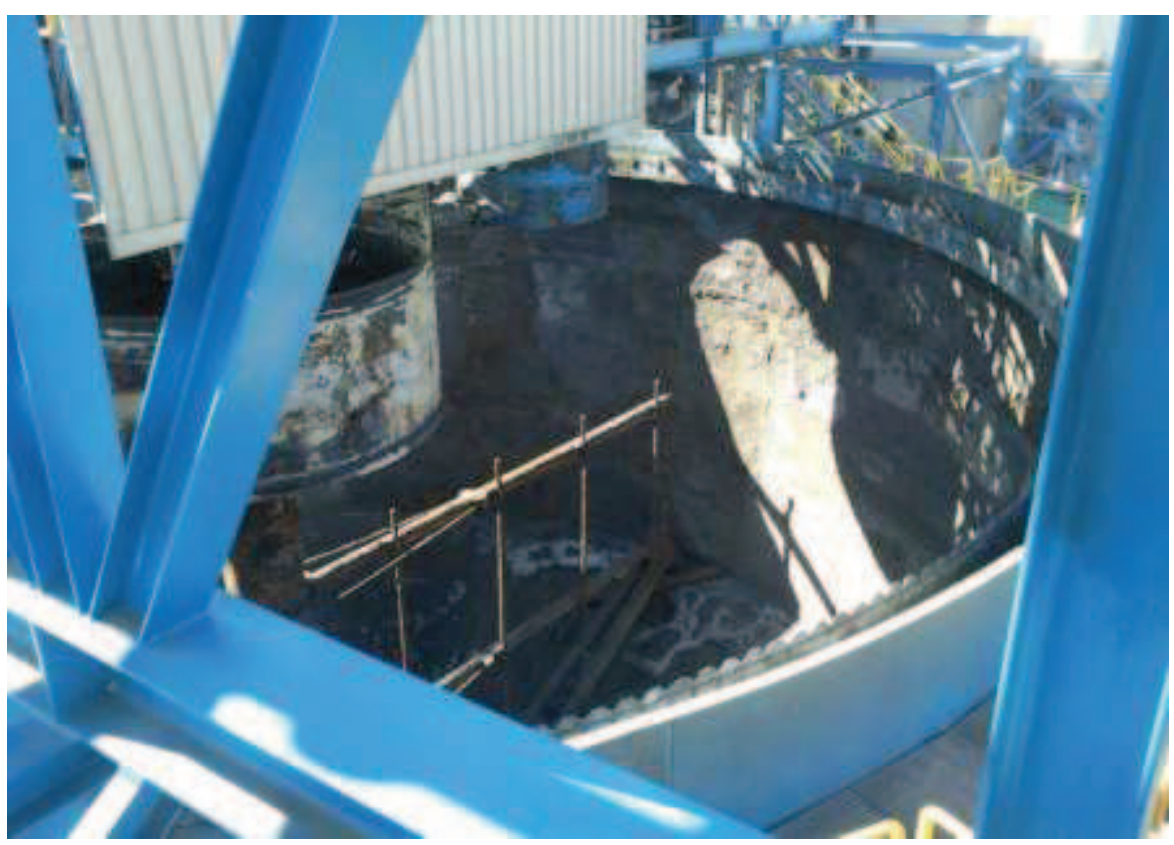

Figura 5-21: Detalle del fondo de un espesador de pasta. Fuente: Cortesía de FLSmidth Dorr-Oliver Eimco Spain S.L.) 


\subsubsection{Tiempo de residencia de los lodos en el espesador de pasta}

El parámetro clave de diseño que más influye sobre la densidad del lodo en el hundido que se puede alcanzar es el volumen de pasta y por tanto el tiempo de residencia de esta pasta. E tiempo de residencia del lodo está influenciado por la velocidad de giro, el tipo de rasquetas y la compresión de la pasta, es decir, por la altura total de la capa de lodos. Los lodos de partículas finas o la forma de las partículas, lamas (arcillas) tienden a estar más influenciadas por el primero y los más gruesos por la forma de los sólidos.

Determinado el tiempo de residencia de los lodos en el laboratorio es relativamente fácil si se simulan los efectos de la compresión sobre el lodo con la profundidad del lecho; por tanto, es preferible realizar estimaciones en equipos de laboratorio que reproduzcan el espesador de pasta. Realizar un ensayo en planta piloto será importante para proporcionar una estimación del tiempo de residencia requerido con gran precisión. Los datos empíricos hasta la fecha indican una escala para el tiempo de residencia del lodo de 1:1 entre la planta piloto y el equipo real. Se puede ser conservadores y añadir un $20 \%$ de tiempo de residencia, siendo usual, especialmente en operaciones que existan variaciones del tipo de material alimentado al espesador.

En ausencia de ensayos piloto, como norma de diseño se tomarán 8 horas de tiempo de residencia como parámetro conservador en el diseño, si bien este tiempo se puede aumentar en el caso de materiales con baja densidad o granulometrías muy finas.

\subsubsection{Diseño del cilindro de descarga}

En general en los espesadores de pasta y espesadores de alta densidad del hundido (HDT), se diseñan con un cilindro de descarga a diferencia de los espesadores convencionales que se diseñan con un cono de descarga. Este cilindro de descarga se diseña con los siguientes objetivos:

a) Proporcionar una salida para la pasta desde el tronco central del espesador.

b) Proporciona un espacio libre para montar el eje del equipo, sobre el que girarán las rasquetas y el mecanismo de piquetas.

c) Proporciona conexiones para extraer y recircular la pasta en caso que el proceso lo requiera.

d) Permite el acceso a la parte baja del espesador a través de bocas de hombre para mantenimiento y limpieza. Ver figura 5-22: Boca de hombre en cilindro de descarga de un espesador de pasta. 


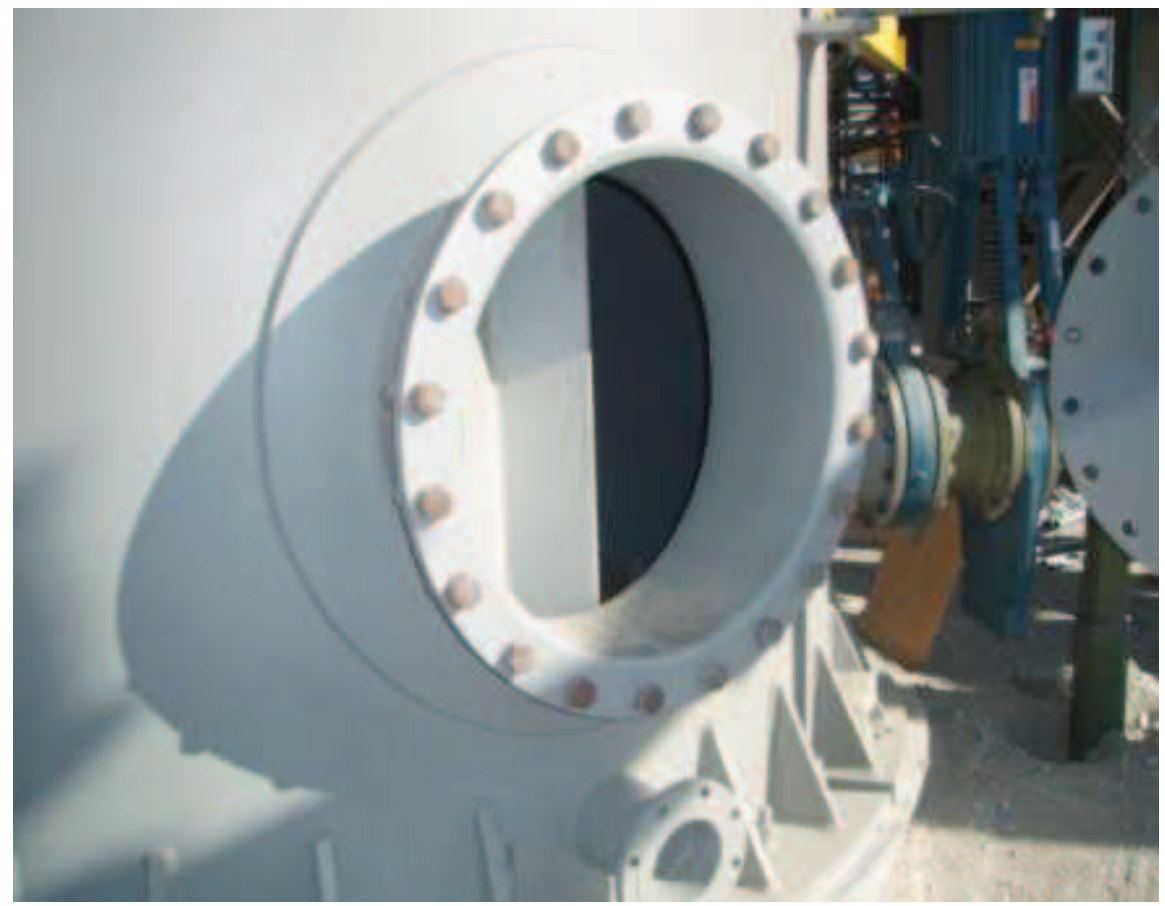

Figura 5-22: Boca de hombre en cilindro de descarga de un espesador de pasta. Fuente: Cortesía de FLSmidth Dorr-Oliver Eimco Spain S.L.)

El diámetro del cilindro de descarga es calculado por la velocidad en la retirada de lodos espesados descontando el volumen del eje central y sistema de apoyo. El tamaño y diámetro será el que se adapte a esa velocidad que se toma como criterio, aproximadamente tomando unidades de 0,5 en 0,5 metros. La altura del cilindro de descarga debe de ser aquella que permita colocar todas las conexiones, no siendo inferior nunca a 2 metros de altura como norma general.

La boca de salida para descarga y recirculación del hundido deben de estar tan bajas como sean posible y práctico. Donde fuera posible se colocarán dos boquillas de descarga del cilindro, más o menos juntas.

Si se requiere una recirculación de la pulpa, la boca de entrada de la recirculación en el cilindro de descarga estará colocada tan alta como sea posible en el cilindro de descarga y cercana a los $180^{\circ}$ de la salida como sea posible. Los requerimientos para la recirculación serán determinados caso por caso, basado preferentemente en las simulaciones de la planta piloto. En general, el propósito de la recirculación es para mantener fluyendo los lodos espesados mediante la rotura de los flóculos, haciendo disminuir la tensión de fluencia de la pasta en el lecho de lodos. La recirculación tiene que ser más significativa en las operaciones con alto ratio de adición de floculantes o en pastas de alta viscosidad, donde se recomienda siempre la instalación de una recirculación de lodos.

La recirculación puede ser útil incluso en aquellos lodos que no necesiten ser recirculados, debido a que este proceso proporciona mejor control del equipo y permite variar las características reológicas de la pasta. Colocando un medidor de densidad en el hundido y un medidor de presión en la línea de recirculación, se puede monitorizar la densidad del hundido y la viscosidad durante los periodos en los que no se retira lodos espesados, por ejemplo en las puestas en marcha o en paradas en la extracción de pasta. 
En todos los cilindros de descarga será requerida una boca de hombre de dimensiones estándar para acceder al interior del cilindro de descarga.

\subsubsection{Diseño del mecanismo y rasquetas}

Diseño de rasquetas

Existen tres tipos principales de rasquetas y brazos para el mecanismo de los espesadores de cono profundo.

a) El tipo "Steds" con o sin piquetas hasta la parte alta

b) Sin rasquetas del fondo, pero con rasquetas hasta la parte superior

c) Tipo Alcan, utilizado en la industria del aluminio.

Para las operaciones fuera del sector de la alúmina, los mecanismos del espesador que se instalan son sobre puente, con eje vertical de accionamiento y miembros simples de brazos con rasquetas en la parte inferior. Las barras verticales son largas hasta la parte superior del lecho de lodos aproximadamente. Debido a las grandes fuerzas de arrastre generadas por la viscosidad del lodo, es importante diseñar los espesadores con los mecanismos de bajo perfil para minimizar el par de giro necesario. Los mecanismos en celosía se deben evitar cuando se trate de espesadores con lodos muy espesos. En la figura 5-23: Mecanismo de un espesador de cono profundo; se muestran las partes internas que componen un espesador de de este tipo.

Para espesadores con $45^{\circ}$ de talud de fondo con partículas muy finas determinadas en su análisis granulométrico es posible considerar los mecanismos sin cuchillas inferiores. En el diseño el rodamiento del brazo que soporta la carga es horizontal y está localizado más arriba en el tanque y adyacente al nudo. Las barras o piquetas verticales se extienden en toda la vertical del tanque y son soportadas en la base por un pequeño puntal. 


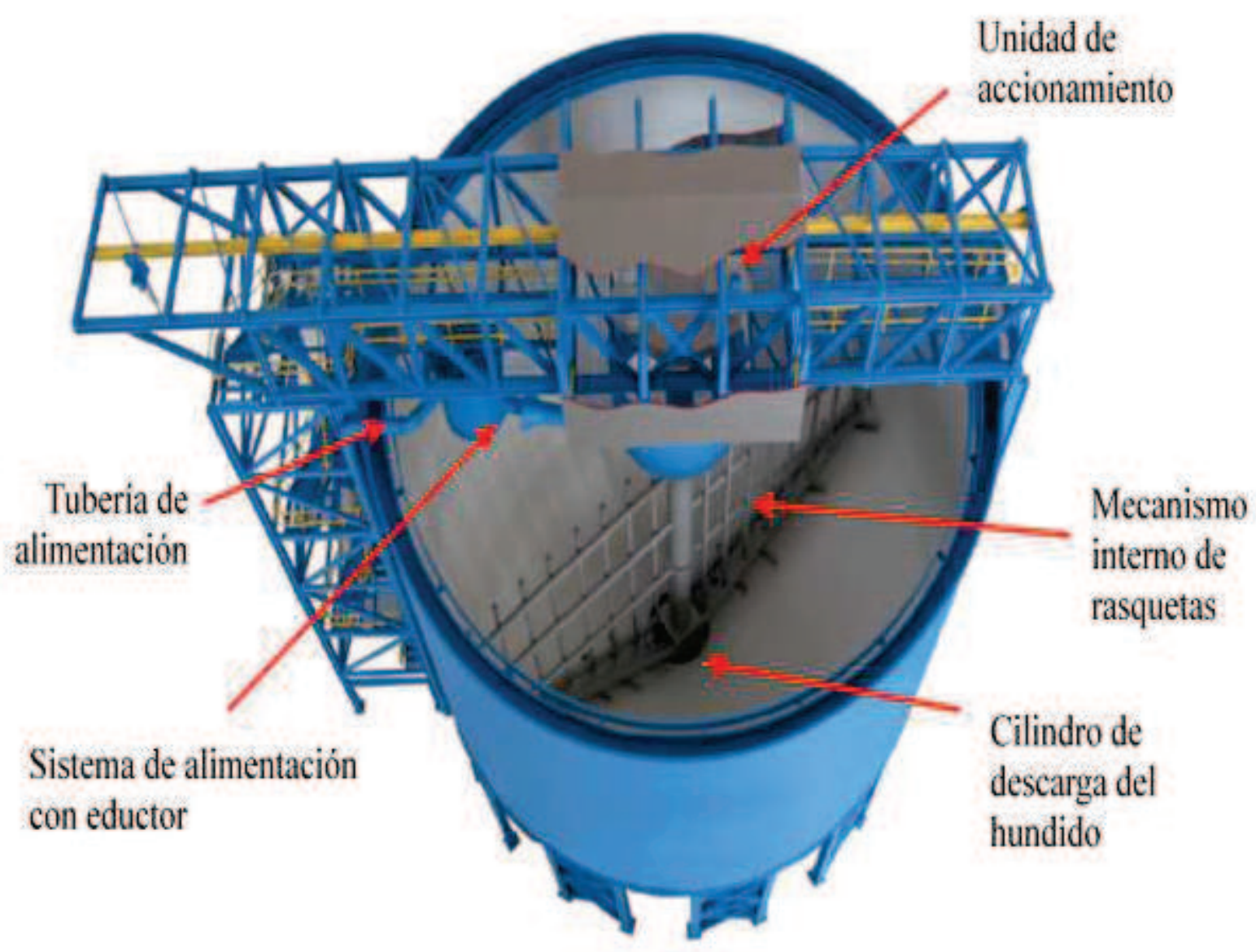

Figura 5-23: Mecanismo de un espesador de cono profundo.

Fuente: Cortesía de FLSmidth Dorr-Oliver Eimco Spain S.L.)

\subsubsection{Diseño del sistema de rasquetas en el espesador de pasta}

El ángulo de las rasquetas será normalmente de $30^{\circ}-40^{\circ}$ desde la perpendicular a los brazos de las rasquetas. Otro tipo de ángulos pueden ser considerados si las cuchillas tienen que empujar partículas gruesas segregadas en el fondo. Las cuchillas o rasquetas del fondo, no son requeridas generalmente para los tanques que tengan más de $45^{\circ}$ de talud. Las rasquetas son requeridas en todos los tanques que tengan un talud menor de $45^{\circ}$. Las rasquetas se colocan en sobre soportes dispuestos en el brazo para permitir su recambio en caso de desgaste.

Las cuchillas serán dimensionadas para proporcionar entre el $15 \%$ y el $30 \%$ de la capacidad de rascado del fondo.

La capacidad de arrastre es definida como el volumen arrastrado por la fila de rasquetas interior (aquella inmediatamente adyacente al cilindro de descarga) en un minuto, dividido por el flujo de pasta que sale del hundido del espesador a la densidad de diseño. Cada conjunto de rasquetas continuo a este primero, debe de ser diseñado para entregar el mismo volumen arrastrado, como las cuchillas de su conjunto interior. En la figura 5-24: Mecanismo interno en un espesador de cono profundo; se muestra la disposición de las rasquetas inferiores y las piquetas a uno de los brazos del mecanismo. 


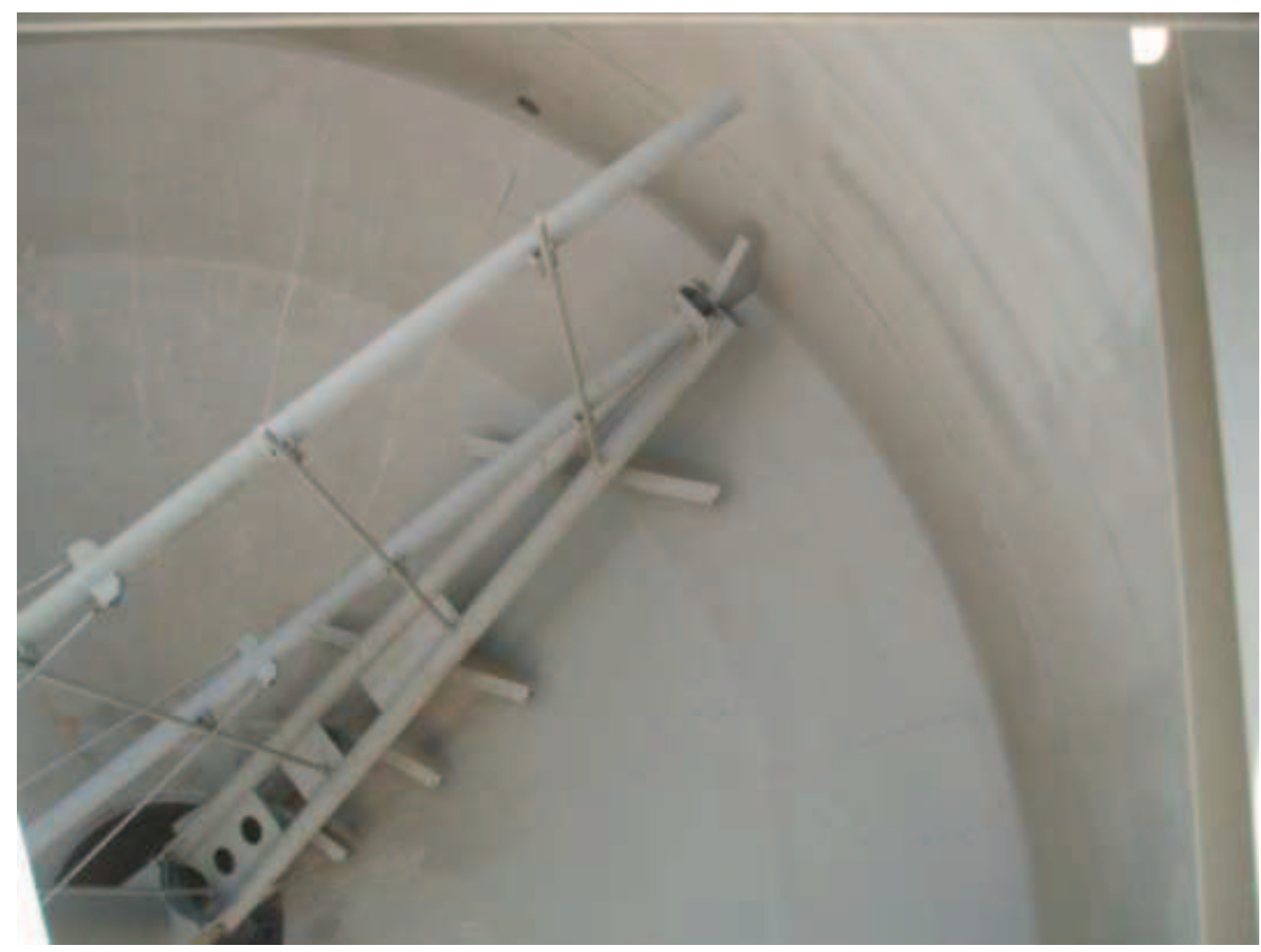

Figura 5-24: Mecanismo interno de un espesador de cono profundo. Fuente: Cortesía de FLSmidth Dorr-Oliver Eimco Spain S.L.)

Como resultado las cuchillas inferiores reducen el tamaño, desde la parte interior del espesador hacia la periferia. Se ha demostrado que las cuchillas más cortas y profundas, son más eficientes, sin embargo, cuando se dimensionan estas cuchillas, se hace con una profundidad mínima de 150 $\mathrm{mm}$ y máxima de $450 \mathrm{~mm}$. También es normal en algunos espesadores de pasta instalar las dos filas de rasquetas más interiores con forma curva de manera que se mejora la eficiencia de arrastre en la parte interior del mecanismo, facilitando la extracción del lodo espesado.

\subsubsection{Diseño del mecanismo del espesador de pasta}

Las piquetas se instalan para incrementar el ratio de desaguado del lecho de lodos mediante la creación de una zona de baja densidad en el espacio tras la piqueta para permitir el agua que escape y suba hacia la zona clarificada. El efecto de las piquetas es más significativo en los lodos de material fino o en arcillas, los cuales no pueden expulsar el agua debido a la baja porosidad que tienen. Es posible reducir a la mitad el tiempo de residencia de algunos lodos mediante la instalación de estas piquetas de gran longitud, llegando incluso al límite de la zona de seguridad. Es importante señalar que estos lodos no responden bien a la compresión si se incrementa la profundidad del lecho de lodos. Los lodos formados de partículas gruesas son mas influenciables por la capa de lodos y el beneficio de las piquetas puede ser menos apreciable.

La altura de las piquetas y su diseño es una función de la distribución de tamaños de las partículas del material a sedimentar y espesar. Las piquetas hasta la parte superior se dispondrán hasta 1 
metro por debajo de la campana de alimentación. El soporte superior de estas piquetas largas será diseñado a 0.5 metros sobre el máximo nivel del lecho de lodos. Es importante soportar las piquetas con un brazo superior tan alto como sea posible parta prevenir que el arrastre las doble. Las piquetas se suelen fabricar en tubo de entre $40 \mathrm{~mm}$ y $90 \mathrm{~mm}$ de diámetro exterior y con espesores gruesos de tubo, según el trabajo a desarrollar. Las piquetas se espacian 1,0 - 2,0 metros entre centros en cada brazo de rasquetas y serán colocadas por la mitad en el espacio entre dos brazos. Por tanto en cada revolución de los brazos, una piqueta irá a través del lecho de lodos cada 1 ó 0,5 metros entre el eje y el final de los brazos.

\subsubsection{Especificación del par de accionamiento}

La especificación del par de accionamiento o arrastre debe ser hecha en conjunto con la selección de la cabeza de accionamiento del equipo. Es importante que el par del mecanismo de rasquetas sea seleccionado en base a la máxima capacidad de par. El mecanismo tiene que poder operar continuamente a la máxima capacidad sin reducción de la vida del mecanismo. La unidad de accionamiento es seleccionada en base a la vida del engranaje y con la máxima capacidad de par, las dos condiciones.

La vida útil de una cabeza de accionamiento se reduce ya que el continuo par de operación a lo largo de la vida va aumentando, por lo que se deben de diseñar con altos factores de seguridad. Si se selecciona una cabeza grande, con alto factor $\mathrm{K}$, para proporcionar una vida útil larga es importante no incrementar en el mecanismo un elevado factor de $\mathrm{K}$ para el mismo valor ya que esto añade peso innecesario al mecanismo y al puente.

La unidad de accionamiento tiene un factor "K" de $300 \mathrm{lb} / \mathrm{ft}$ o superior. Este par extremadamente elevado es capaz de mover las rasquetas y tratar las pulpas de tan alta densidad y con un alto lecho de lodos acumulados en el tanque. En general no tienen sistema de izado de las rasquetas y de hecho no se recomienda que tenga sistema de izado por el comportamiento de la pasta y los sólidos contenidos en ella. El diseño de los brazos de rasquetas se diseña para minimizar el par necesario, maximizar la liberación del licor contenido y mover la pulpa de forma efectiva sin crear canales en el lecho de lodos.

Para la selección y el diseño de la cabeza de accionamiento del espesador de pasta, se emplea como norma general para el diseño de equipos la expresión 5-17:

$$
T=K \cdot D^{2}
$$

Donde:

$$
\begin{aligned}
& T=\text { Par de accionamiento en libras } \cdot \text { pie } \\
& K=\text { constante expresada en libras/pie generalmente } \\
& D=\text { Diámetro del tanque expresado en pies }
\end{aligned}
$$

Para un análisis más detallado del diseño del accionamiento, se puede emplear un método iterativo en el que se tengan en cuenta diversos factores, como son:

a) Diseño de los brazos, rasquetas inferiores y piquetas del mecanismo interno del espesador. 
b) Análisis de la capacidad de arrastre de las rasquetas sobre el lecho de lodos.

c) Par neto producido por cada componente del mecanismo considerando la densidad del lodo espesado y la tensión de fluencia.

d) Factores de seguridad previstos para sobredimensionar el mecanismo del espesador.

Una vez que se han calculado todos los factores anteriores, se selecciona la unidad de accionamiento del espesador y se analizan las variables del proceso para confirmar que la cabeza seleccionada tiene el par necesario para hacer girar el conjunto de mecanismo interno del espesador.

Por tanto, el proceso comienza con el cálculo de la capacidad de arrastre de las rasquetas inferiores que viene determinada por las dimensiones de éstas y la velocidad de giro del mecanismo. En el modelo de cálculo se requieren los siguientes datos: densidad del lodo sedimentado, la tensión de fluencia máxima y la viscosidad plástica del lodo en el hundido del espesador. Todos estos valores deben ser calculados a partir de muestras de laboratorio y para diferentes concentraciones de sólidos, según lo esperado por el ingeniero de proceso.

En general el uso de un factor $\mathrm{K}=300 \mathrm{lb} / \mathrm{ft}$, para espesadores de pasta o cono profundo proporciona un valor conservador del par de accionamiento necesario en el espesador y por tanto la cabeza seleccionada tendrá siempre un par adecuado al proceso que incluya cierto factor de seguridad. En algunos casos, donde los mecanismos requieren de un cálculo preciso será necesario utilizar el proceso iterativo descrito anteriormente.

Actualmente existen dos modelos de cabeza de accionamiento para espesadores de pasta y espesadores de alta densidad "HDT": las cabezas de soporte mediante columna y las cabezas de soporte sobre el puente.

El uso de una u otra cabeza vendrá determinado por el tipo de proceso, el par necesario y el diámetro del espesador. En la tabla 5-2: Valores típicos del factor K; se detallan los valores típicos de este factor en diversos equipos de espesado en función de la tarea requerida y de las características del material a tratar. En el caso de los espesadores de alta densidad en el hundido y de los espesadores de pasta, este valor de K puede llegar hasta $300 \mathrm{lb} / \mathrm{ft}$ para asegurar el arrastre del mecanismo sumergido en el lecho de lodos.

Las cabezas de accionamiento de tipo columna, el accionamiento se monta sobre una columna central que soporta el peso de la cabeza y soporta el mecanismo de rasquetas, además del peso de la pasarela entre la virola lateral y la parte central del espesador. En la figura 5-25: Espesador de alta densidad con cabeza de accionamiento tipo columna; se muestra el conjunto característico de esta configuración.

Las cabezas de accionamiento de sobre puente, se montan sobre el mismo puente diametral del espesador que soporta tanto el accionamiento como el mecanismo de rasquetas del espesador. 
Espesado en pasta.

Tabla 5-2: Valores típicos del factor K.

\begin{tabular}{|c|c|c|c|c|c|c|}
\hline \multirow[b]{3}{*}{ CONCEPTO } & \multicolumn{6}{|c|}{ Clasificación del trabajo y valores típicos en espesadores } \\
\hline & \multicolumn{4}{|c|}{ Espesadores convencionales, HCT y HRT } & \multicolumn{2}{|c|}{$\begin{array}{l}\text { Espesadores cono } \\
\text { profundo y HDT }\end{array}$} \\
\hline & Ligero & Normal & Fuerte & Extrafuerte & $\begin{array}{c}\text { Alta } \\
\text { densidad } \\
\text { HDT }\end{array}$ & Pasta \\
\hline $\begin{array}{l}\text { Carga de sólidos en } \\
\mathrm{m}^{2} / \mathrm{t} / \text { día }\end{array}$ & $>5$ & $1.4-5.0$ & $0.5-1.4$ & $<0.5$ & $0.25-1.5$ & $0.25-1.5$ \\
\hline $\begin{array}{l}\text { Concentración en el } \\
\text { hundido } \\
\text { (\% sólidos) }\end{array}$ & $<5 \%$ & $5 \%-30 \%$ & $30 \%-50 \%$ & $>50 \%$ & $55 \%-65 \%$ & $60 \%-85 \%$ \\
\hline $\begin{array}{l}\text { Porcentaje de sólidos } \\
\text { inferior a } 74 \text { micras }\end{array}$ & $100 \%$ & $85 \%-100 \%$ & $50 \%-85 \%$ & $<50 \%$ & $>60 \%$ & $>60 \%$ \\
\hline $\begin{array}{l}\text { Porcentaje de sólidos } \\
\text { superior a } 200 \text { micras }\end{array}$ & $0 \%$ & $0 \%-5 \%$ & $5 \%-15 \%$ & $>15 \%$ & $<10 \%$ & $<10 \%$ \\
\hline $\begin{array}{l}\text { Peso específico de } \\
\text { sólidos }\end{array}$ & $1.0-1.25$ & $1.25-3.0$ & $3.0-4.0$ & $>4.0$ & $>3.0$ & $>3.0$ \\
\hline $\begin{array}{l}\text { *Valores típicos de K } \\
\text { en } \mathrm{N} / \mathrm{m}\end{array}$ & $15-58$ & $73-131$ & $146-292$ & $>292$ & $145-218$ & $>435$ \\
\hline $\begin{array}{l}\text { *Valores típicos de K } \\
\text { en libras/pie }\end{array}$ & $1-4$ & $5-9$ & $10-20$ & $>20$ & $100-150$ & $>300$ \\
\hline
\end{tabular}

(Fuente: Elaboración propia)

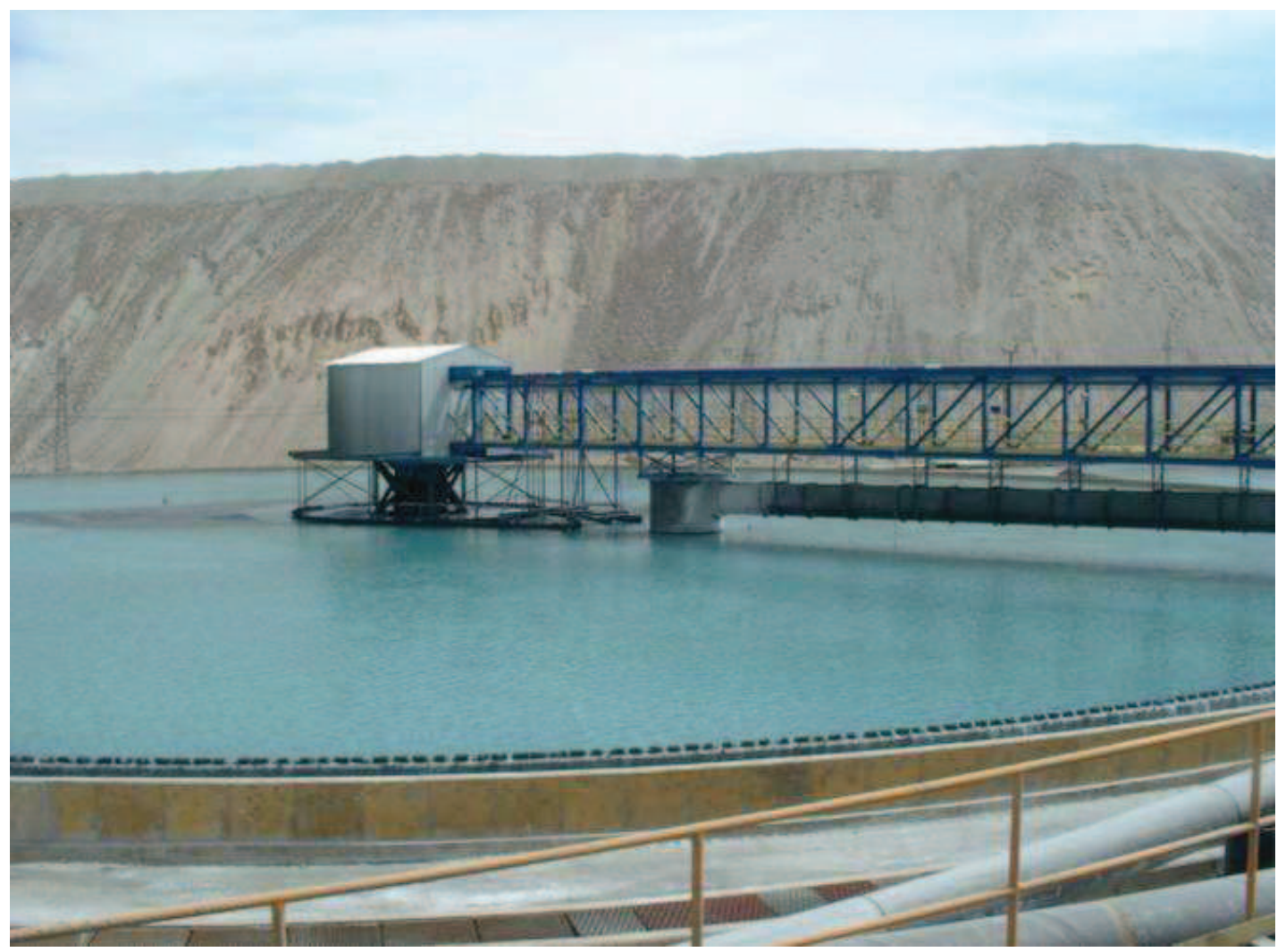

Figura 5-25: Espesador de alta densidad con cabeza de accionamiento tipo columna.

(Fuente: Cortesía de FLSmidth S.A.) 
En la figura 5-26: Cabeza de accionamiento tipo puente en espesador de pasta; se muestra el conjunto característico de esta configuración, donde el puente diametral está soportando el peso del mecanismo y del accionamiento.

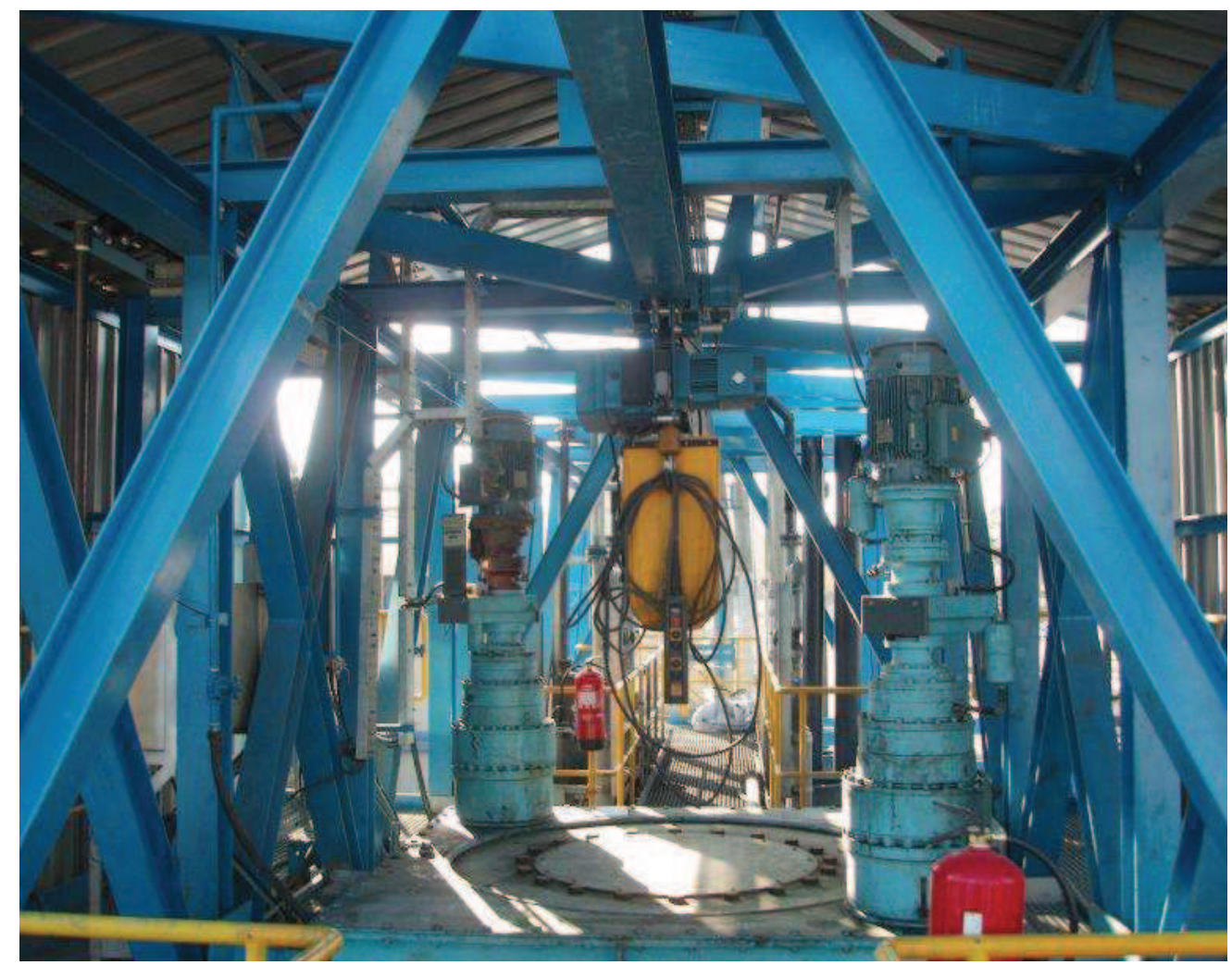

Figura 5-26: Cabeza de accionamiento tipo puente en espesador de pasta (Fuente: Cortesía de FLSmidth S.A.)

Las cabezas de accionamiento sobre puente, se montan sobre el mismo puente diametral del espesador que soporta tanto el accionamiento como el mecanismo de rasquetas del espesador.

El par de arrastre es generado por las fuerzas de accionamiento en los miembros del mecanismo y en las cuchillas en su movimiento dentro del lecho de lodos y es por tanto proporcional al límite de fluencia del lodo y a la sección de las rasquetas y piquetas. Un par adicional se puede producir al segregarse los granos más gruesos en la parte interior del espesador. Este material que presenta propiedades diversas, puede generar un alto par en proporción con el volumen arrastrado por las rasquetas. Debido a la alta densidad del lodo de alrededor en los procesos con espesadores de cono profundo, la segregación de partículas gruesas y arenas es poco común a menos que haya una fracción importante en la alimentación del equipo.

En la tabla 5-3: Tipos de accionamiento; se detallan los pares nominales de diversos modelos de cabezas de accionamiento para espesadores de pasta fabricadas por la compañía FLSmidth DorrOliver Eimco. Una de las características principales en estos equipos, es que no se suelen montar dispositivos de elevación de rasquetas, debido al elevado peso del mecanismo, por lo tanto el par 
de accionamiento tiene que garantizar el giro del mecanismo, de ahí su alto valor del factor " $K$ " en el diseño de espesadores de pasta.

En una sección de las rasquetas, la falta de cuchillas en el mecanismo, si se emplea un fondo de $45^{\circ}$ tendrá menos par de accionamiento que un espesador con el fondo de $30^{\circ}$, el cual deberá llevar rasquetas. Igualmente, los mecanismos con rasquetas largas tendrán más par de accionamiento que aquellos con las rasquetas cortas.

El límite de fluencia del hundido perseguido en el equipo varía según las operaciones entre 100 y $400 \mathrm{~Pa}$. El par de accionamiento para estas operaciones puede variar ampliamente. Es importante considerar que el espesador puede generar durante periodos de operación inestable lodos con un alto límite de fluencia incluso si el límite de operación es inferior a $150 \mathrm{~Pa}$, por tanto es preferible el diseño con un factor "K" elevado.

Como regla general el mecanismo de los espesadores de cono profundo se diseña con un factor $\mathrm{K}$ de $300 \mathrm{lb} / \mathrm{ft}(435 \mathrm{~N} / \mathrm{m})$. Si se emplea otro factor $\mathrm{K}$, es importante considerar el análisis en la ingeniería de detalle del equipo para garantizar el par de accionamiento requerido en la operación.

En la figura 5-27: Cabeza de accionamiento; se muestra como son este tipo de partes para un espesador de pasta. En este caso se muestra un accionamiento por motorreductor hidráulico montado sobre el puente de un espesador.

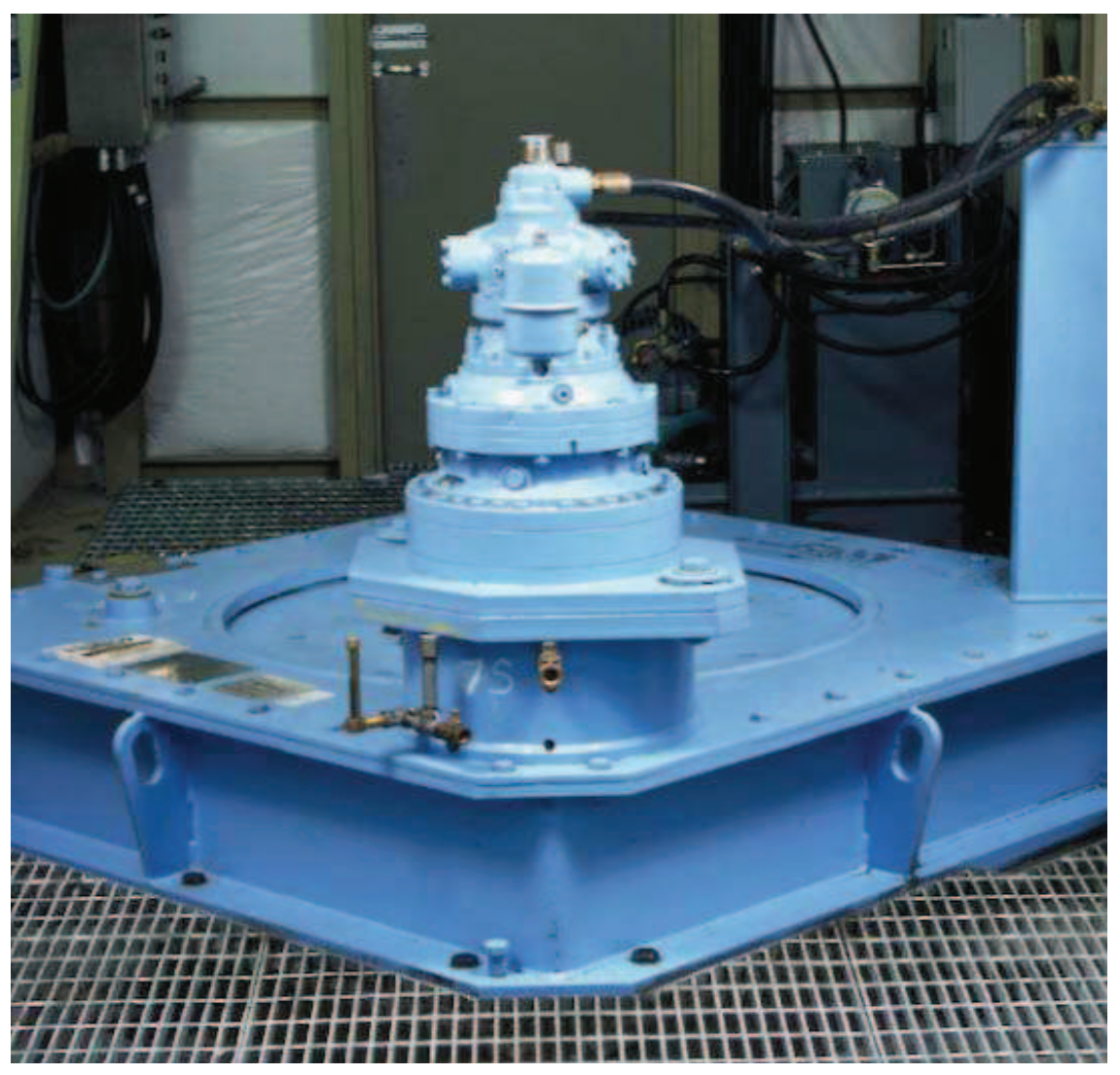

Figura 5-27: Cabeza de accionamiento.

(Fuente: Cortesía de FLSmidth S.A.) 
Tabla 5-3: Tipos de accionamiento.

\begin{tabular}{|c|c|c|c|}
\hline $\begin{array}{c}\text { Modelo } \\
\text { accionamiento }\end{array}$ & $\begin{array}{c}\text { Par Nominal } \\
(\mathrm{lb} \cdot \mathrm{ft})\end{array}$ & $\begin{array}{c}\text { Par Nominal } \\
(\mathbf{N} \cdot \mathbf{m})\end{array}$ & Tipo montaje \\
\hline B60P-1 & 240,000 & 324,000 & Sobre puente \\
\hline B60P-2 & 480,000 & 648,000 & Sobre puente \\
\hline B60P-3 & 720,000 & 972,000 & Sobre puente \\
\hline B60P-4 & 960,000 & $1,296,000$ & Sobre puente \\
\hline B90P-3 & $1,350,000$ & $1,822,500$ & Sobre puente \\
\hline B90P-4 & $1,800,000$ & $2,430,000$ & Sobre puente \\
\hline C84P-2 & 960,000 & $1,296,000$ & En columna \\
\hline C84P-3 & $1,440,000$ & $1,944,000$ & En columna \\
\hline C84P-4 & $1,920,000$ & $2,592,000$ & En columna \\
\hline C120P-2 & $2,400,000$ & $3,240,000$ & En columna \\
\hline C120P-3 & $3,600,000$ & $4,860,000$ & En columna \\
\hline C120P-4 & $4,800,000$ & $6,480,000$ & En columna \\
\hline C140P-5 & $8,333,333$ & $11,250,000$ & En columna \\
\hline C140P-6 & $10,000,000$ & $13,500,000$ & En columna \\
\hline
\end{tabular}

(Fuente: FLSmidth Dorr-Oliver Eimco Spain S.L.)

\subsubsection{Sistema de dilución y campana de alimentación}

Una de las claves para producir pasta o espesado de estériles en un espesador es asegurar que el diseño de la campana de alimentación y del sistema de dilución, generalmente necesario, del espesador proporciona las condiciones adecuadas de floculación. Esto implica que el diseño debe comprender al menos dos importantes soluciones en la forma de la campana para proporcionar:

a) Controlar el rango de variabilidad que presenta la alimentación, incluyendo las variaciones de caudal, contenido en sólidos, densidad del mineral y granulometría.

b) Reducir la energía cinética del caudal de pulpa entrante en el espesador y permitir la formación de los flóculos aumentando los tiempos de residencia previos a la sedimentación de las partículas.

c) Adicionar de forma correcta un floculante o una mezcla de floculantes para tratar los tipos de mineral existentes y las características químicas del agua. 
Siguiendo la investigación y aplicación en este área en los últimos años, uno de los fundamentos para la fabricación de pasta requiere un control importante de la floculación y también manejar de forma correcta cómo las partículas sólidas y el floculante son puestas en contacto.

Los sistemas de dilución con eductores de la alimentación o similares, están considerados actualmente como el mejor sistema de alimentación y adición de floculante para espesadores disponible. Con estos sistemas, las mejoras en la floculación son muy importantes para la formación de la pasta y conseguir los sólidos deseados en el hundido. Los espesadores de cono profundo son un avance más de los espesadores de alta capacidad y de alta densidad descritos anteriormente.

Las campanas de alimentación y floculación fueron desarrolladas en la década de 1970 como una mejora sobre las campanas de alimentación con la adicción de floculante en el interior de la propia campana. Las campanas de alimentación y floculación han avanzado desde los originales diseños de mezcla hidráulica pasando por las placas de inyección en el lecho de lodos. A finales de la década de 1980, las campanas de alimentación con ventanas de dilución y faldones fueron introducidas progresivamente en muchos espesadores de la época para aprovechar la mejora de la floculación con un menor contenido en sólidos en la alimentación. En 1990, se desarrolló el primer sistema de alimentación con eductores, como sistema de alimentación con dilución usado para el espesado de estériles y en los espesadores de lodos rojos en la industria de la alúmina. Después de un número de mejoras en el diseño original y de instalaciones, el sistema de eductores fue introducido en los espesadores de minería metálica y otros procesos que requieren de la dilución previa al espesado de los materiales. Desde entonces es considerado como uno de los mejores y más eficientes sistemas de alimentación y floculación en la industria minera.

En algunos casos se puede llegar a ahorrar del orden de varios cientos de miles de euros anuales en grandes operaciones mineras al reemplazar otros sistemas más antiguos por el sistema de dilución con eductores. En la figura 5-28: Mecanismo interno de un espesador de cono profundo de 18 metros; se muestra visto desde abajo, el eje central que acciona el mecanismo y el sistema de alimentación con la campana de alimentación en el centro y el canal del sistema de educción. 


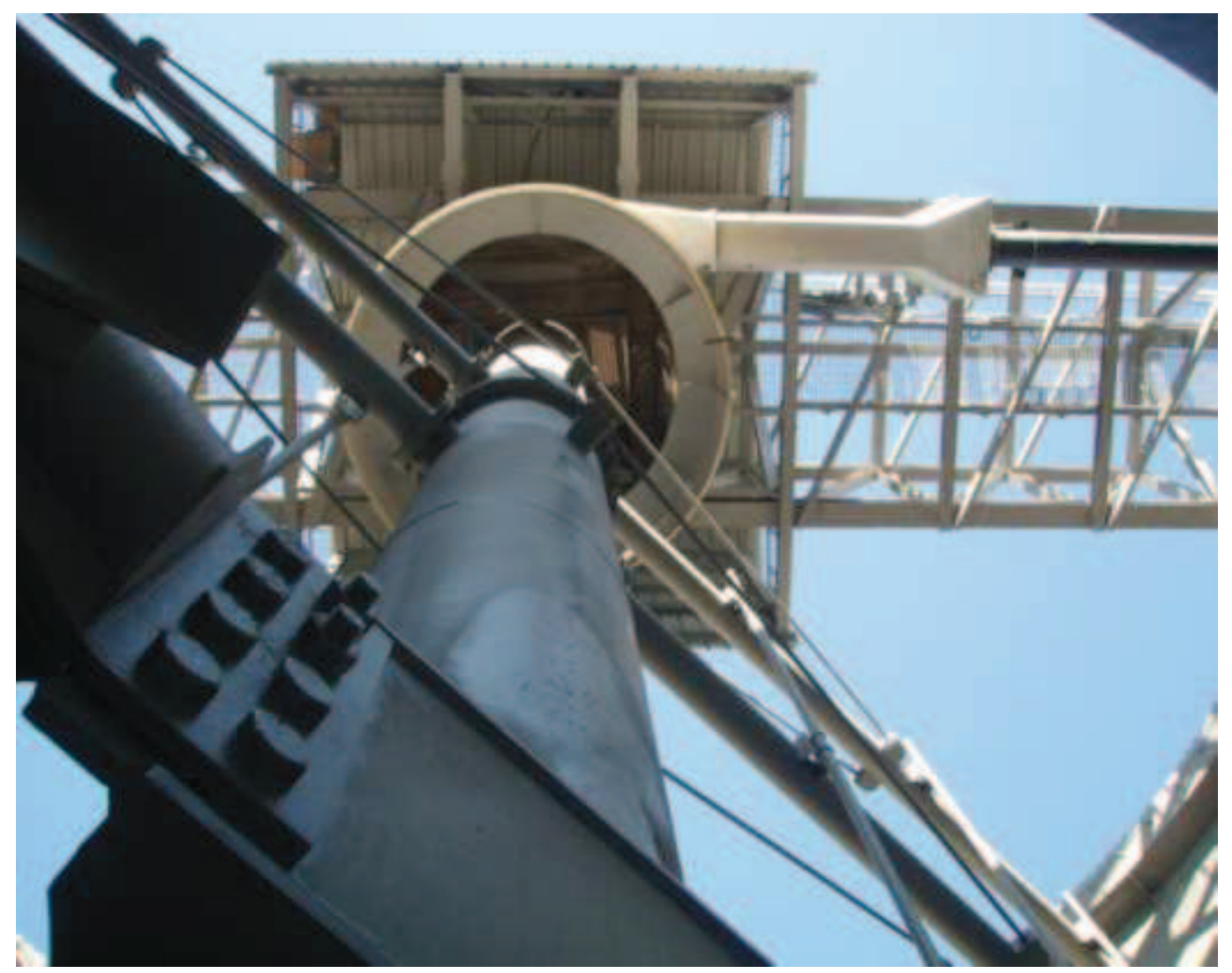

Figura 5-28: Mecanismo interno de un espesador de cono profundo de 18 metros.

(Fuente: Cortesía de FLSmidth S.A.)

Existen varios sistemas de dilución de la alimentación en espesadores de pasta, cada uno presenta una filosofía de operación aunque los objetivos son los mismos: aumentar la capacidad de espesado del equipo y reducir el consumo de floculante.

Las ventajas de estos sistemas de alimentación y dilución son las siguientes:

a) La alimentación es diluida y mezclada antes de alcanzar la campana de alimentación. Esto permite la floculación tenga lugar a la concentración de alimentación ideal para el producto requerido y no a una concentración desconocida que depende de la localización y grado de turbulencia en la campana de alimentación. Algunas otras campanas de alimentación se diseñan para diluir y flocular en la misma zona de mezcla.

b) El sistema de dilución proporciona un control más preciso de la pulpa de alimentación mejor incluso que el diseño de faldones o el diseño de ventanas. El sistema de eductores, es menos propenso a la acumulación de sólidos por incrustaciones que los faldones o ventanas.

c) El floculante puede ser añadido a más bajas concentraciones que con otros tipos de campanas de alimentación. Esto es debido a que el floculante es añadido en múltiples puntos a lo largo del camino de entrada a la campana de alimentación. 
d) El sistema de múltiples puntos de inyección del floculante permiten un mayor control del proceso de floculación y un mejor control del desarrollo de la operación de espesado. Permite la formación, maduración y aumento de las partículas floculadas a lo largo de su recorrido del sistema de dilución.

Es importante el diseño de la colocación de los puntos de adicción de floculante en el sistema de eductores, para conseguir una buena floculación de la pulpa y alcanzar el proceso de crecimiento y maduración del flóculo antes de alcanzar la campana de alimentación. Como norma general, el diseño viene dado por dos boquillas a la entrada del canal, una boquilla en la parte intermedia del canal del sistema y una boquilla de floculante en la campana de alimentación. El diámetro de las boquillas de adicción de floculante debe de ser diseñado para mantener una velocidad del fluido de entre 0,3 y $1,0 \mathrm{~m} / \mathrm{s}$, siendo recomendable una boquilla siempre superior a los $40 \mathrm{~mm}$ de diámetro en todos los puntos de adicción de floculante para evitar atascos en la tubería. En la figura 5-29: Sistema de adición de floculante; se muestra un dispositivo de este tipo montado en un espesador de pasta.

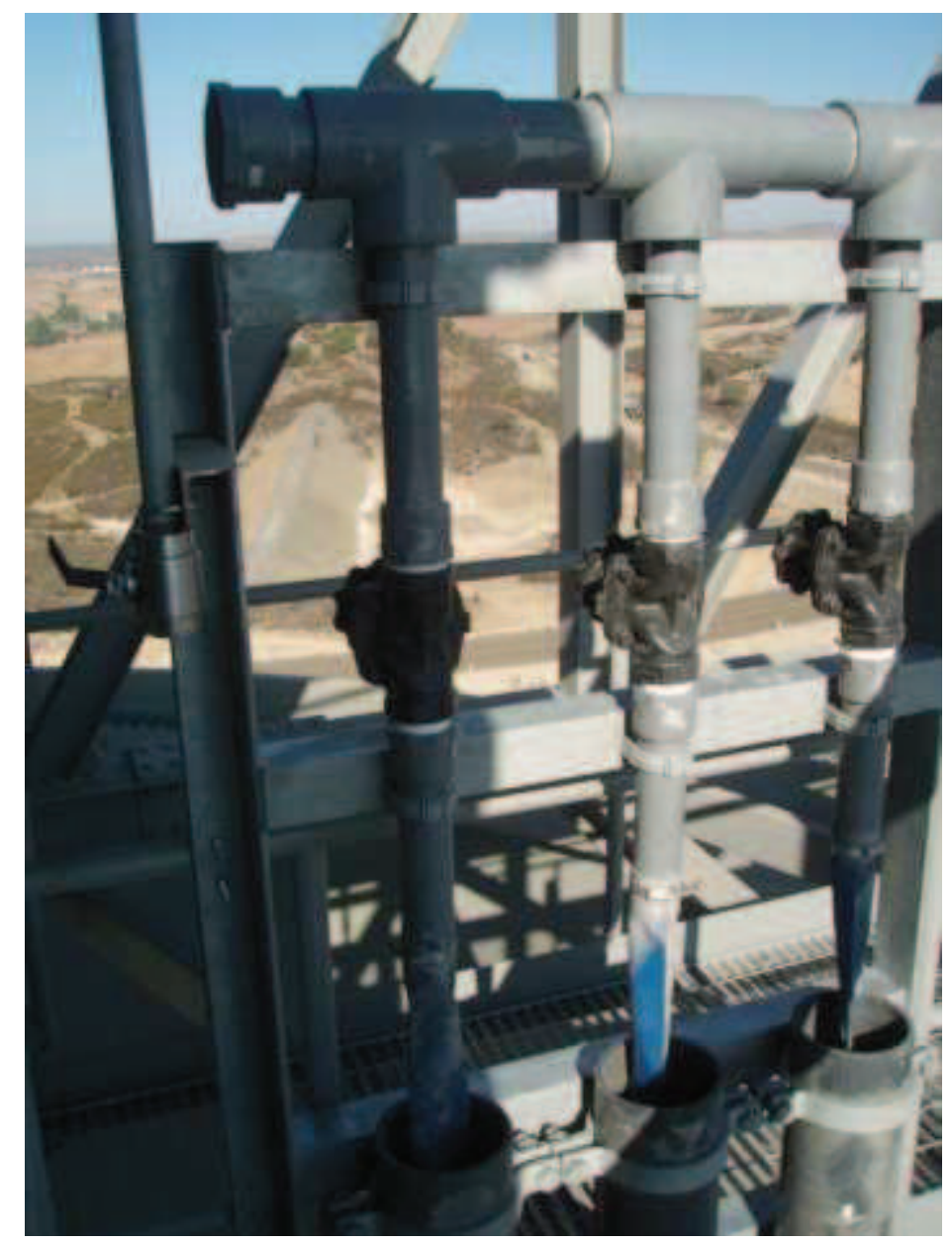

Figura 5-29: Sistema de adición de floculante. (Fuente: Cortesía de FLSmidth S.A.) 


\section{Metodología de ensayos de laboratorio}

En la tarea de dimensionado de los equipos de espesado y en la etapa de ingeniería de cualquier proyecto de sedimentación de estériles, es preciso definir los criterios de diseño del equipo para alcanzar los requerimientos necesarios para evitar construir un equipo mal dimensionado que pueda influir, tanto en la financiación de un proyecto, como en el éxito de la operación a largo plazo. A continuación se destacan las diferentes opciones que existen para el dimensionado de un espesador desde los primeros cálculos preliminares hasta la ingeniería de detalle, explicando en qué momento del proyecto es apropiado emplear cada uno de los métodos disponibles.

Cuando se comienza la planificación de un proyecto que incluye tecnología de espesado, uno de los elementos clave en el proceso es determinar el tamaño y el rendimiento esperado en el equipo o equipos de espesado que forman parte del proyecto. Esta información facilita la implantación, define el coste de capital y los costes de operación estimados con una precisión que dependerá de los datos disponibles y de la experiencia del ingeniero de proceso.

Puesto que el rendimiento del espesador tendrá un efecto directo sobre toda la operación de la planta, las garantías de rendimiento del proceso suelen ser requeridas a los suministradores de equipos en las fases de adjudicación del proyecto. En ciertos casos, estas garantías son un requisito previo a la financiación del proyecto o para la aprobación de la inversión y por tanto, son elementos críticos de estas primeras etapas del proyecto. Los parámetros de rendimiento de un espesador, tales como: densidad del hundido, contenido en sólidos, claridad del rebose, efectos de las variables de alimentación, ratios de sedimentación, pueden variar ampliamente para diferentes alimentaciones del espesador. Incluso para aplicaciones similares, el rendimiento del espesador varía según los proyectos debido a otros factores como el tamaño de partículas, densidad de los sólidos, presencia de arcillas, química del agua y los efectos de los procesos aguas arriba de la instalación; como son: la adicción de reactivos en la fase de flotación o en la fase de molienda. Otros parámetros tales como el porcentaje de sólidos óptimo en la alimentación y el tipo de floculante o su dosificación, también varían según el tipo de aplicación. Por ejemplo, una aplicación particular puede requerir de una dilución adicional en el flujo de entrada con el uso de un sistema de alimentación con eductores mientras que otras aplicaciones pueden diseñarse con una recirculación para mejorar el proceso de la floculación debido a que exista una gran dilución en la propia alimentación. Cada proceso es diferente y único, aunque se trate de espesar materiales similares existiendo variaciones incluso dentro del mismo yacimiento. Por ello, cada operación necesitará de una serie de ensayos de laboratorio o en planta piloto con el fin de determinar los parámetros del proceso y la viabilidad de la operación para producir el espesado con los materiales o estériles disponibles.

\subsection{Objetivos de los ensayos y aproximación del problema}

Dependiendo de la etapa de diseño en la que se encuentra el proyecto y si existen o no, muestras de estériles o pulpa suficiente para realizar las pruebas de laboratorio o pruebas piloto, es 
frecuente emplear una serie de métodos para determinar el tamaño del espesador de pasta a diseñar. En general, estos métodos pueden clasificarse en tres, dependiendo del grado de precisión requerido, éstos son: dimensionado por estimación; dimensionado por ensayo de sedimentación en probetas; y dimensionado en planta piloto.

Estos métodos difieren en el nivel de complejidad y varían en términos de tiempo, esfuerzo, costes y por supuesto, en el nivel de precisión de los datos obtenidos con cada uno de los métodos. Esto afecta posteriormente a la fiabilidad y a las garantías de proceso que puedan aplicarse en cada proyecto.

\subsubsection{Dimensionado por estimación}

Este método de dimensionamiento del espesador, se basa en la experiencia del ingeniero de proceso y en la aplicación de espesado en particular. Este método se utiliza cuando no existen muestras de material o no están disponibles, o bien, se desea hacer un dimensionamiento preliminar de la instalación. El rendimiento de un espesador en minas u operaciones con materiales similares se puede tener en cuenta, si existen dichos datos, como una primera aproximación al proceso.

Generalmente, es normal utilizar en las primeras etapas del proyecto estudios conceptuales y con este dimensionado preliminar obtener unos costes de capital iniciales de forma aproximada (con una precisión de $\pm 15 \%$ ). Este método de dimensionamiento de equipos es el menos preciso de todos aunque las estimaciones realizadas son hechas en base a la retroalimentación de un material que tiene unas propiedades típicas para esa aplicación en particular y los factores específicos de la operación. Es frecuente que se pasen por alto detalles que pueden ser importantes, como: el contenido en arcillas, tipo de agua de proceso, etc. Que pueden no ser siempre analizados o estudiados por el ingeniero de proceso. Por este motivo sería inusual que se obtuviera un tamaño de equipo definitivo para un proyecto o incluir garantías de proceso por parte del suministrador de equipos utilizando sólo este método de cálculo.

A menudo debido a los bajos niveles de precisión de los datos asociados a este método de dimensionamiento es necesario el uso de altos factores de seguridad en el dimensionado del equipo. Esto puede llevar a tamaños de tanques conservadores y por tanto sobredimensionados con las necesidades reales de la operación, lo que hace aumentar los costes de capital del proyecto innecesariamente. Utilizando esta forma conservadora, donde los materiales de la alimentación presentan características de sedimentación pobres, es posible que el espesador sea dimensionado erróneamente, provocando un bajo rendimiento de la operación.

\subsubsection{Ensayos de sedimentación en probeta}

Estos ensayos de sedimentación en probeta están desarrollados a partir de varios modelos clásicos, como son: el modelo de Kynch, modelo de Coe-Clevenger o el de Talmage-Fitch, etc. Estos métodos fueron muy utilizados hasta la década de 1990, y representan un avance respecto al dimensionado por estimación, proporcionando una mayor exactitud. Los ensayos en probeta o los ensayos por lotes, pueden llevarse a cabo con una pequeña muestra de material representativa y a un bajo coste, mucho menor que lo requerido para el ensayo en espesador de 
laboratorio dinámico o un ensayo en planta piloto. En la figura 6-1: Ensayos en probeta estática; se puede observar la simplicidad de los materiales y equipos de laboratorio a emplear en este ensayo, donde el grado de precisión obtenido es demasiado bajo para el dimensionamiento y diseño de equipos de espesado en pasta.

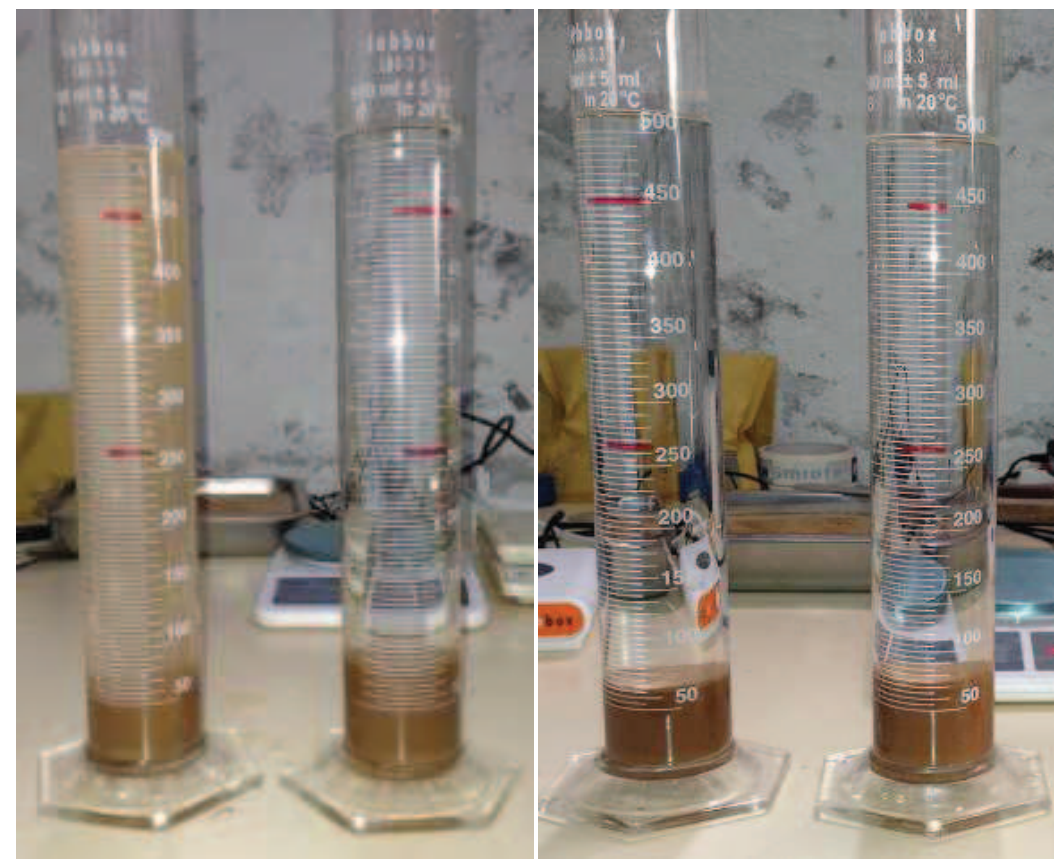

Figura 6-1: Ensayos en probeta estática.

(Fuente: Elaboración propia)

De los resultados de los ensayos de sedimentación en probeta, se pueden realizar interpolaciones de la densidad esperada en el hundido en el espesador real, así como obtener las condiciones de alimentación y dosificación de floculante óptimas de forma más o menos aproximada. La desventaja de los ensayos de sedimentación en probeta es la falta de precisión comparada con el ensayo en probeta dinámica o en espesador piloto, ya que éste no cuenta con los efectos que se representan en un espesador real, como es la acción del mecanismo de rasquetas sobre el lecho de lodos, recirculaciones, altura de tanque, etc. Para compensar estas inexactitudes es necesaria nuevamente la aplicación de factores de seguridad adicionales a los cálculos realizados, lo cual puede resultar en un sobredimensionado del equipo.

Una variante más desarrollada y sofisticada para los ensayos de sedimentación en probetas es el método que describe la presente tesis y que como se confirmará más adelante ha ofrecido unos buenos resultados como método fiable para el dimensionado de espesadores de pasta en laboratorio, empleando pocos recursos económicos y materiales. Este método de ensayo en probeta de tubo profundo o espesador dinámico de laboratorio, permite la realización de multitud de pruebas con un coste relativamente bajo y con poca cantidad de muestra. Estableciendo, como se demostrará más adelante resultados comparables con los espesadores reales.

Este es uno de los métodos más precisos a escala de laboratorio que existen para el dimensionado de un espesador de pasta o de alta densidad en el hundido y el que mejor predice el rendimiento que el proceso puede alcanzar, con resultados extrapolables similares a los que se 
obtendrían en un espesador real o en espesador piloto, como se verá más adelante. Este método se puede emplear con varios tamaños y configuraciones, donde el sistema de espesador de tubo profundo es en esencia una versión a escala de los espesadores comerciales con sistema de alimentación, adicción de floculante dosificada con bomba de bajo caudal, alimentación regulable y mecanismo de rasquetas que simulan el espesador de pasta real.

Para el presente estudio, se ha tomado como punto de partida el ensayo en probeta estática y se ha mejorado el proceso y el equipo de ensayo de laboratorio, añadiendo los componentes que tienen todos los espesadores: rasquetas con accionamiento, bomba de alimentación, bomba de dosificación de floculante e incluso bomba de recirculación del hundido espesado. También se ha aumentado la capacidad de la probeta, permitiendo ensayos con grandes alturas, hasta dos metros, a la vez que se ha aumentado el diámetro del tanque de ensayo para evitar el "efecto pared" en el proceso de sedimentación. Por lo tanto, el estudio y método de ensayo propuestos mejoran este tipo de ensayos y los resultados obtenidos de forma importante.

Para este estudio, se ha fabricado un espesador dinámico de laboratorio y se han realizado con él ensayos a escala de laboratorio. En la figura 6-2: Espesador de tubo profundo de laboratorio; se puede ver una vista completa del equipo y de su funcionamiento en la operación de espesado.

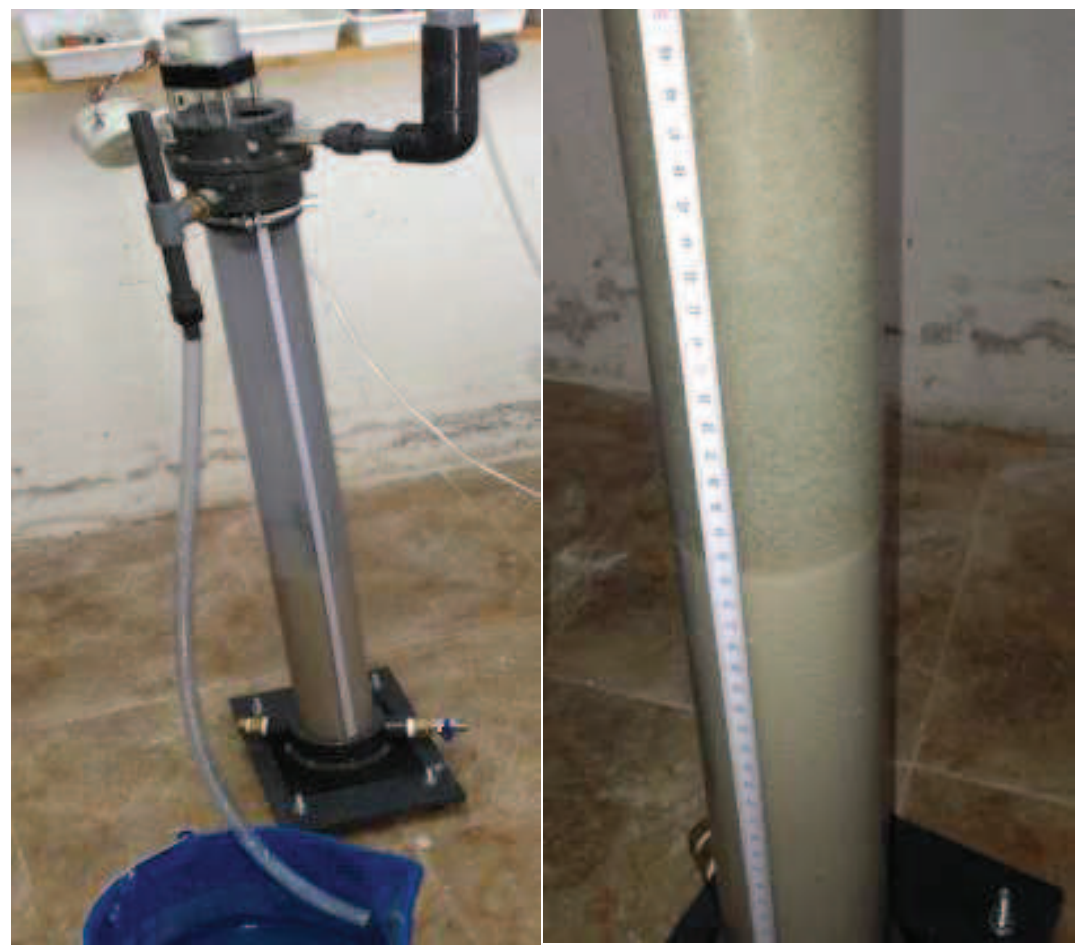

Figura 6-2: Espesador de tubo profundo de laboratorio. (Fuente: Elaboración propia)

Estos equipos se pueden fabricar en diferentes tamaños y configuraciones de hasta $200 \mathrm{~mm}$ de diámetro y con alturas de hasta 2 metros, para simular el proceso de compresión que se origina en los espesadores de pasta. Generalmente y debido a la gran cantidad de muestra requerida para el espesado en los equipos de mayor tamaño, estos ensayos se pueden realizar en la propia planta donde hay una gran cantidad de material disponible para ensayar. Esta es una ventaja que 
representa este sistema a escala de laboratorio para los materiales o estériles que pueden "envejecer" o cambiar sus propiedades durante el transporte de la pulpa a ensayar hasta el laboratorio. Su portabilidad hace que se pueda ensayar en la propia planta o laboratorio de la planta minera con una instalación mínima.

Los ensayos en espesador dinámico de laboratorio presentan una serie de ventajas y beneficios que incluyen:

a) La posibilidad de calcular de forma precisa la relación entre el ratio de alimentación de sólidos y la densidad del hundido; la claridad del rebose esperada y los consumos de floculante.

b) Recrear las condiciones de dilución de la alimentación o recirculación de sólidos para alcanzar las condiciones óptimas de floculación.

c) Los factores de seguridad necesarios con otros métodos menos precisos, no son necesarios utilizando este tipo de equipos. Esto permite que el cálculo sea muy preciso sin necesidad de factores de seguridad, obteniéndose espesadores de tamaños más ajustados y con menores costes de capital.

d) Establecer las garantías de proceso sobre los espesadores dimensionados con este método y por tanto con una confianza elevada para aportar garantías de proceso y rendimientos esperados en el espesador real.

Con este método propuesto, se aseguran ensayos a escala de laboratorio con las características de un ensayo piloto a escala semi-industrial, con las ventajas de poder realizarse en laboratorio a un coste relativamente bajo, lo que significa la diferencia entre alcanzar el rendimiento preciso o bien estimar el rendimiento sin ninguna confianza en el proceso. "Casi" alcanzar las condiciones de proceso objetivo pueden provocar problemas como la posibilidad para comprobar con precisión la relación entre el ratio de sólidos de la alimentación; condiciones de floculación, claridad del rebose y densidad del hundido.

Este sistema de ensayo evita los siguientes problemas y costes asociados:

a) Costes innecesarios de operación altos debido a una no optimización del consumo de floculante.

b) Inaceptable claridad en el rebose del equipo haciendo posible la imposibilidad de reciclar el agua de proceso.

c) Efectos imprevistos aguas abajo del circuito como por ejemplo en operaciones de filtración o de deposición de la pasta.

d) Complicaciones inesperadas con los lodos del hundido en las operaciones de bombeo y transporte.

e) Problemas con la deposición de estériles, así como con el volumen consumido en los depósitos de estériles debido a una inexactitud en el porcentaje de sólidos o el límite de fluencia esperados.

f) Ahorro en el coste de instalación de una planta piloto convencional. 


\subsubsection{Ensayos en planta piloto}

El método más preciso de todos los posibles ensayos, se realiza a escala semi-industrial. Consiste en la realización de ensayos con planta piloto en espesadores de pequeño tamaño que por su caudal de alimentación deben ser instalados en la propia planta, no pudiendo realizarse en laboratorio. Este método está reservado a operaciones existentes donde se asegure un caudal de alimentación continuo y suficiente para alimentar el equipo piloto de grandes dimensiones. Estos equipos piloto son verdaderos espesadores de cono profundo o espesadores de alta densidad en el hundido (HDT) con tamaños que varían desde 1,5 metro de diámetro hasta 8 metros de diámetro y con alturas desde 4 metros hasta 8 metros. Los equipos están dotados de estaciones de bombeo del hundido, alimentación y dosificación de floculante similares al espesador real. Por tanto, estos equipos no son viables para ser instalados en un laboratorio y deben ser instalados en la propia planta donde se quieren realizar los ensayos. Los datos recogidos en la planta piloto son los más fiables y también los más costosos, quedando reservados para las últimas fases del proyecto de diseño de equipos de espesado, cuando existe gran cantidad de muestra. Si bien, cada vez son más frecuentes este tipo de pruebas, habida cuenta de la complejidad de los proyectos, siendo de aplicación especialmente en los proyectos de expansión de minas existentes, donde los operadores optan por incorporar nuevas tecnologías de espesado al proceso minero. En la figura 6-3: Espesador piloto HDT de 4 metros de diámetro; se muestra un equipo de estas características para ensayos piloto instalado en planta.

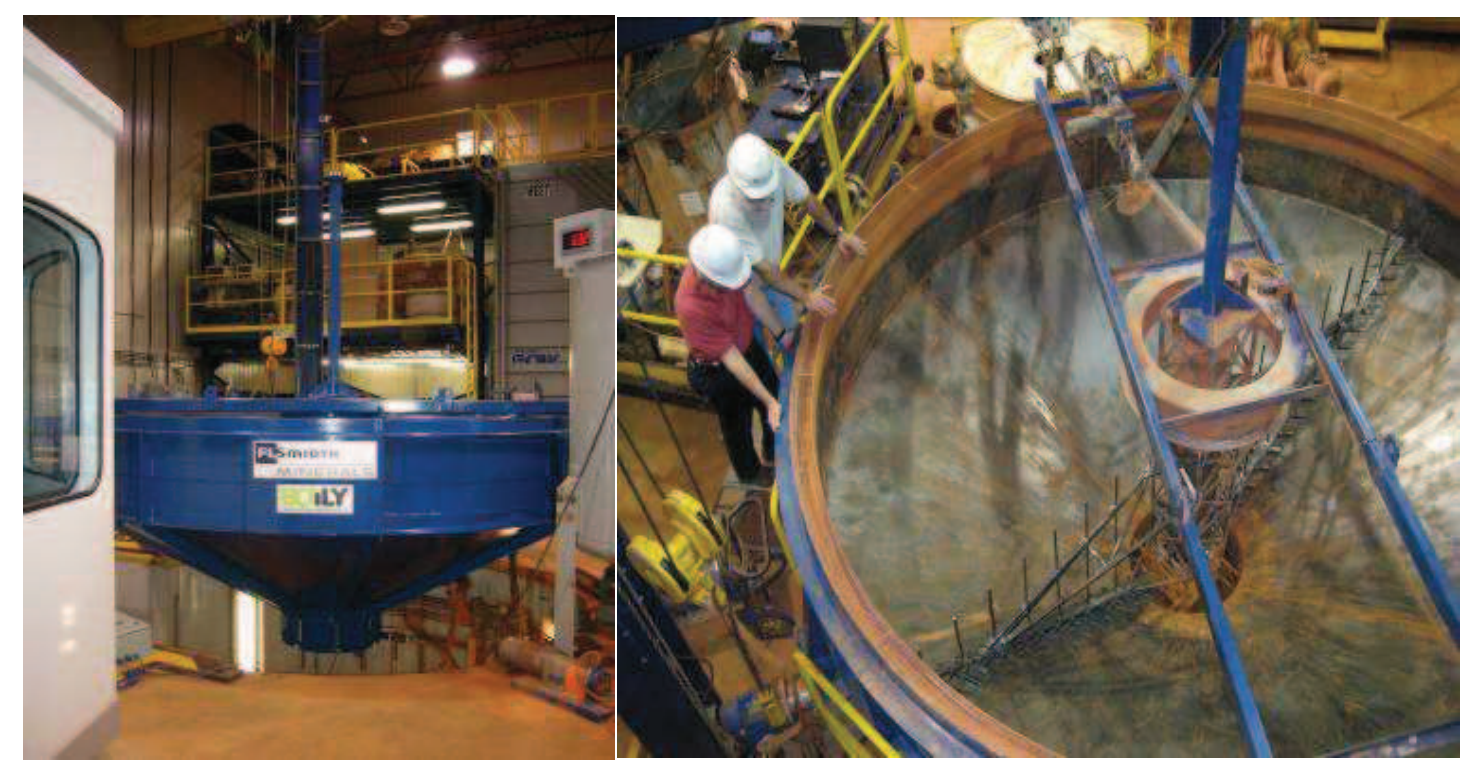

Figura 6-3: Espesador HDT piloto de 4 metros de diámetro.

(Fuente: FLSmidth S.A.)

Por tanto, se puede concluir que en las primeras etapas del proyecto es posible calcular de forma precisa los requerimientos de espesado en función del método empleado para su cálculo. Sin embargo la tendencia de economizar costos y esfuerzos asociados con los trabajos de laboratorio puede tener consecuencias fatales para el proyecto. Los ensayos en un espesador de tubo profundo a escala de laboratorio garantizan el rendimiento óptimo del espesador, la consecución 
de los objetivos del proceso y una disminución de los costes de inversión y operación de estos ensayos piloto. Como en todos los procesos la inversión de un pequeño capital y esfuerzo por adelantado puede ahorrar considerables costes posteriores y evitar así decepciones o sorpresas en la etapa final de construcción y operación del proyecto.

\subsection{Desarrollo experimental. Objetivos del programa de ensayos}

Basándose en los ensayos que son posibles realizar en laboratorio, el principal objetivo del programa de pruebas propuesto en este estudio, es averiguar el comportamiento de la sedimentación de los sólidos, evaluar la aplicación de la tecnología de cono profundo en el espesado en forma de pasta, asegurar la viabilidad de la aplicación con un estéril típico y el posterior uso de los sólidos espesados. El programa de evaluación en laboratorio, incluye: un estudio de las propiedades físico-químicas de la pasta, las propiedades reológicas de los estériles floculados para producir unos sólidos altamente espesados para depositarlos en forma de pasta. También utilizar los datos reológicos obtenidos en los ensayos de laboratorio para obtener datos económicos y técnicos de la operación. La técnica propuesta consiste en evaluar la pasta que se forma a partir de la pulpa alimentada a un espesador de tubo profundo de laboratorio, simulando las condiciones del proceso mediante una serie de ensayos y procedimientos que se desarrollan a continuación. Estas pulpas espesadas en el equipo adecuado, pueden alcanzar la máxima densidad posible llegando a formar una pasta.

Las aplicaciones y procesos de espesado en forma de pasta están basadas en que la zona de compresión es mucho más alta que en los espesadores de alta densidad o alta capacidad, generalmente el lecho de lodos será de 6 a 8 metros como mínimo, en un espesador de pasta. A medida que la zona de compresión se hace mayor, la densidad del hundido para un determinado ratio de flujo se incrementa como resultado de dos factores:

a) Primeramente, hay un mayor tiempo de sedimentación del lecho de lodos. Los flóculos sedimentados se mueven de forma relativa uno con respecto a otros liberando el fluido intersticial cuando éstos se encuentran en compresión. El incremento del lecho de lodos y el tiempo de residencia van aumentando la densidad del hundido a medida que se consigue eliminar más fluido del lecho de lodos, en lo que juegan su papel los brazos y piquetas del mecanismo interno.

b) Por otro lado, el peso del lecho de lodos ejerce una fuerza de compresión que actúa sobre los sólidos inferiores. Esta fuerza se incrementa con la profundidad, ya que los flóculos en el fondo del lecho experimentan una mayor fuerza de compresión. Esta compresión representa la fuerza principal que hace que se libere el líquido intersticial ayudado por el mecanismo e incrementándose por tanto, la densidad del lecho de lodos y el contenido en sólidos.

c) El mecanismo de rasquetas y piquetas verticales de estos equipos de espesado en pasta y su movimiento de rotación ayuda a la creación de canales en el lecho de lodos por donde se va liberando el agua intersticial hacia la superficie del espesador e incrementando su recuperación por el rebose del espesador. 
Estos tres factores actuando de forma conjunta, incrementan el contenido en sólidos de la pulpa, pero es generalmente imposible separar el efecto de cada factor en una situación dinámica.

Uno de los retos principales para el diseñador de espesadores de pasta es aplicar los ensayos y la metodología precisa para determinar el tamaño de los espesadores de pasta y predecir el comportamiento de la pasta sedimentada en el espesador real.

Con este objetivo se ha desarrollado el presente trabajo que incluye tanto la metodología como los equipos de laboratorio adecuados para conseguir una pasta de características reales en el laboratorio.

\subsubsection{Diseño y construcción del espesador de tubo profundo de laboratorio}

Con el fin de obtener las condiciones de operación de un espesador de pasta en el laboratorio y poder realizar ensayos para producir un hundido en forma de pasta, a partir de muestras de cantidad limitada de estériles mineros, se ha desarrollado un método de ensayo basado en un espesador de tubo profundo a escala de laboratorio para reproducir el proceso que se da en un espesador de pasta real. El método descrito en este trabajo ha incluido la fabricación y desarrollo del equipo de espesado de laboratorio en un modelo a escala del espesador de cono profundo basado en una instalación piloto real.

Partiendo del diagrama de flujo de un espesador de cono profundo, como se muestra en la figura 6-4: Diagrama de flujo de un espesador de pasta; se ha diseñado y construido un equipo de laboratorio capaz de reproducir las condiciones de operación del espesador de pasta real a escala de laboratorio. Las principales condiciones de diseño del equipo de laboratorio es que sea capaz de operar de una forma dinámica y tan autónoma como sea posible, es decir, con su diseño se intentó que en la medida de lo posible el proceso tenga una alimentación y una operación continua, mediante el uso de equipos auxiliares (bombas y sistemas) para proporcionar las condiciones principales de trabajo de un espesador real, como son: un alto lecho de lodos y tiempo de residencia elevado.

En el esquema de proceso de la figura 6-4, se observan todos los componentes y equipos auxiliares que existen en un espesador de pasta real, como son: tanque, cilindro de descarga del hundido, sistema de recirculación, entrada de alimentación, salida del rebose clarificado, accionamiento del mecanismo, planta de preparación y dosificación de floculante.

Estos serían los componentes principales y sistemas auxiliares de un espesador de cono profundo para tratamiento de estériles. Partiendo de este mismo criterio y diseño se ha realizado un espesador a escala de laboratorio que reproduce las mismas funciones que el espesador de cono profundo real.

El método experimental será mediante la comparación de los resultados que se obtienen en el espesador de laboratorio construido con los resultados que se obtienen a escala real en un espesador de pasta operando de forma continua. 


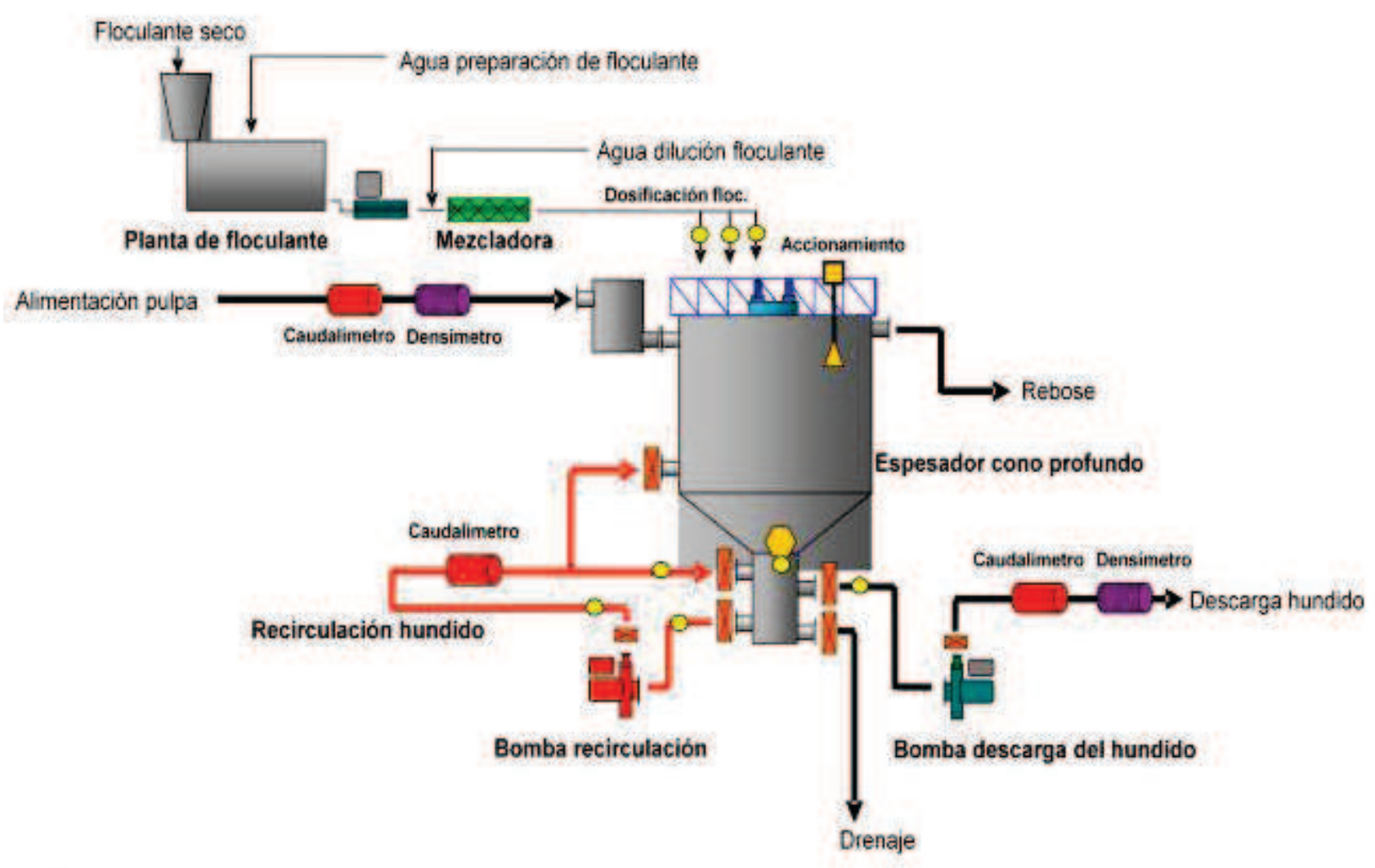

Figura 6-4: Diagrama de flujo de un espesador de pasta.

(Fuente: Elaboración propia)

Partiendo del esquema de proceso mencionado en la figura 6-4 y teniendo en cuenta las características particulares de la operación de un espesador de cono profundo para la producción de pasta, se ha desarrollado el diseño de un espesador dinámico de tubo profundo de laboratorio de la forma más didáctica e instructiva posible para interpretar el proceso de sedimentación y producción de pasta a partir de estériles mineros que pueda ser escalado a los equipos de sedimentación de los procesos reales.

En las fases de diseño que se han seguido en la construcción del equipo de laboratorio se han tenido en cuenta todos los aspectos relacionados con las partes más importantes de la operación de sedimentación de los espesadores de cono profundo, como son:
a) Diseño del tanque
b) Mecanismo de rasquetas
c) Par de accionamiento necesario
d) Campana y sistema de alimentación
e) Sistemas auxiliares y de bombeo
f) Versatilidad del equipo 


\subsubsection{Diseño del tanque}

Para concebir el diseño del equipo y del tanque se tuvieron en cuenta los aspectos relativos a la simulación de la operación de sedimentación en el equipo; en este caso el tanque que contiene la pulpa es un cuerpo cilíndrico que cumple con los requerimientos siguientes:

a) Volumen adecuado a las muestras a tratar.

b) Suficiente altura para simular las fuerzas de compresión sobre el lecho de lodos.

c) Visibilidad interna de la operación, para evaluar la marcha del proceso.

En primer lugar se analizó la necesidad del volumen adecuado a las cantidades de pulpa a ensayar. Puesto que se trata de un equipo de laboratorio, éste se debe ajustar a las muestras y cantidades habituales que son enviadas en las primeras fases del proyecto, en las que una muestra de estériles o pulpa es enviada al laboratorio desde la mina o bien la muestra es molida a tamaños finos en el propio laboratorio. En estos casos es normal disponer de muestras de 20-40 litros de volumen de pulpa, con un contenido en sólidos del 10-20\% de sólidos, o bien disponer de una cantidad de sólidos entre 1,5 y $5 \mathrm{~kg}$. Para asegurar los ensayos de laboratorio sobre pequeñas muestras de material de entre $1,5-3 \mathrm{~kg}$ de estériles, se tomó como referencia una muestra típica de $2 \mathrm{~kg}$ de sólidos. Estos sólidos, es frecuente que tengan una densidad promedio de $2,7 \mathrm{~g} / \mathrm{cm}^{3}$, en el caso de estériles y tomando una densidad del licor o agua de proceso contenida en la pulpa de $1 \mathrm{~g} / \mathrm{cm}^{3}$.

Para calcular el volumen de lecho de lodos formado, se ha supuesto una concentración final de sólidos en el hundido media del $50 \%$ de sólidos en peso una vez espesado. Con estos datos se calculó el volumen de lecho de lodos obtenidos, siendo éstos de: $2.740 \mathrm{~cm}^{3}$ en el hundido del espesador. Por lo tanto, teniendo en cuenta este volumen y los cilindros comerciales de materiales plásticos transparentes existentes en el mercado, se optó por fabricar el cilindro de sedimentación con un tubo de PVC de diámetro interior de $85 \mathrm{~mm}$ y $90 \mathrm{~mm}$ de diámetro exterior, obteniéndose una altura de lecho de lodos de entre 40 y $50 \mathrm{~cm}$ en su interior para una muestra de $2 \mathrm{~kg}$ de sólidos en el hundido, lo que puede considerarse una muestra representativa de un lecho de lodos a escala. El área interna del cilindro es de $56.7 \mathrm{~cm}^{2}$ y la altura teórica alcanzada por el lecho de lodos con las condiciones de muestra anteriores, es de $48 \mathrm{~cm}$ para los datos de partida propuestos.

Para simular la altura del volumen de sólidos y líquido que ejercieran una fuerza de compresión sobre el lecho de lodos formado, se adoptó la solución de construir un cilindro a partir de tramos cilíndricos embridados y modulables de $100 \mathrm{~cm}$ cada uno. De esta forma se pueden conseguir alturas hidrostáticas de 1 ó 2 metros; según las necesidades del ensayo y el criterio del operador. La capacidad de cada tramo modular es de $5,500 \mathrm{~cm}^{3}$; por lo tanto se puede componer un equipo de ensayo desde 5,5 litros de capacidad o en caso de tener suficiente material de ensayos es posible aumentar la capacidad del equipo, con una la altura del tanque de dos metros y una capacidad de 11 litros instalando dos tramos de 1 metro de altura cada uno.

Una vez diseñado el cilindro de sedimentación que forma el tanque del espesador de laboratorio, se diseñaron las entradas y salidas de efluentes y lodos del hundido en el cilindro. Para la 
simulación de la operación del espesador de pasta, se realizaron las siguientes entradas y salidas sobre el tubo cilíndrico:

a) Una salida de líquido clarificado en la parte superior del tubo cilíndrico con tubería de diámetro de $20 \mathrm{~mm}$, para el rebose del efluente.

b) Dos salidas diametralmente opuestas en la parte inferior con los mismos diámetros que la anterior, para la simulación de la recirculación de lodos en el fondo del espesados y provistas de válvulas de regulación para la extracción de muestras de pasta y conexiones a bomba de recirculación, en caso necesario.

En la figura 6-5: Espesador de tubo profundo de laboratorio; se muestra el tanque cilíndrico de 5,5 litros de capacidad con las entradas y salidas del tanque.

Las salidas inferiores de lodos del hundido permiten la obtención de pequeñas muestras de pasta, con el fin de poder realizar ensayos durante distintos tiempos del ensayo, todo ello sin necesidad de parar o desmontar el equipo de espesado dinámico. Se ha calculado que la extracción de una muestra de aproximadamente 500 gramos ( $350 \mathrm{~cm}^{3}$ aproximadamente), el descenso producido en el lecho de lodos, con las dimensiones iniciales del tubo, es de $60 \mathrm{~mm}$, lo que representa una extracción del $12 \%$ del lecho de lodos. Si el ensayo en modo continuo, sin parada de la alimentación, esta cantidad extraída del lecho de lodos se recuperaría en un tiempo breve, volviendo a alcanzarse la altura original en poco minutos.

Las muestras así extraídas, permiten un análisis real del contenido en sólidos y de las propiedades reológicas de la pasta formada en el interior del cilindro.

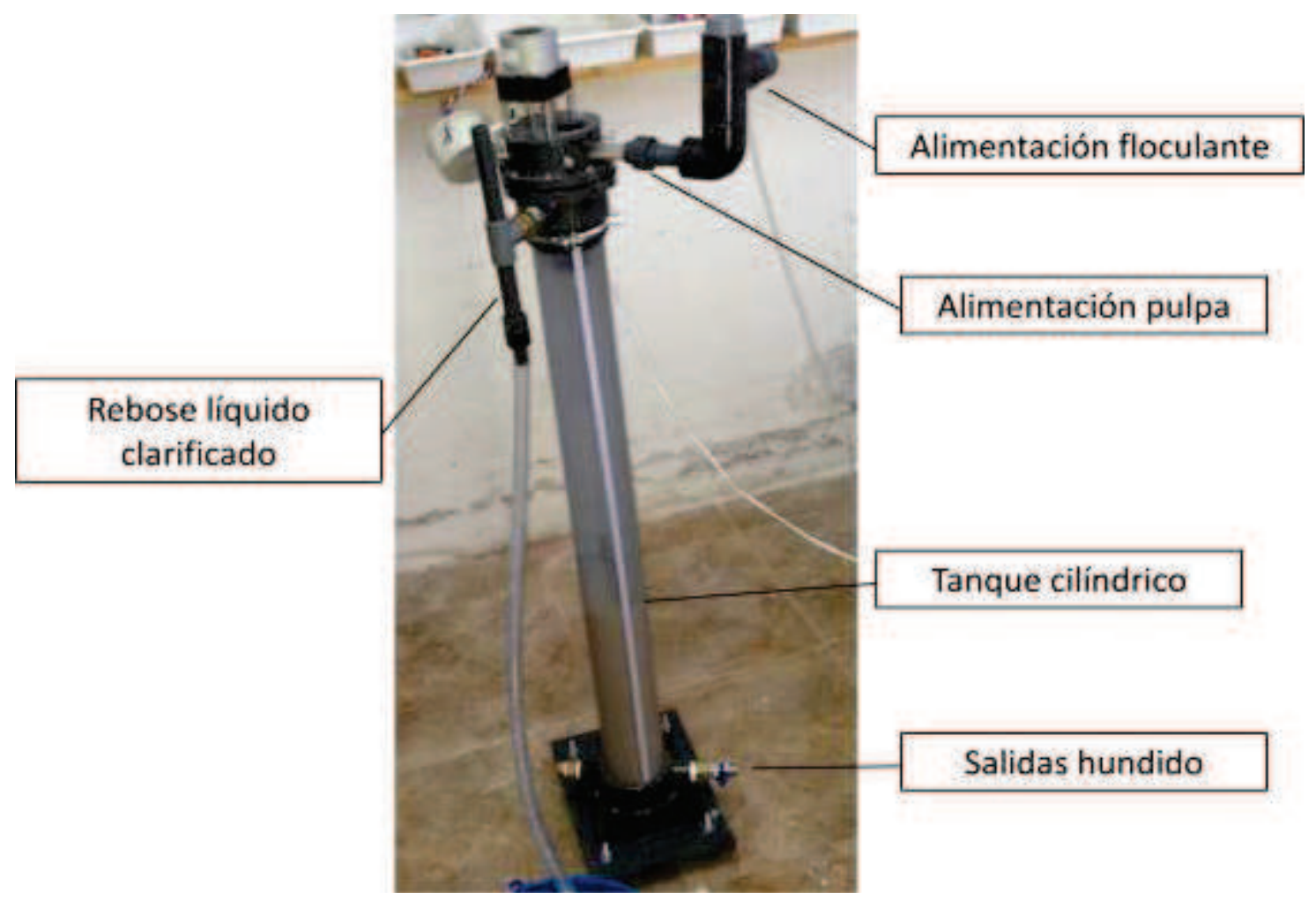

Figura 6-5: Espesador de tubo profundo (dinámico) de laboratorio.

(Fuente: Elaboración propia) 
La relación altura/diámetro (H/D) para los equipos de espesados de estériles reales según las instalaciones analizadas varían desde 1:1 data 4:1 en las instalaciones piloto a escala semiindustrial. En general a medida que disminuye el diámetro, el tanque aumenta su altura así como el ángulo del talud del fondo. En los equipos piloto se ha comprobado en ensayos realizados en planta que la relación 5:1 no afecta a los productos obtenidos en el hundido y se obtienen similares características de la pasta (contenido en sólidos, reología, etc.) en los equipos reales con relaciones altura/diámetro de 1:1 y en los equipos piloto con relaciones altura/diámetro de 5:1. En la tabla 6-1: Relación altura/diámetro típica para espesadores de pasta; se muestran los valores típicos de diseño de los equipos de espesado en forma de pasta.

Tabla 6-1: Relación altura/diámetro típica para espesadores de pasta.

\begin{tabular}{|c|c|c|c|}
\hline Diámetro espesador & Talud fondo & Altura tanque & Relación H/D \\
\hline $28-18 \mathrm{~m}$ & $30^{\circ}$ & $20-18 \mathrm{~m}$ & $0,7-1$ \\
\hline $18-12 \mathrm{~m}$ & $30^{\circ}$ & $18-10 \mathrm{~m}$ & $1-0,8$ \\
\hline $12-8 \mathrm{~m}$ & $45^{\circ}$ & $14-12 \mathrm{~m}$ & $1,2-1,5$ \\
\hline $8-4 \mathrm{~m}$ & $60^{\circ}$ & $12-8 \mathrm{~m}$ & $1,5-2$ \\
\hline $2,5-1,5 \mathrm{~m}$ & $60^{\circ}$ & $8-7,5 \mathrm{~m}$ & $3,2-5$ \\
\hline Laboratorio & $90^{\circ}$ & $0,085 \mathrm{~m}$ & 10 \\
\hline
\end{tabular}

(Fuente: Elaboración propia)

\subsubsection{Mecanismo de rasquetas}

Para el diseño del mecanismo de rasquetas, que permite la liberación del licor contenido en el lecho de lodos, se ha calculado teniendo en cuenta el diámetro del tanque y la altura teórica calculada de $48 \mathrm{~cm}$ que alcanzarían los lodos en el interior del cilindro. Por lo tanto se fabricó un sistema de piquetas verticales de $50 \mathrm{~cm}$ de altura dispuestas a $120^{\circ}$ y con distancias diferentes al eje central del equipo, de tal forma que con cada revolución se generan canales para la liberación del líquido contenido en el material espesado y en toda la sección del lecho de lodos. Estas piquetas verticales de $4 \mathrm{~mm}$ de diámetro, se dispusieron a una distancia de 12, 20 y $30 \mathrm{~mm}$ entre el eje central del mecanismo y el eje de la piqueta. En la figura 6-6: Mecanismo interno del espesador dinámico; se muestran las rasquetas o piquetas verticales que ayudan en su movimiento giratorio a la compactación del lecho de lodos, creando canales para la liberación del agua contenida en el lecho de lodos.

El sistema de hizo de forma que fuera intercambiable pudiendo usarse varios diseños de piquetas y longitudes diferentes. El material utilizado en la fabricación del mecanismo interno ha sido acero inoxidable AISI304 para poder trabajar con pulpas de pH ácido o materiales corrosivos y evitar la oxidación del mecanismo. 


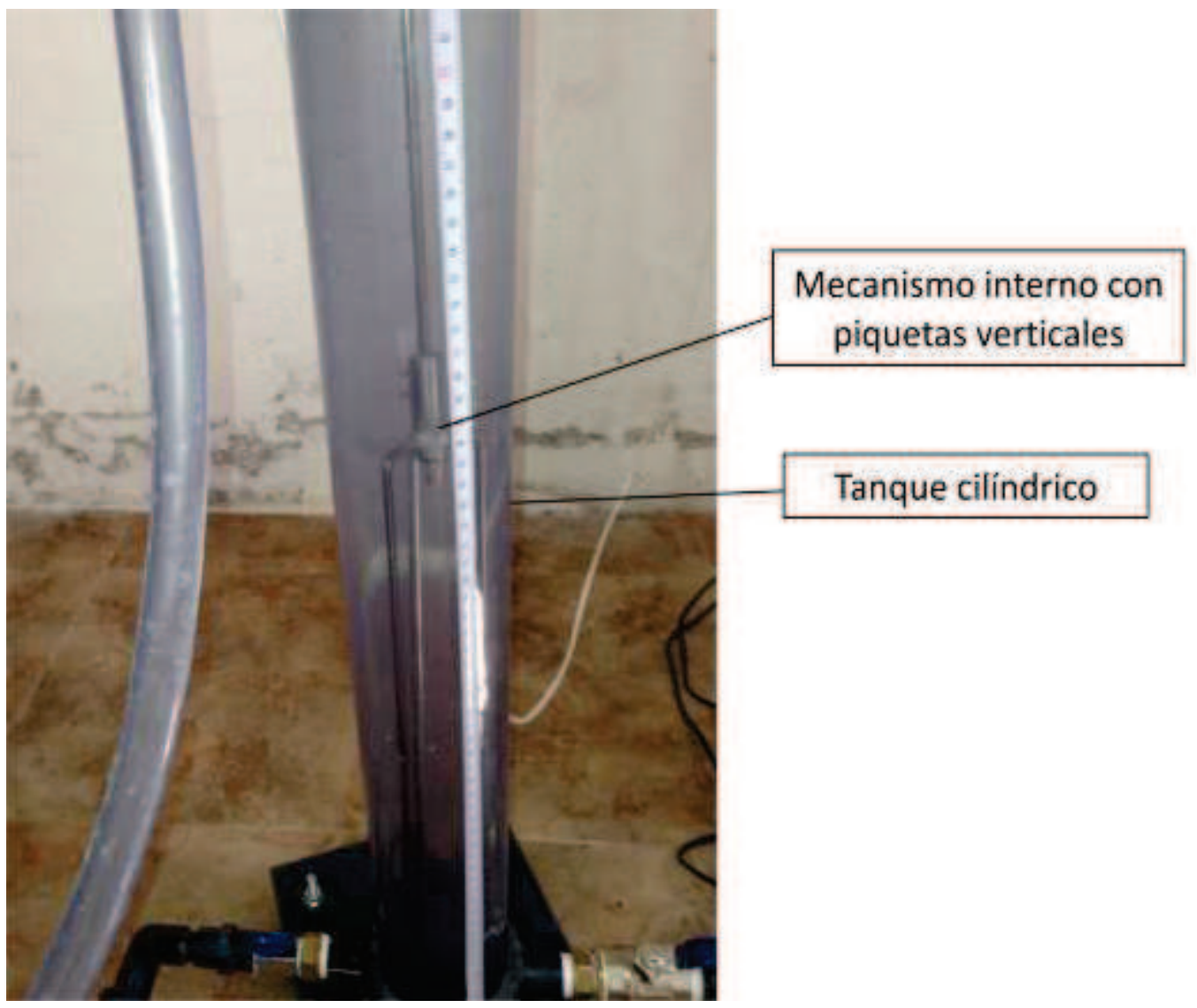

Figura 6-6: Mecanismo interno del espesador de tubo profundo.

(Fuente: Elaboración propia)

\subsubsection{Accionamiento del mecanismo}

Para diseñar el mecanismo de accionamiento se comprobó el par de accionamiento necesario para arrastrar el mecanismo con la expresión clásica, $T=K \cdot D^{2}$ donde:

$\mathrm{T}=$ par de accionamiento medido en $\mathrm{N} \cdot \mathrm{m}$ o en libras $\cdot$ pie

$\mathrm{K}=$ Constante dependiente del esfuerzo de la operación expresada en $\mathrm{N} / \mathrm{m}$ o libras/pie

$\mathrm{D}=$ Diámetro en metros o en pies

Se consideró un factor $\mathrm{K}=25 \mathrm{libras} /$ pie $(364,8 \mathrm{~N} / \mathrm{m})$ que es un factor de trabajo "muy pesado" para espesadores. Con este factor $\mathrm{K}$, se obtuvo un par de accionamiento necesario de 2,63 $\mathrm{N} \cdot \mathrm{m}$. Las expresiones 7-1 y 7-2 muestran el cálculo realizado para determinar el par de accionamiento necesario para el equipo de laboratorio.

$$
T=K \cdot D^{2}
$$

$$
T=364,8 \frac{N}{m} \cdot(0,085 m)^{2}=2,63 N \cdot m
$$

El motor y reductor debían de proporcionar una velocidad de giro máxima de $1 \mathrm{rpm}$ para un giro lento del mecanismo y evitar alteraciones en el lecho de lodos sedimentados, así como alcanzar el 
par de accionamiento de 2,63 N·m mínimo calculado, además de contar con un tamaño pequeño y de reducido peso para poder colocarlo en la parte superior del cilindro de sedimentación.

Se optó por instalar un motor síncrono provisto de caja reductora acoplada, con una velocidad de salida en el eje de 1 rpm y tensión de alimentación de $220 \mathrm{~V} / 50 \mathrm{~Hz}$, que permite el giro en sentido horario y anti-horario.

En la figura 6-7: Sistema de accionamiento; se muestra la instalación del motor en la parte superior y las partes que lo componen.

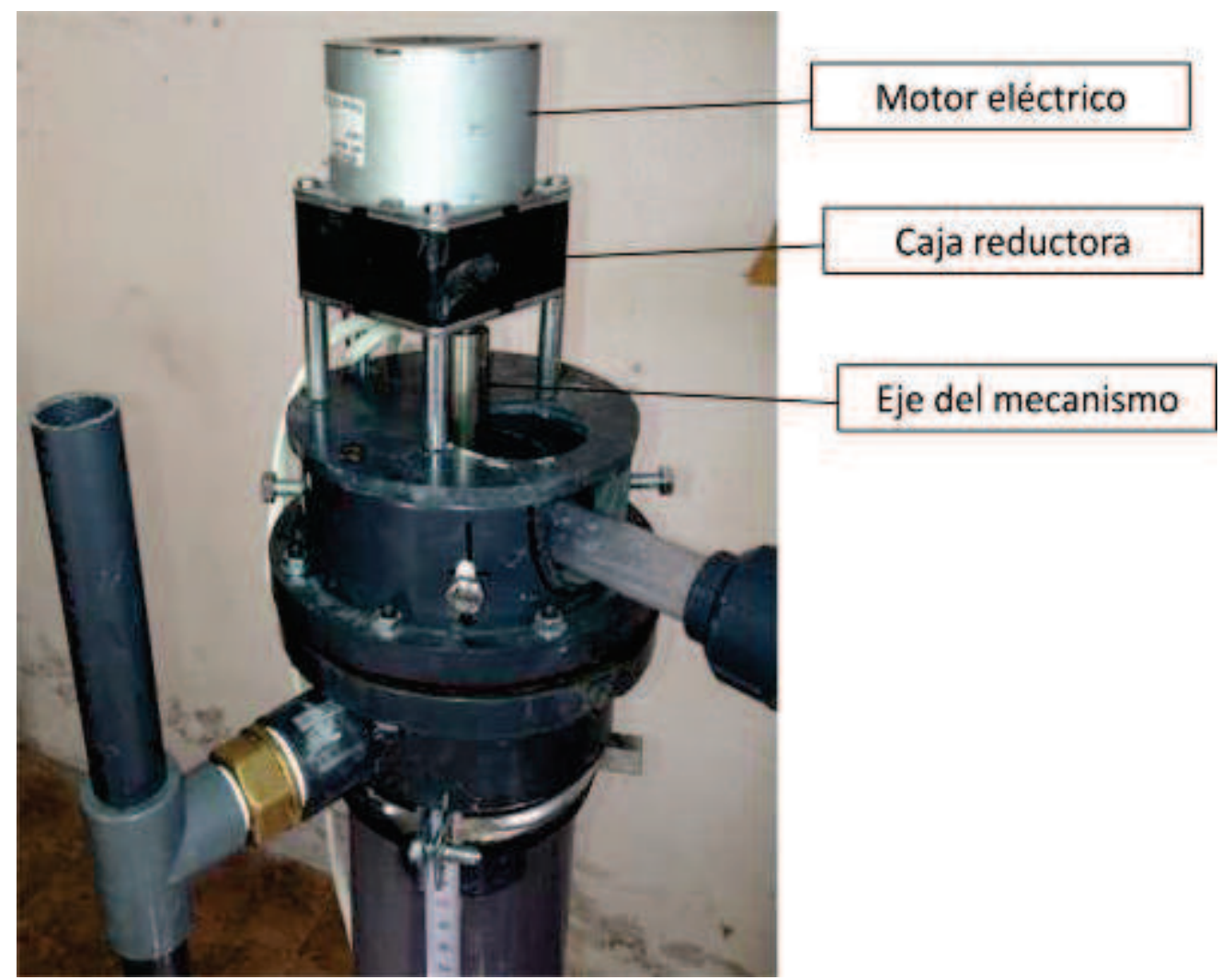

Figura 6-7: Sistema de accionamiento y motor.

(Fuente: Elaboración propia)

Las características técnicas del motor con caja reductora instalado en el equipo de laboratorio se relacionan a continuación:

Fabricante:

Par de salida:

Velocidad de giro:

Potencia del motor:

Diámetro del eje:

Carga axial (estática):

Carga radial (estática):

Peso del conjunto:

Protección del motor:
Crouzet

$5 \mathrm{~N} \cdot \mathrm{m}$

$1 \mathrm{rpm}$

$15 \mathrm{~W}$

$8 \mathrm{~mm}$

$20 \mathrm{~N}$

$30 \mathrm{~N}$

$410 \mathrm{~g}$

IP40 


\subsubsection{Campana y sistema de alimentación}

Para simular la campana de alimentación se ha realizado un diseño provisto de una tubería vertical, que se ajusta en la parte superior del cuerpo cilíndrico, permitiendo el paso del eje central de accionamiento de las piquetas. Este tipo de sistema se ha diseñado de forma intercambiable y permite la utilización de diversos diámetros de tuberías (campana de alimentación) así como diferentes longitudes. La longitud de la tubería, se ha tomado como estándar en $25 \mathrm{~cm}$ de profundidad desde la superficie del agua clarificada, si bien para el caso de materiales difíciles de sedimentar se puede alargar la longitud hasta $40 \mathrm{~cm}$ de profundidad. En la figura 6-8: Sistema de alimentación del espesador dinámico; se muestran todas las partes del sistema de alimentación.

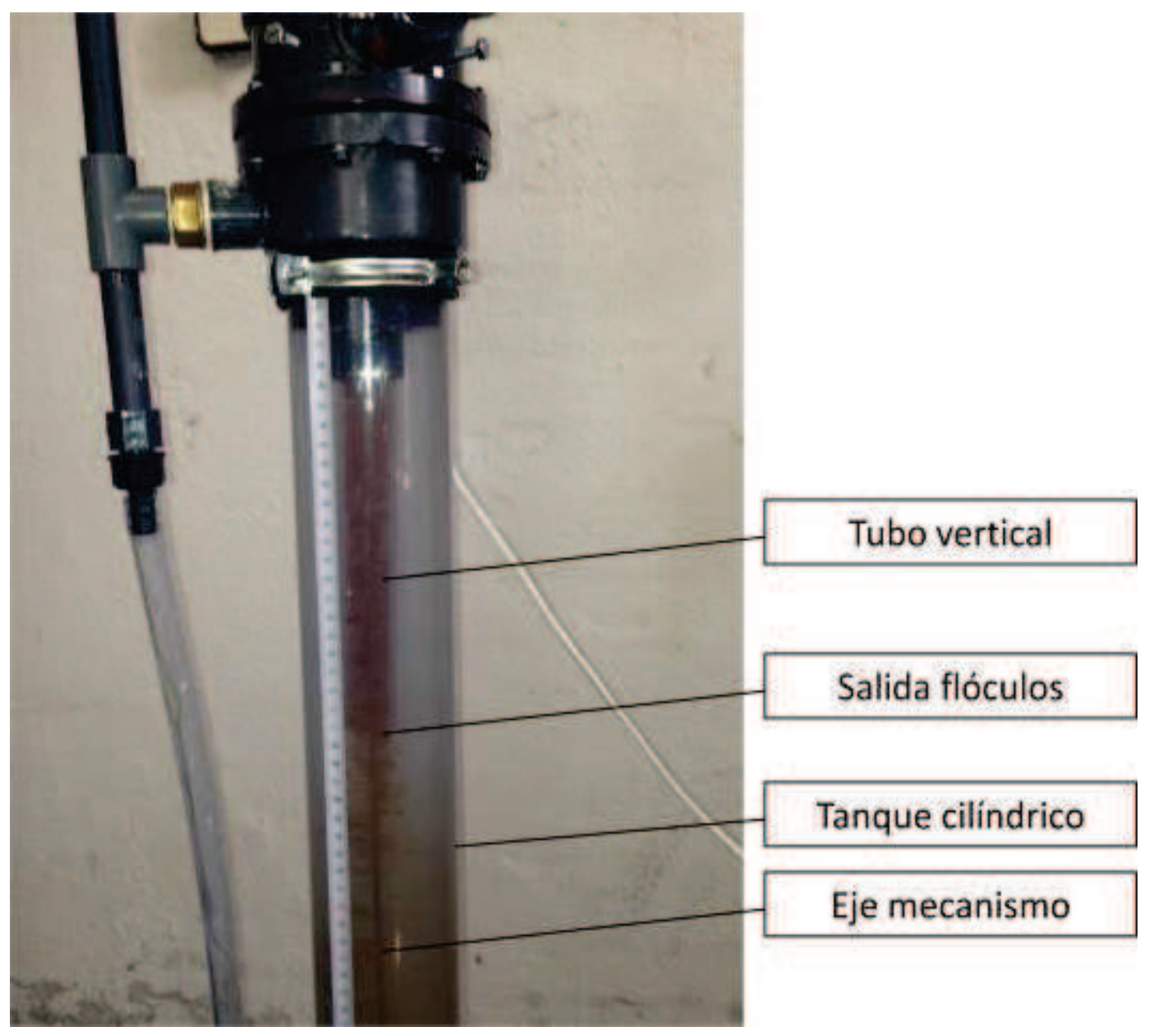

Figura 6-8: Sistema de alimentación del espesador de tubo profundo.

(Fuente: Elaboración propia)

La tubería de alimentación descarga de forma libre sobre este tubo vertical, y está provista de una válvula para regular el caudal de alimentación procedente de la bomba de alimentación de pulpa. Antes de entrar la pulpa alimentada en el tubo vertical, se han dispuesto en la tubería de alimentación varias entradas de floculante, que es dosificado y bombeado por la bomba peristáltica de floculante. El material utilizado para la fabricación de este tubo vertical que actúa de campana de alimentación es PVC transparente lo que permite observar el proceso de formación y crecimiento de los flóculos y la velocidad de caída por el tubo vertical. 


\subsubsection{Sistemas auxiliares y de bombeo}

Dentro de todo este sistema de espesado de laboratorio existen una serie de elementos auxiliares que hacen que el conjunto pueda trabajar de forma autónoma, alimentando pulpa y dosificando el floculante a voluntad del operador. Estos sistemas auxiliares son equipos de agitación y equipos de bombeo, lógicamente están adaptados a la escala del equipo y a los caudales que se desean alimentar.

Las bombas necesarias para la correcta operación del espesador dinámico de laboratorio son:

a) Bomba de alimentación de pulpa: de tipo centrífugo horizontal con una caudal de hasta 2000 litros/hora y una altura máxima de 5 metros, accionada con un motor eléctrico de 500W / 220V. Esta bomba envía la pulpa desde el tanque agitador hasta la campana de alimentación. La alimentación de la pulpa diluida proviene del tanque de agitación previo para homogenizar la pulpa.

b) Bomba dosificadora de floculante: para la dosificación del reactivo se utiliza una bomba peristáltica regulable que permite una dosificación variable entre $0,5 \mathrm{l} / \mathrm{h}$ y $10 \mathrm{l} / \mathrm{h}$, accionada por un motor de 5W / 220V.

c) Bomba de recirculación de lodos, si fuera necesaria para el proceso, de tipo centrífugo con un caudal de hasta $2000 \mathrm{l} / \mathrm{h}$ y con una altura máxima de 4 metros, accionada por un motor eléctrico de 500W / $220 \mathrm{~V}$.

Los agitadores necesarios para la operación del equipo son: un agitador magnético de laboratorio para la agitación de la solución de floculante y un agitador de pulpa para homogeneizar la pulpa en el tanque de alimentación, lo que evita la sedimentación de los sólidos, obteniéndose así una alimentación con un ratio de contenido en sólidos constante durante el ensayo. Es importante para el ensayo conseguir una mezcla homogénea de la pulpa antes de su alimentación al espesador de laboratorio.

\subsubsection{Versatilidad del equipo}

La capacidad de ensayos a realizar en el equipo con las características anteriores, permite analizar y obtener las muestras de todos los procesos que se producen en la sedimentación de estériles y concentrados de mineral, simulando el proceso que se llevaría a cabo en un espesador de pasta o de alta densidad del hundido HDT. El equipo permite la operación tanto de forma continua como de forma discontinua, según el criterio del técnico de laboratorio.

El conjunto en general, permite tener a pequeña escala la simulación del proceso de espesado, e incluso variar parámetros del proceso durante la marcha del equipo dentro del ensayo, como son: altura del lecho de lodos, dosificación de floculante, caudal de alimentación, recirculación del hundido, etc. En la figura 6-9: Esquema del espesador de tubo profundo de un módulo; se pueden ver todos los dispositivos y elementos que forman el modelo creado. 
Otra versión del equipo de laboratorio consiste en la configuración de dos módulos que proporciona una capacidad mayor del equipo y permite la formación de lechos de lodos de hasta 1 metro de altura. En la figura 6-10: Esquema del espesador de tubo profundo de dos módulos.

También permite simular la influencia que tiene la presión hidrostática sobre el lecho de lodos formado debido a su configuración modulable con la que se ha diseñado. Esto permite alcanzar una configuración del equipo de hasta 2 metros de altura y lechos de lodos superiores a 1 metro, parámetros que son difíciles de alcanzar en las probetas convencionales de laboratorio de 2000 $\mathrm{ml}$.

Como se ha comentado, la versatilidad del equipo creado, permite diversos tipos de ensayos y simulaciones para la obtención de muestras de laboratorio suficientemente grandes para tener una medida precisa en el laboratorio del proceso de espesado sobre unos estériles concretos.

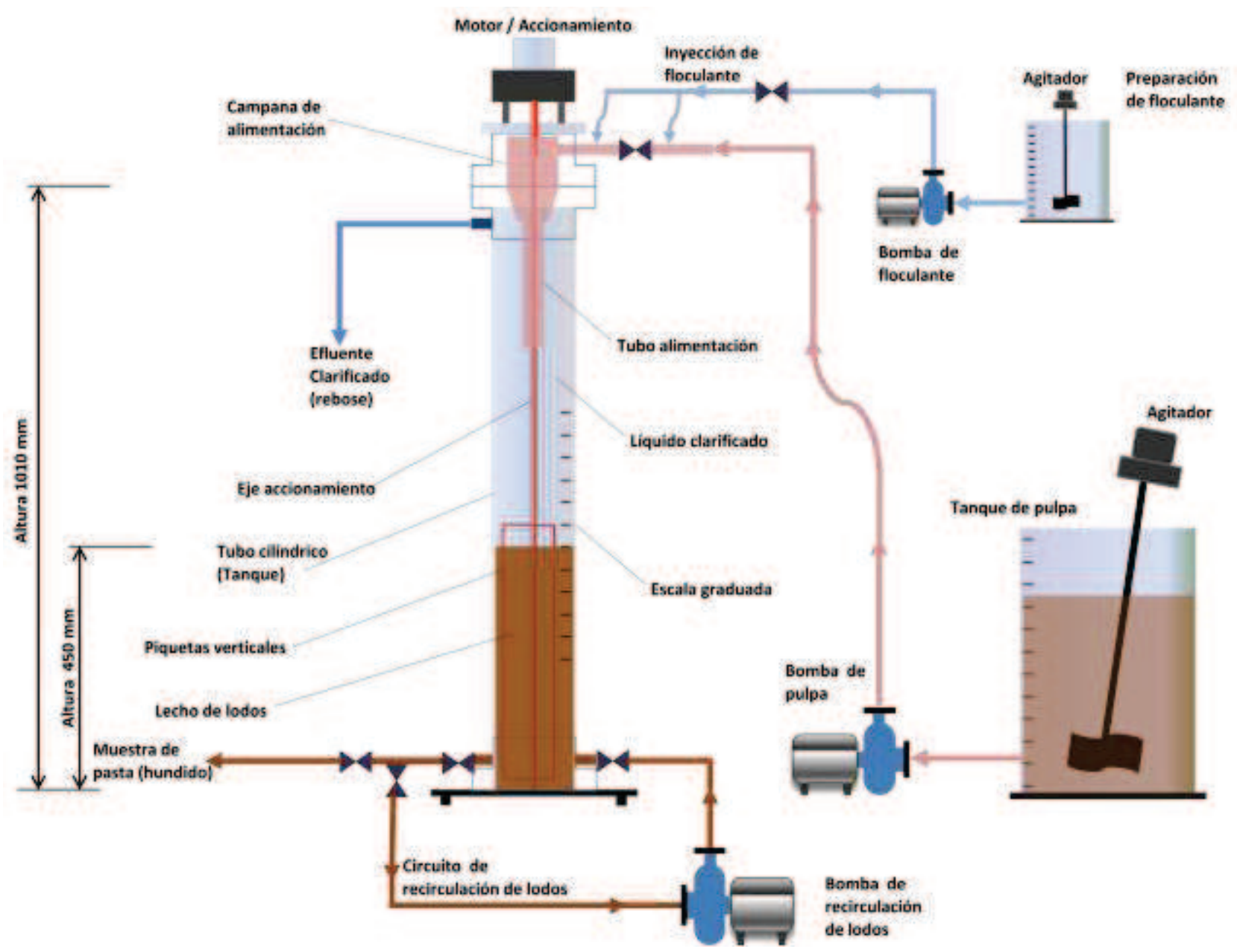

Figura 6-9: Esquema del espesador de tubo profundo de un módulo.

(Fuente: Elaboración propia)

El método de ensayo propuesto con el equipo de espesado dinámico de laboratorio se puede realizar de forma continua, si bien es necesaria una cierta experiencia previa con los materiales y por tanto, es recomendable haber realizado previamente ensayos de selección de floculantes y dosificación de floculantes para aproximar las dosificaciones y su uso durante el procedimiento de ensayo. Esto permite realizar una planificación preliminar de los ensayos que se llevarán a cabo. 
La planificación hace posible disponer de la pulpa, floculante y materiales necesarios para los ensayos, antes de comenzar el ensayo, evitándose así paradas imprevistas que afectan a la continuidad del ensayo.

Las cantidades de material para ensayos requeridas están basadas en la experiencia de la operación del equipo de espesado de laboratorio, pero como mínimo se necesitarán 1500 gramos de muestra de sólidos para el ensayo en espesador de tubo profundo de 5,5 litros de capacidad y un mínimo de $5 \mathrm{~kg}$ de muestra de sólidos en el caso del equipo con capacidad de 11 litros.

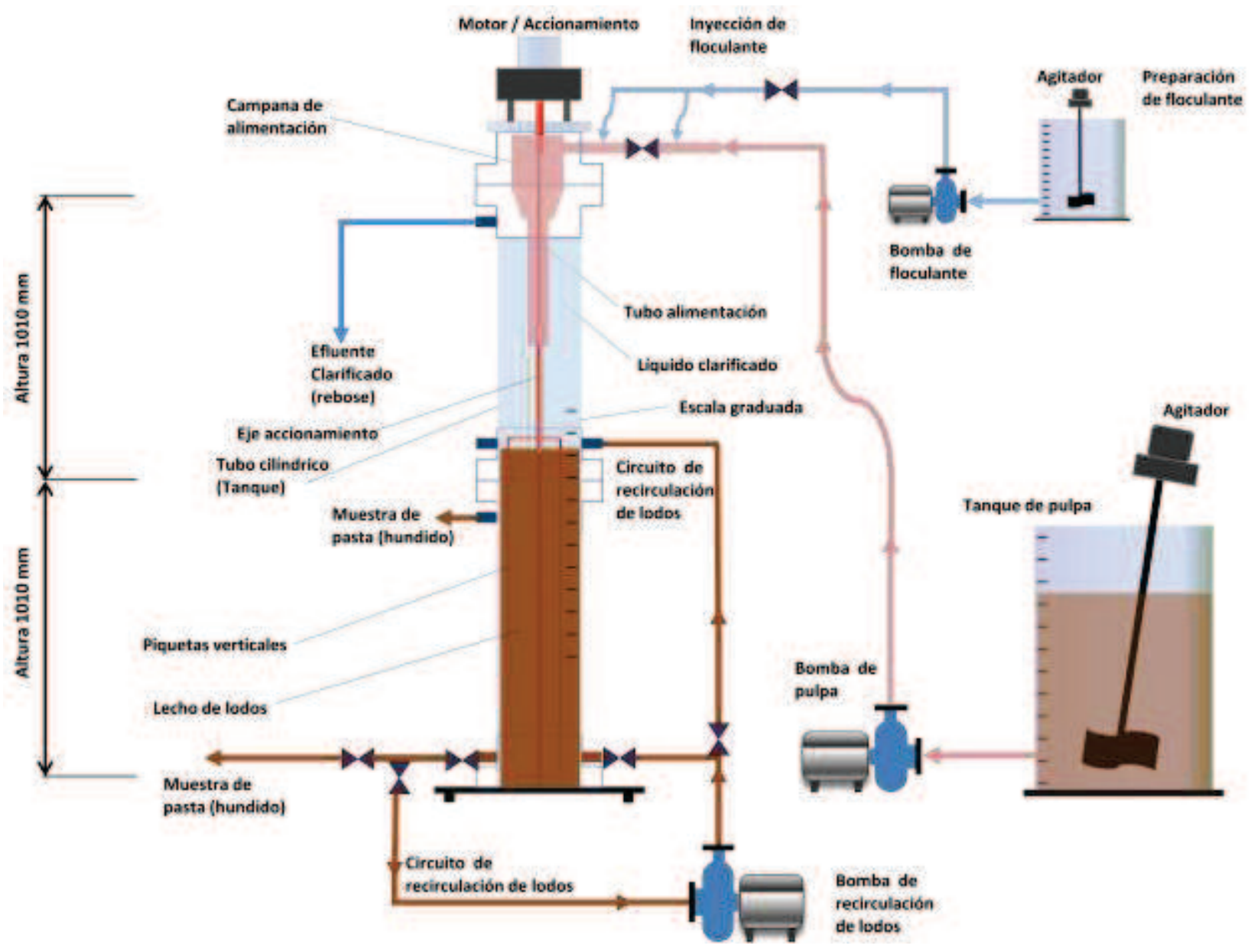

Figura 6-10: Esquema del espesador de tubo profundo de dos módulos.

(Fuente: Elaboración propia)

\subsection{Metodología de ensayos y uso del espesador de tubo profundo de laboratorio}

Para la realización de ensayos en el equipo de espesado dinámico de laboratorio se seguirá un procedimiento establecido para conseguir los mejores resultados. Este procedimiento establece las siguientes etapas para un buen desarrollo de las pruebas y la consecución de los objetivos:

a) Conocimiento de los materiales.

b) Definir el tamaño del equipo de laboratorio a utilizar. 
c) Preparación de los materiales antes de comenzar el ensayo.

d) Ensamblar los equipos periféricos y auxiliares.

e) Ensayo y toma de datos

\subsubsection{Conocimiento de los materiales}

El primer paso antes de comenzar a la realización de pruebas en el equipo es necesario tener algunos conocimientos a priori del material a sedimentar y realizar algunos ensayos previos en el laboratorio, para conocer de antemano el comportamiento previsto de los materiales y el floculante. Estos ensayos previos, serán los siguientes:

a) Análisis de sólidos y agua de proceso. Se ensayará la granulometría de los sólidos, el contenido en sólidos de la pulpa original y las densidades de sólidos y del agua de proceso.

b) Selección y dosificación de floculantes. Se seleccionará el tipo de floculante de mayor rendimiento y el contenido en sólidos adecuado o dilución a la entrada de la campana de alimentación, realizando para ello, ensayos en probeta de $500 \mathrm{ml}$, con una pequeña muestra representativa.

c) Contenido en sólidos óptimo de la alimentación con el mejor floculante seleccionado.

Una vez realizados los análisis previos de laboratorio sobre los materiales a ensayar, se pueden realizar los cálculos aproximados de los consumos previstos de pulpa, floculante y agua de proceso que serán necesarios para alcanzar el lecho de lodos previsto. Es importante ajustar las dosificaciones adecuadas para obtener el máximo rendimiento en el ensayo y reproducir de forma precisa las condiciones que se darían en el espesador de pasta real.

\subsubsection{Definir el tamaño del equipo de laboratorio a utilizar}

Una vez establecidos los datos de partida, se definirá el tamaño del equipo, que será principalmente en función de la cantidad de muestra disponible y de la fuerza de compresión que se quiera establecer sobre el lecho de lodos. Si es necesari un alto lecho de lodos con una alta fuerza de compresión en el fondo del cilindro, se optará por la instalación del equipo de dos módulos (11 litros de capacidad). Utilizando dos módulos se consiguen alturas de lechos de lodos de entre 900 y $1000 \mathrm{~mm}$ si existe suficiente cantidad de muestra para alimentar el espesador. Lo más habitual será utilizar el equipo estándar de laboratorio con un módulo (5,5 litros de capacidad), en los ensayos convencionales las alturas de lecho de lodos son normalmente de 300 a $500 \mathrm{~mm}$.

\subsubsection{Preparación de los materiales antes de comenzar el ensayo}

Las necesidades de los materiales para el ensayo deberán ser previstas con anterioridad al comienzo del mismo, ya que el proceso de alimentación debe ser continuo para simular un proceso de sedimentación real y es recomendable no realizar paradas imprevistas por la falta de 
materiales, como pulpa o floculante. Los materiales que se deben preparar antes de comenzar los ensayos son:

a) Pulpa de alimentación, que tendrá que ser preparada con el contenido en sólidos adecuado, definido en las pruebas de sedimentación previas y con la cantidad suficiente para que el lecho de lodos formado tenga la altura prevista, o la cantidad suficiente con las muestras de hundido previstas para ensayar. Como ejemplo de lechos de lodos estimados y cantidad de muestra necesaria para un lecho determinado, se muestran en la tabla 6-2: Preparación de muestras y lecho de lodos; las cantidades necesarias de muestra inicial, así como el hundido estimado del espesador para una concentración en sólidos del 50\% en peso. Los ratios de alimentación de pulpa se ha comprobado que deben mantenerse en valores de 0,5 a 1,5 litros por minuto para producir una buena sedimentación de los sólidos.

Tabla 6-2: Preparación de muestras y lecho de lodos.

\begin{tabular}{|c|c|c|c|c|c|c|c|}
\hline \multicolumn{8}{|c|}{ PULPA DE ALIMENTACIÓN. PREPARACIÓN DE MUESTRAS. } \\
\hline \multicolumn{8}{|c|}{ Densidad sólidos: $2,7 \mathrm{t} / \mathrm{m}^{3}$} \\
\hline \multicolumn{8}{|c|}{ Densidad líquido: $1,0 \mathrm{t} / \mathrm{m}^{3}$} \\
\hline \multicolumn{4}{|c|}{ ALIMENTACIÓN } & \multicolumn{4}{|c|}{ HUNDIDO (ESTIMADO) } \\
\hline Muestra de sólidos & Alimentación & $\begin{array}{c}\text { Vol. } \\
\text { Líquido }\end{array}$ & $\begin{array}{l}\text { Vol. } \\
\text { Pulpa }\end{array}$ & Hundido & $\begin{array}{c}\text { Vol. } \\
\text { Pasta }\end{array}$ & Densidad pasta & Altura lecho $(*)$ \\
\hline $\mathrm{kg}$ & $\%$ peso & litros & litros & $\%$ peso & litros & kg/litro & $\mathrm{cm}$ \\
\hline 1,00 & 5,00 & 19,0 & 19,37 & 50,00 & 1,4 & 1,5 & 24,1 \\
\hline 1,50 & 5,00 & 28,5 & 29,06 & 50,00 & 2,1 & 1,5 & 36,2 \\
\hline 2,00 & 5,00 & 38,0 & 38,74 & 50,00 & 2,7 & 1,5 & 48,3 \\
\hline 2,50 & 5,00 & 47,5 & 48,43 & 50,00 & 3,4 & 1,5 & 60,4 \\
\hline 3,00 & 5,00 & 57,0 & 58,11 & 50,00 & 4,1 & 1,5 & 72,4 \\
\hline 3,50 & 5,00 & 66,5 & 67,80 & 50,00 & 4,8 & 1,5 & 84,5 \\
\hline 4,00 & 5,00 & 76,0 & 77,48 & 50,00 & 5,5 & 1,5 & 96,6 \\
\hline 4,50 & 5,00 & 85,5 & 87,17 & 50,00 & 6,2 & 1,5 & 108,7 \\
\hline 5,00 & 5,00 & 95,0 & 96,85 & 50,00 & 6,9 & 1,5 & 120,7 \\
\hline
\end{tabular}

(Fuente: Elaboración propia)

b) Floculante del tipo seleccionado y con cantidad suficiente para la dosificación prevista en los ensayos de laboratorio previos. Se necesita tener preparado para bombear al menos, $500 \mathrm{ml}$ de solución de floculante que será dosificada durante el tiempo que dure la alimentación de la pulpa, según el criterio del operador. El ratio de bombeo de floculante varía desde 0,025 I/min hasta 0,2 litros por minuto, siendo beneficioso comenzar los primeros minutos del ensayo con una alta alimentación de floculante durante 1 ó 2 minutos para posteriormente ajustar su valor en función de la marcha de la operación y los parámetros que se observen, como son: tamaño de flóculo, claridad de rebose, etc. 


\subsubsection{Montaje de los equipos periféricos y auxiliares}

A partir de la definición de los datos de partida y el acuerdo de cómo realizar el ensayo, se comienza el montaje y conexiones de todos los equipos auxiliares y de bombeo de pulpa, floculantes, recirculaciones, etc. Como se ha comentado el equipo tiene una gran versatilidad y se puede configurar de diferentes formas para alcanzar los resultados previstos y obtener las muestras necesarias.

\subsection{Método de ensayo en el espesador dinámico de tubo profundo}

Una vez definida cómo será la configuración del equipo y los ensayos que se quieren realizar en él; se analizan a continuación los métodos de ensayo que se pueden realizar en este equipo de laboratorio. Los métodos serán fundamentalmente de tipo discontinuo y de tipo continuo, según se requiera la toma de muestras u otras pruebas complementarias necesarias sobre la reología de la pasta. También serán función de la cantidad de muestra disponible para ensayar.

En primer lugar analizaremos estos modos de operación del equipo para posteriormente tratar otros aspectos del proceso que pueden emplearse con el espesador dinámico de laboratorio. En las descripciones de los métodos de ensayo, se ha considerado el ensayo discontinuo configurando el espesador de tubo profundo con un módulo y el ensayo continuo, considerando la configuración básica de un metro de altura, tal y como se comenta a continuación.

\subsubsection{Método de ensayo discontinuo}

Para el caso de un ensayo discontinuo, en este caso se utilizará una configuración del espesador dinámico de laboratorio con un único módulo de 5,5 litros de capacidad. El montaje del equipo requiere disponer de las siguientes partes y equipos auxiliares:

a) Tanque cilíndrico y campana de alimentación.

b) Mecanismo de rasquetas y motor de accionamiento.

c) Floculante y bomba de dosificación de floculante.

d) Bomba de alimentación de pulpa y tanque de agitación.

El equipo configurado de esta forma, queda representado en la figura 6-11: Espesador de tubo profundo de un módulo en operación.

Antes del ensayo, hay que asegurarse de disponer de la cantidad de muestra necesaria de pulpa a ensayar y tener preparado el floculante diluido a la concentración prevista y en agitación al menos 30 minutos antes del comienzo del ensayo.

Al iniciar el ensayo se anotará la hora de comienzo y se ajustará la alimentación de pulpa y floculante. El tanque cilíndrico estará lleno de agua de proceso hasta el rebose y con el mecanismo de rasquetas accionado, permitiendo de esta forma la sedimentación de los flóculos desde el primer momento. 
El ensayo comienza alimentando la pulpa y el floculante, viendo cómo se desarrolla la operación en el interior del tanque y comprobando si la floculación y la sedimentación de los flóculos es la esperada. Iniciada la sedimentación en el fondo de los flóculos, se irá formando la primera capa del lecho de lodos, siendo preciso anotar las alturas del lecho de lodos a lo largo del tiempo.

Durante la alimentación se prestará especial atención al rebose del líquido clarificado, observando su contenido en sólidos; si existe una salida de sólidos apreciable por el rebose o se experimentan problemas con la velocidad de caída de los flóculos será necesario reducir el caudal de alimentación o bien incrementar el caudal de floculante momentáneamente, hasta la estabilización correcta del proceso de sedimentación.

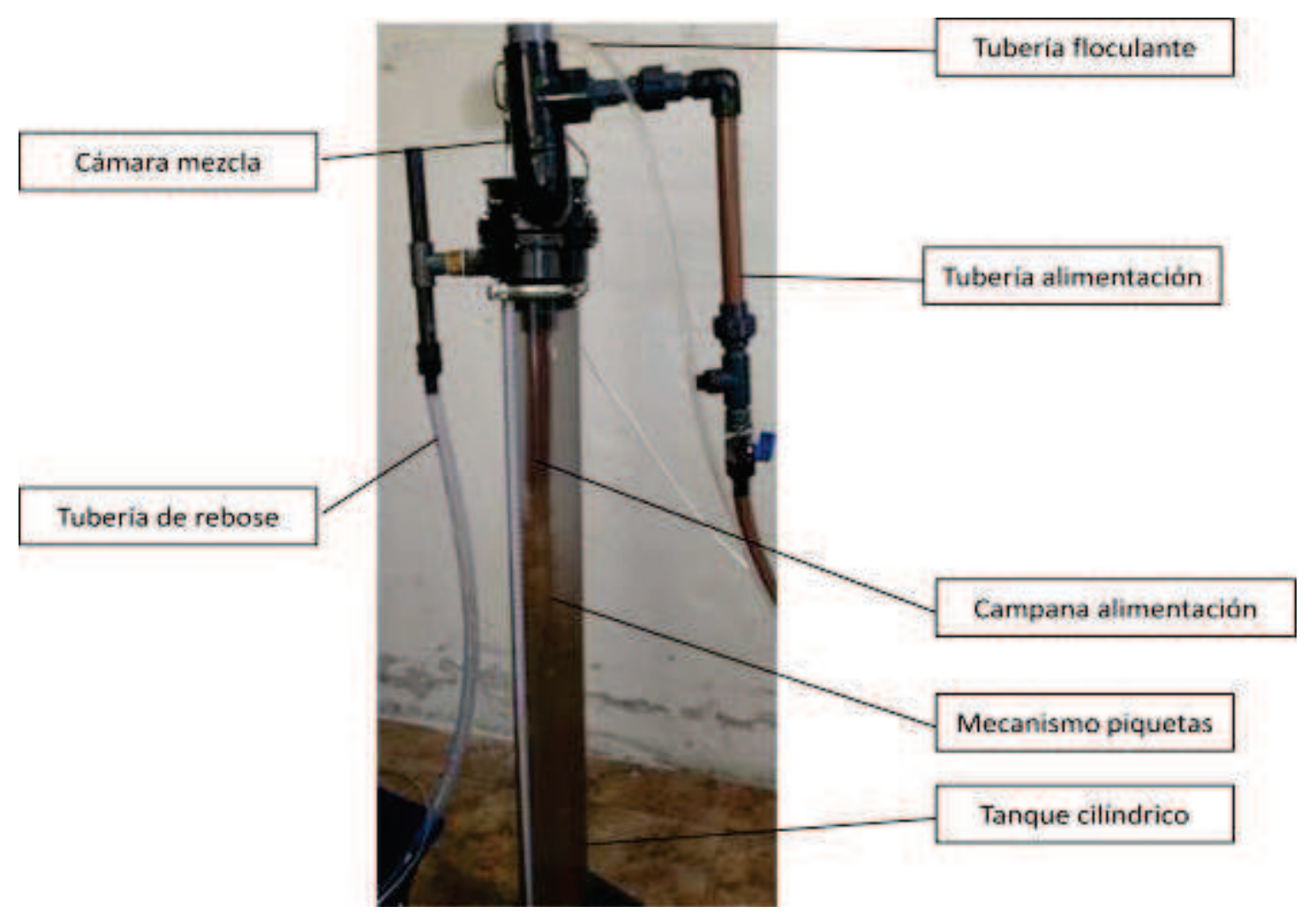

Figura 6-11: Espesador de tubo profundo de un módulo en operación.

(Fuente: Elaboración propia)

Cuando se ha formado el lecho de lodos en el ensayo y se ha alimentado toda la pulpa disponible en el tanque de agitación, se para la bomba de alimentación y se anotan los tiempos y la altura de lodos en el tanque del espesador de laboratorio.

Una vez se ha parado de alimentar el equipo, se toman los datos de: pulpa alimentada, floculante, tiempo del ensayo y la altura de lechos de lodos. Se debe comprobar cómo evoluciona la interfase y si existen flóculos en suspensión en el líquido sobrenadante. Con estos datos es posible calcular el porcentaje de sólidos y el tiempo de residencia de los lodos necesario para alcanzar un determinado contenido de sólidos en el hundido.

Con los lodos acumulados en el hundido se pueden realizar extracciones de pequeñas muestras de lodos para ensayar la reología mediante ensayos de asentamiento o ensayos en viscosímetro y 
comprobar el comportamiento de la pasta con diferentes contenidos en sólidos, etc. si se requieren en el estudio.

Con los datos y registros obtenidos es posible configurar varias gráficas del rendimiento del espesador, siendo las más importantes las que relacionan el contenido en sólidos y la tensión de fluencia de la pasta, así como otras que sean de interés para el técnico de proceso.

\subsubsection{Método de ensayo continuo}

En este tipo de ensayo, será imprescindible disponer de antemano de una cantidad de pulpa y solución de floculante importante con la dosificación y contenido en sólidos preciso. El equipo tendrá la configuración de un módulo de 5,5 litros de capacidad o bien puede estar compuesto de dos módulos con una capacidad total de 11 litros, en el caso que exista una muestra suficientemente grande para permitir el ensayo. El montaje del equipo se configurará de forma similar al que se describe en el punto anterior (6.4.1) pero presenta la ventaja de realizar los ensayos con un mayor tiempo de residencia de los lodos y con una mayor cantidad de muestra disponible para extraer del fondo del espesador y preparar una serie completa de ensayos de reología de la pasta o ensayos de asentamiento en probeta para calcular la tensión de fluencia de la pasta.

Este método de ensayo pretende comprobar el rendimiento de la operación de sedimentación en el equipo de laboratorio y el contenido en sólidos y la tensión de fluencia de la pasta mediante la extracción a intervalos regulares de muestra. Para la utilización del equipo de forma continua es recomendable tener preparada una gran cantidad de muestra representativa tanto de pulpa como de floculante. El objetivo es utilizar el equipo de forma continua durante varias horas a la vez que se extraen muestras del hundido a intervalos de tiempo regulares para comprobar el contenido en sólidos y la tensión de fluencia.

\subsection{Recogida de datos de laboratorio. Presentación de resultados e informe.}

Para la realización del trabajo experimental y como esquema de recogida de datos y almacenamiento de éstos durante los ensayos para un proyecto concreto, se ha realizado un fichero en formato Excel de Microsoft, con el objetivo de realizar un informe que presente los resultados obtenidos en cada uno de los ensayos propuestos para caracterizar las muestras de material y el espesado del mismo.

El objetivo de este fichero de Excel es almacenar los datos de las pruebas llevadas a cabo en el laboratorio, establecer un guión de seguimiento de los ensayos y trabajar con los datos obtenidos. La realización de los cálculos se presenta en una hoja de cálculo de Microsoft Excel que permite analizar los resultados experimentales de cada uno de los ensayos y presentar adecuadamente las gráficas y conclusiones obtenidas para su análisis. Ejemplos de estos informes en formato Microsoft Excel se muestran en los anexos 1 a 8.

Esta guía de ensayos permite al investigador ordenar todos los datos y cálculos, realizar gráficos y anotaciones sobre los procesos, que ayuden al desarrollo del informe final y las conclusiones que 
se deben extraer al finalizar los ensayos para el dimensionado del espesador. Todo esto, permite transmitir a terceras partes implicadas en el proyecto el conocimiento adquirido experimentalmente y cuidar la redacción del informe final.

El fichero para la recogida de los datos de laboratorio se ha dividido en varias hojas y gráficos, siguiendo un esquema lógico y ordenado de los ensayos que es posible efectuar sobre los materiales a ensayar.

El fichero se compone de doce hojas de Excel incluyendo gráficas que completan la recogida y análisis de datos sobre los materiales, un ejemplo de los datos completos realizados sobre diferentes materiales se puede ver en el apartado de Anexos:
a) Portada del informe.
b) Ensayo granulométrico.
c) Selección de floculante.
d) Flujo de sedimentación.
e) Gráfica: Flujo de sólidos frente a dosificación de floculante.
f) Gráfica: Velocidad de sedimentación frente a dosificación de floculante.
g) Ensayo estático en probeta de $2000 \mathrm{ml}$.
h) Gráfica de la curva de sedimentación en probeta de $2000 \mathrm{ml}$.
i) Ensayo en espesador dinámico.
j) Gráfica: Valores de operación del espesador dinámico.
k) Gráfica: Tiempo de residencia frente a porcentaje de sólidos.
I) Ensayo de reología de la pasta.
m) Ensayo de filtración a vacío.

\subsubsection{Portada del informe}

En esta primera página se incluyen los datos generales de los ensayos de sedimentación que se realizan, y el nombre del proyecto, etc.

Los datos que incluye esta primera página del informe de laboratorio son los siguientes:

a) Mina, Compañía, Proyecto y Aplicación del Proyecto.

b) Fecha de los ensayos o recogida de las muestras.

c) Ensayos realizados sobre la muestra.

d) Persona que realiza los ensayos y persona que los supervisa.

e) Nota de confidencialidad de los ensayos y datos recogidos en los ensayos.

Con estos datos queda perfectamente definido el proyecto y las partes implicadas en él. Así mismo se tiene la información de los ensayos de laboratorio y revisiones que se han realizados sobre la muestra. Véase página 1 del Anexo 1. 


\subsubsection{Ensayo granulométrico}

En el estudio del proceso de sedimentación y de la pasta obtenida es importante conocer la distribución granulométrica del material que se va a tratar y que permitirá posteriormente dimensionar algunas partes del espesador como puede ser el talud de fondo y seleccionar el tipo de mecanismo de rasquetas. En la realización de los ensayos se sigue el procedimiento propuesto anteriormente en el punto 6.3.1

El tamaño de partículas de los sólidos y su distribución es importante ya que el fenómeno de la sedimentación es más favorable para las partículas de mayor tamaño y las propiedades reológicas de la pasta están relacionadas con el tamaño de las partículas de los sólidos que la forman.

El informe incluye los siguientes datos que deben ser introducidos por el técnico de proceso para obtener la curva granulométrica, un ejemplo de este tipo de curva se puede ver en la página 2 del Anexo 1:

a) Datos generales e identificación de la muestra a ensayar.

b) Tamices empleados en el ensayo

c) Peso retenido en el tamiz, \% peso retenido, $\%$ retenido acumulado y $\%$ pasante acumulado para calcular la curva granulométrica.

d) Gráfica de la curva granulométrica.

Para la definición de las características físicas de los materiales es importante realizar los ensayos de determinación del peso específico tanto de sólidos como del líquido que forma la pulpa. La metodología a seguir será como se muestra en el punto 6.3.2. Es frecuente que el material sólido sea conocido y se disponga de los datos precisos por parte del laboratorio de la planta, en caso contrario será necesario realizar los ensayos de determinación de la densidad de sólidos y líquido para poder realizar los ensayos siguientes.

\subsubsection{Ensayo de selección de floculantes}

Uno de los principales retos del técnico de proceso en el diseño de los espesadores de espesado en forma de pasta o de alta densidad es realizar el diseño de la campana de alimentación, dosificación de floculante y puntos de floculación adecuados para conseguir el máximo rendimiento del equipo. Por tanto, es necesario un conocimiento en profundidad del tipo de floculante a emplear, el comportamiento de la pulpa, el contenido en sólidos y la dosificación de floculante que permita desarrollar la operación con el máximo rendimiento.

De entre todos los floculantes, fabricantes y tipos que existen en el mercado, en la fase de diseño, el ingeniero de proceso deberá elegir el tipo que mejor se ajuste a las necesidades de la operación. Para facilitar el trabajo de elección al técnico de proceso, siguiendo el procedimiento de ensayo descrito en el punto 6.3.3, se puede crear una base de datos para la selección del floculante más adecuado a los materiales que se quieren espesar.

Esta base de datos se realiza a partir de las pruebas de sedimentación en probeta, donde los resultados que se persiguen son obtener la máxima velocidad de sedimentación con la mínima dosificación de floculante. 
En la página 3 del Anexo 1, se muestra un ejemplo con los campos de datos necesarios para elegir un determinado floculante. El operador debe introducir, aparte de los datos relativos a la muestra que se quiere analizar, los siguientes datos:

a) Número de muestra o identificación de la misma.

b) Tipo de floculante y carga

c) Dilución aplicada a la muestra original

d) Contenido en sólidos de la muestra

e) Distancia de sedimentación

f) Floculante añadido en la prueba de sedimentación

g) Tiempo registrado en recorrer la interfase la distancia de sedimentación.

Con estos datos, se procede a calcular la dosificación de floculante en gramos por tonelada y la velocidad de sedimentación, que se registrarán en la gráfica adjunta del fichero para todos los tipos de floculante empleados en el ensayo.

Con cada una de las pruebas realizadas sobre los floculantes ensayados y con el fin de ayudar a la selección del floculante más adecuado al proceso, se incluyen una serie de parámetros que serán introducidos tras la inspección visual de los ensayos en la probeta de sedimentación. Estos datos son los siguientes:

a) Estructura del flóculo, clasificado en: muy pequeño; pequeño; medio; grande; muy grande.

b) Ratio de sedimentación observada: muy lenta; lenta; media; rápida; muy rápida.

c) Claridad del rebose en probeta observada: muy turbio; turbio; claro; muy claro; cristalino.

Corresponde al técnico de laboratorio en base a su experiencia en este tipo de ensayos distinguir entre las diferentes categorías propuestas y asignar un valor objetivo para cada una de las cuatro características propuestas, comparando los diferentes ensayos. Cada una de ellas se ha dividido en cinco categorías a las cuales el técnico puede asignar valores de 1 a 5 para incluir una calificación general en función del tipo de floculante y de la dosificación empleada.

Para determinar de forma visual el mejor floculante el fichero crea una gráfica de la velocidad de sedimentación en función de la dosificación de los floculantes empleados en los ensayos. Un ejemplo de este ensayo se puede ver en la página 4 del Anexo 1.

En general se seleccionará el floculante de mayor velocidad de sedimentación y que mejor rendimiento presente atendiendo a los criterios de: estructura de flóculo, ratio de sedimentación y la claridad del rebose resultante.

\subsubsection{Ensayo de flujo de sedimentación}

Una vez elegido el floculante que mejor rendimiento presenta para la pulpa a sedimentar se procederá a determinar el flujo de sedimentación y la alimentación óptima a la expresada en forma de contenido en sólidos en la pulpa, que será un dato clave para dimensionar tanto el caudal como el sistema de dilución y campana de alimentación del espesador. 
En la página 5 del Anexo 1 se muestra un ejemplo de todos los datos que se deben de introducir para llegar a obtener las dos gráficas principales, que mostrarán el contenido en sólidos óptimo y la dosificación o consumo de floculante estimada.

Realizando los ensayos según el procedimiento descrito en el punto 6.3.4, se puede completar la base de datos para obtener las siguientes gráficas: consumo de floculante en $\mathrm{g} / \mathrm{t}$ sólido frente a flujo de sedimentación en $\mathrm{t} / \mathrm{di} a / \mathrm{m}^{2}$ y el consumo de floculante en $\mathrm{g} / \mathrm{t}$ de sólido frente a la velocidad de sedimentación en $\mathrm{m} / \mathrm{h}$.

Con ambas gráficas quedan definidos de forma preliminar los parámetros de consumo de floculante y cuál será el rendimiento esperado durante la operación de sedimentación.

Los ensayos se realizarán con el floculante elegido en los ensayos anteriores y para diferentes contenido en sólidos de la pulpa, variando la dosificación de floculante en cada ensayo. Los datos principales que se obtienen son los siguientes:

a) Velocidad de sedimentación en $\mathrm{m} / \mathrm{min}$ y en $\mathrm{m} / \mathrm{h}$.

b) Dosificación de floculante en gramos por tonelada de sólido.

c) Fuljo de sedimentación en $\mathrm{t} / \mathrm{h} / \mathrm{m}^{2}$ y en $\mathrm{t} / \mathrm{día} / \mathrm{m}^{2}$.

d) Valores promedio de la velocidad de sedimentación, dosificación de floculante y flujo de sólidos, tanto en $\mathrm{t} / \mathrm{h} / \mathrm{m}^{2}$, como en $\mathrm{t} / \mathrm{dí} / \mathrm{m}^{2}$.

e) Curvas típicas de flujo de sólidos y velocidad de sedimentación frente a la dosificación de floculante; Véase página 6 del Anexo 1.

\subsubsection{Ensayo de sedimentación estático en probeta de $2000 \mathrm{ml}$}

Esta modalidad de ensayo de la pulpa se puede considerar como una prueba opcional, pero recomendable en el caso de que exista suficiente muestra de material para ensayar. El objetivo es conseguir la curva de sedimentación en probeta de $2000 \mathrm{ml}$, de una pulpa alimentada con el contenido en sólidos óptimo y la dosificación de floculante adecuada según lo establecido en anteriores ensayos. En las páginas 7 y 8 del Anexo 1, se muestra un ejemplo de todos los datos del ensayo de sedimentación en probeta de $2000 \mathrm{ml}$ y las gráficas obtenidas en este ensayo.

El procedimiento de este ensayo se encuentra descrito en el punto 6.3.5, donde los datos obtenidos son:

a) Altura de la interfase frente al tiempo de sedimentación.

b) Dosificación de floculante.

c) Flujo de sedimentación.

d) Curva de sedimentación clásica: altura de interfase-tiempo (Véase página 6 del Anexo 1).

e) Curva de tiempo de retención frente a contenido en sólidos (Véase página 6 del Anexo 1).

\subsubsection{Ensayo en espesador dinámico de tubo profundo en laboratorio}

Los datos se obtienen siguiendo el procedimiento descrito en el punto 6.3.6, con el objetivo de obtener parámetros de funcionamiento reales y la obtención de muestras para realizar ensayos de reología de la pasta, a medida que se produce el asentamiento del lecho de lodos y se consigue el 
aumento del contenido en sólidos dentro del espesador. En las páginas 9 y 10 del Anexo 1, se describen los datos obtenidos y la gráfica de sedimentación frente al tiempo de retención. Este ensayo es obligatorio para el dimensionamiento de equipos de espesado en pasta ya que proporciona el tiempo de residencia mínimo de los lodos para alcanzar una determinada concentración de sólidos en peso en el hundido.

Con los datos del ensayo se obtienen los valores promedio siguientes de las pruebas dinámicas: velocidad de sedimentación, dosificación de floculante, flujo en $\mathrm{t} / \mathrm{día} / \mathrm{m}^{2}$ y área unitaria en $\mathrm{m}^{2} / \mathrm{t} / \mathrm{día}$. El procedimiento de este ensayo se encuentra descrito en el punto 6.3.6, donde los datos obtenidos son:

a) Datos del ensayo dinámico, es decir mientras se procede a alimentar el espesador de laboratorio. (Véase página 9 del Anexo 1)

b) Datos del ensayo estático, mientras se produce la sedimentación y compresión del lecho de lodos. (Véase página 9 del Anexo 1)

c) Los valores promedio de operación del ensayo así como las gráficas de valores de operación y tiempo de residencia frente a contenido en sólidos se muestran por ejemplo, en la página 10 del Anexo 1.

\subsubsection{Ensayo de filtración a vacío}

El ensayo de filtración a vacío, considerado opcional en el presente documento, es recomendable su elaboración siempre que exista material de ensayos suficiente. Es una buena medida de la máxima concentración esperada en el hundido del espesador. El procedimiento del ensayo se describe en el punto 6.3.8. Un ejemplo de este ensayo se puede ver en la página 11 del Anexo 1. El objetivo de este ensayo es conseguir un promedio de la máxima cantidad en sólidos alcanza por el material partiendo de bajas concentraciones en sólidos de la pulpa de alimentación.

\subsubsection{Ensayo de reología de la pasta}

Para el ensayo de reología de la pasta realizado según el procedimiento que se describe en el punto 6.3.9, es importante la realización a partir de muestras obtenidas en el espesador dinámico de laboratorio o bien para muestras preparadas en el laboratorio con un contenido en sólidos exacto, tomando una muestra concentrada y diluyéndola en varias ocasiones para obtener diferente contenido en sólidos.

Un ejemplo de la hoja de datos de este ensayo se muestra en la página 12 del Anexo 1 , incluyendo el gráfico que representa el contenido en sólidos de la pasta frente a la tensión de fluencia estimada con el ensayo de asentamiento. En caso de disponer de un viscosímetro de laboratorio, se podrían introducir los datos de tensión de fluencia obtenidos en el viscosímetro. 


\subsection{Metodología de los ensayos para la caracterización de la pasta}

Los ensayos de laboratorio recomendados para el dimensionado de los equipos de espesado de cono profundo y espesadores de alta densidad HDT, son los que se relacionan a continuación en este punto. Cuando se considera la realización de ensayos de laboratorio para pasta, se pueden requerir grandes cantidades de estériles o materiales, que en ocasiones pueden no estar disponibles debido a las limitaciones de material, especialmente en proyectos en fase de viabilidad o desarrollo. Los ensayos y pruebas realizadas en laboratorio son de gran utilidad para averiguar en las primeras etapas del proyecto la sedimentación y el comportamiento de una suspensión de lodos en la operación de espesado. La lista de ensayos que son viables a escala de laboratorio con una muestra representativa relativamente pequeña de un estéril típico de hasta $2-3 \mathrm{~kg}$ son los siguientes:

a) Análisis granulométrico

El análisis granulométrico de las partículas que forman el lodo es un ensayo esencial, ya que permite tratar con diferentes muestras y pueden ser comparadas unas con otras para comprobar el rendimiento de la operación en un espesador en función de la granulometría de alimentación. También es importante para conocer la curva y distribución granulométrica que definirá el diseño de las rasquetas e inclinación del fondo del equipo en la fase de ingeniería.

b) Análisis del peso específico de sólidos y líquidos

El ensayo para determinar el peso específico de sólidos, la densidad de las partículas mediante la relación entre masa de sólidos y volumen de sólidos.

También se realizará la comprobación del peso específico del licor o agua de proceso que forma la pulpa utilizada en el proceso de sedimentación. En general estos datos serán conocidos y son determinados por los operadores de la planta, si bien en algunas ocasiones no se puede disponer de los datos antes del ensayo, siendo necesario realizar estos ensayos sobre las muestras de material disponible para determinarlos.

c) Ensayo de floculantes y su elección

El ensayo de diversos floculantes ayudará a identificar qué tipo de reactivo tiene el mejor comportamiento con los sólidos que se quieren sedimentar. Esto elimina posteriormente muchos ensayos de laboratorio posteriores y ensayos en equipo piloto innecesarios.

d) Ensayo del ratio de sedimentación

El ensayo de ratio de sedimentación identifica el nivel de sólidos que tienen una tasa de sedimentación y espesado óptima. Este ensayo apunta cual es el valor objetivo del nivel de sólidos en la campana de alimentación del espesador real.

e) Ensayo estático en probeta de 2 litros 
El ensayo de sedimentación en probeta de 2 litros, es el método clásico para determinar la velocidad de sedimentación y obtener una curva de sedimentación característica. Este ensayo puede ser opcional en el caso de análisis de sedimentación para la formación de pastas, si bien en este caso aporta información adicional a otros ensayos realizados sobre la pulpa.

f) Ensayo de sedimentación en probeta de 5,5 litros

El ensayo de sedimentación en probeta de 5,5 litros resulta de utilidad para determinar las propiedades de los sólidos sedimentados y espesados. En este ensayo se determina el tiempo de residencia y también es posible obtener muestras de la pasta del lecho de lodos formado en el proceso de sedimentación.

g) Ensayo de filtración a vacío

Los resultados de filtración a vacío se utilizan para evaluar el máximo nivel de consolidación de los sólidos. Esta máxima concentración de sólidos alcanzable con los ensayos de filtración a vacío es útil en el estudio de pastas que se emplearán posteriormente para relleno de mina; y para el conocimiento de los límites de la máxima consolidación esperada en un espesador de pasta. Este ensayo es una prueba opcional en el estudio del espesador de cono profundo.

h) Ensayos de reología

Los ensayos sobre la reología de los lodos se utilizan para determinar el límite de fluencia de los sólidos sobre los niveles de sólidos esperados en el hundido del espesador. Los valores de límites de fluencia son un factor importante en el dimensionado y diseño del espesador, las rasquetas y el accionamiento del espesador. Es importante conocer la reología de la pasta y su comportamiento para el diseño de tuberías y equipos de bombeo en los sistemas de espesado en pasta.

En la figura 6-12: Cuadro resumen de ensayos de laboratorio; se muestra un resumen de los diferentes ensayos que se pueden aplicar sobre una muestra de material, con el fin de determinar los parámetros que intervienen en la sedimentación de los sólidos y la caracterización de la pasta. 


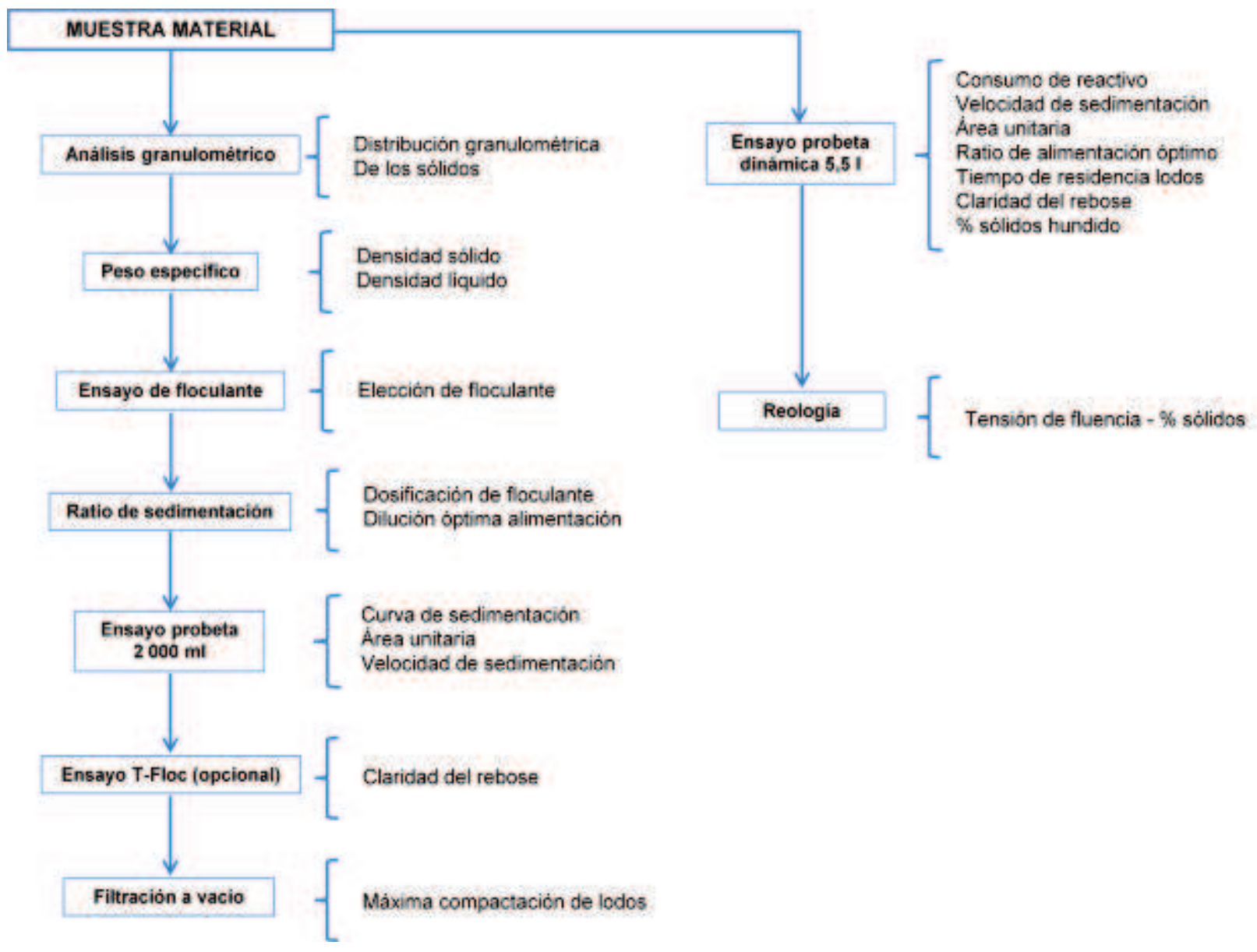

Figura 6-12: Cuadro resumen de ensayos de laboratorio.

(Fuente: Elaboración propia)

\subsection{Metodología de los ensayos de laboratorio para caracterización de la pasta}

\subsubsection{Análisis granulométrico}

En general, las partículas mayores de 38 micras contenidas en los sólidos se analizarán mediante ensayos granulométricos con tamices estándar y mediante los procedimientos habituales para estos ensayos.

Estos tamices de laboratorio son acoplables entre sí y con malla metálica de diversas aberturas, donde los tamices más habituales tienen un diámetro de $200 \mathrm{~mm}$, siendo construidos en acero inoxidable.

Las mallas de cribado son de acero inoxidable y cumplen con las normas UNE 7050-3, ISO 3310-1 y ASTM E11.

En el caso de materiales o estériles finos para espesado en forma de pasta, se recomienda la siguiente serie de tamices para obtener una curva granulométrica de los sólidos a ensayar: 300, 212, 150, 106, 75, 63, 53, 38 micras. Las partículas inferiores a 38 micras, es recomendable analizarlas mediante difracción láser, si fuera una fracción representativa de la muestra. En la figura 6-13: Tamizadora de laboratorio y tamices de ensayo; se muestra un equipo de tamizado tamices para análisis granulométrico. 
El conocimiento de la distribución granulométrica influye en el diseño del mecanismo interno del equipo de espesado y de la inclinación apropiada del fondo del espesador, por lo tanto es muy aconsejable la realización de este ensayo en laboratorio.

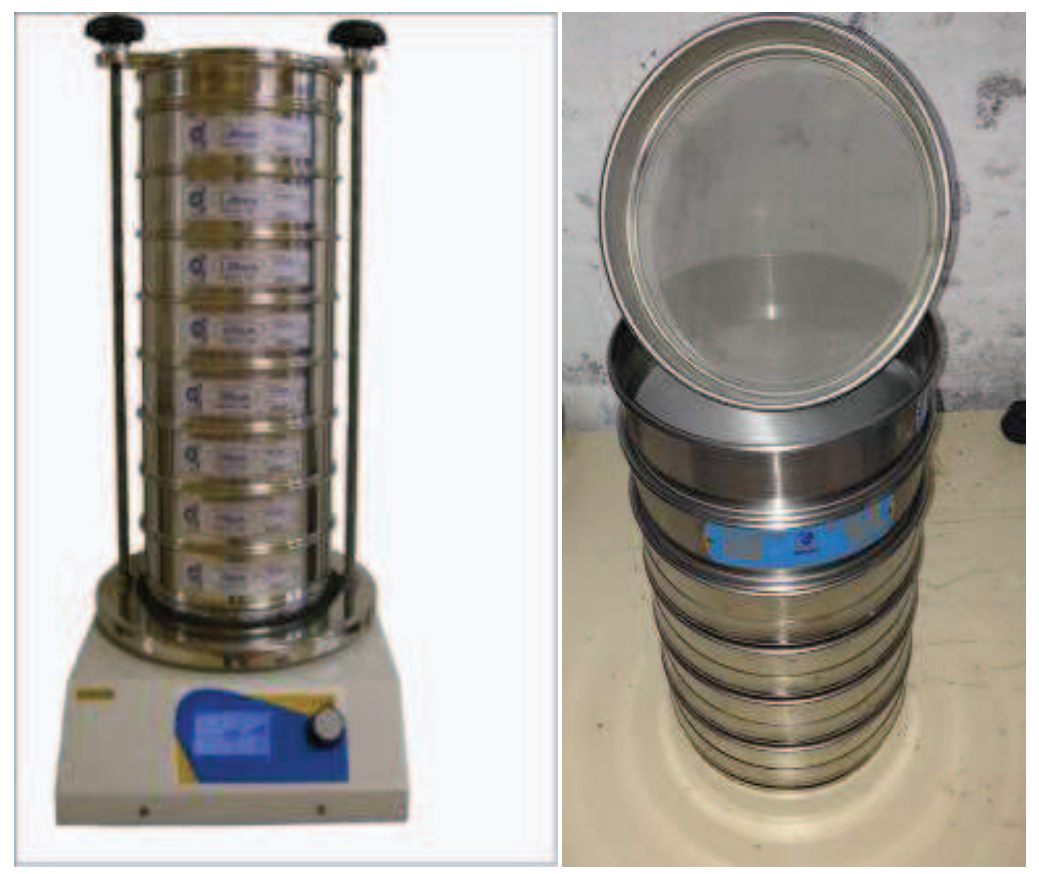

Figura 6-13: Tamizadora de laboratorio y tamices de ensayo.

(Fuente: Elaboración propia)

Los objetivos del ensayo granulométrico es determinar la granulometría de los sólidos y su distribución por tamaños; este ensayo se realiza según la norma UNE-EN 933-1:1998.

Con este ensayo y mediante la serie de tamices seleccionada se procede a la separación y división de los sólidos por tamaños en fracciones granulométricas de tamaños decrecientes.

El instrumental y equipos necesarios serán: un juego de tamices con aberturas de malla por lo general inferiores a 500 micras, en el caso de analizar estériles o materiales mineros típicos para producir pasta.

Otros materiales a emplear son: una estufa de secado con temperatura de $105^{\circ} \mathrm{C} \pm 5^{\circ} \mathrm{C}$; balanza de precisión con una resolución de $0,1 \mathrm{~g}$; bandejas de separación de fracciones y una tamizadora mecánica de laboratorio.

Este método se aplicará a los sólidos secos que forman la pulpa, que por lo general estarán por debajo de 300 micras de tamaño de partícula para el caso de estériles procedentes de una flotación para ser espesados en forma de pasta.

En la ejecución del ensayo se tendrán en cuenta lo dispuesto en la norma UNE-EN 932-2:1999 para este tipo de ensayos. Por lo tanto la muestra mínima para analizar la distribución granulométrica será de $200 \mathrm{~g}$, puesto que generalmente los materiales a ensayar se van a encontrar por debajo del rango de $4 \mathrm{~mm}$ de tamaño máximo, conforme a la norma.

La masa de sólidos secos a analizar se cuartea, para la obtención de una muestra parcial representativa de la muestra general. La muestra se registra con un número de identificación y se 
anota su masa total (M). Los ensayos se realizarán siempre en seco ya que de otra forma se perderían finos con el lavado de las muestras.

Se procede al tamizado de la muestra seca, siempre con una humedad inferior al $0.25 \%$, vertiendo la muestra sobre la torre de tamices dispuestos en orden decreciente de tamaños de abertura, colocando la tapa y el fondo. A la columna de tamices se aplica un movimiento planetario bien de forma mecánica en la tamizadora o bien de forma manual. Una vez tamizada la muestra se procede al pesaje de las fracciones retenidas, registrando el material retenido $\left(R_{1}, R_{2} \ldots R_{n}\right)$. Se pesa también la fracción retenida en el fondo, registrando su masa $\left(R_{f}\right)$.

Para expresar el porcentaje en masa retenida en cada tamiz respecto a la masa total se emplea la expresión 6-1:

$$
\% \text { Retenido tamiz }=\frac{R_{i}}{M} \cdot 100
$$

Los resultados obtenidos se validarán, comprobando que la suma de las masas totales de las fracciones retenidas no difiere en más de un $0.5 \%$ de la masa inicial $(\mathrm{M})$, en caso contrario se debería repetir el ensayo.

Con los datos obtenidos, se calcula el porcentaje de paso por cada malla y el porcentaje de paso acumulado para representar la curva granulométrica. En la figura 6-14: Curva granulométrica; se representa la distribución granulométrica típica para un material fino procedente de una molienda.

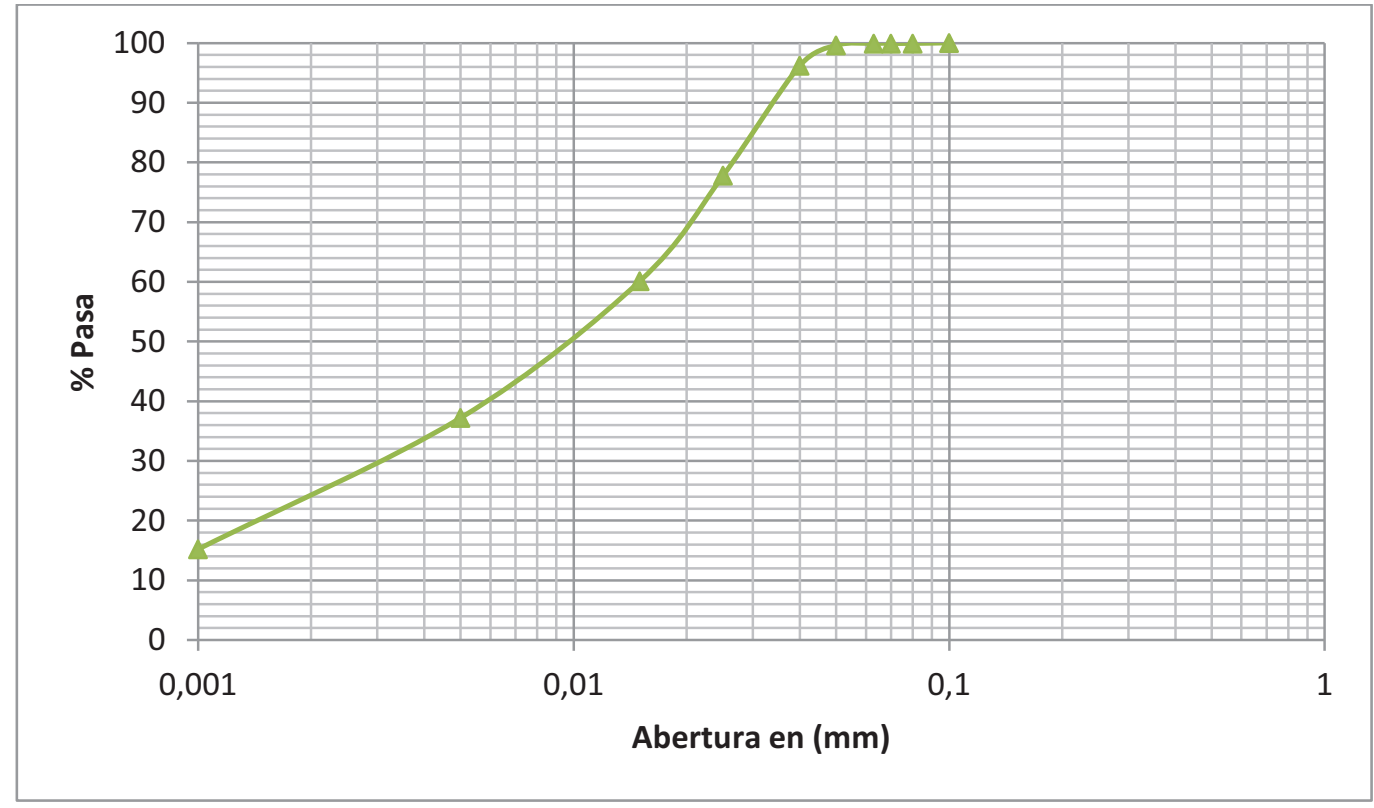

Figura 6-14: Curva granulométrica.

(Fuente: Elaboración propia)

\subsubsection{Análisis del peso específico de sólidos y líquido}

El objetivo de los ensayos es determinar la densidad de los sólidos y la densidad del licor o el agua de proceso. En general estos datos suelen ser conocidos de antemano por los operadores de la planta, pero en el caso de nuevos proyectos o por la necesidad de confirmar los datos del 
peso específico de los sólidos y líquidos que forman la pulpa, será necesario realizar un ensayo en laboratorio, antes de comenzar los ensayos de sedimentación.

Para la determinación del peso específico de los sólidos será de aplicación lo dispuesto en la norma UNE-EN 1097-6:2001.

En la realización de este ensayo será necesaria la utilización del siguiente instrumental y equipo:

a) Una estufa de secado con temperatura de $105^{\circ} \mathrm{C} \pm 5^{\circ} \mathrm{C}$.

b) Balanza de precisión con una resolución de 0,1g (mínimo)

c) Termómetro.

d) Picnómetro.

e) Tamices de 75 micras y 38 micras para lavado de la muestra.

f) Equipo de baño María para calentamiento de la muestra.

Para la ejecución del ensayo se utiliza el ensayo del picnómetro con granulometrías finas. La muestra a ensayar será representativa y de la que se toma una fracción de partículas entre 75 y 38 micras para el ensayo.

Por lo tanto la muestra a ensayar será una fracción que comprenda los tamaños dentro del rango establecido, esta muestra se sumerge en un picnómetro para extraer las burbujas de aire, dando ligeros golpes en una posición inclinada. Se colocará el picnómetro en un baño María y se mantiene una temperatura constante de $22^{\circ} \mathrm{C} \pm 3^{\circ} \mathrm{C}$, durante 24 horas $\pm 0,5$ horas.

Transcurrido este tiempo se extraerá el picnómetro del baño y se enrasará con agua destilada. Se seca el exterior del picnómetro y se anota la masa total $\left(\mathrm{M}_{2}\right)$ y la temperatura del agua. Posteriormente se vacía el contenido del picnómetro sobre una bandeja y se enjuaga para que no queden sólidos dentro de él.

A continuación, el picnómetro se enrasa con agua y se seca el exterior; se pesa y se anota la masa $\left(\mathrm{M}_{3}\right)$ y la temperatura que tiene el agua. La diferencia entra ambas temperaturas del agua medidas, no debe ser superior a $2^{\circ} \mathrm{C}$.

La muestra así obtenida se extiende en una bandeja formando una capa y se seca hasta que la película superficial que tienen las partículas desaparece. El objetivo es conseguir unas partículas saturadas de agua para obtener su masa, mediante pesada $\left(M_{1}\right)$.

Por último, la muestra se introduce en estufa a $105^{\circ} \mathrm{C} \pm 5^{\circ} \mathrm{C}$ para obtener la masa constante seca, anotando la pesada como $\mathrm{M}_{4}$.

Para controlar la posible pérdida de muestra durante este proceso es importante pesar la muestra inicial antes de la primera inmersión y pesar la muestra final para comprobar que es la misma masa de sólidos y no se han producido pérdidas.

Las diferentes densidades obtenidas a lo largo del ensayo se calcularán mediante las ecuaciones 6-2; 6-3; 6-4 y 6-5:

$$
\begin{gathered}
\rho_{a}=\rho_{w} \cdot \frac{M_{4}}{M_{4}-\left(M_{2}-M_{3}\right)} \\
\rho_{r d}=\rho_{w} \cdot \frac{M_{4}}{M_{1}-\left(M_{2}-M_{3}\right)}
\end{gathered}
$$




$$
\begin{gathered}
\rho_{d}=\rho_{w} \cdot \frac{M_{1}}{M_{1}-\left(M_{2}-M_{3}\right)} \\
W A_{24}=100 \cdot \frac{\left(M_{1}-M_{4}\right)}{M_{4}}
\end{gathered}
$$

Siendo:

$\mathrm{M}_{1}$; la masa de partículas saturadas con la superficie seca y pesada al aire $(\mathrm{g})$

$\mathrm{M}_{2}$; la masa aparente en el picnómetro con la muestra saturada $(\mathrm{g})$

$\mathrm{M}_{3}$; la masa aparente del picnómetro lleno de agua $(\mathrm{g})$

$\mathrm{M}_{4}$; la masa de partículas secada en estufa y pesada al aire $(\mathrm{g})$

$\rho_{w}$; densidad del agua la temperatura anotada en la pesada de $\mathrm{M}_{2}$

Para este ensayo es necesario disponer del peso específico del agua en función de la temperatura para calcular el valor de $\rho_{\mathrm{w}}$. En la tabla 6-2: Peso específico del agua en función de la temperatura; se muestran los valores para el valor de $\rho_{w}$ en función de la temperatura del agua

Tabla 6-3: Peso específico del agua en función de la temperatura.

\begin{tabular}{|c|c|}
\hline Temperatura $^{\circ} \mathrm{C}$ & Peso específico $\left(\mathrm{g} / \mathrm{cm}^{3}\right)$ \\
\hline 4 & 0.999968 \\
\hline 6 & 0.999876 \\
\hline 8 & 0.999728 \\
\hline 10 & 0.999526 \\
\hline 12 & 0.999273 \\
\hline 14 & 0.99897 \\
\hline 16 & 0.99862 \\
\hline 18 & 0.99823 \\
\hline 20 & 0.99756 \\
\hline 23 & 0.99681 \\
\hline 26 & 0.99597 \\
\hline 29 & (Fuente: Elaboración propia) \\
\hline
\end{tabular}

Para la determinación del peso específico del agua de proceso, se realizará mediante el pesaje de un volumen fijo de muestra de líquido. El material necesario para este ensayo es el siguiente:

a) Una probeta de $1000 \mathrm{ml}$.

b) Una báscula de laboratorio con una resolución de $0.1 \mathrm{~g}$.

Se pesa la probeta vacía obteniéndose su tara. Se llena la probeta hasta la marca de $1000 \mathrm{ml}$ y se determina el peso total de líquido, obteniéndose de este modo la densidad real del agua de proceso o licor en g/l con la fórmula 6-6. 


$$
\rho_{L}=\frac{P_{L}}{V_{L}}
$$

Siendo:

$\mathrm{P}_{\mathrm{L}}$; Peso de líquido en gramos

$\mathrm{V}_{\mathrm{L}}$; Volumen de líquido en litros

$\rho_{\mathrm{L}}$; densidad del líquido expresada en gramos / litro

\subsubsection{Ensayo de floculantes y su elección}

El objetivo de este ensayo es elegir, de entre una amplia gama de reactivos de uno o varios fabricantes (aniónicos, catiónicos, sin carga, etc.), el que mejor ratio y velocidad de sedimentación presente en el tratamiento de los sólidos; valorando otros factores como claridad del rebose, tiempo de formación del flóculo, tamaño del flóculo, etc.

Para el estudio de sedimentación realizado en el presente trabajo se cuenta con una serie completa de floculantes proporcionados por la compañía Nalco. Estos floculantes serán los empleados para la floculación de las pulpas ensayadas. Estos floculantes son los que se muestran en la tabla 6-3: Floculantes Nalco para ensayos.

Tabla 6-4: Floculantes Nalco para ensayos.

\begin{tabular}{|c|c|c|c|}
\hline Fabricante & Denominación & Tipo de carga & \%Carga \\
\hline NALCO & 71771 & No iónico & Sin carga \\
\hline NALCO & 8172 & Aniónico & Baja \\
\hline NALCO & 9601 & Aniónico & Media \\
\hline NALCO & 9901 & Aniónico & Alta \\
\hline NALCO & 9913 & Catiónico & Baja \\
\hline NALCO & 9907 & Catiónico & Media \\
\hline NALCO & 71687 & Catiónico & Alta \\
\hline NALCO & 9909 & Catiónico & Muy alta \\
\hline
\end{tabular}

(Fuente: Nalco Española, S.L.)

El primer paso antes de utilizar cualquier tipo de floculante o reactivo es seguir las indicaciones del fabricante respecto al uso y forma de preparación del reactivo.

El procedimiento de evaluación de floculantes se realizará de acuerdo al siguiente método de ensayo.

Se prepararán, al menos tres soluciones de diferentes floculantes para cada ensayo que se realice en el laboratorio. Se deben emplear los floculantes comunes utilizados en la industria para el espesado de lodos o bien el floculante recomendado por el fabricante o por el operador de la planta y otros dos, al menos, para comparar los resultados obtenidos. 
Para cada muestra del espesador, se realiza una serie de ensayos de sedimentación a una tasa de sólidos contenidos que permanece constante. Para tal fin se han utilizado probetas de $500 \mathrm{ml}$ como método general. Se recomienda una tasa de alimentación de sólidos en peso del $5 \%$ como condición de sedimentación efectiva y para que los floculantes puedan ser comparados fácilmente. Es conveniente no variar la dilución de la pulpa durante estos ensayos para obtener resultados comparables entre los mismos. Si bien la tasa de alimentación de sólidos, en una nueva serie de ensayos, puede ser variada según: el criterio del operador, la experiencia de los técnicos de proceso en planta $u$ otros ensayos que se hayan realizado previamente.

Los floculantes se evaluarán en base a las siguientes premisas: curva de tasa de sedimentación frente a la curva de adicción de floculante o consumo de floculante; y mediante la inspección visual de la claridad del sobrenadante de la probeta, tamaño del flóculo y velocidad de formación de los flóculos.

El procedimiento para la realización del ensayo será el siguiente:

1) Se rellenará una probeta de $500 \mathrm{ml}$ con pulpa a la concentración de sólidos determinada y conocida, bien realizando la dilución en laboratorio a partir de sólido seco o bien mediante la dilución de la pulpa disponible con agua de proceso. El contenido en sólidos para este ensayo estará generalmente entre el $5 \%$ y el $10 \%$ de sólidos en peso; siendo recomendable realizar el ensayo con el $5 \%$ de sólidos para el caso de estériles mineros y con todos los tipos de floculantes seleccionados.

2) Una vez llena la probeta con pulpa hasta la marca de $500 \mathrm{ml}$, se realizan dos marcas en la parte exterior de la probeta separadas $100 \mathrm{~mm}$ una de otra, colocando la marca superior a 20 $\mathrm{mm}$ del extremo superior de la pulpa. Con una varilla de agitación, se procede a la agitación por tres veces y de forma enérgica la pulpa para poner los sólidos en suspensión.

3) Se añade una cantidad fija y conocida de floculante. Se procede a agitar de forma enérgica la muestra y se observa el proceso de sedimentación, tomando el tiempo que transcurre desde que la interfase líquido-pulpa pasa por las marcas realizadas en la probeta. Este tiempo establece la velocidad de sedimentación para una determinada concentración de sólidos (en este caso $5 \%$ en peso) y una dosificación determinada de floculante introducida en la suspensión.

En la figura: 6-15: Ensayos de sedimentación para elección de floculante; se muestra este tipo de ensayos sobre una muestra de finos de feldespato con el fin de determinar el tipo de floculante más adecuado a los sólidos que se pretenden sedimentar. 

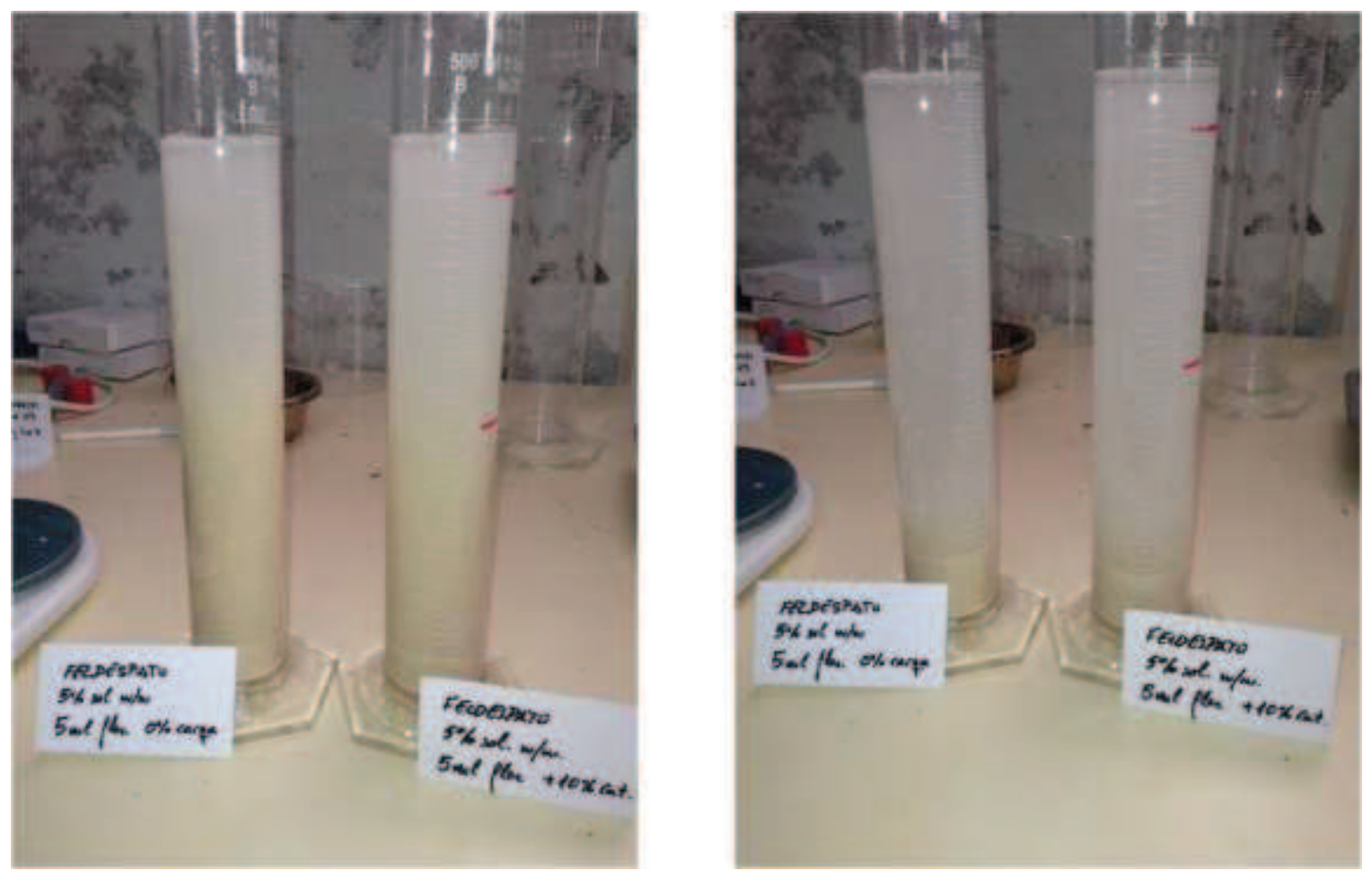

Figura 6-15: Ensayos de sedimentación para elección de floculante.

(Fuente: Elaboración propia)

Otros datos a tener en cuenta en el ensayo es la estimación de forma visual de la formación del flóculo y el tamaño que alcanza una vez madurado. También se procederá a estimar la claridad del rebose obtenida en el ensayo.

Este ensayo se realizará con al menos tres tipos de floculantes y para la misma dilución de la pulpa en cada uno de ellos. En la figura 6-15, se muestra la elaboración del ensayo de finos de feldespato con una dilución del $5 \%$ en peso utilizando dos tipos diferentes de floculante $(0 \%$ de carga iónica y $10 \%$ de carga catiónica). Con los datos obtenidos de la velocidad de sedimentación en $\mathrm{m} / \mathrm{h}$ frente a la dosificación de floculante añadida en cada uno de los ensayos, se representa una gráfica como se muestra en la figura 6-16: Grafica para elección de floculante; en la que se determina la elección del mejor floculante y una estimación de la dosificación necesaria de floculante para el proceso de sedimentación de los sólidos. 


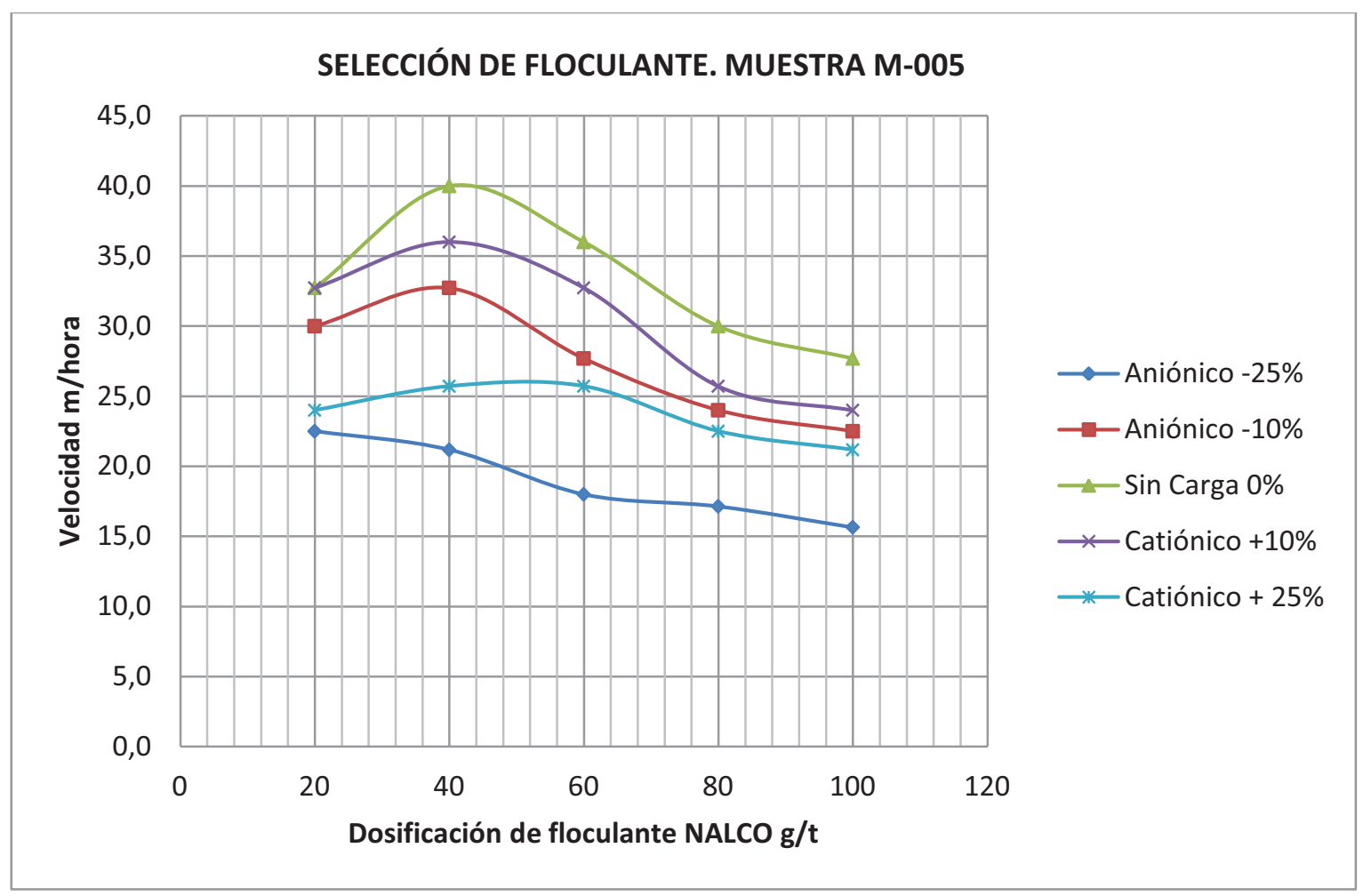

Figura 6-16: Grafica para elección de floculante. (Fuente: Elaboración propia)

\subsubsection{Ensayo del ratio de sedimentación}

Una vez determinado el mejor floculante que se ajusta a las características de la pulpa, se procederá a realizar un ensayo de ratio de sedimentación. El objetivo de este ensayo es determinar el porcentaje de sólidos óptimo y la dosificación de floculante para el proceso de sedimentación. El ensayo pretende reproducir las condiciones óptimas que se deben de producir en el sistema de alimentación con autodilución del espesador real y la dosificación requerida de floculante en la operación.

El ensayo se realizará con el procedimiento es como se describe a continuación:

Este ensayo se lleva a cabo en probeta de $500 \mathrm{ml}$, con una pulpa que tenga una concentración en sólidos conocida, normalmente será un valor entre $2.5 \%$ y $15 \%$ de sólidos en peso. El ensayo se realizará con diferentes porcentajes de contenido en sólidos siendo empleados normalmente con el $2,5 \% ; 5 \% ; 7,5 \%$ y $10 \%$ de contenido en sólidos en peso para evaluar. Se utiliza el mejor floculante que se haya encontrado con el ensayo mencionado anteriormente, en el punto 6.3.3.

Para cada ensayo con un contenido en sólidos distinto se sigue el siguiente procedimiento de ensayo:

1) Una vez llena la probeta de $500 \mathrm{ml}$ se procede a la agitación de la pulpa varias veces de forma enérgica para poner los sólidos en suspensión; se añade una cantidad determinada de floculante y se vuelve a mezclar por agitación; tras esto se produce el comienzo de la formación de los flóculos y la sedimentación de los sólidos. En la probeta se realizarán dos 
marcas separadas $100 \mathrm{~mm}$, estando la marca superior a $20 \mathrm{~mm}$ de la interfase superior de la pulpa.

2) Registrar el tiempo que transcurre en sedimentar estos $100 \mathrm{~mm}$ entre las marcas pintadas en el exterior de la probeta.

3) Repetir el registro del tiempo de sedimentación con varias dosificaciones crecientes de floculante en el mismo cilindro, es decir aumentando la dosificación de floculante para conseguir diferentes valores de velocidad de sedimentación en función de la dosificación de floculante. Si las tasas de sedimentación son menores de 5-10 m/h, generalmente quiere decir que no se ha alcanzado la tasa de sedimentación y habrá que añadir una dosis adicional de floculante; o bien que el floculante no es adecuado para el material ensayado.

4) Representar en una gráfica los resultados de tasa de sedimentación frente al contenido en sólidos.

5) Con los datos obtenidos es posible representar en una gráfica la velocidad de sedimentación frente a la dosificación de floculante para cada contenido en sólidos analizados, como se muestra en la figura 6-17: Curva de flujo de sedimentación. Dosificación-velocidad de sedimentación. Otra gráfica que es posible representar es el flujo de sólidos en función de la dosificación de floculante, como se representa en la figura: 6-18: Curva de flujo de sedimentación. Dosificación-flujo de sólidos.

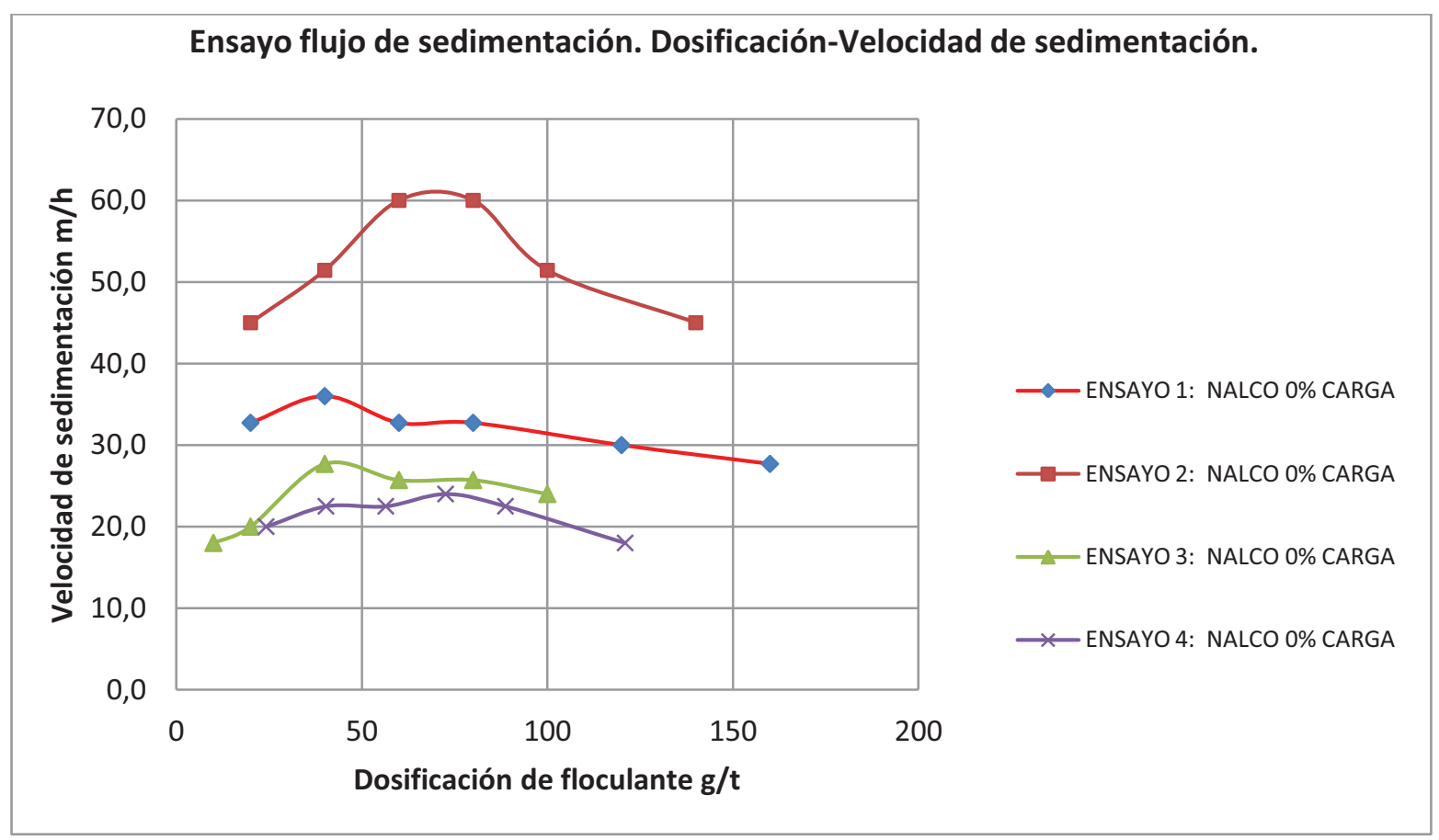

Figura 6-17: Curva de flujo de sedimentación. Dosificación-velocidad de sedimentación.

(Fuente: Elaboración propia) 


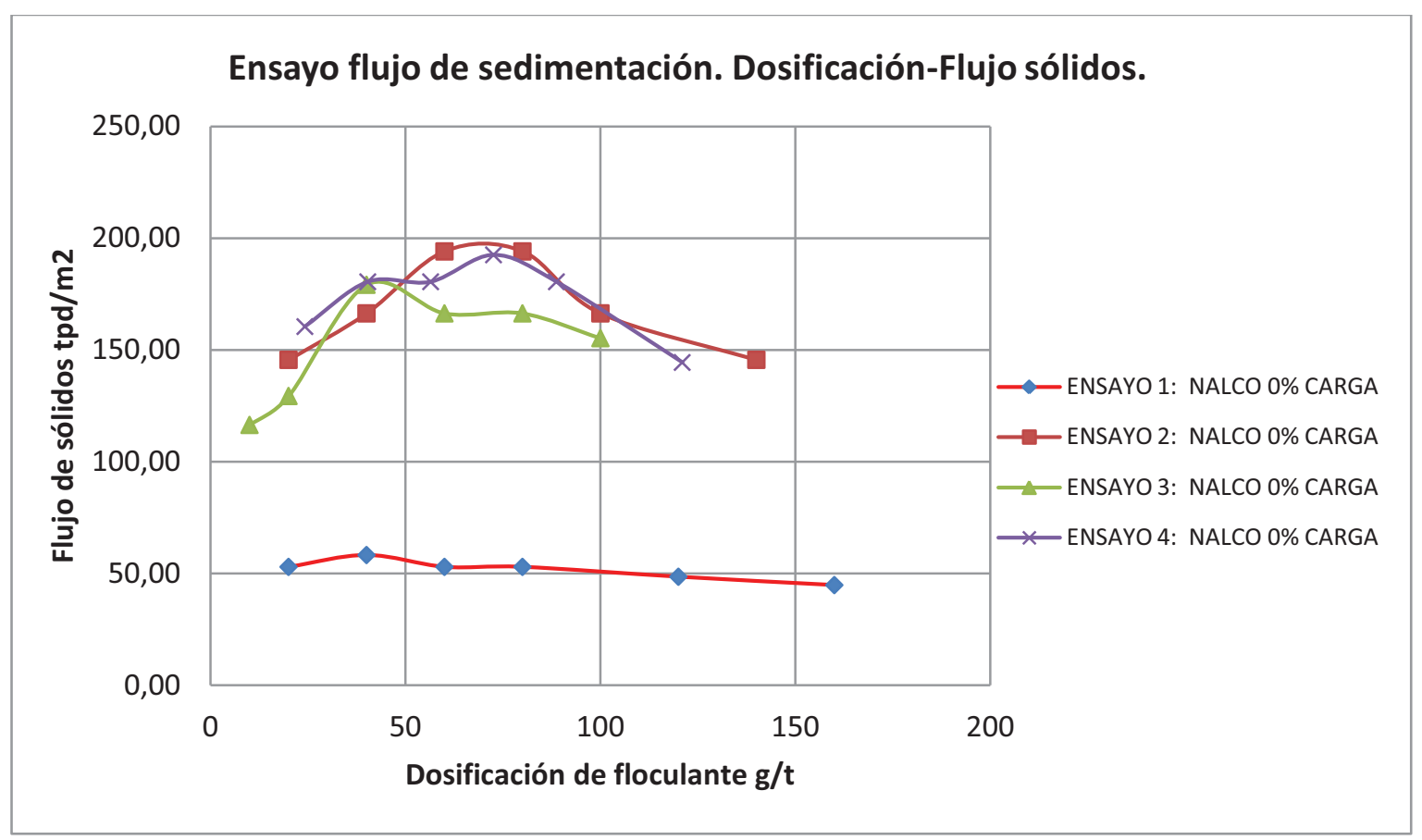

Figura 6-18: Curva de flujo de sedimentación. Dosificación-flujo de sólidos.

(Fuente: Elaboración propia)

\subsubsection{Ensayo estático en probeta de $2000 \mathrm{ml}$}

El ensayo en probeta estática de $2000 \mathrm{ml}$, tiene como objetivo la determinación de los datos de diseño preliminares a partir de los datos obtenidos en la sedimentación de la pulpa floculada en una probeta de 2 litros de capacidad, que se utiliza a modo de espesador discontinuo. A partir de este ensayo se pueden obtener los datos del área de sedimentación necesaria y la altura lateral del espesador necesaria el proceso, partiendo de las características iniciales de la pulpa a sedimentar y de las especificaciones de la suspensión que se desean obtener en el hundido.

La instalación consiste en una probeta graduada de vidrio con $2000 \mathrm{ml}$ de capacidad provista de una regla graduada para medir la altura de la interfase. En la figura 6-19: Ensayo en probeta de $2000 \mathrm{ml}$ con finos de feldespato; se muestra la probeta utilizada para los ensayos realizados en laboratorio. Es recomendable el ensayo en probeta de $2000 \mathrm{ml}$ ya que se elimina el efecto pared en el proceso de sedimentación.

El procedimiento de ensayo se detalla a continuación:

1) El primer paso es verter $2000 \mathrm{ml}$ de pulpa en la probeta con una concentración en sólidos conocida. Se agita la probeta o la pulpa para conseguir homogenizar la suspensión.

2) Se añade una cantidad determinada de floculante y se repite el proceso de agitación para poner los sólidos en suspensión. Una vez que se produce la mezcla homogénea comienzan a formarse los primeros flóculos y por tanto comienza el proceso de sedimentación.

3) Se coloca la probeta en una superficie horizontal y sin vibraciones; comenzándose a medir la altura de la interfase a diferentes tiempos de sedimentación. El proceso de sedimentación es inicialmente rápido, por lo que deben de tomarse los tiempos y alturas de la interfase a intervalos cortos de tiempo. Posteriormente, estos intervalos se pueden alargar. El tiempo 
mínimo del ensayo será de 120 minutos, donde se tomarán medidas de altura de la interfase en función del tiempo.

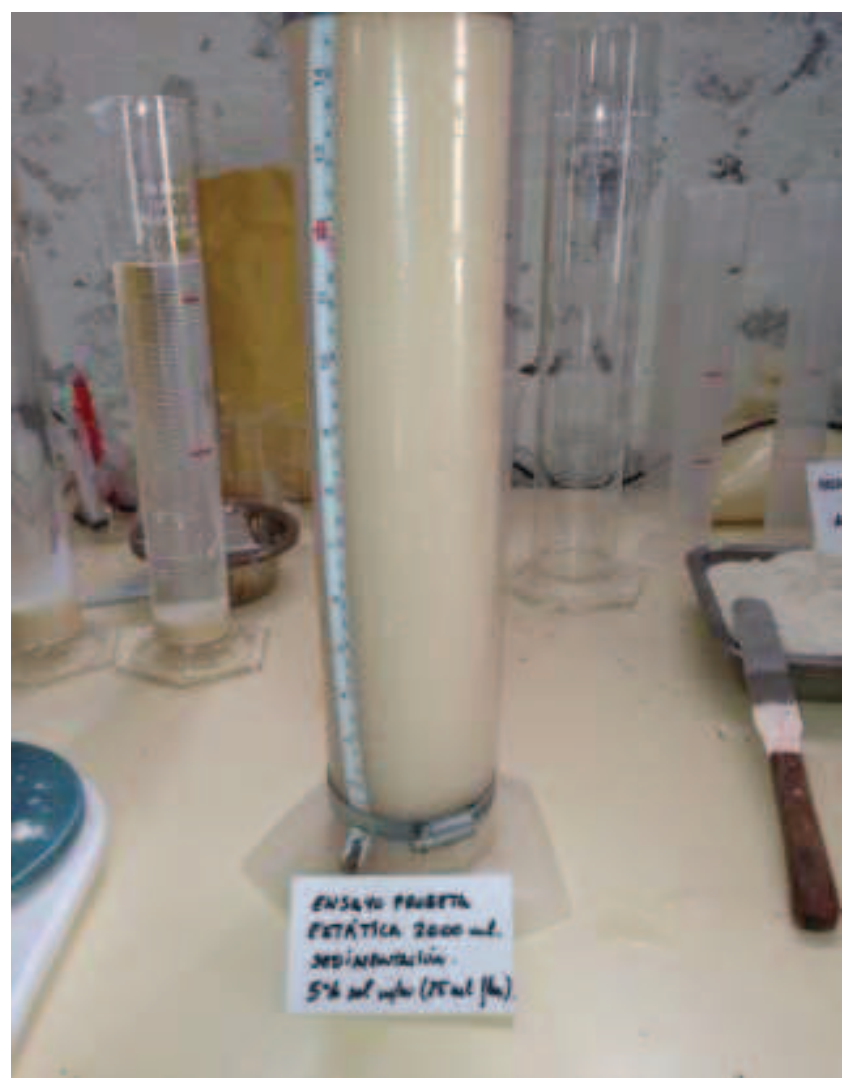

Figura 6-19: Ensayo en probeta de $2000 \mathrm{ml}$ con finos de feldespato. (Fuente: Elaboración propia)

4) Con los datos recogidos en el ensayo se representará gráficamente la altura de la interfase (h) frente al tiempo $(t)$ en minutos. La curva debe de trazarse de forma precisa, ya que su correcta construcción permite la medida de posibles desviaciones y la exactitud de los cálculos posteriores. En la figura 6-20: Curva de sedimentación de ensayo en probeta de $2000 \mathrm{ml}$; se muestra una curva típica obtenida en estos ensayos.

Este ensayo en probeta de 2 litros, es el ensayo clásico que se ha utilizado de forma habitual y del que se tomaban los datos para realizar los cálculos con los métodos clásicos de Coe-Clevenger, Talmage-Fitch y Oltman entre otros.

La curva obtenida en este ensayo puede resultar orientativa para definir el proceso de sedimentación pero no extrapolable en el caso del diseño de espesadores de pasta. Es recomendable realizar este ensayo y compara los tiempos de residencia frente al contenido en sólidos, con el ensayo en probeta estática de $2000 \mathrm{ml}$ y el espesador dinámico de laboratorio. En esta comparativa es posible apreciar el efecto que tiene el tiempo de residencia y el tanque, el efecto del lecho de lodos y el mecanismo de piquetas. 


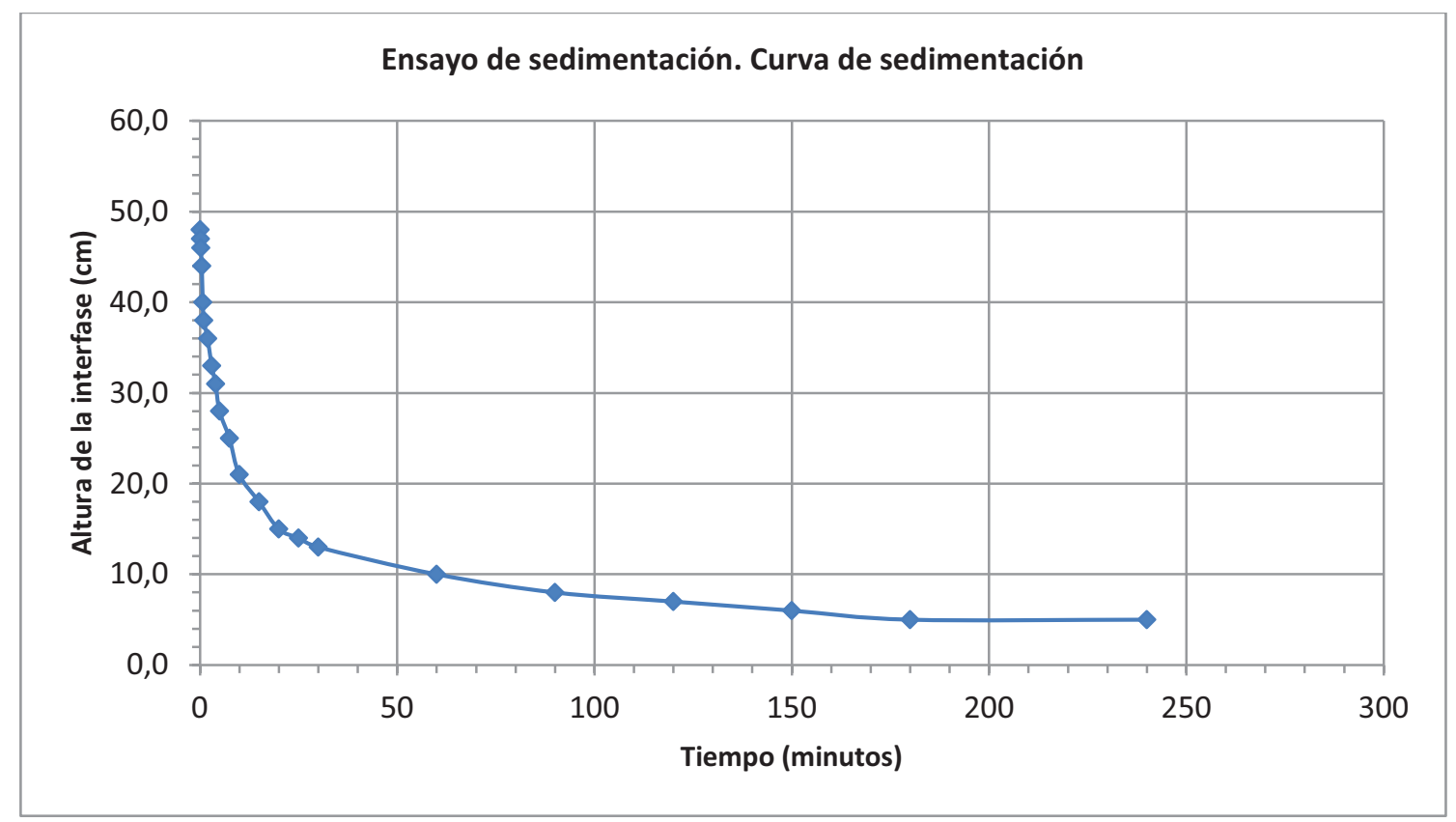

Figura 6-20: Curva de sedimentación de ensayo en probeta de $2000 \mathrm{ml}$. (Fuente: Elaboración propia)

\subsubsection{Ensayo en probeta de tubo profundo}

Con una muestra de material suficiente de 1,5 a $4 \mathrm{~kg}$ de sólidos es posible llevar a cabo el ensayo en una probeta cilíndrica con 5,5 litros de capacidad y provisto de rasquetas dinámicas, introduciendo la alimentación óptima de pulpa y floculante obtenida en los ensayos anteriores. Con este ensayo se pretende reproducir a escala de laboratorio la sedimentación en probeta con un sistema de accionamiento de paletas para la liberación del agua contenida en el lecho de lodos. EI tiempo de duración del ensayo puede ser variable, desde una hora hasta 24 horas para comprobar la compactación del lecho de lodos y el contenido en sólidos de la pasta. Como norma general se realizarán los ensayos con una duración mínima de 6 horas para obtener una curva representativa y unos resultados extrapolables.

Cada ensayo realizado se puede hacer con diferentes dosificaciones de floculantes, utilizando el mejor floculante encontrado en el ensayo de selección de floculantes, así como diferentes diluciones de la alimentación.

Para la realización de estos ensayos se ha construido un equipo de laboratorio con una capacidad de 5,5 litros como se comentó en el apartado 6.2.1.

Si la tasa de alimentación de sólidos óptima encontrada con ensayos anteriores es por ejemplo, del $5 \%$ de contenido en sólidos, se realizará un ensayo con la probeta de tubo profundo con esta tasa de alimentación de sólidos en la pulpa. El floculante dosificado será incrementado en sucesivos ensayos sobre el que se utilizó en los ensayos de sólidos en la alimentación y la dosificación obtenida como óptima, dejándose este incremento al criterio y experiencia del operador. Con este incremento de floculante, se asegura que los problemas asociados a la escasa compactación por el bajo nivel de pulpa no afectan a la sedimentación al realizar el ensayo en la 
probeta de tubo profundo. El procedimiento de ensayo consta de dos partes diferenciadas que se describen a continuación:

1) En una primera parte del ensayo, y una vez introducida la pulpa en el equipo de agitación previo al espesador de laboratorio se ponen en suspensión los sólidos. Tras este paso se alimenta la pulpa mediante bombeo y se añade la dosificación de floculante preparada previamente con una bomba dosificadora. En esta primera parte del ensayo en la probeta de 5,5 litros, se registrará el tiempo de alimentación a intervalos regulares y se mide la cantidad de pulpa alimentada. Los ensayos típicos tienen una duración de 20-30 minutos para alimentar un total de 25-30 litros de pulpa. Una vez alimentada toda la pulpa se pasa a la segunda fase del ensayo en la probeta de tubo profundo.

En esta primera fase, cuando se observa el rebose clarificado es posible tomar una muestra del licor sobrenadante que será analizada para obtener los sólidos en suspensión.

2) La segunda parte del ensayo comprende, la fase de compactación, donde se producirá la liberación del contenido de agua del lecho de lodos, que se produce normalmente a partir de la finalización de la alimentación de la pulpa. En esta segunda parte se encuentra conectado el mecanismo motorizado de rasquetas y se tomarán medidas tanto de la altura de la interfase como del tiempo, obteniendo una tabla tiempo-altura de la interfase. Esto permite conocer el contenido en sólidos que va alcanzando el lecho de lodos. De esta forma se puede representar una gráfica de tiempo frente a contenido en sólidos, como se muestra en la figura 6-21: Gráfica tiempo-porcentaje en sólidos; para determinar el tiempo de retención de lodos necesario en el tanque del espesador para alcanzar una concentración determinada en el hundido.

Una vez terminado el ensayo, se pueden realizar ensayos complementarios para comprobar los datos obtenidos, como es el contenido en sólidos final o los sólidos contenidos en el licor sobrenadante. Para ello se realizan los siguientes pasos:

a) Retirar la rasqueta y el accionamiento.

b) Decantar el licor clarificado.

c) Registrar el nivel de sólidos final.

d) Retirar los sólidos de la probeta.

e) Pesar los sólidos húmedos; secar y pesar nuevamente los sólidos secos para obtener el contenido en sólidos final.

f) Registrar los datos obtenidos en los ensayos. 


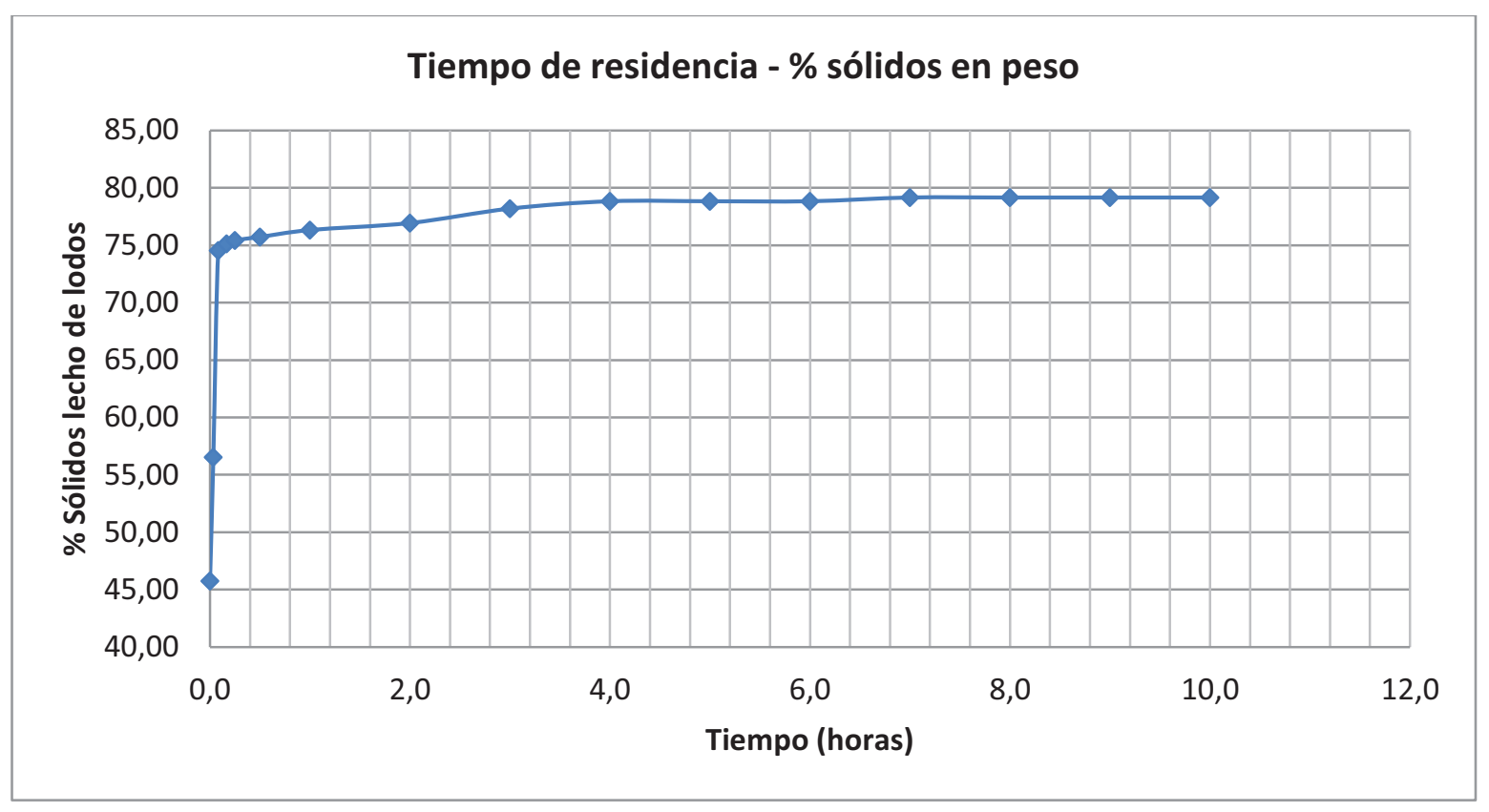

Figura 6-21: Gráfica tiempo-porcentaje de sólidos.

(Fuente: Elaboración propia)

\subsubsection{Ensayo de filtración a vacío (opcional)}

El ensayo de filtración a vacío, es uno de los ensayos opcionales que se pueden aplicar a los sólidos o materiales para conocer el grado máximo de compactación de éstos, o la máxima concentración de sólidos que se puede alcanzar.

Los materiales necesarios para el montaje del equipo de laboratorio mostrado en la figura 6-22: Equipo de laboratorio para filtración a vacío; son los siguientes:

a) Bomba de vacío de laboratorio con una potencia de 0,18 kW como mínimo.

b) Aspiración de 5 litros/minuto a -0,7 bar.

c) Embudo Buchner para ensayos de filtración.

d) Tela o papel filtrante

e) Dos matraces tipo Elenmeyer con cierres en la parte superior

f) Mangueras de conexión y pequeño material de laboratorio

g) Estufa para secado de muestras 


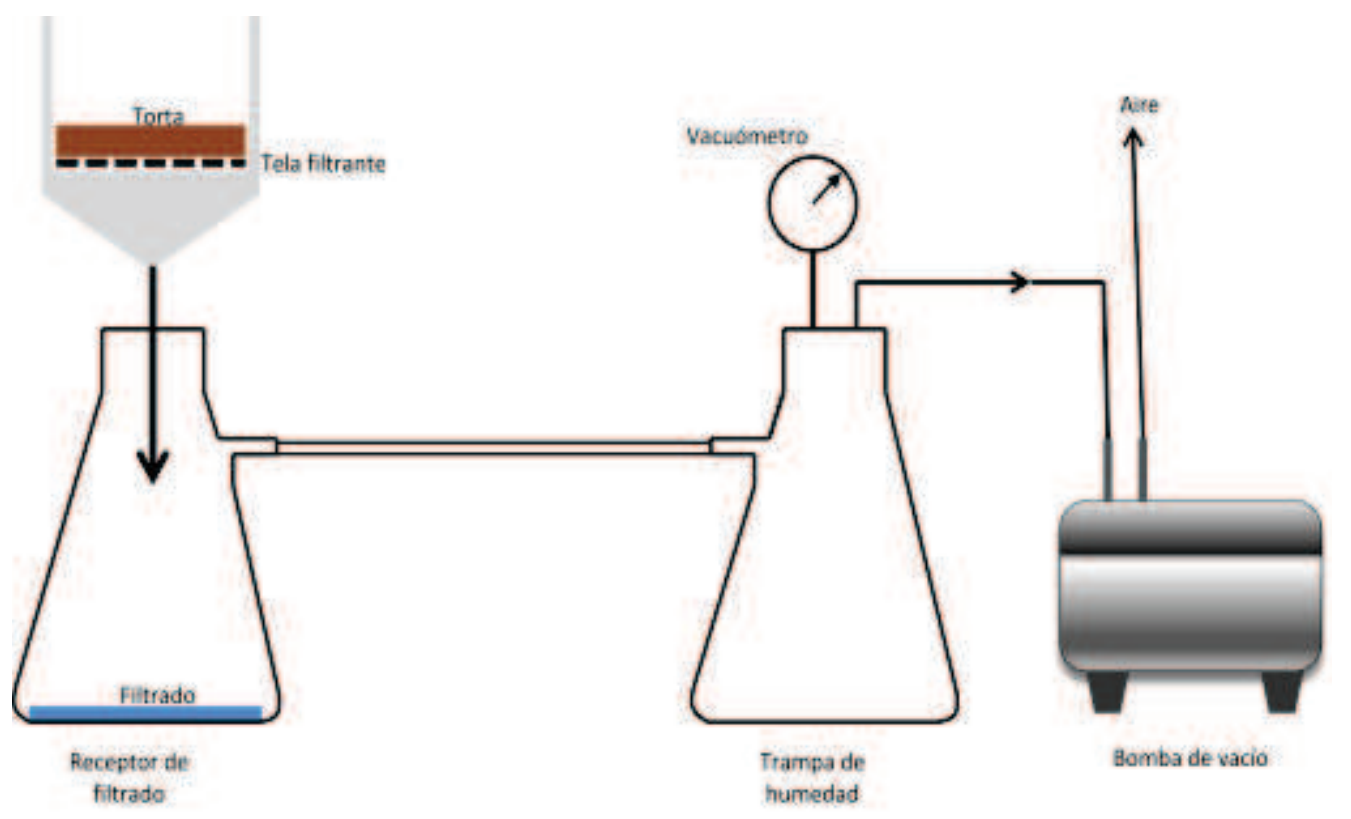

Figura 6-22: Equipo de laboratorio para filtración a vacío.

(Fuente: Elaboración propia)

Para la filtración a vacío en el caso que nos ocupa, el objetivo del ensayo es conocer el máximo contenido en sólidos que puede alcanzar la pulpa. Normalmente no son necesarios lavados a contracorriente de la torta ni tiempos extra de secado de la torta, ya que hay que recordar que se trata de obtener la máxima compactación de los sólidos y no una prueba de filtración a vacío completa.

Una de las ventajas de utilizar este método de ensayo es la obtención de muestras con un contenido en sólidos muy superior al que se obtiene con la sedimentación en probetas. Estas tortas filtradas se emplean en la determinación de la tensión de fluencia mediante viscosímetro o ensayo de asentamiento.

Es recomendable realizar un ensayo de filtración a vacío preliminar para ajustar diferentes parámetros como son: el tipo de tela filtrante, adición de floculante y el tiempo de vacío hasta conseguir una torta filtrada.

El volumen de torta a emplear será el que permita obtener un espesor de torta de al menos tres milímetros como mínimo para obtener una muestra representativa. Para ello se realizará el siguiente procedimiento de ensayo:

1) Preparar una cantidad de pulpa con los sólidos con una concentración conocida de sólidos en peso, con una muestra representativa que forme una torta de espesor mínimo de $3 \mathrm{~mm}$.

2) Añadir una cantidad de floculante determinada por los ensayos anteriores para los sólidos a filtrar y mantener en suspensión la pulpa.

3) Verter la pulpa floculada sobre la tela filtrante y permitir la decantación de los sólidos durante 5 segundos aproximadamente, permitiendo que la pulpa cubra completamente el medio filtrante.

4) Comenzar el proceso de filtrado con vacío hasta que se haya eliminado el agua de la parte superior y se forme una torta uniforme. Comprobar si se produce la rotura de la torta. 
5) Durante la operación, se anotarán todas las medidas y tiempos relevantes observados como son: nivel de vacío, temperatura, tiempo de formación de la torta, volumen de líquido filtrado, etc.

6) Extraer la torta del embudo Buchner y pesar la torta húmeda.

7) Secar la torta en estufa para obtener el contenido en sólidos de la torta.

El resultado del ensayo será obtener el máximo contenido en sólidos que puede alcanzar la pulpa, este dato marca el límite superior de los sólidos contenidos en el espesado en pasta. Las muestras obtenidas se pueden utilizar en el ensayo de la reología de los lodos.

\subsubsection{Ensayo de reología de los lodos}

Se realizará un ensayo de la reología de los lodos sobre un rango de sólidos contenidos tal que se pueda visualizar una gráfica de límite de fluencia frente al contenido en sólidos en tanto por ciento. Este ensayo se realizará con un viscosímetro de paletas, como el modelo Haake o similar. Los viscosímetros de pivote, no deben ser utilizados para medir la reología de pastas, ya que con este tipo de equipos se obtienen valores que son un 30-40\% más alto que aquellos medidos con un viscosímetro de paletas. Por lo tanto, no son valores comparables y el resultado obtenido sería poco preciso. En la figura 6-23: Viscosímetro de paletas para ensayo de la tensión de fluencia.

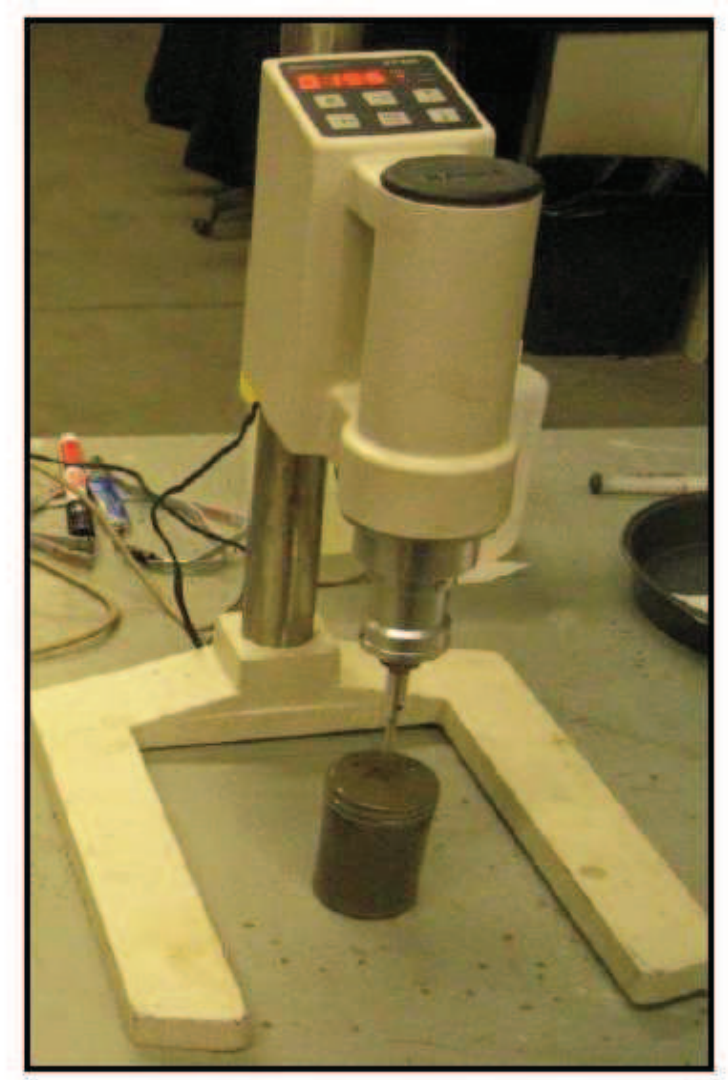

Figura 6-23: Viscosímetro de paletas para ensayo de la tensión de fluencia. (Fuente: Elaboración propia) 
Para poder conseguir los datos de la parte alta de la curva de límite de fluencia, se recomienda comenzar por los sólidos con una viscosidad similar a los obtenidos en el ensayo de filtración a vacío, es decir con una alta concentración de sólidos.

Para ello, se preparará una muestra de $250 \mathrm{ml}$ con una consistencia similar a los sólidos obtenidos en el ensayo de filtración a vacío. Se determina el límite de fluencia usando el viscosímetro disponible y se anotan los datos obtenidos.

Se repetirá el ensayo del límite de fluencia reduciendo el contenido en sólidos añadiendo agua de proceso para ir reduciendo el porcentaje de sólidos en la pulpa. Los ensayos reológicos se realizarán hasta que el límite de fluencia sea inferior a 20-30 Pa. Los datos de tensión de fluencia y contenido en sólidos, se representarán en un gráfico de tensión de fluencia frente al contenido en sólidos en peso, como se muestra en la figura 6-24: Representación de la curva de tensión de fluencia.

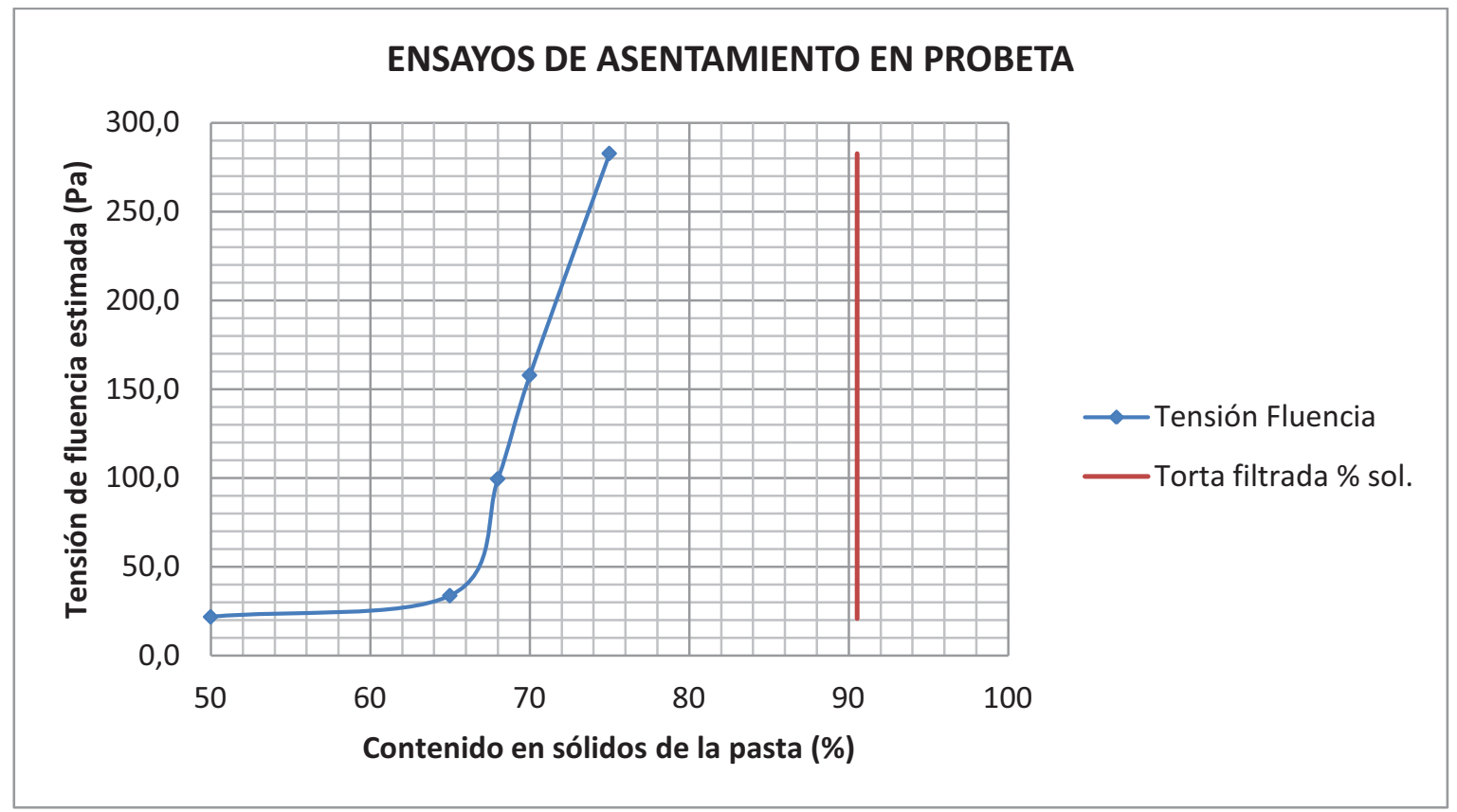

Figura 6-24: Representación de la curva de tensión de fluencia.

(Fuente: Elaboración propia)

En algunas ocasiones, durante los ensayos no se dispone de un viscosímetro de precisión para determinar la reología de los lodos obtenidos en los ensayos o en el hundido de un espesador de pasta. Una forma de estimar en campo la reología de la pasta obtenida sería mediante la realización de un ensayo de asentamiento en probeta.

El ensayo de asentamiento es usado intensamente por los ingenieros para calcular el límite de fluencia y la viscosidad de la pasta. El ensayo de asentamiento estándar según la norma ASTM, fue desarrollado para ensayar la trabajabilidad y consistencia del hormigón. El ensayo de asentamiento ha sido expandido para calcular y medir la trabajabilidad de una gran variedad de fluidos inelásticos no dependientes del tiempo, incluyendo suspensiones de estériles de mineral en 
forma de pastas. El ensayo de asentamiento encuentra actualmente su aplicación industrial extendida en las operaciones de pasta de estériles. Con este ensayo se puede obtener la concentración de sólidos necesaria para la deposición en pilas o galerías de la pasta, con la tensión de fluencia requerida.

Como resultado de esta alta concentración de sólidos en los estériles, se produce la presencia de una tensión de fluencia apreciable que es el esfuerzo cortante mínimo para la deformación irreversible de la pasta y que comience a fluir. Se pueden realizar ensayos de asentamiento a escala de laboratorio o en campo sobre las muestras de pasta a depositar.

En el caso de muestras de laboratorio, se realizan sobre cilindros de 4 a $8 \mathrm{~cm}$ de diámetro y de 8 a $20 \mathrm{~cm}$ de altura, rellenándose con pasta de un determinado contenido en sólidos. El cilindro se levanta rápidamente y se permite que la muestra colapse bajo la acción de su peso. La altura de la deformación final o el asentamiento de la pasta son medidos y anotado. La diferencia entra la altura inicial y final se denomina altura de asentamiento. La figura 6-25: Procedimiento del ensayo de sentamiento; ilustra las acciones a llevar a cabo durante el ensayo de asentamiento.

Los materiales necesarios para la realización de este ensayo son: probeta cilíndrica con las dimensiones adecuadas al tamaño de muestra esperado, varilla de compactación, enrasador y regla para mediciones.

Los pasos a seguir para la realización del ensayo de asentamiento en probeta son los siguientes:

1) Rellenar la probeta con lodos procedentes del hundido del espesador dinámico o de lodo fabricado en laboratorio con una concentración en sólidos conocida.

2) Comprobar el relleno de la probeta con la varilla de compactación de forma suave sin alterar las condiciones de la muestra.

3) Extraer el molde cilíndrico y observar el asentamiento de la pasta.

4) Medir la altura alcanzada una vez que cesa el movimiento de asentamiento de la pasta.

5) Realizar los cálculos para determinar la tensión de fluencia de la forma que se describe a continuación.
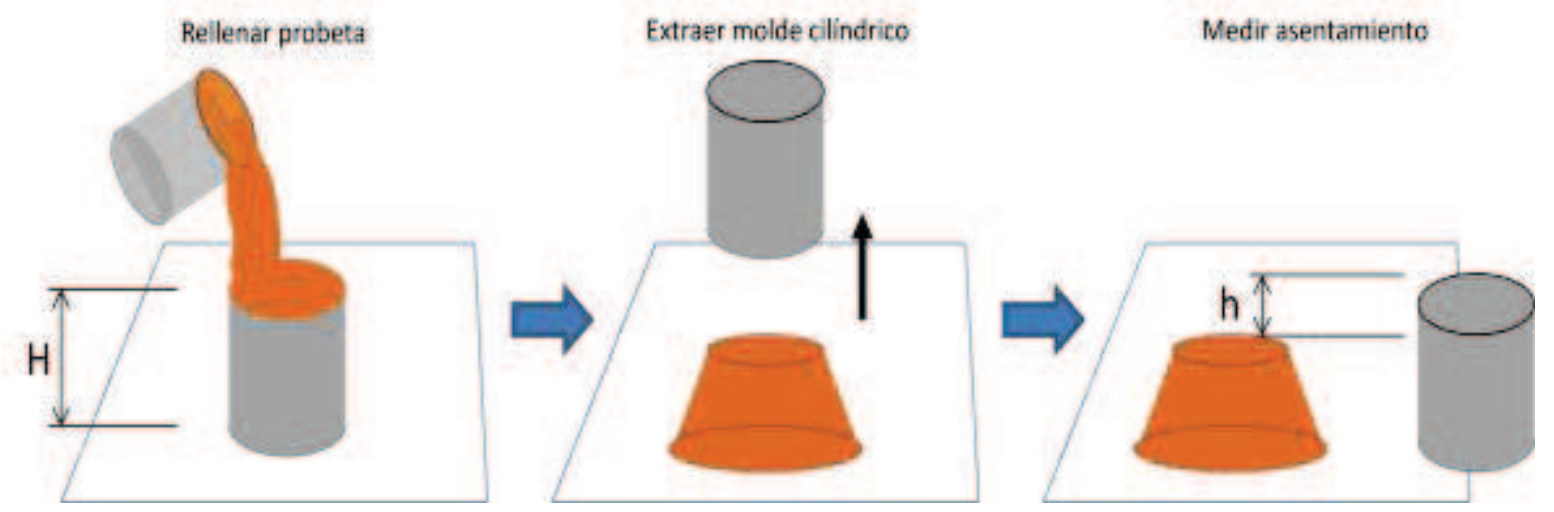

Figura 6-25: Procedimiento del ensayo de asentamiento.

(Fuente: Elaboración propia)

En la figura 6-26: Ensayo de asentamiento de estériles de flotación; se muestra el asentamiento obtenido sobre una muestra medida con probeta de $44 \mathrm{~mm}$ de diámetro y $100 \mathrm{~mm}$ de altura. 


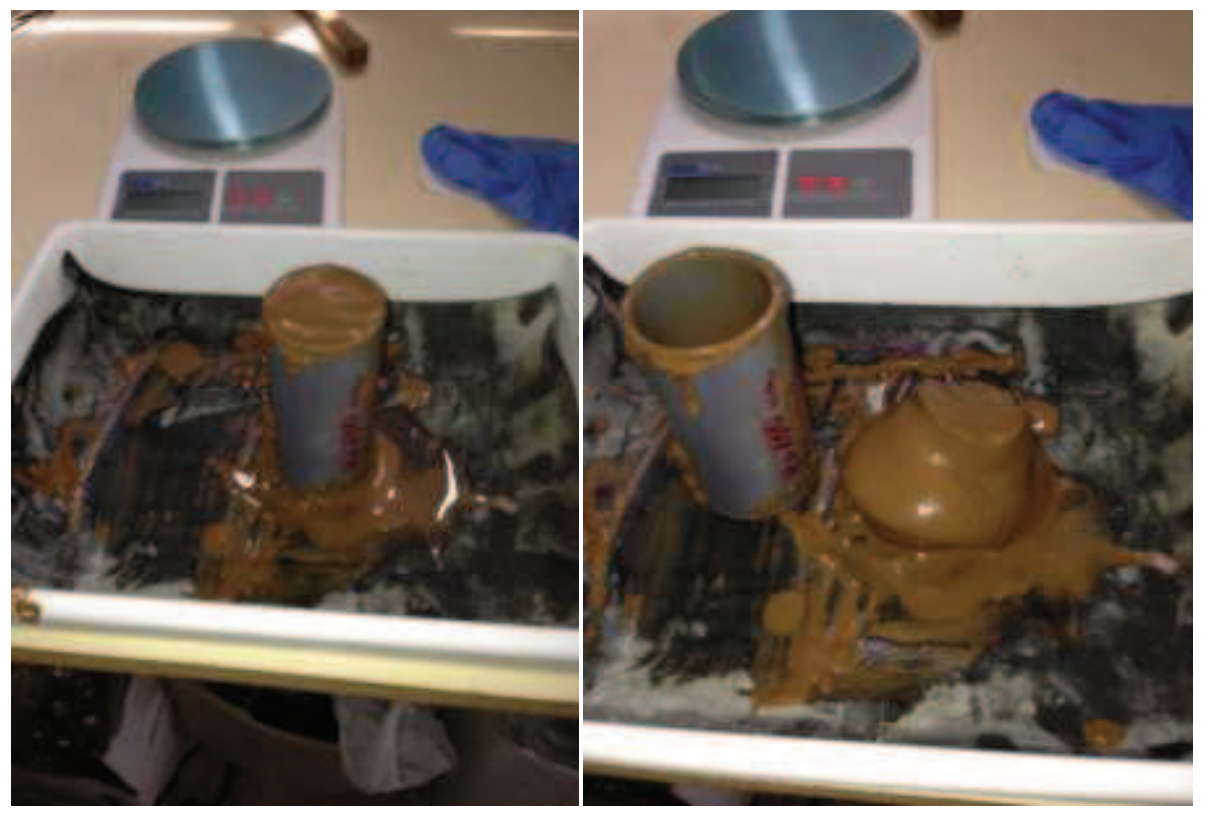

Figura 6-26: Ensayo de asentamiento de estériles de flotación. (Fuente: Elaboración propia)

La altura de asentamiento medida por con este ensayo se usa generalmente como parámetro de control. Esta altura de asentamiento es una medida empírica de la consistencia, dependiente tanto de la tensión de fluencia, contenido en sólidos, densidad de la muestra, peso específico de sólido y líquido y el tamaño de partículas. El ensayo de asentamiento es una aproximación muy buena y una técnica ideal en el trabajo de campo para tener una estimación de la medida de la tensión de fluencia de forma rápida.

La altura de asentamiento (h) se puede medir a partir de la altura del cilindro $(H)$, colocando una regla sobre el cilindro y midiendo la altura, $\mathrm{h}$.

La tensión de fluencia teórica, $\tau^{\prime}$, de la muestra de pasta puede ser calculada de acuerdo a las ecuaciones empíricas 6-7 y 6-8; basadas en la altura de asentamiento relativa a la altura inicial del cilindro y contrastadas con las medidas tomadas en viscosímetro de paletas.

$$
\begin{gathered}
T=\frac{1}{2}+\frac{1}{2} \cdot \sqrt{h / H} \\
\tau^{\prime}=T \cdot \rho \cdot g \cdot(H / 100)
\end{gathered}
$$

\section{Donde:}

$\mathrm{h}$ es la medida de asentamiento en $\mathrm{cm}$.

$\mathrm{H}$ es la altura del cilindro en $\mathrm{cm}$.

T es la densidad de asentamiento que es una constante.

$\rho$ es el peso específico de los lodos a ensayar en $\mathrm{kg} / \mathrm{m}^{3}$

g es la aceleración de la gravedad $9,8 \mathrm{~m} / \mathrm{s}^{2}$ 


\section{Aplicación del modelo experimental con diferentes materiales.}

Se presentan a continuación los trabajos de laboratorio y campo realizados sobre muestras de diferentes materiales que se han utilizado para llevar a cabo pruebas de sedimentación en el espesador de tubo profundo construido como equipo piloto de laboratorio, para la aplicación de la metodología experimental propuesta en el capítulo 6. Los resultados obtenidos con las muestras analizadas de estériles de minerales de cobre polimetálico han sido comparados con los datos obtenidos en dos espesadores reales en operación con los mismos materiales.

Como se ha comentado con anterioridad, la altura de lodos en el fondo del tanque de un espesador de pasta es como mínimo de 3 a 4 metros y en algunos espesadores de cono profundo se pueden alcanzar más de 10 metros de lecho de lodos. A medida que la zona de compresión se hace más elevada, la densidad del hundido para un determinado flujo de sólidos crece, como resultado de tres factores:

a) Un mayor tiempo de residencia del lecho de lodos sedimentado, que permite la liberación del agua contenida en la red de flóculos sedimentados.

b) El peso efectivo del lecho de lodos y la columna hidrostática que generan una fuerza de compresión sobre los flóculos sedimentados.

c) La acción de las piquetas verticales del mecanismo interno que facilitan la creación de canales para la liberación del licor o agua contenida en el lecho de lodos.

En los casos de la comparativa que analizaremos a continuación, los espesadores de la planta de tratamiento se encontraban trabajando con un lecho de lodos superior a 10 metros de altura, de forma continua.

Todos estos factores actuando de forma conjunta generan un incremento de la densidad de la pulpa en el hundido del espesador, con el fin de producir una verdadera pasta con alto contenido en sólidos y una tensión de fluencia característica relacionada con este contenido en sólidos.

Uno de los retos con los que se encuentra el técnico de proceso, es simular de forma precisa ambas acciones en el laboratorio para dimensionar de forma correcta las unidades de espesadores de cono profundo para la producción de pasta, especialmente cuando las muestras disponibles son limitadas o escasas y se reducen a unos pocos kilogramos de material. El método experimental descrito es una aplicación novedosa que se adapta a las características de la operación de los espesadores de pasta, donde no es posible la aplicación de métodos clásicos de experimentación. Estos métodos, como por ejemplo el de Coe-Clevenger o Kynch, están basados en la curva de sedimentación de los estériles en probetas de $2000 \mathrm{ml}$, la cual se ha mostrado insuficiente en la evaluación de un sistema de espesado de estériles en forma de pasta, ya que no se dan los factores y las condiciones enumeradas anteriormente, y que ocurren en el proceso real que tiene lugar en los modernos espesadores de pasta o en los espesadores de alta densidad en el hundido.

El método experimental propuesto hace posible la simulación de estas condiciones de tiempo de residencia, generación de una columna hidrostática mayor que en una probeta de $2000 \mathrm{ml}$ y la 
liberación del agua contenida en el lecho de lodos gracias al mecanismo de piquetas verticales del equipo de laboratorio y al volumen de la probeta de tubo profundo fabricada para este estudio.

La metodología experimental se ha utilizado con diversas muestras de materiales y estériles que son susceptibles de formar una pasta con un elevado contenido en sólidos y una alta tensión de fluencia asociada al contenido en sólidos, con el fin de comprobar la validez del método propuesto. La aplicación de la metodología se ha basado en los medios disponibles para la realización de ensayos y en la accesibilidad de los datos y materiales a ensayar, teniendo en cuenta las fuentes y empresas de han colaborado con sus medios técnicos en la elaboración del presente estudio.

Teniendo en cuenta que este tipo de equipos de espesado de estériles se encuentra implantado a escala industrial en España desde hace relativamente pocos años, se ha contado con la colaboración de la empresa Minas de Aguas Teñidas S.A.U. (MATSA) en la Faja Pirítica de Huelva para la realización de las principales pruebas del modelo experimental y la obtención de los datos de proceso reales para establecer la comparativa y el control de los valores obtenidos en los ensayos de laboratorio.

En la planta de tratamiento de mineral existente en Valdelamusa propiedad de Minas de Aguas Teñidas, existen instalados tres espesadores de cono profundo en operación destinados a la producción de pasta con los estériles procedentes de la planta de flotación aguas arriba del proceso de espesado de estériles.

La planta cuenta con dos espesadores de 18 metros de diámetro y un espesador de 24 metros de diámetro, éste último puesto en servicio durante la ampliación de la planta en el año 2014. Debido a su capacidad de tratamiento, esta instalación es un referente a nivel europeo en el tratamiento de estériles de metales base en forma de pasta.

Para la validación de la metodología experimental, se llevaron a cabo ensayos de sedimentación y pruebas de laboratorio siguiendo los métodos de ensayo propuestos en el capítulo 6. Para ello se realizaron dos ensayos completos sobre dos muestras de estériles de mineral de cobre polimetálico según se recoge en la tabla 7-1: Muestras de estériles de mineral polimetálico; y los resultados fueron comparados con los datos obtenidos a escala real, es decir en los espesadores de estériles reales en planta. Sólo de esta forma es posible comparar si la sedimentación y el proceso en el equipo de tubo profundo de laboratorio es extrapolable al proceso de sedimentación y compactación de los lodos que se obtiene en el espesador real.

Tabla 7-1: Muestras de estériles de mineral polimetálico

\begin{tabular}{|l|l|l|l|}
\hline Muestra & \multicolumn{1}{|c|}{ Material } & \multicolumn{1}{c|}{ Procedencia } & \multicolumn{1}{c|}{ Equipo } \\
\hline M-100 & Estéril de flotación de mineral polimetálico & MATSA (Valdelamusa) & Espesador $18 \mathrm{~m}$ \\
\hline M-101 & Estéril de flotación de mineral polimetálico & MATSA (Calañas) & Espesador $24 \mathrm{~m}$ \\
\hline
\end{tabular}

(Fuente: Elaboración propia)

La primera muestra que denominaremos $\mathrm{M}-100$, fue tomada en la alimentación de un espesador de cono profundo de 18 metros de diámetro en operación; la segunda muestra, denominada M101, fue tomada de la alimentación de un espesador de cono profundo de 24 metros de diámetro en operación. El tercer espesador de 18 metros de diámetro estaba fuera de servicio en el 
momento de la recogida de muestras y no fue posible realizar una tercera comparativa con este equipo.

Ambos espesadores de cono profundo se encuentran al final del proceso de flotación en las dos líneas existentes en MATSA y ambos se operan para el espesado de estériles que serán enviados a la planta de pasta para relleno (backfill) o bien a la balsa de lodos según las necesidades de la operación.

El objetivo de estos estudios llevados a cabo en campo y en laboratorio es obtener una serie de resultados convincentes de la forma en la que se pueden simular los procesos de sedimentación en los espesadores de cono profundo para el tratamiento de estériles en forma de pasta, introduciendo las nociones de tensión de fluencia, contenido en sólidos, área de sedimentación, etc. y comparar estos datos de laboratorio con los datos obtenidos en la planta a escala real.

La finalidad de realizar estas pruebas con el equipo de laboratorio y su comparación con los datos reales de proceso es aprobar la viabilidad del método que se propone en el presente trabajo; así como evaluar todos los procedimientos establecidos para conseguir espesar estériles o materiales finos y obtener los datos característicos de cada uno de los ensayos; y si es posible, mejorar tanto el método propuesto como el equipo de laboratorio fabricado para este proyecto.

Por tanto, los objetivos de las pruebas de laboratorio y de la metodología de ensayos, así como la construcción del equipo de laboratorio fueron:

a) Caracterizar los sólidos y la pasta obtenida tanto en el espesador real, como en el espesador de laboratorio.

b) Determinar la validez del procedimiento de selección el mejor floculante para la sedimentación de las partículas sólidas.

c) Encontrar la concentración óptima de sólidos y la dosificación de floculante para el diseño de la campana de alimentación en el espesador industrial.

d) Llevar a cabo ensayos continuos con el espesador de tubo profundo para determinar las características de los estériles espesados en forma de pasta.

e) Establecer las relaciones entre el contenido en sólidos y la tensión de fluencia para los materiales ensayados a través del método de asentamiento.

f) Comparar los resultados obtenidos en el laboratorio utilizando el espesador de tubo profundo con los resultados obtenidos de la operación del espesador real.

Esta metodología de ensayos propuesta proporciona al ingeniero de proceso una herramienta de gran utilidad en el diseño de equipos de espesado y de tratamiento de estériles, permitiendo el dimensionado de los equipos e instalaciones necesarias en las plantas de proceso. Los resultados de los ensayos permitirán al ingeniero confirmar la densidad del hundido alcanzable y las características de la pasta para el proyecto, usando técnicas de dimensionado de los equipos adaptadas a los datos obtenidos en el laboratorio. 


\subsection{Desarrollo experimental con la muestra M-100. Estériles de flotación.}

\subsubsection{Caracterización de la muestra M-100}

La muestra M-100, se corresponde con el estéril de un mineral de cobre polimetálico procedente de la planta de flotación, según el laboratorio de Minas de Aguas Teñidas, los principales datos de la muestra $\mathrm{M}-100$ recogida en la alimentación del espesador de estériles, son los que se muestran en la figura 7-2: Datos muestra de estériles de flotación M-100.

Tabla 7-2: Datos muestra de estériles de flotación M-100.

\begin{tabular}{|l|l|}
\hline \multicolumn{1}{|c|}{ Parámetro } & \multicolumn{1}{|c|}{ Muestra M-100. Estéril de mineral de cobre polimetálico } \\
\hline \% Sólidos en alimentación (peso) & $29 \%$ sólidos (procedente de la planta de flotación) \\
\hline Peso específico de sólidos & $4,4 \mathrm{~g} / \mathrm{cm}^{3}$ \\
\hline Peso específico agua proceso & $1,0 \mathrm{~g} / \mathrm{cm}^{3}$ \\
\hline pH de la pulpa & 6,9 \\
\hline pH del agua de proceso & 4,1 \\
\hline P50 & 20 micras \\
\hline P90 & 89 micras \\
\hline
\end{tabular}

Se realizó un análisis granulométrico utilizando un dispositivo Malvern de difracción de rayos $X$ en laboratorio, para la determinación de la granulometría de la muestra, obteniendo el resultado que se muestra en la tabla 7-3: Ensayo granulométrico de la muestra M-100. El tamaño P80 de la muestra analizada es de 54,59 micras, lo que se considera una muestra típica para el tipo de estériles que se obtienen en el proceso de tratamiento del mineral polimetálico en la mina de Valdelamusa.

La curva granulométrica de los sólidos es la que se muestra en la figura 7-1: Curva granulométrica de la muestra M-100. Esta muestra se tomó en la alimentación del espesador y es representativa de los estériles que se alimentan habitualmente al espesador de pasta. 


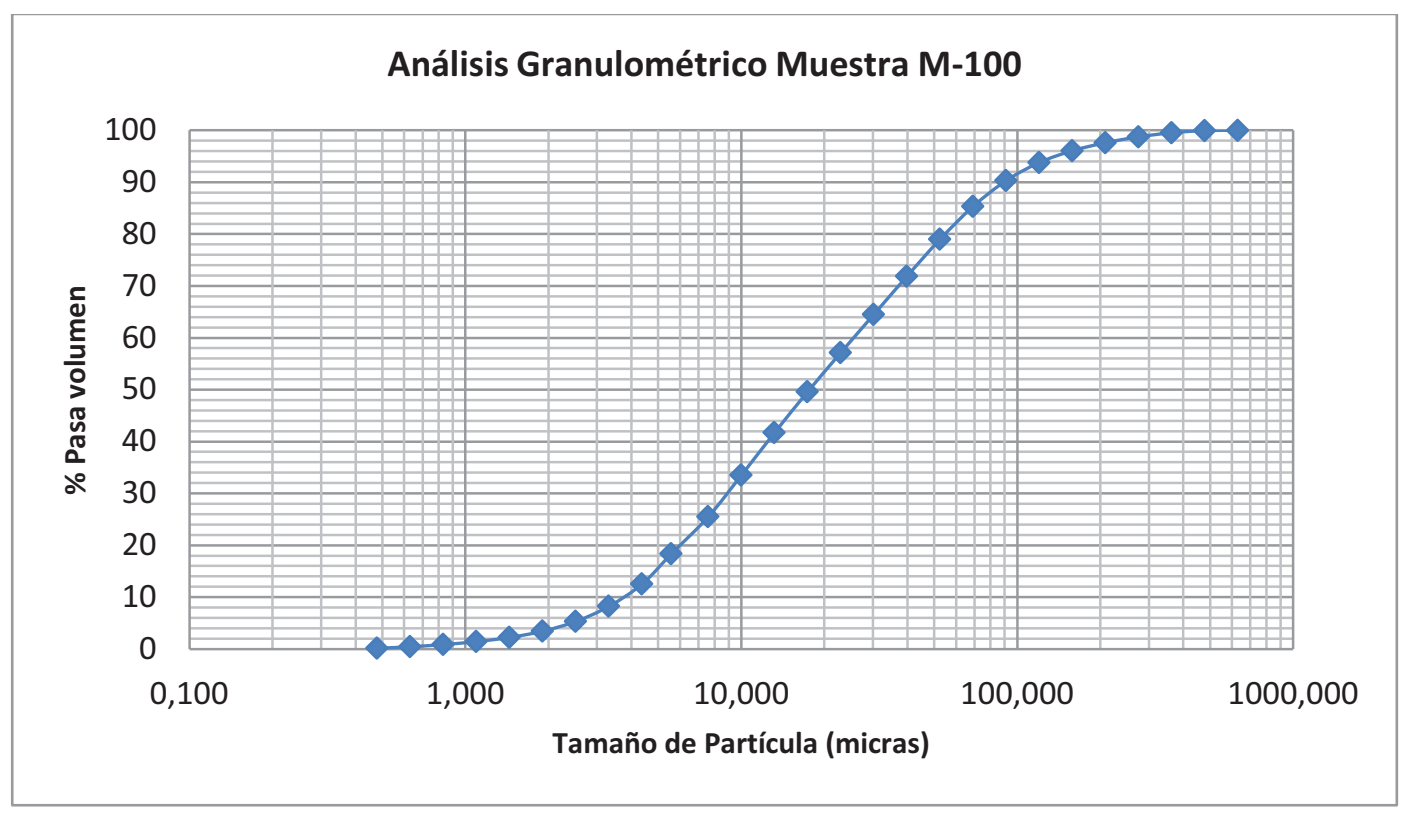

Figura 7-1: Curva granulométrica de la muestra M-100.

(Fuente: Elaboración propia)

Tabla 7-3: Ensayo granulométrico de la muestra M-100

\begin{tabular}{|c|c|c|c|}
\hline Tamiz (micras) & \% pasa vol. & Tamiz (micras) & \% pasa vol. \\
\hline 0,479 & 0,17 & 30,200 & 64,53 \\
\hline 0,631 & 0,47 & 39,811 & 71,89 \\
\hline 0,832 & 0,89 & 52,481 & 79,03 \\
\hline 1,096 & 1,46 & 69,183 & 85,36 \\
\hline 1,445 & 2,26 & 91,201 & 90,34 \\
\hline 1,905 & 3,47 & 120,226 & 93,81 \\
\hline 2,512 & 5,35 & 158,489 & 96,09 \\
\hline 3,311 & 8,27 & 208,930 & 97,63 \\
\hline 4,365 & 12,56 & 275,423 & 98,76 \\
\hline 5,574 & 18,38 & 363,078 & 99,55 \\
\hline 7,586 & 25,54 & 478,630 & 99,96 \\
\hline 10,000 & 33,55 & 630,957 & 100,00 \\
\hline 13,183 & 41,74 & & \\
\hline 17,378 & 49,63 & & \\
\hline 22,909 & 57,16 & & \\
\hline
\end{tabular}

(Fuente: Elaboración propia) 


\subsubsection{Selección de floculante. Muestra M-100}

El siguiente estudio llevado a cabo sobre la muestra fue la selección del floculante adecuado para la sedimentación de los estériles de mineral polimetálico de la muestra M-100. Los floculantes utilizados en el laboratorio representan una amplia muestra del fabricante de reactivos Nalco. Todos los floculantes se han preparado en el laboratorio al $0,1 \%$ en peso y en el momento del ensayo se diluyeron al 0,05\%. En la tabla 7-4: Floculantes Nalco empleados en los ensayos de la muestra M-100; se muestran las características de carga iónica de cada uno de los cinco tipos utilizados en los ensayos de selección de floculante.

Tabla 7-4: Floculante Nalco empleados en los ensayos de la muestra M-100.

\begin{tabular}{|c|c|c|}
\hline Fabricante & Denominación & Carga iónica \\
\hline Nalco & 9601 & $-20 \%$ carga iónica \\
\hline Nalco & 8172 & $-10 \%$ carga iónica \\
\hline Nalco & 71771 & $0 \%$ carga iónica \\
\hline Nalco & 9913 & +10 carga iónica \\
\hline Nalco & 9907 & $+25 \%$ carga iónica \\
\hline
\end{tabular}

(Fuente: Nalco Española, S.L.)

La muestra de estériles se preparó en una probeta de $500 \mathrm{ml}$ con una concentración en sólidos del $10 \%$ en peso para facilitar la dispersión de los flóculos en la probeta y permitir la observación de la claridad del rebose y el ratio de sedimentación durante el ensayo. En la figura 7-2: Elección de floculante. Ensayo de la muestra M-100; se observan las diferentes velocidades de sedimentación obtenidas con el uso de dos floculantes distintos.

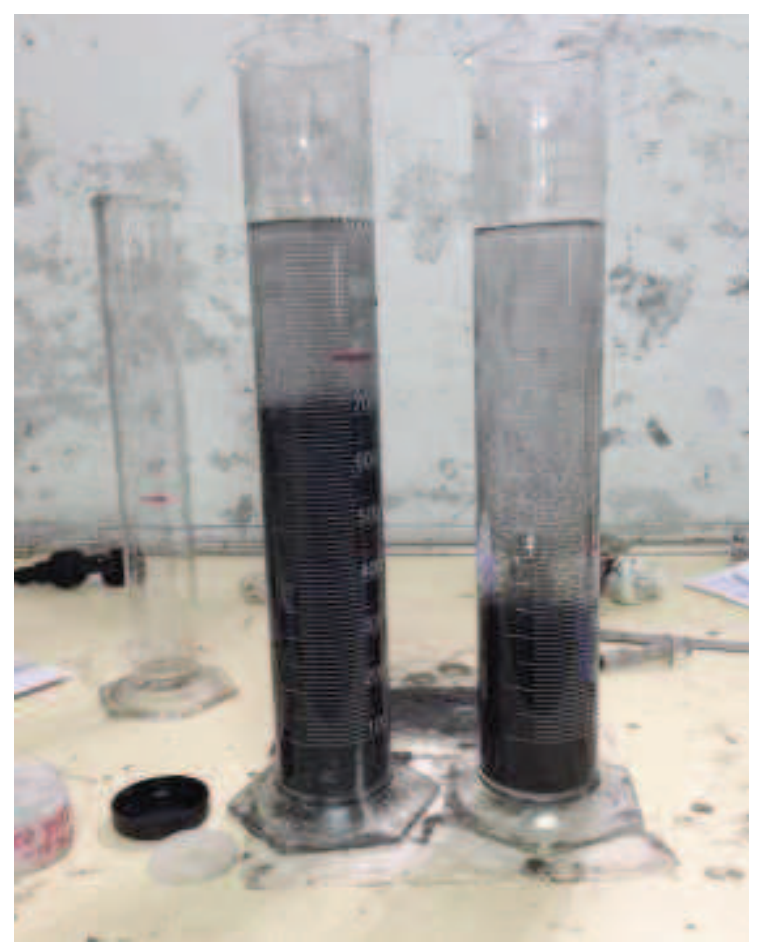

Figura 7-2: Elección de floculante. Ensayo de la muestra M-100. (Fuente: Elaboración propia) 
Los resultados obtenidos en los ensayos de selección de floculante se muestran en la figura 7-3: Gráfica de selección de floculante sobre la muestra M-100.

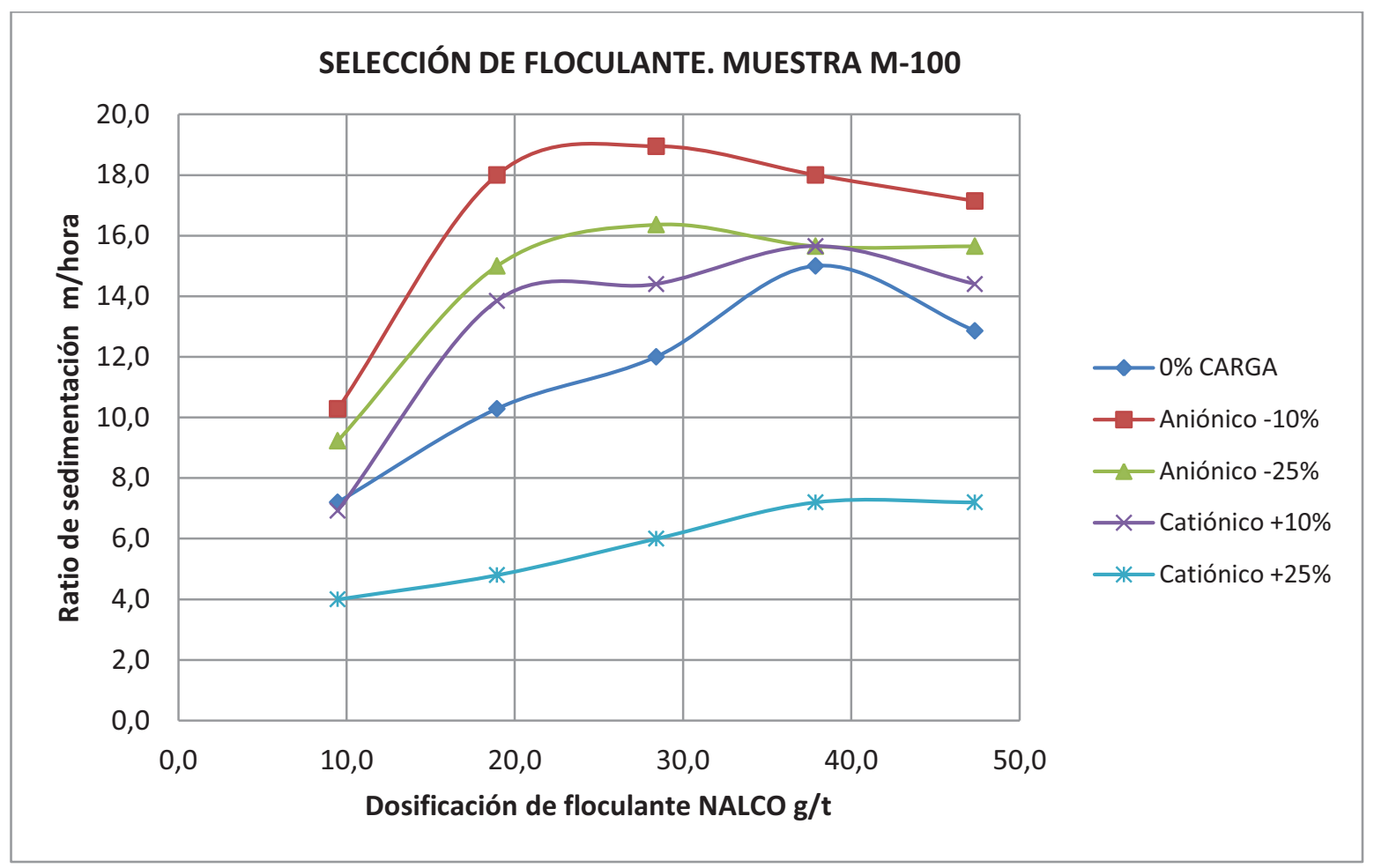

Figura 7-3: Gráfica de selección de floculante sobre la muestra M-100 (Fuente: Elaboración propia)

El floculante Nalco 8172 con una carga aniónica del $10 \%$ es el que mejor resultado produjo en cuanto a ratio de sedimentación en $\mathrm{m} / \mathrm{h}$, mejor claridad del rebose y estructura de flóculo de todos los floculantes analizados. Este floculante es de características similares al que se usa actualmente en la planta de tratamiento de estériles de Minas de Aguas Teñidas.

\subsubsection{Selección del contenido en sólidos óptimo. Muestra M-100}

Una vez seleccionado el tipo de floculante el siguiente ensayo que se realizó fue la determinación del flujo de sedimentación, con el objetivo de obtener la concentración de sólidos óptima en el proceso de sedimentación. Los estériles de mineral polimetálico fueron diluidos con agua de proceso para simular la dilución que produce el sistema de alimentación del espesador de estériles real. Los resultados de los ensayos de flujo de sedimentación se muestran en la figura 7-4: Gráfica de flujo de sedimentación de la muestra M-100. 


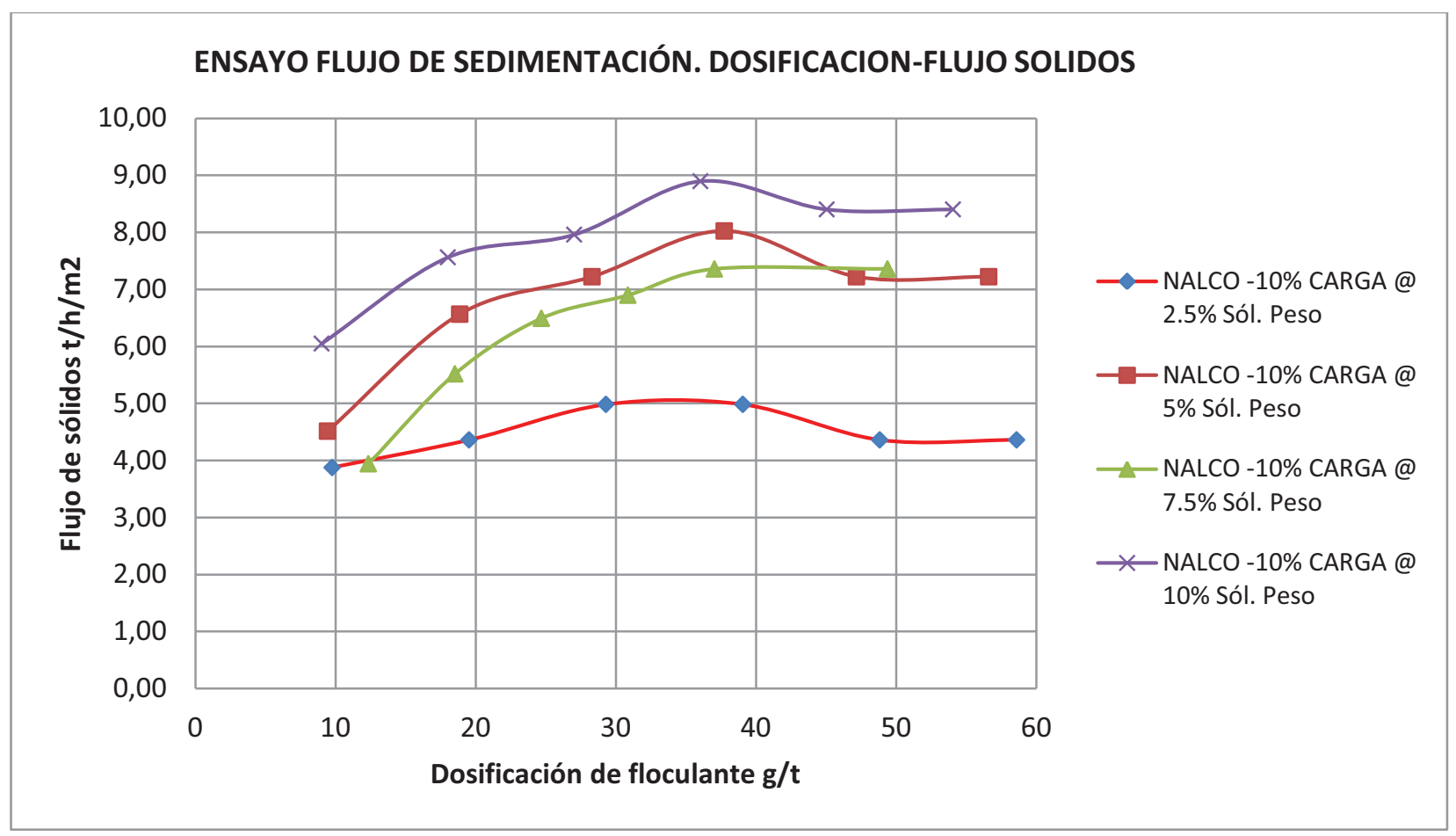

Figura 7-4: Grafica de flujo de sedimentación de la muestra M-100.

(Fuente: Elaboración propia)

Como se observa en la gráfica 7-3, la muestra diluida al 10\% de sólidos en peso, junto con una dosificación de $35 \mathrm{~g} / \mathrm{t}$ del floculante seleccionado, proporciona el mejor flujo de sedimentación.

\subsubsection{Ensayo de sedimentación en probeta de $2000 \mathrm{ml}$. Muestra M-100}

Una vez que ha sido determinada la concentración de sólidos óptima y la dosificación apropiada de floculante se realizó un ensayo en probeta de $2000 \mathrm{ml}$ para comprobar los parámetros de velocidad de sedimentación inicial, dosificación de floculante y claridad del rebose antes de realizar el ensayo de laboratorio en el espesador de tubo profundo.

Los datos obtenidos en el ensayo en probeta de $2000 \mathrm{ml}$ se muestran en la tabla 7-5: Ensayo en probeta de $2000 \mathrm{ml}$. Muestra M-100.

Tabla 7-5: Ensayo en probeta de $2000 \mathrm{ml}$. Muestra M-100.

\begin{tabular}{|l|l|}
\hline \multicolumn{2}{|l|}{ Muestra M-100. Estériles de mineral polimetálico de cobre. } \\
\hline Tamaño probeta & $2000 \mathrm{ml}$ \\
\hline Floculante & Nalco $8172(-10 \%$ carga iónica) \\
\hline Dosificación & $25 \mathrm{~g} / \mathrm{t}$ \\
\hline Dilución & $10 \%$ sólidos en peso \\
\hline Velocidad inicial de sedimentación & $15,8 \mathrm{~m} / \mathrm{h}$ \\
\hline$\%$ sólidos en el hundido & $48,77 \%$ sólidos (1 hora) \\
\hline
\end{tabular}




\subsubsection{Ensayo de sedimentación en probeta de tubo profundo. Muestra M-100}

A continuación se realizó el ensayo en probeta de tubo profundo, donde se requiere el uso de una alimentación continua y en donde es posible observar el área unitaria de forma directa en función de la alimentación y de la carga de sólidos. En las condiciones de alimentación es posible variar la alimentación tanto de la pulpa como del floculante, lo que proporciona una gran versatilidad y la adaptación de las condiciones de alimentación en función de la operación del ensayo. Esto da lugar a la obtención de los parámetros de carga de sólidos y los límites que serán utilizados posteriormente en la fase de diseño del equipo de espesado. En este caso los resultados obtenidos con este ensayo serán comparados con los parámetros de operación del espesador de pasta de 18 metros diámetro en el que fue recogida la muestra para poder establecer la correlación entre los datos de laboratorio, con los parámetros medidos por la instrumentación de campo y el laboratorio de Minas de Aguas Teñidas del espesador real.

En una segunda etapa del ensayo y una vez agotada la alimentación de pulpa preparada en el agitador se observará la compactación del lecho de lodos de un volumen fijo de pulpa espesada por un periodo prolongado de tiempo. Esta parte estática del ensayo proporcionará datos del contenido en sólidos alcanzado en el espesador de laboratorio y éstos serán comparados con el contenido en sólidos del espesador de pasta real. En la figura 7-5: Alimentación de la probeta de tubo profundo con muestra $\mathrm{M}-100$; se puede observar un instante de la primera etapa de la alimentación del espesador de tubo profundo de laboratorio para conseguir el lecho de lodos en el equipo.

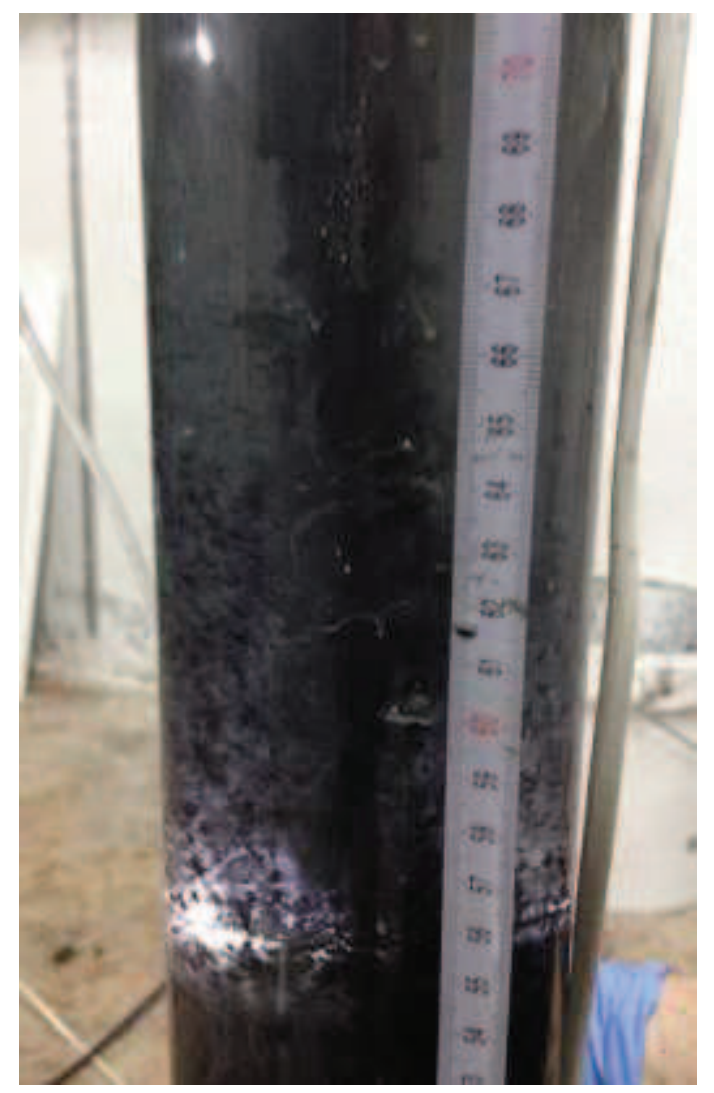

Figura 7-5: Alimentación de la probeta de tubo profundo con muestra M-100. (Fuente: Elaboración propia) 
La obtención de la gráfica de tiempo de residencia frente al contenido en sólidos es uno de los objetivos principales. Esta gráfica es empleada posteriormente para determinar el tiempo de residencia de los lodos requerido en el tanque del espesador real y proporcionar un dato comparable al equipo real instalado.

En la figura 7-6: Curva tiempo de retención muestra M-100; se puede ver la relación entre el contenido en sólidos alcanzado por la pulpa en el hundido del espesador de laboratorio frente al tiempo de residencia en el tanque una vez comenzada la segunda etapa del ensayo.

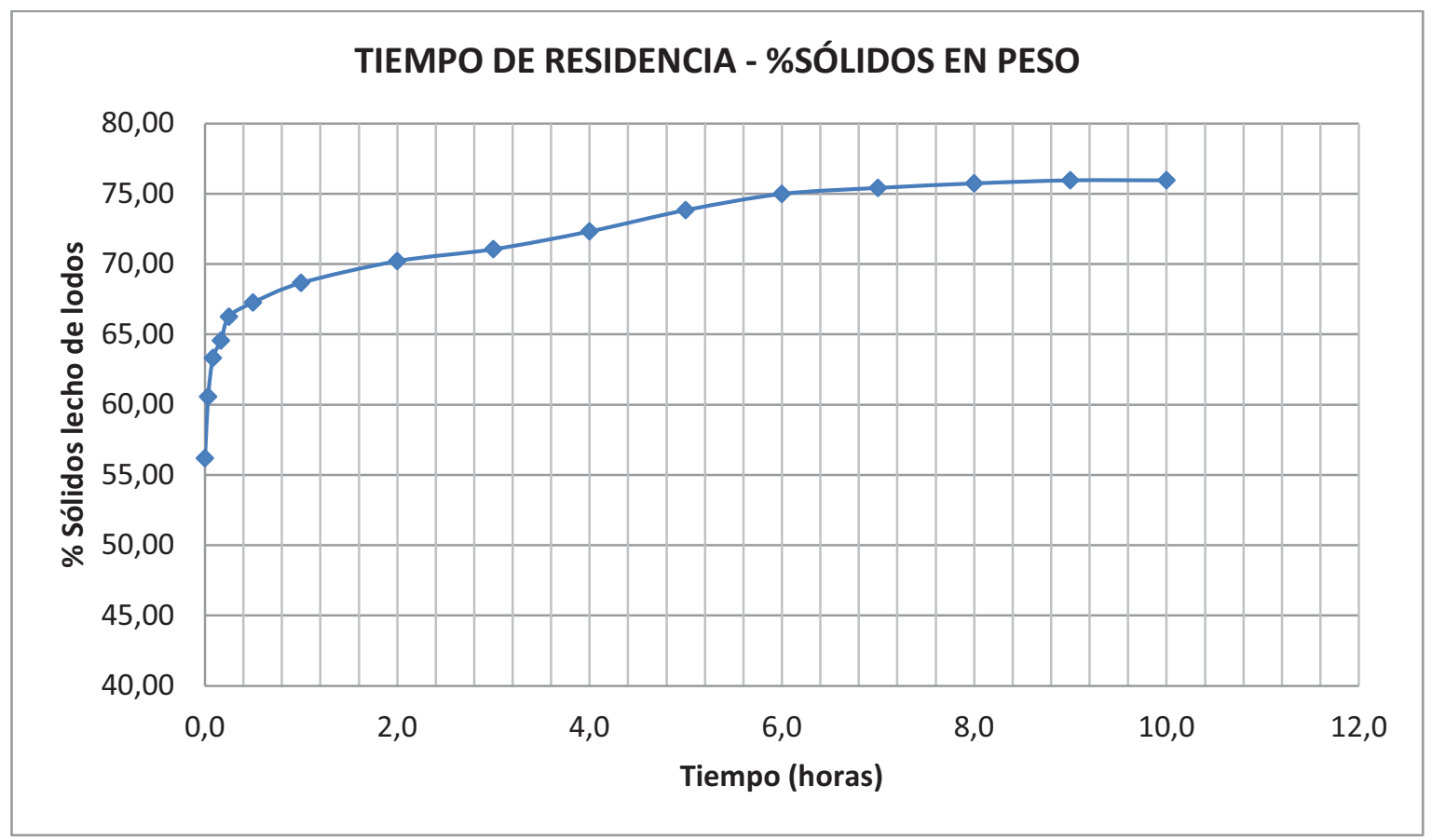

Figura 7-6: Curva tiempo de retención. Muestra M-100.

(Fuente: Elaboración propia)

\subsubsection{Ensayo para la determinación de la tensión de fluencia. Muestra M-100}

Al ser la tensión de fluencia un parámetro importante en el diseño de los espesadores de pasta y de las operaciones de relleno y de almacenamiento de la pasta, se llevó a cabo un estudio de la relación entre el contenido en sólidos y la tensión de fluencia de la pasta obtenida con el material de la muestra M-100. Del lodo espesado en el equipo de laboratorio se tomó una muestra representativa de pasta con el último contenido en sólidos obtenido $(75,95 \%)$ y posteriormente ha sido diluido con agua de proceso para ir alcanzando concentraciones inferiores en sólidos a las cuales también se les realizó una prueba en viscosímetro. Todas las muestras fueron medidas con un viscosímetro Haake VT550 obteniendo la tensión de fluencia en Pascales. Los resultados obtenidos se muestran en la tabla 7-6: Datos tensión de fluencia-contenido en sólidos. Muestra M100. Esta tensión de fluencia fue medida sin manipular en exceso la muestra de pasta para evitar romper la estructura de la pasta y los flóculos formados y obtener una medida lo más exacta posible de las condiciones de la pasta en el interior del espesador de laboratorio. La curva 
característica obtenida en el ensayo se representa en la figura 7-7: Curva tensión de fluenciacontenido en sólidos. Muestra M-100.

Tabla 7-6: Datos tensión de fluencia-contenido en sólidos. Muestra M-100.

\begin{tabular}{|c|c|}
\hline \% Contenido en sólidos & Tensión de fluencia (Pa) \\
\hline 75,95 & 249 \\
\hline 74 & 165 \\
\hline 72 & 141 \\
\hline 70 & 95 \\
\hline 68 & 62 \\
\hline 66 & 37 \\
\hline 64 & 27 \\
\hline 62 & \\
\hline
\end{tabular}

(Fuente: Elaboración propia)

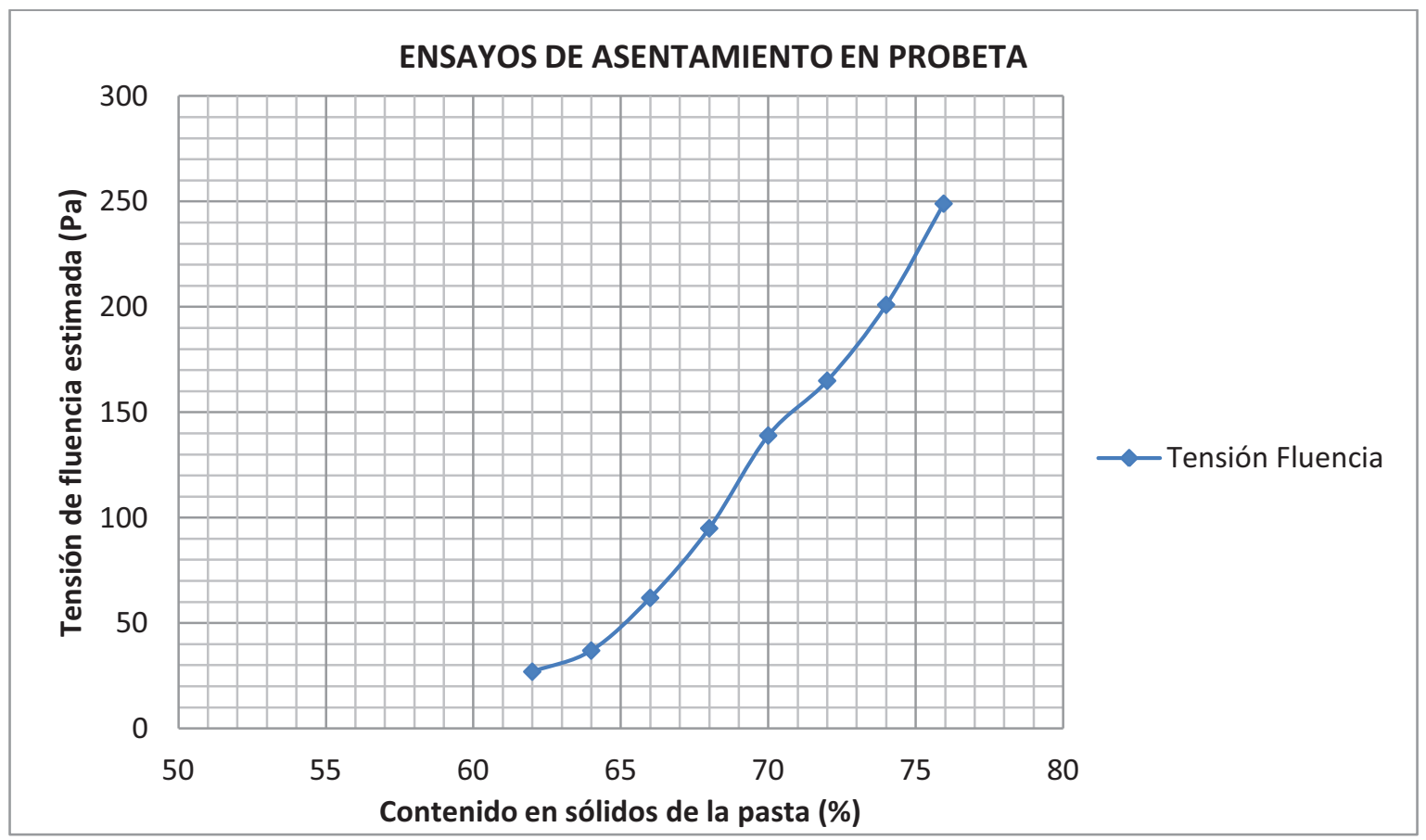

Figura 7-7: Curva tensión de fluencia-contenido en sólidos. Muestra M-100. (Fuente: Elaboración propia)

Todos los datos recogidos en el ensayo de la muestra M-100 se encuentran en el Anexo 1 del presente documento.

Por lo tanto se puede concluir que, los resultados obtenidos durante los ensayos de sedimentación llevados a cabo con los estériles de flotación de la muestra M-100 del espesador de pasta de 18 metros de diámetro fueron los siguientes:

El floculante Nalco 8172 proporcionó una adecuada estructura de flóculo, buen ratio de sedimentación y una buena claridad del rebose con un consumo promedio de 32,8 g/t durante el 
ensayo de espesado en la probeta de tubo profundo. Este tipo de floculante es similar en características y carga iónica al utilizado actualmente en la operación del espesador en Minas de Aguas Teñidas.

El estéril de mineral de cobre polimetálico de la muestra M-100 analizada, se ensayó con una dilución del $10 \%$ de sólidos en peso con la que se obtuvo un valor promedio de $13,1 \mathrm{~m} / \mathrm{h}$ de velocidad de sedimentación y un ratio de sedimentación de $33,3 \mathrm{t} / \mathrm{día} / \mathrm{m}^{2}$ con un consumo de floculante de $32,8 \mathrm{~g} / \mathrm{t}$.

Se consiguieron unos estériles espesados en laboratorio con un contenido en sólidos del 75,95\% con una tensión de fluencia medida con el viscosímetro de $290 \mathrm{~Pa}$, por encima de los 50-100 Pa, lo cual proporciona una pulpa homogénea de pasta no segregable.

Todos los resultados obtenidos con el modelo experimental son comparados con los datos del modelo real más adelante en el punto 7.3.

\subsection{Desarrollo experimental con muestra M-101. Estériles de flotación.}

\subsubsection{Caracterización de la muestra}

Otra de las muestras ensayadas en laboratorio para su comparación con los valores obtenidos en un espesador real, se realizó con una muestra de estériles de mineral de cobre polimetálico que corresponde a la muestra M-101. El estéril proviene de la planta de flotación de Minas de Aguas Teñidas y es tratado en un espesador de pasta de 24 metros de diámetro.

Los principales datos de la muestra M-101 recogida en la alimentación del espesador, son los que se muestran en la tabla 7:7: Datos de la muestra de estériles de flotación M-101.

Tabla 7-7: Datos de la muestra de estériles de flotación M-101

\begin{tabular}{|l|l|}
\hline \multicolumn{1}{|c|}{ Parámetro } & \multicolumn{1}{|c|}{ Muestra M-101. Estéril de mineral de cobre polimetálico } \\
\hline \% Sólidos en alimentación (peso) & $31,5 \%$ sólidos \\
\hline Peso específico de sólidos & $4,0 \mathrm{~g} / \mathrm{cm}^{3}$ \\
\hline Peso específico agua proceso & $1,0 \mathrm{~g} / \mathrm{cm}^{3}$ \\
\hline pH de la pulpa & 6,7 \\
\hline pH del agua de proceso & 4,5 \\
\hline P50 & 7,98 micras \\
\hline P90 & 20,9 micras \\
\hline
\end{tabular}

La curva granulométrica se realizó utilizando un equipo Malvern de difracción de rayos $\mathrm{X}$, para determinar la granulometría de la muestra, obteniendo los datos que se muestran en la tabla 7-8: Ensayo granulométrico de la muestra M-101. Esta muestra corresponde con un material más fino, donde el tamaño característico P80 es de 15,534 micras, lo que corresponde a una molienda más fina debido al tamaño de liberación del mineral. En cualquier caso, esta muestra también 
representa un caso típico en el proceso del mineral polimetálico procedente de la mina de MATSA en Calañas (Huelva) y que se procesa en la planta de Valdelamusa.

Tabla 7-8: Ensayo granulométrico de la muestra M-101.

\begin{tabular}{|c|c|c|c|}
\hline Tamiz (micras) & $\%$ pasa & Tamiz (micras) & $\%$ pasa \\
\hline 0,363 & 0,61 & 22,909 & 92,32 \\
\hline 0,479 & 1,01 & 30,200 & 97,28 \\
\hline 0,631 & 1,53 & 39,811 & 99,57 \\
\hline 0,832 & 2,25 & 52,481 & 100,00 \\
\hline 1,096 & 3,39 & 69,183 & 100,00 \\
\hline 1,445 & 5,17 & 91,201 & 100,00 \\
\hline 1,905 & 7,94 & & \\
\hline 2,512 & 12,08 & & \\
\hline 3,311 & 17,96 & & \\
\hline 4,365 & 25,88 & & \\
\hline 5,754 & 35,87 & & \\
\hline 7,586 & 47,69 & & \\
\hline 10,000 & 60,55 & & \\
\hline 13,183 & 73,19 & & \\
\hline 17,378 & 84,17 & & \\
\hline
\end{tabular}

(Fuente: Elaboración propia)

La curva granulométrica obtenida con los datos de la tabla 7-8, son los que se muestran en la figura 7-8: Curva granulométrica de la muestra M-101. 


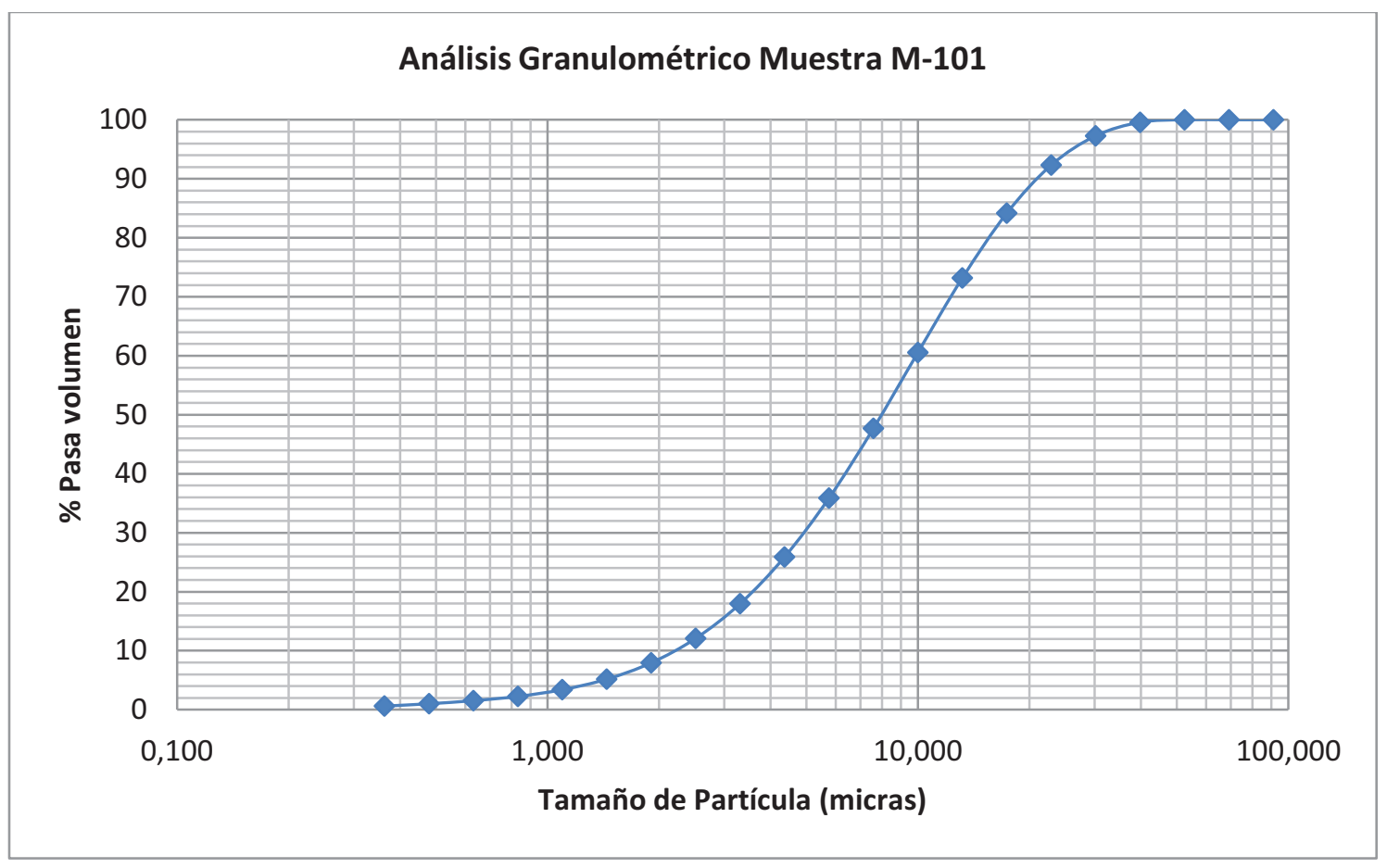

Figura 7-8: Curva granulométrica de la muestra M-101.

(Fuente: Elaboración propia)

\subsubsection{Selección de floculante. Muestra M-101.}

Para el estudio de la selección de floculante se realizaron ensayos de la velocidad de sedimentación sobre los estériles de la muestra M-101. Los floculantes utilizados son muestras de cinco tipos de la marca Nalco, según la tabla 7-9: Floculantes analizados con la muestra M-101.

Tabla 7-9:Floculantes analizados con la muestra M-101.

\begin{tabular}{|c|c|c|}
\hline Fabricante & Denominación & Carga iónica \\
\hline Nalco & 9601 & $-20 \%$ carga iónica \\
\hline Nalco & 8172 & $-10 \%$ carga iónica \\
\hline Nalco & 71771 & $0 \%$ carga iónica \\
\hline Nalco & 9913 & +10 carga iónica \\
\hline Nalco & 9907 & $+25 \%$ carga iónica \\
\hline
\end{tabular}

(Fuente: Nalco Española, S.L.)

Todos los floculantes fueron preparados a una dilución del $0,1 \%$ en peso y en el momento del ensayo fueron diluidos al $0,05 \%$ en peso. Para el ensayo, la muestra de estériles se preparó en una probeta de $500 \mathrm{ml}$ con una concentración de sólidos en peso fija del $10 \%$ en peso.

Los resultados obtenidos en el ensayo de selección de floculante para la muestra M-101 se detallan en la figura 7-9: Grafica de selección de floculantes sobre la muestra M-101. 


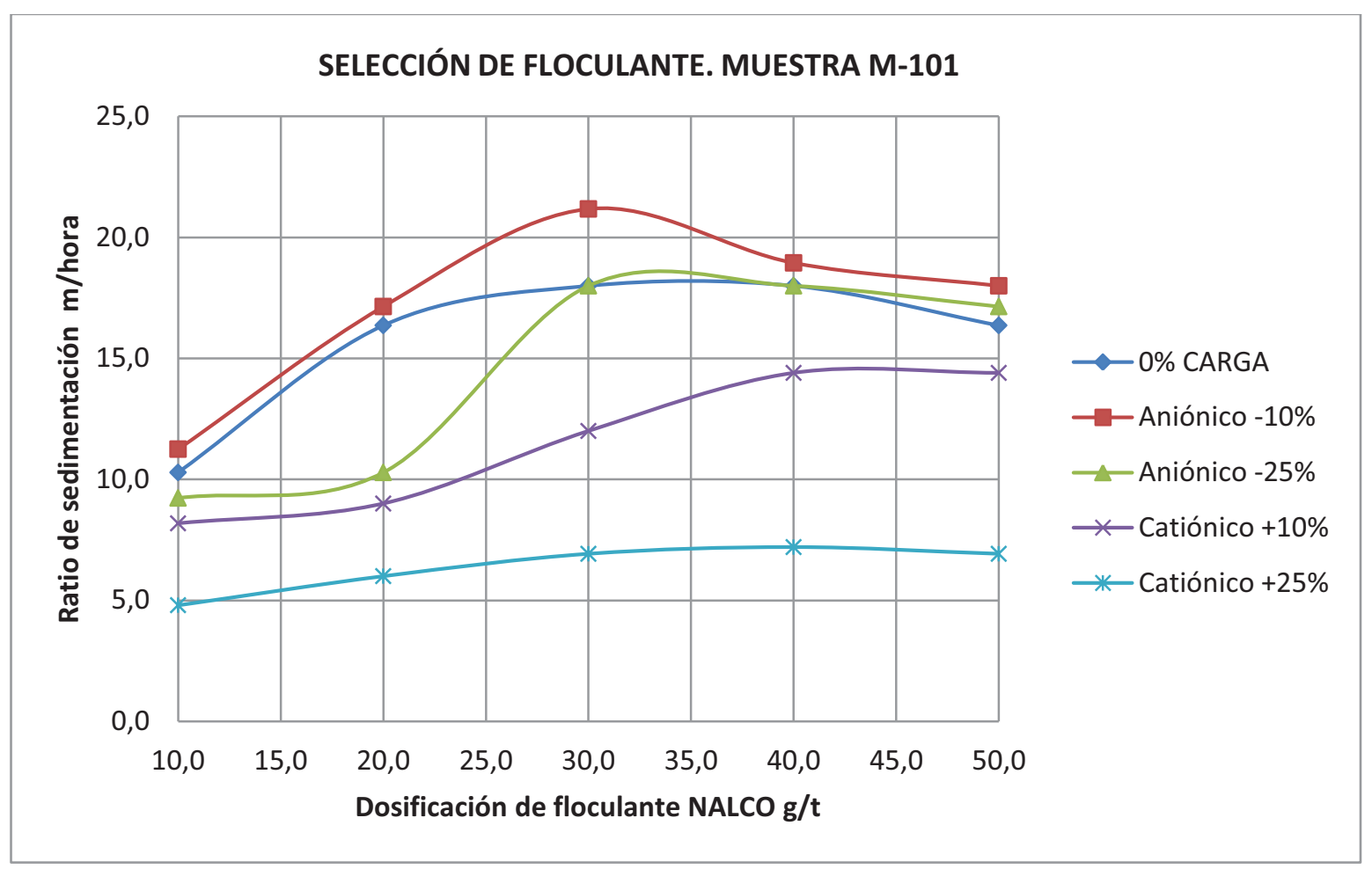

Figura 7-9: Gráfica de selección de floculantes sobre la muestra M-101. (Fuente: Elaboración propia)

Nuevamente, los floculantes con carga iónica fueron los que mejores resultados aportaron en cuanto a ratio de sedimentación en $\mathrm{m} / \mathrm{h}$ y mejor estructura de flóculo mostraron. El floculante elegido en este caso fue el de $-10 \%$ de carga iónica de referencia Nalco 9913.

\subsubsection{Selección de contenido en sólidos. Muestra M-101.}

En cuanto a la selección del contenido en sólidos, el flujo de sedimentación mostró un resultado favorable a la dilución del $10 \%$ de sólidos en peso como la opción con mejor ratio de sedimentación, con un ratio superior a $10 \mathrm{t} / \mathrm{h} / \mathrm{m}^{2}$ con un consumo de floculante de $50 \mathrm{~g} / \mathrm{t}$. En las muestras analizadas se demuestra que la dilución del $10 \%$ de sólidos en peso es una dilución óptima para el diseño del sistema de alimentación de estos equipos en el tratamiento de los estériles de la planta.

En la figura 7-10: Gráfica de flujo de sedimentación de la muestra M-101; se pueden ver los resultados obtenidos en este ensayo. 


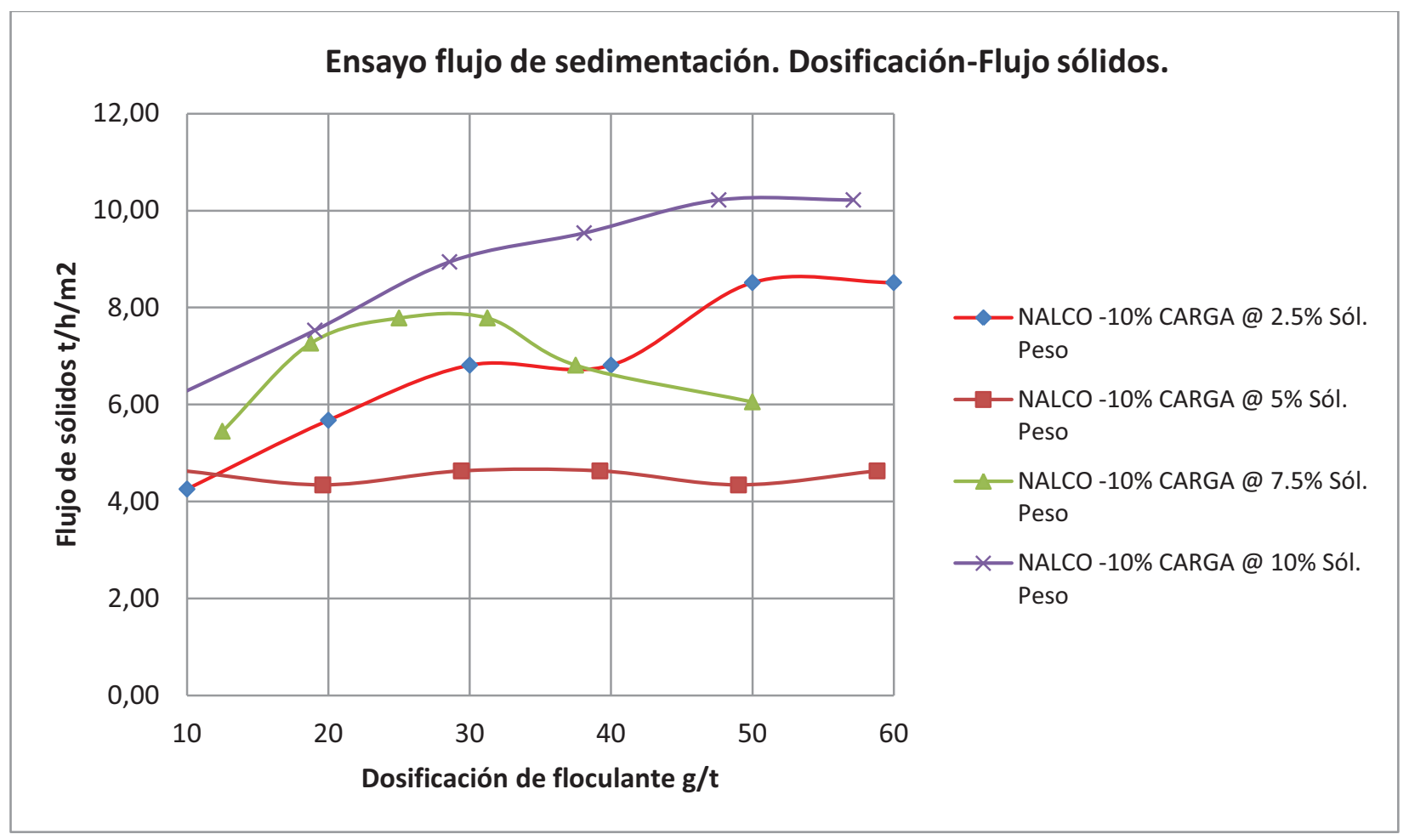

Figura 7-10: Gráfica de flujo de sedimentación de la muestra M-101.

(Fuente: Elaboración propia)

\subsubsection{Ensayo de sedimentación en probeta de 2000 ml. Muestra M-101.}

Con los datos de concentración óptima de sólidos y el floculante más apropiado se ha realizado un ensayo en probeta de $2000 \mathrm{ml}$ para determinar el parámetro de velocidad de sedimentación inicial previo a la realización del ensayo de laboratorio en el espesador de tubo profundo.

Los datos obtenidos en el ensayo en probeta de $2000 \mathrm{ml}$ se muestran en la tabla 7-10: Ensayo en probeta de $2000 \mathrm{ml}$. Muestra M-101.

Tabla 7-10: Ensayo en probeta de $2000 \mathrm{ml}$. Muestra M-101.

\begin{tabular}{|l|l|}
\hline \multicolumn{2}{|l|}{ Muestra M-101. Estériles de mineral polimetálico de cobre. } \\
\hline Tamaño probeta & $2000 \mathrm{ml}$ \\
\hline Floculante & Nalco 8172 (-10\% carga iónica) \\
\hline Dosificación & $30 \mathrm{~g} / \mathrm{t}$ \\
\hline Dilución & $10 \%$ sólidos en peso \\
\hline Velocidad inicial de sedimentación & $17,7 \mathrm{~m} / \mathrm{h}$ \\
\hline$\%$ sólidos en el hundido & $52 \%$ sólidos (90 minutos) \\
\hline
\end{tabular}

(Fuente: Elaboración propia)

\subsubsection{Ensayo de sedimentación en tubo profundo. Muestra M-101.}

El ensayo en probeta de tubo profundo se realizó con las condiciones de floculante y contenido en sólidos en peso que mejores resultados mostraron en los ensayos previos. En este caso los 
resultados serán comparados posteriormente con los datos de proceso de la operación obtenidos en la planta de tratamiento en el espesador de 24 metros de diámetro.

En la segunda etapa del ensayo y una vez finalizada la alimentación continua del espesador de laboratorio se midió la compactación del lecho de lodos formado por la acción del mecanismo de rasquetas durante un periodo prolongado de tiempo.

La parte estática del ensayo proporcionará los datos del contenido en sólidos alcanzado en el espesador de laboratorio y su comparativa con los datos de contenido en sólidos y tiempo de residencia que se obtienen en el espesador real de 24 metros de diámetro.

En la figura 7-11: Curva de tiempo de residencia. Muestra M-101; se puede comprobar la relación entre el contenido en sólidos alcanzado en el espesador de laboratorio frente al tiempo de residencia en el tanque del espesador.

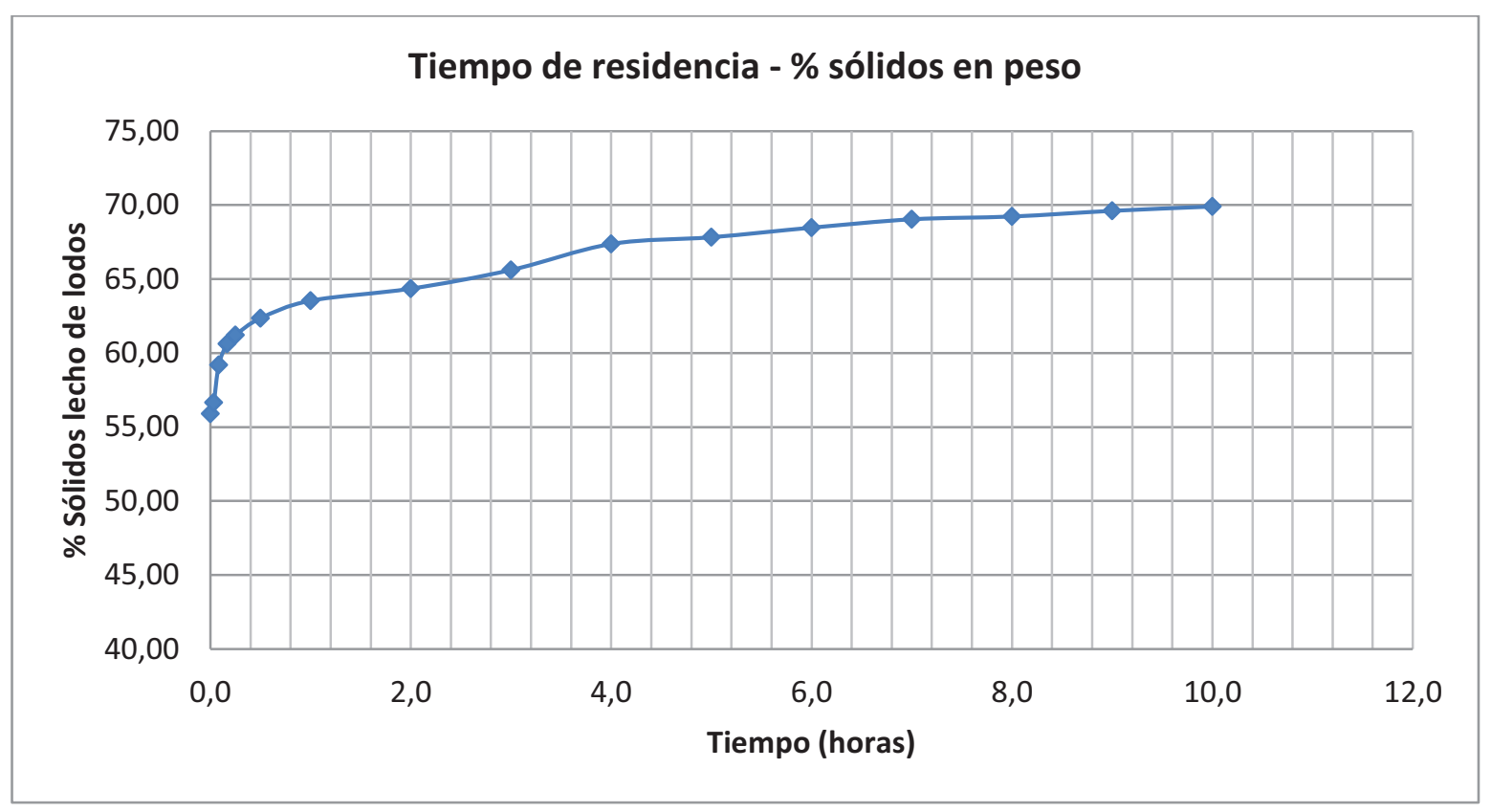

Figura 7-11: Curva de tiempo de residencia. Muestra M-101.

(Fuente: Elaboración propia)

En el ensayo de laboratorio se alcanzaron concentraciones en el hundido del $69 \%$ de sólidos en peso tras 8 horas de tiempo de residencia.

\subsubsection{Ensayo para la determinación de la tensión de fluencia. Muestra M-101.}

En el ensayo para la determinación de la tensión de fluencia se realizó el ensayo de asentamiento en probeta. Este ensayo se hizo en planta preparando una serie de muestras comenzando con el último contenido en sólidos alcanzado en el ensayo del espesador de tubo profundo de laboratorio. Como se recoge en el Anexo 2, se comenzó el ensayo con el $70 \%$ de contenido en sólidos en peso para la primera muestra y posteriormente se diluyó progresivamente con agua de proceso para las siguientes muestras. La tensión de fluencia alcanzada se muestra en la tabla 7-11: Datos de tensión de fluencia contenido en sólidos. Muestra M-101. 
Tabla 7-11: Datos tensión de fluencia-contenido en sólidos. Muestra M-101.

\begin{tabular}{|c|c|}
\hline \% Contenido en sólidos & Tensión de fluencia (Pa) \\
\hline 70 & 267 \\
\hline 68 & 194 \\
\hline 66 & 159 \\
\hline 64 & 126 \\
\hline 62 & 97 \\
\hline 58 & 45 \\
\hline
\end{tabular}

(Fuente: Elaboración propia)

En la figura 7-12: Curva tensión de fluencia-contenido en sólidos. Muestra M-101; se encuentran representados los valores de la tabla 7-11.

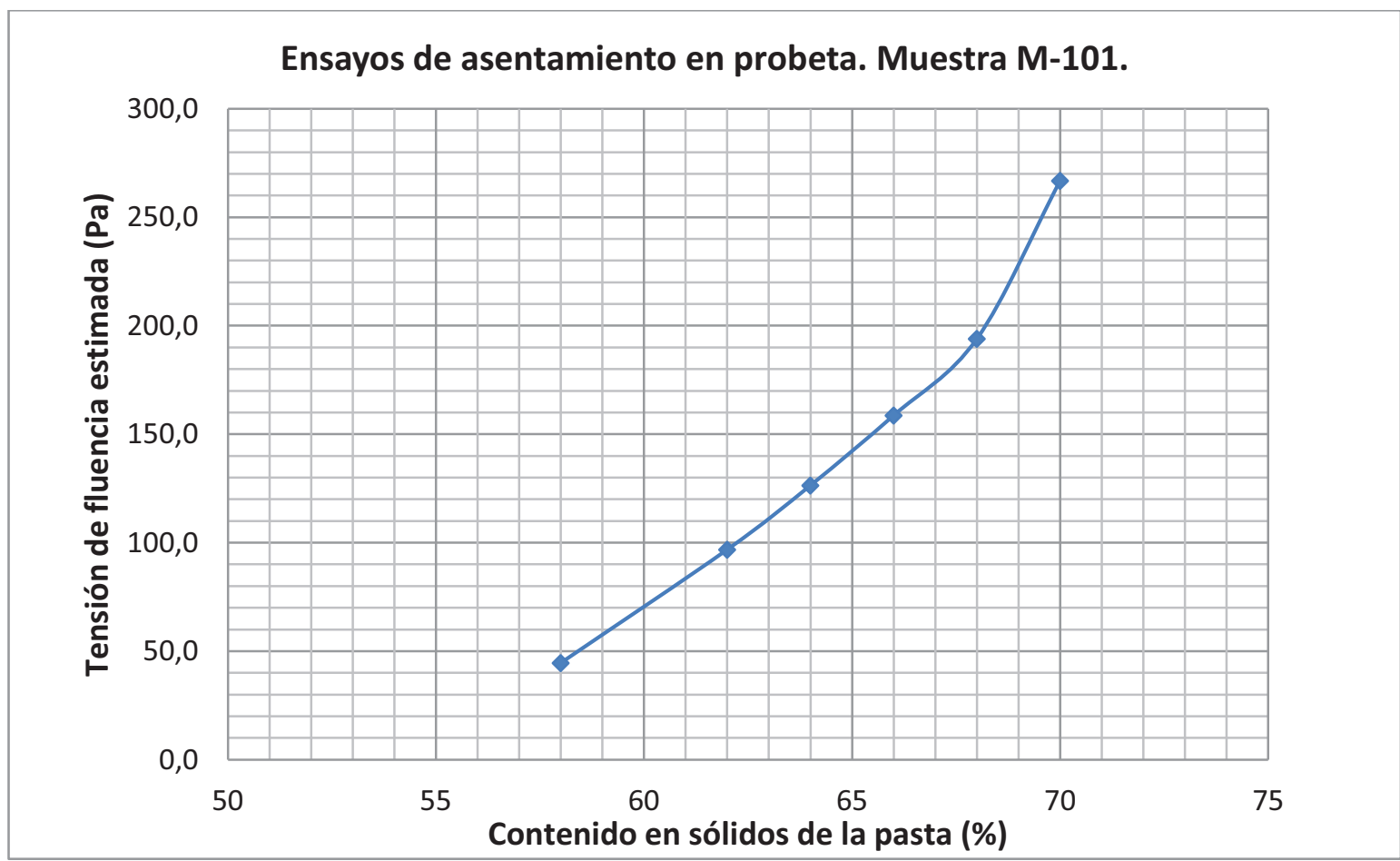

Figura 7-12: Curva tensión de fluencia-contenido en sólidos. Muestra M-101.

(Fuente: Elaboración propia)

Como resumen de los ensayos realizados sobre la muestra M-101 de estériles de flotación del espesador de 24 metros de diámetro se puede concluir que:

El floculante Nalco 8172 fue el que mejores resultados mostró en los ensayos de sedimentación realizados, obteniendo alta claridad en el rebose y buen ratio de sedimentación. El consumo promedio de floculante durante el ensayo en espesador de tubo profundo fue de $36,7 \mathrm{~g} / \mathrm{t}$. El estéril de mineral de cobre polimetálico fue alimentado con un $10 \%$ de contenido de sólidos en peso, 
simulando las condiciones del espesador real. Durante el ensayo se obtuvo una velocidad de 11,4 $\mathrm{m} / \mathrm{h}$ y un ratio de sedimentación de $28,6 \mathrm{t} / \mathrm{día} / \mathrm{m}^{2}$.

El espesado final de la muestra en el espesador de laboratorio fue del $69 \%$ de sólidos en peso tras un periodo de residencia de 8 horas, alcanzando una tensión de fluencia de $266 \mathrm{~Pa}$, lo cual representa una pulpa homogénea de pasta no segregable con características reológicas típicas en estos materiales.

\subsection{Comparativa del modelo experimental y el modelo real}

Para la validación del modelo experimental se realizará la comparativa de los datos obtenidos en el espesador real en operación y los valores recogidos en los ensayos de laboratorio realizados sobre la muestra de laboratorio analizada con la metodología propuesta.

Puesto que el sistema de tratamiento de estériles a escala de laboratorio propuesto en la tesis, es un sistema a escala de laboratorio que permite simular condiciones de espesado reales utilizando la metodología adecuada. El objetivo final es obtener resultados precisos que sean de aplicación en el dimensionamiento de los equipos de espesado y en la caracterización de los lodos obtenidos a partir de estériles de minería. La comparativa entre el espesador real en planta y los datos obtenidos en la metodología de estudio propuesta permite el análisis de la escala del método al aplicarlo a un proyecto de espesado real.

Los datos de proceso del espesador real son conocidos a partir de mediciones efectuadas en el laboratorio, las lecturas de la instrumentación de campo instalada en los espesadores y los valores de diseño establecidos en la ingeniería del equipo.

A continuación se analizan los datos obtenidos en el espesador real y se comparan con los datos obtenidos en el equipo de laboratorio de tubo profundo. Puesto que el sistema de tratamiento de estériles propuesto a escala de laboratorio permite simular las condiciones reales con los estudios experimentales y la metodología adecuada, es posible obtener resultados precisos que sean de aplicación en el tratamiento de un estéril específico susceptible de formar una pasta.

El sistema de tratamiento de estériles a escala de laboratorio propuesto permite simular las condiciones reales que se dan en un espesador de pasta de dimensiones considerables. El objetivo es comparar ambos resultados y ver la posibilidad de escalar los datos obtenidos en el laboratorio a un espesador real.

\subsubsection{Espesador de pasta de 18 metros de diámetro. Muestra M-100.}

En el caso del espesador de pasta de 18 metros, presenta los datos de proceso y de diseño que se muestran en la tabla 7-12: Datos de proceso y diseño del espesador de 18 metros en MATSA. Los datos mostrados corresponden al día 10 de febrero de 2015, en el que se tomaron las muestras y datos de la instrumentación en planta.

Con estos datos promedio obtenidos en el día que se toma la muestra para realizar el ensayo en el espesador de tubo profundo es posible conocer los datos relativos al consumo de floculante, ratio de sedimentación, flujo de sedimentación, contenido en sólidos del hundido y altura de lecho 
de lodos, donde los valores promedio se muestran en la tabla 7-13: Parámetros promedio de operación del espesador de 18 metros.

Los valores obtenidos en los ensayos de laboratorio llevados a cabo sobre la muestra M-100 de estériles se muestran en el anexo 1: Datos de laboratorio de la muestra M-100.

En la tabla 7-14: Comparativa espesador de laboratorio y espesador 18 metros. Muestra M-100; se han anotado los datos obtenidos en el espesador real en operación y los valores obtenidos en el espesador de laboratorio empleando la metodología propuesta, sobre los principales datos y valores que se necesitan para el diseño e ingeniería de cualquier espesador de pasta.

Tabla 7-12: Datos de proceso y diseño del espesador de 18 metros en MATSA.

\begin{tabular}{|l|l|}
\hline Turno 1: alimentación de sólidos en el espesador de pasta & 134 t/h sólidos \\
\hline Turno 2: alimentación de sólidos en el espesador de pasta & 119 t/h sólidos \\
\hline Turno 3: alimentación de sólidos en el espesador de pasta & 128 t/h sólidos \\
\hline Promedio de alimentación de sólidos al espesador de pasta & 127 t/h sólidos \\
\hline \% sólidos en peso de la alimentación al espesador & $29 \%$ sólidos en peso \\
\hline \% sólidos en peso tras la dilución de la alimentación & $12 \%$ sólidos en peso \\
\hline Turno 1: \% sólidos en peso del hundido obtenido en el espesador & $68 \%$ sólidos en peso \\
\hline Turno 2: \% sólidos en peso del hundido obtenido en el espesador & $69 \%$ sólidos en peso \\
\hline Turno 3: \% sólidos en peso del hundido obtenido en el espesador & $67 \%$ sólidos en peso \\
\hline Promedio \% sólidos en peso del hundido obtenido en el espesador & $68 \%$ sólidos en peso \\
\hline Consumo promedio de floculante & $35 \mathrm{~g} / \mathrm{t}$ \\
\hline Turno 1: Altura del lecho de lodos desde la descarga & $11,5 \mathrm{~m}$ \\
\hline Turno 2: Altura del lecho de lodos desde la descarga & $10,5 \mathrm{~m}$ \\
\hline Turno 3: Altura del lecho de lodos desde la descarga & $10,5 \mathrm{~m}$ \\
\hline Promedio de la altura del lecho de lodos desde la descarga & $10,8 \mathrm{~m}$ \\
\hline
\end{tabular}

(Fuente: Minas de Aguas Teñidas S.A.U.)

Tabla 7-13: Parámetros promedio de operación del espesador de 18 metros.

\begin{tabular}{|l|l|}
\hline Promedio de alimentación de sólidos al espesador de pasta & $127 \mathrm{t} / \mathrm{h}$ sólidos \\
\hline Promedio \% sólidos en peso del hundido obtenido en el espesador & $68 \%$ sólidos en peso \\
\hline Consumo promedio de floculante & $35 \mathrm{~g} / \mathrm{t}$ \\
\hline Promedio de la altura del lecho de lodos desde la descarga & $10,8 \mathrm{~m}$ \\
\hline
\end{tabular}

(Fuente: Minas de Aguas Teñidas S.A.U.)

Los principales valores y datos de diseño utilizados para el dimensionado de un equipo real de sedimentación en forma de pasta aplicado a estériles de minería, son perfectamente alcanzables con la metodología y el equipo de laboratorio propuesto en la presente tesis y por tanto es viable el uso del espesador de tubo profundo de laboratorio con pequeñas muestras de alimentación de pulpa para simular el funcionamiento del espesador de pasta a escala real. 
Tabla 7-14: Comparativa espesador de laboratorio y espesador de 18 metros. Muestra M-100.

\begin{tabular}{|l|c|c|}
\hline & Espesador real 18 metros & Espesador laboratorio \\
\hline Dilución alimentación: & $12 \%$ en peso (diseño) & $10 \%$ en peso \\
\hline Sólidos en el hundido: & $68 \%$ sólidos & $70 \%$ sólidos \\
\hline Tiempo de residencia: & 3 horas (diseño) & 2 horas \\
\hline Consumo promedio floculante & $35 \mathrm{~g} / \mathrm{t}$ & $32.8 \mathrm{~g} / \mathrm{t}$ \\
\hline Área unitaria de sedimentación: & $0,083 \mathrm{~m}^{2} / \mathrm{t} /$ día & $0,033 \mathrm{~m}^{2} / \mathrm{t} / \mathrm{día}$ \\
\hline Velocidad de sedimentación: & $10 \mathrm{~m} / \mathrm{h}$ (diseño) & $13,1 \mathrm{~m} / \mathrm{h}$ \\
\hline
\end{tabular}

(Fuente: Elaboración propia)

\subsubsection{Espesador de pasta de 24 metros de diámetro. Muestra M-101.}

En el caso del espesador de pasta de 24 metros que se opera en Minas de Aguas Teñidas desde octubre de 2014, éste fue diseñado con una capacidad de $260 \mathrm{t} / \mathrm{h}$ de sólidos con un contenido en sólidos del $25-28 \%$ en peso antes de la dilución. El objetivo de diseño para los lodos espesados es de obtener una pasta con el $70 \%$ de sólidos en peso que se envía bien a la balsa de estériles o bien a la planta de pasta para relleno (backfill).

En la tabla 7-15: Datos de proceso y diseño del espesador de 24 metros en MATSA, se puede ver una relación completa de los parámetros de operación del día en que se tomaron las muestras para ser ensayas en el laboratorio.

Tabla 7-15: Datos de proceso y diseño del espesador de 24 metros en MATSA.

\begin{tabular}{|l|l|}
\hline Turno 1: alimentación de sólidos en el espesador de pasta & $252 \mathrm{t} / \mathrm{h}$ sólidos \\
\hline Turno 2: alimentación de sólidos en el espesador de pasta & $239 \mathrm{t} / \mathrm{h}$ sólidos \\
\hline Turno 3: alimentación de sólidos en el espesador de pasta & $241 \mathrm{t} / \mathrm{h}$ sólidos \\
\hline Promedio de alimentación de sólidos al espesador de pasta & $244 \mathrm{t} / \mathrm{h}$ sólidos \\
\hline \% sólidos en peso de la alimentación al espesador & $28 \%$ sólidos en peso \\
\hline \% sólidos en peso tras la dilución de la alimentación & $12 \%$ sólidos en peso \\
\hline Turno 1: \% sólidos en peso del hundido obtenido en el espesador & $68 \%$ sólidos en peso \\
\hline Turno 2: \% sólidos en peso del hundido obtenido en el espesador & $67 \%$ sólidos en peso \\
\hline Turno 3: \% sólidos en peso del hundido obtenido en el espesador & $67 \%$ sólidos en peso \\
\hline Promedio \% sólidos en peso del hundido obtenido en el espesador & $67,3 \%$ sólidos en peso \\
\hline Consumo promedio de floculante & $39 \mathrm{~g} / \mathrm{t}$ \\
\hline Turno 1: Altura del lecho de lodos desde la descarga & $12,5 \mathrm{~m}$ \\
\hline Turno 2: Altura del lecho de lodos desde la descarga & $13,5 \mathrm{~m}$ \\
\hline Turno 3: Altura del lecho de lodos desde la descarga & $13,5 \mathrm{~m}$ \\
\hline Promedio de la altura del lecho de lodos desde la descarga & $13,2 \mathrm{~m}$ \\
\hline
\end{tabular}

(Fuente: Minas de Aguas Teñidas S.A.U.)

Con estos datos promedio obtenidos en el día que se toma la muestra para realizar el ensayo en el espesador de tubo profundo es posible conocer los datos relativos al consumo de floculante, 
ratio de sedimentación, flujo de sedimentación, contenido en sólidos del hundido y altura de lecho de lodos, donde los valores promedio se muestran en la tabla 7-16: Parámetros promedio de operación del espesador de 24 metros.

Tabla 7-16: Parámetros promedio de operación del espesador de 24 metros.

\begin{tabular}{|l|l|}
\hline Promedio de alimentación de sólidos al espesador de pasta & 244 t/h sólidos \\
\hline Promedio \% sólidos en peso del hundido obtenido en el espesador & $67,3 \%$ sólidos en peso \\
\hline Consumo promedio de floculante & $39 \mathrm{~g} / \mathrm{t}$ \\
\hline Promedio de la altura del lecho de lodos desde la descarga & $13,2 \mathrm{~m}$ \\
\hline
\end{tabular}

(Fuente: Minas de Aguas Teñidas S.A.U.)

Una vez que se tomó la muestra de la alimentación en el tanque de alimentación, se realizaron los ensayos conforme a la metodología propuesta, para comprobar los resultados obtenidos y se comparan con los valores de la operación real. Los resultados de laboratorio se muestran en el anexo 2 del presente documento.

En la tabla 7-17: Comparativa espesador de laboratorio y espesador 24 metros. Muestra M-101; se puede obtener las diferencias entre los datos obtenidos en el espesador real en operación y los valores obtenidos en el espesador de laboratorio empleando la metodología propuesta, sobre los principales datos y valores que se necesitan para el diseño e ingeniería de cualquier espesador de pasta.

Tabla 7-17: Comparativa espesador de laboratorio y espesador de 24 metros. Muestra M-101.

\begin{tabular}{|l|c|c|}
\hline & Espesador real 24 metros & Espesador laboratorio \\
\hline Dilución alimentación: & $12 \%$ en peso (diseño) & $10 \%$ en peso \\
\hline Sólidos en el hundido: & $67,3 \%$ sólidos & $69 \%$ sólidos \\
\hline Tiempo de residencia: & 5 horas (diseño) & 8 horas \\
\hline Consumo promedio floculante & $39 \mathrm{~g} / \mathrm{t}$ & $36,7 \mathrm{~g} / \mathrm{t}$ \\
\hline Área unitaria de sedimentación: & $0,077 \mathrm{~m}^{2} / \mathrm{t} /$ día & $0,036 \mathrm{~m}^{2} / \mathrm{t} / \mathrm{día}$ \\
\hline Velocidad de sedimentación: & $10 \mathrm{~m} / \mathrm{h}$ (diseño) & $11,4 \mathrm{~m} / \mathrm{h}$ \\
\hline
\end{tabular}

(Fuente: Elaboración propia)

Una vez más se ha comprobado que los principales valores y datos de diseño utilizados para el dimensionado de un equipo real de sedimentación son reproducidos con la metodología y el equipo de laboratorio propuesto en la presente tesis y por tanto el método reproduce las condiciones de espesado.

7.3.3 Comparativa de los datos de diseño. Espesador de laboratorio frente al espesador real

El ensayo de la muestra M-100 fue el punto de partida para una serie de ensayos que se realizaron sobre la misma muestra de pulpa. El ensayo inicial se muestra en el anexo 1. El objetivo 
es determinar diferentes velocidades de sedimentación de los sólidos floculados hasta conocer cuál es la máxima velocidad de sedimentación a la que el rebose comienza a perder claridad y por tanto, nos indica que los sólidos están escapando por el rebose. Esta sería una forma empírica y rápida de obtener los datos de velocidad de sedimentación máxima. Estos valores fueron comparados posteriormente con los valores históricos obtenidos en el espesador real instalado en la planta. Por otro lado, con la repetición del ensayo con los mismos parámetros de consumo de floculante, tiempo de residencia y con el mismo material en la alimentación se comprueba el comportamiento del equipo de espesado de laboratorio fabricado.

La obtención de diferentes velocidades de sedimentación sirve para ajustar los parámetros de velocidad de sedimentación y de área de sedimentación requerida en la operación. La experiencia en el diseño de este tipo de tanques de espesado, se ha determinado como norma general que las velocidades de sedimentación varían entre 5 y $10 \mathrm{~m} / \mathrm{h}$ de velocidad de sedimentación. Este valor preliminar de 5-10 m/h es válido como una primera aproximación para conseguir un rebose clarificado en las condiciones reales de operación de los modernos espesadores de pasta y es frecuentemente usado por los fabricantes de espesadores como dimensionado preliminar. Por otro lado, el espesador de estériles analizado en MATSA tiene una vida de operación de más de 5 años, ya que entró en servicio en el año 2009 y se mantiene desde entonces un fichero histórico de los tonelajes horarios tratados por el espesador. Puesto que la velocidad de sedimentación y la operación de sedimentación estará influida por otros factores, como pueden ser: el peso específico de los sólidos, adición de floculante, etc. los datos son muy variables, pero se pueden tomar dos valores significativos: el valor nominal al que trabaja normalmente el espesador $127 \mathrm{t} / \mathrm{h}$ de sólidos y los valores máximos alcanzados en algunas puntas de alimentación, que es de $235 \mathrm{t} / \mathrm{h}$.

El espesador real de 18 metros de diámetro analizado, fue instalado en el año 2009 y por tanto tiene un registro histórico de tonelajes tratados en él durante estos últimos años. El régimen nominal de trabajo del equipo ha sido de 100-130 t/h de sólidos como norma general, si bien en ocasiones el espesador ha sido capaz de tratar hasta $235 \mathrm{t} / \mathrm{h}$ de sólidos en algunas ocasiones, especialmente cuando otros espesadores en la planta han estado parados por mantenimiento. Este caudal máximo de $235 \mathrm{t} / \mathrm{h}$ se mantuvo durante varios turnos en la planta, sin pérdida en las propiedades de la claridad del agua de rebose gracias a las características del material tratado. Esto es debido a diversos factores que facilitan la sedimentación de los flóculos, como son: el peso específico de los sólidos, granulometrías más gruesas y la ausencia de arcillas en los estériles tratados. Por lo tanto, en la operación se pueden apreciar las grandes diferencias en la operación de espesado que pueden existir en función de los materiales que se alimentan al espesador de estériles.

Tomando como referencia los datos de diseño del equipo y las dimensiones del tanque del espesador de 18 metros de diámetro, es posible establecer los parámetros de área de sedimentación y velocidad de sedimentación, tanto para el caudal nominal como para el caudal máximo.

En el espesador instalado en la planta de MATSA, con los valores de diseño se obtuvieron los datos del proceso para tres escenarios, que se basan en los caudales horarios del archivo 
histórico del espesador, y que se han denominado: mínimo, nominal y máximo. Estos tres escenarios y los principales datos de operación y diseño se muestran en la tabla 7-18: Espesador de 18 metros en MATSA. Escenarios de operación.

Tabla 7-18: Espesador de 18 metros en MATSA. Escenarios de operación.

\begin{tabular}{|l|c|c|c|}
\hline & Mínimo & Nominal & Máximo \\
\hline Caudal de sólidos (t/h) & 100 & 127 & 235 \\
\hline Caudal de sólidos (t/día) & 2400 & 3048 & 5640 \\
\hline Superficie del espesador $\left(\mathrm{m}^{2}\right)$ & 254,5 & 254,5 & 254,5 \\
\hline Área Unitaria de Sedimentación (m²/t/día) & 0,106 & 0,083 & 0,045 \\
\hline Velocidad interna ascensional (m/h) & 3,7 & 4,8 & 8,8 \\
\hline Tiempo de residencia (h) & 14,7 & 11,5 & 6,7 \\
\hline \% sólidos en el hundido (promedio) & $72-74 \%$ & $70-72 \%$ & $68-70 \%$ \\
\hline
\end{tabular}

(Fuente: Elaboración propia)

En los ensayos realizados sobre la muestra de estériles $\mathrm{M}-100$ en el laboratorio, se obtuvieron diferentes valores de área unitaria de sedimentación y de velocidad de sedimentación. Para que la partícula sedimente en la operación real, la velocidad de sedimentación debe de ser mayor que la velocidad interna ascensional que se origina en el espesador de pasta. Durante los ensayos de laboratorio en el espesador de tubo profundo se ensayaron diferentes caudales hasta la obtención de un caudal máximo en el cual el rebose comienza a aparecer turbio y por tanto indicativo de que la velocidad de sedimentación y la velocidad ascensional del agua clarificada comienzan a igualarse. Los datos del ensayo se encuentran representados en la página 9 del anexo 9. La velocidad máxima promedio que se alcanza en el espesador de tubo profundo de laboratorio es de $16,2 \mathrm{~m} / \mathrm{h}$, a partir de esta velocidad se observa un rebose turbio, lo que hace disminuir el caudal de alimentación para evitar la pérdida de estériles o finos por el rebose. Para esta velocidad de sedimentación máxima, se obtiene el área unitaria mínima de 0,026 m²/t/día.

Este ensayo con la velocidad máxima obtenido en el laboratorio ha sido comparado con el valor máximo registrado en el espesador real de 18 metros en la planta de MATSA, como se muestra en la tabla: 7-19: Comparativa de valores con máximo caudal de alimentación.

Tabla 7-19: Comparativa de valores con máximo caudal de alimentación.

\begin{tabular}{|l|c|c|c|}
\hline & $\begin{array}{c}\text { Espesador } \\
\text { real } 18 \mathrm{~m} .\end{array}$ & $\begin{array}{c}\text { Espesador de } \\
\text { laboratorio }\end{array}$ & $\begin{array}{c}\text { Ratio de } \\
\text { escala }\end{array}$ \\
\hline Área Unitaria de Sedimentación ( $\mathrm{m}^{2} / \mathrm{t} /$ día) & 0,045 & 0,026 & 1,73 \\
\hline Velocidad interna ascensional $(\mathrm{m} / \mathrm{h})$ & 8,8 & 16,2 & 0,54 \\
\hline
\end{tabular}

(Fuente: Elaboración propia)

El espesador de tubo profundo de laboratorio, al ser un equipo con un comportamiento ideal y fácilmente regulable es fácil obtener un mayor valor de velocidad de sedimentación y por tanto un área unitaria de sedimentación menor. Al tener el equipo de laboratorio un comportamiento ideal, 
los tiempos de respuesta a las variaciones de caudal de alimentación y floculante son casi instantáneos y por esto, es más fácil obtener mejores resultados de velocidad de sedimentación y de área unitaria. Por contra, los equipos reales se deben operar con mayor cautela y de forma más conservadora ya que muestran un tiempo de respuesta elevado, incluso de horas, cuando se varían las condiciones de alimentación.

Partiendo de estas premisas, si se comparan los valores obtenidos en el espesador de laboratorio y en el espesador real, se puede obtener un primer ratio de escala con los valores obtenidos en el espesador real y el espesador de tubo profundo de laboratorio, ambos alimentados con su máximo caudal de sólidos. Como se observa en la tabla 7-19, los ratios de escala para la velocidad de sedimentación es de 0,54 y en el caso del área unitaria de sedimentación es de 1,73. Estos valores se ajustan a los de diseño en este tipo de espesadores de estériles trabajando en una operación real con materiales similares al ensayado en el laboratorio. Como se comentó anteriormente, los valores medios en el diseño de este tipo de operaciones de espesado de estériles, con similares granulometrías y pesos específicos se encuentran en los siguientes rangos mostrados en la tabla: 7-20: Valores promedio para el diseño de espesadores de pasta. Los datos obtenidos en el laboratorio y en el espesador de pasta real se ajustan a este rango teórico utilizado por los fabricantes de espesadores para este tipo de equipos.

Tabla 7-20: Valores promedio para el diseño de espesadores de pasta.

\begin{tabular}{|c|c|c|c|}
\hline & $\begin{array}{c}\text { Mínimo } \\
\text { (teórico) }\end{array}$ & $\begin{array}{c}\text { Máximo } \\
\text { (teórico) }\end{array}$ & $\begin{array}{c}\text { Promedio } \\
\text { (teórico) }\end{array}$ \\
\hline Área Unitaria de Sedimentación $\left(\mathrm{m}^{2} / \mathrm{t} / \mathrm{día}\right)$ & 0,015 & 0,06 & $0,03-0,04$ \\
\hline Velocidad interna ascensional $(\mathrm{m} / \mathrm{h})$ & 5 & 10 & $6-8$ \\
\hline
\end{tabular}

(Fuente: Elaboración propia)

Otro dato importante para el diseño de los equipos de espesado en forma de pasta es el contenido de sólidos máximo que se puede alcanzar en la operación de espesado. En este caso el ratio de escala es mínimo y se puede considerar que el hundido que se alcanza en el espesador de tubo profundo de laboratorio es el esperado en el espesador de pasta real. Se realizaron los ensayos de espesado con diferentes velocidades de sedimentación, como se muestran en los Anexos 1, 9, 10 y 11. El resultado obtenido del contenido en sólidos final apenas tuvo variaciones obteniéndose unos contenidos en sólidos que varían entre los valores de 74,2\% y 76,3\% para un mismo tiempo de residencia de 10 horas para todos los ensayos. En la figura: 7-13: Curvas de contenido en sólidos-tiempo de residencia. Muestra M-100.

El comportamiento del equipo de laboratorio es muy regular con la muestra $\mathrm{M}-100$, como se puede comprobar en los cuatro ensayos realizados, obteniéndose en todos ellos, unos valores similares en la concentración final de sólidos en el hundido del equipo. Como era de esperar la concentración de sólidos es algo superior a la que se obtendría en el espesador real, debido a las condiciones ideales del ensayo y al pequeño diámetro del tubo de ensayo que influye en la compactación del lecho de lodos, aumentando la concentración de los sólidos. 


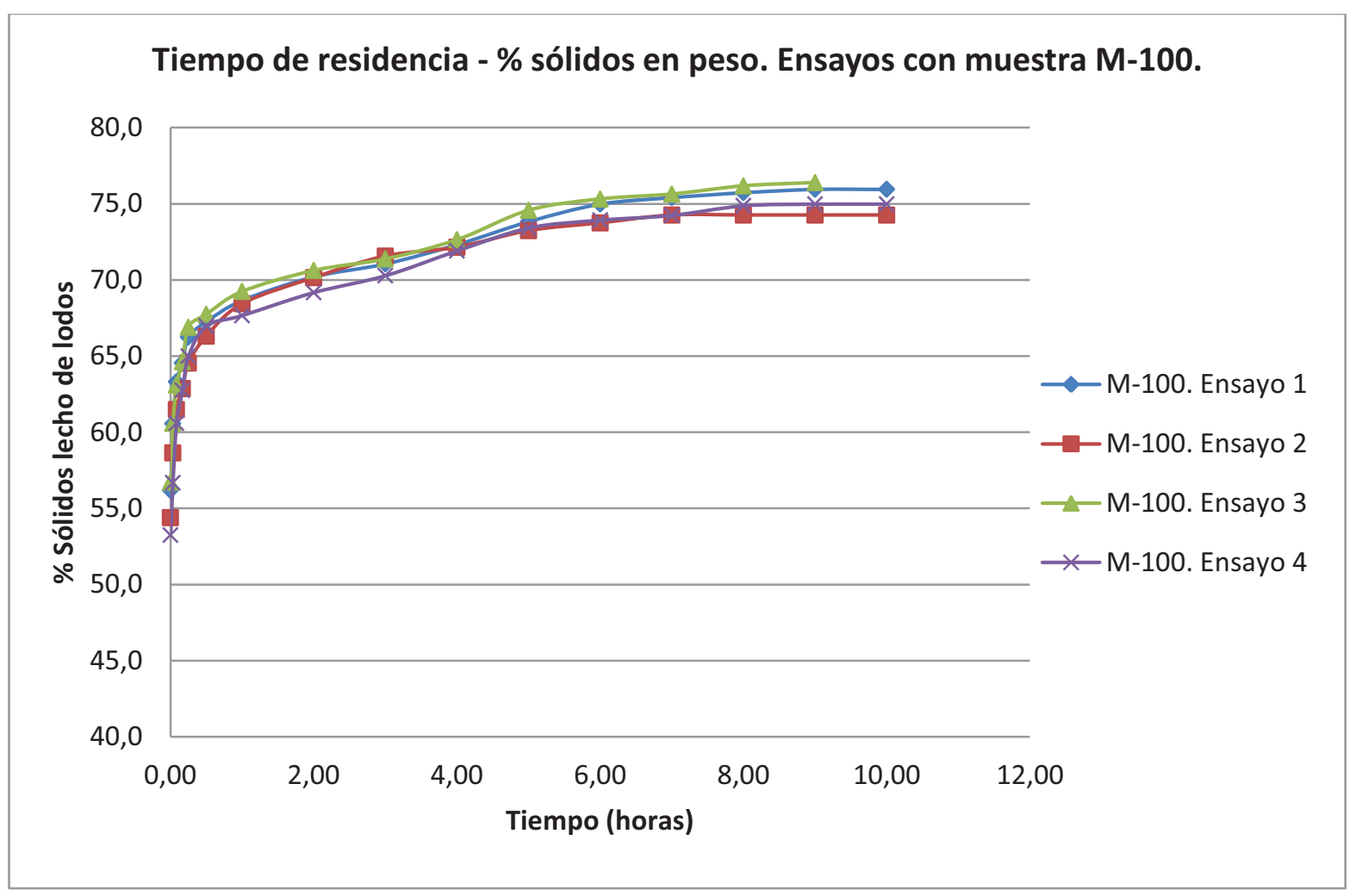

Figura 7-13: Curvas de contenido en sólidos-tiempo de residencia. Muestra M-100.

(Fuente: Elaboración propia)

\subsection{Aplicación del método de ensayo con otras sustancias minerales}

Con el objetivo de evaluar la metodología de ensayos con diferentes sustancias minerales, se ensayaron otras muestras de minerales finos diferentes de las muestras de estériles, para ajustar el método de ensayo y el equipo de laboratorio construido para este estudio. Todas las muestras utilizadas tienen una distribución granulométrica y finura similares a los estériles mineros típicos, presentando unos tamaños de partículas inferiores a 100 micras. Los materiales ensayados fueron:

a) Finos de caliza (Véase Anexo 3, Anexo 4 y Anexo 5)

b) Arcillas procedentes de lavado de áridos (Véase Anexo 6)

c) Finos de feldespato (Véase Anexo 7)

Como pruebas complementarias a las realizadas con las muestras de estériles de mineral de cobre polimetálico analizadas en los puntos 7.1 y 7.2 ; se han ensayado una amplia variedad de muestras en el laboratorio de materiales con curvas granulométricas similares a las de alimentación típica de los espesadores de pasta, como prueba del espesador de tubo profundo de 5,5 litros de capacidad.

Los diferentes materiales ensayados se muestran en la tabla 7-21: Otros materiales ensayados en laboratorio. 
Tabla 7-21: Materiales ensayados.

\begin{tabular}{|l|l|l|}
\hline Material & Muestra & Origen \\
\hline Caliza & M-002 & Finos procedentes de molienda en seco. \\
\hline Arcillas & M-004 & Arcillas de lavado de áridos \\
\hline Feldespato & M-005 & Finos procedentes de molienda en seco \\
\hline
\end{tabular}

(Fuente: Elaboración propia)

Los ensayos que se llevaron a cabo con las diferentes muestras fueron:

a) Tamaño y distribución de partículas.

b) Caracterización de sólidos y líquido.

c) Selección del floculante adecuado.

d) Selección del contenido en sólidos óptimo en la alimentación.

e) Ensayo en probeta estática.

f) Ensayo en espesador dinámico de 5,5 litros de capacidad.

g) Ensayos de filtración a vacío

h) Ensayos de reología de la pasta.

\subsubsection{Caracterización de la muestra}

Las muestras fueron recibidas en forma de sólido seco, por lo que la pulpa se debía de preparar en el laboratorio con las diluciones indicadas en cada caso. Para el caso de muestras de material recibidas como sólido seco presentan la ventaja de poder realizar las diluciones de forma precisa y con la desventaja es que el agua de proceso no es igual a la que se pueda utiliza en la planta, por lo que siempre es recomendable usar el mismo agua de proceso que en la planta de tratamiento. Este no era el caso de este ensayo ya que estos materiales no proceden de un tratamiento por vía húmeda y fue necesario repulpar con agua para los ensayos en laboratorio.

Se realizaron análisis granulométricos de cada una de las muestras para obtener el tamaño de las partículas y el $\mathrm{P}_{80}$ característico de cada uno de ellos. En la tabla 7-22: Caracterización granulométrica de los materiales, se muestran los valores características de todas ellas.

Tabla 7-22: Caracterización granulométrica de los materiales.

\begin{tabular}{|c|c|c|c|c|}
\hline Material & Muestra & $P_{80}$ & $\%$ finos $<20 \mu m$ & Peso específico $\left(\mathrm{g} / \mathrm{cm}^{3}\right)$ \\
\hline Caliza & M-002 & 34 micras & $68 \%$ & 2,65 \\
\hline Arcillas & M-004 & 38 micras & $62 \%$ & 2,0 \\
\hline Feldespato & M-005 & 65 micras & $24 \%$ & 2,65 \\
\hline
\end{tabular}

(Fuente: Elaboración propia)

Véase el apartado de Anexos para una descripción detallada de las características de cada uno de los materiales ensayados. 
Como se muestra en la tabla $7-22$, todos los materiales ensayados tienen un alto contenido en sólidos inferior a 20 micras y por tanto susceptibles de formar una pasta.

\subsubsection{Selección de floculante y flujo de sedimentación}

Con todas las muestras de materiales se realizaron varias pruebas de sedimentación en probeta con el objetivo de determinar el mejor floculante y su dosificación. Se realizaron al menos cuatro pruebas de velocidad de sedimentación con cada material, utilizando pulpas con el $5 \%$ de sólidos en peso y añadiendo diversas dosis de floculantes con diferentes cargas. En la tabla 7-23: Ensayo de velocidad de sedimentación; se detallan los valores de velocidad de sedimentación frente a la dosificación de floculante con cada una de las muestras.

Tabla 7-23: Ensayo de velocidad de sedimentación.

\begin{tabular}{|c|c|c|c|c|}
\hline Material & Muestra & Floculante & Velocidad $(\mathbf{m} / \mathbf{h})$ & Dosificación $\mathbf{( g / t )}$ \\
\hline Caliza & M-002 & Nalco 0\% carga & 40 & 80 \\
\hline Arcillas & M-004 & Nalco 0\% carga & 36 & 57 \\
\hline Feldespato & M-005 & Nalco 0\% carga & 40 & 40 \\
\hline
\end{tabular}

(Fuente: Elaboración propia)

En todos los casos el procedimiento seguido fue el método descrito en el punto 6.5, con el fin de obtener la gráfica que relaciona la dosificación de floculante en $\mathrm{g} / \mathrm{t}$ con la velocidad de sedimentación en $\mathrm{m} / \mathrm{h}$ alcanzada por la muestra al sedimentar en la probeta.

En todos los casos, se realizó una observación visual de cada ensayo de sedimentación para determinar que floculante es el más adecuado para el proceso de sedimentación.

Hay que advertir que esta dosificación de floculante es preliminar y debe ser confirmada con ensayos posteriores.

Con esta prueba de ensayo de la velocidad de sedimentación se realizó el siguiente ensayo de flujo de sedimentación, con el fin de determinar la dosificación de sólidos en la pulpa más eficiente. Este ensayo es importante para el dimensionado de la campana de alimentación y del sistema de dilución del espesador. Este contenido en sólidos óptimo determinado con este ensayo sirve de punto de partida para el diseño del sistema de alimentación del equipo industrial.

Para el siguiente ensayo de flujo de sedimentación se utilizará este tipo de floculante y se prepararán varias muestras de pulpa con diferentes cantidades de sólidos en peso: 2,5\%; $5 \%$; $7,5 \%$ y $10 \%$, generalmente. Sobre estas muestras se realizarán al menos cuatro pruebas de flujo de sedimentación para cada una de las diluciones de la pulpa, anotando los tiempos de velocidad de sedimentación y el flujo de sólidos con respecto a la dosificación de floculante.

En la figura 7-14: Flujo de sedimentación para finos de caliza; se muestran tres fases del ensayo llevado a cabo para las muestras con el $7,5 \%$ y el $10 \%$ de sólidos en peso sobre la muestra de caliza M-002. 

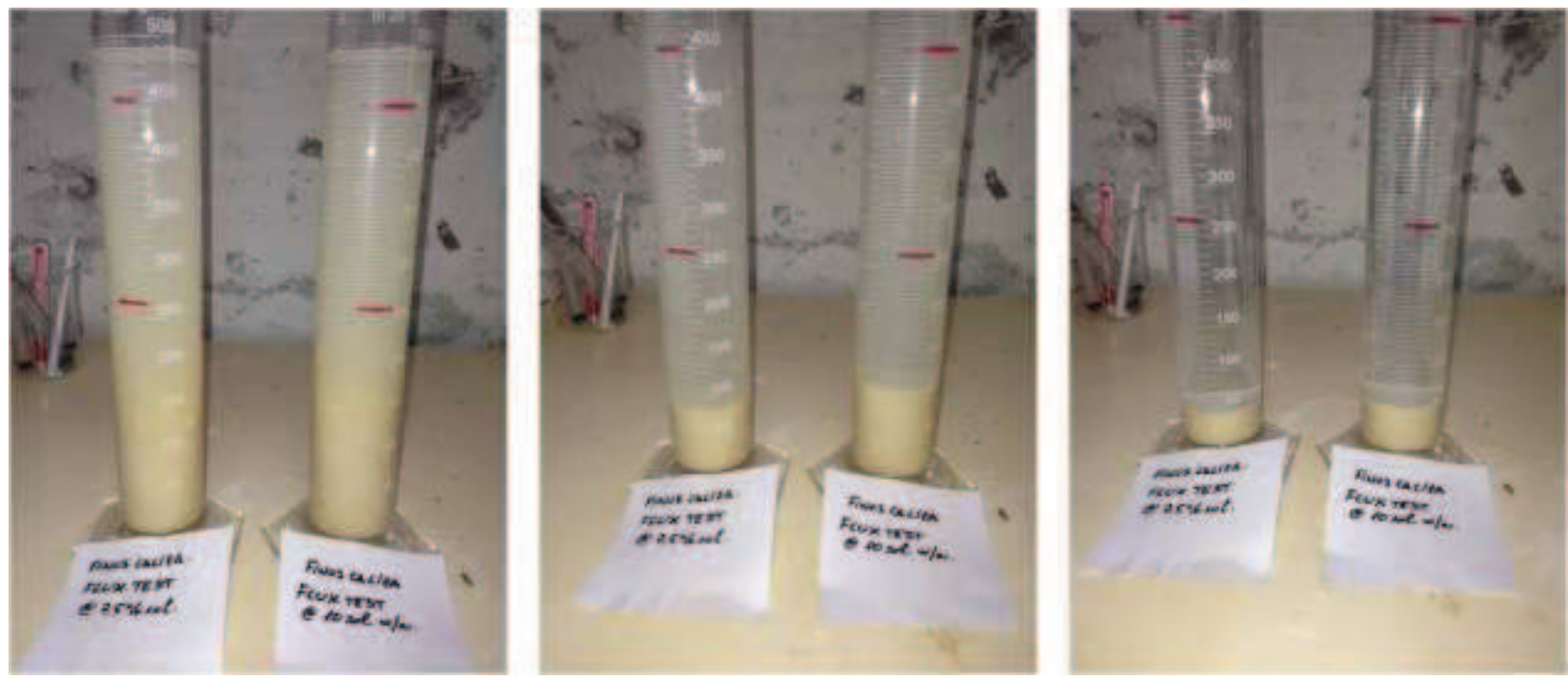

Figura 7-14: Flujo de sedimentación para finos de caliza.

(Fuente: Elaboración propia)

Los mejores resultados de velocidad de sedimentación y flujo de sólidos se toman como parámetro de diseño para el sistema de alimentación del espesador.

En la tabla 7-24: Flujos de sedimentación de los materiales; se muestran los mejores resultados obtenidos para cada uno de los materiales ensayados.

Tabla 7-24: Flujos de sedimentación de los materiales.

\begin{tabular}{|c|c|c|c|c|c|}
\hline Material & Muestra & $\begin{array}{c}\text { \% Sólidos } \\
\text { óptima }\end{array}$ & $\begin{array}{c}\text { Velocidad } \\
(\mathbf{m} / \mathbf{h})\end{array}$ & $\begin{array}{c}\text { Dosificación } \\
(\mathbf{g} / \mathbf{t})\end{array}$ & $\begin{array}{c}\text { Flujo sólidos } \\
\left(\mathbf{t} / \mathbf{d i ́} / \mathbf{m}^{\mathbf{2}}\right)\end{array}$ \\
\hline Caliza & M-002 & $5 \%$ en peso & 45 & 40 & 145,6 \\
\hline Arcillas & M-004 & $15 \%$ en peso & 32,7 & 50 & 338,7 \\
\hline Feldespato & M-005 & $5 \%$ en peso & 60 & 60 & 194,1 \\
\hline
\end{tabular}

(Fuente: Elaboración propia)

Por lo tanto en esta primera parte de los ensayos de pruebas con diferentes materiales, se ha conseguido ajustar los parámetros básicos de la operación de sedimentación con la recogida de datos. Una vez seleccionado el contenido en sólidos y la dosificación de floculante óptima se realizarán las pruebas de sedimentación tanto en probeta de $2000 \mathrm{ml}$ como en el equipo de espesado dinámico de laboratorio.

\subsubsection{Prueba de sedimentación en probeta de 2 litros}

Como ensayo para comprobar la sedimentación de la pulpa y previo al ensayo en tubo profundo o espesador dinámico, se han realizado una serie de pruebas de sedimentación en probeta de 2 litros para cada uno de los materiales. Esta probeta es de un diámetro mayor que las probetas de $500 \mathrm{ml}$ utilizadas hasta este momento y que minimizan la posibilidad de la interferencia de la operación de sedimentación con el "efecto pared" que puede aparecer en las probetas de 
diámetros pequeños. Siguiendo el método descrito en el punto 6.5 , se realizó el ensayo de sedimentación en probeta de $2000 \mathrm{ml}$ con el objetivo de determinar la curva de sedimentación y el máximo contenido en sólidos alcanzado por las diferentes pulpas. En el apartado de Anexos, se muestran los datos detallados de estos ensayos.

En la figura 7-15: Curvas de sedimentación en probeta de 2000ml; se representan las curvas de sedimentación obtenidas en el ensayo en probeta de 2 litros sobre los diferentes materiales.

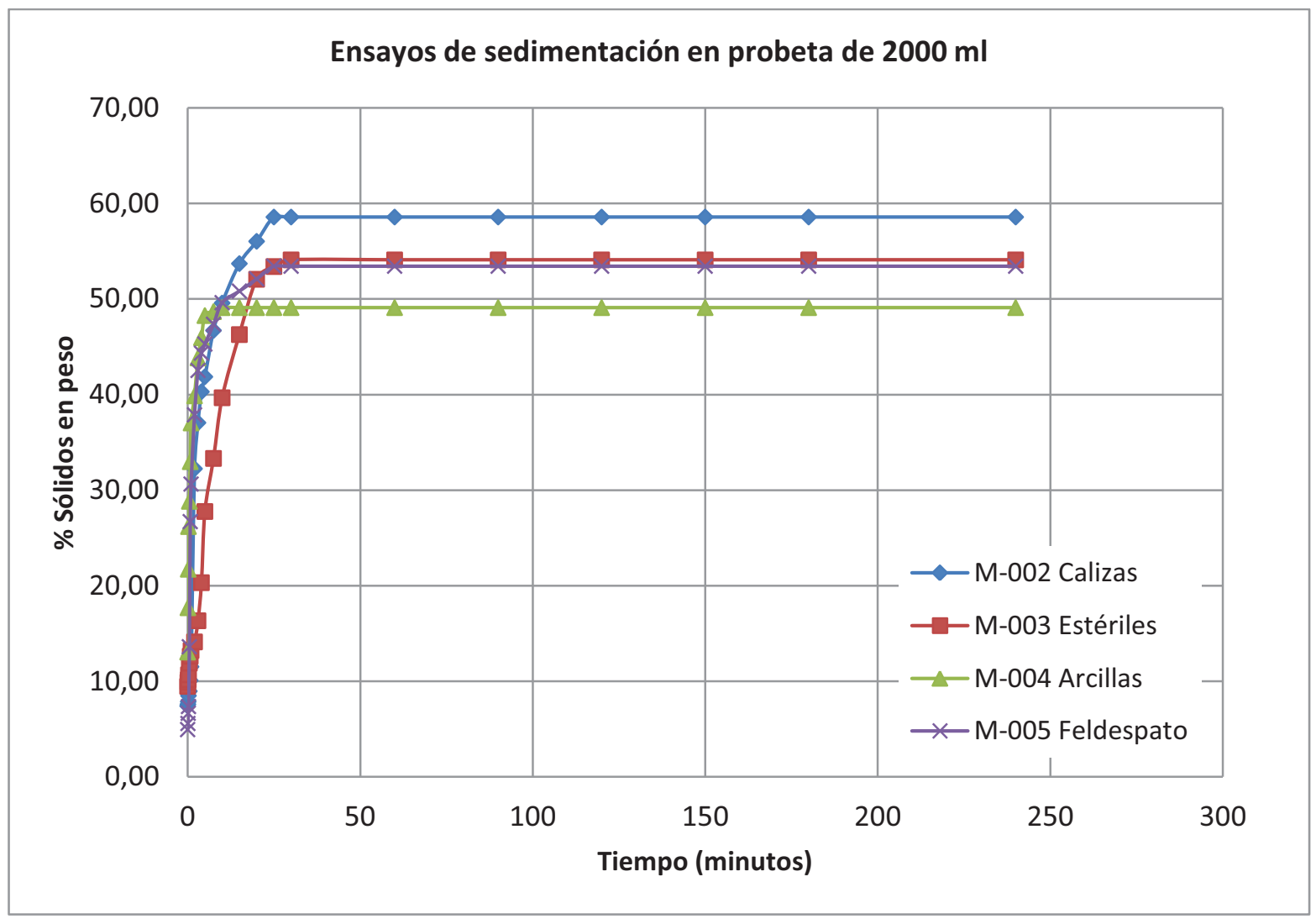

Figura 7-15: Curva de sedimentación en probeta de 2000ml.

(Fuente: Elaboración propia)

En todos los materiales ensayados se alcanza el punto de compresión de la pulpa, si bien se observa que la falta de un mecanismo de rasquetas impide alcanzar mayores densidades en el hundido de la probeta.

\subsubsection{Pruebas en espesador dinámico o de tubo profundo}

Para probar el sistema desarrollado de espesado de laboratorio, se han realizado varios ensayos en el espesador de tubo profundo de laboratorio con diferentes contenidos en sólidos del $5 \%$; $7,5 \%$ y $10 \%$ según el tipo de material. Las muestras ensayadas fueron representativas de todos los materiales disponibles y en todas se siguió el mismo procedimiento:

a) Preparación de la pulpa en un tanque de agitación externo con la dilución correspondiente.

b) Preparación del floculante seleccionado. 
c) Alimentación de forma continua al espesador de laboratorio de la totalidad de la muestra de pulpa preparada. Alimentación del floculante y sistema de rasquetas interiores en funcionamiento.

d) Una vez alimentada la pulpa se comienza la toma de datos para determinar el contenido en sólidos alcanzado en el espesador.

Una vez preparada la pulpa en el tanque de alimentación, con una dilución de sólidos en peso y tras una agitación mecánica continua, se procedió a alimentar la pulpa con bomba centrífuga para proporcionar un caudal uniforme durante el proceso de alimentación.

Todos los casos ensayados se muestran en el apartado de Anexos. En la figura 7-16: Espesador de tubo profundo con finos de caliza; se muestra un ejemplo de las diferentes etapas del ensayo de sedimentación en el espesador de laboratorio.
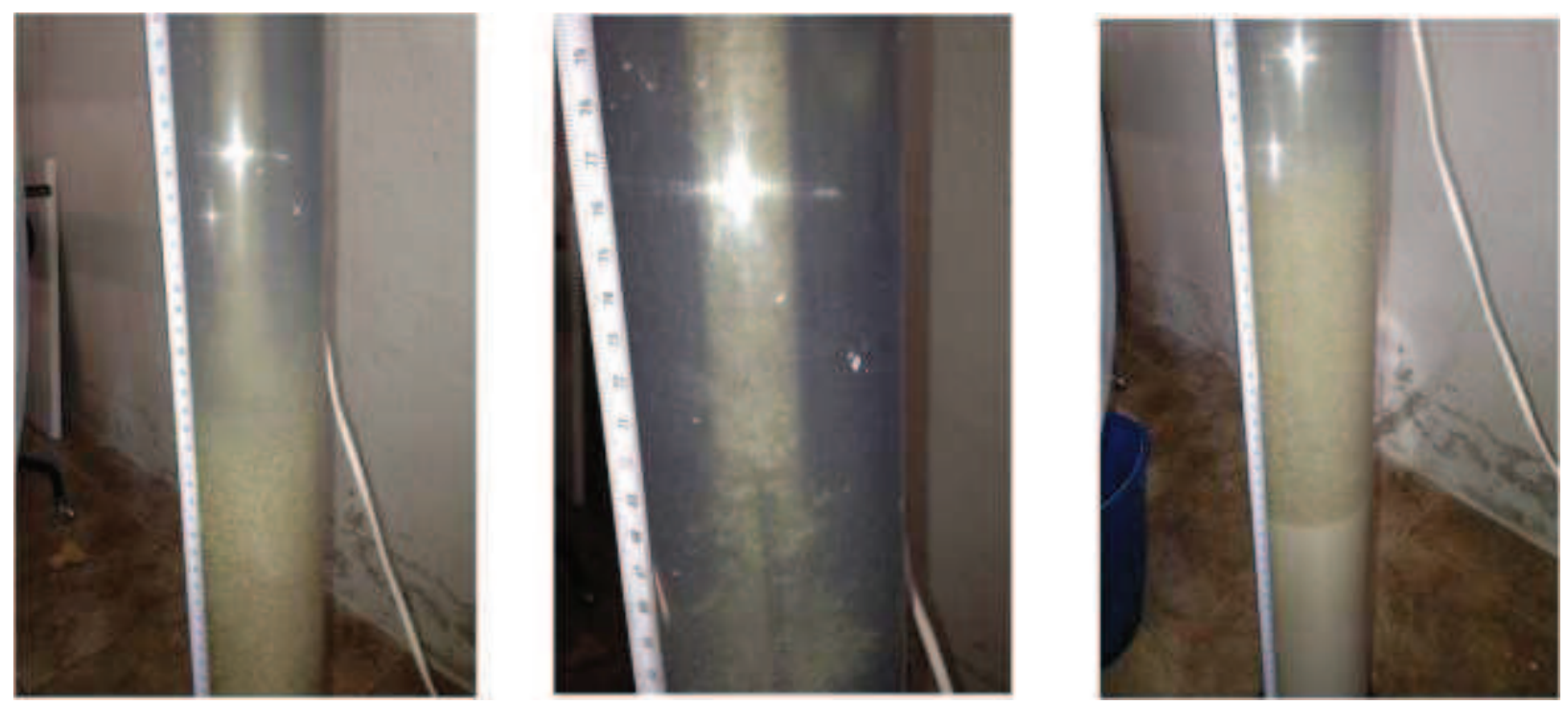

Figura 7-16: Espesador dinámico con finos de caliza.

(Fuente: Elaboración propia)

Uno de los principales retos del operador del equipo de laboratorio es ajustar la alimentación de pulpa y floculante es conseguir una dosificación eficiente de ambos en el equipo. Es aconsejable en este punto realizar pruebas iniciales de bombeo en probetas para comprobar los flujos que se producen para corregir la dosificación en caso necesario.

Una vez alimentado el espesador dinámico con toda la pulpa, se observó que algunos sólidos quedan en el circuito de bombeo, por lo que se corrigieron las hojas de toma de datos para poder predecir los sólidos que se hubieran quedado sin alimentar. Este porcentaje de sólidos que teóricamente se pierden en el circuito es de aproximadamente entre el 3\% y el $5 \%$ del peso total de sólidos que debe ser descontado de los cálculos finales, para la obtención del contenido en sólidos final.

En la figura 7-17: Tiempo de residencia - contenido en sólidos; se muestran los máximos contenido en sólidos alcanzados por los materiales ensayados. 


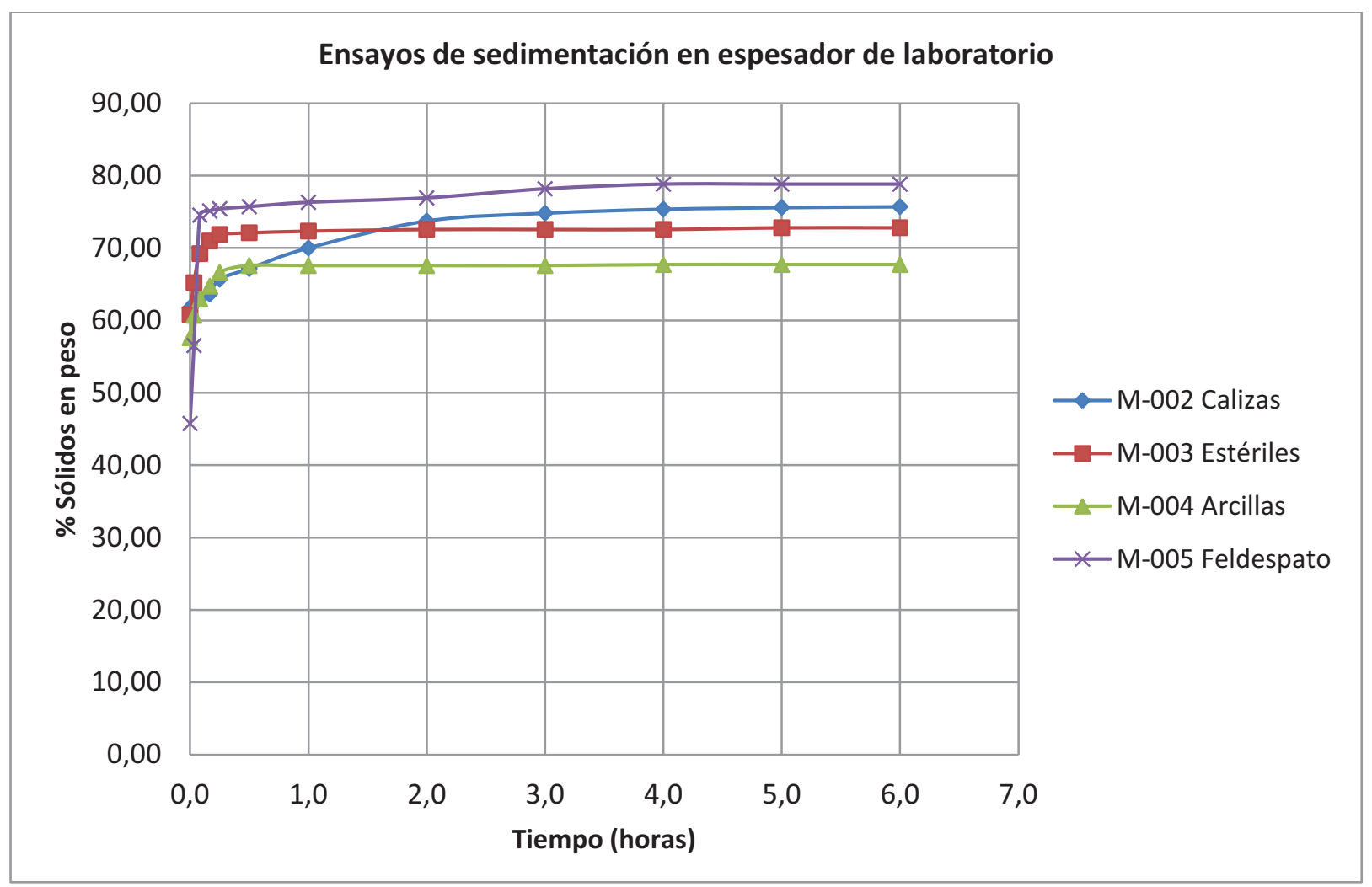

Figura 7-17: Tiempo de residencia - contenido en sólidos.

(Fuente: Elaboración propia)

Una vez realizados los ensayos en el espesador piloto, se puede observar cómo se alcanzan valores de contenido en sólidos cercanos a una pasta y mucho mayores que los alcanzados en los ensayos de sedimentación en probeta de $2000 \mathrm{ml}$, como se quería conseguir.

\subsubsection{Ensayos de filtración a vacío}

El objetivo de los ensayos de filtración a vacío es determinar el máximo contenido en sólidos que se puede alcanzar con este material. Para este ensayo se siguió el método descrito en el punto 6.3.8. En el ensayo de filtración, el contenido en sólidos será siempre superior al contenido en sólidos obtenido en el espesador dinámico o en la operación de espesado pero representa un límite máximo de la operación de espesado. Se prepararon las muestras con todos los materiales para comprobar el contenido en sólidos de la torta que se alcanzaba. En la figura 7-18: Torta formada con finos de caliza; se muestra un ejemplo de las tortas conseguidas con estos ensayos. Se ha observado que los valores preliminares obtenidos en los ensayos de filtración, si se obtienen con la medición del líquido filtrado recogido en la trampa de filtrado, tienen un valor similar de contenido en sólidos al que se obtiene secando la muestra en horno de secado. En el apartado de Anexos se encuentran todos los datos de los ensayos de filtración a vacío. 


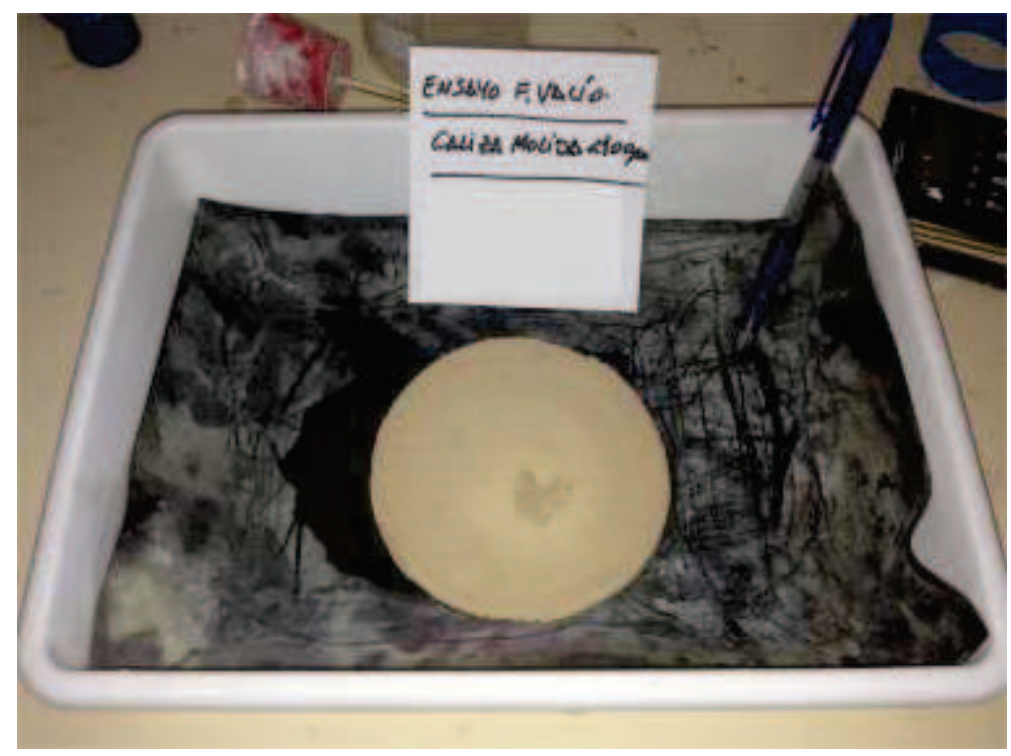

Figura 7-18: Torta formada con finos de caliza.

(Fuente: Elaboración propia)

\subsubsection{Ensayo de asentamiento}

El material obtenido en ensayos de filtración a vacío fue utilizado para producir una pasta con varias concentraciones de sólidos, partiendo de muestras de $100 \mathrm{~g}$ a $200 \mathrm{~g}$ de material diluidas al $20 \%$ de sólidos que eran filtradas en lotes. En este caso se midió la tensión de fluencia como una función de la concentración de sólidos a medida que las diferentes muestras de pastas eran preparadas.

El método utilizado para medir esta tensión de fluencia fue el ensayo de asentamiento realizado en el propio laboratorio. El objetivo de estos ensayos era predecir los límites de las densidades de hundido manejables en cada tipo de espesador y comprobar el comportamiento reológico de la pasta obtenida, determinando la tensión de fluencia, con el método descrito en el punto 6.3.9. En la figura 7-19: Ensayo de asentamiento para feldespato potásico; se observan dos asentamientos de la probeta para diferentes contenidos en sólidos.
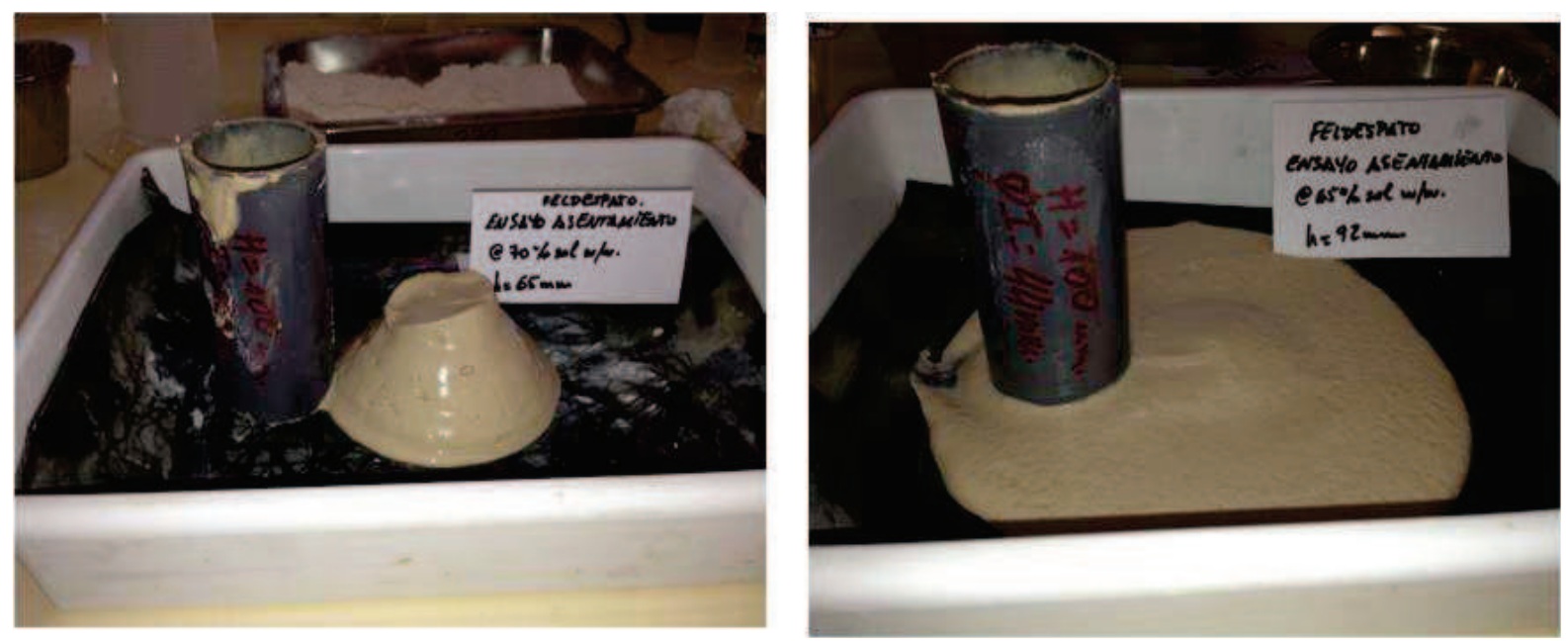

Figura 7-19: Ensayo de asentamiento para feldespato potásico.

(Fuente: Elaboración propia) 
Se realizaron varios ensayos con diferente contenido en sólidos y con todos los materiales para obtener la curva de tensión de fluencia frente a contenido en sólidos para estas concentraciones, como se muestra en la figura 7-20: Curva de asentamiento para feldespato potásico.

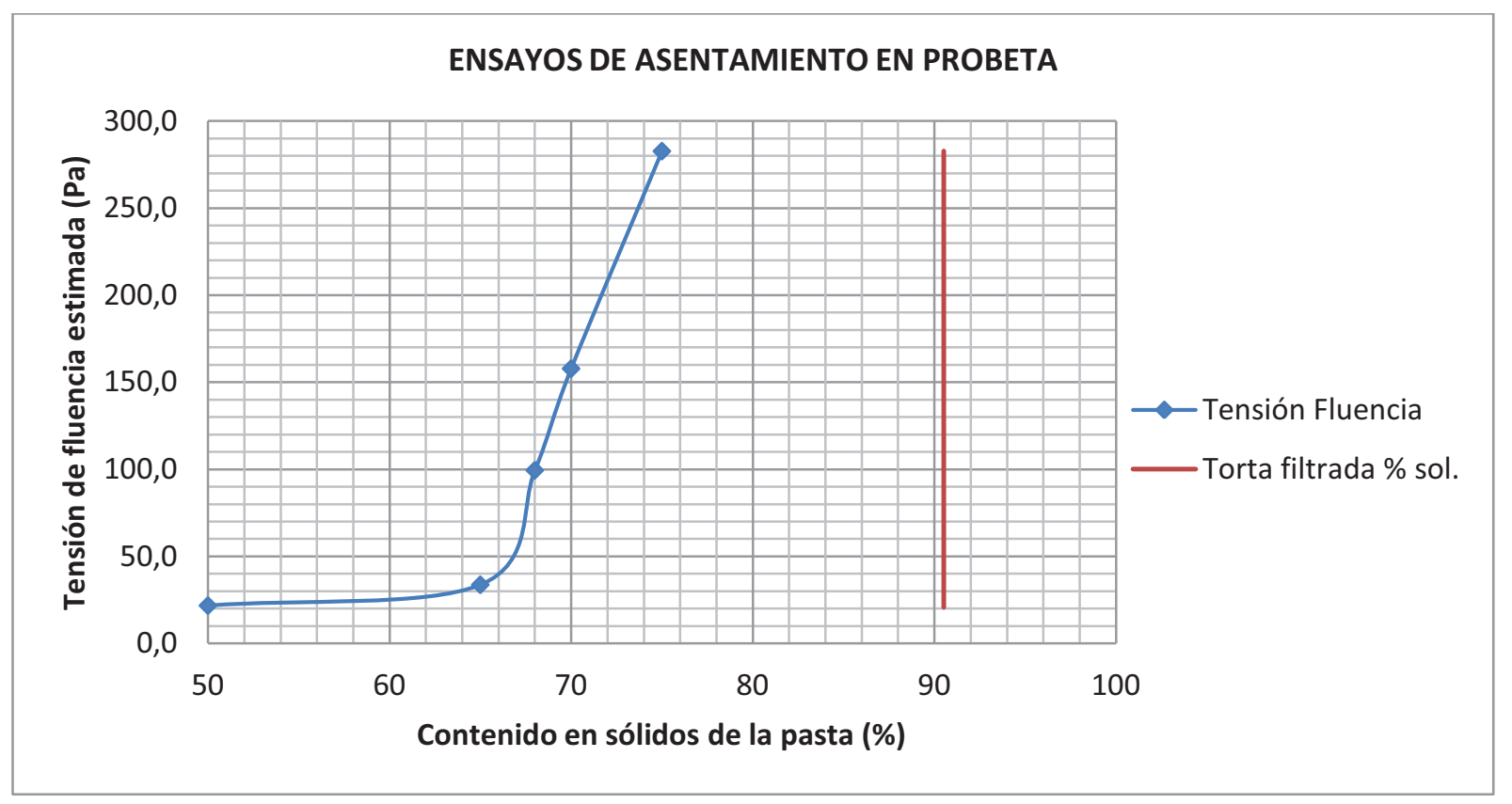

Figura 7-20: Curva de asentamiento para feldespato potásico.

(Fuente: Elaboración propia)

\subsection{Conclusiones sobre las pruebas realizadas y el modelo experimental}

El espesador dinámico de laboratorio fabricado y el método de análisis propuesto, se postulan como un método fiable, barato y preciso para reproducir en laboratorio las operaciones de espesado en forma de pasta a partir de pequeñas muestras de material y obtener una gran variedad de datos de gran utilidad para el diseño de un sistema de espesado en pasta, especialmente para el espesador.

El método de ensayos propuesto es de gran utilidad especialmente cuando no existe una gran cantidad de muestra disponible especialmente en las primeras fases del proyecto donde sólo se dispone de pequeñas muestras y es preciso evaluar la viabilidad de los sistemas de espesado y de manejo de estériles.

La aplicación de este método es relativamente sencilla y permite ensayos "in situ" con los materiales que van a ser espesados en forma de pasta para nuevos proyectos y proyectos existentes, evitando grandes instalaciones de plantas piloto para el estudio de mejoras en las operaciones de espesado o para el diseño y dimensionado del equipo.

Se ha demostrado con los dos tipos de materiales finos empleados en los ensayos, que el proceso y los métodos de evaluación consiguen caracterizar los sólidos y las suspensiones de pasta formadas por éstos. Estos datos permiten dimensionar y elegir el tipo de espesador y proceso adecuado a cada sistema de espesado en forma de pasta. 
En el siguiente capítulo se realizará un ensayo sobre los estériles procedentes de un proyecto que actualmente es objeto de estudio conceptual y de viabilidad para su futura explotación.

Una vez realizados los ensayos con todos los material de finos se obtienen las siguientes conclusiones para el diseño y la mejora del sistema de ensayos propuesto:

a) Los materiales ensayados tienen un alto contenido en finos y por lo tanto son susceptibles de formar una pasta.

b) Los floculantes seleccionados con el sistema de ensayos en probetas de $500 \mathrm{ml}$, midiendo la velocidad de sedimentación y flujo de sólidos presentan unos buenos resultados en el espesador de laboratorio.

c) Las diluciones de mayor rendimiento a la entrada del espesador de laboratorio es en general, de entre 5 y 7,5\% de contenido en sólidos para obtener dosificaciones de floculante relativamente bajas.

d) En el ensayo de sedimentación en probeta estática no reproduce con exactitud el proceso de sedimentación en un espesador de cono profundo, ya que las concentraciones del hundido han sido ampliamente superadas por el espesador dinámico de laboratorio construido para este trabajo.

e) En todas las pruebas y con todos los materiales ensayados en el espesador de tubo profundo se consigue mejorar el contenido en sólidos en el hundido, llegando hasta el $75 \%$ de sólidos en peso tras dos horas de tiempo de residencia en algunos materiales. Por lo tanto en el caso de diseño de un espesador de alta densidad o pasta se tendrá en cuenta este método para obtener el tiempo de retención y contenido en sólidos en la operación de espesado en pasta.

f) El ensayo de filtración a vacío muestra que el máximo contenido en sólidos alcanzado por el material tras una filtración a vacío está cerca del límite máximo de concentración alcanzable en el espesador de laboratorio.

g) El ensayo de asentamiento permite conocer de forma empírica la tensión de fluencia de la pasta imprescindible para el diseño del sistema de espesado. Las curvas conseguidas en el laboratorio tienen un perfil característico para este tipo de materiales, con un aumento exponencial de la tensión de fluencia, con respecto al contenido en sólidos de la pasta, como cabría esperar. 


\section{Aplicación del modelo a un caso real de espesado de estériles de mina}

Como aplicación práctica de la metodología propuesta, se ha analizado material de estériles para un futuro proyecto en el yacimiento de Laza en Orense. Actualmente este proyecto se encuentra en fase de estudio de viabilidad económica. Centrándose en la parte del espesado y tratamiento de estériles se ha realizado un estudio para determinar la viabilidad de utilizar un sistema de espesado en pasta para tratar los estériles que se obtendrían de la futura explotación del yacimiento.

El objetivo de esta aplicación es dimensionar y diseñar el sistema de espesado y tratamiento de estériles óptimo para el material procedente del yacimiento de Laza en Orense, centrando el interés en determinar si los estériles pueden alcanzar la condición y las características de una pasta, es decir la obtención final de un material espesado con alto contenido en sólidos, no segregable y con una alta tensión de fluencia para su deposición de forma segura en un depósito de estériles.

En este caso, se está llevando a cabo un estudio de viabilidad para la reapertura de la mina y se han evaluado las alternativas existentes para el tratamiento de los estériles que se generarán durante la operación de la explotación, investigando la tecnología más adecuada y viable para ofrecer la mejor solución para la futura explotación de la mina.

Estos ensayos se han llevado a cabo en laboratorio utilizando la metodología de ensayos y equipos de laboratorio descritos en los capítulos anteriores.

\subsection{Ensayos de laboratorio y resultados}

Para el desarrollo de estos ensayos se ha trabajado con una muestra de sólidos finamente molidos en el molino de bolas del Laboratorio de Menas de la Escuela Técnica Superior de Ingenieros de Minas. Estos sólidos corresponden a una muestra de los estériles esperados en la futura explotación del yacimiento de Laza, donde se beneficiarán minerales de estaño y wolframio, que tras las operaciones de beneficio se generan unos estériles procedentes de la planta que serán depositados en balsa o escombrera para su acopio.

Para cumplir con los objetivos y caracterizar correctamente la muestra y su comportamiento en las operaciones de espesado, se han realizado los siguientes ensayos:

a) Tamaño y distribución de partículas.

b) Densidad de sólidos y líquido.

c) Selección del floculante.

d) Selección del contenido en sólidos óptimo en la alimentación.

e) Ensayo en probeta estática.

f) Ensayo en espesador dinámico de 5,5 litros de capacidad.

g) Ensayo de la reología de la pasta obtenida.

h) Ensayos de filtración a vacío 


\subsubsection{Caracterización de la muestra}

La muestra de estériles fue recibida en forma de sólidos etiquetada con el número M-074. El hecho de recibir la muestra en forma de sólidos implica que la pulpa se ha de preparar en el propio laboratorio ya que en este caso no hay disponible agua de proceso por tratarse de un proyecto nuevo en fase de estudio de viabilidad para la explotación económica del yacimiento. En la figura 8-1: Muestra de estériles M-074; se puede ver la muestra recibida (1620 g de sólidos) en forma de material molido.

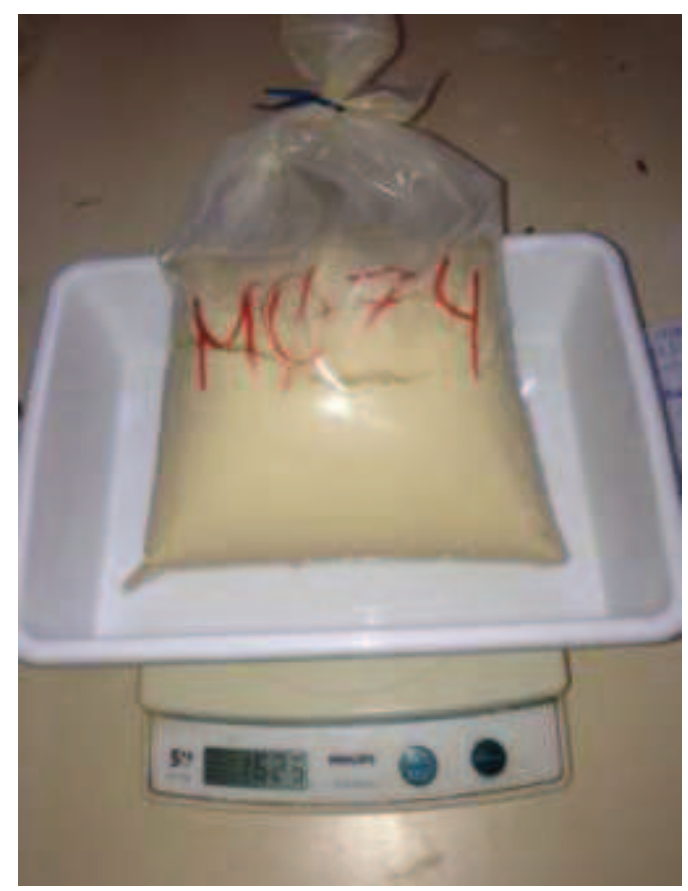

Figura 8-1: Muestra de estériles M-074.

(Fuente: Elaboración propia)

La muestra contiene 1620 gramos de sólidos por lo que se siguió el orden de todos los ensayos propuestos en la metodología de análisis para poder realizar el mayor número de ensayos posible con ella. El método aplicado permite trabajar con pequeñas muestras de material y realizar varios tipos de ensayos. Puesto que los sólidos fueron obtenidos por molienda en seco en el laboratorio, éstos se mantuvieron durante 24 horas en agua formando la pulpa con agitaciones periódicas, antes de realizar ninguna prueba de sedimentación, para simular un agua de proceso.

El primer paso fue la caracterización granulométrica y el ensayo de densidad de los sólidos. En este caso la densidad del líquido (agua) se ha tomado de $1 \mathrm{~kg} / \mathrm{dm}^{3}$.

Se tomó una muestra de 200 gramos de material y se procedió a analizar el tamaño y distribución de partículas mediante ensayo granulométrico con tamices en el laboratorio. Los contenidos en peso de cada fracción se muestran en la tabla 8-1: Curva granulométrica de la muestra M-074.

Para la obtención de la curva granulométrica se tamizó la muestra en una serie de tamices con las siguientes aberturas de malla en micras: $212 ; 100 ; 75 ; 63 ; 50 ; 38$. Los tamaños inferiores a 38 micras no pudieron ser analizados ya que para el tamizado de forma mecánica, se ha considerado 38 micras el límite inferior para obtener una buena precisión. En cualquier caso, se recomienda 
analizar las fracciones más finas en una etapa posterior del proyecto en un equipo de difracción láser.

La composición química de la muestra fue determinada en laboratorio por la propiedad de la mina, encontrando que está compuesta principalmente por sílice, arcillas y caolín como elementos mayoritarios y mica como elemento minoritario.

Tabla 8-1: Curva granulométrica de la muestra M-074.

\begin{tabular}{|c|c|c|c|c|}
\hline \multicolumn{5}{|c|}{ ENSAYO GRANULOMÉTRICO } \\
\hline \multirow{2}{*}{$\begin{array}{l}\text { Tamiz } \\
\text { Micras }\end{array}$} & \multirow{2}{*}{$\begin{array}{l}\text { Pesos (g) } \\
\text { Peso Ret. }\end{array}$} & \multicolumn{3}{|c|}{ Porcentajes } \\
\hline & & $\%$ Peso Ret. & \% Ret. Ac. & \% Pasa Ac. \\
\hline 300 & 0 & 0,0 & 0,0 & 100,0 \\
\hline 212 & 0 & 0,0 & 0,0 & 100,0 \\
\hline 100 & 24,4 & 12,2 & 12,2 & 87,8 \\
\hline 75 & 26,8 & 13,4 & 25,6 & 74,4 \\
\hline 63 & 18,0 & 9,0 & 34,6 & 65,4 \\
\hline 50 & 17,6 & 8,8 & 43,4 & 56,6 \\
\hline \multirow[t]{2}{*}{38} & 20,4 & 10,2 & 53,6 & 46,4 \\
\hline & 92,8 & 46,4 & 100,0 & 0,0 \\
\hline TOTAL: & 200,0 & 100,0 & & \\
\hline
\end{tabular}

En la figura 8-2: Distribución granulométrica de la muestra $M-074$; se puede ver la curva característica del material analizado, comprobando que existen un porcentaje superior al $40 \%$ de finos, con tamaños inferiores a 38 micras, lo que indica que el material es susceptible de producir un espesado en forma de pasta y alcanzar una elevada tensión de fluencia con la formación de una red de partículas finas que es la característica propia de una pasta con alto contenido y una elevada tensión de fluencia. 


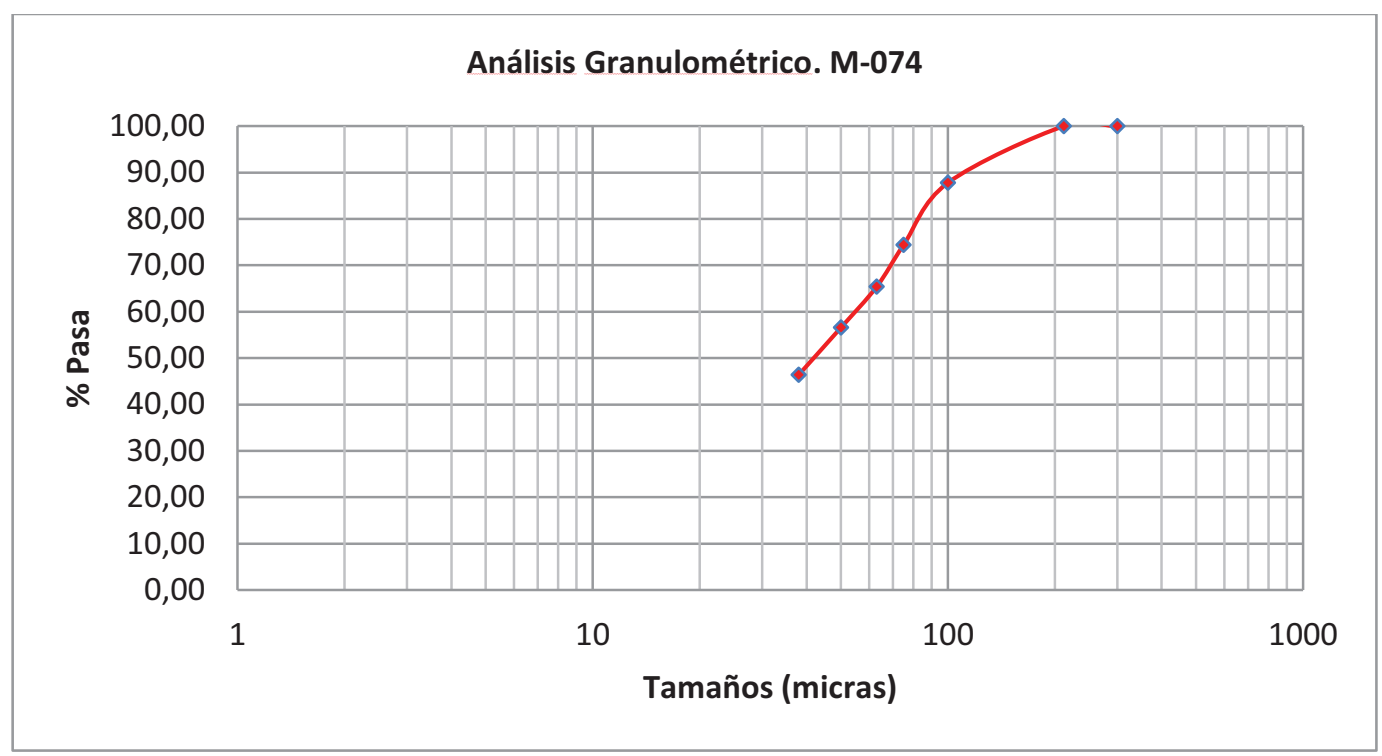

Figura 8-2: Distribución granulométrica de la muestra M-074 (Fuente: Elaboración propia)

Otros datos importantes para la caracterización de la muestra es conocer la densidad de los sólidos y el líquido que forma la pulpa. En la tabla 8-2: Datos para caracterización de la pulpa; se muestran otros valores característicos de la muestra M-074 obtenidos mediante ensayos en el laboratorio. Estos datos de densidad serán utilizados a lo largo de los estudios de sedimentación y reología llevados a cabo en el laboratorio.

Tabla 8-2: Datos para caracterización de la pulpa.

\begin{tabular}{|l|l|}
\hline Densidad de los sólidos & $2,4 \mathrm{~kg} / \mathrm{dm}^{3}$ \\
\hline Densidad del líquido & $1,0 \mathrm{~kg} / \mathrm{dm}^{3}$ \\
\hline $\mathrm{pH}$ de la pulpa & $6,0-6,5$ \\
\hline $\mathrm{P}_{80}$ de la muestra de sólidos & 82 micras \\
\hline
\end{tabular}

(Fuente: Elaboración propia)

\subsubsection{Selección de floculante}

Como se ha comentado en el capítulo 6, el propósito del ensayo de selección de floculante es seleccionar el floculante genérico que se muestra más efectivo en la sedimentación y por tanto, que sea viable para su uso en el espesador real. De entre toda la variedad de fabricantes y tipos de floculantes existentes en el mercado, para este estudio se han utilizado diversos tipos de floculantes de la marca Nalco. Los floculantes utilizados durante los ensayos se muestran en la tabla 8-3: Tabla de floculantes seleccionados. 
Tabla 8-3: Tabla de floculantes seleccionados.

\begin{tabular}{|c|c|c|c|c|}
\hline Marca & Carga & $\begin{array}{c}\text { Densidad de } \\
\text { carga }\end{array}$ & $\begin{array}{c}\text { Peso } \\
\text { molecular }\end{array}$ & $\begin{array}{c}\text { Concentración } \\
\text { preparada }\end{array}$ \\
\hline NALCO & Aniónico & $-10 \%$ & Medio & $0,05 \%$ en peso \\
\hline NALCO & Sin carga & $0 \%$ & Medio & $0,05 \%$ en peso \\
\hline NALCO & Catiónico & $+25 \%$ & Medio & $0,05 \%$ en peso \\
\hline NALCO & Catiónico & $+35 \%$ & Medio & $0,05 \%$ en peso \\
\hline NALCO & Mezcla (An. + Cat.) & $-25 \% \mathrm{y}+25 \%$ & Alto & $0,05 \%$ en peso \\
\hline
\end{tabular}

(Fuente: Elaboración propia)

Todas las soluciones de floculante se prepararon con 0,1 g de floculante sólido en $200 \mathrm{ml}$ de agua, es decir con una concentración de $0,5 \mathrm{~g} / \mathrm{l}$ y todas las muestras de pulpa de estériles se diluyeron al $5 \%$ de sólidos en peso con agua. El pH de las muestras analizadas se encuentra entre 6,0 y 6,5. Los ensayos fueron llevados a cabo en probeta de $500 \mathrm{ml}$, añadiendo floculante de cada tipo y con diferentes dosificaciones a intervalos, observando y midiendo el proceso de sedimentación para cada adición de floculante.

Los resultados obtenidos en forma de gráfica para la selección del mejor floculante se muestran en la figura 8-3: Gráfica de selección de floculante. Muestra M-074; Donde se buscan las mayores velocidades de sedimentación con bajas dosificaciones y se complementa la selección con las observaciones de turbidez del rebose, tamaño de flóculo y cohesión de los flóculos, obtenidas en los ensayos de sedimentación en probeta.

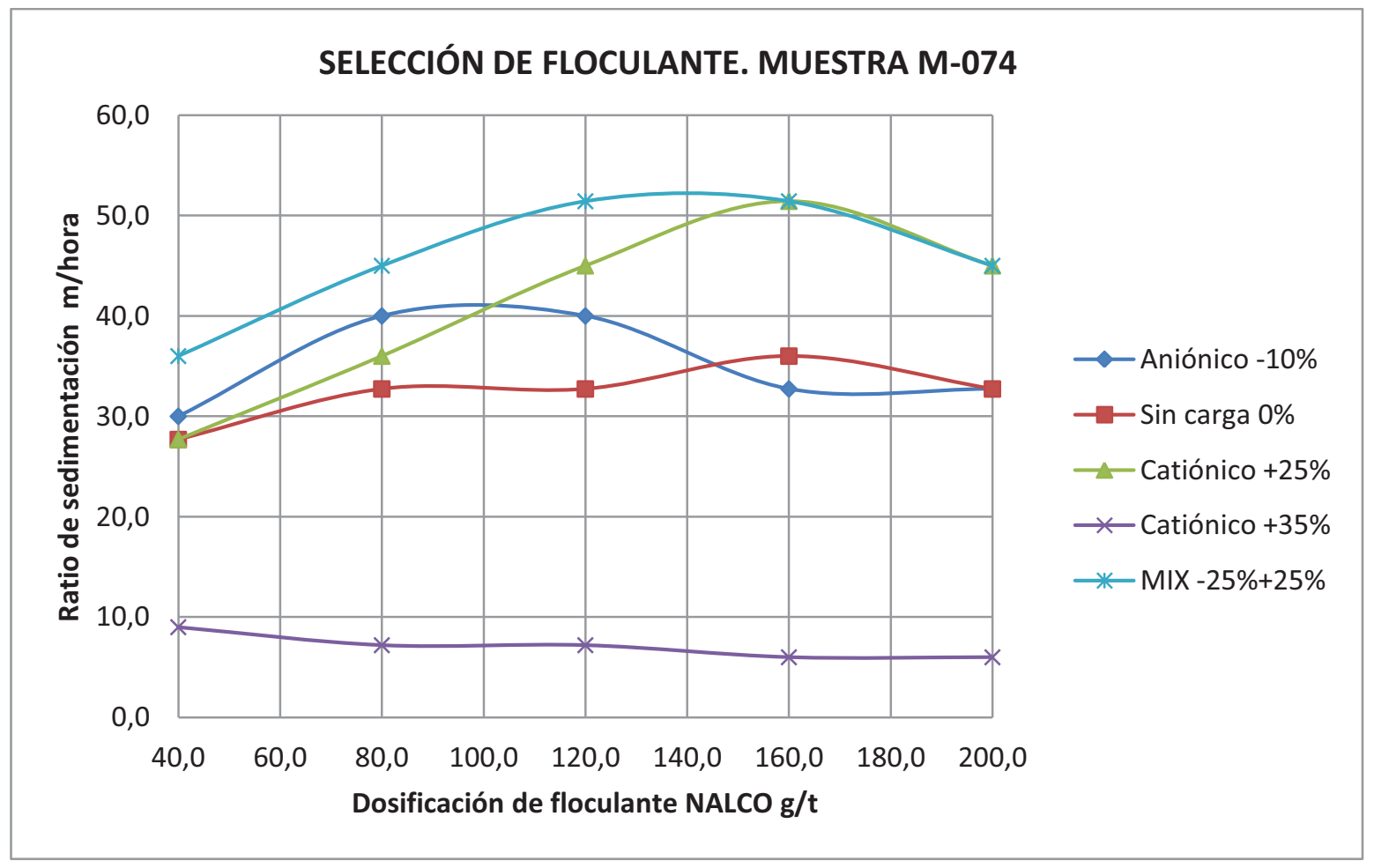

Figura 8-3: Gráfica de selección de floculante. Muestra M-074 (Fuente: Elaboración propia) 
Los resultados indican que los mejores resultados de ratio de sedimentación a una dosificación relativamente baja se producen con la combinación de dos floculantes. Este floculante se denominó "Mix 25\%-25\%"; formado por una mezcla de floculantes aniónico y catiónico dosificado a partes iguales. En la figura 8-4: Ensayo de sedimentación para selección de floculante; se pueden ver las muestras obtenidas con el uso de este floculante. Esta imagen muestra las pruebas de sedimentación en probeta de $500 \mathrm{ml}$ realizadas para la determinación del ensayo. El uso de una mezcla de floculantes, en este caso un tipo aniónico y otro catiónico a partes iguales, fue debido a que de los floculantes disponibles, ninguno por separado obtenía buenas tasas de sedimentación y alta claridad en el rebose. Al realizarse la prueba con una mezcla de ambos floculantes se comprobó que era mucho más efectivo. No obstante es conveniente realizar nuevas pruebas de floculación en una etapa posterior, cuando exista más muestra disponible.

En este caso el floculante catiónico actúa como coagulante y el aniónico como floculante, que siendo utilizados de forma conjunta dan un resultado excelente en cuanto a tamaño de flóculo y claridad del rebose.
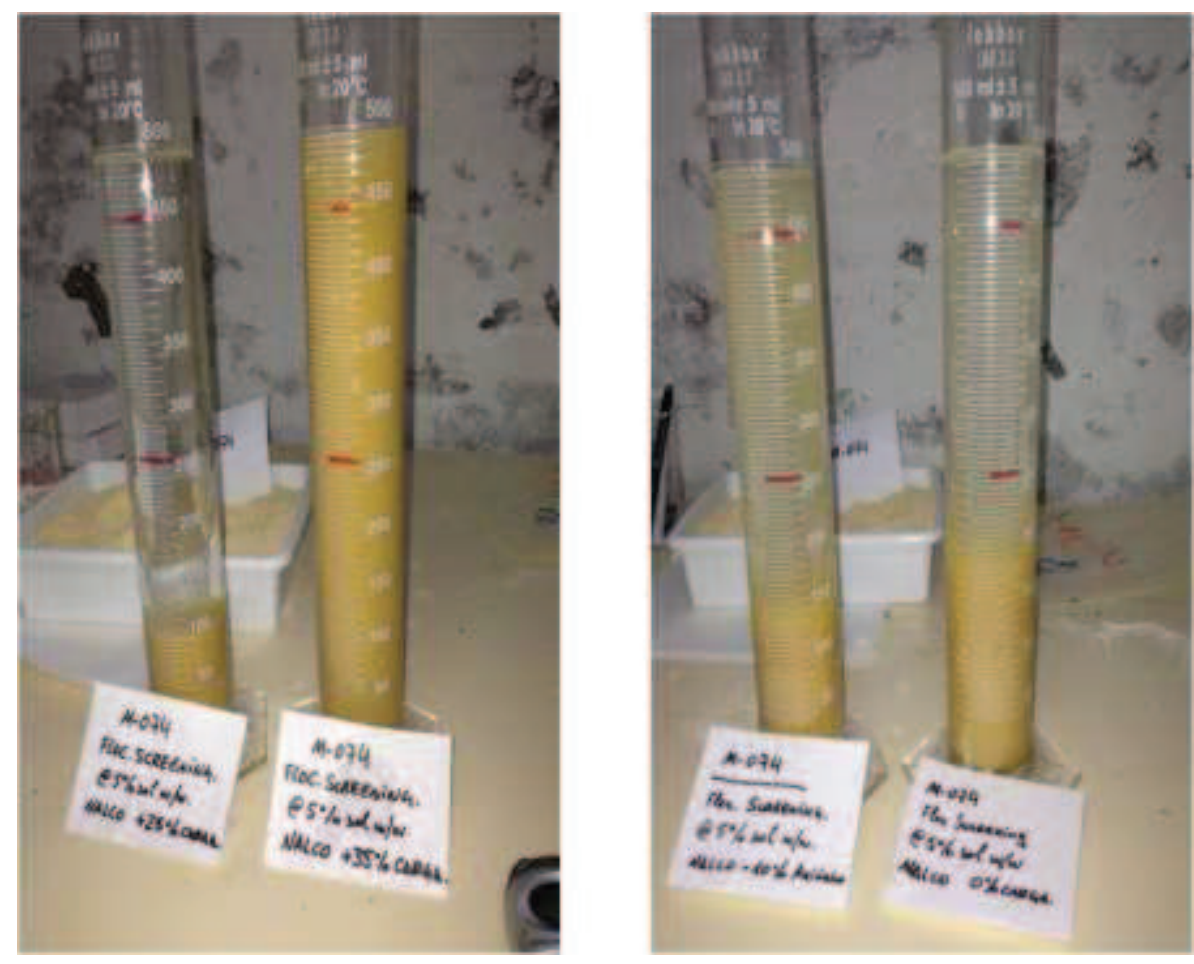

Figura 8-4: Ensayo de sedimentación para selección de floculante.

(Fuente: Elaboración propia)

\subsubsection{Ensayo de flujo de sedimentación.}

Una vez que el tipo de floculante ha sido seleccionado, el siguiente paso fue realizar una serie de ensayos con el floculante seleccionado para probar los efectos sobre la pulpa a alimentar y su efectividad en función del contenido en sólidos en la alimentación, así como el ratio de sedimentación observado. El objetivo era comprobar el ratio de alimentación de sólidos para el cual la efectividad de la floculación es maximizada, resultando en una mejora de la velocidad de 
sedimentación y la floculación observadas. El resultado de operar el espesador con el ratio de alimentación de sólidos óptimo se traduce en menores diámetros de tanque, mayores densidades del hundido, mejor claridad del rebose y un menor consumo de floculante.

En la página 5 del Anexo 8, se pueden ver los valores y datos recopilados en los ensayos de flujo de sedimentación, con el fin de determinar la óptima concentración de sólidos en la alimentación.

Una serie de pulpas fueron preparadas en probetas de $500 \mathrm{ml}$ con diferentes concentraciones de sólidos: $10,3 \% ; 7,4 \% ; 4,8 \%$ y $2,9 \%$ de sólidos en peso.

Se añadió el floculante de forma dosificada sobre el rango de muestras seleccionado para comprobar la efectividad del floculante en cada uno de los casos. Los resultados indicaron que la pulpa con el $5 \%$ de sólidos en peso proporciona las mejores condiciones de floculación para el proceso de sedimentación, como se puede ver en la tabla 8-5.

En la figura 8-5: Gráfica de flujo de sedimentación. Muestra M-074 y en la figura 8-6: Gráfica de velocidad de sedimentación. Muestra M-074; se muestran los datos obtenidos presentados en una gráfica en función de la dosificación de floculante para todas las muestras ensayadas. En general todas las concentraciones de sólidos sedimentaron de forma rápida destacando los valores obtenidos en el ensayo 3 , con un contenido en sólidos de la pulpa del $4,76 \%$ en peso. Con la concentración del $5 \%$ de sólidos en peso se realizaron los posteriores ensayos de sedimentación en probeta de 2 litros y con el espesador de tubo profundo de 5,5 litros de capacidad.

Hasta este momento se han acotado los parámetros de la operación con varios ensayos de laboratorio y con estos datos se realizaron los ensayos de sedimentación en probeta estática de $2000 \mathrm{ml}$ y en probeta dinámica de tubo profundo de 5,5 litros; utilizando una mezcla de floculante aniónico y catiónico $(-25 \%$ y $+25 \%$ de carga) a partes iguales.

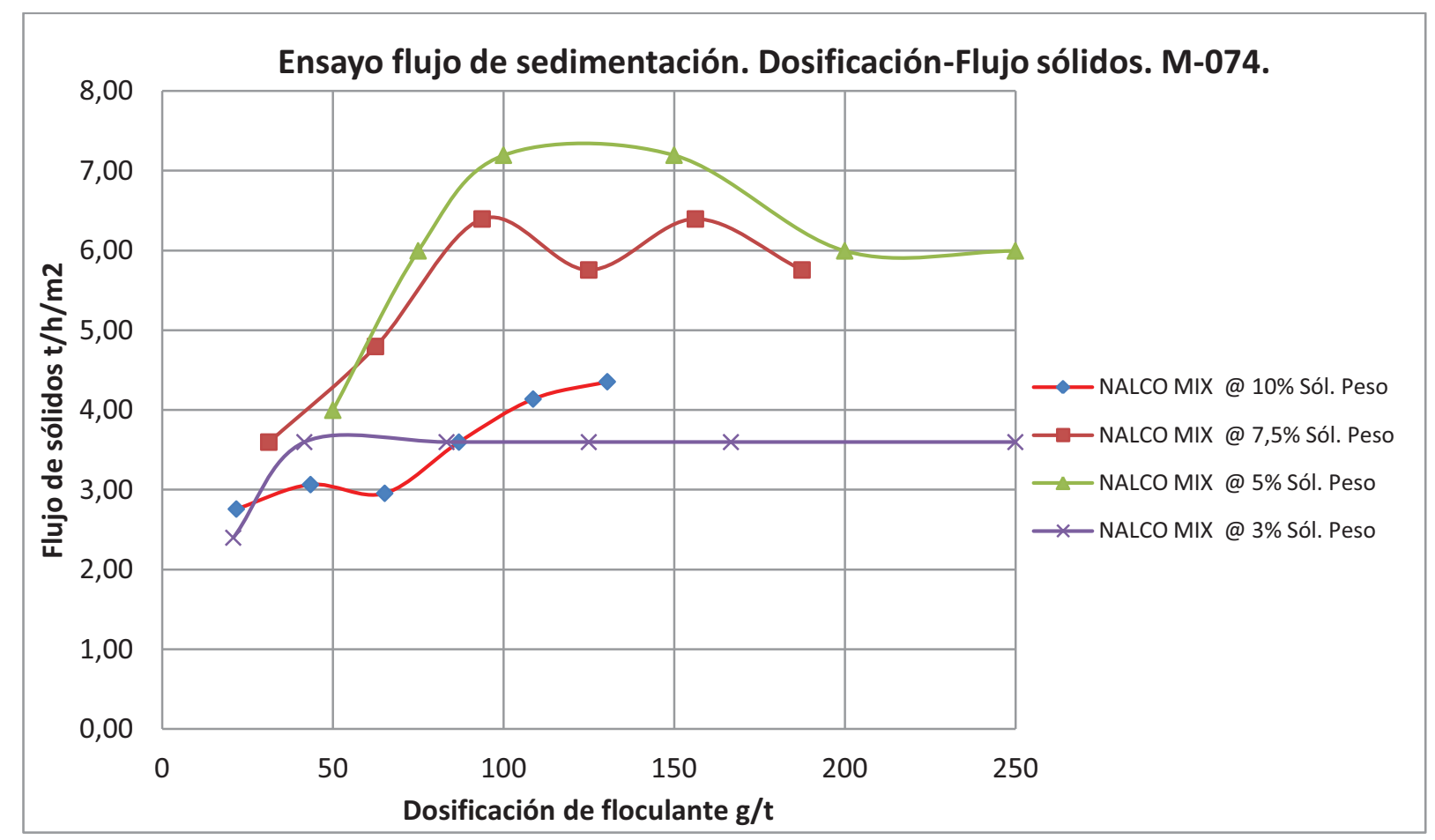

Figura 8-5: Gráfica de flujo de sedimentación. Muestra M-074.

(Fuente: Elaboración propia) 


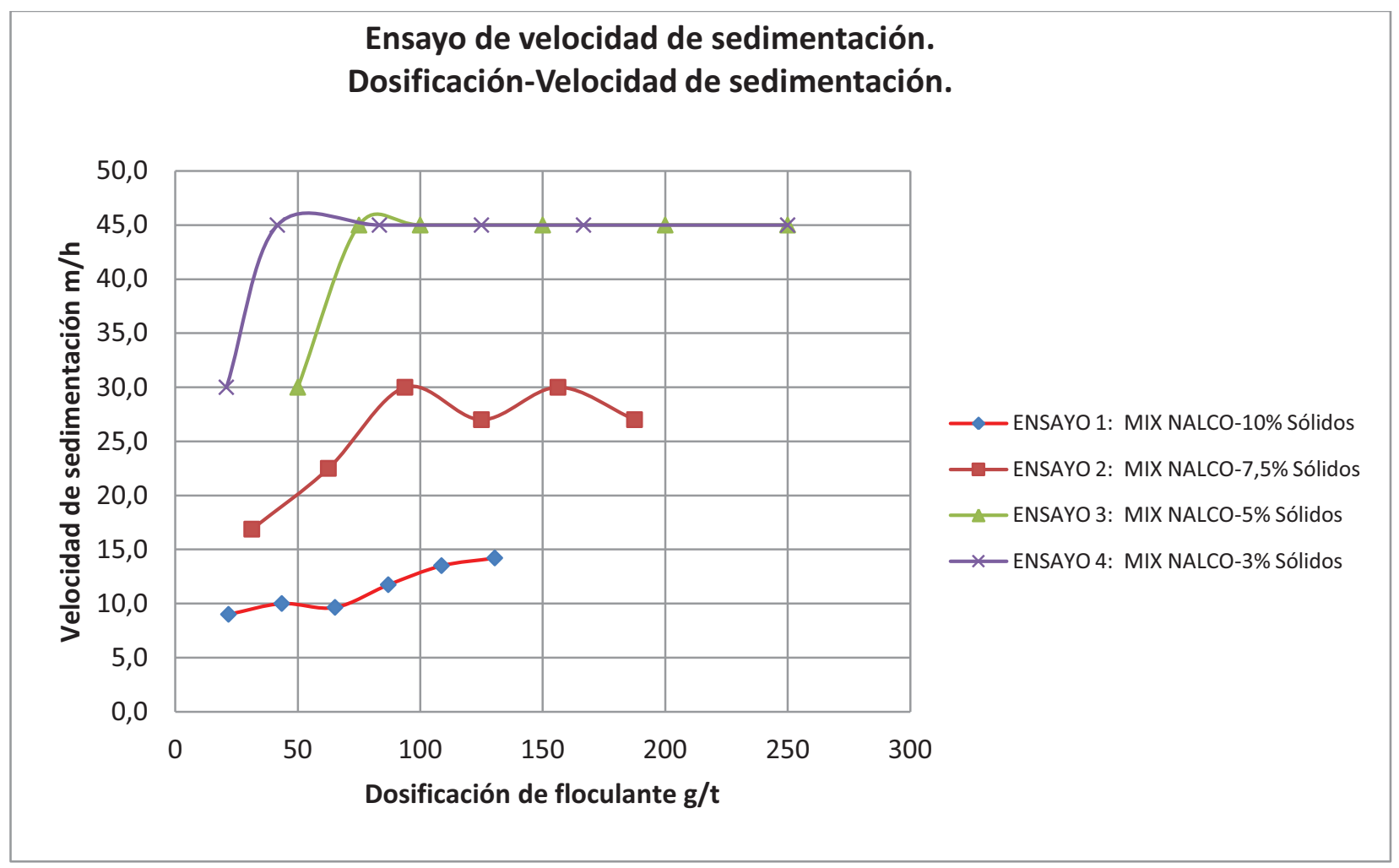

Figura 8-6: Gráfica de velocidad de sedimentación. Muestra M-074.

(Fuente: Elaboración propia)

\subsubsection{Ensayo de sedimentación en probeta de 2 litros}

Se ha realizado un ensayo de sedimentación en probeta de $2000 \mathrm{ml}$ para comprobar la velocidad de sedimentación inicial de la muestra con una probeta de diámetro superior y que tuviera un menor efecto de pared que pudiera influir en el ensayo de sedimentación. Para tal fin se preparó una muestra con el $5 \%$ de contenido en sólidos y se realizó el ensayo con una dosificación de floculante de $25 \mathrm{~g} / \mathrm{t}$. La metodología de mezcla del floculante y la suave agitación a la que se somete a la pulpa durante 15-20 segundos como máximo en la probeta y la adición de floculante junto con la retención de la pulpa en la probeta, hace posible simular los tiempos típicos de un sistema de alimentación con campana de alimentación de cualquier moderno espesador.

Una vez que el floculante ha sido añadido y se ha mezclado con la pulpa se toman las medidas de la altura de la interfase frente al tiempo. Los datos se tomaron desde el inicio del proceso de sedimentación hasta que se aprecia que existe una zona de compresión en la probeta, en este caso un tiempo de 4 horas.

En la página 7 del Anexo 8, están representados todos los valores iniciales de la pulpa y del floculante utilizado en el ensayo de sedimentación estático en probeta de 2 litros.

Según los valores característicos de la tabla 8-4: Resumen de datos ensayo en probeta de 2 litros; se procede a preparar los ensayos de sedimentación en espesador dinámico de tubo profundo de 5,5 litros. 
Tabla 8-4: Resumen de datos ensayo en probeta de 2 litros.

\begin{tabular}{|l|c|}
\hline Ensayo en probeta de 2 litros & Resumen de datos \\
\hline Alimentación de sólidos & $5 \%$ sólidos peso \\
\hline Floculante Nalco “25\% catiónico + 25\% aniónico" & $25 \mathrm{~g} / \mathrm{t}$ \\
\hline Velocidad de sedimentación inicial (promedio) & $27 \mathrm{~m} / \mathrm{h}$ \\
\hline Densidad de lodos final (\% sólidos) & $46 \%$ sólidos peso \\
\hline
\end{tabular}

(Fuente: Elaboración propia)

Los datos obtenidos en el ensayo de sedimentación se pueden comprobar en la tabla 8-8: Datos de sedimentación en probeta de 2 litros; comprobando que la zona de compresión comienza en el primer minuto de ensayo. Por lo tanto se trata de un material que sedimenta con una gran velocidad como se aprecia en la gráfica por la fuerte pendiente de la curva de sedimentación; véase página 8 del anexo 8. En la figura 8-7: Curva de sedimentación en probeta de 2 litros; se muestran de forma gráfica los resultados de altura de la interfase en función del tiempo.

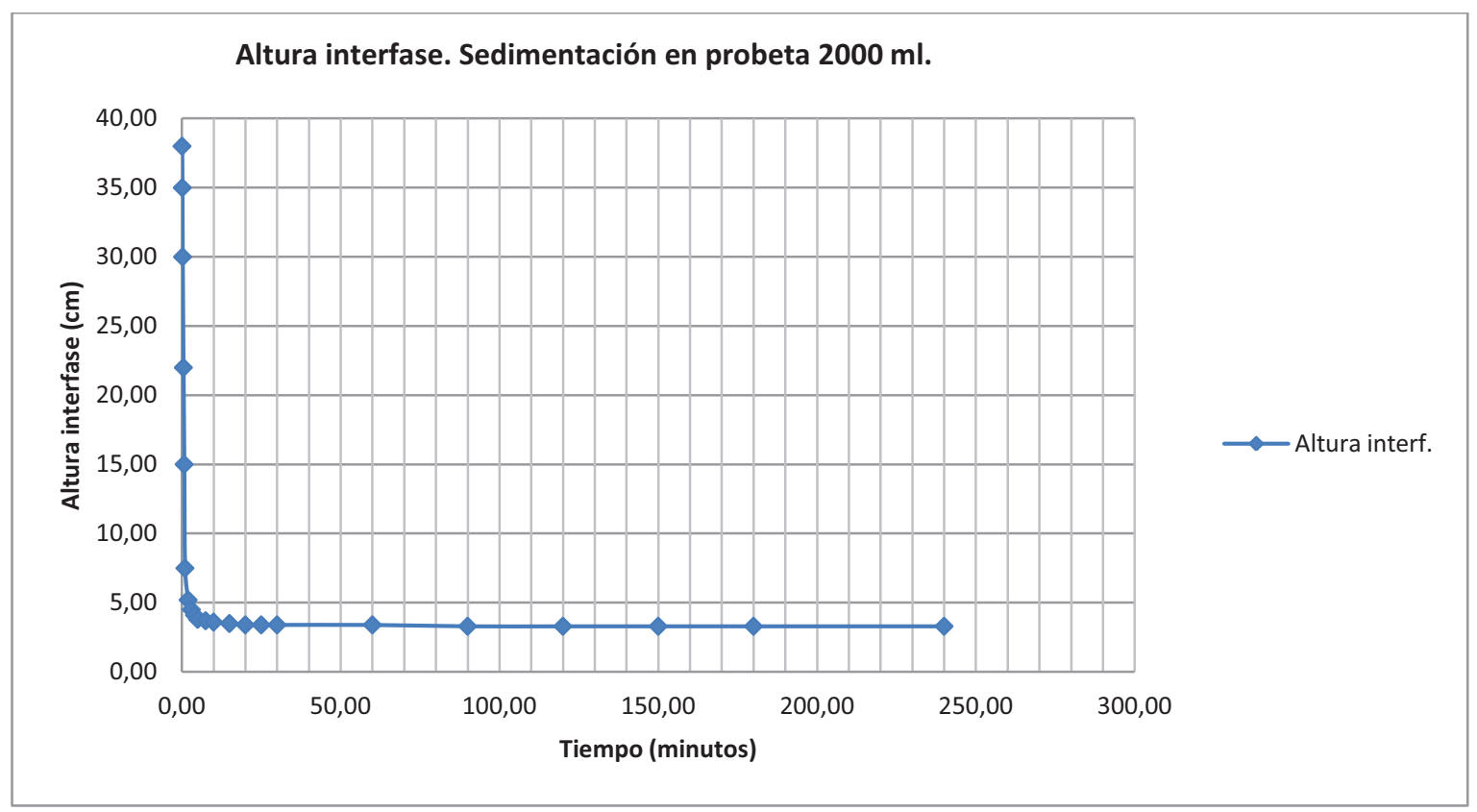

Figura 8-7: Curva de sedimentación en probeta de 2 litros. Muestra M-074.

(Fuente: Elaboración propia)

\subsection{Ensayo en espesador dinámico de tubo profundo de 5,5 litros de capacidad}

Este ensayo se realizó bombeando de forma continua la pulpa preparada con los sólidos de la muestra M-074 disponibles tras los primeros ensayos efectuados. Con la información obtenida en los ensayos previos se dispone de información suficiente para realizar el ensayo en tubo profundo que simula las condiciones de operación de un espesador de pasta. La pulpa preparada con los estériles es alimentada al espesador de laboratorio mediante una bomba centrífuga de caudal apropiado a las dimensiones del equipo; a su vez el floculante es dosificado con una bomba 
peristáltica de bajo caudal y regulable. El objetivo es simular el flujo de sólidos previsto en los ensayos y la dosificación de floculante determinada en el ensayo de flujo.

El ensayo en el espesador dinámico de tubo profundo tiene varios objetivos fundamentales: confirmación del flujo de sólidos y la dosificación de floculante lo cual fija el área unitaria y por otro lado comprobar que se produce una acumulación del lecho de lodos con cierta profundidad, en función del contenido en sólidos de la alimentación, para establecer una predicción del contenido en sólidos alcanzable en el espesador real y el tiempo de residencia necesario para alcanzar determinada concentración de sólidos en el hundido del espesador real.

Para el ensayo en espesador dinámico se prepara una muestra de pulpa con los valores obtenidos en los ensayos anteriores, en este caso al $5 \%$ de sólidos en peso determinado por el ensayo de flujo. Esta dilución en teoría sería la que debe proporcionar el sistema de dilución por eductor antes de la entrada a la campana de alimentación en el espesador real. Se preparó una solución de floculante con una dosificación de 0,2 gramos por litro, mezclando dos tipos de floculante aniónico y catiónico, que obtuvo los mejores resultados en los ensayos en probeta.

El tiempo de llenado típico de este volumen de espesador dinámico varía entre 10 minutos y 30 minutos, dependiendo de la velocidad de sedimentación de los sólidos y de la cantidad de muestra preparada como alimentación. La dosificación de floculante y la pulpa son fijados en base a la experiencia del operador del equipo de laboratorio. Con tal fin, se ha realizado un apartado de cálculos previos donde se pueden ver los datos iniciales de la operación y establecer una estimación de los caudales y los tiempos del ensayo. Estos datos se muestran en la página 9 del Anexo 8.

Una vez iniciado el ensayo en el espesador dinámico y observadas la estructura del flóculo formado y la velocidad de sedimentación, el operador del equipo puede incrementar o disminuir tanto el flujo de floculante como de alimentación si observa que los criterios esperados no se están cumpliendo en los primeros minutos del ensayo dinámico. Si pasados unos minutos del inicio de la operación se observa un rebose clarificado y una buena velocidad de sedimentación, se puede reducir la dosificación de floculante o aumentar el ratio de alimentación. Por el contrario, si se observa un incremento de la degradación de la estructura del flóculo o una disminución de la claridad, se puede actuar aumentando la dosificación de floculante o bien, reduciendo la alimentación hasta que la sedimentación vuelva a tener el rendimiento esperado y volver a los valores anteriores. En la figura 8-8: Etapas de ensayo dinámico en el espesador de laboratorio; se muestran cuatro fases diferentes del ensayo dinámico en espesador de tubo profundo con los estériles de la muestra M-074. La etapa de llenado y alimentación con pulpa al espesador de tubo profundo tuvo una duración de 14 minutos, bombeándose la pulpa a un ratio de 1,98 litros/minuto. La fase de compactación del lecho de lodos creado por la pulpa en el espesador tuvo una duración de 10 horas.

Las rasquetas del equipo operan en todo momento de forma continua a una velocidad baja (1 rpm) durante el llenado del equipo y en la operación estática posterior. 


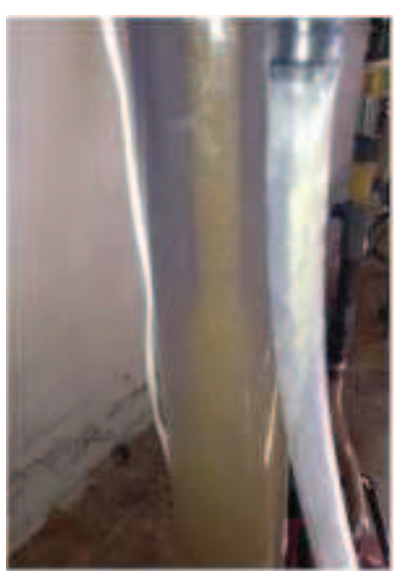

Inicio del ensayo

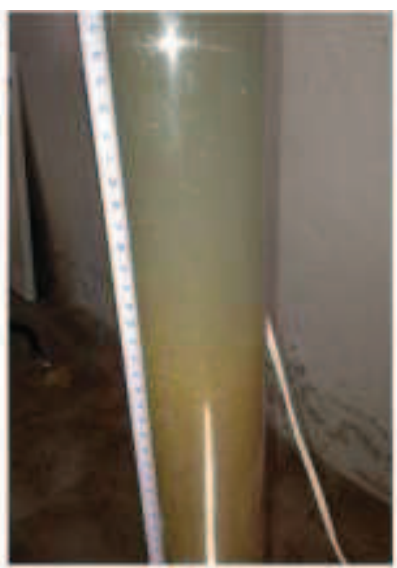

Flóculos

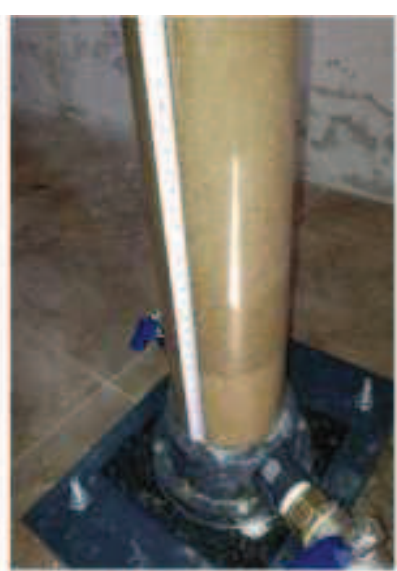

Formación lecho de lodos

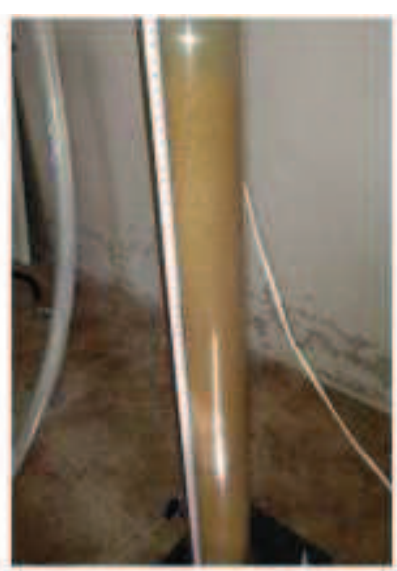

Crecimiento del lecho de lodos

Figura 8-8: Etapas de ensayo dinámico en el espesador de laboratorio. (Fuente: Elaboración propia)

Los resultados obtenidos en el ensayo con espesador de laboratorio se muestran en la página 9 del Anexo 8.

Una vez que todos los sólidos fueron alimentados en forma de pulpa al espesador de tubo profundo, el lecho de lodos en el equipo alcanzó una altura de $380 \mathrm{~mm}$. En este instante se paró la bomba de alimentación y se dio comienzo a la fase estática del ensayo.

En la segunda parte estática, se deja actuar el mecanismo de rasquetas sobre el lecho de lodos conseguido. El movimiento de las rasquetas crea una serie de surcos verticales que permite el desaguado y la compactación del lecho de lodos en el equipo, simulando el proceso que ocurre en un espesador de pasta real. En este momento comienza el descenso de la interfase formada y se produce el fenómeno de compresión del lecho de lodos para crear una pasta de alto contenido en sólidos y una alta tensión de fluencia.

Es importante hacer una estimación del volumen de pulpa o de sólidos que no han llegado al equipo de espesado. Esto se consigue midiendo o pesando el volumen de pulpa residual en bomba, tuberías u otras pérdidas en el ensayo, con el objetivo de obtener la mayor precisión posible en el ensayo.

Se tomarán lecturas de la altura del lecho de lodos desde la parada de la alimentación frente al tiempo transcurrido durante al menos seis horas.

Una vez que ha pasado el tiempo estimado de ensayo estático y el mecanismo de rasquetas y la fuerza de compresión del lecho de lodos y se ha compactado los sólidos hasta la densidad final, es posible obtener una muestra del hundido para comprobar el contenido en sólidos mediante secado de la muestra.

Uno de los objetivos del ensayo estático es la obtención de la curva tiempo de residencia frente a contenido en sólidos. La curva obtenida con los estériles de la muestra ha sido trazada en la figura 8-9: Curva tiempo de residencia-contenido en sólidos. Muestra M-074; es importante destacar a la vista de los resultados que el tiempo de residencia para alcanzar una alta concentración de sólidos superior al $70 \%$ en el ensayo es de 5 horas, a partir de este tiempo el contenido en sólidos no 
aumenta de forma significativa. Los detalles de los datos se muestran en las páginas 9 y 10 del Anexo 8.

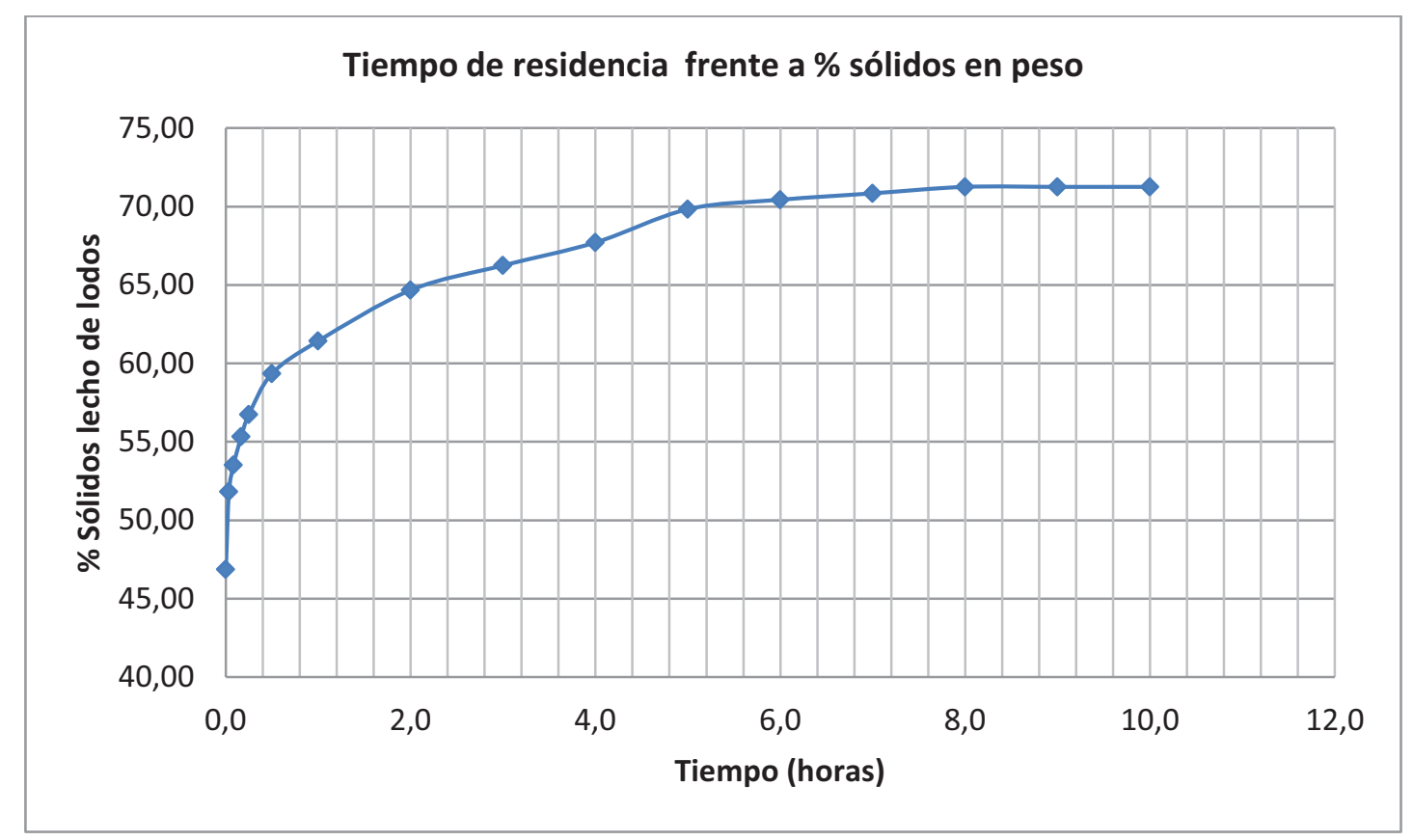

Figura 8-9: Curva tiempo de residencia-contenido en sólidos. Muestra M-074 (Fuente: Elaboración propia)

Si se dispone de suficiente muestra de material es conveniente realizar varios ensayos siguiendo esta metodología con el fin de contrastar diferentes resultados variando las condiciones de alimentación y floculación.

\subsection{Reología del hundido}

Para el estudio de la reología del hundido se emplearán dos métodos de ensayos: la filtración a vacío y el ensayo de asentamiento. El objetivo de estos ensayos es determinar el máximo contenido en sólidos alcanzable a partir de la pulpa y determinar la tensión de fluencia de la pasta obtenida en el hundido relacionada con el contenido en sólidos. Ambos datos son importantes para determinar el diseño y dimensionado de los equipos de transporte, bombeo y deposición de la pasta, así como de la estabilidad del depósito de pasta formado.

Se prepararon muestras de pulpa para proceder a los ensayos de filtración a vacío para producir una torta filtrada representativa del máximo contenido en sólidos consolidados alcanzable. El filtrado fue guardado y se diluyó en varias muestras con distintos contenido en sólidos. La tensión de fluencia de las muestras es medida como una función del contenido en sólidos mediante el modelo empírico del ensayo de asentamiento que proporciona un valor estimado de la tensión de fluencia de la pasta con una precisión aceptable para un proyecto de viabilidad. 


\subsubsection{Ensayos de filtración a vacío}

Los ensayos de filtración a vacío fueron realizados con diferentes concentraciones de sólidos y diferentes volúmenes de pulpa con el fin de obtener un valor promedio de los sólidos contenidos en la torta filtrada y conocer la máxima consolidación de los sólidos en los estériles de la Mina de Laza.

Se llevaron a cabo varios ensayos preliminares para ajustar el equipo de laboratorio y los tiempos de filtración.

Otra utilidad de los ensayos es realizar con la torta filtrada pruebas de asentamiento en probeta cilíndrica para conocer la viscosidad y la tensión de fluencia.

La máxima consolidación de los sólidos analizados está en un promedio de $77,7 \%$ de contenido en sólidos, presentando una elevada tensión de fluencia.

Los ensayos se llevaron a cabo en un equipo de laboratorio con una bomba de vacío con un vacío de $-0,7$ bar.

En la figura 8-10: Ensayo de filtración y equipo de laboratorio; se pueden ver las muestras obtenidas en los ensayos.

El objetivo final del ensayo de filtración es comparar el contenido en sólidos de la torta con los resultados obtenidos en el hundido del espesador de tubo profundo. Esto da una idea muy aproximada de si se ha conseguido la máxima concentración de sólidos en el hundido. Normalmente, la diferencia entre el contenido en sólidos obtenido en el ensayo de filtración a vacío y el obtenido en un espesador de pasta oscila entre el $10 \%$ y el $25 \%$, como norma general.
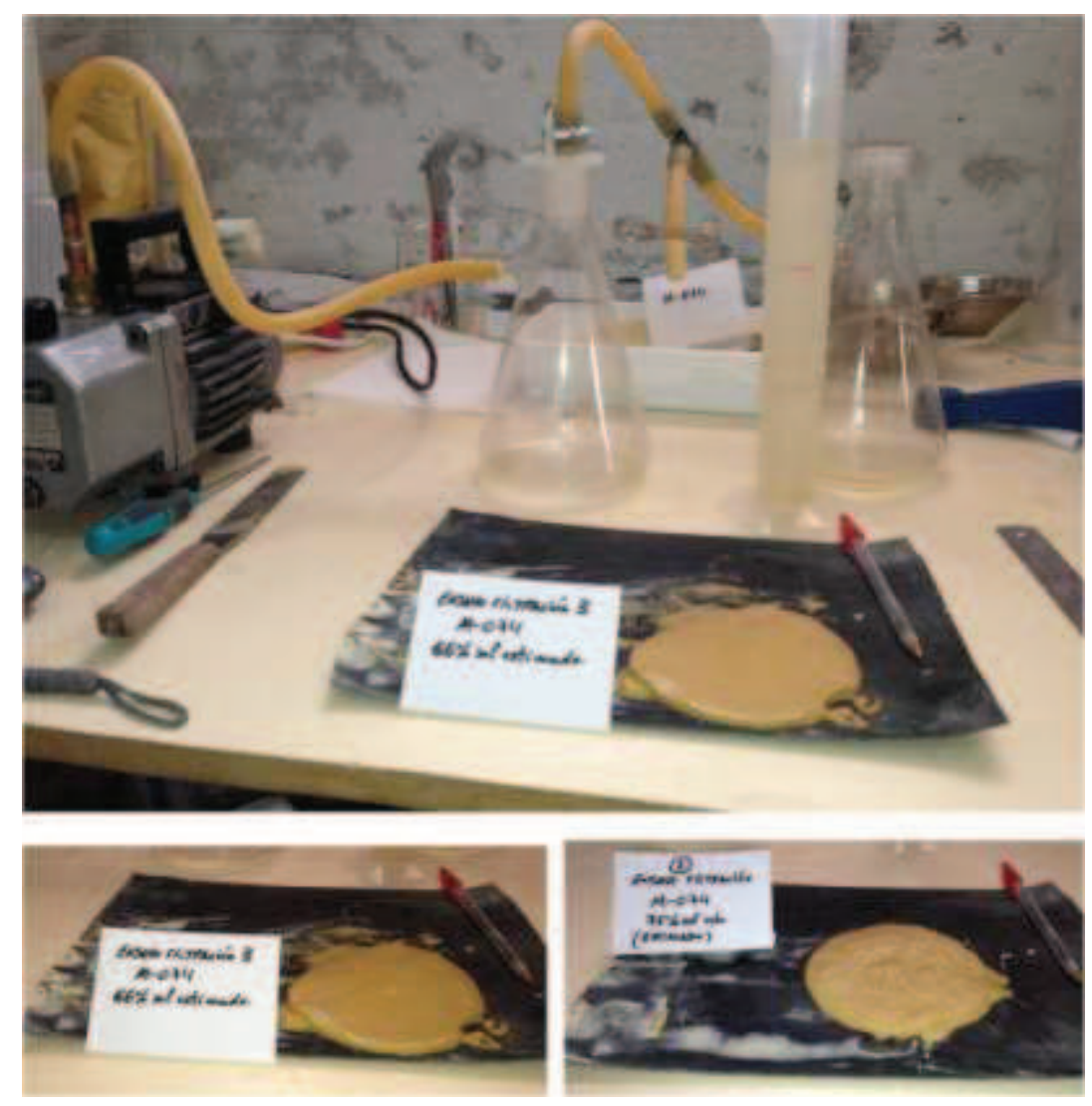

Figura 8-10: Ensayo de filtración y equipo de laboratorio.

(Fuente: Elaboración propia) 
Los datos de los ensayos de filtración a vacío realizados con la muestra M-074 se encuentran listados en la página 11 del Anexo 8.

\subsubsection{Ensayos de reología de la pasta}

El material obtenido en los diversos ensayos de filtración a vacío fue reservado para producir una pasta con varias concentraciones de sólidos, partiendo de muestras de $200 \mathrm{~g}$ de material diluidas al $40 \%$ de sólidos que eran filtradas a vacío en el equipo de laboratorio. En este caso se midió la tensión de fluencia como una función de la concentración de sólidos a medida que las diferentes muestras de pasta eran preparadas y obtenidas en forma de torta filtrada.

El método utilizado para medir esta tensión de fluencia fue el ensayo de asentamiento realizado en el propio laboratorio. El objetivo de estos ensayos era predecir los límites de las densidades de hundido manejables en cada tipo de espesador y comprobar el comportamiento reológico de la pasta obtenida. En la figura 8-11: Ensayos de asentamiento en probeta. Muestra M-074; se muestran los diferentes asentamientos de las muestras analizadas durante este ensayo.

El valor típico de tensión de fluencia para los lodos obtenido en el hundido de los diferentes tipos de espesadores se muestra en la tabla 8-5: Tipo de espesador y tensión de fluencia característica.

Tabla 8-5: Tipo de espesador y tensión de fluencia característica.

\begin{tabular}{|l|c|c|}
\hline \multicolumn{1}{|c|}{ Tipo de espesador } & $\begin{array}{c}\text { Tensión de } \\
\text { fluencia (Pa) }\end{array}$ & $\begin{array}{c}\text { Rango } \\
\% \text { Sólidos } \\
\text { Hundido }\end{array}$ \\
\hline Espesadores convencionales & $<60$ & $30-50 \%$ \\
\hline Espesadores HCT (Alta Capacidad) & $<60$ & $30-50 \%$ \\
\hline Espesadores HRT (Alto Ratio Alimentación) & $<60$ & $30-50 \%$ \\
\hline Espesadores HDT (Alta Densidad Hundido) & $60-125$ & $45-65 \%$ \\
\hline Espesadores de pasta (Cono Profundo) & $>125$ & $>60 \%$ \\
\hline
\end{tabular}

(Fuente: Elaboración propia)

Los resultados obtenidos con diferentes contenidos en sólidos de la pasta. Como se comprueba, a partir del $65 \%$ de contenido en sólidos, la tensión de fluencia aumenta considerablemente hasta valores superiores a $150 \mathrm{~Pa}$, por lo tanto se puede considerar una autentica pasta de estériles.

En la figura 8-12: Rango de operación para estériles del yacimiento de Laza; se comparan las diferentes tecnologías de espesado sobre los datos obtenidos en el laboratorio con la muestra de estériles analizada. Como se puede comprobar la forma de tratar estos estériles es susceptible de utilizar todas las tecnologías de espesado disponibles en función de las características del hundido que se requieran y en función de los sistemas de almacenamiento de estériles planeados.

Los resultados del ensayo dinámico en el espesador de tubo profundo de 5,5 litros y los ensayos de filtración a vacío y reología indican que al $68-70 \%$ de sólidos en peso, la tensión de fluencia es superior a $200 \mathrm{~Pa}$ y puede ser obtenida en un espesador de pasta real. El tiempo de retención 
para alcanzar esta densidad de lodos en el hundido según la figura 8-8 es de 5 horas como mínimo.

En el Anexo 8, se presentan todos los resultados en el Informe de Sedimentación y Reología de los estériles de la Mina de Laza.
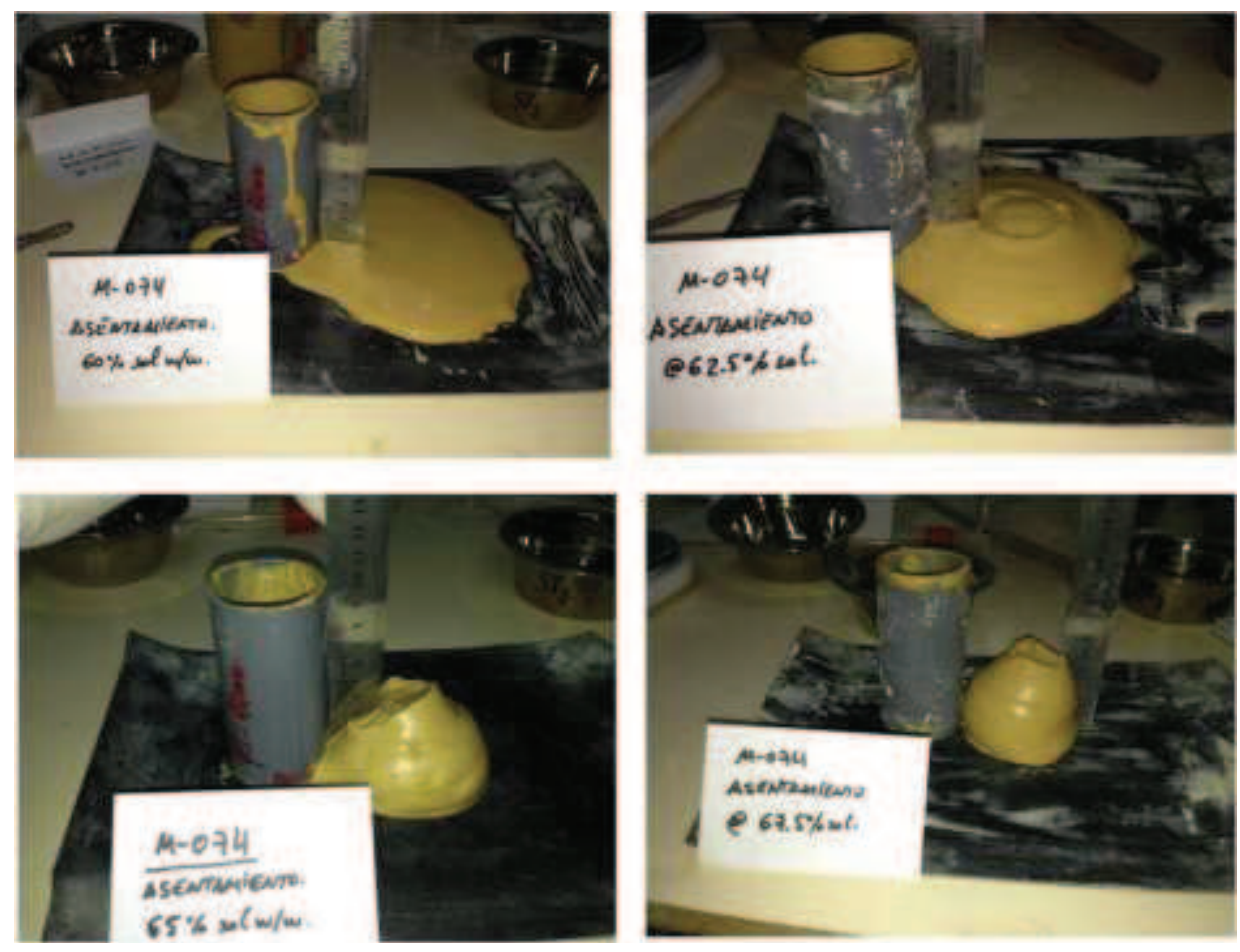

Figura 8-11: Ensayos de asentamiento en probeta. Muestra M-074.

(Fuente: Elaboración propia)

\section{ENSAYOS DE ASENTAMIENTO EN PROBETA}

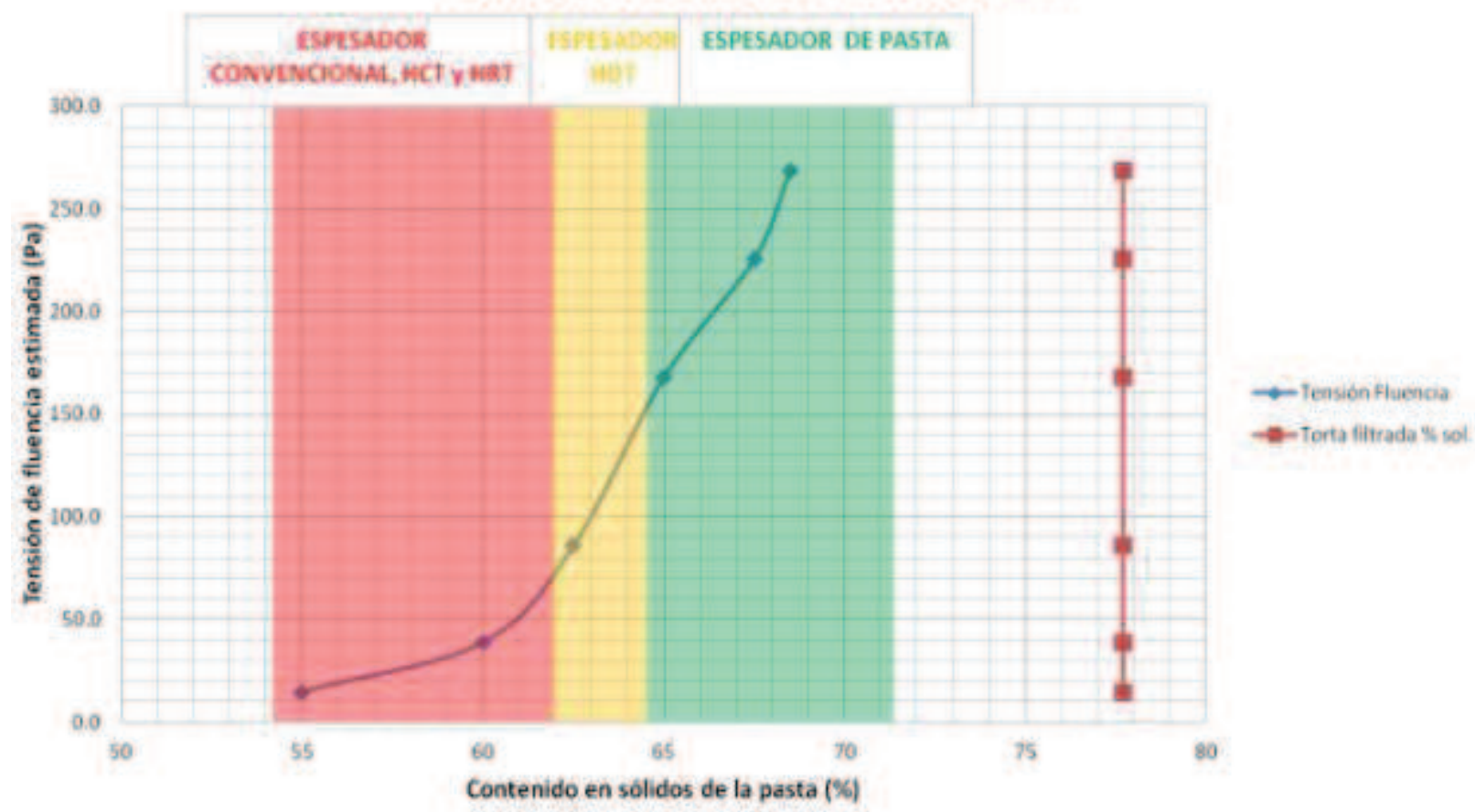

Figura 8-12: Rango de operación para estériles del yacimiento de Laza.

(Fuente: Elaboración propia) 


\subsection{Conclusiones de los ensayos realizados sobre la muestra de estériles M-074}

Una vez realizados todos los ensayos sobre la muestra de estériles M-074, según la metodología propuesta en este trabajo, se pueden establecer a la vista de los resultados las siguientes conclusiones sobre los estériles del yacimiento de Laza-Orense.

La selección de floculante indica que una mezcla de floculantes aniónico y catiónico parece ser la mejor opción para flocular los sólidos con una baja dosificación de floculante en torno a 40-45 gramos por tonelada de sólido, produciendo los mejores ratios de sedimentación. El tipo de floculante es una mezcla de $25 \%$ de carga catiónica y $25 \%$ de carga iónica. Cualquier floculante de otros fabricantes que cumpla estas características puede ser utilizado en la planta de proceso. Se han realizado pruebas con un único floculan te pero no se ha conseguido un mejor rendimiento de la operación, por ello se decidió usar esta mezcla de floculantes aniónico y catiónico.

La concentración óptima de la concentración de sólidos en la alimentación para el mayor flujo de sedimentación está en el $5 \%$ de sólidos en peso, ya que esta dilución mostró mejores resultados. En el caso de los ensayos en espesador de laboratorio se realizaron con el $5 \%$ de sólidos en peso y por tanto, el sistema de alimentación del futuro espesador debe ser diseñado para alcanzar estas diluciones. Esta concentración óptima junto a la dosificación correcta representa el mayor rendimiento del flujo de sólidos que puede entrar al espesador. Esta dilución del $5 \%$ de sólidos en peso en la alimentación se debe de conseguir mediante un sistema de eductor colocado de forma previa a la campana de alimentación ya que se supone según los datos de proceso que la pulpa llegará al espesador, previsiblemente, con un contenido en sólidos del 25-30\%. El flujo de sólidos óptimo encontrado en los ensayos ha sido con una alimentación del $5 \%$ de sólidos y una dosificación de 40-50 gramos por tonelada de floculante.

El dimensionamiento del equipo basado en los estudios y ensayos realizados, permite afirmar que los estériles del yacimiento de Laza pueden ser tratados por los tres tipos de espesadores: espesadores tipo HRT; espesadores HDT y espesadores de pasta. Corresponde al ingeniero del proyecto en base a factores económicos y de sostenibilidad de la operación, la elección de un tipo u otro, basado en las características del lugar de deposición, propiedades de la pasta, método de tratamiento de los estériles, etc.

El espesador diseñado deberá incorporar la tecnología que permita el tratamiento de estériles espesados con una alta tensión de fluencia, en el caso de optar por un espesado en forma de pasta con alto contenido en sólidos.

Estas características del espesador son:

a) El sistema de rasquetas y el accionamiento de las rasquetas deberá ser diseñado con el suficiente torque para desarrollar tareas de alta densidad o pasta, según el tratamiento final seleccionado. Esto elimina la necesidad de instalar un sistema de elevación de rasquetas, con un sistema de control de par. En el caso de los estériles analizados los factores "K" recomendados para el diseño del sistema de accionamiento, son los que se muestran a continuación en la tabla 8-6: Recomendaciones de factores de accionamiento. 
Tabla 8-6: Recomendaciones de factores de accionamiento

\begin{tabular}{|l|c|c|}
\hline \multicolumn{1}{|c|}{ Tipo de espesador } & $\begin{array}{c}\text { Tensión de } \\
\text { fluencia máxima } \\
\text { (Estimada) en Pa. }\end{array}$ & $\begin{array}{c}\text { Factor K para diseño mecanismo } \\
\text { accionamiento } \\
\text { (Ib/ft) }\end{array}$ \\
\hline Espesadores HRT & $60 \mathrm{~Pa}$ & 50 (Con elevación) \\
\hline Espesador alta densidad HDT & $150 \mathrm{~Pa}$ & 175 (Sin elevación) \\
\hline Espesador de pasta o cono & $350 \mathrm{~Pa}$ & 300 (Sin elevación) \\
\hline
\end{tabular}

(Fuente: Elaboración propia)

b) El ángulo de talud del fondo del espesador se debe fijar según las recomendaciones del fabricante. En el caso de espesadores de pasta, este ángulo final viene fijado por el diámetro final del espesador. Los ángulos para el fondo característicos para cada tipo de espesador se definen para el diseño en la tabla 8-7: Angulo de fondo para diseño del proyecto.

Tabla 8-7: Angulo de fondo para diseño del proyecto.

\begin{tabular}{|l|c|}
\hline \multicolumn{1}{|c|}{ Tipo de espesador } & $\begin{array}{c}\text { Ángulo de fondo del } \\
\text { espesador }\end{array}$ \\
\hline Espesadores HRT & $10^{\circ}$ \\
\hline Espesador alta densidad HDT & $15^{\circ}$ \\
\hline Espesador de pasta o cono & $30^{\circ}$ \\
\hline
\end{tabular}

(Fuente: Elaboración propia)

c) El espesador deberá ser diseñado con la altura de pared correspondiente a cada tipo de espesador, que permita el incremento de lodos correcto y el tiempo de residencia para alcanzar el volumen de lodos y altura de lecho de lodos para obtener el hundido deseado con el contenido en sólidos y la tensión de fluencia esperada en cada caso. En general los espesadores de pasta y de alta densidad en el hundido permitirán reducir el diámetro del tanque y por tanto la superficie ocupada por el equipo de espesado a la vez que mejoran la concentración en sólidos en la descarga del espesador.

\subsection{Estudio y alternativas de diseño del equipo de espesado en el yacimiento de Laza}

A continuación se presenta el estudio y diseño de los sistemas de tratamiento de estériles para el proyecto de Laza-Orense. El estudio de viabilidad del proyecto determinará el tratamiento de estériles del beneficio de mineral de estaño y wolframio utilizando el caso base de 1,5 millones de toneladas por año en la planta de tratamiento durante una vida de la mina prevista de 10 años.

El diseño se ha realizado en base a tres premisas fundamentales en todo proyecto de espesado y tratamiento de estériles: maximizar la cantidad y la calidad del agua recuperada en el proceso, 
minimizar los costes de energía y floculante por tonelada de sólidos depositada en las instalaciones de almacenamiento de estériles y la sostenibilidad de la operación. Hay que considerar este estudio como un proyecto preliminar y válido para una fase de previabilidad del proyecto, donde los costes económicos y las alternativas evaluadas tienen un margen de aproximación típico para la fase del proyecto.

Para este estudio se ha considerado la producción de estériles de bajo, medio y alto contenido en sólidos del material y la reología característica en cada caso, con el fin de determinar la opción más económica y sostenible.

Un análisis basado en los costes de capital y operación en cada uno de los escenarios de tratamiento de estériles mostrará la opción más viable de espesado. Incluso aunque el sistema propuesto resulte ser más caro en consumo energético por tonelada depositada hay que atender a otros factores de sostenibilidad durante la vida de la mina así como, los posibles requerimientos medioambientales, sociales y económicos de las autoridades competentes para la obtención de permisos y autorizaciones.

A medida que el coste del agua, floculante, electricidad y mano de obra es probable que se incremente en el futuro, los estériles tratados en espesadores de alta densidad y espesadores de pasta parecen la opción más económica, siendo ésta la más atractiva a priori.

Las razones para considerar la pasta de estériles como operación alternativa al espesado convencional de estériles se origina a partir de los beneficios económicos de ingeniería, medioambientales y sociales que este método conlleva. En general, para casi todos los proyectos mineros se descubren los beneficios asociados con el espesado en pasta como ampliamente alcanzados por el ahorro de costes de capital y costes de operación que conllevan, además de otros beneficios como son: el ahorro de agua en las explotaciones mineras, sostenibilidad de la operación, menor riesgo medioambiental, etc.

Con estas premisas, se ha desarrollado un sistema para determinar el escenario óptimo de diseño para el espesado y depósito de estériles mineros procedentes de la planta de flotación.

Conforme a los ensayos realizados en laboratorio se han establecido los siguientes escenarios que se definen según el rango de concentración de los estériles de la Mina de Laza requerido y el método de deposición a utilizar. Estos supuestos de escenario de proceso son los tres siguientes:

a) Espesado de baja densidad de estériles con un contenido en sólidos de $45 \%-50 \%$ y almacenamiento en balsa convencional.

b) Espesado de media densidad de sólidos con un contenido en $62 \%$ - $65 \%$ con almacenamiento en balsa de pasta.

c) Espesado de alta densidad de estériles con un contenido en sólidos del $68 \%-71 \%$ con almacenamiento en depósito de pasta.

\subsubsection{Datos de diseño de la operación de espesado el yacimiento de Laza}

Los datos de proceso y los supuestos realizados para el estudio de viabilidad se presentan en la tabla 8-8: Parámetros de diseño. 
Tabla 8-8: Parámetros de diseño

\begin{tabular}{|l|l|}
\hline Parámetro & Datos de diseño \\
\hline Tonelaje diseño & $185 \mathrm{t} / \mathrm{h}$ \\
\hline Operación de la planta & 8000 horas/año \\
\hline Disponibilidad de la planta & $91.3 \%$ \\
\hline Densidad sólidos & $2.400 \mathrm{~kg} / \mathrm{m}^{3}$ \\
\hline Densidad líquido & $1.000 \mathrm{~kg} / \mathrm{m}^{3}$ \\
\hline Tamaño partículas P80 & $82 \mathrm{micras}$ \\
\hline Coste energía eléctrica & $0.165 € / \mathrm{kWh}$ \\
\hline Coste de agua fresca para proceso & $0,98 € / \mathrm{m} 3$ \\
\hline Coste de floculantes & $1,25 € / \mathrm{kg}$ \\
\hline
\end{tabular}

(Fuente: Elaboración propia)

Con los datos de diseño obtenidos de estudios previos y basados en la experiencia de este tipo de proyectos, se han dimensionado los equipos de espesado necesarios así como los equipos auxiliares. La definición de las instalaciones necesarias implica un conocimiento de los costes de capital, costes de operación y mantenimiento, que junto a los datos aportados por los ensayos de laboratorio permite obtener los costes del proyecto con la precisión necesaria en esta fase de estudio.

\subsubsection{Datos de proceso}

Con el objetivo de definir los datos de proceso para cada una de las alternativas planteadas, se ha calculado para cada caso en particular los datos de proceso para dimensionar los equipos una vez fijados los valores críticos como tonelaje de alimentación, contenido en sólidos de la alimentación y densidad del hundido para cada uno de los casos estudiados.

En la tabla 8-9: Datos de proceso para espesador de pasta. Proyecto de Laza; se muestran los valores obtenidos en el dimensionado del equipo de espesado de estériles en forma de pasta. La tabla 8-10: Datos de proceso para espesador HDT. Proyecto de Laza se detallan los valores del proceso y datos diseño del espesador para la opción de espesado en alta densidad (HDT).

Para ambos casos el espesador propuesto tiene el mismo diámetro, si bien varían en cuanto a la altura lateral de la virola y en el accionamiento debido a las diferencias de tiempo de residencia y reología esperada en el hundido del espesador.

En la tabla 8-11: Datos de proceso para espesador HRT; se muestran los valores considerados para el dimensionado del equipo HRT de espesado en forma de pulpa para la obtención de un hundido con bajo contenido en sólidos ( $45 \%$ de sólidos en peso). 
Tabla 8-9: Datos de proceso para espesador de pasta. Proyecto de Laza.

\begin{tabular}{|c|c|c|}
\hline \multirow{2}{*}{ DIMENSIONADO DE EQUIPOS DE ESPESADO } & \multicolumn{2}{|c|}{ Diseño Espesador Pasta } \\
\hline & Nominal & Máximo (+15\%) \\
\hline \multicolumn{3}{|l|}{ DATOS PRODUCCIÓN } \\
\hline Número de espesadores & 1 & 1 \\
\hline Producción total (t/h) & 185 & 217,6 \\
\hline Total producción anual (t/año) & 1480000 & 1741176 \\
\hline Horas de operación anuales (h/año) & 8000 & 8000 \\
\hline Producción por espesador (t/día) & 4440 & 5224 \\
\hline Producción horaria por espesador (t/h) & 185,0 & 217,6 \\
\hline \multicolumn{3}{|l|}{ ALIMENTACIÓN } \\
\hline Contenido en sólidos alimentación (\% peso) & $22,0 \%$ & $22,0 \%$ \\
\hline Dilución de sólidos en la campana (\% peso) & $5,0 \%$ & $5,0 \%$ \\
\hline Peso específico de sólidos $\left(\mathrm{g} / \mathrm{cm}^{3}\right)$ & 2,50 & 2,50 \\
\hline Peso específico de licor $\left(\mathrm{g} / \mathrm{cm}^{3}\right)$ & 1,00 & 1,00 \\
\hline Peso específico de la alimentación $\left(\mathrm{g} / \mathrm{cm}^{3}\right)$ & 1,15 & 1,15 \\
\hline Ratio de alimentación de pulpa $\left(\mathrm{m}^{3} / \mathrm{h}\right)$ & 730 & 859 \\
\hline \multicolumn{3}{|l|}{ HUNDIDO DEL ESPESADOR } \\
\hline Sólidos del hundido (\% peso) & $68,0 \%$ & $68,0 \%$ \\
\hline Peso específico del hundido $\left(\mathrm{g} / \mathrm{cm}^{3}\right)$ & 1,69 & 1,69 \\
\hline Caudal de lodos hundido $\left(\mathrm{m}^{3} / \mathrm{h}\right)$ & 161 & 189 \\
\hline \multicolumn{3}{|l|}{ REBOSE DEL ESPESADOR } \\
\hline Flujo en el rebose $\left(\mathrm{m}^{3} / \mathrm{h}\right)$ & 602 & 708 \\
\hline Sólidos en suspensión en rebose $(\mathrm{g} / \mathrm{m} 3)$ & 50 & 50 \\
\hline Pérdidas de sólidos por rebose $(\mathrm{kg} / \mathrm{h})$ & 30 & 35 \\
\hline \multicolumn{3}{|l|}{ FLOCULANTE } \\
\hline Dosificación de floculante (g/t) & 45 & 45 \\
\hline Concentración de floculante (g/litro) & 0,25 & 0,25 \\
\hline Caudal de floculante (litros/h) & 33300 & 39176 \\
\hline Consumo de floculante diario (kg/día) & 199,8 & 235,1 \\
\hline \multicolumn{3}{|l|}{ DIMENSIONADO Y RATIOS } \\
\hline Área Unitaria operación (m²/t/día) & 0,035 & 0,030 \\
\hline Flujo de sólidos $\mathrm{t} / \mathrm{dí} a / \mathrm{m}^{2}$ & 29 & 34 \\
\hline Flujo de sólidos $\mathrm{t} / \mathrm{dí} / \mathrm{m}^{2}$ & 1,2 & 1,4 \\
\hline Diámetro del equipo (metros) & 14,07 & 14,07 \\
\hline Ratio de ascenso interno $(\mathrm{m} / \mathrm{h})^{*}$ & 24,2 & 28,5 \\
\hline Ratio de ascenso $(\mathrm{m} / \mathrm{h})$ & 4,2 & 5,0 \\
\hline Factor "K" dimensionado accionamiento (ft-lbs./ft²) & 300 & 300 \\
\hline Par de accionamiento (ft-lbs.) & 659538 & 659538 \\
\hline Accionamiento seleccionado & B60P-3 & B60P-3 \\
\hline Par máximo del accionamiento seleccionado (ft/lbs) & 720000 & 720000 \\
\hline Factor $\mathrm{K}$ instalado en el equipo & 328 & 328 \\
\hline \multicolumn{3}{|l|}{ CAMPANA DE ALIMENTACIÓN } \\
\hline Diámetro $(\mathrm{m})$ & 4 & 4,0 \\
\hline Profundidad de la campana $(\mathrm{m})$ & 3 & 3,0 \\
\hline Volumen de la campana $\left(\mathrm{m}^{3}\right)$ & 37,7 & 37,7 \\
\hline Velocidad media salida (m/minuto) & 4,5 & 5,4 \\
\hline Tiempo de residencia dilución campana (minutos) & 0,6 & 0,5 \\
\hline \multicolumn{3}{|l|}{ TANQUE DEL ESPESADOR } \\
\hline Diámetro (m) & 14 & 14 \\
\hline Altura de tanque $(\mathrm{m})$ & 15,8 & 15,8 \\
\hline Zona superior libre $(\mathrm{m})$ & 0,3 & 0,3 \\
\hline Zona de seguridad bajo campana $(\mathrm{m})$ & 1,0 & 1,0 \\
\hline Altura de virola lateral $(\mathrm{m})$ & 10,00 & 10,00 \\
\hline Talud de fondo ( ${ }^{\circ}$ desde la horizontal) & 30,0 & 30,0 \\
\hline Diámetro del cilindro de descarga $(\mathrm{m})$ & 2,00 & 2,00 \\
\hline Altura del cilindro de descarga $(\mathrm{m})$ & 2,00 & 2,00 \\
\hline Volumen del cilindro de descarga $\left(\mathrm{m}^{3}\right)$ & 6,283 & 6,283 \\
\hline Altura del lecho de lodos (sobre la virola) (m) & 6,0 & 6,0 \\
\hline Profundidad total de la pulpa (m) & 11,5 & 11,5 \\
\hline Contenido medio en sólidos del lecho de lodos (\% sólidos) & $66 \%$ & $66 \%$ \\
\hline Densidad promedio del lecho de lodos & 1,66 & 1,66 \\
\hline Volumen del lecho de lodos $\left(\mathrm{m}^{3}\right)$ & 1148 & 1148 \\
\hline Tiempo de residencia de la pulpa $(\mathrm{h})$ & 6,8 & 5,8 \\
\hline
\end{tabular}


Tabla 8-10: Datos de proceso para espesador HDT. Proyecto de Laza.

\begin{tabular}{|c|c|c|}
\hline \multirow[t]{2}{*}{ DIMENSIONADO DE EQUIPOS DE ESPESADO } & \multicolumn{2}{|c|}{ Diseño HDT } \\
\hline & Nominal & Máximo (+15\%) \\
\hline \multicolumn{3}{|l|}{ DATOS PRODUCCIÓN } \\
\hline Número de espesadores & 1 & 1 \\
\hline Producción total (t/h) & 185 & 217,6 \\
\hline Total producción anual (t/año) & 1.480 .000 & 1.741.176 \\
\hline Horas de operación anuales (h/año) & 8000 & 8000 \\
\hline Producción por espesador (t/día) & 4440 & 5224 \\
\hline Producción horaria por espesador (t/h) & 185,0 & 217,6 \\
\hline \multicolumn{3}{|l|}{ ALIMENTACIÓN } \\
\hline Contenido en sólidos alimentación (\% peso) & $22,0 \%$ & $22,0 \%$ \\
\hline Dilución de sólidos en la campana (\% peso) & $5,0 \%$ & $5,0 \%$ \\
\hline Peso específico de sólidos $\left(\mathrm{g} / \mathrm{cm}^{3}\right)$ & 2,50 & 2,50 \\
\hline Peso específico de licor $\left(\mathrm{g} / \mathrm{cm}^{3}\right)$ & 1,00 & 1,00 \\
\hline Peso específico de la alimentación $\left(\mathrm{g} / \mathrm{cm}^{3}\right)$ & 1,15 & 1,15 \\
\hline Ratio de alimentación de pulpa $\left(\mathrm{m}^{3} / \mathrm{h}\right)$ & 730 & 859 \\
\hline \multicolumn{3}{|l|}{ HUNDIDO DEL ESPESADOR } \\
\hline Sólidos del hundido (\% peso) & $62,0 \%$ & $62,0 \%$ \\
\hline Peso específico del hundido $\left(\mathrm{g} / \mathrm{cm}^{3}\right)$ & 1,59 & 1,59 \\
\hline Caudal de lodos hundido $\left(\mathrm{m}^{3} / \mathrm{h}\right)$ & 187 & 220 \\
\hline \multicolumn{3}{|l|}{ REBOSE DEL ESPESADOR } \\
\hline Flujo en el rebose $\left(\mathrm{m}^{3} / \mathrm{h}\right)$ & 576 & 677 \\
\hline Sólidos en suspensión en rebose $\left(\mathrm{g} / \mathrm{m}^{3}\right)$ & 50 & 50 \\
\hline Pérdidas de sólidos por rebose $(\mathrm{kg} / \mathrm{h})$ & 29 & 34 \\
\hline \multicolumn{3}{|l|}{ FLOCULANTE } \\
\hline Dosificación de floculante (g/t) & 45 & 45 \\
\hline Concentración de floculante (g/litro) & 0,25 & 0,25 \\
\hline Caudal de floculante (litros/h) & 33300 & 39176 \\
\hline Consumo de floculante diario (kg/día) & 199,8 & 235,1 \\
\hline \multicolumn{3}{|l|}{ DIMENSIONADO Y RATIOS } \\
\hline Área Unitaria operación (m²/t/día) & 0,035 & 0,030 \\
\hline Flujo de sólidos $\mathrm{t} / \mathrm{dia} a / \mathrm{m}^{2}$ & 29 & 34 \\
\hline Flujo de sólidos $\mathrm{t} / \mathrm{dí} a / \mathrm{m}^{2}$ & 1,2 & 1,4 \\
\hline Diámetro del equipo (metros) & 14,07 & 14,07 \\
\hline Ratio de ascenso interno $(\mathrm{m} / \mathrm{h})^{*}$ & 24,0 & 28,3 \\
\hline Ratio de ascenso $(\mathrm{m} / \mathrm{h})$ & 4,0 & 4,7 \\
\hline Factor "K" dimensionado accionamiento (ft-lbs./ft') & 200 & 200 \\
\hline Par de accionamiento (ft-lbs.) & 439692 & 439692 \\
\hline Accionamiento seleccionado & B60P-2 & B60P-2 \\
\hline Par máximo del accionamiento seleccionado (ft/lbs) & 480000 & 480000 \\
\hline Factor $\mathrm{K}$ instalado en el equipo & 218 & 218 \\
\hline \multicolumn{3}{|l|}{$\begin{array}{l}\text { CAMPANA DE ALIMENTACIÓN } \\
\text { CAMP }\end{array}$} \\
\hline Diámetro (m) & $\overline{4}$ & $4, \overline{0}$ \\
\hline Profundidad de la campana $(\mathrm{m})$ & 3 & 3,0 \\
\hline Volumen de la campana $\left(\mathrm{m}^{3}\right)$ & 37,7 & 37,7 \\
\hline Velocidad media salida (m/minuto) & 4,5 & 5,3 \\
\hline Tiempo de residencia dilución campana (minutos) & 0,6 & 0,5 \\
\hline \multicolumn{3}{|l|}{ TANQUE DEL ESPESADOR } \\
\hline Diámetro (m) & 14 & 14 \\
\hline Altura de tanque $(\mathrm{m})$ & 10,4 & 10,4 \\
\hline Zona superior libre (m) & 0,3 & 0,3 \\
\hline Zona de seguridad bajo campana $(\mathrm{m})$ & 1,0 & 1,0 \\
\hline Altura de virola lateral $(\mathrm{m})$ & 6,50 & 6,50 \\
\hline Talud de fondo ( ${ }^{\circ}$ desde la horizontal) & 15,0 & 15,0 \\
\hline Diámetro del cilindro de descarga $(\mathrm{m})$ & 2,00 & 2,00 \\
\hline Altura del cilindro de descarga $(\mathrm{m})$ & 2,00 & 2,00 \\
\hline Volumen del cilindro de descarga $\left(\mathrm{m}^{3}\right)$ & 6,283 & 6,283 \\
\hline Altura del lecho de lodos (sobre la virola) (m) & 2,5 & 2,5 \\
\hline Profundidad total de la pulpa (m) & 6,1 & 6,1 \\
\hline Contenido medio en sólidos del lecho de lodos (\% sólidos) & $60 \%$ & $60 \%$ \\
\hline Densidad promedio del lecho de lodos & 1,56 & 1,56 \\
\hline Volumen del lecho de lodos $\left(\mathrm{m}^{3}\right)$ & 492 & 492 \\
\hline Tiempo de residencia de la pulpa (h) & 2,5 & 2,1 \\
\hline
\end{tabular}


Tabla 8-11: Datos de proceso para espesador HRT. Proyecto de Laza.

\begin{tabular}{|c|c|c|}
\hline \multirow[t]{2}{*}{ DIMENSIONADO DE EQUIPO DE ESPESADO } & \multicolumn{2}{|c|}{ Diseño Espesador HRT } \\
\hline & Nominal & Máximo (+15\%) \\
\hline \multicolumn{3}{|l|}{ DATOS PRODUCCIÓN } \\
\hline Número de espesadores & 1 & 1 \\
\hline Producción total (t/h) & 185,0 & 217,6 \\
\hline Total producción anual (t/año) & 1480000 & 1741176 \\
\hline Horas de operación anuales (h/año) & 8000 & 8000 \\
\hline Producción por espesador (t/día) & 4440 & 5224 \\
\hline Producción horaria por espesador (t/h) & 185 & 218 \\
\hline \multicolumn{3}{|l|}{ ALIMENTACIÓN } \\
\hline Contenido en sólidos alimentación (\% peso) & $22,0 \%$ & $22,0 \%$ \\
\hline Dilución de sólidos en la campana (\% peso) & $5,0 \%$ & $5,0 \%$ \\
\hline Peso específico de sólidos $\left(\mathrm{g} / \mathrm{cm}^{3}\right)$ & 2,50 & 2,50 \\
\hline Peso específico de licor $\left(\mathrm{g} / \mathrm{cm}^{3}\right)$ & 1,00 & 1,00 \\
\hline Peso específico de la alimentación $\left(\mathrm{g} / \mathrm{cm}^{3}\right)$ & 1,15 & 1,15 \\
\hline Ratio de alimentación de pulpa $\left(\mathrm{m}^{3} / \mathrm{h}\right)$ & 730 & 859 \\
\hline \multicolumn{3}{|l|}{ HUNDIDO DEL ESPESADOR } \\
\hline Sólidos del hundido (\% peso) & $45,0 \%$ & $45,0 \%$ \\
\hline Peso específico del hundido $\left(\mathrm{g} / \mathrm{cm}^{3}\right)$ & 1,37 & 1,37 \\
\hline Caudal de lodos hundido $\left(\mathrm{m}^{3} / \mathrm{h}\right)$ & 300 & 300 \\
\hline \multicolumn{3}{|l|}{ REBOSE DEL ESPESADOR } \\
\hline Flujo en el rebose $\left(\mathrm{m}^{3} / \mathrm{h}\right)$ & 452 & 585 \\
\hline Sólidos en suspensión en rebose $\left(\mathrm{g} / \mathrm{m}^{3}\right)$ & 50 & 50 \\
\hline Pérdidas de sólidos por rebose $(\mathrm{kg} / \mathrm{h})$ & 23 & 29 \\
\hline \multicolumn{3}{|l|}{ FLOCULANTE } \\
\hline Dosificación de floculante (g/t) & 30 & 30 \\
\hline Concentración de floculante (g/litro) & 0,25 & 0,25 \\
\hline Caudal de floculante (litros/h) & 22200 & 26118 \\
\hline Consumo de floculante diario (kg/día) & 133,2 & 156,7 \\
\hline \multicolumn{3}{|l|}{ DIMENSIONADO Y RATIOS } \\
\hline Área Unitaria operación ( $\left.\mathrm{m}^{2} / \mathrm{t} / \mathrm{día}\right)$ & 0,100 & 0,100 \\
\hline Flujo de sólidos $\mathrm{t} / \mathrm{dí} a / \mathrm{m}^{2}$ & 10 & 10 \\
\hline Flujo de sólidos $\mathrm{t} / \mathrm{d} \mathbf{a} / \mathrm{m}^{2}$ & 0,4 & 0,4 \\
\hline Diámetro del equipo (metros) & 23,78 & 23,78 \\
\hline Ratio de ascenso interno $(\mathrm{m} / \mathrm{h})^{*}$ & 7,7 & 9,2 \\
\hline Ratio de ascenso (m/h) & 1,1 & 1,4 \\
\hline Factor "K" dimensionado accionamiento (ft-lbs./ft²) & 50 & 50 \\
\hline Par de accionamiento (ft-lbs.) & 314066 & 314066 \\
\hline Accionamiento seleccionado & B60P-2 & B60P-2 \\
\hline Par máximo del accionamiento seleccionado (ft/lbs) & 480000 & 480000 \\
\hline Factor $\mathrm{K}$ instalado en el equipo & 76 & 76 \\
\hline \multicolumn{3}{|l|}{ CAMPANA DE ALIMENTACIÓN } \\
\hline Diámetro (m) & $4, \overline{5}$ & $4, \overline{5}$ \\
\hline Profundidad de la campana $(\mathrm{m})$ & 2 & 2,0 \\
\hline Volumen de la campana $\left(\mathrm{m}^{3}\right)$ & 31,8 & 31,8 \\
\hline Velocidad media salida (m/minuto) & 3,4 & 4,1 \\
\hline Tiempo de residencia dilución campana (minutos) & 0,5 & 0,4 \\
\hline \multicolumn{3}{|l|}{ TANQUE DEL ESPESADOR } \\
\hline Diámetro (m) & 24 & 24 \\
\hline Altura de tanque $(\mathrm{m})$ & 7,6 & 7,1 \\
\hline Zona superior libre (m) & 0,3 & 0,3 \\
\hline Zona de seguridad bajo campana $(\mathrm{m})$ & 1,5 & 1,0 \\
\hline Altura de virola lateral $(\mathrm{m})$ & 4,00 & 3,50 \\
\hline Talud de fondo ( ${ }^{\circ}$ desde la horizontal) & 9,0 & 9,0 \\
\hline Diámetro del cilindro de descarga $(\mathrm{m})$ & 1,50 & 1,50 \\
\hline Altura del cilindro de descarga $(\mathrm{m})$ & 1,50 & 1,50 \\
\hline Volumen del cilindro de descarga $\left(\mathrm{m}^{3}\right)$ & 2,651 & 2,651 \\
\hline Altura del lecho de lodos (sobre la virola) (m) & 0,5 & 0,5 \\
\hline Profundidad total de la pulpa $(\mathrm{m})$ & 3,8 & 3,8 \\
\hline Contenido medio en sólidos del lecho de lodos (\% sólidos) & $40 \%$ & $40 \%$ \\
\hline Densidad promedio del lecho de lodos & 1,32 & 1,32 \\
\hline Volumen del lecho de lodos $\left(\mathrm{m}^{3}\right)$ & 503 & 503 \\
\hline Tiempo de residencia de la pulpa $(\mathrm{h})$ & 1,4 & 1,2 \\
\hline
\end{tabular}


Las propiedades de los estériles espesados con los ratios de concentración propuestos se muestran en la tabla 8-13: Resumen de datos. Sistemas de espesado; en este cuadro de datos se pueden comparar las recuperaciones de agua para el tratamiento de un mismo tonelaje de sólidos.

Tabla 8-12: Resumen de datos. Sistemas de espesado.

\begin{tabular}{|l|c|c|c|}
\hline & $\begin{array}{c}\text { Espesador } \\
\text { HRT }\end{array}$ & $\begin{array}{c}\text { Espesador } \\
\text { HDT }\end{array}$ & $\begin{array}{c}\text { Espesador de } \\
\text { pasta }\end{array}$ \\
\hline \% Sólidos en el hundido & $45 \%$ & $62 \%$ & $68 \%$ \\
\hline Densidad pulpa & $1.370 \mathrm{t} / \mathrm{m} 3$ & $1.590 \mathrm{t} / \mathrm{m}^{3}$ & $1.690 \mathrm{t} / \mathrm{m}^{3}$ \\
\hline Alimentación de sólidos & $185 \mathrm{tph}$ & $185 \mathrm{tph}$ & $185 \mathrm{tph}$ \\
\hline Agua transportada a balsa & $226,1 \mathrm{~m} 3 / \mathrm{h}$ & $113,4 \mathrm{~m} 3 / \mathrm{h}$ & $87,1 \mathrm{~m} 3 / \mathrm{h}$ \\
\hline Tensión fluencia Pa & $10-20 \mathrm{~Pa}$ & $70-100 \mathrm{~Pa}$ & $200-250 \mathrm{~Pa}$ \\
\hline Agua recuperada & $429,8 \mathrm{~m}^{3} / \mathrm{h}$ & $542,5 \mathrm{~m} / \mathrm{h}$ & $568,8 \mathrm{~m}^{3} / \mathrm{h}$ \\
\hline Agua recuperada en & $65,5 \%$ & $82,6 \%$ & $86,7 \%$ \\
\hline espesador de estériles & & & \\
\hline
\end{tabular}

(Fuente: Elaboración propia)

El tratamiento de estériles para baja, media y alta densidad requiere de diferentes equipamientos y diseños en la selección del espesador, bombeo de tuberías, que dependerá del grado de concentración de sólidos en el hundido del espesador y de las propiedades reológicas de la pasta. Para los tres casos estudiados se ha propuesto una lista de equipos y un diagrama de flujo para cada uno. Esta selección de equipos y material auxiliar servirá de base para realizar un estudio previo de los costes de operación y mantenimiento referido a cada sistema de espesado. El depósito de almacenamiento se tratará en un punto posterior debido a que el estudio que se va a realizar será de forma conceptual y por fases, lo cual implica que se van a realizar una serie de estimaciones para obtener los costes de capital y operación de los diferentes tipos de proceso y escenarios propuestos para el tratamiento de los estériles.

Por ejemplo, los espesadores HRT serán para generar estériles de baja densidad con bombeo mediante bomba centrífuga para su transporte y tuberías de baja presión para la transferencia de estériles. Los espesadores de HDT y cono profundo, dependiendo de las condiciones de la pasta requieren de equipos algo más particulares, especialmente para el bombeo y transporte de los lodos recogidos en el hundido. Esto es debido a que en el espesador, debido a su mecanismo de piquetas permite un mayor desaguado de los lodos y serán precisas bombas de alta presión con desplazamiento positivo y espesadores más pesados y con un mayor coste de capital en los proyectos, incluso mayor instrumentación en el proceso de espesado y bombeo para el control de la operación.

Para dimensionar los diferentes tipos de espesadores se han tomado como referencia los datos de las tablas 8-9, 8-10 y 8-11. Las bombas, tuberías y equipos auxiliares serán dimensionados de acuerdo al mantenimiento de un ratio de flujo mínimo en la tubería para prevenir atascos.

Es importante destacar, que las instalaciones mineras de este tipo precisan considerar un sistema de agua de proceso sin vertidos, es decir con "cero efluentes" en muchos proyectos mineros, por 
lo que en todos los casos se va a considerar necesaria la construcción y operación de una planta de tratamiento de aguas (P.T.A.) para regenerar el agua de proceso que proviene de los espesadores de estériles y de la balsa, que será enviada a la planta pasando por este proceso de tratamiento de aguas. En la figura 8-13: Plano de situación de los equipos; se muestra una posible ubicación de la planta de tratamiento, espesador de estériles y balsas de estériles. Para todos los casos se ha considerado la instalación de la planta de tratamiento en la zona comprendida entre la mina y las balsas de estériles.

En todos los supuestos realizados la planta de tratamiento de estériles y agua se ha situado a la cota 750 m.s.n.m. mientras que la parte inferior de la balsa se ha considerado una cota de 620 m.s.n.m. Las instalaciones de bombeo de pasta y de agua recuperada que retorna a la planta de tratamiento se han considerado a una cota de 730 m.s.n.m.

En una fase posterior del proyecto será necesario un estudio más detallado de las ubicaciones consideradas para estas instalaciones.

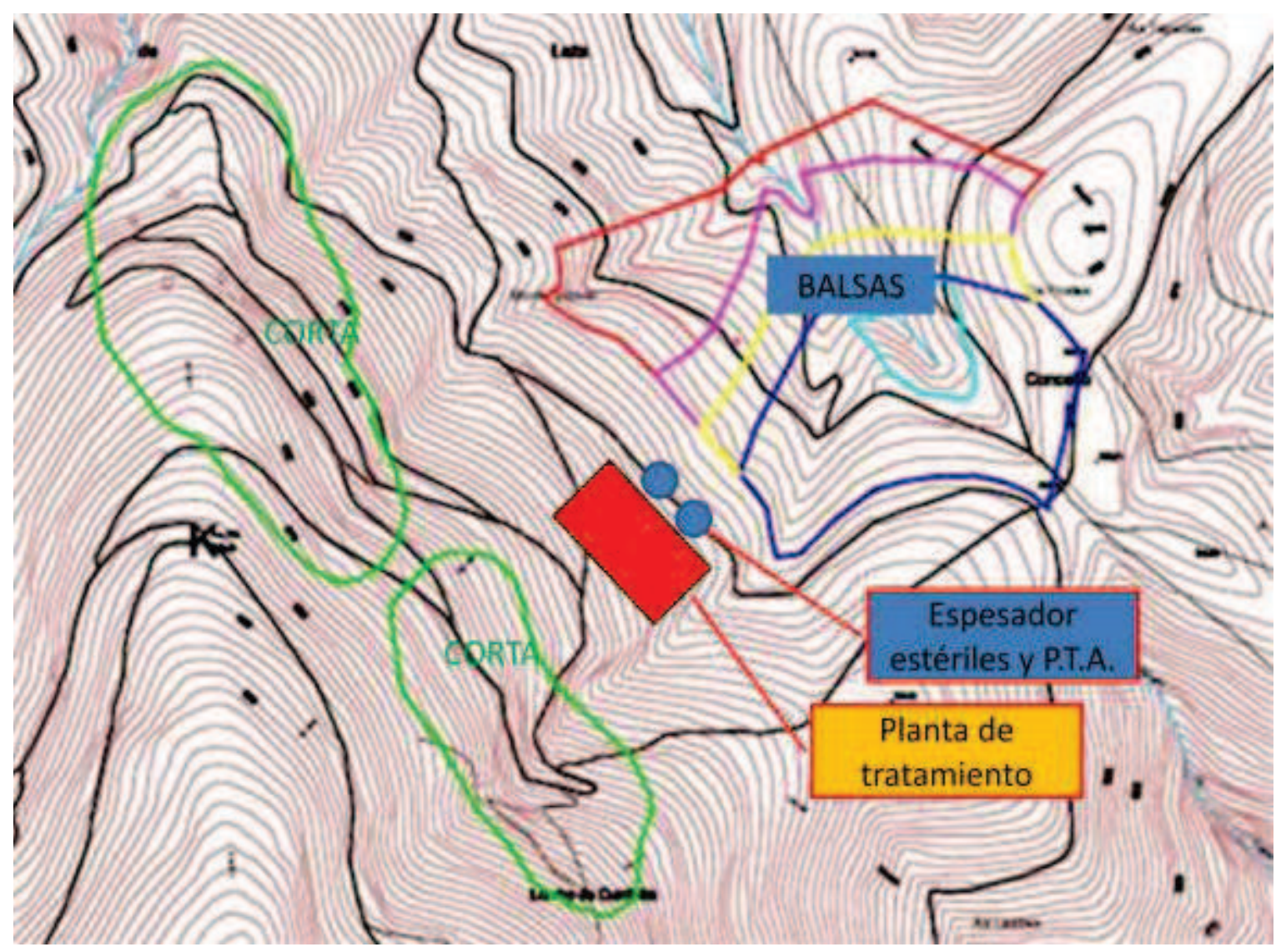

Figura 8-13: Plano de situación de los equipos.

(Fuente: Elaboración propia) 


\subsection{Equipos e instalaciones propuestos. Planta de estériles del proyecto}

A continuación se detalla el diagrama de proceso para cada supuesto realizado con los datos preliminares del proyecto minero de Mina de Laza. Cada uno de los casos ha considerado la ubicación de los equipos, distancias y alturas necesarias para el bombeo del agua de proceso y de los estériles.

A continuación se presentan las tres alternativas propuestas para el tratamiento de los estériles de la Mina de Laza. Con ello se pretende obtener una comparación entre los diferentes equipos y sistemas de almacenamiento de estériles que forman la última tecnología disponible.

a) La alternativa 1, representa el tratamiento de estériles de la Mina de Laza en un espesador de tipo HRT para alcanzar un contenido en sólidos en el hundido de $45 \%$ de sólidos en peso, con baja tensión de fluencia. Esto obliga a la realización de una presa de estériles convencional para recuperar una gran parte del agua en ella.

b) En la alternativa 2, el tratamiento se realiza en un espesador de alta densidad HDT donde se alcanzarían concentraciones de sólidos en el hundido de hasta el $62 \%$ de sólidos en peso y una tensión de fluencia superior a $100 \mathrm{~Pa}$, por lo que el método de deposición elegido sería un depósito de pasta en superficie.

c) La alternativa 3 propuesta es realizar el tratamiento de estériles en un espesador de pasta de cono profundo, en el que se llegarían a obtener concentraciones en el hundido del $68 \%$ de sólidos en peso y tensiones de fluencia de la pasta de $200 \mathrm{~Pa}$, para su almacenamiento en un depósito de pasta en superficie.

En todas las alternativas propuestas se ha incluido la construcción y operación de una planta de tratamiento de aguas (PTA) para regenerar el agua de proceso recuperada en todos los casos.

\subsubsection{Equipos para un sistema de estériles de baja concentración de sólidos}

El diagrama de flujo de un sistema de tratamiento de estériles de baja concentración con un espesador HRT de 24 metros de diámetro se muestra en la figura 8-14: Diagrama de proceso para espesado de estériles de baja densidad. En el diagrama de proceso, el espesador es alimentado desde la planta de tratamiento con el caudal de $185 \mathrm{t} / \mathrm{h}$ de sólidos en forma de pulpa al $22 \%$ de sólidos en peso. Los sólidos son espesados obteniéndose dos flujos: el efluente clarificado y un lodo en el hundido del espesador con el $45 \%$ de sólidos en peso. Esto supone un lodo segregable con 10-20 Pa de tensión de fluencia, fácilmente bombeable pero también con un alto contenido en agua.

La planta de espesado y tratamiento de aguas comparten una estación dosificadora y preparadora de floculante de hasta $120 \mathrm{~g} / \mathrm{t}$ que lo distribuye al espesador de estériles y a al reactor clarificador de la planta de tratamiento de aguas. En el reactor clarificador se ha considerado la instalación de tanques de reactivos para su preparación y adición al agua a tratar en el reactor clarificador. Los lodos obtenidos en el hundido del reactor clarificador son llevados al espesador de estériles para su tratamiento. 
El efluente clarificado en el rebose del espesador pasa por gravedad a un tanque de bombeo, desde donde es enviado a la planta de tratamiento de aguas. El lodo del hundido del espesador de 24 metros, pasa a un tanque agitador próximo al espesador para ser bombeado hacia la balsa de lodos.

En la balsa de lodos se ha construido una red de recogida de efluentes y filtraciones para ser enviada por bombeo a la planta de tratamiento de aguas. Debido al bajo contenido en sólidos de los lodos, el agua retornada a la planta es una cantidad significativa que puede ser reutilizada. Se ha estimado un retorno de agua a la planta de tratamiento del $60 \%$ del agua enviada con los estériles a la balsa de lodos.

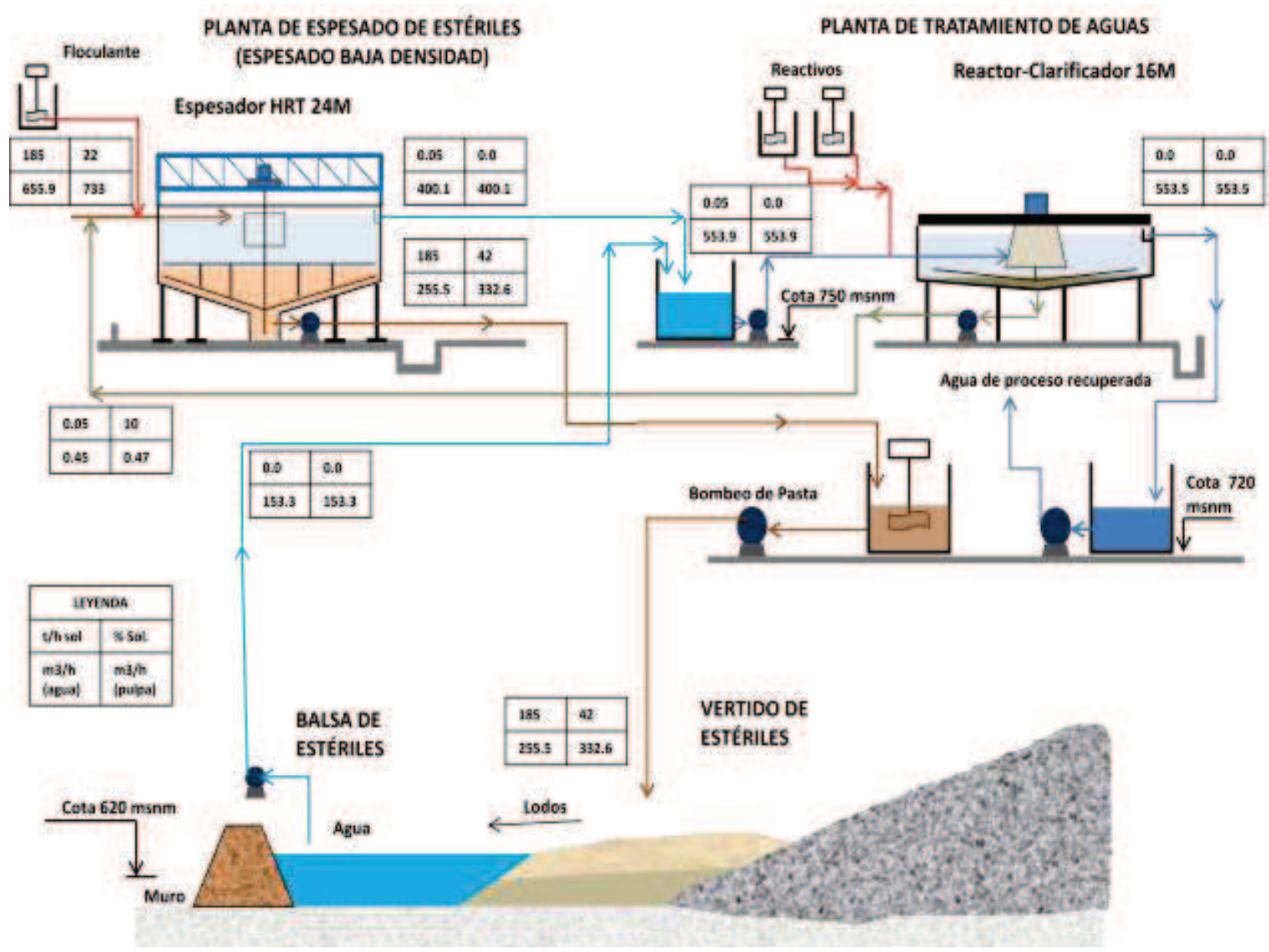

Figura 8-14: Diagrama de proceso para espesado de estériles de baja densidad. (Fuente: Elaboración propia)

\subsubsection{Equipos para un sistema de espesado de alta densidad (HDT)}

El diagrama de flujo de un sistema de tratamiento de estériles de media concentración de sólidos en peso utilizando un espesador HDT de 14 metros de diámetro se muestra en la figura 8-15: Diagrama de proceso para espesado de estériles de alta densidad. En este diagrama de proceso, 
el espesador es alimentado desde la planta de tratamiento con el caudal de $185 \mathrm{t} / \mathrm{h}$ de sólidos en forma de pulpa al $22 \%$ de sólidos en peso para su tratamiento. Los sólidos son espesados en el equipo de alta densidad (HDT) obteniéndose dos flujos: un efluente clarificado en el rebose y el lodo del hundido con el $62 \%$ de sólidos en peso con una reología característica de un lodo no sedimentable y no segregable. La tensión de fluencia estimada es de 75-100 Pa de acuerdo a los ensayos de laboratorio para este contenido en sólidos esperado.

La planta de espesado y tratamiento de aguas comparten una estación dosificadora y preparadora de floculante de hasta $120 \mathrm{~g} / \mathrm{t}$ que lo distribuye al espesador de estériles y a al reactor clarificador de la planta de tratamiento de aguas. En el reactor clarificador se ha considerado la instalación de tanques de reactivos para añadir cal y reactivos para el tratamiento del agua de proceso recuperada. Los lodos obtenidos en el hundido del reactor clarificador son llevados al espesador de estériles para su tratamiento.

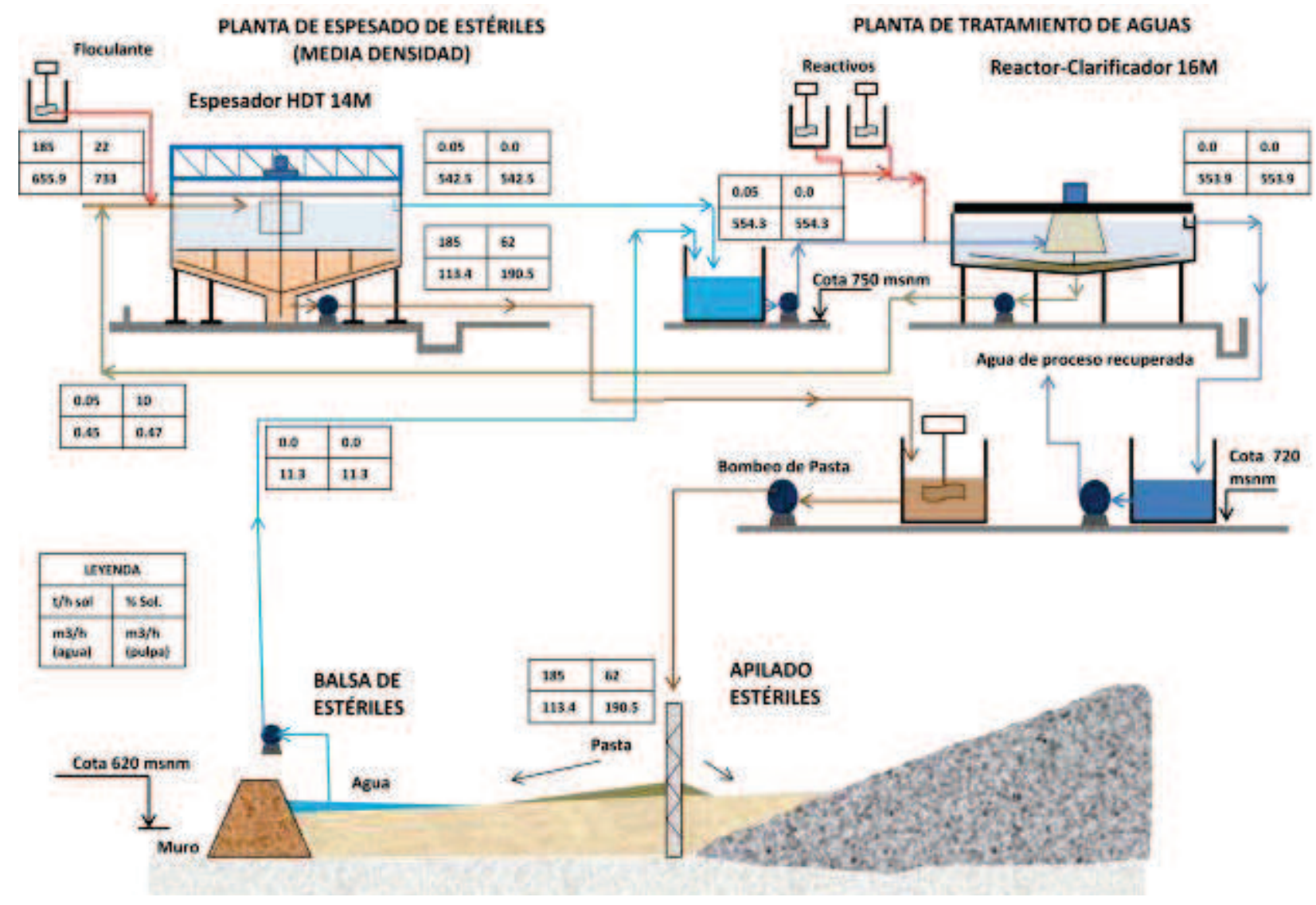

Figura 8-15: Diagrama de proceso para espesado de estériles de alta densidad.

(Fuente: Elaboración propia)

El efluente clarificado en el rebose del espesador pasa por gravedad a un tanque de bombeo, desde donde es enviado a la planta de tratamiento de aguas. El lodo del hundido del espesador HDT de 14 metros, es bombeado hacia el depósito de estériles.

En la balsa de lodos se ha construido una red de recogida de efluentes y filtraciones para ser devuelta por bombeo a la planta de tratamiento de aguas. Debido al bajo contenido en sólidos de los lodos, el agua retornada a la planta no es una cantidad significativa ya que no existe apenas 
liberación de agua con densidades de lodos tan altas. Se ha estimado un retorno de agua a la planta de tratamiento del $10 \%$ del agua enviada con los estériles a la balsa de lodos.

En un estudio de detalle posterior se deberán de considerar las condiciones de un balance hídrico sobre la superficie afectada por la balsa de lodos para considerar los aportes de aguas (lluvias, acuíferos, etc.) o bien pérdidas de agua por evaporación o filtraciones al terreno.

\subsubsection{Equipos para un sistema de espesado en pasta}

El diagrama de flujo de un sistema de tratamiento de estériles de baja concentración con un espesador de cono profundo de 14 metros de diámetro se muestra en la figura 8-16: Diagrama de proceso para espesado de estériles en forma de pasta. En el diagrama de proceso, el espesador es alimentado desde la planta de tratamiento con el caudal de 185 t/h de sólidos en forma de pulpa al $22 \%$ de sólidos en peso. Los sólidos son espesados obteniéndose dos flujos: el efluente clarificado y el lodo del hundido al $68 \%$ de sólidos con la reología propia de un lodo no sedimentable y no segregable. La tensión de fluencia estimada es de 200-250 Pa, por lo que las características son las de una pasta.

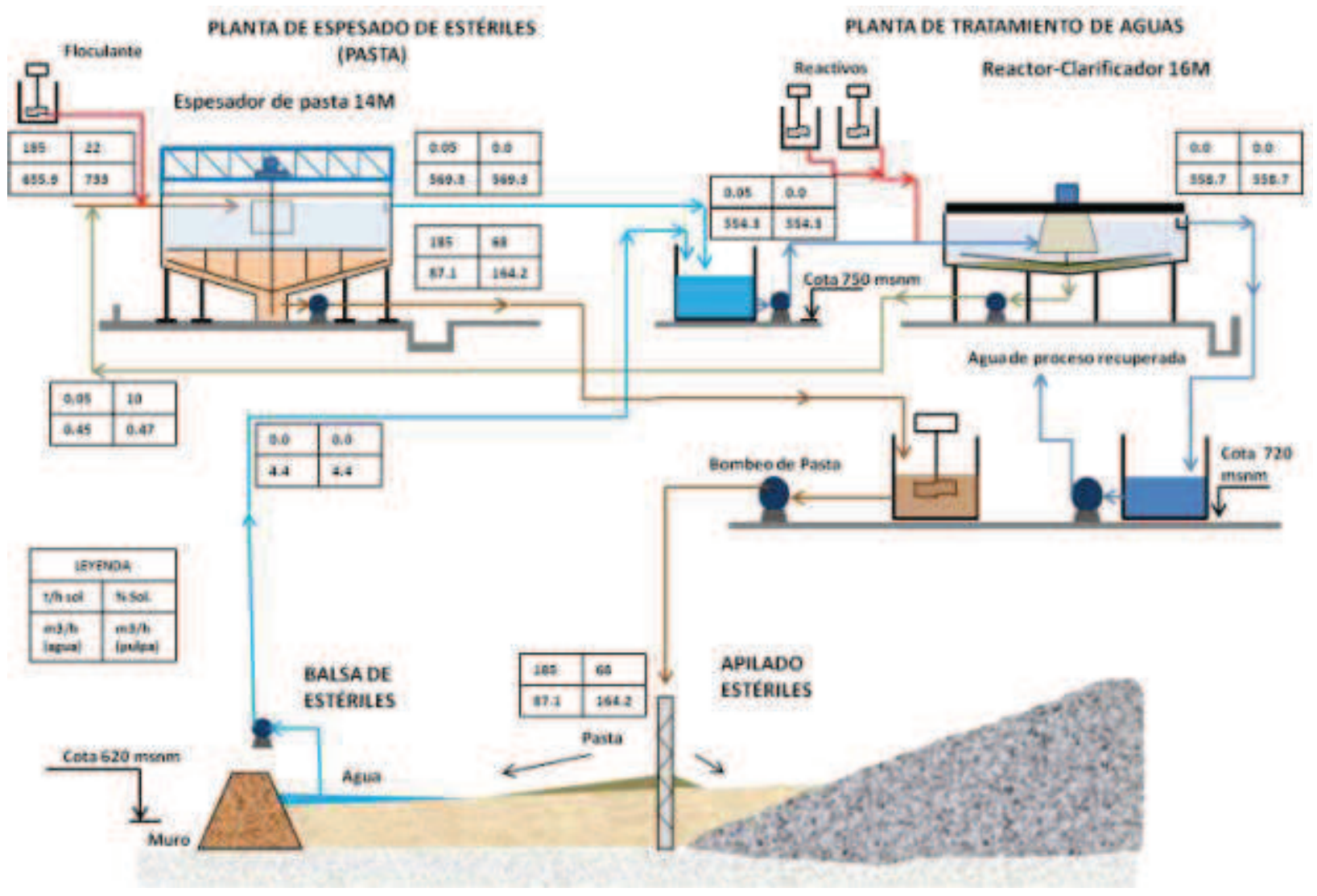

Figura 8-16: Diagrama de proceso para espesado de estériles en forma de pasta.

(Fuente: Elaboración propia)

La planta de espesado y tratamiento de aguas comparten una estación dosificadora y preparadora de floculante de hasta $120 \mathrm{~g} / \mathrm{t}$ que lo distribuye al espesador de estériles y a al reactor clarificador 
de la planta de tratamiento de aguas. En el reactor clarificador se ha considerado la instalación de tanques de reactivos para añadir cal o reactivos al agua a tratar. Los lodos obtenidos en el hundido del reactor clarificador son llevados al espesador de estériles para su tratamiento.

El efluente clarificado en el rebose del espesador pasa por gravedad a un tanque de bombeo, desde donde es enviado a la planta de tratamiento de aguas. El lodo del hundido del espesador de cono profundo de 14 metros, se bombea hacia el depósito de pasta con bombas de desplazamiento positivo.

En la balsa de lodos se ha construido una red de recogida de efluentes y filtraciones para ser enviada por bombeo a la planta de tratamiento de aguas. Debido al alto contenido en sólidos de los lodos depositados, el agua retornada a la planta no es una cantidad significativa ya que no existe apenas liberación de agua con una densidad de lodos tan alta. Se ha estimado un retorno de agua a la planta de tratamiento del $5 \%$ del agua enviada con los estériles al depósito de pasta.

\subsubsection{Equipos para la planta de tratamiento de agua de proceso}

La planta de tratamiento de aguas comprende un reactor clarificador de 16 metros de diámetro con capacidad de hasta $600 \mathrm{~m}^{3} / \mathrm{h}$. El objetivo de esta instalación es obtener un agua de proceso de alta calidad. Los equipos auxiliares que componen esta planta de tratamiento de aguas de proceso son: planta de almacenamiento y dosificación de reactivos, dos agitadores para reactivos, el reactor clarificador mencionado, un tanque para bombeo de efluentes, un tanque para bombeo del hundido al espesador de estériles.

\subsubsection{Estimación de volumen y superficie de la balsa}

Cada uno de los sistemas de espesado propuestos para el proyecto de Mina de Laza proporciona unos lodos espesados con características diferentes, lo que hace que las balsas de estériles y depósitos tengan diferentes configuraciones. Mientras que el caso del proyecto con un espesador HRT para deposición convencional al $45 \%$ de sólidos es necesaria una balsa con un gran muro de contención. En los casos de los espesadores de pasta o alta densidad en el hundido la reología de los lodos hace que esta balsa pueda ser diseñada con un muro menos voluminoso, puesto que las características reológicas de la pasta permiten este diseño y el muro sería utilizado únicamente como contención de efluentes líquidos.

Para todos los casos se ha considerado la misma ubicación de las plantas de espesado, planta de tratamiento de aguas y balsa de estériles. En este estudio preliminar de las balsas y deposición de estériles se han considerado datos preliminares que deberán ser estudiados y comprobados en profundidad en una etapa posterior del proyecto debido a su importancia en el diseño del proceso. Para la estimación de los volúmenes y ubicaciones de la balsa se dispone de un plano topográfico del terreno, como se muestra en la figura 8-17: Plano topográfico del terreno. Sobre este plano se han realizado estimaciones de la ubicación y las distancias entre la planta de espesado y la balsa de estériles. 


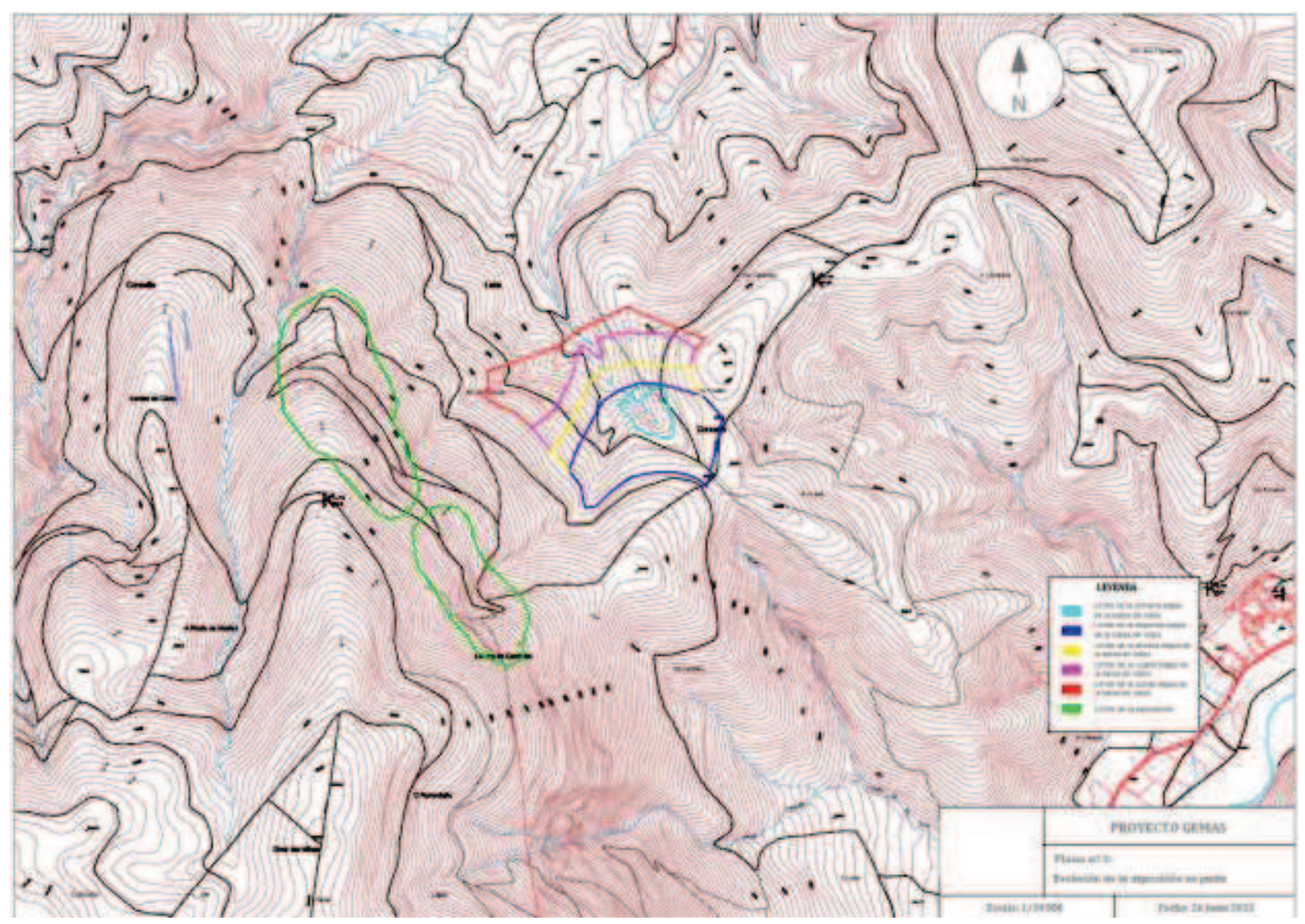

Figura 8-17: Mapa topográfico del terreno.

(Fuente: Elaboración propia)

Los volúmenes de balsa necesarios para toda la vida útil del proyecto se detallan en la tabla 8-13: Volúmenes de balsa de estériles para el proyecto Mina de Laza. Como se puede comprobar aplicando las concentraciones de de sólidos en el hundido obtenidas en los distintos sistemas de espesado, la capacidad de las balsas varía de manera considerable.

Como se comprueba en la tabla $8-13$, los volúmenes de la balsa o depósito de estériles considerados para toda la vida de la mina se reducen entre un $18 \%$ y un $20 \%$ si se comparan los volúmenes de los estériles espesados en forma de pasta con el volumen necesario para una balsa convencional de lodos.

Otro aspecto significativo en la construcción y diseño de la balsa de estériles es el tipo de muro de contención que se debe construir en un caso u otro dependiendo de las condiciones reológicas de los lodos, como se muestra en la figura 8-18: Tipos de balsas de estériles; en el caso de los estériles espesados de forma convencional, en general se requieren muros de contención de mayores dimensiones y un sistema más sofisticado de drenajes y recogida de aguas para devolver el agua recuperada al proceso. Por el contrario en los sistemas de espesado en forma de pasta, el agua liberada por los estériles una vez depositados es mínima, ya que se forman suspensiones de sólidos que son no sedimentables y no segregables, por lo que el sistema de drenaje y recogida de aguas es mucho menos costoso de construir y mantener. Incluso no será operado en algunas ocasiones, especialmente en la época estival. 
Tabla 8-13: Volúmenes de balsa de estériles para el proyecto Mina de Laza.

\begin{tabular}{|l|c|c|c|}
\hline \multicolumn{1}{|c|}{$\begin{array}{c}\text { Datos de diseño } \\
\text { para balsa de estériles }\end{array}$} & Balsa convencional & $\begin{array}{c}\text { Balsa para } \\
\text { estériles HDT }\end{array}$ & Balsa para pasta \\
\hline Tipo de espesador y operación & Espesador HRT & Espesador HDT & Cono profundo \\
\hline Tonelaje de estériles (sólido seco) & $1.480 .000 \mathrm{t} / \mathrm{año}$ & $1.480 .000 \mathrm{t} / \mathrm{año}$ & $1.480 .000 \mathrm{t} / \mathrm{año}$ \\
\hline$\%$ Sólidos en el hundido & $45 \%$ & $62 \%$ & $68 \%$ \\
\hline Densidad lodos enviados a balsa & $1,370 \mathrm{t} / \mathrm{m}^{3}$ & $1,590 \mathrm{t} / \mathrm{m}^{3}$ & $1,690 \mathrm{t}^{3} \mathrm{~m}^{3}$ \\
\hline Volumen de balsa ocupado & $1.080 .292 \mathrm{~m}^{3} / \mathrm{año}$ & $930.837 \mathrm{~m}^{3} / \mathrm{año}$ & $875.740 \mathrm{~m}^{3} / \mathrm{año}$ \\
\hline Vida útil de la explotación & 10 años & 10 años & 10 años \\
\hline Volumen final balsa & $10.802 .920 \mathrm{~m}^{3}$ & $9.380 .370 \mathrm{~m}^{3}$ & $8.757 .400 \mathrm{~m}^{3}$ \\
\hline
\end{tabular}

(Fuente: Elaboración propia)

Otra ventaja del espesado en pasta es que con elevadas tensiones de fluencia, la pasta permanece inmóvil en pendientes moderadas y el muro de confinamiento puede ser construido de forma más ligera sin riesgos de roturas por empuje de la pasta, siempre y cuando la pendiente de la pasta sea moderada. En el presente estudio no se ha entrado a valorar los costes de construcción o el diseño más apropiado de la balsa para la contención de estériles. Este asunto debe ser tratado posteriormente con un estudio o proyecto específico para esta instalación. Por el momento la tesis doctoral se centra en los equipos de espesado de estériles y no en las instalaciones de almacenamiento que requieren de un estudio más complejo.

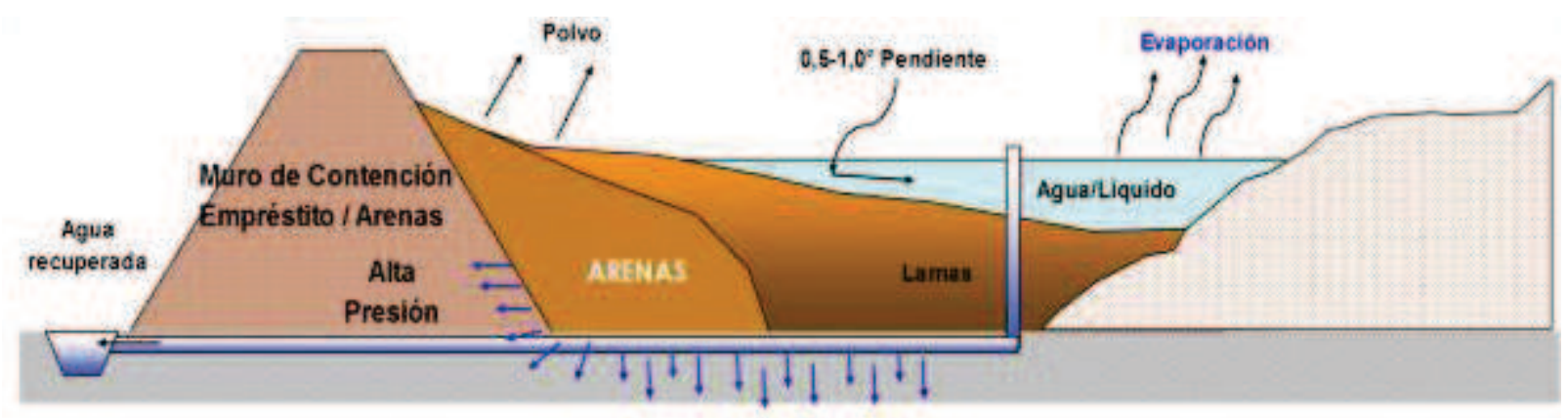

Infiltraciones

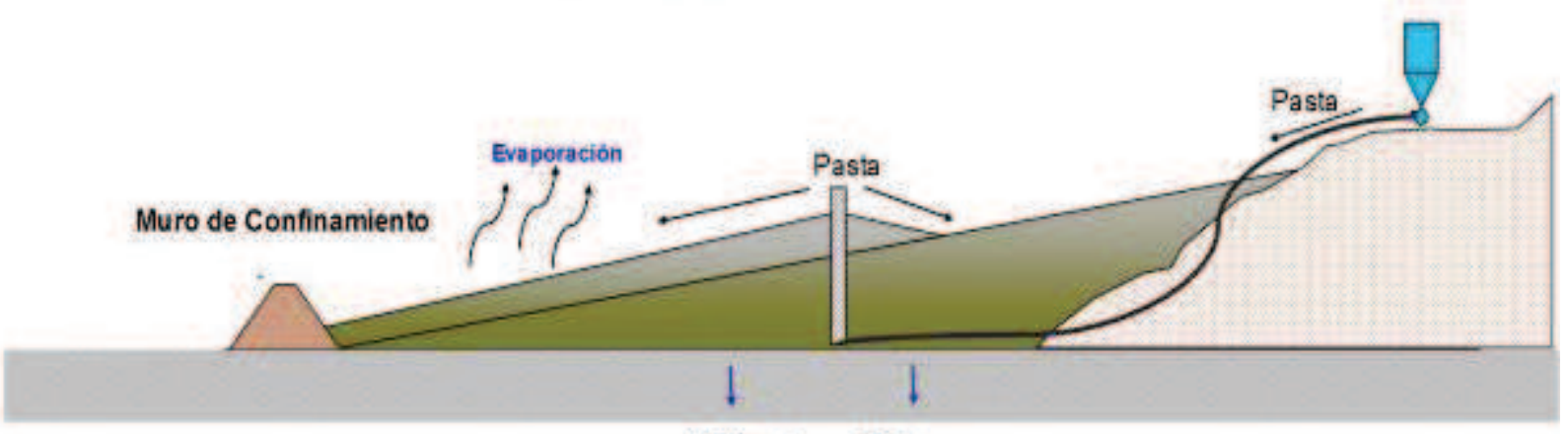

Infiltraciones Minimas

Figura 8-18: Tipos de balsas de estériles.

(Fuente: Elaboración propia) 
Los datos más importantes en el diseño del depósito de estériles son el porcentaje en sólidos esperado, el volumen de estériles espesados y la tensión de fluencia esperada, todos estos datos han sido determinado mediante estudios de laboratorio.

El objetivo de los datos es la evaluación técnica y económica para la construcción de cada uno de los tipos de balsas y almacenamientos en superficie, que requieren de estudios específicos y que se han abordado en el presente trabajo. Este diseño de la balsa o depósito de estériles deberá ser evaluado de forma más detallada en la etapa final del proyecto de la explotación.

\subsection{Costes de capital del proyecto de espesado de estériles del yacimiento de Laza}

Para obtener la estimación de los costes de capital del proyecto, se han establecido una serie de valores y parámetros que se utilizarán a lo largo del estudio económico del proyecto. Los objetivos de los cálculos realizados para los costes de operación y mantenimiento es establecer un estudio económico preliminar de los costes de operación y mantenimiento de los diferentes sistemas de espesado. Para una evaluación posterior mediante el análisis de sensibilidad de los factores clave para el proyecto de espesado, como son el coste de energía, el coste del agua de proceso y el coste de mano de obra entre otros.

En la tabla 8-14: Estimación de costes para el proyecto de tratamiento de estériles; se muestras todas las condiciones y datos económicos preliminares que se han establecido para calcular los costes del proyecto.

Tabla 8-14: Estimación de costes para el proyecto de tratamiento de estériles.

\begin{tabular}{|l|c|}
\hline \multicolumn{1}{|c|}{ Concepto estimado en el proyecto } & Datos \\
\hline Ingeniería básica proyecto y de detalle & $12 \%$ coste \\
\hline Instalación y montaje equipos de proceso & $20 \%$ coste \\
\hline Gastos generales del proyecto & $5 \%$ coste \\
\hline Contingencias del proyecto & $2 \%$ coste \\
\hline Supervisión de montaje y puesta en marcha & Ver tablas \\
\hline Coste de equipos de proceso (año 2013 según suministradores) & $2,5 \%$ \\
\hline Coste anual de mantenimiento equipos (\% del coste de capital) & $165 € / \mathrm{m}^{3}$ \\
\hline Coste hormigón armado HA-25 para construcción (incl. Acero) & $250 € / \mathrm{m}$ \\
\hline Coste tuberías de PEAD 100-200 mm con montaje y soportes & $380 € / \mathrm{m}$ \\
\hline Coste tuberías de PEAD 250-400 mm con montaje y soportes & \\
\hline
\end{tabular}

(Fuente: Elaboración propia)

La componente económica en el estudio de viabilidad es muy importante y para llegar a tener una definición es preciso basar el estudio en toda la información disponible; este volumen de información irá aumentando conforme se vayan concluyendo las sucesivas etapas del proyecto del yacimiento de Laza. En consecuencia un análisis económico puede llevarse a cabo si se efectúan estimaciones de los diferentes costes de capital y operación que conlleva el proyecto de espesado 
de estériles. En el presente trabajo se va a llevar a cabo una estimación proporcional, en la que los costes calculados están basados en el coste de capital de los equipos e instalaciones principales, ya que no se conoce en detalle todos los datos para llevar a cabo una estimación más precisa. E objetivo de este estudio económico es asistir al estudio de viabilidad y a la decisión de la operación de tratamiento de estériles más adecuada al proyecto. Las estimaciones están efectuadas a partir de un modelo conceptual que se ha creado para el diseño de la planta de tratamiento de estériles que se basa en los estudios de laboratorio descritos anteriormente sobre la muestra de estériles del yacimiento de Laza.

Algunos parámetros han sido estimados en base a la experiencia en este tipo de proyectos de espesado de estériles y tratamiento de aguas de proceso, donde los costes de capital de los equipos principales se han tomado de los precios de referencia del año 2014 y de los diferentes suministradores mundiales de equipos y materiales.

Para el estudio económico que se detalla a continuación la precisión está en el orden de $+/-15 \%$; lo que representa una estimación de costes preliminar de acuerdo a la fase en la que se encuentra el proyecto de la mina.

Las contingencias e imprevistos se han cuantificado en un $6 \%$ del coste de capital de los equipos e infraestructuras necesarias para la construcción de la planta de tratamiento de estériles. En una etapa posterior del proyecto se deberán afinar las estimaciones de los costes de capital, especialmente en los capítulos de infraestructuras y construcción de balsas así como de instalaciones auxiliares.

En los puntos siguientes se detallan los costes de capital directos para los tres sistemas estudiados, con baja, media y alta concentración de sólidos en el hundido.

Para todos los casos estudiados se han dividido en varios capítulos los diferentes costes de capital siguiendo un esquema de agrupamiento lógico basado en el diagrama de proceso de cada caso; éstos son:

a) Ingeniería y administración del proyecto

b) Equipos e instalaciones para espesado de estériles

c) Equipos de bombeo de efluente clarificado

d) Equipos de bombeo de lodos

e) Planta de tratamiento de aguas (P.T.A.)

Si bien las instalaciones son casi idénticas en todos los casos, la diferencia de operación y el rendimiento esperado en cada supuesto hace que los costes de capital y operación, así como de algunas instalaciones varíen de forma considerable en función del escenario analizado.

En las siguientes tablas se muestran los costes de capital de cada supuesto en particular:

Tabla 8-15: Costes de capital para el proyecto de espesado en baja densidad

Tabla 8-16: Costes de capital para el proyecto de espesado en alta densidad (HDT)

Tabla 8-17: Costes de capital para el proyecto de espesado en pasta 
Tabla 8-15: Costes de capital para el proyecto de espesado en baja densidad

\begin{tabular}{|c|c|}
\hline PROYECTO ESPESADO BAJA DENSIDAD & $\begin{array}{l}\text { Coste de capital } \\
\text { (EUR) }\end{array}$ \\
\hline \multicolumn{2}{|l|}{ Ingeniería y administración proyecto } \\
\hline Ingeniería básica y de detalle & $918.759,44$ \\
\hline Gastos generales & $382.816,43$ \\
\hline Contingencias & $459.379,72$ \\
\hline Total ingeniería y administración & $1.760 .955,59$ \\
\hline \multicolumn{2}{|l|}{ Equipos para espesado de estériles } \\
\hline Obra civil para espesador 24M diámetro & $153.216,00$ \\
\hline Espesador de $24 \mathrm{M} \times 4 \mathrm{M}$ (completo) & $960.000,00$ \\
\hline Bomba extracción hundido (en operación) 6x4 & $34.500,00$ \\
\hline Bomba extracción hundido (en reserva) 6x4 & $34.500,00$ \\
\hline Bomba de pocillo (vertical) 4" & $15.900,00$ \\
\hline Estación preparación de floculante para $150 \mathrm{~g} / \mathrm{t}$ & $68.500,00$ \\
\hline Instalación eléctrica & $38.000,00$ \\
\hline Instrumentación y control & $21.000,00$ \\
\hline Instalación y montaje de equipos & $265.123,20$ \\
\hline Supervisión montaje y puesta en marcha de equipos & $26.512,32$ \\
\hline Total espesado estériles & $1.617 .251,52$ \\
\hline \multicolumn{2}{|l|}{ Equipos de bombeo de efluente clarificado } \\
\hline Tanque almacenamiento $100 \mathrm{~m} 3$ & $78.350,00$ \\
\hline Bomba de agua para envío a P.T.Aguas $8 \times 6$ & $39.200,00$ \\
\hline Bomba de agua para envío a P.T.Aguas (en reserva) $8 \times 6$ & $39.200,00$ \\
\hline Tubería PE 300 mm - 25m & $9.500,00$ \\
\hline Instalación eléctrica & $9.000,00$ \\
\hline Instrumentación y control & $6.000,00$ \\
\hline Instalación y montaje de equipos & $36.250,00$ \\
\hline Supervisión y puesta en marcha de equipos & $3.625,00$ \\
\hline Total equipos de bombeo de efluente clarificado & 221.125,00 \\
\hline \multicolumn{2}{|l|}{ Equipos de bombeo lodos } \\
\hline Obra civil & $26.000,00$ \\
\hline Tanque de bombeo $50 \mathrm{~m} 3$ con agitador & $25.000,00$ \\
\hline Bomba de envío de lodos a balsa $8 \times 6$ & $39.200,00$ \\
\hline Bomba de envío de lodos a balsa (reserva) 8x6 & $39.200,00$ \\
\hline Tubería PE 200 mm - 300M & $75.000,00$ \\
\hline Instalación eléctrica & $19.250,00$ \\
\hline Instrumentación y control & $6.000,00$ \\
\hline Instalación y montaje de equipos & $45.930,00$ \\
\hline Supervisión y puesta en marcha de equipos & $4.593,00$ \\
\hline Total equipos de bombeo de lodos & $280.173,00$ \\
\hline \multicolumn{2}{|l|}{ Balsa de estériles } \\
\hline Construcción y obra civil presa de confinamiento & $3.388 .000,00$ \\
\hline Bomba de envío de agua recuperada a P.T.Aguas $6 \times 4$ & $38.500,00$ \\
\hline Bomba de envío de agua recuperada a P.T.Aguas (reserva) & $38.500,00$ \\
\hline Tubería PE 150 mm - 300M & $75.000,00$ \\
\hline Instalación y montaje de equipos & $708.000,00$ \\
\hline Supervisión y puesta en marcha de equipos & $84.960,00$ \\
\hline Total balsa estériles & $4.248 .000,00$ \\
\hline \multicolumn{2}{|l|}{ Planta de tratamiento de aguas (PTA) } \\
\hline Obra civil para Reactor-Clarificador 16M diámetro & $68.096,00$ \\
\hline Reactor-Clarificador de $16 \mathrm{M} \times 5 \mathrm{M}$ (completo) & $545.000,00$ \\
\hline Bomba extracción hundido (en operación) 4×3 & $19.500,00$ \\
\hline Bomba extracción hundido (en reserva) $4 \times 3$ & $19.500,00$ \\
\hline Tubería PE 100 mm - 50M & $12.500,00$ \\
\hline Bomba de pocillo (vertical) 4" & $15.900,00$ \\
\hline Almacenamiento y dosificación de reactivos & $63.000,00$ \\
\hline Tanque de agitación para reactivos (cal)-6 m3 & $16.000,00$ \\
\hline Tanque de agitación para reactivos (reactivos) -6 m3 & $16.000,00$ \\
\hline Bombas e instalación para reactivos & $12.500,00$ \\
\hline Tanque almacenamiento agua clarificada $200 \mathrm{~m} 3$ & $92.000,00$ \\
\hline Bomba de agua para envío a proceso $10 \times 8$ & $53.600,00$ \\
\hline Bomba de agua para envío a proceso (en reserva) 10x8 & $53.600,00$ \\
\hline Tubería PE 300 mm - 50M & $19.000,00$ \\
\hline Instalación eléctrica & $42.000,00$ \\
\hline Instrumentación y control & $9.000,00$ \\
\hline Instalación y montaje de equipos & $211.439,20$ \\
\hline Supervisión y puesta en marcha de equipos & $21.143,92$ \\
\hline Total planta de tratamiento de aguas & $1.289 .779,12$ \\
\hline Total proyecto & $9.417 .284,23$ \\
\hline
\end{tabular}

(Fuente: Elaboración propia) 
Tabla 8-16: Costes de capital para el proyecto de espesado en alta densidad (HDT)

\begin{tabular}{|c|c|}
\hline PROYECTO ESPESADO ALTA DENSIDAD (HDT) & $\begin{array}{r}\text { Coste de capital } \\
\text { (EUROS) }\end{array}$ \\
\hline \multicolumn{2}{|l|}{ Ingeniería y administración proyecto } \\
\hline Ingeniería básica y de detalle & $806.080,07$ \\
\hline Gastos generales & $335.866,70$ \\
\hline Contingencias & $403.040,04$ \\
\hline Total ingeniería y administración & $1.544 .986,80$ \\
\hline \multicolumn{2}{|l|}{ Equipos para espesado de estériles } \\
\hline Obra civil para espesador HDT 14M diámetro & $65.340,00$ \\
\hline Espesador de $14 \mathrm{M} \times 6.50 \mathrm{M}$ (completo) & $1.560 .000,00$ \\
\hline Bomba extracción hundido (en operación) 6x4 & $31.250,00$ \\
\hline Bomba extracción hundido (en reserva) $6 \times 4$ & $31.250,00$ \\
\hline Bomba de pocillo (vertical) 4" & $15.900,00$ \\
\hline Estación preparación de floculante para $150 \mathrm{~g} / \mathrm{t}$ & $68.500,00$ \\
\hline Instalación eléctrica & $43.400,00$ \\
\hline Instrumentación y control & $32.350,00$ \\
\hline Instalación y montaje de equipos & $369.598,00$ \\
\hline Supervisión montaje y puesta en marcha de equipos & $36.959,80$ \\
\hline Total espesado estériles & 2.254.547,80 \\
\hline \multicolumn{2}{|l|}{ Equipos de bombeo de efluente clarificado } \\
\hline Tanque almacenamiento $100 \mathrm{~m} 3$ & $78.350,00$ \\
\hline Bomba de agua para envío a P.T.Aguas $8 \times 6$ & $29.500,00$ \\
\hline Bomba de agua para envío a P.T.Aguas (en reserva) $8 \times 6$ & $29.500,00$ \\
\hline Tubería PE 150 mm - 50M & $12.500,00$ \\
\hline Instalación eléctrica & $9.000,00$ \\
\hline Instrumentación y control & $6.000,00$ \\
\hline Instalación y montaje de equipos & $32.970,00$ \\
\hline Supervisión y puesta en marcha de equipos & $3.297,00$ \\
\hline Total equipos de bombeo de efluente clarificado & $201.117,00$ \\
\hline \multicolumn{2}{|l|}{ Equipos de bombeo lodos } \\
\hline Obra civil & $26.000,00$ \\
\hline Tanque de bombeo $50 \mathrm{~m} 3$ con agitador & $25.000,00$ \\
\hline Bomba de envío de lodos a balsa centrífuga $8 \times 6$ & $41.500,00$ \\
\hline Bomba de envío de lodos a balsa centrífuga (reserva) $8 \times 6$ & $41.500,00$ \\
\hline Tubería PE 200 mm - 300M & $75.000,00$ \\
\hline Instalación eléctrica & $38.000,00$ \\
\hline Instrumentación y control & $9.500,00$ \\
\hline Instalación y montaje de equipos & $51.300,00$ \\
\hline Supervisión y puesta en marcha de equipos & $5.130,00$ \\
\hline Total equipos de bombeo de lodos & $312.930,00$ \\
\hline \multicolumn{2}{|l|}{ Balsa de estériles } \\
\hline Construcción y obra civil presa de confinamiento & $2.094 .400,00$ \\
\hline Bomba de envío de agua recuperada a P.T.Aguas $4 \times 3$ & $23.200,00$ \\
\hline Bomba de envío de agua recuperada a P.T.Aguas (reserva) $4 \times 3$ & $23.200,00$ \\
\hline Tubería PE 75 mm - 300M & $75.000,00$ \\
\hline Instalación y montaje de equipos & $443.160,00$ \\
\hline Supervisión y puesta en marcha de equipos & $53.179,20$ \\
\hline Total balsa estériles & 2.658.960,00 \\
\hline \multicolumn{2}{|l|}{ Planta de tratamiento de aguas (PTA) } \\
\hline Obra civil para Reactor-Clarificador $16 \mathrm{M}$ diámetro & $68.096,00$ \\
\hline Reactor-Clarificador de $16 \mathrm{M} \times 5 \mathrm{M}$ (completo) & $545.000,00$ \\
\hline Bomba extracción hundido (en operación) 4x3 & $19.500,00$ \\
\hline Bomba extracción hundido (en reserva) $4 \times 3$ & $19.500,00$ \\
\hline Tubería PE 100 mm - 50M & $12.500,00$ \\
\hline Bomba de pocillo (vertical) 4" & $15.900,00$ \\
\hline Almacenamiento y dosificación de reactivos & $63.000,00$ \\
\hline Tanque de agitación para reactivos (cal)-6 m3 & $16.000,00$ \\
\hline Tanque de agitación para reactivos (cloruro férrico) - 6 m3 & $16.000,00$ \\
\hline Bombas e instalación para reactivos & $12.500,00$ \\
\hline Tanque almacenamiento agua clarificada $200 \mathrm{~m} 3$ & $92.000,00$ \\
\hline Bomba de agua para envío a proceso $10 \times 8$ & $53.600,00$ \\
\hline Bomba de agua para envío a proceso (en reserva) $10 \times 8$ & $53.600,00$ \\
\hline Tubería PE $300 \mathrm{~mm}-50 \mathrm{M}$ & $19.000,00$ \\
\hline Instalación eléctrica & $42.000,00$ \\
\hline Instrumentación y control & $9.000,00$ \\
\hline Instalación y montaje de equipos & $211.439,20$ \\
\hline Supervisión y puesta en marcha de equipos & $21.143,92$ \\
\hline Total planta de tratamiento de aguas & $1.289 .779,12$ \\
\hline Total proyecto & $8.262 .320,72$ \\
\hline
\end{tabular}


Tabla 8-17: Costes de capital para el proyecto de espesado en pasta

\author{
Ingeniería y administración proyecto \\ Ingeniería básica y de detalle \\ Gastos generales \\ Contingencias
}

PROYECTO ESPESADO ALTA DENSIDAD (PASTA)

Equipos para espesado de estériles

Obra civil para espesador Cono 14M diámetro

Espesador de $14 \mathrm{M} \times 10.50 \mathrm{M}$ (completo)

Bomba extracción hundido (en operación) $6 \times 4$

Bomba extracción hundido (en reserva) $6 \times 4$

Bomba de recirculación de lodos (en operación) $6 \times 4$

Bomba de recirculación de lodos (en reserva) 6x4

Bomba de pocillo (vertical) 4"

Estación preparación de floculante para $150 \mathrm{~g} / \mathrm{t}$

Instalación eléctrica

Instrumentación y control

Instalación y montaje de equipos

Supervisión montaje y puesta en marcha de equipos

Equipos de bombeo de efluente clarificado

Total espesado estériles

Tanque almacenamiento $100 \mathrm{~m} 3$

Bomba de agua para envío a P.T.Aguas $8 \times 6$

Bomba de agua para envío a P.T.Aguas (en reserva) $8 \times 6$

Tubería PE $150 \mathrm{~mm}$ - 50M

Instalación eléctrica

Instrumentación y control

Instalación y montaje de equipos

Supervisión y puesta en marcha de equipos

Equipos de bombeo lodos

Total equipos de bombeo de efluente clarificado

Obra civil

Tanque de bombeo $50 \mathrm{~m} 3$ con agitador

Bomba de envío de lodos a balsa centrífuga $8 \times 6$

Bomba de envío de lodos a balsa centrífuga (reserva) $8 \times 6$

Tubería PE 200 mm - 300M

Instalación eléctrica

Instrumentación y control

Instalación y montaje de equipos

Supervisión y puesta en marcha de equipos

Balsa de estériles

Total equipos de bombeo de lodos

Construcción y obra civil presa de confinamiento

Bomba de envío de agua recuperada a P.T.Aguas $4 \times 3$

Bomba de envío de agua recuperada a P.T.Aguas (reserva) $4 \times 3$

Tubería PE $75 \mathrm{~mm}$ - 300M

Instalación y montaje de equipos

Supervisión y puesta en marcha de equipos

Planta de tratamiento de aguas (PTA)

Total balsa estériles

Obra civil para Reactor-Clarificador 16M diámetro

Reactor-Clarificador de 16M x 5M (completo)

Bomba extracción hundido (en operación) $4 \times 3$

Bomba extracción hundido (en reserva) $4 \times 3$

Tubería PE $100 \mathrm{~mm}$ - 50M

Bomba de pocillo (vertical) 4"

Almacenamiento y dosificación de reactivos

Tanque de agitación para reactivos (cal)- $6 \mathrm{~m} 3$

Tanque de agitación para reactivos (cloruro férrico) - $6 \mathrm{~m} 3$

Bombas e instalación para reactivos

Tanque almacenamiento agua clarificada $200 \mathrm{~m} 3$

Bomba de agua para envío a proceso $10 \times 8$

Bomba de agua para envío a proceso (en reserva) 10x8

Tubería PE $300 \mathrm{~mm}$ - 50M

Instalación eléctrica

Instrumentación y control

Instalación y montaje de equipos

Supervisión y puesta en marcha de equipos

Total planta de tratamiento de aguas

Total proyecto
Coste de capital

(EUROS)

$888.407,35$

$370.169,73$

$444.203,68$

$1.702 .780,76$

$71.875,00$

$2.054 .000,00$

$31.250,00$

$31.250,00$

$32.500,00$

$32.500,00$

$15.900,00$

$68.500,00$

$43.400,00$

$32.350,00$

$482.705,00$

$48.270,50$

2.944.500,50

$78.350,00$

$29.500,00$

$29.500,00$

$12.500,00$

$9.000,00$

$6.000,00$

$32.970,00$

$3.297,00$

201.117,00

$26.000,00$

$25.000,00$

$43.200,00$

$43.200,00$

$75.000,00$

$38.000,00$

$9.500,00$

$51.980,00$

$5.198,00$

$317.078,00$

2.094.400,00

$22.900,00$

$22.900,00$

$75.000,00$

$443.040,00$

$53.164,80$

2.658.240,00

$68.096,00$

$545.000,00$

$16.500,00$

$16.500,00$

$12.500,00$

$15.900,00$

$63.000,00$

$16.000,00$

$16.000,00$

$12.500,00$

$92.000,00$

$53.600,00$

$53.600,00$

$19.000,00$

$42.000,00$

$9.000,00$

$210.239,20$

$21.023,92$

$1.282 .459,12$

$9.106 .175,38$

(Fuente: Elaboración propia) 
En resumen, los costes de capital por tonelada de estéril tratada con el sistema propuesto se resume en la tabla 8-18: Costes de capital: Resumen.

Tabla 8-18: Costes de capital: Resumen.

\begin{tabular}{|c|c|c|c|c|}
\hline $\begin{array}{l}\text { Proyecto de Laza. } \\
\text { Sistema de espesado. }\end{array}$ & $\begin{array}{c}\text { Costes capital } \\
\text { EUROS }\end{array}$ & $\begin{array}{c}\text { Vida de la mina } \\
\text { Años }\end{array}$ & $\begin{array}{c}\text { Tonelaje } \\
\text { estéril } \\
\text { (t/año) }\end{array}$ & $\begin{array}{c}\text { Coste } \\
\text { anual } \\
€ / \text { estéril }\end{array}$ \\
\hline Espesado baja densidad HRT & 9.417 .284 & 10 & 1.480 .000 & 0,64 \\
\hline Espesado alta densidad HDT & 8.262 .320 & 10 & 1.480 .000 & 0,56 \\
\hline Espesado alta densidad. Pasta. & 9.106 .175 & 10 & 1.480 .000 & 0,62 \\
\hline
\end{tabular}

Como se comprueba, en el proyecto de espesado con alta densidad y de espesado en pasta, los costes de tonelada de estériles tratada son inferiores al proceso con estériles de baja densidad y balsa convencional.

\subsection{Costes de operación para la planta de espesado de estériles Laza-Orense}

Se analizan a continuación los costes relacionados con la operación de los equipos que componen cada uno de los proyectos. Se analizan cada uno de los costes que representan la operación de la planta:

a) Consumos de agua y coste por tonelada tratada

b) Consumo de energía y coste por tonelada

c) Consumo de floculante y coste por tonelada

\subsubsection{Consumo de agua y coste por tonelada}

El consumo de agua de proceso de la planta varía dependiendo del escenario de espesado que se analice. Partiendo de unas necesidades de la planta igual al caudal de agua que proviene de la alimentación al espesador de estériles, se ha calculado la cantidad de agua consumida en cada operación y que es necesario aportar. El consumo de agua de cada sistema de espesado se representa en la tabla 8-19: Consumo de agua en la operación de espesado de estériles; donde se evalúan tanto el consumo como la recuperación de agua en cada supuesto.

Para este estudio preliminar no se ha tenido en cuenta el balance hídrico de la región donde se ubica el proyecto. Este balance de agua en la zona de la mina debe ser tenido en cuenta en una etapa posterior del proyecto, una vez definido el sistema de espesado de estériles propuesto para el proyecto.

La tabla 8-19 muestra los cálculos obtenidos para el consumo de agua teniendo en cuenta las pérdidas por deposición de estériles debido a las pérdidas de agua contenida en la pasta y no por evaporación que no se han evaluado en esta fase del proyecto. Como era de esperar, los datos indican que hay un decrecimiento en el consumo de agua de proceso a medida que la densidad 
del hundido se incrementa. El peor escenario se supone que será en verano, ya que el consumo se incrementa por la falta de precipitaciones.

Tabla 8-19: Consumo de agua en la operación de espesado de estériles.

\begin{tabular}{|c|c|c|c|c|c|c|}
\hline $\begin{array}{c}\text { Proyecto } \\
\text { Sistema de espesado }\end{array}$ & $\begin{array}{l}\text { Agua de } \\
\text { proceso }\end{array}$ & $\begin{array}{c}\text { Agua } \\
\text { recuperada }\end{array}$ & $\begin{array}{l}\text { Aporte } \\
\text { agua }\end{array}$ & $\begin{array}{l}\text { Coste del } \\
\text { agua }\end{array}$ & $\begin{array}{c}\text { Coste del } \\
\text { agua }\end{array}$ & $\begin{array}{c}\text { Coste del } \\
\text { agua }\end{array}$ \\
\hline & $(\mathrm{m} 3 / \mathrm{h})$ & $(\mathrm{m} 3 / \mathrm{h})$ & $(\mathrm{m} 3 / \mathrm{h})$ & $€ /$ hora op. & $€ / a n ̃ o$ & $€ /$ t estéril \\
\hline Espesado baja densidad HRT & 655,9 & 553,5 & 102,40 & 100,35 & $802.816,00$ & 0,54 \\
\hline Espesado alta densidad HDT & 655,9 & 553,9 & 102,00 & 99,96 & $799.680,00$ & 0,54 \\
\hline Espesado alta densidad. Pasta. & 655,9 & 558,7 & 97,20 & 95,26 & $762.048,00$ & 0,51 \\
\hline
\end{tabular}

(Fuente: Elaboración propia)

\subsubsection{Consumo de energía y coste por tonelada}

Se han estimado las potencias instaladas en toda la planta de tratamiento de estériles y en la planta de tratamiento de aguas. Al existir bombas y equipos en reserva, para el consumo de energía en operación no se ha contemplado la potencia instalada de los equipos en reserva.

Los costes relacionados con el consumo de energía se muestran en las siguientes tablas:

a) Tabla 8-20: Potencias y consumos eléctricos para un sistema de baja densidad.

b) Tabla 8-21: Potencias y consumos eléctricos para un sistema de media densidad (HDT).

c) Tabla 8-22: Potencias y consumos eléctricos para un sistema de alta densidad. Pasta.

El consumo de energía por tonelada depositada para cada uno de los escenarios propuestos está dado en las tablas 8-20, 8-21 y 8-22. El caso de estériles de media densidad es el de energía más eficiente, mientras que el de baja densidad o convencional es el menos eficiente. Es evidente que tanto la densidad de la pulpa y los caudales que se deben de transportar juegan un papel importante en determinar la opción más eficiente, ya que existen grandes distancias de bombeo en cada uno de los tres supuestos. 
Tabla 8-20: Potencias y consumos eléctricos para un sistema de baja densidad.

\begin{tabular}{|c|c|c|c|}
\hline PROYECTO ESPESADO BAJA DENSIDAD & $\begin{array}{l}\text { Potencia total } \\
\text { inst. } \\
(\mathrm{kW})\end{array}$ & $\begin{array}{c}\text { Potencia } \\
\text { operación } \\
(\mathrm{kW})\end{array}$ & $\begin{array}{c}\text { Consumo } \\
\text { eléctrico } \\
\text { (kWh) }\end{array}$ \\
\hline \multicolumn{4}{|l|}{ Equipos para espesado de estériles } \\
\hline Espesador de $24 \mathrm{M} \times 4 \mathrm{M}$ (completo) & 7,00 & 7,00 & 5,60 \\
\hline Bomba extracción hundido (en operación) $6 \times 4$ & 55,00 & 55,00 & 44,00 \\
\hline Bomba extracción hundido (en reserva) 6x4 & 55,00 & 0,00 & 0,00 \\
\hline Bomba de pocillo (vertical) 4" & 7,50 & 7,50 & 6,00 \\
\hline Estación preparación de floculante para $150 \mathrm{~g} / \mathrm{t}$ & 15,00 & 15,00 & 12,00 \\
\hline \multicolumn{3}{|l|}{ Equipos de bombeo de efluente clarificado } & 67,60 \\
\hline Bomba de agua para envío a P.T.Aguas $8 \times 6$ & 90,00 & 90,00 & 72,00 \\
\hline Bomba de agua para envío a P.T.Aguas (en reserva) $8 \times 6$ & 90,00 & 0,00 & 0,00 \\
\hline $\begin{array}{l}\text { Total equipos de bombeo de efluente clarificado } \\
\text { Equipos de bombeo lodos }\end{array}$ & 180,00 & 90,00 & 72,00 \\
\hline Tanque de bombeo $50 \mathrm{~m} 3$ con agitador & 75,00 & 75,00 & 60,00 \\
\hline Bomba de envío de lodos a balsa $8 \times 6$ & 90,00 & 90,00 & 72,00 \\
\hline Bomba de envío de lodos a balsa (reserva) $8 \times 6$ & 90,00 & 0,00 & 0,00 \\
\hline $\begin{array}{ll}\text { Balsa de estériles } & \text { Total equipos de bombeo de lodos }\end{array}$ & 255,00 & 165,00 & 132,00 \\
\hline Bomba de envío de agua recuperada a P.T.Aguas $6 \times 4$ & 150,00 & 150,00 & 120,00 \\
\hline Bomba de envío de agua recuperada a P.T.Aguas (reserva) & 150,00 & 0,00 & 0,00 \\
\hline $\begin{array}{ll}\text { Planta de tratamiento de aguas (PTA) } & \text { Total balsa estériles }\end{array}$ & 300,00 & 150,00 & 120,00 \\
\hline Reactor-Clarificador de $16 \mathrm{M} \times 5 \mathrm{M}$ (completo) & 3,30 & 3,3 & 2,64 \\
\hline Bomba extracción hundido (en operación) $4 \times 3$ & 5,50 & 5,5 & 4,40 \\
\hline Bomba extracción hundido (en reserva) $4 \times 3$ & 5,50 & 0 & 0,00 \\
\hline Bomba de pocillo (vertical) 4" & 7,50 & 7,5 & 6,00 \\
\hline Almacenamiento y dosificación de reactivos & 10,00 & 10 & 8,00 \\
\hline Tanque de agitación para reactivos (cal)-6 m3 & 7,50 & 7,5 & 6,00 \\
\hline Tanque de agitación para reactivos (coagulante) - $6 \mathrm{~m} 3$ & 7,50 & 7,5 & 6,00 \\
\hline Bombas e instalación para reactivos & 5,50 & 5,5 & 4,40 \\
\hline Bomba de agua para envío a proceso $10 \times 8$ & 150,00 & 150 & 120,00 \\
\hline Bomba de agua para envío a proceso (en reserva) $10 \times 8$ & 150,00 & 0 & 0,00 \\
\hline Total planta de tratamiento de aguas & 352,30 & 196,80 & 157,44 \\
\hline Total proyecto & 1226,80 & 686,30 & 549,04 \\
\hline
\end{tabular}

(Fuente: Elaboración propia) 
Tabla 8-21: Potencias y consumos eléctricos para un sistema de media densidad (HDT).

\begin{tabular}{|c|c|c|c|}
\hline \multicolumn{4}{|l|}{ CONSUMOS ELÉCTRICOS } \\
\hline PROYECTO ESPESADO ALTA DENSIDAD (HDT) & $\begin{array}{c}\text { Potencia total } \\
\text { inst. } \\
\text { (kW) }\end{array}$ & $\begin{array}{c}\text { Potencia operación } \\
(\mathrm{kW})\end{array}$ & $\begin{array}{c}\text { Consumo eléctrico } \\
(\mathrm{kWh})\end{array}$ \\
\hline \multicolumn{4}{|l|}{ Equipos para espesado de estériles } \\
\hline Espesador de $14 \mathrm{M} \times 10.50 \mathrm{M}$ (completo) & 11,00 & 11,00 & 8,80 \\
\hline Bomba extracción hundido (en operación) 4×3 & 37,00 & 37,00 & 29,60 \\
\hline Bomba extracción hundido (en reserva) $4 \times 3$ & 37,00 & 0,00 & 0,00 \\
\hline Bomba de recirculación de lodos (en operación) $6 \times 4$ & 55,00 & 55,00 & 44,00 \\
\hline Bomba de recirculación de lodos (en reserva) $6 \times 4$ & 55,00 & 0,00 & 0,00 \\
\hline Bomba de pocillo (vertical) 4" & 7,50 & 7,50 & 6,00 \\
\hline Estación preparación de floculante para $150 \mathrm{~g} / \mathrm{t}$ & 15,00 & 15,00 & 12,00 \\
\hline Total espesado estériles & 217,50 & 125,50 & 100,40 \\
\hline \multicolumn{4}{|l|}{ Equipos de bombeo de efluente clarificado } \\
\hline Bomba de agua para envío a P.T.Aguas $8 \times 6$ & 90,00 & 90,00 & 72,00 \\
\hline Bomba de agua para envío a P.T.Aguas (en reserva) $8 \times 6$ & 90,00 & 0,00 & 0,00 \\
\hline Total equipos de bombeo de efluente clarificado & 180,00 & 90,00 & 72,00 \\
\hline \multicolumn{4}{|l|}{ Equipos de bombeo lodos } \\
\hline Tanque de bombeo $50 \mathrm{~m} 3$ con agitador & 75,00 & 75,00 & 60,00 \\
\hline Bomba de envío de lodos a balsa centrífuga $8 \times 6$ & 110,00 & 110,00 & 88,00 \\
\hline Bomba de envío de lodos a balsa centrífuga (reserva) $8 \times 6$ & 110,00 & 0,00 & 0,00 \\
\hline Total equipos de bombeo de lodos & 295,00 & 185,00 & 148,00 \\
\hline \multicolumn{4}{|l|}{ Balsa de estériles } \\
\hline Bomba de envío de agua recuperada a P.T.Aguas $4 \times 3$ & 15,00 & 15,00 & 12,00 \\
\hline Bomba de envío de agua recuperada a P.T.Aguas (reserva) $4 \times 3$ & 15,00 & 0,00 & 0,00 \\
\hline Total balsa estériles & 30,00 & 15,00 & 12,00 \\
\hline \multicolumn{4}{|l|}{ Planta de tratamiento de aguas (PTA) } \\
\hline Reactor-Clarificador de 16M x 5M (completo) & 3,30 & 3,30 & 2,64 \\
\hline Bomba extracción hundido (en operación) 4x3 & 22,00 & 22,00 & 17,60 \\
\hline Bomba extracción hundido (en reserva) $4 \times 3$ & 22,00 & 0,00 & 0,00 \\
\hline Bomba de pocillo (vertical) 4" & 7,50 & 7,50 & 6,00 \\
\hline Almacenamiento y dosificación de reactivos & 10,00 & 10,00 & 8,00 \\
\hline Tanque de agitación para reactivos (cal)-6 m3 & 7,50 & 7,50 & 6,00 \\
\hline Tanque de agitación para reactivos (cloruro férrico) - 6 m3 & 7,50 & 7,50 & 6,00 \\
\hline Bombas e instalación para reactivos & 5,50 & 5,50 & 4,40 \\
\hline Bomba de agua para envío a proceso $10 \times 8$ & 150,00 & 150,00 & 120,00 \\
\hline Bomba de agua para envío a proceso (en reserva) $10 \times 8$ & 150,00 & 0,00 & 0,00 \\
\hline Total planta de tratamiento de aguas & 385,30 & 213,30 & 170,64 \\
\hline Total consumos y potencias del proyecto & 1107,80 & 628,80 & 503,04 \\
\hline
\end{tabular}


Tabla 8-22: Potencias y consumos eléctricos para un sistema de alta densidad. Pasta.

\begin{tabular}{|c|c|c|c|}
\hline PROYECTO ESPESADO ALTA DENSIDAD (PASTA) & $\begin{array}{c}\text { Potencia } \\
\text { inst. } \\
(\mathrm{kW})\end{array}$ & $\begin{array}{l}\text { Potencia operación } \\
\qquad(\mathrm{kW})\end{array}$ & $\begin{array}{c}\text { Consumo eléctrico } \\
(\mathrm{kWh})\end{array}$ \\
\hline \multicolumn{4}{|l|}{ Equipos para espesado de estériles } \\
\hline Espesador de $14 \mathrm{M} \times 10.50 \mathrm{M}$ (completo) & 16,50 & 16,50 & 13,20 \\
\hline Bomba extracción hundido (en operación) 4x3 & 37,00 & 37,00 & 29,60 \\
\hline Bomba extracción hundido (en reserva) $4 \times 3$ & 37,00 & 0,00 & 0,00 \\
\hline Bomba de recirculación de lodos (en operación) 6x4 & 55,00 & 55,00 & 44,00 \\
\hline Bomba de recirculación de lodos (en reserva) 6x4 & 55,00 & 0,00 & 0,00 \\
\hline Bomba de pocillo (vertical) 4" & 7,50 & 7,50 & 6,00 \\
\hline Estación preparación de floculante para $150 \mathrm{~g} / \mathrm{t}$ & 15,00 & 15,00 & 12,00 \\
\hline Total espesado estériles & 223,00 & 131,00 & 104,80 \\
\hline \multicolumn{4}{|l|}{ Equipos de bombeo de efluente clarificado } \\
\hline Bomba de agua para envío a P.T.Aguas $8 \times 6$ & 90,00 & 90,00 & 72,00 \\
\hline Bomba de agua para envío a P.T.Aguas (en reserva) $8 \times 6$ & 90,00 & 0,00 & 0,00 \\
\hline \multicolumn{3}{|l|}{ Equipos de bombeo lodos } & 72,00 \\
\hline Tanque de bombeo $50 \mathrm{~m} 3$ con agitador & 75,00 & 75,00 & 60,00 \\
\hline Bomba de envío de lodos a balsa centrífuga $8 \times 6$ & 150,00 & 150,00 & 120,00 \\
\hline Bomba de envío de lodos a balsa centrífuga (reserva) $8 \times 6$ & 150,00 & 0,00 & 0,00 \\
\hline 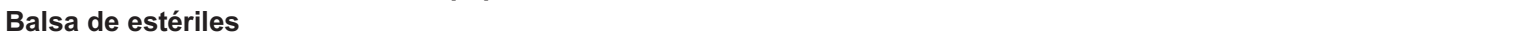 & 375,00 & 225,00 & 180,00 \\
\hline Bomba de envío de agua recuperada a P.T.Aguas $6 \times 4$ & 11,00 & 11,00 & 8,80 \\
\hline Bomba de envío de agua recuperada a P.T.Aguas (reserva) & 11,00 & 0,00 & 0,00 \\
\hline Total balsa estériles & 22,00 & 11,00 & 8,80 \\
\hline \multicolumn{4}{|l|}{ Planta de tratamiento de aguas (PTA) } \\
\hline Reactor-Clarificador de $16 \mathrm{M}$ x 5M (completo) & 3,30 & 3,30 & 2,64 \\
\hline Bomba extracción hundido (en operación) 4×3 & 22,00 & 22,00 & 17,60 \\
\hline Bomba extracción hundido (en reserva) $4 \times 3$ & 22,00 & 0,00 & 0,00 \\
\hline Bomba de pocillo (vertical) 4" & 7,50 & 7,50 & 6,00 \\
\hline Almacenamiento y dosificación de reactivos & 10,00 & 10,00 & 8,00 \\
\hline Tanque de agitación para reactivos (cal)-6 m3 & 7,50 & 7,50 & 6,00 \\
\hline Tanque de agitación para reactivos (cloruro férrico) -6 m3 & 7,50 & 7,50 & 6,00 \\
\hline Bombas e instalación para reactivos & 5,50 & 5,50 & 4,40 \\
\hline Bomba de agua para envío a proceso $10 \times 8$ & 150,00 & 150,00 & 120,00 \\
\hline Bomba de agua para envío a proceso (en reserva) 10x8 & 150,00 & 0,00 & 0,00 \\
\hline Total planta de tratamiento de aguas & 385,30 & 213,30 & 170,64 \\
\hline Total proyecto & 1185,30 & 670,30 & 536,24 \\
\hline
\end{tabular}

(Fuente: Elaboración propia)

El consumo de energía por tonelada depositada para cada uno de los escenarios propuestos y a la vista de los datos de las tablas anteriores, se puede concluir que el caso de estériles de media densidad es el de energía más eficiente, mientras que el de baja densidad es el menos eficiente y de mayor consumo energético. Como se ha comentado con anterioridad la topografía del terreno y las distancias de bombeo juegan un papel muy importante en el coste energético de cada uno de los sistemas. En la tabla 8-23: Consumo eléctrico y coste anual; se muestran por cada tipo de proyecto los consumos unitarios y costes anuales de la energía eléctrica. Como se puede comprobar los escenarios propuestos de espesado en alta densidad o en forma de pasta son claramente más eficientes que el método convencional. 
Tabla 8-23: Consumo eléctrico y coste anual

\begin{tabular}{|lcccc|}
\hline Proyecto. Sistema de espesado. & $\begin{array}{c}\text { Consumo } \\
\text { operación } \\
\mathbf{( k W h )}\end{array}$ & $\begin{array}{c}\text { Consumo unitario } \\
\mathbf{( k W h / t} \text { estéril) }\end{array}$ & $\begin{array}{c}\text { Coste } \\
\text { unitario } \\
\text { (€/t estéril) }\end{array}$ & $\begin{array}{c}\text { Coste anual } \\
\text { (€/año) }\end{array}$ \\
Espesado baja densidad HRT & 549,04 & 2,97 & 0,49 & $724.732,80$ \\
Espesado alta densidad HDT & 503,04 & 2,72 & 0,45 & $664.012,80$ \\
Espesado alta densidad. Pasta. & 536,24 & 2,90 & 0,48 & $707.836,80$ \\
\hline
\end{tabular}

\subsubsection{Consumo de floculante}

El consumo de floculante para cada una de las alternativas propuestas está condicionado por los resultados que se han obtenido en las pruebas de sedimentación realizadas en el laboratorio. Se ha estimado un consumo de floculante de $30 \mathrm{~g} / \mathrm{t}$ de sólido para el sistema de espesado convencional y de $45 \mathrm{~g} / \mathrm{t}$ para los sistemas de alta densidad. Con estos datos preliminares y el coste en $€ / \mathrm{kg}$ de estos reactivos, se han obtenido los consumos unitarios y el coste del floculante en los diversos sistemas de operación propuestos, como se puede comprobar en la tabla 8-24: Consumo de floculante y coste anual.

Tabla 8-24: Consumo de floculante y coste anual.

\begin{tabular}{|lcccc|} 
Consumo floculante. Proyecto. & $\begin{array}{c}\text { Consumo floculante } \\
\text { (g/t) }\end{array}$ & $\begin{array}{c}\text { Consumo unitario } \\
\text { (kg/t estéril) }\end{array}$ & $\begin{array}{c}\text { Coste unitario } \\
(\boldsymbol{\epsilon} / \text { t estéril) }\end{array}$ & $\begin{array}{c}\text { Coste } \\
\text { anual } \\
(\boldsymbol{\epsilon} / \mathbf{a n ̃ o})\end{array}$ \\
Espesado baja densidad HRT & 30 & 0,03 & 0,04 & $55.500,00$ \\
Espesado alta densidad HDT & 45 & 0,05 & 0,06 & $83.250,00$ \\
Espesado alta densidad. Pasta. & 45 & 0,05 & 0,06 & $83.250,00$ \\
\hline
\end{tabular}

\subsubsection{Resumen de los costes de operación}

Sumando cada uno de los costes de operación, consumo de agua, floculante y energía eléctrica y estimando un coste de mantenimiento de $2,5 \%$ del coste de capital de los equipos e instalaciones, se ha calculado el coste anual de operación estimado para cada una de las alternativas de espesado de los estériles de la Mina de Laza. En la tabla 8-25: Resumen de costes anuales de operación; se puede comprobar que no existen grandes diferencias entre un sistema y otro, siendo el espesado de alta densidad HDT como el de menor coste anual seguido por el sistema de espesado en forma de pasta.

Como se aprecia en los costes de operación de la planta, el consumo de floculante es igual en todos los casos, pero sí parece que hay un ahorro anual a medida que aumenta la concentración de sólidos en el hundido.

Los costes totales combinados para operación y costes de capital de los supuestos realizados para un periodo de operación de la mina de un año, establecen que el sistema más óptimo para la vida del proyecto es el sistema de estériles de media densidad con espesador HDT, siendo los costes de operación de la pasta un 1,5\% superiores. La elección final deberá ser seleccionada en 
base a un análisis en profundidad del precio de energía, precio del agua y costes generales de operación en una etapa posterior de ingeniería de detalle. Estos resultados se muestran en la tabla 8-26: Costes anuales totales.

Tabla 8-25: Resumen de costes anuales de operación.

\begin{tabular}{|lccc|}
\hline & \multicolumn{3}{c|}{ Costes anuales de operación } \\
Espesado baja & $\begin{array}{c}\text { Espesalta } \\
\text { densidad HDT }\end{array}$ & $\begin{array}{c}\text { Espesado en } \\
\text { pasta }\end{array}$ \\
Coste agua fresca de proceso & $802.816,00$ & $799.680,00$ & $762.048,00$ \\
Coste de energía & $724.732,80$ & $664.012,80$ & $707.836,80$ \\
Coste de mantenimiento & $235.432,10$ & $206.558,00$ & $227.654,38$ \\
Coste floculante & $55.500,00$ & $83.250,00$ & $83.250,00$ \\
Total coste anual & $1.818 .480,90$ & $1.753 .500,80$ & $1.780 .789,18$ \\
Total coste en $(€ /$ t estéril) & 1,23 & 1,18 & 1,20 \\
\hline \multicolumn{4}{l}{}
\end{tabular}

Tabla 8-26: Costes anuales totales.

\begin{tabular}{|c|c|c|c|}
\hline & \multicolumn{3}{|c|}{ Costes anuales total (Vida del proyecto: 10 años) } \\
\hline & $\begin{array}{l}\text { Espesado baja } \\
\text { densidad }\end{array}$ & $\begin{array}{c}\text { Espesado alta densidad } \\
\text { HDT }\end{array}$ & $\begin{array}{c}\text { Espesado en } \\
\text { pasta }\end{array}$ \\
\hline Coste de capital & $9.417 .284,00$ & $8.262 .320,00$ & $9.106 .175,00$ \\
\hline Coste de operación (10 años) & $18.184 .809,00$ & $17.535 .008,00$ & $17.807 .891,75$ \\
\hline Total coste (10 años) & $27.602 .093,00$ & $25.797 .328,00$ & $26.914 .066,75$ \\
\hline Coste anual (promedio) & $2.760 .209,30$ & $2.579 .732,80$ & $2.691 .406,68$ \\
\hline Total coste en (€/t estéril) & 1,87 & 1,74 & 1,82 \\
\hline
\end{tabular}

El estudio de los sistemas de espesado estériles de la Mina de Laza, ha mostrado que se ahorra gran cantidad de agua y se alcanzan adicionales ahorros de energía, incrementando la densidad del hundido del espesador hasta el $62-71 \%$ de contenido en sólidos en peso, consiguiendo a la vez una alta tensión de fluencia en la pasta obtenida que permite un almacenamiento en superficie sin necesidad de una balsa convencional. Este estudio ha demostrado que los ahorros de energía y agua para los estériles de alta densidad son evidentes, con distinciones claras en el coste de capital y operación de los diferentes escenarios propuestos de bajo, medio y alto contenido en sólidos en el espesado de estériles.

Los costes de energía y agua varían de acuerdo a las características de los materiales de cada explotación en concreto con respecto a: la mineralogía, tamaño de partículas, reología, química del agua, etc. y que por tanto será necesaria una nueva fase de investigación de mayor detalle para la obtención de nuevos datos cuando exista disponible una mayor cantidad de muestra de estériles.

\subsection{Observaciones sobre la muestra de estériles del yacimiento de Laza}

Las condiciones de diseño del sistema de tratamiento de estériles del yacimiento de Laza se deben establecer en base al sistema final de deposición de estériles elegido. El objetivo de establecer varias alternativas en el estudio conceptual de todas ellas para estimar los costes 
económicos de capital y operación durante la vida de la mina así como la sostenibilidad de la operación.

Las alternativas de diseño existentes para los estériles de la Mina de Laza que será explotada mediante minería a cielo abierto son:

a) Apilado en superficie en forma de pasta

b) Deposición en superficie en balsa convencional

No existe la posibilidad de estudiar el uso de la pasta como relleno de mina (backfill) al tratarse de una futura explotación a cielo abierto.

Las alternativas propuestas serán analizadas en el presente documento con especial interés en el sistema de espesado de estériles.

\subsubsection{Apilado en superficie en forma de pasta}

El apilado de estériles en superficie en forma de pasta se realiza en forma de una suspensión de sólidos no segregable y no sedimentable, con una mínima liberación de agua. Existen diferentes métodos para llevar a cabo este apilado dependiendo de la superficie del terreno, topografía y de la reología de la pasta obtenida en el espesador. La pasta en general apilada tendrá taludes de hasta un $5 \%$ de pendiente.

Para llegar a producir el apilado en superficie las características reológicas de la pasta producida deben de cumplir ciertos requerimientos como son: alcanzar un talud determinado y que la pasta pueda ser bombeada y transportada por tubería hasta el lugar de deposición. Dependiendo de la distancia del espesador y de las bombas utilizadas para el transporte de la pasta, se elegirá la ubicación previamente estudiada en detalle en una fase posterior del proyecto.

El método de apilado ofrece más ventajas que el método convencional de balsas de estériles a priori, ya que el almacenamiento en forma de pasta con altas concentraciones de sólidos requiere menos superficie para depositar los estériles. Además existen otras ventajas respecto al sistema convencional como es la mejora de la calidad del agua de proceso, menor riesgo de rotura de la balsa, menor riesgo de filtración a los acuíferos de contaminantes así como una mejor restauración del terreno afectado por los estériles.

\subsubsection{Estudios de apilado y transporte de la pasta}

Las condiciones de operación y bombeo de estériles espesados han sido seleccionados de forma preliminar, considerando tres posibles escenarios que deberán ser confirmados en etapas posteriores del proyecto de la Mina de Laza mediante investigaciones sucesivas, cuando exista una mayor cantidad de muestra de estériles disponible.

Los ensayos de deposición de estériles deben ser diseñados para evaluar el apilado en superficie, relleno de huecos o cortas superficiales y vertido en balsa convencional. Se han de ensayar con un amplio rango de reologías del hundido para proporcionar los datos base para considerar varios métodos de deposición y lugares para ello. 
Se ha de considerar a escala de laboratorio unos canales de $10 \mathrm{~cm}$ de anchura, $5 \mathrm{~cm}$ de altura y $100 \mathrm{~cm}$ de largo, para probar con pasta de diferentes características reológicas.

Se han seleccionado tres densidades diferentes de pulpa con diferentes contenidos en sólidos y tensiones de fluencia determinadas con el ensayo de asentamiento en probeta o con viscosímetro.

a) Una pulpa obtenida en espesador de alta capacidad con baja tensión de fluencia, espesada al $45 \%$ de contenido en sólidos y densidad de $1,4 \mathrm{~kg} / \mathrm{dm}^{3}$.

b) Una pasta de media tensión de fluencia conteniendo el $62 \%$ de sólidos obtenida en un espesador de alta densidad HDT y densidad de $1,6 \mathrm{~kg} / \mathrm{dm}^{3}$.

c) Finalmente una tercera muestra de pasta obtenida en un espesador de cono profundo con una alta tensión de fluencia con el $68 \%$ de sólidos y una densidad de $1,7 \mathrm{~kg} / \mathrm{dm}^{3}$.

Los ensayos de laboratorio para los estériles de la Mina de Laza produjeron un hundido que varía entre el $45 \%$ y $71 \%$ de contenido en sólidos en función del equipo y método de operación elegido. Los ensayos de apilado de estériles en superficie que producen unos estériles en forma de pasta no sedimentable y no segregable es normal que se tengan taludes de deposición que se pueden estimar entre el 5 y el $7 \%$ de inclinación.

Una floculación efectiva y una alimentación diluida al $5 \%$ de sólidos en peso previa a la campana de alimentación es necesaria para alcanzar los máximos rendimientos de en el equipo de espesado para producir flóculos compresibles para el espesado en forma de pasta.

Se ha observado que una dosificación óptima de 40-50 gramos por tonelada de estéril produce mejor floculación y flujo de sedimentación.

El modo de adición del floculante en etapas es importante para obtener un mayor flujo de sedimentación a la entrada del espesador.

El ensayo en el espesador dinámico de laboratorio ha sido capaz de producir un material en forma de pasta conteniendo hasta un $71 \%$ de sólidos en el hundido tras 5 horas de tiempo de residencia y una altura total en el espesador de 1 metro. La pasta producida está próxima al grado de humedad que se obtendría en la torta de un filtro a vacío.

La pasta producida por el espesador de pasta con un contenido en sólidos entre $68 \%$ y $70 \%$ de sólidos tiene una tensión de fluencia estimada de 200-250 Pa, favorable en principio para su bombeo y transporte, con equipos adecuados a esta reología.

Se recomienda realizar estudios de bombeo de pasta así como la monitorización del sitio de deposición en el proyecto para obtener información más detallada.

En el proyecto final de la Mina de Laza se recomienda el uso de un equipo piloto de espesado de cono profundo para comprobar la viabilidad de los datos presentados en este trabajo, siempre que se disponga de suficiente material de ensayos para realizar pruebas piloto durante varios días. 


\subsection{Conclusiones sobre los ensayos de los estériles del yacimiento de Laza}

Para este tratamiento de estériles de mineral de estaño y wolframio, la opción del espesado de estériles en forma de pasta con una alta concentración de sólidos parece la más económica a lo largo de la explotación de la mina, bien en forma de pasta o bien con alta densidad en el hundido. La densidad del hundido para los estériles de la mina alcanzan las concentraciones esperadas en un sistema de sedimentación en forma de pasta, con un grado máximo de concentración de sólidos en peso del $71 \%$ y una alta tensión de fluencia superior a $200 \mathrm{~Pa}$. El máximo contenido en sólidos esperado puede llegar al $71 \%-75 \%$ de sólidos en peso, como indican los ensayos de filtración a vacío, por lo que parece se ha alcanzado el límite práctico en el uso del espesador de pasta.

La alimentación ideal y su dilución a la entrada del espesador deben ser alcanzada con algún sistema de eductores o similar para alimentar el espesador a un $5 \%$ de sólidos en peso, como dilución óptima.

El consumo de floculante para los sistemas de alta densidad se estima en $45 \mathrm{~g} / \mathrm{t}$ de estéril alimentado al espesador.

El objetivo de obtener una pasta a partir de una pequeña muestra de sólidos ha quedado demostrado con el equipo de espesado de tubo profundo tras 5 horas de tiempo de residencia en el espesador de laboratorio. Este tiempo es aplicable al equipo de espesado real, si bien sería recomendable una prueba en planta piloto de mayores dimensiones para confirmar este dato.

La tensión de fluencia medida con ensayo de asentamiento está en el rango de la pasta con valores entre 100 y $250 \mathrm{~Pa}$. Se considera necesario confirmar esta viscosidad de la pasta con mayor cantidad de muestra en una etapa posterior del proyecto.

Con un ratio de alimentación de estériles de $185 \mathrm{t} / \mathrm{h}$ e implementando en el equipo las partes necesarias para optimizar la alimentación se requiere un espesador de 14 metros de diámetro con una altura de 10,5 metros de altura lateral de virola para un espesador de pasta con un talud de fondo del tanque de $30^{\circ}$. En el caso de un espesador de alta densidad, con menor tiempo de residencia ( 2,5 horas) y un contenido en sólidos del $62 \%$ en peso, la altura vertical del espesador se ha calculado en 6,5 metros con un talud de fondo de $15^{\circ}$.

La reducción de la superficie de implantación, así como los parámetros de operación del espesador de pasta presentan un mejor rendimiento que los datos obtenidos para el espesador de estériles convencional. 


\subsection{Sostenibilidad de las operaciones de espesado en pasta}

El interés potencial en el uso de los estériles espesados de alta densidad y en forma de pasta no está centrado exclusivamente en criterios económicos, como pueden ser los costes de capital y de operación. Existen otros motivos que impulsan a las compañías mineras a adoptar estos sistemas en sus operaciones, como son: la necesidad de conservar el agua de proceso, disminuir el riesgo de fallo en una balsa o depósito, facilitar la clausura de los depósitos de estériles, el respeto medioambiental y de forma general la sostenibilidad del proyecto.

En este capítulo y mediante el uso de un sistema de clasificación basado en un baremo objetivo, se analizan ocho importantes beneficios relacionados con la sostenibilidad y otros factores medioambientales que afectan a cualquier proyecto minero con operaciones de espesado de estériles.

Se han evaluado los datos obtenidos en el estudio sobre los estériles de la Mina de Laza, que sirven como punto de partida para discutir y comprobar estos beneficios obtenidos con la operación de espesado en forma de pasta. Como factores clave se sugiere que los beneficios comprobados parecen reducir los costos de operación en algunos casos, la reducción de los costos de construcción de muros y la reducción del consumo de agua. Un beneficio potencial que no se ha logrado de forma general es la eliminación en la huella de la instalación de balsas o depósitos de estériles en minería a cielo abierto, si bien se ha conseguido reducir sustancialmente en el caso de minas subterráneas con operaciones de relleno en forma de pasta (backfill).

La necesidad de establecer una base coherente para los estudios comparativos debe realizarse en profundidad a medida que avanza el grado de conocimiento del proyecto y se llega a la ingeniería de detalle.

En la actualidad y desde el año 2009 , los altos precios de la mayoría de los recursos minerales, han hecho que muchas compañías mineras comiencen a plantearse la explotación de depósitos de baja ley o antiguas minas abandonadas hace años, como es el caso de la Mina de Laza. No es raro comprobar que muchos proyectos con un grado de menos de $1 \mathrm{~g}$ de oro por tonelada, o minas de cobre con leyes inferiores al $1 \%$ en metal contenido, comiencen a ser consideradas viables o al menos estudiadas. Junto con la creciente demanda de minerales y los altos precios, el resultado es que muchos proyectos comienzan a explotarse, y requieren almacenar y gestionar de forma segura los depósitos de residuos cada vez mayores. En particular, la preocupación general de estos proyectos son los volúmenes de residuos producidos en las nuevas explotaciones y en las existentes, así como los fallos que pudieran producirse en las instalaciones de almacenamiento de estériles (balsas), que aunque muy infrecuentes pueden resultar desastrosos en caso de producirse. Con esto en cuenta, la industria minera a nivel internacional continúa la investigación de las opciones alternativas para la gestión de residuos mineros. La práctica convencional de espesado de estériles con un $50 \%$ de sólidos en peso o menor obtenidos en los sistemas convencionales, requiere bombear grandes volúmenes de agua, junto con residuos mineros y gran parte de esta agua posteriormente debe ser gestionada y transportada de nuevo, con las consiguientes pérdidas de agua y costes que se originan. Este agua libre es la que ha provocado 
en el pasado la gran mayoría de los fallos y roturas de balsas, así como ha contribuido a otros problemas asociados a estas instalaciones, tales como contaminación del agua subterránea y la destrucción de la vegetación en el medio ambiente circundante. Como se ha comprobado con el caso de la Mina de Laza, una potencial solución y alternativa a las balsas convencionales es el uso de las operaciones de espesado en alta densidad y en pasta de los estériles mineros para depositar estos estériles bien en superficie o bien utilizarlos como relleno de explotaciones subterráneas.

Es evidente que hay un interés continuo y creciente en el proceso de tratamiento de estériles en forma de pasta dentro de la industria minera y por lo tanto, es conveniente analizar estos sistemas e instalaciones para el tratamiento de los estériles mineros.

Es importante en este análisis establecer un baremo para clasificar todos los factores y aspectos clave que se deben de considerar al adoptar un sistema de tratamiento y almacenamiento de estériles en forma de pasta. Se deberá analizar si la tecnología de espesado de alta densidad o pasta está a la altura prevista de los beneficios que se esperan de un sistema de tratamiento de estériles de este tipo.

En este capítulo, se analizan los principales factores que influyen en la sostenibilidad de forma directa en este tipo de depósitos y sus afecciones tanto al proyecto como al medioambiente.

Se ha realizado un baremo para establecer la clasificación entre los distintos sistemas y tecnologías de espesado, con una escala de 1 a 5 , para clasificar el beneficio de los depósitos de pasta en superficie frente a los sistemas convencionales. El sistema de clasificación utilizado se destina a especificar la evaluación de los depósitos de pasta frente a los sistemas convencionales: El baremo o puntuación asignada se muestra en la tabla 8-27: Baremo de evaluación; donde se presenta el resultado de la comparación obtenida al evaluar los dos sistemas de espesado de estériles: el espesado de forma convencional y el espesado en pasta.

Tabla 8-27: Baremo de evaluación.

\begin{tabular}{|c|l|}
\hline Baremo & $\begin{array}{l}\text { Evaluación y comparativa entre la tecnología de espesado convencional y el } \\
\text { espesado en forma de pasta. }\end{array}$ \\
\hline 1 & $\begin{array}{l}\text { La tecnología de espesado en pasta no ha logrado beneficios sobre el sistema } \\
\text { convencional. Es claramente inferior a la tecnología convencional. }\end{array}$ \\
\hline 2 & $\begin{array}{l}\text { No existen beneficios importantes en comparación con la tecnología de espesado } \\
\text { convencional. }\end{array}$ \\
\hline 3 & $\begin{array}{l}\text { No hay diferencias entre las tecnologías de espesado. Es indiferente el uso de la } \\
\text { tecnología de espesado en pasta o la tecnología convencional. }\end{array}$ \\
\hline 4 & $\begin{array}{l}\text { Se han evidenciado beneficios con la tecnología de espesado en pasta, pero } \\
\text { persisten algunas dudas sobre la aplicación del método. }\end{array}$ \\
\hline 5 & $\begin{array}{l}\text { La tecnología de espesado en pasta tiene beneficios significativos y es claramente } \\
\text { superior a los sistemas convencionales. }\end{array}$ \\
\hline
\end{tabular}

(Fuente: Elaboración propia) 
Estas evaluaciones son subjetivas y existen muchas formas de evaluar la sostenibilidad de las operaciones mineras que pueden hacer variar este baremo, aunque el fin último es proporcionar un punto de partida para evaluar si los sistemas de espesado en forma de pasta son sostenibles, viables y fiables a largo plazo en una operación minera.

La definición de "espesado en pasta" utilizada de forma genérica y aplicada a las operaciones de tratamiento de estériles puede resultar engañosa por lo general de su definición, ya que existen muy pocas instalaciones las que se pueda depositar una verdadera pasta. La gran mayoría de espesadores de alta densidad y de pasta para estériles de última generación, pueden producir un alto contenido en sólidos de los estériles espesados, pero es necesario que los lodos obtenidos tengan las características reológicas necesarias.

La figura 8-19: Diagrama para la definición de pasta; ayuda a ilustrar la terminología de uso común que se ha seguido para las diferentes tecnologías de espesado. En el eje horizontal se representa el contenido en sólidos y que es una medida de la densidad de la pulpa, por lo general definida como porcentaje de sólidos en peso. El eje vertical es una medida de la tensión de fluencia, por lo general se define como tensión de fluencia, medida con viscosímetro o mediante ensayo de asentamiento medido en Pascales. Los espesadores convencionales producen material que no tiene prácticamente ninguna tensión de fluencia y, cuando se deposita en una balsa de estériles producen la liberación del agua que forma la pulpa, lo que resulta en láminas de agua o embalses de agua y formación de "playas". La definición de pasta puede ser definida a partir de un valor de la tensión de fluencia, con unos valores mínimos que oscilan entre $50 \mathrm{~Pa}$ y $75 \mathrm{~Pa}$. Es importante notar, que hay que hacer una distinción entre la tensión de fluencia de la pasta medida a la salida del espesador o justo después de la deposición en la balsa, ya que las propiedades reológicas pueden variar significativamente como resultado de las tensiones cortantes o esfuerzos aplicados durante el transporte y bombeo. Como puede verse en la figura 8-19, la consistencia de una pasta comienza a acercarse al límite de contenido en sólidos que se obtendría mediante filtración, aunque esto sería un caso extremo. La gran mayoría de las operaciones que se han visto en el presente trabajo, se encuentran en la región de alta densidad o pasta de la figura 8-19, donde el transporte todavía es posible gracias al uso de bombas centrífugas y bombas de desplazamiento positivo. Sólo en los casos más extremos o con pastas muy difíciles de transportar por su alta tensión de fluencia se recurrirá a bombas de desplazamiento positivo, mucho más costosas que las centrífugas. 


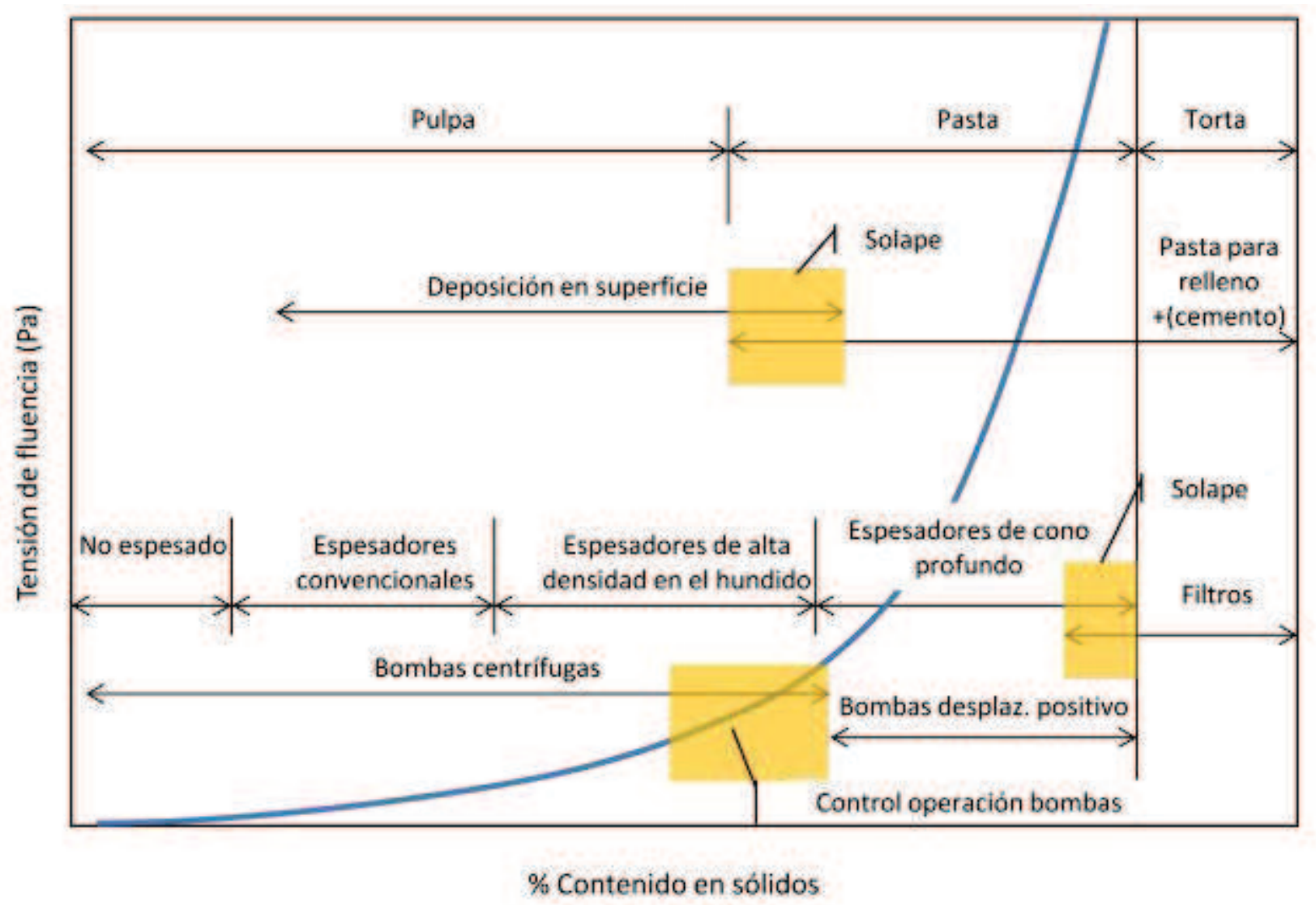

Figura 8-19: Diagrama para la definición de pasta.

(Fuente: Elaboración propia)

\subsection{Sostenibilidad de las operaciones de deposición de estériles en superficie}

Para la discusión sobre la sostenibilidad de las operaciones en forma de pasta, se puede hacer una pregunta razonable, que podría ser: ¿Cuál es la diferencia entre el espesado convencional y el espesado de alta densidad?. Las principales diferencias son que un espesado de alta densidad libera muy poca agua, si no ninguna y además, forma una pasta no sedimentable y no segregable con características de fluido no newtoniano, lo que evita la formación de lagos y "playas" en las balsas de estériles. Una de las ventajas potenciales clave del espesado de alta densidad o en pasta, es la certeza de tener un diseño que reduce el volumen de agua transportada por tonelada de residuos depositados y reduce el volumen del depósito de estériles. Como en el caso estudiado de la Mina de Laza, el aumento de los sólidos contenidos en la pulpa desde un 42\% (un valor común para la tecnología convencional) al $62 \%$ para el espesado de alta densidad o al $68 \%$ para el espesado en forma de pasta, se consiguen reducciones importantes del agua transportada con los sólidos secos a la balsa y reduciendo el volumen del depósito en un $15-20 \%$. Si bien, en las operaciones convencionales el agua es recuperada durante un proceso de sedimentación de la pulpa que ocurre en la propia balsa y que puede ser reutilizada, originando un coste de bombeo hasta la planta de proceso. La deposición en forma de espesado de alta densidad se produce muy poca liberación de agua de los estériles, a diferencia de las operaciones de espesado 
convencionales, donde la recuperación de agua es mucho mayor en la operación de espesado. Es difícil cuantificar si este ahorro potencial de agua es real o no, ya que entran en juego otras muchas variables, como el balance hídrico de la zona, pérdidas por filtraciones, etc.; aunque la experiencia ha demostrado que el ahorro es significativo en todos los casos.

Algunos autores sostienen que la propia balsa de estériles se puede hacer funcionar a un alto ratio de sedimentación de estériles actuando como un espesador por gravedad gigante que puede recuperar gran cantidad de agua a partir de estériles de un espesador convencional. Sin embargo, los datos obtenidos en ensayos y en operaciones existentes muestran que la aplicación de espesado en alta densidad contradice esta opinión y muestra que el ahorro de agua es posible en todas las operaciones.

Se ha realizado en el capítulo anterior un estudio de viabilidad y de los beneficios esperados con el uso de un sistema de espesado de alta densidad comparando los tres sistemas de espesado en la operación de estériles en la Mina de Laza. Para esta etapa del proyecto se dispone de una cantidad razonable de información que permite establecer las comparaciones entre los diferentes sistemas de espesado.

Los puntos sobre los que se discute el modelo de sostenibilidad propuesto son los siguientes:

a) Costes de capital y costes de operación.

b) Resistencia de los depósitos de pasta.

c) Disminución de los terrenos ocupados por el depósito.

d) Disminución de la demanda de materiales para la construcción del muro de confinamiento.

e) Disminución del riesgo de lixiviación y filtración.

f) Reducción o eliminación del agua superficial del depósito.

g) Superficie de lixiviación y drenaje.

h) Reducción del uso del agua.

\subsubsection{Coste de capital y costes de operación}

En el análisis de los costes de capital y operación existen varios puntos de vista cuando se evalúa este criterio; el primero sería el grado de detalle del estudio a realizar, ya que dependiendo de la etapa del proyecto en la que se encuentre, la diferencia entre un sistema de espesado convencional y uno de alta densidad puede ser considerable. En general cuando se analizan las operaciones entre unos límites de batería definidos se llega a la conclusión que pueden obtenerse costes de capital y operación similares entre el espesado en pasta y el convencional, tanto en el capital inicial como en operación, dependiendo de otros factores del proyecto para adoptar una decisión final. Sin embargo la evaluación efectuada para el proyecto de la Mina de Laza, aunque en una etapa temprana, se han considerado otros factores como la topografía y los métodos de bombeo de agua de proceso y de los lodos. Se obtienen ahorros significativos tanto en los costes de capital de equipos y en la construcción como en los costes de capital como en los costes de operación. En el proyecto se ha considerado la construcción de una presa para todos los casos estudiados, pero como se ha comprobado en algunas operaciones existentes a nivel mundial donde se opera en forma de "apilado en seco", pudiera no ser necesaria la construcción de una 
presa, lo cual reduciría de forma considerable los costes de capital del proyecto. En el caso de la Mina de Laza se ha considerado en todos los casos un muro de contención debido a la orografía del terreno con fuertes pendientes, parece lo más idóneo en este caso.

En la comparación de los costes del proyecto de la Mina de Laza analizado para toda la vida útil prevista en el proyecto se indica un coste de capital de 0,58 €/t estéril depositada para los estériles de alta densidad frente a un coste de 0,66 €/t depositada de forma convencional. En cuanto a los costes de operación la diferencia es poco significativa, resultando los costes de los procesos de alta densidad ligeramente inferiores con 1,05 €/t depositada frente al coste de 1,07 €/t en el sistema convencional.

Quizás el grado de detalle estudiado para este proyecto influye en la comparativa, aunque los datos comienzan a desvelar que los sistemas de alta densidad y de pasta tienen ventajas significativas frente a los sistemas convencionales.

En una etapa posterior del proyecto sería interesante y correcto realizar un estudio más exhaustivo y detallado de los costes finales de capital y de operación. En este punto se ha considerado una ventaja y un beneficio económico del espesado de alta densidad frente a la tecnología de espesado convencional, pero existen algunos puntos que deben ser estudiados en detalle y por lo tanto asignar un baremo de 4 para este punto parece correcto.

\subsubsection{Resistencia de los depósitos de pasta}

Sobre este asunto no existen muchas referencias sobre instalaciones de pasta que hayan sido objeto de una rotura de la balsa bien de forma accidental o por causas naturales, como puede ser un terremoto. Se observa que los estériles espesados con sistemas de alta densidad presentan una importante ventaja sobre los convencionales, ya que la rotura de un muro de confinamiento no debe provocar un desastre medioambiental ni afectar a las zonas circundantes a la balsa. En el caso de un espesado convencional, los estériles tendrían una gran resistencia a fluir aunque existiera una gran altura de apilamiento.

El baremo establecido en este punto se puede considerar de 4 ya que sugiere que el espesado en forma de pasta tiene una ventaja significativa aunque existen puntos que deben ser analizados en profundidad.

\subsubsection{Disminución de los terrenos ocupados por el depósito.}

En este punto hay un acuerdo generalizado en toda la literatura consultada y se ha comprobado también en el caso estudiado, que las operaciones en forma de pasta tienen siempre una reducción de la huella y de los terrenos ocupados por la balsa o depósito de estériles. Incluso se pueden obtener alturas de apilado superiores a los sistemas convencionales ya que no existe una segregación del agua y sólidos que produzca una "playa" ni una zona de lago. En general con altas densidades se han observado pendientes que oscilan entre el $4 \%$ y el $10 \%$ dependiendo de la consistencia de la pasta y el método de deposición empleado.

Para el caso de la Mina de Laza, el volumen de balsa necesario disminuye en casi un $20 \%$ comparando el volumen de una balsa convencional y un depósito de pasta. Por lo tanto, la pasta 
tiene una ventaja significativa y cuantificable económicamente, que le otorgan a esta condición un baremo de 5, por las ventajas superiores presenta frente a los depósitos convencionales. En un estudio detallado sobre el proyecto de la Mina de Laza, este volumen se podría ver reducido con una optimización en la etapa de diseño del depósito.

8.12.4 Disminución de la demanda de materiales para la construcción del muro de confinamiento Los beneficios generados por la operación en alta densidad son convincentes y se considera justificado un baremo de 5 . En general siempre se ha informado en la literatura consultada de ahorros de costes de construcción de las balsas de alta densidad, debido principalmente a la menor demanda de materiales (escollera, arenas, lámina de PEAD, etc.) y de las instalaciones auxiliares que evitan la filtración y cuyo objetivo es la recogida de aguas en cunetas o drenajes para recuperar el agua liberada en los sistemas convencionales. Es claro que los estériles no segregables y con mínima liberación de agua representan una ventaja significativa en los sistemas de espesado.

\subsubsection{Disminución del riesgo de lixiviación y filtración}

En general, no existirán balsas o zonas de decantación dentro de los depósitos de estériles en forma de pasta. En ocasiones se ha constatado que el apilado de capas sucesivas de estériles puede provocar una autocompactación de la pasta provocando una liberación el agua contenida en ella. Si bien esta liberación de agua es mínima requiere de la atención y el cuidado para proporcionar a las instalaciones la calidad necesaria que evite la infiltración de estas aguas al terreno. En general los ratios de infiltración de aguas se reducen de forma significativa en los depósitos de pasta. Claramente los sistemas de espesado de alta densidad con contenidos en sólidos de entre el $65 \%$ y el $75 \%$ pueden alcanzar en superficie consolidaciones cercanas al $95 \%$ debido a otros factores como son la evaporación superficial, lo que indica que sólo son posibles pequeñas infiltraciones del agua de lluvia que lixivia los estériles. Se puede considerar un baremo de 4, en el caso de la Mina de Laza ya que la ventaja es significativa pero se debería estudiar estos fenómenos en la fase de ingeniería de detalle.

\subsubsection{Reducción o eliminación de agua superficial en el depósito}

Como se ha señalado en el punto anterior, la operación en alta densidad elimina la balsa de decantación de estériles. El caso propuesto de la Mina de Laza, donde se esperan concentraciones de más del $62 \%$ de contenido en sólidos en peso y teniendo en cuenta los valores de la tensión de fluencia obtenidos es poco probable que se produzca una segregación de los estériles una vez depositados. En general por la experiencia de otros depósitos existentes la eliminación de una zona de decantación de sólidos dentro de la balsa, se corresponde con una mayor resistencia del depósito de estériles. Es necesaria la precaución de no saber exactamente el comportamiento final de los estériles hasta que no se detalla el proyecto final de la balsa ya que 
si se desarrollara una capa de decantación influiría en el diseño del muro de contención aguas abajo. En el caso de la Mina de Laza este supuesto es poco probable y se supone un beneficio importante aunque hay una preocupación con algunos aspectos y por lo tanto sería de aplicación un baremo de 4 , sobre este punto.

\subsubsection{Superficie de lixiviación y drenaje}

En las operaciones de espesado de estériles en forma de pasta puede existir un proceso de lixiviación de sustancias tóxicas en la superficie y por tanto un establecimiento más temprano de la vegetación, lo que provocaría la reducción de polvo y la creación de una cobertera vegetal. En los climas áridos donde esta tecnología se está aplicando recientemente, la formación de esta cubierta vegetal puede no desarrollarse y provocar que el polvo sea un problema significativo en algunos depósitos de estériles de pasta.

Una gran superficie del depósito se puede secar entre ciclos de deposición, produciendo las condiciones propicias para la generación de polvo. Este aspecto necesita ser vigilado ya que parece que no existen ventajas significativas comparadas con los estériles depositados de forma convencional. En este caso es posible que el baremo propuesto sea una calificación de 2, para los depósitos de estériles en forma de pasta.

\subsubsection{Reducción del uso del agua}

Este asunto cuenta con la más convincente y apreciable evidencia en cualquier operación minera y por tanto se ha asignado un baremo de 5 . A medida que el coste del agua sigue aumentando en algunas zonas y la disponibilidad de agua es cada vez mayor; este punto se consolida como uno de los aspectos más importantes que determinan la elección de la tecnología de espesado en forma de pasta como preferido frente a los sistemas convencionales.

A medida que los condicionantes para obtener el permiso de explotación se endurecen para las compañías mineras en el apartado de uso y tratamiento del agua, llegando incluso a proponerse en alguno proyectos como condición de otorgamiento de los permisos por parte de la Administración, de un sistema de vertido de "cero efluentes"; hace que la decisión sea favorable al diseño de sistemas de espesado de estériles de alta densidad. Este aspecto tiene especial importancia en zonas desérticas donde se operan grandes minas a cielo abierto.

Para el caso estudiado de la Mina de Laza, el ahorro obtenido en los sistemas de alta densidad es de aproximadamente el $5 \%$ teniendo en cuanta la etapa temprana de estudio en la que se encuentra el proyecto y que se encuentra ubicado en una región de España que en principio no presenta problemas de disponibilidad de agua. 


\subsection{Otros asuntos clave relativos a los sistemas de espesado}

Se ha puesto de manifiesto que uno de los factores clave para ser cuantificados cuando se evalúa la viabilidad de un sistema de espesado de estériles en forma de pasta, ya sea en un proyecto nuevo o existente, es el ángulo de deposición que se desarrollará. A diferencia de los sistemas convencionales, donde el ángulo de inclinación no dicta la superficie del depósito si no que es la futura formación de los lagos de decantación lo que provoca el aumento de la superficie ocupada. Un sistema de espesado en forma de pasta puede estar altamente influido por la pendiente alcanzada por la pasta depositada, a menos que se construya un muro de contención para confinar esta pasta. Pese a que en ocasiones se pueden llegar a pendientes de hasta el 10\%, la experiencia hasta la fecha analizando proyectos existentes, indica que una pendiente promedio del 4-5\% es más probable de lograr. Este es un tema clave en la fase de diseño y debe ser evaluado con antelación a la puesta en marcha de la explotación y en la fase de ingeniería de detalle, especialmente en depósitos ubicados en pendientes que pueden provocar el deslizamiento aguas abajo.

Otro aspecto importante en el diseño de los sistemas de espesado y deposición de estériles es la reducción de los costes de cierre o sellado de la escombrera de estériles. Se ha constatado en la literatura que la reducción de costes de cierre de las minas y de las instalaciones de forma segura y sostenible es un requisito indispensable en cualquier proyecto minero para asegurar la aceptación por parte de la sociedad de la actividad minera.

Por último, aunque la tecnología de espesado en forma de pasta ha demostrado sin duda ser favorable en muchas circunstancias y tiene el potencial de reducir el gasto del agua en la industria minera así como proporcionar estructuras de depósitos de estériles más estables y perdurables en el tiempo, es necesario un estudio detallado que identifique todos los puntos del proyecto susceptibles de mejora para garantizar la sostenibilidad del proyecto minero.

\subsubsection{Valoración del sistema de espesado propuesto}

En la tabla 8-28: Calificación final del estudio de sostenibilidad; se presentan las claves y un resumen de las ventajas que presentan los sistemas de espesado en forma de pasta o con alta densidad. 
Tabla 8-28: Calificación final del estudio de sostenibilidad

\begin{tabular}{|c|c|c|c|}
\hline Característica & $\begin{array}{l}\text { Beneficios } \\
\text { económico / } \\
\text { Ingeniería }\end{array}$ & Beneficio social/Medioambiental & Baremo \\
\hline $\begin{array}{l}\text { Coste de capital y costes } \\
\text { de operación }\end{array}$ & $\begin{array}{l}\text { Beneficio económico } \\
\text { general }\end{array}$ & $\begin{array}{l}\text { Menos recursos aplicados en el final de } \\
\text { la línea (tubería) y menos acciones } \\
\text { correctivas }\end{array}$ & 4 \\
\hline $\begin{array}{l}\text { Resistencia del depósito } \\
\text { de estériles }\end{array}$ & $\begin{array}{l}\text { Reduce el riesgo de } \\
\text { rotura de la instalación }\end{array}$ & $\begin{array}{l}\text { Evita la contaminación área circundante } \\
\text { y aumenta el impacto en seguridad }\end{array}$ & 4 \\
\hline $\begin{array}{l}\text { Superficie ocupada por la } \\
\text { balsa de estériles y } \\
\text { aumento de la altura de } \\
\text { almacenamiento. }\end{array}$ & $\begin{array}{l}\text { Reduce el coste de } \\
\text { adquisición de terrenos }\end{array}$ & $\begin{array}{l}\text { Reduce la desertización de tierra } \\
\text { productiva }\end{array}$ & 5 \\
\hline $\begin{array}{l}\text { Demanda de materiales } \\
\text { para la construcción del } \\
\text { muro de confinamiento }\end{array}$ & $\begin{array}{l}\text { Menos transporte y } \\
\text { construcción }\end{array}$ & $\begin{array}{l}\text { Reduce la adquisición de materiales y } \\
\text { reduce los gases efecto invernadero en } \\
\text { la construcción }\end{array}$ & 5 \\
\hline $\begin{array}{l}\text { Riesgo de producción de } \\
\text { lixiviados y su filtración a } \\
\text { los acuíferos }\end{array}$ & $\begin{array}{l}\text { Mejora de los lixiviados y } \\
\text { su recuperación }\end{array}$ & $\begin{array}{l}\text { Reduce el riesgo de contaminación de } \\
\text { agua subterránea y superficial }\end{array}$ & 4 \\
\hline $\begin{array}{l}\text { Riesgos de la lámina de } \\
\text { agua y agua libre en los } \\
\text { depósitos }\end{array}$ & $\begin{array}{l}\text { Incrementa el acceso a } \\
\text { la superficie de la balsa }\end{array}$ & $\begin{array}{l}\text { Reduce los daños a la fauna e } \\
\text { incrementa la seguridad del operador. }\end{array}$ & 4 \\
\hline $\begin{array}{l}\text { Superficie de lixiviación y } \\
\text { drenaje }\end{array}$ & $\begin{array}{l}\text { Facilidad de recoger } \\
\text { efluentes y } \\
\text { contaminantes lixiviados } \\
\text { de la superficie }\end{array}$ & $\begin{array}{l}\text { Establecimiento más rápido de } \\
\text { vegetación, reduce la generación de } \\
\text { polvo }\end{array}$ & 2 \\
\hline $\begin{array}{l}\text { Uso y aprovechamiento } \\
\text { del agua }\end{array}$ & $\begin{array}{l}\text { Reduce la necesidad de } \\
\text { agua e instalaciones de } \\
\text { suministro y ahorro de } \\
\text { energía de bombeos }\end{array}$ & $\begin{array}{l}\text { Reduce la huella de agua, necesidad } \\
\text { de presas o impactos de falta de agua }\end{array}$ & 5 \\
\hline
\end{tabular}

(Fuente: Elaboración propia)

\subsection{Desarrollo sostenible y beneficios económicos, medioambientales y sociales}

A menudo se tiene la visión de que el concepto de desarrollo sostenible es incompatible con la industria extractiva y que la minería en cualquiera de sus formas es insostenible. La característica del desarrollo humano es conseguir mejores estándares de vida para las generaciones presentes y futuras. Si se considera que la población mundial estimada en el año 2050 será de 9000 millones de personas, la minería será una industria fundamental y necesaria para producir el crecimiento y expansión de la población en el futuro. Si se acepta el buen hacer y el progreso de la humanidad, las generaciones actuales están moralmente obligadas a dirigir la explotación de los recursos de una forma sostenible en todos los aspectos. Realmente y de acuerdo con el informe Brundtland de las Naciones Unidas del año 1987, desarrollo sostenible, se define como: "satisfacer las necesidades del presente sin comprometer la disposición de las generaciones futuras para satisfacer las suyas propias".

Por lo tanto, "el desarrollo sostenible implica la integración de las consideraciones económicas, medioambientales y sociales, como la clave para asegurar que en el presente se mantienen la calidad de vida sin comprometer la integridad del ambiente natural o la disposición de las futuras generaciones de disponer de sus recursos".

Todo ello no implica que el desarrollo deba tener un impacto "cero" sobre el medioambiente, ya que esto es imposible tratándose de la extracción de materias no renovables de la Tierra, sino que 
debe implicar que las perturbaciones que se crean tengan un equilibrio con la capacidad del planeta para absorber este cambio. En el caso que nos ocupa, esto no quiere decir que haya que suprimir todas las industrias extractivas o concretamente eliminar los depósitos de estériles, si no que se deben desarrollar las tecnologías más limpias y eficientes, atendiendo a tres pilares fundamentales de la sostenibilidad de las operaciones mineras: económica, medioambiental y social. 


\section{Conclusiones}

- Con el estudio de la teoría y tecnologías de espesado se ha destacado la importancia de la implementación de un nuevo sistema de ensayos y forma de evaluar los modernos espesadores de pasta y alta densidad. Estos recientes sistemas de espesado necesitan de nuevas teorías y nuevos procedimientos de laboratorio para estimar los resultados de una operación, que con las técnicas de ensayo de laboratorio "convencionales" no se pueden reproducir a esta escala. En la presente tesis, se ha propuesto un nuevo método de ensayos y la fabricación de un equipo de laboratorio específico, que basa su funcionamiento en las nuevas condiciones de operación de los equipos de espesado con su demostración práctica en el laboratorio, obteniendo unos resultados óptimos.

- La industria minera se ha volcado desde hace poco tiempo en el uso de estos sistemas de espesado en pasta que tienen características de operación y de diseño muy diferentes de los espesadores convencionales, como son: nuevos diseños de tanque, diseños más eficientes de campanas de alimentación, nuevos sistemas de dosificación de floculantes, sistemas de recirculación y bombeo de lodos junto con sistemas de control para producir la pasta con las características que requiere el proyecto en cuanto a contenido en sólidos, reología, viscosidad, etc.

- El modelo experimental propuesto ensayado sobre diferentes materiales ha resultado en todos los casos con la formación de una pasta con un comportamiento y propiedades reológicas características para este tipo de materiales. Este modelo experimental se ha comparado con un espesador real en operación para obtener el ratio de escala de los principales parámetros de diseño de espesadores de pasta.

- Todos los materiales ensayados con la metodología propuesta han alcanzado un contenido en sólidos que varía entre el 67\% y el 76\% dependiendo del material; lo cual es muy superior a la concentración que se obtiene en un ensayo por lotes en probeta de $2000 \mathrm{ml}$. Esto indica que el espesador de laboratorio construido representa las condiciones de operación de un espesador real y que pueda ser escalable en la fase de ingeniería del proyecto.

- La inclusión de los ensayos de asentamiento en la metodología permite conocer de forma empírica la tensión de fluencia para diferentes concentraciones de sólidos, lo que resulta imprescindible para el diseño de los sistemas de espesado y de transporte de la pulpa en el proyecto.

- Con respecto al caso estudiado del yacimiento de Laza y con la metodología de ensayos propuesta se ha evaluado y realizado un estudio conceptual para proponer un sistema de espesado de estériles en el futuro proyecto de la mina de Laza en Orense con unos buenos resultados. La técnica de ensayo de laboratorio ha demostrado que se pueden alcanzar concentraciones de hasta el $71 \%$ de contenido en sólidos con altas tensiones de fluencia, superiores a $200 \mathrm{~Pa}$, y extrapolables al espesador industrial del futuro proyecto. 
- Los resultados han demostrado que los espesadores de alta densidad y de pasta son capaces de crear sistemas de tratamiento de estériles más eficientes y sostenibles, obteniendo grados de humedad casi comparables a los obtenidos por operaciones de filtración a vacío, lo que implica unas reducciones importantes en el consumo de agua, aprovechando todos los recursos hídricos disponibles. Esto resulta de interés especial en el estudio de viabilidad que se está llevando a cabo para el nuevo proyecto de la Mina de Laza.

- El método propuesto para el tratamiento de estériles a escala de laboratorio puede ser utilizado en el futuro como una referencia y una herramienta de optimización del diseño de los sistemas de espesado, tanto en nuevos proyectos como en operaciones existentes que deseen actualizar sus métodos de operación.

- El espesador dinámico de laboratorio fabricado y el método de análisis propuesto, representan una alternativa fiable para reproducir operaciones de espesado en forma de pasta a partir de pequeñas muestras de material. Esto evita grandes inversiones económicas en las primeras etapas de los proyectos en fase de viabilidad, como se ha comprobado en el caso del yacimiento de Laza. Su aplicación no es exclusiva de nuevos proyectos y puede ser aplicado en proyectos existentes, evitando grandes instalaciones de plantas piloto para estudiar mejoras en operaciones de espesado existentes.

- El desarrollo de proyectos mineros sostenibles deben incluir el uso de la tecnología de espesado en pasta como una mejora imprescindible frente a los sistemas convencionales. El futuro de la tecnología de espesado en pasta comprende el esfuerzo para el desarrollo y mejora de los sistemas existentes y debe involucrar a todas las partes del proyecto: empresas mineras, ingenierías, suministradores de equipos, suministradores de reactivos, etc. para proporcionar y desarrollar mayores espesadores, mejoras de los métodos de control de la reología, modificadores de las características reológicas más eficientes, que den lugar a sistemas más sostenibles. 


\section{Futuras investigaciones}

En el presente trabajo se ha realizado el estudio de la operación de sedimentación en los espesadores de alta densidad en el hundido partiendo de un equipo de espesado de laboratorio que simula los modernos espesadores de estériles para la obtención de una pasta.

Se ha analizado la tecnología, los equipos y se ha propuesto un método de ensayos de laboratorio conducente al estudio del fenómeno de espesado y formación de una pasta en equipo de espesado. Como se ha mencionado en el capítulo 7: Espesado en pasta; este estudio forma una de las tres partes de un proyecto de pasta y por lo tanto, los siguientes pasos en las investigaciones de laboratorio deben ir en la dirección de estudiar y definir los sistemas de ensayos para los equipos de bombeo y la estabilidad de la pasta una vez depositada, bien sea en un depósito exterior o en galería en forma de relleno.

Por lo tanto, son varias las líneas de investigaciones que se pueden sugerir en el futuro partiendo de los datos y el método propuesto, que determinen de forma experimental el sistema de bombeo para transporte de la pasta y la estabilidad del depósito de pasta.

Debido a la importancia del transporte y la energía consumida en esta operación el siguiente avance en el estudio sería la creación de un modelo a escala de laboratorio para simular las operaciones de bombeo de la pasta generada en el equipo de espesador de tubo profundo de laboratorio y obtener datos extrapolables a las condiciones de proceso reales. Esto permitiría la elección del tipo de bombeo más adecuado a cada operación en función de los parámetros de los lodos espesados, pudiendo probar diferentes sistemas de transporte.

En cuanto al método de deposición se pueden establecer una serie de ensayos para comprobar la estabilidad de los taludes formados en el apilado de los estériles o bien las condiciones de estabilidad de los sistemas de relleno de galerías de mina (backfill). La importancia de la estabilidad de los depósitos de estériles es fundamental a largo plazo y requiere de una serie de importantes estudios y ensayos que garanticen un almacenamiento seguro de los estériles incluso después de clausurada la operación de la mina. 


\section{Bibliografía}

[ 1 ] Aldea C.; Cornelius B.; Davies M.; Why Paste Backfill Rheology Matters. International Mining Magazine. 2009

[ 2 ] Arbuthnot I.; Testwork and Sizing for Paste Thickeners. Outokumpu. Output Australia. 2007

[ 3 ] Baczek F.; Paste Tailings Management. International Mining Magazine. 2008

[ 4 ] Boger D.; Rheological Concepts; University of Melbourne. Australia. 2006

[ 5 ] Brandt H.; Thickening Rake Mechanisms. International Mining Magazine. 2006

[ 6 ] Cooke R.; Thickened and Paste Tailings Pipeline System Design Procedure. Paterson \& Cooke. South Africa. 2008

[ 7 ] Dorr-Oliver Eimco; Report for Sedimentation and Rheology Test. Salt Lake City-USA. Internal Report. 2007

[ 8 ] Dorr-Oliver; Selecting and Sizing Dorr-Oliver Filters. Filtration Leaf Test Procedures. Dorr-Oliver USA. Internal Report. 1993

[ 9 ] Eimco Process Equipment Co.; Clarifier and Sludge Thickener Sales Manual; Eimco. 1989

[ 10 ] Emmett R.C.; Laros T.J.; The Eimco E-Duc system for Flocculant Optimization in Thickeners. Eimco Process Equipment Co. Internal Report. 1994

[11] Engels J.; Evaluation of the Behaviour of High-Density Tailings Deposition-Codelco Pilot Plant. The Journal of The Southern African Institute of Mining and Metallurgy. 2012

[ 12 ] Fiscor S.; Paste Processing Potential. Engineering \& Mining Journal Magazine. 2009

[13 ] FLSmidth; Improving Densification of Fine Coal Refuse to Eliminate Slurry Ponds. FLSmidth Technical Progress. Internal Report. 2008

[ 14 ] Fourie A. B.; Perceived and Realized Benefits of Paste and Thickened Tailings for Surface Deposition. University of Western Australia. 2012

[ 15 ] Garraway B.; Feedwell Designs. International Mining Magazine. 2009

[ 16 ] Hart G.; Thickener Tank Design Options. Outotec. Output Australia. 2009

[ 17] Laros T.J.; E-Duc Design and Standardization. Eimco Process Equipment. Internal Report. 1995

[ 18 ] Loan C.; Arbuthnot I.; Get Set Go. Outotec. Output Australia. 2010

[ 19 ] Loan C.; Trigglavcanin R.; A Quantum Change in the Thickening Process; Outotec. 2009

[ 20 ] MacNamara L.; Conveying the Future of Paste. FLSmidth. International Mining Magazine. 2009.

[ 21 ] MacNamara L.; Development of the Eimco DCT. FLSmidth. International Mining Magazine. 2006.

[ 22 ] McIntosh A.; Thickener Sizing and the Importance of Testwork. Outotec. Output Australia. 2009

[ 23 ] Moolman P.; Vietti A.; Tailings disposal an approach to optimize water and energy efficiency. The Southern African Institute of Mining and Metallurgy. Platinum Congress. 2012

[ 24 ] Newman P.; White R.; Cadden A.; The Future of Tailings Disposal. Golder Associates. 2004

[ 25 ] Okely A.; What's in your water?. Outokumpu. Output Australia. 2006

[ 26 ] Olcay R.; Deveplopment and Testing of a Paste Thickener. XII International Seminar on Paste and Thickened Tailings. 2009

[ 27 ] Richards J.; Sustainable Development and the Minerals Industry. Society of Economic Geologists Newsletters. 2002

[ 28 ] Schoenbrunn F.; A Short History of deep cone Thickeners. FLSmidth Internal Report. 2007

[ 29 ] Slade N.; Increasing Value in Mining operations Through the Application of Paste. X Mill Operators' Conference. Australia. 2009

[ 30 ] Slade N.; Kuyucak, N.; Tailings thickening to reduce impacts on water resources. Golder Associates. International Mining Magazine. 2009

[ 31 ] Slottee S.; Application of Thickeners in the Mineral Industry. Eimco. Internal Report. 2002

[ 32 ] Slottee S.; Crozier M.; Paste Thickener Technology. International Mining Magazine. 2006

[ 33 ] Slottee S.; Johnson J.; Paste Thickening Iron Ore Tailings. VI Bazilian Symposium on Iron Ore. Brasil. 2005

[ 34 ] Slottee S.; Paste Thickener Technology for Mine Backfill. Paste Thick Associates. Salt Lake City. 2009 
[ 35 ] Slottee S.; State of Art Deep Cone Paste. Generating Thickener Systems for Processing Mineral Tailings. Eimco Process Equipment Co.-Salt Lake City. Internal Report. 2002

[ 36 ] Toit T.; Khumani Iron Ore Mine Paste Disposal and Water Recovery System. The Journal of The Southern African Institute of Mining and Metallurgy. 2012

[ 37 ] Wennberg T.; Pumping Evaluations with Paste Tailings Thickened Closed to the Surface Disposal Area. LKAB. Sweden. 2007 


\section{Anexos}




\section{ENSAYOS DE SEDIMENTACIÓN Y REOLOGÍA}

\section{Mina:}

MINAS DE AGUAS TEÑIDAS

\section{Empresa:}

DOCTORANDO JOSE A. BUTRAGUEÑO

\section{Proyecto:}

Estudio sedimentación y reología de estériles espesados

\section{Aplicación}

Sedimentación. Estériles de flotación mineral Cu Polimetálico (Valdelamusa)

Fecha:

$28 / 01 / 2015$

\section{Ensayos:}

\begin{tabular}{|c|c|}
\hline $\mathbf{x}$ & Distribución granulométrica y caracterización de muestras \\
\hline $\mathbf{X}$ & Selección de floculantes \\
\hline $\mathbf{x}$ & Área de flujo \\
\hline $\mathbf{x}$ & Sedimentación en probeta estática \\
\hline $\mathbf{x}$ & Ensayo en espesador dinámico de laboratorio de $85 \mathrm{~mm}$ DIA \\
\hline $\mathbf{x}$ & Reología de los lodos \\
\hline & Ensayo de filtración a vacío \\
\hline
\end{tabular}

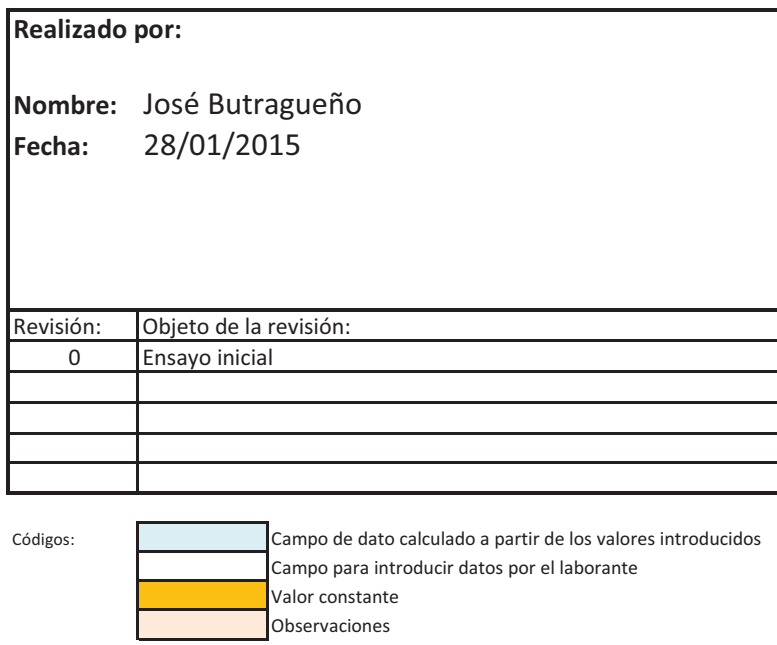


ENSAYO GRANULOMÉTRICO DE SÓLIDOS

Mina: MINAS DE AGUAS TEÑIDAS

Proyecto: Estudio sedimentación y reología de estériles espesados Realizado por: José Butragueño

\begin{tabular}{|ll|}
\hline Muestra ID: & M-100 \\
Material: & Estériles mineral polimetálico cobre \\
Preparado por: & José A. Butragueño \\
pH muestra: & - \\
Fecha: & $28 / 01 / 2015$ \\
\hline
\end{tabular}

CURVA GRANULOMÉTRICA DE SÓLIDOS

\begin{tabular}{|c|c|c|c|c|}
\hline \multicolumn{3}{|c|}{ DATOS DE LA PULPA A SEDIMENTAR } & \multicolumn{2}{|c|}{ Observaciones: Muestra de sólido seco } \\
\hline Densidad sólidos: & 4,50 & $\mathrm{~kg} / \mathrm{dm}^{3}$ & & \\
\hline Densidad líquido: & 1,00 & $\mathrm{~kg} / \mathrm{dm}^{3}$ & & \\
\hline Densidad pulpa: & & $\mathrm{kg} / \mathrm{l}$ & & \\
\hline Tara: & & $g$ & & \\
\hline Pulpa húmeda: & 0 & $g$ & Peso pulpa: & $0 \mathrm{~g}$ \\
\hline Sólido seco: & 0 & $\mathrm{~g}$ & Peso sólido: & $0 \mathrm{~g}$ \\
\hline \% Peso sólidos: & \#DIV/0! & $\%$ & & \\
\hline
\end{tabular}

\section{CURVA GRANULOMÉTRICA DE SÓLIDOS}

ENSAYO GRANULOMÉTRICO Muestra M-100

\begin{tabular}{|c|c|c|r|}
\hline Tamiz (micras) & \% pasa & Tamiz (micras) & \multicolumn{1}{c|}{ \% pasa } \\
\hline 0,479 & 0,17 & 30,200 & 64,53 \\
\hline 0,631 & 0,47 & 39,811 & 71,89 \\
\hline 0,832 & 0,89 & 52,481 & 79,03 \\
\hline 1,096 & 1,46 & 69,183 & 85,36 \\
\hline 1,445 & 2,26 & 91,201 & 90,34 \\
\hline 1,905 & 3,47 & 120,226 & 93,81 \\
\hline 2,512 & 5,35 & 158,489 & 96,09 \\
\hline 3,311 & 8,27 & 208,930 & 97,63 \\
\hline 4,365 & 12,56 & 275,423 & 98,76 \\
\hline 5,574 & 18,38 & 363,078 & 99,55 \\
\hline 7,586 & 25,54 & 478,630 & 99,96 \\
\hline 10,000 & 33,55 & 630,957 & 100,00 \\
\hline 13,183 & 41,74 & & \\
\hline 17,378 & 49,63 & & \\
\hline 22,909 & 57,16 & & \\
\hline
\end{tabular}

$P 80=54.59$ micras

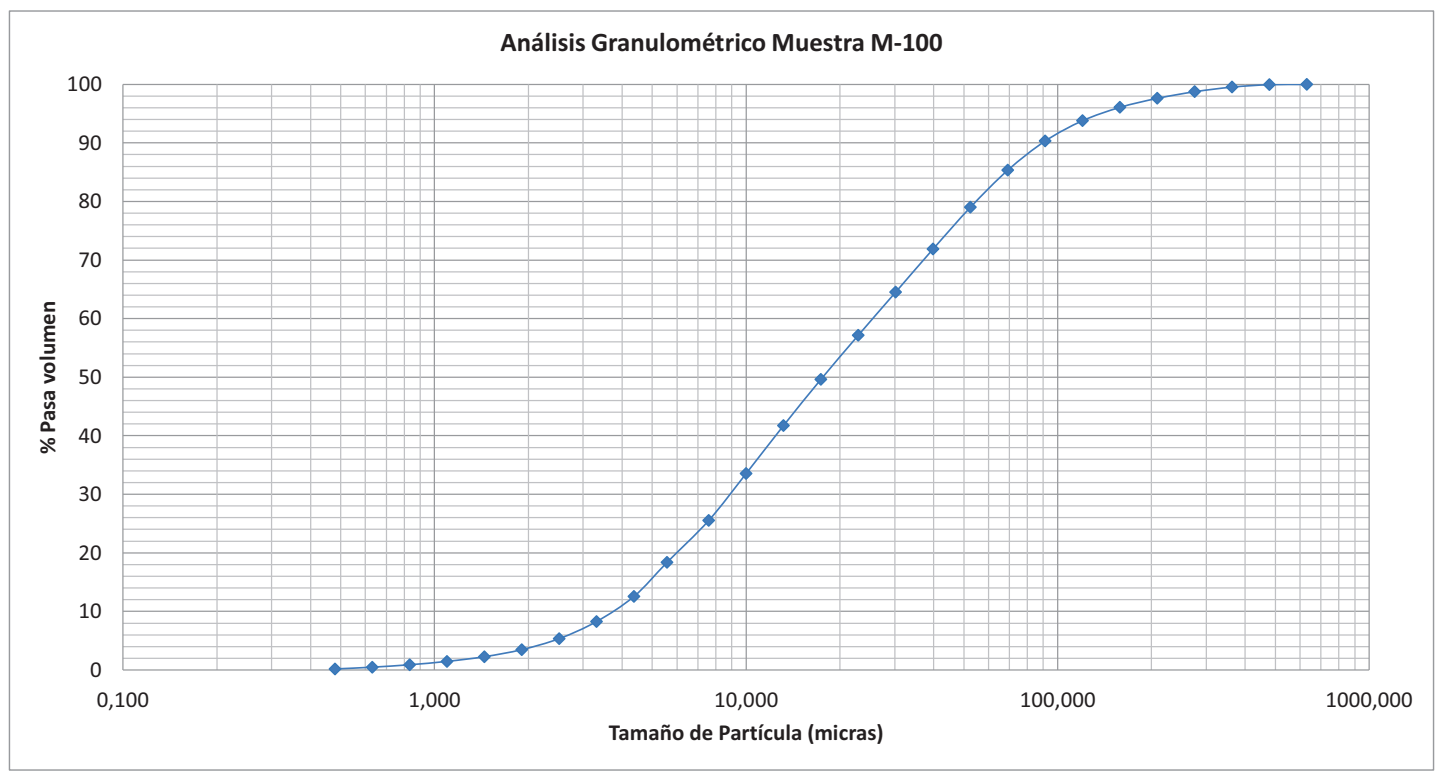




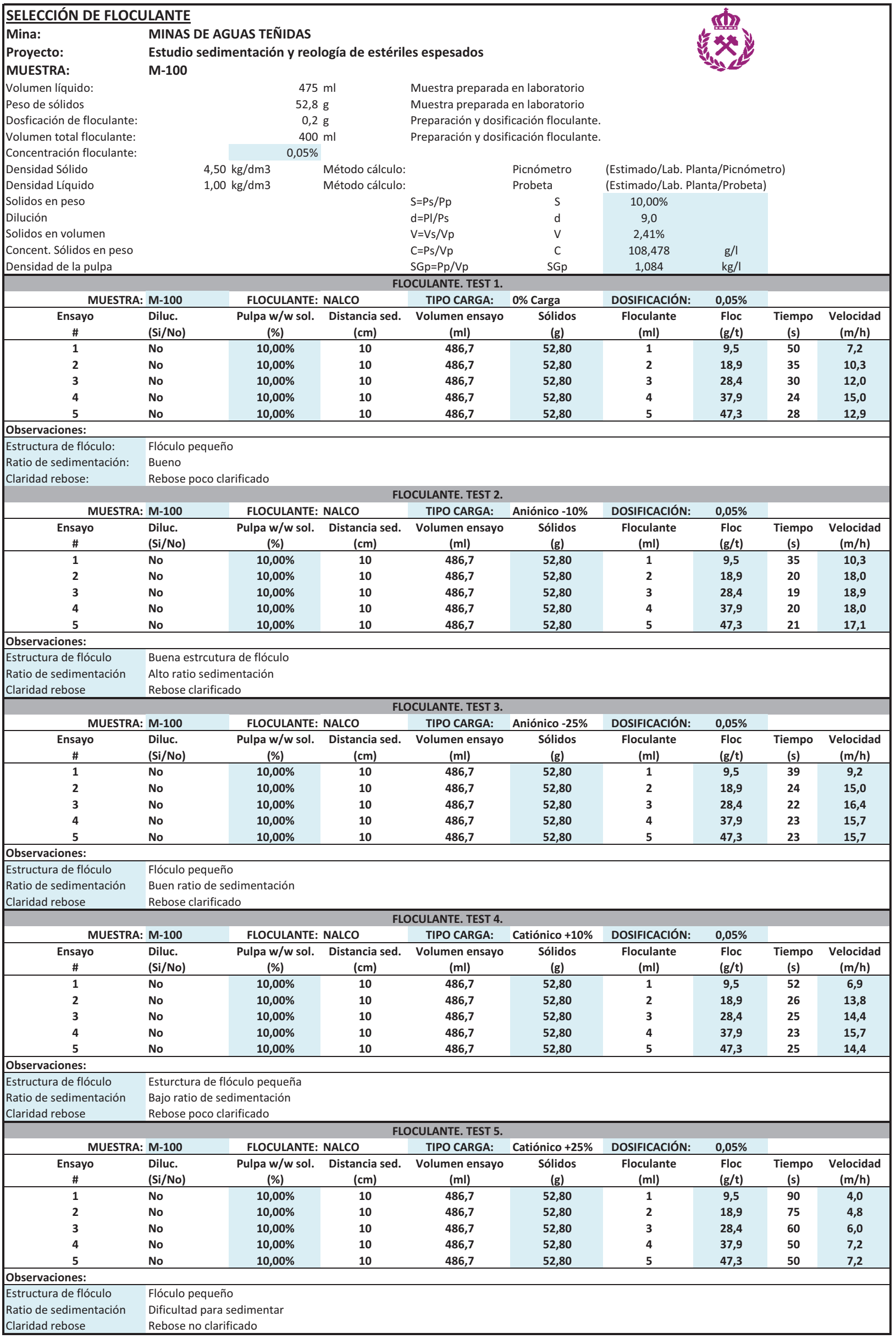


SELECCIÓN DE FLOCULANTE. ANÁLISIS DE DATOS.

Mina:

Proyecto:

MUESTRA:

Volumen líquido:

$\%$ sólidos en peso:

Dosficación de floculante:

Volumen total:

Concentración floculante:

Densidad Sólido

Densidad Líquido
MINAS DE AGUAS TEÑIDAS

Estudio sedimentación y reología de estériles espesados

M-100

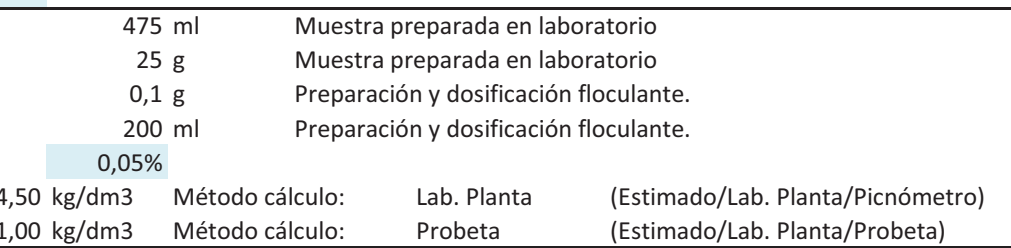

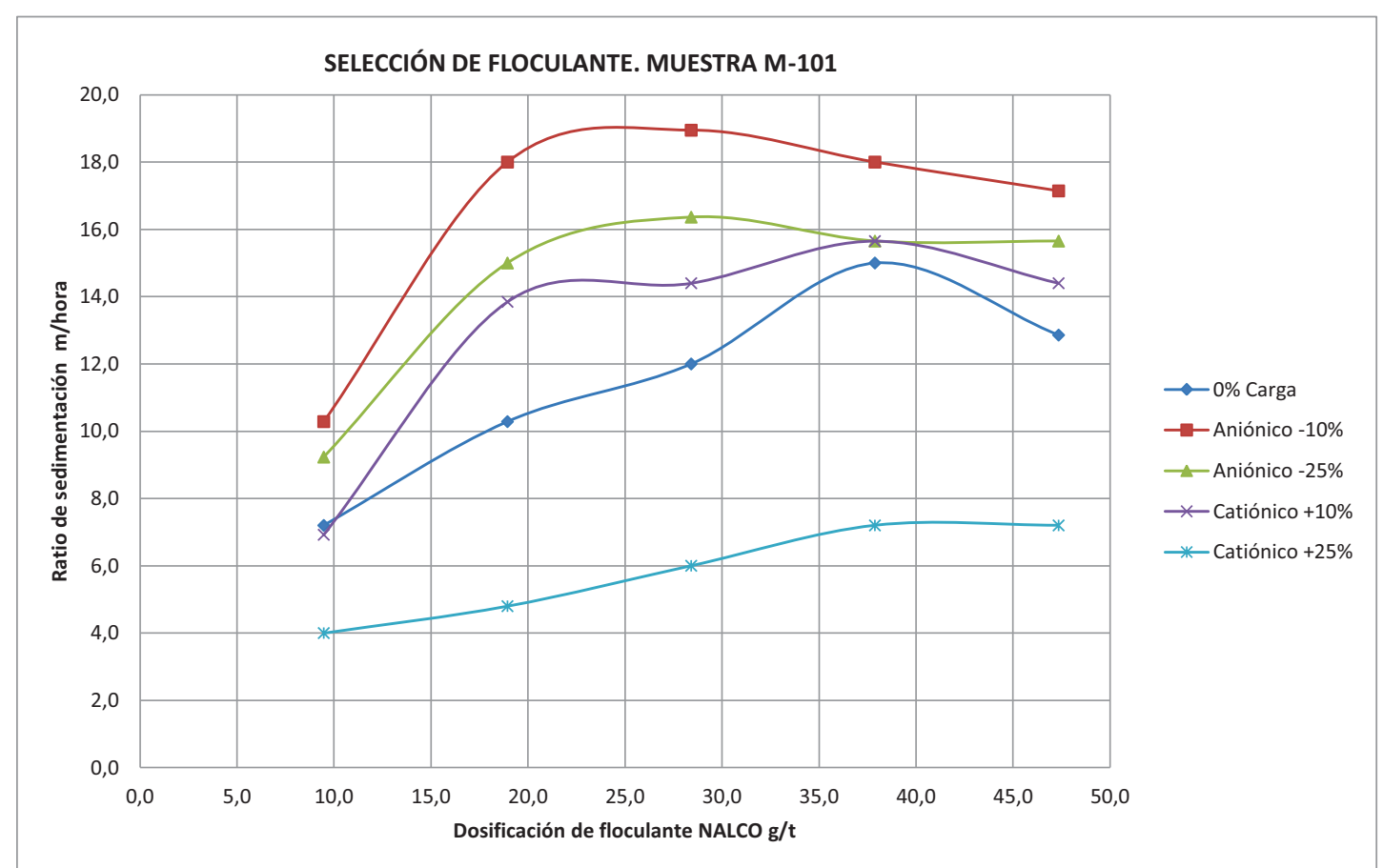

Los ensayos de sedimentación para la selección del floculante han tenido en cuenta tanto los valores de velocidad de sedimentación cómo los datos de observación visual de: tamaño de flóculo, velocidad de sedimentación, cohesión del flóculo y la claridad del rebose obtenida en la probeta de laboratorio. El floculante seleccionado será empleado en los ensayos de flujo de sedimentación. 
ENSAYO FLUJO SEDIMENTACIÓN

Mina: MINAS DE AGUAS TEÑIDAS

Proyecto: Estudio sedimentación y reología de estériles espesados

DATOS

FLOCULANTE SELECCIONADO

Volumen probeta:

$1000 \mathrm{ml}$

NALCO - $10 \%$ CARGA

Diámetro probeta: $\quad 58 \mathrm{~mm}$

Floc. Dosificac: $\quad \quad 0,2 \mathrm{~g}$

Volumen floc: $\quad 400 \mathrm{ml}$

Floculante dosific. $\quad 0,05 \%$

Floc. Conc. $\quad 0,50 \mathrm{~g} / \mathrm{l}$

Densidad Sólido $\quad 4,50 \mathrm{~kg} / \mathrm{dm} 3$

Densidad Líquido $\quad 1,00 \mathrm{~kg} / \mathrm{dm} 3$

NALCO -10\% CARGA @ 2.5\% Sól. Peso

$\begin{array}{lrr}\text { Diámetros de probetas: } & \\ 250 \mathrm{ml} & 35,7 & \mathrm{~mm} \\ 500 \mathrm{ml} & 48,6 & \mathrm{~mm} \\ 2000 \mathrm{ml} & 78,2 & \mathrm{~mm}\end{array}$

MUESTRA SÓLIDOS

M-100

NALCO -10\% CARGA @ 2.5\% Só. Peso

\begin{tabular}{|c|c|c|c|c|c|c|c|c|c|c|c|}
\hline \multicolumn{2}{|c|}{ MUESTRA: M-100 } & FLOCULANTE & \multicolumn{2}{|c|}{ NALCO - $10 \%$ CARGA } & \multicolumn{2}{|r|}{ CARGA SÓLIDOS: } & 2,50 & \multicolumn{4}{|l|}{$\%$} \\
\hline $\begin{array}{c}\text { Peso sólidos } \\
\text { (g) }\end{array}$ & $\begin{array}{c}\text { Vol. líquido } \\
(\mathrm{ml})\end{array}$ & $\begin{array}{c}\text { Sólidos } \\
(\% \mathrm{w} / \mathrm{w})\end{array}$ & $\begin{array}{c}\text { Densidad pulpa } \\
(\mathrm{kg} / \mathrm{l})\end{array}$ & $\begin{array}{c}\text { Conc. Solids } \\
(\mathrm{g} / \mathrm{l})\end{array}$ & $\begin{array}{c}\text { Floculant. } \\
(\mathrm{ml})\end{array}$ & $\begin{array}{l}\text { Dist. Sediment. } \\
(\mathrm{cm})\end{array}$ & $\begin{array}{c}\text { Tiempo sed. } \\
\text { (s) }\end{array}$ & $\begin{array}{c}\text { Velocidad sed. } \\
(\mathrm{m} / \mathrm{h})\end{array}$ & $\begin{array}{l}\text { Floc dosific. } \\
(\mathrm{g} / \mathrm{t})\end{array}$ & $\begin{array}{c}\text { Flujo } \\
\text { (tph/m2) }\end{array}$ & $\begin{array}{c}\begin{array}{c}\text { Flujo } \\
\text { (tpd/m2) }\end{array} \\
\end{array}$ \\
\hline 25,6 & 1000 & 2,50 & 1,020 & 25,46 & 0,5 & 10,0 & 9 & 40,0 & 10 & 3,88 & 93,02 \\
\hline 25,6 & 1000 & 2,50 & 1,020 & 25,46 & 1 & 10,0 & 8 & 45,0 & 20 & 4,36 & 104,64 \\
\hline 25,6 & 1000 & 2,50 & 1,020 & 25,46 & 1,5 & 10,0 & 7 & 51,4 & 29 & 4,98 & 119,59 \\
\hline 25,6 & 1000 & 2,50 & 1,020 & 25,46 & 2 & 10,0 & 7 & 51,4 & 39 & 4,98 & 119,59 \\
\hline 25,6 & 1000 & 2,50 & 1,020 & 25,46 & 2,5 & 10,0 & 8 & 45,0 & 49 & 4,36 & 104,64 \\
\hline 25,6 & 1000 & 2,50 & 1,020 & 25,46 & 3 & 10,0 & 8 & 45,0 & 59 & 4,36 & 104,64 \\
\hline
\end{tabular}

NALCO -10\% CARGA @ 5\% Sól. Peso

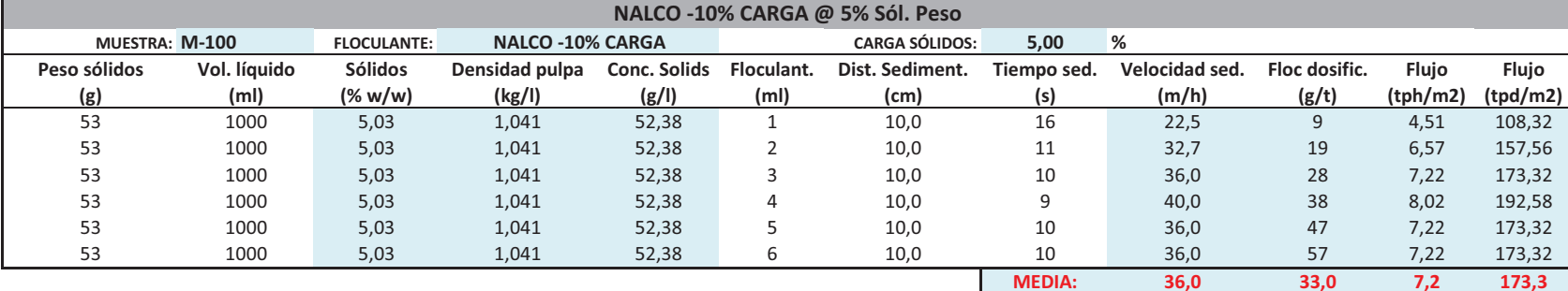

NALCO -10\% CARGA @ 7.5\% Sól. Peso

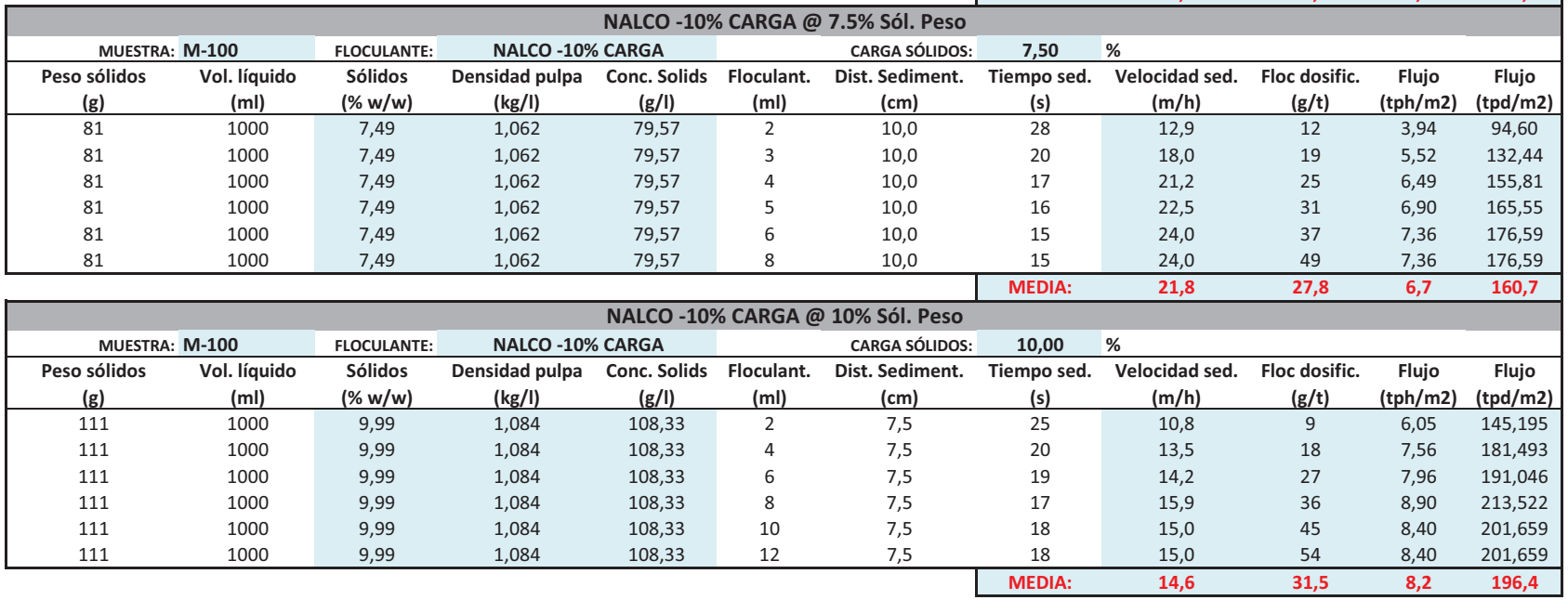


ENSAYO FLUJO SEDIMENTACIÓN. ANÁLISIS DE RESULTADOS.

Mina: MINAS DE AGUAS TEÑIDAS

Proyecto: $\quad$ Estudio sedimentación y reología de estériles espesados

DATOS

Volumen probeta:

$1000 \mathrm{ml}$

$58 \mathrm{~mm}$

Diámetro probeta:

Área sedimentac.

$26,42 \mathrm{~cm} 2$

Floc. Dosificac.:

Volumen floc:

Floculante dosific.

$0,2 \mathrm{~g}$

$400 \mathrm{ml}$

$0,05 \%$

Floc. Conc.

$0,50 \mathrm{~g} / \mathrm{l}$

$4,50 \mathrm{~kg} / \mathrm{dm} 3$

FLOCULANTE SELECCIONADO

Densidad Sólido

$1,00 \mathrm{~kg} / \mathrm{dm} 3$

NALCO -10\% CARGA IÓNICA

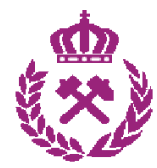

MUESTRA SÓLIDOS

M-100

Diámetros de probetas:

$250 \mathrm{ml} \quad 35,7 \quad \mathrm{~mm}$

$500 \mathrm{ml} \quad 48,6 \quad \mathrm{~mm}$

$2000 \mathrm{ml} \quad 78,2 \quad \mathrm{~mm}$

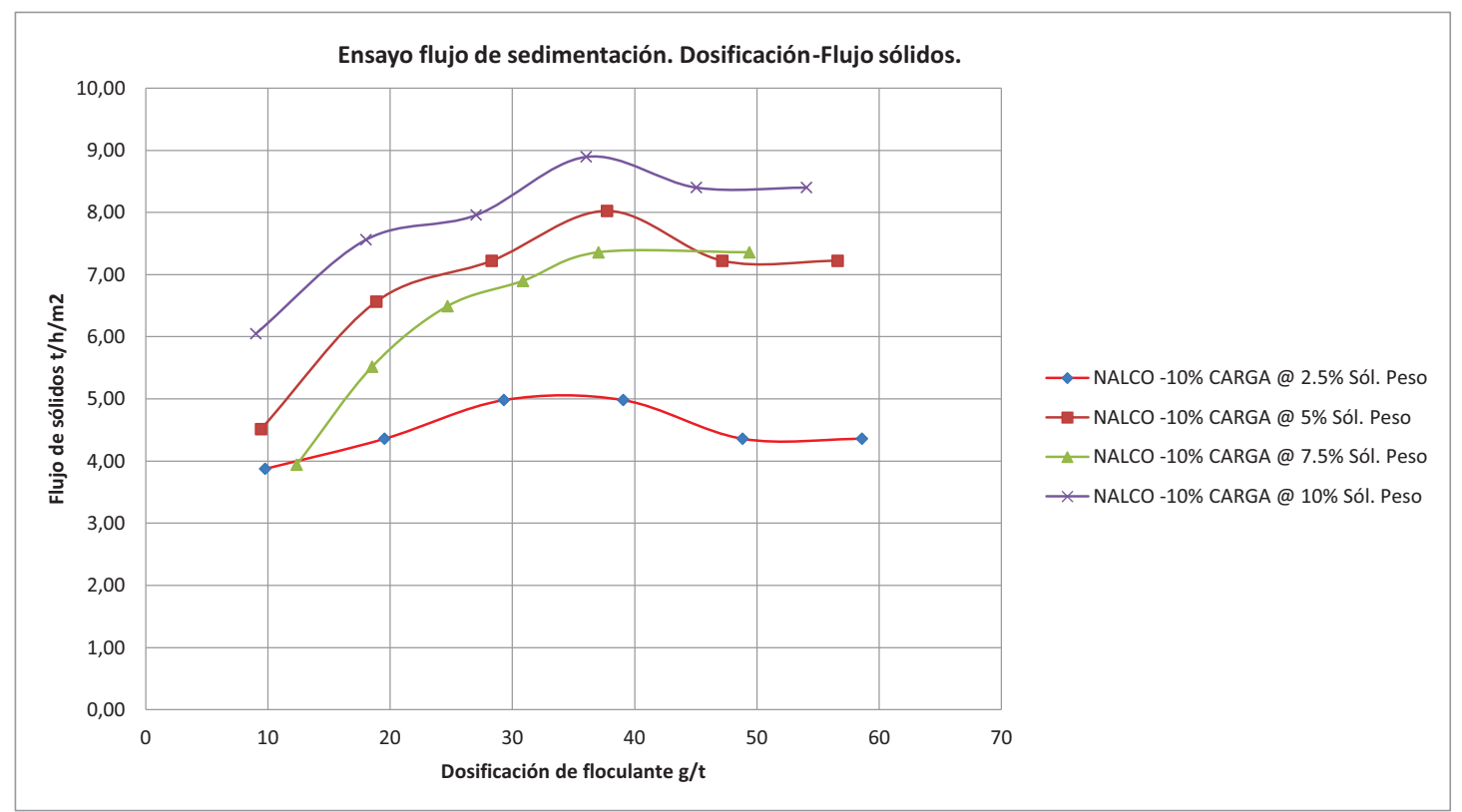

Los ensayos de flujos de sedimentación determinan la dilución óptima de los sólidos para la alimentación en el espesador.

El valor obtenido sirve de base para el diseño de la campana de alimentación y el sistema de dilución previsto. 
ENSAYO SEDIMENTACIÓN PROBETA $2000 \mathrm{ml}$ ESTÁTICO

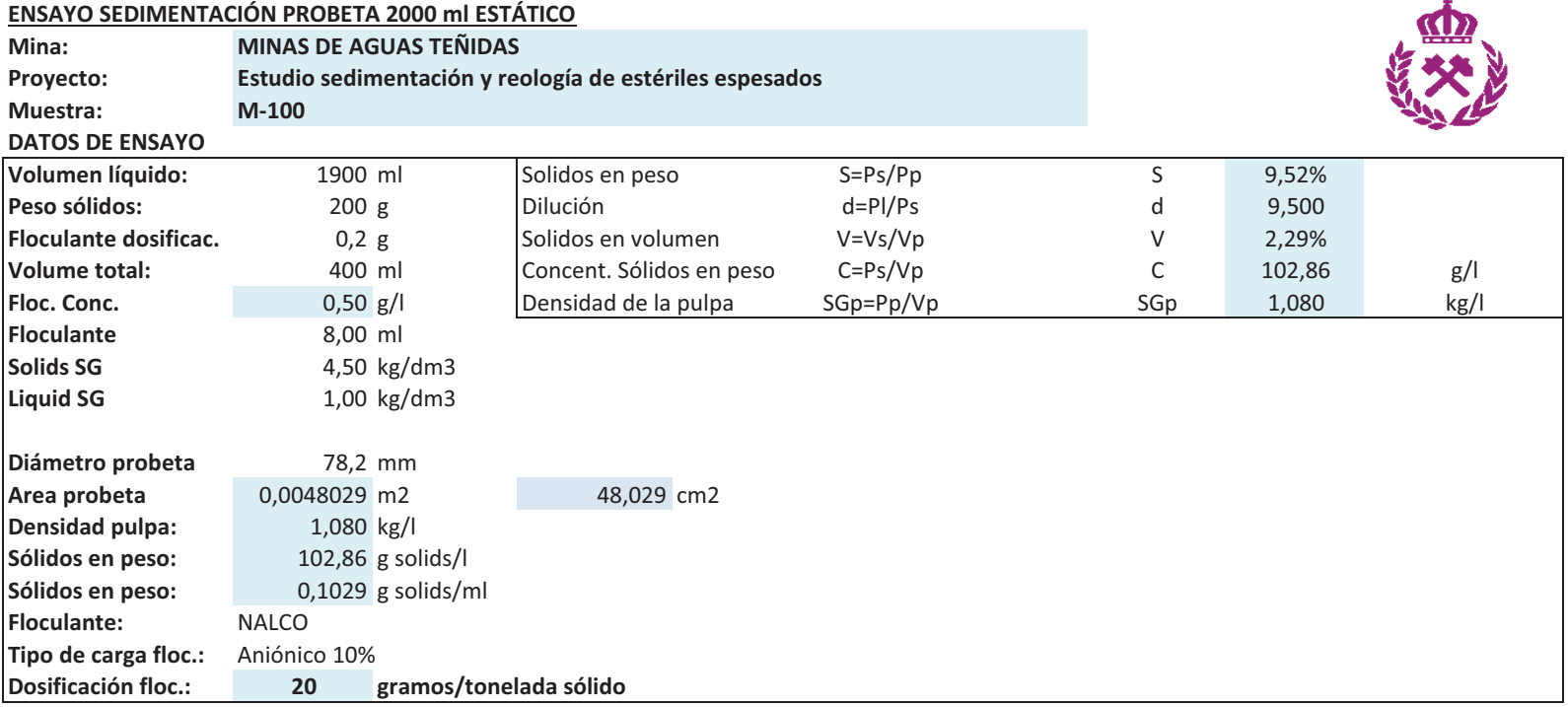

DATOS DE SEDIMENTACIÓN

\begin{tabular}{|c|c|c|c|c|c|c|c|c|c|}
\hline $\begin{array}{l}\text { Tiempo info } \\
\text { (sec) }\end{array}$ & $\begin{array}{c}\text { Tiempo } \\
\text { (min) }\end{array}$ & $\begin{array}{l}\text { Vol. Lodos } \\
\text { (ml) }\end{array}$ & $\begin{array}{l}\text { Altura interf. } \\
(\mathrm{cm})\end{array}$ & $\begin{array}{l}\text { Velocidad } \\
\text { (m/hr) }\end{array}$ & $\begin{array}{l}\text { SG. Lodos } \\
\text { (g/cm3) }\end{array}$ & $\begin{array}{l}\text { Lodos } \\
\text { \% Sol. Peso }\end{array}$ & $\begin{array}{c}\text { Flujo } \\
\text { (tph/m2) }\end{array}$ & $\begin{array}{c}\text { Flujo } \\
\text { (tpd/m2) }\end{array}$ & $\begin{array}{c}\text { Área Unit. Espes. } \\
\text { (m2/tpd) }\end{array}$ \\
\hline 0 & 0 & 1969 & 41,00 & 0 & 1,079 & 9,41 & 0 & 0 & 0 \\
\hline 5 & 0,08 & 1849 & 38,50 & 18,000 & 1,084 & 9,98 & 29,9820 & 719,57 & 0,001 \\
\hline 10 & 0,17 & 1753 & 36,50 & 14,400 & 1,089 & 10,48 & 29,9818 & 719,56 & 0,001 \\
\hline 15 & 0,25 & 1647 & 34,30 & 15,840 & 1,094 & 11,09 & 29,9819 & 719,57 & 0,001 \\
\hline 30 & 0,50 & 1345 & 28,00 & 15,120 & 1,116 & 13,33 & 9,9940 & 239,86 & 0,004 \\
\hline 45 & 0,75 & 1153 & 24,00 & 9,600 & 1,135 & 15,29 & 9,9940 & 239,86 & 0,004 \\
\hline 60 & 1,00 & 1009 & 21,00 & 7,200 & 1,154 & 17,18 & 9,9940 & 239,86 & 0,004 \\
\hline 120 & 2,00 & 552 & 11,50 & 5,700 & 1,282 & 28,25 & 2,4985 & 59,96 & 0,017 \\
\hline 180 & 3,00 & 432 & 9,00 & 1,500 & 1,360 & 34,02 & 2,4985 & 59,96 & 0,017 \\
\hline 240 & 4,00 & 394 & 8,20 & 0,480 & 1,395 & 36,40 & 2,4985 & 59,96 & 0,017 \\
\hline 300 & 5,00 & 360 & 7,50 & 0,420 & 1,432 & 38,78 & 2,4985 & 59,96 & 0,017 \\
\hline 450 & 7,50 & 307 & 6,40 & 0,264 & 1,506 & 43,20 & 0,9994 & 23,99 & 0,042 \\
\hline 600 & 10,00 & 288 & 6,00 & 0,096 & 1,540 & 45,07 & 0,9994 & 23,99 & 0,042 \\
\hline 900 & 15,00 & 279 & 5,80 & 0,024 & 1,558 & 46,07 & 0,4997 & 11,99 & 0,083 \\
\hline 1200 & 20,00 & 274 & 5,70 & 0,012 & 1,568 & 46,59 & 0,4997 & 11,99 & 0,083 \\
\hline 1500 & 25,00 & 264 & 5,50 & 0,024 & 1,589 & 47,65 & 0,4997 & 11,99 & 0,083 \\
\hline 1800 & 30,00 & 259 & 5,40 & 0,012 & 1,600 & 48,20 & 0,4997 & 11,99 & 0,083 \\
\hline 3600 & 60,00 & 255 & 5,30 & 0,002 & 1,611 & 48,77 & 0,0833 & 2,00 & 0,500 \\
\hline 5400 & 90,00 & 255 & 5,30 & 0,000 & 1,611 & 48,77 & 0,0833 & 2,00 & 0,500 \\
\hline 7200 & 120,00 & 255 & 5,30 & 0,000 & 1,611 & 48,77 & 0,0833 & 2,00 & 0,500 \\
\hline 9000 & 150,00 & 255 & 5,30 & 0,000 & 1,611 & 48,77 & 0,0833 & 2,00 & 0,500 \\
\hline 10800 & 180,00 & 255 & 5,30 & 0,000 & 1,611 & 48,77 & 0,0833 & 2,00 & 0,500 \\
\hline 14400 & 240,00 & 255 & 5,30 & 0,000 & 1,611 & 48,77 & 0,0416 & 1,00 & 1,001 \\
\hline
\end{tabular}

DATOS OBTENIDOS:

Velocidad de sedimentación promedio: $15.8 \mathrm{~m} / \mathrm{h}$

$\%$ sólidos - tiempo: $48,7 \%$ sólidos en peso - 60 minutos tiempo residencia 
Mina:

Proyecto:

Muestra
MINAS DE AGUAS TEÑIDAS

Estudio sedimentación y reología de estériles espesados M-100
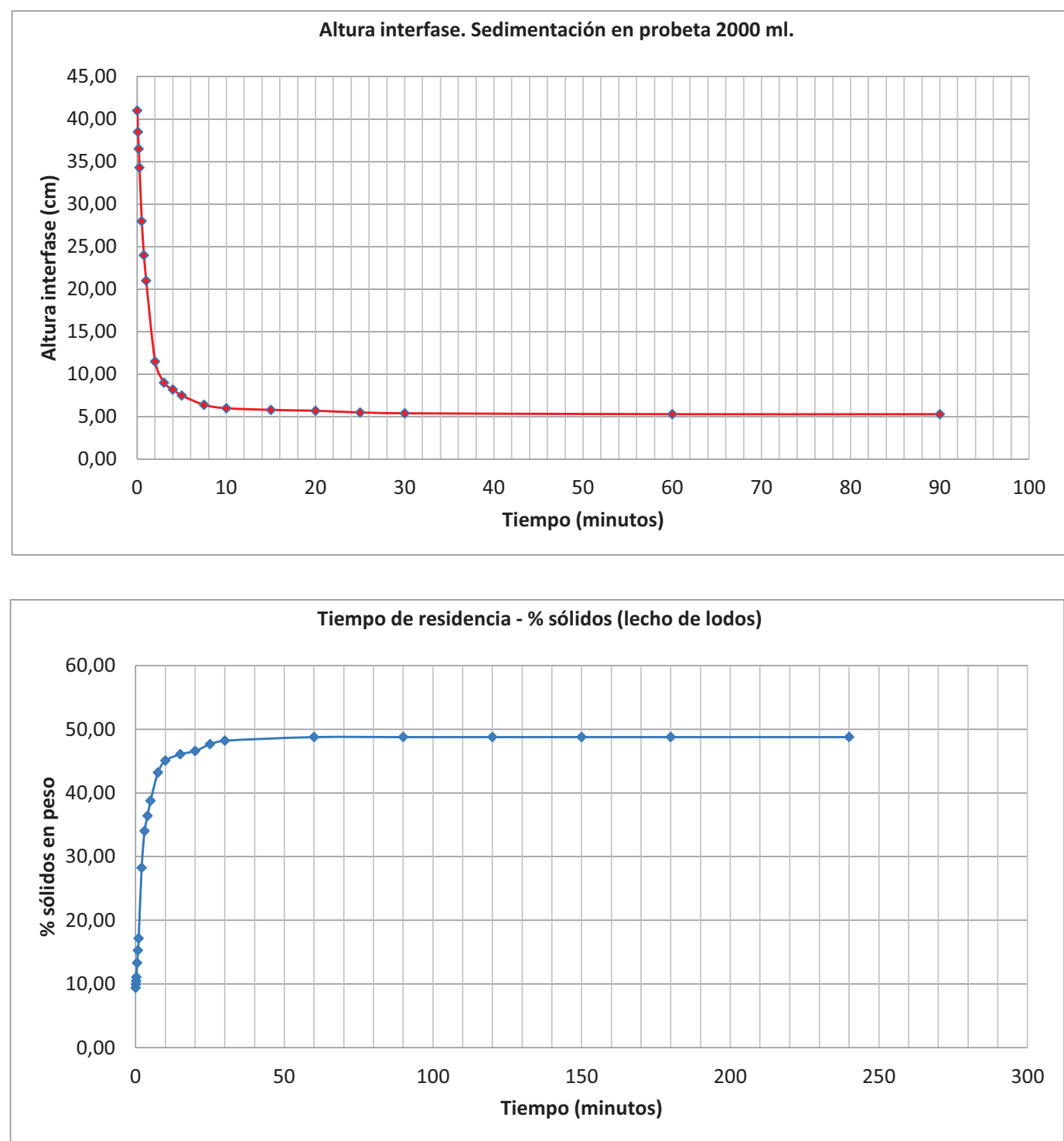


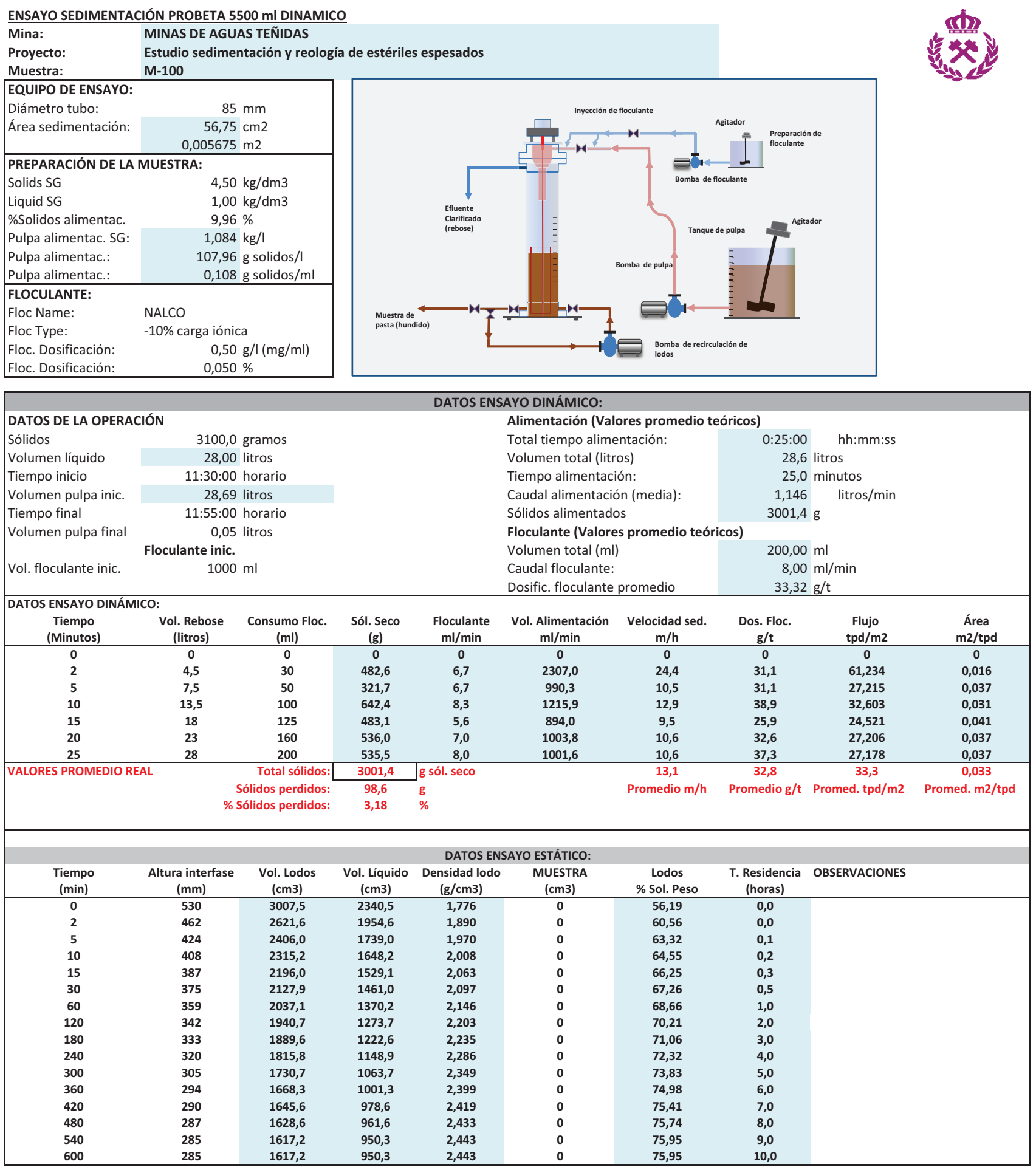


ENSAYO SEDIMENTACIÓN PROBETA 5500 mI DINAMICO

Mina: MINAS DE AGUAS TEÑIDAS

Proyecto: $\quad$ Estudio sedimentación y reología de estériles espesados

Muestra: $\quad \mathrm{M}-100$

DATOS DE OPERACIÓN DEL ESPESADOR DE TUBO PROFUNDO

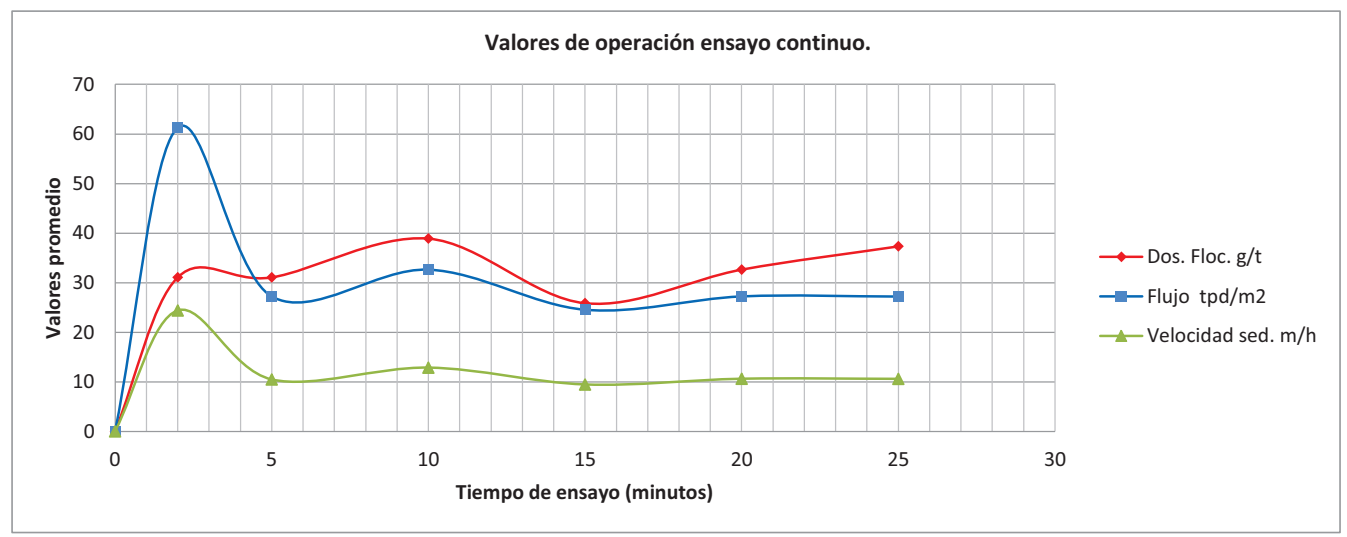

Datos Promedio:

Velocidad de sedimentación:

$13,1 \mathrm{~m} / \mathrm{h}$

Dosificación de floculante:

32,8

$0,0330 \mathrm{~m}^{2} / \mathrm{t} / \mathrm{día}$

Flujo de sedimentación:

$33,3 \mathrm{t} / \mathrm{dí} a / \mathrm{m}^{2}$

Flujo de sedimentación:

ENSAYO SEDIMENTACIÓN PROBETA $5500 \mathrm{mI}$ DINAMICO
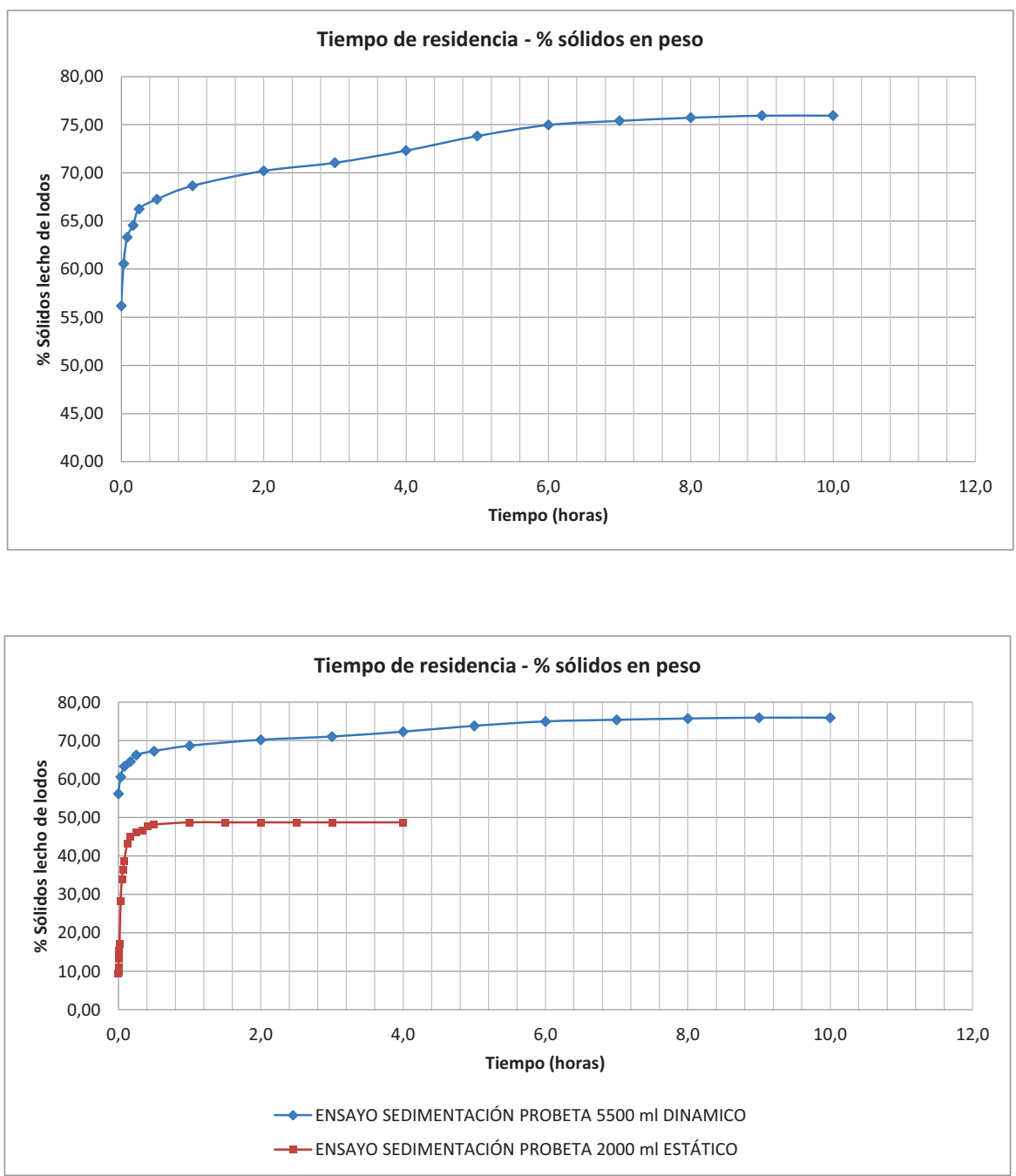
ENSAYO FILTRACIÓN A VACIO

Mina: MINAS DE AGUAS TEÑIDAS

Proyecto: $\quad$ Estudio sedimentación y reología de estériles espesados

Material:

Estudio sedimentación y reología de estériles espesados

Muestra:

M-100

Preparado por:

pH muestra:

Fecha:

$28 / 01 / 2015$

\begin{tabular}{|c|c|c|}
\hline \multicolumn{3}{|c|}{ DATOS DE LA MUESTRA: } \\
\hline Solidos SG & & $0,00 \mathrm{~kg} / \mathrm{dm} 3$ \\
\hline Liquido SG & & $0,00 \mathrm{~kg} / \mathrm{dm} 3$ \\
\hline \multicolumn{3}{|l|}{ FLOCULANTE: } \\
\hline Floc Name: & No & \\
\hline Tipo de floculante: & No & \\
\hline Floc. Dosificación: & & $0,00 \mathrm{~g} / \mathrm{l}(\mathrm{mg} / \mathrm{ml})$ \\
\hline Floc. Dosificación: & & $0,000 \%$ \\
\hline
\end{tabular}
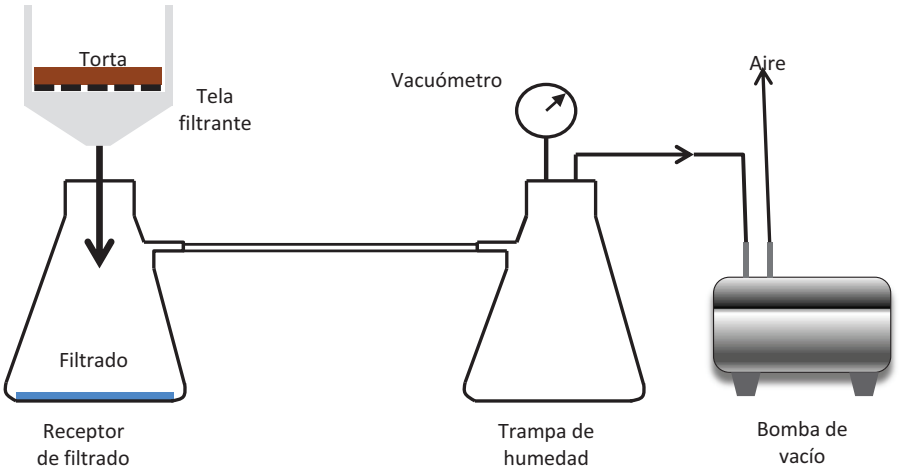

\begin{tabular}{|c|c|c|c|c|c|c|c|c|c|}
\hline \multicolumn{10}{|c|}{ ENSAYO FILTRACIÓN A VACÍO. TEST 1.} \\
\hline \multicolumn{2}{|c|}{ MUESTRA: M-100 } & & \multicolumn{7}{|c|}{ Tiempos de ensayo de filtración } \\
\hline $\begin{array}{l}\text { Vacío } \\
\text { (bar) }\end{array}$ & $\begin{array}{c}\text { Peso sólidos } \\
\text { (g) }\end{array}$ & $\begin{array}{l}\text { Vol. Líquido } \\
\text { (ml) }\end{array}$ & $\begin{array}{c}\text { \% Sól. Peso } \\
\text { (\%) }\end{array}$ & $\begin{array}{l}\text { Vol. Pulpa } \\
\text { (ml) }\end{array}$ & $\begin{array}{l}\text { Formación torta } \\
\text { (s) }\end{array}$ & $\begin{array}{l}\text { Secado torta } \\
\text { (s) }\end{array}$ & $\begin{array}{l}\text { Total ciclo } \\
\text { (s) }\end{array}$ & $\begin{array}{l}\text { Líq. Filtrado } \\
\quad(\mathrm{ml})\end{array}$ & $\begin{array}{c}\text { Espesor } \\
(\mathrm{mm})\end{array}$ \\
\hline 0 & 0 & 0,0 & \#DIV/0! & \#DIV/0! & 0 & 0 & 0 & 0 & 0,0 \\
\hline \% Solidos estimado: & \#DIV/0! & & \multirow{2}{*}{\multicolumn{2}{|c|}{ Observaciones: }} & & & & & \\
\hline Peso muestra húmedo: & 0 & $\mathrm{~g}$ & \multirow{3}{*}{\multicolumn{2}{|c|}{ Observaciones: }} & & & & & \\
\hline \multicolumn{3}{|c|}{\begin{tabular}{|l} 
Secado de la muestra: \\
\end{tabular}} & & & & & & & \\
\hline Peso muestra seco & 0 & $\mathrm{~g}$ & & & & & & & \\
\hline$\%$ humedad torta & \#DIV/0! & $\%$ & & & & & & & \\
\hline
\end{tabular}

\begin{tabular}{|c|c|c|c|c|c|c|c|c|c|}
\hline \multicolumn{10}{|c|}{ ENSAYO FILTRACIÓN A VACÍO. TEST 2.} \\
\hline \multicolumn{3}{|c|}{ MUESTRA: M-100 } & \multicolumn{7}{|c|}{ Tiempos de ensayo de filtración } \\
\hline $\begin{array}{l}\text { Vacío } \\
\text { (bar) }\end{array}$ & $\begin{array}{l}\text { Peso sólidos } \\
\text { (g) }\end{array}$ & $\begin{array}{l}\text { Vol. Líquido } \\
\text { (ml) }\end{array}$ & $\begin{array}{l}\text { \% Sól. Peso } \\
\text { (\%) }\end{array}$ & $\begin{array}{l}\text { Vol. Pulpa } \\
\text { (ml) }\end{array}$ & $\begin{array}{l}\text { Formación torta } \\
\text { (s) }\end{array}$ & $\begin{array}{l}\text { Secado torta } \\
\text { (s) }\end{array}$ & $\begin{array}{l}\text { Total ciclo } \\
\text { (s) }\end{array}$ & $\begin{array}{l}\text { Líq. Filtrado } \\
\text { (ml) }\end{array}$ & $\begin{array}{l}\text { Espesor } \\
(\mathrm{mm})\end{array}$ \\
\hline 0 & 0 & 0,0 & \#DIV/0! & \#DIV/0! & 0 & 0 & 0 & & 0,0 \\
\hline \% Solidos estimado: & \#DIV/O! & & & & & & & & \\
\hline Peso muestra húmedo: & 0 & $\mathrm{~g}$ & \multirow{3}{*}{\multicolumn{2}{|c|}{ Observaciones: }} & & & & & \\
\hline \multicolumn{3}{|c|}{ Secado de la muestra: } & & & & & & & \\
\hline Peso muestra seco & 0 & $\mathrm{~g}$ & & & & & & & \\
\hline$\%$ humedad torta & \#DIV/0! & $\%$ & \multicolumn{2}{|c|}{ Los pesos incluyen la tara } & & & & & \\
\hline
\end{tabular}

\begin{tabular}{|c|c|c|c|c|c|c|c|c|c|}
\hline \multicolumn{10}{|c|}{ ENSAYO FILTRACIÓN A VACÍO. TEST 3.} \\
\hline \multicolumn{3}{|c|}{ MUESTRA: M-100 } & \multicolumn{7}{|c|}{ Tiempos de ensayo de filtración } \\
\hline $\begin{array}{l}\text { Vacío } \\
\text { (bar) }\end{array}$ & $\begin{array}{l}\text { Peso sólidos } \\
\text { (g) }\end{array}$ & $\begin{array}{l}\text { Vol. Líquido } \\
\text { (ml) }\end{array}$ & $\begin{array}{c}\text { \% Sól. Peso } \\
\text { (\%) }\end{array}$ & $\begin{array}{l}\text { Vol. Pulpa } \\
\text { (ml) }\end{array}$ & $\begin{array}{l}\text { Formación torta } \\
\text { (s) }\end{array}$ & $\begin{array}{l}\text { Secado torta } \\
\text { (s) }\end{array}$ & $\begin{array}{l}\text { Total ciclo } \\
\text { (s) }\end{array}$ & $\begin{array}{l}\text { Líq. Filtrado } \\
\text { (ml) }\end{array}$ & $\begin{array}{c}\text { Espesor } \\
\text { (mm) }\end{array}$ \\
\hline 0 & 0 & 0,0 & \#DIV/0! & \#DIV/0! & 0 & 0 & 0 & 0 & 0,0 \\
\hline \% Solidos estimado: & \#DIV/0! & & & & & & & & \\
\hline Peso muestra húmedo: & 0 & $\mathrm{~g}$ & \multirow{4}{*}{\multicolumn{7}{|c|}{$\begin{array}{l}\text { Observaciones: } \\
\text { Contenido en sólidos de la torta filtrada: } 100-21,71=78,29 \%\end{array}$}} \\
\hline \multicolumn{3}{|c|}{ Secado de la muestra: } & & & & & & & \\
\hline Peso muestra seco & 0 & $\mathrm{~g}$ & & & & & & & \\
\hline$\%$ humedad torta & \#DIV/0! & $\%$ & & & & & & & \\
\hline
\end{tabular}

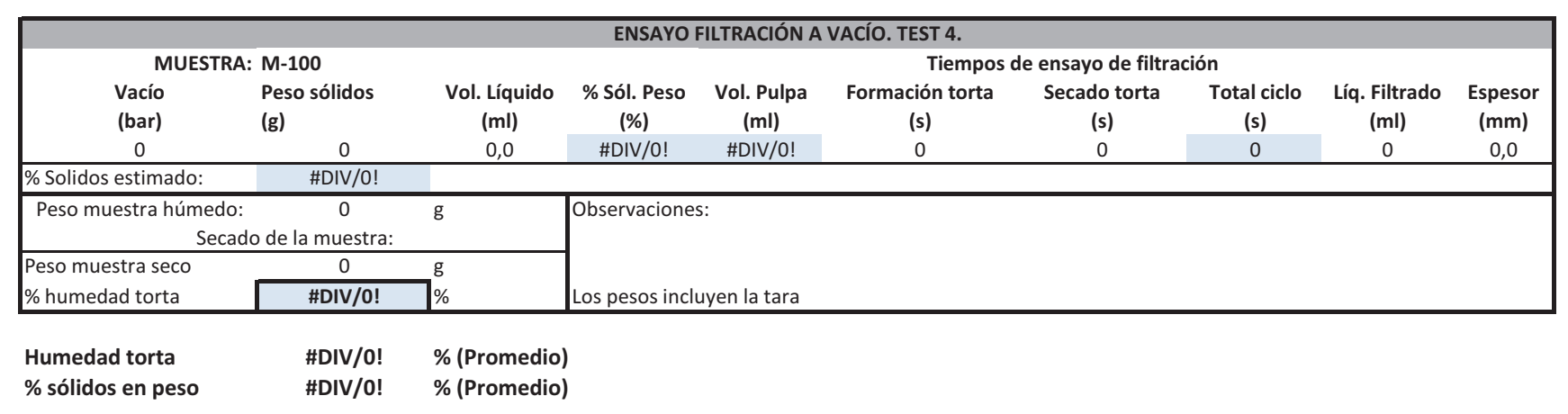


ENSAYO ASENTAMIENTO EN PROBETA

\section{Mina:}

Proyecto:

Material:

Preparado por:

pH muestra:

Fecha:

Aceleración gravedad (g):

Diámetro probeta:

Altura probeta $(\mathrm{H})$ :

Volumen probeta:

Solidos SG

Líquido SG

Expresiones empíricas

$T=0.5-0.5(h / H)^{\wedge} 0.5$

T.F. $=\mathrm{T}^{*} \mathrm{~d}^{*} \mathrm{~g}^{*}(\mathrm{H} / 100)$

\section{MINAS DE AGUAS TEÑIDAS}

Estudio sedimentación y reología de estériles espesados

Estériles mineral polimetálico cobre

José A. Butragueño

$28 / 01 / 2015$
$9,81 \mathrm{~m} / \mathrm{s} 2$

$44 \mathrm{~mm}$

$100 \mathrm{~mm}$

$152,1 \mathrm{~cm} 3$

$4,50 \mathrm{~kg} / \mathrm{dm} 3$

$1,00 \mathrm{~kg} / \mathrm{dm} 3$

\begin{tabular}{|c|c|c|c|c|c|c|c|c|c|c|}
\hline \multicolumn{11}{|c|}{ ENSAYOS DE ASENTAMIENTO EN PROBETA } \\
\hline $\begin{array}{l}\text { Muestra } \\
\text { ID }\end{array}$ & $\begin{array}{c}\text { Cont. Sólidos } \\
\text { (\%) }\end{array}$ & $\begin{array}{c}\text { Solidos SG } \\
\mathrm{g} / \mathrm{cm} 3\end{array}$ & $\begin{array}{l}\text { Peso Liq. } \\
\text { (kg liq/kg sol) }\end{array}$ & $\begin{array}{l}\text { Vol. Pulpa } \\
\text { (1/kg sol) }\end{array}$ & $\begin{array}{l}\text { Pulpa SG (d) } \\
\text { kg/dm3 }\end{array}$ & $\begin{array}{l}\text { Sólidos prob. } \\
\text { (g) }\end{array}$ & $\begin{array}{l}\text { Liq. Probeta } \\
\text { (g) }\end{array}$ & $\begin{array}{c}\text { Asentamiento (h) } \\
\mathrm{mm}\end{array}$ & $\begin{array}{l}\text { Factor "T" } \\
\text { Adimens. }\end{array}$ & $\begin{array}{c}\text { Tensión Fluencia } \\
\text { (Pa) }\end{array}$ \\
\hline 1 & 68,5 & 4,50 & 0,460 & 0,682 & 2,140 & 222,9 & 102,5 & 45 & 0,16459 & 345,6 \\
\hline 2 & 67,5 & 4,50 & 0,481 & 0,704 & 2,105 & 216,1 & 104,0 & 52 & 0,13944 & 288,0 \\
\hline 3 & 65 & 4,50 & 0,538 & 0,761 & 2,022 & 199,9 & 107,6 & 62 & 0,10630 & 210,9 \\
\hline 4 & 62,5 & 4,50 & 0,600 & 0,822 & 1,946 & 184,9 & 111,0 & 79 & 0,05559 & 106,1 \\
\hline 5 & 60 & 4,50 & 0,667 & 0,889 & 1,875 & 171,1 & 114,0 & 90 & 0,02566 & 47,2 \\
\hline 6 & 55 & 4,50 & 0,818 & 1,040 & 1,748 & 146,1 & 119,6 & 96 & 0,01010 & 17,3 \\
\hline
\end{tabular}

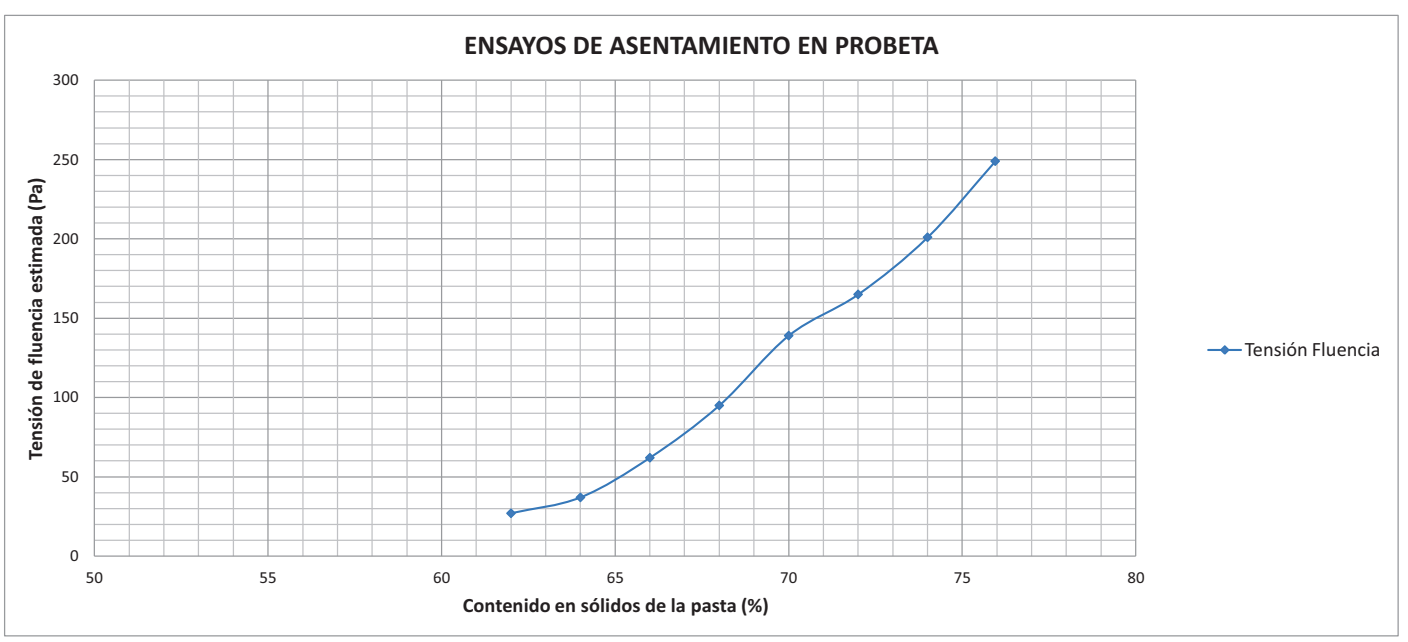




\section{ENSAYOS DE SEDIMENTACIÓN Y REOLOGÍA}

\section{Mina:}

\section{MINAS DE AGUAS TEÑIDAS}

\section{Empresa:}

DOCTORANDO JOSE A. BUTRAGUEÑO

\section{Proyecto:}

Estudio sedimentación y reología de estériles espesados

\section{Aplicación}

Sedimentación. Estériles de flotación mineral Cu Polimetálico (Calañas)

Fecha:

$07 / 03 / 2015$

\section{Ensayos:}

\begin{tabular}{|c|c|}
\hline $\mathbf{X}$ & Distribución granulométrica y caracterización de muestras \\
\hline $\mathbf{X}$ & Selección de floculantes \\
\hline $\mathbf{X}$ & Área de flujo \\
\hline $\mathbf{x}$ & Sedimentación en probeta estática \\
\hline $\mathbf{x}$ & Ensayo en espesador dinámico de laboratorio de $85 \mathrm{~mm}$ DIA \\
\hline $\mathbf{X}$ & Reología de los lodos \\
\hline & Ensayo de filtración a vacío \\
\hline
\end{tabular}

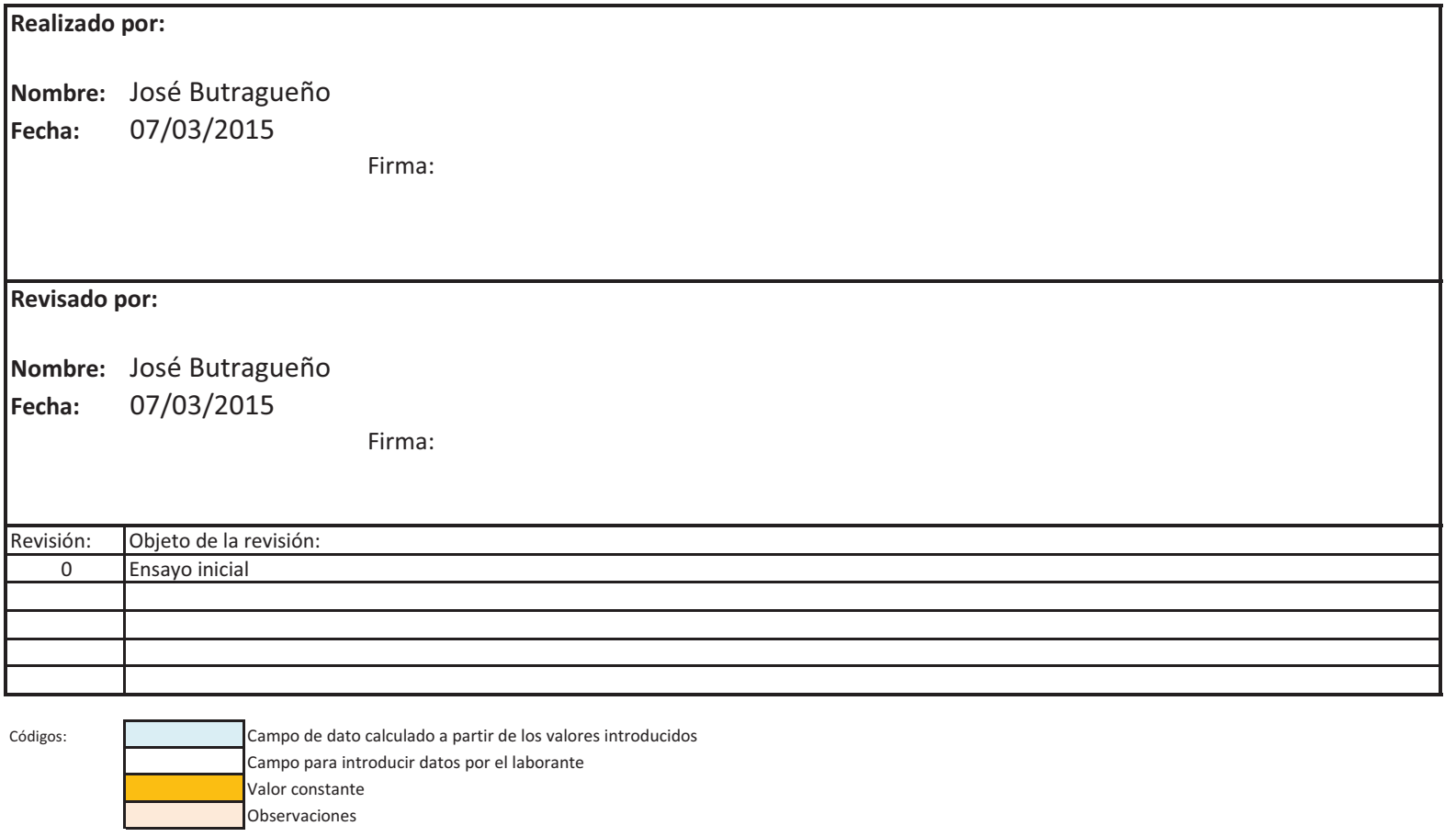

CONFIDENCIAL: Este documento contiene información propiedad de DOCTORANDO JOSE A. BUTRAGUEÑO y está sujeto a ser devuelto bajo demanda; estando prohibida su reproducción, copia, préstamo o cualquier otro uso que no sea el fin para el que fue expresamente realizado, sin el consentimiento expreso por escrito de: DOCTORANDO JOSE A. BUTRAGUEÑO 
ENSAYO GRANULOMÉTRICO DE SÓLIDOS

Mina: MINAS DE AGUAS TEÑIDAS

Proyecto: Estudio sedimentación y reología de estériles espesados Realizado por: José Butragueño

\begin{tabular}{|ll|}
\hline Muestra ID: & M-101 \\
Material: & Estériles mineral polimetálico cobre-Calañas \\
Preparado por: & José A. Butragueño \\
pH muestra: & - \\
Fecha: & $07 / 03 / 2015$ \\
\hline
\end{tabular}

Fecha:

$07 / 03 / 2015$

CURVA GRANULOMÉTRICA DE SÓLIDOS

\begin{tabular}{|c|c|c|c|c|}
\hline \multicolumn{3}{|c|}{ DATOS DE LA PULPA A SEDIMENTAR } & \multirow{2}{*}{\multicolumn{2}{|c|}{ Observaciones: Muestra de sólido seco }} \\
\hline Densidad sólidos: & 4,00 & $\mathrm{~kg} / \mathrm{dm}^{3}$ & & \\
\hline Densidad líquido: & 1,00 & $\mathrm{~kg} / \mathrm{dm}^{3}$ & & \\
\hline Densidad pulpa: & & $\mathrm{kg} / \mathrm{l}$ & & \\
\hline Tara: & 0 & $\mathrm{~g}$ & & \\
\hline Pulpa húmeda: & 0 & $\mathrm{~g}$ & Peso pulpa: & $0 \mathrm{~g}$ \\
\hline Sólido seco: & 0 & $\mathrm{~g}$ & Peso sólido: & \begin{tabular}{l|l|}
0 & $\mathrm{~g}$ \\
\end{tabular} \\
\hline \% Peso sólidos: & \#DIV/O! & $\%$ & & \\
\hline
\end{tabular}

\section{CURVA GRANULOMÉTRICA DE SÓLIDOS}

ENSAYO GRANULOMÉTRICO Muestra M-100

\begin{tabular}{|c|c|c|r|}
\hline Tamiz (micras) & \% pasa & Tamiz (micras) & \% pasa \\
\hline 0,363 & 0,61 & 22,909 & 92,32 \\
\hline 0,479 & 1,01 & 30,200 & 97,28 \\
\hline 0,631 & 1,53 & 39,811 & 99,57 \\
\hline 0,832 & 2,25 & 52,481 & 100,00 \\
\hline 1,096 & 3,39 & 69,183 & 100,00 \\
\hline 1,445 & 5,17 & 91,201 & 100,00 \\
\hline 1,905 & 7,94 & & \\
\hline 2,512 & 12,08 & & \\
\hline 3,311 & 17,96 & & \\
\hline 4,365 & 25,88 & & \\
\hline 5,754 & 35,87 & & \\
\hline 7,586 & 47,69 & & \\
\hline 10,000 & 60,55 & & \\
\hline 13,183 & 73,19 & & \\
\hline 17,378 & 84,17 & & \\
\hline
\end{tabular}

$P 80=15,534$ micras

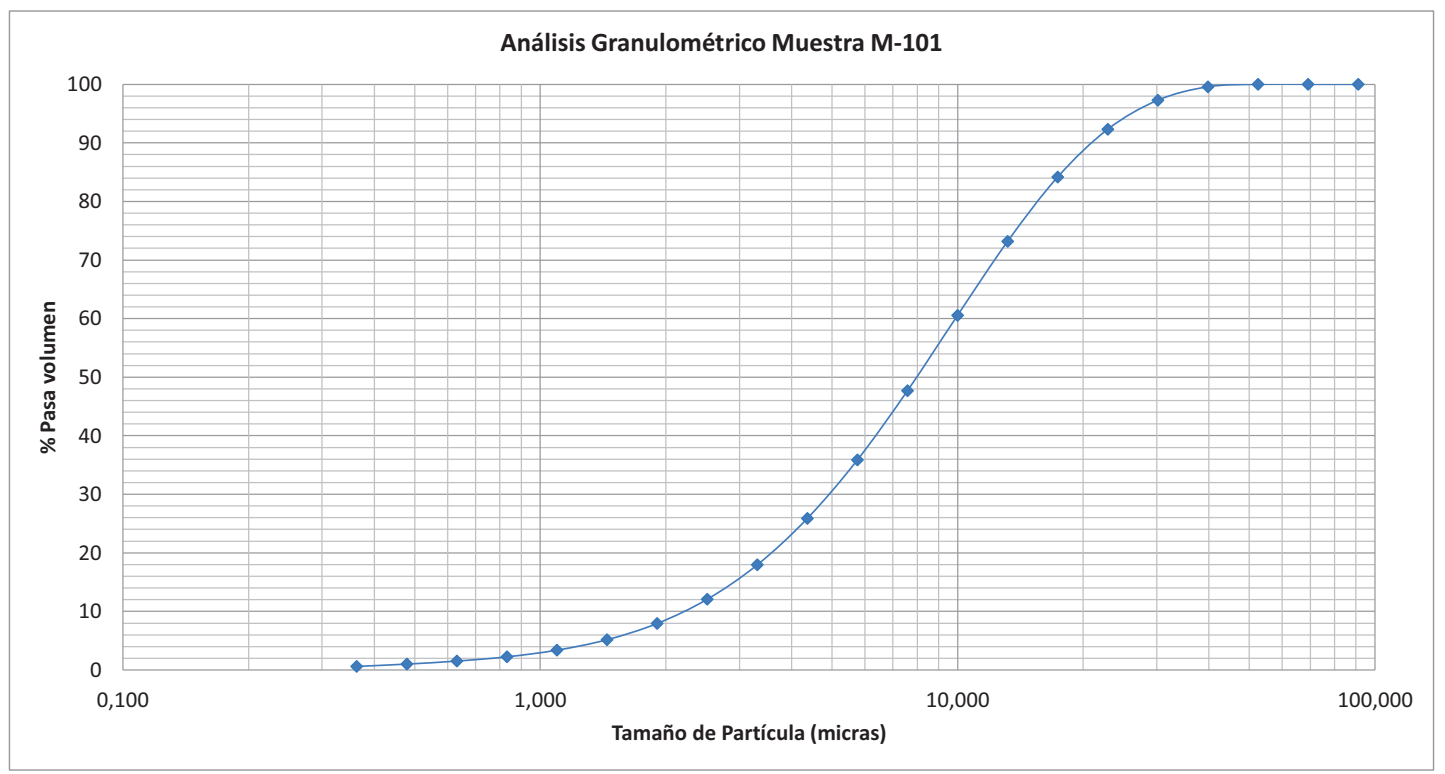




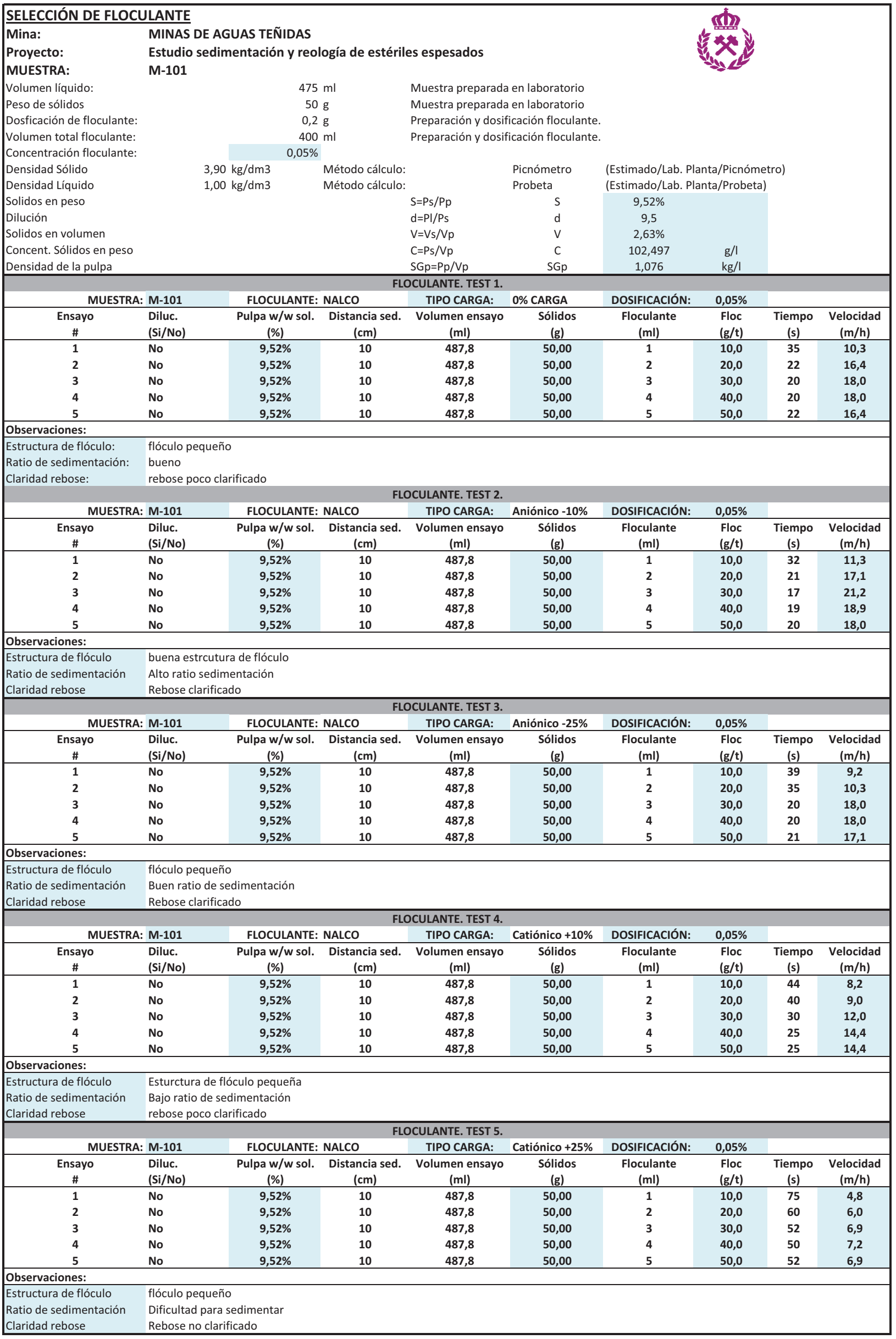


SELECCIÓN DE FLOCULANTE. ANÁLISIS DE DATOS.

\section{Mina: MINAS DE AGUAS TEÑIDAS}

Proyecto:

Estudio sedimentación y reología de estériles espesados

MUESTRA:

M-101

Volumen líquido:

$\%$ sólidos en peso:

Dosficación de floculante:

Volumen total:

Concentración floculante:

Densidad Sólido

Densidad Líquido

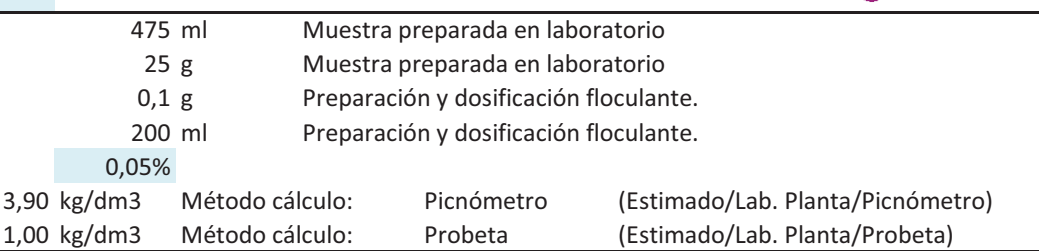

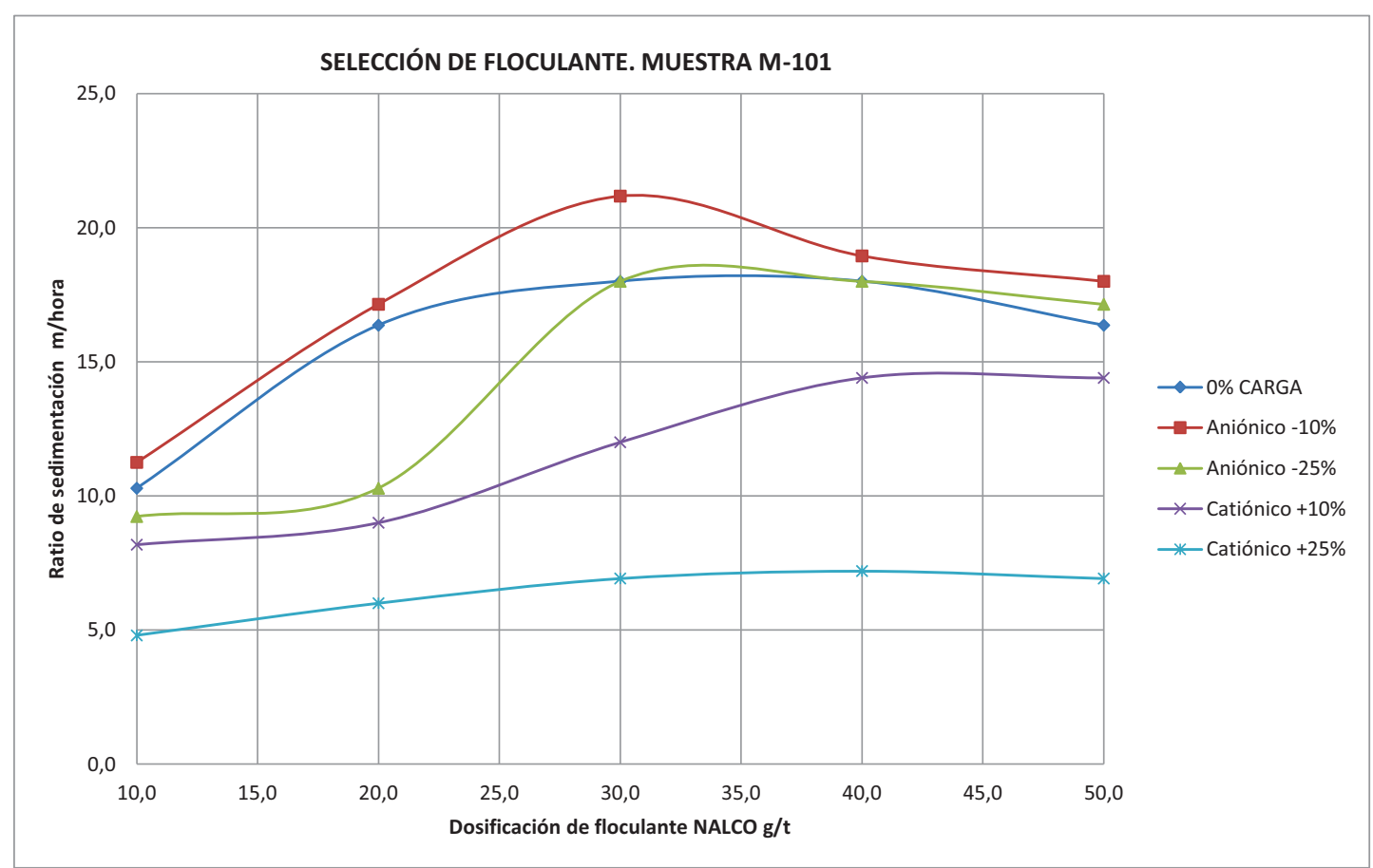

Los ensayos de sedimentación para la selección del floculante han tenido en cuenta tanto los valores de velocidad de sedimentación cómo los datos de observación visual de: tamaño de flóculo, velocidad de sedimentación, cohesión del flóculo y la claridad del rebose obtenida en la probeta de laboratorio. El floculante seleccionado será empleado en los ensayos de flujo de sedimentación. 
ENSAYO FLUJO SEDIMENTACIÓN

Mina: MINAS DE AGUAS TEÑIDAS

Proyecto: Estudio sedimentación y reología de estériles espesados

DATOS

Volumen probeta:

$1000 \mathrm{ml}$

$58 \mathrm{~mm}$

Área sedimentac. $\quad 26,42 \mathrm{~cm} 2$

Floc. Dosificac.: $\quad 0,2 \mathrm{~g}$

Volumen floc.:

Floculante dosific.

$400 \mathrm{ml}$

$0,05 \%$

Floc. Conc. $\quad 0,50 \mathrm{~g} / \mathrm{l}$

Densidad Sólido $\quad 3,90 \mathrm{~kg} / \mathrm{dm} 3$

Densidad Líquido $1,00 \mathrm{~kg} / \mathrm{dm} 3$

FLOCULANTE SELECCIONADO

NALCO - $10 \%$ CARGA

MUESTRA SÓLIDOS

M-101

$\begin{array}{lrr}\text { Diámetros de probetas: } & \\ 250 \mathrm{ml} & 35,7 & \mathrm{~mm} \\ 500 \mathrm{ml} & 48,6 & \mathrm{~mm} \\ 2000 \mathrm{ml} & 78,2 & \mathrm{~mm}\end{array}$

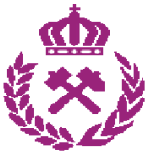

\begin{tabular}{|c|c|c|c|c|c|c|c|c|c|c|c|}
\hline \multicolumn{12}{|c|}{ NALCO -10\% CARGA @ 2.5\% Sól. Peso } \\
\hline \multicolumn{2}{|c|}{ MUESTRA: M-101 } & \multirow{2}{*}{$\begin{array}{l}\text { FLOCULANTE: } \\
\text { Sólidos } \\
\text { (\% w/w) }\end{array}$} & \multicolumn{2}{|c|}{ NALCO - $10 \%$ CARGA } & \multirow[b]{2}{*}{$\begin{array}{c}\text { Floculant. } \\
\text { (ml) }\end{array}$} & \multirow{2}{*}{$\begin{array}{l}\text { CARGA SóLIDOS } \\
\text { Dist. Sediment. } \\
\text { (cm) }\end{array}$} & \multirow{2}{*}{$\begin{array}{c}2,50 \\
\text { Tiempo sed. } \\
\text { (s) }\end{array}$} & \multirow{2}{*}{$\begin{array}{l}\% \\
\begin{array}{c}\text { Velocidad sed. } \\
(\mathrm{m} / \mathrm{h})\end{array}\end{array}$} & \multirow[b]{2}{*}{$\begin{array}{c}\text { Floc dosific. } \\
(\mathrm{g} / \mathrm{t})\end{array}$} & \multirow[b]{2}{*}{$\begin{array}{c}\begin{array}{c}\text { Flujo } \\
\text { (tph/m2) }\end{array} \\
\end{array}$} & \multirow[b]{2}{*}{$\begin{array}{c}\text { Flujo } \\
\text { (tpd/m2) }\end{array}$} \\
\hline $\begin{array}{c}\text { Peso sólidos } \\
\text { (g) }\end{array}$ & $\begin{array}{c}\text { Vol. líquido } \\
\text { (ml) }\end{array}$ & & $\begin{array}{c}\text { Densidad pulpa } \\
(\mathrm{kg} / \mathrm{l})\end{array}$ & $\begin{array}{c}\text { Conc. Solids } \\
(\mathrm{g} / \mathrm{l})\end{array}$ & & & & & & & \\
\hline 25,0 & 1000 & 2,44 & 1,018 & 24,84 & 0,5 & 10,0 & 8 & 45,0 & 10 & 4,26 & 102,19 \\
\hline 25,0 & 1000 & 2,44 & 1,018 & 24,84 & 1 & 10,0 & 6 & 60,0 & 20 & 5,68 & 136,26 \\
\hline 25,0 & 1000 & 2,44 & 1,018 & 24,84 & 1,5 & 10,0 & 5 & 72,0 & 30 & 6,81 & 163,51 \\
\hline 25,0 & 1000 & 2,44 & 1,018 & 24,84 & 2 & 10,0 & 5 & 72,0 & 40 & 6,81 & 163,51 \\
\hline 25,0 & 1000 & 2,44 & 1,018 & 24,84 & 2,5 & 10,0 & 4 & 90,0 & 50 & 8,52 & 204,38 \\
\hline 25,0 & 1000 & 2,44 & 1,018 & 24,84 & 3 & 10,0 & 4 & 90,0 & 60 & 8,52 & 204,38 \\
\hline
\end{tabular}

NALCO -10\% CARGA @ 5\% Sól. Peso

\begin{tabular}{|c|c|c|c|c|c|c|c|c|c|c|c|}
\hline \multicolumn{12}{|c|}{ NALCO -10\% CARGA @ 5\% Sól. Peso } \\
\hline \multicolumn{2}{|c|}{ MUESTRA: M-101 } & \multirow{2}{*}{$\begin{array}{l}\text { FLOCULANTE: } \\
\text { Sólidos } \\
(\% \mathrm{w} / \mathrm{w})\end{array}$} & \multicolumn{2}{|c|}{ NALCO $-10 \%$ CARGA } & \multirow[b]{2}{*}{$\begin{array}{c}\text { Floculant. } \\
\text { (ml) }\end{array}$} & \multirow{2}{*}{$\begin{array}{l}\text { CARGA SóLIDOS } \\
\text { Dist. Sediment. } \\
\text { (cm) }\end{array}$} & \multirow{2}{*}{$\begin{array}{c}\mathbf{5 , 0 0} \\
\text { Tiempo sed. } \\
\text { (s) }\end{array}$} & \multirow{2}{*}{$\begin{array}{l}\% \\
\begin{array}{c}\text { Velocidad sed. } \\
(\mathrm{m} / \mathrm{h})\end{array}\end{array}$} & \multirow[b]{2}{*}{$\begin{array}{l}\text { Floc dosific. } \\
(\mathrm{g} / \mathrm{t})\end{array}$} & \multirow[b]{2}{*}{$\begin{array}{c}\text { Flujo } \\
\text { (tph/m2) }\end{array}$} & \multirow[b]{2}{*}{$\begin{array}{c}\text { Flujo } \\
\text { (tpd/m2) }\end{array}$} \\
\hline $\begin{array}{l}\text { Peso sólidos } \\
\text { (g) }\end{array}$ & $\begin{array}{c}\text { Vol. líquido } \\
\text { (ml) }\end{array}$ & & $\begin{array}{c}\text { Densidad pulpa } \\
(\mathrm{kg} / \mathrm{l})\end{array}$ & $\begin{array}{c}\text { Conc. Solids } \\
(\mathrm{g} / \mathrm{l})\end{array}$ & & & & & & & \\
\hline 51 & 1000 & 4,85 & 1,037 & 50,34 & 1 & 10,0 & 15 & 24,0 & 10 & 4,63 & 111,19 \\
\hline 51 & 1000 & 4,85 & 1,037 & 50,34 & 2 & 10,0 & 16 & 22,5 & 20 & 4,34 & 104,24 \\
\hline 51 & 1000 & 4,85 & 1,037 & 50,34 & 3 & 10,0 & 15 & 24,0 & 29 & 4,63 & 111,19 \\
\hline 51 & 1000 & 4,85 & 1,037 & 50,34 & 4 & 10,0 & 15 & 24,0 & 39 & 4,63 & 111,19 \\
\hline 51 & 1000 & 4,85 & 1,037 & 50,34 & 5 & 10,0 & 16 & 22,5 & 49 & 4,34 & 104,24 \\
\hline 51 & 1000 & 4,85 & 1,037 & 50,34 & 6 & 10,0 & 15 & 24,0 & 59 & 4,63 & 111,19 \\
\hline
\end{tabular}

NALCO -10\% CARGA @ 7.5\% Sól. Peso

\begin{tabular}{|c|c|c|c|c|c|c|c|c|c|c|c|}
\hline \multicolumn{12}{|c|}{ NALCO -10\% CARGA @ 7.5\% Sól. Peso } \\
\hline \multicolumn{2}{|c|}{ MUESTRA: M-101 } & \multirow{2}{*}{$\begin{array}{l}\text { FLOCULANTE: } \\
\text { Sólidos } \\
(\% \mathrm{w} / \mathrm{w})\end{array}$} & \multicolumn{2}{|c|}{ NALCO - $10 \%$ CARGA } & \multirow[b]{2}{*}{$\begin{array}{l}\text { Floculant. } \\
\text { (ml) }\end{array}$} & \multirow{2}{*}{$\begin{array}{l}\text { CARGA SóLIDOS: } \\
\text { Dist. Sediment. } \\
(\mathrm{cm})\end{array}$} & \multirow{2}{*}{$\begin{array}{c}\text { 7,50 } \\
\text { Tiempo sed. } \\
\text { (s) }\end{array}$} & \multirow{2}{*}{$\begin{array}{l}\% \\
\begin{array}{c}\text { Velocidad sed. } \\
(\mathrm{m} / \mathrm{h})\end{array}\end{array}$} & \multirow[b]{2}{*}{$\begin{array}{l}\text { Floc dosific. } \\
(\mathrm{g} / \mathrm{t})\end{array}$} & \multirow[b]{2}{*}{$\begin{array}{c}\text { Flujo } \\
\text { (tph/m2) }\end{array}$} & \multirow[b]{2}{*}{$\begin{array}{c}\text { Flujo } \\
\text { (tpd/m2) }\end{array}$} \\
\hline $\begin{array}{c}\text { Peso sólidos } \\
\text { (g) }\end{array}$ & $\begin{array}{l}\text { Vol. líquido } \\
\text { (ml) }\end{array}$ & & $\begin{array}{c}\text { Densidad pulpa } \\
(\mathrm{kg} / \mathrm{l})\end{array}$ & $\begin{array}{c}\text { Conc. Solids } \\
(\mathrm{g} / \mathrm{l})\end{array}$ & & & & & & & \\
\hline 80 & 1000 & 7,41 & 1,058 & 78,39 & 2 & 10,0 & 20 & 18,0 & 13 & 5,45 & 130,81 \\
\hline 80 & 1000 & 7,41 & 1,058 & 78,39 & 3 & 10,0 & 15 & 24,0 & 19 & 7,27 & 174,41 \\
\hline 80 & 1000 & 7,41 & 1,058 & 78,39 & 4 & 10,0 & 14 & 25,7 & 25 & 7,79 & 186,87 \\
\hline 80 & 1000 & 7,41 & 1,058 & 78,39 & 5 & 10,0 & 14 & 25,7 & 31 & 7,79 & 186,87 \\
\hline 80 & 1000 & 7,41 & 1,058 & 78,39 & 6 & 10,0 & 16 & 22,5 & 38 & 6,81 & 163,51 \\
\hline 80 & 1000 & 7,41 & 1,058 & 78,39 & 8 & 10,0 & 18 & 20,0 & 50 & 6,06 & 145,34 \\
\hline & & & & & & & MEDIA: & 22,7 & 29,2 & 6,9 & 164,6 \\
\hline
\end{tabular}

NALCO -10\% CARGA @ 10\% Sól. Peso

\begin{tabular}{|c|c|c|c|c|c|c|c|c|c|c|c|}
\hline \multicolumn{12}{|c|}{ NALCO -10\% CARGA @ 10\% Sól. Peso } \\
\hline \multicolumn{2}{|c|}{ MUESTRA: M-101 } & \multirow{2}{*}{$\begin{array}{l}\text { FLOCULANTE: } \\
\text { Sólidos } \\
(\% \mathrm{w} / \mathrm{w})\end{array}$} & \multicolumn{2}{|c|}{ NALCO - $10 \%$ CARGA } & \multirow[b]{2}{*}{$\begin{array}{l}\text { Floculant. } \\
\text { (ml) }\end{array}$} & \multirow{2}{*}{$\begin{array}{l}\text { CARGA SóLIDOS: } \\
\text { Dist. Sediment. } \\
(\mathrm{cm})\end{array}$} & \multirow{2}{*}{$\begin{array}{c}10,00 \\
\text { Tiempo sed. } \\
\text { (s) }\end{array}$} & \multirow{2}{*}{$\begin{array}{l}\% \\
\begin{array}{c}\text { Velocidad sed. } \\
(\mathrm{m} / \mathrm{h})\end{array}\end{array}$} & \multirow[b]{2}{*}{$\begin{array}{l}\text { Floc dosific. } \\
\qquad(\mathrm{g} / \mathrm{t})\end{array}$} & \multirow[b]{2}{*}{$\begin{array}{c}\text { Flujo } \\
\text { (tph/m2) }\end{array}$} & \multirow[b]{2}{*}{$\begin{array}{c}\text { Flujo } \\
\text { (tpd/m2) }\end{array}$} \\
\hline $\begin{array}{l}\text { Peso sólidos } \\
\text { (g) }\end{array}$ & $\begin{array}{l}\text { Vol. líquido } \\
\text { (ml) }\end{array}$ & & $\begin{array}{c}\text { Densidad pulpa } \\
(\mathrm{kg} / \mathrm{l})\end{array}$ & $\begin{array}{l}\text { Conc. Solids } \\
\text { (g/l) }\end{array}$ & & & & & & & \\
\hline 105 & 1000 & 9,50 & 1,076 & 102,25 & 2 & 7,5 & 23 & 11,7 & 10 & 6,22 & 149,290 \\
\hline 105 & 1000 & 9,50 & 1,076 & 102,25 & 4 & 7,5 & 19 & 14,2 & 19 & 7,53 & 180,719 \\
\hline 105 & 1000 & 9,50 & 1,076 & 102,25 & 6 & 7,5 & 16 & 16,9 & 29 & 8,94 & 214,604 \\
\hline 105 & 1000 & 9,50 & 1,076 & 102,25 & 8 & 7,5 & 15 & 18,0 & 38 & 9,54 & 228,911 \\
\hline 105 & 1000 & 9,50 & 1,076 & 102,25 & 10 & 7,5 & 14 & 19,3 & 48 & 10,22 & 245,261 \\
\hline 105 & 1000 & 9,50 & 1,076 & 102,25 & 12 & 7,5 & 14 & 19,3 & 57 & 10,22 & 245,261 \\
\hline & & & & & & & MEDIA: & 16,6 & 33,3 & 8,8 & 210,7 \\
\hline
\end{tabular}


ENSAYO FLUJO SEDIMENTACIÓN. ANÁLISIS DE RESULTADOS.

Mina: MINAS DE AGUAS TEÑIDAS

Proyecto: $\quad$ Estudio sedimentación y reología de estériles espesados

DATOS

Volumen probeta:

$250 \mathrm{ml}$

FLOCULANTE SELECCIONADO

Diámetro probeta:

$35,7 \mathrm{~mm}$

Área sedimentac.

$10,01 \mathrm{~cm} 2$

Floc. Dosificac.:

Volumen floc:

Floculante dosific.

$0,2 \mathrm{~g}$

$400 \mathrm{ml}$

$0,05 \%$

$0,50 \mathrm{~g} / \mathrm{l}$

$4,50 \mathrm{~kg} / \mathrm{dm} 3$

NALCO -10\% CARGA IÓNICA

Floc. Conc.

$1,00 \mathrm{~kg} / \mathrm{dm} 3$

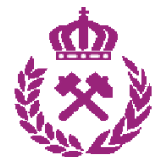

sidad Sólido

MUESTRA SÓLIDOS

M-100

Diámetros de probetas:

$250 \mathrm{ml} \quad 35,7 \quad \mathrm{~mm}$

$500 \mathrm{ml} \quad 48,6 \quad \mathrm{~mm}$

$2000 \mathrm{ml} \quad 78,2 \quad \mathrm{~mm}$

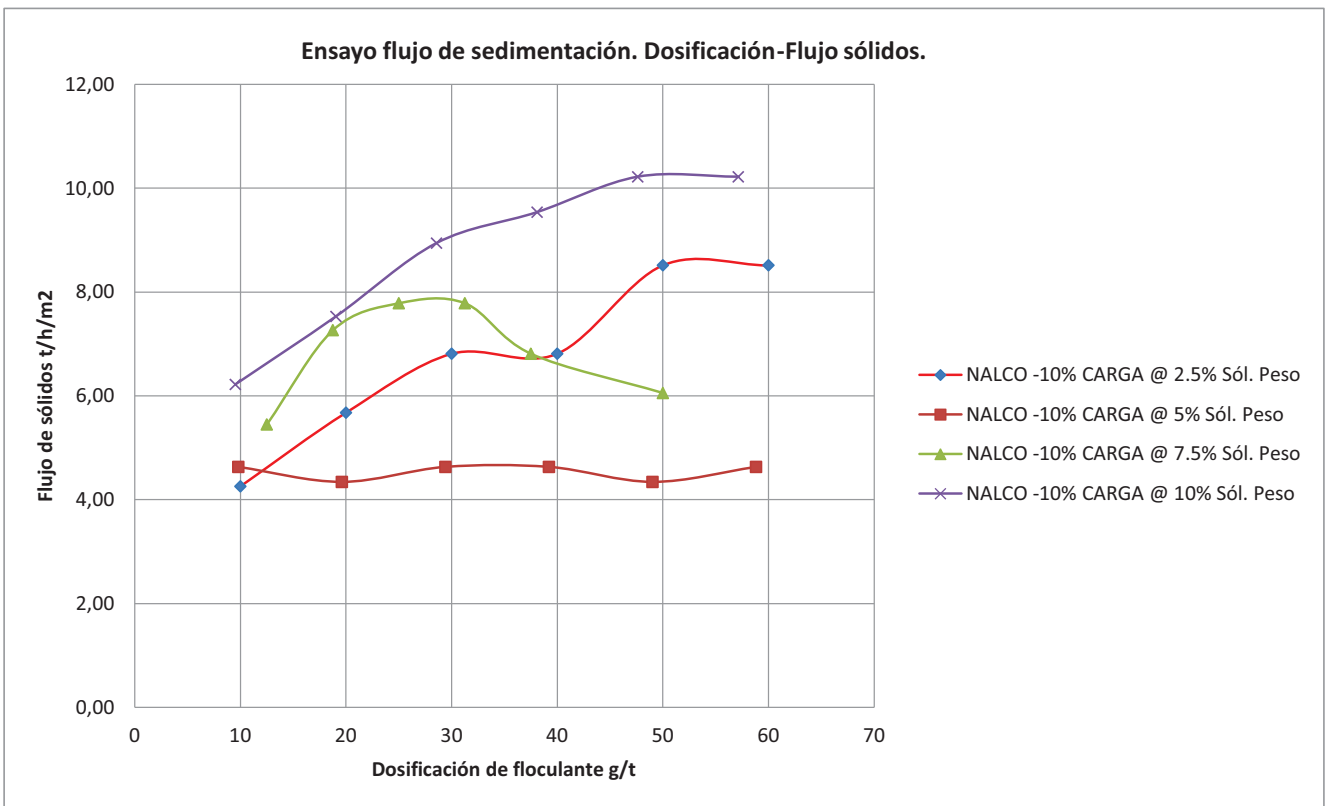

Los ensayos de flujos de sedimentación determinan la dilución óptima de los sólidos para la alimentación en el espesador.

El valor obtenido sirve de base para el diseño de la campana de alimentación y el sistema de dilución previsto. 


\begin{tabular}{|c|c|c|c|c|c|c|}
\hline \multicolumn{2}{|c|}{ ENSAYO SEDIMENTACIÓN PROBETA 2000 mI ESTÁTICO } & ÁTICO & & & & \\
\hline Mina: & \multicolumn{6}{|c|}{ MINAS DE AGUAS TEÑIDAS } \\
\hline Proyecto: & \multicolumn{6}{|c|}{ Estudio sedimentación y reología de estériles espesados } \\
\hline Muestra: & & & & \\
\hline \multicolumn{7}{|l|}{ DATOS DE ENSAYO } \\
\hline Volumen líquido: & $1900 \mathrm{ml}$ & Solidos en peso & $\mathrm{S}=\mathrm{Ps} / \mathrm{Pp}$ & $\mathrm{S}$ & $9,52 \%$ & \\
\hline Peso sólidos: & $200 \mathrm{~g}$ & Dilución & $d=P I / P s$ & d & 9,500 & \\
\hline Floculante dosificac. & $0,2 \mathrm{~g}$ & Solidos en volumen & $\mathrm{V}=\mathrm{Vs} / \mathrm{Vp}$ & $\mathrm{V}$ & $2,63 \%$ & \\
\hline Volume total: & $400 \mathrm{ml}$ & Concent. Sólidos en peso & $\mathrm{C}=\mathrm{Ps} / \mathrm{Vp}$ & $\mathrm{C}$ & 102,50 & $g / l$ \\
\hline Floc. Conc. & $0,50 \mathrm{~g} / \mathrm{l}$ & Densidad de la pulpa & $S G p=P p / V p$ & SGp & 1,076 & $\mathrm{~kg} / \mathrm{l}$ \\
\hline Floculante & $8,00 \mathrm{ml}$ & & & & & \\
\hline Solids SG & $3,90 \mathrm{~kg} / \mathrm{dm} 3$ & & & & & \\
\hline Liquid SG & $1,00 \mathrm{~kg} / \mathrm{dm} 3$ & & & & & \\
\hline Diámetro probeta & $78,2 \mathrm{~mm}$ & & & & & \\
\hline Area probeta & $0,0048029 \mathrm{~m} 2$ & $48,029 \mathrm{~cm} 2$ & & & & \\
\hline Densidad pulpa: & $1,076 \mathrm{~kg} / \mathrm{l}$ & & & & & \\
\hline Sólidos en peso: & 102,50 g solids/l & & & & & \\
\hline Sólidos en peso: & 0,1025 g solids $/ \mathrm{ml}$ & & & & & \\
\hline Floculante: & NALCO & & & & & \\
\hline Tipo de carga floc.: & $-10 \%$ aniónico & & & & & \\
\hline Dosificación floc.: & gramos/ton & lada sólido & & & & \\
\hline
\end{tabular}

\section{DATOS DE SEDIMENTACIÓN}

\begin{tabular}{|c|c|c|c|c|c|c|c|c|c|}
\hline $\begin{array}{l}\text { Tiempo info } \\
\text { (sec) }\end{array}$ & $\begin{array}{c}\text { Tiempo } \\
\text { (min) }\end{array}$ & $\begin{array}{l}\text { Vol. Lodos } \\
\text { (ml) }\end{array}$ & $\begin{array}{l}\text { Altura interf. } \\
\text { (cm) }\end{array}$ & $\begin{array}{c}\text { Velocidad } \\
(\mathrm{m} / \mathrm{hr})\end{array}$ & $\begin{array}{l}\text { SG. Lodos } \\
(\mathrm{g} / \mathrm{cm} 3)\end{array}$ & $\begin{array}{c}\text { Lodos } \\
\% \text { Sol. Peso }\end{array}$ & $\begin{array}{c}\text { Flujo } \\
\text { (tph/m2) }\end{array}$ & $\begin{array}{c}\text { Flujo } \\
(\mathrm{tpd} / \mathrm{m} 2)\end{array}$ & $\begin{array}{l}\text { Área Unit. Espes. } \\
\text { (m2/tpd) }\end{array}$ \\
\hline 0 & 0 & 1969 & 41,00 & 0 & 1,076 & 9,44 & 0 & 0 & 0 \\
\hline 5 & 0,08 & 1825 & 38,00 & 21,600 & 1,081 & 10,13 & 29,9820 & 719,57 & 0,001 \\
\hline 10 & 0,17 & 1729 & 36,00 & 14,400 & 1,086 & 10,65 & 29,9818 & 719,56 & 0,001 \\
\hline 15 & 0,25 & 1585 & 33,00 & 21,600 & 1,094 & 11,54 & 29,9819 & 719,57 & 0,001 \\
\hline 30 & 0,50 & 1321 & 27,50 & 13,200 & 1,113 & 13,61 & 9,9940 & 239,86 & 0,004 \\
\hline 45 & 0,75 & 1201 & 25,00 & 6,000 & 1,124 & 14,82 & 9,9940 & 239,86 & 0,004 \\
\hline 60 & 1,00 & 1081 & 22,50 & 6,000 & 1,138 & 16,27 & 9,9940 & 239,86 & 0,004 \\
\hline 120 & 2,00 & 624 & 13,00 & 5,700 & 1,238 & 25,87 & 2,4985 & 59,96 & 0,017 \\
\hline 180 & 3,00 & 504 & 10,50 & 1,500 & 1,295 & 30,63 & 2,4985 & 59,96 & 0,017 \\
\hline 240 & 4,00 & 384 & 8,00 & 1,500 & 1,387 & 37,53 & 2,4985 & 59,96 & 0,017 \\
\hline 300 & 5,00 & 336 & 7,00 & 0,600 & 1,442 & 41,24 & 2,4985 & 59,96 & 0,017 \\
\hline 450 & 7,50 & 264 & 5,50 & 0,360 & 1,563 & 48,44 & 0,9994 & 23,99 & 0,042 \\
\hline 600 & 10,00 & 255 & 5,30 & 0,048 & 1,584 & 49,59 & 0,9994 & 23,99 & 0,042 \\
\hline 900 & 15,00 & 250 & 5,20 & 0,012 & 1,595 & 50,19 & 0,4997 & 11,99 & 0,083 \\
\hline 1200 & 20,00 & 245 & 5,10 & 0,012 & 1,607 & 50,80 & 0,4997 & 11,99 & 0,083 \\
\hline 1500 & 25,00 & 240 & 5,00 & 0,012 & 1,619 & 51,43 & 0,4997 & 11,99 & 0,083 \\
\hline 1800 & 30,00 & 240 & 5,00 & 0,000 & 1,619 & 51,43 & 0,4997 & 11,99 & 0,083 \\
\hline 3600 & 60,00 & 240 & 5,00 & 0,000 & 1,619 & 51,43 & 0,0833 & 2,00 & 0,500 \\
\hline 5400 & 90,00 & 235 & 4,90 & 0,002 & 1,632 & 52,08 & 0,0833 & 2,00 & 0,500 \\
\hline 7200 & 120,00 & 235 & 4,90 & 0,000 & 1,632 & 52,08 & 0,0833 & 2,00 & 0,500 \\
\hline 9000 & 150,00 & 235 & 4,90 & 0,000 & 1,632 & 52,08 & 0,0833 & 2,00 & 0,500 \\
\hline 10800 & 180,00 & 235 & 4,90 & 0,000 & 1,632 & 52,08 & 0,0833 & 2,00 & 0,500 \\
\hline 14400 & 240,00 & 235 & 4,90 & 0,000 & 1,632 & 52,08 & 0,0416 & 1,00 & 1,001 \\
\hline
\end{tabular}

DATOS OBTENIDOS:

Velocidad de sedimentación promedio: $17,7 \mathrm{~m} / \mathrm{h}$

\% sólidos - tiempo: 52 \% sólidos en peso - 90 minutos tiempo residencia 


\section{ENSAYO SEDIMENTACIÓN PROBETA 2000mI ESTÁTICO. ANÁLISIS DE RESULTADOS.}

Mina:

Proyecto:

Muestra
MINAS DE AGUAS TEÑIDAS

Estudio sedimentación y reología de estériles espesados

M-101
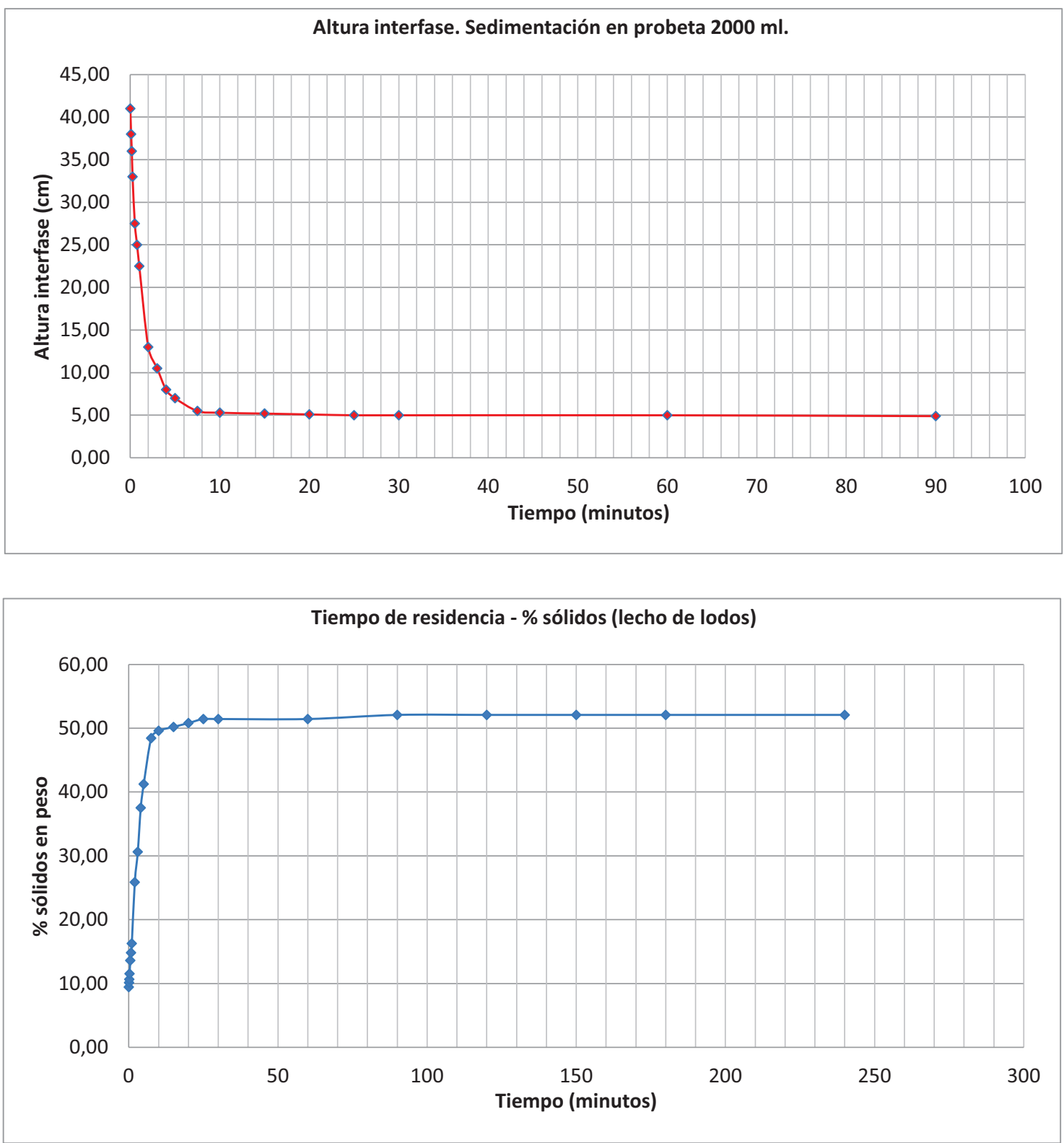


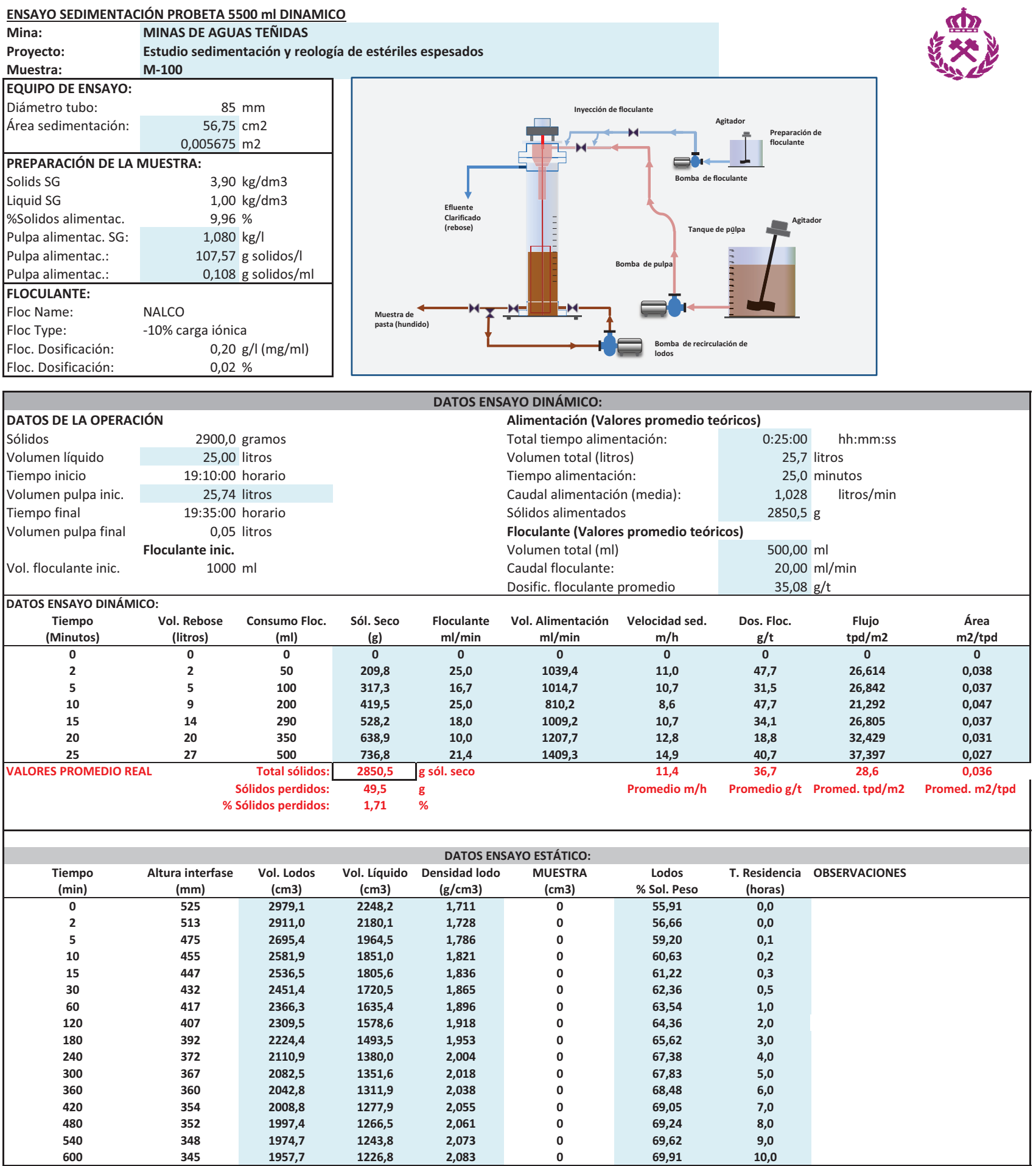


ENSAYO SEDIMENTACIÓN PROBETA 5500 mI DINAMICO

Mina: MINAS DE AGUAS TEÑIDAS

Proyecto: $\quad$ Estudio sedimentación y reología de estériles espesados

Muestra: M-101

DATOS DE OPERACIÓN DEL ESPESADOR DE TUBO PROFUNDO

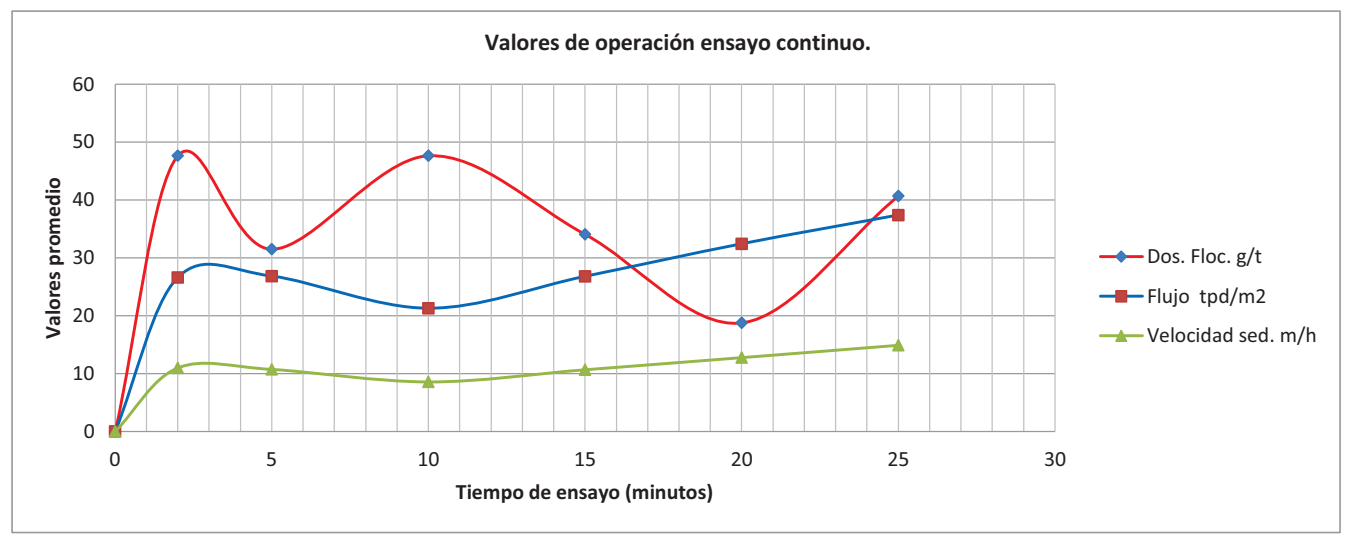

Datos Promedio:

Velocidad de sedimentación:

Dosificación de floculante:

$\begin{array}{cl}11,4 & \mathrm{~m} / \mathrm{h} \\ 36,7 & \mathrm{~g} / \mathrm{t} \\ 0,0361 & \mathrm{~m}^{2} / \mathrm{t} / \text { día } \\ 28,6 & \mathrm{t} / \mathrm{dí} a / \mathrm{m}^{2}\end{array}$

je sedimentación:

28,6 $\mathrm{t} / \mathrm{di} a / \mathrm{m}^{2}$

ENSAYO SEDIMENTACIÓN PROBETA $5500 \mathrm{mI}$ DINAMICO
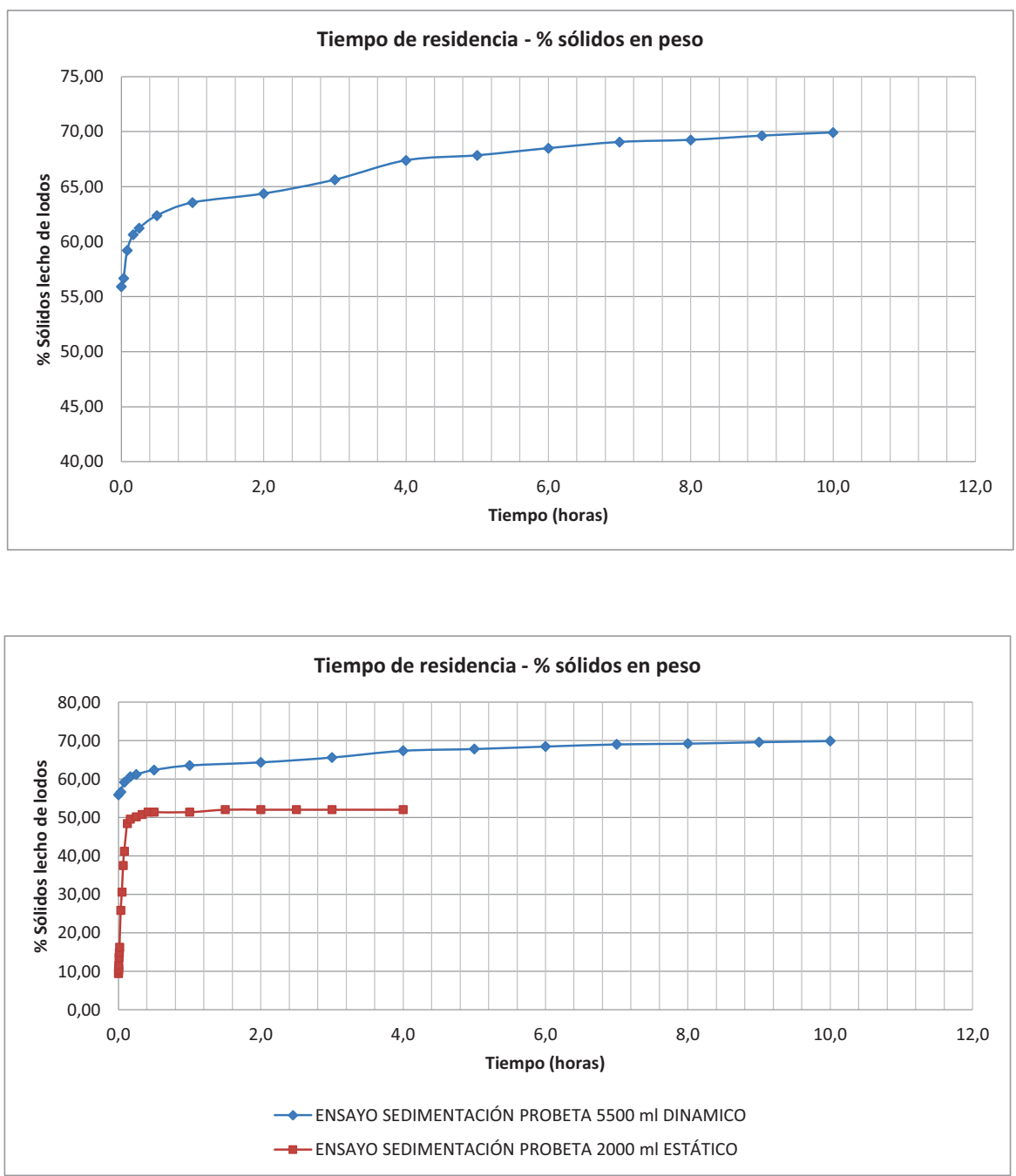
ENSAYO FILTRACIÓN A VACIO

Mina:

Proyecto:

Material:

Muestra:

Preparado por: José A. Butragueño pH muestra: $\quad 6$

Fecha:

$07 / 03 / 2015$

\begin{tabular}{|lc|}
\hline \begin{tabular}{ll}
\hline DATOS DE LA MUESTRA: \\
Solidos SG
\end{tabular} & $2,40 \mathrm{~kg} / \mathrm{dm} 3$ \\
Liquido SG & $1,00 \mathrm{~kg} / \mathrm{dm} 3$ \\
\hline FLOCULANTE: & \\
Floc Name: & No \\
Tipo de floculante: $\quad$ No & \\
Floc. Dosificación: & $0,00 \mathrm{~g} / \mathrm{l}(\mathrm{mg} / \mathrm{ml})$ \\
Floc. Dosificación: & $0,000 \%$ \\
\hline
\end{tabular}

\section{MINAS DE AGUAS TEÑIDAS}

$\mathrm{M}-101$ $0,000 \%$
Estudio sedimentación y reología de estériles espesados

Estériles mineral polimetálico cobre-Calañas

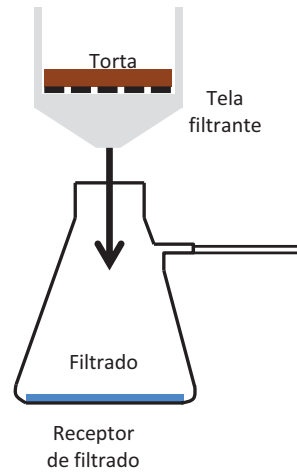

de filtrado
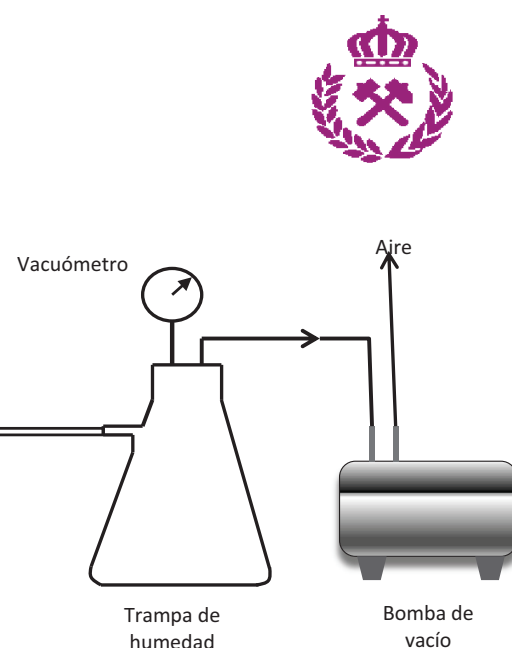

\begin{tabular}{|c|c|c|c|c|c|c|c|c|c|}
\hline \multicolumn{10}{|c|}{ ENSAYO FILTRACIÓN A VACÍO. TEST 1.} \\
\hline \multicolumn{3}{|c|}{ MUESTRA: M-101 } & \multicolumn{7}{|c|}{ Tiempos de ensayo de filtración } \\
\hline $\begin{array}{l}\text { Vacío } \\
\text { (bar) }\end{array}$ & $\begin{array}{c}\text { Peso sólidos } \\
\text { (g) }\end{array}$ & $\begin{array}{l}\text { Vol. Líquido } \\
\text { (ml) }\end{array}$ & $\begin{array}{l}\text { \% Sól. Peso } \\
\text { (\%) }\end{array}$ & $\begin{array}{l}\text { Vol. Pulpa } \\
\text { (ml) }\end{array}$ & $\begin{array}{l}\text { Formación torta } \\
\text { (s) }\end{array}$ & $\begin{array}{l}\text { Secado torta } \\
\text { (s) }\end{array}$ & $\begin{array}{l}\text { Total ciclo } \\
\text { (s) }\end{array}$ & $\begin{array}{l}\text { Líq. Filtrado } \\
(\mathrm{ml})\end{array}$ & $\begin{array}{c}\text { Espesor } \\
(\mathrm{mm})\end{array}$ \\
\hline$-0,6$ & 30 & 150,0 & 16,7 & 162,5 & 15 & 10 & 25 & 142 & 2,0 \\
\hline \% Solidos estimado: & 78,9 & & & & & & & & \\
\hline Peso muestra húmedo: & 70 & $\bar{g}$ & \multirow{4}{*}{\multicolumn{2}{|c|}{ Observaciones: }} & & & & & \\
\hline Secad & o de la muestra & & & & & & & & \\
\hline Peso muestra seco & 54 & g & & & & & & & \\
\hline$\%$ humedad torta & 22,86 & $\%$ & & & & & & & \\
\hline
\end{tabular}

\begin{tabular}{|c|c|c|c|c|c|c|c|c|c|}
\hline \multicolumn{10}{|c|}{ ENSAYO FILTRACIÓN A VACÍO. TEST 2.} \\
\hline \multicolumn{3}{|c|}{ MUESTRA: M-101 } & \multicolumn{7}{|c|}{ Tiempos de ensayo de filtración } \\
\hline $\begin{array}{l}\text { Vacío } \\
\text { (bar) }\end{array}$ & $\begin{array}{l}\text { Peso sólidos } \\
\text { (g) }\end{array}$ & $\begin{array}{l}\text { Vol. Líquido } \\
\text { (ml) }\end{array}$ & $\begin{array}{c}\text { \% Sól. Peso } \\
\text { (\%) }\end{array}$ & $\begin{array}{l}\text { Vol. Pulpa } \\
\text { (ml) }\end{array}$ & $\begin{array}{l}\text { Formación torta } \\
\text { (s) }\end{array}$ & $\begin{array}{l}\text { Secado torta } \\
\text { (s) }\end{array}$ & $\begin{array}{l}\text { Total ciclo } \\
\text { (s) }\end{array}$ & $\begin{array}{l}\text { Líq. Filtrado } \\
\text { (ml) }\end{array}$ & $\begin{array}{c}\text { Espesor } \\
(\mathrm{mm})\end{array}$ \\
\hline$-0,6$ & 50 & 210,0 & 19,2 & 230,8 & 60 & 10 & 70 & 198 & 5,0 \\
\hline \% Solidos estimado: & 80,6 & & & & & & & & \\
\hline Peso muestra húmedo: & 90 & $\bar{g}$ & \multirow{4}{*}{\multicolumn{2}{|c|}{ Observaciones: }} & & & & & \\
\hline \multicolumn{3}{|c|}{ Secado de la muestra: } & & & & & & & \\
\hline Peso muestra seco & 71,5 & $\mathrm{~g}$ & & & & & & & \\
\hline$\%$ humedad torta & 20,56 & $\%$ & & & & & & & \\
\hline
\end{tabular}

\begin{tabular}{|c|c|c|c|c|c|c|c|c|c|}
\hline \multicolumn{10}{|c|}{ ENSAYO FILTRACIÓN A VACÍO. TEST 3.} \\
\hline \multicolumn{3}{|c|}{ MUESTRA: M-101 } & \multicolumn{7}{|c|}{ Tiempos de ensayo de filtración } \\
\hline $\begin{array}{l}\text { Vacío } \\
\text { (bar) }\end{array}$ & $\begin{array}{l}\text { Peso sólidos } \\
\text { (g) }\end{array}$ & $\begin{array}{l}\text { Vol. Líquido } \\
\text { (ml) }\end{array}$ & $\begin{array}{c}\text { \% Sól. Peso } \\
\text { (\%) }\end{array}$ & $\begin{array}{l}\text { Vol. Pulpa } \\
\text { (ml) }\end{array}$ & $\begin{array}{l}\text { Formación torta } \\
\text { (s) }\end{array}$ & $\begin{array}{l}\text { Secado torta } \\
\text { (s) }\end{array}$ & $\begin{array}{l}\text { Total ciclo } \\
\text { (s) }\end{array}$ & $\begin{array}{l}\text { Líq. Filtrado } \\
\text { (ml) }\end{array}$ & $\begin{array}{c}\text { Espesor } \\
(\mathrm{mm})\end{array}$ \\
\hline$-0,6$ & 75 & 300,0 & 20,0 & 331,3 & 60 & 15 & 75 & 279 & 5,5 \\
\hline \% Solidos estimado: & 78,1 & & & & & \\
\hline Peso muestra húmedo: & 123 & $\mathrm{~g}$ & \multirow{4}{*}{\multicolumn{7}{|c|}{\begin{tabular}{|l} 
Observaciones: \\
Contenido en sólidos de la torta filtrada: $100-21,71=78,29 \%$
\end{tabular}}} \\
\hline \multicolumn{3}{|c|}{ Secado de la muestra: } & & & & & & & \\
\hline Peso muestra seco & 96,3 & $\mathrm{~g}$ & & & & & & & \\
\hline$\%$ humedad torta & 21,71 & $\%$ & & & & & & & \\
\hline
\end{tabular}

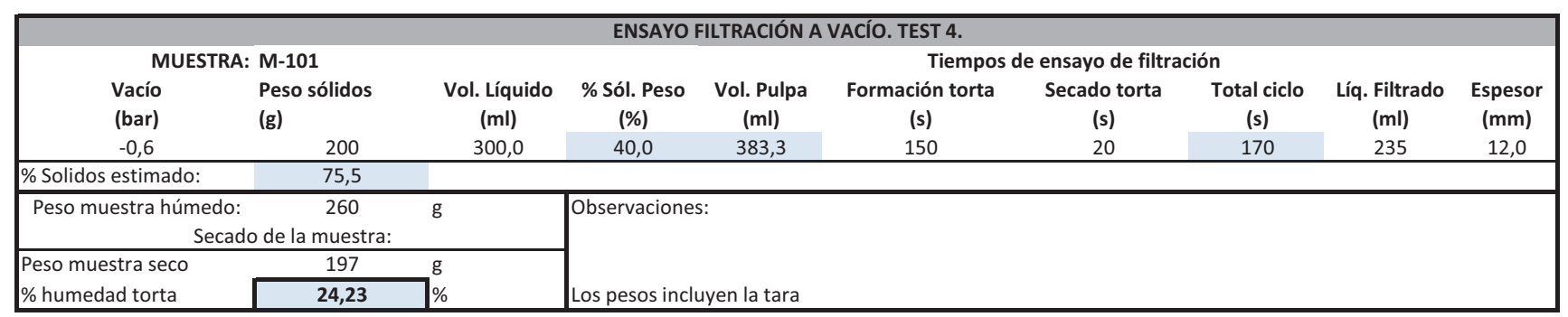

Humedad torta

$\%$ sólidos en peso
22,3 \% (Promedio)

77,7 \% (Promedio) 
ENSAYO ASENTAMIENTO EN PROBETA

\section{Mina:}

Proyecto:

Material:

Preparado por:

pH muestra:

Fecha:

Aceleración gravedad (g):

Diámetro probeta:

Altura probeta $(\mathrm{H})$ :

Volumen probeta:

Solidos SG

Líquido SG

Expresiones empíricas

$T=0.5-0.5(h / H)^{\wedge} 0.5$

T.F. $=T^{*} \mathrm{~d}^{*} \mathrm{~g}^{*}(\mathrm{H} / 100)$

\section{MINAS DE AGUAS TEÑIDA}

Estudio sedimentación y reología de estériles espesados

Estériles mineral polimetálico cobre-Calañas

José A. Butragueño

07/03/2015

$9,81 \mathrm{~m} / \mathrm{s} 2$
$44 \mathrm{~mm}$
$100 \mathrm{~mm}$
$152,1 \mathrm{~cm} 3$
$4,00 \mathrm{~kg} / \mathrm{dm} 3$
$1,00 \mathrm{~kg} / \mathrm{dm} 3$

$\mathrm{H}$
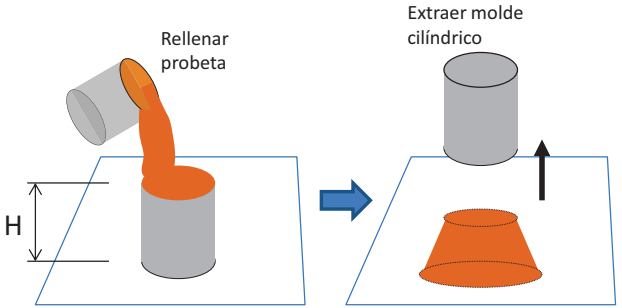

Medir

asentamiento

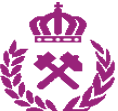

ENSAYOS DE ASENTAMIENTO EN PROBETA

\begin{tabular}{|c|c|c|c|c|c|c|c|c|c|c|}
\hline \multirow[b]{2}{*}{$\begin{array}{l}\text { Muestra } \\
\text { ID }\end{array}$} & \multicolumn{9}{|c|}{ ENSAYOS DE ASENTAMIENTO EN PROBETA } & \multirow[b]{2}{*}{$\begin{array}{c}\text { Tensión Fluenci } \\
(\mathrm{Pa})\end{array}$} \\
\hline & $\begin{array}{c}\text { Cont. Sólidos } \\
\text { (\%) }\end{array}$ & $\begin{array}{l}\text { Solidos SG } \\
\mathrm{g} / \mathrm{cm} 3\end{array}$ & $\begin{array}{c}\text { Peso Liq. } \\
\text { (kg liq/kg sol) }\end{array}$ & $\begin{array}{l}\text { Vol. Pulpa } \\
\text { (1/kg sol) }\end{array}$ & $\begin{array}{l}\text { Pulpa SG (d) } \\
\mathrm{kg} / \mathrm{dm} 3\end{array}$ & $\begin{array}{l}\text { Sólidos prob. } \\
\text { (g) }\end{array}$ & $\begin{array}{l}\text { Liq. Probeta } \\
\text { (g) }\end{array}$ & $\begin{array}{c}\text { Asentamiento (h) } \\
\mathrm{mm}\end{array}$ & $\begin{array}{l}\text { Factor "T" } \\
\text { Adimens. }\end{array}$ & \\
\hline 1 & 70 & 4,00 & 0,429 & 0,679 & 2,105 & 224,1 & 96,0 & 55 & 0,12919 & 266,8 \\
\hline 2 & 68 & 4,00 & 0,471 & 0,721 & 2,041 & 211,0 & 99,3 & 65 & 0,09689 & 194,0 \\
\hline 3 & 66 & 4,00 & 0,515 & 0,765 & 1,980 & 198,7 & 102,4 & 70 & 0,08167 & 158,7 \\
\hline 4 & 64 & 4,00 & 0,563 & 0,813 & 1,923 & 187,1 & 105,3 & 75 & 0,06699 & 126,4 \\
\hline 5 & 62 & 4,00 & 0,613 & 0,863 & 1,869 & 176,2 & 108,0 & 80 & 0,05279 & 96,8 \\
\hline 6 & 58 & 4,00 & 0,724 & 0,974 & 1,770 & 156,1 & 113,0 & 90 & 0,02566 & 44,6 \\
\hline
\end{tabular}
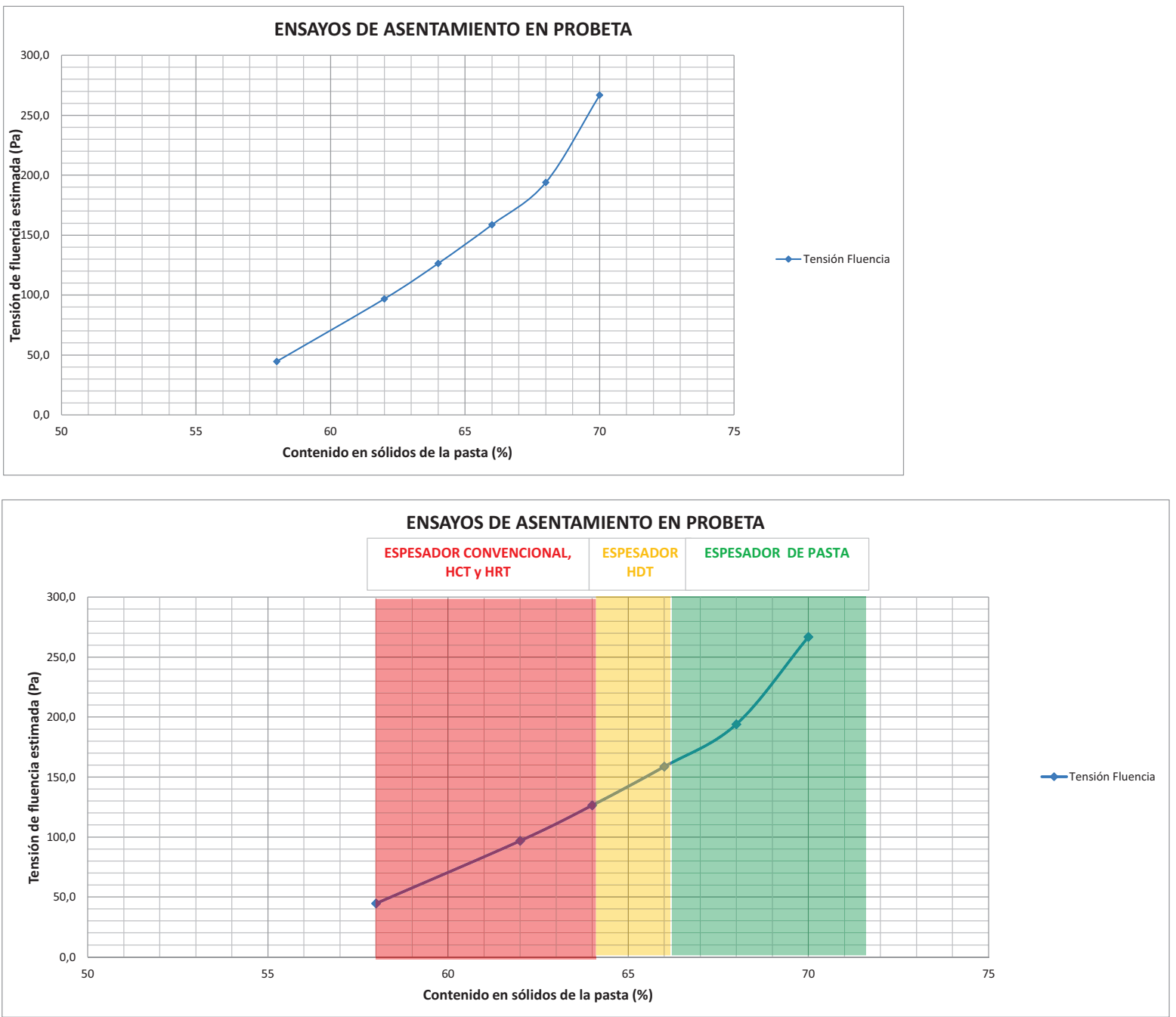

Página 12 de 12 


\section{SEDIMENTACIÓN Y REOLOGÍA}

Mina:

Cantera de Caliza

\section{Empresa:}

JOSÉ BUTRAGUEÑO

\section{Proyecto:}

Estudio sedimentación y reología de finos de caliza

\section{Aplicación}

Sedimentación. Estériles de flotación.
Fecha:
$23 / 07 / 2013$

\section{Ensayos:}

\begin{tabular}{|c|c|}
\hline $\mathbf{x}$ & Distribución granulométrica y caracterización de muestras \\
\hline $\mathbf{x}$ & Selección de floculantes \\
\hline $\mathbf{x}$ & Área de flujo \\
\hline $\mathbf{x}$ & Sedimentación en probeta estática \\
\hline $\mathbf{x}$ & Ensayo en espesador dinámico de laboratorio de $85 \mathrm{~mm}$ DIA \\
\hline $\mathbf{x}$ & Reología de los lodos \\
\hline $\mathbf{x}$ & Ensayo de filtración a vacío \\
\hline
\end{tabular}

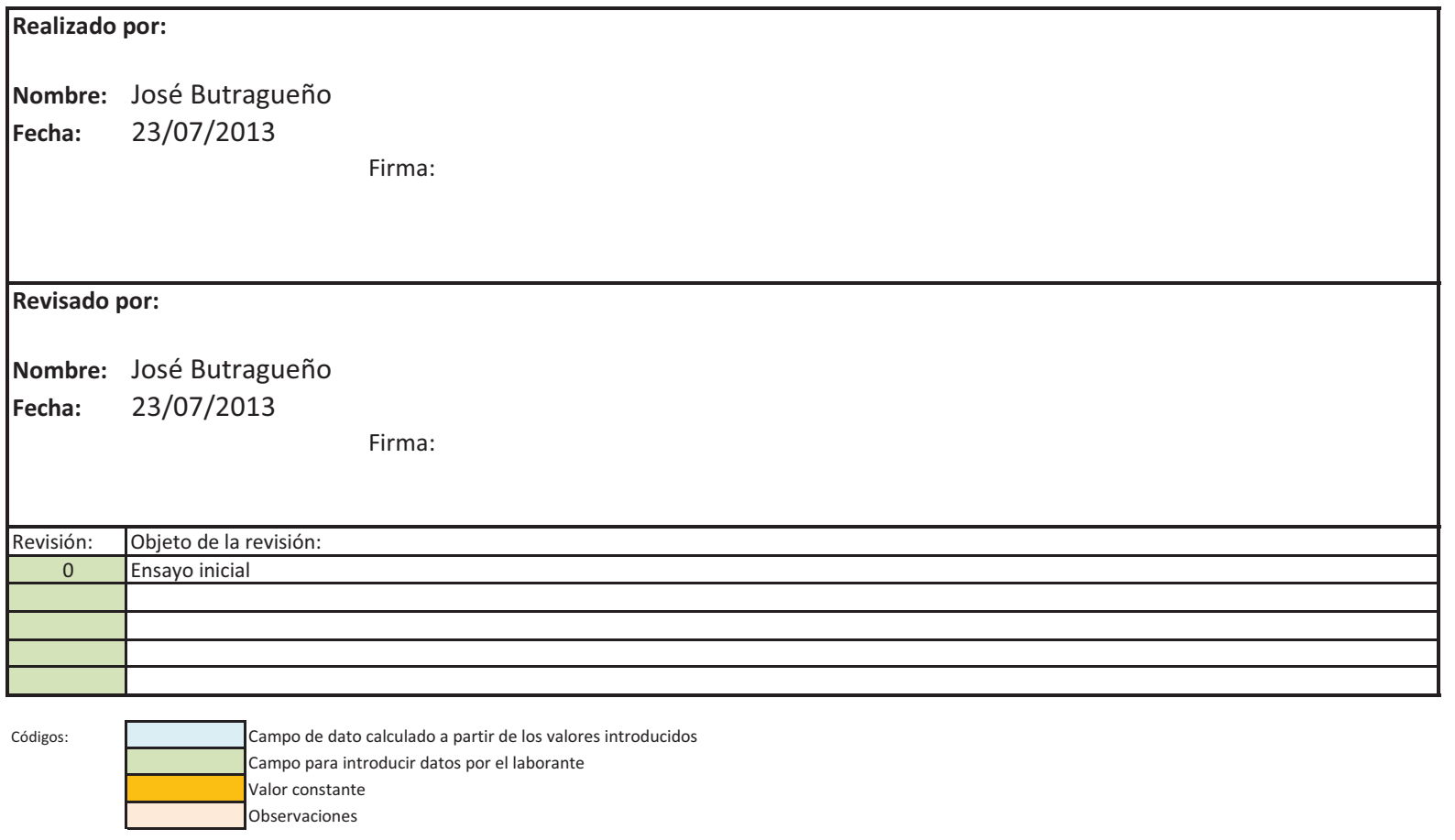

CONFIDENCIAL: Este documento contiene información propiedad de JOSÉ BUTRAGUEÑO y está sujeto a ser

devuelto bajo demanda; estando prohibida su reproducción, copia, préstamo o cualquier otro uso que no sea el fin para el que fue expresamente realizado, sin el consentimiento expreso por escrito de: JOSÉ BUTRAGUEÑO 
ENSAYO GRANULOMÉTRICO DE SÓLIDOS

Mina: Cantera de Caliza

Proyecto: $\quad$ Estudio sedimentación y reología de finos de caliza

Realizado por: José Butragueño

\begin{tabular}{|ll|}
\hline Muestra ID: & M-002 \\
Material: & Finos de caliza \\
Preparado por: & José A. Butragueño \\
pH muestra: & - \\
Fecha: & $23 / 07 / 2013$ \\
\hline
\end{tabular}

CURVA GRANULOMÉTRICA DE SÓLIDOS

\begin{tabular}{|c|c|c|c|c|c|}
\hline \multicolumn{3}{|c|}{ DATOS DE LA PULPA A SEDIMENTAR } & \multirow{5}{*}{\multicolumn{3}{|c|}{ Observaciones: Muestra de sólido seco }} \\
\hline Densidad sólidos: & 2,65 & $\mathrm{~kg} / \mathrm{dm}^{3}$ & & & \\
\hline Densidad líquido: & 1,00 & $\mathrm{~kg} / \mathrm{dm}^{3}$ & & & \\
\hline Densidad pulpa: & & $\mathrm{kg} / \mathrm{l}$ & & & \\
\hline Tara: & 0 & g & & & \\
\hline Pulpa húmeda: & 0 & g & Peso pulpa: & 0 & g \\
\hline Sólido seco: & 0 & $\mathrm{~g}$ & Peso sólido: & & $\mathrm{g}$ \\
\hline \% Peso sólidos: & \#DIV/0! & $\%$ & & & \\
\hline
\end{tabular}

CURVA GRANULOMÉTRICA DE SÓLIDOS

\begin{tabular}{|c|c|c|c|c|}
\hline \multicolumn{5}{|c|}{ ENSAYO GRANULOMÉTRICO } \\
\hline \multirow{2}{*}{$\begin{array}{l}\text { Tamiz } \\
\text { Micras }\end{array}$} & \multirow{2}{*}{\begin{tabular}{|l|} 
Pesos \\
Peso Ret. \\
\end{tabular}} & \multicolumn{3}{|c|}{ Porcentajes } \\
\hline & & $\%$ Peso Ret & $\%$ Ret. Ac. & \%Pasa Ac. \\
\hline 125 & 0 & 0,00 & 0,00 & 100,00 \\
\hline 80 & 2,1 & 2,10 & 2,10 & 97,90 \\
\hline 63 & 6,2 & 6,20 & 8,30 & 91,70 \\
\hline 40 & 8,9 & 8,90 & 17,20 & 82,80 \\
\hline 20 & 14,1 & 14,10 & 31,30 & 68,70 \\
\hline 10 & 27 & 27,00 & 58,30 & 41,70 \\
\hline 5 & 6,8 & 6,80 & 65,10 & 34,90 \\
\hline & 34,9 & 34,90 & 100,00 & 0,00 \\
\hline TOTALES: & 100,0 & 100,0 & & \\
\hline
\end{tabular}

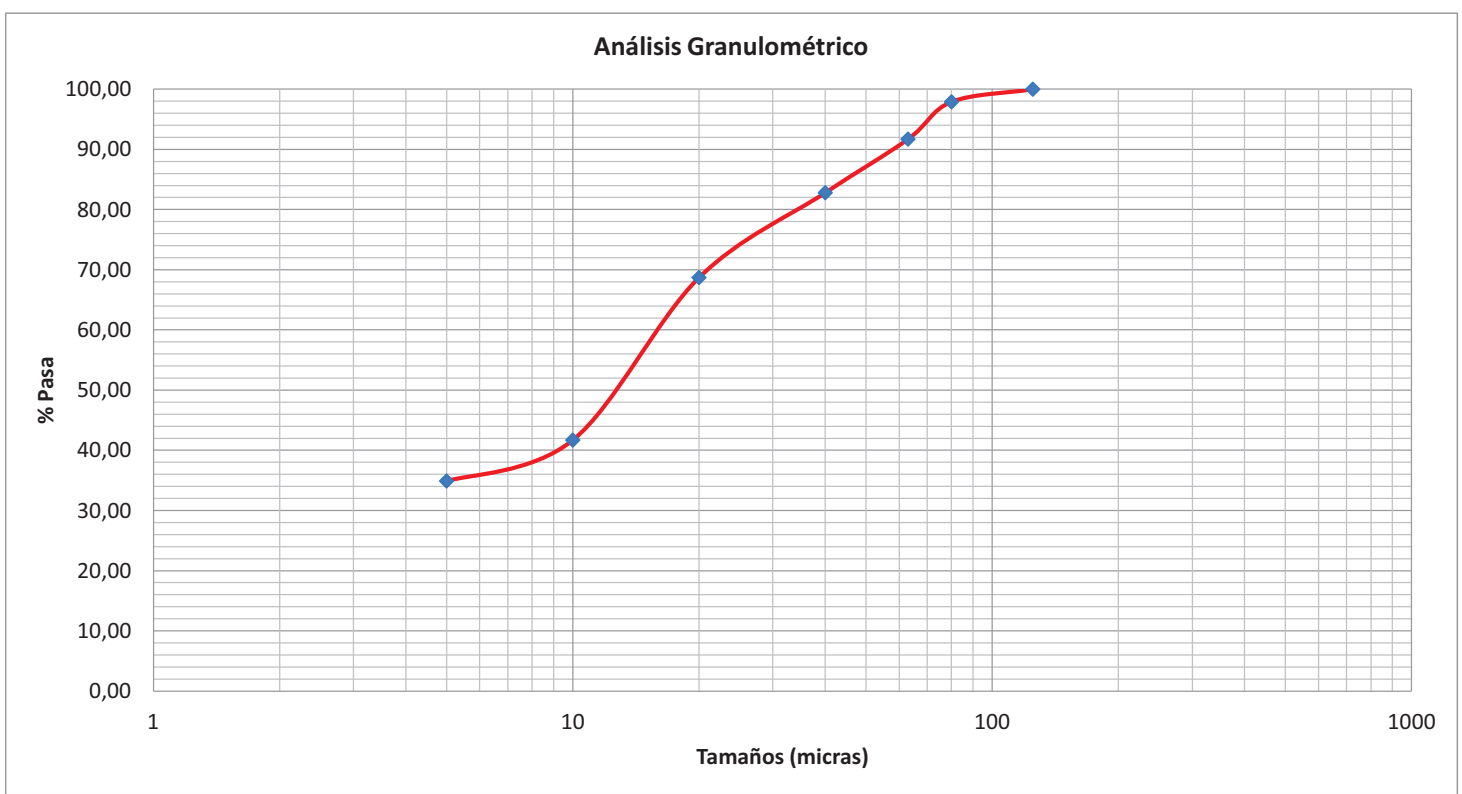




\section{SELECCIÓN DE FLOCULANTE}

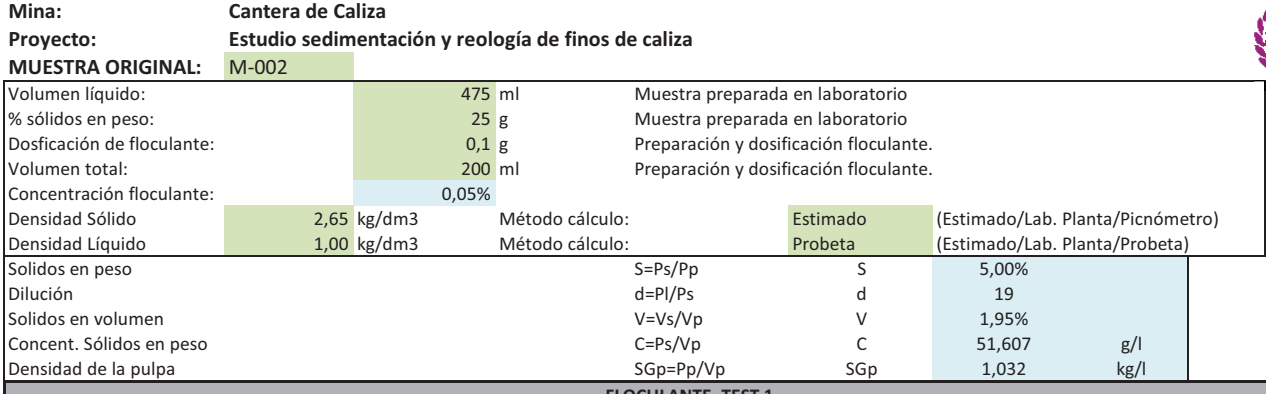

\section{MUESTRA ORIGINAL: M-002}

\begin{tabular}{|c|c|c|c|c|c|c|c|c|c|}
\hline \multicolumn{10}{|c|}{ FLOCULANTE. TEST 1.} \\
\hline \multicolumn{2}{|c|}{ MUESTRA: M-002 } & \multicolumn{2}{|c|}{ FLOCULANTE: NALCO } & \multicolumn{2}{|c|}{ TIPO CARGA: Aniónico -25\% } & \multicolumn{2}{|c|}{ DOSIFICACIÓN: $0,05 \%$} & \multirow[b]{2}{*}{$\begin{array}{l}\text { Tiempo } \\
\text { (s) }\end{array}$} & \multirow[b]{2}{*}{$\begin{array}{l}\text { Velocidad } \\
(\mathrm{m} / \mathrm{h})\end{array}$} \\
\hline $\begin{array}{c}\text { Ensayo } \\
\#\end{array}$ & $\begin{array}{l}\text { Diluc. } \\
\text { (Si/No) }\end{array}$ & $\begin{array}{l}\text { Pulpa w/w sol. } \\
(\%)\end{array}$ & $\begin{array}{l}\text { Distancia sed. } \\
\quad(\mathrm{cm})\end{array}$ & $\begin{array}{c}\text { Volumen ensayo } \\
(\mathrm{ml})\end{array}$ & $\begin{array}{l}\text { Sólidos } \\
\text { (g) }\end{array}$ & $\begin{array}{c}\text { Floculante } \\
(\mathrm{ml})\end{array}$ & $\begin{array}{l}\text { Floc } \\
(\mathrm{g} / \mathrm{t})\end{array}$ & & \\
\hline 1 & No & $5,00 \%$ & 10 & 484,4 & 25,00 & 2 & 40 & 14 & 25,7 \\
\hline 2 & No & $5,00 \%$ & 10 & 484,4 & 25,00 & 4 & 80 & 11 & 32,7 \\
\hline 3 & No & $5,00 \%$ & 10 & 484,4 & 25,00 & 6 & 120 & 10 & 36,0 \\
\hline 4 & No & $5,00 \%$ & 10 & 484,4 & 25,00 & 8 & 160 & 10 & 36,0 \\
\hline \multirow[t]{2}{*}{5} & No & $5,00 \%$ & 10 & 484,4 & 25,00 & 10 & 200 & 11 & 32,7 \\
\hline & $\begin{array}{l}\text { Velocidad } \\
\text { Sediment. }\end{array}$ & $\begin{array}{l}\text { Tamaño } \\
\text { Floculo } \\
\end{array}$ & $\begin{array}{l}\text { Cohesión } \\
\text { Flóculo }\end{array}$ & $\begin{array}{l}\text { Claridad } \\
\text { Rebose }\end{array}$ & & & & & \\
\hline 1 & Media & Medio & Parcial & Claro & Datos (para observa & ción visual): & & & \\
\hline 2 & Media & Medio & Parcial & Claro & Tamaño flóculo: & Muy pequeño/Pec & /Medio/ & nde/Muy gra & \\
\hline 3 & Media & Medio & Parcial & Claro & Velocidad sedim.: & Muy lenta/Lenta/ & a/Rápida/ & ay rápida & \\
\hline 4 & Media & Medio & Parcial & Claro & Cohesión de flóc.: & Pobre/Parcial/Buc & luy buen & ccelente & \\
\hline 5 & Media & Medio & Parcial & Claro & Claridad rebose: & Muy turbio/Turbi & o/Muy cl & /Cristalino & \\
\hline & & & & CULANTE. TEST 2. & & & & & \\
\hline & M-002 & FLOCULANTE: & NALCO & TIPO CARGA: & Aniónico -10\% & DOSIFICACIÓN & & & \\
\hline $\begin{array}{c}\text { Ensayo } \\
\quad \#\end{array}$ & $\begin{array}{l}\text { Diluc. } \\
\text { (Si/No) }\end{array}$ & $\begin{array}{l}\text { Pulpa w/w sol. } \\
(\%)\end{array}$ & $\begin{array}{l}\text { Distancia sed. } \\
\text { (cm) }\end{array}$ & $\begin{array}{c}\text { Volumen ensayo } \\
(\mathrm{ml})\end{array}$ & $\begin{array}{c}\text { Sólidos } \\
\text { (g) }\end{array}$ & $\begin{array}{l}\text { Floc } \\
\text { (ml) }\end{array}$ & $\begin{array}{l}\text { Floc } \\
(\mathrm{g} / \mathrm{t})\end{array}$ & $\begin{array}{c}\text { Tiempo } \\
\text { (s) }\end{array}$ & $\begin{array}{c}\text { Velocidad } \\
(\mathrm{m} / \mathrm{h})\end{array}$ \\
\hline 1 & No & $5,00 \%$ & 10 & 484,4 & 25,00 & 2 & 40 & 13 & 27,7 \\
\hline 2 & No & $5,00 \%$ & 10 & 484,4 & 25,00 & 4 & 80 & 12 & 30,0 \\
\hline 3 & No & $5,00 \%$ & 10 & 484,4 & 25,00 & 6 & 120 & 12 & 30,0 \\
\hline 4 & No & $5,00 \%$ & 10 & 484,4 & 25,00 & 8 & 160 & 13 & 27,7 \\
\hline 5 & No & $5,00 \%$ & 10 & 484,4 & 25,00 & 10 & 200 & 17 & 21,2 \\
\hline & Velocidad & Tamaño & Cohesión & Claridad & & & & & \\
\hline Ensayo & Sediment. & Floculo & Flóculo & Rebose & & & & & \\
\hline 1 & Media & Medio & Parcial & Claro & Datos (para observa & ación visual): & & & \\
\hline 2 & Media & Medio & Parcial & Claro & Tamaño flóculo: & Muy pequeño/Pe & /Medio/ & nde/Muy gra & \\
\hline 3 & Media & Medio & Parcial & Claro & Velocidad sedim.: & Muy lenta/Lenta/ & /Rápida/ & yy rápida & \\
\hline 4 & Media & Medio & Parcial & Claro & Cohesión de flóc.: & Pobre/Parcial/Bu & luy buen & xcelente & \\
\hline 5 & Media & Medio & Parcial & Claro & Claridad rebose: & Muy turbio/Turbi & o/Muy cl & /Cristalino & \\
\hline & & & & CULANTE. TEST 3. & & & & & \\
\hline & $\mathrm{M}-002$ & FLOCULANTE: & NALCO & TIPO CARGA: & Sin Carga 0\% & DOSIFICACIÓN & & & \\
\hline $\begin{array}{c}\text { Ensayo } \\
\#\end{array}$ & $\begin{array}{l}\text { Diluc. } \\
\text { (Si/No) }\end{array}$ & $\begin{array}{c}\text { Pulpa w/w sol. } \\
(\%)\end{array}$ & $\begin{array}{l}\text { Distancia sed. } \\
(\mathrm{cm})\end{array}$ & $\begin{array}{c}\text { Volumen ensayo } \\
(\mathrm{ml})\end{array}$ & $\begin{array}{c}\text { Sólidos } \\
\text { (g) }\end{array}$ & $\begin{array}{l}\text { Floc } \\
\text { (ml) }\end{array}$ & $\begin{array}{l}\text { Floc } \\
(\mathrm{g} / \mathrm{t}) \\
\end{array}$ & $\begin{array}{c}\text { Tiempo } \\
\text { (s) }\end{array}$ & $\begin{array}{c}\text { Velocidad } \\
(\mathrm{m} / \mathrm{h})\end{array}$ \\
\hline 1 & No & $5,00 \%$ & 10 & 484,4 & 25,00 & 2 & 40 & 11 & 32,7 \\
\hline 2 & No & $5,00 \%$ & 10 & 484,4 & 25,00 & 4 & 80 & 9 & 40,0 \\
\hline 3 & No & $5,00 \%$ & 10 & 484,4 & 25,00 & 6 & 120 & 10 & 36,0 \\
\hline 4 & No & $5,00 \%$ & 10 & 484,4 & 25,00 & 8 & 160 & 12 & 30,0 \\
\hline 5 & No & $5,00 \%$ & 10 & 484,4 & 25,00 & 10 & 200 & 15 & 24,0 \\
\hline Ensayo & $\begin{array}{l}\text { Velocidad } \\
\text { Sediment. }\end{array}$ & $\begin{array}{l}\text { Tamaño } \\
\text { Floculo } \\
\end{array}$ & $\begin{array}{l}\text { Cohesión } \\
\text { Flóculo }\end{array}$ & $\begin{array}{l}\text { Claridad } \\
\text { Rebose }\end{array}$ & & & & & \\
\hline 1 & Alta & Grande & Buena & Claro & Datos (para observa & ación visual): & & & \\
\hline 2 & Alta & Grande & Buena & Muy claro & Tamaño flóculo: & Muy pequeño/Pe & /Medio/ & nde/Muy gra & \\
\hline 3 & Alta & Grande & Buena & Muy claro & Velocidad sedim.: & Muy lenta/Lenta/ & a/Rápida & uy rápida & \\
\hline 4 & Media & Grande & Buena & Muy claro & Cohesión de flóc.: & Pobre/Parcial/Bu & huy buen & xcelente & \\
\hline 5 & Media & Grande & Buena & Muy claro & Claridad rebose: & Muy turbio/Turbi & ro/Muy c & /Cristalino & \\
\hline & & & & CULANTE. TEST 4. & & & & & \\
\hline & $\mathrm{M}-002$ & FLOCULANTE: & NALCO & TIPO CARGA: & Catiónico $+\mathbf{1 0} \%$ & DOSIFICACIÓN & $55 \%$ & & \\
\hline $\begin{array}{c}\text { Ensayo } \\
\quad \#\end{array}$ & $\begin{array}{l}\text { Diluc. } \\
\text { (Si/No) }\end{array}$ & $\begin{array}{c}\text { Pulpa w/w sol. } \\
(\%)\end{array}$ & $\begin{array}{l}\text { Distancia sed. } \\
\quad(\mathrm{cm})\end{array}$ & $\begin{array}{c}\text { Volumen ensayo } \\
(\mathrm{ml})\end{array}$ & $\begin{array}{c}\text { Sólidos } \\
\text { (g) }\end{array}$ & $\begin{array}{l}\text { Floc } \\
\text { (ml) }\end{array}$ & $\begin{array}{l}\text { Floc } \\
(\mathrm{g} / \mathrm{t})\end{array}$ & $\begin{array}{c}\text { Tiempo } \\
(s)\end{array}$ & $\begin{array}{c}\text { Velocidad } \\
(\mathrm{m} / \mathrm{h})\end{array}$ \\
\hline 1 & No & $5,00 \%$ & 10 & 484,4 & 25,00 & 2 & 40 & 12 & 30,0 \\
\hline 2 & No & $5,00 \%$ & 10 & 484,4 & 25,00 & 4 & 80 & 13 & 27,7 \\
\hline 3 & No & $5,00 \%$ & 10 & 484,4 & 25,00 & 6 & 120 & 11 & 32,7 \\
\hline 4 & No & $5,00 \%$ & 10 & 484,4 & 25,00 & 8 & 160 & 15 & 24,0 \\
\hline 5 & No & $5,00 \%$ & 10 & 484,4 & 25,00 & 10 & 200 & 18 & 20,0 \\
\hline & Velocidad & Tamaño & Cohesión & Claridad & & & & & \\
\hline Ensayo & Sediment. & Floculo & Flóculo & Rebose & & & & & \\
\hline 1 & Media & Medio & Parcial & Claro & Datos (para observa & ación visual): & & & \\
\hline 2 & Media & Medio & Parcial & Claro & Tamaño flóculo: & Muy pequeño/Pe & /Medio/ & nde/Muy gra & \\
\hline 3 & Media & Medio & Parcial & Claro & Velocidad sedim.: & Muy lenta/Lenta & a/Rápida & «y rápida & \\
\hline 4 & Media & Medio & Parcial & Claro & Cohesión de flóc.: & Pobre/Parcial/Bu & huy buen & xcelente & \\
\hline 5 & Media & Medio & Parcial & Claro & Claridad rebose: & Muy turbio/Turb & o/Muy c & /Cristalino & \\
\hline & & & & CULANTE. TEST 5. & & & & & \\
\hline & $\mathrm{M}-002$ & FLOCULANTE: & NALCO & TIPO CARGA: & Catiónico $+25 \%$ & DOSIFICACIÓI & $5 \% \%$ & & \\
\hline $\begin{array}{c}\text { Ensayo } \\
\quad \#\end{array}$ & $\begin{array}{l}\text { Diluc. } \\
\text { (Si/No) }\end{array}$ & $\begin{array}{c}\text { Pulpa w/w sol. } \\
\text { (\%) }\end{array}$ & $\begin{array}{l}\text { Distancia sed. } \\
\qquad(\mathrm{cm})\end{array}$ & $\begin{array}{c}\text { Volumen ensayo } \\
(\mathrm{ml})\end{array}$ & $\begin{array}{l}\text { Sólidos } \\
\text { (g) }\end{array}$ & $\begin{array}{l}\text { Floc } \\
\text { (ml) }\end{array}$ & $\begin{array}{l}\text { Floc } \\
(g / t)\end{array}$ & $\begin{array}{c}\text { Tiempo } \\
\text { (s) }\end{array}$ & $\begin{array}{c}\text { Velocidad } \\
(\mathrm{m} / \mathrm{h})\end{array}$ \\
\hline 1 & No & $5,00 \%$ & 10 & 484,4 & 25,00 & 2 & 40 & 15 & 24,0 \\
\hline 2 & No & $5,00 \%$ & 10 & 484,4 & 25,00 & 4 & 80 & 14 & 25,7 \\
\hline 3 & No & $5,00 \%$ & 10 & 484,4 & 25,00 & 6 & 120 & 14 & 25,7 \\
\hline 4 & No & $5,00 \%$ & 10 & 484,4 & 25,00 & 8 & 160 & 19 & 18,9 \\
\hline 5 & No & $5,00 \%$ & 10 & 484,4 & 25,00 & 10 & 200 & 21 & 17,1 \\
\hline & Velocidad & Tamaño & Cohesión & Claridad & & & & & \\
\hline Ensayo & Sediment. & Floculo & Flóculo & Rebose & & & & & \\
\hline 1 & Baja & Medio & Parcial & Turbio & Datos (para observa & ación visual): & & & \\
\hline 2 & Baja & Medio & Parcial & Turbio & Tamaño flóculo: & Muy pequeño/Pe & /Medio/ & nde/Muy gra & \\
\hline 3 & Baja & Medio & Parcial & Turbio & Velocidad sedim.: & Muy lenta/Lenta & a/Rápida & uy rápida & \\
\hline 4 & Baja & Medio & Parcial & Turbio & Cohesión de flóc.: & Pobre/Parcial/Bu & huy buen & xcelente & \\
\hline 5 & Baja & Medio & Parcial & Turbio & Claridad rebose: & Muy turbio/Turb & ro/Muy c & /Cristalino & \\
\hline
\end{tabular}


SELECCIÓN DE FLOCULANTE. ANÁLISIS DE DATOS.

Mina:

Proyecto:

MUESTRA ORIGINAL:

Volumen líquido:

$\%$ sólidos en peso:

Dosficación de floculante:

Volumen total:

Concentración floculante:

Densidad Sólido

Densidad Líquido
Cantera de Caliza

Estudio sedimentación y reología de finos de caliza M-002

\begin{tabular}{clll}
$475 \mathrm{ml}$ & Muestra preparada en laboratorio \\
$25 \mathrm{~g}$ & Muestra preparada en laboratorio \\
$0,1 \mathrm{~g}$ & $\begin{array}{l}\text { Preparación y dosificación floculante. } \\
200 \mathrm{ml}\end{array}$ & Preparación y dosificación floculante. & \\
$0,05 \%$ & & & \\
$2,65 \mathrm{~kg} / \mathrm{dm} 3$ & Método cálculo: & Picnómetro & (Estimado/Lab. Planta/Picnómetro) \\
$1,00 \mathrm{~kg} / \mathrm{dm} 3$ & Método cálculo: & Probeta & (Estimado/Lab. Planta/Probeta) \\
\hline
\end{tabular}

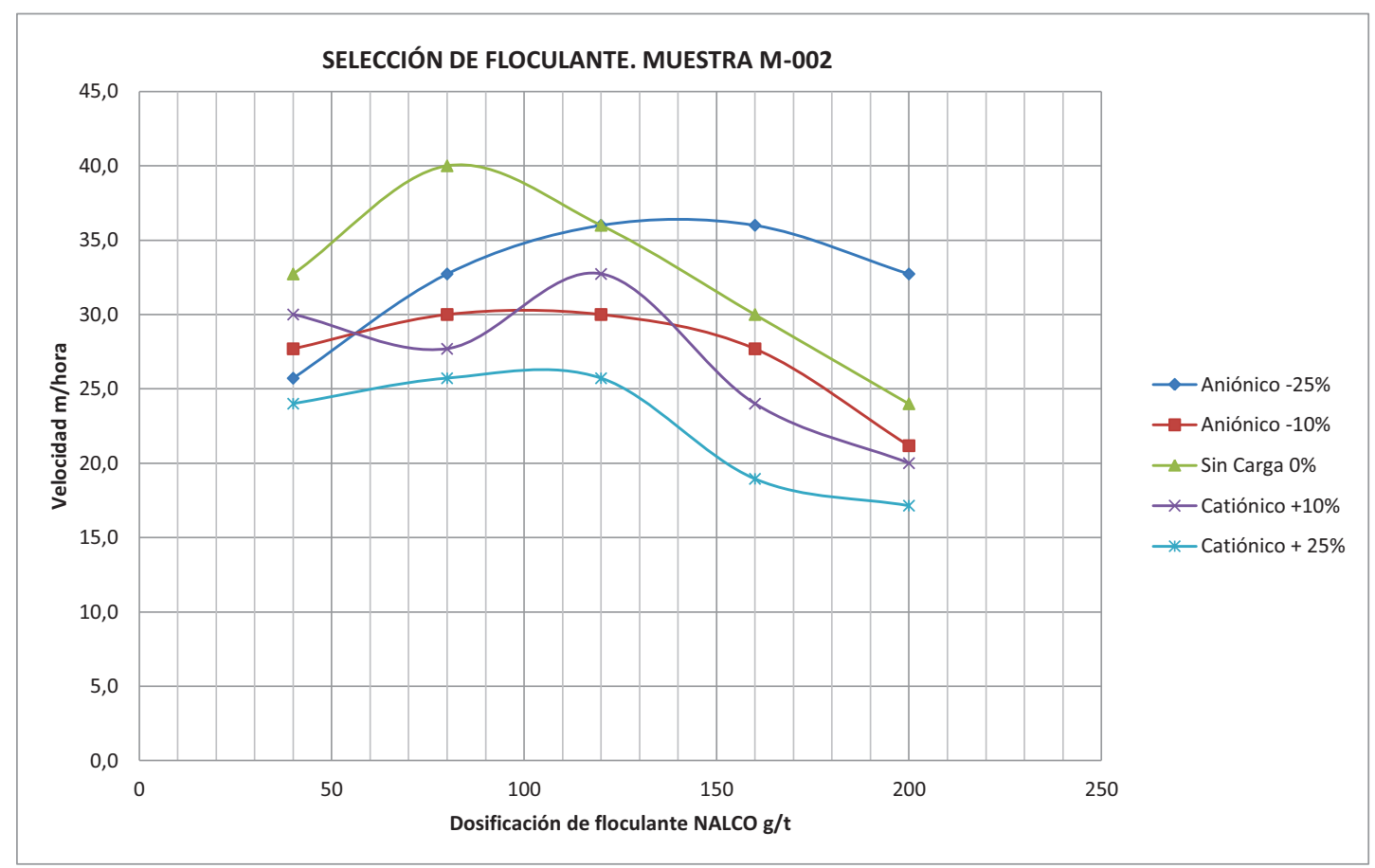

Los ensayos de sedimentación para la selección del floculante han tenido en cuenta tanto los valores de velocidad de sedimentación cómo los datos de observación visual de: tamaño de flóculo, velocidad de sedimentación, cohesión del flóculo y la claridad del rebose obtenida en la probeta de laboratorio. El floculante seleccionado será empleado en los ensayos de flujo de sedimentación. 
ENSAYO FLUJO SEDIMENTACIÓN

\begin{tabular}{|c|c|c|}
\hline $\begin{array}{l}\text { Mina: } \\
\text { Provecto: }\end{array}$ & \multicolumn{2}{|c|}{$\begin{array}{l}\text { Cantera de Caliza } \\
\text { Estudio sedimentación y reología de finos de caliza }\end{array}$} \\
\hline DATOS & & FLOCULANTE SELECCIONADO \\
\hline Volumen probeta: & $500 \mathrm{ml}$ & NALCO $0 \%$ CARGA \\
\hline Diámetro probeta: & $48,6 \mathrm{~mm}$ & \\
\hline Área sedimentac. & $18,55 \mathrm{~cm} 2$ & \\
\hline Floc. Dosificac.: & $0,1 \mathrm{~g}$ & \\
\hline Volumen floc.: & $200 \mathrm{ml}$ & MUESTRA SÓLIDOS \\
\hline Floculante dosific. & $0,05 \%$ & M-002 \\
\hline Floc. Conc. & $0,50 \mathrm{~g} / \mathrm{l}$ & \\
\hline Densidad Sólido & $2,65 \mathrm{~kg} / \mathrm{dm} 3$ & \\
\hline Densidad Líquido & $1,00 \mathrm{~kg} / \mathrm{dm} 3$ & \\
\hline
\end{tabular}

Proyecto: $\quad$ Estudio sedimentación y reología de finos de caliza

ENSAYO 1: $2.5 \%$ SOLIDOS

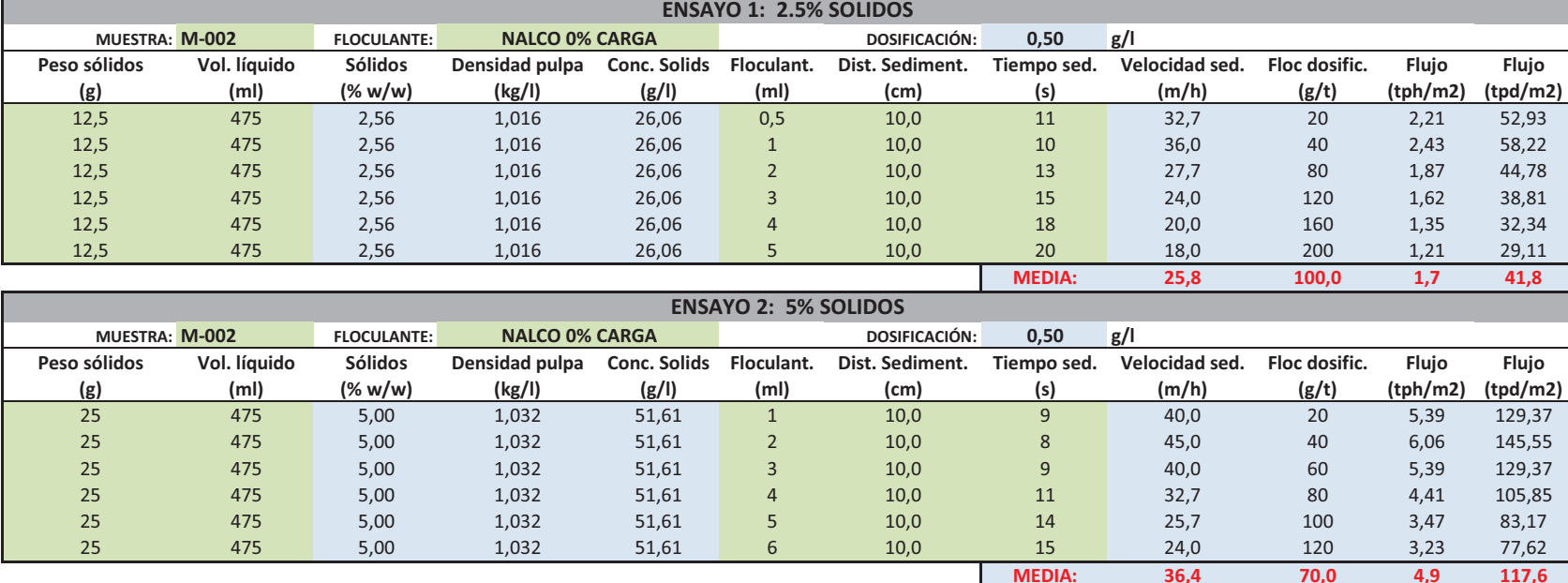

\begin{tabular}{|c|c|c|c|c|c|c|c|c|c|c|c|}
\hline \multicolumn{12}{|c|}{ ENSAYO 3: $7.5 \%$ SOLIDOS } \\
\hline \multicolumn{2}{|c|}{ MUESTRA: M-002 } & \multirow{2}{*}{$\begin{array}{l}\text { FLOCULANTE: } \\
\text { Sólidos } \\
(\% \mathrm{w} / \mathrm{w})\end{array}$} & \multicolumn{2}{|c|}{ NALCO $0 \%$ CARGA } & \multirow[b]{2}{*}{$\begin{array}{c}\text { Floculant. } \\
\text { (ml) }\end{array}$} & DOSIFICACIÓN: & \multirow{2}{*}{$\begin{array}{c}0,50 \\
\text { Tiempo sed. } \\
\text { (s) }\end{array}$} & \multirow{2}{*}{$\frac{\mathrm{g} / \mathrm{l}}{\begin{array}{c}\text { Velocidad sed. } \\
(\mathrm{m} / \mathrm{h})\end{array}}$} & \multirow[b]{2}{*}{$\begin{array}{l}\text { Floc dosific. } \\
(\mathrm{g} / \mathrm{t})\end{array}$} & \multirow[b]{2}{*}{$\begin{array}{c}\text { Flujo } \\
\text { (tph/m2) }\end{array}$} & \multirow[b]{2}{*}{$\begin{array}{c}\text { Flujo } \\
\text { (tpd/m2) }\end{array}$} \\
\hline $\begin{array}{c}\text { Peso sólidos } \\
\text { (g) }\end{array}$ & $\begin{array}{c}\text { Vol. líquido } \\
\text { (ml) }\end{array}$ & & $\begin{array}{c}\text { Densidad pulpa } \\
(\mathrm{kg} / \mathrm{l})\end{array}$ & $\begin{array}{l}\text { Conc. Solids } \\
(\mathrm{g} / \mathrm{l})\end{array}$ & & $\begin{array}{l}\text { Dist. Sediment. } \\
\text { (cm) }\end{array}$ & & & & & \\
\hline 38 & 475 & 7,41 & 1,048 & 77,66 & 1 & 10,0 & 15 & 24,0 & 13 & 4,92 & 117,99 \\
\hline 38 & 475 & 7,41 & 1,048 & 77,66 & 2 & 10,0 & 10 & 36,0 & 26 & 7,37 & 176,98 \\
\hline 38 & 475 & 7,41 & 1,048 & 77,66 & 4 & 10,0 & 11 & 32,7 & 53 & 6,70 & 160,89 \\
\hline 38 & 475 & 7,41 & 1,048 & 77,66 & 6 & 10,0 & 12 & 30,0 & 79 & 6,15 & 147,49 \\
\hline 38 & 475 & 7,41 & 1,048 & 77,66 & 8 & 10,0 & 14 & 25,7 & 105 & 5,27 & 126,42 \\
\hline 38 & 475 & 7,41 & 1,048 & 77,66 & 10 & 10,0 & 16 & 22,5 & 132 & 4,61 & 110,62 \\
\hline & & & & & & & MEDIA: & 27,9 & 65,8 & 5,7 & 137,0 \\
\hline
\end{tabular}

\begin{tabular}{|c|c|c|c|c|c|c|c|c|c|c|c|}
\hline \multicolumn{12}{|c|}{ ENSAYO 4: $10 \%$ SOLIDOS } \\
\hline \multicolumn{2}{|c|}{ MUESTRA: M-002 } & \multirow{2}{*}{$\begin{array}{l}\text { FLOCULANTE: } \\
\text { Sólidos } \\
\text { (\% w/w) }\end{array}$} & \multicolumn{2}{|c|}{ NALCO 0\% CARGA } & \multicolumn{2}{|r|}{ DOSIFICACIÓN: } & \multirow{2}{*}{$\begin{array}{c}0,50 \\
\text { Tiempo sed. } \\
\text { (s) }\end{array}$} & \multirow{2}{*}{$\begin{array}{l}\mathrm{g} / \mathrm{l} \\
\begin{array}{c}\text { Velocidad sed. } \\
(\mathrm{m} / \mathrm{h})\end{array}\end{array}$} & \multirow[b]{2}{*}{$\begin{array}{l}\text { Floc dosific. } \\
(\mathrm{g} / \mathrm{t})\end{array}$} & \multirow[b]{2}{*}{$\begin{array}{c}\text { Flujo } \\
\text { (tph/m2) }\end{array}$} & \multirow[b]{2}{*}{$\begin{array}{c}\text { Flujo } \\
\text { (tpd/m2) }\end{array}$} \\
\hline $\begin{array}{c}\text { Peso sólidos } \\
\text { (g) }\end{array}$ & $\begin{array}{l}\text { Vol. líquido } \\
\text { (ml) }\end{array}$ & & $\begin{array}{c}\text { Densidad pulpa } \\
(\mathrm{kg} / \mathrm{l})\end{array}$ & $\begin{array}{c}\text { Conc. Solids } \\
(\mathrm{g} / \mathrm{l})\end{array}$ & $\begin{array}{l}\text { Floculant. } \\
(\mathrm{ml})\end{array}$ & $\begin{array}{l}\text { Dist. Sediment. } \\
(\mathrm{cm})\end{array}$ & & & & & \\
\hline 50 & 475 & 9,52 & 1,063 & 101,24 & 2 & 10,0 & 25 & 14,4 & 20 & 3,88 & 93,150 \\
\hline 50 & 475 & 9,52 & 1,063 & 101,24 & 4 & 10,0 & 16 & 22,5 & 40 & 6,06 & 145,546 \\
\hline 50 & 475 & 9,52 & 1,063 & 101,24 & 6 & 10,0 & 17 & 21,2 & 60 & 5,71 & 136,985 \\
\hline 50 & 475 & 9,52 & 1,063 & 101,24 & 8 & 10,0 & 19 & 18,9 & 80 & 5,11 & 122,565 \\
\hline 50 & 475 & 9,52 & 1,063 & 101,24 & 10 & 10,0 & 20 & 18,0 & 100 & 4,85 & 116,437 \\
\hline 50 & 475 & 9,52 & 1,063 & 101,24 & 12 & 10,0 & 20 & 18,0 & 120 & 4,85 & 116,437 \\
\hline & & & & & & & MEDIA: & 18,5 & 70,0 & 5,0 & 119,5 \\
\hline
\end{tabular}


ENSAYO FLUJO SEDIMENTACIÓN. ANÁLISIS DE RESULTADOS.

Mina:

Proyecto:

DATOS

Volumen probeta:

Diámetro probeta:

Área sedimentac.

Floc. Dosificac.:

Volumen floc:

Floculante dosific.

Floc. Conc.

Densidad Sólido

Densidad Líquido

Cantera de Caliza

Estudio sedimentación y reología de finos de caliza

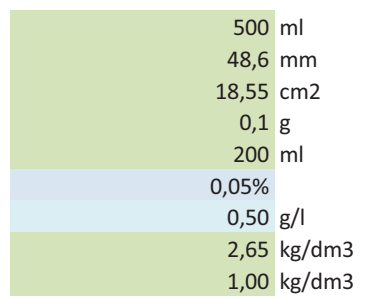

FLOCULANTE SELECCIONADO

NALCO 0\% CARGA

MUESTRA SÓLIDOS

M-002

\begin{tabular}{clll}
\hline M-002 & \multicolumn{3}{c}{} \\
& Diámetros de probetas: & \\
& $250 \mathrm{ml}$ & 35,7 & $\mathrm{~mm}$ \\
& $500 \mathrm{ml}$ & 48,6 & $\mathrm{~mm}$ \\
& $2000 \mathrm{ml}$ & 78,2 & $\mathrm{~mm}$
\end{tabular}
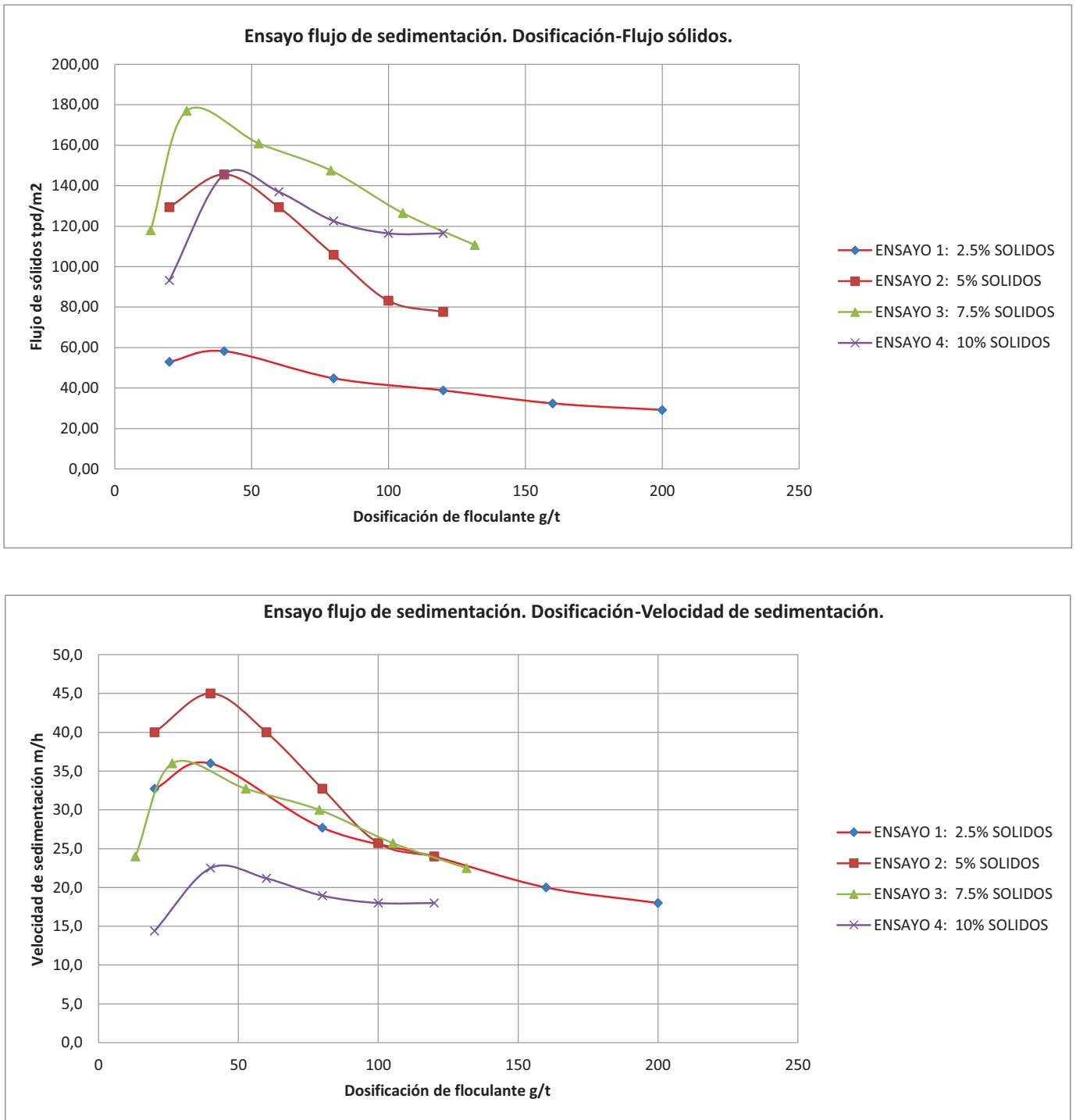

Los ensayos de flujos de sedimentación determinan la dilución óptima de los sólidos para la alimentación en el espesador.

El valor obtenido sirve de base para el diseño de la campana de alimentación y el sistema de dilución previsto. 
ENSAYO SEDIMENTACIÓN PROBETA 2000mI ESTÁTICO

\begin{tabular}{ll}
\hline Mina: & Cantera de Caliza \\
Proyecto: & Estudio sedimentación y reología de finos de caliza \\
Muestra: & M-002
\end{tabular}

Muestra:

M-002

\begin{tabular}{|c|c|c|c|c|c|c|}
\hline Volumen líquido: & $1900 \mathrm{ml}$ & Solidos en peso & $\mathrm{S}=\mathrm{Ps} / \mathrm{Pp}$ & $\mathrm{s}$ & $7,54 \%$ & \\
\hline Peso sólidos: & $155 \mathrm{~g}$ & Dilución & $d=P I / P s$ & $d$ & 12,258 & \\
\hline Floculante dosificac. & $0,1 \mathrm{~g}$ & Solidos en volumen & $V=V_{s} / V p$ & $\mathrm{~V}$ & $2,99 \%$ & \\
\hline Volume total: & $200 \mathrm{ml}$ & Concent. Sólidos en peso & $C=P s / V p$ & c & 79,14 & $\mathrm{~g} / \mathrm{l}$ \\
\hline Floc. Conc. & $0,20 \mathrm{~g} / \mathrm{l}$ & Densidad de la pulpa & $S G p=P p / V p$ & SGp & 1,049 & $\mathrm{~kg} / \mathrm{l}$ \\
\hline Floculante & $8,00 \mathrm{ml}$ & & & & & \\
\hline Solids SG & $2,65 \mathrm{~kg} / \mathrm{dm} 3$ & & & & & \\
\hline Liquid SG & $1,00 \mathrm{~kg} / \mathrm{dm} 3$ & & & & & \\
\hline Diámetro probeta & $78,2 \mathrm{~mm}$ & & & & & \\
\hline Area probeta & $0,0048029 \mathrm{~m} 2$ & $48,029 \mathrm{~cm} 2$ & & & & \\
\hline Densidad pulpa: & $1,049 \mathrm{~kg} / \mathrm{l}$ & & & & & \\
\hline Sólidos en peso: & 79,14 g solids/l & & & & & \\
\hline Sólidos en peso: & $0,0791 \mathrm{~g}$ solids $/ \mathrm{ml}$ & & & & & \\
\hline Floculante: & NALCO & & & & & \\
\hline Tipo de carga floc.: & 0\% CARGA & & & & & \\
\hline Dosificación floc.: & gramos/tor & lada sólido & & & & \\
\hline
\end{tabular}

\section{DATOS DE SEDIMENTACIÓN}

\begin{tabular}{|c|c|c|c|c|c|c|c|c|c|}
\hline $\begin{array}{l}\text { Tiempo info } \\
\text { (sec) }\end{array}$ & $\begin{array}{c}\text { Tiempo } \\
\text { (min) }\end{array}$ & $\begin{array}{l}\text { Vol. Lodos } \\
\text { (ml) }\end{array}$ & $\begin{array}{l}\text { Altura interf. } \\
(\mathrm{cm})\end{array}$ & $\begin{array}{c}\text { Velocidad } \\
\text { (m/hr) }\end{array}$ & $\begin{array}{l}\text { SG. Lodos } \\
(\mathrm{g} / \mathrm{cm} 3)\end{array}$ & $\begin{array}{c}\text { Lodos } \\
\% \text { Sol. Peso }\end{array}$ & $\begin{array}{c}\text { Flujo } \\
\text { (tph/m2) }\end{array}$ & $\begin{array}{c}\text { Flujo } \\
\text { (tpd/m2) }\end{array}$ & $\begin{array}{l}\text { Área Unit. Espes. } \\
\text { (m2/tpd) }\end{array}$ \\
\hline 0 & 0 & 1993 & 41,50 & 0 & 1,048 & 7,42 & 0 & 0 & 0 \\
\hline 5 & 0,08 & 1945 & 40,50 & 7,200 & 1,050 & 7,59 & 23,2361 & 557,67 & 0,002 \\
\hline 10 & 0,17 & 1873 & 39,00 & 10,800 & 1,052 & 7,87 & 23,2359 & 557,66 & 0,002 \\
\hline 15 & 0,25 & 1729 & 36,00 & 21,600 & 1,056 & 8,49 & 23,2360 & 557,66 & 0,002 \\
\hline 30 & 0,50 & 1633 & 34,00 & 4,800 & 1,059 & 8,96 & 7,7453 & 185,89 & 0,005 \\
\hline 45 & 0,75 & 1441 & 30,00 & 9,600 & 1,067 & 10,08 & 7,7453 & 185,89 & 0,005 \\
\hline 60 & 1,00 & 1249 & 26,00 & 9,600 & 1,077 & 11,52 & 7,7453 & 185,89 & 0,005 \\
\hline 120 & 2,00 & 384 & 8,00 & 10,800 & 1,251 & 32,24 & 1,9363 & 46,47 & 0,022 \\
\hline 180 & 3,00 & 322 & 6,70 & 0,780 & 1,300 & 37,05 & 1,9363 & 46,47 & 0,022 \\
\hline 240 & 4,00 & 288 & 6,00 & 0,420 & 1,335 & 40,29 & 1,9363 & 46,47 & 0,022 \\
\hline 300 & 5,00 & 274 & 5,70 & 0,180 & 1,353 & 41,86 & 1,9363 & 46,47 & 0,022 \\
\hline 450 & 7,50 & 235 & 4,90 & 0,192 & 1,410 & 46,71 & 0,7745 & 18,59 & 0,054 \\
\hline 600 & 10,00 & 216 & 4,50 & 0,096 & 1,447 & 49,58 & 0,7745 & 18,59 & 0,054 \\
\hline 900 & 15,00 & 192 & 4,00 & 0,060 & 1,502 & 53,70 & 0,3873 & 9,29 & 0,108 \\
\hline 1200 & 20,00 & 180 & 3,75 & 0,030 & 1,536 & 56,03 & 0,3873 & 9,29 & 0,108 \\
\hline 1500 & 25,00 & 168 & 3,50 & 0,030 & 1,574 & 58,58 & 0,3873 & 9,29 & 0,108 \\
\hline 1800 & 30,00 & 168 & 3,50 & 0,000 & 1,574 & 58,58 & 0,3873 & 9,29 & 0,108 \\
\hline 3600 & 60,00 & 168 & 3,50 & 0,000 & 1,574 & 58,58 & 0,0645 & 1,55 & 0,646 \\
\hline 5400 & 90,00 & 168 & 3,50 & 0,000 & 1,574 & 58,58 & 0,0645 & 1,55 & 0,646 \\
\hline 7200 & 120,00 & 168 & 3,50 & 0,000 & 1,574 & 58,58 & 0,0645 & 1,55 & 0,646 \\
\hline 9000 & 150,00 & 168 & 3,50 & 0,000 & 1,574 & 58,58 & 0,0645 & 1,55 & 0,646 \\
\hline 10800 & 180,00 & 168 & 3,50 & 0,000 & 1,574 & 58,58 & 0,0645 & 1,55 & 0,646 \\
\hline 14400 & 240,00 & 168 & 3,50 & 0,000 & 1,574 & 58,58 & 0,0323 & 0,77 & 1,291 \\
\hline
\end{tabular}

DATOS OBTENIDOS:

1a Caída de velocidad: 1 minuto

2a Caída de velocidad, comienzo régimen de compresión: 20 minutos

$\%$ sólidos - tiempo: 58 \% sólidos en peso - $30 \mathrm{~min}$. tiempo residencia 
ENSAYO SEDIMENTACIÓN PROBETA 2000mI ESTÁTICO. ANÁLISIS DE RESULTADOS.

Mina:

Proyecto:

Muestra
Cantera de Caliza

Estudio sedimentación y reología de finos de caliza

M-002
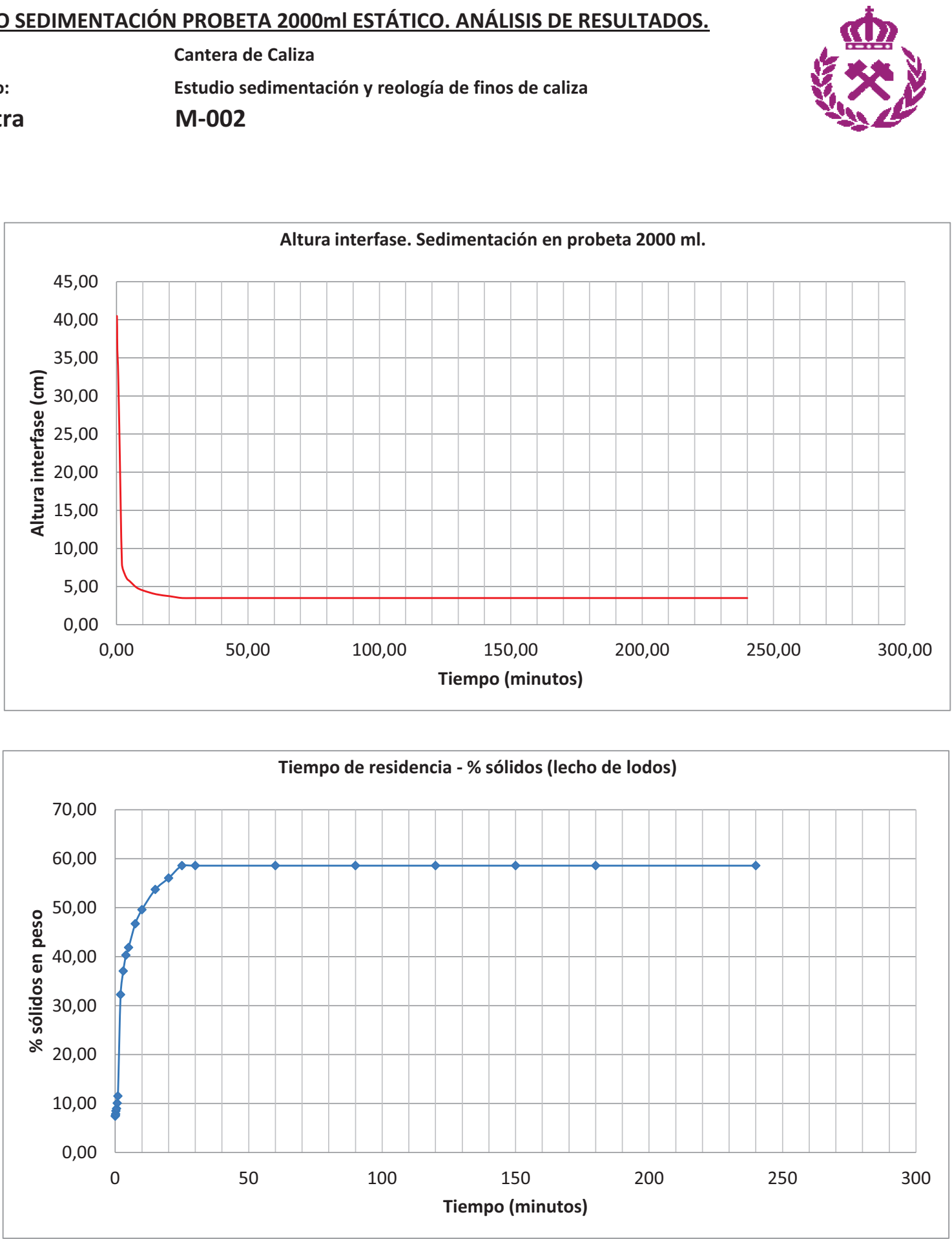


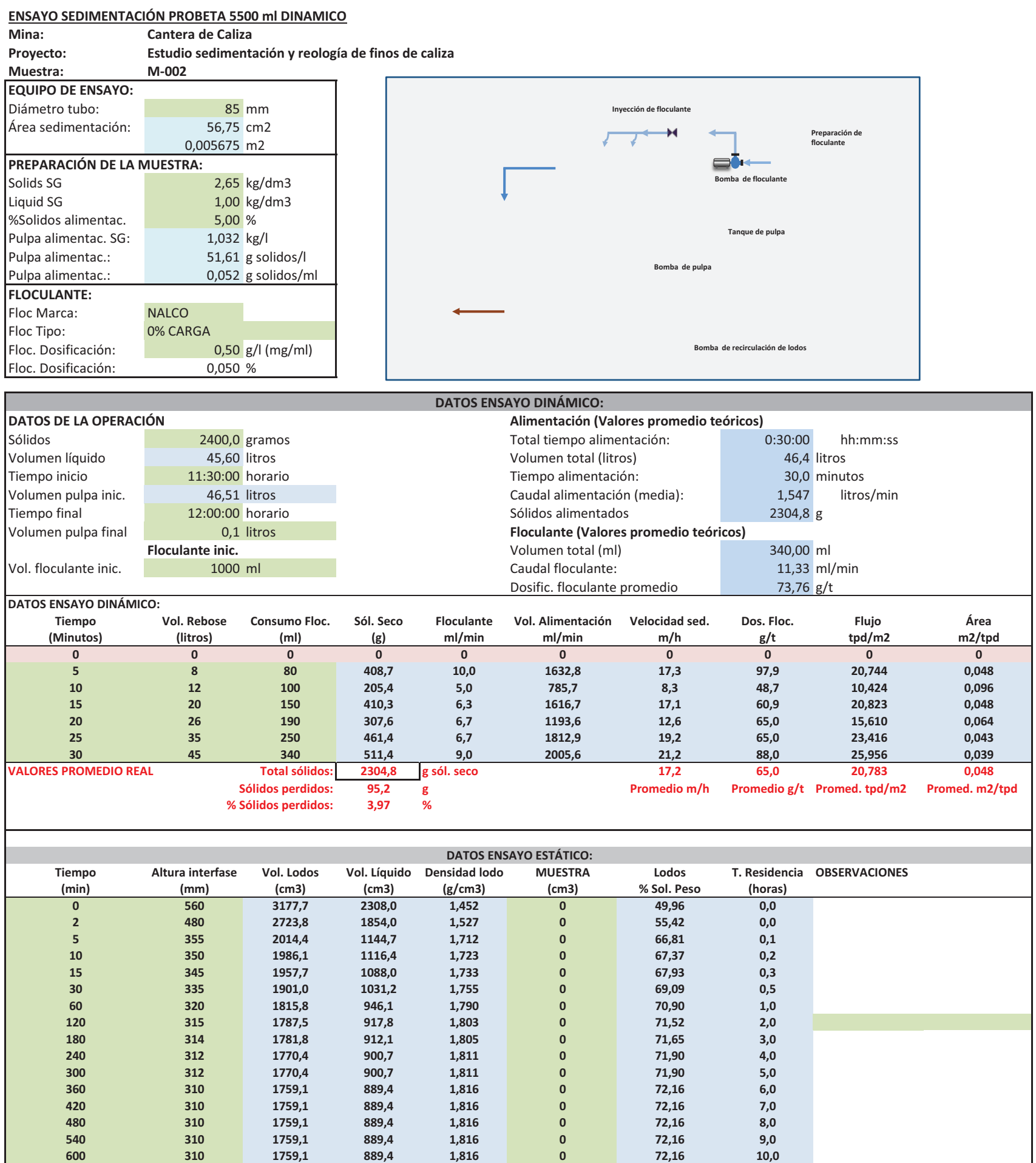


ENSAYO SEDIMENTACIÓN PROBETA 5500 mI DINAMICO

Mina: Cantera de Caliza

Proyecto: Estudio sedimentación y reología de finos de caliza

Muestra: M-002

DATOS DE OPERACIÓN DEL ESPESADOR DE TUBO PROFUNDO

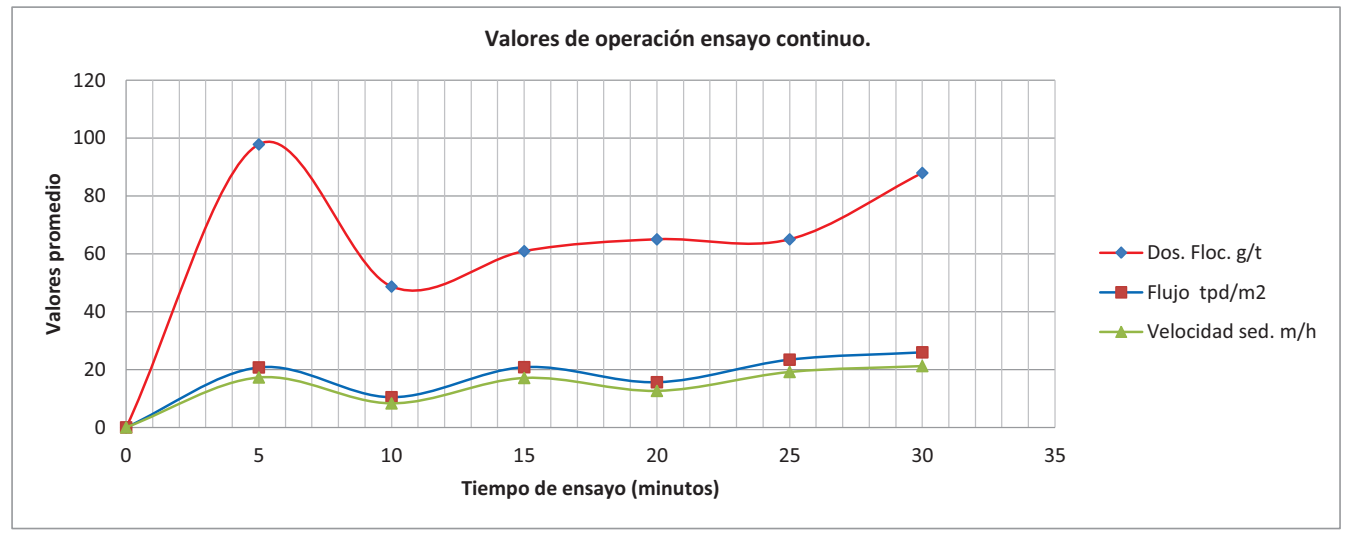

Datos Promedio:

Velocidad de sedimentación:

$17,2 \mathrm{~m} / \mathrm{h}$

Dosificación de floculante:

$65,0 \mathrm{~g} / \mathrm{t}$

Flujo de sedimentación:

$0,0481 \mathrm{~m}^{2} / \mathrm{t} / \mathrm{día}$

Flujo de sedimentación:

$20,8 \mathrm{t} / \mathrm{dí} a / \mathrm{m}^{2}$

ENSAYO SEDIMENTACIÓN PROBETA $5500 \mathrm{mI}$ DINAMICO
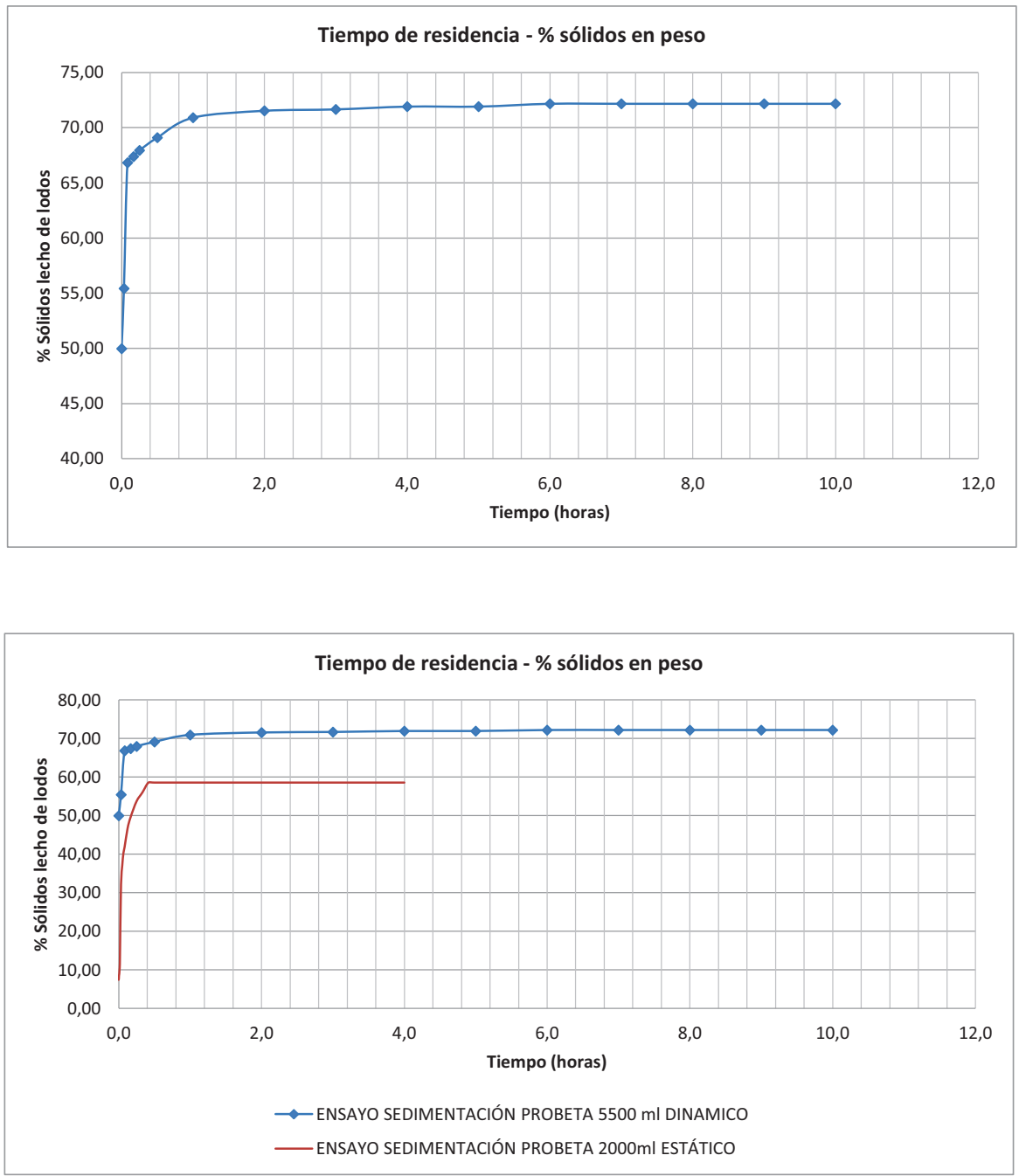
ENSAYO FILTRACIÓN A VACIO

Mina: Cantera de Caliza

Proyecto: $\quad$ Estudio sedimentación y reología de finos de caliza

Material:

Finos de caliza

Muestra:

$\mathrm{M}-002$

Preparado por: José A. Butragueño

pH muestra: 8

Fecha: $\quad 23 / 07 / 2013$

\begin{tabular}{|c|c|c|}
\hline \multicolumn{3}{|c|}{ DATOS DE LA MUESTRA: } \\
\hline Solidos SG & & $2,65 \mathrm{~kg} / \mathrm{dm} 3$ \\
\hline Liquido SG & & $1,00 \mathrm{~kg} / \mathrm{dm} 3$ \\
\hline \multicolumn{3}{|l|}{ FLOCULANTE: } \\
\hline Floc Name: & No & \\
\hline Tipo de floculante: & No & \\
\hline Floc. Dosificación: & & $0,00 \mathrm{~g} / \mathrm{l}(\mathrm{mg} / \mathrm{ml})$ \\
\hline
\end{tabular}
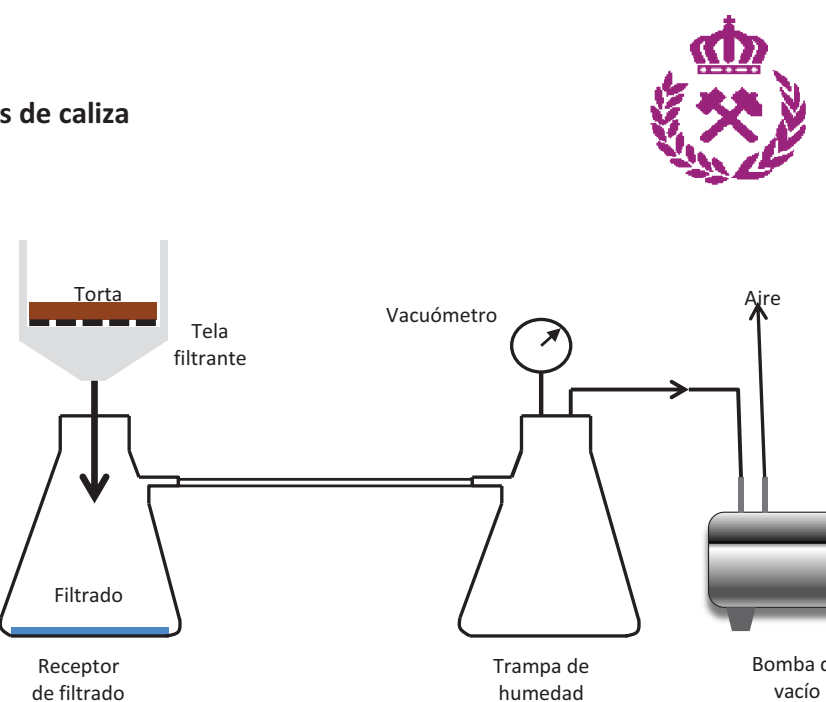
$0,000 \%$

\begin{tabular}{|c|c|c|c|c|c|c|c|c|c|}
\hline \multicolumn{10}{|c|}{ ENSAYO FILTRACIÓN A VACÍO. TEST 1.} \\
\hline \multicolumn{2}{|c|}{ MUESTRA: M-002 } & \multirow[b]{2}{*}{$\begin{array}{l}\text { Vol. Líquido } \\
\text { (ml) }\end{array}$} & \multicolumn{7}{|c|}{ Tiempos de ensayo de filtración } \\
\hline $\begin{array}{l}\text { Vacío } \\
\text { (bar) }\end{array}$ & Peso sólidos & & $\begin{array}{l}\text { \% Sól. Peso } \\
\text { (\%) }\end{array}$ & $\begin{array}{l}\text { Vol. Pulpa } \\
\text { (ml) }\end{array}$ & $\begin{array}{l}\text { Formación torta } \\
\text { (s) }\end{array}$ & $\begin{array}{c}\text { Secado torta } \\
\text { (s) }\end{array}$ & $\begin{array}{c}\text { Total ciclo } \\
\text { (s) }\end{array}$ & $\begin{array}{l}\text { Líq. Filtrado } \\
(\mathrm{ml})\end{array}$ & $\begin{array}{c}\text { Espesor } \\
(\mathrm{mm})\end{array}$ \\
\hline$-0,6$ & 100 & 425,0 & 19,0 & 462,7 & 60 & 30 & 90 & 390 & 5,0 \\
\hline \% Solidos estimado: & 74,1 & & & & & & & & \\
\hline Peso muestra húmedo: & 129 & $\mathrm{~g}$ & \multirow{4}{*}{\multicolumn{2}{|c|}{ Observaciones: }} & & & & & \\
\hline Secac & de la muestra & & & & & & & & \\
\hline Peso muestra seco & 99 & $\mathrm{~g}$ & & & & & & & \\
\hline$\%$ humedad torta & 23,26 & $\%$ & & & & & & & \\
\hline
\end{tabular}

\begin{tabular}{|c|c|c|c|c|c|c|c|c|c|}
\hline \multicolumn{10}{|c|}{ ENSAYO FILTRACIÓN A VACÍO. TEST 2.} \\
\hline \multicolumn{2}{|c|}{ MUESTRA: M-002 } & & \multicolumn{7}{|c|}{ Tiempos de ensayo de filtración } \\
\hline $\begin{array}{l}\text { Vacío } \\
\text { (bar) }\end{array}$ & $\begin{array}{l}\text { Peso sólidos } \\
\text { (g) }\end{array}$ & $\begin{array}{l}\text { Vol. Líquido } \\
\text { (ml) }\end{array}$ & $\begin{array}{c}\text { \% Sól. Peso } \\
\text { (\%) }\end{array}$ & $\begin{array}{l}\text { Vol. Pulpa } \\
\text { (ml) }\end{array}$ & $\begin{array}{l}\text { Formación torta } \\
\text { (s) }\end{array}$ & $\begin{array}{c}\text { Secado torta } \\
\text { (s) }\end{array}$ & $\begin{array}{l}\text { Total ciclo } \\
\text { (s) }\end{array}$ & $\begin{array}{l}\text { Líq. Filtrado } \\
\text { (ml) }\end{array}$ & $\begin{array}{c}\text { Espesor } \\
(\mathrm{mm})\end{array}$ \\
\hline$-0,6$ & 50 & 300,0 & 14,3 & 318,9 & 60 & 10 & 70 & 285 & 2,5 \\
\hline \% Solidos estimado: & 76,9 & & & & & & & & \\
\hline Peso muestra húmedo: & 62,5 & $\mathrm{~g}$ & \multirow{4}{*}{\multicolumn{2}{|c|}{ |Observaciones: }} & & & & & \\
\hline Secad & o de la muestr & & & & & & & & \\
\hline Peso muestra seco & 49 & $\mathrm{~g}$ & & & & & & & \\
\hline$\%$ humedad torta & 21,60 & $7 \%$ & & & & & & & \\
\hline
\end{tabular}

\begin{tabular}{|c|c|c|c|c|c|c|c|c|c|}
\hline \multicolumn{10}{|c|}{ ENSAYO FILTRACIÓN A VACÍO. TEST 3.} \\
\hline \multicolumn{2}{|c|}{ MUESTRA: M-002 } & \multirow[b]{2}{*}{$\begin{array}{l}\text { Vol. Líquido } \\
\text { (ml) }\end{array}$} & \multicolumn{7}{|c|}{ Tiempos de ensayo de filtración } \\
\hline $\begin{array}{l}\text { Vacío } \\
\text { (bar) }\end{array}$ & $\begin{array}{l}\text { Peso sólidos } \\
\text { (g) }\end{array}$ & & $\begin{array}{l}\text { \% Sól. Peso } \\
\text { (\%) }\end{array}$ & $\begin{array}{l}\text { Vol. Pulpa } \\
\text { (ml) }\end{array}$ & $\begin{array}{l}\text { Formación torta } \\
\text { (s) }\end{array}$ & $\begin{array}{l}\text { Secado torta } \\
\text { (s) }\end{array}$ & $\begin{array}{l}\text { Total ciclo } \\
\text { (s) }\end{array}$ & $\begin{array}{l}\text { Líq. Filtrado } \\
\text { (ml) }\end{array}$ & $\begin{array}{c}\text { Espesor } \\
(\mathrm{mm})\end{array}$ \\
\hline$-0,6$ & 75 & 300,0 & 20,0 & 328,3 & 60 & 30 & 90 & 276 & 4,0 \\
\hline \% Solidos estimado: & 75,8 & & & & & & & & \\
\hline Peso muestra húmedo: & 89 & $\mathrm{~g}$ & \multirow{4}{*}{\multicolumn{7}{|c|}{$\begin{array}{l}\text { Observaciones: } \\
\text { Contenido en sólidos de la torta filtrada: } 100-21,71=78,29 \%\end{array}$}} \\
\hline \multicolumn{3}{|c|}{ Secado de la muestra: } & & & & & & & \\
\hline Peso muestra seco & 70 & $\mathrm{~g}$ & & & & & & & \\
\hline$\%$ humedad torta & 21,35 & $\%$ & & & & & & & \\
\hline
\end{tabular}

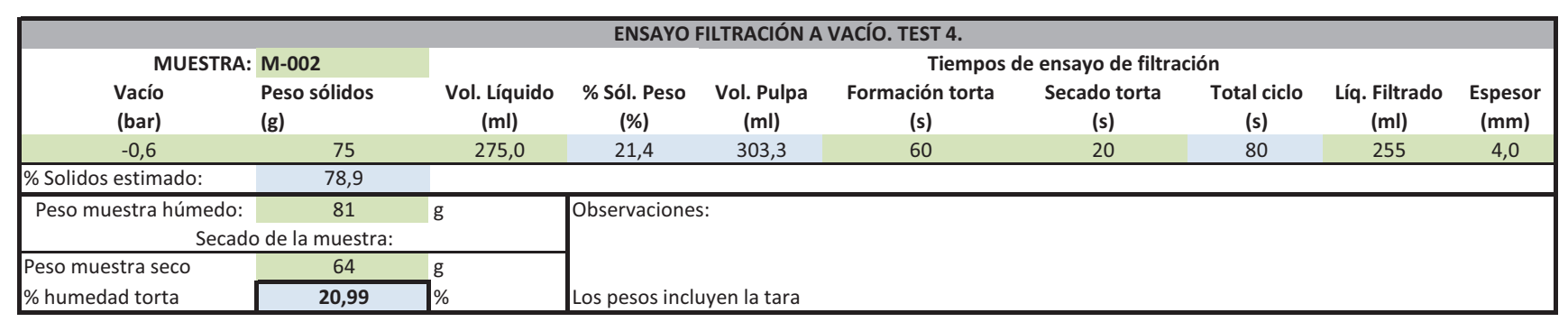


ENSAYO ASENTAMIENTO EN PROBETA

\begin{tabular}{|ll|} 
Mina: & Cantera de Caliza \\
Proyecto: & Estudio sedimentación y reología de finos de caliza \\
\cline { 2 - 2 } Material: & Jinos de caliza \\
Preparado por: & 8 \\
pH muestra: & $23 / 07 / 2013$ \\
\hline Fecha: & Jutragueño \\
\hline
\end{tabular}

Fecha: $23 / 07 / 2013$

Aceleración gravedad (g):

Diámetro probeta:

Altura probeta $(\mathrm{H})$

Volumen probeta:

Solidos SG

$9,81 \mathrm{~m} / \mathrm{s} 2$
$44 \mathrm{~mm}$

$100 \mathrm{~mm}$

$152,1 \mathrm{~cm} 3$

$2,65 \mathrm{~kg} / \mathrm{dm} 3$

Líquido SG

$1,00 \mathrm{~kg} / \mathrm{dm} 3$

Expresiones empíricas

$T=0.5-0.5(h / H)^{\wedge} 0.5$

T.F. $=\mathrm{T}^{*} \mathrm{~d}^{*} \mathrm{~g} *(\mathrm{H} / 100)$

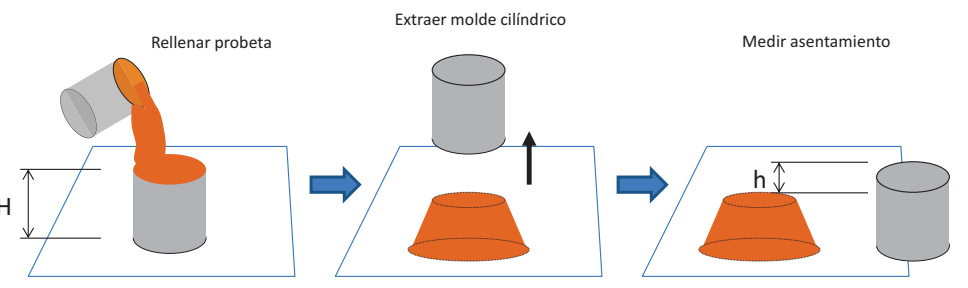

\begin{tabular}{|c|c|c|c|c|c|c|c|c|c|c|}
\hline \multicolumn{11}{|c|}{ ENSAYOS DE ASENTAMIENTO EN PROBETA } \\
\hline $\begin{array}{l}\text { Muestra } \\
\text { ID }\end{array}$ & $\begin{array}{c}\text { Cont. Sólidos } \\
\text { (\%) }\end{array}$ & $\begin{array}{l}\text { Solidos SG } \\
\mathrm{g} / \mathrm{cm} 3\end{array}$ & $\begin{array}{c}\text { Peso Liq. } \\
\text { (kg liq/kg sol) }\end{array}$ & $\begin{array}{l}\text { Vol. Pulpa } \\
\text { (I/kg sol) }\end{array}$ & $\begin{array}{c}\text { Pulpa SG (d) } \\
\text { kg/dm3 }\end{array}$ & $\begin{array}{c}\text { Sólidos prob. } \\
\text { (g) }\end{array}$ & $\begin{array}{l}\text { Liq. Probeta } \\
\text { (g) }\end{array}$ & $\begin{array}{c}\text { Asentamiento }(\mathrm{h}) \\
\mathrm{mm}\end{array}$ & $\begin{array}{l}\text { Factor "T" } \\
\text { Adimens. }\end{array}$ & $\begin{array}{c}\text { Tensión Fluencia } \\
\text { (Pa) }\end{array}$ \\
\hline 1 & 68 & 2,65 & 0,471 & 0,848 & 1,734 & 179,3 & 84,4 & 45 & 0,16459 & 280,0 \\
\hline 2 & 67 & 2,65 & 0,493 & 0,870 & 1,716 & 174,8 & 86,1 & 52 & 0,13944 & 234,7 \\
\hline 3 & 65 & 2,65 & 0,538 & 0,916 & 1,680 & 166,0 & 89,4 & 62 & 0,10630 & 175,2 \\
\hline 4 & 62,5 & 2,65 & 0,600 & 0,977 & 1,637 & 155,6 & 93,3 & 79 & 0,05559 & 89,3 \\
\hline 5 & 60 & 2,65 & 0,667 & 1,044 & 1,596 & 145,6 & 97,1 & 90 & 0,02566 & 40,2 \\
\hline 6 & 50 & 2,65 & 1,000 & 1,377 & 1,452 & 110,4 & 110,4 & 97 & 0,00756 & 10,8 \\
\hline
\end{tabular}

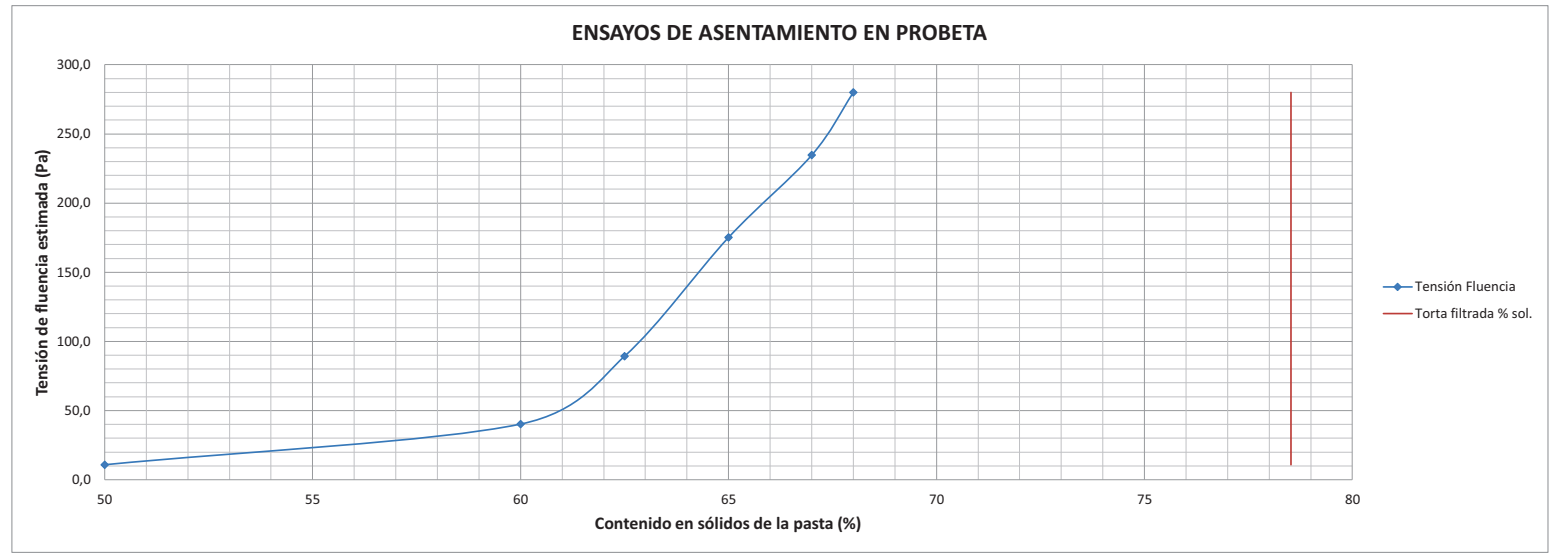

Página 12 de 12 


\section{SEDIMENTACIÓN Y REOLOGÍA}

Mina:

Cantera de Caliza

\section{Empresa:}

JOSÉ BUTRAGUEÑO

\section{Proyecto:}

Estudio sedimentación y reología de finos de caliza

\section{Aplicación}

Sedimentación. Estériles de flotación.

Fecha:

$26 / 07 / 2013$

\section{Ensayos:}

\begin{tabular}{|c|c|}
\hline $\mathbf{x}$ & Distribución granulométrica y caracterización de muestras \\
\hline $\mathbf{x}$ & Selección de floculantes \\
\hline $\mathbf{x}$ & Área de flujo \\
\hline $\mathbf{x}$ & Sedimentación en probeta estática \\
\hline $\mathbf{x}$ & Ensayo en espesador dinámico de laboratorio de $85 \mathrm{~mm}$ DIA \\
\hline $\mathbf{x}$ & Reología de los lodos \\
\hline $\mathbf{x}$ & Ensayo de filtración a vacío \\
\hline
\end{tabular}

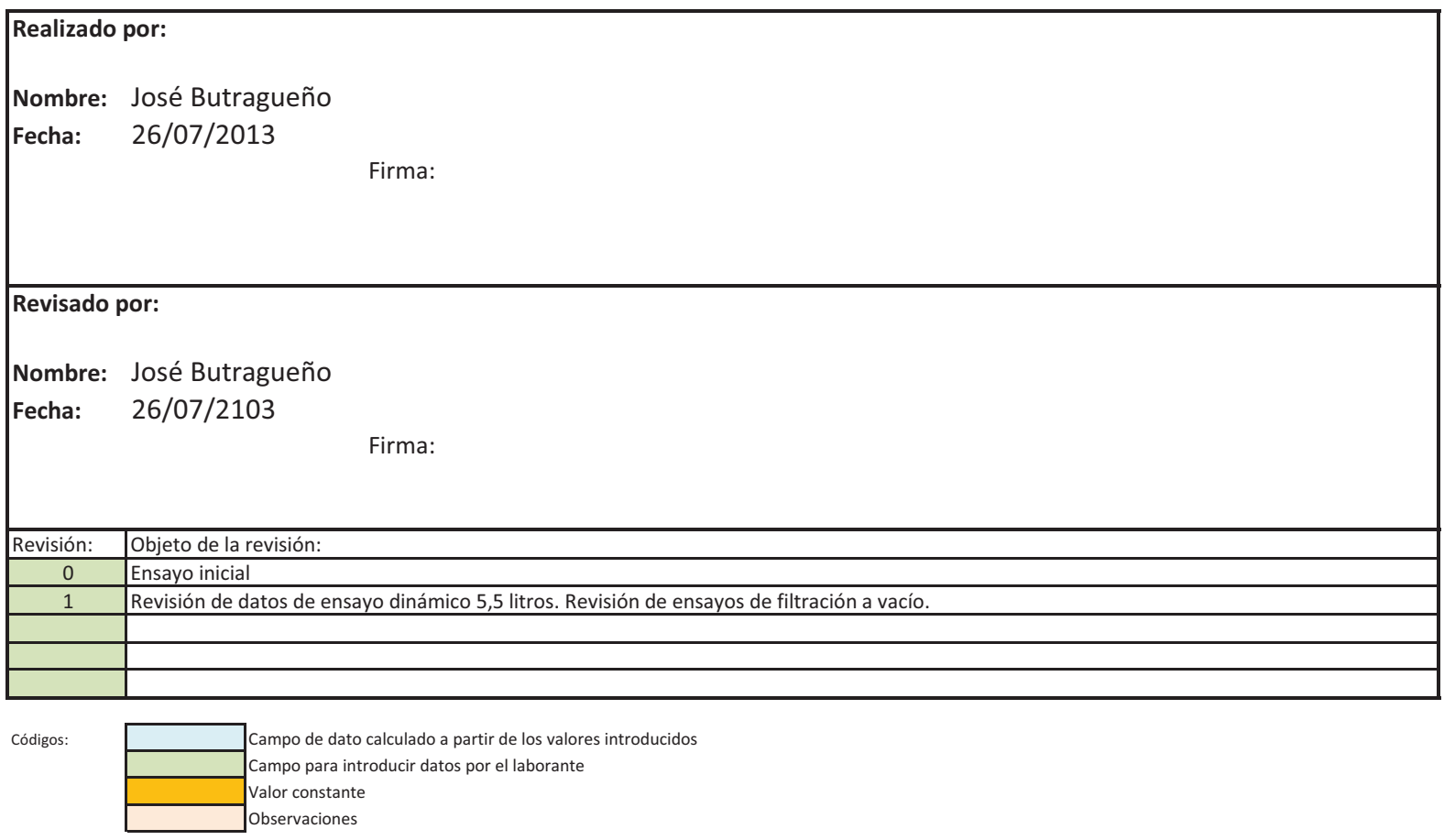

CONFIDENCIAL: Este documento contiene información propiedad de JOSÉ BUTRAGUEÑO y está sujeto a ser

devuelto bajo demanda; estando prohibida su reproducción, copia, préstamo o cualquier otro uso que no sea el fin para el que fue expresamente realizado, sin el consentimiento expreso por escrito de: JOSÉ BUTRAGUEÑO 
ENSAYO GRANULOMÉTRICO DE SÓLIDOS

Mina: Cantera de Caliza

Proyecto: $\quad$ Estudio sedimentación y reología de finos de caliza

Realizado por: José Butragueño

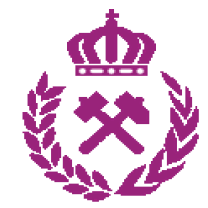

\begin{tabular}{|ll|}
\hline Muestra ID: & M-002 \\
Material: & Finos de caliza \\
Preparado por: & José A. Butragueño \\
pH muestra: & - \\
Fecha: & $26 / 07 / 2013$ \\
\hline
\end{tabular}

CURVA GRANULOMÉTRICA DE SÓLIDOS

\begin{tabular}{|c|c|c|c|c|}
\hline \multicolumn{3}{|c|}{ DATOS DE LA PULPA A SEDIMENTAR } & \multicolumn{2}{|c|}{ Observaciones: Muestra de sólido seco } \\
\hline Densidad sólidos: & 2,65 & $\mathrm{~kg} / \mathrm{dm}^{3}$ & & \\
\hline Densidad líquido: & 1,00 & $\mathrm{~kg} / \mathrm{dm}^{3}$ & & \\
\hline Densidad pulpa: & & $\mathrm{kg} / \mathrm{l}$ & & \\
\hline Tara: & 0 & $\mathrm{~g}$ & & \\
\hline Pulpa húmeda: & 0 & $\mathrm{~g}$ & Peso pulpa: & \begin{tabular}{l|l}
0 & $g$ \\
\end{tabular} \\
\hline Sólido seco: & 0 & g & Peso sólido: & \begin{tabular}{l|l}
$\mathrm{g}$ \\
\end{tabular} \\
\hline \% Peso sólidos: & $0 !$ & $\%$ & & \\
\hline
\end{tabular}

\section{CURVA GRANULOMÉTRICA DE SÓLIDOS}

\begin{tabular}{|c|c|c|c|c|}
\hline \multicolumn{5}{|c|}{ ENSAYO GRANULOMÉTRICO } \\
\hline \multirow{2}{*}{$\begin{array}{l}\text { Tamiz } \\
\text { Micras }\end{array}$} & \multirow{2}{*}{\begin{tabular}{|l} 
Pesos \\
Peso Ret.
\end{tabular}} & \multicolumn{3}{|c|}{ Porcentajes } \\
\hline & & \% Peso Ret. & $\%$ Ret. Ac. & \%Pasa Ac. \\
\hline 125 & 0 & 0,00 & 0,00 & 100,00 \\
\hline 80 & 2,1 & 2,10 & 2,10 & 97,90 \\
\hline 63 & 6,2 & 6,20 & 8,30 & 91,70 \\
\hline 40 & 8,9 & 8,90 & 17,20 & 82,80 \\
\hline 20 & 14,1 & 14,10 & 31,30 & 68,70 \\
\hline 10 & 27 & 27,00 & 58,30 & 41,70 \\
\hline 5 & 6,8 & 6,80 & 65,10 & 34,90 \\
\hline & 34,9 & 34,90 & 100,00 & 0,00 \\
\hline TOTALES: & 100,0 & 100,0 & & \\
\hline
\end{tabular}

$P 80=34$ micras

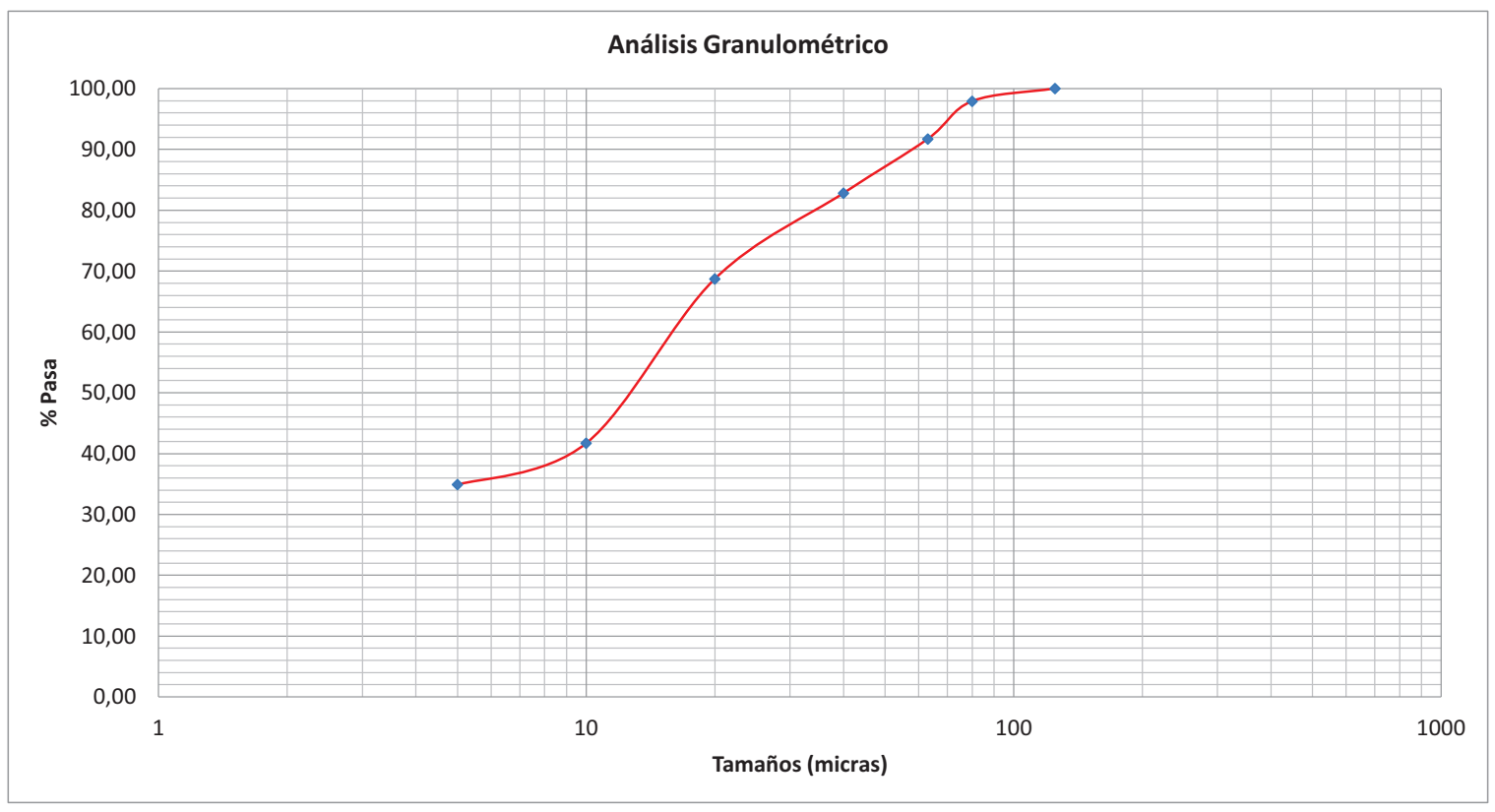




\section{SELECCIÓN DE FLOCULANTE}

$\begin{array}{ll}\text { Mina: } & \text { Cantera de Caliza } \\ \text { Proyecto: } & \text { Estudio sedimentación y reología de finos de caliza }\end{array}$

\begin{tabular}{ll} 
Proyecto: & Estudio sediment \\
MUESTRA ORIGINAL: & M-002 \\
\hline
\end{tabular}

\begin{tabular}{|lcl|}
\hline Volumen líquido: & $475 \mathrm{ml}$ & Muestra preparada en laboratorio \\
\% sólidos en peso: & $25 \mathrm{~g}$ & Muestra preparada en laboratorio \\
Dosficación de floculante: & $0,1 \mathrm{~g}$ & Preparación y dosificación floculante. \\
Volumen total: & $200 \mathrm{ml}$ & Preparación y dosificación floculante. \\
Concentración floculante: & $0,05 \%$ &
\end{tabular}

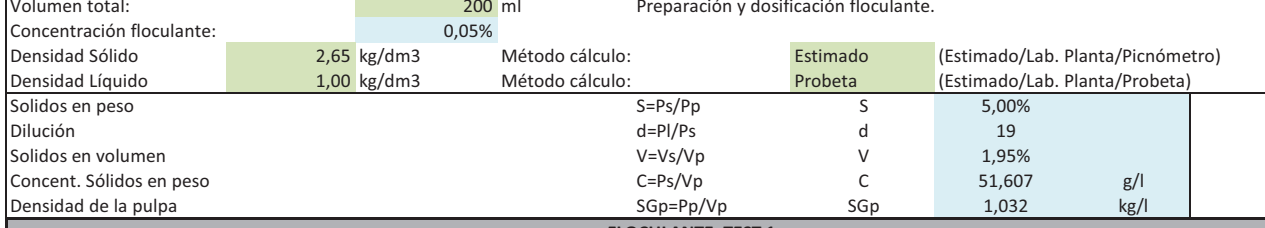

FLOCULANTE. TEST 1.

\begin{tabular}{|c|c|c|c|c|c|c|c|c|c|}
\hline \multicolumn{7}{|c|}{ CULANTE. TEST 1.} & & & \\
\hline \multicolumn{2}{|c|}{ MUESTRA: M-002 } & \multicolumn{2}{|c|}{ FLOCULANTE: NALCO } & TIPO CARGA: & Aniónico -25\% & \multicolumn{2}{|c|}{ DOSIFICACIÓN: $0,05 \%$} & \multirow[b]{2}{*}{$\begin{array}{l}\text { Tiempo } \\
\text { (s) }\end{array}$} & \multirow[b]{2}{*}{$\begin{array}{l}\text { Velocidad } \\
(\mathrm{m} / \mathrm{h})\end{array}$} \\
\hline $\begin{array}{c}\text { Ensayo } \\
\#\end{array}$ & $\begin{array}{l}\text { Diluc. } \\
\text { (Si/No) }\end{array}$ & $\begin{array}{c}\text { Pulpa w/w sol. } \\
(\%)\end{array}$ & $\begin{array}{l}\text { Distancia sed. } \\
\text { (cm) }\end{array}$ & $\begin{array}{c}\text { Volumen ensayo } \\
\text { (ml) }\end{array}$ & $\begin{array}{c}\text { Sólidos } \\
\text { (g) }\end{array}$ & $\begin{array}{c}\text { Floculante } \\
(\mathrm{ml})\end{array}$ & $\begin{array}{l}\text { Floc } \\
(\mathrm{g} / \mathrm{t})\end{array}$ & & \\
\hline 1 & No & $5,00 \%$ & 10 & 484,4 & 25,00 & 2 & 40 & 14 & 25,7 \\
\hline 2 & No & $5,00 \%$ & 10 & 484,4 & 25,00 & 4 & 80 & 11 & 32,7 \\
\hline 3 & No & $5,00 \%$ & 10 & 484,4 & 25,00 & 6 & 120 & 10 & 36,0 \\
\hline 4 & No & $5,00 \%$ & 10 & 484,4 & 25,00 & 8 & 160 & 10 & 36,0 \\
\hline \multirow[t]{2}{*}{5} & No & $5,00 \%$ & 10 & 484,4 & 25,00 & 10 & 200 & 11 & 32,7 \\
\hline & Velocidad & Tamaño & Cohesión & Claridad & & & & & \\
\hline Ensayo & Sediment. & Floculo & Flóculo & Rebose & & & & & \\
\hline 1 & Media & Medio & Parcial & Claro & Datos (para observa & ación visual): & & & \\
\hline 2 & Media & Medio & Parcial & Claro & Tamaño flóculo: & Muy pequeño/Pec & /Medio/ & ande/Muy gra & \\
\hline 3 & Media & Medio & Parcial & Claro & Velocidad sedim.: & Muy lenta/Lenta/ & a/Rápida & luy rápida & \\
\hline 4 & Media & Medio & Parcial & Claro & Cohesión de flóc.: & Pobre/Parcial/Bue & huy buen & Excelente & \\
\hline 5 & Media & Medio & Parcial & Claro & Claridad rebose: & Muy turbio/Turbic & o/Muy c & o/Cristalino & \\
\hline & & & & CULANTE. TEST 2. & & & & & \\
\hline & $\mathrm{M}-002$ & FLOCULANTE: & NALCO & TIPO CARGA: & Aniónico -10\% & DOSIFICACIÓN & $5 \% \%$ & & \\
\hline $\begin{array}{c}\text { Ensayo } \\
\#\end{array}$ & $\begin{array}{l}\text { Diluc. } \\
\text { (Si/No) }\end{array}$ & $\begin{array}{c}\text { Pulpa w/w sol. } \\
(\%)\end{array}$ & $\begin{array}{c}\text { Distancia sed. } \\
(\mathrm{cm})\end{array}$ & $\begin{array}{c}\text { Volumen ensayo } \\
(\mathrm{ml})\end{array}$ & $\begin{array}{c}\text { Sólidos } \\
(\mathrm{g})\end{array}$ & $\begin{array}{l}\text { Floc } \\
\text { (ml) } \\
\end{array}$ & $\begin{array}{l}\text { Floc } \\
(\mathrm{g} / \mathrm{t}) \\
\end{array}$ & $\begin{array}{c}\text { Tiempo } \\
\text { (s) }\end{array}$ & $\begin{array}{c}\text { Velocidad } \\
(\mathrm{m} / \mathrm{h})\end{array}$ \\
\hline 1 & No & $5,00 \%$ & 10 & 484,4 & 25,00 & 2 & 40 & 13 & 27,7 \\
\hline 2 & No & $5,00 \%$ & 10 & 484,4 & 25,00 & 4 & 80 & 12 & 30,0 \\
\hline 3 & No & $5,00 \%$ & 10 & 484,4 & 25,00 & 6 & 120 & 12 & 30,0 \\
\hline 4 & No & $5,00 \%$ & 10 & 484,4 & 25,00 & 8 & 160 & 13 & 27,7 \\
\hline 5 & No & $5,00 \%$ & 10 & 484,4 & 25,00 & 10 & 200 & 17 & 21,2 \\
\hline Ensayo & $\begin{array}{l}\text { Velocidad } \\
\text { Sediment. }\end{array}$ & $\begin{array}{l}\text { Tamaño } \\
\text { Floculo }\end{array}$ & $\begin{array}{l}\text { Cohesión } \\
\text { Flóculo }\end{array}$ & $\begin{array}{l}\text { Claridad } \\
\text { Rebose }\end{array}$ & & & & & \\
\hline 1 & Media & Medio & Parcial & Claro & Datos (para observa & ación visual): & & & \\
\hline 2 & Media & Medio & Parcial & Claro & Tamaño flóculo: & Muy pequeño/Pec & /Medio/ & ande/Muy gra & \\
\hline 3 & Media & Medio & Parcial & Claro & Velocidad sedim.: & Muy lenta/Lenta/ & a/Rápida, & luy rápida & \\
\hline 4 & Media & Medio & Parcial & Claro & Cohesión de flóc.: & Pobre/Parcial/Bue & Muy buen & xcelente & \\
\hline 5 & Media & Medio & Parcial & Claro & Claridad rebose: & Muy turbio/Turbic & ro/Muy c & o/Cristalino & \\
\hline & & & & CULANTE. TEST 3. & & & & & \\
\hline & M-002 & FLOCULANTE: & NALCO & TIPO CARGA: & Sin Carga $0 \%$ & DOSIFICACIÓN & $05 \%$ & & \\
\hline $\begin{array}{c}\text { Ensayo } \\
\#\end{array}$ & $\begin{array}{l}\text { Diluc. } \\
\text { (Si/No) }\end{array}$ & $\begin{array}{c}\text { Pulpa w/w sol. } \\
(\%)\end{array}$ & $\begin{array}{l}\text { Distancia sed. } \\
\text { (cm) }\end{array}$ & $\begin{array}{c}\text { Volumen ensayo } \\
(\mathrm{ml})\end{array}$ & $\begin{array}{c}\text { Sólidos } \\
\text { (g) }\end{array}$ & $\begin{array}{l}\text { Floc } \\
\text { (ml) }\end{array}$ & $\begin{array}{l}\text { Floc } \\
(\mathrm{g} / \mathrm{t})\end{array}$ & $\begin{array}{c}\text { Tiempo } \\
\text { (s) }\end{array}$ & $\begin{array}{c}\begin{array}{c}\text { Velocidad } \\
(\mathrm{m} / \mathrm{h})\end{array} \\
\end{array}$ \\
\hline 1 & No & $5,00 \%$ & 10 & 484,4 & 25,00 & 2 & 40 & 11 & 32,7 \\
\hline 2 & No & $5,00 \%$ & 10 & 484,4 & 25,00 & 4 & 80 & 9 & 40,0 \\
\hline 3 & No & $5,00 \%$ & 10 & 484,4 & 25,00 & 6 & 120 & 10 & 36,0 \\
\hline 4 & No & $5,00 \%$ & 10 & 484,4 & 25,00 & 8 & 160 & 12 & 30,0 \\
\hline 5 & No & $5,00 \%$ & 10 & 484,4 & 25,00 & 10 & 200 & 15 & 24,0 \\
\hline & Velocidad & Tamaño & Cohesión & Claridad & & & & & \\
\hline Ensayo & Sediment. & Floculo & Flóculo & Rebose & & & & & \\
\hline 1 & Alta & Grande & Buena & Claro & Datos (para observa & ación visual): & & & \\
\hline 2 & Alta & Grande & Buena & Muy claro & Tamaño flóculo: & Muy pequeño/Pec & /Medio/ & ande/Muy gra & \\
\hline 3 & Alta & Grande & Buena & Muy claro & Velocidad sedim.: & Muy lenta/Lenta/ & a/Rápida & luy rápida & \\
\hline 4 & Media & Grande & Buena & Muy claro & Cohesión de flóc.: & Pobre/Parcial/Bue & huy buen & Excelente & \\
\hline 5 & Media & Grande & Buena & Muy claro & Claridad rebose: & Muy turbio/Turbic & ro/Muy c & o/Cristalino & \\
\hline & & & & CULANTE. TEST 4. & & & & & \\
\hline & M-002 & FLOCULANTE: & NALCO & TIPO CARGA: & Catiónico $+\mathbf{1 0} \%$ & DOSIFICACIÓN & $05 \%$ & & \\
\hline $\begin{array}{c}\text { Ensayo } \\
\#\end{array}$ & $\begin{array}{l}\text { Diluc. } \\
\text { (Si/No) }\end{array}$ & $\begin{array}{l}\text { Pulpa w/w sol. } \\
(\%)\end{array}$ & $\begin{array}{l}\text { Distancia sed. } \\
(\mathrm{cm})\end{array}$ & $\begin{array}{c}\text { Volumen ensayo } \\
(\mathrm{ml})\end{array}$ & $\begin{array}{c}\text { Sólidos } \\
\text { (g) }\end{array}$ & $\begin{array}{l}\text { Floc } \\
(\mathrm{ml}) \\
\end{array}$ & $\begin{array}{l}\text { Floc } \\
(\mathrm{g} / \mathrm{t})\end{array}$ & $\begin{array}{l}\text { Tiempo } \\
\text { (s) }\end{array}$ & $\begin{array}{c}\begin{array}{c}\text { Velocidad } \\
(\mathrm{m} / \mathrm{h})\end{array} \\
\end{array}$ \\
\hline 1 & No & $5,00 \%$ & 10 & 484,4 & 25,00 & 2 & 40 & 12 & 30,0 \\
\hline 2 & No & $5,00 \%$ & 10 & 484,4 & 25,00 & 4 & 80 & 13 & 27,7 \\
\hline 3 & No & $5,00 \%$ & 10 & 484,4 & 25,00 & 6 & 120 & 11 & 32,7 \\
\hline 4 & No & $5,00 \%$ & 10 & 484,4 & 25,00 & 8 & 160 & 15 & 24,0 \\
\hline 5 & No & $5,00 \%$ & 10 & 484,4 & 25,00 & 10 & 200 & 18 & 20,0 \\
\hline Ensayo & $\begin{array}{l}\text { Velocidad } \\
\text { Sediment. }\end{array}$ & $\begin{array}{l}\text { Tamaño } \\
\text { Floculo }\end{array}$ & $\begin{array}{l}\text { Cohesión } \\
\text { Flóculo }\end{array}$ & $\begin{array}{l}\text { Claridad } \\
\text { Rebose }\end{array}$ & & & & & \\
\hline 1 & Media & Medio & Parcial & Claro & Datos (para observa & ación visual): & & & \\
\hline 2 & Media & Medio & Parcial & Claro & Tamaño flóculo: & Muy pequeño/Pec & o/Medio/ & ande/Muy gra & \\
\hline 3 & Media & Medio & Parcial & Claro & Velocidad sedim.: & Muy lenta/Lenta/I & ia/Rápida, & luy rápida & \\
\hline 4 & Media & Medio & Parcial & Claro & Cohesión de flóc.: & Pobre/Parcial/Bue & Muy buen & Excelente & \\
\hline 5 & Media & Medio & Parcial & Claro & Claridad rebose: & Muy turbio/Turbic & ro/Muy c & o/Cristalino & \\
\hline & & & & CULANTE. TEST 5. & & & & & \\
\hline & $M-002$ & FLOCULANTE: & NALCO & TIPO CARGA: & Catiónico + $25 \%$ & DOSIFICACIÓN & $05 \%$ & & \\
\hline $\begin{array}{c}\text { Ensayo } \\
\quad \#\end{array}$ & $\begin{array}{l}\text { Diluc. } \\
\text { (Si/No) }\end{array}$ & $\begin{array}{l}\text { Pulpa w/w sol. } \\
(\%)\end{array}$ & $\begin{array}{l}\text { Distancia sed. } \\
\text { (cm) }\end{array}$ & $\begin{array}{c}\text { Volumen ensayo } \\
(\mathrm{ml})\end{array}$ & $\begin{array}{l}\text { Sólidos } \\
\text { (g) }\end{array}$ & $\begin{array}{l}\text { Floc } \\
\text { (ml) }\end{array}$ & $\begin{array}{l}\text { Floc } \\
(\mathrm{g} / \mathrm{t})\end{array}$ & $\begin{array}{c}\text { Tiempo } \\
\text { (s) }\end{array}$ & $\begin{array}{c}\begin{array}{c}\text { Velocidad } \\
(\mathrm{m} / \mathrm{h})\end{array} \\
\end{array}$ \\
\hline 1 & No & $5,00 \%$ & 10 & 484,4 & 25,00 & 2 & 40 & 15 & 24,0 \\
\hline 2 & No & $5,00 \%$ & 10 & 484,4 & 25,00 & 4 & 80 & 14 & 25,7 \\
\hline 3 & No & $5,00 \%$ & 10 & 484,4 & 25,00 & 6 & 120 & 14 & 25,7 \\
\hline 4 & No & $5,00 \%$ & 10 & 484,4 & 25,00 & 8 & 160 & 19 & 18,9 \\
\hline 5 & No & $5,00 \%$ & 10 & 484,4 & 25,00 & 10 & 200 & 21 & 17,1 \\
\hline & Velocidad & Tamaño & Cohesión & Claridad & & & & & \\
\hline Ensayo & Sediment. & Floculo & Flóculo & Rebose & & & & & \\
\hline 1 & Baja & Medio & Parcial & Turbio & Datos (para observa & ación visual): & & & \\
\hline 2 & Baja & Medio & Parcial & Turbio & Tamaño flóculo: & Muy pequeño/Pec & o/Medio/ & ande/Muy gra & \\
\hline 3 & Baja & Medio & Parcial & Turbio & Velocidad sedim.: & Muy lenta/Lenta/ & ia/Rápida & luy rápida & \\
\hline 4 & Baja & Medio & Parcial & Turbio & Cohesión de flóc.: & Pobre/Parcial/Bue & Muy buen & xcelente & \\
\hline 5 & Baja & Medio & Parcial & Turbio & Claridad rebose: & Muy turbio/Turbic & ro/Muy c & o/Cristalino & \\
\hline
\end{tabular}


SELECCIÓN DE FLOCULANTE. ANÁLISIS DE DATOS.

Mina:

Proyecto:

MUESTRA ORIGINAL:

Volumen líquido:

$\%$ sólidos en peso:

Dosficación de floculante:

Volumen total:

Concentración floculante:

Densidad Sólido

Densidad Líquido
Cantera de Caliza

Estudio sedimentación y reología de finos de caliza M-002

\begin{tabular}{clll}
$475 \mathrm{ml}$ & Muestra preparada en laboratorio \\
$25 \mathrm{~g}$ & Muestra preparada en laboratorio \\
$0,1 \mathrm{~g}$ & $\begin{array}{l}\text { Preparación y dosificación floculante. } \\
200 \mathrm{ml}\end{array}$ & Preparación y dosificación floculante. \\
$0,05 \%$ & & & \\
$2,65 \mathrm{~kg} / \mathrm{dm} 3$ & Método cálculo: & Picnómetro & (Estimado/Lab. Planta/Picnómetro) \\
$1,00 \mathrm{~kg} / \mathrm{dm} 3$ & Método cálculo: & Probeta & (Estimado/Lab. Planta/Probeta) \\
\hline
\end{tabular}

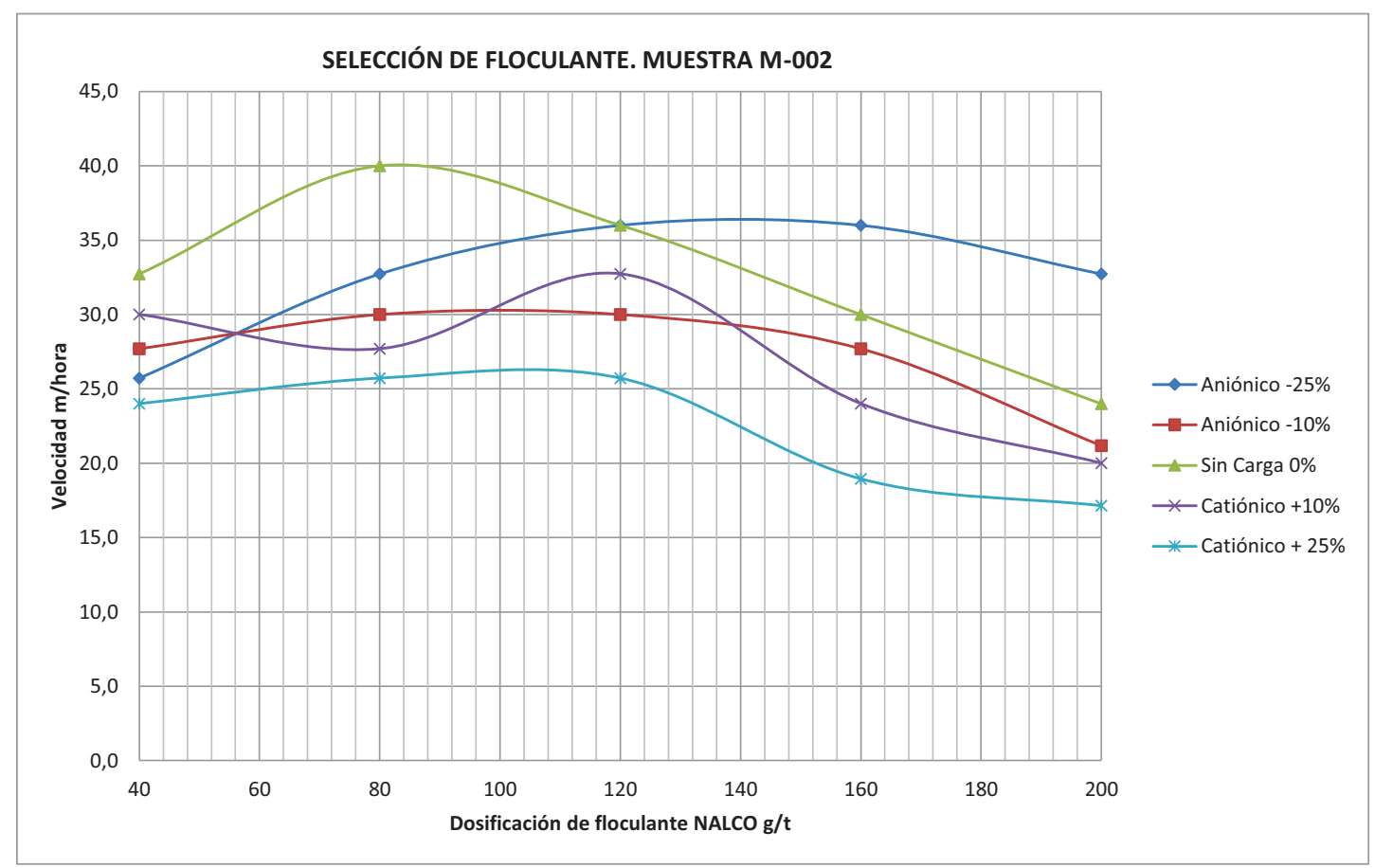

Los ensayos de sedimentación para la selección del floculante han tenido en cuenta tanto los valores de velocidad de sedimentación cómo los datos de observación visual de: tamaño de flóculo, velocidad de sedimentación, cohesión del flóculo y la claridad del rebose obtenida en la probeta de laboratorio. El floculante seleccionado será empleado en los ensayos de flujo de sedimentación. 
ENSAYO FLUJO SEDIMENTACIÓN

\begin{tabular}{l|cc}
$\begin{array}{l}\text { Mina: } \\
\text { Proyecto: } \\
\text { DATOS }\end{array}$ & $\begin{array}{l}\text { Cantera de Caliza } \\
\text { Estudio sedimentación y reología de finos de caliza } \\
\text { FLOCULANTE SELECCIONADO }\end{array}$ \\
Volumen probeta: & $500 \mathrm{ml}$ & \\
Diámetro probeta: & $48,6 \mathrm{~mm}$ & \\
Área sedimentac. & $18,55 \mathrm{~cm} 2$ & \\
Floc. Dosificac.: & $0,1 \mathrm{~g}$ & CARGA \\
Volumen floc.: & $200 \mathrm{ml}$ & MUESTRA SóLIDOS \\
Floculante dosific. & $0,05 \%$ & \\
Floc. Conc. & $0,50 \mathrm{~g} / \mathrm{l}$ \\
Densidad Sólido & $2,65 \mathrm{~kg} / \mathrm{dm} 3$ & \\
Densidad Líquido & $1,00 \mathrm{~kg} / \mathrm{dm} 3$ & \\
\hline
\end{tabular}

Proyecto: $\quad$ Estudio sedimentación y reología de finos de caliza

NSAYO 1: NALCO 0\% CARGA

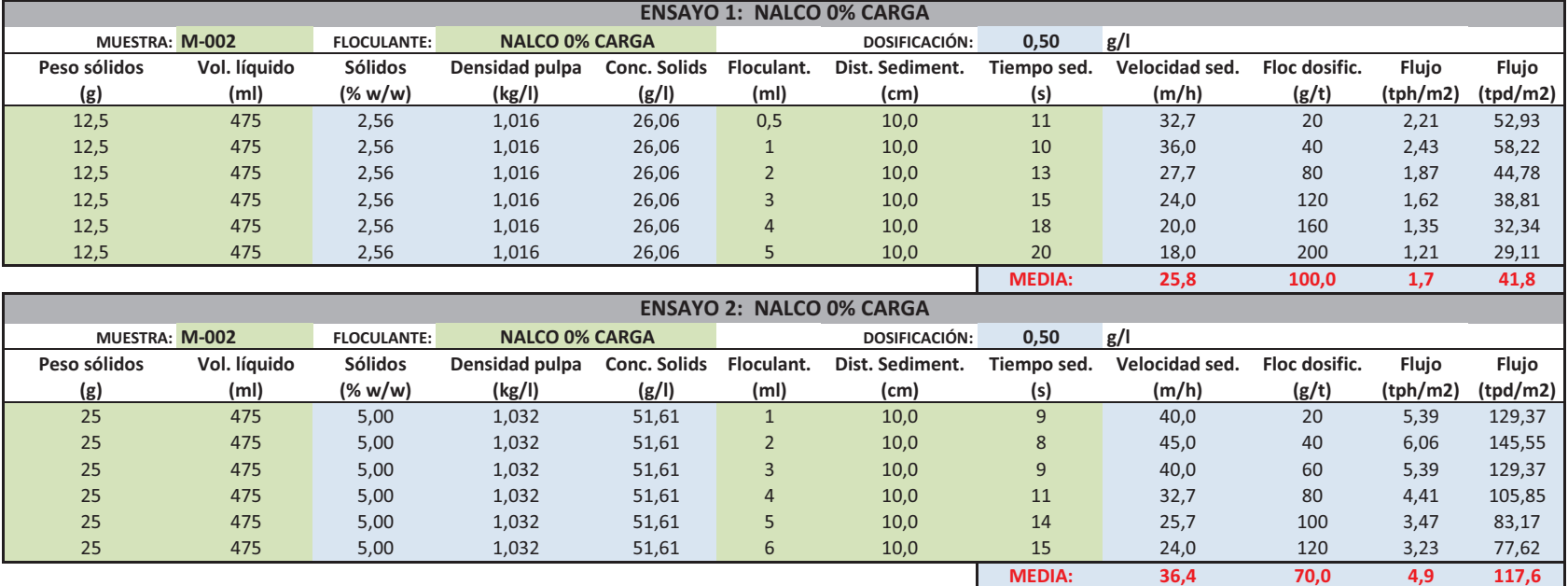

\begin{tabular}{|c|c|c|c|c|c|c|c|c|c|c|c|}
\hline \multicolumn{12}{|c|}{ ENSAYO 3: NALCO 0\% CARGA } \\
\hline \multicolumn{2}{|c|}{ MUESTRA: M-002 } & \multirow{2}{*}{$\begin{array}{l}\text { FLOCULANTE: } \\
\text { Sólidos } \\
(\% \mathrm{w} / \mathrm{w})\end{array}$} & \multicolumn{2}{|c|}{ NALCO $0 \%$ CARGA } & \multirow[b]{2}{*}{$\begin{array}{c}\text { Floculant. } \\
\text { (ml) }\end{array}$} & DOSIFICACIÓN: & \multirow{2}{*}{$\begin{array}{c}0,50 \\
\text { Tiempo sed. } \\
\text { (s) }\end{array}$} & \multirow{2}{*}{$\frac{\mathrm{g} / \mathrm{l}}{\begin{array}{c}\text { Velocidad sed. } \\
(\mathrm{m} / \mathrm{h})\end{array}}$} & \multirow[b]{2}{*}{$\begin{array}{l}\text { Floc dosific. } \\
(\mathrm{g} / \mathrm{t})\end{array}$} & \multirow[b]{2}{*}{$\begin{array}{c}\text { Flujo } \\
\text { (tph/m2) }\end{array}$} & \multirow[b]{2}{*}{$\begin{array}{c}\text { Flujo } \\
\text { (tpd/m2) }\end{array}$} \\
\hline $\begin{array}{c}\text { Peso sólidos } \\
\text { (g) }\end{array}$ & $\begin{array}{c}\text { Vol. líquido } \\
\text { (ml) }\end{array}$ & & $\begin{array}{c}\text { Densidad pulpa } \\
(\mathrm{kg} / \mathrm{l})\end{array}$ & $\begin{array}{c}\text { Conc. Solids } \\
\text { (g/l) }\end{array}$ & & $\begin{array}{l}\text { Dist. Sediment. } \\
\text { (cm) }\end{array}$ & & & & & \\
\hline 38 & 475 & 7,41 & 1,048 & 77,66 & 1 & 10,0 & 15 & 24,0 & 13 & 4,92 & 117,99 \\
\hline 38 & 475 & 7,41 & 1,048 & 77,66 & 2 & 10,0 & 10 & 36,0 & 26 & 7,37 & 176,98 \\
\hline 38 & 475 & 7,41 & 1,048 & 77,66 & 4 & 10,0 & 11 & 32,7 & 53 & 6,70 & 160,89 \\
\hline 38 & 475 & 7,41 & 1,048 & 77,66 & 6 & 10,0 & 12 & 30,0 & 79 & 6,15 & 147,49 \\
\hline 38 & 475 & 7,41 & 1,048 & 77,66 & 8 & 10,0 & 14 & 25,7 & 105 & 5,27 & 126,42 \\
\hline 38 & 475 & 7,41 & 1,048 & 77,66 & 10 & 10,0 & 16 & 22,5 & 132 & 4,61 & 110,62 \\
\hline & & & & & & & MEDIA: & 27,9 & 65,8 & 5,7 & 137,0 \\
\hline
\end{tabular}

\begin{tabular}{|c|c|c|c|c|c|c|c|c|c|c|c|}
\hline \multicolumn{12}{|c|}{ ENSAYO 4: NALCO $0 \%$ CARGA } \\
\hline \multicolumn{2}{|c|}{ MUESTRA: M-002 } & \multirow{2}{*}{$\begin{array}{l}\text { FLOCULANTE: } \\
\text { Sólidos } \\
(\% \mathrm{w} / \mathrm{w})\end{array}$} & \multicolumn{2}{|c|}{ NALCO 0\% CARGA } & \multirow[b]{2}{*}{$\begin{array}{c}\text { Floculant. } \\
\text { (ml) }\end{array}$} & \multirow{2}{*}{$\begin{array}{l}\text { DOSIFICACIÓN: } \\
\text { ist. Sediment. } \\
(\mathrm{cm})\end{array}$} & \multirow{2}{*}{$\begin{array}{c}0,50 \\
\text { Tiempo sed. } \\
\text { (s) }\end{array}$} & \multirow{2}{*}{$\begin{array}{l}\mathrm{g} / \mathrm{l} \\
\begin{array}{c}\text { Velocidad sed. } \\
(\mathrm{m} / \mathrm{h})\end{array}\end{array}$} & \multirow[b]{2}{*}{$\begin{array}{l}\text { Floc dosific. } \\
(\mathrm{g} / \mathrm{t})\end{array}$} & \multirow[b]{2}{*}{$\begin{array}{c}\text { Flujo } \\
\text { (tph/m2) }\end{array}$} & \multirow[b]{2}{*}{$\begin{array}{c}\text { Flujo } \\
\text { (tpd/m2) }\end{array}$} \\
\hline $\begin{array}{c}\text { Peso sólidos } \\
\text { (g) }\end{array}$ & $\begin{array}{c}\text { Vol. líquido } \\
(\mathrm{ml})\end{array}$ & & $\begin{array}{c}\text { Densidad pulpa } \\
(\mathrm{kg} / \mathrm{l})\end{array}$ & $\begin{array}{c}\text { Conc. Solids } \\
(\mathrm{g} / \mathrm{l})\end{array}$ & & & & & & & \\
\hline 50 & 475 & 9,52 & 1,063 & 101,24 & 2 & 10,0 & 25 & 14,4 & 20 & 3,88 & 93,150 \\
\hline 50 & 475 & 9,52 & 1,063 & 101,24 & 4 & 10,0 & 16 & 22,5 & 40 & 6,06 & 145,546 \\
\hline 50 & 475 & 9,52 & 1,063 & 101,24 & 6 & 10,0 & 17 & 21,2 & 60 & 5,71 & 136,985 \\
\hline 50 & 475 & 9,52 & 1,063 & 101,24 & 8 & 10,0 & 19 & 18,9 & 80 & 5,11 & 122,565 \\
\hline 50 & 475 & 9,52 & 1,063 & 101,24 & 10 & 10,0 & 20 & 18,0 & 100 & 4,85 & 116,437 \\
\hline 50 & 475 & 9,52 & 1,063 & 101,24 & 12 & 10,0 & 20 & 18,0 & 120 & 4,85 & 116,437 \\
\hline & & & & & & & MEDIA: & 18,5 & 70,0 & 5,0 & 119,5 \\
\hline
\end{tabular}


ENSAYO FLUJO SEDIMENTACIÓN. ANÁLISIS DE RESULTADOS.

Mina:

Proyecto:

DATOS

Volumen probeta:

Diámetro probeta:

Área sedimentac.

Floc. Dosificac.:

Volumen floc:

Floculante dosific.

Floc. Conc.

Densidad Sólido

Densidad Líquido
Cantera de Caliza

Estudio sedimentación y reología de finos de caliza

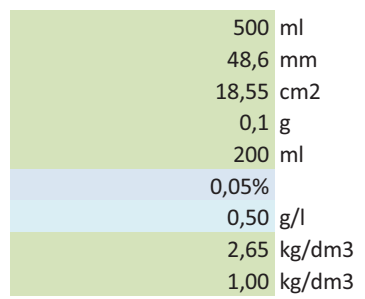

FLOCULANTE SELECCIONADO

NALCO 0\% CARGA
MUESTRA SÓLIDOS

M-002
Diámetros de probetas:

$250 \mathrm{ml} \quad 35,7 \quad \mathrm{~mm}$

$500 \mathrm{ml} \quad 48,6 \quad \mathrm{~mm}$

$2000 \mathrm{ml} \quad 78,2 \quad \mathrm{~mm}$
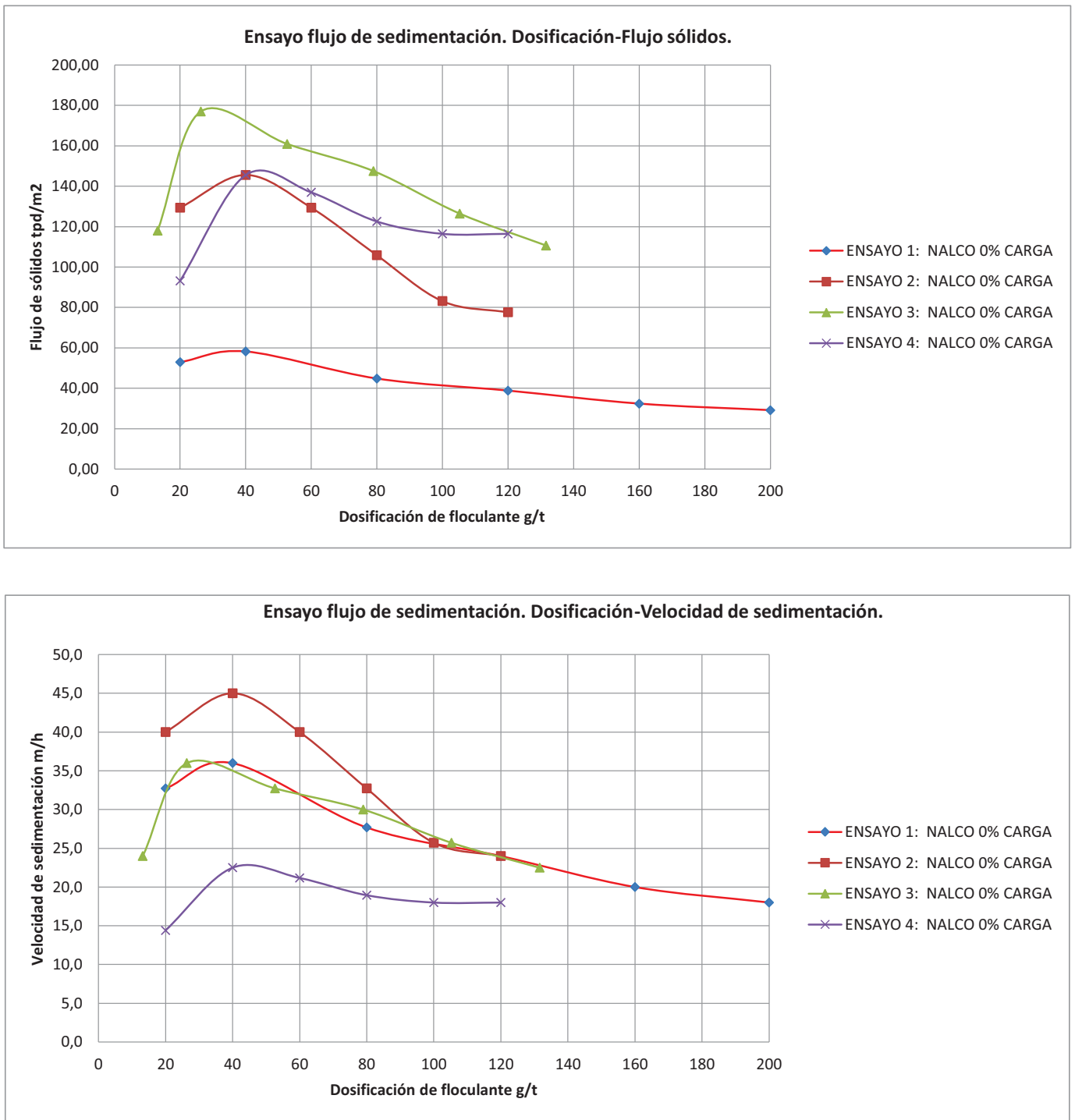

Los ensayos de flujos de sedimentación determinan la dilución óptima de los sólidos para la alimentación en el espesador.

El valor obtenido sirve de base para el diseño de la campana de alimentación y el sistema de dilución previsto. 
ENSAYO SEDIMENTACIÓN PROBETA 2000mI ESTÁTICO

\begin{tabular}{ll}
\hline Mina: & Cantera de Caliza \\
Proyecto: & Estudio sedimentación y reología de finos de caliza \\
Muestra: & M-002
\end{tabular}

Muestra:

M-002

\begin{tabular}{|c|c|c|c|c|c|c|}
\hline Volumen líquido: & $1900 \mathrm{ml}$ & Solidos en peso & $\mathrm{S}=\mathrm{Ps} / \mathrm{Pp}$ & $\mathrm{s}$ & $7,54 \%$ & \\
\hline Peso sólidos: & $155 \mathrm{~g}$ & Dilución & $d=P l / P s$ & d & 12,258 & \\
\hline Floculante dosificac. & $0,1 \mathrm{~g}$ & Solidos en volumen & $V=V s / V p$ & V & $2,99 \%$ & \\
\hline Volume total: & $200 \mathrm{ml}$ & Concent. Sólidos en peso & $\mathrm{C}=\mathrm{Ps} / \mathrm{Vp}$ & c & 79,14 & $g / l$ \\
\hline Floc. Conc. & $0,20 \mathrm{~g} / \mathrm{l}$ & Densidad de la pulpa & $S G p=P p / V p$ & SGp & 1,049 & $\mathrm{~kg} / \mathrm{l}$ \\
\hline Floculante & $8,00 \mathrm{ml}$ & & & & & \\
\hline Solids SG & $2,65 \mathrm{~kg} / \mathrm{dm} 3$ & & & & & \\
\hline Liquid SG & $1,00 \mathrm{~kg} / \mathrm{dm} 3$ & & & & & \\
\hline Diámetro probeta & $78,2 \mathrm{~mm}$ & & & & & \\
\hline Area probeta & $0,0048029 \mathrm{~m} 2$ & $48,029 \mathrm{~cm} 2$ & & & & \\
\hline Densidad pulpa: & $1,049 \mathrm{~kg} / \mathrm{l}$ & & & & & \\
\hline Sólidos en peso: & 79,14 g solids/l & & & & & \\
\hline Sólidos en peso: & 0,0791 g solids/ml & & & & & \\
\hline |Floculante: & NALCO & & & & & \\
\hline Tipo de carga floc.: & 0\% CARGA & & & & & \\
\hline Dosificación floc.: & gramos/ton & lada sólido & & & & \\
\hline
\end{tabular}

DATOS DE SEDIMENTACIÓN

\begin{tabular}{|c|c|c|c|c|c|c|c|c|c|}
\hline $\begin{array}{c}\text { Tiempo info } \\
\text { (sec) }\end{array}$ & $\begin{array}{c}\text { Tiempo } \\
\text { (min) }\end{array}$ & $\begin{array}{l}\text { Vol. Lodos } \\
\text { (ml) }\end{array}$ & $\begin{array}{l}\text { Altura interf. } \\
\text { (cm) }\end{array}$ & $\begin{array}{c}\text { Velocidad } \\
(\mathrm{m} / \mathrm{hr})\end{array}$ & $\begin{array}{c}\text { SG. Lodos } \\
(\mathrm{g} / \mathrm{cm} 3)\end{array}$ & $\begin{array}{c}\text { Lodos } \\
\% \text { Sol. Peso }\end{array}$ & $\begin{array}{c}\text { Flujo } \\
\text { (tph/m2) }\end{array}$ & $\begin{array}{c}\text { Flujo } \\
(\mathrm{tpd} / \mathrm{m} 2)\end{array}$ & $\begin{array}{c}\text { Área Unit. Espes } \\
(\mathrm{m} 2 / \mathrm{tpd})\end{array}$ \\
\hline 0 & 0 & 1993 & 41,50 & 0 & 1,048 & 7,42 & 0 & 0 & 0 \\
\hline 5 & 0,08 & 1945 & 40,50 & 7,200 & 1,050 & 7,59 & 23,2361 & 557,67 & 0,002 \\
\hline 10 & 0,17 & 1873 & 39,00 & 10,800 & 1,052 & 7,87 & 23,2359 & 557,66 & 0,002 \\
\hline 15 & 0,25 & 1729 & 36,00 & 21,600 & 1,056 & 8,49 & 23,2360 & 557,66 & 0,002 \\
\hline 30 & 0,50 & 1633 & 34,00 & 4,800 & 1,059 & 8,96 & 7,7453 & 185,89 & 0,005 \\
\hline 45 & 0,75 & 1441 & 30,00 & 9,600 & 1,067 & 10,08 & 7,7453 & 185,89 & 0,005 \\
\hline 60 & 1,00 & 1249 & 26,00 & 9,600 & 1,077 & 11,52 & 7,7453 & 185,89 & 0,005 \\
\hline 120 & 2,00 & 384 & 8,00 & 10,800 & 1,251 & 32,24 & 1,9363 & 46,47 & 0,022 \\
\hline 180 & 3,00 & 322 & 6,70 & 0,780 & 1,300 & 37,05 & 1,9363 & 46,47 & 0,022 \\
\hline 240 & 4,00 & 288 & 6,00 & 0,420 & 1,335 & 40,29 & 1,9363 & 46,47 & 0,022 \\
\hline 300 & 5,00 & 274 & 5,70 & 0,180 & 1,353 & 41,86 & 1,9363 & 46,47 & 0,022 \\
\hline 450 & 7,50 & 235 & 4,90 & 0,192 & 1,410 & 46,71 & 0,7745 & 18,59 & 0,054 \\
\hline 600 & 10,00 & 216 & 4,50 & 0,096 & 1,447 & 49,58 & 0,7745 & 18,59 & 0,054 \\
\hline 900 & 15,00 & 192 & 4,00 & 0,060 & 1,502 & 53,70 & 0,3873 & 9,29 & 0,108 \\
\hline 1200 & 20,00 & 180 & 3,75 & 0,030 & 1,536 & 56,03 & 0,3873 & 9,29 & 0,108 \\
\hline 1500 & 25,00 & 168 & 3,50 & 0,030 & 1,574 & 58,58 & 0,3873 & 9,29 & 0,108 \\
\hline 1800 & 30,00 & 168 & 3,50 & 0,000 & 1,574 & 58,58 & 0,3873 & 9,29 & 0,108 \\
\hline 3600 & 60,00 & 168 & 3,50 & 0,000 & 1,574 & 58,58 & 0,0645 & 1,55 & 0,646 \\
\hline 5400 & 90,00 & 168 & 3,50 & 0,000 & 1,574 & 58,58 & 0,0645 & 1,55 & 0,646 \\
\hline 7200 & 120,00 & 168 & 3,50 & 0,000 & 1,574 & 58,58 & 0,0645 & 1,55 & 0,646 \\
\hline 9000 & 150,00 & 168 & 3,50 & 0,000 & 1,574 & 58,58 & 0,0645 & 1,55 & 0,646 \\
\hline 10800 & 180,00 & 168 & 3,50 & 0,000 & 1,574 & 58,58 & 0,0645 & 1,55 & 0,646 \\
\hline 14400 & 240,00 & 168 & 3,50 & 0,000 & 1,574 & 58,58 & 0,0323 & 0,77 & 1,291 \\
\hline
\end{tabular}

DATOS OBTENIDOS:

1a Caída de velocidad: 1 minuto

2a Caída de velocidad, comienzo régimen de compresión: 20 minutos

$\%$ sólidos - tiempo: 58 \% sólidos en peso - $30 \mathrm{~min}$. tiempo residencia 
ENSAYO SEDIMENTACIÓN PROBETA 2000mI ESTÁTICO. ANÁLISIS DE RESULTADOS.

Mina:

Proyecto:

Muestra
Cantera de Caliza

Estudio sedimentación y reología de finos de caliza

M-002
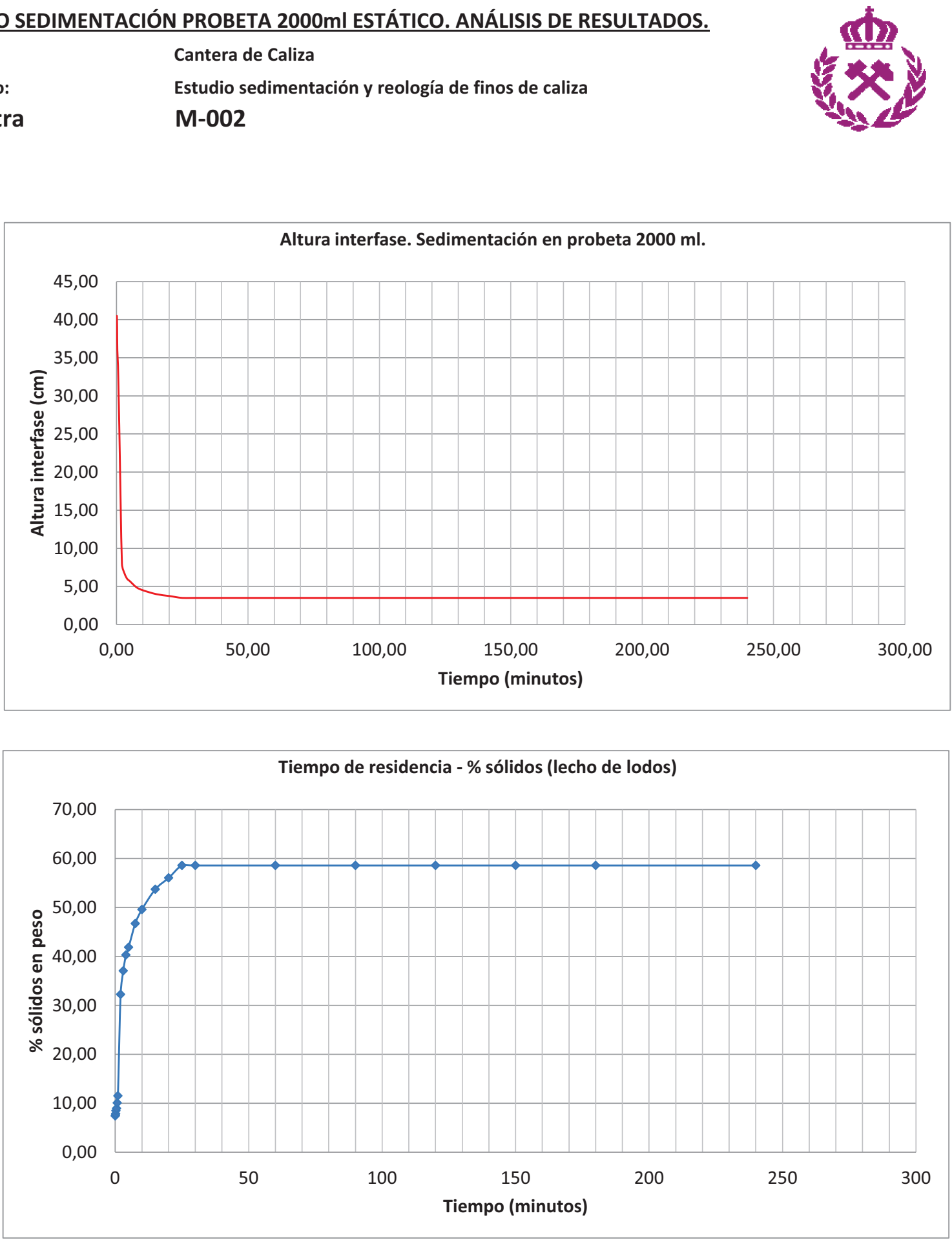


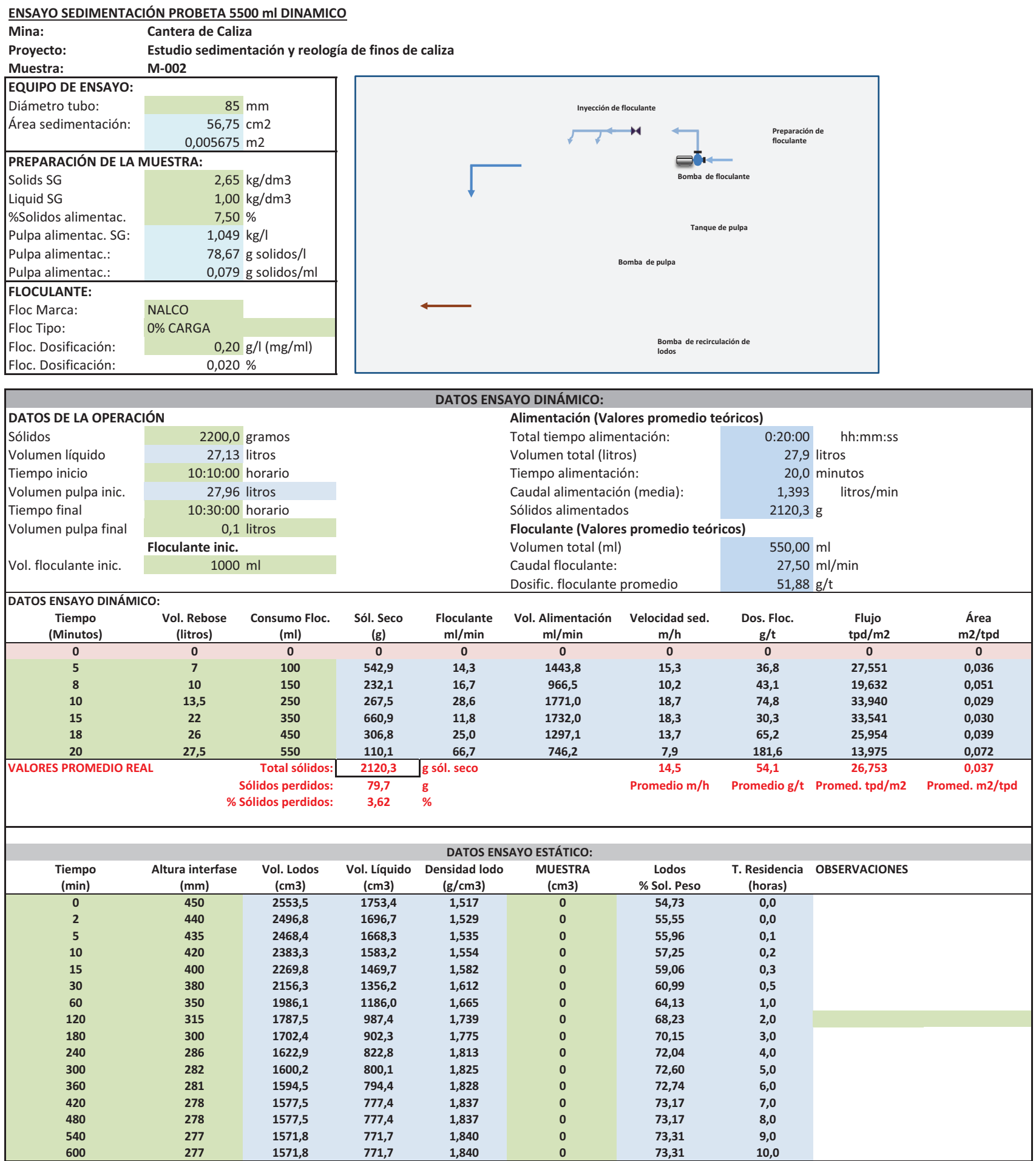


ENSAYO SEDIMENTACIÓN PROBETA 5500 mI DINAMICO

Mina: Cantera de Caliza

Proyecto: Estudio sedimentación y reología de finos de caliza

Muestra: M-002

DATOS DE OPERACIÓN DEL ESPESADOR DE TUBO PROFUNDO

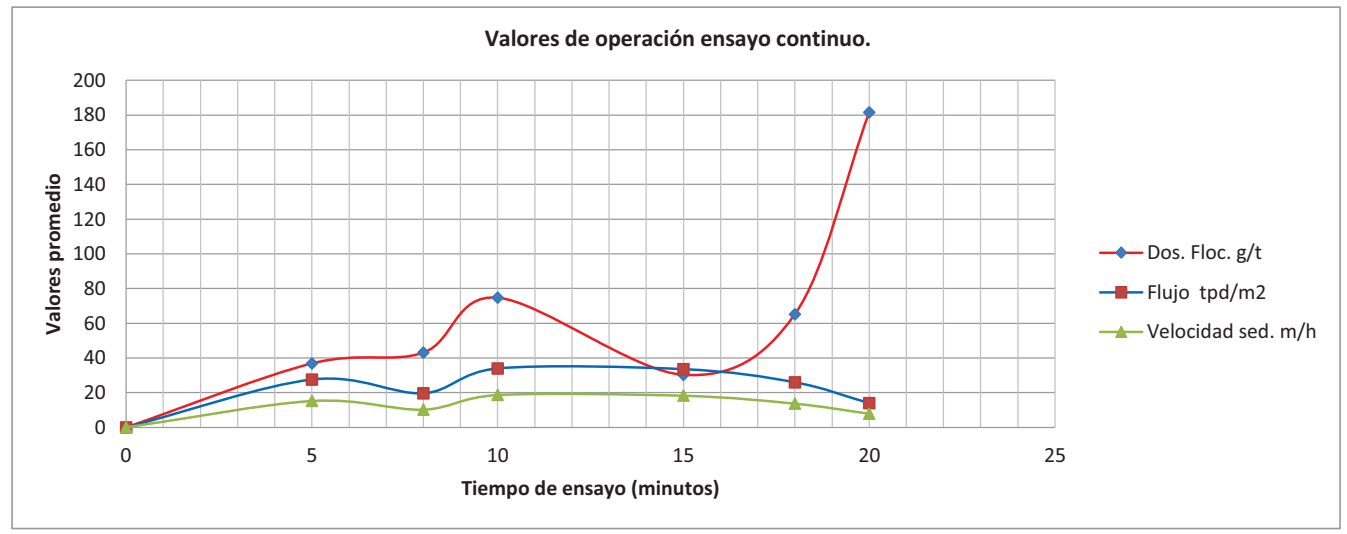

Datos Promedio:

Velocidad de sedimentación:

$14,5 \mathrm{~m} / \mathrm{h}$

Dosificación de floculante:

$54,1 \mathrm{~g} / \mathrm{t}$

Flujo de sedimentación:

$0,0374 \mathrm{~m}^{2} / \mathrm{t} / \mathrm{día}$

Flujo de sedimentación:

$26,8 \mathrm{t} / \mathrm{di} a / \mathrm{m}^{2}$

ENSAYO SEDIMENTACIÓN PROBETA $5500 \mathrm{mI}$ DINAMICO
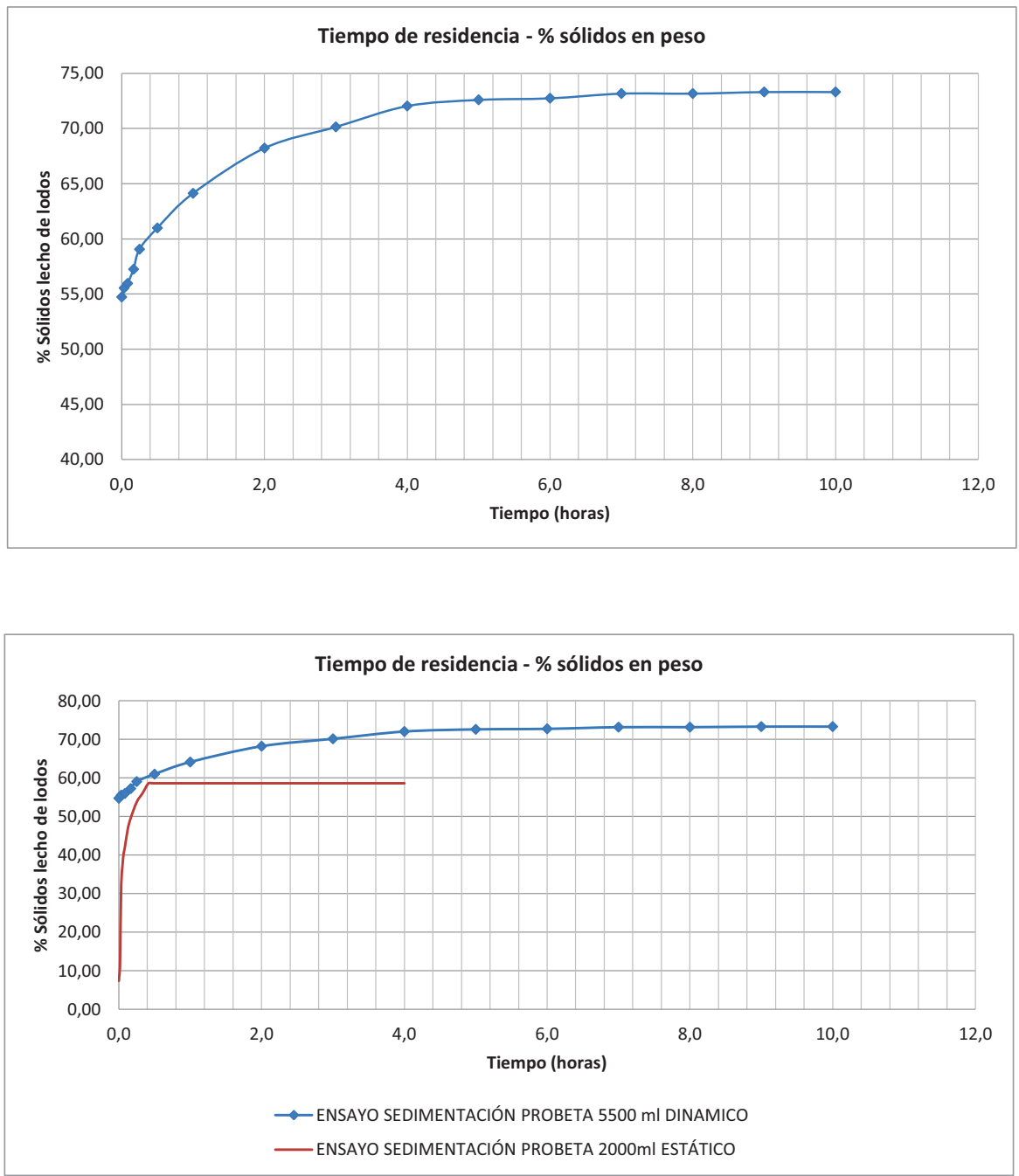
ENSAYO FILTRACIÓN A VACIO

Mina: Cantera de Caliza

Proyecto: $\quad$ Estudio sedimentación y reología de finos de caliza

Material:

Finos de caliza

Muestra:

$\mathrm{M}-002$

Preparado por: José A. Butragueño

pH muestra: 8

Fecha: $\quad 26 / 07 / 2013$

\begin{tabular}{|c|c|c|}
\hline \multicolumn{3}{|c|}{ DATOS DE LA MUESTRA: } \\
\hline Solidos SG & & $2,65 \mathrm{~kg} / \mathrm{dm} 3$ \\
\hline Liquido SG & & $1,00 \mathrm{~kg} / \mathrm{dm} 3$ \\
\hline \multicolumn{3}{|l|}{ FLOCULANTE: } \\
\hline Floc Name: & No & \\
\hline Tipo de floculante: & No & \\
\hline $\begin{array}{l}\text { Floc. Dosificación: } \\
\text { Floc. Dosificación: }\end{array}$ & & $\begin{array}{l}0,00 \mathrm{~g} / \mathrm{l}(\mathrm{mg} / \mathrm{ml}) \\
0,000 \%\end{array}$ \\
\hline
\end{tabular}
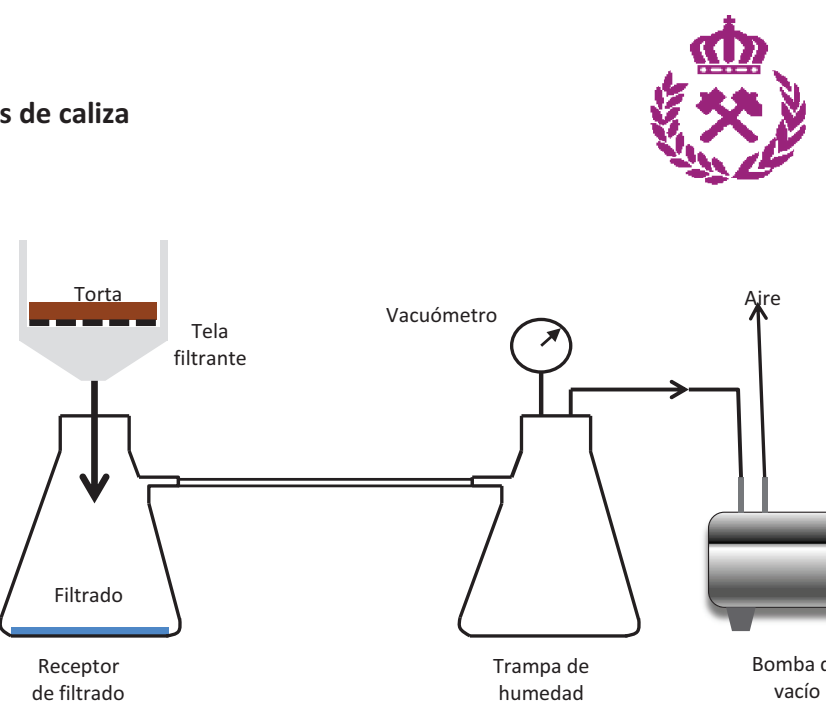
$0,000 \%$

\begin{tabular}{|c|c|c|c|c|c|c|c|c|c|}
\hline \multicolumn{10}{|c|}{ ENSAYO FILTRACIÓN A VACÍO. TEST 1.} \\
\hline \multicolumn{2}{|c|}{ MUESTRA: M-002 } & & \multicolumn{7}{|c|}{ Tiempos de ensayo de filtración } \\
\hline $\begin{array}{l}\text { Vacío } \\
\text { (bar) }\end{array}$ & Peso sólidos & $\begin{array}{l}\text { Vol. Líquido } \\
\text { (ml) }\end{array}$ & $\begin{array}{l}\text { \% Sól. Peso } \\
\text { (\%) }\end{array}$ & $\begin{array}{l}\text { Vol. Pulpa } \\
\text { (ml) }\end{array}$ & $\begin{array}{l}\text { Formación torta } \\
\text { (s) }\end{array}$ & $\begin{array}{c}\text { Secado torta } \\
\text { (s) }\end{array}$ & $\begin{array}{c}\text { Total ciclo } \\
\text { (s) }\end{array}$ & $\begin{array}{l}\text { Líq. Filtrado } \\
(\mathrm{ml})\end{array}$ & $\begin{array}{c}\text { Espesor } \\
(\mathrm{mm})\end{array}$ \\
\hline$-0,6$ & 100 & 425,0 & 19,0 & 462,7 & 60 & 30 & 90 & 390 & 5,0 \\
\hline \% Solidos estimado: & 74,1 & & & & & & & & \\
\hline Peso muestra húmedo: & 114 & $\mathrm{~g}$ & \multirow{4}{*}{\multicolumn{2}{|c|}{ Observaciones: }} & & & & & \\
\hline Secad & de la muestra & & & & & & & & \\
\hline Peso muestra seco & 87,1 & $\mathrm{~g}$ & & & & & & & \\
\hline$\%$ humedad torta & 23,60 & $\%$ & & & & & & & \\
\hline
\end{tabular}

\begin{tabular}{|c|c|c|c|c|c|c|c|c|c|}
\hline \multicolumn{10}{|c|}{ ENSAYO FILTRACIÓN A VACÍO. TEST 2.} \\
\hline \multicolumn{2}{|c|}{ MUESTRA: M-002 } & & \multicolumn{7}{|c|}{ Tiempos de ensayo de filtración } \\
\hline $\begin{array}{l}\text { Vacío } \\
\text { (bar) }\end{array}$ & $\begin{array}{l}\text { Peso sólidos } \\
\text { (g) }\end{array}$ & $\begin{array}{l}\text { Vol. Líquido } \\
\text { (ml) }\end{array}$ & $\begin{array}{c}\text { \% Sól. Peso } \\
\text { (\%) }\end{array}$ & $\begin{array}{l}\text { Vol. Pulpa } \\
\text { (ml) }\end{array}$ & $\begin{array}{l}\text { Formación torta } \\
\text { (s) }\end{array}$ & $\begin{array}{c}\text { Secado torta } \\
\text { (s) }\end{array}$ & $\begin{array}{l}\text { Total ciclo } \\
\text { (s) }\end{array}$ & $\begin{array}{l}\text { Líq. Filtrado } \\
\text { (ml) }\end{array}$ & $\begin{array}{c}\text { Espesor } \\
(\mathrm{mm})\end{array}$ \\
\hline$-0,6$ & 50 & 300,0 & 14,3 & 318,9 & 60 & 10 & 70 & 285 & 2,5 \\
\hline \% Solidos estimado: & 76,9 & & & & & & & & \\
\hline Peso muestra húmedo: & 56 & $\mathrm{~g}$ & \multirow{3}{*}{\multicolumn{2}{|c|}{ Observaciones: }} & & & & & \\
\hline \multicolumn{3}{|c|}{ Secado de la muestra: } & & & & & & & \\
\hline Peso muestra seco & 43,8 & $\mathrm{~g}$ & & & & & & & \\
\hline$\%$ humedad torta & 21,79 & $\%$ & \multicolumn{2}{|c|}{ Los pesos incluyen la tara } & & & & & \\
\hline
\end{tabular}

\begin{tabular}{|c|c|c|c|c|c|c|c|c|c|}
\hline \multicolumn{10}{|c|}{ ENSAYO FILTRACIÓN A VACÍO. TEST 3.} \\
\hline \multicolumn{2}{|c|}{ MUESTRA: M-002 } & \multirow[b]{2}{*}{$\begin{array}{l}\text { Vol. Líquido } \\
\text { (ml) }\end{array}$} & \multicolumn{7}{|c|}{ Tiempos de ensayo de filtración } \\
\hline $\begin{array}{l}\text { Vacío } \\
\text { (bar) }\end{array}$ & $\begin{array}{l}\text { Peso sólidos } \\
\text { (g) }\end{array}$ & & $\begin{array}{l}\text { \% Sól. Peso } \\
\text { (\%) }\end{array}$ & $\begin{array}{l}\text { Vol. Pulpa } \\
\text { (ml) }\end{array}$ & $\begin{array}{l}\text { Formación torta } \\
\text { (s) }\end{array}$ & $\begin{array}{l}\text { Secado torta } \\
\text { (s) }\end{array}$ & $\begin{array}{l}\text { Total ciclo } \\
\text { (s) }\end{array}$ & $\begin{array}{l}\text { Líq. Filtrado } \\
\text { (ml) }\end{array}$ & $\begin{array}{c}\text { Espesor } \\
(\mathrm{mm})\end{array}$ \\
\hline$-0,6$ & 75 & 300,0 & 20,0 & 328,3 & 60 & 30 & 90 & 276 & 4,0 \\
\hline \% Solidos estimado: & 75,8 & & & & & & & & \\
\hline Peso muestra húmedo: & 80 & $\mathrm{~g}$ & \multirow{4}{*}{\multicolumn{7}{|c|}{$\begin{array}{l}\text { Observaciones: } \\
\text { Contenido en sólidos de la torta filtrada: } 100-21,71=78,29 \%\end{array}$}} \\
\hline \multicolumn{3}{|c|}{ Secado de la muestra: } & & & & & & & \\
\hline Peso muestra seco & 63 & $\mathrm{~g}$ & & & & & & & \\
\hline$\%$ humedad torta & 21,25 & $\%$ & & & & & & & \\
\hline
\end{tabular}

\begin{tabular}{|c|c|c|c|c|c|c|c|c|c|}
\hline \multicolumn{10}{|c|}{ ENSAYO FILTRACIÓN A VACÍO. TEST 4.} \\
\hline \multicolumn{2}{|c|}{ MUESTRA: M-002 } & & \multicolumn{7}{|c|}{ Tiempos de ensayo de filtración } \\
\hline $\begin{array}{l}\text { Vacío } \\
\text { (bar) }\end{array}$ & $\begin{array}{l}\text { Peso sólidos } \\
\text { (g) }\end{array}$ & $\begin{array}{l}\text { Vol. Líquido } \\
\text { (ml) }\end{array}$ & $\begin{array}{l}\text { \% Sól. Peso } \\
\text { (\%) }\end{array}$ & $\begin{array}{l}\text { Vol. Pulpa } \\
\text { (ml) }\end{array}$ & $\begin{array}{l}\text { Formación torta } \\
\text { (s) }\end{array}$ & $\begin{array}{l}\text { Secado torta } \\
\text { (s) }\end{array}$ & $\begin{array}{l}\text { Total ciclo } \\
\text { (s) }\end{array}$ & $\begin{array}{l}\text { Líq. Filtrado } \\
\text { (ml) }\end{array}$ & $\begin{array}{c}\text { Espesor } \\
(\mathrm{mm})\end{array}$ \\
\hline$-0,6$ & 75 & 275,0 & 21,4 & 303,3 & 60 & 20 & 80 & 255 & 4,0 \\
\hline \% Solidos estimado: & 78,9 & & & & & & & & \\
\hline Peso muestra húmedo: & 81 & $\mathrm{~g}$ & \multirow{4}{*}{\multicolumn{2}{|c|}{ Observaciones: }} & & & & & \\
\hline Secad & de la muestr & & & & & & & & \\
\hline Peso muestra seco & 64 & $\mathrm{~g}$ & & & & & & & \\
\hline$\%$ humedad torta & 20,99 & $\%$ & & & & & & & \\
\hline
\end{tabular}


ENSAYO ASENTAMIENTO EN PROBETA

\begin{tabular}{|ll|} 
Mina: & Cantera de Caliza \\
Proyecto: & Estudio sedimentación y reología de finos de caliza \\
\cline { 2 - 2 } Material: & Jinos de caliza \\
Preparado por: & 8 \\
pH muestra: & $26 / 07 / 2013$ \\
\hline Fecha: & Jutragueño \\
\hline
\end{tabular}

Fecha:

$26 / 07 / 2013$

Aceleración gravedad (g):

Diámetro probeta:

Altura probeta $(\mathrm{H})$

Volumen probeta:

Solidos SG

Líquido SG

$9,81 \mathrm{~m} / \mathrm{s} 2$

$44 \mathrm{~mm}$

$100 \mathrm{~mm}$

$152,1 \mathrm{~cm} 3$

$2,65 \mathrm{~kg} / \mathrm{dm} 3$

$1,00 \mathrm{~kg} / \mathrm{dm} 3$

Expresiones empírica

$T=0.5-0.5(h / H)^{\wedge} 0.5$

T.F. $=\mathrm{T}^{*} \mathrm{~d}^{*} \mathrm{~g}^{*}(\mathrm{H} / 100)$

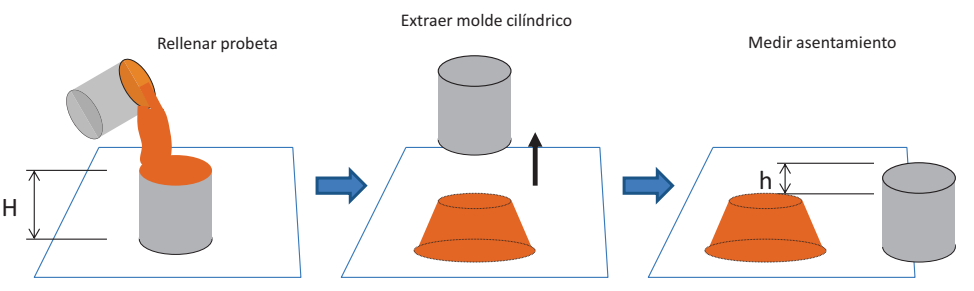

\begin{tabular}{|c|c|c|c|c|c|c|c|c|c|c|}
\hline \multicolumn{11}{|c|}{ ENSAYOS DE ASENTAMIENTO EN PROBETA } \\
\hline $\begin{array}{l}\text { Muestra } \\
\text { ID }\end{array}$ & $\begin{array}{c}\text { Cont. Sólidos } \\
\text { (\%) }\end{array}$ & $\begin{array}{l}\text { Solidos SG } \\
\mathrm{g} / \mathrm{cm} 3\end{array}$ & $\begin{array}{c}\text { Peso Liq. } \\
\text { (kg liq/kg sol) }\end{array}$ & $\begin{array}{l}\text { Vol. Pulpa } \\
\text { (I/kg sol) }\end{array}$ & $\begin{array}{c}\text { Pulpa SG (d) } \\
\text { kg/dm3 }\end{array}$ & $\begin{array}{c}\text { Sólidos prob. } \\
\text { (g) }\end{array}$ & $\begin{array}{l}\text { Liq. Probeta } \\
\text { (g) }\end{array}$ & $\begin{array}{l}\text { Asentamiento }(\mathrm{h}) \\
\mathrm{mm}\end{array}$ & $\begin{array}{l}\text { Factor "T" } \\
\text { Adimens. }\end{array}$ & $\begin{array}{c}\text { Tensión Fluencia } \\
\text { (Pa) }\end{array}$ \\
\hline 1 & 68 & 2,65 & 0,471 & 0,848 & 1,734 & 179,3 & 84,4 & 45 & 0,16459 & 280,0 \\
\hline 2 & 67 & 2,65 & 0,493 & 0,870 & 1,716 & 174,8 & 86,1 & 52 & 0,13944 & 234,7 \\
\hline 3 & 65 & 2,65 & 0,538 & 0,916 & 1,680 & 166,0 & 89,4 & 62 & 0,10630 & 175,2 \\
\hline 4 & 62,5 & 2,65 & 0,600 & 0,977 & 1,637 & 155,6 & 93,3 & 79 & 0,05559 & 89,3 \\
\hline 5 & 60 & 2,65 & 0,667 & 1,044 & 1,596 & 145,6 & 97,1 & 90 & 0,02566 & 40,2 \\
\hline 6 & 50 & 2,65 & 1,000 & 1,377 & 1,452 & 110,4 & 110,4 & 97 & 0,00756 & 10,8 \\
\hline
\end{tabular}

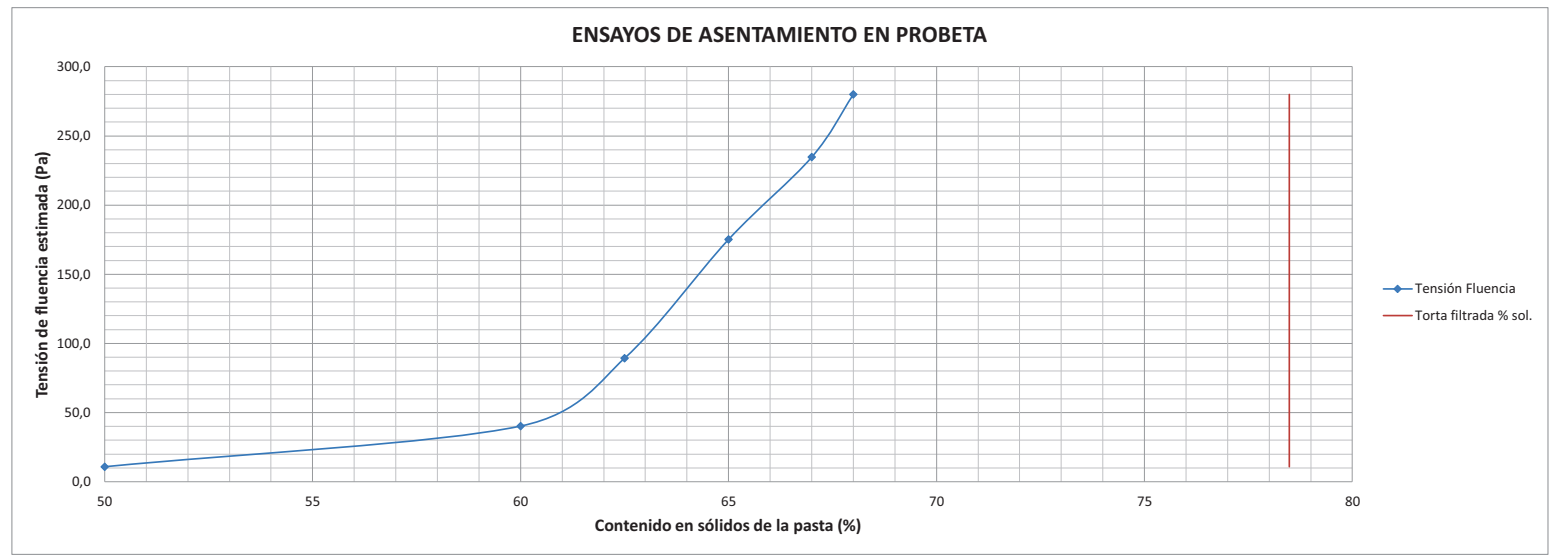

Página 12 de 12 


\section{SEDIMENTACIÓN Y REOLOGÍA}

Mina:

Cantera de Caliza

\section{Empresa:}

JOSÉ BUTRAGUEÑO

\section{Proyecto:}

Estudio sedimentación y reología de finos de caliza

\section{Aplicación}

Sedimentación. Estériles de flotación.

Fecha:

$27 / 07 / 2013$

\section{Ensayos:}

\begin{tabular}{|c|c|}
\hline $\mathbf{x}$ & Distribución granulométrica y caracterización de muestras \\
\hline $\mathbf{x}$ & Selección de floculantes \\
\hline $\mathbf{x}$ & Área de flujo \\
\hline $\mathbf{x}$ & Sedimentación en probeta estática \\
\hline $\mathbf{x}$ & Ensayo en espesador dinámico de laboratorio de $85 \mathrm{~mm}$ DIA \\
\hline $\mathbf{x}$ & Reología de los lodos \\
\hline $\mathbf{x}$ & Ensayo de filtración a vacío \\
\hline
\end{tabular}

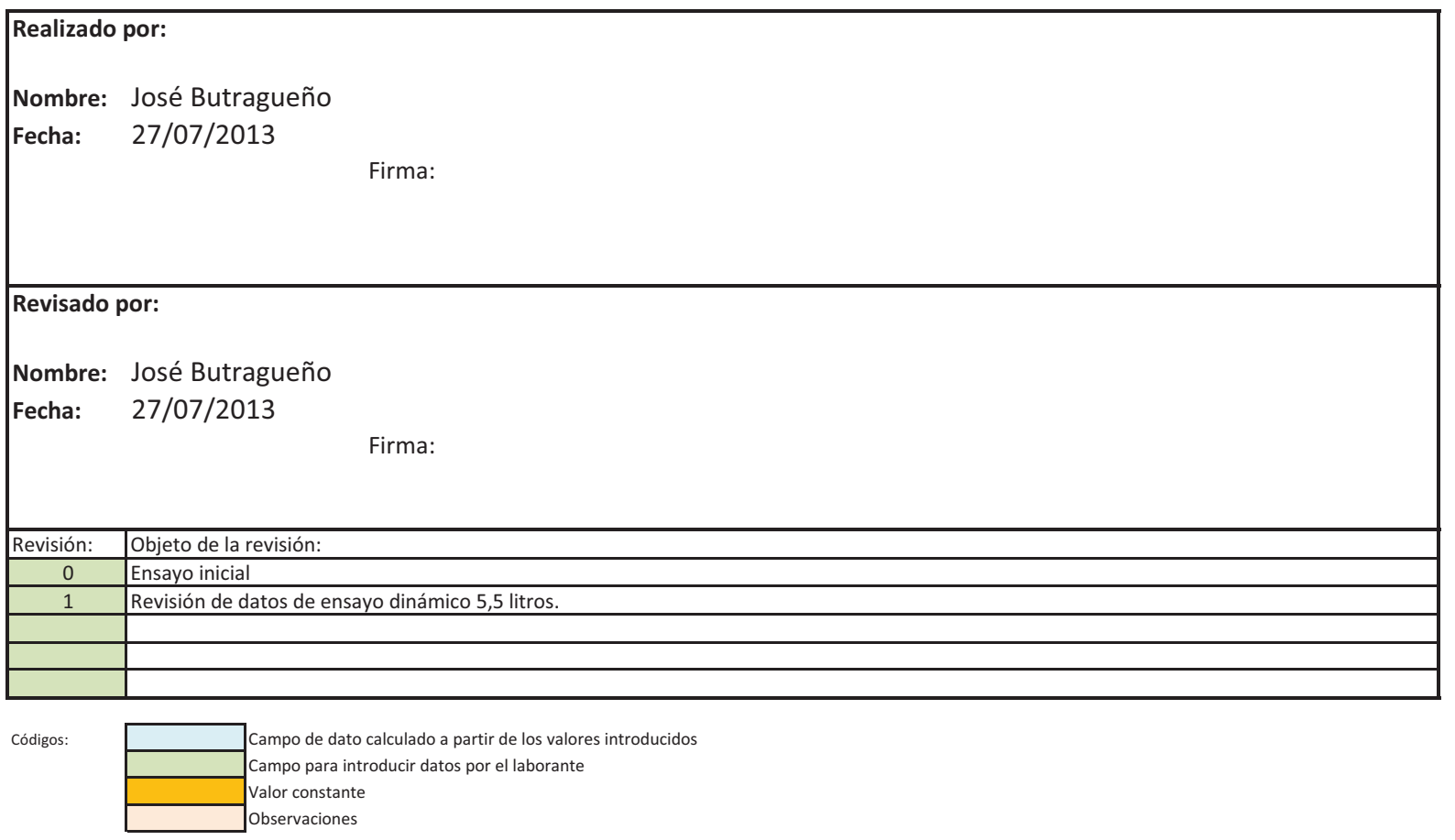

CONFIDENCIAL: Este documento contiene información propiedad de JOSÉ BUTRAGUEÑO y está sujeto a ser

devuelto bajo demanda; estando prohibida su reproducción, copia, préstamo o cualquier otro uso que no sea el fin para el que fue expresamente realizado, sin el consentimiento expreso por escrito de: JOSÉ BUTRAGUEÑO 
ENSAYO GRANULOMÉTRICO DE SÓLIDOS

Mina: Cantera de Caliza

Proyecto: Estudio sedimentación y reología de finos de caliza

Realizado por: José Butragueño

\begin{tabular}{|ll|}
\hline Muestra ID: & M-002 \\
Material: & Finos de caliza \\
Preparado por: & José A. Butragueño \\
pH muestra: & - \\
Fecha: & $27 / 07 / 2013$ \\
\hline
\end{tabular}

CURVA GRANULOMÉTRICA DE SÓLIDOS

\begin{tabular}{|c|c|c|c|c|c|}
\hline \multicolumn{3}{|c|}{ DATOS DE LA PULPA A SEDIMENTAR } & \multicolumn{3}{|c|}{ Observaciones: Muestra de sólido seco } \\
\hline Densidad sólidos: & 2,65 & $\mathrm{~kg} / \mathrm{dm}^{3}$ & & & \\
\hline Densidad líquido: & 1,00 & $\mathrm{~kg} / \mathrm{dm}^{3}$ & & & \\
\hline Densidad pulpa: & & $\mathrm{kg} / \mathrm{l}$ & & & \\
\hline Tara: & 0 & g & & & \\
\hline Pulpa húmeda: & 0 & g & Peso pulpa: & & $g$ \\
\hline Sólido seco: & 0 & g & Peso sólido: & & $g$ \\
\hline \% Peso sólidos: & \#DIV/0! & $\%$ & & & \\
\hline
\end{tabular}

\section{CURVA GRANULOMÉTRICA DE SÓLIDOS}

\begin{tabular}{|c|c|c|c|c|}
\hline \multicolumn{5}{|c|}{ ENSAYO GRANULOMÉTRICO } \\
\hline \multirow{2}{*}{$\begin{array}{l}\text { Tamiz } \\
\text { Micras }\end{array}$} & \multirow{2}{*}{\begin{tabular}{|l|} 
Pesos \\
Peso Ret.
\end{tabular}} & \multicolumn{3}{|c|}{ Porcentajes } \\
\hline & & \% Peso Ret. & $\%$ Ret. Ac. & $\%$ Pasa Ac. \\
\hline 125 & 0 & 0,00 & 0,00 & 100,00 \\
\hline 80 & 2,1 & 2,10 & 2,10 & 97,90 \\
\hline 63 & 6,2 & 6,20 & 8,30 & 91,70 \\
\hline 40 & 8,9 & 8,90 & 17,20 & 82,80 \\
\hline 20 & 14,1 & 14,10 & 31,30 & 68,70 \\
\hline 10 & 27 & 27,00 & 58,30 & 41,70 \\
\hline 5 & 6,8 & 6,80 & 65,10 & 34,90 \\
\hline & 34,9 & 34,90 & 100,00 & 0,00 \\
\hline TOTALES: & 100,0 & 100,0 & & \\
\hline
\end{tabular}

$\mathrm{P} 80=34$ micras

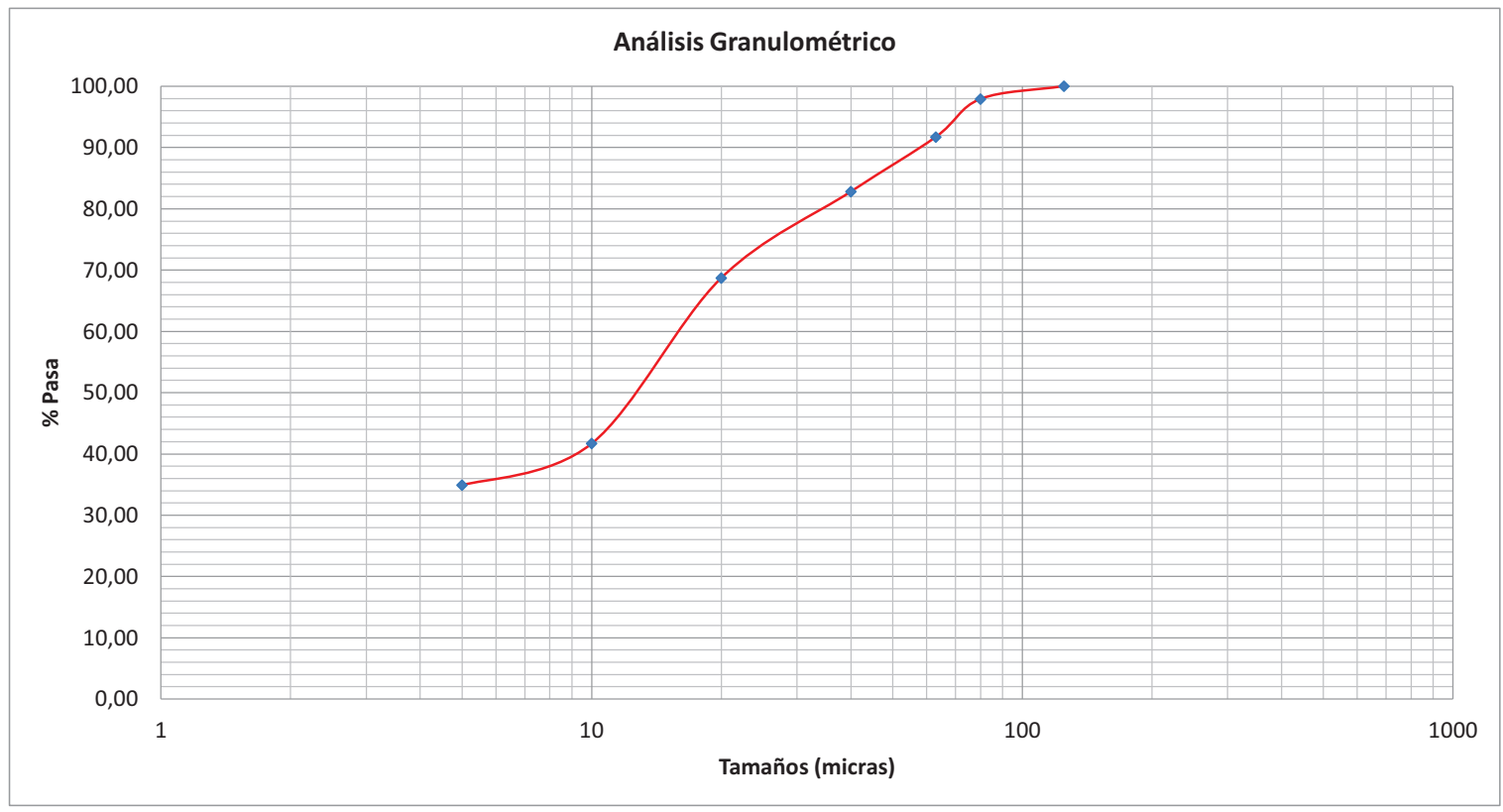




\section{SELECCIÓN DE FLOCULANTE}

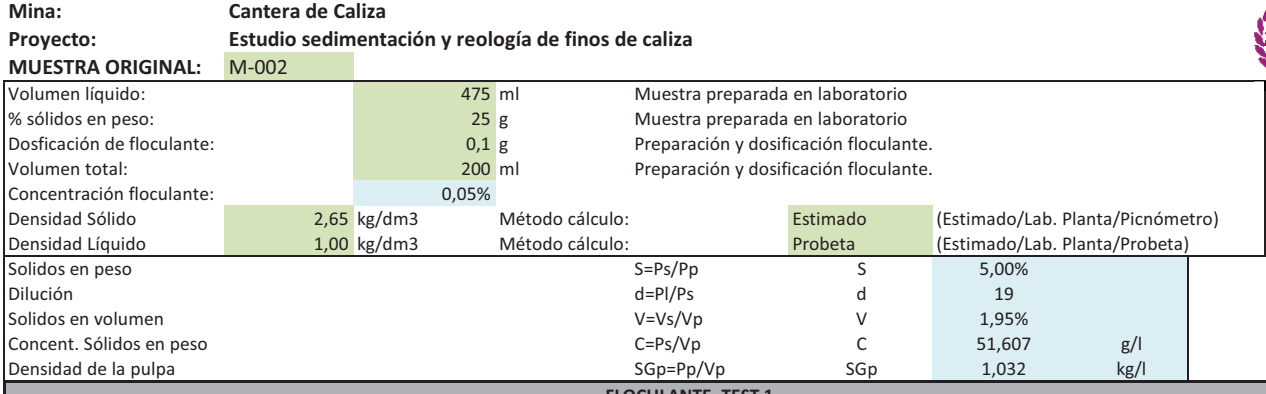

\section{MUESTRA ORIGINAL: M-002}

\begin{tabular}{|c|c|c|c|c|c|c|c|c|c|}
\hline \multicolumn{10}{|c|}{ FLOCULANTE. TEST 1.} \\
\hline \multicolumn{2}{|c|}{ MUESTRA: M-002 } & \multicolumn{2}{|c|}{ FLOCULANTE: NALCO } & \multicolumn{2}{|c|}{ TIPO CARGA: Aniónico -25\% } & \multicolumn{2}{|c|}{ DOSIFICACIÓN: $0,05 \%$} & \multirow[b]{2}{*}{$\begin{array}{l}\text { Tiempo } \\
\text { (s) }\end{array}$} & \multirow[b]{2}{*}{$\begin{array}{l}\text { Velocidad } \\
(\mathrm{m} / \mathrm{h})\end{array}$} \\
\hline $\begin{array}{c}\text { Ensayo } \\
\#\end{array}$ & $\begin{array}{l}\text { Diluc. } \\
\text { (Si/No) }\end{array}$ & $\begin{array}{l}\text { Pulpa w/w sol. } \\
(\%)\end{array}$ & $\begin{array}{l}\text { Distancia sed. } \\
\quad(\mathrm{cm})\end{array}$ & $\begin{array}{c}\text { Volumen ensayo } \\
(\mathrm{ml})\end{array}$ & $\begin{array}{l}\text { Sólidos } \\
\text { (g) }\end{array}$ & $\begin{array}{c}\text { Floculante } \\
(\mathrm{ml})\end{array}$ & $\begin{array}{l}\text { Floc } \\
(\mathrm{g} / \mathrm{t})\end{array}$ & & \\
\hline 1 & No & $5,00 \%$ & 10 & 484,4 & 25,00 & 2 & 40 & 14 & 25,7 \\
\hline 2 & No & $5,00 \%$ & 10 & 484,4 & 25,00 & 4 & 80 & 11 & 32,7 \\
\hline 3 & No & $5,00 \%$ & 10 & 484,4 & 25,00 & 6 & 120 & 10 & 36,0 \\
\hline 4 & No & $5,00 \%$ & 10 & 484,4 & 25,00 & 8 & 160 & 10 & 36,0 \\
\hline \multirow[t]{2}{*}{5} & No & $5,00 \%$ & 10 & 484,4 & 25,00 & 10 & 200 & 11 & 32,7 \\
\hline & $\begin{array}{l}\text { Velocidad } \\
\text { Sediment. }\end{array}$ & $\begin{array}{l}\text { Tamaño } \\
\text { Floculo } \\
\end{array}$ & $\begin{array}{l}\text { Cohesión } \\
\text { Flóculo }\end{array}$ & $\begin{array}{l}\text { Claridad } \\
\text { Rebose }\end{array}$ & & & & & \\
\hline 1 & Media & Medio & Parcial & Claro & Datos (para observa & ción visual): & & & \\
\hline 2 & Media & Medio & Parcial & Claro & Tamaño flóculo: & Muy pequeño/Pec & /Medio/ & nde/Muy gra & \\
\hline 3 & Media & Medio & Parcial & Claro & Velocidad sedim.: & Muy lenta/Lenta/ & a/Rápida/ & ay rápida & \\
\hline 4 & Media & Medio & Parcial & Claro & Cohesión de flóc.: & Pobre/Parcial/Buc & luy buen & ccelente & \\
\hline 5 & Media & Medio & Parcial & Claro & Claridad rebose: & Muy turbio/Turbi & o/Muy cl & /Cristalino & \\
\hline & & & & CULANTE. TEST 2. & & & & & \\
\hline & M-002 & FLOCULANTE: & NALCO & TIPO CARGA: & Aniónico -10\% & DOSIFICACIÓN & & & \\
\hline $\begin{array}{c}\text { Ensayo } \\
\quad \#\end{array}$ & $\begin{array}{l}\text { Diluc. } \\
\text { (Si/No) }\end{array}$ & $\begin{array}{l}\text { Pulpa w/w sol. } \\
(\%)\end{array}$ & $\begin{array}{l}\text { Distancia sed. } \\
\text { (cm) }\end{array}$ & $\begin{array}{c}\text { Volumen ensayo } \\
(\mathrm{ml})\end{array}$ & $\begin{array}{c}\text { Sólidos } \\
\text { (g) }\end{array}$ & $\begin{array}{l}\text { Floc } \\
\text { (ml) }\end{array}$ & $\begin{array}{l}\text { Floc } \\
(\mathrm{g} / \mathrm{t})\end{array}$ & $\begin{array}{c}\text { Tiempo } \\
\text { (s) }\end{array}$ & $\begin{array}{c}\text { Velocidad } \\
(\mathrm{m} / \mathrm{h})\end{array}$ \\
\hline 1 & No & $5,00 \%$ & 10 & 484,4 & 25,00 & 2 & 40 & 13 & 27,7 \\
\hline 2 & No & $5,00 \%$ & 10 & 484,4 & 25,00 & 4 & 80 & 12 & 30,0 \\
\hline 3 & No & $5,00 \%$ & 10 & 484,4 & 25,00 & 6 & 120 & 12 & 30,0 \\
\hline 4 & No & $5,00 \%$ & 10 & 484,4 & 25,00 & 8 & 160 & 13 & 27,7 \\
\hline 5 & No & $5,00 \%$ & 10 & 484,4 & 25,00 & 10 & 200 & 17 & 21,2 \\
\hline & Velocidad & Tamaño & Cohesión & Claridad & & & & & \\
\hline Ensayo & Sediment. & Floculo & Flóculo & Rebose & & & & & \\
\hline 1 & Media & Medio & Parcial & Claro & Datos (para observa & ación visual): & & & \\
\hline 2 & Media & Medio & Parcial & Claro & Tamaño flóculo: & Muy pequeño/Pe & /Medio/ & nde/Muy gra & \\
\hline 3 & Media & Medio & Parcial & Claro & Velocidad sedim.: & Muy lenta/Lenta/ & /Rápida/ & yy rápida & \\
\hline 4 & Media & Medio & Parcial & Claro & Cohesión de flóc.: & Pobre/Parcial/Bu & luy buen & xcelente & \\
\hline 5 & Media & Medio & Parcial & Claro & Claridad rebose: & Muy turbio/Turbi & o/Muy cl & /Cristalino & \\
\hline & & & & CULANTE. TEST 3. & & & & & \\
\hline & $\mathrm{M}-002$ & FLOCULANTE: & NALCO & TIPO CARGA: & Sin Carga 0\% & DOSIFICACIÓN & & & \\
\hline $\begin{array}{c}\text { Ensayo } \\
\#\end{array}$ & $\begin{array}{l}\text { Diluc. } \\
\text { (Si/No) }\end{array}$ & $\begin{array}{c}\text { Pulpa w/w sol. } \\
(\%)\end{array}$ & $\begin{array}{l}\text { Distancia sed. } \\
(\mathrm{cm})\end{array}$ & $\begin{array}{c}\text { Volumen ensayo } \\
(\mathrm{ml})\end{array}$ & $\begin{array}{c}\text { Sólidos } \\
\text { (g) }\end{array}$ & $\begin{array}{l}\text { Floc } \\
\text { (ml) }\end{array}$ & $\begin{array}{l}\text { Floc } \\
(\mathrm{g} / \mathrm{t}) \\
\end{array}$ & $\begin{array}{c}\text { Tiempo } \\
\text { (s) }\end{array}$ & $\begin{array}{c}\text { Velocidad } \\
(\mathrm{m} / \mathrm{h})\end{array}$ \\
\hline 1 & No & $5,00 \%$ & 10 & 484,4 & 25,00 & 2 & 40 & 11 & 32,7 \\
\hline 2 & No & $5,00 \%$ & 10 & 484,4 & 25,00 & 4 & 80 & 9 & 40,0 \\
\hline 3 & No & $5,00 \%$ & 10 & 484,4 & 25,00 & 6 & 120 & 10 & 36,0 \\
\hline 4 & No & $5,00 \%$ & 10 & 484,4 & 25,00 & 8 & 160 & 12 & 30,0 \\
\hline 5 & No & $5,00 \%$ & 10 & 484,4 & 25,00 & 10 & 200 & 15 & 24,0 \\
\hline Ensayo & $\begin{array}{l}\text { Velocidad } \\
\text { Sediment. }\end{array}$ & $\begin{array}{l}\text { Tamaño } \\
\text { Floculo } \\
\end{array}$ & $\begin{array}{l}\text { Cohesión } \\
\text { Flóculo }\end{array}$ & $\begin{array}{l}\text { Claridad } \\
\text { Rebose }\end{array}$ & & & & & \\
\hline 1 & Alta & Grande & Buena & Claro & Datos (para observa & ación visual): & & & \\
\hline 2 & Alta & Grande & Buena & Muy claro & Tamaño flóculo: & Muy pequeño/Pe & /Medio/ & nde/Muy gra & \\
\hline 3 & Alta & Grande & Buena & Muy claro & Velocidad sedim.: & Muy lenta/Lenta/ & a/Rápida & uy rápida & \\
\hline 4 & Media & Grande & Buena & Muy claro & Cohesión de flóc.: & Pobre/Parcial/Bu & huy buen & xcelente & \\
\hline 5 & Media & Grande & Buena & Muy claro & Claridad rebose: & Muy turbio/Turbi & ro/Muy c & /Cristalino & \\
\hline & & & & CULANTE. TEST 4. & & & & & \\
\hline & $\mathrm{M}-002$ & FLOCULANTE: & NALCO & TIPO CARGA: & Catiónico $+\mathbf{1 0} \%$ & DOSIFICACIÓN & $55 \%$ & & \\
\hline $\begin{array}{c}\text { Ensayo } \\
\quad \#\end{array}$ & $\begin{array}{l}\text { Diluc. } \\
\text { (Si/No) }\end{array}$ & $\begin{array}{c}\text { Pulpa w/w sol. } \\
(\%)\end{array}$ & $\begin{array}{l}\text { Distancia sed. } \\
\quad(\mathrm{cm})\end{array}$ & $\begin{array}{c}\text { Volumen ensayo } \\
(\mathrm{ml})\end{array}$ & $\begin{array}{c}\text { Sólidos } \\
\text { (g) }\end{array}$ & $\begin{array}{l}\text { Floc } \\
\text { (ml) }\end{array}$ & $\begin{array}{l}\text { Floc } \\
(\mathrm{g} / \mathrm{t})\end{array}$ & $\begin{array}{c}\text { Tiempo } \\
(s)\end{array}$ & $\begin{array}{c}\text { Velocidad } \\
(\mathrm{m} / \mathrm{h})\end{array}$ \\
\hline 1 & No & $5,00 \%$ & 10 & 484,4 & 25,00 & 2 & 40 & 12 & 30,0 \\
\hline 2 & No & $5,00 \%$ & 10 & 484,4 & 25,00 & 4 & 80 & 13 & 27,7 \\
\hline 3 & No & $5,00 \%$ & 10 & 484,4 & 25,00 & 6 & 120 & 11 & 32,7 \\
\hline 4 & No & $5,00 \%$ & 10 & 484,4 & 25,00 & 8 & 160 & 15 & 24,0 \\
\hline 5 & No & $5,00 \%$ & 10 & 484,4 & 25,00 & 10 & 200 & 18 & 20,0 \\
\hline & Velocidad & Tamaño & Cohesión & Claridad & & & & & \\
\hline Ensayo & Sediment. & Floculo & Flóculo & Rebose & & & & & \\
\hline 1 & Media & Medio & Parcial & Claro & Datos (para observa & ación visual): & & & \\
\hline 2 & Media & Medio & Parcial & Claro & Tamaño flóculo: & Muy pequeño/Pe & /Medio/ & nde/Muy gra & \\
\hline 3 & Media & Medio & Parcial & Claro & Velocidad sedim.: & Muy lenta/Lenta & a/Rápida & «y rápida & \\
\hline 4 & Media & Medio & Parcial & Claro & Cohesión de flóc.: & Pobre/Parcial/Bu & huy buen & xcelente & \\
\hline 5 & Media & Medio & Parcial & Claro & Claridad rebose: & Muy turbio/Turb & o/Muy c & /Cristalino & \\
\hline & & & & CULANTE. TEST 5. & & & & & \\
\hline & $\mathrm{M}-002$ & FLOCULANTE: & NALCO & TIPO CARGA: & Catiónico $+25 \%$ & DOSIFICACIÓI & $5 \% \%$ & & \\
\hline $\begin{array}{c}\text { Ensayo } \\
\quad \#\end{array}$ & $\begin{array}{l}\text { Diluc. } \\
\text { (Si/No) }\end{array}$ & $\begin{array}{c}\text { Pulpa w/w sol. } \\
\text { (\%) }\end{array}$ & $\begin{array}{l}\text { Distancia sed. } \\
\qquad(\mathrm{cm})\end{array}$ & $\begin{array}{c}\text { Volumen ensayo } \\
(\mathrm{ml})\end{array}$ & $\begin{array}{l}\text { Sólidos } \\
\text { (g) }\end{array}$ & $\begin{array}{l}\text { Floc } \\
\text { (ml) }\end{array}$ & $\begin{array}{l}\text { Floc } \\
(g / t)\end{array}$ & $\begin{array}{c}\text { Tiempo } \\
\text { (s) }\end{array}$ & $\begin{array}{c}\text { Velocidad } \\
(\mathrm{m} / \mathrm{h})\end{array}$ \\
\hline 1 & No & $5,00 \%$ & 10 & 484,4 & 25,00 & 2 & 40 & 15 & 24,0 \\
\hline 2 & No & $5,00 \%$ & 10 & 484,4 & 25,00 & 4 & 80 & 14 & 25,7 \\
\hline 3 & No & $5,00 \%$ & 10 & 484,4 & 25,00 & 6 & 120 & 14 & 25,7 \\
\hline 4 & No & $5,00 \%$ & 10 & 484,4 & 25,00 & 8 & 160 & 19 & 18,9 \\
\hline 5 & No & $5,00 \%$ & 10 & 484,4 & 25,00 & 10 & 200 & 21 & 17,1 \\
\hline & Velocidad & Tamaño & Cohesión & Claridad & & & & & \\
\hline Ensayo & Sediment. & Floculo & Flóculo & Rebose & & & & & \\
\hline 1 & Baja & Medio & Parcial & Turbio & Datos (para observa & ación visual): & & & \\
\hline 2 & Baja & Medio & Parcial & Turbio & Tamaño flóculo: & Muy pequeño/Pe & /Medio/ & nde/Muy gra & \\
\hline 3 & Baja & Medio & Parcial & Turbio & Velocidad sedim.: & Muy lenta/Lenta & a/Rápida & uy rápida & \\
\hline 4 & Baja & Medio & Parcial & Turbio & Cohesión de flóc.: & Pobre/Parcial/Bu & huy buen & xcelente & \\
\hline 5 & Baja & Medio & Parcial & Turbio & Claridad rebose: & Muy turbio/Turb & ro/Muy c & /Cristalino & \\
\hline
\end{tabular}


SELECCIÓN DE FLOCULANTE. ANÁLISIS DE DATOS.

Mina:

Proyecto:

MUESTRA ORIGINAL:

Volumen líquido:

$\%$ sólidos en peso:

Dosficación de floculante:

Volumen total:

Concentración floculante:

Densidad Sólido

Densidad Líquido
Cantera de Caliza

Estudio sedimentación y reología de finos de caliza M-002

\begin{tabular}{clll|}
$475 \mathrm{ml}$ & Muestra preparada en laboratorio \\
$25 \mathrm{~g}$ & Muestra preparada en laboratorio \\
$0,1 \mathrm{~g}$ & $\begin{array}{l}\text { Preparación y dosificación floculante. } \\
200 \mathrm{ml}\end{array}$ & Preparación y dosificación floculante. & \\
$0,05 \%$ & & & \\
$2,65 \mathrm{~kg} / \mathrm{dm} 3$ & Método cálculo: & Picnómetro & (Estimado/Lab. Planta/Picnómetro) \\
$1,00 \mathrm{~kg} / \mathrm{dm} 3$ & Método cálculo: & Probeta & (Estimado/Lab. Planta/Probeta) \\
\hline
\end{tabular}

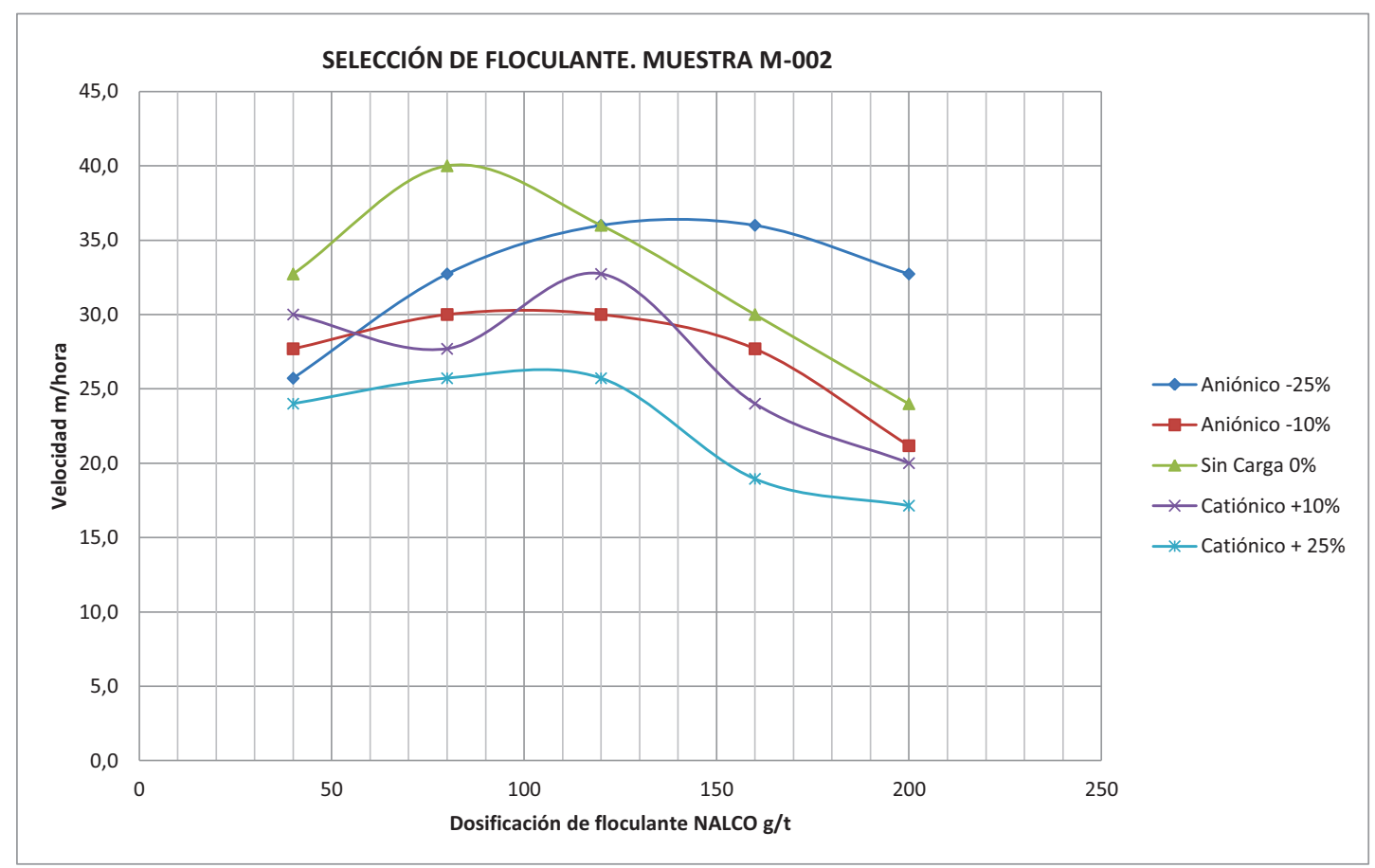

Los ensayos de sedimentación para la selección del floculante han tenido en cuenta tanto los valores de velocidad de sedimentación cómo los datos de observación visual de: tamaño de flóculo, velocidad de sedimentación, cohesión del flóculo y la claridad del rebose obtenida en la probeta de laboratorio. El floculante seleccionado será empleado en los ensayos de flujo de sedimentación. 
ENSAYO FLUJO SEDIMENTACIÓN

\begin{tabular}{l|cc}
$\begin{array}{l}\text { Mina: } \\
\text { Proyecto: } \\
\text { DATOS }\end{array}$ & $\begin{array}{l}\text { Cantera de Caliza } \\
\text { Estudio sedimentación y reología de finos de caliza } \\
\text { FLOCULANTE SELECCIONADO }\end{array}$ \\
Volumen probeta: & $500 \mathrm{ml}$ & \\
Diámetro probeta: & $48,6 \mathrm{~mm}$ & \\
Área sedimentac. & $18,55 \mathrm{~cm} 2$ & \\
Floc. Dosificac.: & $0,1 \mathrm{~g}$ & CARGA \\
Volumen floc.: & $200 \mathrm{ml}$ & MUESTRA SóLIDOS \\
Floculante dosific. & $0,05 \%$ & \\
Floc. Conc. & $0,50 \mathrm{~g} / \mathrm{l}$ \\
Densidad Sólido & $2,65 \mathrm{~kg} / \mathrm{dm} 3$ & \\
Densidad Líquido & $1,00 \mathrm{~kg} / \mathrm{dm} 3$ & \\
\hline
\end{tabular}

Proyecto: $\quad$ Estudio sedimentación y reología de finos de caliza

NSAYO 1: NALCO 0\% CARGA

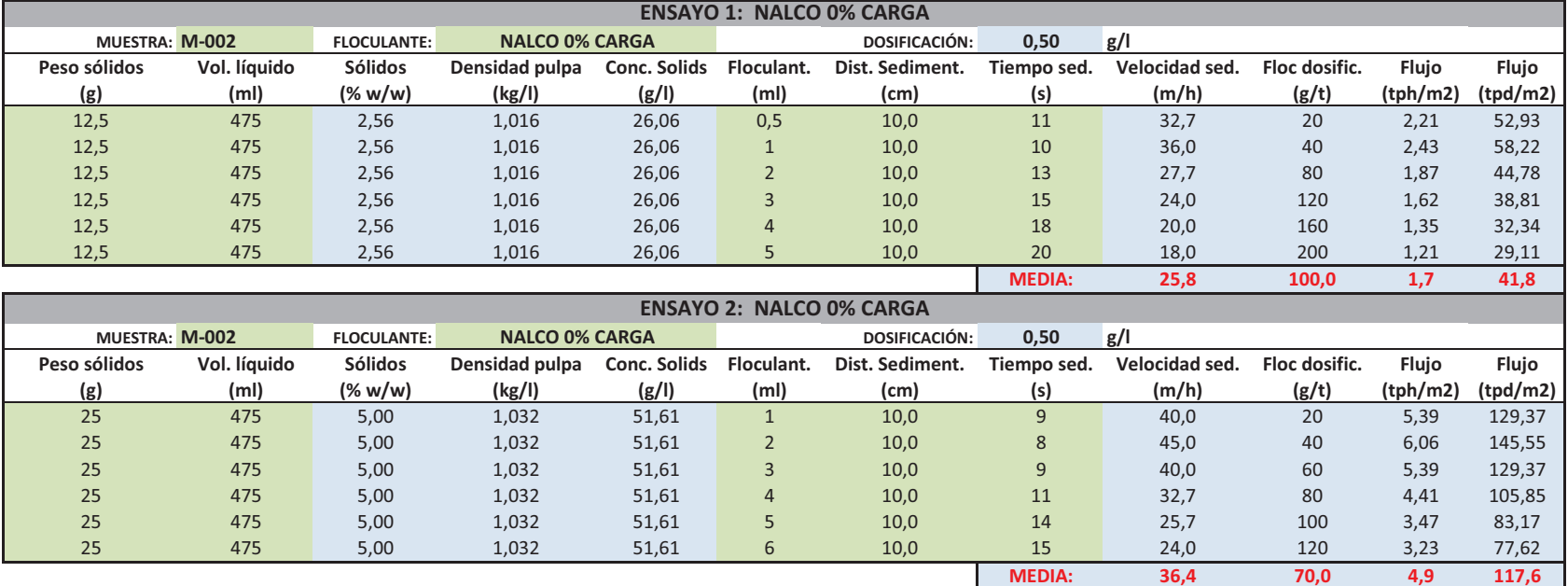

\begin{tabular}{|c|c|c|c|c|c|c|c|c|c|c|c|}
\hline \multicolumn{12}{|c|}{ ENSAYO 3: NALCO 0\% CARGA } \\
\hline \multicolumn{2}{|c|}{ MUESTRA: M-002 } & \multirow{2}{*}{$\begin{array}{l}\text { FLOCULANTE: } \\
\text { Sólidos } \\
(\% \mathrm{w} / \mathrm{w})\end{array}$} & \multicolumn{2}{|c|}{ NALCO $0 \%$ CARGA } & \multirow[b]{2}{*}{$\begin{array}{c}\text { Floculant. } \\
\text { (ml) }\end{array}$} & DOSIFICACIÓN: & \multirow{2}{*}{$\begin{array}{c}0,50 \\
\text { Tiempo sed. } \\
\text { (s) }\end{array}$} & \multirow{2}{*}{$\frac{\mathrm{g} / \mathrm{l}}{\begin{array}{c}\text { Velocidad sed. } \\
(\mathrm{m} / \mathrm{h})\end{array}}$} & \multirow[b]{2}{*}{$\begin{array}{l}\text { Floc dosific. } \\
(\mathrm{g} / \mathrm{t})\end{array}$} & \multirow[b]{2}{*}{$\begin{array}{c}\text { Flujo } \\
\text { (tph/m2) }\end{array}$} & \multirow[b]{2}{*}{$\begin{array}{c}\text { Flujo } \\
\text { (tpd/m2) }\end{array}$} \\
\hline $\begin{array}{c}\text { Peso sólidos } \\
\text { (g) }\end{array}$ & $\begin{array}{c}\text { Vol. líquido } \\
\text { (ml) }\end{array}$ & & $\begin{array}{c}\text { Densidad pulpa } \\
(\mathrm{kg} / \mathrm{l})\end{array}$ & $\begin{array}{c}\text { Conc. Solids } \\
\text { (g/l) }\end{array}$ & & $\begin{array}{l}\text { Dist. Sediment. } \\
\text { (cm) }\end{array}$ & & & & & \\
\hline 38 & 475 & 7,41 & 1,048 & 77,66 & 1 & 10,0 & 15 & 24,0 & 13 & 4,92 & 117,99 \\
\hline 38 & 475 & 7,41 & 1,048 & 77,66 & 2 & 10,0 & 10 & 36,0 & 26 & 7,37 & 176,98 \\
\hline 38 & 475 & 7,41 & 1,048 & 77,66 & 4 & 10,0 & 11 & 32,7 & 53 & 6,70 & 160,89 \\
\hline 38 & 475 & 7,41 & 1,048 & 77,66 & 6 & 10,0 & 12 & 30,0 & 79 & 6,15 & 147,49 \\
\hline 38 & 475 & 7,41 & 1,048 & 77,66 & 8 & 10,0 & 14 & 25,7 & 105 & 5,27 & 126,42 \\
\hline 38 & 475 & 7,41 & 1,048 & 77,66 & 10 & 10,0 & 16 & 22,5 & 132 & 4,61 & 110,62 \\
\hline & & & & & & & MEDIA: & 27,9 & 65,8 & 5,7 & 137,0 \\
\hline
\end{tabular}

\begin{tabular}{|c|c|c|c|c|c|c|c|c|c|c|c|}
\hline \multicolumn{12}{|c|}{ ENSAYO 4: NALCO $0 \%$ CARGA } \\
\hline \multicolumn{2}{|c|}{ MUESTRA: M-002 } & \multirow{2}{*}{$\begin{array}{l}\text { FLOCULANTE: } \\
\text { Sólidos } \\
(\% \mathrm{w} / \mathrm{w})\end{array}$} & \multicolumn{2}{|c|}{ NALCO 0\% CARGA } & \multirow[b]{2}{*}{$\begin{array}{c}\text { Floculant. } \\
\text { (ml) }\end{array}$} & \multirow{2}{*}{$\begin{array}{l}\text { DOSIFICACIÓN: } \\
\text { ist. Sediment. } \\
(\mathrm{cm})\end{array}$} & \multirow{2}{*}{$\begin{array}{c}0,50 \\
\text { Tiempo sed. } \\
\text { (s) }\end{array}$} & \multirow{2}{*}{$\begin{array}{l}\mathrm{g} / \mathrm{l} \\
\begin{array}{c}\text { Velocidad sed. } \\
(\mathrm{m} / \mathrm{h})\end{array}\end{array}$} & \multirow[b]{2}{*}{$\begin{array}{l}\text { Floc dosific. } \\
(\mathrm{g} / \mathrm{t})\end{array}$} & \multirow[b]{2}{*}{$\begin{array}{c}\text { Flujo } \\
\text { (tph/m2) }\end{array}$} & \multirow[b]{2}{*}{$\begin{array}{c}\text { Flujo } \\
\text { (tpd/m2) }\end{array}$} \\
\hline $\begin{array}{c}\text { Peso sólidos } \\
\text { (g) }\end{array}$ & $\begin{array}{c}\text { Vol. líquido } \\
(\mathrm{ml})\end{array}$ & & $\begin{array}{c}\text { Densidad pulpa } \\
(\mathrm{kg} / \mathrm{l})\end{array}$ & $\begin{array}{c}\text { Conc. Solids } \\
(\mathrm{g} / \mathrm{l})\end{array}$ & & & & & & & \\
\hline 50 & 475 & 9,52 & 1,063 & 101,24 & 2 & 10,0 & 25 & 14,4 & 20 & 3,88 & 93,150 \\
\hline 50 & 475 & 9,52 & 1,063 & 101,24 & 4 & 10,0 & 16 & 22,5 & 40 & 6,06 & 145,546 \\
\hline 50 & 475 & 9,52 & 1,063 & 101,24 & 6 & 10,0 & 17 & 21,2 & 60 & 5,71 & 136,985 \\
\hline 50 & 475 & 9,52 & 1,063 & 101,24 & 8 & 10,0 & 19 & 18,9 & 80 & 5,11 & 122,565 \\
\hline 50 & 475 & 9,52 & 1,063 & 101,24 & 10 & 10,0 & 20 & 18,0 & 100 & 4,85 & 116,437 \\
\hline 50 & 475 & 9,52 & 1,063 & 101,24 & 12 & 10,0 & 20 & 18,0 & 120 & 4,85 & 116,437 \\
\hline & & & & & & & MEDIA: & 18,5 & 70,0 & 5,0 & 119,5 \\
\hline
\end{tabular}


ENSAYO FLUJO SEDIMENTACIÓN. ANÁLISIS DE RESULTADOS.

Mina:

Proyecto:

DATOS

Volumen probeta:

Diámetro probeta:

Área sedimentac.

Floc. Dosificac.:

Volumen floc:

Floculante dosific

Floc. Conc.

Densidad Sólido

Densidad Líquido
Cantera de Caliza

Estudio sedimentación y reología de finos de caliza

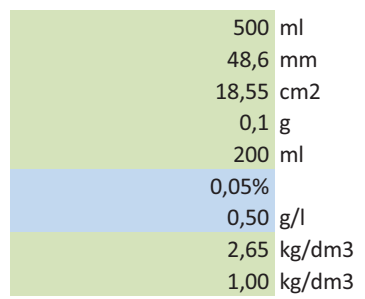

FLOCULANTE SELECCIONADO

NALCO 0\% CARGA
MUESTRA SÓLIDOS

M-002
Diámetros de probetas:

$250 \mathrm{ml} \quad 35,7 \quad \mathrm{~mm}$

$500 \mathrm{ml} \quad 48,6 \quad \mathrm{~mm}$

$2000 \mathrm{ml} \quad 78,2 \quad \mathrm{~mm}$
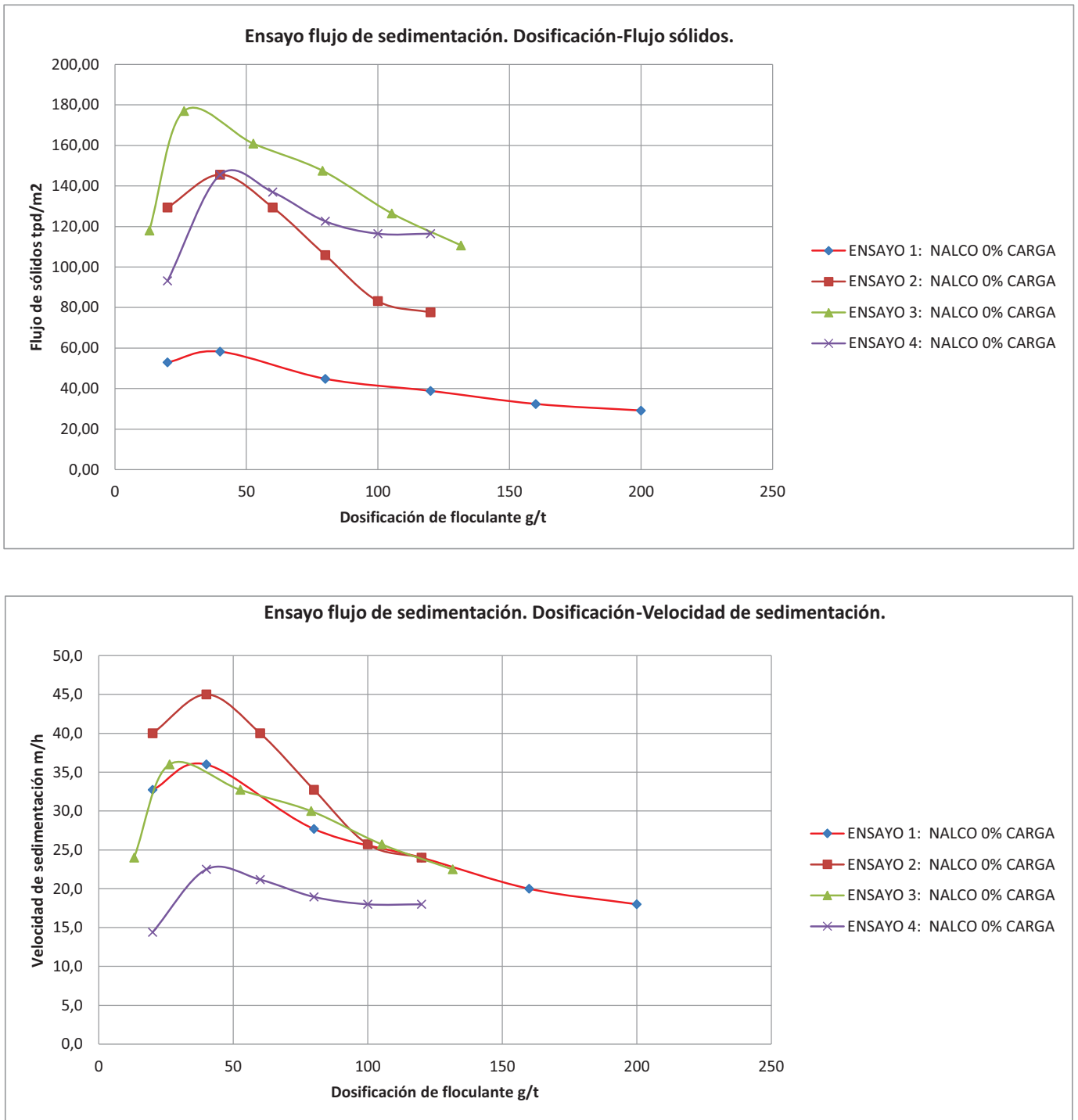

Los ensayos de flujos de sedimentación determinan la dilución óptima de los sólidos para la alimentación en el espesador.

El valor obtenido sirve de base para el diseño de la campana de alimentación y el sistema de dilución previsto. 
ENSAYO SEDIMENTACIÓN PROBETA 2000mI ESTÁTICO

\begin{tabular}{ll}
\hline Mina: & Cantera de Caliza \\
Proyecto: & Estudio sedimentación y reología de finos de caliza \\
Muestra: & M-002
\end{tabular}

Muestra:

M-002

\begin{tabular}{|c|c|c|c|c|c|c|}
\hline Volumen líquido: & $1900 \mathrm{ml}$ & Solidos en peso & $\mathrm{S}=\mathrm{Ps} / \mathrm{Pp}$ & $\mathrm{s}$ & $7,54 \%$ & \\
\hline Peso sólidos: & $155 \mathrm{~g}$ & Dilución & $d=P l / P s$ & d & 12,258 & \\
\hline Floculante dosificac. & $0,1 \mathrm{~g}$ & Solidos en volumen & $V=V s / V p$ & V & $2,99 \%$ & \\
\hline Volume total: & $200 \mathrm{ml}$ & Concent. Sólidos en peso & $\mathrm{C}=\mathrm{Ps} / \mathrm{Vp}$ & c & 79,14 & $g / l$ \\
\hline Floc. Conc. & $0,20 \mathrm{~g} / \mathrm{l}$ & Densidad de la pulpa & $S G p=P p / V p$ & SGp & 1,049 & $\mathrm{~kg} / \mathrm{l}$ \\
\hline Floculante & $8,00 \mathrm{ml}$ & & & & & \\
\hline Solids SG & $2,65 \mathrm{~kg} / \mathrm{dm} 3$ & & & & & \\
\hline Liquid SG & $1,00 \mathrm{~kg} / \mathrm{dm} 3$ & & & & & \\
\hline Diámetro probeta & $78,2 \mathrm{~mm}$ & & & & & \\
\hline Area probeta & $0,0048029 \mathrm{~m} 2$ & $48,029 \mathrm{~cm} 2$ & & & & \\
\hline Densidad pulpa: & $1,049 \mathrm{~kg} / \mathrm{l}$ & & & & & \\
\hline Sólidos en peso: & 79,14 g solids/l & & & & & \\
\hline Sólidos en peso: & 0,0791 g solids/ml & & & & & \\
\hline |Floculante: & NALCO & & & & & \\
\hline Tipo de carga floc.: & 0\% CARGA & & & & & \\
\hline Dosificación floc.: & gramos/ton & lada sólido & & & & \\
\hline
\end{tabular}

DATOS DE SEDIMENTACIÓN

\begin{tabular}{|c|c|c|c|c|c|c|c|c|c|}
\hline $\begin{array}{c}\text { Tiempo info } \\
\text { (sec) }\end{array}$ & $\begin{array}{c}\text { Tiempo } \\
\text { (min) }\end{array}$ & $\begin{array}{l}\text { Vol. Lodos } \\
\text { (ml) }\end{array}$ & $\begin{array}{l}\text { Altura interf. } \\
\text { (cm) }\end{array}$ & $\begin{array}{c}\text { Velocidad } \\
(\mathrm{m} / \mathrm{hr})\end{array}$ & $\begin{array}{c}\text { SG. Lodos } \\
(\mathrm{g} / \mathrm{cm} 3)\end{array}$ & $\begin{array}{c}\text { Lodos } \\
\% \text { Sol. Peso }\end{array}$ & $\begin{array}{c}\text { Flujo } \\
\text { (tph/m2) }\end{array}$ & $\begin{array}{c}\text { Flujo } \\
(\mathrm{tpd} / \mathrm{m} 2)\end{array}$ & $\begin{array}{c}\text { Área Unit. Espes } \\
(\mathrm{m} 2 / \mathrm{tpd})\end{array}$ \\
\hline 0 & 0 & 1993 & 41,50 & 0 & 1,048 & 7,42 & 0 & 0 & 0 \\
\hline 5 & 0,08 & 1945 & 40,50 & 7,200 & 1,050 & 7,59 & 23,2361 & 557,67 & 0,002 \\
\hline 10 & 0,17 & 1873 & 39,00 & 10,800 & 1,052 & 7,87 & 23,2359 & 557,66 & 0,002 \\
\hline 15 & 0,25 & 1729 & 36,00 & 21,600 & 1,056 & 8,49 & 23,2360 & 557,66 & 0,002 \\
\hline 30 & 0,50 & 1633 & 34,00 & 4,800 & 1,059 & 8,96 & 7,7453 & 185,89 & 0,005 \\
\hline 45 & 0,75 & 1441 & 30,00 & 9,600 & 1,067 & 10,08 & 7,7453 & 185,89 & 0,005 \\
\hline 60 & 1,00 & 1249 & 26,00 & 9,600 & 1,077 & 11,52 & 7,7453 & 185,89 & 0,005 \\
\hline 120 & 2,00 & 384 & 8,00 & 10,800 & 1,251 & 32,24 & 1,9363 & 46,47 & 0,022 \\
\hline 180 & 3,00 & 322 & 6,70 & 0,780 & 1,300 & 37,05 & 1,9363 & 46,47 & 0,022 \\
\hline 240 & 4,00 & 288 & 6,00 & 0,420 & 1,335 & 40,29 & 1,9363 & 46,47 & 0,022 \\
\hline 300 & 5,00 & 274 & 5,70 & 0,180 & 1,353 & 41,86 & 1,9363 & 46,47 & 0,022 \\
\hline 450 & 7,50 & 235 & 4,90 & 0,192 & 1,410 & 46,71 & 0,7745 & 18,59 & 0,054 \\
\hline 600 & 10,00 & 216 & 4,50 & 0,096 & 1,447 & 49,58 & 0,7745 & 18,59 & 0,054 \\
\hline 900 & 15,00 & 192 & 4,00 & 0,060 & 1,502 & 53,70 & 0,3873 & 9,29 & 0,108 \\
\hline 1200 & 20,00 & 180 & 3,75 & 0,030 & 1,536 & 56,03 & 0,3873 & 9,29 & 0,108 \\
\hline 1500 & 25,00 & 168 & 3,50 & 0,030 & 1,574 & 58,58 & 0,3873 & 9,29 & 0,108 \\
\hline 1800 & 30,00 & 168 & 3,50 & 0,000 & 1,574 & 58,58 & 0,3873 & 9,29 & 0,108 \\
\hline 3600 & 60,00 & 168 & 3,50 & 0,000 & 1,574 & 58,58 & 0,0645 & 1,55 & 0,646 \\
\hline 5400 & 90,00 & 168 & 3,50 & 0,000 & 1,574 & 58,58 & 0,0645 & 1,55 & 0,646 \\
\hline 7200 & 120,00 & 168 & 3,50 & 0,000 & 1,574 & 58,58 & 0,0645 & 1,55 & 0,646 \\
\hline 9000 & 150,00 & 168 & 3,50 & 0,000 & 1,574 & 58,58 & 0,0645 & 1,55 & 0,646 \\
\hline 10800 & 180,00 & 168 & 3,50 & 0,000 & 1,574 & 58,58 & 0,0645 & 1,55 & 0,646 \\
\hline 14400 & 240,00 & 168 & 3,50 & 0,000 & 1,574 & 58,58 & 0,0323 & 0,77 & 1,291 \\
\hline
\end{tabular}

DATOS OBTENIDOS:

1a Caída de velocidad: 1 minuto

2a Caída de velocidad, comienzo régimen de compresión: 20 minutos

$\%$ sólidos - tiempo: 58 \% sólidos en peso - $30 \mathrm{~min}$. tiempo residencia 
ENSAYO SEDIMENTACIÓN PROBETA 2000mI ESTÁTICO. ANÁLISIS DE RESULTADOS.

Mina:

Proyecto:

Muestra
Cantera de Caliza

Estudio sedimentación y reología de finos de caliza

M-002
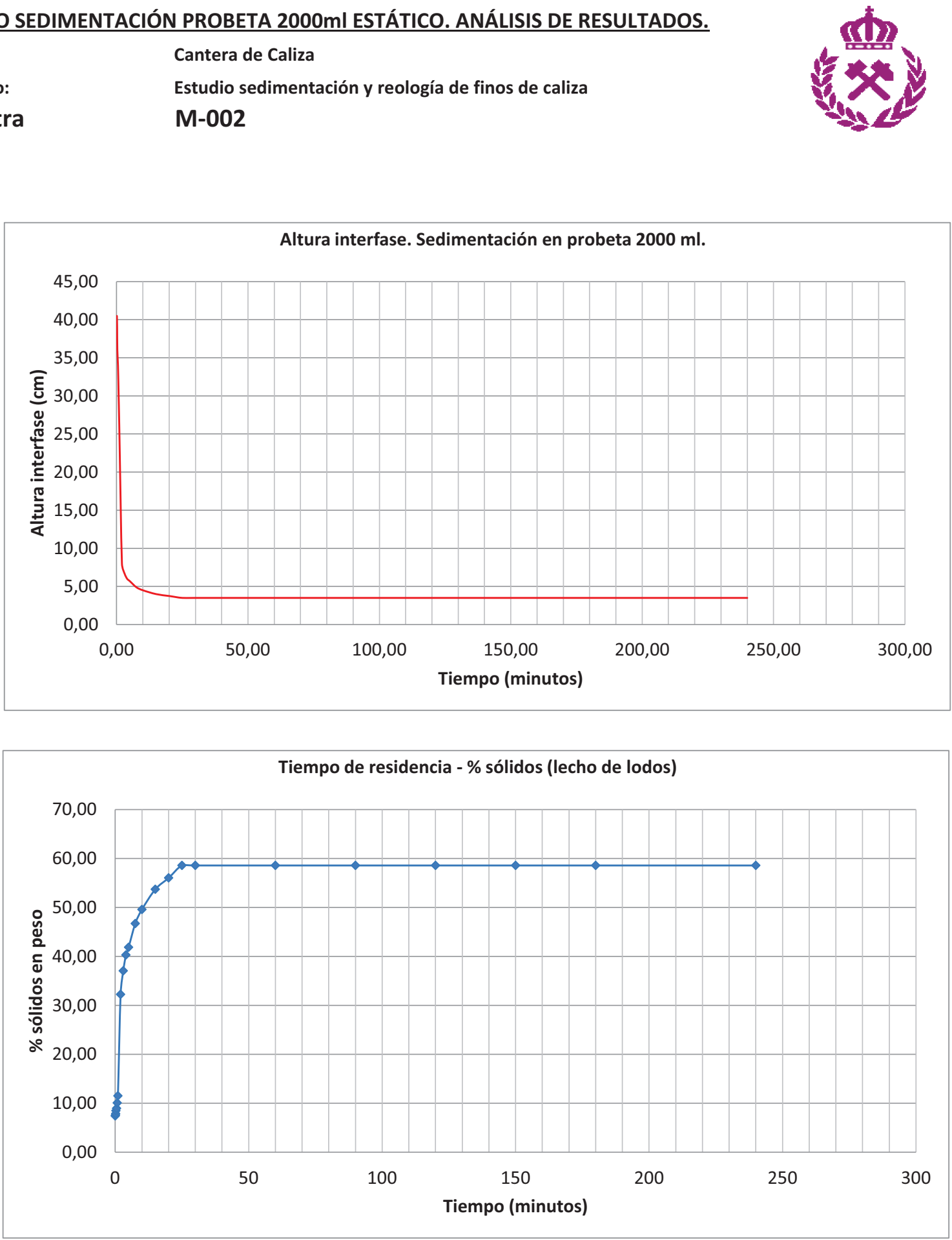


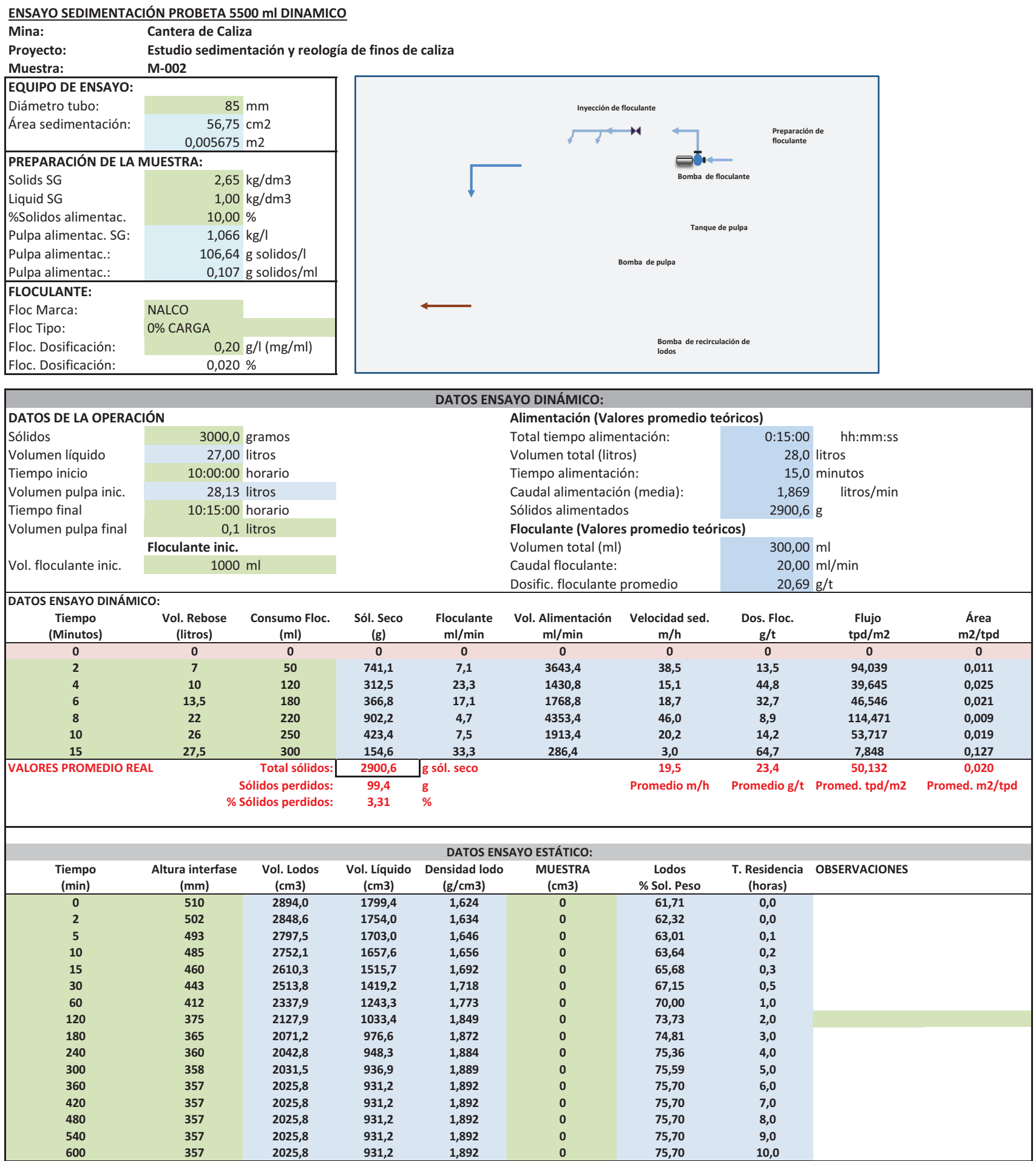


ENSAYO SEDIMENTACIÓN PROBETA 5500 mI DINAMICO

Mina: Cantera de Caliza

Proyecto: Estudio sedimentación y reología de finos de caliza

Muestra: M-002

DATOS DE OPERACIÓN DEL ESPESADOR DE TUBO PROFUNDO

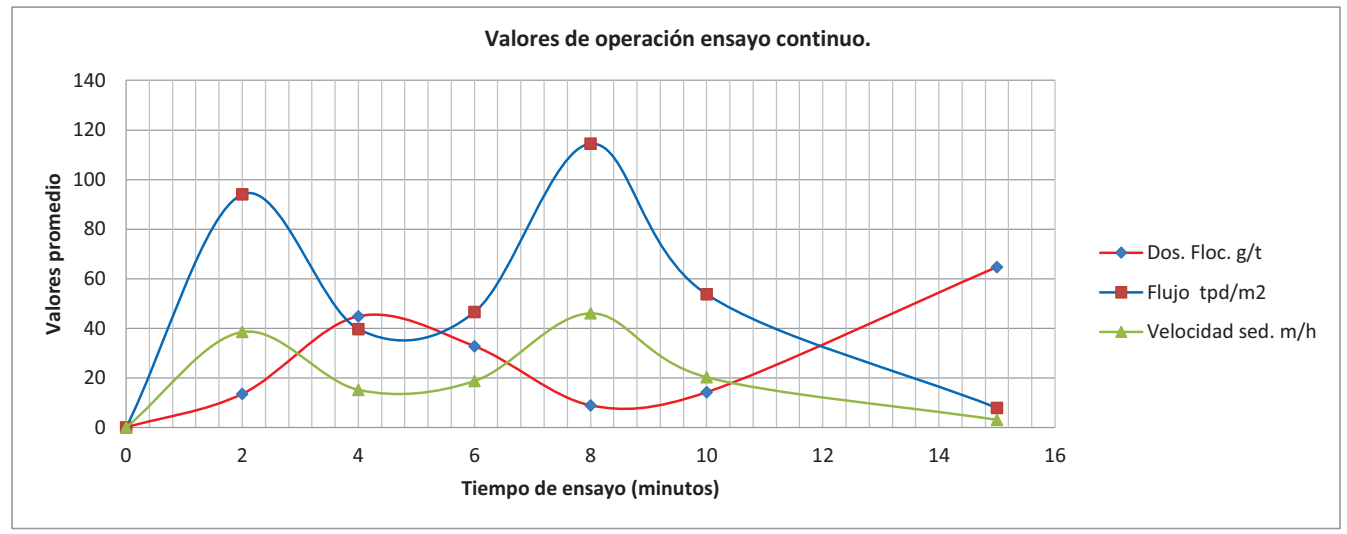

Datos Promedio:

Velocidad de sedimentación:

$19,5 \mathrm{~m} / \mathrm{h}$

Dosificación de floculante:

23,4

Flujo de sedimentación:

$0,0201 \mathrm{~m}^{2} / \mathrm{t} / \mathrm{día}$

Flujo de sedimentación:

$50,1 \mathrm{t} / \mathrm{di} a / \mathrm{m}^{2}$

ENSAYO SEDIMENTACIÓN PROBETA $5500 \mathrm{mI}$ DINAMICO
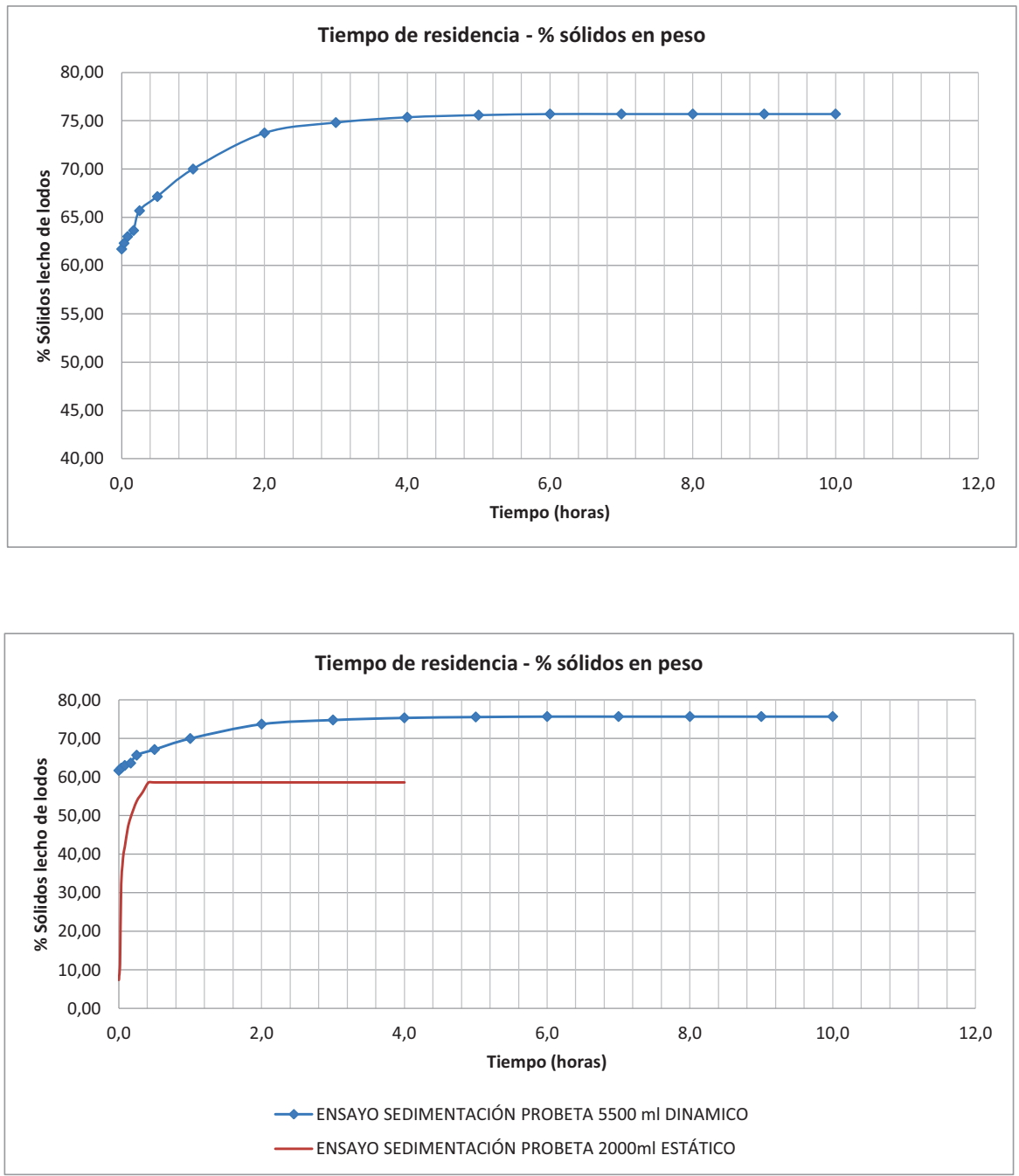
ENSAYO FILTRACIÓN A VACIO

Mina: Cantera de Caliza

Proyecto: $\quad$ Estudio sedimentación y reología de finos de caliza

Material:

Finos de caliza

Muestra:

$\mathrm{M}-002$

Preparado por: José A. Butragueño

pH muestra: 8

Fecha: $\quad 27 / 07 / 2013$

\begin{tabular}{|c|c|c|}
\hline \multicolumn{3}{|c|}{ DATOS DE LA MUESTRA: } \\
\hline Solidos SG & & $2,65 \mathrm{~kg} / \mathrm{dm} 3$ \\
\hline Liquido SG & & $1,00 \mathrm{~kg} / \mathrm{dm} 3$ \\
\hline \multicolumn{3}{|l|}{ FLOCULANTE: } \\
\hline Floc Name: & No & \\
\hline Tipo de floculante: & No & \\
\hline Floc. Dosificación: & & $0,00 \mathrm{~g} / \mathrm{l}(\mathrm{mg} / \mathrm{ml})$ \\
\hline
\end{tabular}
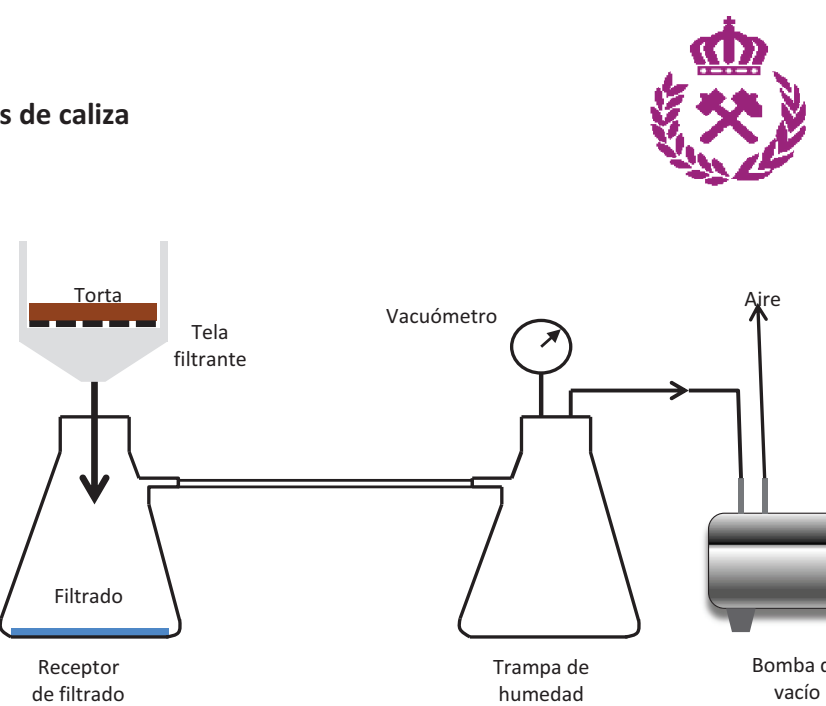
$0,000 \%$

\begin{tabular}{|c|c|c|c|c|c|c|c|c|c|}
\hline \multicolumn{10}{|c|}{ ENSAYO FILTRACIÓN A VACÍO. TEST 1.} \\
\hline \multicolumn{2}{|c|}{ MUESTRA: M-002 } & & \multicolumn{7}{|c|}{ Tiempos de ensayo de filtración } \\
\hline $\begin{array}{l}\text { Vacío } \\
\text { (bar) }\end{array}$ & Peso sólidos & $\begin{array}{l}\text { Vol. Líquido } \\
\text { (ml) }\end{array}$ & $\begin{array}{l}\text { \% Sól. Peso } \\
\text { (\%) }\end{array}$ & $\begin{array}{l}\text { Vol. Pulpa } \\
\text { (ml) }\end{array}$ & $\begin{array}{l}\text { Formación torta } \\
\text { (s) }\end{array}$ & $\begin{array}{c}\text { Secado torta } \\
\text { (s) }\end{array}$ & $\begin{array}{c}\text { Total ciclo } \\
\text { (s) }\end{array}$ & $\begin{array}{l}\text { Líq. Filtrado } \\
(\mathrm{ml})\end{array}$ & $\begin{array}{c}\text { Espesor } \\
(\mathrm{mm})\end{array}$ \\
\hline$-0,6$ & 100 & 425,0 & 19,0 & 462,7 & 60 & 30 & 90 & 390 & 5,0 \\
\hline \% Solidos estimado: & 74,1 & & & & & & & & \\
\hline Peso muestra húmedo: & 114 & $\mathrm{~g}$ & \multirow{4}{*}{\multicolumn{2}{|c|}{ Observaciones: }} & & & & & \\
\hline Secad & de la muestra & & & & & & & & \\
\hline Peso muestra seco & 87,1 & $\mathrm{~g}$ & & & & & & & \\
\hline$\%$ humedad torta & 23,60 & $\%$ & & & & & & & \\
\hline
\end{tabular}

\begin{tabular}{|c|c|c|c|c|c|c|c|c|c|}
\hline \multicolumn{10}{|c|}{ ENSAYO FILTRACIÓN A VACÍO. TEST 2.} \\
\hline \multicolumn{2}{|c|}{ MUESTRA: M-002 } & & \multicolumn{7}{|c|}{ Tiempos de ensayo de filtración } \\
\hline $\begin{array}{l}\text { Vacío } \\
\text { (bar) }\end{array}$ & $\begin{array}{l}\text { Peso sólidos } \\
\text { (g) }\end{array}$ & $\begin{array}{l}\text { Vol. Líquido } \\
\text { (ml) }\end{array}$ & $\begin{array}{c}\text { \% Sól. Peso } \\
\text { (\%) }\end{array}$ & $\begin{array}{l}\text { Vol. Pulpa } \\
\text { (ml) }\end{array}$ & $\begin{array}{l}\text { Formación torta } \\
\text { (s) }\end{array}$ & $\begin{array}{c}\text { Secado torta } \\
\text { (s) }\end{array}$ & $\begin{array}{l}\text { Total ciclo } \\
\text { (s) }\end{array}$ & $\begin{array}{l}\text { Líq. Filtrado } \\
\text { (ml) }\end{array}$ & $\begin{array}{c}\text { Espesor } \\
(\mathrm{mm})\end{array}$ \\
\hline$-0,6$ & 50 & 300,0 & 14,3 & 318,9 & 60 & 10 & 70 & 285 & 2,5 \\
\hline \% Solidos estimado: & 76,9 & & & & & & & & \\
\hline Peso muestra húmedo: & 56 & $\mathrm{~g}$ & \multirow{4}{*}{\multicolumn{2}{|c|}{ Observaciones: }} & & & & & \\
\hline Secad & o de la muestr & & & & & & & & \\
\hline Peso muestra seco & 43,8 & $\mathrm{~g}$ & & & & & & & \\
\hline$\%$ humedad torta & 21,79 & $7 \%$ & & & & & & & \\
\hline
\end{tabular}

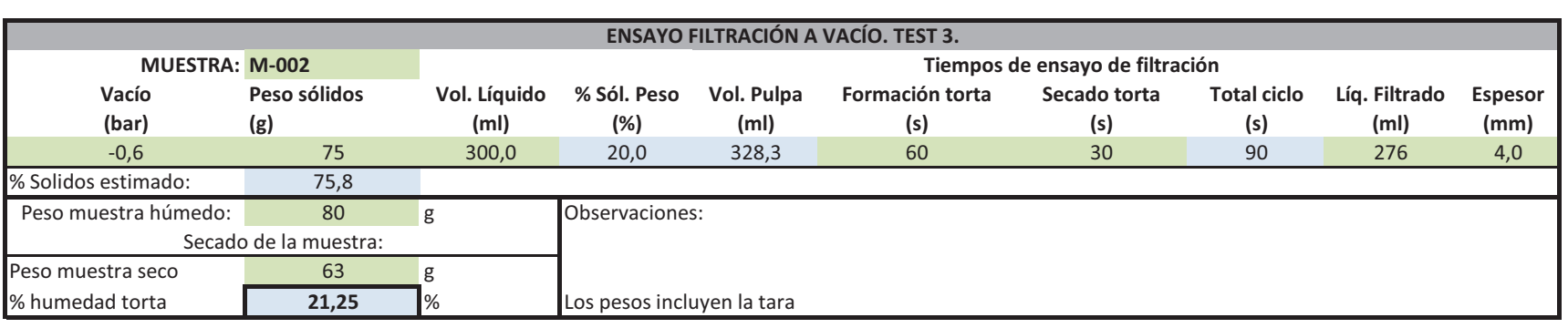

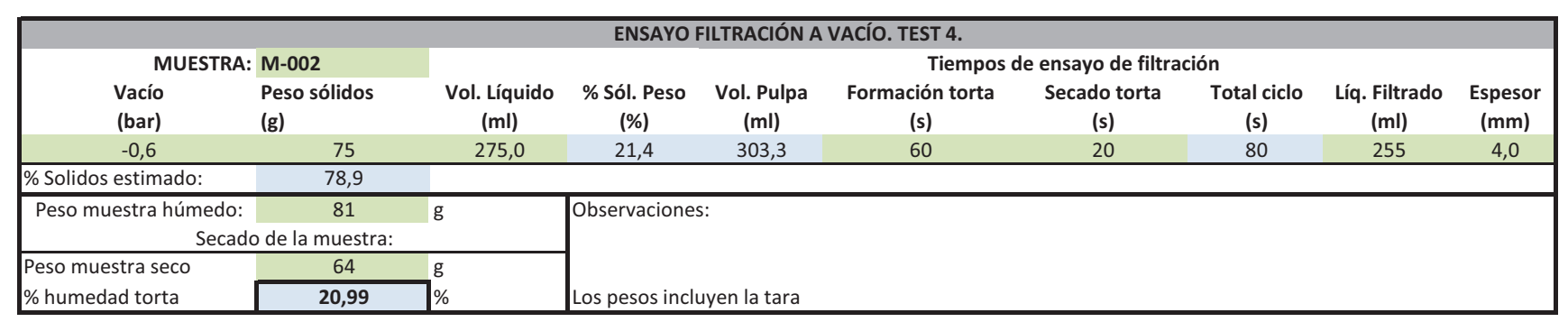


ENSAYO ASENTAMIENTO EN PROBETA

\begin{tabular}{|ll|} 
Mina: & Cantera de Caliza \\
Proyecto: & Estudio sedimentación y reología de finos de caliza \\
\cline { 2 - 2 } Material: & Jinos de caliza \\
Preparado por: & 8 \\
pH muestra: & $27 / 07 / 2013$ \\
\hline Fecha: & Jutragueño \\
\hline
\end{tabular}

Fecha: $27 / 07 / 2013$

Aceleración gravedad (g):

Diámetro probeta:

Altura probeta $(\mathrm{H})$

$9,81 \mathrm{~m} / \mathrm{s} 2$

Volumen probeta:

Solidos SG

$44 \mathrm{~mm}$

$100 \mathrm{~mm}$

$152,1 \mathrm{~cm} 3$

$2,65 \mathrm{~kg} / \mathrm{dm} 3$

Líquido SG

$1,00 \mathrm{~kg} / \mathrm{dm} 3$

Expresiones empíricas

$T=0.5-0.5(h / H)^{\wedge} 0.5$

T.F. $=\mathrm{T}^{*} \mathrm{~d}^{*} \mathrm{~g} *(\mathrm{H} / 100)$

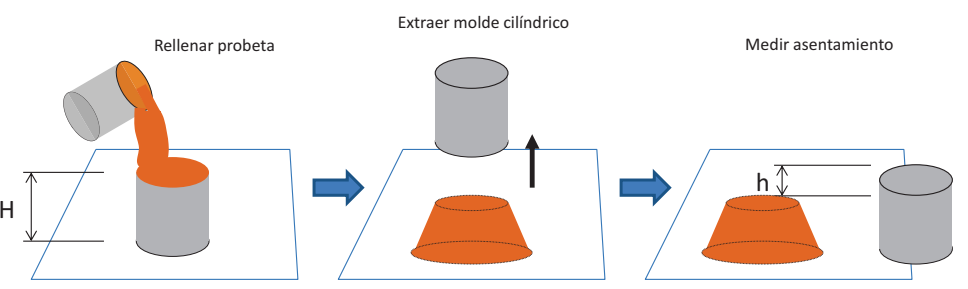

\begin{tabular}{|c|c|c|c|c|c|c|c|c|c|c|}
\hline \multicolumn{11}{|c|}{ ENSAYOS DE ASENTAMIENTO EN PROBETA } \\
\hline $\begin{array}{l}\text { Muestra } \\
\text { ID }\end{array}$ & $\begin{array}{c}\text { Cont. Sólidos } \\
\text { (\%) }\end{array}$ & $\begin{array}{l}\text { Solidos SG } \\
\mathrm{g} / \mathrm{cm} 3\end{array}$ & $\begin{array}{c}\text { Peso Liq. } \\
\text { (kg liq/kg sol) }\end{array}$ & $\begin{array}{l}\text { Vol. Pulpa } \\
\text { (I/kg sol) }\end{array}$ & $\begin{array}{c}\text { Pulpa SG (d) } \\
\text { kg/dm3 }\end{array}$ & $\begin{array}{c}\text { Sólidos prob. } \\
\text { (g) }\end{array}$ & $\begin{array}{l}\text { Liq. Probeta } \\
\text { (g) }\end{array}$ & $\begin{array}{c}\text { Asentamiento }(\mathrm{h}) \\
\mathrm{mm}\end{array}$ & $\begin{array}{l}\text { Factor "T" } \\
\text { Adimens. }\end{array}$ & $\begin{array}{c}\text { Tensión Fluencia } \\
\text { (Pa) }\end{array}$ \\
\hline 1 & 68 & 2,65 & 0,471 & 0,848 & 1,734 & 179,3 & 84,4 & 45 & 0,16459 & 280,0 \\
\hline 2 & 67 & 2,65 & 0,493 & 0,870 & 1,716 & 174,8 & 86,1 & 52 & 0,13944 & 234,7 \\
\hline 3 & 65 & 2,65 & 0,538 & 0,916 & 1,680 & 166,0 & 89,4 & 62 & 0,10630 & 175,2 \\
\hline 4 & 62,5 & 2,65 & 0,600 & 0,977 & 1,637 & 155,6 & 93,3 & 79 & 0,05559 & 89,3 \\
\hline 5 & 60 & 2,65 & 0,667 & 1,044 & 1,596 & 145,6 & 97,1 & 90 & 0,02566 & 40,2 \\
\hline 6 & 50 & 2,65 & 1,000 & 1,377 & 1,452 & 110,4 & 110,4 & 97 & 0,00756 & 10,8 \\
\hline
\end{tabular}

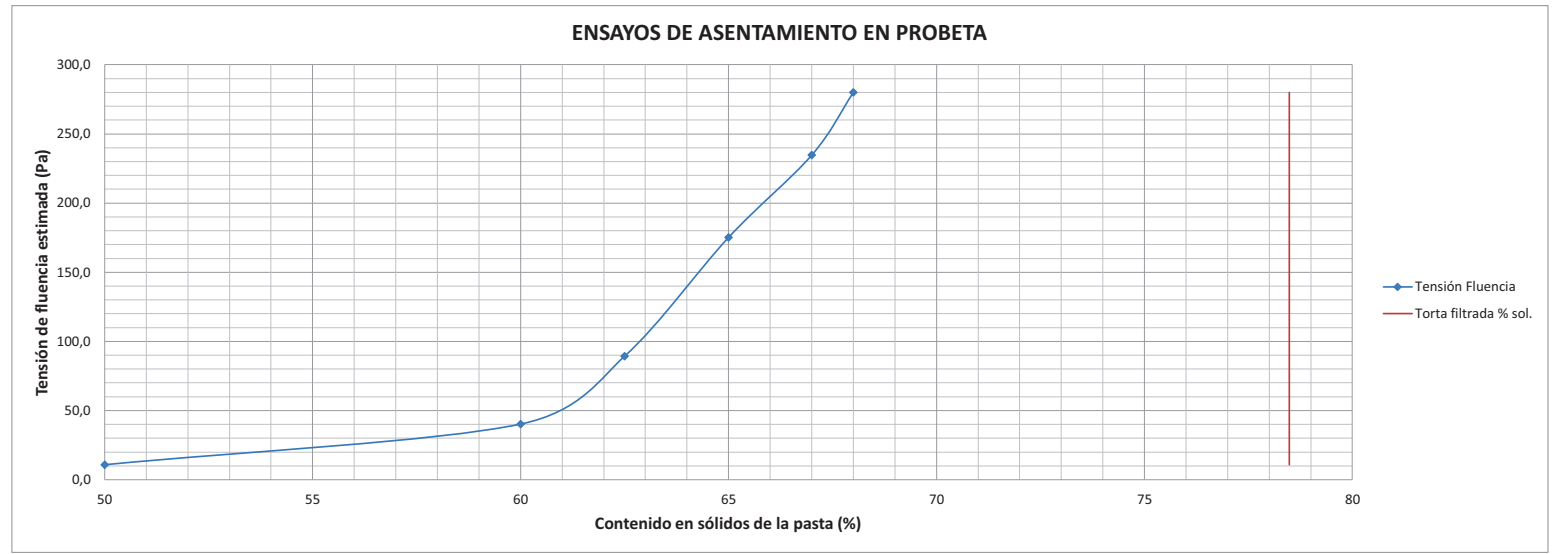

Página 12 de 12 


\section{SEDIMENTACIÓN Y REOLOGÍA}

Mina:

Planta lavado arenas

Empresa:

JOSÉ BUTRAGUEÑO

\section{Proyecto:}

Estudio sedimentación y reología de estériles

\section{Aplicación}

\section{Sedimentación. Arcillas}

Fecha: $\quad 08 / 08 / 2013$

\section{Ensayos:}

\begin{tabular}{|c|c|}
\hline $\mathbf{x}$ & Distribución granulométrica y caracterización de muestras \\
\hline $\mathrm{x}$ & Selección de floculantes \\
\hline $\mathbf{x}$ & Área de flujo \\
\hline $\mathbf{x}$ & Sedimentación en probeta estática \\
\hline $\mathbf{x}$ & Ensayo en espesador dinámico de laboratorio de $85 \mathrm{~mm}$ DIA \\
\hline $\mathbf{x}$ & Reología de los lodos \\
\hline $\mathbf{x}$ & Ensayo de filtración a vacío \\
\hline
\end{tabular}

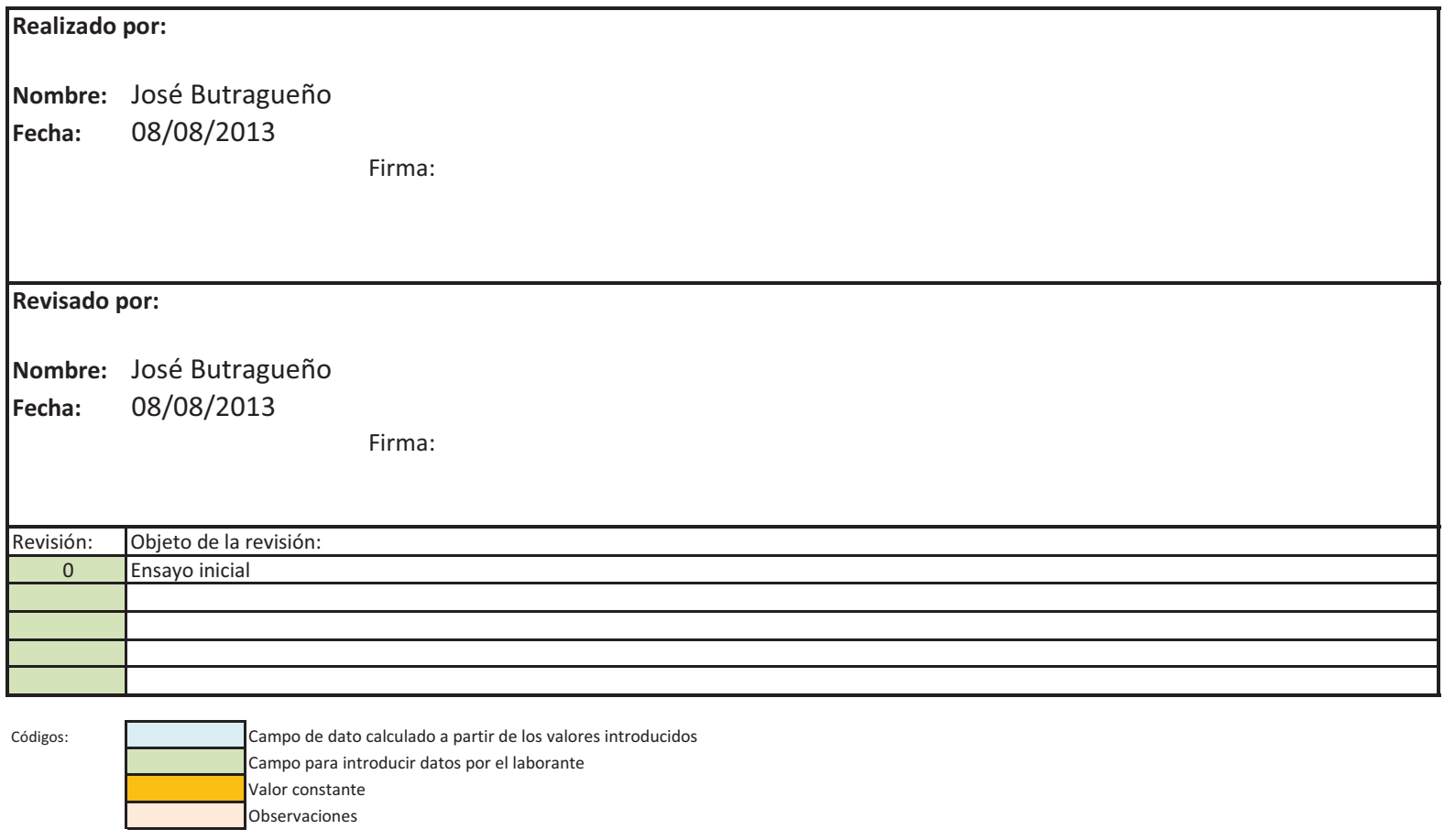

CONFIDENCIAL: Este documento contiene información propiedad de JOSÉ BUTRAGUEÑO y está sujeto a ser

devuelto bajo demanda; estando prohibida su reproducción, copia, préstamo o cualquier otro uso que no sea el fin para el que fue expresamente realizado, sin el consentimiento expreso por escrito de: JOSÉ BUTRAGUEÑO 
ENSAYO GRANULOMÉTRICO DE SÓLIDOS

Mina: Planta lavado arenas

Proyecto: $\quad$ Estudio sedimentación y reología de estériles

Realizado por: José Butragueño

\begin{tabular}{|ll|}
\hline Muestra ID: & M-004 \\
Material: & Arcillas \\
Preparado por: & José A. Butragueño \\
pH muestra: & - \\
Fecha: & $08 / 08 / 2013$ \\
\hline
\end{tabular}

CURVA GRANULOMÉTRICA DE SÓLIDOS

\begin{tabular}{|c|c|c|c|c|c|}
\hline \multicolumn{3}{|c|}{ DATOS DE LA PULPA A SEDIMENTAR } & \multicolumn{3}{|c|}{ Observaciones: Muestra de sólido seco } \\
\hline Densidad sólidos: & 2,00 & $\mathrm{~kg} / \mathrm{dm}^{3}$ & & & \\
\hline Densidad líquido: & 1,00 & $\mathrm{~kg} / \mathrm{dm}^{3}$ & & & \\
\hline Densidad pulpa: & & $\mathrm{kg} / \mathrm{l}$ & & & \\
\hline Tara: & 0 & g & & & \\
\hline Pulpa húmeda: & 0 & g & Peso pulpa: & & $g$ \\
\hline Sólido seco: & 0 & g & Peso sólido: & & $g$ \\
\hline \% Peso sólidos: & \#DIV/0! & $\%$ & & & \\
\hline
\end{tabular}

\section{CURVA GRANULOMÉTRICA DE SÓLIDOS}

\begin{tabular}{|c|c|c|c|c|}
\hline \multicolumn{5}{|c|}{ ENSAYO GRANULOMÉTRICO } \\
\hline \multirow{2}{*}{\begin{tabular}{|l|} 
Tamiz \\
Micras
\end{tabular}} & \multirow{2}{*}{\begin{tabular}{|l|} 
Pesos \\
Peso Ret.
\end{tabular}} & \multicolumn{3}{|c|}{ Porcentajes } \\
\hline & & \% Peso Ret. & $\%$ Ret. Ac. & $\%$ Pasa Ac. \\
\hline 300 & 0 & 0,00 & 0,00 & 100,00 \\
\hline 212 & 0 & 0,00 & 0,00 & 100,00 \\
\hline 100 & 0 & 0,00 & 0,00 & 100,00 \\
\hline 75 & 0 & 0,00 & 0,00 & 100,00 \\
\hline 63 & 0 & 0,00 & 0,00 & 100,00 \\
\hline 50 & 0 & 0,00 & 0,00 & 100,00 \\
\hline 38 & 20 & 21,05 & 21,05 & 78,95 \\
\hline & 75 & 78,95 & 100,00 & 0,00 \\
\hline TOTALES: & 95,0 & 100,0 & & \\
\hline
\end{tabular}

$\mathrm{P} 80=38$ micras

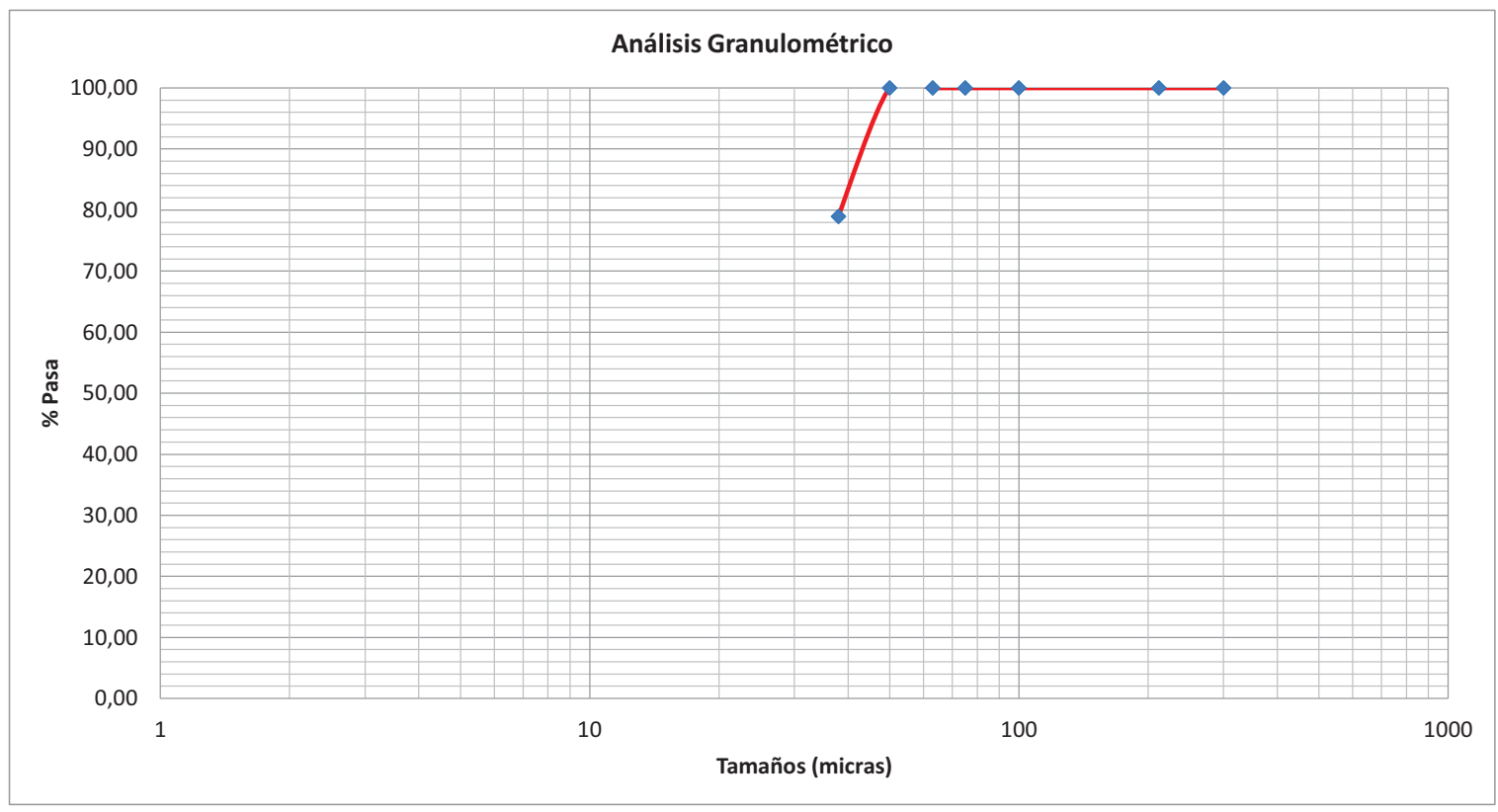




\section{SELECCIÓN DE FLOCULANTE}

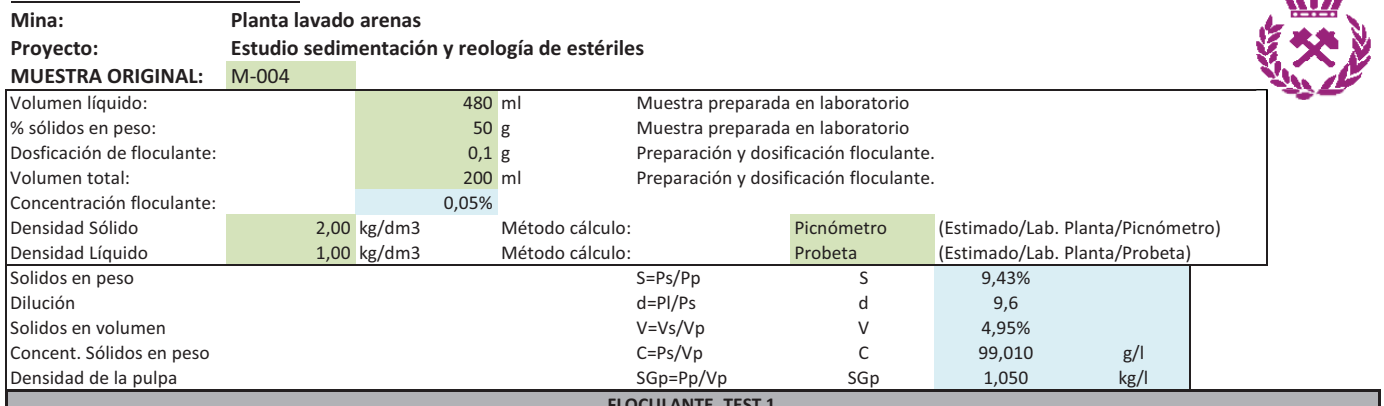

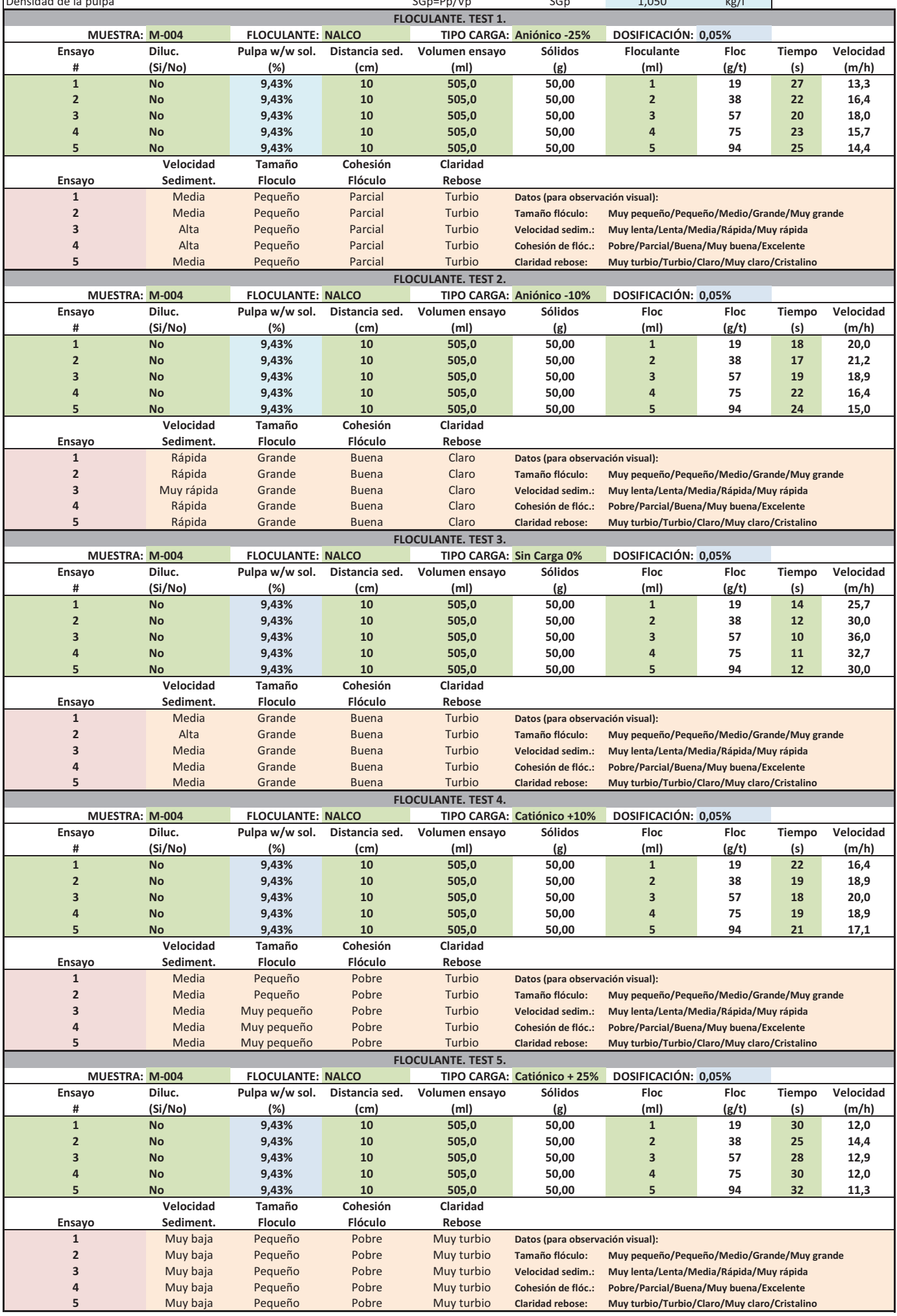


SELECCIÓN DE FLOCULANTE. ANÁLISIS DE DATOS.

Mina:

Proyecto:

MUESTRA ORIGINAL:

Volumen líquido:

$\%$ sólidos en peso:

Dosficación de floculante:

Volumen total:

Concentración floculante:

Densidad Sólido

Densidad Líquido
Planta lavado arenas

Estudio sedimentación y reología de estériles

M-004

$\begin{array}{ccll}475 \mathrm{ml} & \text { Muestra preparada en laboratorio } \\ 25 \mathrm{~g} & \text { Muestra preparada en laboratorio } \\ 0,1 \mathrm{~g} & \begin{array}{l}\text { Preparación y dosificación floculante. } \\ 200 \mathrm{ml}\end{array} & \text { Preparación y dosificación floculante. } \\ 0,05 \% & & & \\ 2,00 \mathrm{~kg} / \mathrm{dm} 3 & \text { Método cálculo: } & \text { Picnómetro } & \text { (Estimado/Lab. Planta/Picnómetro) } \\ 1,00 \mathrm{~kg} / \mathrm{dm} 3 & \text { Método cálculo: } & \text { Probeta } & \text { (Estimado/Lab. Planta/Probeta) }\end{array}$

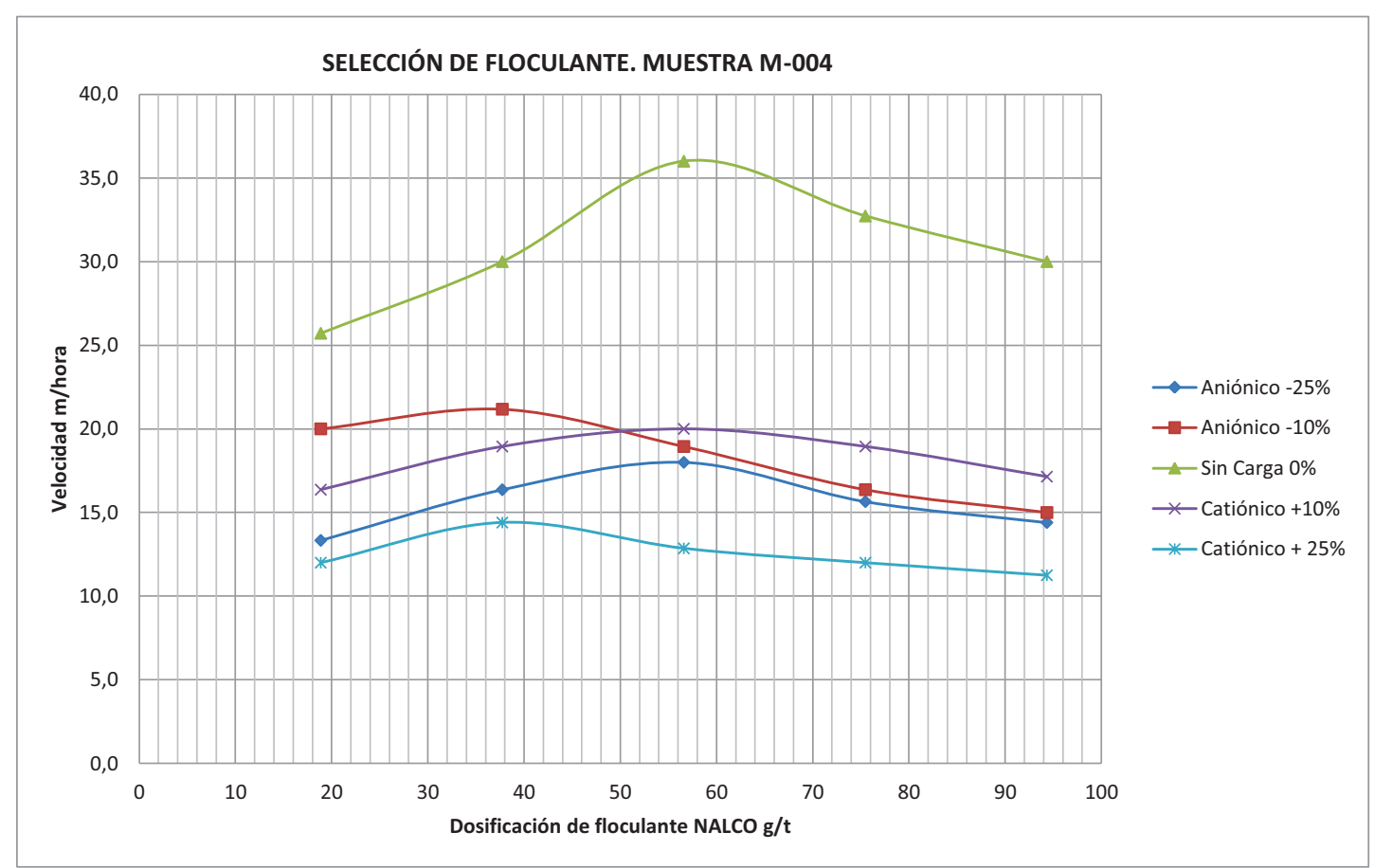

Los ensayos de sedimentación para la selección del floculante han tenido en cuenta tanto los valores de velocidad de sedimentación cómo los datos de observación visual de: tamaño de flóculo, velocidad de sedimentación, cohesión del flóculo y la claridad del rebose obtenida en la probeta de laboratorio. El floculante seleccionado será empleado en los ensayos de flujo de sedimentación. 
ENSAYO FLUJO SEDIMENTACIÓN

\begin{tabular}{l|cc|}
$\begin{array}{l}\text { Mina: } \\
\text { Proyecto: }\end{array}$ & \multicolumn{2}{c|}{$\begin{array}{l}\text { Planta lavado arenas } \\
\text { Estudio sedimentación y y reología de estériles } \\
\text { DATOS }\end{array}$} \\
$\begin{array}{l}\text { FLOCULANTE SELECCIONADO } \\
\text { Volumen probeta: }\end{array}$ & $500 \mathrm{ml}$ & Nalco O\% CARGA IÓNICA \\
\hline $\begin{array}{l}\text { Diámetro probeta: } \\
\text { Área sedimentac. }\end{array}$ & $48,6 \mathrm{~mm}$ & \\
Floc. Dosificac.: & $18,55 \mathrm{~cm} 2$ & \\
Volumen floc.: & $0,1 \mathrm{~g}$ & \\
Floculante dosific. & $200 \mathrm{ml}$ & MUESTRA SóLIDOS \\
Floc. Conc. & $0,05 \%$ & M-004 \\
Densidad Sólido & $0,50 \mathrm{~g} / \mathrm{l}$ & \\
Densidad Líquido & $2,00 \mathrm{~kg} / \mathrm{dm} 3$ & \\
\hline & $1,00 \mathrm{~kg} / \mathrm{dm} 3$ & \\
\hline
\end{tabular}

Proyecto: Estudio sedimentación y reología de estériles

ENSAYO 1: NaICO 0\% CARGA IONICA

\begin{tabular}{|c|c|c|c|c|c|c|c|c|c|c|c|}
\hline \multicolumn{12}{|c|}{ ENSAYO 1: Nalco 0\% CARGA IONICA } \\
\hline \multicolumn{2}{|c|}{ MUESTRA: M-004 } & \multirow{2}{*}{$\begin{array}{c}\text { FLOCULANTE: } \\
\text { Sólidos } \\
(\% \mathrm{w} / \mathrm{w})\end{array}$} & \multicolumn{2}{|c|}{ Nalco 0\% CARGA IÓNICA } & \multicolumn{2}{|r|}{ DOSIFICACIÓN: } & \multirow{2}{*}{$\begin{array}{c}\mathbf{0 , 5 0} \\
\text { Tiempo sed. } \\
\text { (s) }\end{array}$} & \multicolumn{4}{|l|}{$\mathrm{g} / \mathrm{l}$} \\
\hline $\begin{array}{c}\text { Peso sólidos } \\
\text { (g) }\end{array}$ & $\begin{array}{l}\text { Vol. líquido } \\
(\mathrm{ml})\end{array}$ & & $\begin{array}{c}\text { Densidad pulpa } \\
(\mathrm{kg} / \mathrm{l})\end{array}$ & $\begin{array}{c}\text { Conc. Solids } \\
\text { (g/l) }\end{array}$ & $\begin{array}{l}\text { Floculant. } \\
\text { (ml) }\end{array}$ & $\begin{array}{l}\text { Dist. Sediment. } \\
(\mathrm{cm})\end{array}$ & & $\begin{array}{l}\text { Velocidad sed. } \\
\qquad(\mathrm{m} / \mathrm{h})\end{array}$ & $\begin{array}{l}\text { Floc dosific. } \\
(\mathrm{g} / \mathrm{t})\end{array}$ & $\begin{array}{c}\text { Flujo } \\
\text { (tph/m2) }\end{array}$ & $\begin{array}{c}\text { Flujo } \\
\text { (tpd/m2) }\end{array}$ \\
\hline 80,0 & 475 & 14,41 & 1,078 & 155,34 & 2 & 10,0 & 18 & 20,0 & 13 & 8,62 & 207,00 \\
\hline 80,0 & 475 & 14,41 & 1,078 & 155,34 & 4 & 10,0 & 14 & 25,7 & 25 & 11,09 & 266,14 \\
\hline 80,0 & 475 & 14,41 & 1,078 & 155,34 & 6 & 10,0 & 12 & 30,0 & 38 & 12,94 & 310,50 \\
\hline 80,0 & 475 & 14,41 & 1,078 & 155,34 & 8 & 10,0 & 11 & 32,7 & 50 & 14,11 & 338,73 \\
\hline 80,0 & 475 & 14,41 & 1,078 & 155,34 & 10 & 10,0 & 12 & 30,0 & 63 & 12,94 & 310,50 \\
\hline \multirow[t]{2}{*}{80,0} & 475 & 14,41 & 1,078 & 155,34 & 12 & 10,0 & 14 & 25,7 & 75 & 11,09 & 266,14 \\
\hline & & & & & & & MEDIA: & 27,9 & 43,8 & 12,0 & 288,3 \\
\hline \multicolumn{12}{|c|}{ ENSAYO 2: Nalco 0\% CARGA IÓNICA } \\
\hline \multicolumn{2}{|c|}{ MUESTRA: M-004 } & FLOCULANTE: & \multicolumn{2}{|c|}{ Nalco 0\% CARGA IÓNICA } & & DOSIFICACIÓN: & 0,50 & $\mathrm{~g} / \mathrm{I}$ & & & \\
\hline $\begin{array}{c}\text { Peso sólidos } \\
\text { (g) }\end{array}$ & $\begin{array}{l}\text { Vol. líquido } \\
(\mathrm{ml})\end{array}$ & $\begin{array}{l}\text { Sólidos } \\
\text { (\% w/w) }\end{array}$ & $\begin{array}{c}\text { Densidad pulpa } \\
(\mathrm{kg} / \mathrm{l})\end{array}$ & $\begin{array}{c}\text { Conc. Solids } \\
\text { (g/l) }\end{array}$ & $\begin{array}{l}\text { Floculant. } \\
\text { (ml) }\end{array}$ & $\begin{array}{l}\text { Dist. Sediment. } \\
(\mathrm{cm})\end{array}$ & $\begin{array}{l}\text { Tiempo sed. } \\
\text { (s) }\end{array}$ & $\begin{array}{l}\text { Velocidad sed. } \\
\qquad(\mathrm{m} / \mathrm{h})\end{array}$ & $\begin{array}{l}\text { Floc dosific. } \\
(\mathrm{g} / \mathrm{t})\end{array}$ & $\begin{array}{c}\text { Flujo } \\
\text { (tph/m2) }\end{array}$ & $\begin{array}{c}\text { Flujo } \\
\text { (tpd/m2) }\end{array}$ \\
\hline 50 & 475 & 9,52 & 1,050 & 100,00 & 2 & 10,0 & 14 & 25,7 & 20 & 6,93 & 166,34 \\
\hline 50 & 475 & 9,52 & 1,050 & 100,00 & 4 & 10,0 & 12 & 30,0 & 40 & 8,09 & 194,06 \\
\hline 50 & 475 & 9,52 & 1,050 & 100,00 & 6 & 10,0 & 11 & 32,7 & 60 & 8,82 & 211,70 \\
\hline 50 & 475 & 9,52 & 1,050 & 100,00 & 8 & 10,0 & 14 & 25,7 & 80 & 6,93 & 166,34 \\
\hline 50 & 475 & 9,52 & 1,050 & 100,00 & 10 & 10,0 & 15 & 24,0 & 100 & 6,47 & 155,25 \\
\hline \multirow[t]{2}{*}{50} & 475 & 9,52 & 1,050 & 100,00 & 12 & 10,0 & 16 & 22,5 & 120 & 6,06 & 145,55 \\
\hline & & & & & & & MEDIA: & 25,7 & 70,0 & 6,9 & 166,3 \\
\hline \multicolumn{12}{|c|}{ ENSAYO 3: Nalco 0\% CARGA IÓNICA } \\
\hline \multicolumn{2}{|c|}{ MUESTRA: M-004 } & FLOCULANTE: & \multicolumn{2}{|c|}{ Nalco 0\% CARGA IÓNICA } & & DOSIFICACIÓN: & 0,50 & $\mathrm{~g} / \mathrm{l}$ & & & \\
\hline $\begin{array}{c}\text { Peso sólidos } \\
\text { (g) }\end{array}$ & $\begin{array}{l}\text { Vol. líquido } \\
\text { (ml) }\end{array}$ & $\begin{array}{l}\text { Sólidos } \\
\text { (\% w/w) }\end{array}$ & $\begin{array}{c}\text { Densidad pulpa } \\
(\mathrm{kg} / \mathrm{l})\end{array}$ & $\begin{array}{c}\text { Conc. Solids } \\
(\mathrm{g} / \mathrm{l})\end{array}$ & $\begin{array}{c}\text { Floculant. } \\
\text { (ml) }\end{array}$ & $\begin{array}{l}\text { Dist. Sediment. } \\
(\mathrm{cm})\end{array}$ & $\begin{array}{l}\text { Tiempo sed. } \\
\text { (s) }\end{array}$ & $\begin{array}{l}\text { Velocidad sed. } \\
(\mathrm{m} / \mathrm{h})\end{array}$ & $\begin{array}{l}\text { Floc dosific. } \\
(\mathrm{g} / \mathrm{t})\end{array}$ & $\begin{array}{c}\text { Flujo } \\
\text { (tph/m2) }\end{array}$ & $\begin{array}{c}\text { Flujo } \\
\text { (tpd/m2) }\end{array}$ \\
\hline 25 & 475 & 5,00 & 1,026 & 51,28 & 1 & 10,0 & 10 & 36,0 & 20 & 4,85 & 116,44 \\
\hline 25 & 475 & 5,00 & 1,026 & 51,28 & 2 & 10,0 & 11 & 32,7 & 40 & 4,41 & 105,85 \\
\hline 25 & 475 & 5,00 & 1,026 & 51,28 & 3 & 10,0 & 11 & 32,7 & 60 & 4,41 & 105,85 \\
\hline 25 & 475 & 5,00 & 1,026 & 51,28 & 4 & 10,0 & 10 & 36,0 & 80 & 4,85 & 116,44 \\
\hline 25 & 475 & 5,00 & 1,026 & 51,28 & 5 & 10,0 & 11 & 32,7 & 100 & 4,41 & 105,85 \\
\hline \multirow[t]{2}{*}{25} & 475 & 5,00 & 1,026 & 51,28 & 6 & 10,0 & 11 & 32,7 & 120 & 4,41 & 105,85 \\
\hline & & & & & & & MEDIA: & 32,7 & 70,0 & 4,4 & 105,9 \\
\hline \multicolumn{12}{|c|}{ ENSAYO 4: Nalco 0\% CARGA IÓNICA } \\
\hline \multicolumn{2}{|c|}{ MUESTRA: M-004 } & FLOCULANTE: & \multicolumn{2}{|c|}{ Nalco 0\% CARGA IÓNICA } & & DOSIFICACIÓN: & 0,50 & $\mathrm{~g} / \mathrm{l}$ & & & \\
\hline $\begin{array}{c}\text { Peso sólidos } \\
\text { (g) }\end{array}$ & $\begin{array}{c}\text { Vol. líquido } \\
\text { (ml) }\end{array}$ & $\begin{array}{c}\text { Sólidos } \\
\text { (\% w/w) }\end{array}$ & $\begin{array}{c}\text { Densidad pulpa } \\
(\mathrm{kg} / \mathrm{l})\end{array}$ & $\begin{array}{c}\text { Conc. Solids } \\
(\mathrm{g} / \mathrm{l})\end{array}$ & $\begin{array}{c}\text { Floculant. } \\
(\mathrm{ml})\end{array}$ & $\begin{array}{l}\text { Dist. Sediment. } \\
(\mathrm{cm})\end{array}$ & $\begin{array}{c}\text { Tiempo sed. } \\
\text { (s) }\end{array}$ & $\begin{array}{l}\text { Velocidad sed. } \\
(\mathrm{m} / \mathrm{h})\end{array}$ & $\begin{array}{l}\text { Floc dosific. } \\
(\mathrm{g} / \mathrm{t})\end{array}$ & $\begin{array}{c}\text { Flujo } \\
\text { (tph/m2) }\end{array}$ & $\begin{array}{c}\text { Flujo } \\
\text { (tpd//m2) }\end{array}$ \\
\hline 12 & 475 & 2,46 & 1,012 & 24,95 & 1 & 10,0 & 10 & 36,0 & 42 & 2,33 & 55,890 \\
\hline 12 & 475 & 2,46 & 1,012 & 24,95 & 1,5 & 10,0 & 9 & 40,0 & 63 & 2,59 & 62,100 \\
\hline 12 & 475 & 2,46 & 1,012 & 24,95 & 2 & 10,0 & 11 & 32,7 & 83 & 2,12 & 50,809 \\
\hline 12 & 475 & 2,46 & 1,012 & 24,95 & 2,5 & 10,0 & 12 & 30,0 & 104 & 1,94 & 46,575 \\
\hline 12 & 475 & 2,46 & 1,012 & 24,95 & 3 & 10,0 & 13 & 27,7 & 125 & 1,79 & 42,992 \\
\hline \multirow[t]{2}{*}{12} & 475 & 2,46 & 1,012 & 24,95 & 3,5 & 10,0 & 15 & 24,0 & 146 & 1,55 & 37,260 \\
\hline & & & & & & & MEDIA: & 31,4 & 93,8 & 2,0 & 48,7 \\
\hline
\end{tabular}


ENSAYO FLUJO SEDIMENTACIÓN. ANÁLISIS DE RESULTADOS.

Mina:

Proyecto:

DATOS

Volumen probeta:

Diámetro probeta:

Área sedimentac.

Floc. Dosificac.:

Volumen floc.:

Floculante dosific

Floc. Conc.

Densidad Sólido

Densidad Líquido
Planta lavado arenas

Estudio sedimentación y reología de estériles

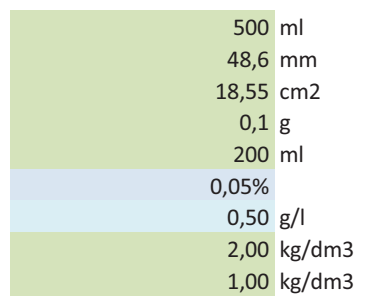

FLOCULANTE SELECCIONADO

Nalco 0\% CARGA IÓNICA
MUESTRA SÓLIDOS

M-004
Diámetros de probetas:

$250 \mathrm{ml} \quad 35,7 \quad \mathrm{~mm}$

$500 \mathrm{ml} \quad 48,6 \quad \mathrm{~mm}$

$2000 \mathrm{ml} \quad 78,2 \quad \mathrm{~mm}$
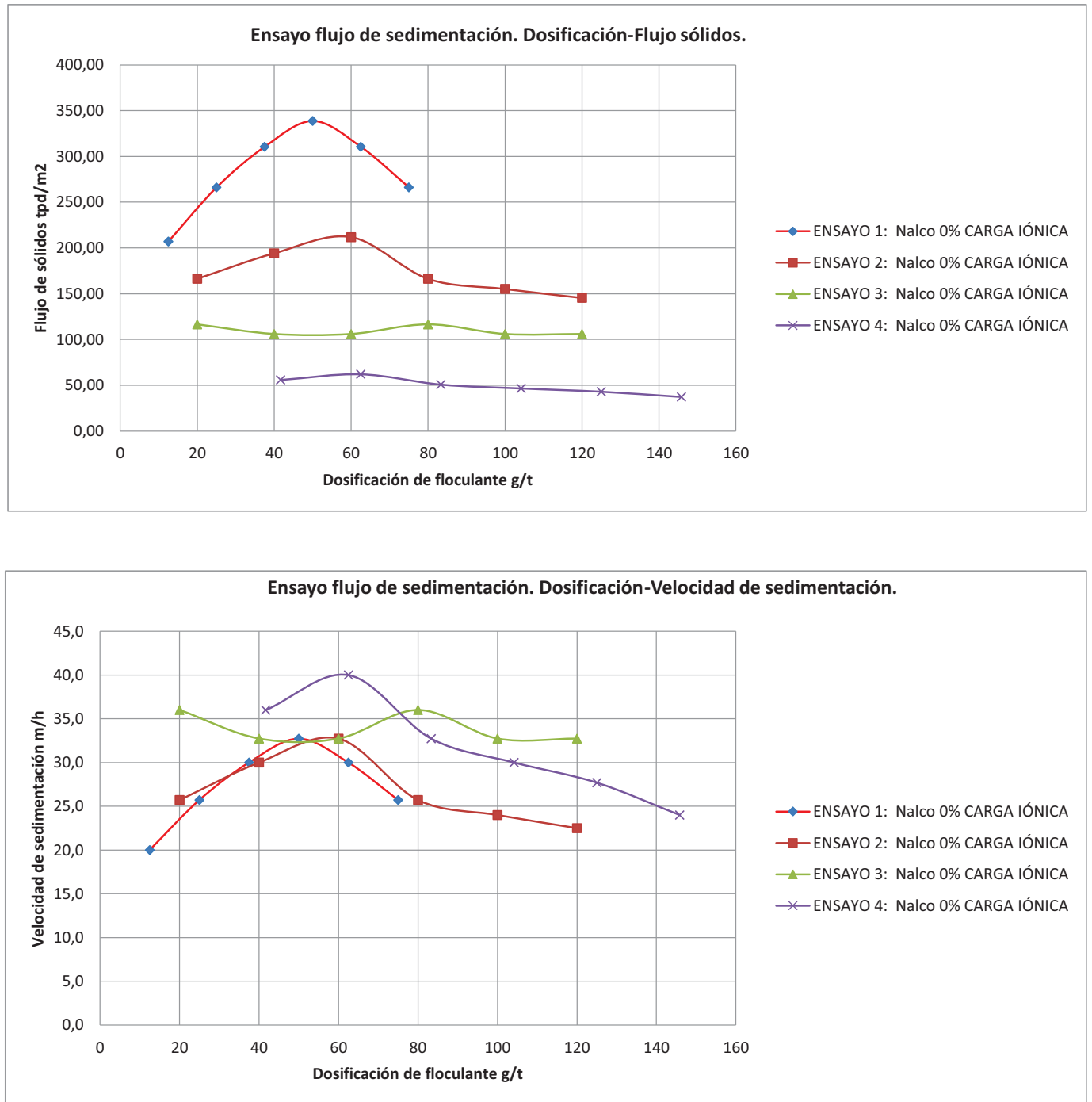

Los ensayos de flujos de sedimentación determinan la dilución óptima de los sólidos para la alimentación en el espesador.

El valor obtenido sirve de base para el diseño de la campana de alimentación y el sistema de dilución previsto. 
ENSAYO SEDIMENTACIÓN PROBETA 2000mI ESTÁTICO

$\begin{array}{ll}\text { Mina: } & \text { Planta lavado arenas } \\ \text { Proyecto: } & \text { Estudio sedimentación y reología de estériles } \\ \text { Muestra: } & \text { M-004 }\end{array}$

Muestra:

M-004

\begin{tabular}{|c|c|c|c|c|c|c|}
\hline Volumen líquido: & $1800 \mathrm{ml}$ & Solidos en peso & $\mathrm{S}=\mathrm{Ps} / \mathrm{Pp}$ & $\mathrm{s}$ & $13,25 \%$ & \\
\hline Peso sólidos: & $275 \mathrm{~g}$ & Dilución & $d=P l / P s$ & d & 6,545 & \\
\hline Floculante dosificac. & $0,1 \mathrm{~g}$ & Solidos en volumen & $V=V s / V p$ & V & $7,10 \%$ & \\
\hline Volume total: & $200 \mathrm{ml}$ & Concent. Sólidos en peso & $\mathrm{C}=\mathrm{Ps} / \mathrm{Vp}$ & c & 141,94 & $g / l$ \\
\hline Floc. Conc. & $0,50 \mathrm{~g} / \mathrm{l}$ & Densidad de la pulpa & $S G p=P p / V p$ & SGp & 1,071 & $\mathrm{~kg} / \mathrm{l}$ \\
\hline Floculante & $5,00 \mathrm{ml}$ & & & & & \\
\hline Solids SG & $2,00 \mathrm{~kg} / \mathrm{dm} 3$ & & & & & \\
\hline Liquid SG & $1,00 \mathrm{~kg} / \mathrm{dm} 3$ & & & & & \\
\hline Diámetro probeta & $78,2 \mathrm{~mm}$ & & & & & \\
\hline Area probeta & $0,0048029 \mathrm{~m} 2$ & $48,029 \mathrm{~cm} 2$ & & & & \\
\hline Densidad pulpa: & $1,071 \mathrm{~kg} / \mathrm{l}$ & & & & & \\
\hline Sólidos en peso: & 141,94 g solids/l & & & & & \\
\hline Sólidos en peso: & $0,1419 \mathrm{~g}$ solids $/ \mathrm{ml}$ & & & & & \\
\hline |Floculante: & NALCO & & & & & \\
\hline Tipo de carga floc.: & 0\% CARGA & & & & & \\
\hline Dosificación floc.: & gramos/ton & lada sólido & & & & \\
\hline
\end{tabular}

\section{DATOS DE SEDIMENTACIÓN}

\begin{tabular}{|c|c|c|c|c|c|c|c|c|c|}
\hline $\begin{array}{l}\text { Tiempo info } \\
\text { (sec) }\end{array}$ & $\begin{array}{c}\text { Tiempo } \\
\text { (min) }\end{array}$ & $\begin{array}{l}\text { Vol. Lodos } \\
\text { (ml) }\end{array}$ & $\begin{array}{l}\text { Altura interf. } \\
(\mathrm{cm})\end{array}$ & $\begin{array}{c}\text { Velocidad } \\
\text { (m/hr) }\end{array}$ & $\begin{array}{l}\text { SG. Lodos } \\
(\mathrm{g} / \mathrm{cm} 3)\end{array}$ & $\begin{array}{c}\text { Lodos } \\
\% \text { Sol. Peso }\end{array}$ & $\begin{array}{c}\text { Flujo } \\
\text { (tph/m2) }\end{array}$ & $\begin{array}{c}\text { Flujo } \\
\text { (tpd/m2) }\end{array}$ & $\begin{array}{l}\text { Área Unit. Espes. } \\
\text { (m2/tpd) }\end{array}$ \\
\hline 0 & 0 & 1969 & 41,00 & 0 & 1,070 & 13,05 & 0 & 0 & 0 \\
\hline 5 & 0,08 & 1417 & 29,50 & 82,800 & 1,097 & 17,69 & 41,2253 & 989,41 & 0,001 \\
\hline 10 & 0,17 & 1129 & 23,50 & 43,200 & 1,122 & 21,72 & 41,2249 & 989,40 & 0,001 \\
\hline 15 & 0,25 & 913 & 19,00 & 32,400 & 1,151 & 26,19 & 41,2251 & 989,40 & 0,001 \\
\hline 30 & 0,50 & 816 & 17,00 & 4,800 & 1,168 & 28,83 & 13,7417 & 329,80 & 0,003 \\
\hline 45 & 0,75 & 696 & 14,50 & 6,000 & 1,197 & 32,98 & 13,7417 & 329,80 & 0,003 \\
\hline 60 & 1,00 & 605 & 12,60 & 4,560 & 1,227 & 37,03 & 13,7417 & 329,80 & 0,003 \\
\hline 120 & 2,00 & 552 & 11,50 & 0,660 & 1,249 & 39,86 & 3,4354 & 82,45 & 0,012 \\
\hline 180 & 3,00 & 490 & 10,20 & 0,780 & 1,281 & 43,83 & 3,4354 & 82,45 & 0,012 \\
\hline 240 & 4,00 & 461 & 9,60 & 0,360 & 1,298 & 45,94 & 3,4354 & 82,45 & 0,012 \\
\hline 300 & 5,00 & 432 & 9,00 & 0,360 & 1,318 & 48,27 & 3,4354 & 82,45 & 0,012 \\
\hline 450 & 7,50 & 427 & 8,90 & 0,024 & 1,322 & 48,68 & 1,3742 & 32,98 & 0,030 \\
\hline 600 & 10,00 & 423 & 8,80 & 0,024 & 1,325 & 49,09 & 1,3742 & 32,98 & 0,030 \\
\hline 900 & 15,00 & 423 & 8,80 & 0,000 & 1,325 & 49,09 & 0,6871 & 16,49 & 0,061 \\
\hline 1200 & 20,00 & 423 & 8,80 & 0,000 & 1,325 & 49,09 & 0,6871 & 16,49 & 0,061 \\
\hline 1500 & 25,00 & 423 & 8,80 & 0,000 & 1,325 & 49,09 & 0,6871 & 16,49 & 0,061 \\
\hline 1800 & 30,00 & 423 & 8,80 & 0,000 & 1,325 & 49,09 & 0,6871 & 16,49 & 0,061 \\
\hline 3600 & 60,00 & 423 & 8,80 & 0,000 & 1,325 & 49,09 & 0,1145 & 2,75 & 0,364 \\
\hline 5400 & 90,00 & 423 & 8,80 & 0,000 & 1,325 & 49,09 & 0,1145 & 2,75 & 0,364 \\
\hline 7200 & 120,00 & 423 & 8,80 & 0,000 & 1,325 & 49,09 & 0,1145 & 2,75 & 0,364 \\
\hline 9000 & 150,00 & 423 & 8,80 & 0,000 & 1,325 & 49,09 & 0,1145 & 2,75 & 0,364 \\
\hline 10800 & 180,00 & 423 & 8,80 & 0,000 & 1,325 & 49,09 & 0,1145 & 2,75 & 0,364 \\
\hline 14400 & 240,00 & 423 & 8,80 & 0,000 & 1,325 & 49,09 & 0,0573 & 1,37 & 0,728 \\
\hline
\end{tabular}

DATOS OBTENIDOS:

1a Caída de velocidad: 1.5 minuto

2a Caída de velocidad, comienzo régimen de compresión: 5 minutos

$\%$ sólidos - tiempo: 49 \% sólidos en peso - $10 \mathrm{~min}$. tiempo residencia 
ENSAYO SEDIMENTACIÓN PROBETA 2000mI ESTÁTICO. ANÁLISIS DE RESULTADOS.

Mina:

Proyecto:

Muestra
Planta lavado arenas

Estudio sedimentación y reología de estériles

M-004
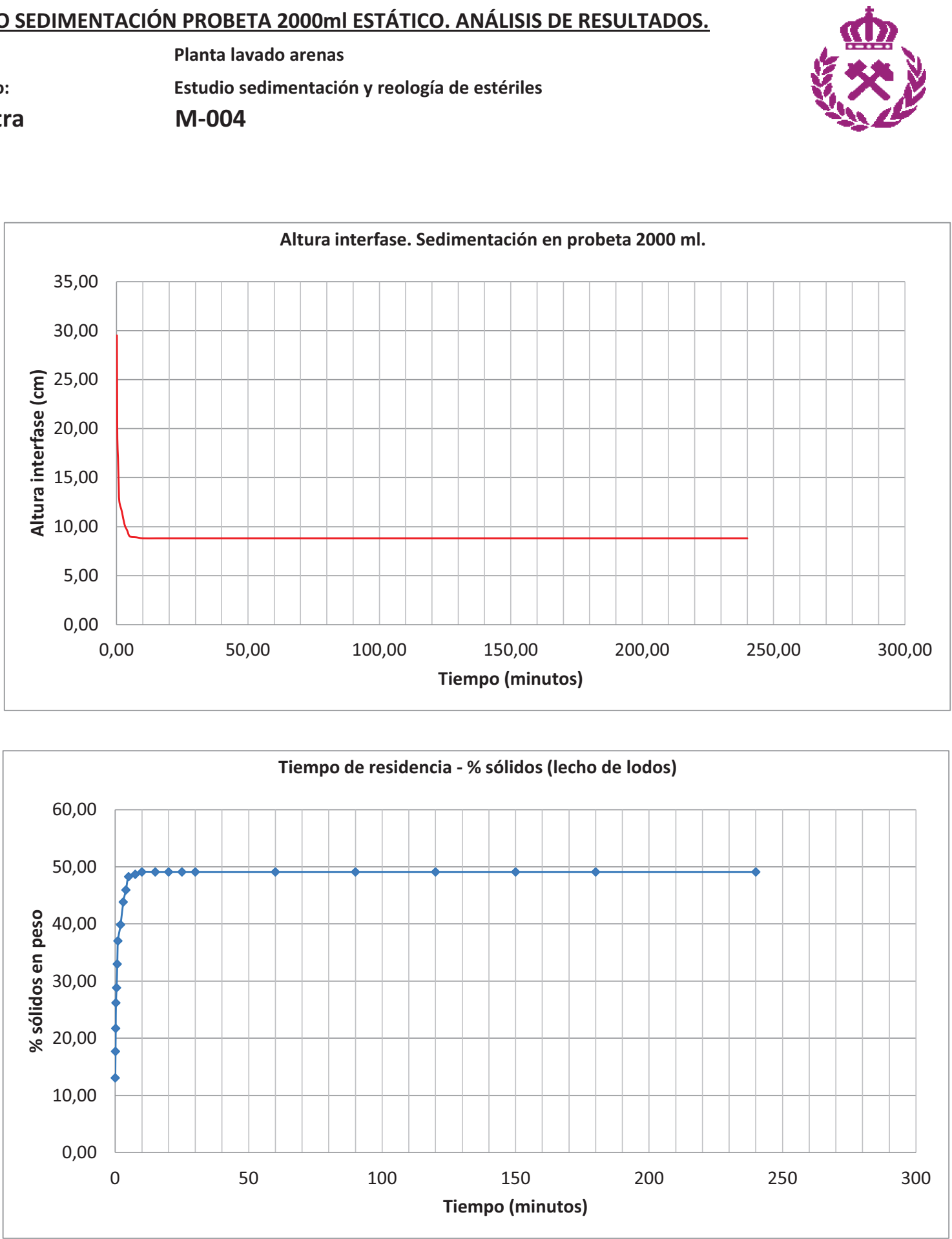


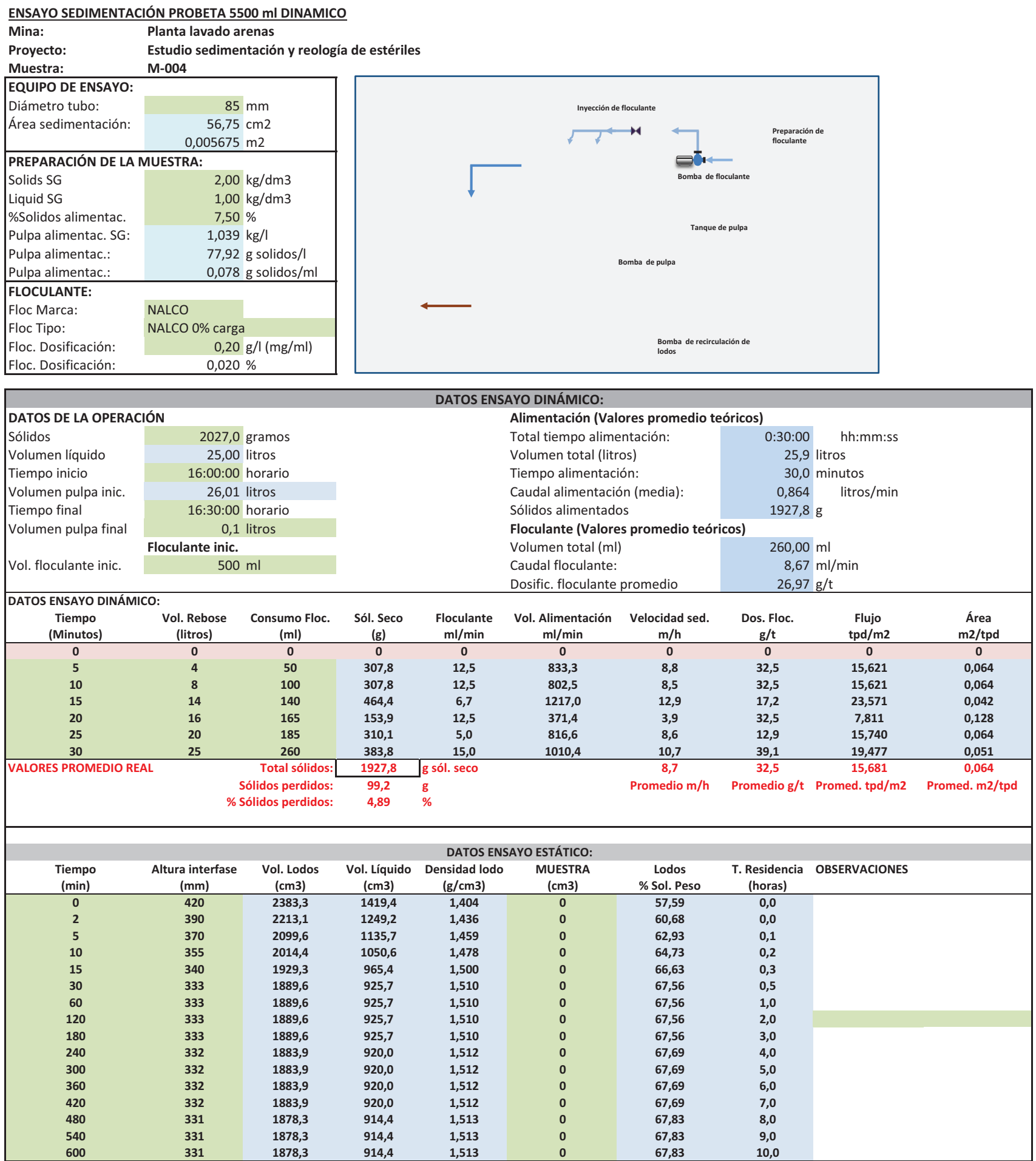


ENSAYO SEDIMENTACIÓN PROBETA 5500 mI DINAMICO

Mina: Planta lavado arenas

Proyecto: $\quad$ Estudio sedimentación y reología de estériles

Muestra: M-004

DATOS DE OPERACIÓN DEL ESPESADOR DE TUBO PROFUNDO

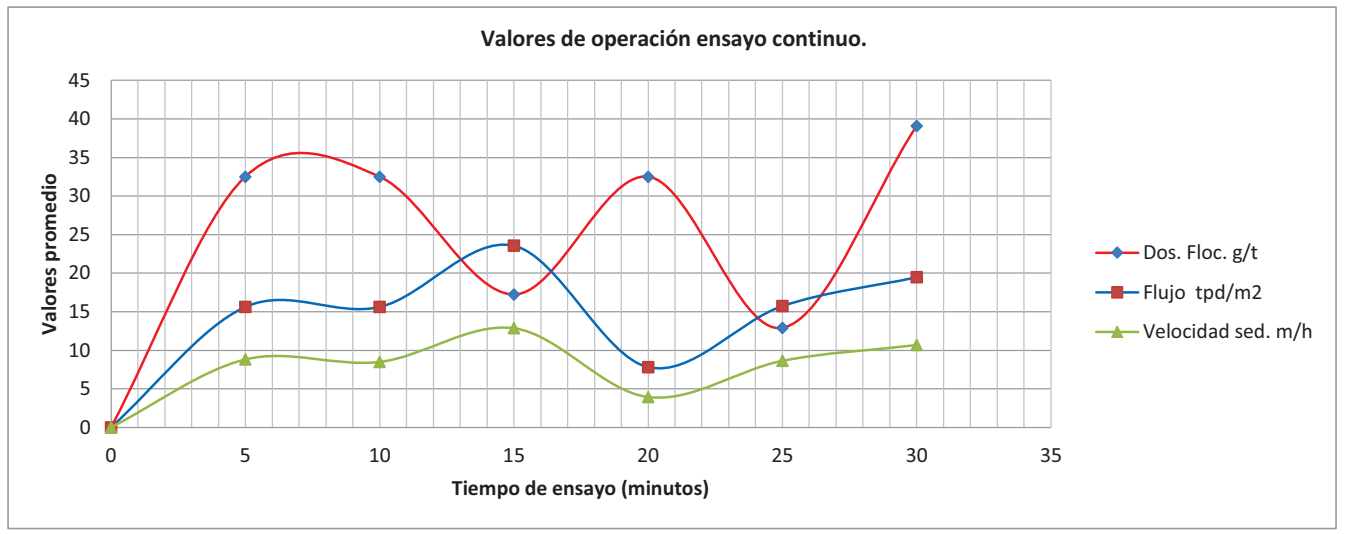

Datos Promedio:

Velocidad de sedimentación:

$8,7 \mathrm{~m} / \mathrm{h}$

Dosificación de floculante:

32,5

Flujo de sedimentación:

$0,0638 \mathrm{~m}^{2} / \mathrm{t} / \mathrm{dí} a$

Flujo de sedimentación:

$15,7 \mathrm{t} / \mathrm{dí} / \mathrm{m}^{2}$

ENSAYO SEDIMENTACIÓN PROBETA $5500 \mathrm{mI}$ DINAMICO
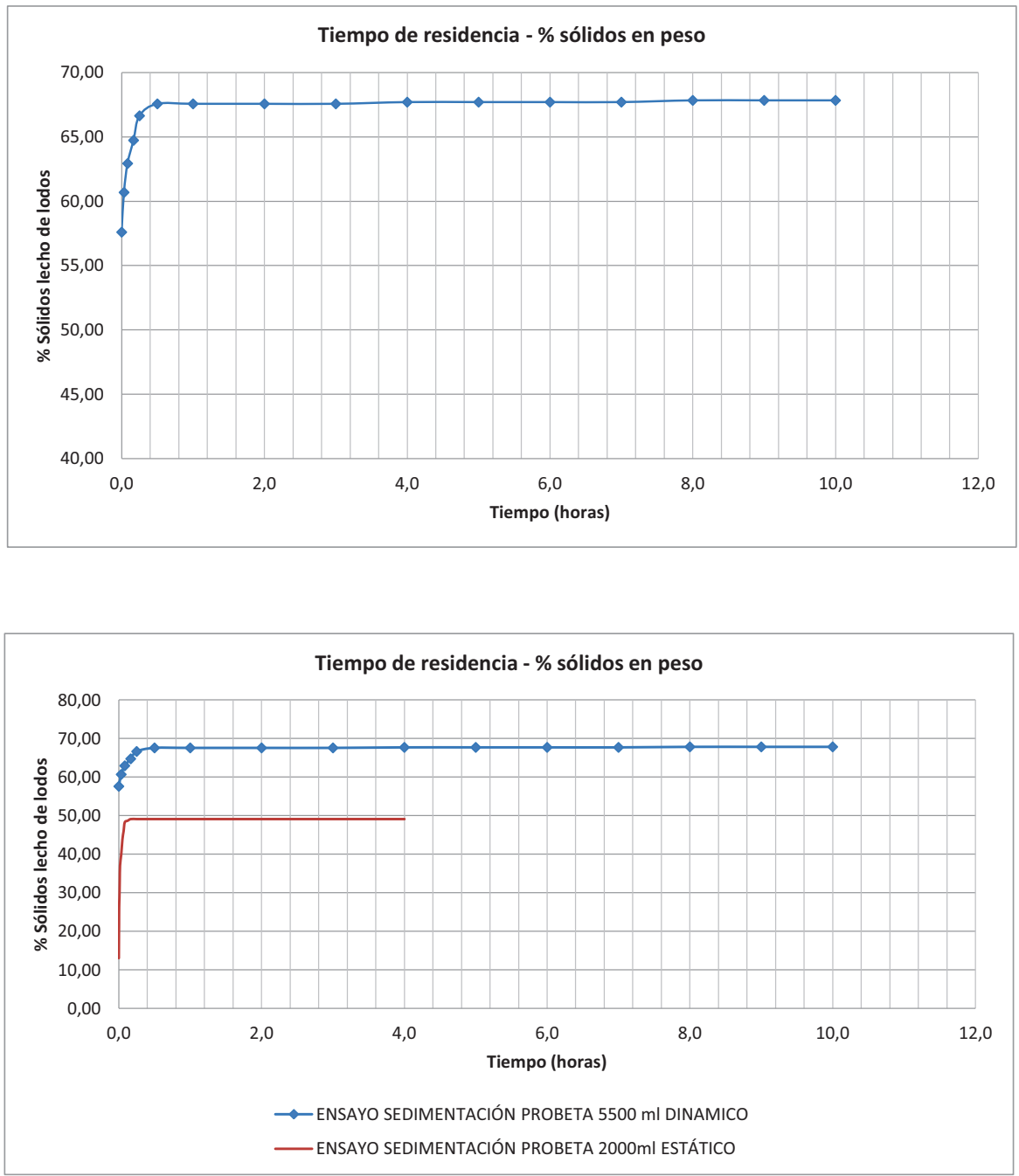
ENSAYO FILTRACIÓN A VACIO

Mina: Planta lavado arenas

Proyecto: Estudio sedimentación y reología de estériles

Material:

Arcillas

Muestra:

M-004

Preparado por: José A. Butragueño

pH muestra: $\quad 7$

Fecha: $\quad 08 / 08 / 2013$

\begin{tabular}{|c|c|c|}
\hline \multicolumn{3}{|c|}{ DATOS DE LA MUESTRA: } \\
\hline Solidos SG & & $2,00 \mathrm{~kg} / \mathrm{dm} 3$ \\
\hline Liquido SG & & $1,00 \mathrm{~kg} / \mathrm{dm} 3$ \\
\hline \multicolumn{3}{|l|}{ FLOCULANTE: } \\
\hline Floc Name: & No & \\
\hline Tipo de floculante: & No & \\
\hline Floc. Dosificación: & & $0,00 \mathrm{~g} / \mathrm{l}(\mathrm{mg} / \mathrm{ml})$ \\
\hline Floc. Dosificación: & & $0,000 \%$ \\
\hline
\end{tabular}
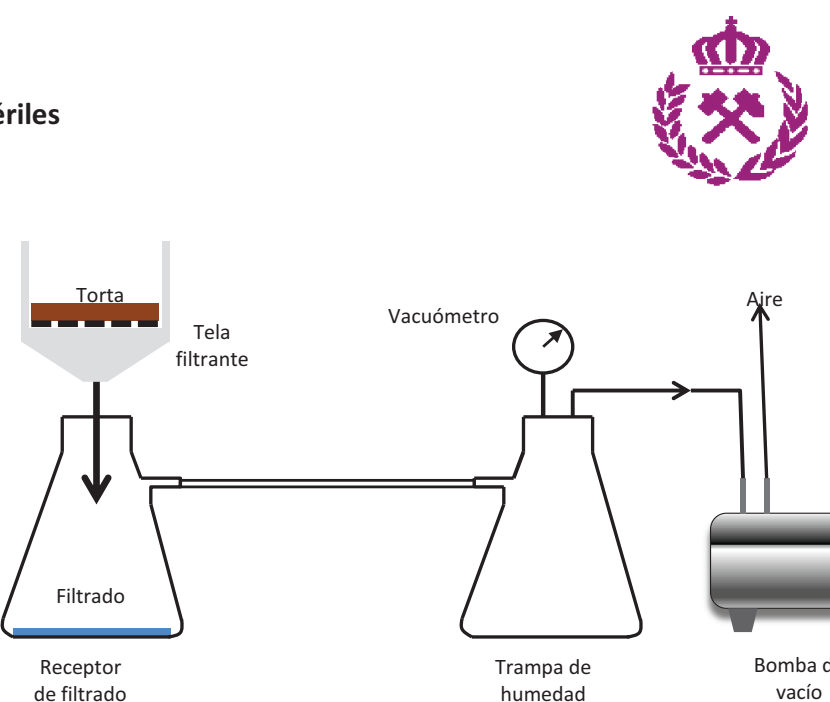

Floc. Dosificación: $0,000 \%$

\begin{tabular}{|c|c|c|c|c|c|c|c|c|c|}
\hline \multicolumn{10}{|c|}{ ENSAYO FILTRACIÓN A VACÍO. TEST 1.} \\
\hline \multicolumn{2}{|c|}{ MUESTRA: M-004 } & & \multicolumn{7}{|c|}{ Tiempos de ensayo de filtración } \\
\hline $\begin{array}{l}\text { Vacío } \\
\text { (bar) }\end{array}$ & Peso sólidos & $\begin{array}{l}\text { Vol. Líquido } \\
\text { (ml) }\end{array}$ & $\begin{array}{l}\text { \% Sól. Peso } \\
\text { (\%) }\end{array}$ & $\begin{array}{l}\text { Vol. Pulpa } \\
\text { (ml) }\end{array}$ & $\begin{array}{l}\text { Formación torta } \\
\text { (s) }\end{array}$ & $\begin{array}{c}\text { Secado torta } \\
\text { (s) }\end{array}$ & $\begin{array}{c}\text { Total ciclo } \\
\text { (s) }\end{array}$ & $\begin{array}{l}\text { Líq. Filtrado } \\
(\mathrm{ml})\end{array}$ & $\begin{array}{c}\text { Espesor } \\
(\mathrm{mm})\end{array}$ \\
\hline$-0,6$ & 50 & 250,0 & 16,7 & 275,0 & 90 & 20 & 110 & 230 & 4,0 \\
\hline \% Solidos estimado: & 71,4 & & & & & & & & \\
\hline Peso muestra húmedo: & 70 & $\mathrm{~g}$ & \multirow{4}{*}{\multicolumn{2}{|c|}{ Observaciones: }} & & & & & \\
\hline Secac & de la muestra & & & & & & & & \\
\hline Peso muestra seco & 48 & $\mathrm{~g}$ & & & & & & & \\
\hline$\%$ humedad torta & 31,43 & $\%$ & & & & & & & \\
\hline
\end{tabular}

\begin{tabular}{|c|c|c|c|c|c|c|c|c|c|}
\hline \multicolumn{10}{|c|}{ ENSAYO FILTRACIÓN A VACÍO. TEST 2.} \\
\hline \multicolumn{2}{|c|}{ MUESTRA: M-004 } & & \multicolumn{7}{|c|}{ Tiempos de ensayo de filtración } \\
\hline $\begin{array}{l}\text { Vacío } \\
\text { (bar) }\end{array}$ & $\begin{array}{l}\text { Peso sólidos } \\
\text { (g) }\end{array}$ & $\begin{array}{l}\text { Vol. Líquido } \\
\text { (ml) }\end{array}$ & $\begin{array}{c}\text { \% Sól. Peso } \\
\text { (\%) }\end{array}$ & $\begin{array}{l}\text { Vol. Pulpa } \\
\text { (ml) }\end{array}$ & $\begin{array}{l}\text { Formación torta } \\
\text { (s) }\end{array}$ & $\begin{array}{c}\text { Secado torta } \\
\text { (s) }\end{array}$ & $\begin{array}{l}\text { Total ciclo } \\
\text { (s) }\end{array}$ & $\begin{array}{l}\text { Líq. Filtrado } \\
\text { (ml) }\end{array}$ & $\begin{array}{c}\text { Espesor } \\
(\mathrm{mm})\end{array}$ \\
\hline$-0,6$ & 50 & 250,0 & 16,7 & 275,0 & 60 & 20 & 80 & 225 & 4,0 \\
\hline \% Solidos estimado: & 66,7 & & & & & & & & \\
\hline Peso muestra húmedo: & 69 & $\mathrm{~g}$ & \multirow{4}{*}{\multicolumn{2}{|c|}{ |Observaciones: }} & & & & & \\
\hline Secad & o de la muestr & & & & & & & & \\
\hline Peso muestra seco & 45 & $\mathrm{~g}$ & & & & & & & \\
\hline$\%$ humedad torta & 34,78 & $7 \%$ & & & & & & & \\
\hline
\end{tabular}

\begin{tabular}{|c|c|c|c|c|c|c|c|c|c|}
\hline \multicolumn{10}{|c|}{ ENSAYO FILTRACIÓN A VACÍO. TEST 3.} \\
\hline \multicolumn{2}{|c|}{ MUESTRA: M-004 } & \multirow[b]{2}{*}{$\begin{array}{l}\text { Vol. Líquido } \\
\text { (ml) }\end{array}$} & \multicolumn{7}{|c|}{ Tiempos de ensayo de filtración } \\
\hline $\begin{array}{l}\text { Vacío } \\
\text { (bar) }\end{array}$ & $\begin{array}{l}\text { Peso sólidos } \\
\text { (g) }\end{array}$ & & $\begin{array}{l}\text { \% Sól. Peso } \\
\text { (\%) }\end{array}$ & $\begin{array}{l}\text { Vol. Pulpa } \\
\text { (ml) }\end{array}$ & $\begin{array}{l}\text { Formación torta } \\
\text { (s) }\end{array}$ & $\begin{array}{l}\text { Secado torta } \\
\text { (s) }\end{array}$ & $\begin{array}{l}\text { Total ciclo } \\
\text { (s) }\end{array}$ & $\begin{array}{l}\text { Líq. Filtrado } \\
\text { (ml) }\end{array}$ & $\begin{array}{c}\text { Espesor } \\
(\mathrm{mm})\end{array}$ \\
\hline$-0,6$ & 40 & 300,0 & 11,8 & 320,0 & 60 & 20 & 80 & 280 & 2,5 \\
\hline \% Solidos estimado: & 66,7 & & & & & & & & \\
\hline Peso muestra húmedo: & 56 & $\mathrm{~g}$ & \multirow{4}{*}{\multicolumn{7}{|c|}{$\begin{array}{l}\text { Observaciones: } \\
\text { Contenido en sólidos de la torta filtrada: } 100-21,71=78,29 \%\end{array}$}} \\
\hline \multicolumn{3}{|c|}{ Secado de la muestra: } & & & & & & & \\
\hline Peso muestra seco & 39 & $\mathrm{~g}$ & & & & & & & \\
\hline$\%$ humedad torta & 30,36 & $7 \%$ & & & & & & & \\
\hline
\end{tabular}

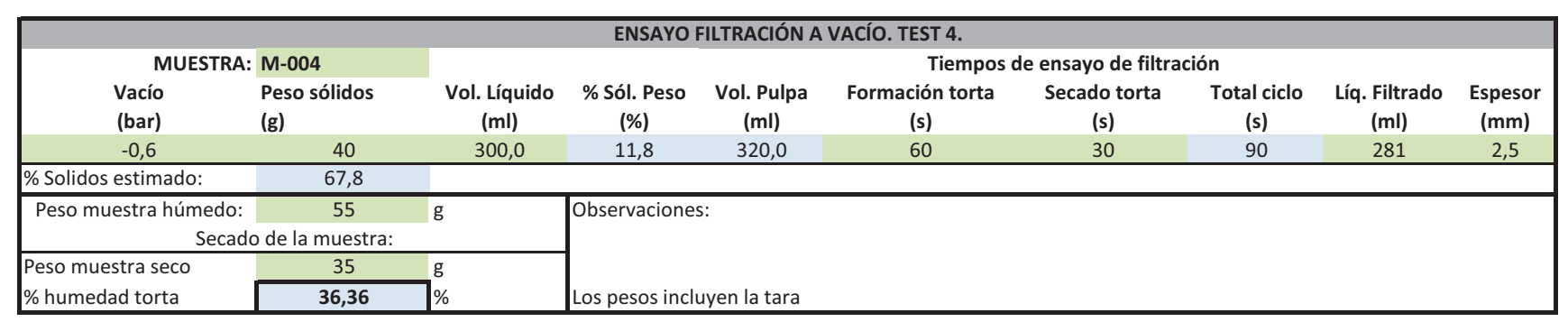

Humedad torta

$\%$ sólidos en peso
33,1 \% (Promedio)

66,9 \% (Promedio) 


\section{ENSAYO ASENTAMIENTO EN PROBETA}

\begin{tabular}{|ll|}
\hline Mina: & Planta lavado arenas \\
Proyecto: & Estudio sedimentación y reología de estériles \\
\cline { 2 - 2 } Material: & Arcillas \\
Preparado por: & José A. Butragueño \\
pH muestra: & 7 \\
Fecha: & $08 / 08 / 2013$ \\
\hline
\end{tabular}

\begin{tabular}{lr} 
Aceleración gravedad (g): & $9,81 \mathrm{~m} / \mathrm{s} 2$ \\
\hline Diámetro probeta: & $44 \mathrm{~mm}$ \\
\hline Altura probeta (H): & $100 \mathrm{~mm}$ \\
Volumen probeta: & $152,1 \mathrm{~cm} 3$ \\
Solidos SG & $2,00 \mathrm{~kg} / \mathrm{dm}$ \\
Líquido SG & $1,00 \mathrm{~kg} / \mathrm{dm}$
\end{tabular}

Líquido SG

$1,00 \mathrm{~kg} / \mathrm{dm} 3$

Expresiones empíricas

$\mathrm{T}=0.5-0.5(\mathrm{~h} / \mathrm{H})^{\wedge} 0.5$

T.F. $=\mathrm{T}^{*} \mathrm{~d}^{*} \mathrm{~g}^{*}(\mathrm{H} / 100)$

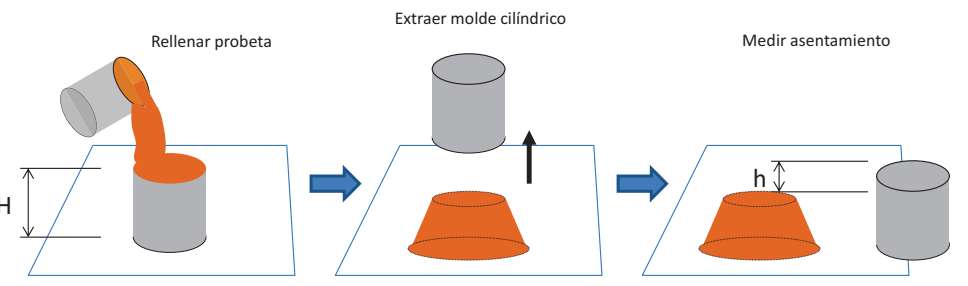

\begin{tabular}{|c|c|c|c|c|c|c|c|c|c|c|}
\hline \multicolumn{11}{|c|}{ ENSAYOS DE ASENTAMIENTO EN PROBETA } \\
\hline $\begin{array}{l}\text { Muestra } \\
\text { ID }\end{array}$ & $\begin{array}{c}\text { Cont. Sólidos } \\
\text { (\%) }\end{array}$ & $\begin{array}{l}\text { Solidos SG } \\
\mathrm{g} / \mathrm{cm} 3\end{array}$ & $\begin{array}{c}\text { Peso Liq. } \\
\text { (kg liq/kg sol) }\end{array}$ & $\begin{array}{l}\text { Vol. Pulpa } \\
\text { (I/kg sol) }\end{array}$ & $\begin{array}{c}\text { Pulpa SG (d) } \\
\text { kg/dm3 }\end{array}$ & $\begin{array}{c}\text { Sólidos prob. } \\
\text { (g) }\end{array}$ & $\begin{array}{l}\text { Liq. Probeta } \\
\text { (g) }\end{array}$ & $\begin{array}{c}\text { Asentamiento }(\mathrm{h}) \\
\mathrm{mm}\end{array}$ & $\begin{array}{l}\text { Factor "T" } \\
\text { Adimens. }\end{array}$ & $\begin{array}{c}\text { Tensión Fluencia } \\
\text { (Pa) }\end{array}$ \\
\hline 1 & 62 & 2,00 & 0,613 & 1,113 & 1,449 & 136,6 & 83,7 & 50 & 0,14645 & 208,2 \\
\hline 2 & 60 & 2,00 & 0,667 & 1,167 & 1,429 & 130,3 & 86,9 & 72 & 0,07574 & 106,1 \\
\hline 3 & 55 & 2,00 & 0,818 & 1,318 & 1,379 & 115,4 & 94,4 & 89 & 0,02830 & 38,3 \\
\hline 4 & 50 & 2,00 & 1,000 & 1,500 & 1,333 & 101,4 & 101,4 & 95 & 0,01266 & 16,6 \\
\hline 5 & 45 & 2,65 & 1,222 & 1,600 & 1,389 & 95,1 & 116,2 & 96 & 0,01010 & 13,8 \\
\hline 6 & 40 & 2,65 & 1,500 & 1,877 & 1,332 & 81,0 & 121,5 & 96 & 0,01010 & 13,2 \\
\hline
\end{tabular}

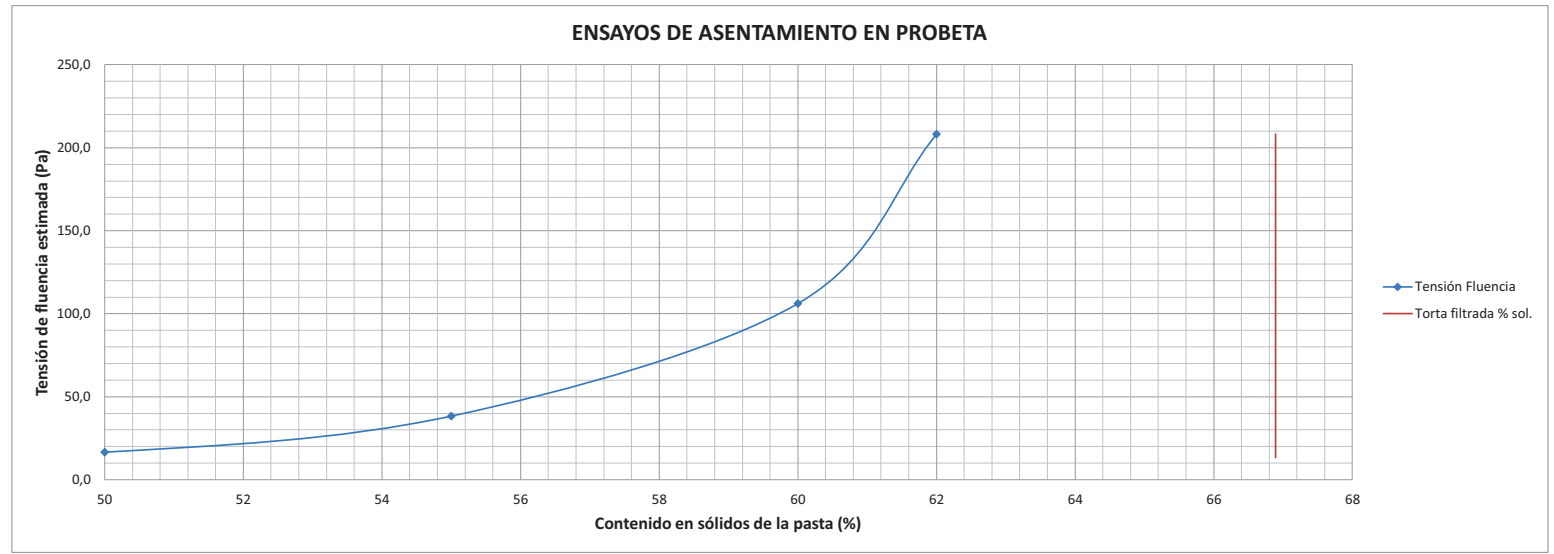

Página 12 de 12 


\section{SEDIMENTACIÓN Y REOLOGÍA}

Mina:

Molienda de feldespato

\section{Empresa:}

JOSÉ BUTRAGUEÑO

\section{Proyecto:}

Estudio sedimentación y reología de finos de feldespato

\section{Aplicación}

Sedimentación. Estériles de flotación.

Fecha:

$09 / 08 / 2013$

\section{Ensayos:}

\begin{tabular}{|c|c|}
\hline $\mathbf{x}$ & Distribución granulométrica y caracterización de muestras \\
\hline $\mathbf{x}$ & Selección de floculantes \\
\hline $\mathbf{x}$ & Área de flujo \\
\hline $\mathbf{x}$ & Sedimentación en probeta estática \\
\hline $\mathbf{x}$ & Ensayo en espesador dinámico de laboratorio de $85 \mathrm{~mm}$ DIA \\
\hline $\mathbf{x}$ & Reología de los lodos \\
\hline $\mathbf{x}$ & Ensayo de filtración a vacío \\
\hline
\end{tabular}

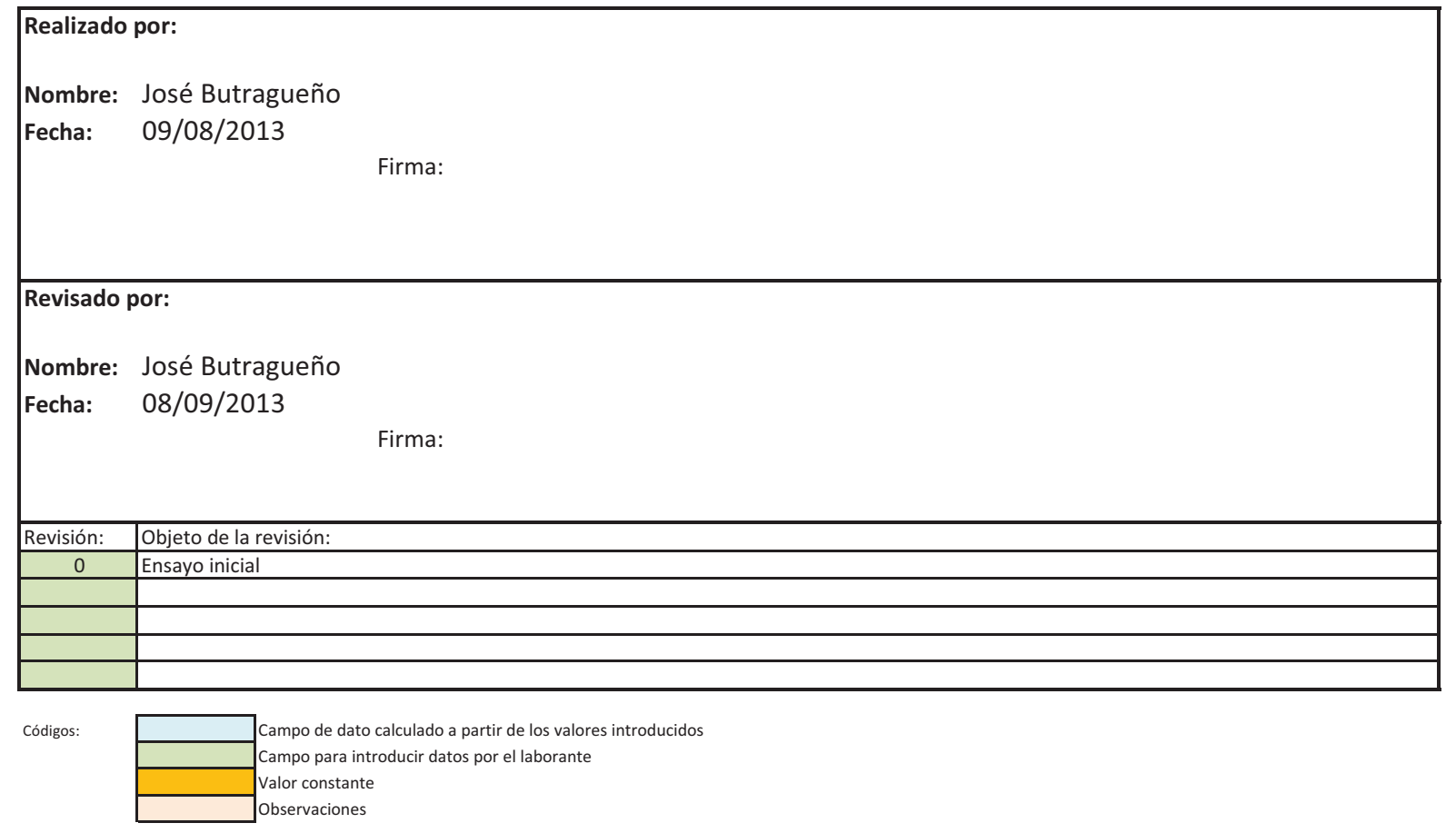

CONFIDENCIAL: Este documento contiene información propiedad de JOSÉ BUTRAGUEÑO y está sujeto a ser

devuelto bajo demanda; estando prohibida su reproducción, copia, préstamo o cualquier otro uso que no sea el fin para el que fue expresamente realizado, sin el consentimiento expreso por escrito de: JOSÉ BUTRAGUEÑO 
ENSAYO GRANULOMÉTRICO DE SÓLIDOS

Mina: Molienda de feldespato

Proyecto: Estudio sedimentación y reología de finos de feldespato

Realizado por: José Butragueño

\begin{tabular}{|ll|}
\hline Muestra ID: & M-005 \\
Material: & Finos de feldespato potásico \\
Preparado por: & José A. Butragueño \\
pH muestra: & - \\
Fecha: & $09 / 08 / 2013$ \\
\hline
\end{tabular}

CURVA GRANULOMÉTRICA DE SÓLIDOS

\begin{tabular}{|c|c|c|c|c|}
\hline \multicolumn{3}{|c|}{ DATOS DE LA PULPA A SEDIMENTAR } & \multicolumn{2}{|c|}{ Observaciones: Muestra de sólido seco } \\
\hline Densidad sólidos: & 2,65 & $\mathrm{~kg} / \mathrm{dm}^{3}$ & & \\
\hline Densidad líquido: & 1,00 & $\mathrm{~kg} / \mathrm{dm}^{3}$ & & \\
\hline Densidad pulpa: & & $\mathrm{kg} / \mathrm{l}$ & & \\
\hline Tara: & 0 & $\mathrm{~g}$ & & \\
\hline Pulpa húmeda: & & g & Peso pulpa: & \begin{tabular}{l|l}
0 & $g$
\end{tabular} \\
\hline Sólido seco: & 0 & g & Peso sólido: & \begin{tabular}{l|l}
0 & $\mathrm{~g}$ \\
\end{tabular} \\
\hline \% Peso sólidos: & \#DIV/0! & $\%$ & & \\
\hline
\end{tabular}

CURVA GRANULOMÉTRICA DE SÓLIDOS

\begin{tabular}{|c|c|c|c|c|}
\hline \multicolumn{5}{|c|}{ ENSAYO GRANULOMÉTRICO } \\
\hline \multirow{2}{*}{\begin{tabular}{|l|} 
Tamiz \\
Micras
\end{tabular}} & \multirow{2}{*}{$\begin{array}{l}\text { Pesos } \\
\text { Peso Ret. }\end{array}$} & \multicolumn{3}{|c|}{ Porcentajes } \\
\hline & & \% Peso Ret. & $\%$ Ret. Ac. & \%Pasa Ac. \\
\hline 212 & 0 & 0,00 & 0,00 & 100,00 \\
\hline 100 & 2,5 & 3,60 & 3,60 & 96,40 \\
\hline 75 & 5 & 7,19 & 10,79 & 89,21 \\
\hline 63 & 8 & 11,51 & 22,30 & 77,70 \\
\hline 50 & 12 & 17,27 & 39,57 & 60,43 \\
\hline 38 & 17 & 24,46 & 64,03 & 35,97 \\
\hline 20 & 20 & 28,78 & 92,81 & 7,19 \\
\hline & 5 & 7,19 & 100,00 & 0,00 \\
\hline TOTALES: & 69,5 & 100,0 & & \\
\hline
\end{tabular}

$P 80=65$ micras

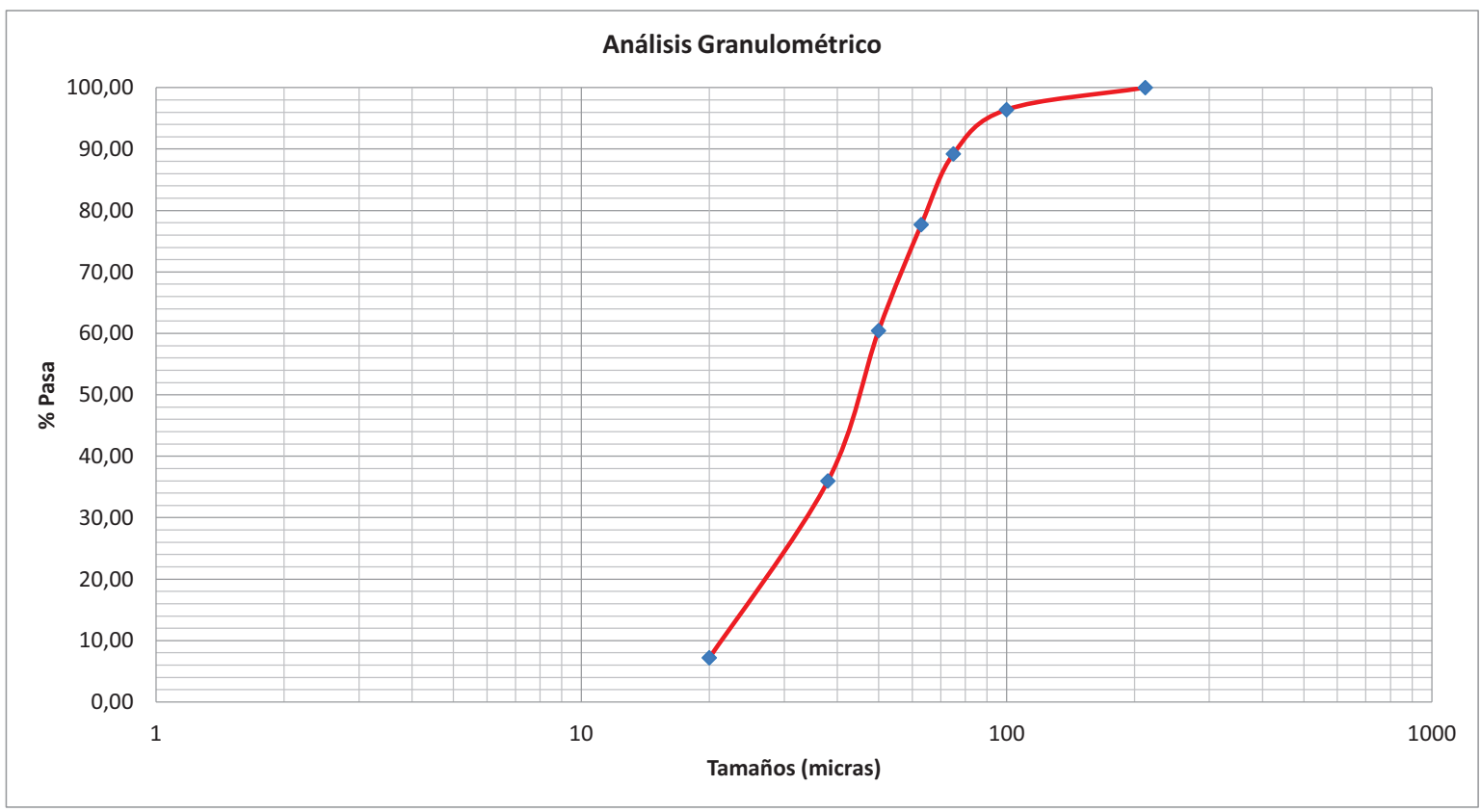


SELECCIÓN DE FLOCULANTE

Mina: Molienda de feldespato

Proyecto: $\quad$ Estudio sedimentación y reología de finos de feldespato

MUESTRA ORIGINAL: M-005

\begin{tabular}{|lll|}
\hline Volumen líquido: & $475 \mathrm{ml}$ & Muestra preparada en laboratorio \\
\% sólidos en peso: & $25 \mathrm{~g}$ & Muestra preparada en laboratorio \\
Dosficación de floculante: & $0,1 \mathrm{~g}$ & Preparación y dosificación floculante. \\
Volumen total: & $200 \mathrm{ml}$ & Preparación y dosificación floculante. \\
Concentración floculante: & $0,05 \%$ &
\end{tabular}

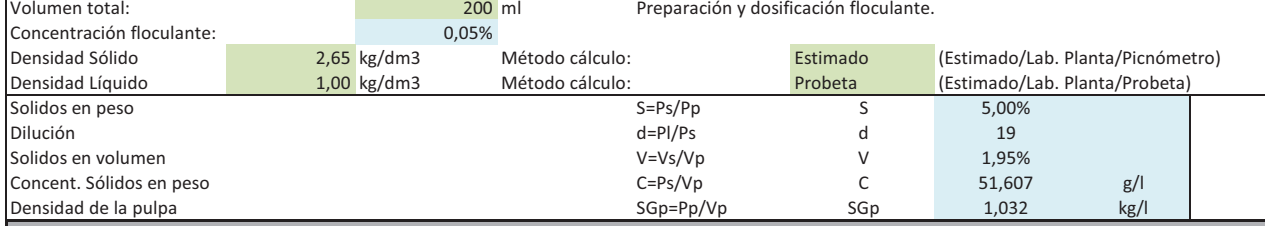

Densidad de la pulpa

FLOCULANTE. TEST 1.

\begin{tabular}{|c|c|c|c|c|c|c|c|c|c|}
\hline \multicolumn{7}{|c|}{ CULANTE. TEST 1.} & & & \\
\hline \multicolumn{2}{|c|}{ MUESTRA: M-005 } & \multicolumn{2}{|c|}{ FLOCULANTE: NALCO } & \multicolumn{2}{|c|}{ TIPO CARGA: Aniónico -25\% } & \multicolumn{2}{|c|}{ DOSIFICACIÓN: $0,05 \%$} & \multirow[b]{2}{*}{$\begin{array}{l}\text { Tiempo } \\
\text { (s) }\end{array}$} & \multirow[b]{2}{*}{$\begin{array}{l}\text { Velocidad } \\
(\mathrm{m} / \mathrm{h})\end{array}$} \\
\hline $\begin{array}{c}\text { Ensayo } \\
\#\end{array}$ & $\begin{array}{l}\text { Diluc. } \\
\text { (Si/No) }\end{array}$ & $\begin{array}{c}\text { Pulpa w/w sol. } \\
(\%)\end{array}$ & $\begin{array}{l}\text { Distancia sed. } \\
\text { (cm) }\end{array}$ & $\begin{array}{c}\text { Volumen ensayo } \\
\text { (ml) }\end{array}$ & $\begin{array}{c}\text { Sólidos } \\
\text { (g) }\end{array}$ & $\begin{array}{c}\text { Floculante } \\
\text { (ml) }\end{array}$ & $\begin{array}{l}\text { Floc } \\
(\mathrm{g} / \mathrm{t})\end{array}$ & & \\
\hline 1 & No & $5,00 \%$ & 10 & 484,4 & 25,00 & 1 & 20 & 16 & 22,5 \\
\hline 2 & No & $5,00 \%$ & 10 & 484,4 & 25,00 & 2 & 40 & 17 & 21,2 \\
\hline 3 & No & $5,00 \%$ & 10 & 484,4 & 25,00 & 3 & 60 & 20 & 18,0 \\
\hline 4 & No & $5,00 \%$ & 10 & 484,4 & 25,00 & 4 & 80 & 21 & 17,1 \\
\hline \multirow[t]{2}{*}{5} & No & $5,00 \%$ & 10 & 484,4 & 25,00 & 5 & 100 & 23 & 15,7 \\
\hline & Velocidad & Tamaño & Cohesión & Claridad & & & & & \\
\hline Ensayo & Sediment. & Floculo & Flóculo & Rebose & & & & & \\
\hline 1 & Media & Pequeño & Parcial & Turbio & Datos (para observa & ación visual): & & & \\
\hline 2 & Media & Pequeño & Parcial & Turbio & Tamaño flóculo: & Muy pequeño/Pe & /Medio/ & ande/Muy gra & \\
\hline 3 & Media & Pequeño & Parcial & Turbio & Velocidad sedim.: & Muy lenta/Lenta & a/Rápida & luy rápida & \\
\hline 4 & Media & Muy pequeño & Parcial & Turbio & Cohesión de flóc.: & Pobre/Parcial/Bu & huy buen & Excelente & \\
\hline 5 & Media & Muy pequeño & Parcial & Turbio & Claridad rebose: & Muy turbio/Turb & o/Muy c & o/Cristalino & \\
\hline & & & & CULANTE. TEST 2. & & & & & \\
\hline & M-005 & FLOCULANTE: & NALCO & TIPO CARGA: & Aniónico -10\% & DOSIFICACIÓ & $5 \% \%$ & & \\
\hline $\begin{array}{c}\text { Ensayo } \\
\#\end{array}$ & $\begin{array}{l}\text { Diluc. } \\
\text { (Si/No) }\end{array}$ & $\begin{array}{c}\text { Pulpa w/w sol. } \\
(\%)\end{array}$ & $\begin{array}{l}\text { Distancia sed. } \\
(\mathrm{cm})\end{array}$ & $\begin{array}{c}\text { Volumen ensayo } \\
(\mathrm{ml})\end{array}$ & $\begin{array}{c}\text { Sólidos } \\
(\mathrm{g})\end{array}$ & $\begin{array}{l}\text { Floc } \\
\text { (ml) }\end{array}$ & $\begin{array}{l}\text { Floc } \\
(\mathrm{g} / \mathrm{t}) \\
\end{array}$ & $\begin{array}{c}\text { Tiempo } \\
\text { (s) }\end{array}$ & $\begin{array}{c}\text { Velocidad } \\
(\mathrm{m} / \mathrm{h})\end{array}$ \\
\hline 1 & No & $5,00 \%$ & 10 & 484,4 & 25,00 & 1 & 20 & 12 & 30,0 \\
\hline 2 & No & $5,00 \%$ & 10 & 484,4 & 25,00 & 2 & 40 & 11 & 32,7 \\
\hline 3 & No & $5,00 \%$ & 10 & 484,4 & 25,00 & 3 & 60 & 13 & 27,7 \\
\hline 4 & No & $5,00 \%$ & 10 & 484,4 & 25,00 & 4 & 80 & 15 & 24,0 \\
\hline 5 & No & $5,00 \%$ & 10 & 484,4 & 25,00 & 5 & 100 & 16 & 22,5 \\
\hline Ensayo & $\begin{array}{l}\text { Velocidad } \\
\text { Sediment. }\end{array}$ & $\begin{array}{l}\text { Tamaño } \\
\text { Floculo }\end{array}$ & $\begin{array}{l}\text { Cohesión } \\
\text { Flóculo }\end{array}$ & $\begin{array}{l}\text { Claridad } \\
\text { Rebose }\end{array}$ & & & & & \\
\hline 1 & Rápida & Medio & Parcial & Turbio & Datos (para observa & ación visual): & & & \\
\hline 2 & Media & Medio & Parcial & Turbio & Tamaño flóculo: & Muy pequeño/Pe & /Medio/ & ande/Muy gra & \\
\hline 3 & Media & Medio & Parcial & Turbio & Velocidad sedim.: & Muy lenta/Lenta & a/Rápida & luy rápida & \\
\hline 4 & Media & Medio & Parcial & Turbio & Cohesión de flóc.: & Pobre/Parcial/Bu & Muy buen & xcelente & \\
\hline 5 & Media & Medio & Parcial & Turbio & Claridad rebose: & Muy turbio/Turb & ro/Muy c & o/Cristalino & \\
\hline & & & & CULANTE. TEST 3. & & & & & \\
\hline & M-005 & FLOCULANTE: & NALCO & TIPO CARGA: & Sin Carga $0 \%$ & DOSIFICACIÓ & $05 \%$ & & \\
\hline $\begin{array}{c}\text { Ensayo } \\
\#\end{array}$ & $\begin{array}{l}\text { Diluc. } \\
\text { (Si/No) }\end{array}$ & $\begin{array}{c}\text { Pulpa w/w sol. } \\
(\%)\end{array}$ & $\begin{array}{l}\text { Distancia sed. } \\
\text { (cm) }\end{array}$ & $\begin{array}{c}\text { Volumen ensayo } \\
(\mathrm{ml})\end{array}$ & $\begin{array}{c}\text { Sólidos } \\
\text { (g) }\end{array}$ & $\begin{array}{l}\text { Floc } \\
\text { (ml) }\end{array}$ & $\begin{array}{l}\text { Floc } \\
(\mathrm{g} / \mathrm{t})\end{array}$ & $\begin{array}{c}\text { Tiempo } \\
\text { (s) }\end{array}$ & $\begin{array}{c}\begin{array}{c}\text { Velocidad } \\
(\mathrm{m} / \mathrm{h})\end{array} \\
\end{array}$ \\
\hline 1 & No & $5,00 \%$ & 10 & 484,4 & 25,00 & 1 & 20 & 11 & 32,7 \\
\hline 2 & No & $5,00 \%$ & 10 & 484,4 & 25,00 & 2 & 40 & 9 & 40,0 \\
\hline 3 & No & $5,00 \%$ & 10 & 484,4 & 25,00 & 3 & 60 & 10 & 36,0 \\
\hline 4 & No & $5,00 \%$ & 10 & 484,4 & 25,00 & 4 & 80 & 12 & 30,0 \\
\hline 5 & No & $5,00 \%$ & 10 & 484,4 & 25,00 & 5 & 100 & 13 & 27,7 \\
\hline & Velocidad & Tamaño & Cohesión & Claridad & & & & & \\
\hline Ensayo & Sediment. & Floculo & Flóculo & Rebose & & & & & \\
\hline 1 & Alta & Grande & Buena & Claro & Datos (para observa & ación visual): & & & \\
\hline 2 & Alta & Grande & Buena & Claro & Tamaño flóculo: & Muy pequeño/Pe & /Medio/ & ande/Muy gra & \\
\hline 3 & Alta & Grande & Buena & Claro & Velocidad sedim.: & Muy lenta/Lenta & a/Rápida & luy rápida & \\
\hline 4 & Alta & Grande & Buena & Muy claro & Cohesión de flóc.: & Pobre/Parcial/Bu & huy buen & Excelente & \\
\hline 5 & Alta & Grande & Buena & Muy claro & Claridad rebose: & Muy turbio/Turb & ro/Muy c & o/Cristalino & \\
\hline & & & & CULANTE. TEST 4. & & & & & \\
\hline & M-005 & FLOCULANTE: & NALCO & TIPO CARGA: & Catiónico $+\mathbf{1 0} \%$ & DOSIFICACIÓ & $05 \%$ & & \\
\hline $\begin{array}{c}\text { Ensayo } \\
\#\end{array}$ & $\begin{array}{l}\text { Diluc. } \\
\text { (Si/No) }\end{array}$ & $\begin{array}{l}\text { Pulpa w/w sol. } \\
(\%)\end{array}$ & $\begin{array}{l}\text { Distancia sed. } \\
(\mathrm{cm})\end{array}$ & $\begin{array}{c}\text { Volumen ensayo } \\
(\mathrm{ml})\end{array}$ & $\begin{array}{c}\text { Sólidos } \\
\text { (g) }\end{array}$ & $\begin{array}{l}\text { Floc } \\
(\mathrm{ml}) \\
\end{array}$ & $\begin{array}{l}\text { Floc } \\
(\mathrm{g} / \mathrm{t})\end{array}$ & $\begin{array}{l}\text { Tiempo } \\
\text { (s) }\end{array}$ & $\begin{array}{c}\begin{array}{c}\text { Velocidad } \\
(\mathrm{m} / \mathrm{h})\end{array} \\
\end{array}$ \\
\hline 1 & No & $5,00 \%$ & 10 & 484,4 & 25,00 & 1 & 20 & 11 & 32,7 \\
\hline 2 & No & $5,00 \%$ & 10 & 484,4 & 25,00 & 2 & 40 & 10 & 36,0 \\
\hline 3 & No & $5,00 \%$ & 10 & 484,4 & 25,00 & 3 & 60 & 11 & 32,7 \\
\hline 4 & No & $5,00 \%$ & 10 & 484,4 & 25,00 & 4 & 80 & 14 & 25,7 \\
\hline 5 & No & $5,00 \%$ & 10 & 484,4 & 25,00 & 5 & 100 & 15 & 24,0 \\
\hline Ensayo & $\begin{array}{l}\text { Velocidad } \\
\text { Sediment. }\end{array}$ & $\begin{array}{l}\text { Tamaño } \\
\text { Floculo }\end{array}$ & $\begin{array}{l}\text { Cohesión } \\
\text { Flóculo }\end{array}$ & $\begin{array}{l}\text { Claridad } \\
\text { Rebose }\end{array}$ & & & & & \\
\hline 1 & Muy baja & Pequeño & Pobre & Turbio & Datos (para observa & ación visual): & & & \\
\hline 2 & Muy baja & Pequeño & Pobre & Muy turbio & Tamaño flóculo: & Muy pequeño/Pe & o/Medio/ & ande/Muy gra & \\
\hline 3 & Muy baja & Muy pequeño & Pobre & Muy turbio & Velocidad sedim.: & Muy lenta/Lenta & ia/Rápida, & luy rápida & \\
\hline 4 & Muy baja & Muy pequeño & Pobre & Muy turbio & Cohesión de flóc.: & Pobre/Parcial/Bu & Muy buen & Excelente & \\
\hline 5 & Muy baja & Muy pequeño & Pobre & Muy turbio & Claridad rebose: & Muy turbio/Turb & ro/Muy c & o/Cristalino & \\
\hline & & & $\overline{F L}$ & CULANTE. TEST 5. & & & & & \\
\hline & M-005 & FLOCULANTE: & NALCO & TIPO CARGA: & Catiónico + $25 \%$ & DOSIFICACIÓ & $05 \%$ & & \\
\hline $\begin{array}{c}\text { Ensayo } \\
\quad \#\end{array}$ & $\begin{array}{l}\text { Diluc. } \\
\text { (Si/No) }\end{array}$ & $\begin{array}{l}\text { Pulpa w/w sol. } \\
(\%)\end{array}$ & $\begin{array}{l}\text { Distancia sed. } \\
\text { (cm) }\end{array}$ & $\begin{array}{c}\text { Volumen ensayo } \\
(\mathrm{ml})\end{array}$ & $\begin{array}{l}\text { Sólidos } \\
\text { (g) }\end{array}$ & $\begin{array}{l}\text { Floc } \\
\text { (ml) }\end{array}$ & $\begin{array}{l}\text { Floc } \\
(\mathrm{g} / \mathrm{t})\end{array}$ & $\begin{array}{c}\text { Tiempo } \\
\text { (s) }\end{array}$ & $\begin{array}{c}\begin{array}{c}\text { Velocidad } \\
(\mathrm{m} / \mathrm{h})\end{array} \\
\end{array}$ \\
\hline 1 & No & $5,00 \%$ & 10 & 484,4 & 25,00 & 1 & 20 & 15 & 24,0 \\
\hline 2 & No & $5,00 \%$ & 10 & 484,4 & 25,00 & 2 & 40 & 14 & 25,7 \\
\hline 3 & No & $5,00 \%$ & 10 & 484,4 & 25,00 & 3 & 60 & 14 & 25,7 \\
\hline 4 & No & $5,00 \%$ & 10 & 484,4 & 25,00 & 4 & 80 & 16 & 22,5 \\
\hline 5 & No & $5,00 \%$ & 10 & 484,4 & 25,00 & 5 & 100 & 17 & 21,2 \\
\hline & Velocidad & Tamaño & Cohesión & Claridad & & & & & \\
\hline Ensayo & Sediment. & Floculo & Flóculo & Rebose & & & & & \\
\hline 1 & Muy baja & Pequeño & Pobre & Muy turbio & Datos (para observa & ación visual): & & & \\
\hline 2 & Muy baja & Pequeño & Pobre & Muy turbio & Tamaño flóculo: & Muy pequeño/Pe & o/Medio/ & ande/Muy gra & \\
\hline 3 & Muy baja & Pequeño & Pobre & Muy turbio & Velocidad sedim.: & Muy lenta/Lenta & ia/Rápida & luy rápida & \\
\hline 4 & Muy baja & Pequeño & Pobre & Muy turbio & Cohesión de flóc.: & Pobre/Parcial/Bu & Muy buen & xcelente & \\
\hline 5 & Muy baja & Pequeño & Pobre & Muy turbio & Claridad rebose: & Muy turbio/Turb & ro/Muy c & o/Cristalino & \\
\hline
\end{tabular}


SELECCIÓN DE FLOCULANTE. ANÁLISIS DE DATOS.

Mina:

Proyecto:

MUESTRA ORIGINAL:

Volumen líquido:

$\%$ sólidos en peso:

Dosficación de floculante:

Volumen total:

Concentración floculante:

Densidad Sólido

Densidad Líquido
Molienda de feldespato

Estudio sedimentación y reología de finos de feldespato

M-005

$\begin{array}{ccll}475 \mathrm{ml} & \text { Muestra preparada en laboratorio } \\ 25 \mathrm{~g} & \begin{array}{l}\text { Muestra preparada en laboratorio } \\ 0,1 \mathrm{~g}\end{array} & \begin{array}{l}\text { Preparación y dosificación floculante. } \\ 200 \mathrm{ml}\end{array} & \text { Preparación y dosificación floculante. } \\ 0,05 \% & & & \\ 2,65 \mathrm{~kg} / \mathrm{dm} 3 & \text { Método cálculo: } & \text { Picnómetro } & \text { (Estimado/Lab. Planta/Picnómetro) } \\ 1,00 \mathrm{~kg} / \mathrm{dm} 3 & \text { Método cálculo: } & \text { Probeta } & \text { (Estimado/Lab. Planta/Probeta) }\end{array}$

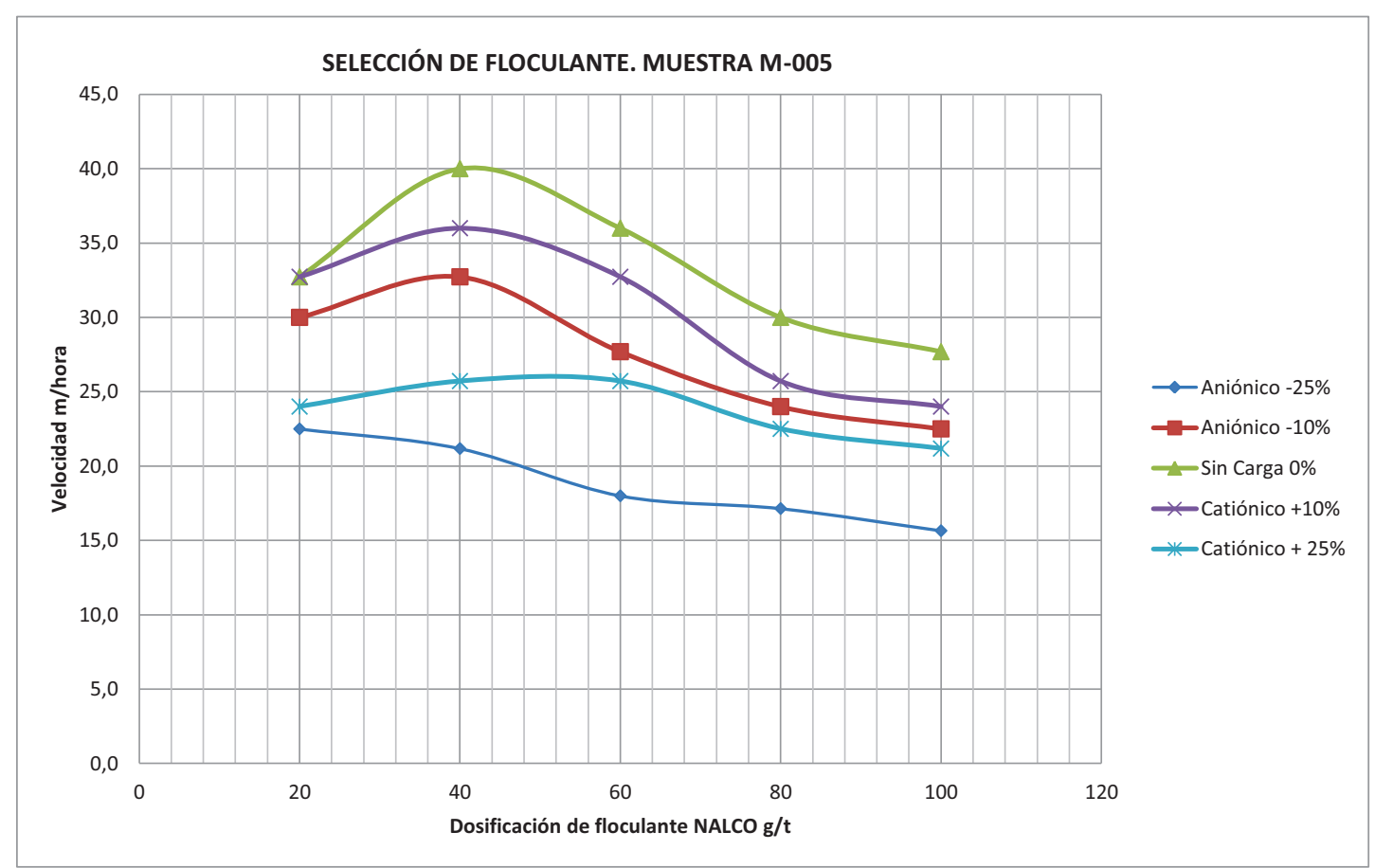

Los ensayos de sedimentación para la selección del floculante han tenido en cuenta tanto los valores de velocidad de sedimentación cómo los datos de observación visual de: tamaño de flóculo, velocidad de sedimentación, cohesión del flóculo y la claridad del rebose obtenida en la probeta de laboratorio. El floculante seleccionado será empleado en los ensayos de flujo de sedimentación. 
ENSAYO FLUJO SEDIMENTACIÓN

\begin{tabular}{|c|c|c|}
\hline $\begin{array}{l}\text { Mina: } \\
\text { Proyecto: }\end{array}$ & \multicolumn{2}{|c|}{$\begin{array}{l}\text { Molienda de feldespato } \\
\text { Estudio sedimentación y reología de finos de feldespato }\end{array}$} \\
\hline DATOS & & FLOCULANTE SELECCIONADO \\
\hline Volumen probeta: & $500 \mathrm{ml}$ & NALCO 0\% CARGA \\
\hline Diámetro probeta: & $48,6 \mathrm{~mm}$ & \\
\hline Área sedimentac. & $18,55 \mathrm{~cm} 2$ & \\
\hline Floc. Dosificac.: & $0,1 \mathrm{~g}$ & \\
\hline Volumen floc.: & $200 \mathrm{ml}$ & MUESTRA SÓLIDOS \\
\hline Floculante dosific. & $0,05 \%$ & M-005 \\
\hline Floc. Conc. & $0,50 \mathrm{~g} / \mathrm{l}$ & \\
\hline Densidad Sólido & $2,65 \mathrm{~kg} / \mathrm{dm} 3$ & \\
\hline Densidad Líquido & $1,00 \mathrm{~kg} / \mathrm{dm} 3$ & \\
\hline
\end{tabular}

Proyecto: Estudio sedimentación y reología de finos de feldespato

ENSAYO 1: NALCO 0\% CARGA

\begin{tabular}{|c|c|c|c|c|c|c|c|c|c|c|c|}
\hline \multicolumn{12}{|c|}{ ENSAYO 1: NALCO 0\% CARGA } \\
\hline \multicolumn{2}{|c|}{ MUESTRA: M-005 } & \multirow{2}{*}{$\begin{array}{l}\text { FLOCULANTE: } \\
\text { Sólidos } \\
(\% \mathrm{w} / \mathrm{w}) \\
\end{array}$} & \multicolumn{2}{|c|}{ NALCO 0\% CARGA } & \multicolumn{2}{|c|}{ DOSIFICACIÓN: } & \multirow{2}{*}{$\begin{array}{c}0,50 \\
\text { Tiempo sed. } \\
\text { (s) }\end{array}$} & \multirow{2}{*}{$\begin{array}{l}\mathrm{g} / \mathrm{l} \\
\begin{array}{c}\text { Velocidad sed. } \\
(\mathrm{m} / \mathrm{h})\end{array}\end{array}$} & \multirow[b]{2}{*}{$\begin{array}{l}\text { Floc dosific. } \\
(\mathrm{g} / \mathrm{t})\end{array}$} & \multirow[b]{2}{*}{$\begin{array}{c}\begin{array}{c}\text { Flujo } \\
\text { (tph/m2) }\end{array} \\
\end{array}$} & \multirow[b]{2}{*}{$\begin{array}{c}\text { Flujo } \\
\text { (tpd/m2) }\end{array}$} \\
\hline $\begin{array}{c}\text { Peso sólidos } \\
\text { (g) }\end{array}$ & $\begin{array}{c}\text { Vol. líquido } \\
(\mathrm{ml})\end{array}$ & & $\begin{array}{c}\text { Densidad pulpa } \\
(\mathrm{kg} / \mathrm{l})\end{array}$ & $\begin{array}{c}\text { Conc. Solids } \\
(\mathrm{g} / \mathrm{l})\end{array}$ & $\begin{array}{c}\text { Floculant. } \\
(\mathrm{ml})\end{array}$ & $\begin{array}{l}\text { Dist. Sediment. } \\
(\mathrm{cm})\end{array}$ & & & & & \\
\hline 12,5 & 475 & 2,56 & 1,016 & 26,06 & 0,5 & 10,0 & 11 & 32,7 & 20 & 2,21 & 52,93 \\
\hline 12,5 & 475 & 2,56 & 1,016 & 26,06 & 1 & 10,0 & 10 & 36,0 & 40 & 2,43 & 58,22 \\
\hline 12,5 & 475 & 2,56 & 1,016 & 26,06 & 1,5 & 10,0 & 11 & 32,7 & 60 & 2,21 & 52,93 \\
\hline 12,5 & 475 & 2,56 & 1,016 & 26,06 & 2 & 10,0 & 11 & 32,7 & 80 & 2,21 & 52,93 \\
\hline 12,5 & 475 & 2,56 & 1,016 & 26,06 & 3 & 10,0 & 12 & 30,0 & 120 & 2,02 & 48,52 \\
\hline 12,5 & 475 & 2,56 & 1,016 & 26,06 & 4 & 10,0 & 13 & 27,7 & 160 & 1,87 & 44,78 \\
\hline & & & & & & & MEDIA: & 32,7 & 70,0 & 2,2 & 52,9 \\
\hline
\end{tabular}

\begin{tabular}{|c|c|c|c|c|c|c|c|c|c|c|c|}
\hline \multicolumn{12}{|c|}{ ENSAYO 2: NALCO 0\% CARGA } \\
\hline \multicolumn{2}{|c|}{ MUESTRA: M-005 } & \multirow{2}{*}{$\begin{array}{l}\text { FLOCULANTE: } \\
\text { Sólidos } \\
(\% \mathrm{w} / \mathrm{w})\end{array}$} & \multicolumn{2}{|c|}{ NALCO $0 \%$ CARGA } & \multirow[b]{2}{*}{$\begin{array}{l}\text { Floculant. } \\
\text { (ml) }\end{array}$} & \multirow{2}{*}{$\begin{array}{l}\text { DOSIFICACIÓN: } \\
\text { ist. Sediment. } \\
\text { (cm) }\end{array}$} & \multirow{2}{*}{$\begin{array}{c}0,50 \\
\text { Tiempo sed. } \\
\text { (s) }\end{array}$} & \multirow{2}{*}{$\begin{array}{c}\mathrm{g} / \mathrm{l} \\
\begin{array}{c}\text { Velocidad sed. } \\
(\mathrm{m} / \mathrm{h})\end{array}\end{array}$} & \multirow[b]{2}{*}{$\begin{array}{l}\text { Floc dosific } \\
(\mathrm{g} / \mathrm{t})\end{array}$} & \multirow[b]{2}{*}{$\begin{array}{c}\text { Flujo } \\
\text { (tph/m2) }\end{array}$} & \multirow[b]{2}{*}{$\begin{array}{c}\text { Flujo } \\
\text { (tpd/m2) }\end{array}$} \\
\hline $\begin{array}{c}\text { Peso sólidos } \\
\text { (g) }\end{array}$ & $\begin{array}{c}\text { Vol. líquido } \\
(\mathrm{ml})\end{array}$ & & $\begin{array}{c}\text { Densidad pulpa } \\
(\mathrm{kg} / \mathrm{l})\end{array}$ & $\begin{array}{c}\text { Conc. Solids } \\
(\mathrm{g} / \mathrm{l})\end{array}$ & & & & & & & \\
\hline 25 & 475 & 5,00 & 1,032 & 51,61 & 1 & 10,0 & 8 & 45,0 & 20 & 6,06 & 145,55 \\
\hline 25 & 475 & 5,00 & 1,032 & 51,61 & 2 & 10,0 & 7 & 51,4 & 40 & 6,93 & 166,34 \\
\hline 25 & 475 & 5,00 & 1,032 & 51,61 & 3 & 10,0 & 6 & 60,0 & 60 & 8,09 & 194,06 \\
\hline 25 & 475 & 5,00 & 1,032 & 51,61 & 4 & 10,0 & 6 & 60,0 & 80 & 8,09 & 194,06 \\
\hline 25 & 475 & 5,00 & 1,032 & 51,61 & 5 & 10,0 & 7 & 51,4 & 100 & 6,93 & 166,34 \\
\hline 25 & 475 & 5,00 & 1,032 & 51,61 & 7 & 10,0 & 8 & 45,0 & 140 & 6,06 & 145,55 \\
\hline & & & & & & & MEDIA: & 51,4 & 70,0 & 6,9 & 166,3 \\
\hline
\end{tabular}

\begin{tabular}{|c|c|c|c|c|c|c|c|c|c|c|c|}
\hline \multicolumn{12}{|c|}{ ENSAYO 3: NALCO $0 \%$ CARGA } \\
\hline \multicolumn{2}{|c|}{ MUESTRA: M-005 } & \multirow{2}{*}{$\begin{array}{l}\text { FLOCULANTE: } \\
\text { Sólidos } \\
(\% \mathrm{w} / \mathrm{w})\end{array}$} & \multicolumn{2}{|c|}{ NALCO $0 \%$ CARGA } & \multirow[b]{2}{*}{$\begin{array}{c}\text { Floculant. } \\
\text { (ml) }\end{array}$} & DOSIFICACIÓN: & \multirow{2}{*}{$\begin{array}{c}0,50 \\
\text { Tiempo sed. } \\
\text { (s) }\end{array}$} & \multirow{2}{*}{$\frac{\mathrm{g} / \mathrm{l}}{\begin{array}{c}\text { Velocidad sed. } \\
(\mathrm{m} / \mathrm{h})\end{array}}$} & \multirow[b]{2}{*}{$\begin{array}{l}\text { Floc dosific. } \\
(\mathrm{g} / \mathrm{t})\end{array}$} & \multirow[b]{2}{*}{$\begin{array}{c}\text { Flujo } \\
\text { (tph/m2) }\end{array}$} & \multirow[b]{2}{*}{$\begin{array}{c}\text { Flujo } \\
\text { (tpd/m2) }\end{array}$} \\
\hline $\begin{array}{c}\text { Peso sólidos } \\
\text { (g) }\end{array}$ & $\begin{array}{c}\text { Vol. líquido } \\
\text { (ml) }\end{array}$ & & $\begin{array}{c}\text { Densidad pulpa } \\
(\mathrm{kg} / \mathrm{l})\end{array}$ & $\begin{array}{c}\text { Conc. Solids } \\
\text { (g/l) }\end{array}$ & & $\begin{array}{l}\text { Dist. Sediment. } \\
\text { (cm) }\end{array}$ & & & & & \\
\hline 50 & 475 & 9,52 & 1,063 & 101,24 & 1 & 10,0 & 20 & 18,0 & 10 & 4,85 & 116,44 \\
\hline 50 & 475 & 9,52 & 1,063 & 101,24 & 2 & 10,0 & 18 & 20,0 & 20 & 5,39 & 129,37 \\
\hline 50 & 475 & 9,52 & 1,063 & 101,24 & 4 & 10,0 & 13 & 27,7 & 40 & 7,46 & 179,13 \\
\hline 50 & 475 & 9,52 & 1,063 & 101,24 & 6 & 10,0 & 14 & 25,7 & 60 & 6,93 & 166,34 \\
\hline 50 & 475 & 9,52 & 1,063 & 101,24 & 8 & 10,0 & 14 & 25,7 & 80 & 6,93 & 166,34 \\
\hline 50 & 475 & 9,52 & 1,063 & 101,24 & 10 & 10,0 & 15 & 24,0 & 100 & 6,47 & 155,25 \\
\hline & & & & & & & MEDIA: & 24,9 & 50,0 & 6,7 & 160,8 \\
\hline
\end{tabular}

\begin{tabular}{|c|c|c|c|c|c|c|c|c|c|c|c|}
\hline \multicolumn{12}{|c|}{ ENSAYO 4: NALCO 0\% CARGA } \\
\hline \multicolumn{2}{|c|}{ MUESTRA: M-005 } & \multirow{2}{*}{$\begin{array}{l}\text { FLOCULANTE: } \\
\text { Sólidos } \\
\text { (\% } \mathrm{w} / \mathrm{w}) \\
\end{array}$} & \multicolumn{2}{|c|}{ NALCO 0\% CARGA } & \multirow[b]{2}{*}{$\begin{array}{c}\text { Floculant. } \\
(\mathrm{ml})\end{array}$} & \multirow{2}{*}{$\begin{array}{l}\text { DOSIFICACIÓN: } \\
\text { Dist. Sediment. } \\
\text { (cm) }\end{array}$} & \multirow{2}{*}{$\begin{array}{c}\mathbf{0 , 5 0} \\
\text { Tiempo sed. } \\
\text { (s) }\end{array}$} & \multirow{2}{*}{$\begin{array}{l}\mathrm{g} / \mathrm{l} \\
\begin{array}{c}\text { Velocidad sed. } \\
(\mathrm{m} / \mathrm{h})\end{array}\end{array}$} & \multirow[b]{2}{*}{$\begin{array}{l}\text { Floc dosific. } \\
(\mathrm{g} / \mathrm{t})\end{array}$} & \multirow[b]{2}{*}{$\begin{array}{c}\begin{array}{c}\text { Flujo } \\
\text { (tph/m2) }\end{array} \\
\end{array}$} & \multirow[b]{2}{*}{$\begin{array}{c}\begin{array}{c}\text { Flujo } \\
\text { (tpd/m2) }\end{array} \\
\end{array}$} \\
\hline $\begin{array}{c}\text { Peso sólidos } \\
\text { (g) }\end{array}$ & $\begin{array}{c}\text { Vol. líquido } \\
(\mathrm{ml})\end{array}$ & & $\begin{array}{c}\text { Densidad pulpa } \\
(\mathrm{kg} / \mathrm{l})\end{array}$ & $\begin{array}{c}\text { Conc. Solids } \\
(\mathrm{g} / \mathrm{l})\end{array}$ & & & & & & & \\
\hline 62 & 475 & 11,55 & 1,077 & 124,40 & 3 & 10,0 & 18 & 20,0 & 24 & 6,68 & 160,424 \\
\hline 62 & 475 & 11,55 & 1,077 & 124,40 & 5 & 10,0 & 16 & 22,5 & 40 & 7,52 & 180,477 \\
\hline 62 & 475 & 11,55 & 1,077 & 124,40 & 7 & 10,0 & 16 & 22,5 & 56 & 7,52 & 180,477 \\
\hline 62 & 475 & 11,55 & 1,077 & 124,40 & 9 & 10,0 & 15 & 24,0 & 73 & 8,02 & 192,509 \\
\hline 62 & 475 & 11,55 & 1,077 & 124,40 & 11 & 10,0 & 16 & 22,5 & 89 & 7,52 & 180,477 \\
\hline 62 & 475 & 11,55 & 1,077 & 124,40 & 15 & 10,0 & 20 & 18,0 & 121 & 6,02 & 144,382 \\
\hline & & & & & & & MEDIA: & 22,5 & 64,5 & 7,5 & 180,5 \\
\hline
\end{tabular}


ENSAYO FLUJO SEDIMENTACIÓN. ANÁLISIS DE RESULTADOS.

Mina: Molienda de feldespato

Proyecto: Estudio sedimentación y reología de finos de feldespato

DATOS

Volumen probeta:

$500 \mathrm{ml}$
$48,6 \mathrm{~mm}$
$18,55 \mathrm{~cm} 2$
$0,1 \mathrm{~g}$
$200 \mathrm{ml}$
$0,05 \%$
$0,50 \mathrm{~g} / \mathrm{l}$
$2,65 \mathrm{~kg} / \mathrm{dm} 3$
$1,00 \mathrm{~kg} / \mathrm{dm} 3$

FLOCULANTE SELECCIONADO

Diámetro probeta:

Área sedimentac.

Floc. Dosificac.:

Volumen floc.:

Floculante dosific.

Floc. Conc.

Densidad Sólido

$1,00 \mathrm{~kg} / \mathrm{dm} 3$ NALCO 0\% CARGA

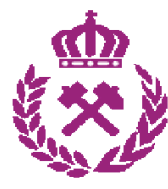

MUESTRA SÓLIDOS

M-005

Diámetros de probetas:

$250 \mathrm{ml} \quad 35,7 \quad \mathrm{~mm}$

$500 \mathrm{ml} \quad 48,6 \quad \mathrm{~mm}$

$2000 \mathrm{ml} \quad 78,2 \quad \mathrm{~mm}$
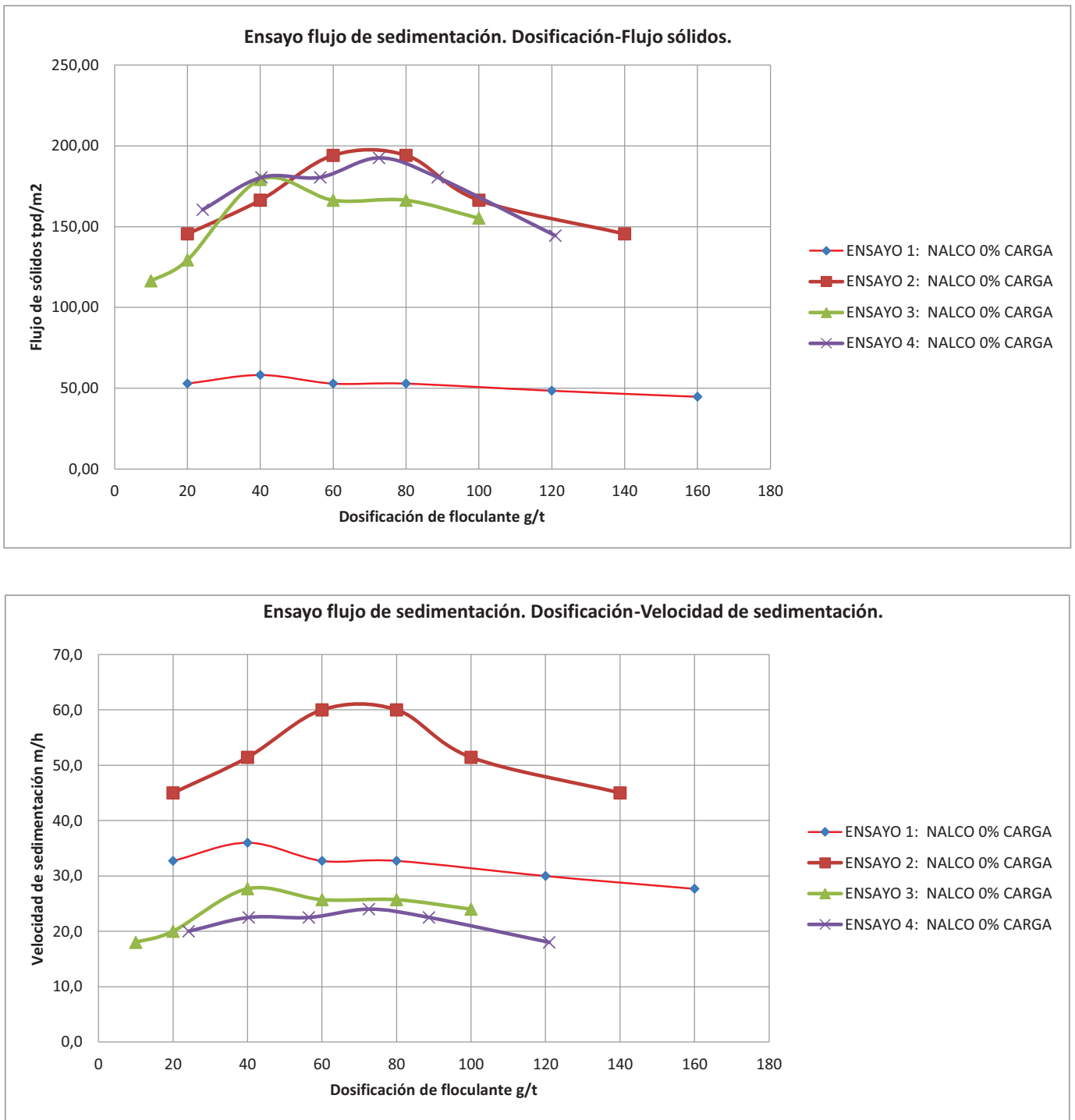

Los ensayos de flujos de sedimentación determinan la dilución óptima de los sólidos para la alimentación en el espesador.

El valor obtenido sirve de base para el diseño de la campana de alimentación y el sistema de dilución previsto. 
ENSAYO SEDIMENTACIÓN PROBETA 2000mI ESTÁTICO

$\begin{array}{ll}\text { Mina: } & \text { Molienda de feldespato } \\ \text { Proyecto: } & \text { Estudio sedimentación y reología de finos de feldespato } \\ \text { Muestra: } & \text { M-005 }\end{array}$

DATOS DE ENSAYO

\begin{tabular}{|c|c|c|c|c|c|c|c|}
\hline Volumen líquido: & 1900 & & Solidos en peso & $\mathrm{S}=\mathrm{Ps} / \mathrm{Pp}$ & $\mathrm{S}$ & $5,00 \%$ & \\
\hline Peso sólidos: & 100 & & Dilución & $d=P I / P s$ & $d$ & 19,000 & \\
\hline Floculante dosificac. & 0,1 & & Solidos en volumen & $\mathrm{V}=\mathrm{Vs} / \mathrm{Vp}$ & $\mathrm{v}$ & $1,95 \%$ & \\
\hline Volume total: & 200 & $\mathrm{ml}$ & Concent. Sólidos en peso & $\mathrm{C}=\mathrm{Ps} / \mathrm{Vp}$ & C & 51,61 & $\mathrm{~g} / \mathrm{l}$ \\
\hline Floc. Conc. & 0,50 & $\mathrm{~g} / \mathrm{l}$ & Densidad de la pulpa & $S G p=P p / V p$ & SGp & 1,032 & $\mathrm{~kg} / \mathrm{l}$ \\
\hline Floculante & 5,00 & $\mathrm{ml}$ & & & & & \\
\hline Solids SG & 2,65 & $\mathrm{~kg} / \mathrm{dm} 3$ & & & & & \\
\hline Liquid SG & 1,00 & $\mathrm{~kg} / \mathrm{dm} 3$ & & & & & \\
\hline Diámetro probeta & 78,2 & $\mathrm{~mm}$ & & & & & \\
\hline Area probeta & 0,0048029 & $\mathrm{~m} 2$ & $48,029 \mathrm{~cm} 2$ & & & & \\
\hline Densidad pulpa: & 1,032 & $\mathrm{~kg} / \mathrm{l}$ & & & & & \\
\hline Sólidos en peso: & 51,61 & g solids/l & & & & & \\
\hline Sólidos en peso: & 0,0516 & g solids/ml & & & & & \\
\hline Floculante: & NALCO & & & & & & \\
\hline Tipo de carga floc.: & 0\% CARGA & & & & & & \\
\hline Dosificación floc.: & 25 & gramos/ton & lada sólido & & & & \\
\hline
\end{tabular}

\section{DATOS DE SEDIMENTACIÓN}

\begin{tabular}{|c|c|c|c|c|c|c|c|c|c|}
\hline $\begin{array}{l}\text { Tiempo info } \\
\text { (sec) }\end{array}$ & $\begin{array}{c}\text { Tiempo } \\
\text { (min) }\end{array}$ & $\begin{array}{l}\text { Vol. Lodos } \\
\text { (ml) }\end{array}$ & $\begin{array}{l}\text { Altura interf. } \\
\text { (cm) }\end{array}$ & $\begin{array}{c}\text { Velocidad } \\
\text { (m/hr) }\end{array}$ & $\begin{array}{l}\text { SG. Lodos } \\
(\mathrm{g} / \mathrm{cm} 3)\end{array}$ & $\begin{array}{c}\text { Lodos } \\
\% \text { Sol. Peso }\end{array}$ & $\begin{array}{c}\text { Flujo } \\
\text { (tph/m2) }\end{array}$ & $\begin{array}{c}\text { Flujo } \\
\text { (tpd/m2) }\end{array}$ & $\begin{array}{l}\text { Área Unit. Espes. } \\
\text { (m2/tpd) }\end{array}$ \\
\hline 0 & 0 & 1960 & 40,80 & 0 & 1,032 & 4,95 & 0 & 0 & 0 \\
\hline 5 & 0,08 & 1729 & 36,00 & 34,560 & 1,036 & 5,58 & 14,9910 & 359,78 & 0,003 \\
\hline 10 & 0,17 & 1441 & 30,00 & 43,200 & 1,043 & 6,65 & 14,9909 & 359,78 & 0,003 \\
\hline 15 & 0,25 & 1297 & 27,00 & 21,600 & 1,048 & 7,36 & 14,9909 & 359,78 & 0,003 \\
\hline 30 & 0,50 & 672 & 14,00 & 31,200 & 1,093 & 13,61 & 4,9970 & 119,93 & 0,008 \\
\hline 45 & 0,75 & 312 & 6,50 & 18,000 & 1,199 & 26,71 & 4,9970 & 119,93 & 0,008 \\
\hline 60 & 1,00 & 264 & 5,50 & 2,400 & 1,236 & 30,64 & 4,9970 & 119,93 & 0,008 \\
\hline 120 & 2,00 & 202 & 4,20 & 0,780 & 1,309 & 37,88 & 1,2492 & 29,98 & 0,033 \\
\hline 180 & 3,00 & 173 & 3,60 & 0,360 & 1,360 & 42,52 & 1,2492 & 29,98 & 0,033 \\
\hline 240 & 4,00 & 163 & 3,40 & 0,120 & 1,381 & 44,33 & 1,2492 & 29,98 & 0,033 \\
\hline 300 & 5,00 & 158 & 3,30 & 0,060 & 1,393 & 45,30 & 1,2492 & 29,98 & 0,033 \\
\hline 450 & 7,50 & 149 & 3,10 & 0,048 & 1,418 & 47,36 & 0,4997 & 11,99 & 0,083 \\
\hline 600 & 10,00 & 139 & 2,90 & 0,048 & 1,447 & 49,62 & 0,4997 & 11,99 & 0,083 \\
\hline 900 & 15,00 & 134 & 2,80 & 0,012 & 1,463 & 50,83 & 0,2498 & 6,00 & 0,167 \\
\hline 1200 & 20,00 & 130 & 2,70 & 0,012 & 1,480 & 52,10 & 0,2498 & 6,00 & 0,167 \\
\hline 1500 & 25,00 & 125 & 2,60 & 0,012 & 1,499 & 53,44 & 0,2498 & 6,00 & 0,167 \\
\hline 1800 & 30,00 & 125 & 2,60 & 0,000 & 1,499 & 53,44 & 0,2498 & 6,00 & 0,167 \\
\hline 3600 & 60,00 & 125 & 2,60 & 0,000 & 1,499 & 53,44 & 0,0416 & 1,00 & 1,001 \\
\hline 5400 & 90,00 & 125 & 2,60 & 0,000 & 1,499 & 53,44 & 0,0416 & 1,00 & 1,001 \\
\hline 7200 & 120,00 & 125 & 2,60 & 0,000 & 1,499 & 53,44 & 0,0416 & 1,00 & 1,001 \\
\hline 9000 & 150,00 & 125 & 2,60 & 0,000 & 1,499 & 53,44 & 0,0416 & 1,00 & 1,001 \\
\hline 10800 & 180,00 & 125 & 2,60 & 0,000 & 1,499 & 53,44 & 0,0416 & 1,00 & 1,001 \\
\hline 14400 & 240,00 & 125 & 2,60 & 0,000 & 1,499 & 53,44 & 0,0208 & 0,50 & 2,001 \\
\hline
\end{tabular}

DATOS OBTENIDOS:

1a Caída de velocidad: 1 minuto

2a Caída de velocidad, comienzo régimen de compresión: 10 minutos

\% sólidos - tiempo: 52 \% sólidos en peso - 1 hora tiempo residencia 
ENSAYO SEDIMENTACIÓN PROBETA 2000mI ESTÁTICO. ANÁLISIS DE RESULTADOS.

Mina:

Proyecto:

Muestra
Molienda de feldespato

Estudio sedimentación y reología de finos de feldespato

M-005
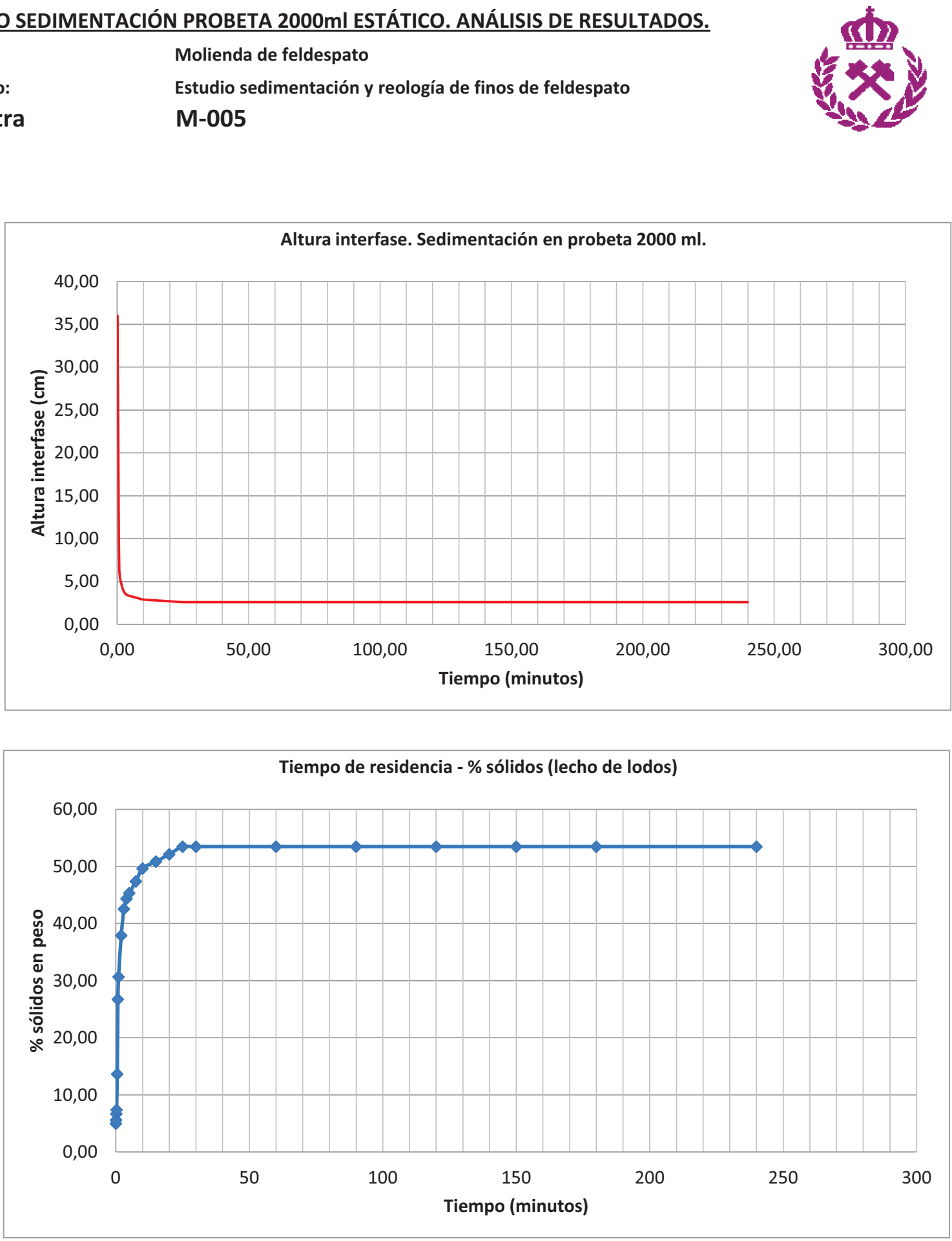


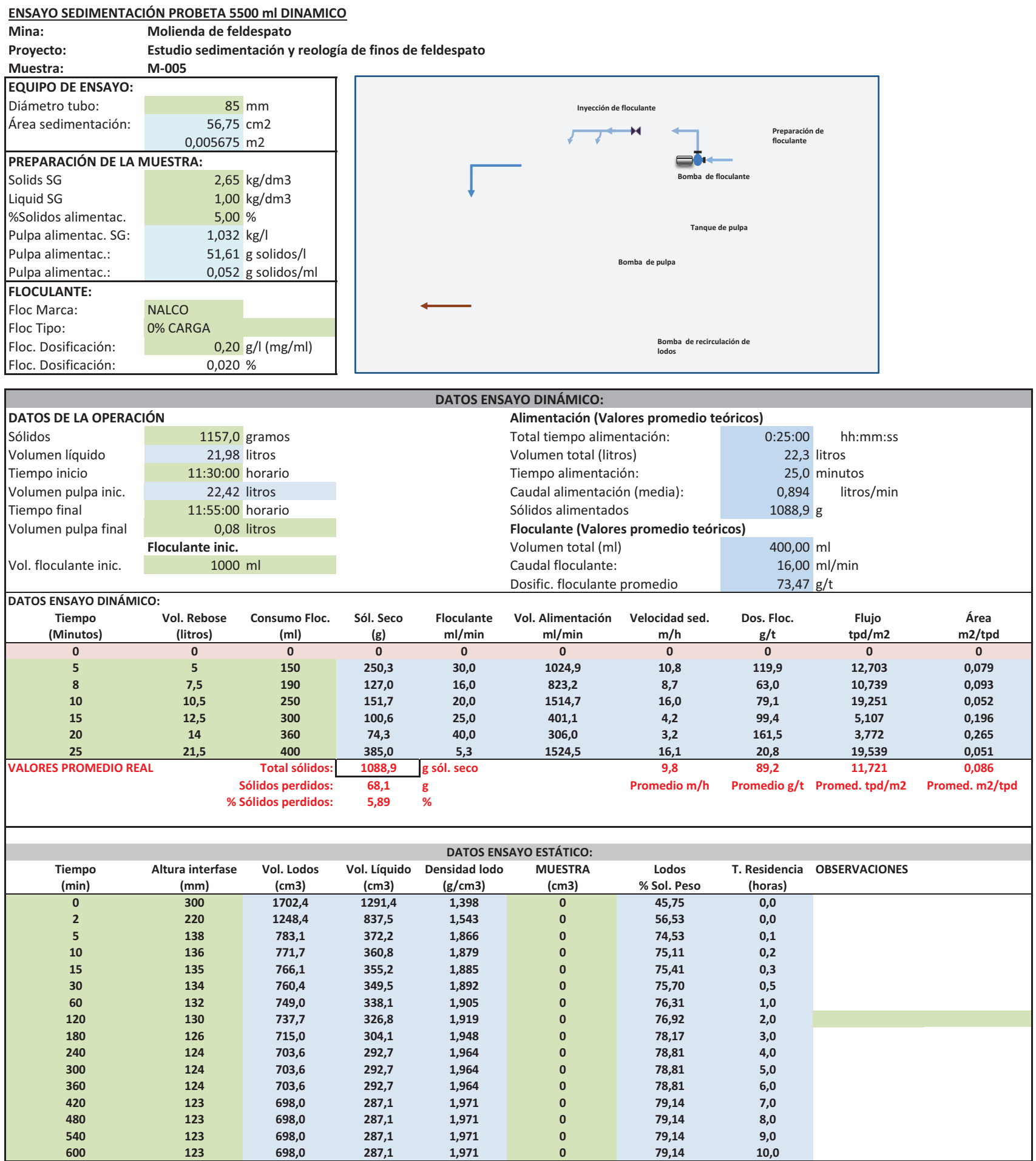


ENSAYO SEDIMENTACIÓN PROBETA 5500 mI DINAMICO

Mina: Molienda de feldespato

Proyecto: $\quad$ Estudio sedimentación y reología de finos de feldespato

Muestra: M-005

DATOS DE OPERACIÓN DEL ESPESADOR DE TUBO PROFUNDO

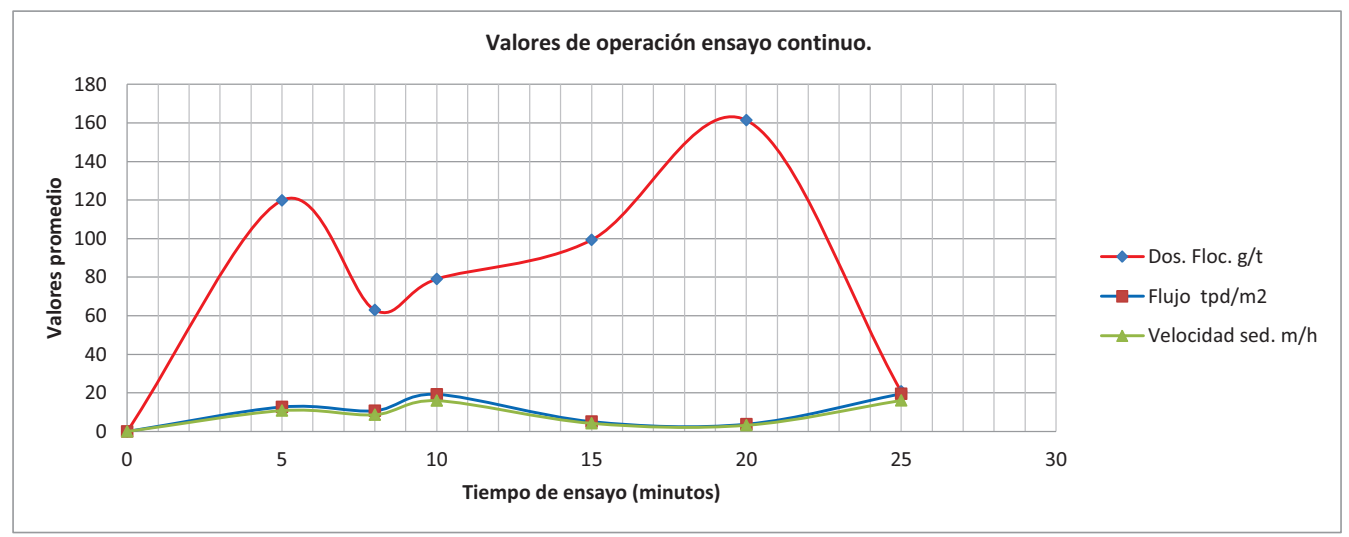

Datos Promedio:

Velocidad de sedimentación:

Dosificación de floculante:

$\begin{array}{cl}9,8 & \mathrm{~m} / \mathrm{h} \\ 89,2 & \mathrm{~g} / \mathrm{t} \\ 0,0859 & \mathrm{~m}^{2} / \mathrm{t} / \mathrm{día} \\ 11,7 & \mathrm{t} / \mathrm{dí} a / \mathrm{m}^{2}\end{array}$

jo de sedimentación:

$11,7 \mathrm{t} / \mathrm{dí} a / \mathrm{m}^{2}$

ENSAYO SEDIMENTACIÓN PROBETA $5500 \mathrm{mI}$ DINAMICO
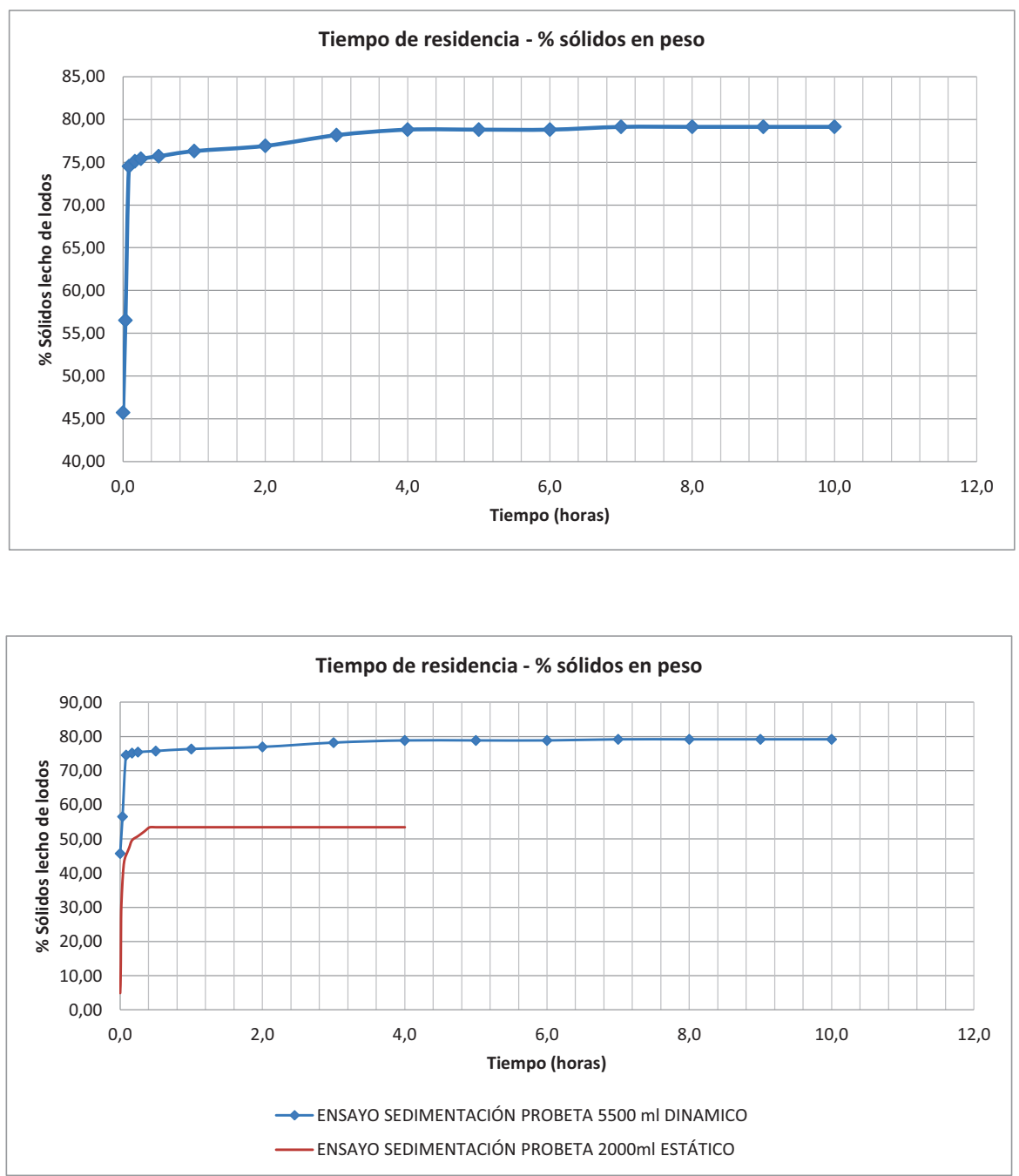


\section{ENSAYO FILTRACIÓN A VACIO}

Mina:

Proyecto:

Material:

Muestra:

Preparado por:

pH muestra:

Fecha:

\section{Molienda de feldespato}

Estudio sedimentación y reología de finos de feldespato

Finos de feldespato potásico

M-005

José A. Butragueño

6

09/08/2013

\begin{tabular}{|c|c|c|}
\hline \multicolumn{3}{|c|}{ DATOS DE LA MUESTRA: } \\
\hline Solidos SG & & $2,65 \mathrm{~kg} / \mathrm{dm} 3$ \\
\hline Liquido SG & & $1,00 \mathrm{~kg} / \mathrm{dm} 3$ \\
\hline \multicolumn{3}{|l|}{ FLOCULANTE: } \\
\hline Floc Name: & No & \\
\hline Tipo de floculante: & No & \\
\hline Floc. Dosificación: & & $0,00 \mathrm{~g} / \mathrm{l}(\mathrm{mg} / \mathrm{ml})$ \\
\hline Floc. Dosificación: & & $0,000 \%$ \\
\hline
\end{tabular}
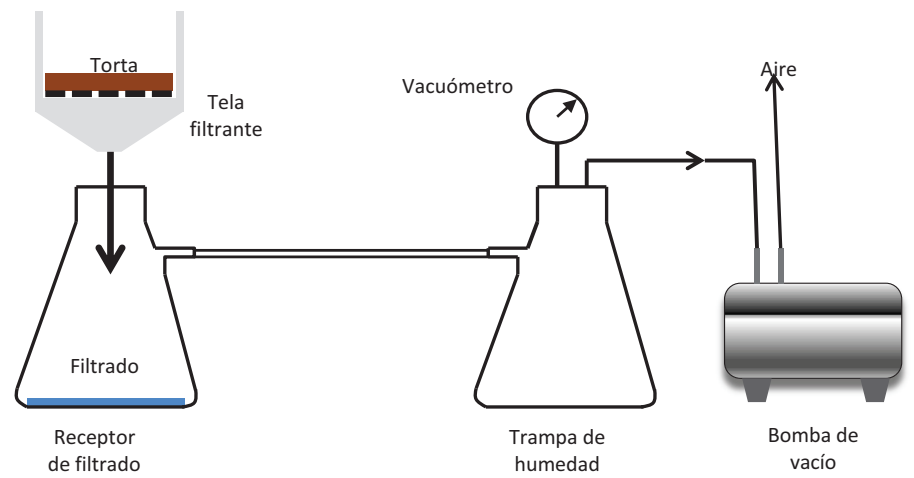

\begin{tabular}{|c|c|c|c|c|c|c|c|c|c|}
\hline \multicolumn{10}{|c|}{ ENSAYO FILTRACIÓN A VACÍO. TEST 1.} \\
\hline \multicolumn{2}{|c|}{ MUESTRA: M-005 } & \multirow[b]{2}{*}{$\begin{array}{l}\text { Vol. Líquido } \\
\text { (ml) }\end{array}$} & \multicolumn{7}{|c|}{ Tiempos de ensayo de filtración } \\
\hline $\begin{array}{l}\text { Vacío } \\
\text { (bar) }\end{array}$ & $\begin{array}{c}\text { Peso sólidos } \\
\text { (g) }\end{array}$ & & $\begin{array}{c}\text { \% Sól. Peso } \\
\text { (\%) }\end{array}$ & $\begin{array}{l}\text { Vol. Pulpa } \\
\text { (ml) }\end{array}$ & $\begin{array}{l}\text { Formación torta } \\
\text { (s) }\end{array}$ & $\begin{array}{l}\text { Secado torta } \\
\text { (s) }\end{array}$ & $\begin{array}{l}\text { Total ciclo } \\
\text { (s) }\end{array}$ & $\begin{array}{l}\text { Líq. Filtrado } \\
(\mathrm{ml})\end{array}$ & $\begin{array}{c}\text { Espesor } \\
(\mathrm{mm})\end{array}$ \\
\hline$-0,6$ & 75 & 300,0 & 20,0 & 328,3 & 70 & 20 & 90 & 275 & 6,0 \\
\hline \% Solidos estimado: & 75,0 & & & & & & & & \\
\hline Peso muestra húmedo: & 85 & $\mathrm{~g}$ & \multirow{4}{*}{\multicolumn{2}{|c|}{ Observaciones: }} & & & & & \\
\hline \multicolumn{3}{|c|}{ Secado de la muestra: } & & & & & & & \\
\hline Peso muestra seco & 75 & $\mathrm{~g}$ & & & & & & & \\
\hline$\%$ humedad torta & 11,76 & $\%$ & & & & & & & \\
\hline
\end{tabular}

\begin{tabular}{|c|c|c|c|c|c|c|c|c|c|}
\hline \multicolumn{10}{|c|}{ ENSAYO FILTRACIÓN A VACÍO. TEST 2.} \\
\hline \multicolumn{2}{|c|}{ MUESTRA: M-005 } & \multirow[b]{2}{*}{$\begin{array}{l}\text { Vol. Líquido } \\
\text { (ml) }\end{array}$} & \multicolumn{7}{|c|}{ Tiempos de ensayo de filtración } \\
\hline $\begin{array}{l}\text { Vacío } \\
\text { (bar) }\end{array}$ & $\begin{array}{l}\text { Peso sólidos } \\
\text { (g) }\end{array}$ & & $\begin{array}{l}\text { \% Sól. Peso } \\
\text { (\%) }\end{array}$ & $\begin{array}{l}\text { Vol. Pulpa } \\
\text { (ml) }\end{array}$ & $\begin{array}{l}\text { Formación torta } \\
\text { (s) }\end{array}$ & $\begin{array}{l}\text { Secado torta } \\
\text { (s) }\end{array}$ & $\begin{array}{l}\text { Total ciclo } \\
\text { (s) }\end{array}$ & $\begin{array}{l}\text { Líq. Filtrado } \\
(\mathrm{ml})\end{array}$ & $\begin{array}{c}\text { Espesor } \\
(\mathrm{mm})\end{array}$ \\
\hline$-0,6$ & 50 & 200,0 & 20,0 & 218,9 & 60 & 10 & 70 & 190 & 4,0 \\
\hline \% Solidos estimado: & 83,3 & & & & & & & & \\
\hline Peso muestra húmedo: & 62 & $\bar{g}$ & \multirow{4}{*}{\multicolumn{2}{|c|}{ Los pesos incluyen la tara }} & & & & & \\
\hline \multicolumn{3}{|c|}{ Secado de la muestra: } & & & & & & & \\
\hline Peso muestra seco & 57 & $\mathrm{~g}$ & & & & & & & \\
\hline$\%$ humedad torta & 8,06 & ]\% & & & & & & & \\
\hline
\end{tabular}

\begin{tabular}{|c|c|c|c|c|c|c|c|c|c|}
\hline \multicolumn{10}{|c|}{ ENSAYO FILTRACIÓN A VACÍO. TEST 3.} \\
\hline \multicolumn{2}{|c|}{ MUESTRA: M-005 } & \multirow[b]{2}{*}{$\begin{array}{l}\text { Vol. Líquido } \\
\text { (ml) }\end{array}$} & \multicolumn{7}{|c|}{ Tiempos de ensayo de filtración } \\
\hline $\begin{array}{l}\text { Vacío } \\
\text { (bar) }\end{array}$ & $\begin{array}{l}\text { Peso sólidos } \\
\text { (g) }\end{array}$ & & $\begin{array}{c}\text { \% Sól. Peso } \\
\text { (\%) }\end{array}$ & $\begin{array}{l}\text { Vol. Pulpa } \\
\text { (ml) }\end{array}$ & $\begin{array}{l}\text { Formación torta } \\
\text { (s) }\end{array}$ & $\begin{array}{l}\text { Secado torta } \\
\text { (s) }\end{array}$ & $\begin{array}{l}\text { Total ciclo } \\
\text { (s) }\end{array}$ & $\begin{array}{l}\text { Líq. Filtrado } \\
\text { (ml) }\end{array}$ & $\begin{array}{c}\text { Espesor } \\
(\mathrm{mm})\end{array}$ \\
\hline$-0,6$ & 40 & 200,0 & 16,7 & 215,1 & 60 & 10 & 70 & 191 & 3,0 \\
\hline \% Solidos estimado: & 81,6 & & & & & & & & \\
\hline Peso muestra húmedo: & 50 & $\mathrm{~g}$ & \multirow{4}{*}{\multicolumn{7}{|c|}{$\begin{array}{l}\text { Observaciones: } \\
\text { Contenido en sólidos de la torta filtrada: } 100-21,71=78,29 \%\end{array}$}} \\
\hline \multicolumn{3}{|c|}{ Secado de la muestra: } & & & & & & & \\
\hline Peso muestra seco & 46 & $\mathrm{~g}$ & & & & & & & \\
\hline$\%$ humedad torta & 8,00 & $\%$ & & & & & & & \\
\hline
\end{tabular}

\begin{tabular}{|c|c|c|c|c|c|c|c|c|c|}
\hline \multicolumn{10}{|c|}{ ENSAYO FILTRACIÓN A VACÍO. TEST 4.} \\
\hline \multicolumn{2}{|c|}{ MUESTRA: M-005 } & \multirow[b]{2}{*}{$\begin{array}{l}\text { Vol. Líquido } \\
\text { (ml) }\end{array}$} & \multicolumn{7}{|c|}{ Tiempos de ensayo de filtración } \\
\hline $\begin{array}{l}\text { Vacío } \\
\text { (bar) }\end{array}$ & $\begin{array}{l}\text { Peso sólidos } \\
\text { (g) }\end{array}$ & & $\begin{array}{c}\text { \% Sól. Peso } \\
\text { (\%) }\end{array}$ & $\begin{array}{l}\text { Vol. Pulpa } \\
\text { (ml) }\end{array}$ & $\begin{array}{l}\text { Formación torta } \\
\text { (s) }\end{array}$ & $\begin{array}{l}\text { Secado torta } \\
\text { (s) }\end{array}$ & $\begin{array}{l}\text { Total ciclo } \\
\text { (s) }\end{array}$ & $\begin{array}{l}\text { Líq. Filtrado } \\
(\mathrm{ml})\end{array}$ & $\begin{array}{c}\text { Espesor } \\
(\mathrm{mm})\end{array}$ \\
\hline$-0,6$ & 50 & 300,0 & 14,3 & 318,9 & 60 & 10 & 70 & 285 & 4,0 \\
\hline$\%$ Solidos estimado: & 76,9 & & & & & & & & \\
\hline Peso muestra húmedo: & 55 & $\bar{g}$ & \multirow{4}{*}{\multicolumn{2}{|c|}{ Observaciones: }} & & & & & \\
\hline Secad & o de la muestra & & & & & & & & \\
\hline Peso muestra seco & 49 & $\mathrm{~g}$ & & & & & & & \\
\hline$\%$ humedad torta & 10,91 & $\%$ & & & & & & & \\
\hline
\end{tabular}




\section{ENSAYO ASENTAMIENTO EN PROBETA}

\begin{tabular}{|ll|}
\hline Mina: & $\begin{array}{l}\text { Molienda de feldespato } \\
\text { Estudio sedimentación y reología de finos de feldespato }\end{array}$ \\
\cline { 2 - 2 } Proyecto: & Finos de feldespato potásico \\
Material: & José A. Butragueño \\
\hline Preparado por: & 6 \\
\hline Fechuestra: & $09 / 08 / 2013$ \\
\hline
\end{tabular}

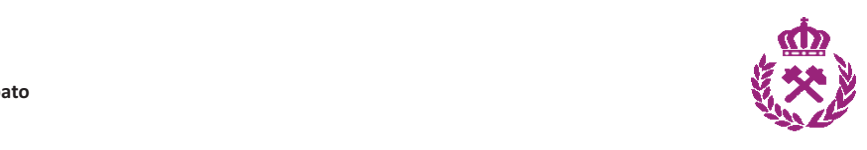
09/08/2013

Aceleración gravedad (s):

$9,81 \mathrm{~m} / \mathrm{s} 2$ $44 \mathrm{~mm}$

Diámetro probeta:

Altura probeta $(\mathrm{H})$

Volumen probeta:

Solidos SG

$100 \mathrm{~mm}$

$152,1 \mathrm{~cm} 3$

$2,65 \mathrm{~kg} / \mathrm{dm} 3$

Líquido SG

$1,00 \mathrm{~kg} / \mathrm{dm} 3$

Expresiones empíricas

$\mathrm{T}=0.5-0.5(\mathrm{~h} / \mathrm{H})^{\wedge} 0.5$

T.F. $=\mathrm{T}^{*} \mathrm{~d}^{*} \mathrm{~g} *(\mathrm{H} / 100)$

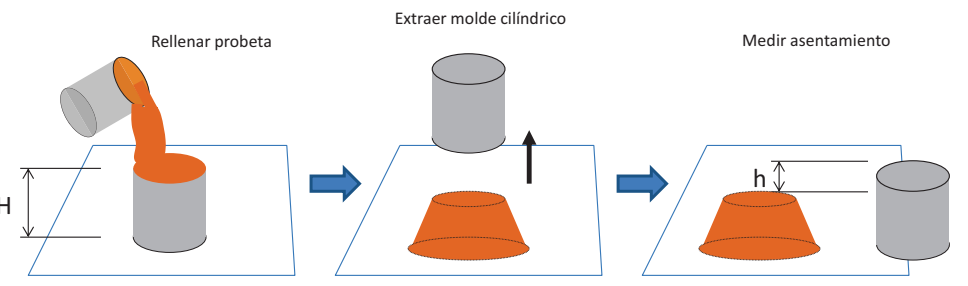

\begin{tabular}{|c|c|c|c|c|c|c|c|c|c|c|}
\hline \multicolumn{11}{|c|}{ ENSAYOS DE ASENTAMIENTO EN PROBETA } \\
\hline $\begin{array}{l}\text { Muestra } \\
\text { ID }\end{array}$ & $\begin{array}{c}\text { Cont. Sólidos } \\
\text { (\%) }\end{array}$ & $\begin{array}{l}\text { Solidos SG } \\
\mathrm{g} / \mathrm{cm} 3\end{array}$ & $\begin{array}{c}\text { Peso Liq. } \\
\text { (kg liq/kg sol) }\end{array}$ & $\begin{array}{l}\text { Vol. Pulpa } \\
\text { (I/kg sol) }\end{array}$ & $\begin{array}{c}\text { Pulpa SG (d) } \\
\text { kg/dm3 }\end{array}$ & $\begin{array}{c}\text { Sólidos prob. } \\
\text { (g) }\end{array}$ & $\begin{array}{l}\text { Liq. Probeta } \\
\text { (g) }\end{array}$ & $\begin{array}{c}\text { Asentamiento }(\mathrm{h}) \\
\mathrm{mm}\end{array}$ & $\begin{array}{l}\text { Factor "T" } \\
\text { Adimens. }\end{array}$ & $\begin{array}{c}\text { Tensión Fluencia } \\
\text { (Pa) }\end{array}$ \\
\hline 1 & 75 & 2,65 & 0,333 & 0,711 & 1,876 & 214,0 & 71,3 & 48 & 0,15359 & 282,7 \\
\hline 2 & 70 & 2,65 & 0,429 & 0,806 & 1,773 & 188,7 & 80,9 & 67 & 0,09073 & 157,8 \\
\hline 3 & 68 & 2,65 & 0,471 & 0,848 & 1,734 & 179,3 & 84,4 & 78 & 0,05841 & 99,4 \\
\hline 4 & 65 & 2,65 & 0,538 & 0,916 & 1,680 & 166,0 & 89,4 & 92 & 0,02042 & 33,6 \\
\hline 5 & 50 & 2,65 & 1,000 & 1,377 & 1,452 & 110,4 & 110,4 & 94 & 0,01523 & 21,7 \\
\hline 6 & 45 & 2,65 & 1,222 & 1,600 & 1,389 & 95,1 & 116,2 & 94 & 0,01523 & 20,8 \\
\hline
\end{tabular}

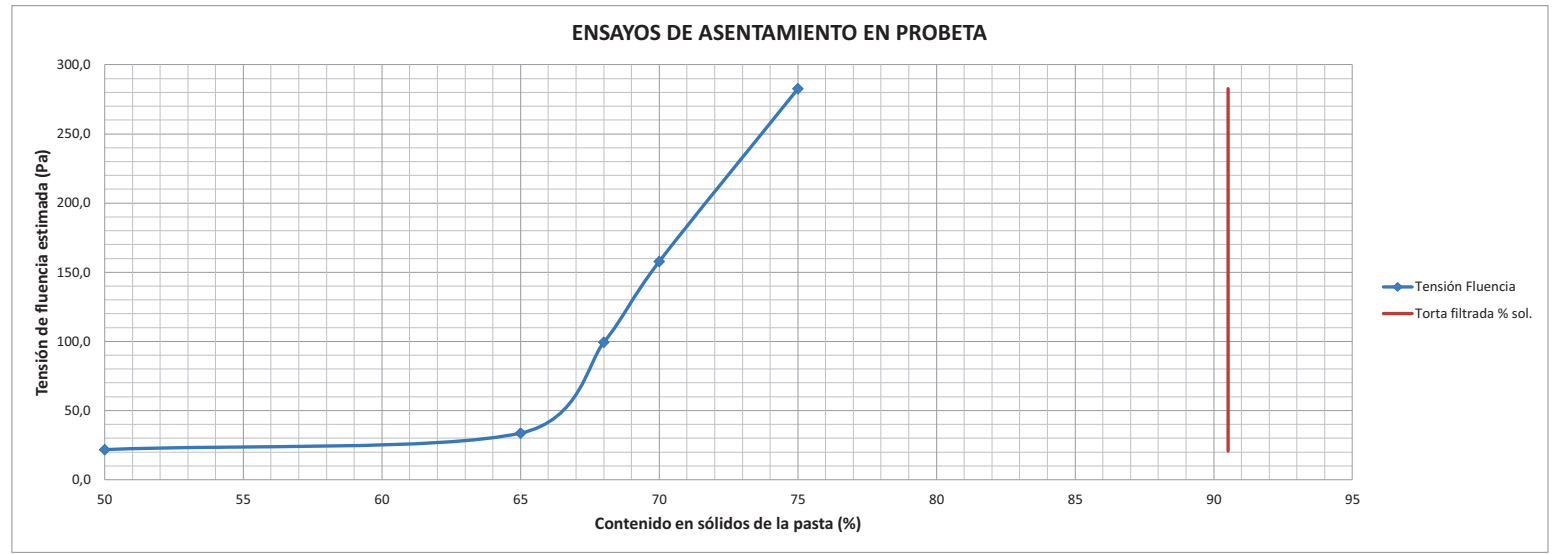

Página 12 de 12 


\section{SEDIMENTACIÓN Y REOLOGÍA}

\section{Mina:}

\section{Laza-Orense}

\section{Empresa:}

JOSÉ BUTRAGUEÑO

\section{Proyecto:}

Estudio sedimentación y reología de estériles espesados

\section{Aplicación}

Sedimentación. Estériles de flotación.

Fecha:

$18 / 08 / 2013$

\section{Ensayos:}

\begin{tabular}{|c|c|}
\hline $\mathbf{x}$ & Distribución granulométrica y caracterización de muestras \\
\hline $\mathbf{x}$ & Selección de floculantes \\
\hline $\mathbf{X}$ & Área de flujo \\
\hline $\mathbf{x}$ & Sedimentación en probeta estática \\
\hline $\mathbf{x}$ & Ensayo en espesador dinámico de laboratorio de $85 \mathrm{~mm}$ DIA \\
\hline $\mathbf{x}$ & Reología de los lodos \\
\hline $\mathbf{X}$ & Ensayo de filtración a vacío \\
\hline
\end{tabular}

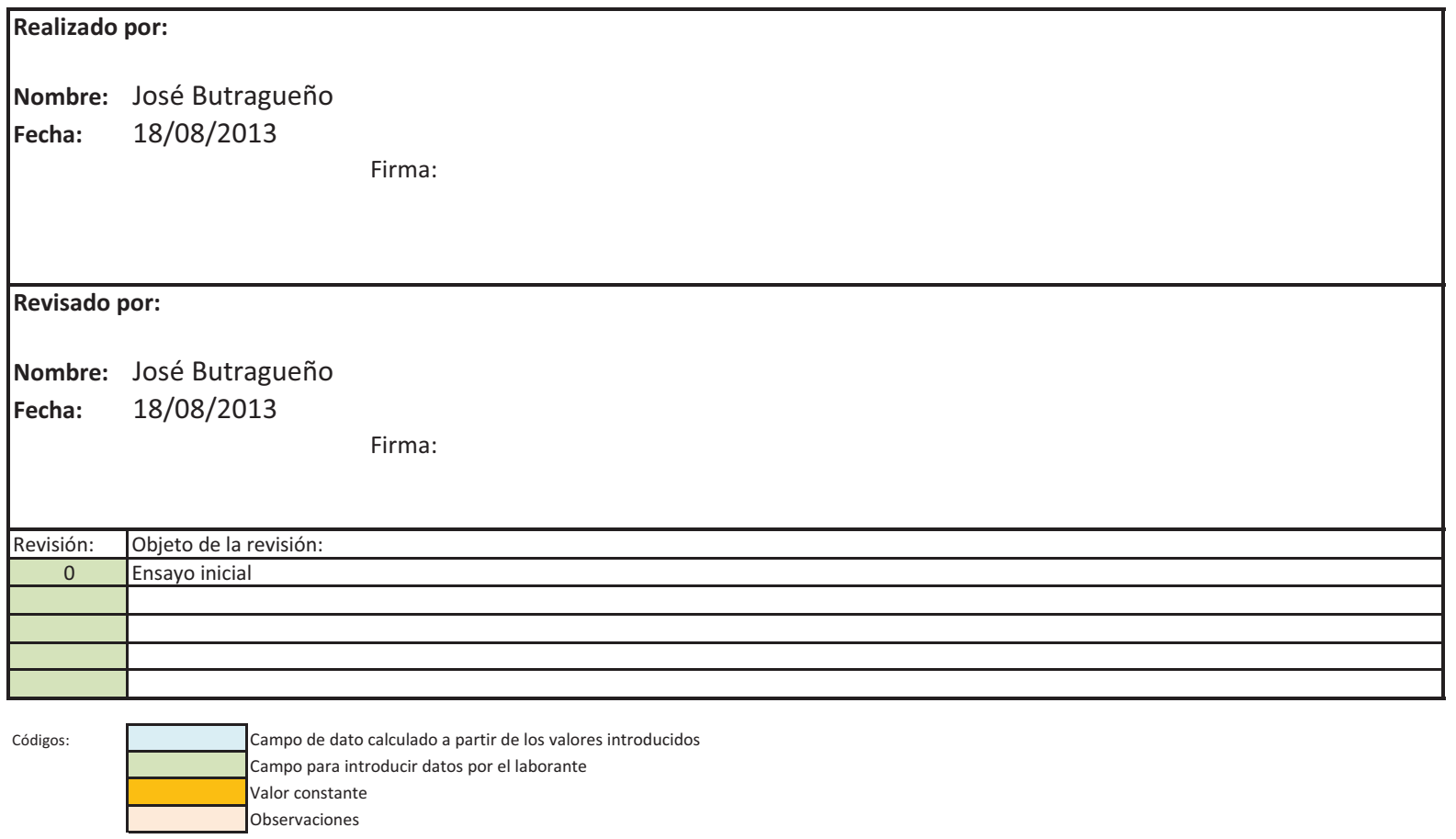

CONFIDENCIAL: Este documento contiene información propiedad de JOSÉ BUTRAGUEÑO y está sujeto a ser

devuelto bajo demanda; estando prohibida su reproducción, copia, préstamo o cualquier otro uso que no sea el fin para el que fue expresamente realizado, sin el consentimiento expreso por escrito de: JOSÉ BUTRAGUEÑO 
ENSAYO GRANULOMÉTRICO DE SÓLIDOS

$\begin{array}{ll}\text { Mina: } & \text { Laza-Orense } \\ \text { Proyecto: } & \text { Estudio sedimentación y reología de estériles espesados } \\ \text { Realizado por: } & \text { José Butragueño }\end{array}$

\begin{tabular}{ll}
\hline Muestra ID: & M-074 \\
Material: & Estériles \\
Preparado por: & José A. Butragueño \\
pH muestra: & - \\
Fecha: & $18 / 08 / 2013$ \\
\hline
\end{tabular}

CURVA GRANULOMÉTRICA DE SÓLIDOS

\begin{tabular}{|c|c|c|c|c|}
\hline \multicolumn{3}{|c|}{ DATOS DE LA PULPA A SEDIMENTAR } & \multicolumn{2}{|c|}{ Observaciones: Muestra de sólido seco } \\
\hline Densidad sólidos: & 2,40 & $\mathrm{~kg} / \mathrm{dm}^{3}$ & & \\
\hline Densidad líquido: & 1,00 & $\mathrm{~kg} / \mathrm{dm}^{3}$ & & \\
\hline Densidad pulpa: & & $\mathrm{kg} / \mathrm{l}$ & & \\
\hline Tara: & 0 & $\mathrm{~g}$ & & \\
\hline Pulpa húmeda: & & g & Peso pulpa: & \begin{tabular}{l|l}
0 & $g$
\end{tabular} \\
\hline Sólido seco: & 0 & g & Peso sólido: & \begin{tabular}{l|l}
0 & $\mathrm{~g}$ \\
\end{tabular} \\
\hline \% Peso sólidos: & \#DIV/0! & $\%$ & & \\
\hline
\end{tabular}

\section{CURVA GRANULOMÉTRICA DE SÓLIDOS}

\begin{tabular}{|c|c|c|c|c|}
\hline \multicolumn{5}{|c|}{ ENSAYO GRANULOMÉTRICO } \\
\hline \multirow{2}{*}{\begin{tabular}{|l|} 
Tamiz \\
Micras \\
\end{tabular}} & \multirow{2}{*}{\begin{tabular}{|l|} 
Pesos \\
Peso Ret. \\
\end{tabular}} & \multicolumn{3}{|c|}{ Porcentajes } \\
\hline & & \% Peso Ret. & $\%$ Ret. Ac. & \%Pasa Ac. \\
\hline 300 & 0 & 0,00 & 0,00 & 100,00 \\
\hline 212 & 0 & 0,00 & 0,00 & 100,00 \\
\hline 100 & 6,1 & 12,20 & 12,20 & 87,80 \\
\hline 75 & 6,7 & 13,40 & 25,60 & 74,40 \\
\hline 63 & 4,5 & 9,00 & 34,60 & 65,40 \\
\hline 50 & 4,4 & 8,80 & 43,40 & 56,60 \\
\hline 38 & 5,1 & 10,20 & 53,60 & 46,40 \\
\hline & 23,2 & 46,40 & 100,00 & 0,00 \\
\hline TOTALES: & 50,0 & 100,0 & & \\
\hline
\end{tabular}

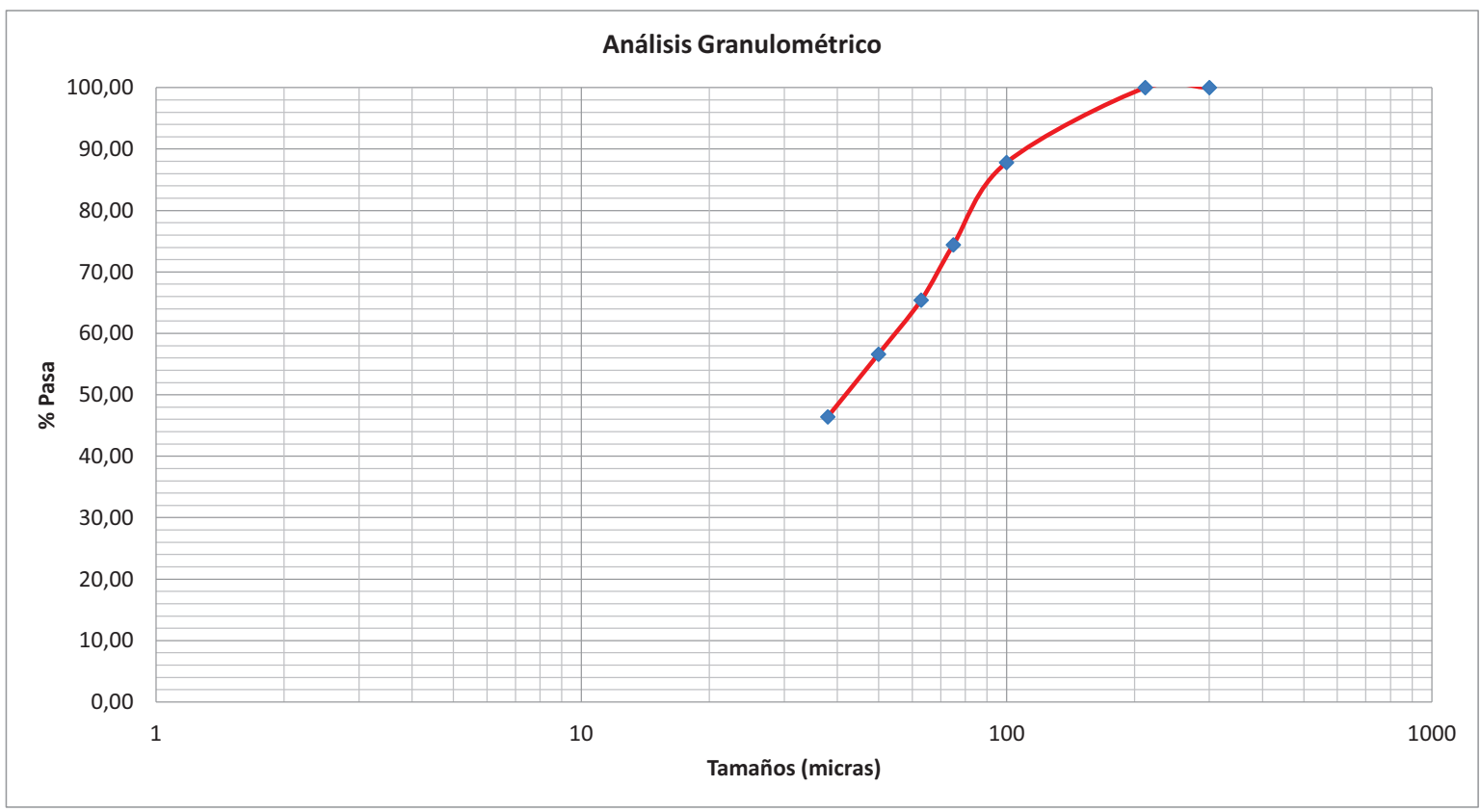




\section{SELECCIÓN DE FLOCULANTE}

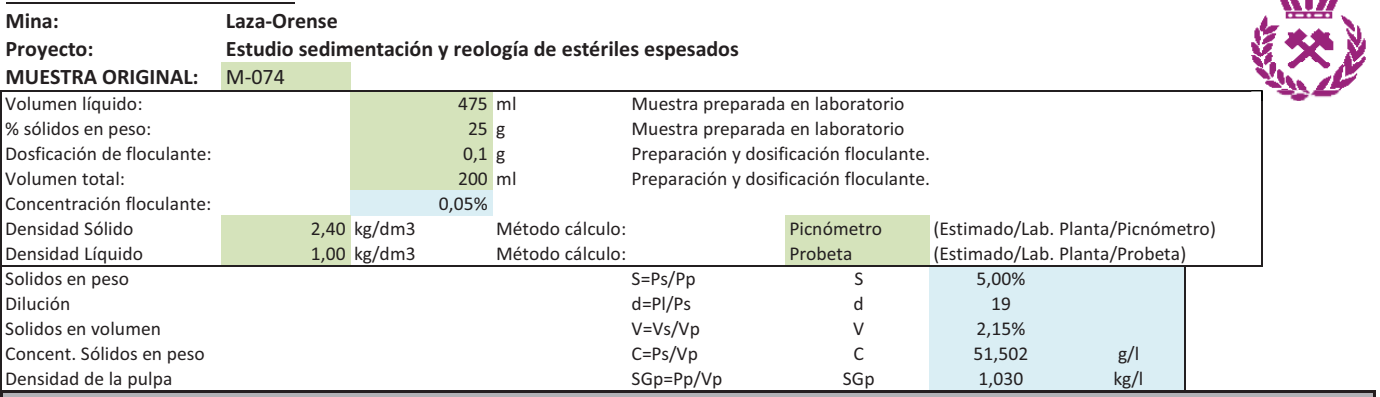

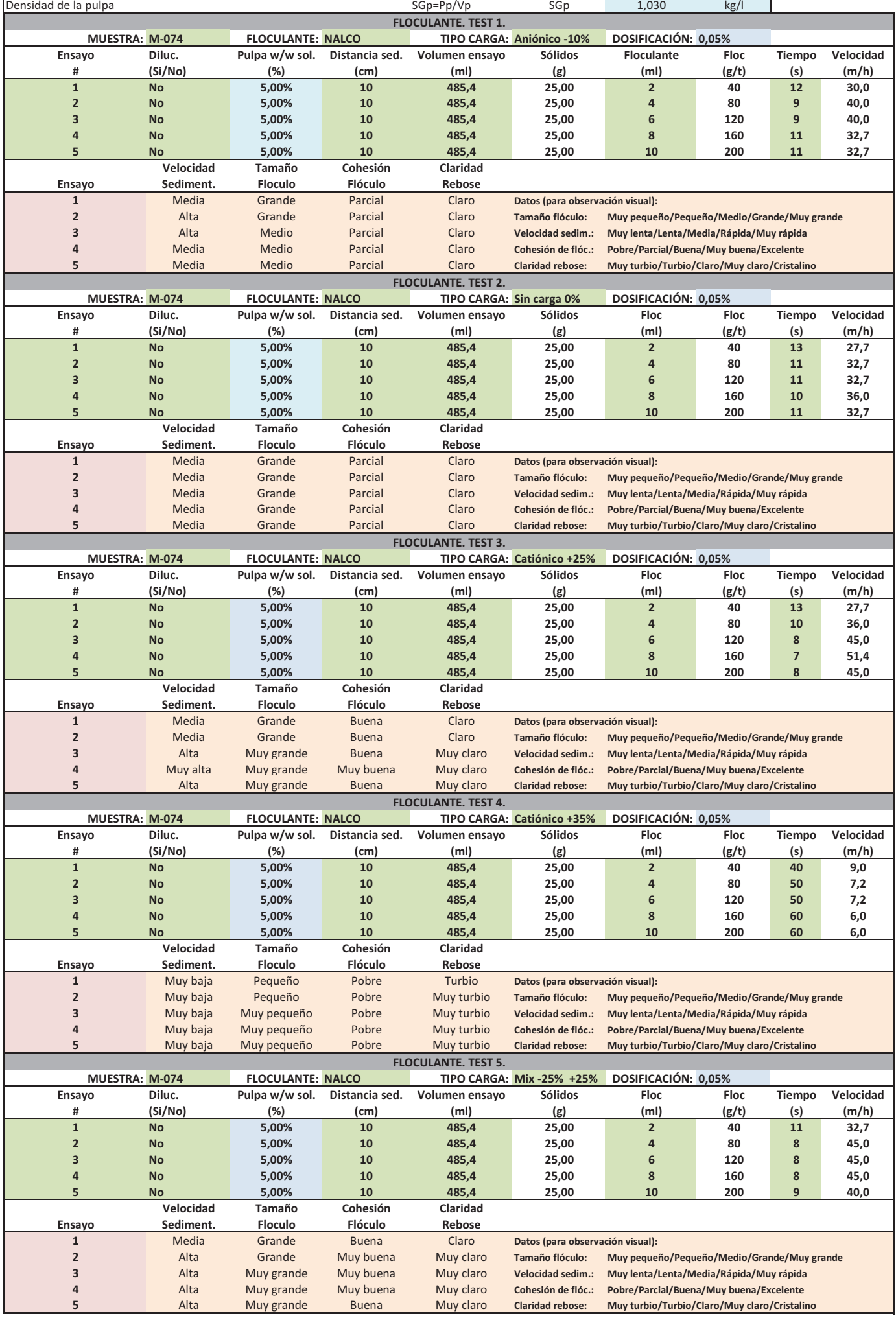


SELECCIÓN DE FLOCULANTE. ANÁLISIS DE DATOS.

Mina:

Proyecto:

MUESTRA ORIGINAL:

Volumen líquido:

$\%$ sólidos en peso:

Dosficación de floculante:

Volumen total:

Concentración floculante:

Densidad Sólido

Densidad Líquido
Laza-Orense

Estudio sedimentación y reología de estériles espesados M-074

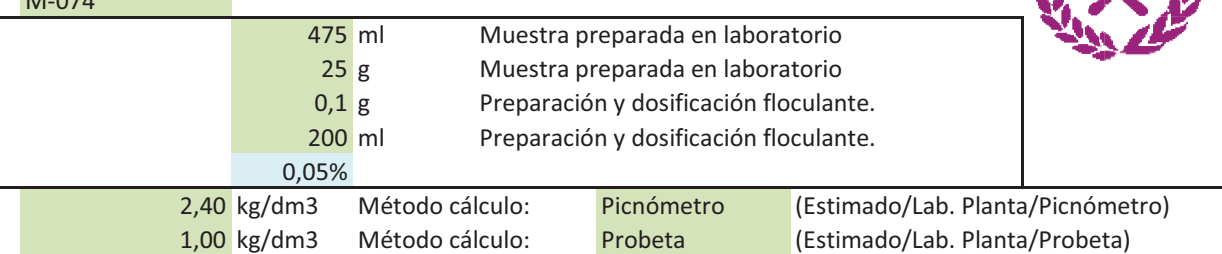

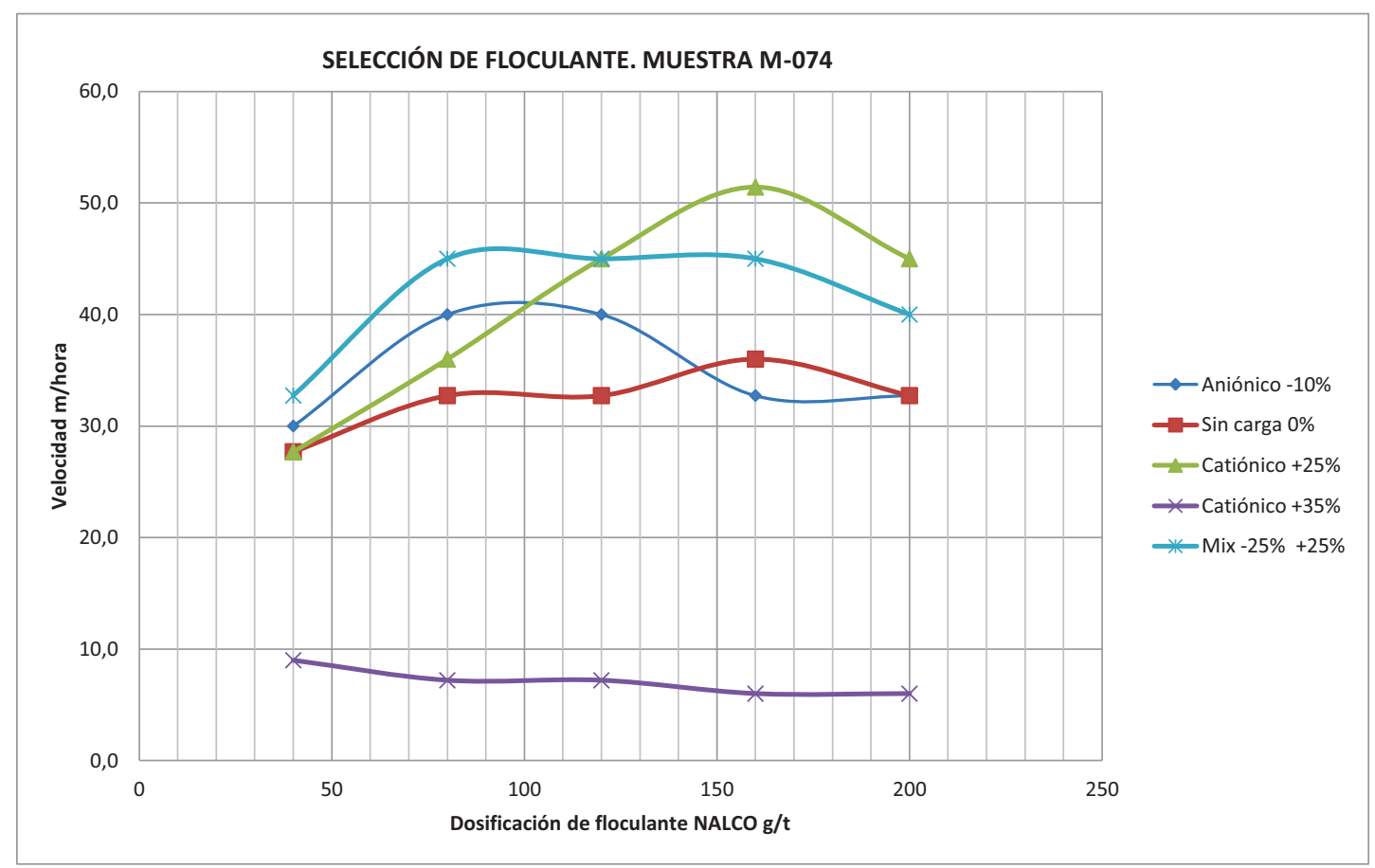

Los ensayos de sedimentación para la selección del floculante han tenido en cuenta tanto los valores de velocidad de sedimentación cómo los datos de observación visual de: tamaño de flóculo, velocidad de sedimentación, cohesión del flóculo y la claridad del rebose obtenida en la probeta de laboratorio. El floculante seleccionado será empleado en los ensayos de flujo de sedimentación. 


\section{ENSAYO FLUJO SEDIMENTACIÓN}

\section{Mina: Laza-Orense}

Proyecto: Estudio sedimentación y reología de estériles espesados

DATOS

FLOCULANTE SELECCIONADO

Volumen probeta: $250 \mathrm{ml}$ MIX NALCO $-25 \%$ An y $25 \%$ Cat.

Diámetro probeta: $\quad 35,7 \mathrm{~mm}$

Área sedimentac. $\quad 10,01 \mathrm{~cm} 2$

Floc. Dosificac.: $\quad 0,2 \mathrm{~g}$

Volumen floc: $\quad 400 \mathrm{ml}$

Floculante dosific. $\quad 0,05 \%$

Floc. Conc. $\quad 0,50 \mathrm{~g} / \mathrm{I}$

Densidad Sólido $\quad 2,40 \mathrm{~kg} / \mathrm{dm} 3$

Densidad Líquido $\quad 1,00 \mathrm{~kg} / \mathrm{dm} 3$

\begin{tabular}{|c|c|c|c|c|c|c|c|c|c|c|c|}
\hline \multicolumn{12}{|c|}{ ENSAYO 1: MIX NALCO -25\% An y 25\%Cat. } \\
\hline \multicolumn{2}{|c|}{ MUESTRA: M-074 } & \multirow{2}{*}{$\begin{array}{l}\text { FLOCULANTE: } \\
\text { Sólidos } \\
(\% \mathrm{w} / \mathrm{w})\end{array}$} & \multicolumn{2}{|c|}{ MIX NALCO $-25 \%$ An y $25 \%$ Cat. } & \multirow[b]{2}{*}{$\begin{array}{c}\text { Floculant. } \\
(\mathrm{ml})\end{array}$} & \multirow{2}{*}{$\begin{array}{l}\text { DOSIFICACIÓN } \\
\text { Dist. Sediment. } \\
(\mathrm{cm})\end{array}$} & \multirow{2}{*}{$\begin{array}{c}0,50 \\
\text { Tiempo sed. } \\
\text { (s) }\end{array}$} & \multirow{2}{*}{$\begin{array}{l}\mathrm{g} / \mathrm{l} \\
\begin{array}{c}\text { Velocidad sed. } \\
(\mathrm{m} / \mathrm{h})\end{array}\end{array}$} & \multirow[b]{2}{*}{$\begin{array}{c}\text { Floc dosific. } \\
(\mathrm{g} / \mathrm{t})\end{array}$} & \multirow[b]{2}{*}{$\begin{array}{c}\text { Flujo } \\
\text { (tph/m2) }\end{array}$} & \multirow[b]{2}{*}{$\begin{array}{c}\begin{array}{c}\text { Flujo } \\
\text { (tpd/m2) }\end{array} \\
\text { (t) }\end{array}$} \\
\hline $\begin{array}{c}\text { Peso sólidos } \\
\text { (g) }\end{array}$ & $\begin{array}{c}\text { Vol. líquido } \\
(\mathrm{ml})\end{array}$ & & $\begin{array}{c}\text { Densidad pulpa } \\
(\mathrm{kg} / \mathrm{l})\end{array}$ & $\begin{array}{c}\text { Conc. Solids } \\
\text { (g/l) }\end{array}$ & & & & & & & \\
\hline 23,0 & 200 & 10,31 & 1,064 & 109,74 & 1 & 7,5 & 30 & 9,0 & 22 & 2,76 & 66,18 \\
\hline 23,0 & 200 & 10,31 & 1,064 & 109,74 & 2 & 7,5 & 27 & 10,0 & 43 & 3,06 & 73,53 \\
\hline 23,0 & 200 & 10,31 & 1,064 & 109,74 & 3 & 7,5 & 28 & 9,6 & 65 & 2,95 & 70,90 \\
\hline 23,0 & 200 & 10,31 & 1,064 & 109,74 & 4 & 7,5 & 23 & 11,7 & 87 & 3,60 & 86,32 \\
\hline 23,0 & 200 & 10,31 & 1,064 & 109,74 & 5 & 7,5 & 20 & 13,5 & 109 & 4,14 & 99,26 \\
\hline 23,0 & 200 & 10,31 & 1,064 & 109,74 & 6 & 7,5 & 19 & 14,2 & 130 & 4,35 & 104,49 \\
\hline & & & & & & & MEDIA: & 10,9 & 76,1 & 3,3 & 79,9 \\
\hline
\end{tabular}

\begin{tabular}{|c|c|c|c|c|c|c|c|c|c|c|c|}
\hline \multirow{2}{*}{\multicolumn{12}{|c|}{ ENSAYO 2: MIX NALCO $-25 \%$ An y $25 \%$ Cat. }} \\
\hline & & & & & & & & & & & \\
\hline \multicolumn{2}{|c|}{ MUESTRA: M-074 } & \multirow{2}{*}{$\begin{array}{l}\text { FLOCULANTE: } \\
\text { Sólidos } \\
(\% \mathrm{w} / \mathrm{w})\end{array}$} & \multicolumn{2}{|c|}{ MIX NALCO $-25 \%$ An y $25 \%$ Cat. } & \multicolumn{2}{|r|}{ DOSIFICACIÓN: } & \multirow{2}{*}{$\begin{array}{l}0,50 \\
\text { Tiempo sed. } \\
\text { (s) }\end{array}$} & \multicolumn{4}{|l|}{$\mathrm{g} / \mathrm{I}$} \\
\hline $\begin{array}{l}\text { Peso sólidos } \\
\text { (g) }\end{array}$ & $\begin{array}{l}\text { Vol. líquido } \\
\text { (ml) }\end{array}$ & & $\begin{array}{c}\text { Densidad pulpa } \\
(\mathrm{kg} / \mathrm{l})\end{array}$ & $\begin{array}{l}\text { Conc. Solids } \\
\text { (g/l) }\end{array}$ & $\begin{array}{l}\text { Floculant. } \\
\text { (ml) }\end{array}$ & $\begin{array}{l}\text { Dist. Sediment. } \\
(\mathrm{cm})\end{array}$ & & $\begin{array}{c}\text { Velocidad sed. } \\
(\mathrm{m} / \mathrm{h})\end{array}$ & $\begin{array}{l}\text { Floc dosific. } \\
(\mathrm{g} / \mathrm{t})\end{array}$ & $\begin{array}{c}\text { Flujo } \\
\text { (tph/m2) }\end{array}$ & $\begin{array}{c}\text { Flujo } \\
\text { (tpd/m2) }\end{array}$ \\
\hline 16 & 200 & 7,41 & 1,045 & 77,42 & 1 & 7,5 & 16 & 16,9 & 31 & 3,60 & 86,32 \\
\hline 16 & 200 & 7,41 & 1,045 & 77,42 & 2 & 7,5 & 12 & 22,5 & 63 & 4,80 & 115,09 \\
\hline 16 & 200 & 7,41 & 1,045 & 77,42 & 3 & 7,5 & 9 & 30,0 & 94 & 6,39 & 153,45 \\
\hline 16 & 200 & 7,41 & 1,045 & 77,42 & 4 & 7,5 & 10 & 27,0 & 125 & 5,75 & 138,10 \\
\hline 16 & 200 & 7,41 & 1,045 & 77,42 & 5 & 7,5 & 9 & 30,0 & 156 & 6,39 & 153,45 \\
\hline 16 & 200 & 7,41 & 1,045 & 77,42 & 6 & 7,5 & 10 & 27,0 & 188 & 5,75 & 138,10 \\
\hline & & & & & & & MEDIA: & 27,0 & 109,4 & 5,8 & 138,1 \\
\hline
\end{tabular}

MUESTRA SÓLIDOS

M-074

\begin{tabular}{|c|c|}
\hline Diámetro & betas: \\
\hline $250 \mathrm{ml}$ & 35,7 \\
\hline $500 \mathrm{ml}$ & 48,6 \\
\hline $000 \mathrm{ml}$ & 78,2 \\
\hline
\end{tabular}

\begin{tabular}{|c|c|c|c|c|c|c|c|c|c|c|c|}
\hline \multicolumn{2}{|c|}{ MUESTRA: M-074 } & \multirow{2}{*}{$\begin{array}{c}\text { FLOCULANTE: } \\
\text { Sólidos } \\
(\% \mathrm{w} / \mathrm{w})\end{array}$} & \multicolumn{2}{|c|}{ MIX NALCO $-25 \%$ An y $25 \%$ Cat. } & \multicolumn{2}{|r|}{ DOSIFICACIÓN: } & 0,50 & \multicolumn{4}{|l|}{$\mathrm{g} / \mathrm{I}$} \\
\hline $\begin{array}{c}\text { Peso sólidos } \\
\text { (g) }\end{array}$ & $\begin{array}{c}\text { Vol. líquido } \\
\text { (ml) }\end{array}$ & & $\begin{array}{c}\text { Densidad pulpa } \\
(\mathrm{kg} / \mathrm{l})\end{array}$ & $\begin{array}{c}\text { Conc. Solids } \\
\text { (g/l) }\end{array}$ & $\begin{array}{c}\text { Floculant. } \\
(\mathrm{ml})\end{array}$ & $\begin{array}{l}\text { Dist. Sediment. } \\
\text { (cm) }\end{array}$ & $\begin{array}{c}\text { Tiempo sed. } \\
\text { (s) }\end{array}$ & $\begin{array}{l}\text { Velocidad sed. } \\
(\mathrm{m} / \mathrm{h})\end{array}$ & $\begin{array}{l}\text { Floc dosific. } \\
(\mathrm{g} / \mathrm{t})\end{array}$ & $\begin{array}{c}\text { Flujo } \\
\text { (tph/m2) }\end{array}$ & $\begin{array}{c}\begin{array}{c}\text { Flujo } \\
\text { (tpd/m2) }\end{array} \\
\text { (n) }\end{array}$ \\
\hline 10 & 200 & 4,76 & 1,029 & 48,98 & 1 & 7,5 & 9 & 30,0 & 50 & 4,00 & 95,91 \\
\hline 10 & 200 & 4,76 & 1,029 & 48,98 & 1,5 & 7,5 & 6 & 45,0 & 75 & 5,99 & 143,86 \\
\hline 10 & 200 & 4,76 & 1,029 & 48,98 & 2 & 7,5 & 6 & 45,0 & 100 & 5,99 & 143,86 \\
\hline 10 & 200 & 4,76 & 1,029 & 48,98 & 3 & 7,5 & 6 & 45,0 & 150 & 5,99 & 143,86 \\
\hline 10 & 200 & 4,76 & 1,029 & 48,98 & 4 & 7,5 & 6 & 45,0 & 200 & 5,99 & 143,86 \\
\hline 10 & 200 & 4,76 & 1,029 & 48,98 & 5 & 7,5 & 6 & 45,0 & 250 & 5,99 & 143,86 \\
\hline & & & & & & & MEDIA: & 45,0 & 125,0 & 6,0 & 143,9 \\
\hline
\end{tabular}

ENSAYO 4: MIX NALCO -25\% An y 25\%Cat.

\begin{tabular}{|c|c|c|c|c|c|c|c|c|c|c|c|}
\hline \multicolumn{12}{|c|}{ ENSAYO 4: MIX NALCO $-25 \%$ An y $25 \%$ Cat. } \\
\hline \multicolumn{2}{|c|}{ MUESTRA: M-074 } & \multirow{2}{*}{$\begin{array}{l}\text { FLOCULANTE: } \\
\text { Sólidos } \\
(\% \mathrm{w} / \mathrm{w}) \\
\end{array}$} & \multicolumn{2}{|c|}{ MIX NALCO $-25 \%$ An y $25 \%$ Cat. } & \multicolumn{2}{|c|}{ DOSIFICACIÓN: } & \multirow{2}{*}{$\begin{array}{c}0,50 \\
\text { Tiempo sed. } \\
\text { (s) }\end{array}$} & \multirow{2}{*}{$\begin{array}{l}\mathrm{g} / \mathrm{l} \\
\begin{array}{c}\text { Velocidad sed. } \\
(\mathrm{m} / \mathrm{h})\end{array}\end{array}$} & \multirow[b]{2}{*}{$\begin{array}{l}\text { Floc dosific. } \\
(\mathrm{g} / \mathrm{t})\end{array}$} & \multirow[b]{2}{*}{$\begin{array}{c}\text { Flujo } \\
\text { (tph/m2) }\end{array}$} & \multirow[b]{2}{*}{$\begin{array}{c}\text { Flujo } \\
\text { (tpd/m2) }\end{array}$} \\
\hline $\begin{array}{c}\text { Peso sólidos } \\
\text { (g) }\end{array}$ & $\begin{array}{l}\text { Vol. líquido } \\
\text { (ml) }\end{array}$ & & $\begin{array}{c}\text { Densidad pulpa } \\
(\mathrm{kg} / \mathrm{l})\end{array}$ & $\begin{array}{l}\text { Conc. Solids } \\
\text { (g/l) }\end{array}$ & $\begin{array}{l}\text { Floculant. } \\
(\mathrm{ml})\end{array}$ & $\begin{array}{l}\text { Dist. Sediment. } \\
(\mathrm{cm})\end{array}$ & & & & & \\
\hline 6 & 200 & 2,91 & 1,017 & 29,63 & 0,25 & 7,5 & 9 & 30,0 & 21 & 2,40 & 57,543 \\
\hline 6 & 200 & 2,91 & 1,017 & 29,63 & 0,5 & 7,5 & 6 & 45,0 & 42 & 3,60 & 86,315 \\
\hline 6 & 200 & 2,91 & 1,017 & 29,63 & 1 & 7,5 & 6 & 45,0 & 83 & 3,60 & 86,315 \\
\hline 6 & 200 & 2,91 & 1,017 & 29,63 & 1,5 & 7,5 & 6 & 45,0 & 125 & 3,60 & 86,315 \\
\hline 6 & 200 & 2,91 & 1,017 & 29,63 & 2 & 7,5 & 6 & 45,0 & 167 & 3,60 & 86,315 \\
\hline 6 & 200 & 2,91 & 1,017 & 29,63 & 3 & 7,5 & 6 & 45,0 & 250 & 3,60 & 86,315 \\
\hline & & & & & & & MEDIA: & 45,0 & 104,2 & 3,6 & 86,3 \\
\hline
\end{tabular}


ENSAYO FLUJO SEDIMENTACIÓN. ANÁLISIS DE RESULTADOS.

Mina:

Proyecto:

DATOS

Volumen probeta:

Diámetro probeta:

Área sedimentac.

Floc. Dosificac.:

Volumen floc:

Floculante dosific

Floc. Conc.

Densidad Sólido

Densidad Líquido
Laza-Orense

Estudio sedimentación y reología de estériles espesados

FLOCULANTE SELECCIONADO

MIX NALCO $-25 \%$ An y $25 \%$ Cat.

$250 \mathrm{ml}$

$35,7 \mathrm{~mm}$

$10,01 \mathrm{~cm} 2$

$0,2 \mathrm{~g}$

$400 \mathrm{ml}$

$0,05 \%$

$0,50 \mathrm{~g} / \mathrm{l}$

$2,40 \mathrm{~kg} / \mathrm{dm} 3$

$1,00 \mathrm{~kg} / \mathrm{dm} 3$

\section{MUESTRA SÓLIDOS}

M-074

Diámetros de probetas:

$250 \mathrm{ml} \quad 35,7 \quad \mathrm{~mm}$

$500 \mathrm{ml} \quad 48,6 \quad \mathrm{~mm}$

$2000 \mathrm{ml} \quad 78,2 \quad \mathrm{~mm}$
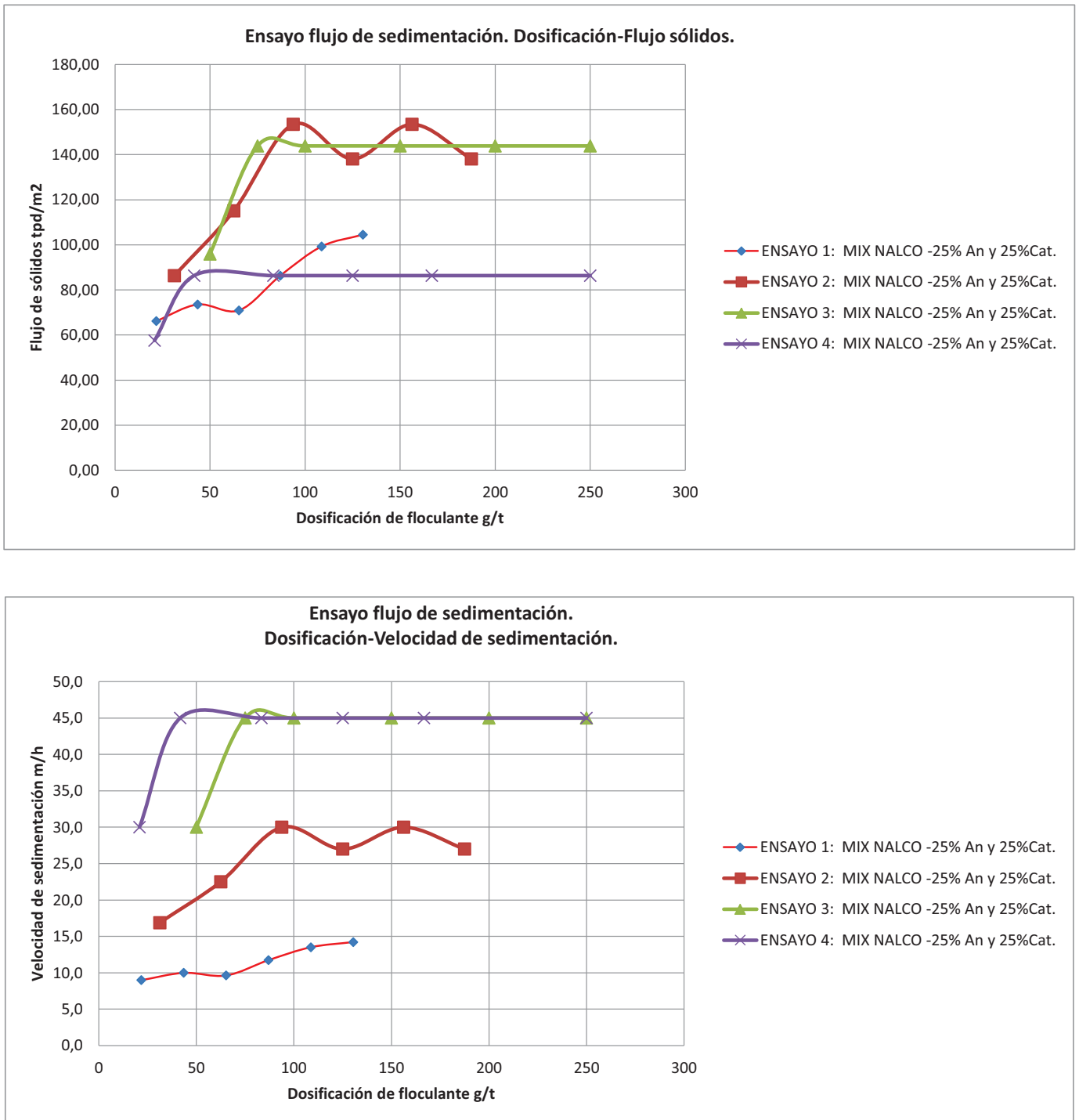

Los ensayos de flujos de sedimentación determinan la dilución óptima de los sólidos para la alimentación en el espesador.

El valor obtenido sirve de base para el diseño de la campana de alimentación y el sistema de dilución previsto. 


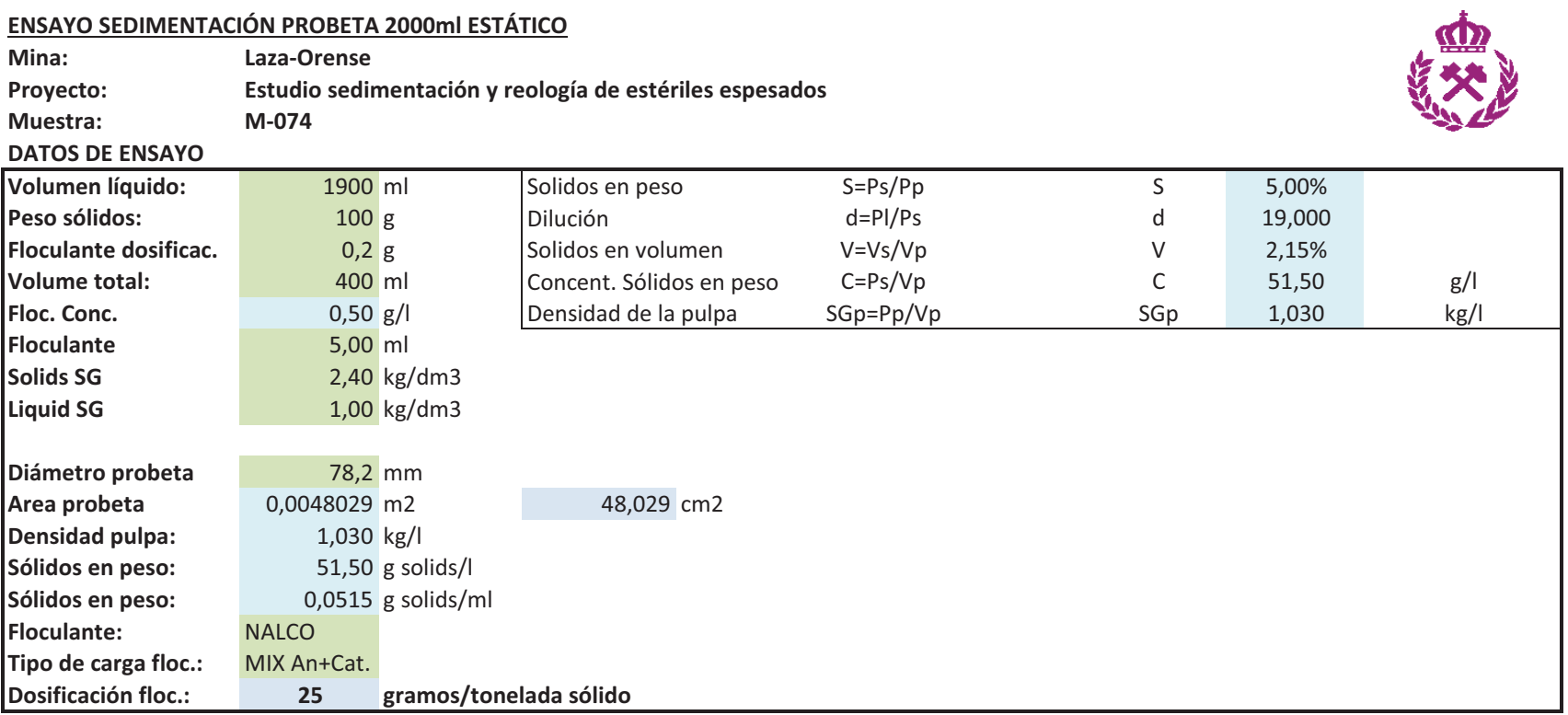

\section{DATOS DE SEDIMENTACIÓN}

\begin{tabular}{|c|c|c|c|c|c|c|c|c|c|}
\hline $\begin{array}{l}\text { Tiempo info } \\
\text { (sec) }\end{array}$ & $\begin{array}{c}\text { Tiempo } \\
\text { (min) }\end{array}$ & $\begin{array}{l}\text { Vol. Lodos } \\
\text { (ml) }\end{array}$ & $\begin{array}{l}\text { Altura interf. } \\
\text { (cm) }\end{array}$ & $\begin{array}{c}\text { Velocidad } \\
\text { (m/hr) }\end{array}$ & $\begin{array}{l}\text { SG. Lodos } \\
(\mathrm{g} / \mathrm{cm} 3)\end{array}$ & $\begin{array}{c}\text { Lodos } \\
\% \text { Sol. Peso }\end{array}$ & $\begin{array}{c}\text { Flujo } \\
\text { (tph/m2) }\end{array}$ & $\begin{array}{c}\text { Flujo } \\
\text { (tpd/m2) }\end{array}$ & $\begin{array}{l}\text { Área Unit. Espes. } \\
\text { (m2/tpd) }\end{array}$ \\
\hline 0 & 0 & 1969 & 41,00 & 0 & 1,030 & 4,93 & 0 & 0 & 0 \\
\hline 5 & 0,08 & 1825 & 38,00 & 21,600 & 1,032 & 5,31 & 14,9910 & 359,78 & 0,003 \\
\hline 10 & 0,17 & 1681 & 35,00 & 21,600 & 1,035 & 5,75 & 14,9909 & 359,78 & 0,003 \\
\hline 15 & 0,25 & 1441 & 30,00 & 36,000 & 1,040 & 6,67 & 14,9909 & 359,78 & 0,003 \\
\hline 30 & 0,50 & 1057 & 22,00 & 19,200 & 1,055 & 8,97 & 4,9970 & 119,93 & 0,008 \\
\hline 45 & 0,75 & 720 & 15,00 & 16,800 & 1,081 & 12,84 & 4,9970 & 119,93 & 0,008 \\
\hline 60 & 1,00 & 360 & 7,50 & 18,000 & 1,162 & 23,89 & 4,9970 & 119,93 & 0,008 \\
\hline 120 & 2,00 & 250 & 5,20 & 1,380 & 1,234 & 32,46 & 1,2492 & 29,98 & 0,033 \\
\hline 180 & 3,00 & 216 & 4,50 & 0,420 & 1,270 & 36,43 & 1,2492 & 29,98 & 0,033 \\
\hline 240 & 4,00 & 197 & 4,10 & 0,240 & 1,296 & 39,18 & 1,2492 & 29,98 & 0,033 \\
\hline 300 & 5,00 & 183 & 3,80 & 0,180 & 1,320 & 41,52 & 1,2492 & 29,98 & 0,033 \\
\hline 450 & 7,50 & 178 & 3,70 & 0,024 & 1,328 & 42,37 & 0,4997 & 11,99 & 0,083 \\
\hline 600 & 10,00 & 173 & 3,60 & 0,024 & 1,337 & 43,25 & 0,4997 & 11,99 & 0,083 \\
\hline 900 & 15,00 & 168 & 3,50 & 0,012 & 1,347 & 44,16 & 0,2498 & 6,00 & 0,167 \\
\hline 1200 & 20,00 & 163 & 3,40 & 0,012 & 1,357 & 45,12 & 0,2498 & 6,00 & 0,167 \\
\hline 1500 & 25,00 & 163 & 3,40 & 0,000 & 1,357 & 45,12 & 0,2498 & 6,00 & 0,167 \\
\hline 1800 & 30,00 & 163 & 3,40 & 0,000 & 1,357 & 45,12 & 0,2498 & 6,00 & 0,167 \\
\hline 3600 & 60,00 & 163 & 3,40 & 0,000 & 1,357 & 45,12 & 0,0416 & 1,00 & 1,001 \\
\hline 5400 & 90,00 & 158 & 3,30 & 0,002 & 1,368 & 46,12 & 0,0416 & 1,00 & 1,001 \\
\hline 7200 & 120,00 & 158 & 3,30 & 0,000 & 1,368 & 46,12 & 0,0416 & 1,00 & 1,001 \\
\hline 9000 & 150,00 & 158 & 3,30 & 0,000 & 1,368 & 46,12 & 0,0416 & 1,00 & 1,001 \\
\hline 10800 & 180,00 & 158 & 3,30 & 0,000 & 1,368 & 46,12 & 0,0416 & 1,00 & 1,001 \\
\hline 14400 & 240,00 & 158 & 3,30 & 0,000 & 1,368 & 46,12 & 0,0208 & 0,50 & 2,001 \\
\hline
\end{tabular}

DATOS OBTENIDOS:

1a Caída de velocidad: 1 minuto

2a Caída de velocidad, comienzo régimen de compresión: 5 minutos

\% sólidos - tiempo: 45 \% sólidos en peso - 1 hora tiempo residencia 
ENSAYO SEDIMENTACIÓN PROBETA 2000mI ESTÁTICO. ANÁLISIS DE RESULTADOS.

Mina:

Proyecto:

Muestra
Laza-Orense

Estudio sedimentación y reología de estériles espesados

M-074
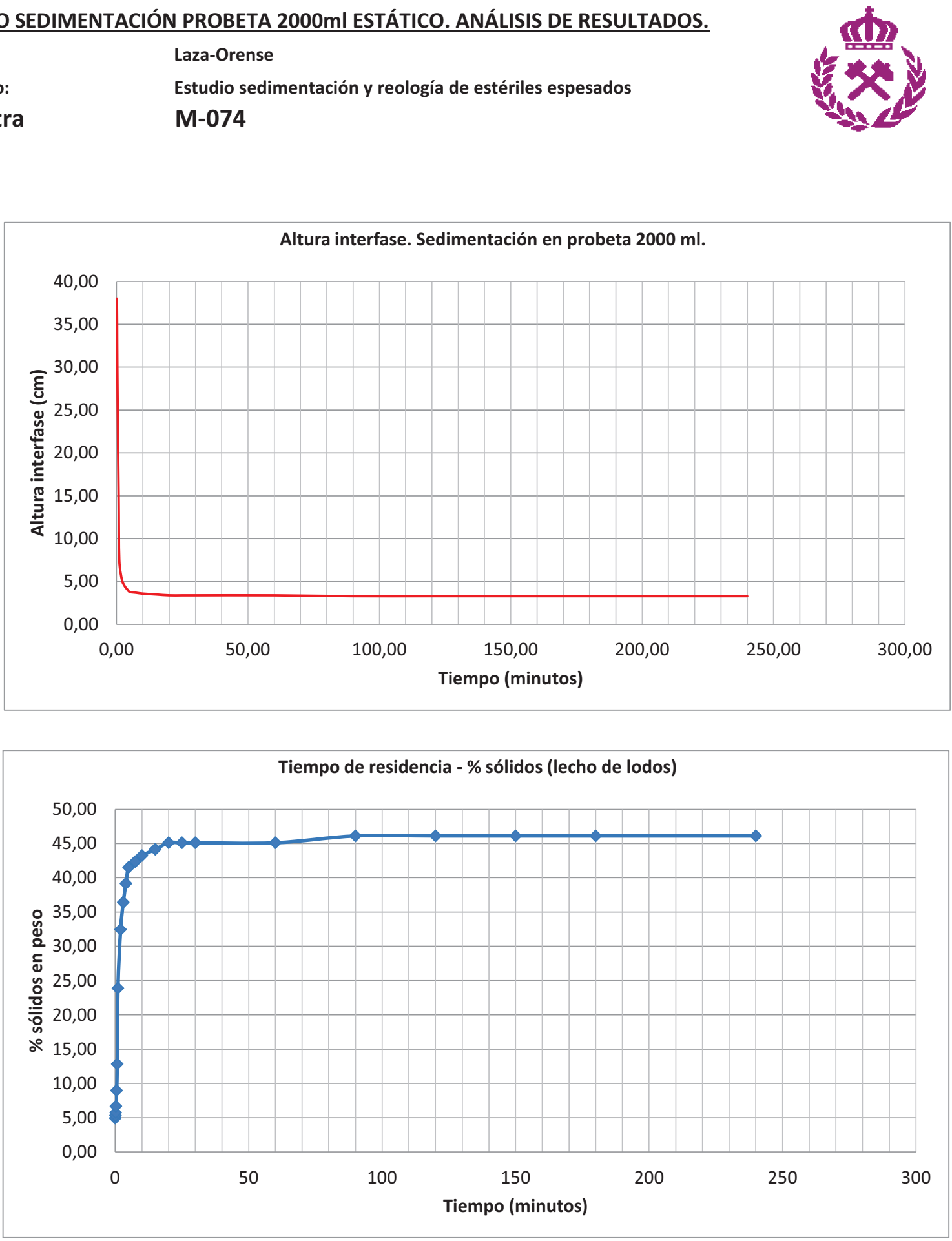


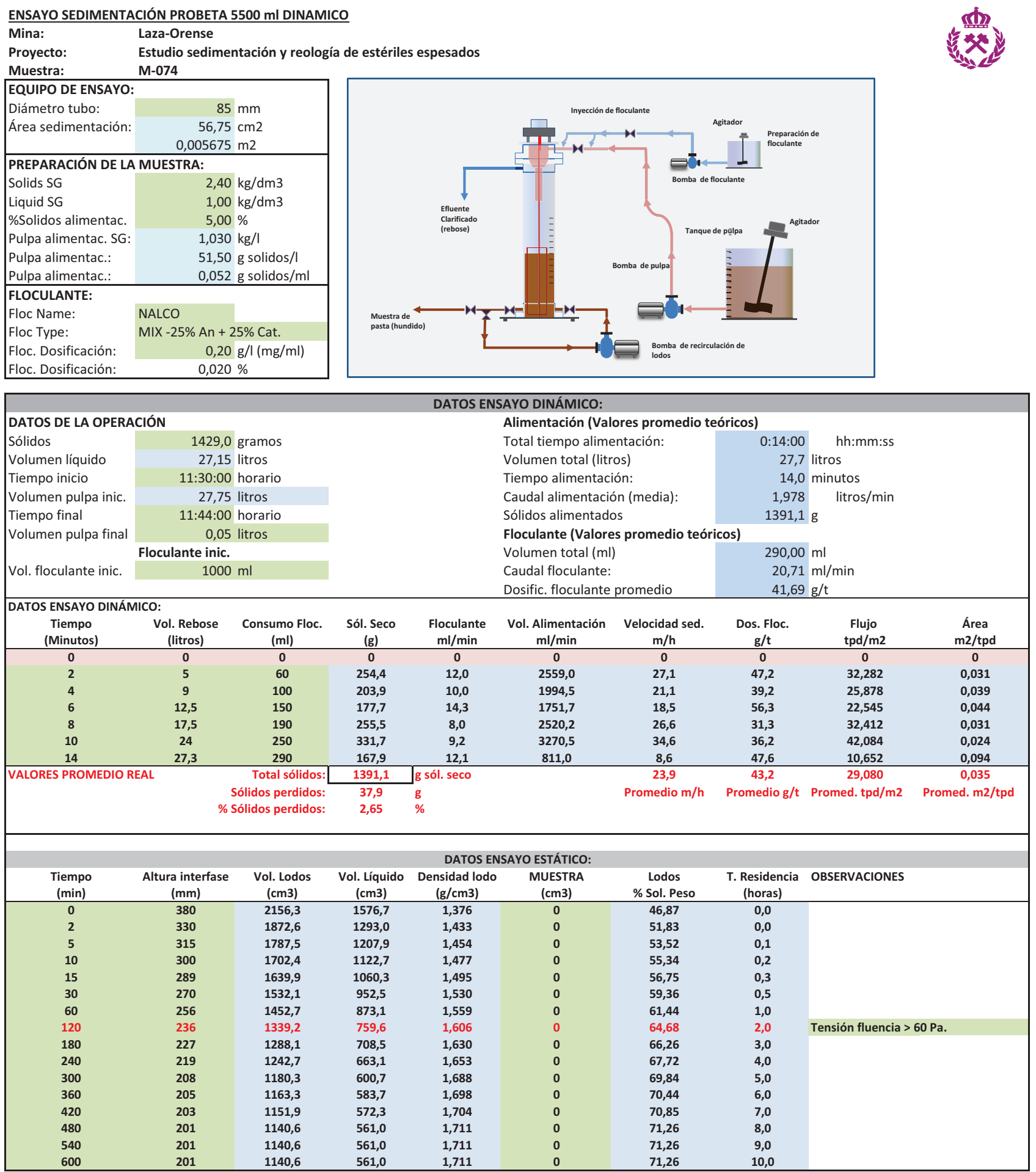


ENSAYO SEDIMENTACIÓN PROBETA 5500 mI DINAMICO

Mina: Laza-Orense

Proyecto: $\quad$ Estudio sedimentación y reología de estériles espesados

Muestra: M-074

DATOS DE OPERACIÓN DEL ESPESADOR DE TUBO PROFUNDO

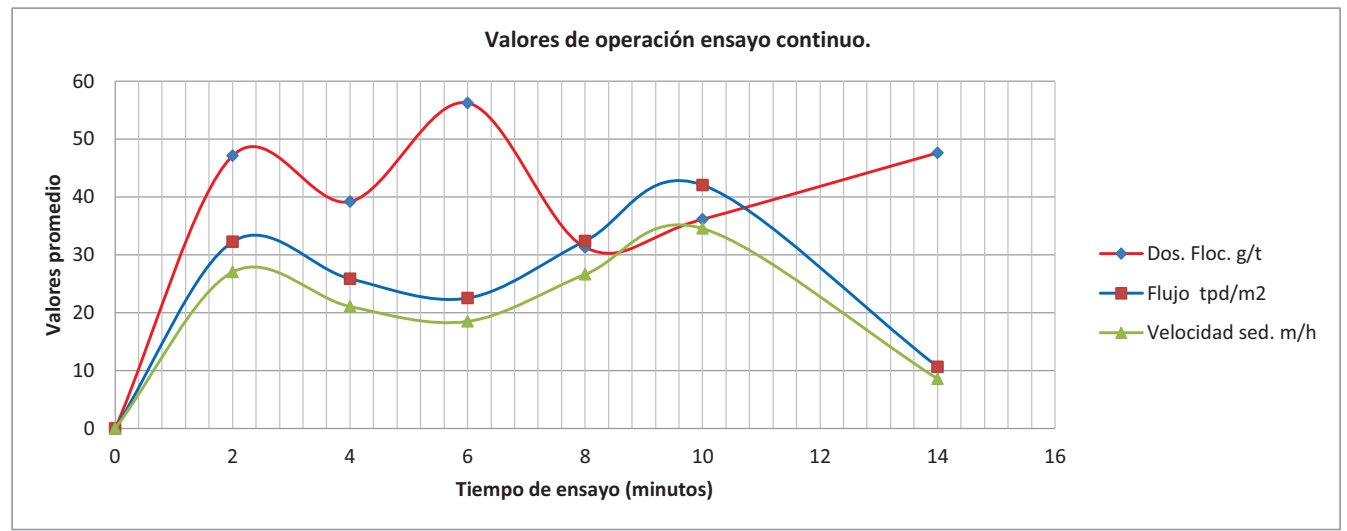

Datos Promedio:

Velocidad de sedimentación:

$23,9 \mathrm{~m} / \mathrm{h}$

Dosificación de floculante:

$43,2 \mathrm{~g} / \mathrm{t}$

$0,0348 \mathrm{~m}^{2} / \mathrm{t} / \mathrm{día}$

Flujo de sedimentación:

$29,1 \mathrm{t} / \mathrm{dí} a / \mathrm{m}^{2}$

Flujo de sedimentación:

ENSAYO SEDIMENTACIÓN PROBETA $5500 \mathrm{mI}$ DINAMICO
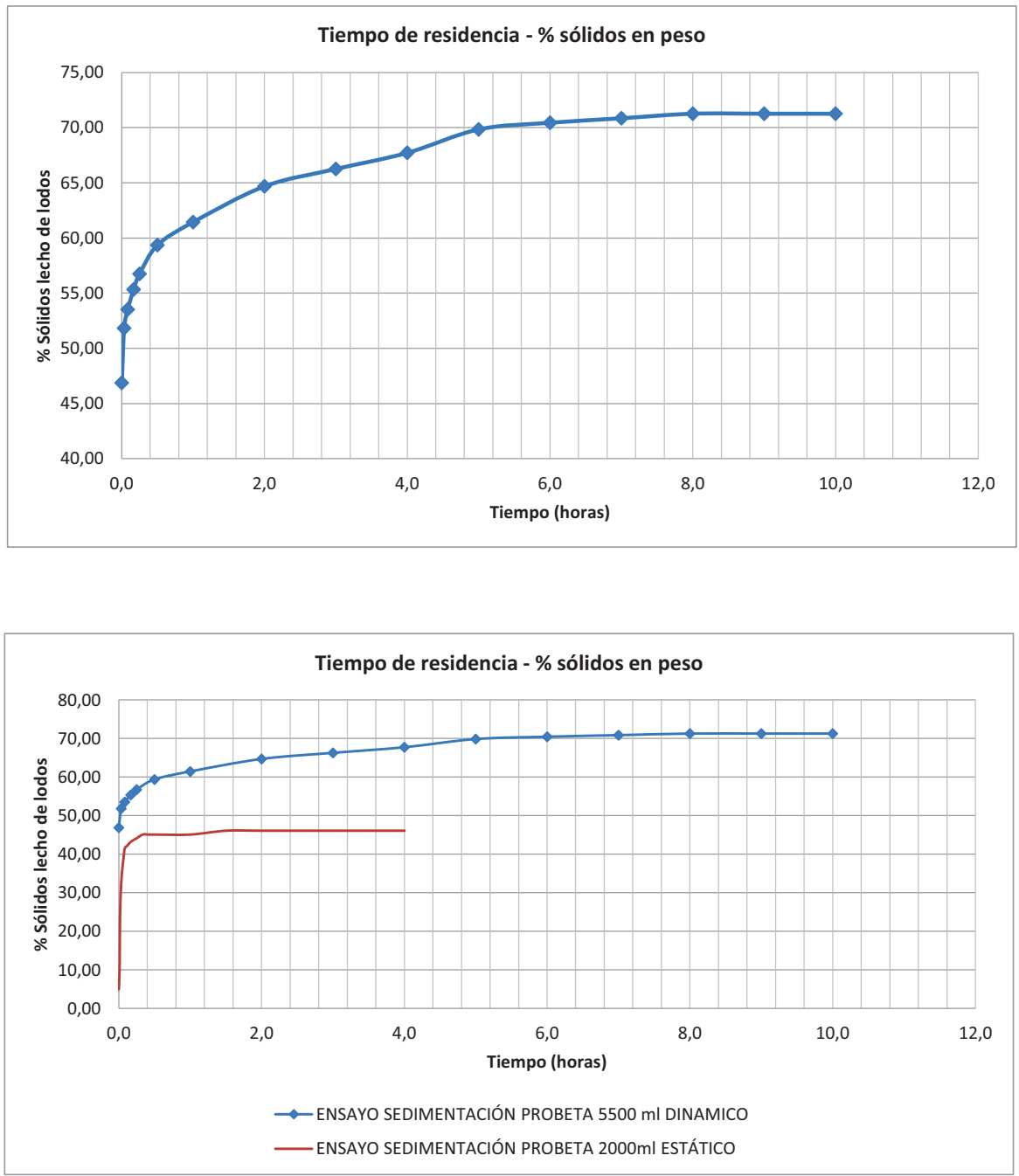
ENSAYO FILTRACIÓN A VACIO

Mina: Laza-Orense

Proyecto: $\quad$ Estudio sedimentación y reología de estériles espesados

\begin{tabular}{ll|}
\hline Material: & Estériles \\
Muestra: & M-074 \\
Preparado por: & José A. Butragueño \\
pH muestra: & 6 \\
Fecha: & $18 / 08 / 2013$ \\
\hline
\end{tabular}
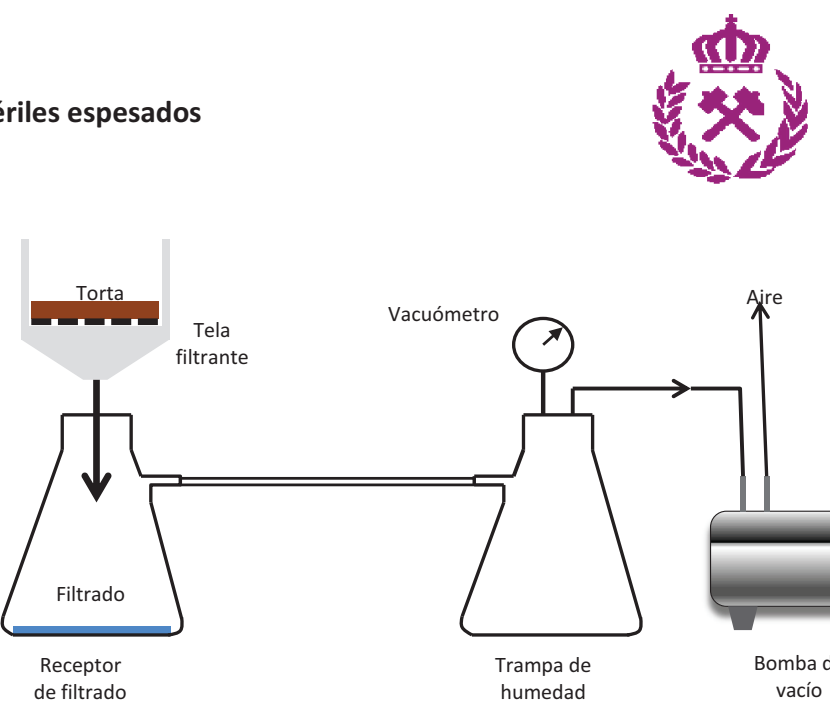

\begin{tabular}{|c|c|c|}
\hline \multicolumn{3}{|c|}{ DATOS DE LA MUESTRA: } \\
\hline Solidos SG & & $2,40 \mathrm{~kg} / \mathrm{dm} 3$ \\
\hline Liquido SG & & $1,00 \mathrm{~kg} / \mathrm{dm} 3$ \\
\hline \multicolumn{3}{|l|}{ FLOCULANTE: } \\
\hline Floc Name: & No & \\
\hline Tipo de floculante: & No & \\
\hline Floc. Dosificación: & & $0,00 \mathrm{~g} / \mathrm{l}(\mathrm{mg} / \mathrm{ml})$ \\
\hline Floc. Dosificación: & & $0,000 \%$ \\
\hline
\end{tabular}

ENSAYO FILTRACIÓN A VACÍO. TEST 1.

\begin{tabular}{|c|c|c|c|c|c|c|c|c|c|}
\hline \multicolumn{10}{|c|}{ ENSAYO FILTRACIÓN A VACÍO. TEST 1.} \\
\hline \multicolumn{2}{|c|}{ MUESTRA: M-074 } & \multirow[b]{2}{*}{$\begin{array}{l}\text { Vol. Líquido } \\
\text { (ml) }\end{array}$} & \multicolumn{7}{|c|}{ Tiempos de ensayo de filtración } \\
\hline $\begin{array}{l}\text { Vacío } \\
\text { (bar) }\end{array}$ & $\begin{array}{c}\text { Peso sólidos } \\
\text { (g) }\end{array}$ & & $\begin{array}{l}\text { \% Sól. Peso } \\
\text { (\%) }\end{array}$ & $\begin{array}{l}\text { Vol. Pulpa } \\
\text { (ml) }\end{array}$ & $\begin{array}{l}\text { Formación torta } \\
\text { (s) }\end{array}$ & $\begin{array}{l}\text { Secado torta } \\
\text { (s) }\end{array}$ & $\begin{array}{l}\text { Total ciclo } \\
\text { (s) }\end{array}$ & $\begin{array}{l}\text { Líq. Filtrado } \\
\text { (ml) }\end{array}$ & $\begin{array}{c}\text { Espesor } \\
(\mathrm{mm})\end{array}$ \\
\hline$-0,6$ & 30 & 150,0 & 16,7 & 162,5 & 15 & 10 & 25 & 142 & 2,0 \\
\hline \% Solidos estimado: & 78,9 & & \multirow{2}{*}{\multicolumn{2}{|c|}{ Observaciones: }} & & & & & \\
\hline Peso muestra húmedo: & 31 & $\mathrm{~g}$ & \multirow{3}{*}{\multicolumn{2}{|c|}{ Observaciones: }} & & & & & \\
\hline \multicolumn{3}{|c|}{ Secado de la muestra: } & & & & & & & \\
\hline Peso muestra seco & 24 & $\mathrm{~g}$ & & & & & & & \\
\hline$\%$ humedad torta & 22,58 & \% & & & & & & & \\
\hline
\end{tabular}

\begin{tabular}{|c|c|c|c|c|c|c|c|c|c|}
\hline \multicolumn{10}{|c|}{ ENSAYO FILTRACIÓN A VACÍO. TEST 2.} \\
\hline \multicolumn{2}{|c|}{ MUESTRA: M-074 } & \multirow[b]{2}{*}{$\begin{array}{l}\text { Vol. Líquido } \\
\text { (ml) }\end{array}$} & \multicolumn{7}{|c|}{ Tiempos de ensayo de filtración } \\
\hline $\begin{array}{l}\text { Vacío } \\
\text { (bar) }\end{array}$ & $\begin{array}{l}\text { Peso sólidos } \\
\text { (g) }\end{array}$ & & $\begin{array}{l}\text { \% Sól. Peso } \\
\text { (\%) }\end{array}$ & $\begin{array}{l}\text { Vol. Pulpa } \\
\text { (ml) }\end{array}$ & $\begin{array}{l}\text { Formación torta } \\
\text { (s) }\end{array}$ & $\begin{array}{l}\text { Secado torta } \\
\text { (s) }\end{array}$ & $\begin{array}{l}\text { Total ciclo } \\
\text { (s) }\end{array}$ & $\begin{array}{l}\text { Líq. Filtrado } \\
\text { (ml) }\end{array}$ & $\begin{array}{c}\text { Espesor } \\
(\mathrm{mm})\end{array}$ \\
\hline$-0,6$ & 50 & 210,0 & 19,2 & 230,8 & 60 & 10 & 70 & 198 & 5,0 \\
\hline \% Solidos estimado: & 80,6 & & & & & & & \\
\hline Peso muestra húmedo: & 39,5 & $\mathrm{~g}$ & \multirow{4}{*}{\multicolumn{2}{|c|}{ Observaciones: }} & & & & & \\
\hline \multicolumn{3}{|c|}{ Secado de la muestra: } & & & & & & & \\
\hline Peso muestra seco & 30 & $\mathrm{~g}$ & & & & & & & \\
\hline$\%$ humedad torta & 24,05 & $\%$ & & & & & & & \\
\hline
\end{tabular}

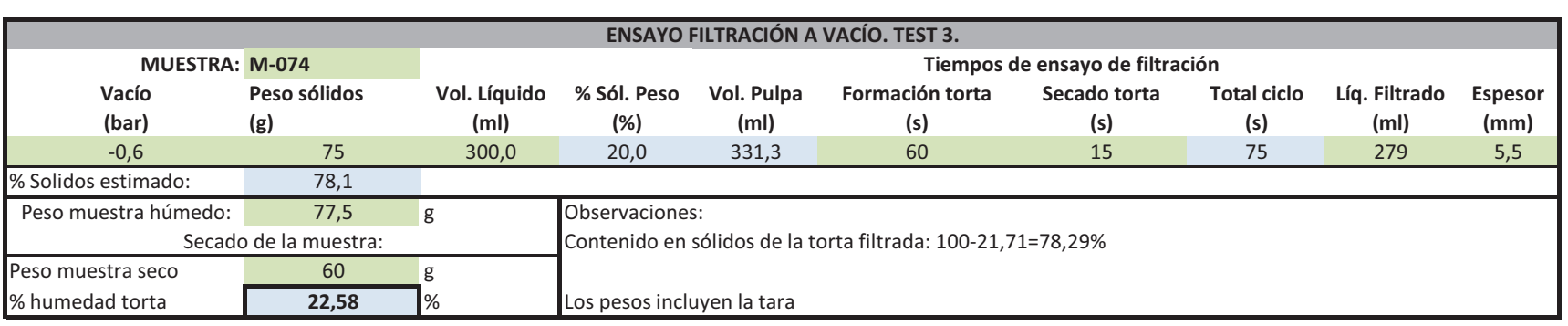

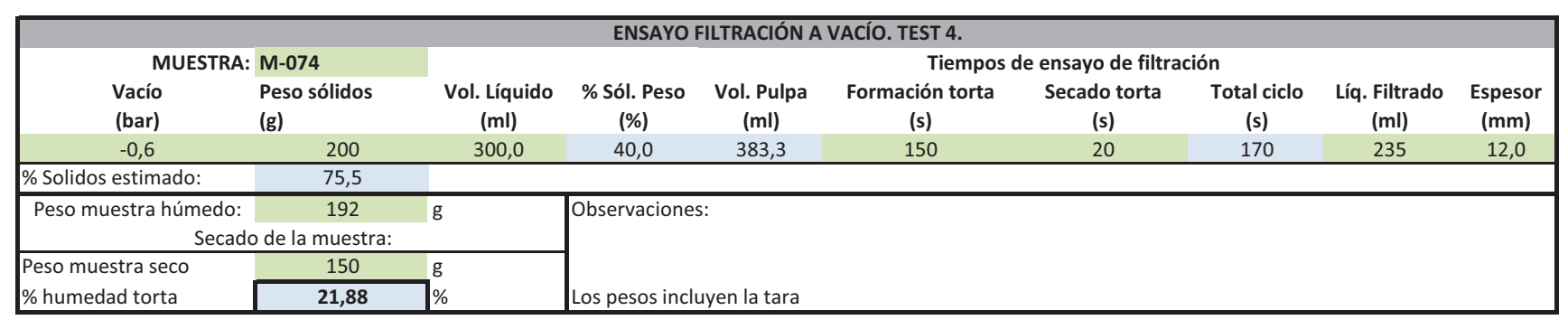


ENSAYO ASENTAMIENTO EN PROBETA

\begin{tabular}{|ll|}
\hline Mina: & Laza-Orense \\
Proyecto: & Estudio sedimentación y reología de estériles espesados \\
\cline { 2 - 2 } Material: & Estériles \\
Preparado por: & José A. Butragueño \\
pH muestra: & 6 \\
\hline Fecha: & $18 / 08 / 2013$ \\
\hline
\end{tabular}

Fecha:

$18 / 08 / 2013$

\begin{tabular}{lc} 
Aceleración gravedad (g): & $9,81 \mathrm{~m} / \mathrm{s} 2$ \\
\hline Diámetro probeta: & $44 \mathrm{~mm}$ \\
\hline Altura probeta (H): & $100 \mathrm{~mm}$ \\
\hline Volumen probeta: & $152,1 \mathrm{~cm} 3$ \\
\hline Solidos SG & $2,40 \mathrm{~kg} / \mathrm{dm} 3$ \\
Líquido SG & $1,00 \mathrm{~kg} / \mathrm{dm} 3$
\end{tabular}

Líquido SG

$1,00 \mathrm{~kg} / \mathrm{dm} 3$

Expresiones empíricas

$\mathrm{T}=0.5-0.5(\mathrm{~h} / \mathrm{H})^{\wedge} 0.5$

T.F. $=\mathrm{T}^{*} \mathrm{~d}^{*} \mathrm{~g}^{*}(\mathrm{H} / 100)$

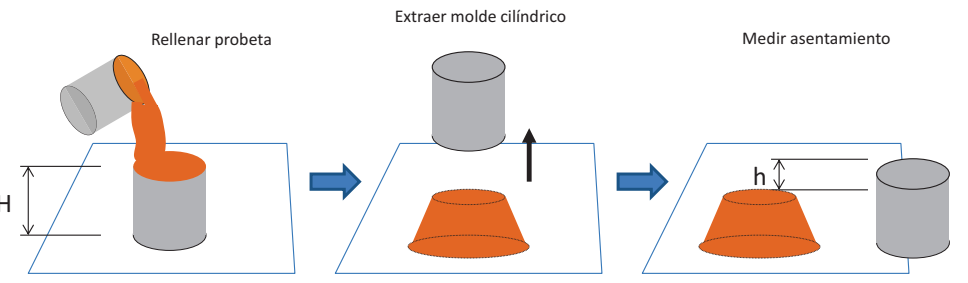

\begin{tabular}{|c|c|c|c|c|c|c|c|c|c|c|}
\hline \multicolumn{11}{|c|}{ ENSAYOS DE ASENTAMIENTO EN PROBETA } \\
\hline $\begin{array}{l}\text { Muestra } \\
\text { ID }\end{array}$ & $\begin{array}{c}\text { Cont. Sólidos } \\
\text { (\%) }\end{array}$ & $\begin{array}{l}\text { Solidos SG } \\
\mathrm{g} / \mathrm{cm} 3\end{array}$ & $\begin{array}{l}\text { Peso Liq. } \\
\text { (kg liq/kg sol) }\end{array}$ & $\begin{array}{l}\text { Vol. Pulpa } \\
\text { (I/kg sol) }\end{array}$ & $\begin{array}{l}\text { Pulpa SG (d) } \\
\text { kg/dm3 }\end{array}$ & $\begin{array}{l}\text { Sólidos prob. } \\
\text { (g) }\end{array}$ & $\begin{array}{l}\text { Liq. Probeta } \\
\text { (g) }\end{array}$ & $\begin{array}{c}\text { Asentamiento }(\mathrm{h}) \\
\mathrm{mm}\end{array}$ & $\begin{array}{l}\text { Factor "T" } \\
\text { Adimens. }\end{array}$ & $\begin{array}{c}\text { Tensión Fluencia } \\
\text { (Pa) }\end{array}$ \\
\hline 1 & 68,5 & 2,40 & 0,460 & 0,877 & 1,666 & 173,5 & 79,8 & 45 & 0,16459 & 268,9 \\
\hline 2 & 67,5 & 2,40 & 0,481 & 0,898 & 1,649 & 169,3 & 81,5 & 52 & 0,13944 & 225,6 \\
\hline 3 & 65 & 2,40 & 0,538 & 0,955 & 1,611 & 159,2 & 85,7 & 62 & 0,10630 & 168,0 \\
\hline 4 & 62,5 & 2,40 & 0,600 & 1,017 & 1,574 & 149,6 & 89,7 & 79 & 0,05559 & 85,8 \\
\hline 5 & 60 & 2,40 & 0,667 & 1,083 & 1,538 & 140,4 & 93,6 & 90 & 0,02566 & 38,7 \\
\hline 6 & 55 & 2,40 & 0,818 & 1,235 & 1,472 & 123,1 & 100,7 & 96 & 0,01010 & 14,6 \\
\hline
\end{tabular}
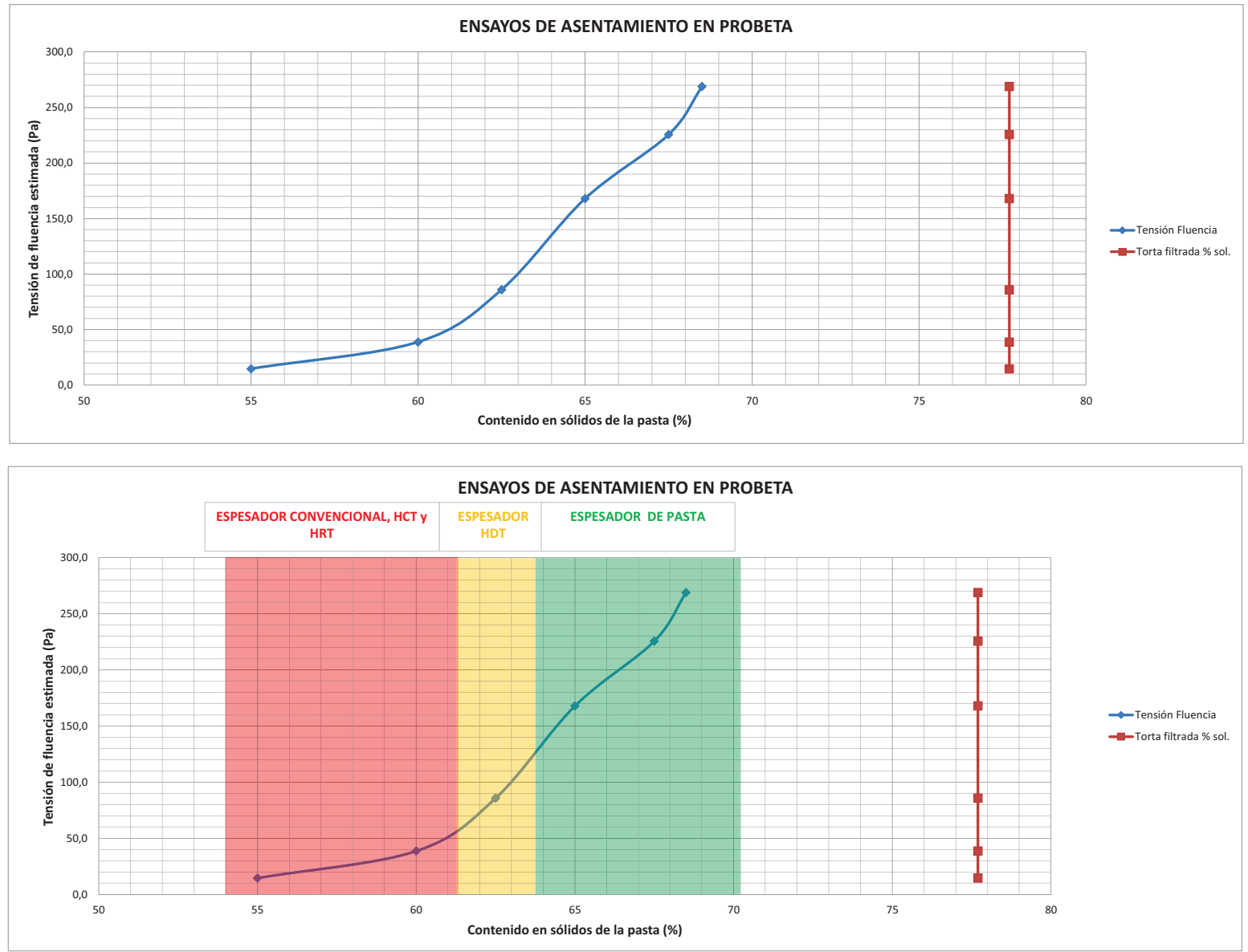

Página 12 de 12 


\section{ENSAYOS DE SEDIMENTACIÓN Y REOLOGÍA}

\section{Mina:}

MINAS DE AGUAS TEÑIDAS

\section{Empresa:}

DOCTORANDO JOSE A. BUTRAGUEÑO

\section{Proyecto:}

Estudio sedimentación y reología de estériles espesados

Aplicación

Sedimentación. Estériles de flotación mineral Cu Polimetálico (Valdelamusa)

Fecha:

$28 / 06 / 2015$

\section{Ensayos:}

\begin{tabular}{|c|c|}
\hline $\mathbf{X}$ & Distribución granulométrica y caracterización de muestras \\
\hline $\mathbf{X}$ & Selección de floculantes \\
\hline $\mathbf{X}$ & Área de flujo \\
\hline $\mathbf{X}$ & Sedimentación en probeta estática \\
\hline $\mathbf{X}$ & Ensayo en espesador dinámico de laboratorio de $85 \mathrm{~mm}$ DIA \\
\hline $\mathbf{X}$ & Reología de los lodos \\
\hline & Ensayo de filtración a vacío \\
\hline
\end{tabular}

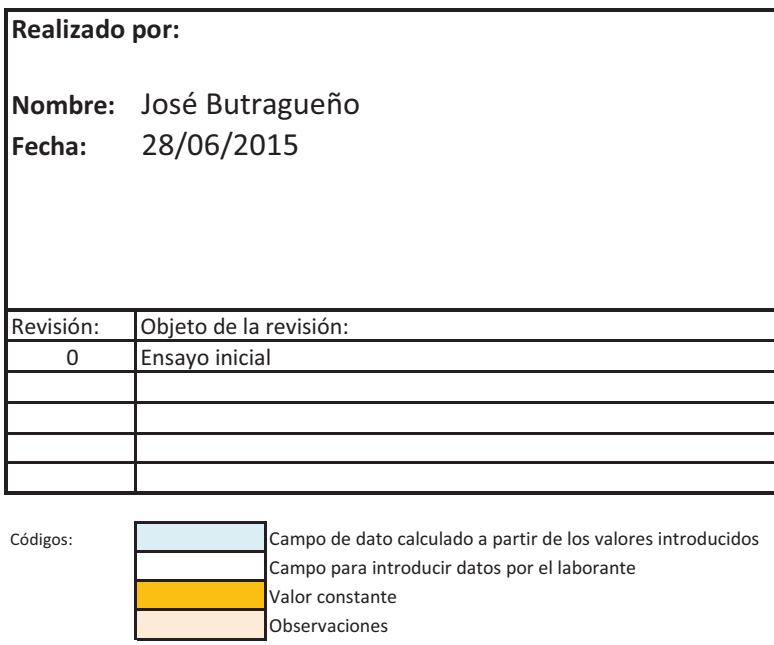


ENSAYO GRANULOMÉTRICO DE SÓLIDOS

Mina: MINAS DE AGUAS TEÑIDAS

Proyecto: Estudio sedimentación y reología de estériles espesados Realizado por: José Butragueño

\begin{tabular}{|ll|}
\hline Muestra ID: & M-100 \\
Material: & Estériles mineral polimetálico cobre \\
Preparado por: & José A. Butragueño \\
pH muestra: & - \\
Fecha: & $28 / 06 / 2015$ \\
\hline
\end{tabular}

CURVA GRANULOMÉTRICA DE SÓLIDOS

\begin{tabular}{|c|c|c|c|c|}
\hline \multicolumn{3}{|c|}{ DATOS DE LA PULPA A SEDIMENTAR } & \multicolumn{2}{|c|}{ Observaciones: Muestra de sólido seco } \\
\hline Densidad sólidos: & 4,50 & $\mathrm{~kg} / \mathrm{dm}^{3}$ & & \\
\hline Densidad líquido: & 1,00 & $\mathrm{~kg} / \mathrm{dm}^{3}$ & & \\
\hline Densidad pulpa: & & $\mathrm{kg} / \mathrm{l}$ & & \\
\hline Tara: & & $g$ & & \\
\hline Pulpa húmeda: & 0 & $g$ & Peso pulpa: & $0 \mathrm{~g}$ \\
\hline Sólido seco: & 0 & $\mathrm{~g}$ & Peso sólido: & $0 \mathrm{~g}$ \\
\hline \% Peso sólidos: & \#DIV/0! & $\%$ & & \\
\hline
\end{tabular}

\section{CURVA GRANULOMÉTRICA DE SÓLIDOS}

ENSAYO GRANULOMÉTRICO Muestra M-100

\begin{tabular}{|c|c|c|r|}
\hline Tamiz (micras) & \% pasa & Tamiz (micras) & \multicolumn{1}{c|}{ \% pasa } \\
\hline 0,479 & 0,17 & 30,200 & 64,53 \\
\hline 0,631 & 0,47 & 39,811 & 71,89 \\
\hline 0,832 & 0,89 & 52,481 & 79,03 \\
\hline 1,096 & 1,46 & 69,183 & 85,36 \\
\hline 1,445 & 2,26 & 91,201 & 90,34 \\
\hline 1,905 & 3,47 & 120,226 & 93,81 \\
\hline 2,512 & 5,35 & 158,489 & 96,09 \\
\hline 3,311 & 8,27 & 208,930 & 97,63 \\
\hline 4,365 & 12,56 & 275,423 & 98,76 \\
\hline 5,574 & 18,38 & 363,078 & 99,55 \\
\hline 7,586 & 25,54 & 478,630 & 99,96 \\
\hline 10,000 & 33,55 & 630,957 & 100,00 \\
\hline 13,183 & 41,74 & & \\
\hline 17,378 & 49,63 & & \\
\hline 22,909 & 57,16 & & \\
\hline
\end{tabular}

$P 80=54.59$ micras

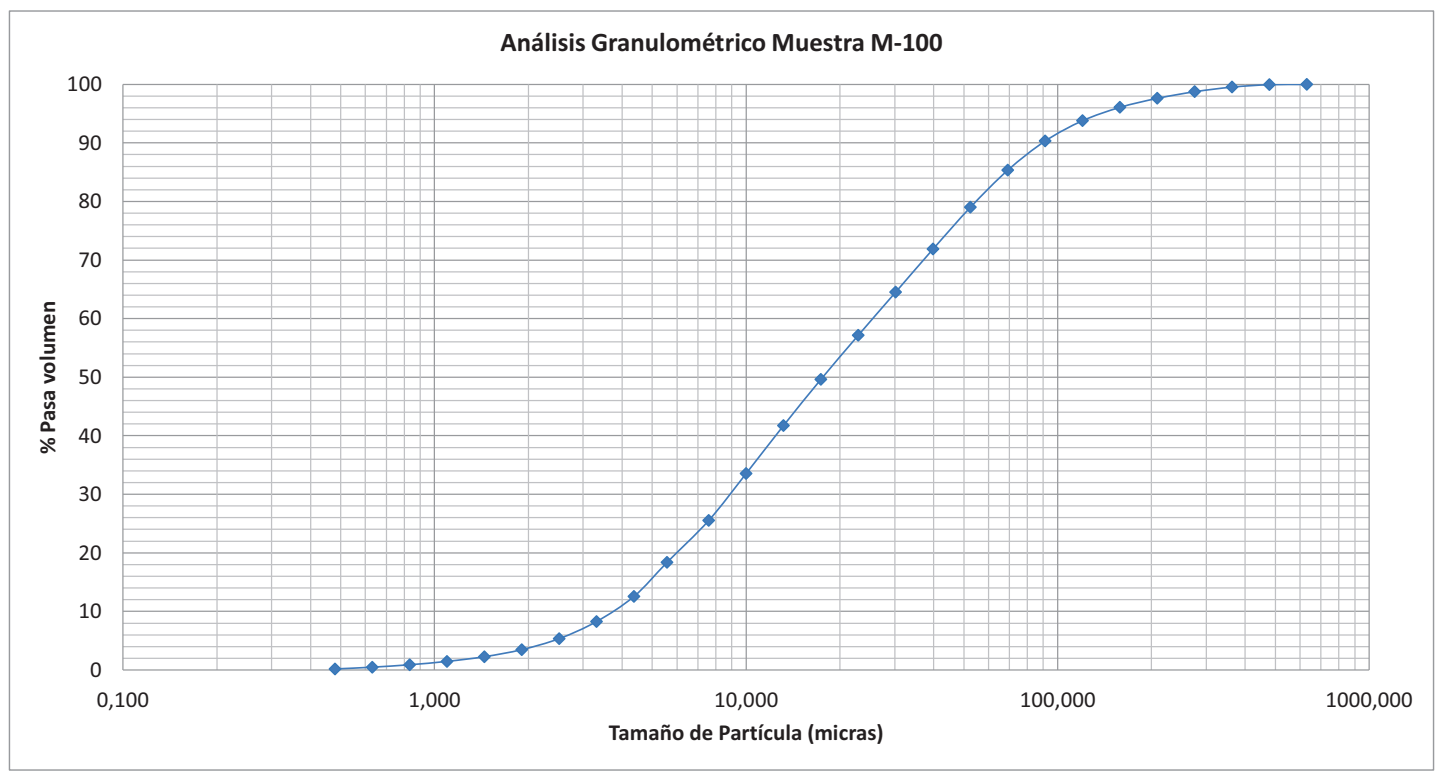




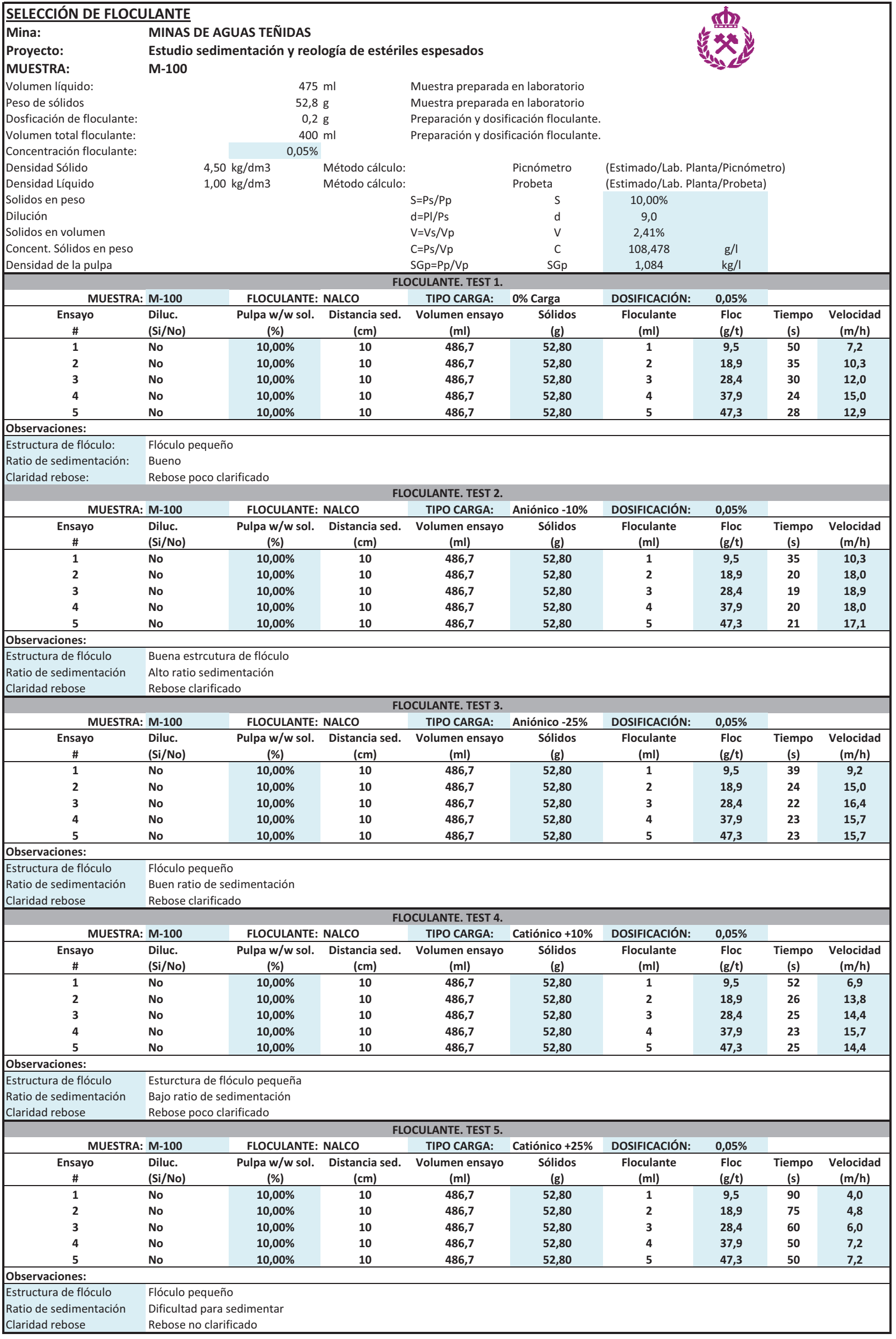


SELECCIÓN DE FLOCULANTE. ANÁLISIS DE DATOS.

Mina:

Proyecto:

MUESTRA:

Volumen líquido:

$\%$ sólidos en peso:

Dosficación de floculante:

Volumen total:

Concentración floculante:

Densidad Sólido

Densidad Líquido

MINAS DE AGUAS TEÑIDAS

Estudio sedimentación y reología de estériles espesados

M-100

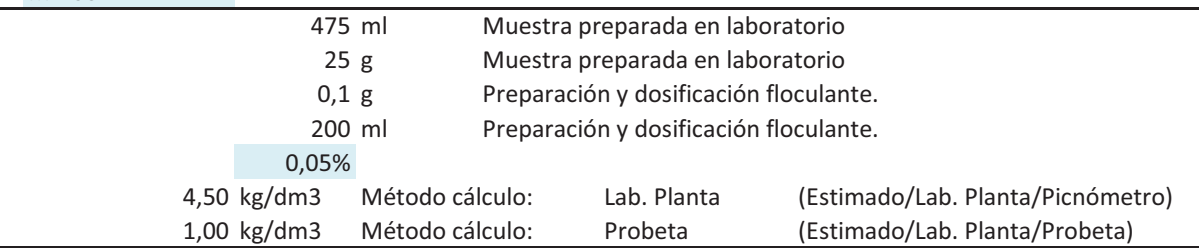

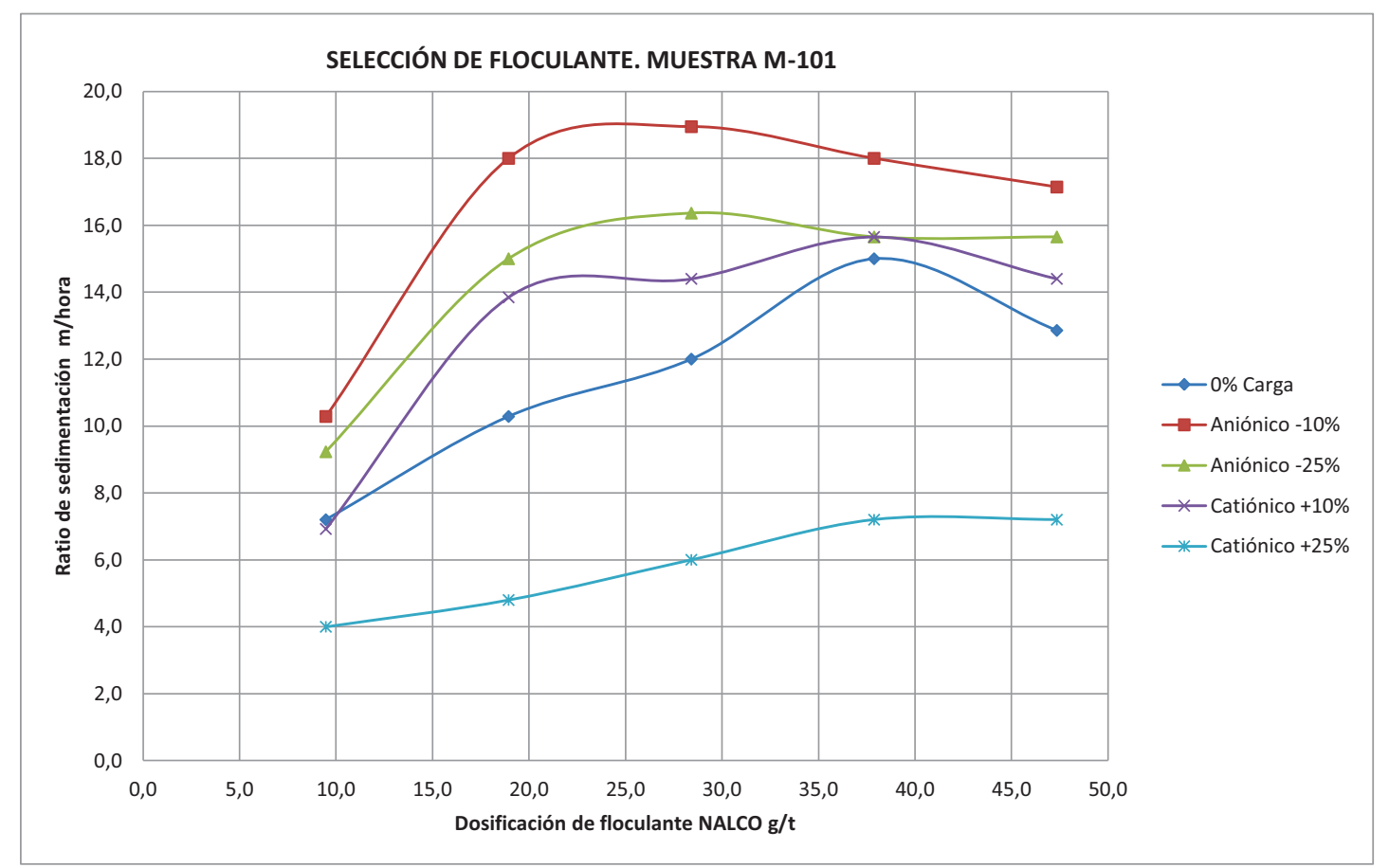

Los ensayos de sedimentación para la selección del floculante han tenido en cuenta tanto los valores de velocidad de sedimentación cómo los datos de observación visual de: tamaño de flóculo, velocidad de sedimentación, cohesión del flóculo y la claridad del rebose obtenida en la probeta de laboratorio. El floculante seleccionado será empleado en los ensayos de flujo de sedimentación.

FLOCULANTE SELECCIONADO:

NALCO -10\% CARGA 
ENSAYO FLUJO SEDIMENTACIÓN

Mina: MINAS DE AGUAS TEÑIDAS

Proyecto: Estudio sedimentación y reología de estériles espesados

DATOS

FLOCULANTE SELECCIONADO

Volumen probeta:

$1000 \mathrm{ml}$

NALCO - $10 \%$ CARGA

Diámetro probeta: $\quad 58 \mathrm{~mm}$

Floc. Dosificac: $\quad \quad 0,2 \mathrm{~g}$

Volumen floc: $\quad 400 \mathrm{ml}$

Floculante dosific. $\quad 0,05 \%$

Floc. Conc. $\quad 0,50 \mathrm{~g} / \mathrm{l}$

Densidad Sólido $\quad 4,50 \mathrm{~kg} / \mathrm{dm} 3$

Densidad Líquido $\quad 1,00 \mathrm{~kg} / \mathrm{dm} 3$

NALCO -10\% CARGA @ 2.5\% Sól. Peso

$\begin{array}{lrr}\text { Diámetros de probetas: } & \\ 250 \mathrm{ml} & 35,7 & \mathrm{~mm} \\ 500 \mathrm{ml} & 48,6 & \mathrm{~mm} \\ 2000 \mathrm{ml} & 78,2 & \mathrm{~mm}\end{array}$

MUESTRA SÓLIDOS

$\mathrm{M}-100$

NALCO -10\% CARGA @ 2.5\% Só. Peso

\begin{tabular}{|c|c|c|c|c|c|c|c|c|c|c|c|}
\hline \multicolumn{2}{|c|}{ MUESTRA: M-100 } & \multirow{2}{*}{$\begin{array}{l}\text { FLOCULANTE: } \\
\text { Sólidos } \\
(\% \mathrm{w} / \mathrm{w})\end{array}$} & \multicolumn{2}{|c|}{ NALCO - $10 \%$ CARGA } & \multirow[b]{2}{*}{$\begin{array}{c}\text { Floculant. } \\
(\mathrm{ml})\end{array}$} & \multirow{2}{*}{$\begin{array}{l}\text { CARGA SóLIDOS: } \\
\text { Dist. Sediment. } \\
(\mathrm{cm})\end{array}$} & \multirow{2}{*}{$\begin{array}{c}2,50 \\
\text { Tiempo sed. } \\
\text { (s) }\end{array}$} & \multicolumn{4}{|l|}{$\%$} \\
\hline $\begin{array}{c}\text { Peso sólidos } \\
\text { (g) }\end{array}$ & $\begin{array}{c}\text { Vol. líquido } \\
(\mathrm{ml})\end{array}$ & & $\begin{array}{c}\text { Densidad pulpa } \\
(\mathrm{kg} / \mathrm{l})\end{array}$ & $\begin{array}{c}\text { Conc. Solids } \\
\text { (g/l) }\end{array}$ & & & & $\begin{array}{c}\text { Velocidad sed. } \\
(\mathrm{m} / \mathrm{h})\end{array}$ & $\begin{array}{c}\text { Floc dosific. } \\
(\mathrm{g} / \mathrm{t})\end{array}$ & $\begin{array}{c}\begin{array}{c}\text { Flujo } \\
\text { (tph/m2) }\end{array} \\
\end{array}$ & $\begin{array}{c}\begin{array}{c}\text { Flujo } \\
\text { (tpd/m2) }\end{array} \\
\end{array}$ \\
\hline 25,6 & 1000 & 2,50 & 1,020 & 25,46 & 0,5 & 10,0 & 9 & 40,0 & 10 & 3,88 & 93,02 \\
\hline 25,6 & 1000 & 2,50 & 1,020 & 25,46 & 1 & 10,0 & 8 & 45,0 & 20 & 4,36 & 104,64 \\
\hline 25,6 & 1000 & 2,50 & 1,020 & 25,46 & 1,5 & 10,0 & 7 & 51,4 & 29 & 4,98 & 119,59 \\
\hline 25,6 & 1000 & 2,50 & 1,020 & 25,46 & 2 & 10,0 & 7 & 51,4 & 39 & 4,98 & 119,59 \\
\hline 25,6 & 1000 & 2,50 & 1,020 & 25,46 & 2,5 & 10,0 & 8 & 45,0 & 49 & 4,36 & 104,64 \\
\hline 25,6 & 1000 & 2,50 & 1,020 & 25,46 & 3 & 10,0 & 8 & 45,0 & 59 & 4,36 & 104,64 \\
\hline & & & & & & & MEDIA: & 45,0 & 34,2 & 4,4 & 104,6 \\
\hline
\end{tabular}

NALCO -10\% CARGA @ 5\% Sól. Peso

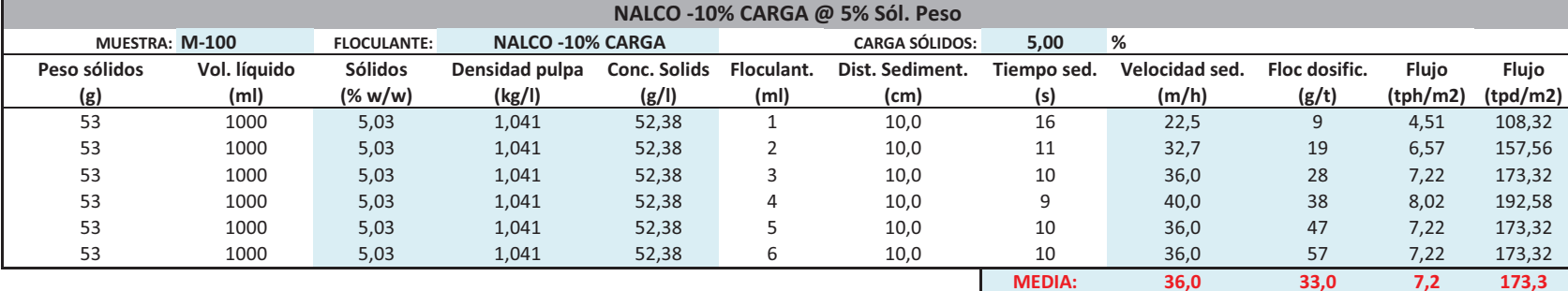

NALCO -10\% CARGA @ 7.5\% Sól. Peso

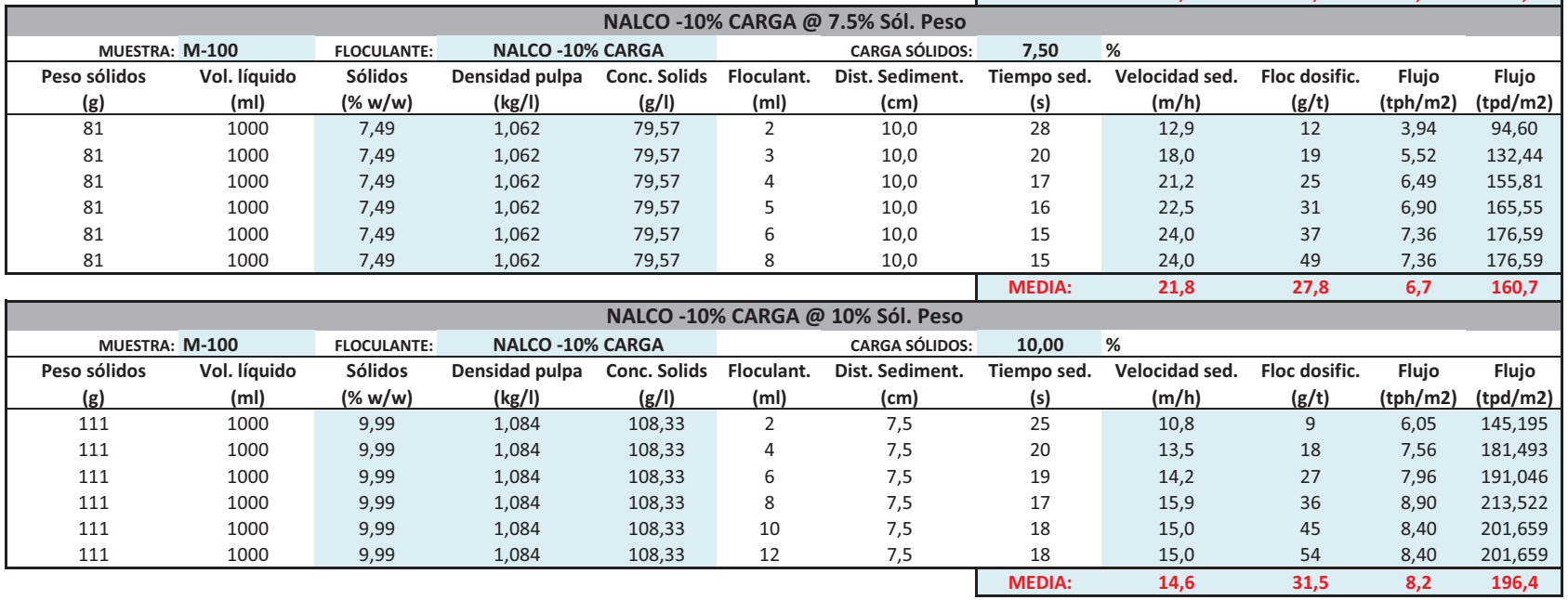


ENSAYO FLUJO SEDIMENTACIÓN. ANÁLISIS DE RESULTADOS.

Mina: MINAS DE AGUAS TEÑIDAS

Proyecto: $\quad$ Estudio sedimentación y reología de estériles espesados

DATOS

Volumen probeta:

$1000 \mathrm{ml}$

$58 \mathrm{~mm}$

Diámetro probeta:

$26,42 \mathrm{~cm} 2$

Floc. Dosificac.:

Volumen floc:

Floculante dosific.

$0,2 \mathrm{~g}$

$400 \mathrm{ml}$

$0,05 \%$

Floc. Conc.

$0,50 \mathrm{~g} / \mathrm{l}$

$4,50 \mathrm{~kg} / \mathrm{dm} 3$

FLOCULANTE SELECCIONADO

Densidad Sólido

$1,00 \mathrm{~kg} / \mathrm{dm} 3$

NALCO -10\% CARGA IÓNICA

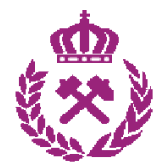

MUESTRA SÓLIDOS

M-100

Diámetros de probetas:

$250 \mathrm{ml} \quad 35,7 \quad \mathrm{~mm}$

$500 \mathrm{ml} \quad 48,6 \quad \mathrm{~mm}$

$2000 \mathrm{ml} \quad 78,2 \quad \mathrm{~mm}$

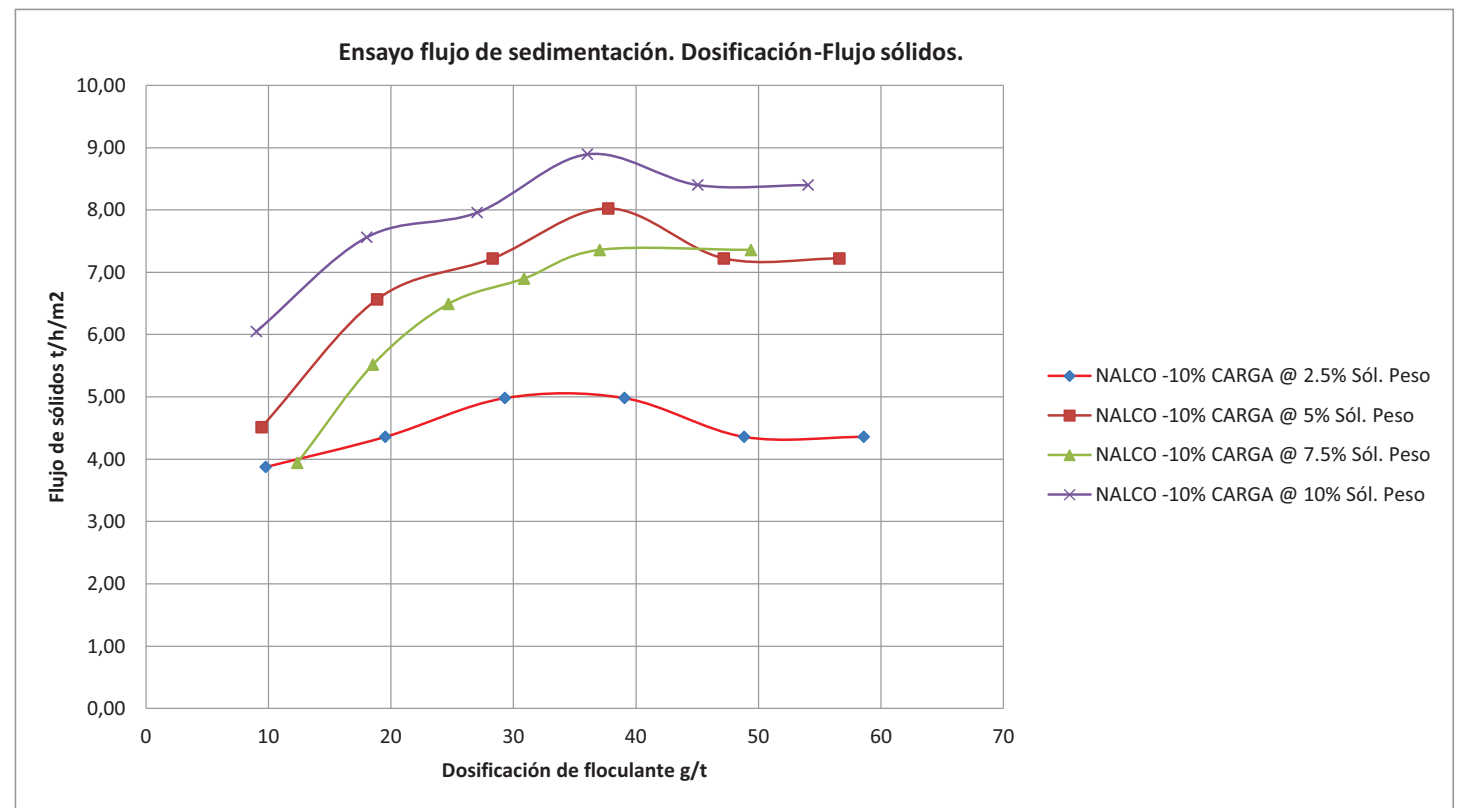

Los ensayos de flujos de sedimentación determinan la dilución óptima de los sólidos para la alimentación en el espesador.

El valor obtenido sirve de base para el diseño de la campana de alimentación y el sistema de dilución previsto. 
ENSAYO SEDIMENTACIÓN PROBETA 2000 ml ESTÁTICO

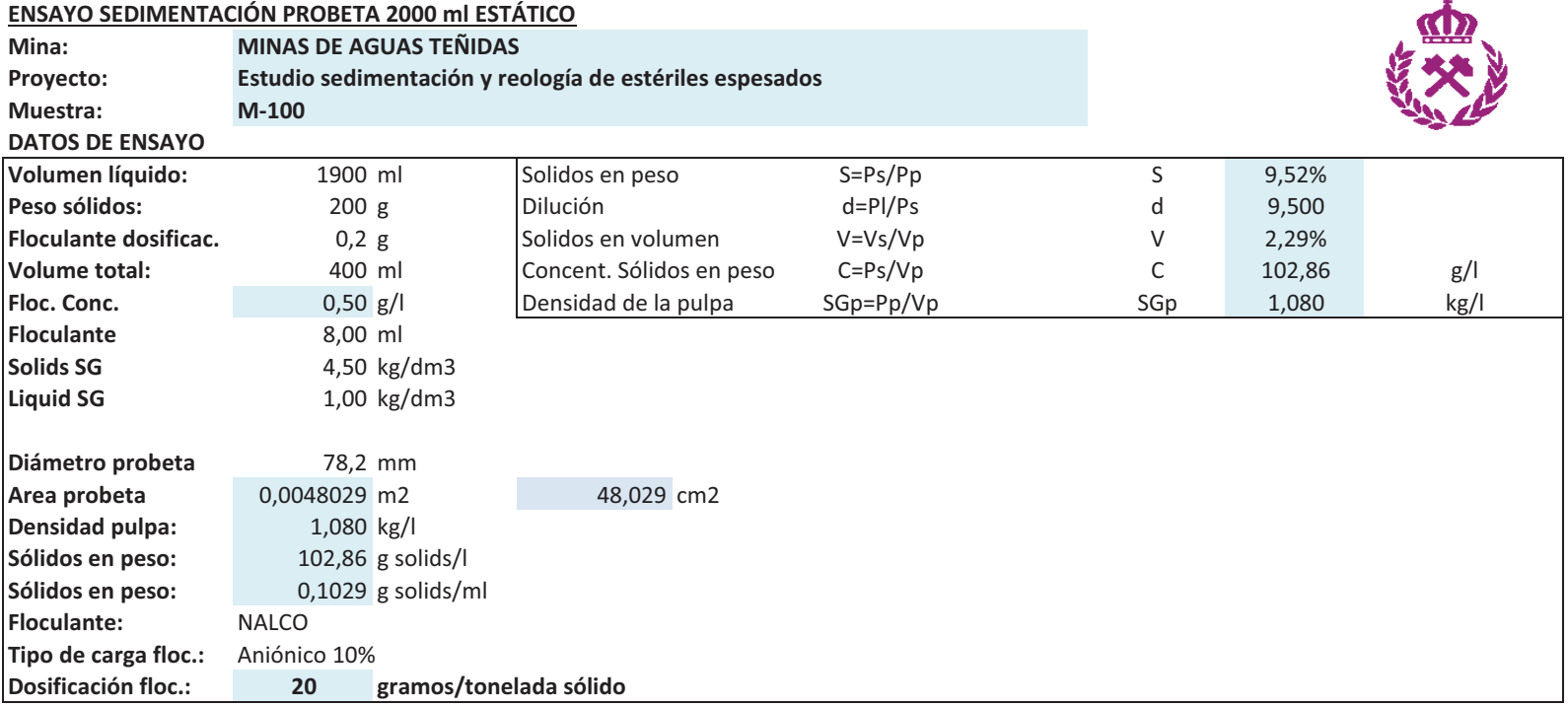

DATOS DE SEDIMENTACIÓN

\begin{tabular}{|c|c|c|c|c|c|c|c|c|c|}
\hline $\begin{array}{l}\text { Tiempo info } \\
\text { (sec) }\end{array}$ & $\begin{array}{c}\text { Tiempo } \\
\text { (min) }\end{array}$ & $\begin{array}{l}\text { Vol. Lodos } \\
\text { (ml) }\end{array}$ & $\begin{array}{l}\text { Altura interf. } \\
(\mathrm{cm})\end{array}$ & $\begin{array}{l}\text { Velocidad } \\
\text { (m/hr) }\end{array}$ & $\begin{array}{l}\text { SG. Lodos } \\
\text { (g/cm3) }\end{array}$ & $\begin{array}{l}\text { Lodos } \\
\text { \% Sol. Peso }\end{array}$ & $\begin{array}{c}\text { Flujo } \\
\text { (tph/m2) }\end{array}$ & $\begin{array}{c}\text { Flujo } \\
\text { (tpd/m2) }\end{array}$ & $\begin{array}{l}\text { Área Unit. Espes. } \\
\text { (m2/tpd) }\end{array}$ \\
\hline 0 & 0 & 1969 & 41,00 & 0 & 1,079 & 9,41 & 0 & 0 & 0 \\
\hline 5 & 0,08 & 1849 & 38,50 & 18,000 & 1,084 & 9,98 & 29,9820 & 719,57 & 0,001 \\
\hline 10 & 0,17 & 1753 & 36,50 & 14,400 & 1,089 & 10,48 & 29,9818 & 719,56 & 0,001 \\
\hline 15 & 0,25 & 1647 & 34,30 & 15,840 & 1,094 & 11,09 & 29,9819 & 719,57 & 0,001 \\
\hline 30 & 0,50 & 1345 & 28,00 & 15,120 & 1,116 & 13,33 & 9,9940 & 239,86 & 0,004 \\
\hline 45 & 0,75 & 1153 & 24,00 & 9,600 & 1,135 & 15,29 & 9,9940 & 239,86 & 0,004 \\
\hline 60 & 1,00 & 1009 & 21,00 & 7,200 & 1,154 & 17,18 & 9,9940 & 239,86 & 0,004 \\
\hline 120 & 2,00 & 552 & 11,50 & 5,700 & 1,282 & 28,25 & 2,4985 & 59,96 & 0,017 \\
\hline 180 & 3,00 & 432 & 9,00 & 1,500 & 1,360 & 34,02 & 2,4985 & 59,96 & 0,017 \\
\hline 240 & 4,00 & 394 & 8,20 & 0,480 & 1,395 & 36,40 & 2,4985 & 59,96 & 0,017 \\
\hline 300 & 5,00 & 360 & 7,50 & 0,420 & 1,432 & 38,78 & 2,4985 & 59,96 & 0,017 \\
\hline 450 & 7,50 & 307 & 6,40 & 0,264 & 1,506 & 43,20 & 0,9994 & 23,99 & 0,042 \\
\hline 600 & 10,00 & 288 & 6,00 & 0,096 & 1,540 & 45,07 & 0,9994 & 23,99 & 0,042 \\
\hline 900 & 15,00 & 279 & 5,80 & 0,024 & 1,558 & 46,07 & 0,4997 & 11,99 & 0,083 \\
\hline 1200 & 20,00 & 274 & 5,70 & 0,012 & 1,568 & 46,59 & 0,4997 & 11,99 & 0,083 \\
\hline 1500 & 25,00 & 264 & 5,50 & 0,024 & 1,589 & 47,65 & 0,4997 & 11,99 & 0,083 \\
\hline 1800 & 30,00 & 259 & 5,40 & 0,012 & 1,600 & 48,20 & 0,4997 & 11,99 & 0,083 \\
\hline 3600 & 60,00 & 255 & 5,30 & 0,002 & 1,611 & 48,77 & 0,0833 & 2,00 & 0,500 \\
\hline 5400 & 90,00 & 255 & 5,30 & 0,000 & 1,611 & 48,77 & 0,0833 & 2,00 & 0,500 \\
\hline 7200 & 120,00 & 255 & 5,30 & 0,000 & 1,611 & 48,77 & 0,0833 & 2,00 & 0,500 \\
\hline 9000 & 150,00 & 255 & 5,30 & 0,000 & 1,611 & 48,77 & 0,0833 & 2,00 & 0,500 \\
\hline 10800 & 180,00 & 255 & 5,30 & 0,000 & 1,611 & 48,77 & 0,0833 & 2,00 & 0,500 \\
\hline 14400 & 240,00 & 255 & 5,30 & 0,000 & 1,611 & 48,77 & 0,0416 & 1,00 & 1,001 \\
\hline
\end{tabular}

DATOS OBTENIDOS:

Velocidad de sedimentación promedio: $15.8 \mathrm{~m} / \mathrm{h}$

$\%$ sólidos - tiempo: $48,7 \%$ sólidos en peso - 60 minutos tiempo residencia 
Mina:

Proyecto:

Muestra
MINAS DE AGUAS TEÑIDAS

Estudio sedimentación y reología de estériles espesados

M-100
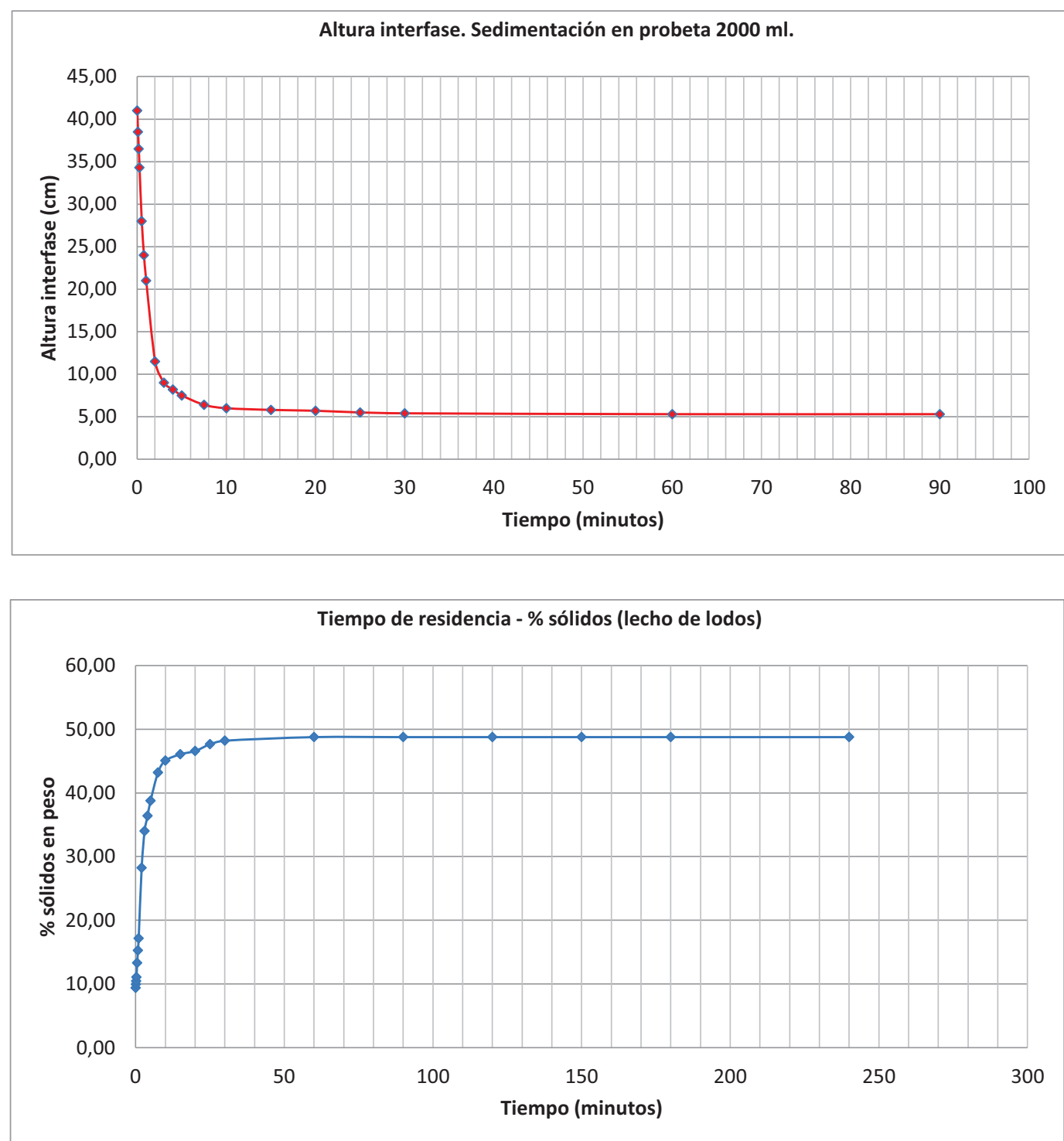


\begin{tabular}{|c|c|c|c|c|c|c|c|c|c|}
\hline \multicolumn{10}{|c|}{ ENSAYO SEDIMENTACIÓN PROBETA $5500 \mathrm{mI}$ DINAMICO } \\
\hline Mina: & MINAS DE AGUA & S TEÑIDAS & & & & & & & \\
\hline Proyecto: & Estudio sedimen & tación y reologí & a de estérile & es espesados & & & & & \\
\hline Muestra: & M-100 & & & & & & & & \\
\hline EQUIPO DE ENSAYO: & & & & & & & & & \\
\hline Diámetro tubo: & & & & & Inyección de & floculante & & & \\
\hline Área sedimentación: & 56,75 & $\mathrm{~cm} 2$ & & & & & gitador & & \\
\hline & 0,005675 & & & & & & floculante & & \\
\hline PREPARACIÓN DE LA I & MUESTRA: & & & & & & $\perp$ & & \\
\hline Solids SG & 4,50 & $\mathrm{~kg} / \mathrm{dm} 3$ & & & & Bomba de & sculante & & \\
\hline Liquid SG & 1,00 & $\mathrm{~kg} / \mathrm{dm} 3$ & & fluent & & & & & \\
\hline \%Solidos alimentac. & 9,96 & & & larificado & & & & & \\
\hline Pulpa alimentac. SG: & 1,084 & $\mathrm{~kg} / \mathrm{l}$ & & ose) & & Tanque & e & & \\
\hline Pulpa alimentac.: & 107,96 & g solidos/l & & & & & & & \\
\hline Pulpa alimentac.: & 0,108 & g solidos $/ \mathrm{ml}$ & & & & & & & \\
\hline FLOCULANTE: & & & & & & & & & \\
\hline Floc Name: & NALCO & & pastats thut & & & 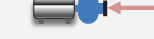 & & & \\
\hline Floc Type: & $-10 \%$ carga iónic & & pasta (hund & & & & & & \\
\hline Floc. Dosificación: & 0,50 & $\mathrm{~g} / \mathrm{l}(\mathrm{mg} / \mathrm{ml})$ & & & & $\begin{array}{l}\text { Bomba de recir } \\
\text { lodos }\end{array}$ & ión de & & \\
\hline Floc. Dosificación: & 0,050 & & & & & & & & \\
\hline & & & & DATOS ENS & SAYO DINÁMICO: & & & & \\
\hline DATOS DE LA OPERAC & CIÓN & & & & Alimentación (Valc & res promedio $t$ & óricos) & & \\
\hline Sólidos & 3100,0 & gramos & & & Total tiempo alime & ntación: & $0: 20: 00$ & hh:mm:ss & \\
\hline Volumen líquido & 28,00 & litros & & & Volumen total (litr & & 28,6 & 5 litros & \\
\hline Tiempo inicio & $11: 30: 00$ & horario & & & Tiempo alimentaci & & 20,0 & minutos & \\
\hline Volumen pulpa inic. & 28,69 & litros & & & Caudal alimentació & n (media): & 1,432 & litros/min & \\
\hline Tiempo final & $11: 50: 00$ & horario & & & Sólidos alimentado & & 3022,4 & $\mathrm{~g}$ & \\
\hline Volumen pulpa final & 0,05 & litros & & & Floculante (Valore & $s$ promedio teór & $\cos )$ & & \\
\hline & Floculante inic. & & & & Volumen total (ml) & & 205,00 & $\mathrm{ml}$ & \\
\hline Vol. floculante inic. & 1000 & & & & Caudal floculante: & & 10,25 & $\mathrm{ml} / \mathrm{min}$ & \\
\hline & & & & & Dosific. floculante & oromedio & 33,91 & $\mathrm{~g} / \mathrm{t}$ & \\
\hline DATOS ENSAYO DINÁMI & ICO: & & & & & & & & \\
\hline $\begin{array}{c}\text { Tiempo } \\
\text { (Minutos) }\end{array}$ & $\begin{array}{c}\text { Vol. Rebose } \\
\text { (litros) }\end{array}$ & $\begin{array}{c}\text { Consumo Floc. } \\
(\mathrm{ml})\end{array}$ & $\begin{array}{l}\text { Sól. Seco } \\
\text { (g) }\end{array}$ & $\begin{array}{c}\text { Floculante } \\
\mathrm{ml} / \mathrm{min}\end{array}$ & $\begin{array}{l}\text { Vol. Alimentación } \\
\mathrm{ml} / \mathrm{min}\end{array}$ & $\begin{array}{c}\text { Velocidad sed. } \\
\mathrm{m} / \mathrm{h}\end{array}$ & $\begin{array}{c}\text { Dos. Floc. } \\
\mathrm{g} / \mathrm{t}\end{array}$ & $\begin{array}{l}\text { Flujo } \\
\text { tpd/m2 }\end{array}$ & $\begin{array}{l}\text { Área } \\
\mathrm{m} 2 / \mathrm{tpd}\end{array}$ \\
\hline 0 & 0 & 0 & 0 & 0 & 0 & 0 & 0 & 0 & 0 \\
\hline 2 & 4 & 30 & 428,6 & 7,5 & 2051,4 & 21,7 & 35,0 & 54,384 & 0,018 \\
\hline 5 & 8 & 60 & 428,6 & 7,5 & 1335,8 & 14,1 & 35,0 & 36,256 & 0,028 \\
\hline 10 & 15 & 110 & 750,3 & 7,1 & 1415,7 & 15,0 & 33,3 & 38,083 & 0,026 \\
\hline 12 & 18,5 & 135 & 375,2 & 7,1 & 1711,9 & 18,1 & 33,3 & 47,603 & 0,021 \\
\hline 15 & 24 & 170 & 590,0 & 6,4 & 1851,4 & 19,6 & 29,7 & 49,909 & 0,020 \\
\hline 20 & 28,2 & 205 & 449,7 & 8,3 & 835,4 & 8,8 & 38,9 & 22,822 & 0,044 \\
\hline VALORES PROMEDIO RE & & Total sólidos: & 3022,4 & g sól. seco & & 16,2 & 34,2 & 41,5 & 0,026 \\
\hline & & ólidos perdidos: & 77,6 & $\mathrm{~g}$ & & Promedio m/h & Promedio g/t & Promed. tpd/m2 & Promed. $\mathrm{m} 2 / \mathrm{tpd}$ \\
\hline & $\% \mathrm{~S}$ & ólidos perdidos: & 2,50 & $\%$ & & & & & \\
\hline & & & & DATOS ENS & ISAYO ESTÁTICO: & & & & \\
\hline $\begin{array}{l}\text { Tiempo } \\
\text { (min) }\end{array}$ & $\begin{array}{l}\text { Altura interfase } \\
(\mathrm{mm})\end{array}$ & $\begin{array}{l}\text { Vol. Lodos } \\
\text { (cm3) }\end{array}$ & $\begin{array}{l}\text { Vol. Líquido } \\
\text { (cm3) }\end{array}$ & $\begin{array}{c}\text { Densidad lodo } \\
(\mathrm{g} / \mathrm{cm} 3)\end{array}$ & $\begin{array}{l}\text { MUESTRA } \\
(\mathrm{cm} 3)\end{array}$ & $\begin{array}{l}\text { Lodos } \\
\text { \% Sol. Peso }\end{array}$ & $\begin{array}{l}\text { T. Residencia } \\
\text { (horas) }\end{array}$ & OBSERVACIONES & \\
\hline 0 & 565 & 3206,1 & 2534,4 & 1,733 & 0 & 54,39 & 0,0 & & \\
\hline 2 & 494 & 2803,2 & 2131,6 & 1,839 & 0 & 58,64 & 0,0 & & \\
\hline 5 & 452 & 2564,9 & 1893,2 & 1,917 & 0 & 61,49 & 0,1 & & \\
\hline 10 & 433 & 2457,1 & 1785,4 & 1,957 & 0 & 62,86 & 0,2 & & \\
\hline 15 & 411 & 2332,2 & 1660,6 & 2,008 & 0 & 64,54 & 0,3 & & \\
\hline 30 & 389 & 2207,4 & 1535,7 & 2,065 & 0 & 66,31 & 0,5 & & \\
\hline 60 & 364 & 2065,5 & 1393,9 & 2,138 & 0 & 68,44 & 1,0 & & \\
\hline 120 & 345 & 1957,7 & 1286,0 & 2,201 & 0 & 70,15 & 2,0 & & \\
\hline 180 & 330 & 1872,6 & 1200,9 & 2,255 & 0 & 71,56 & 3,0 & & \\
\hline 240 & 324 & 1838,5 & 1166,9 & 2,279 & 0 & 72,15 & 4,0 & & \\
\hline 300 & 313 & 1776,1 & 1104,5 & 2,324 & 0 & 73,24 & 5,0 & & \\
\hline 360 & 308 & 1747,7 & 1076,1 & 2,345 & 0 & 73,74 & 6,0 & & \\
\hline 420 & 303 & 1719,4 & 1047,7 & 2,367 & 0 & 74,26 & 7,0 & & \\
\hline 480 & 303 & 1719,4 & 1047,7 & 2,367 & 0 & 74,26 & 8,0 & & \\
\hline 540 & 303 & 1719,4 & 1047,7 & 2,367 & 0 & 74,26 & 9,0 & & \\
\hline 600 & 303 & 1719,4 & 1047,7 & 2,367 & 0 & 74,26 & 10,0 & & \\
\hline
\end{tabular}


ENSAYO SEDIMENTACIÓN PROBETA 5500 mI DINAMICO

Mina: MINAS DE AGUAS TEÑIDAS

Proyecto: $\quad$ Estudio sedimentación y reología de estériles espesados

Muestra: $\quad \mathrm{M}-100$

DATOS DE OPERACIÓN DEL ESPESADOR DE TUBO PROFUNDO

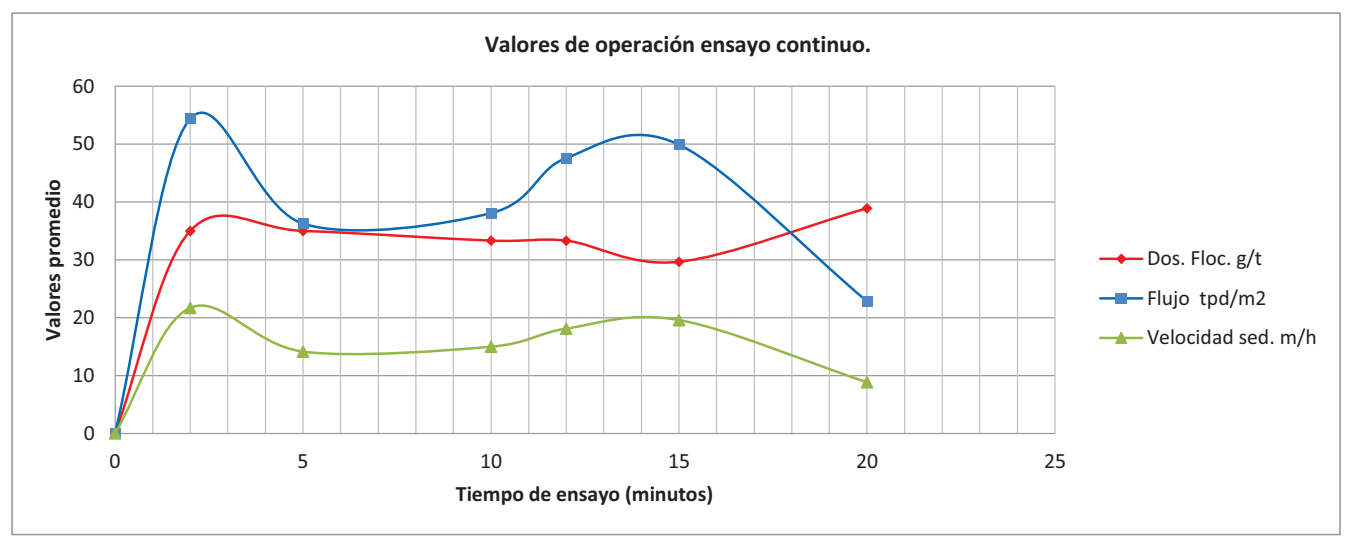

Datos Promedio:

Velocidad de sedimentación:

$16,2 \mathrm{~m} / \mathrm{h}$

Dosificación de floculante:

$34,2 \mathrm{~g} / \mathrm{t}$

Flujo de sedimentación:

$0,0262 \mathrm{~m}^{2} / \mathrm{t} / \mathrm{día}$

Flujo de sedimentación:

$41,5 \mathrm{t} / \mathrm{di} a / \mathrm{m}^{2}$

ENSAYO SEDIMENTACIÓN PROBETA 5500 mI DINAMICO
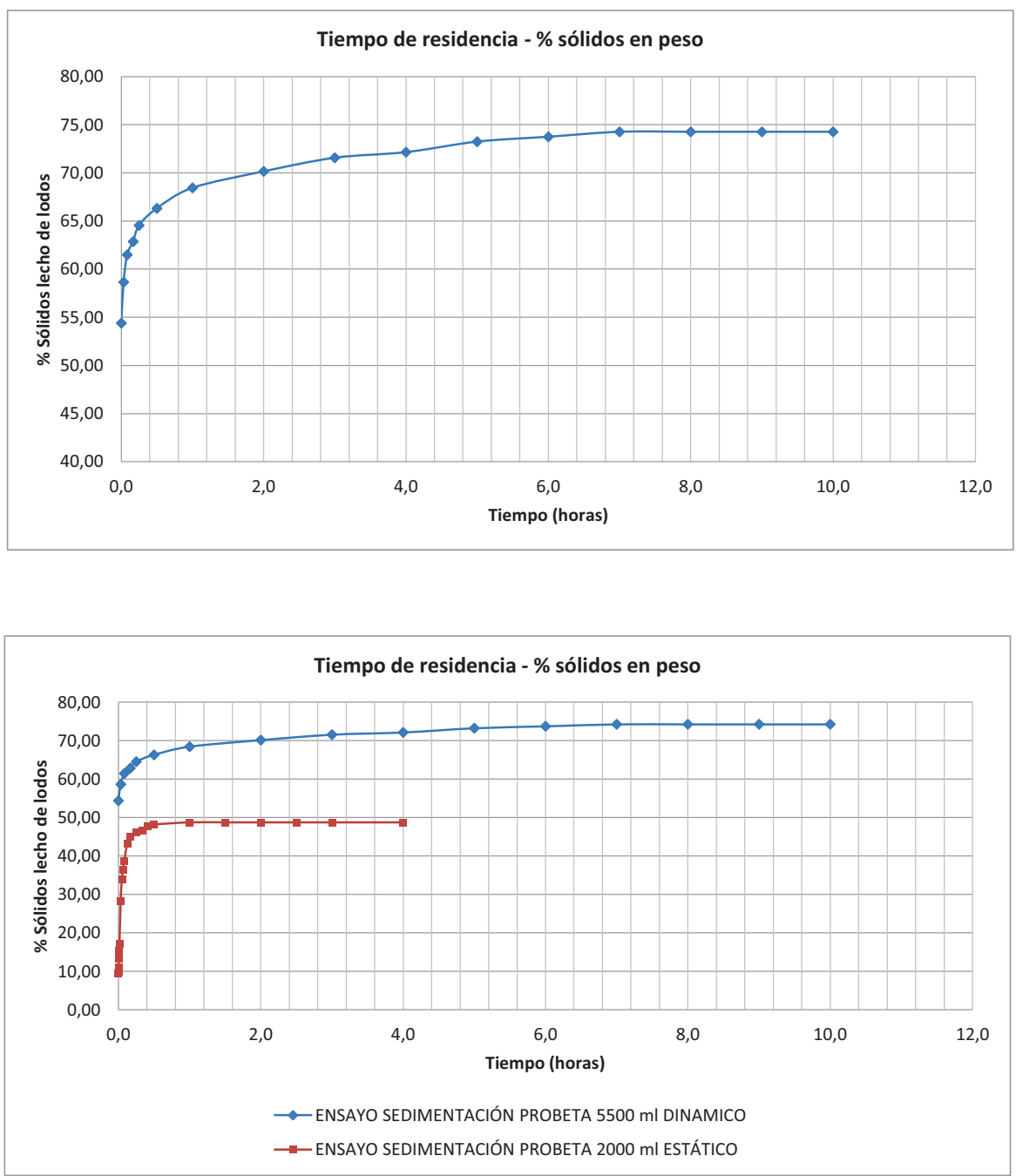
ENSAYO FILTRACIÓN A VACIO

Mina: MINAS DE AGUAS TEÑIDAS

Proyecto: $\quad$ Estudio sedimentación y reología de estériles espesados

Material:

Estudio sedimentación y reología de estériles espesados

Muestra:

M-100

Preparado por:

pH muestra:

Fecha:

$28 / 06 / 2015$

\begin{tabular}{|c|c|c|}
\hline \multicolumn{3}{|c|}{ DATOS DE LA MUESTRA: } \\
\hline Solidos SG & & $0,00 \mathrm{~kg} / \mathrm{dm} 3$ \\
\hline Liquido SG & & $0,00 \mathrm{~kg} / \mathrm{dm} 3$ \\
\hline \multicolumn{3}{|l|}{ FLOCULANTE: } \\
\hline Floc Name: & No & \\
\hline Tipo de floculante: & No & \\
\hline Floc. Dosificación: & & $0,00 \mathrm{~g} / \mathrm{l}(\mathrm{mg} / \mathrm{ml})$ \\
\hline Floc. Dosificación: & & $0,000 \%$ \\
\hline
\end{tabular}
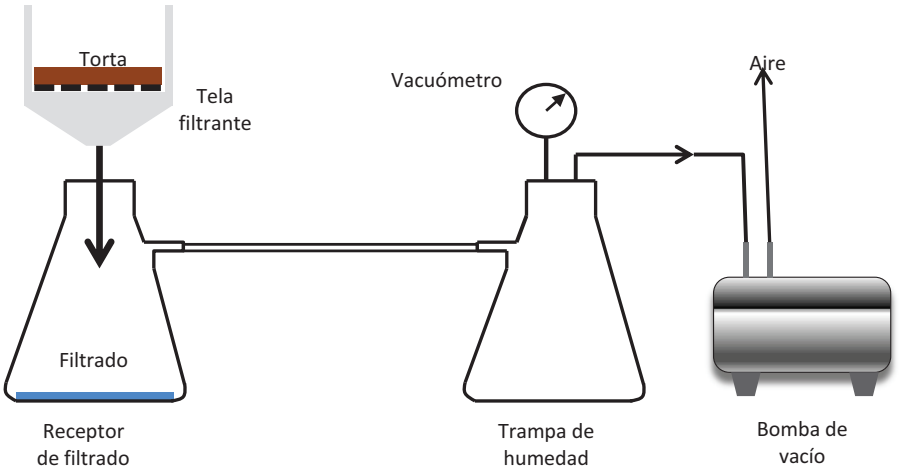

\begin{tabular}{|c|c|c|c|c|c|c|c|c|c|}
\hline \multicolumn{10}{|c|}{ ENSAYO FILTRACIÓN A VACÍO. TEST 1.} \\
\hline \multicolumn{2}{|c|}{ MUESTRA: M-100 } & & \multicolumn{7}{|c|}{ Tiempos de ensayo de filtración } \\
\hline $\begin{array}{l}\text { Vacío } \\
\text { (bar) }\end{array}$ & $\begin{array}{c}\text { Peso sólidos } \\
\text { (g) }\end{array}$ & $\begin{array}{l}\text { Vol. Líquido } \\
\text { (ml) }\end{array}$ & $\begin{array}{c}\text { \% Sól. Peso } \\
\text { (\%) }\end{array}$ & $\begin{array}{l}\text { Vol. Pulpa } \\
\text { (ml) }\end{array}$ & $\begin{array}{l}\text { Formación torta } \\
\text { (s) }\end{array}$ & $\begin{array}{l}\text { Secado torta } \\
\text { (s) }\end{array}$ & $\begin{array}{l}\text { Total ciclo } \\
\text { (s) }\end{array}$ & $\begin{array}{l}\text { Líq. Filtrado } \\
\quad(\mathrm{ml})\end{array}$ & $\begin{array}{c}\text { Espesor } \\
(\mathrm{mm})\end{array}$ \\
\hline 0 & 0 & 0,0 & \#DIV/0! & \#DIV/0! & 0 & 0 & 0 & 0 & 0,0 \\
\hline \% Solidos estimado: & \#DIV/0! & & \multirow{2}{*}{\multicolumn{2}{|c|}{ Observaciones: }} & & & & & \\
\hline Peso muestra húmedo: & 0 & $\mathrm{~g}$ & \multirow{3}{*}{\multicolumn{2}{|c|}{ Observaciones: }} & & & & & \\
\hline \multicolumn{3}{|c|}{\begin{tabular}{|l} 
Secado de la muestra: \\
\end{tabular}} & & & & & & & \\
\hline Peso muestra seco & 0 & $\mathrm{~g}$ & & & & & & & \\
\hline$\%$ humedad torta & \#DIV/0! & $\%$ & & & & & & & \\
\hline
\end{tabular}

\begin{tabular}{|c|c|c|c|c|c|c|c|c|c|}
\hline \multicolumn{10}{|c|}{ ENSAYO FILTRACIÓN A VACÍO. TEST 2.} \\
\hline \multicolumn{2}{|c|}{ MUESTRA: M-100 } & & \multicolumn{7}{|c|}{ Tiempos de ensayo de filtración } \\
\hline $\begin{array}{l}\text { Vacío } \\
\text { (bar) }\end{array}$ & $\begin{array}{l}\text { Peso sólidos } \\
\text { (g) }\end{array}$ & $\begin{array}{l}\text { Vol. Líquido } \\
\text { (ml) }\end{array}$ & $\begin{array}{c}\text { \% Sól. Peso } \\
\text { (\%) }\end{array}$ & $\begin{array}{l}\text { Vol. Pulpa } \\
\text { (ml) }\end{array}$ & $\begin{array}{l}\text { Formación torta } \\
\text { (s) }\end{array}$ & $\begin{array}{l}\text { Secado torta } \\
\text { (s) }\end{array}$ & $\begin{array}{c}\text { Total ciclo } \\
\text { (s) }\end{array}$ & $\begin{array}{l}\text { Líq. Filtrado } \\
\text { (ml) }\end{array}$ & $\begin{array}{c}\text { Espesor } \\
(\mathrm{mm})\end{array}$ \\
\hline 0 & 0 & 0,0 & \#DIV/0! & \#DIV/0! & 0 & 0 & 0 & 0 & 0,0 \\
\hline \% Solidos estimado: & \#DIV/0! & & & & & & & & \\
\hline Peso muestra húmedo: & 0 & $\mathrm{~g}$ & \multirow{3}{*}{\multicolumn{2}{|c|}{ Observaciones: }} & & & & & \\
\hline \multicolumn{3}{|c|}{$\begin{array}{r}\text { Secado de la muestra: } \\
\end{array}$} & & & & & & & \\
\hline Peso muestra seco & 0 & $\mathrm{~g}$ & & & & & & & \\
\hline$\%$ humedad torta & \#DIV/0! & $7 \%$ & \multicolumn{2}{|c|}{ Los pesos incluyen la tara } & & & & & \\
\hline
\end{tabular}

\begin{tabular}{|c|c|c|c|c|c|c|c|c|c|}
\hline \multicolumn{10}{|c|}{ ENSAYO FILTRACIÓN A VACÍO. TEST 3.} \\
\hline \multicolumn{3}{|c|}{ MUESTRA: M-100 } & \multicolumn{7}{|c|}{ Tiempos de ensayo de filtración } \\
\hline $\begin{array}{l}\text { Vacío } \\
\text { (bar) }\end{array}$ & $\begin{array}{l}\text { Peso sólidos } \\
\text { (g) }\end{array}$ & $\begin{array}{l}\text { Vol. Líquido } \\
\text { (ml) }\end{array}$ & \% Sól. Peso & $\begin{array}{l}\text { Vol. Pulpa } \\
\text { (ml) }\end{array}$ & $\begin{array}{l}\text { Formación torta } \\
\text { (s) }\end{array}$ & $\begin{array}{l}\text { Secado torta } \\
\text { (s) }\end{array}$ & $\begin{array}{l}\text { Total ciclo } \\
\text { (s) }\end{array}$ & $\begin{array}{l}\text { Líq. Filtrado } \\
\text { (ml) }\end{array}$ & $\begin{array}{r}\text { Espeso } \\
(\mathrm{mm})\end{array}$ \\
\hline 0 & 0 & 0,0 & \#DIV/0! & \#DIV/0! & & & 0 & & 0,0 \\
\hline \% Solidos estimado: & \#DIV/0! & & & & & & & & \\
\hline Peso muestra húmedo: & 0 & $\mathrm{~g}$ & \multirow{3}{*}{\multicolumn{7}{|c|}{$\begin{array}{l}\text { Observaciones: } \\
\text { Contenido en sólidos de la torta filtrada: } 100-21,71=78,29 \%\end{array}$}} \\
\hline \multicolumn{3}{|c|}{ Secado de la muestra: } & & & & & & & \\
\hline Peso muestra seco & 0 & $\mathrm{~g}$ & & & & & & & \\
\hline$\%$ humedad torta & \#DIV/0! & $\%$ & Los pesos incl & yyen la tara & & & & & \\
\hline
\end{tabular}

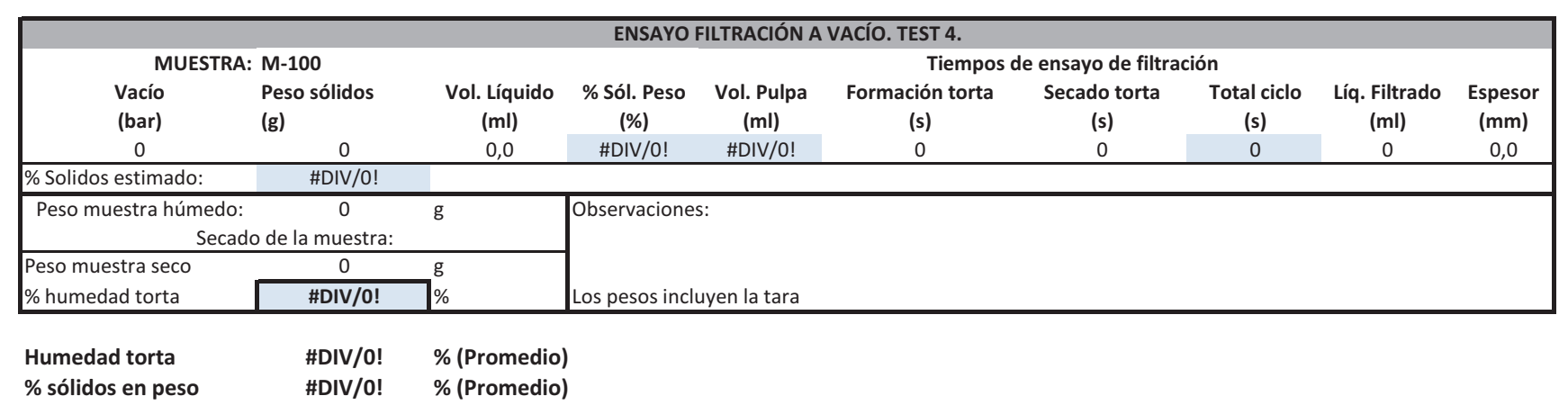


ENSAYO ASENTAMIENTO EN PROBETA

Mina:

Proyecto:

Material:

Preparado por:

pH muestra:

Fecha:

Aceleración gravedad (g):

Diámetro probeta:

Altura probeta $(\mathrm{H})$ :

Volumen probeta:

Solidos SG

Líquido SG

Expresiones empíricas

$T=0.5-0.5(h / H)^{\wedge} 0.5$

T.F. $=\mathrm{T}^{*} \mathrm{~d}^{*} \mathrm{~g}^{*}(\mathrm{H} / 100)$

\section{MINAS DE AGUAS TEÑIDAS}

Estudio sedimentación y reología de estériles espesados

Estériles mineral polimetálico cobre

José A. Butragueño

$28 / 06 / 2015$

$9,81 \mathrm{~m} / \mathrm{s} 2$
$44 \mathrm{~mm}$
$100 \mathrm{~mm}$
$152,1 \mathrm{~cm} 3$
$4,50 \mathrm{~kg} / \mathrm{dm} 3$
$1,00 \mathrm{~kg} / \mathrm{dm} 3$

\section{$\mathrm{H}$}

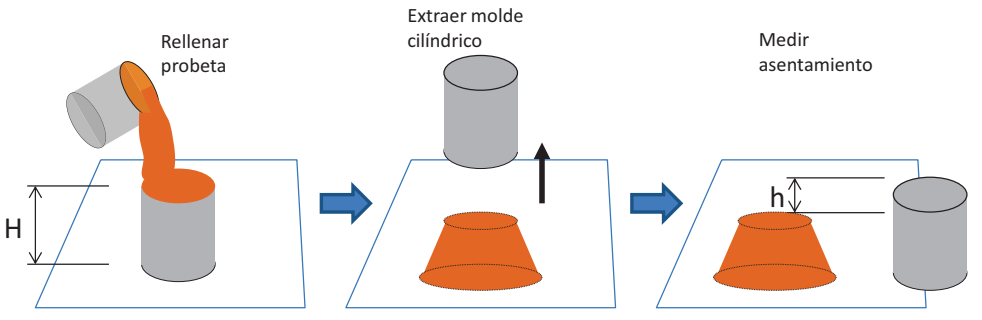

\begin{tabular}{|c|c|c|c|c|c|c|c|c|c|c|}
\hline \multicolumn{11}{|c|}{ ENSAYOS DE ASENTAMIENTO EN PROBETA } \\
\hline $\begin{array}{l}\text { Muestra } \\
\text { ID }\end{array}$ & $\begin{array}{l}\text { Cont. Sólidos } \\
\text { (\%) }\end{array}$ & $\begin{array}{l}\text { Solidos SG } \\
\mathrm{g} / \mathrm{cm} 3\end{array}$ & $\begin{array}{c}\text { Peso Liq. } \\
\text { (kg liq/kg sol) }\end{array}$ & $\begin{array}{l}\text { Vol. Pulpa } \\
\text { (1/kg sol) }\end{array}$ & $\begin{array}{l}\text { Pulpa SG (d) } \\
\text { kg/dm3 }\end{array}$ & $\begin{array}{l}\text { Sólidos prob. } \\
\text { (g) }\end{array}$ & $\begin{array}{l}\text { Liq. Probeta } \\
\text { (g) }\end{array}$ & $\begin{array}{c}\text { Asentamiento (h) } \\
\mathrm{mm}\end{array}$ & $\begin{array}{l}\text { Factor "T" } \\
\text { Adimens. }\end{array}$ & $\begin{array}{c}\text { Tensión Fluencia } \\
(\mathrm{Pa})\end{array}$ \\
\hline 1 & 68,5 & 4,50 & 0,460 & 0,682 & 2,140 & 222,9 & 102,5 & 45 & 0,16459 & 345,6 \\
\hline 2 & 67,5 & 4,50 & 0,481 & 0,704 & 2,105 & 216,1 & 104,0 & 52 & 0,13944 & 288,0 \\
\hline 3 & 65 & 4,50 & 0,538 & 0,761 & 2,022 & 199,9 & 107,6 & 62 & 0,10630 & 210,9 \\
\hline 4 & 62,5 & 4,50 & 0,600 & 0,822 & 1,946 & 184,9 & 111,0 & 79 & 0,05559 & 106,1 \\
\hline 5 & 60 & 4,50 & 0,667 & 0,889 & 1,875 & 171,1 & 114,0 & 90 & 0,02566 & 47,2 \\
\hline 6 & 55 & 4,50 & 0,818 & 1,040 & 1,748 & 146,1 & 119,6 & 96 & 0,01010 & 17,3 \\
\hline
\end{tabular}

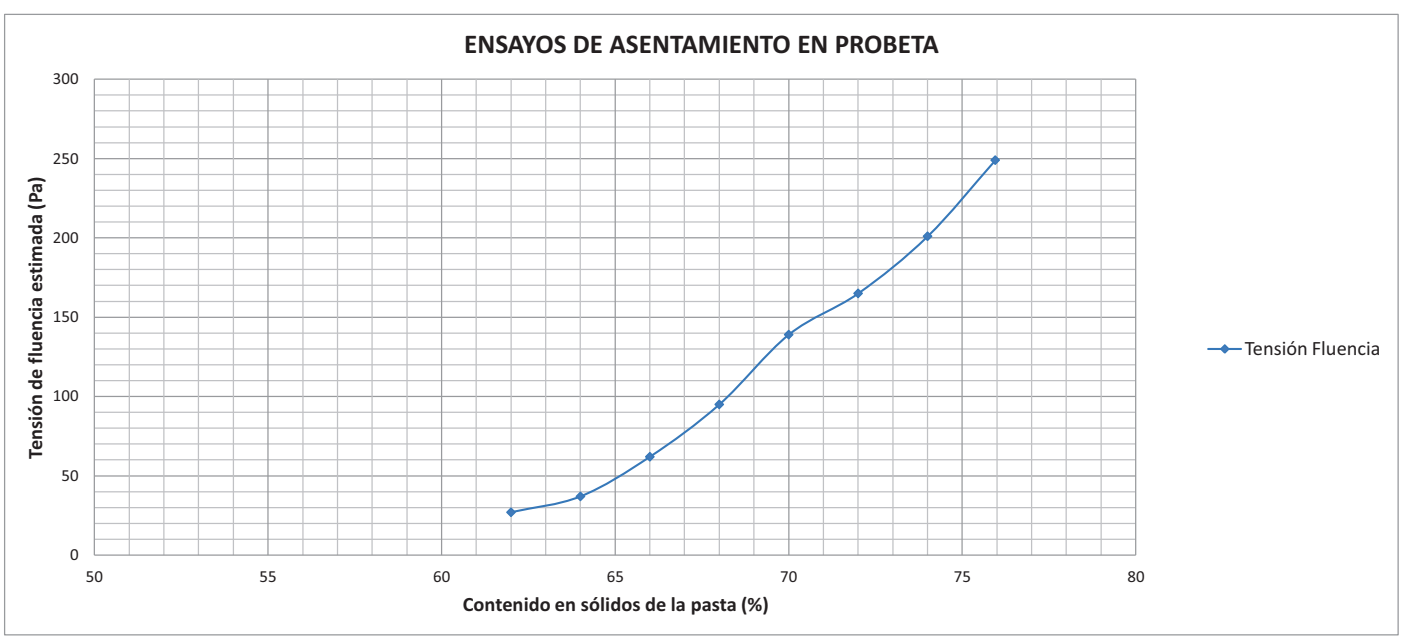

Página 12 de 12 


\section{ENSAYOS DE SEDIMENTACIÓN Y REOLOGÍA}

\section{Mina:}

MINAS DE AGUAS TEÑIDAS

\section{Empresa:}

DOCTORANDO JOSE A. BUTRAGUEÑO

\section{Proyecto:}

Estudio sedimentación y reología de estériles espesados

\section{Aplicación}

Sedimentación. Estériles de flotación mineral Cu Polimetálico (Valdelamusa)

Fecha:

$28 / 06 / 2015$

\section{Ensayos:}

\begin{tabular}{|c|c|}
\hline $\mathbf{x}$ & Distribución granulométrica y caracterización de muestras \\
\hline $\mathbf{X}$ & Selección de floculantes \\
\hline $\mathbf{x}$ & Área de flujo \\
\hline $\mathbf{x}$ & Sedimentación en probeta estática \\
\hline $\mathbf{x}$ & Ensayo en espesador dinámico de laboratorio de $85 \mathrm{~mm}$ DIA \\
\hline $\mathbf{x}$ & Reología de los lodos \\
\hline & Ensayo de filtración a vacío \\
\hline
\end{tabular}

\begin{tabular}{|c|c|}
\hline \multicolumn{2}{|c|}{ Realizado por: } \\
\hline Nombre: & José Butragueño \\
\hline \multicolumn{2}{|c|}{ Fecha: $\quad 28 / 06 / 2015$} \\
\hline Revisión: & Objeto de la revisión: \\
\hline 0 & Ensayo inicial \\
\hline & \\
\hline & \\
\hline \multirow[t]{3}{*}{ Códigos: } & Campo de dato calculado a partir de los valores introducidos \\
\hline & Campo para introducir datos por el laborante \\
\hline & $\begin{array}{l}\text { Valor constante } \\
\text { observaciones }\end{array}$ \\
\hline
\end{tabular}


ENSAYO GRANULOMÉTRICO DE SÓLIDOS

Mina: MINAS DE AGUAS TEÑIDAS

Proyecto: Estudio sedimentación y reología de estériles espesados Realizado por: José Butragueño

\begin{tabular}{|ll|}
\hline Muestra ID: & M-100 \\
Material: & Estériles mineral polimetálico cobre \\
Preparado por: & José A. Butragueño \\
pH muestra: & - \\
Fecha: & $28 / 06 / 2015$ \\
\hline
\end{tabular}

CURVA GRANULOMÉTRICA DE SÓLIDOS

\begin{tabular}{|c|c|c|c|c|}
\hline \multicolumn{3}{|c|}{ DATOS DE LA PULPA A SEDIMENTAR } & \multicolumn{2}{|c|}{ Observaciones: Muestra de sólido seco } \\
\hline Densidad sólidos: & 4,50 & $\mathrm{~kg} / \mathrm{dm}^{3}$ & & \\
\hline Densidad líquido: & 1,00 & $\mathrm{~kg} / \mathrm{dm}^{3}$ & & \\
\hline Densidad pulpa: & & $\mathrm{kg} / \mathrm{l}$ & & \\
\hline Tara: & & $g$ & & \\
\hline Pulpa húmeda: & 0 & $g$ & Peso pulpa: & $0 \mathrm{~g}$ \\
\hline Sólido seco: & 0 & $\mathrm{~g}$ & Peso sólido: & $0 \mathrm{~g}$ \\
\hline \% Peso sólidos: & \#DIV/0! & $\%$ & & \\
\hline
\end{tabular}

\section{CURVA GRANULOMÉTRICA DE SÓLIDOS}

ENSAYO GRANULOMÉTRICO Muestra M-100

\begin{tabular}{|c|c|c|r|}
\hline Tamiz (micras) & \% pasa & Tamiz (micras) & \multicolumn{1}{c|}{ \% pasa } \\
\hline 0,479 & 0,17 & 30,200 & 64,53 \\
\hline 0,631 & 0,47 & 39,811 & 71,89 \\
\hline 0,832 & 0,89 & 52,481 & 79,03 \\
\hline 1,096 & 1,46 & 69,183 & 85,36 \\
\hline 1,445 & 2,26 & 91,201 & 90,34 \\
\hline 1,905 & 3,47 & 120,226 & 93,81 \\
\hline 2,512 & 5,35 & 158,489 & 96,09 \\
\hline 3,311 & 8,27 & 208,930 & 97,63 \\
\hline 4,365 & 12,56 & 275,423 & 98,76 \\
\hline 5,574 & 18,38 & 363,078 & 99,55 \\
\hline 7,586 & 25,54 & 478,630 & 99,96 \\
\hline 10,000 & 33,55 & 630,957 & 100,00 \\
\hline 13,183 & 41,74 & & \\
\hline 17,378 & 49,63 & & \\
\hline 22,909 & 57,16 & & \\
\hline
\end{tabular}

$P 80=54.59$ micras

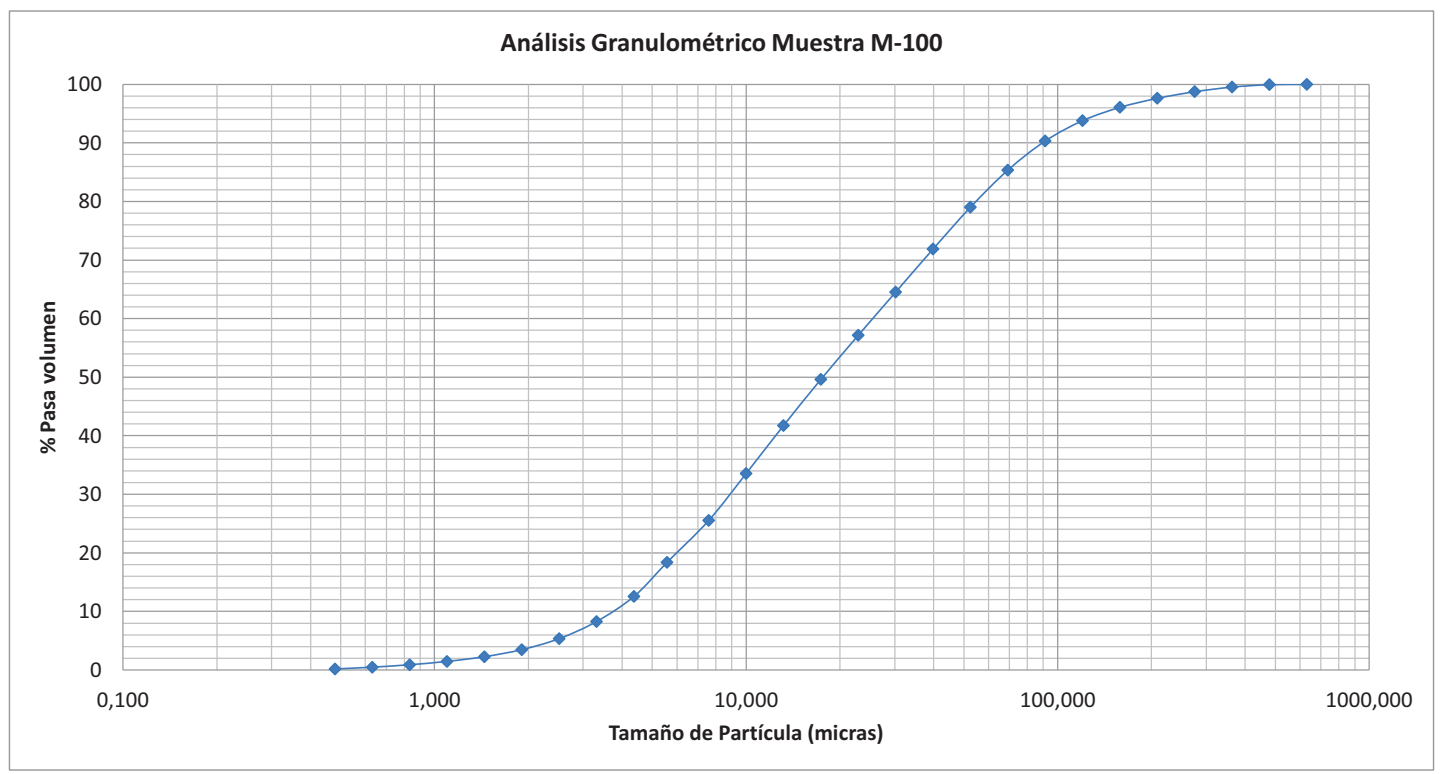




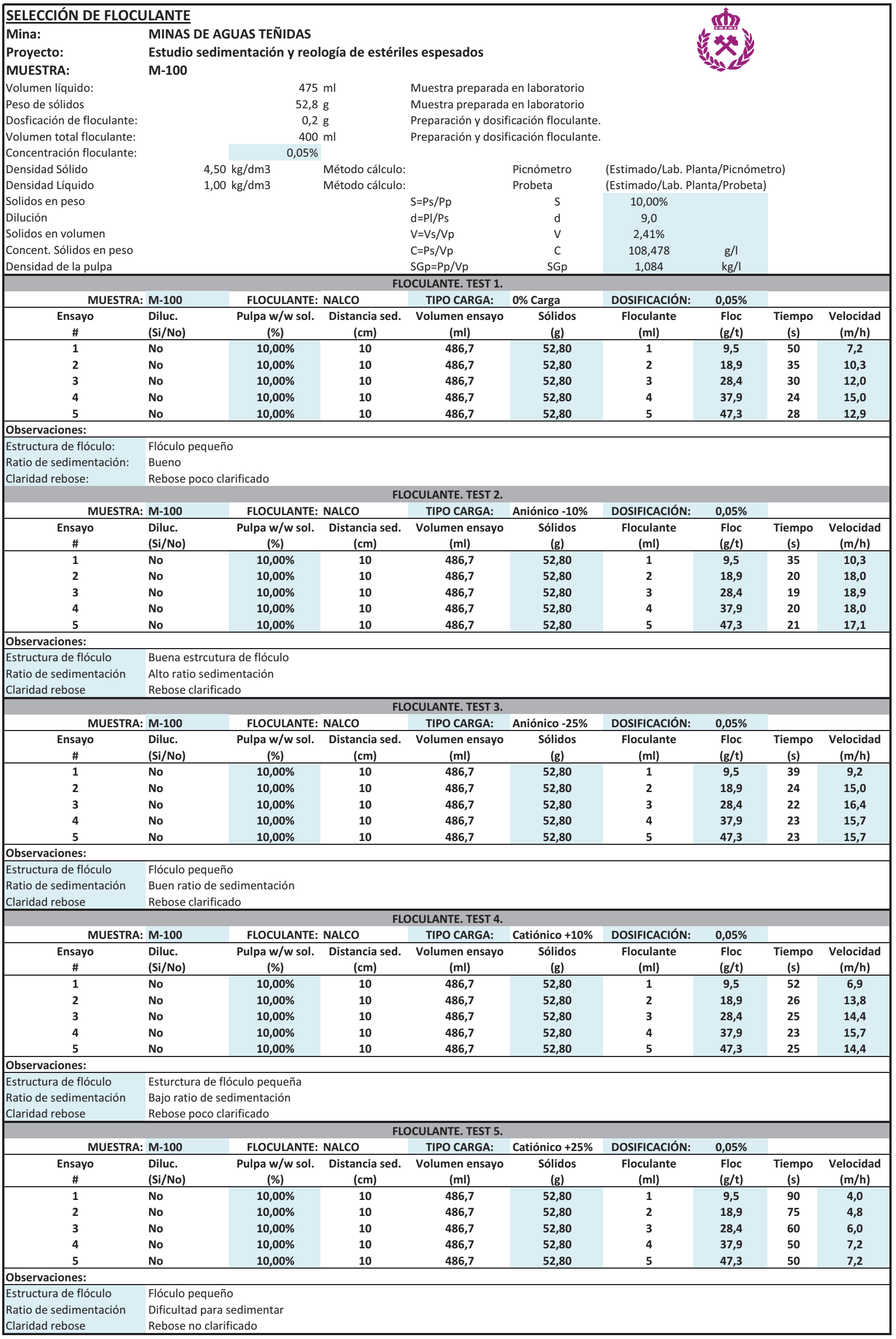


SELECCIÓN DE FLOCULANTE. ANÁLISIS DE DATOS.

$\begin{array}{ll}\text { Mina: } & \text { MINAS DE AGUAS TEÑIDAS } \\ \text { Proyecto: } & \text { Estudio sedimentación y re }\end{array}$

MUESTRA:

M-100

Volumen líquido:

$\%$ sólidos en peso:

Dosficación de floculante:

Volumen total:

Concentración floculante:

Densidad Sólido

Densidad Líquido

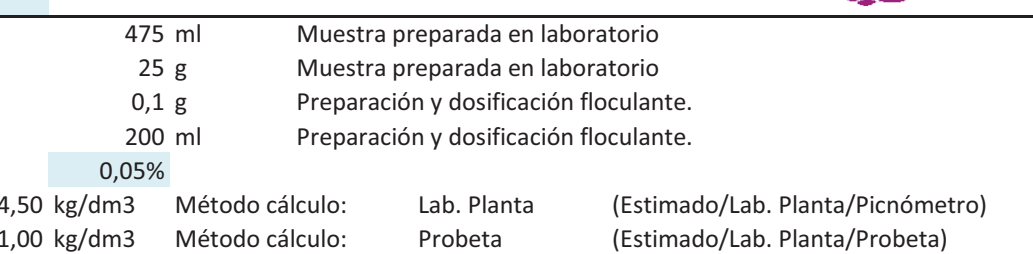

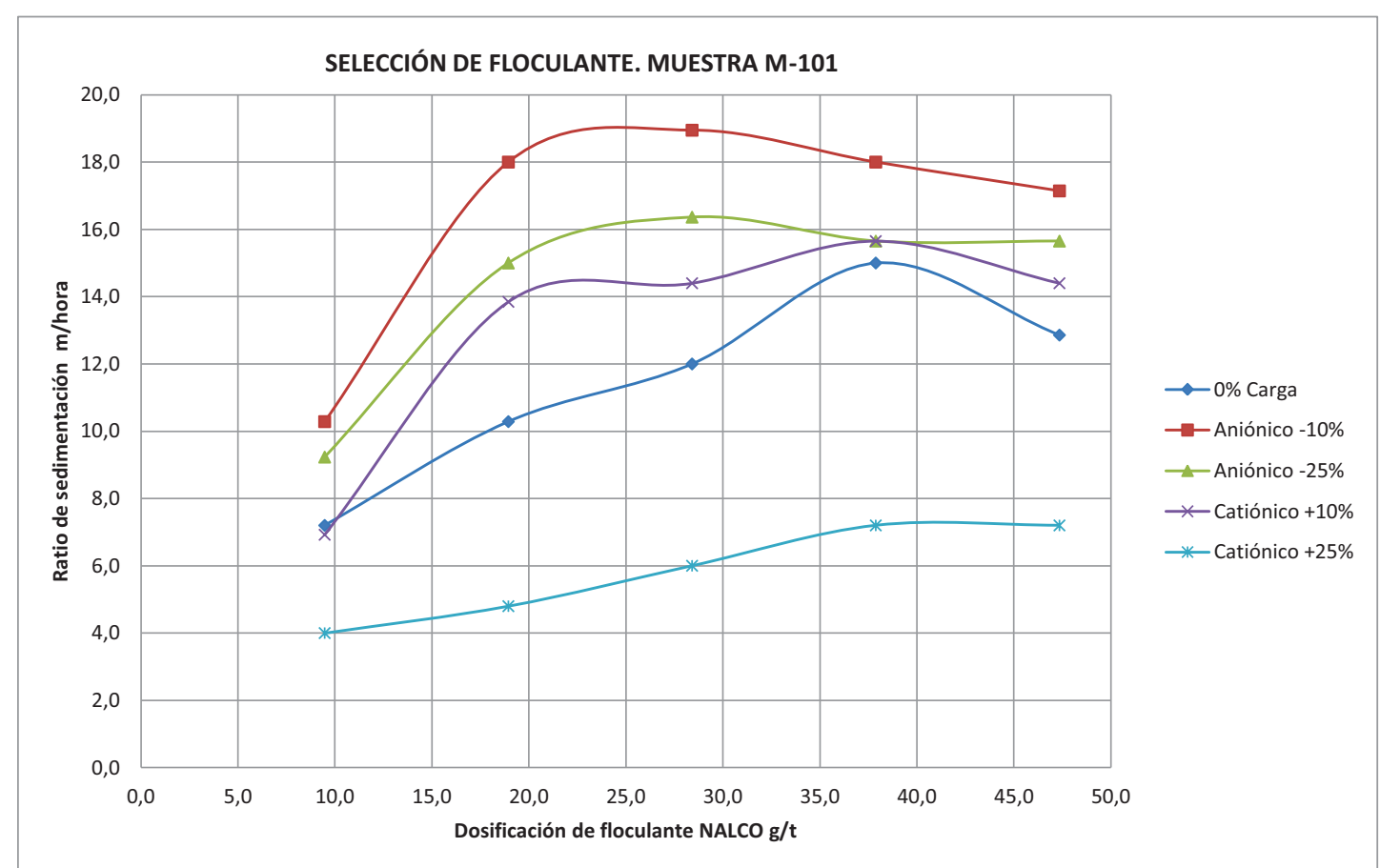

Los ensayos de sedimentación para la selección del floculante han tenido en cuenta tanto los valores de velocidad de sedimentación cómo los datos de observación visual de: tamaño de flóculo, velocidad de sedimentación, cohesión del flóculo y la claridad del rebose obtenida en la probeta de laboratorio. El floculante seleccionado será empleado en los ensayos de flujo de sedimentación.

FLOCULANTE SELECCIONADO:

NALCO -10\% CARGA 
ENSAYO FLUJO SEDIMENTACIÓN

Mina: MINAS DE AGUAS TEÑIDAS

Proyecto: Estudio sedimentación y reología de estériles espesados

DATOS

FLOCULANTE SELECCIONADO

Volumen probeta:

$1000 \mathrm{ml}$

NALCO - $10 \%$ CARGA

Diámetro probeta: $\quad 58 \mathrm{~mm}$

Floc. Dosificac: $\quad \quad 0,2 \mathrm{~g}$

Volumen floc: $\quad 400 \mathrm{ml}$

Floculante dosific. $\quad 0,05 \%$

Floc. Conc. $\quad 0,50 \mathrm{~g} / \mathrm{l}$

Densidad Sólido $\quad 4,50 \mathrm{~kg} / \mathrm{dm} 3$

Densidad Líquido $\quad 1,00 \mathrm{~kg} / \mathrm{dm} 3$

NALCO -10\% CARGA @ 2.5\% Sól. Peso

$\begin{array}{lrr}\text { Diámetros de probetas: } & \\ 250 \mathrm{ml} & 35,7 & \mathrm{~mm} \\ 500 \mathrm{ml} & 48,6 & \mathrm{~mm} \\ 2000 \mathrm{ml} & 78,2 & \mathrm{~mm}\end{array}$

MUESTRA SÓLIDOS

M-100

NALCO -10\% CARGA @ 2.5\% Só. Peso

\begin{tabular}{|c|c|c|c|c|c|c|c|c|c|c|c|}
\hline \multicolumn{2}{|c|}{ MUESTRA: M-100 } & FLOCULANTE & \multicolumn{2}{|c|}{ NALCO - $10 \%$ CARGA } & \multicolumn{2}{|r|}{ CARGA SÓLIDOS: } & 2,50 & \multicolumn{4}{|l|}{$\%$} \\
\hline $\begin{array}{c}\text { Peso sólidos } \\
\text { (g) }\end{array}$ & $\begin{array}{c}\text { Vol. líquido } \\
(\mathrm{ml})\end{array}$ & $\begin{array}{c}\text { Sólidos } \\
(\% \mathrm{w} / \mathrm{w})\end{array}$ & $\begin{array}{c}\text { Densidad pulpa } \\
(\mathrm{kg} / \mathrm{l})\end{array}$ & $\begin{array}{c}\text { Conc. Solids } \\
(\mathrm{g} / \mathrm{l})\end{array}$ & $\begin{array}{c}\text { Floculant. } \\
(\mathrm{ml})\end{array}$ & $\begin{array}{l}\text { Dist. Sediment. } \\
(\mathrm{cm})\end{array}$ & $\begin{array}{c}\text { Tiempo sed. } \\
\text { (s) }\end{array}$ & $\begin{array}{c}\text { Velocidad sed. } \\
(\mathrm{m} / \mathrm{h})\end{array}$ & $\begin{array}{l}\text { Floc dosific. } \\
(\mathrm{g} / \mathrm{t})\end{array}$ & $\begin{array}{c}\text { Flujo } \\
\text { (tph/m2) }\end{array}$ & $\begin{array}{c}\begin{array}{c}\text { Flujo } \\
\text { (tpd/m2) }\end{array} \\
\end{array}$ \\
\hline 25,6 & 1000 & 2,50 & 1,020 & 25,46 & 0,5 & 10,0 & 9 & 40,0 & 10 & 3,88 & 93,02 \\
\hline 25,6 & 1000 & 2,50 & 1,020 & 25,46 & 1 & 10,0 & 8 & 45,0 & 20 & 4,36 & 104,64 \\
\hline 25,6 & 1000 & 2,50 & 1,020 & 25,46 & 1,5 & 10,0 & 7 & 51,4 & 29 & 4,98 & 119,59 \\
\hline 25,6 & 1000 & 2,50 & 1,020 & 25,46 & 2 & 10,0 & 7 & 51,4 & 39 & 4,98 & 119,59 \\
\hline 25,6 & 1000 & 2,50 & 1,020 & 25,46 & 2,5 & 10,0 & 8 & 45,0 & 49 & 4,36 & 104,64 \\
\hline 25,6 & 1000 & 2,50 & 1,020 & 25,46 & 3 & 10,0 & 8 & 45,0 & 59 & 4,36 & 104,64 \\
\hline
\end{tabular}

NALCO -10\% CARGA @ 5\% Sól. Peso

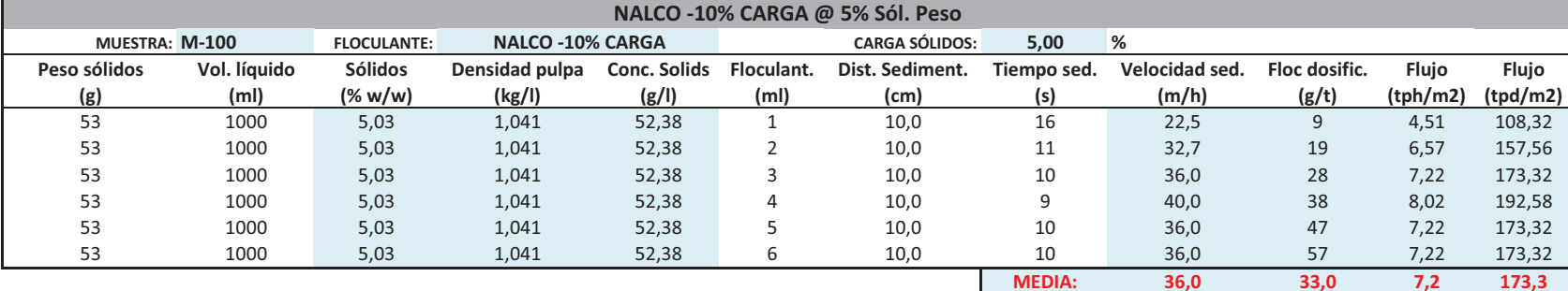

NALCO -10\% CARGA @ 7.5\% Sól. Peso

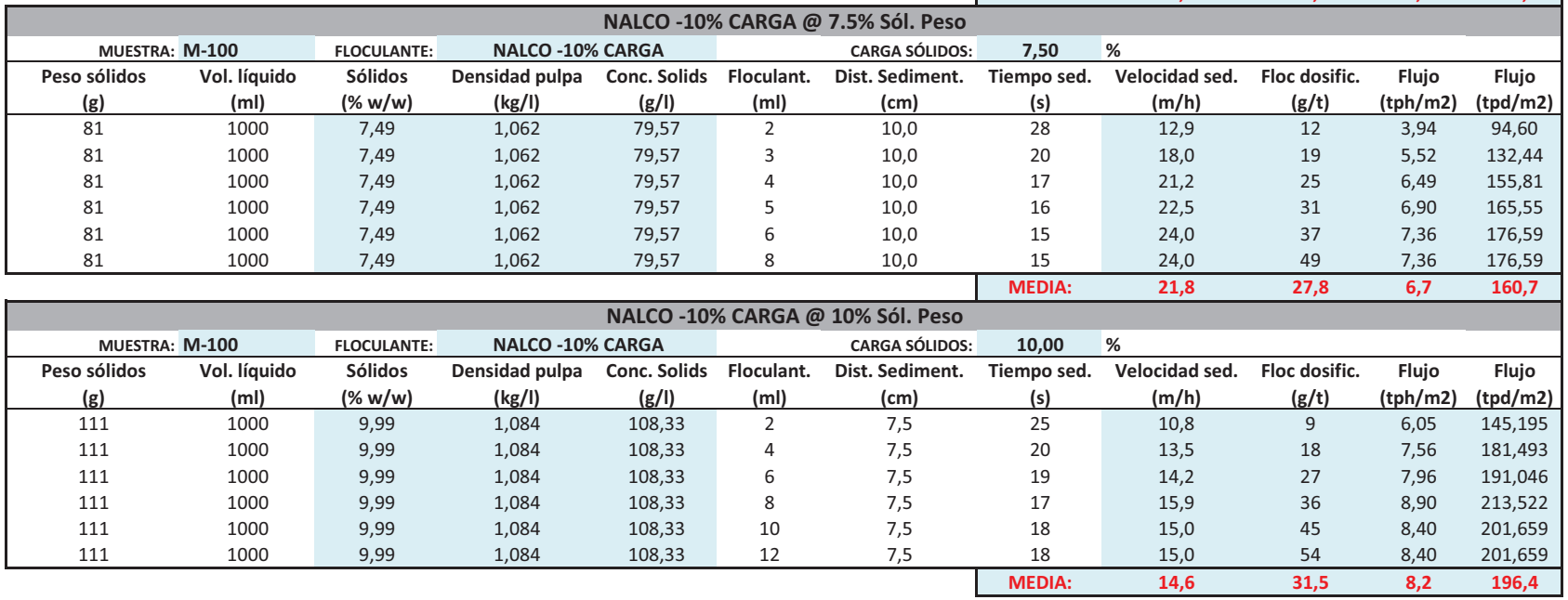


ENSAYO FLUJO SEDIMENTACIÓN. ANÁLISIS DE RESULTADOS.

Mina: MINAS DE AGUAS TEÑIDAS

Proyecto: $\quad$ Estudio sedimentación y reología de estériles espesados

DATOS

Volumen probeta:

$1000 \mathrm{ml}$

$58 \mathrm{~mm}$

Diámetro probeta:

Área sedimentac.

$26,42 \mathrm{~cm} 2$

Floc. Dosificac.:

Volumen floc:

Floculante dosific.

$0,2 \mathrm{~g}$

$400 \mathrm{ml}$

$0,05 \%$

Floc. Conc.

$0,50 \mathrm{~g} / \mathrm{l}$

$4,50 \mathrm{~kg} / \mathrm{dm} 3$

FLOCULANTE SELECCIONADO

Densidad Sólido

$1,00 \mathrm{~kg} / \mathrm{dm} 3$

NALCO -10\% CARGA IÓNICA

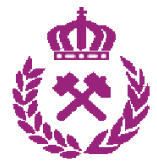

MUESTRA SÓLIDOS

M-100

Diámetros de probetas:

$250 \mathrm{ml} \quad 35,7 \quad \mathrm{~mm}$

$500 \mathrm{ml} \quad 48,6 \quad \mathrm{~mm}$

$2000 \mathrm{ml} \quad 78,2 \quad \mathrm{~mm}$

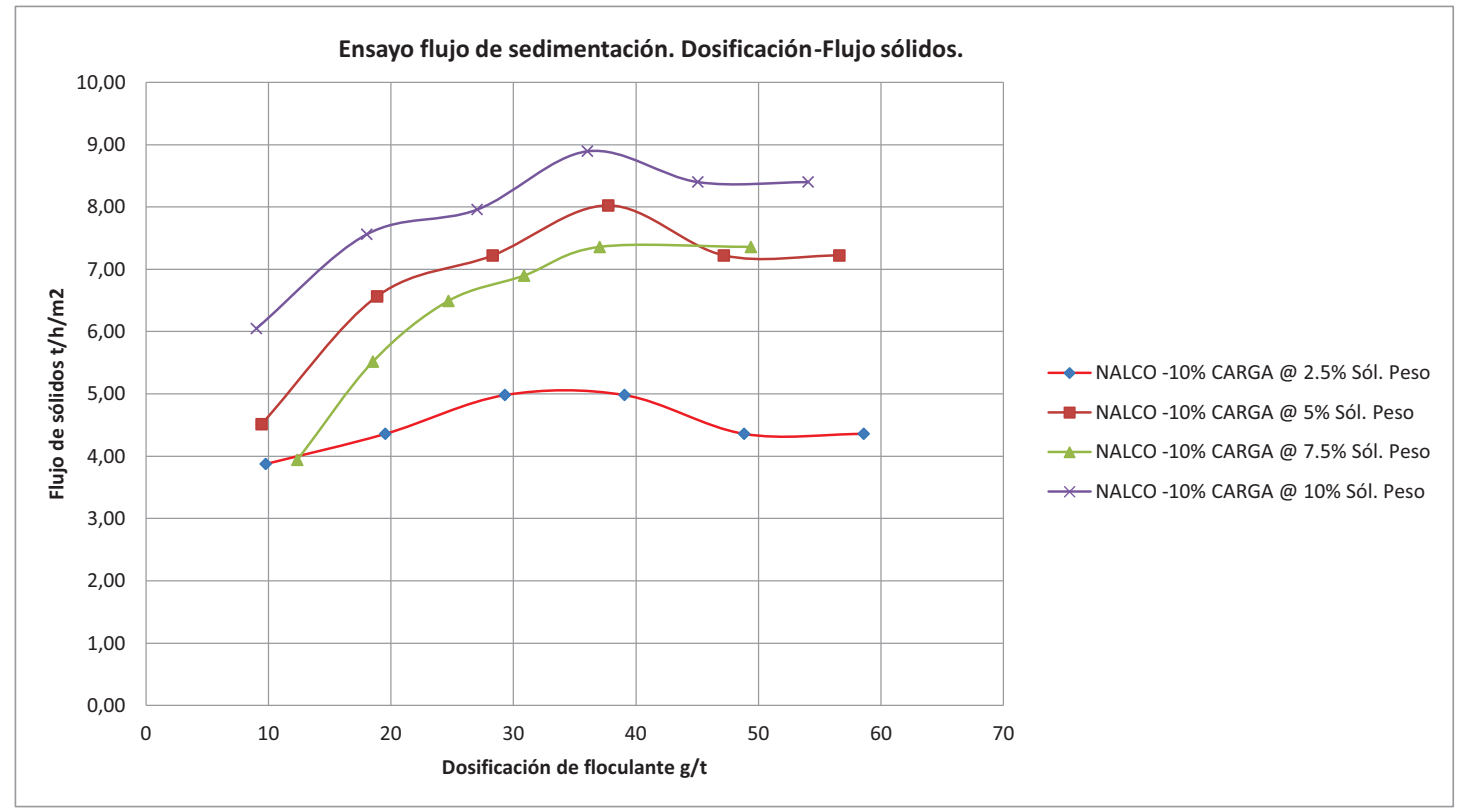

Los ensayos de flujos de sedimentación determinan la dilución óptima de los sólidos para la alimentación en el espesador.

El valor obtenido sirve de base para el diseño de la campana de alimentación y el sistema de dilución previsto. 
ENSAYO SEDIMENTACIÓN PROBETA 2000 mI ESTÁTICO

\begin{tabular}{|c|c|c|c|c|c|c|}
\hline \multicolumn{4}{|l|}{ NSAYO } & & & \\
\hline Mina: & MINAS DE AGUAS TEÑIDA & & & & & \\
\hline Proyecto: & Estudio sedimentación y & eología de estériles espesa & & & & \\
\hline Muestra: & M-100 & & & & & \\
\hline DATOS DE ENSAYO & & & & & & \\
\hline Volumen líquido: & $1900 \mathrm{ml}$ & Solidos en peso & $\mathrm{S}=\mathrm{Ps} / \mathrm{Pp}$ & $\mathrm{s}$ & $9,52 \%$ & \\
\hline Peso sólidos: & $200 \mathrm{~g}$ & Dilución & $d=P l / P s$ & d & 9,500 & \\
\hline Floculante dosificac. & $0,2 \mathrm{~g}$ & Solidos en volumen & $V=V s / V p$ & $\mathrm{v}$ & $2,29 \%$ & \\
\hline Volume total: & $400 \mathrm{ml}$ & Concent. Sólidos en peso & $C=P_{s} / V p$ & c & 102,86 & $g / l$ \\
\hline Floc. Conc. & $0,50 \mathrm{~g} / \mathrm{l}$ & Densidad de la pulpa & $S G p=P p / V p$ & SGp & 1,080 & $\mathrm{~kg} / \mathrm{l}$ \\
\hline Floculante & $8,00 \mathrm{ml}$ & & & & & \\
\hline Solids SG & $4,50 \mathrm{~kg} / \mathrm{dm} 3$ & & & & & \\
\hline Liquid SG & $1,00 \mathrm{~kg} / \mathrm{dm} 3$ & & & & & \\
\hline Diámetro probeta & $78,2 \mathrm{~mm}$ & & & & & \\
\hline Area probeta & $0,0048029 \mathrm{~m} 2$ & $48,029 \mathrm{~cm} 2$ & & & & \\
\hline Densidad pulpa: & $1,080 \mathrm{~kg} / \mathrm{l}$ & & & & & \\
\hline Sólidos en peso: & 102,86 g solids/I & & & & & \\
\hline Sólidos en peso: & $0,1029 \mathrm{~g}$ solids $/ \mathrm{ml}$ & & & & & \\
\hline Floculante: & NALCO & & & & & \\
\hline Tipo de carga floc.: & Aniónico 10\% & & & & & \\
\hline Dosificación floc.: & gramos/ton & elada sólido & & & & \\
\hline
\end{tabular}

DATOS DE SEDIMENTACIÓN

\begin{tabular}{|c|c|c|c|c|c|c|c|c|c|}
\hline $\begin{array}{l}\text { Tiempo info } \\
\text { (sec) }\end{array}$ & $\begin{array}{c}\text { Tiempo } \\
\text { (min) }\end{array}$ & $\begin{array}{l}\text { Vol. Lodos } \\
\text { (ml) }\end{array}$ & $\begin{array}{l}\text { Altura interf. } \\
(\mathrm{cm})\end{array}$ & $\begin{array}{c}\text { Velocidad } \\
\text { (m/hr) }\end{array}$ & $\begin{array}{l}\text { SG. Lodos } \\
\text { (g/cm3) }\end{array}$ & $\begin{array}{c}\text { Lodos } \\
\% \text { Sol. Peso }\end{array}$ & $\begin{array}{c}\text { Flujo } \\
(\mathrm{tph} / \mathrm{m} 2)\end{array}$ & $\begin{array}{c}\text { Flujo } \\
\text { (tpd/m2) }\end{array}$ & $\begin{array}{l}\text { Área Unit. Espes. } \\
\qquad(\mathrm{m} 2 / \mathrm{tpd})\end{array}$ \\
\hline 0 & 0 & 1969 & 41,00 & 0 & 1,079 & 9,41 & 0 & 0 & 0 \\
\hline 5 & 0,08 & 1849 & 38,50 & 18,000 & 1,084 & 9,98 & 29,9820 & 719,57 & 0,001 \\
\hline 10 & 0,17 & 1753 & 36,50 & 14,400 & 1,089 & 10,48 & 29,9818 & 719,56 & 0,001 \\
\hline 15 & 0,25 & 1647 & 34,30 & 15,840 & 1,094 & 11,09 & 29,9819 & 719,57 & 0,001 \\
\hline 30 & 0,50 & 1345 & 28,00 & 15,120 & 1,116 & 13,33 & 9,9940 & 239,86 & 0,004 \\
\hline 45 & 0,75 & 1153 & 24,00 & 9,600 & 1,135 & 15,29 & 9,9940 & 239,86 & 0,004 \\
\hline 60 & 1,00 & 1009 & 21,00 & 7,200 & 1,154 & 17,18 & 9,9940 & 239,86 & 0,004 \\
\hline 120 & 2,00 & 552 & 11,50 & 5,700 & 1,282 & 28,25 & 2,4985 & 59,96 & 0,017 \\
\hline 180 & 3,00 & 432 & 9,00 & 1,500 & 1,360 & 34,02 & 2,4985 & 59,96 & 0,017 \\
\hline 240 & 4,00 & 394 & 8,20 & 0,480 & 1,395 & 36,40 & 2,4985 & 59,96 & 0,017 \\
\hline 300 & 5,00 & 360 & 7,50 & 0,420 & 1,432 & 38,78 & 2,4985 & 59,96 & 0,017 \\
\hline 450 & 7,50 & 307 & 6,40 & 0,264 & 1,506 & 43,20 & 0,9994 & 23,99 & 0,042 \\
\hline 600 & 10,00 & 288 & 6,00 & 0,096 & 1,540 & 45,07 & 0,9994 & 23,99 & 0,042 \\
\hline 900 & 15,00 & 279 & 5,80 & 0,024 & 1,558 & 46,07 & 0,4997 & 11,99 & 0,083 \\
\hline 1200 & 20,00 & 274 & 5,70 & 0,012 & 1,568 & 46,59 & 0,4997 & 11,99 & 0,083 \\
\hline 1500 & 25,00 & 264 & 5,50 & 0,024 & 1,589 & 47,65 & 0,4997 & 11,99 & 0,083 \\
\hline 1800 & 30,00 & 259 & 5,40 & 0,012 & 1,600 & 48,20 & 0,4997 & 11,99 & 0,083 \\
\hline 3600 & 60,00 & 255 & 5,30 & 0,002 & 1,611 & 48,77 & 0,0833 & 2,00 & 0,500 \\
\hline 5400 & 90,00 & 255 & 5,30 & 0,000 & 1,611 & 48,77 & 0,0833 & 2,00 & 0,500 \\
\hline 7200 & 120,00 & 255 & 5,30 & 0,000 & 1,611 & 48,77 & 0,0833 & 2,00 & 0,500 \\
\hline 9000 & 150,00 & 255 & 5,30 & 0,000 & 1,611 & 48,77 & 0,0833 & 2,00 & 0,500 \\
\hline 10800 & 180,00 & 255 & 5,30 & 0,000 & 1,611 & 48,77 & 0,0833 & 2,00 & 0,500 \\
\hline 14400 & 240,00 & 255 & 5,30 & 0,000 & 1,611 & 48,77 & 0,0416 & 1,00 & 1,001 \\
\hline
\end{tabular}

DATOS OBTENIDOS:

Velocidad de sedimentación promedio: $15.8 \mathrm{~m} / \mathrm{h}$

$\%$ sólidos - tiempo: $48,7 \%$ sólidos en peso - 60 minutos tiempo residencia 
Mina:

Proyecto:

Muestra
MINAS DE AGUAS TEÑIDAS

Estudio sedimentación y reología de estériles espesados M-100
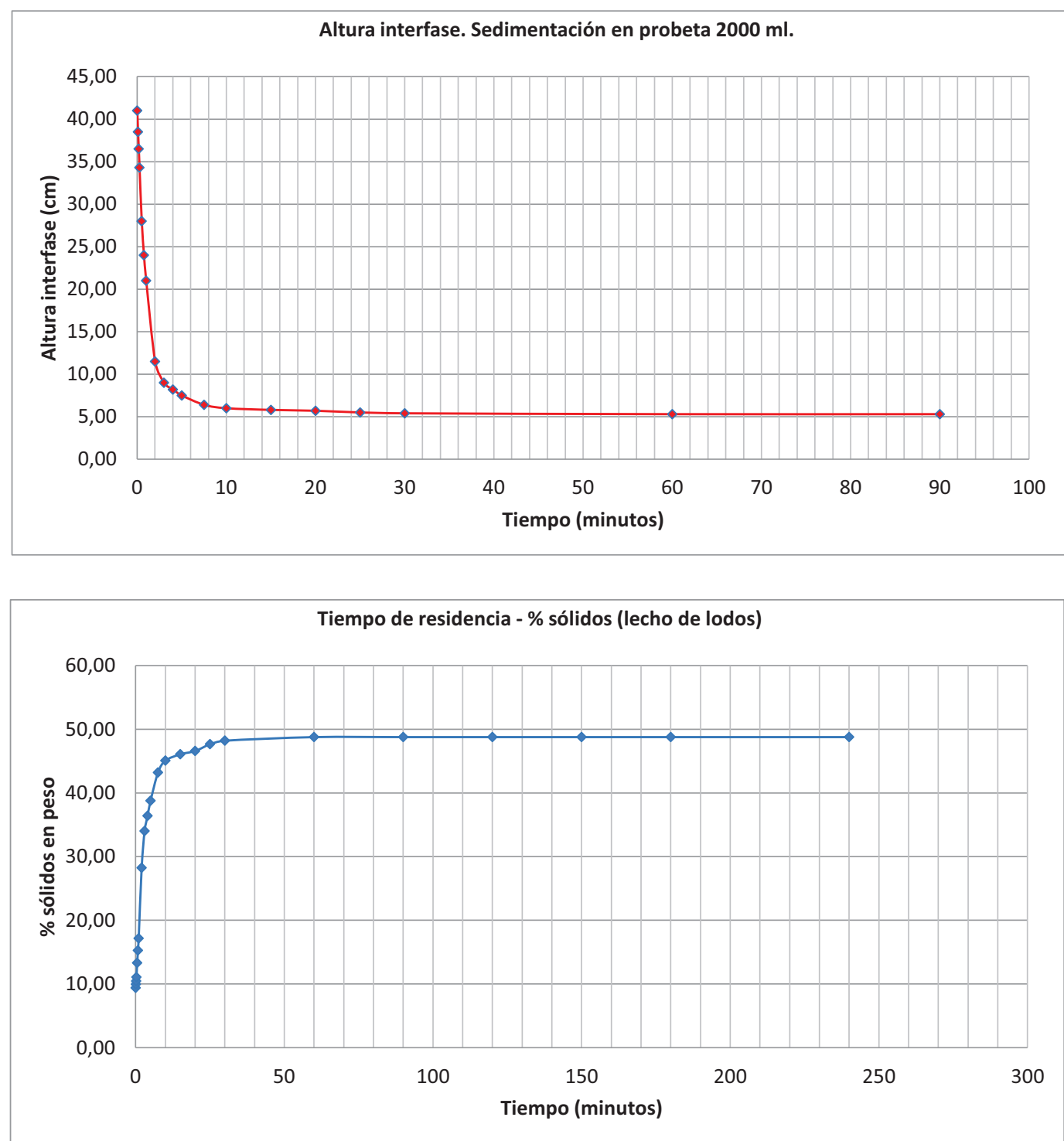


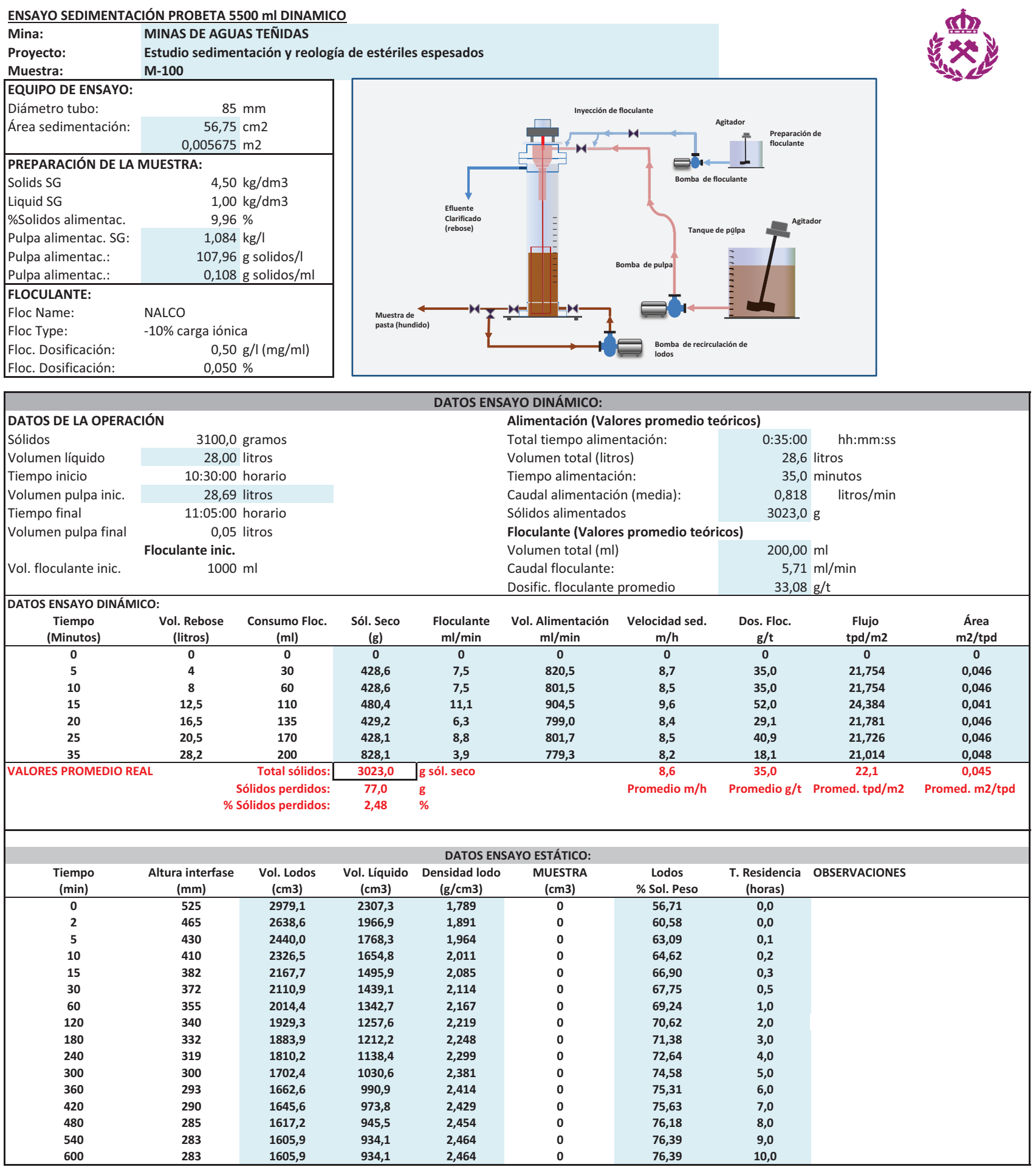


ENSAYO SEDIMENTACIÓN PROBETA 5500 mI DINAMICO

Mina: MINAS DE AGUAS TEÑIDAS

Proyecto: $\quad$ Estudio sedimentación y reología de estériles espesados

Muestra: $\quad \mathrm{M}-100$

DATOS DE OPERACIÓN DEL ESPESADOR DE TUBO PROFUNDO

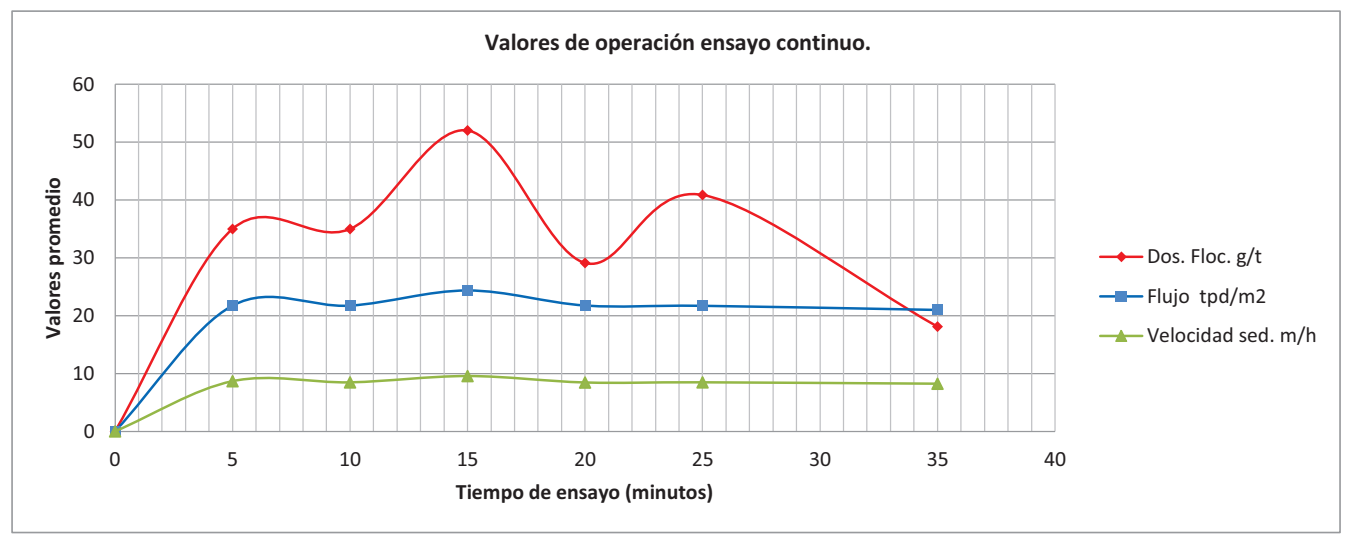

Datos Promedio:

Velocidad de sedimentación:

$8,6 \mathrm{~m} / \mathrm{h}$

Dosificación de floculante:

$35,0 \mathrm{~g} / \mathrm{t}$

Flujo de sedimentación:

$0,0454 \mathrm{~m}^{2} / \mathrm{t} / \mathrm{dí} a$

Flujo de sedimentación:

$22,1 \mathrm{t} / \mathrm{di} a / \mathrm{m}^{2}$

ENSAYO SEDIMENTACIÓN PROBETA 5500 mI DINAMICO
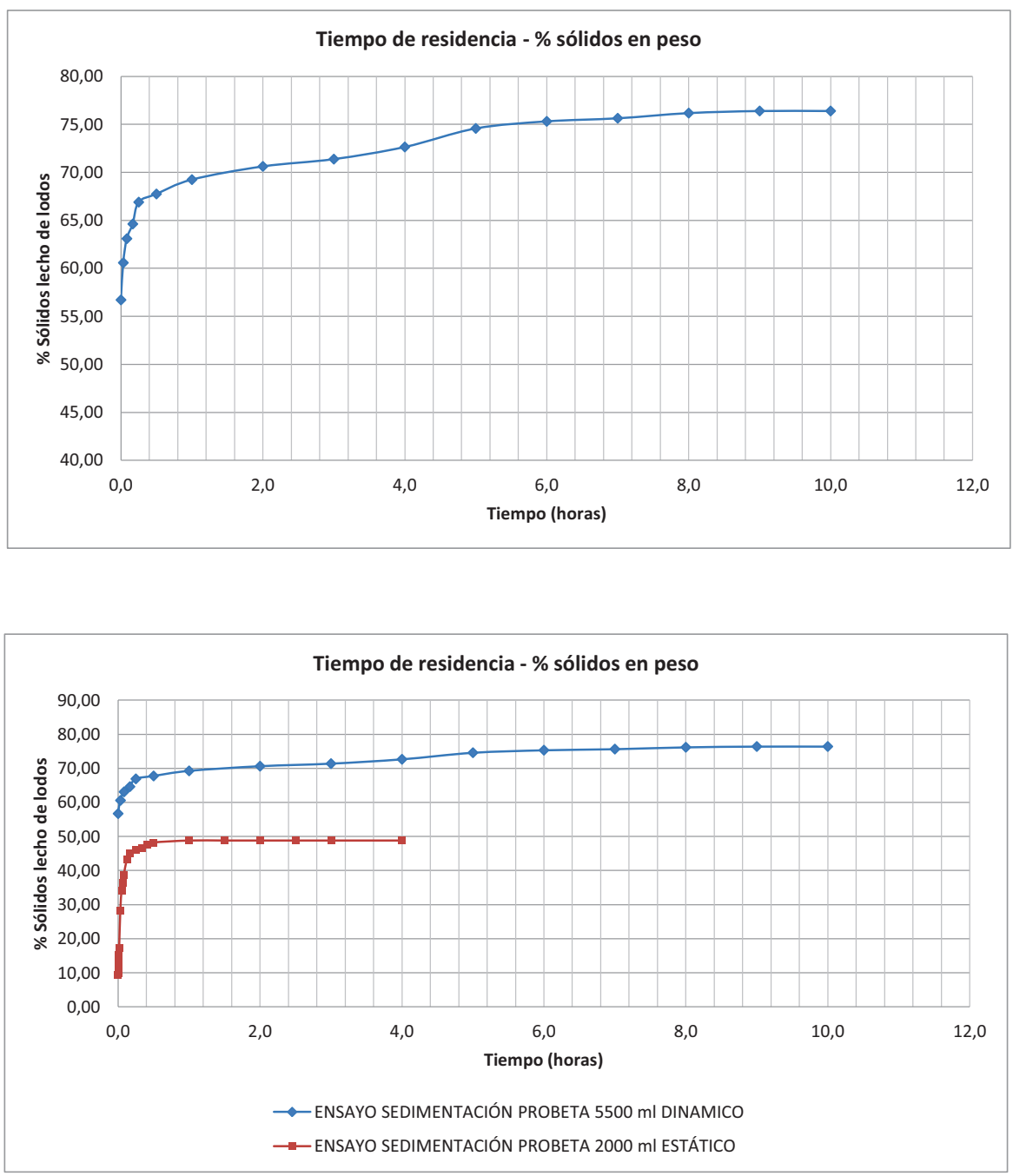
ENSAYO FILTRACIÓN A VACIO

Mina: MINAS DE AGUAS TEÑIDAS

Proyecto: $\quad$ Estudio sedimentación y reología de estériles espesados

Material:

Estudio sedimentación y reología de estériles espesados

Muestra:

M-100

Preparado por:

pH muestra:

Fecha:

$28 / 06 / 2015$

\begin{tabular}{|c|c|c|}
\hline \multicolumn{3}{|c|}{ DATOS DE LA MUESTRA: } \\
\hline Solidos SG & & $0,00 \mathrm{~kg} / \mathrm{dm} 3$ \\
\hline Liquido SG & & $0,00 \mathrm{~kg} / \mathrm{dm} 3$ \\
\hline \multicolumn{3}{|l|}{ FLOCULANTE: } \\
\hline Floc Name: & No & \\
\hline Tipo de floculante: & No & \\
\hline Floc. Dosificación: & & $0,00 \mathrm{~g} / \mathrm{l}(\mathrm{mg} / \mathrm{ml})$ \\
\hline Floc. Dosificación: & & $0,000 \%$ \\
\hline
\end{tabular}
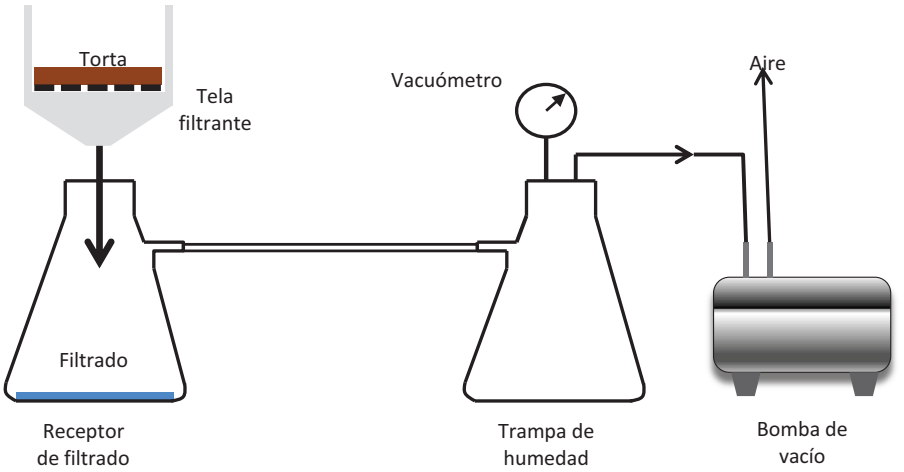

\begin{tabular}{|c|c|c|c|c|c|c|c|c|c|}
\hline \multicolumn{10}{|c|}{ ENSAYO FILTRACIÓN A VACÍO. TEST 1.} \\
\hline \multicolumn{2}{|c|}{ MUESTRA: M-100 } & & \multicolumn{7}{|c|}{ Tiempos de ensayo de filtración } \\
\hline $\begin{array}{l}\text { Vacío } \\
\text { (bar) }\end{array}$ & $\begin{array}{c}\text { Peso sólidos } \\
\text { (g) }\end{array}$ & $\begin{array}{l}\text { Vol. Líquido } \\
\text { (ml) }\end{array}$ & $\begin{array}{c}\text { \% Sól. Peso } \\
\text { (\%) }\end{array}$ & $\begin{array}{l}\text { Vol. Pulpa } \\
\text { (ml) }\end{array}$ & $\begin{array}{l}\text { Formación torta } \\
\text { (s) }\end{array}$ & $\begin{array}{l}\text { Secado torta } \\
\text { (s) }\end{array}$ & $\begin{array}{l}\text { Total ciclo } \\
\text { (s) }\end{array}$ & $\begin{array}{l}\text { Líq. Filtrado } \\
\quad(\mathrm{ml})\end{array}$ & $\begin{array}{c}\text { Espesor } \\
(\mathrm{mm})\end{array}$ \\
\hline 0 & 0 & 0,0 & \#DIV/0! & \#DIV/0! & 0 & 0 & 0 & 0 & 0,0 \\
\hline \% Solidos estimado: & \#DIV/0! & & \multirow{2}{*}{\multicolumn{2}{|c|}{ Observaciones: }} & & & & & \\
\hline Peso muestra húmedo: & 0 & $\mathrm{~g}$ & \multirow{3}{*}{\multicolumn{2}{|c|}{ Observaciones: }} & & & & & \\
\hline \multicolumn{3}{|c|}{\begin{tabular}{|l} 
Secado de la muestra: \\
\end{tabular}} & & & & & & & \\
\hline Peso muestra seco & 0 & $\mathrm{~g}$ & & & & & & & \\
\hline$\%$ humedad torta & \#DIV/0! & $\%$ & & & & & & & \\
\hline
\end{tabular}

\begin{tabular}{|c|c|c|c|c|c|c|c|c|c|}
\hline \multicolumn{10}{|c|}{ ENSAYO FILTRACIÓN A VACÍO. TEST 2.} \\
\hline \multicolumn{3}{|c|}{ MUESTRA: M-100 } & \multicolumn{7}{|c|}{ Tiempos de ensayo de filtración } \\
\hline $\begin{array}{l}\text { Vacío } \\
\text { (bar) }\end{array}$ & $\begin{array}{l}\text { Peso sólidos } \\
\text { (g) }\end{array}$ & $\begin{array}{l}\text { Vol. Líquido } \\
\text { (ml) }\end{array}$ & $\begin{array}{c}\text { \% Sól. Peso } \\
\text { (\%) }\end{array}$ & $\begin{array}{l}\text { Vol. Pulpa } \\
\text { (ml) }\end{array}$ & $\begin{array}{l}\text { Formación torta } \\
\text { (s) }\end{array}$ & $\begin{array}{l}\text { Secado torta } \\
\text { (s) }\end{array}$ & $\begin{array}{c}\text { Total ciclo } \\
\text { (s) }\end{array}$ & $\begin{array}{l}\text { Líq. Filtrado } \\
\text { (ml) }\end{array}$ & $\begin{array}{c}\text { Espesor } \\
(\mathrm{mm})\end{array}$ \\
\hline 0 & 0 & 0,0 & \#DIV/0! & \#DIV/0! & 0 & & 0 & & 0,0 \\
\hline \% Solidos estimado: & \#DIV/O! & & & & & & & & \\
\hline Peso muestra húmedo: & $\overline{0}$ & $\mathrm{~g}$ & \multirow{3}{*}{\multicolumn{2}{|c|}{ Observaciones: }} & & & & & \\
\hline \multicolumn{3}{|c|}{ Secado de la muestra: } & & & & & & & \\
\hline Peso muestra seco & 0 & $\mathrm{~g}$ & & & & & & & \\
\hline$\%$ humedad torta & \#DIV/0! & $\%$ & Los pesos incl & iyen la tara & & & & & \\
\hline
\end{tabular}

\begin{tabular}{|c|c|c|c|c|c|c|c|c|c|}
\hline \multicolumn{10}{|c|}{ ENSAYO FILTRACIÓN A VACÍO. TEST 3.} \\
\hline \multicolumn{3}{|c|}{ MUESTRA: M-100 } & \multicolumn{7}{|c|}{ Tiempos de ensayo de filtración } \\
\hline $\begin{array}{l}\text { Vacío } \\
\text { (bar) }\end{array}$ & $\begin{array}{l}\text { Peso sólidos } \\
\text { (g) }\end{array}$ & $\begin{array}{l}\text { Vol. Líquido } \\
\text { (ml) }\end{array}$ & $\begin{array}{c}\text { \% Sól. Peso } \\
\text { (\%) }\end{array}$ & $\begin{array}{l}\text { Vol. Pulpa } \\
\text { (ml) }\end{array}$ & $\begin{array}{l}\text { Formación torta } \\
\text { (s) }\end{array}$ & $\begin{array}{l}\text { Secado torta } \\
\text { (s) }\end{array}$ & $\begin{array}{l}\text { Total ciclo } \\
\text { (s) }\end{array}$ & $\begin{array}{l}\text { Líq. Filtrado } \\
\text { (ml) }\end{array}$ & $\begin{array}{c}\text { Espesor } \\
\text { (mm) }\end{array}$ \\
\hline 0 & 0 & 0,0 & \#DIV/0! & \#DIV/0! & 0 & 0 & 0 & 0 & 0,0 \\
\hline \% Solidos estimado: & \#DIV/0! & & & & & & & & \\
\hline Peso muestra húmedo: & 0 & $\mathrm{~g}$ & \multirow{4}{*}{\multicolumn{7}{|c|}{$\begin{array}{l}\text { Observaciones: } \\
\text { Contenido en sólidos de la torta filtrada: } 100-21,71=78,29 \%\end{array}$}} \\
\hline \multicolumn{3}{|c|}{ Secado de la muestra: } & & & & & & & \\
\hline Peso muestra seco & 0 & $\mathrm{~g}$ & & & & & & & \\
\hline$\%$ humedad torta & \#DIV/0! & $\%$ & & & & & & & \\
\hline
\end{tabular}

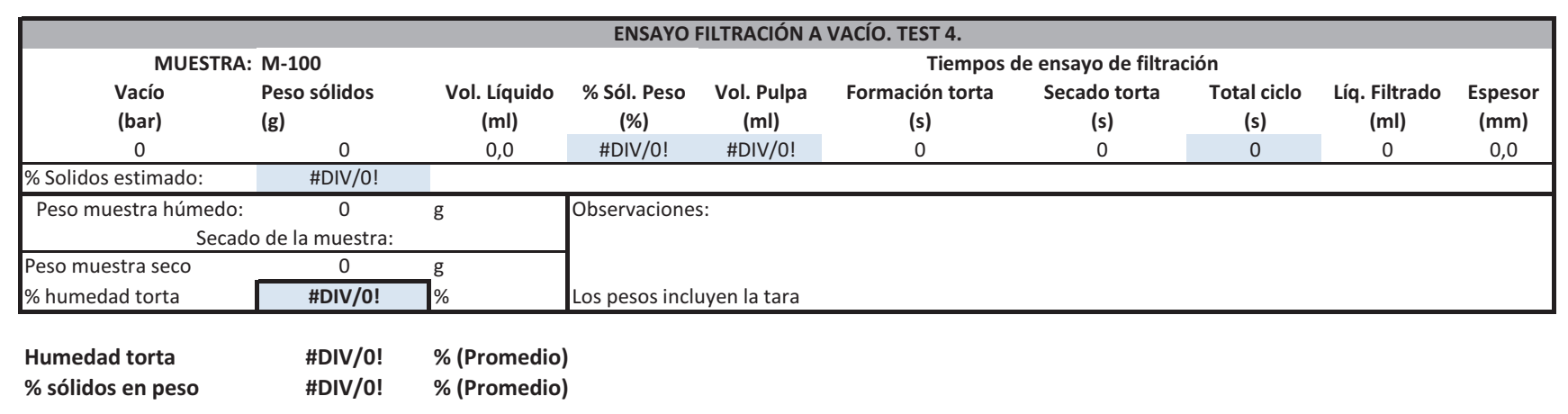


ENSAYO ASENTAMIENTO EN PROBETA

\section{Mina:}

Proyecto:

Material:

Preparado por:

pH muestra:

Fecha:

Aceleración gravedad (g):

Diámetro probeta:

Altura probeta $(\mathrm{H})$ :

Volumen probeta:

Solidos SG

Líquido SG

Expresiones empíricas

$T=0.5-0.5(\mathrm{~h} / \mathrm{H})^{\wedge} 0.5$

T.F. $=\mathrm{T}^{*} \mathrm{~d}^{*} \mathrm{~g}^{*}(\mathrm{H} / 100)$

\section{MINAS DE AGUAS TEÑIDAS}

Estudio sedimentación y reología de estériles espesados

Estériles mineral polimetálico cobre

José A. Butragueño

$28 / 06 / 2015$

$9,81 \mathrm{~m} / \mathrm{s} 2$
$44 \mathrm{~mm}$
$100 \mathrm{~mm}$
$152,1 \mathrm{~cm} 3$
$4,50 \mathrm{~kg} / \mathrm{dm} 3$
$1,00 \mathrm{~kg} / \mathrm{dm} 3$

$\mathrm{H}$

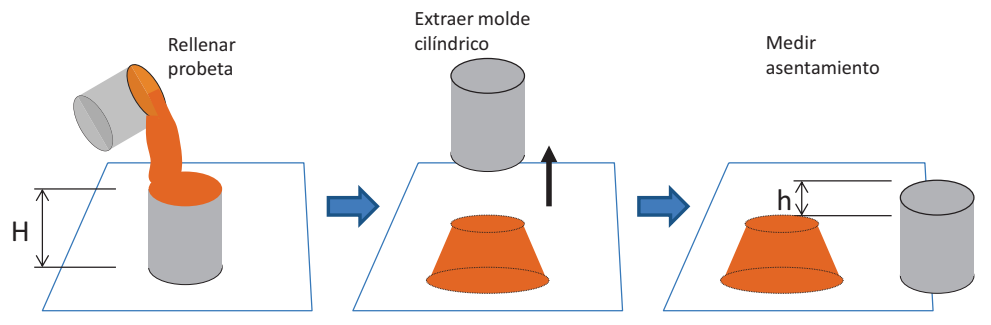

\begin{tabular}{|c|c|c|c|c|c|c|c|c|c|c|}
\hline \multicolumn{11}{|c|}{ ENSAYOS DE ASENTAMIENTO EN PROBETA } \\
\hline $\begin{array}{l}\text { Muestra } \\
\text { ID }\end{array}$ & $\begin{array}{c}\text { Cont. Sólidos } \\
\text { (\%) }\end{array}$ & $\begin{array}{l}\text { Solidos SG } \\
\mathrm{g} / \mathrm{cm} 3\end{array}$ & $\begin{array}{c}\text { Peso Liq. } \\
\text { (kg liq/kg sol) }\end{array}$ & $\begin{array}{l}\text { Vol. Pulpa } \\
\text { (1/kg sol) }\end{array}$ & $\begin{array}{l}\text { Pulpa SG (d) } \\
\text { kg/dm3 }\end{array}$ & $\begin{array}{c}\text { Sólidos prob. } \\
\text { (g) }\end{array}$ & $\begin{array}{l}\text { Liq. Probeta } \\
\text { (g) }\end{array}$ & $\begin{array}{l}\text { Asentamiento (h) } \\
\mathrm{mm}\end{array}$ & $\begin{array}{l}\text { Factor "T" } \\
\text { Adimens. }\end{array}$ & $\begin{array}{c}\text { Tensión Fluencia } \\
\text { (Pa) }\end{array}$ \\
\hline 1 & 68,5 & 4,50 & 0,460 & 0,682 & 2,140 & 222,9 & 102,5 & 45 & 0,16459 & 345,6 \\
\hline 2 & 67,5 & 4,50 & 0,481 & 0,704 & 2,105 & 216,1 & 104,0 & 52 & 0,13944 & 288,0 \\
\hline 3 & 65 & 4,50 & 0,538 & 0,761 & 2,022 & 199,9 & 107,6 & 62 & 0,10630 & 210,9 \\
\hline 4 & 62,5 & 4,50 & 0,600 & 0,822 & 1,946 & 184,9 & 111,0 & 79 & 0,05559 & 106,1 \\
\hline 5 & 60 & 4,50 & 0,667 & 0,889 & 1,875 & 171,1 & 114,0 & 90 & 0,02566 & 47,2 \\
\hline 6 & 55 & 4,50 & 0,818 & 1,040 & 1,748 & 146,1 & 119,6 & 96 & 0,01010 & 17,3 \\
\hline
\end{tabular}

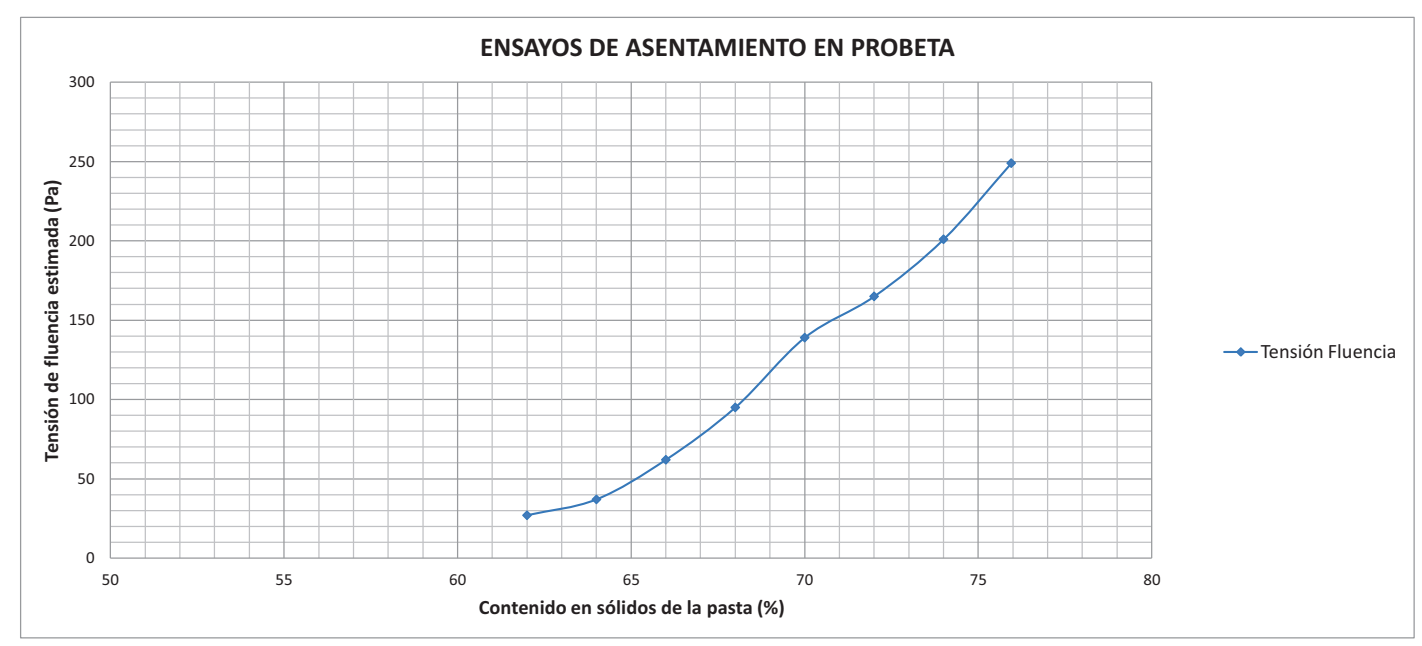

Página 12 de 12 


\section{ENSAYOS DE SEDIMENTACIÓN Y REOLOGÍA}

\section{Mina:}

MINAS DE AGUAS TEÑIDAS

\section{Empresa:}

DOCTORANDO JOSE A. BUTRAGUEÑO

\section{Proyecto:}

Estudio sedimentación y reología de estériles espesados

\section{Aplicación}

Sedimentación. Estériles de flotación mineral Cu Polimetálico (Valdelamusa)

Fecha:

$28 / 06 / 2015$

\section{Ensayos:}

\begin{tabular}{|c|c|}
\hline $\mathbf{x}$ & Distribución granulométrica y caracterización de muestras \\
\hline $\mathbf{X}$ & Selección de floculantes \\
\hline $\mathbf{x}$ & Área de flujo \\
\hline $\mathbf{x}$ & Sedimentación en probeta estática \\
\hline $\mathbf{x}$ & Ensayo en espesador dinámico de laboratorio de $85 \mathrm{~mm}$ DIA \\
\hline $\mathbf{x}$ & Reología de los lodos \\
\hline & Ensayo de filtración a vacío \\
\hline
\end{tabular}

\begin{tabular}{|c|c|}
\hline \multicolumn{2}{|c|}{ Realizado por: } \\
\hline Nombre: & José Butragueño \\
\hline \multicolumn{2}{|c|}{ Fecha: $\quad 28 / 06 / 2015$} \\
\hline Revisión: & Objeto de la revisión: \\
\hline 0 & Ensayo inicial \\
\hline & \\
\hline & \\
\hline \multirow[t]{3}{*}{ Códigos: } & Campo de dato calculado a partir de los valores introducidos \\
\hline & Campo para introducir datos por el laborante \\
\hline & $\begin{array}{l}\text { Valor constante } \\
\text { observaciones }\end{array}$ \\
\hline
\end{tabular}


ENSAYO GRANULOMÉTRICO DE SÓLIDOS

Mina: MINAS DE AGUAS TEÑIDAS

Proyecto: Estudio sedimentación y reología de estériles espesados Realizado por: José Butragueño

\begin{tabular}{|ll|}
\hline Muestra ID: & M-100 \\
Material: & Estériles mineral polimetálico cobre \\
Preparado por: & José A. Butragueño \\
pH muestra: & - \\
Fecha: & $28 / 06 / 2015$ \\
\hline
\end{tabular}

CURVA GRANULOMÉTRICA DE SÓLIDOS

\begin{tabular}{|c|c|c|c|c|}
\hline \multicolumn{3}{|c|}{ DATOS DE LA PULPA A SEDIMENTAR } & \multicolumn{2}{|c|}{ Observaciones: Muestra de sólido seco } \\
\hline Densidad sólidos: & 4,50 & $\mathrm{~kg} / \mathrm{dm}^{3}$ & & \\
\hline Densidad líquido: & 1,00 & $\mathrm{~kg} / \mathrm{dm}^{3}$ & & \\
\hline Densidad pulpa: & & $\mathrm{kg} / \mathrm{l}$ & & \\
\hline Tara: & & $g$ & & \\
\hline Pulpa húmeda: & 0 & $g$ & Peso pulpa: & $0 \mathrm{~g}$ \\
\hline Sólido seco: & 0 & $\mathrm{~g}$ & Peso sólido: & $0 \mathrm{~g}$ \\
\hline \% Peso sólidos: & \#DIV/0! & $\%$ & & \\
\hline
\end{tabular}

\section{CURVA GRANULOMÉTRICA DE SÓLIDOS}

ENSAYO GRANULOMÉTRICO Muestra M-100

\begin{tabular}{|c|c|c|r|}
\hline Tamiz (micras) & \% pasa & Tamiz (micras) & \multicolumn{1}{c|}{ \% pasa } \\
\hline 0,479 & 0,17 & 30,200 & 64,53 \\
\hline 0,631 & 0,47 & 39,811 & 71,89 \\
\hline 0,832 & 0,89 & 52,481 & 79,03 \\
\hline 1,096 & 1,46 & 69,183 & 85,36 \\
\hline 1,445 & 2,26 & 91,201 & 90,34 \\
\hline 1,905 & 3,47 & 120,226 & 93,81 \\
\hline 2,512 & 5,35 & 158,489 & 96,09 \\
\hline 3,311 & 8,27 & 208,930 & 97,63 \\
\hline 4,365 & 12,56 & 275,423 & 98,76 \\
\hline 5,574 & 18,38 & 363,078 & 99,55 \\
\hline 7,586 & 25,54 & 478,630 & 99,96 \\
\hline 10,000 & 33,55 & 630,957 & 100,00 \\
\hline 13,183 & 41,74 & & \\
\hline 17,378 & 49,63 & & \\
\hline 22,909 & 57,16 & & \\
\hline
\end{tabular}

$P 80=54.59$ micras

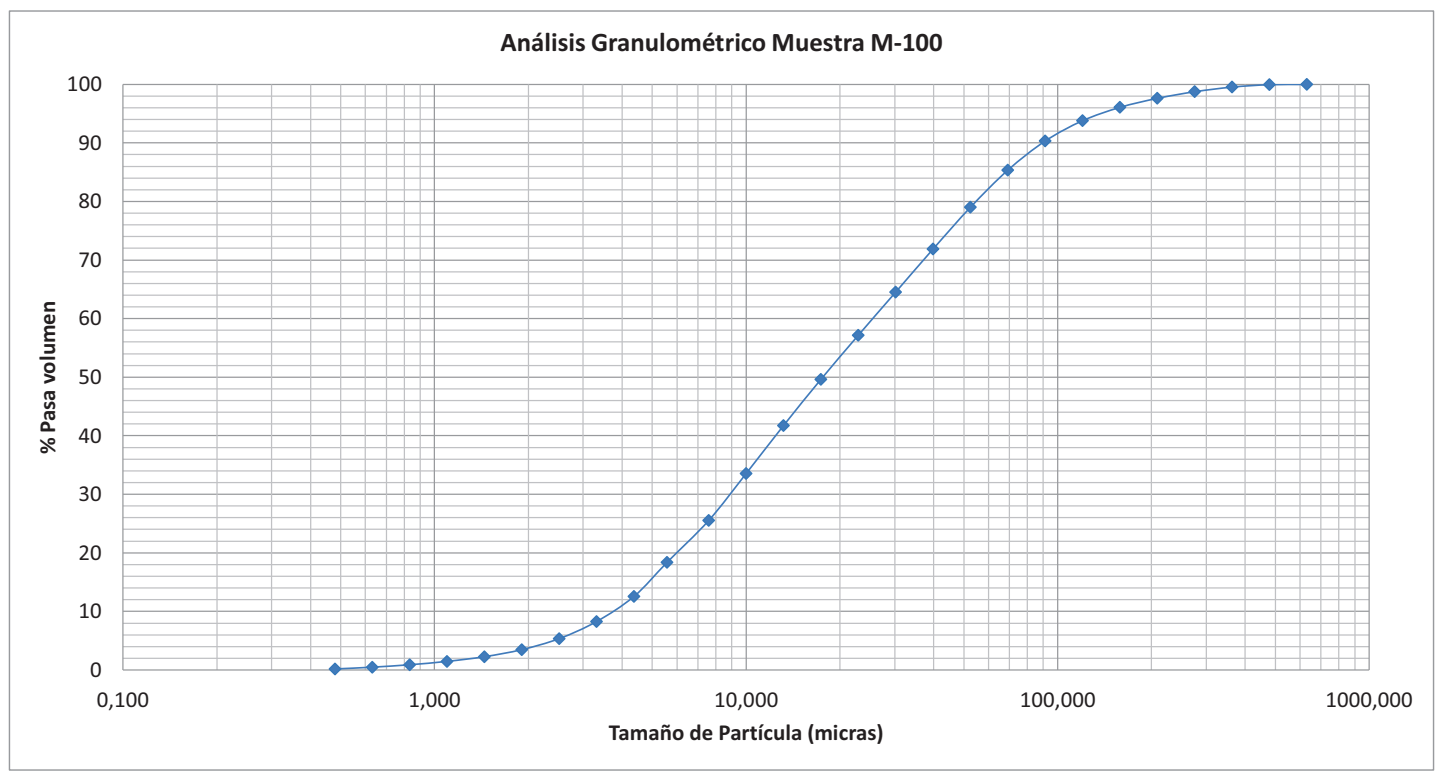




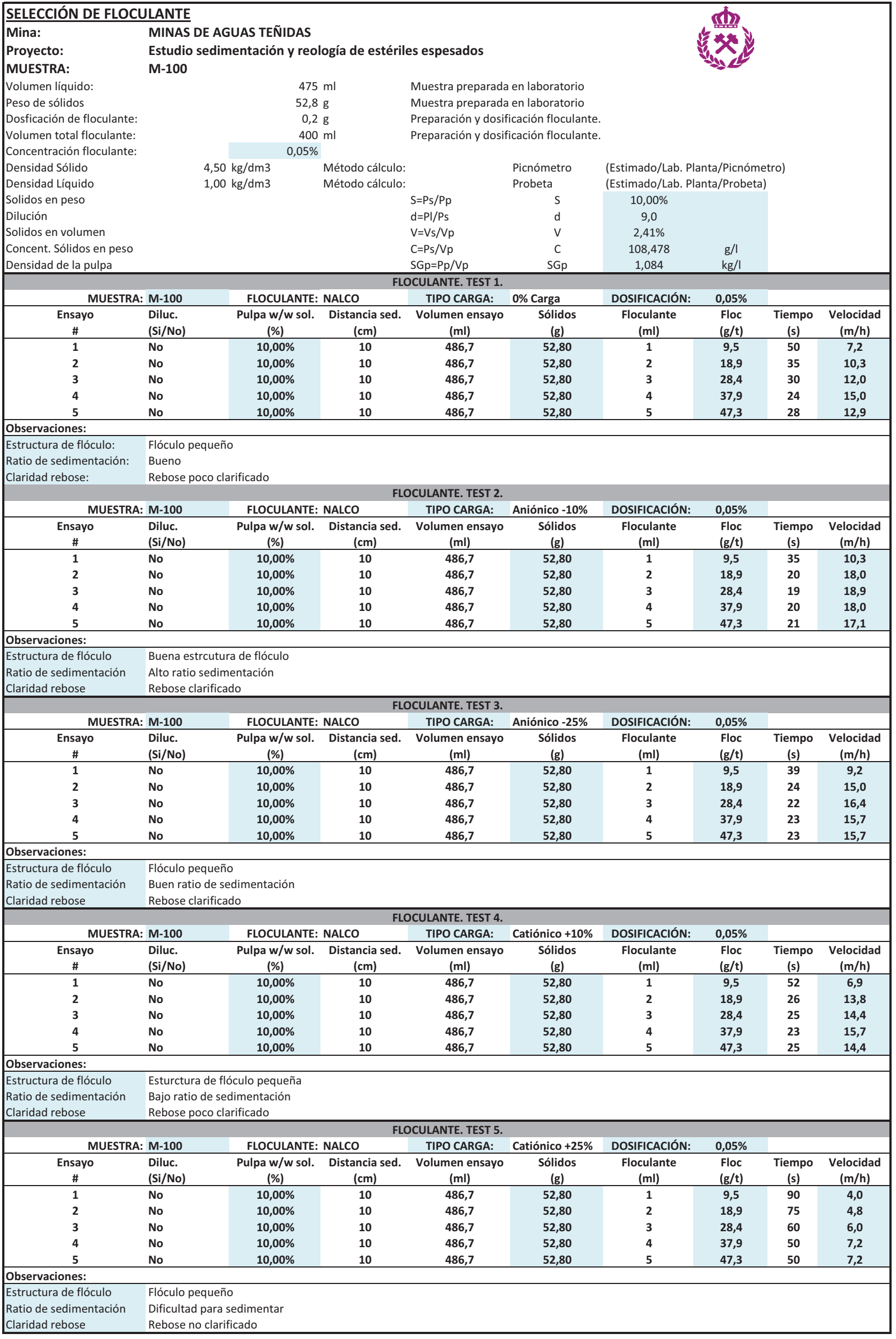


SELECCIÓN DE FLOCULANTE. ANÁLISIS DE DATOS.

Mina:

Proyecto:

MUESTRA:

Volumen líquido:

$\%$ sólidos en peso:

Dosficación de floculante:

Volumen total:

Concentración floculante:

Densidad Sólido

Densidad Líquido
MINAS DE AGUAS TEÑIDAS

Estudio sedimentación y reología de estériles espesados

M-100

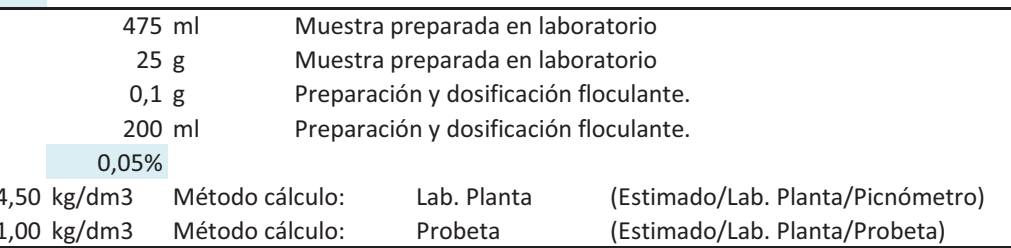

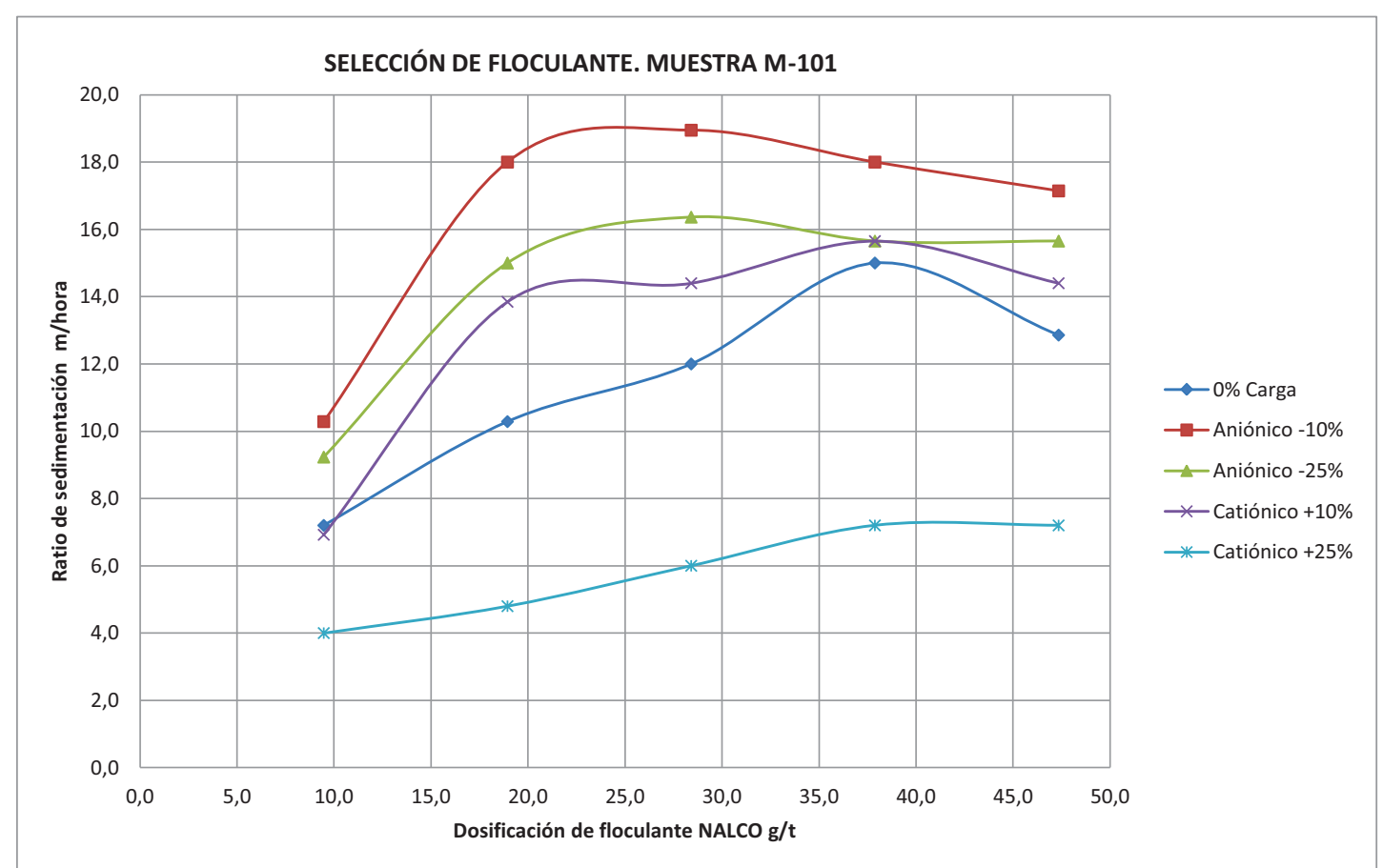

Los ensayos de sedimentación para la selección del floculante han tenido en cuenta tanto los valores de velocidad de sedimentación cómo los datos de observación visual de: tamaño de flóculo, velocidad de sedimentación, cohesión del flóculo y la claridad del rebose obtenida en la probeta de laboratorio. El floculante seleccionado será empleado en los ensayos de flujo de sedimentación. 
ENSAYO FLUJO SEDIMENTACIÓN

Mina: MINAS DE AGUAS TEÑIDAS

Proyecto: Estudio sedimentación y reología de estériles espesados

DATOS

FLOCULANTE SELECCIONADO

Volumen probeta:

$1000 \mathrm{ml}$

NALCO - $10 \%$ CARGA

Diámetro probeta: $\quad 58 \mathrm{~mm}$

Floc. Dosificac: $\quad 0,2 \mathrm{~g}$

Volumen floc.:

Floculante dosific.

$400 \mathrm{ml}$

$0,05 \%$

Floc. Conc. $\quad 0,50 \mathrm{~g} / \mathrm{l}$

Densidad Sólido $\quad 4,50 \mathrm{~kg} / \mathrm{dm} 3$

Densidad Líquido $\quad 1,00 \mathrm{~kg} / \mathrm{dm} 3$

NALCO -10\% CARGA @ 2.5\% Sól. Peso

$\begin{array}{lrr}\text { Diámetros de probetas: } & \\ 250 \mathrm{ml} & 35,7 & \mathrm{~mm} \\ 500 \mathrm{ml} & 48,6 & \mathrm{~mm} \\ 2000 \mathrm{ml} & 78,2 & \mathrm{~mm}\end{array}$

MUESTRA SÓLIDOS

M-100

NALCO -10\% CARGA @ 2.5\% Só. Peso

\begin{tabular}{|c|c|c|c|c|c|c|c|c|c|c|c|}
\hline \multicolumn{2}{|c|}{ MUESTRA: M-100 } & \multirow{2}{*}{$\begin{array}{l}\text { FLOCULANTE: } \\
\text { Sólidos } \\
(\% \mathrm{w} / \mathrm{w})\end{array}$} & \multicolumn{2}{|c|}{ NALCO - $10 \%$ CARGA } & \multirow[b]{2}{*}{$\begin{array}{c}\text { Floculant. } \\
(\mathrm{ml})\end{array}$} & \multirow{2}{*}{$\begin{array}{l}\text { CARGA SóLIDOS: } \\
\text { Dist. Sediment. } \\
(\mathrm{cm})\end{array}$} & \multirow{2}{*}{$\begin{array}{c}2,50 \\
\text { Tiempo sed. } \\
\text { (s) }\end{array}$} & \multicolumn{4}{|l|}{$\%$} \\
\hline $\begin{array}{c}\text { Peso sólidos } \\
\text { (g) }\end{array}$ & $\begin{array}{c}\text { Vol. líquido } \\
(\mathrm{ml})\end{array}$ & & $\begin{array}{c}\text { Densidad pulpa } \\
(\mathrm{kg} / \mathrm{l})\end{array}$ & $\begin{array}{c}\text { Conc. Solids } \\
\text { (g/l) }\end{array}$ & & & & $\begin{array}{c}\text { Velocidad sed. } \\
(\mathrm{m} / \mathrm{h})\end{array}$ & $\begin{array}{c}\text { Floc dosific. } \\
(\mathrm{g} / \mathrm{t})\end{array}$ & $\begin{array}{c}\begin{array}{c}\text { Flujo } \\
\text { (tph/m2) }\end{array} \\
\end{array}$ & $\begin{array}{c}\begin{array}{c}\text { Flujo } \\
\text { (tpd/m2) }\end{array} \\
\end{array}$ \\
\hline 25,6 & 1000 & 2,50 & 1,020 & 25,46 & 0,5 & 10,0 & 9 & 40,0 & 10 & 3,88 & 93,02 \\
\hline 25,6 & 1000 & 2,50 & 1,020 & 25,46 & 1 & 10,0 & 8 & 45,0 & 20 & 4,36 & 104,64 \\
\hline 25,6 & 1000 & 2,50 & 1,020 & 25,46 & 1,5 & 10,0 & 7 & 51,4 & 29 & 4,98 & 119,59 \\
\hline 25,6 & 1000 & 2,50 & 1,020 & 25,46 & 2 & 10,0 & 7 & 51,4 & 39 & 4,98 & 119,59 \\
\hline 25,6 & 1000 & 2,50 & 1,020 & 25,46 & 2,5 & 10,0 & 8 & 45,0 & 49 & 4,36 & 104,64 \\
\hline 25,6 & 1000 & 2,50 & 1,020 & 25,46 & 3 & 10,0 & 8 & 45,0 & 59 & 4,36 & 104,64 \\
\hline & & & & & & & MEDIA: & 45,0 & 34,2 & 4,4 & 104,6 \\
\hline
\end{tabular}

NALCO -10\% CARGA @ 5\% Sól. Peso

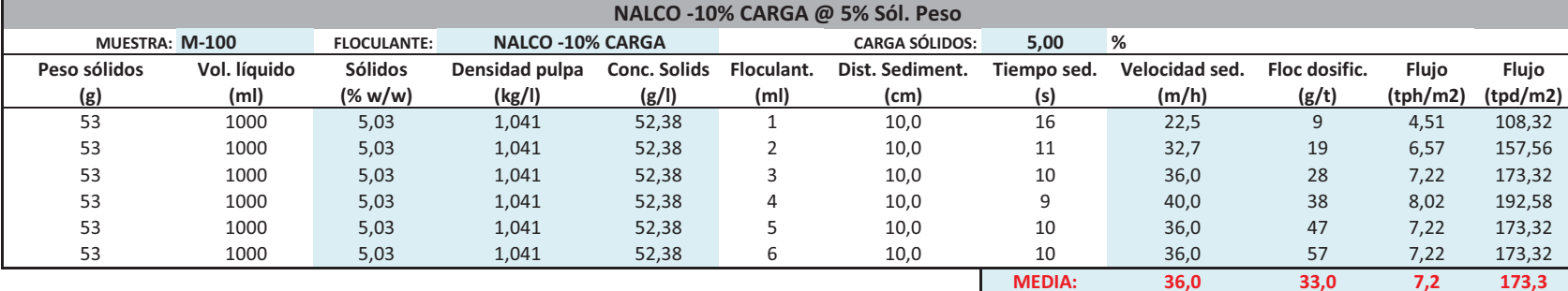

NALCO -10\% CARGA @ 7.5\% Sól. Peso

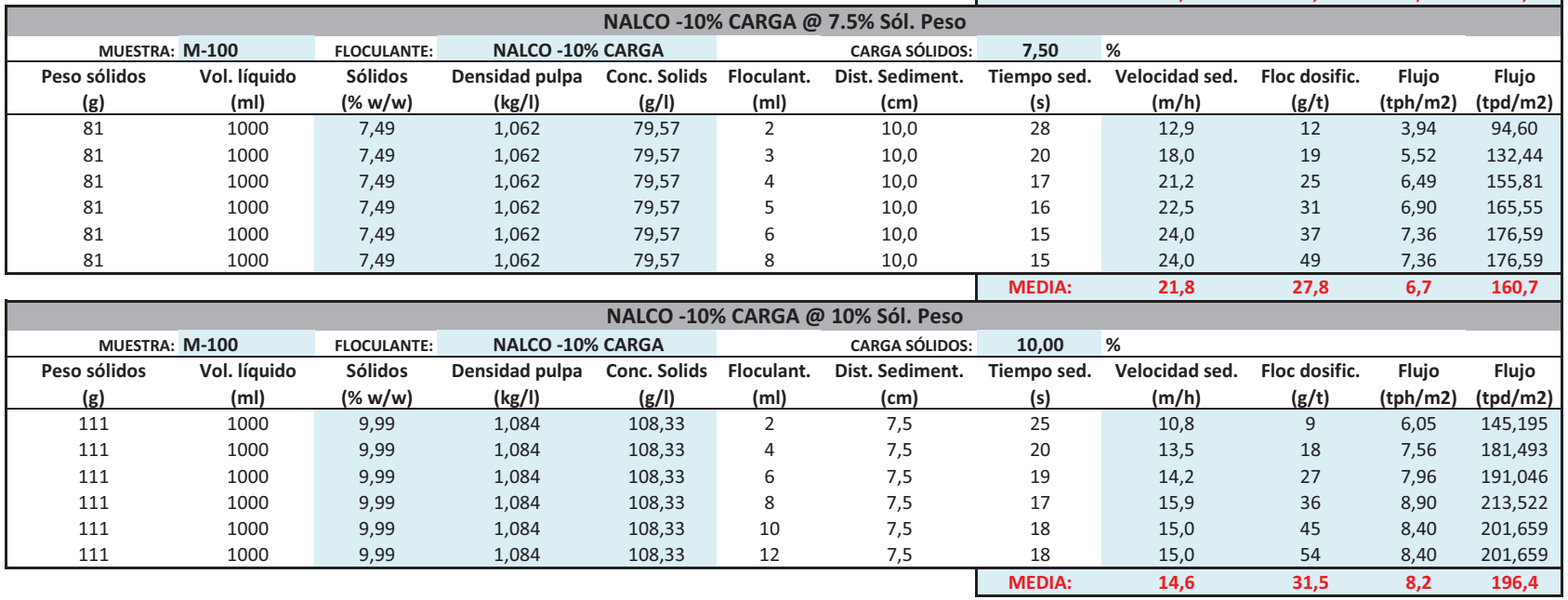


ENSAYO FLUJO SEDIMENTACIÓN. ANÁLISIS DE RESULTADOS.

Mina: MINAS DE AGUAS TEÑIDAS

Proyecto: $\quad$ Estudio sedimentación y reología de estériles espesados

DATOS

Volumen probeta:

$1000 \mathrm{ml}$

$58 \mathrm{~mm}$

Diámetro probeta:

Área sedimentac.

$26,42 \mathrm{~cm} 2$

Floc. Dosificac.:

Volumen floc:

Floculante dosific.

$0,2 \mathrm{~g}$

$400 \mathrm{ml}$

$0,05 \%$

Floc. Conc.

$0,50 \mathrm{~g} / \mathrm{l}$

$4,50 \mathrm{~kg} / \mathrm{dm} 3$

FLOCULANTE SELECCIONADO

Densidad Sólido

$1,00 \mathrm{~kg} / \mathrm{dm} 3$

NALCO -10\% CARGA IÓNICA

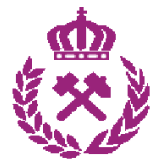

MUESTRA SÓLIDOS

M-100

Diámetros de probetas:

$250 \mathrm{ml} \quad 35,7 \quad \mathrm{~mm}$

$500 \mathrm{ml} \quad 48,6 \quad \mathrm{~mm}$

$2000 \mathrm{ml} \quad 78,2 \quad \mathrm{~mm}$

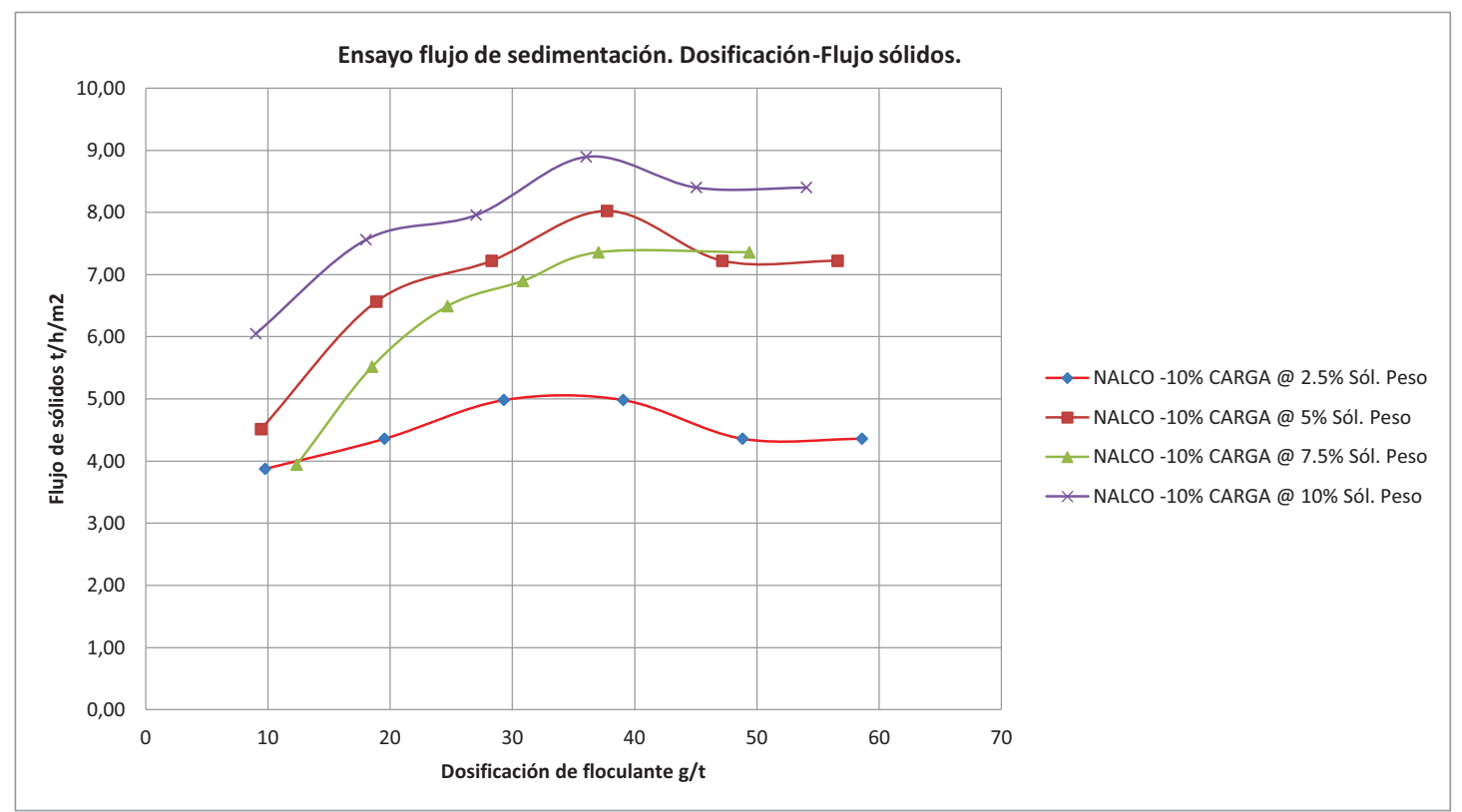

Los ensayos de flujos de sedimentación determinan la dilución óptima de los sólidos para la alimentación en el espesador.

El valor obtenido sirve de base para el diseño de la campana de alimentación y el sistema de dilución previsto. 
ENSAYO SEDIMENTACIÓN PROBETA $2000 \mathrm{ml}$ ESTÁTICO

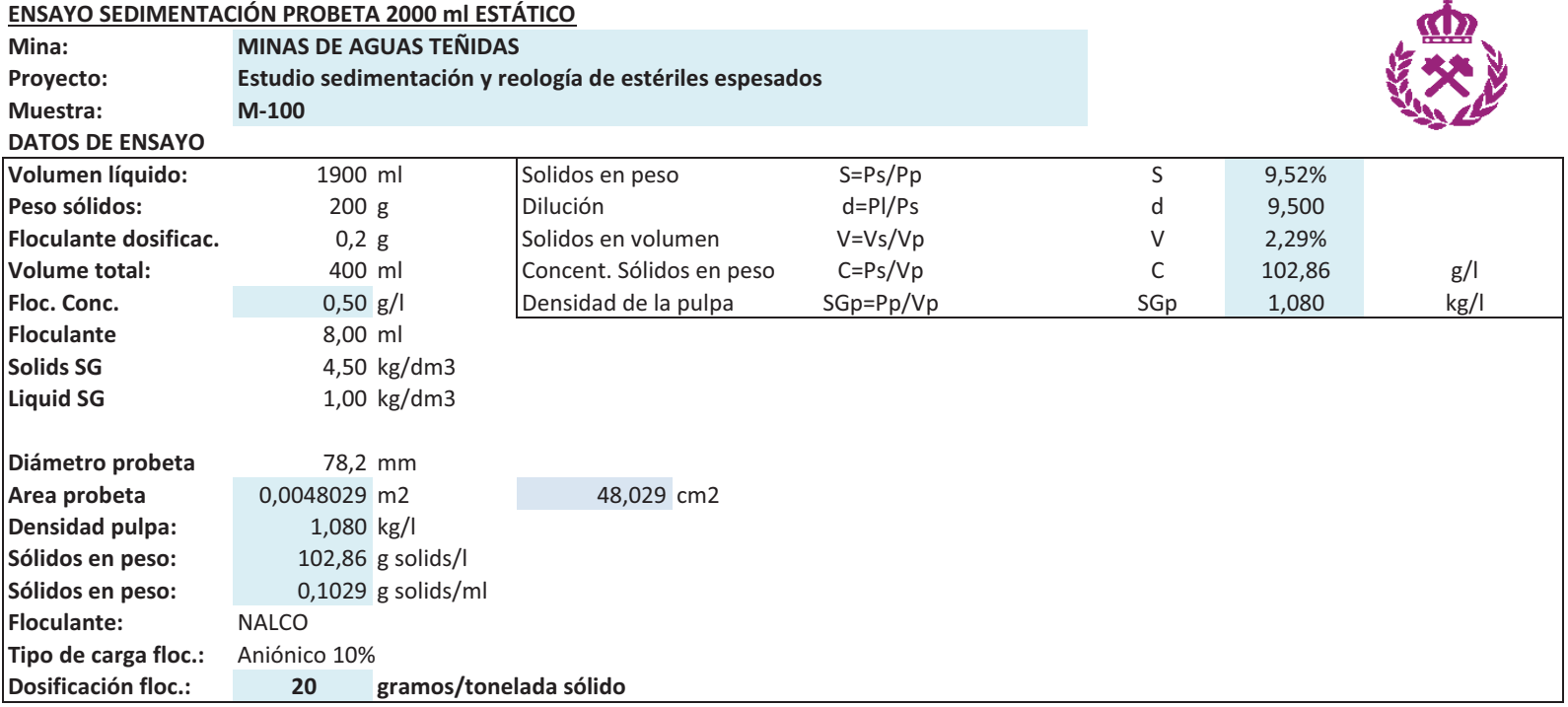

DATOS DE SEDIMENTACIÓN

\begin{tabular}{|c|c|c|c|c|c|c|c|c|c|}
\hline $\begin{array}{l}\text { Tiempo info } \\
\text { (sec) }\end{array}$ & $\begin{array}{c}\text { Tiempo } \\
\text { (min) }\end{array}$ & $\begin{array}{l}\text { Vol. Lodos } \\
\text { (ml) }\end{array}$ & $\begin{array}{l}\text { Altura interf. } \\
(\mathrm{cm})\end{array}$ & $\begin{array}{l}\text { Velocidad } \\
\text { (m/hr) }\end{array}$ & $\begin{array}{l}\text { SG. Lodos } \\
\text { (g/cm3) }\end{array}$ & $\begin{array}{l}\text { Lodos } \\
\text { \% Sol. Peso }\end{array}$ & $\begin{array}{c}\text { Flujo } \\
\text { (tph/m2) }\end{array}$ & $\begin{array}{c}\text { Flujo } \\
\text { (tpd/m2) }\end{array}$ & $\begin{array}{l}\text { Área Unit. Espes. } \\
\text { (m2/tpd) }\end{array}$ \\
\hline 0 & 0 & 1969 & 41,00 & 0 & 1,079 & 9,41 & 0 & 0 & 0 \\
\hline 5 & 0,08 & 1849 & 38,50 & 18,000 & 1,084 & 9,98 & 29,9820 & 719,57 & 0,001 \\
\hline 10 & 0,17 & 1753 & 36,50 & 14,400 & 1,089 & 10,48 & 29,9818 & 719,56 & 0,001 \\
\hline 15 & 0,25 & 1647 & 34,30 & 15,840 & 1,094 & 11,09 & 29,9819 & 719,57 & 0,001 \\
\hline 30 & 0,50 & 1345 & 28,00 & 15,120 & 1,116 & 13,33 & 9,9940 & 239,86 & 0,004 \\
\hline 45 & 0,75 & 1153 & 24,00 & 9,600 & 1,135 & 15,29 & 9,9940 & 239,86 & 0,004 \\
\hline 60 & 1,00 & 1009 & 21,00 & 7,200 & 1,154 & 17,18 & 9,9940 & 239,86 & 0,004 \\
\hline 120 & 2,00 & 552 & 11,50 & 5,700 & 1,282 & 28,25 & 2,4985 & 59,96 & 0,017 \\
\hline 180 & 3,00 & 432 & 9,00 & 1,500 & 1,360 & 34,02 & 2,4985 & 59,96 & 0,017 \\
\hline 240 & 4,00 & 394 & 8,20 & 0,480 & 1,395 & 36,40 & 2,4985 & 59,96 & 0,017 \\
\hline 300 & 5,00 & 360 & 7,50 & 0,420 & 1,432 & 38,78 & 2,4985 & 59,96 & 0,017 \\
\hline 450 & 7,50 & 307 & 6,40 & 0,264 & 1,506 & 43,20 & 0,9994 & 23,99 & 0,042 \\
\hline 600 & 10,00 & 288 & 6,00 & 0,096 & 1,540 & 45,07 & 0,9994 & 23,99 & 0,042 \\
\hline 900 & 15,00 & 279 & 5,80 & 0,024 & 1,558 & 46,07 & 0,4997 & 11,99 & 0,083 \\
\hline 1200 & 20,00 & 274 & 5,70 & 0,012 & 1,568 & 46,59 & 0,4997 & 11,99 & 0,083 \\
\hline 1500 & 25,00 & 264 & 5,50 & 0,024 & 1,589 & 47,65 & 0,4997 & 11,99 & 0,083 \\
\hline 1800 & 30,00 & 259 & 5,40 & 0,012 & 1,600 & 48,20 & 0,4997 & 11,99 & 0,083 \\
\hline 3600 & 60,00 & 255 & 5,30 & 0,002 & 1,611 & 48,77 & 0,0833 & 2,00 & 0,500 \\
\hline 5400 & 90,00 & 255 & 5,30 & 0,000 & 1,611 & 48,77 & 0,0833 & 2,00 & 0,500 \\
\hline 7200 & 120,00 & 255 & 5,30 & 0,000 & 1,611 & 48,77 & 0,0833 & 2,00 & 0,500 \\
\hline 9000 & 150,00 & 255 & 5,30 & 0,000 & 1,611 & 48,77 & 0,0833 & 2,00 & 0,500 \\
\hline 10800 & 180,00 & 255 & 5,30 & 0,000 & 1,611 & 48,77 & 0,0833 & 2,00 & 0,500 \\
\hline 14400 & 240,00 & 255 & 5,30 & 0,000 & 1,611 & 48,77 & 0,0416 & 1,00 & 1,001 \\
\hline
\end{tabular}

DATOS OBTENIDOS:

Velocidad de sedimentación promedio: $15.8 \mathrm{~m} / \mathrm{h}$

$\%$ sólidos - tiempo: $48,7 \%$ sólidos en peso - 60 minutos tiempo residencia 
Mina:

Proyecto:

Muestra
MINAS DE AGUAS TEÑIDAS

Estudio sedimentación y reología de estériles espesados M-100
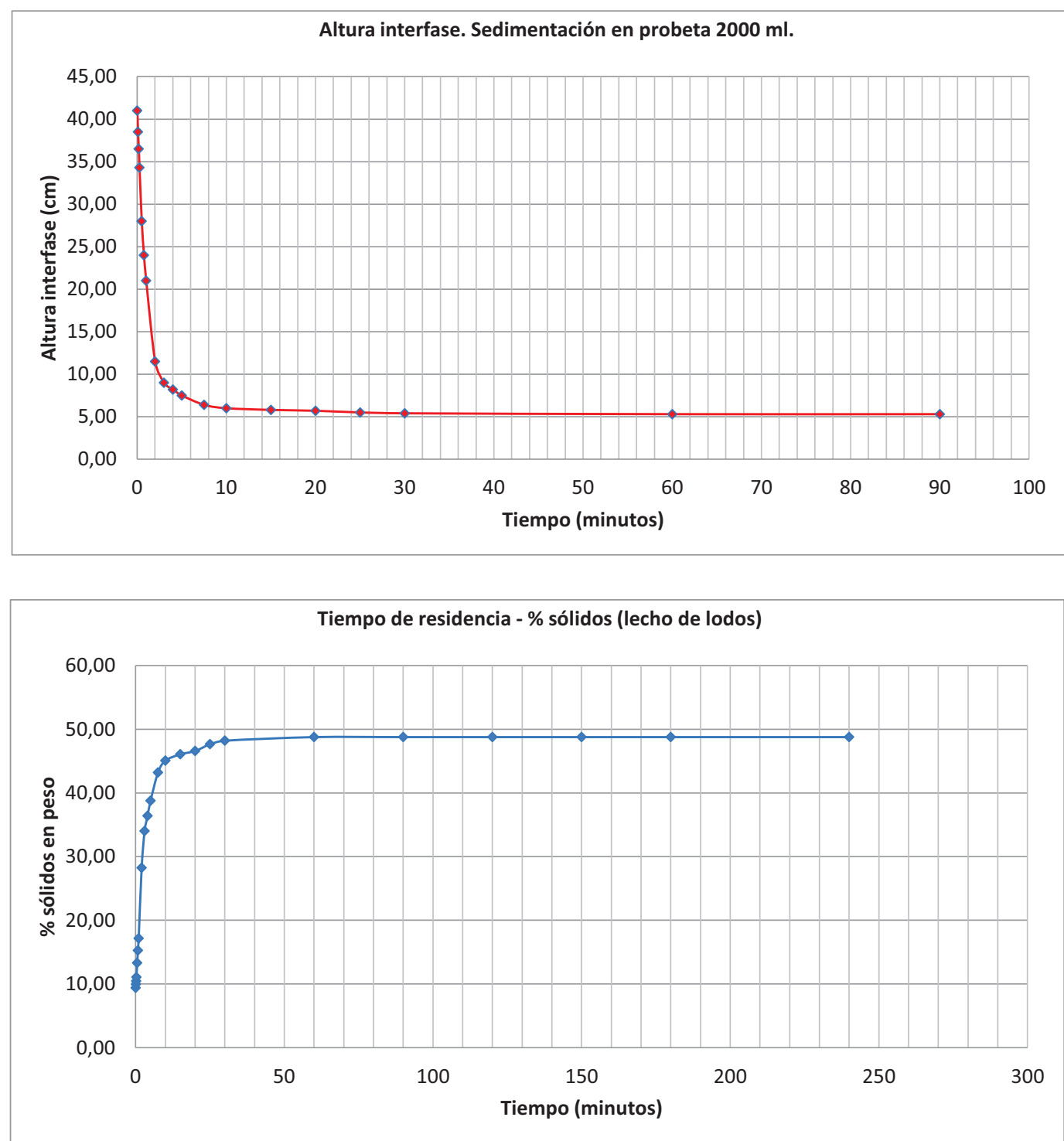


\begin{tabular}{|c|c|c|c|c|c|c|c|c|c|}
\hline \multicolumn{10}{|c|}{ ENSAYO SEDIMENTACIÓN PROBETA $5500 \mathrm{mI}$ DINAMICO } \\
\hline Mina: & MINAS DE AGUA & S TEÑIDAS & & & & & & & \\
\hline Proyecto: & Estudio sedimen & tación y reologí & a de estériles & es espesados & & & & & \\
\hline Muestra: & M-100 & & & & & & & & \\
\hline EQUIPO DE ENSAYO: & & & & & & & & & \\
\hline Diámetro tubo: & & & & & Inyección de & floculante & & & \\
\hline Área sedimentación: & 56,75 & $\mathrm{~cm} 2$ & & & & & gitador & & \\
\hline & 0,005675 & & & & & & $\begin{array}{l}\text { floculante } \\
\text { fons }\end{array}$ & & \\
\hline PREPARACIÓN DE LA I & MUESTRA: & & & & & & 1 & & \\
\hline Solids SG & 4,50 & $\mathrm{~kg} / \mathrm{dm} 3$ & & & & Bomba de & sculante & & \\
\hline Liquid SG & 1,00 & $\mathrm{~kg} / \mathrm{dm} 3$ & & flluen & & & & & \\
\hline \%Solidos alimentac. & 9,96 & & & larificado & & & & & \\
\hline Pulpa alimentac. SG: & 1,084 & $\mathrm{~kg} / \mathrm{l}$ & & ose) & & Tanque & e & & \\
\hline Pulpa alimentac.: & 107,96 & g solidos/l & & & & & & & \\
\hline Pulpa alimentac.: & 0,108 & g solidos $/ \mathrm{ml}$ & & & & & & & \\
\hline FLOCULANTE: & & & & & & & & & \\
\hline Floc Name: & NALCO & & $\begin{array}{l}\text { Muestra de } \\
\text { pastath hund }\end{array}$ & & & 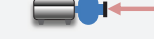 & & & \\
\hline Floc Type: & $-10 \%$ carga iónic & & pasta (hund & & & & & & \\
\hline Floc. Dosificación: & 0,50 & $\mathrm{~g} / \mathrm{l}(\mathrm{mg} / \mathrm{ml})$ & & & & $\begin{array}{l}\text { Bomba de recircu } \\
\text { lodos }\end{array}$ & ación de & & \\
\hline Floc. Dosificación: & 0,050 & & & & & & & & \\
\hline & & & & DATOS ENS & SAYO DINÁMICO: & & & & \\
\hline DATOS DE LA OPERAC & CIÓN & & & & Alimentación (Val & res promedio t & óricos) & & \\
\hline Sólidos & 3100,0 & gramos & & & Total tiempo alime & ntación: & $0: 45: 00$ & hh:mm:ss & \\
\hline Volumen líquido & 28,00 & litros & & & Volumen total (litr & & 28,6 & 5 litros & \\
\hline Tiempo inicio & $11: 00: 00$ & horario & & & Tiempo alimentaci & & 45,0 & minutos & \\
\hline Volumen pulpa inic. & 28,69 & litros & & & Caudal alimentacic & n (media): & 0,636 & litros/min & \\
\hline Tiempo final & $11: 45: 00$ & horario & & & Sólidos alimentado & & 2991,1 & & \\
\hline Volumen pulpa final & 0,05 & litros & & & Floculante (Valore & s promedio teór & $\cos )$ & & \\
\hline & Floculante inic. & & & & Volumen total (ml) & & 195,00 & $\mathrm{ml}$ & \\
\hline Vol. floculante inic. & 1000 & & & & Caudal floculante: & & 4,33 & $3 \mathrm{ml} / \mathrm{min}$ & \\
\hline & & & & & Dosific. floculante & oromedio & 32,60 & $\mathrm{~g} / \mathrm{t}$ & \\
\hline DATOS ENSAYO DINÁMI & ICO: & & & & & & & & \\
\hline $\begin{array}{c}\text { Tiempo } \\
\text { (Minutos) }\end{array}$ & $\begin{array}{l}\text { Vol. Rebose } \\
\text { (litros) }\end{array}$ & $\begin{array}{l}\text { Consumo Floc. } \\
\text { (ml) }\end{array}$ & $\begin{array}{l}\text { Sól. Seco } \\
\text { (g) }\end{array}$ & $\begin{array}{l}\text { Floculante } \\
\mathrm{ml} / \mathrm{min}\end{array}$ & $\begin{array}{l}\text { Vol. Alimentación } \\
\mathrm{ml} / \mathrm{min}\end{array}$ & $\begin{array}{l}\text { Velocidad sed. } \\
\mathrm{m} / \mathrm{h}\end{array}$ & $\begin{array}{l}\text { Dos. Floc. } \\
\mathrm{g} / \mathrm{t}\end{array}$ & $\begin{array}{l}\text { Flujo } \\
\text { tpd/m2 }\end{array}$ & $\begin{array}{l}\text { Área } \\
\mathrm{m} 2 / \mathrm{tpd}\end{array}$ \\
\hline 0 & 0 & 0 & 0 & 0 & 0 & 0 & 0 & 0 & 0 \\
\hline 5 & 3,5 & 30 & 374,6 & 8,6 & 718,4 & 7,6 & 40,0 & 19,014 & 0,053 \\
\hline 10 & 8 & 60 & 482,6 & 6,7 & 906,1 & 9,6 & 31,1 & 24,493 & 0,041 \\
\hline 20 & 14 & 110 & 642,4 & 8,3 & 604,4 & 6,4 & 38,9 & 16,302 & 0,061 \\
\hline 30 & 20 & 150 & 643,5 & 6,7 & 600,7 & 6,4 & 31,1 & 16,329 & 0,061 \\
\hline 40 & 24 & 170 & 429,7 & 5,0 & 395,7 & 4,2 & 23,3 & 10,904 & 0,092 \\
\hline 45 & 27,9 & 195 & 418,4 & 6,4 & 780,8 & 8,3 & 29,9 & 21,233 & 0,047 \\
\hline VALORES PROMEDIO RE & & Total sólidos: & 2991,1 & g sól. seco & & 7,1 & 32,4 & 18,0 & 0,059 \\
\hline & $\begin{array}{r}S \\
\% s\end{array}$ & $\begin{array}{l}\text { ólidos perdidos: } \\
\text { ólidos perdidos: }\end{array}$ & $\begin{array}{c}108,9 \\
3,51\end{array}$ & $\begin{array}{l}\mathrm{g} \\
\%\end{array}$ & & Promedio $\mathrm{m} / \mathrm{h}$ & Promedio g/t & Promed. tpd/m2 & Promed. $\mathrm{m} 2 / \mathrm{tpd}$ \\
\hline & & & & DATOS ENS & SAYO ESTÁTICO: & & & & \\
\hline $\begin{array}{l}\text { Tiempo } \\
\text { (min) }\end{array}$ & $\begin{array}{l}\text { Altura interfase } \\
\qquad(\mathrm{mm})\end{array}$ & $\begin{array}{l}\text { Vol. Lodos } \\
\text { (cm3) }\end{array}$ & $\begin{array}{l}\text { Vol. Líquido } \\
\text { (cm3) }\end{array}$ & $\begin{array}{l}\text { Densidad lodo } \\
\text { (g/cm3) }\end{array}$ & $\begin{array}{l}\text { MUESTRA } \\
(\mathrm{cm} 3)\end{array}$ & $\begin{array}{l}\text { Lodos } \\
\text { \% Sol. Peso }\end{array}$ & $\begin{array}{l}\text { T. Residencia } \\
\text { (horas) }\end{array}$ & OBSERVACIONES & \\
\hline 0 & 580 & 3291,2 & 2626,5 & 1,707 & 0 & 53,25 & 0,0 & & \\
\hline 2 & 520 & 2950,7 & 2286,0 & 1,788 & 0 & 56,68 & 0,0 & & \\
\hline 5 & 460 & 2610,3 & 1945,6 & 1,891 & 0 & 60,59 & 0,1 & & \\
\hline 10 & 430 & 2440,0 & 1775,3 & 1,953 & 0 & 62,75 & 0,2 & & \\
\hline 15 & 401 & 2275,5 & 1610,8 & 2,022 & 0 & 65,00 & 0,3 & & \\
\hline 30 & 377 & 2139,3 & 1474,6 & 2,087 & 0 & 66,98 & 0,5 & & \\
\hline 60 & 369 & 2093,9 & 1429,2 & 2,111 & 0 & 67,67 & 1,0 & & \\
\hline 120 & 352 & 1997,4 & 1332,7 & 2,165 & 0 & 69,18 & 2,0 & & \\
\hline 180 & 340 & 1929,3 & 1264,6 & 2,206 & 0 & 70,28 & 3,0 & & \\
\hline 240 & 323 & 1832,9 & 1168,2 & 2,269 & 0 & 71,91 & 4,0 & & \\
\hline 300 & 308 & 1747,7 & 1083,1 & 2,331 & 0 & 73,42 & 5,0 & & \\
\hline 360 & 303 & 1719,4 & 1054,7 & 2,353 & 0 & 73,93 & 6,0 & & \\
\hline 420 & 300 & 1702,4 & 1037,7 & 2,367 & 0 & 74,24 & 7,0 & & \\
\hline 480 & 294 & 1668,3 & 1003,6 & 2,394 & 0 & 74,88 & 8,0 & & \\
\hline 540 & 293 & 1662,6 & 997,9 & 2,399 & 0 & 74,98 & 9,0 & & \\
\hline 600 & 293 & 1662,6 & 997,9 & 2,399 & 0 & 74,98 & 10,0 & & \\
\hline
\end{tabular}


ENSAYO SEDIMENTACIÓN PROBETA 5500 mI DINAMICO

Mina: MINAS DE AGUAS TEÑIDAS

Proyecto: $\quad$ Estudio sedimentación y reología de estériles espesados

Muestra: $\quad \mathrm{M}-100$

DATOS DE OPERACIÓN DEL ESPESADOR DE TUBO PROFUNDO

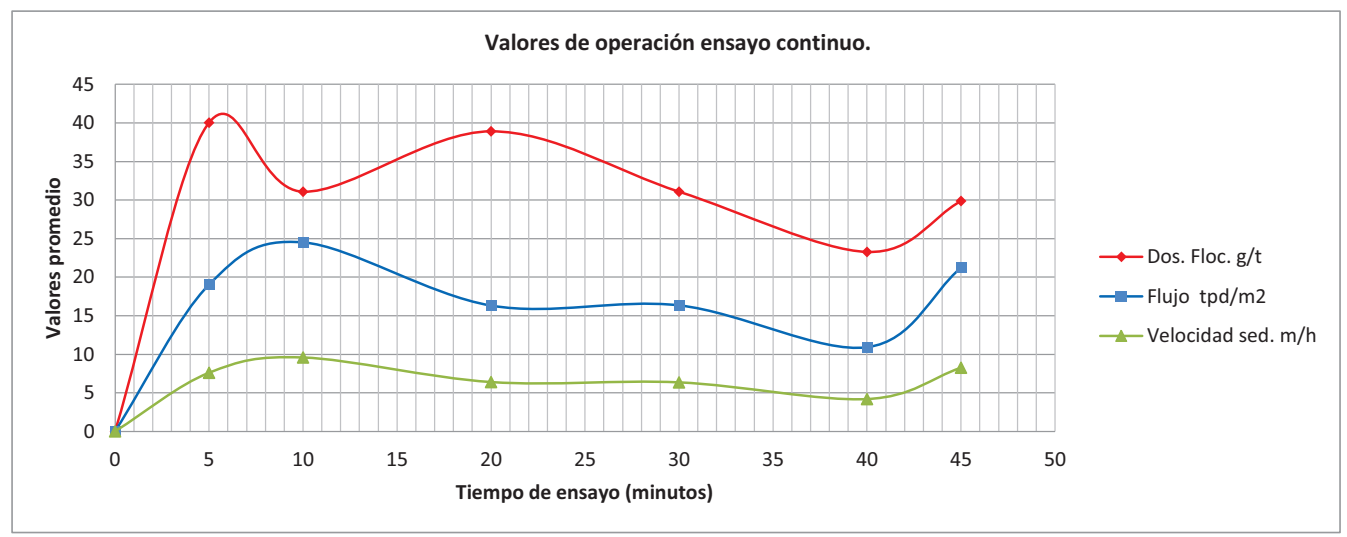

Datos Promedio:

Velocidad de sedimentación:

Dosificación de floculante:

$7,1 \mathrm{~m} / \mathrm{h}$

Flujo de sedimentación:

$32,4 \mathrm{~g} / \mathrm{t}$

Flujo de sedimentación:

$0,0591 \mathrm{~m}^{2} / \mathrm{t} / \mathrm{día}$

$18,0 \mathrm{t} / \mathrm{dí} a / \mathrm{m}^{2}$

ENSAYO SEDIMENTACIÓN PROBETA $5500 \mathrm{mI}$ DINAMICO
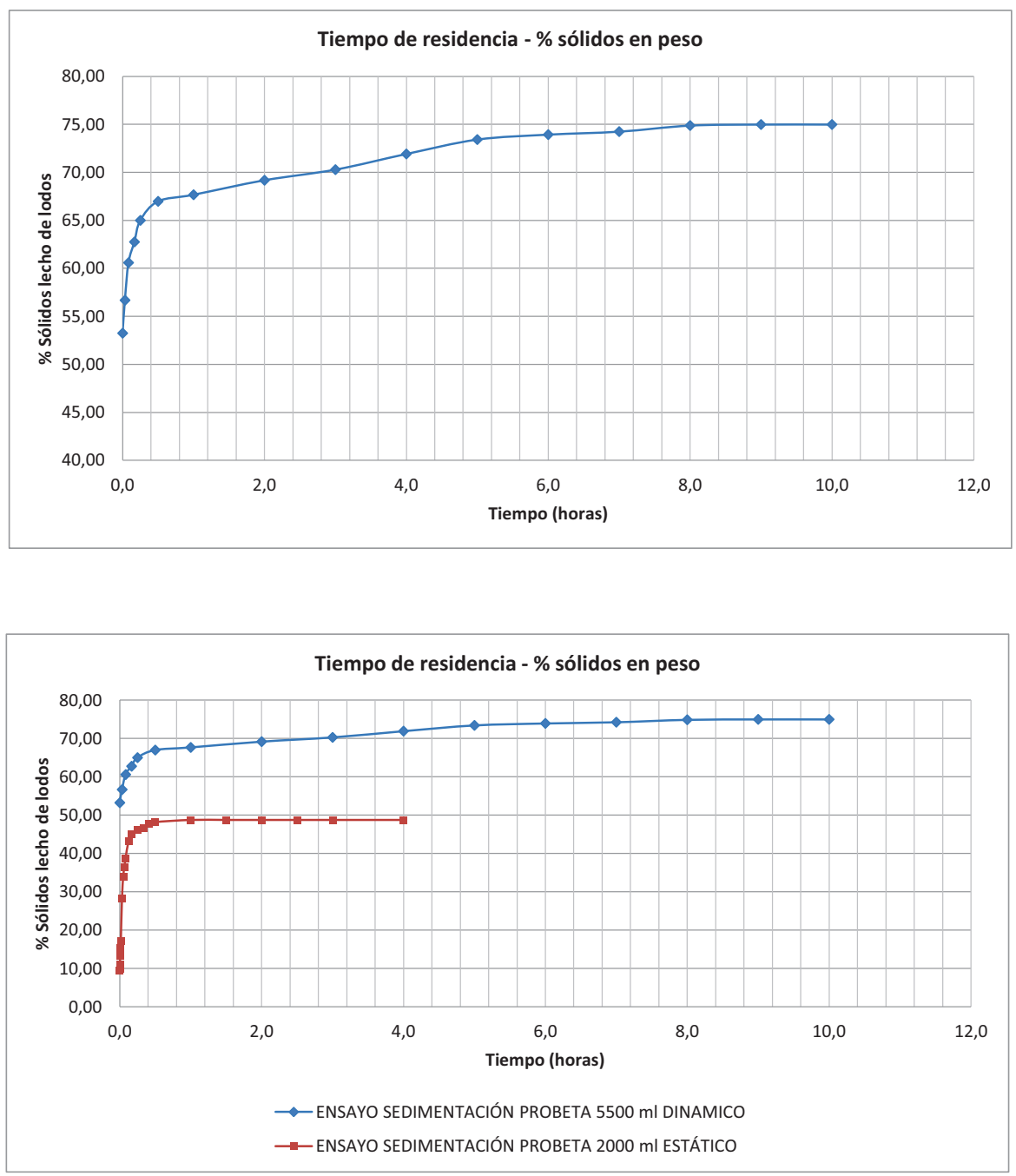
ENSAYO FILTRACIÓN A VACIO

Mina: MINAS DE AGUAS TEÑIDAS

Proyecto: $\quad$ Estudio sedimentación y reología de estériles espesados

Material:

Estudio sedimentación y reología de estériles espesados

Muestra:

M-100

Preparado por:

pH muestra:

Fecha:

$28 / 06 / 2015$

\begin{tabular}{|c|c|c|}
\hline \multicolumn{3}{|c|}{ DATOS DE LA MUESTRA: } \\
\hline Solidos SG & & $0,00 \mathrm{~kg} / \mathrm{dm} 3$ \\
\hline Liquido SG & & $0,00 \mathrm{~kg} / \mathrm{dm} 3$ \\
\hline \multicolumn{3}{|l|}{ FLOCULANTE: } \\
\hline Floc Name: & No & \\
\hline Tipo de floculante: & No & \\
\hline Floc. Dosificación: & & $0,00 \mathrm{~g} / \mathrm{l}(\mathrm{mg} / \mathrm{ml})$ \\
\hline Floc. Dosificación: & & $0,000 \%$ \\
\hline
\end{tabular}
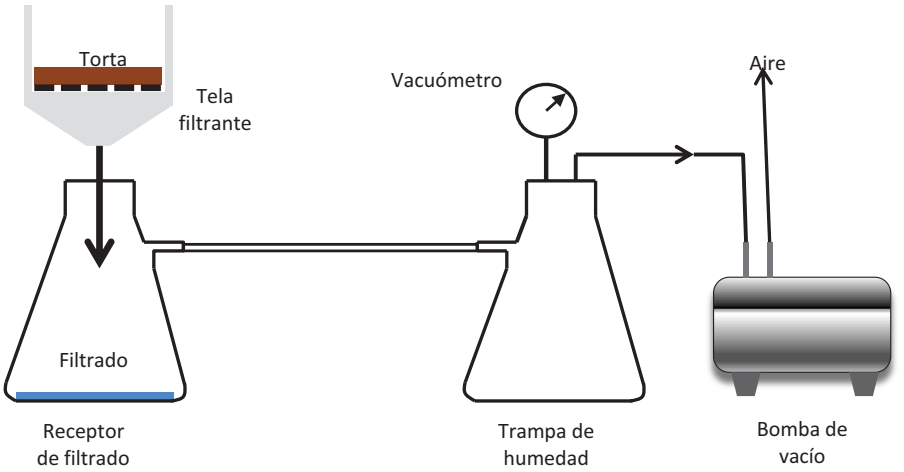

\begin{tabular}{|c|c|c|c|c|c|c|c|c|c|}
\hline \multicolumn{10}{|c|}{ ENSAYO FILTRACIÓN A VACÍO. TEST 1.} \\
\hline \multicolumn{2}{|c|}{ MUESTRA: M-100 } & & \multicolumn{7}{|c|}{ Tiempos de ensayo de filtración } \\
\hline $\begin{array}{l}\text { Vacío } \\
\text { (bar) }\end{array}$ & $\begin{array}{c}\text { Peso sólidos } \\
\text { (g) }\end{array}$ & $\begin{array}{l}\text { Vol. Líquido } \\
\text { (ml) }\end{array}$ & $\begin{array}{c}\text { \% Sól. Peso } \\
\text { (\%) }\end{array}$ & $\begin{array}{l}\text { Vol. Pulpa } \\
\text { (ml) }\end{array}$ & $\begin{array}{l}\text { Formación torta } \\
\text { (s) }\end{array}$ & $\begin{array}{l}\text { Secado torta } \\
\text { (s) }\end{array}$ & $\begin{array}{l}\text { Total ciclo } \\
\text { (s) }\end{array}$ & $\begin{array}{l}\text { Líq. Filtrado } \\
\quad(\mathrm{ml})\end{array}$ & $\begin{array}{c}\text { Espesor } \\
(\mathrm{mm})\end{array}$ \\
\hline 0 & 0 & 0,0 & \#DIV/0! & \#DIV/0! & 0 & 0 & 0 & 0 & 0,0 \\
\hline \% Solidos estimado: & \#DIV/0! & & \multirow{2}{*}{\multicolumn{2}{|c|}{ Observaciones: }} & & & & & \\
\hline Peso muestra húmedo: & 0 & $\mathrm{~g}$ & \multirow{3}{*}{\multicolumn{2}{|c|}{ Observaciones: }} & & & & & \\
\hline \multicolumn{3}{|c|}{\begin{tabular}{|l} 
Secado de la muestra: \\
\end{tabular}} & & & & & & & \\
\hline Peso muestra seco & 0 & $\mathrm{~g}$ & & & & & & & \\
\hline$\%$ humedad torta & \#DIV/0! & $\%$ & & & & & & & \\
\hline
\end{tabular}

\begin{tabular}{|c|c|c|c|c|c|c|c|c|c|}
\hline \multicolumn{10}{|c|}{ ENSAYO FILTRACIÓN A VACÍO. TEST 2.} \\
\hline \multicolumn{3}{|c|}{ MUESTRA: M-100 } & \multicolumn{7}{|c|}{ Tiempos de ensayo de filtración } \\
\hline $\begin{array}{l}\text { Vacío } \\
\text { (bar) }\end{array}$ & $\begin{array}{l}\text { Peso sólidos } \\
\text { (g) }\end{array}$ & $\begin{array}{l}\text { Vol. Líquido } \\
\text { (ml) }\end{array}$ & $\begin{array}{c}\text { \% Sól. Peso } \\
\text { (\%) }\end{array}$ & $\begin{array}{l}\text { Vol. Pulpa } \\
\text { (ml) }\end{array}$ & $\begin{array}{l}\text { Formación torta } \\
\text { (s) }\end{array}$ & $\begin{array}{l}\text { Secado torta } \\
\text { (s) }\end{array}$ & $\begin{array}{c}\text { Total ciclo } \\
\text { (s) }\end{array}$ & $\begin{array}{l}\text { Líq. Filtrado } \\
\text { (ml) }\end{array}$ & $\begin{array}{c}\text { Espesor } \\
(\mathrm{mm})\end{array}$ \\
\hline 0 & 0 & 0,0 & \#DIV/0! & \#DIV/0! & 0 & & 0 & & 0,0 \\
\hline \% Solidos estimado: & \#DIV/O! & & & & & & & & \\
\hline Peso muestra húmedo: & $\overline{0}$ & $\mathrm{~g}$ & \multirow{3}{*}{\multicolumn{2}{|c|}{ Observaciones: }} & & & & & \\
\hline \multicolumn{3}{|c|}{ Secado de la muestra: } & & & & & & & \\
\hline Peso muestra seco & 0 & $\mathrm{~g}$ & & & & & & & \\
\hline$\%$ humedad torta & \#DIV/0! & $\%$ & Los pesos incl & iyen la tara & & & & & \\
\hline
\end{tabular}

\begin{tabular}{|c|c|c|c|c|c|c|c|c|c|}
\hline \multicolumn{10}{|c|}{ ENSAYO FILTRACIÓN A VACÍO. TEST 3.} \\
\hline \multicolumn{3}{|c|}{ MUESTRA: M-100 } & \multicolumn{7}{|c|}{ Tiempos de ensayo de filtración } \\
\hline $\begin{array}{l}\text { Vacío } \\
\text { (bar) }\end{array}$ & $\begin{array}{l}\text { Peso sólidos } \\
\text { (g) }\end{array}$ & $\begin{array}{l}\text { Vol. Líquido } \\
\text { (ml) }\end{array}$ & $\begin{array}{c}\text { \% Sól. Peso } \\
\text { (\%) }\end{array}$ & $\begin{array}{l}\text { Vol. Pulpa } \\
\text { (ml) }\end{array}$ & $\begin{array}{l}\text { Formación torta } \\
\text { (s) }\end{array}$ & $\begin{array}{l}\text { Secado torta } \\
\text { (s) }\end{array}$ & $\begin{array}{l}\text { Total ciclo } \\
\text { (s) }\end{array}$ & $\begin{array}{l}\text { Líq. Filtrado } \\
\text { (ml) }\end{array}$ & $\begin{array}{c}\text { Espesor } \\
\text { (mm) }\end{array}$ \\
\hline 0 & 0 & 0,0 & \#DIV/0! & \#DIV/0! & 0 & 0 & 0 & 0 & 0,0 \\
\hline \% Solidos estimado: & \#DIV/0! & & & & & & & & \\
\hline Peso muestra húmedo: & 0 & $\mathrm{~g}$ & \multirow{4}{*}{\multicolumn{7}{|c|}{$\begin{array}{l}\text { Observaciones: } \\
\text { Contenido en sólidos de la torta filtrada: } 100-21,71=78,29 \%\end{array}$}} \\
\hline \multicolumn{3}{|c|}{ Secado de la muestra: } & & & & & & & \\
\hline Peso muestra seco & 0 & $\mathrm{~g}$ & & & & & & & \\
\hline$\%$ humedad torta & \#DIV/0! & $\%$ & & & & & & & \\
\hline
\end{tabular}

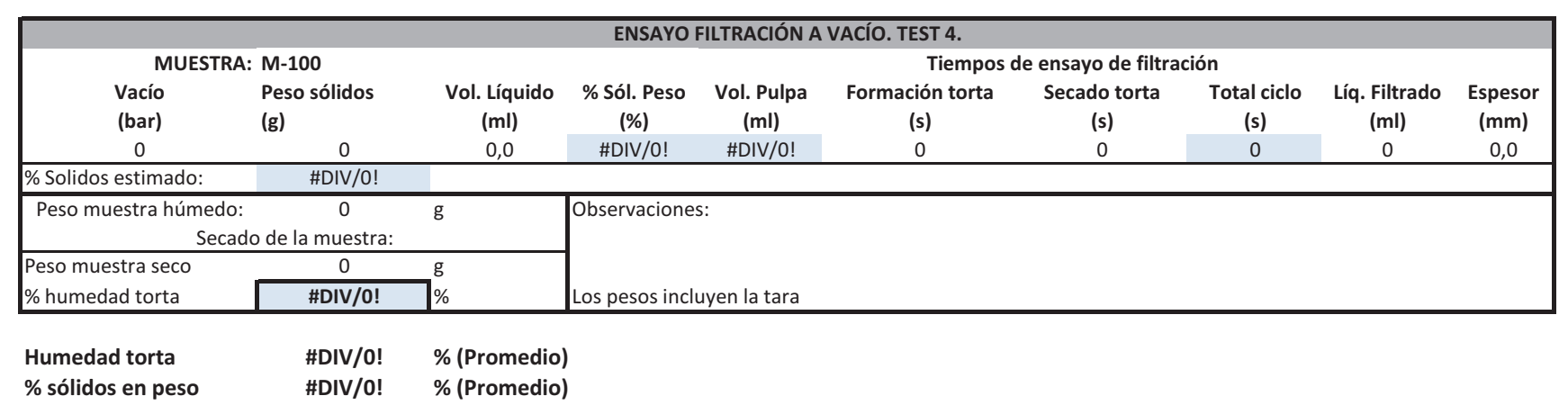


ENSAYO ASENTAMIENTO EN PROBETA

\section{Mina:}

Proyecto:

Material:

Preparado por:

pH muestra:

Fecha:

Aceleración gravedad (g):

Diámetro probeta:

Altura probeta $(\mathrm{H})$ :

Volumen probeta:

Solidos SG

Líquido SG

Expresiones empíricas

$T=0.5-0.5(\mathrm{~h} / \mathrm{H})^{\wedge} 0.5$

T.F. $=\mathrm{T}^{*} \mathrm{~d}^{*} \mathrm{~g}^{*}(\mathrm{H} / 100)$

\section{MINAS DE AGUAS TEÑIDAS}

Estudio sedimentación y reología de estériles espesados

Estériles mineral polimetálico cobre

José A. Butragueño

$28 / 06 / 2015$

$$
\begin{aligned}
9,81 \mathrm{~m} / \mathrm{s} 2 \\
44 \mathrm{~mm} \\
100 \mathrm{~mm} \\
152,1 \mathrm{~cm} 3 \\
4,50 \mathrm{~kg} / \mathrm{dm} 3 \\
1,00 \mathrm{~kg} / \mathrm{dm} 3
\end{aligned}
$$

\begin{tabular}{|c|c|c|c|c|c|c|c|c|c|c|}
\hline \multicolumn{11}{|c|}{ ENSAYOS DE ASENTAMIENTO EN PROBETA } \\
\hline $\begin{array}{l}\text { Muestra } \\
\text { ID }\end{array}$ & $\begin{array}{c}\text { Cont. Sólidos } \\
\text { (\%) }\end{array}$ & $\begin{array}{l}\text { Solidos SG } \\
\mathrm{g} / \mathrm{cm} 3\end{array}$ & $\begin{array}{c}\text { Peso Liq. } \\
\text { (kg liq/kg sol) }\end{array}$ & $\begin{array}{l}\text { Vol. Pulpa } \\
\text { (I/kg sol) }\end{array}$ & $\begin{array}{c}\text { Pulpa SG (d) } \\
\mathrm{kg} / \mathrm{dm} 3\end{array}$ & $\begin{array}{l}\text { Sólidos prob. } \\
\text { (g) }\end{array}$ & $\begin{array}{l}\text { Liq. Probeta } \\
\text { (g) }\end{array}$ & $\begin{array}{c}\text { Asentamiento (h) } \\
\mathrm{mm}\end{array}$ & $\begin{array}{l}\text { Factor "T" } \\
\text { Adimens. }\end{array}$ & $\begin{array}{c}\text { Tensión Fluencia } \\
\text { (Pa) }\end{array}$ \\
\hline 1 & 68,5 & 4,50 & 0,460 & 0,682 & 2,140 & 222,9 & 102,5 & 45 & 0,16459 & 345,6 \\
\hline 2 & 67,5 & 4,50 & 0,481 & 0,704 & 2,105 & 216,1 & 104,0 & 52 & 0,13944 & 288,0 \\
\hline 3 & 65 & 4,50 & 0,538 & 0,761 & 2,022 & 199,9 & 107,6 & 62 & 0,10630 & 210,9 \\
\hline 4 & 62,5 & 4,50 & 0,600 & 0,822 & 1,946 & 184,9 & 111,0 & 79 & 0,05559 & 106,1 \\
\hline 5 & 60 & 4,50 & 0,667 & 0,889 & 1,875 & 171,1 & 114,0 & 90 & 0,02566 & 47,2 \\
\hline 6 & 55 & 4,50 & 0,818 & 1,040 & 1,748 & 146,1 & 119,6 & 96 & 0,01010 & 17,3 \\
\hline
\end{tabular}

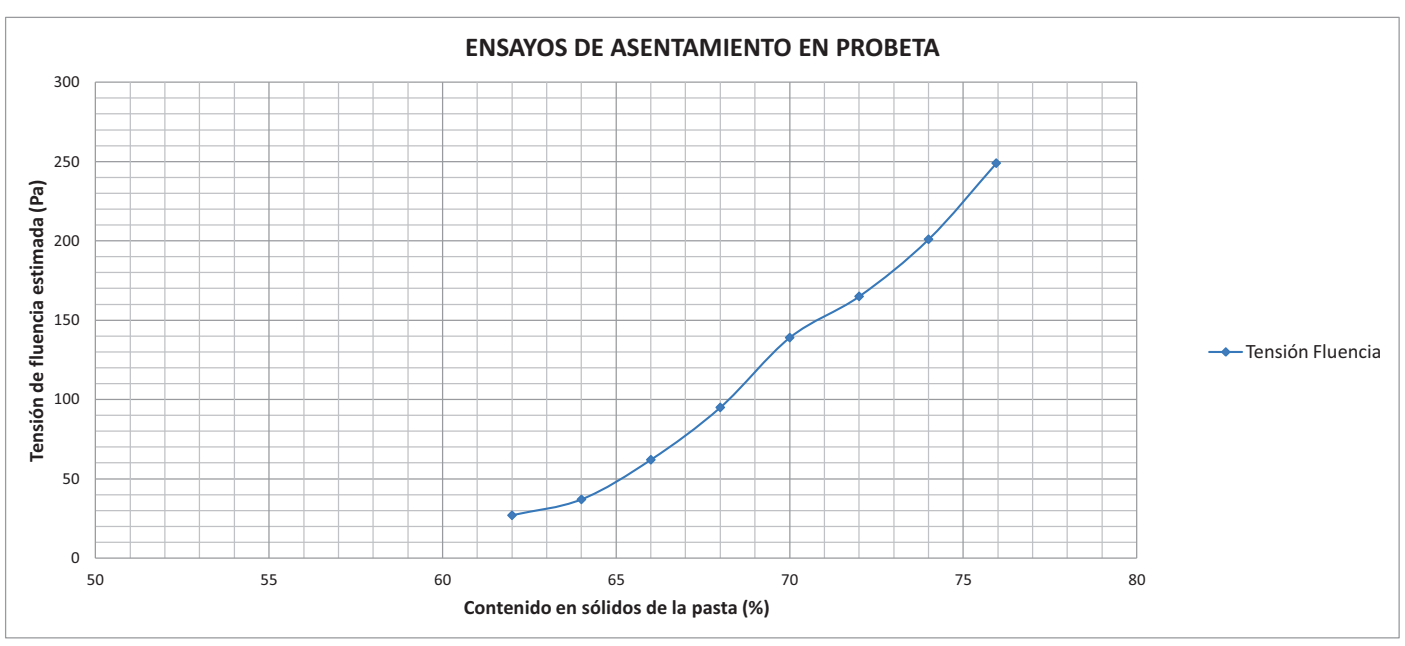

